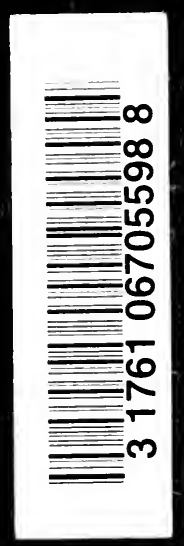


$\frac{4}{4}$ 
Digitized by the Internet Airchive in 2007 with funding from Microsoft Cörporation 


\section{DIETOTHERAPY}





\section{DIETOTHERAPY}

\section{CHEMISTRY AND PHYSIOLOGY OF DIGESTION CLASSIFICATION AND ANALYSIS OF FOODS}

BY

WILLIAM EDWARD FITCH, M.D.

MAJOR MED. RES. CORPS, U. S. A.

FORMERLY LECTURER ON SURGERY, FORDHAM UNIVERSITY SCHOOL OF MEDICINE; ASSISTANT ATTENDING GYNECOLOGIST PRESBYTERIAN HOSPITAL DISPEN-

SARY; ATTENDING PHYSICIAN TO THE VANDERBILT CliNiC, COLLEGE PIIYS. \& SURGS., NEW YORK CITY

AND

FORTY CONTRIBUTORS

\section{VOL UME I}
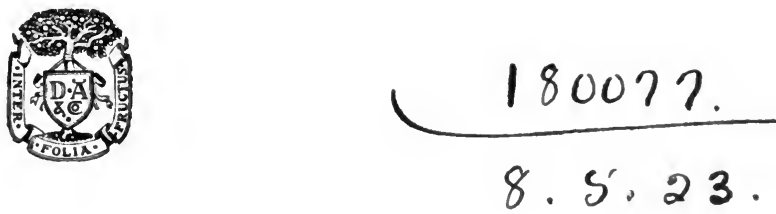

PUBLISHED WITH THE PERMISSION OF THE SURGEON GENERAL OF THE ARMY

SECONI EDITION, REVISED

\section{APPLETON AND COMPANY}

NEW YORK 
Copyright, 1918, 1922, в

D. APPLETON AND COMPANY

Printed in the United States of America 


\section{PREFA CE}

While much has been written of late on the subject of nutrition and dietetics, it is widely scattered through various books, journals, pamphlets, and government and scientific reports, which are not readily accessible nor sufficiently comprehensive to furnish the physician with a foundation upon which to build a practical working knowledge of the scientific application of foods in either health, or diseased conditions. Besides, much of this matter is too ultrascientific to be of practical value to the busy physician. Moreover, in actual practice the physician is often confronted with many cases where a knowledge of the approximate caloric value of foodstuffs, as well as of the proper kind and dosage, will be of far greater value to him than any knowledge of the therapeutic action of drugs. This knowledge is beginning to sprinkle down upon the students of nutrition like the plenteous showers from Heaven-too fast, indeed, for assimilation-but the excess is being collected in the reservoirs of trophotherapeutic knowledge from which only those who understand may drink intelligently.

In order to understand the rationale of nutrition, a working knowledge of the chemical changes which the foods undergo in the body is necessary. Therefore the body must be regarded as a human laboratory of nicely balanced chemical reactions. This knowledge of physiological chemistry is so essential that much space is devoted to the subject in Volume I, embracing a concise presentation of the fundamental principles, including the most essential facts of physiological chemistry, with a brief but succinct description of the digestive organs, explaining the special functions of each in the process of digestion, and graphically describing the physiology of the absorption of foods. Without such a knowledge of the chemistry and physiology of digestion, many of the statements with regard to nutrition would convey but the most vague ideas to the reader.

Life can proceed in a normal manner only when the body cells are supplied with a well-balanced dietary suitable for their needs. This demands a certain number of heat units or calories daily, supplied from the ternary food elements in the proper proportion of protein, fat and carbohydrate. To enable each cell in the body to maintain its proper place in 
the human edifice according to its architectural specification, it must be supplied with building stones of a proper pattern. These building stones are the amino-acids contained in all protein foods, whether from the vegetable or animal kingdom, although the kind and proportion are not always the same. Biological experiment has once for all definitely shown that life, growth and health cannot be maintained when certain of these aminoacids are lacking. It is also a well-known physiological axiom that life camnot be supported on foods deficient in inorganic salts. It is recognized at the present time that something more is essential for the maintenance, growth and well-being of man than protein, fat, carbohydrate, mineral salts, etc. Foods must contain a minute proportion of certain accessory substances, which Funk and his followers have described as "vitamines." When these are deficient, or absent from the dietary, the immature body fails to grow, the mature body does not maintain its normal state of health, and in any stage of growth, manifestations of disease soon appear. We know, for instance, that fresh milk prevents scurvy, and that boiled milk will produce this disease; that oatmeal causes more rapid and greater growth than bread made from the patent roller process flour; that wholemeal bread causes a greater growth than white bread; and that deficiency of vitamines in the foodstuffs causes beriberi, scurvy and some other diseases. Vitamines are beginning to be regarded as a sine qua non of proper nutrition. The subject is at present little understood, but it is so far-reaching that it involves a large proportion of the foods of civilized man. The lipoidal constituents of the diet, and the rôle these substances play in the life and metabolism of the cells, brings into prominence certain groups of disease due to phosphorus deficiency. Enzymes and the striking specificity of the lipoids have been studied of late by eminent physiologists, and the insufficiency of certain proteins has been pointed out by Osborne and Mendel, while the vitamines have been most earefully studied by Funk, Macallum and Vedder during the last few years, all of which investigations have added to the advaneement of dietetics. Since these discoveries are so important, and since as much seems to depend upon these accessory bodies - the vitamines, enzymes and lipoids-as on the primary elements of the diet, an attempt has been made in Volume II to give an account of the researches into these subjects, and to place the results in a proper light.

The subject of dietotherapy has not received the attention in medical literature it deserves, neither has it been accorded the prominence in the curriculum of medical schools which its importance demands; therefore, the subject has been and still is sadly neglected by the medical profession. 
Indeed, it is one of the most deplorably neglected subjects in the whole domain of medieine. While it is true that the question is more widely appreciated than formerly, yet the average practitioner is unable to tell the exact fuel value of a glass of lemon jelly or the definite amount of the various elements of food substances contained in a pound of beef; he might not be able to recognize the necessity for maintaining a carbohydrate, fat and protein balance, nor how to do it; he might not clearly understand how the metabolism in certain diseases differs from that of a healthy individual, nor appreciate what pathological processes take place in the alimentary canal and other parts of the body, that may render digestion and assimilation of particular foodstuffs difficult or impossible. Functional pathology has supplied the information required in the latter, while the actual, calorimetric study of metabolic processes in disease is illuminating the former.

I have undertaken the preparation of the present work with the purpose of overcoming these shortcomings, and of supplying the needs of the practitioner of medicine, the dietitian, the hospital interne and medical student, as well as of furnishing a reference work for the Domestic Science and Nurses' Training Schools.

This work is the outcome of nearly two decades of laboratory research and slinical investigation of the practical application of the principles of trophotherapy to the science of nutrition in both health and disease. The purpose of the work, from a purely therapeutic standpoint, is to awaken in the mind of the general practitioner the great importance for a biochemic study of nutrition, and to encourage in him a line of inquiry leading to a thorough understanding of the subject of trophology, trophodynamics and trophotherapy.

My aim in presenting a work on this subject in extenso is to produce a book so complete that few questions which may confront the physician or dietitian, pertaining to trophology, trophodynamics and trophotherapy, will remain unanswered. Recently, nutrition and dietetics have been placed upon a scientific basis, and in the future the thoughtful physician will realize that a knowledge of the proper kind and dosage of foods is of as great importance as any knowledge of therapentics.

I long since realized that, to produce a work of this kind, comprising all that is known or worth knowing, I must invite the coöperation of specialists in the science of nutrition. The authors who have honored me by collaborating and by writing certain chapters were selected because I considered them thoroughly equipped and able to write authoritatively upon the subjects assigned them. Their names, their reputations, 
and their literary productions are a guarantee for the quality of their contributions. My best thanks are due to all of these men for their ready coöperation, for the manner in which they have carried out the plan of the work, and for the time and labor they so cheerfully gave, often at great personal inconvenience. The readiness with which they complied with my request for assistance has rendered my own task an easy and pleasant one.

It is with grateful appreciation that I extend thanks to Prof. W. B. Cannon for reading the chapters, "The Mechanical Processes of Digestion" and "The Hygiene of Eating," and to Professor Donald D. Van Slyke for reading the chapters, "Protein and Nutrition" and "General Sitologic and Mineral Metabolism." I acknowledge special obligations to Prof. Carl Voegtlin for many valuable suggestions concerning the vitamine content of foodstuffs and its bearing on pellagra. Moreover, I also desire to express my obligations to Dr. Harvey W. Wiley for carefully reading and improving the chapter on Vegetable Foods.

The citation of authorities for facts that are universally established is not considered necessary. It may seem to appear, in some instances, that scant credit is accorded to many workers from whose writings I have borrowed thoughts, results, sometimes words or even sentences to bridge the gap in my own knowledge, but at the end of each chapter will be found a numbered list of references in loco; this is followed by a bibliography for the convenience of those who may wish to go deeper into the subject. In every case I have endeavored to make suitable acknowledgment to the proper source, and if this has not been done in any instance, it is a lapsus ralami, and not intentional.

W. Е. Fiтсн.

New York City. 


\section{PREFACE TO THE SECOND EDITION}

During recent years no subject in medicine has received the same amount of considerate attention as dietetics and the study of nutrition. Laboratory research and clinical investigation have placed Dietotherapy upon a scientific basis, and the thoughtful physician must, now, realize that a thorough understanding of the proper kinds, and dosage of foods will be of as great value to him as any knowledge of therapeutics.

The rapid progress of the newer knowledge of nutrition, since the appearance of the first edition, has made it necessary to entirely recast and rewrite the chapter on Vitamines; their necessity in the dietary; their classification; the foodstuffs in which vitamines $\mathrm{A}, \mathrm{B}$ and $\mathrm{C}$ prevail, and the peculiar action of each in the intricate process of nutrition; and to rewrite anew the entire chapter on Deficiency Diseases, including Beriberi, Scurvy, Rickets, and Pellagra, incorporating the latest findings of research workers and nutrition laboratories of this and other countries. A number of new additions have been made to the text, among which are Food Preservation, Dehydration, The Karell Cure, Oxaluria and numerous minor changes and emendations, throughout the work, to bring it abreast with the recent advances in the science of nutrition. The opportunity has been taken to eliminate typographical errors, and to change the wording in certain paragraphs where there was ambiguity of statement.

The cordial reception of the first edition of this work has been particularly gratifying to the author, indicating that the results of his efforts to awaken in the minds of the general practitioner the great importance for a biochemic study of nutrition, has met with the approval of the profession. This evidence of appreciation has added greatly to the endeavor to make this edition of more scientific interest and practical value than the first, 
and if this work should by chance stimulate further research into the science of trophology, trophodynamics and trophotherapy, the author's most cherished wish will have been attained. He also avails himself of the opportunity to thank his colleagues for many valuable suggestions and for their encouraging commendation of the work. Acknowledgment is also made to Doctors A. B. Macallum and Casimir Funk for their valued collaboration in this revision.

W. E. Fitch

New York City 


\section{LIST OF CONTRIBUTORS}

J. W. AMESSE, M.D.

Denver

A. EVERETT AUSTIN, A.B., A.M., M.D.

Boston

E. H. S. BAILEY, Ph.B., Ph.D.

U. S. Dept. Agriculture

ELIAS H. BARTLEY, B.S., M.D., A.M., F.A.C.P.

Brooklyn, N. Y.

A. L. BENEDICT, A.M., M.D., F.A.C.P.

Buffalo, N. Y.

GEORGE FRANK BUTLER, Ph.G., A.M., M.D.

Mudlavia, Ind.

JOHN H. CARROLL, M.D.

New York City

GEORGE W. CRILE, A.M., M.D., F.A.C.S.

Cleveland, Ohio

ALFRED C. CROFTAN, Ph.G., M.D.

Chicago

WILLIAM P. CUNNINGHAM, A.M., M.D.

New York City

W. A. NEWMAN DORLAND, A.M., M.D., F.A.C.S.

Chicago

WILLIAM EDWARD FITCH, M.D.

New York City

CASIMIR FUNK, D.Sc., Ph.D.

New York City

DAVID GEIRINGER, M.D.

New York City

H. S. GRINDLEY, B.S., Sc.D.

Urbana, Ill. 
WINFIELD S. HALL, B.S., M.S., M.D., Ph.D.

Chicago

GRAEME M. HAMMOND, A.M., M.D.

New York City

HENRY R. HARROWER, M.D., F.R.S.M. (Lond.)

California

JOHN C. HEMMETER, M.D., Ph.D., Sc.D., LL.D.

Baltimore

J. ALLISON HODGES, A.M., M.D., F.A.C.P. Richmond, Va.

WILLIAM C. HOLLOPETER, A.M., M.D., LL.D. Philadelphia

H. LYONS HUNT, M.D., L.R.C.P. (Edin.)

New York City

M. E. JAFFA, M.D.

Agri. Exp. Station, Berkeley, Cal.

RICHARD A. KEARNY, M.Ph., M.D.

Surg. U.S.P.H. Service

ROBERT COLEMAN KEMP, A.B., M.D.

New York City

ARTHUR I. KENDALL, B.Sc., Ph.D., Dr.P.H. Chicago

LE GRAND KERR, M.D., F.A.C.P.

Brooklyn, N. Y.

GEORGE N. KREIDER, A.M., M.D., F.A.C.S.

Springfield, Ill.

CLAUDE H. LAVINDER, M.D.

Surg. U.S.P.H. Service

H. EDWIN LEWIS, M.D.

New York City

A. BRUCE MACALLUM, A.B., M.D.

Toronto, Ont., Can. 
GEORGE M. NILES, M.D.

Atlanta, Ga.

S. J. NIISON, M.D.

New York City

EDWARD C. REGISTER, M.D.

Charlotte, N. C.

E. E. SMITH, Ph.D., M.D.

New York City

FREDERICK J. SMITH, A.M., M.D. (Oxon.)

F.R.C.P. (Lond.), F.R.C.S. (Eng.)

London

FRANK SMITHIES, M.D.

Chicago

THOMAS P. SHUPE, M.D.

Cleveland, Ohio

SAMUEL W. S. TOMS, Ph.G., M.D.

New York

JOHN W. TORBETT, B.S., M.D.

Texas

EDWARD B. VEDDER, A.M., M.D.

Lt. Col. M.C., U. S. A.

KARL VON RUCK, B.S., M.D.

Asheville, N. C.

ARThUR W. WEYsse, A.M., M.D., Ph.D.

Boston

TOM A. WILLIAMS, M.B.C.M. (Edin.)

Washington, D. C. 


\section{-}




\title{
CONTRIBUTORS TO VOLUME I
}

\author{
E. H. S. BAILEY, Ph.B., Ph.D.
}

Professor of Food Chemistry, and Director of Chemical Laboratories, Univ. of Kansas, Lawrence, Kansas; Collaborating Chemist

U. S. Department of Agriculture

A. L. BENEDICT, A.M., M.D., F.A.C.P.

Capt. Med. Res. Corps, U. S. A.; Consulting Gastro-Enterologist Buffalo Hospital, Buffalo, New York

WILLIAM E. FITCH, M.D.

Major Med. Res. Corps, U. S. A., New York City

JOHN C. HEMMETER, M.D., Ph.D., ScD., LL.D.

Professor of Physiology, Maryland University and College of Physicians and Surgeons, Baltimore, Md.

M. E. JAFFA, M.D.

Professor of Nutrition, University of California, College of Agriculture, Agricultural Experiment Station, Berkeley, Cal.

ARTHUR I. KENDALL, B.Sc., Ph.D., Dr.P.H.

Professor of Bacteriology, Northwestern University Medical School, Chicago, Ill.

E. E. SMITH, Ph.D., M.D.

President Academy of Sciences, New York City Formerly Professor of Physiology and Biological Chemistry, Fordham University Medical School, New York City

S. W. S. TOMS, Ph.G., M.D.

Capt. Med. Res. Corps, U. S. A.; Member Visiting Staff Nyack Hospital; Vice-President Medical Society of New York, Nyack, New York

ARTHUR W. WEYSSE, A.M., Ph.D., M.D.

Professor of Exper. Physiology, Boston University School of Medicine, Boston, Mass. 



\title{
CONTENTS
}

\author{
VOLUME I
}

CHAPTER I

THE EVOLUTION OF MAN'S DIET

General Introduction . . . . . . . . . . . . . . . . . 1

Diet Epochs . . . . . . . . . . . . . . . . . . . . 8

Precookery Period . . . . . . . . . . . . . . . . . . . . . . . 10

Simian Period . . . . . . . . . . . . . . . . . . . . . . . . 10

Homosimian Period . . . . . . . . . . . . . . . . . . . . . . 10

Precibicultural Cookery Period . . . . . . . . . . . . . . . . . . . . . 13

The Development of Cookery . . . . . . . . . . . . . . . . . . . . . . . 14

Systematic Use of Fire . . . . . . . . . . . . . . . . . . . . . . . . 14

Discovery of Cooking . . . . . . . . . . . . . . . . . . . 14

Evolution of Cookery . . . . . . . . . . . . . . . . . . . 14

Fire Applied to Meat . . . . . . . . . . . . . . . 15

The Food of Precibiculturists . . . . . . . . . . . . . . . . . . . . . 21

Cibiculturist Period . . . . . . . . . . . . . . . . . . . 32

Domestication of Animals . . . . . . . . . . . . . . . . . . . . . . . 32

Introduction of Agriculture . . . . . . . . . . . . . . . . . . . . . . 33

Changes in Bodily Structure and Function Due to Evolution . . . . . . . . . . 40

Modification Due to Variation of Diet . . . . . . . . . . . . . . 40

Modification Due to Evolution from an Arboreal Ancestor . . . . . . . . . . 42

Changes in Digestive Organs . . . . . . . . . . . . . . . . . . 43

Evolution of the Teeth . . . . . . . . . . . . 45

Changes in the Mammary Function Due to the Artificial Feeding of Children 48
General Summary . . . . . . . . . . . . . . . . 49

\section{CHAPTER II}

\section{CHEMISTRY AND PHYSIOLOGY OF DIGESTION}

Chemical Elements in the Human Body . . . . . . . . . . . . . . . . 53

Organic Compounds . . . . . . . . . . . . . . . . . . . . . . 54

Fats . . . . . . . . . . . . . . . . . 55

Carbohydrates . . . . . . . . . . . . . . . . 55

Proteins . . . . . . . . . . . . . . . . . . . 55

Albumins . . . . . . . . . . . . . . . . . . 55

Proximate Principles . . . . . . . . . . . . . . . . . . . . . . 55

Inorganic Compounds . . . . . . . . . . . . . . . . . . . . . . . . 55

Water . . . . . . . . . . . . . . 55

Acids . . . . . . . . . . . . . . . . . . . 55

Salts . . . . . . . . . . . . . . . 55

Scientific Classification of Foorls . . . . . . . . . . . . . . . . . . . 56

Nitrogenous . . . . . . . . . . . . . . . . . 56

Non-nitrogenous . . . . . . . . . . . . . . 56

Test to Determine Food Value . . . . . . . . . . . . . . . . . . 58

Chemical .. . . . . . . . . . . . . . . . . . 58

Physical . . . . . . . . . . . . . . . . . 58

Physiological : . . . . . . . . . . . . . . 60

Economic. . . . . . . . . . . . . . . . . . 61 


\section{CHAPTER III}

\section{CHEMISTRY AND PHYSIOLOGY OF THE PROXIMATE PRINCIPLES OF FOODSTUFFS}

E. E. Sмiтh, Рн.D., M.D.

Vitamines

Hormones

Enzymes

Proteins

Chemical Classification of Proteins. . . . . . . . . . . . . . 73

Simple Proteins . . . . . . . . . . . . . . . . . . 75

Conjugated Proteins . . . . . . . . . . . . . . . . . . . . 80

Derived Proteins . . . . . . . . . . . . . . . . . . 82

Carbohydrates . . . . . . . . . . . . . . . . 84

Classification of Carbohydrates . . . . . . . . . . . . . . . . 84

Monosaccharids .. . . . . . . . . . . . . . . . 84

Disaccharids . . . . . . . . . . . . . . . . . 87

Trisaccharids . . . . . . . . . . . . . . . . . . . . . 89

Polysaccharids . . . . . . . . . . . . . . . . . . . . . 89

Hydrocarbons . . . . . . . . . . . . . . . . . . . . . . 92

Terpenes . . . . . . . . . . . . . . . . . . . . 93

Aldehyds . . . . . . . . . . . . . . . . . . . . . . 94

Acids . . . . . . . . . . . . . . . . . . . 94

Esters 97

Pigments . . . . . . . . . . . . . . . . . . . . 101

Inorganic Salts . . . . . . . . . . . . . . . . . . . . 102

Water . . . . . . . . . . . . . . . . . 103

\section{CHAPTER IV}

\section{DESCRIPTION AND FUNCTIONS OF THE DIGESTIVE ORGANS}

S. W. S. Toмs, Pн.G., M.D.

Alimentary Tract . . . . . . . . . . . . . . . . . . . 108

Mouth . . . . . . . . . . . . . . . . . . 108

Pharynx . . . . . . . . . . . . . . . . . . 110

Esophagus . . . . . . . . . . . . . . . . . . . . 110

Stomach . . . . . . . . . . . . . . . . . 111

Small Intestine . . . . . . . . . . . . . . . . . . . . . . . . 111

Large Intestine . . . . . . . . . . . . . . . . . . . . . 113

Sigmoid Rectum. . . . . . . . . . . . . . . . . . . . 115

Digestive Glands . . . . . . . . . . . . . . . . . . . . . . . . 115

Duodenal Glands . . . . . . . . . . . . . . . . . . . . . . 115

Salivary Glands . . . . . . . . . . . . . . . . . . . . . 116

Parotid Glands . . . . . . . . . . . . . . . . . . . . 116

Pancreatic Gland . . . . . . . . . . . . . . 117

Spleen . . . . . . . . . . . . . . . . . . . . 118

Liver . . . . . . . . . . . . . . . . . 118

CHAPTER V

MECHANICAL AND CHEMICAL PROCESSES OF DIGESTION IN THE ALIMENTARY TRACT

Mastication of Food . . . . . . . . . . . 121

Insalivation. . . . . . . . . . . . . . . 123

Deglutition . . . . . . . . . . . . . . . 126

Nerve Action in Digestive Processes . . . . . . . . . . . 127

Secretion and Action of Digestive Juices . . . . . . . . . . . 130 
Functions of the Stomach. . . . . . . . . . . . . . . 133

Stomach as Reservoir . . . . . . . . . . . . . . . . . . . 133

Maceration of Food in the Stomach . . . . . . . . . . . . . 134

Sterilization of Food . . . . . . . . . . . . . . . . . 140

Regulation of Temperature . . . . . . . . . . . . . . . 140

Absorption of Food . . . . . . . . . . . . . . . . . 141

CHAPTER VI

\section{THE PHYSIOLOGY OF ENZYMES AND HORMONES AS APPLIED JN THE PROCESS OF DIGESTION}

Arthur W. Weysse, Ph.D., M.D.

Ferments . . . . . . . . . . . . . 145

Nature of Enzymatic Processes . . . . . . . . 146

Classification of Enzymes . . . . . . . . . . . . . . . . . . . 148

Proteolytic Enzymes . . . . . . . . . . . . . . . . . . . . . . . 148

Amylolytic Enzymes . . . . . . . . . . . . . . . . . . . . . 148

Fat-splitting Enzymes . . . . . . . . . . . . . . . . . . 148

Sugar-splitting Enzymes . . . . . . . . . . . . . . . . . . . . . 148

Peptolytic Enzymes . . . . . . . . . . . . . . . . . . . . . . . . 148

Coagulating Enzymes . . . . . . . . . . . . . . . . . 148

Oxidizing Enzymes

Specific Action . . . . . . . . . . . . . . . . . . . . . 150

Temperature Control . . . . . . . . . . . 150

Reversibility ...................... 150

Gastric Digestion . . . . . . . . . . . . . . . . 159

\section{CHAPTER VII}

\section{PHYSIOLOGY OF ABSORPTION}

John C. Hemmeter, M.D., Ph.D., Sc.D., LL.D.

Absorptive Powers of the Digestive Organs . . . . . . . . . . . . . . . . . 163

Absorption in the Stomach . . . . . . . . . . . . . . . . . . . . . . . 163

Absorption in the Small Intestine . . . . . . . . . . . . . . . . . . . . . 169

Absorption in the Large Intestine . . . . . . . . . . . . . . . . . . . . . 174

Absorption of Foods . . . . . . . . . . . . . . . . . . 177

Fats . . . . . . . . . . . . . . 178

Carbohydrates . . . . . . . . . . . . . . . . 184

Protein Absorption

The Rôle of the White Blood Corpuscles in the Absorption of Food . . . . . . . . 203

Osmosis, Dialysis and Diffusion . . . . . . . . . . . . . . . . . . 204

Filtration. . . . . . . . . . . . . . 207

\section{CHAPTER VIII}

\section{BACTERIAL DECOMPOSITION OF FOOD IN THE GASTRO-INTESTINAL TRACT DURING THE PROCESS OF DIGESTION}

Arthur I. Kendall, B.S., Ph.D., Dr.P.H.

Experimental Observations of Bacterial Metabolism . . . . . . . . . . . 211

Nature of Bacterial Metabolism . . . . . . . . . . . . . . . . . . . 214

Gastro-Intestinal Bacteriology

Normal Infants . . . . . . . . . . . . . . . . . . . . . . . 224

Adolescents . . . . . . . . . . . . . . . . . . . 225

Adults . . . . . . . . . . . . . . . . . . . 225

Regional Bacteriology . . . . . . . . . . . . . . . . . . . . . . 226 


\section{CHAPTER IX}

\section{GENERAL CLASSIFICATION OF FOOD}

Nitrogenous and Non-Nitrogenous Foods . . . . . . . . . . . . 231

Definition of Food . . . . . . . . . . . . . . . . . . . 232

Classification of Foods . . . . . . . . . . . . . . . . 232

Foodstuffs . . . . . . . . . . . . . . . . . . . . . 233

Combinations . . . . . . . . . . . . . . . . . . 233

Chief Elements . . . . . . . . . . . . . . . . . . 234

Accessory Substances . . . . . . . . . . . . . . . . 234

\section{CHAPTER X}

\section{WATER IN THE BODY AND IN FOODS}

Composition of Water . . . . . . . . . . . . . . . . . . . 238

Physical and Chemical Properties . . . . . . . . . . . . . . . 238

Substances in Suspension and Solution . . . . . . . . . . . . . . . . . 239

Sources of Water . . . . . . . . . . . . . . . . . . . . . . 244

Uses of Water in the Human System . . . . . . . . . . . . . . . . . . . 248

Eliminative Function . . . . . . . . . . . . . . . . 248

Function as Food . . . . . . . . . . . . . . . . . . . . . . . . 248

Aid in Digestion.

Diuretic and Diaphoretic Function . . . . . . . . . . . . . 250

\section{CHAPTER XI}

\section{THE MINERAL CONTENT OF THE BODY AND OF FOODS}

General Considerations. . . . . . . . . . . . . . . . . . . 255

Utilization of Mineral Substances . . . . . . . . . . . . . . . 259

Form of Mineral Salts in the Body . . . . . . . . . 259

Function of Salts in the Body . . . . . . . . . . . . . . . . . . 262

Mineral Content in Foods . . . . . . . . . . . . . . . 265

Calcium . . . . . . . . . . . . . . . . . . . . 265

Magnesium . . . . . . . . . . . . . . . . . . . 265

Iron . . . . . . . . . . . . . . . . . 266

Sodium and Potassium . . . . . . . . . . . . . . . . . . . . . . 269

Sulphur . . . . . . . . . . . . . . . . 272

Iodin . . . . . . . . . . . . . . 273

Fluorin and Silica . . . . . . . . . . . . . . . . 274

Bromin . . . . . . . . . . . . . . . 274

Oxalic Acid . . . . . . . . . . . . . . . . . . . . . . . . . 274

Manganese . . . . . . . . . . . . . . . . 275

CHAPTER XII

ANIMAL AND FISH FOODS

E. H. S. Balley, Рh.B., Ph.D.

Meats . . . . . . . . . . . . . . . . . 277

Meat Extracts . . . . . . . . . . . . . . . . . . . . 287

Gelatin and Gelatin Foods . . . . . . . . . . . . . 293

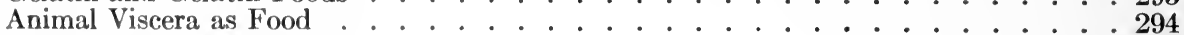

Domestic and Wild Fowl . . . . . . . . . . . . . . . . . . . .296

Fish and Shell Fish . . . . . . . . . . . . . . . 300

Milk and Milk Products . . . . . . . . . . . . . . . . . . . . . 307

Eggs and Egg Products . . . . . . . . . . . . . . 349 
CHAPTER XIII

VEGETABLE FOODS

General Considerations . . . . . . 365

Chemical Characteristies . . . . . . . . . . . . . . . 365

Food Value . . . . . . . . . . . . . . . 367

Nutritive Substances . . . . . . . . . . . . . . . 367

Digestion and Absorption. . . . . . . . . . . . . . . . . . . . . . 371

Varieties of Vegetable Foods . . . . . . . . . . . 375

Cereals . . . . . . . . . . . . . . . . . . . 375

Breakfast Foods . . . . . . . . . . . . . . . . . . . . . 404

Roots and Tubers . . . . . . . . . . . . . . . . . . . . . 409

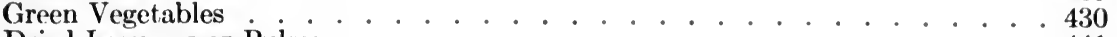

Dried Legumes or Pulses . . . . . . . . . . . . . . . . . . . . . . . 441

Fungi, Lichens, Algae . . . . . . . . . . . . . . . . . . . 447

\section{CHAPTER XIV}

FATS AND OILS

General Considerations . . . . . . . . . . . . . . . . . 4457

Importance of Fats . . . . . . . . . . . . . . . 459

Animal Fats . . . . . . . . . . . . . . . . . . . . 461

Butter . . . . . . . . . . . . . . . . 461

Lard . . . . . . . . . . . . . . . . . . . . . 465

Suet . . . . . . . . . . . . . . . . . . . 4 466

Tallow . . . . . . . . . . . . . . . . . . . 466

Oleomargarin . . . . . . . . . . . . . . . . . . . 466

Vegetable Fats . . . . . . . . . . . . . . . . . . . . . . . . . . .

Value of Vegetable Fats . . . . . . . . . . . . . . . . . . 467

Absorption of Vegetable Oils . . . . . . . . . . . . . . . . 467

Almond Oil . . . . . . . . . . . . . . . . . . . . . . . . . . . . . . . 469

Olive Oil . . . . . . . . . . . . . . . . . . . . . . . . . . . . 469

Peanut Oil . . . . . . . . . . . . . . . . . . . . . . 469

Cottonseed Oil . . . . . . . . . . . . . . . . 470

CHAPTER XV

FRUITS, NUTS AND GARDEN FRUITS

M. F. JAFFA, M.D.

General Considerations . . . . . . . . . . . . . . . . . . 475

Classification of Fruits . . . . . . . . . . . . . . 476

Composition of Fruits . . . . . . . . . . . . . . . . . . . . . . . 477

Importance of Fruits . . . . . . . . . . . . . . . . . . . . . . 479

Digestion and Absorption of Fruits . . . . . . . . . . . . . . . . . . 479

Tree Fruits . . . . . . . . . . . . . . . . . . . . . 480

Ampelidaceous or Vine Fruits . . . . . . . . . . . . . . . . . . . . . . . . 496

Small Bush Berries . . . . . . . . . . . . . . . . . . . . . . . . 498

Herb-like Fruits . . . . . . . . . . . . . . . . . . . . . . 502

Nuts . . . . . . . . . . . . . . . . . . . . . 504

Garden Fruits . . . . . . . . . . . . . . . . . . . 512

Preservation of Fruits by Cold Storage . . . . . . . . . . . . . 515

CHAPTER XVI

WATER, BEVERAGES, MALT LIQUORS, STIMULANTS, WINES, CIDERS AND VINEGARS

Waters . . . . . . . . . 519

Classification of Waters . . . . . . . . . . . . . 521

Drinking of Water at Meals . . . . . . . . . 538 
Beverages . . . . . . . . . . . . . . . . . 539

Теа...................... . . . 540

Coffee . . . . . . . . . . . . . . . . . . . . . 545

Cocoa . . . . . . . . . . . . . . . . . . . . . . . 551

Chocolate . . . . . . . . . . . . . . . . . . 555

Nutritive Value of Beverages . . . . . . . . . . . . . . . . . . 558

Deleterious Effects ot Their Use . . . . . . . . . . . . . . . . . . . . . 559

Malt Liquors . . . . . . . . . . . . . . . . . . . . . . . . . . . . 559

Preparation of Malt Liquors . . . . . . . . . . . . . . . . . . 560

Composition of Malt Liquors . . . . . . . . . . . . . . . . . . 561

Action of Malt Liquors on Digestion . . . . . . . . . . . . . . . . . . . 566

Stimulants . . . . . . . . . . . . . . . . . 568

Effects of Alcohol on the Body . . . . . . . . . . . . . . . . . . . 570

Whiskey . . . . . . . . . . . . . . . . . . . 582

Brandy. . . . . . . . . . . . . . . . . . . . . . . 585

Gin . . . . . . . . . . . . . . . . . . . . 587

Liqueurs . . . . . . . . . . . . . . . . . . . . . . 587

Use of Alcohol . . . . . . . . . . . . . . . . . . . . . . . . . . . . . 592

Wine. . . . . . . . . . . . . . . . 594

Preparation of Wine . . . . . . . . . . . . . . . . . . 595

Varieties of Wines . . . . . . . . . . . . . . . . . . . . . 596

Effects of Wine on Digestion . . . . . . . . . . . . . . . . 600

Wine as Source of Nutriment . . . . . . . . . . . . . . 601

Use of Wines . . . . . . . . . . . . . . . . . . . . . . . . . . 601

Cider, Perry - . . . . . . . . . . . . . . . . . . 602

CHAPTER XVII

SUGAR, SPICES AND CONDIMENTS

Sugar . . . . . . . . . . . . . . . . . . . . 609

Sugar Cane . . . . . . . . . . . . . . . . . . . . 609

Beet Root Sugar . . . . . . . . . . . . . . . . . . . . . . . . . . . .614

Sorghum Sugar . . . . . . . . . . . . . . . . . . . . .616

Palm Sugar . . . . . . . . . . . . . . . . . . 618

Principles of Sugar Refining. . . . . . . . . . . . . . . . . . 620

Molasses . . . . . . . . . . . . . . . . . . . . . 622

Sirup . . . . . . . . . . . . . . . 622

Confectionery . . . . . . . . . . . . . . . . . . . 627

Honey . . . . . . . . . . . . . . . . . . . 628

Digestibility of Sugar . . . . . . . . . . . . . . 631

Value of Sugar as Food . . . . . . . . . . . . . 635

Spices and Condiments

Value of Spices and Condiments . . . . . . . . . . . . . . 639

Sources of Condiments and Spices . . . . . . . . . . . . . . . . . . . . . 640

Stems and Leaves . . . . . . . . . . . . . . . . . . . . . 640

Buds and Flowers . . . . . . . . . . . . . . . . . . . . . . 642

Barks . . . . . . . . . . . . . . . . . . . 643

Roots or Rootstalks . . . . . . . . . . . . . . . . . . . 644

Immature and Ripe Fruits . . . . . . . . . . . . . . . . . . . . 645

Seeds . . . . . . . . . . . . . . . . 647

Pickles and Salads . . . . . . . . . . . . . . . . . 651

\title{
CHAPTER XVIII
}

\section{TOXIC SUBSTANCES OF EDIBLE FOODS-SOME CONSEQUENT DISEASES}

\author{
A. L. Benedict, A.M., M.D., F.A.C.P
}

Source in Vegetable Foods of Toxic and Medicinal Substances. . . . . . . . 657

Diseases Caused by Various Food Poisons . . . . . . . 662 


\section{CHAPTER XIX}

ANAI,YSIS OF AMERICAN FOODS-FUEL VALUE PER POUND AND PER PORTION

Meaning of Protein

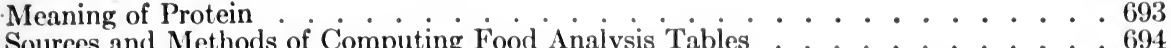

Composition of Food Materials . . . . . . . . . . . . . . . . 695 Atwater and Bryant's Average Chemical Composition of American Food Ma-

terials . . . . . . . . . . . . . . 702

\section{CHAPTER XX}

UNUSUAL ANIMALS, BIRDS, REPTILES, ETC., SOMETIMES USED FOR FOOD

Alphabetical List of Unusual Animals . . . . . . . . . . . . 763-775

INDEX . . . . . . . . . . . . . . . . . . . . 781 



\section{LIST OF ILLUSTRATIONS}

\section{VOLUME I}

FIGURE

1.-Stone-Boiling. Lifting the Hot Stones into the Food Basket......... 18

2.-Stone-Boiling. Removing the Stones from the Boiling Basket........ 18

3.-Pueblo Indians Planting Corn ...................... 23

4.-Chart illustrating the Pecuniary Economy of Various Meats, Milk and

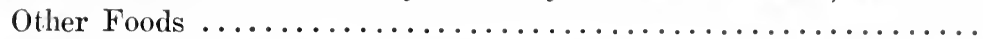

5.-Esophagus, Curvatures of the Stomach and the Situation of the Pars Pyloriea, the Descending and Inferior Duodenum. . . . . . . . . . . . 109

6 . The Normal Stomach . . . . . . . . . . . . . . . . . . . . . . . . . 110

7.-The Longitudinal Fibers of the Musculature of the Stomach.......... 111

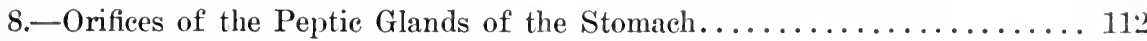

9.-The Greater and Lesser Curvatures of the Stomach............. 112

10.-The Duodenum in its Anatomical Relations............... 113

11.-Diagram of the Alimentary Canal, Stomach, Liver, Pancreas and the

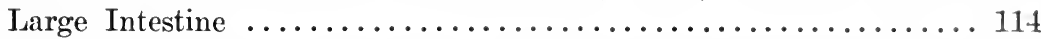

12.-The Duodenum Opened, Showing the Valrulæ Conniventes, and the Open-

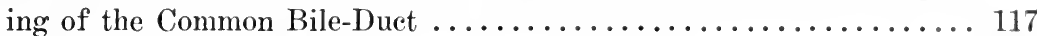

13.-Circular Fibers of the Musculature of the Stomach.............. 123

14.- Series of Radiographs Showing the Diastole and the Systole in the Mechanical Movements of the Stomach.................... 135

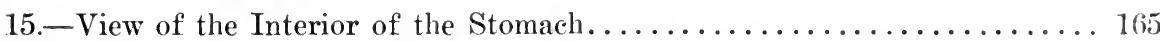

16.-Stomach, Intestines and Mesentery; Vessels and Lacteals.......... 170

17.-Lymphaties of the Trunk, Including the Thoracic Duct.......... 173

18.-Chemical Composition of Poultry in Comparison with Steak or Chop.... 298

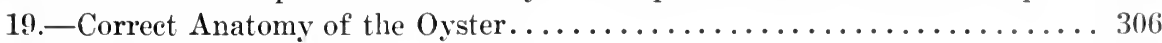

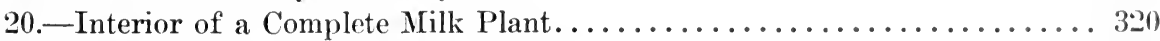

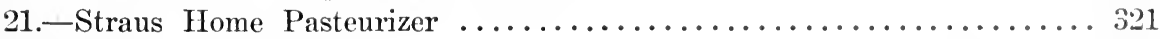

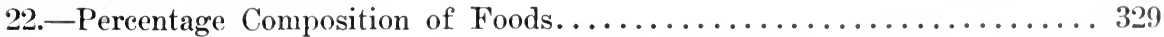

23.-Percentage Composition and Fuel Value per Pound of Whole Milk and

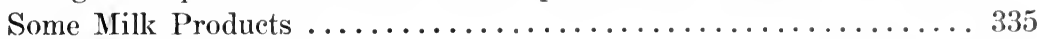

24.-Percentage Composition and Fuel Value per Pound of Butter, Cheese and

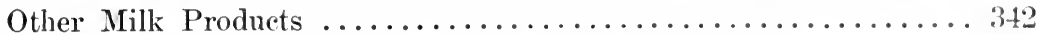

25.-Appearance of Different Grades of Eggs before the Candle......... 350

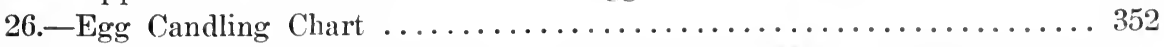

27.-Chemical Composition of Eggs as Compared with Milk, Beefsteak, Cream

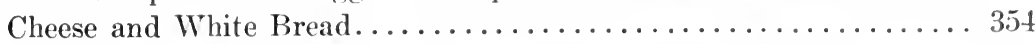

28.-Chemical Composition of Whole Egg, Egg White, Egg Yolk, Desiceated

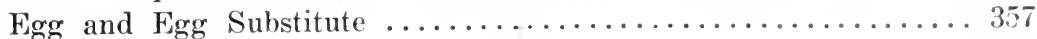

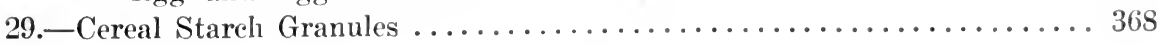


30.-Diagrammatic Section of a Grain of Wheat.................. 377

31.-Diagrammatic Section of a Grain of Corn................... 393

32.-Transverse and Longitudinal Sections of the Potato............. 411

33.-Composition of the Potato .......................... 412

34.-Composition of Common Starehy Root Vegetables .............. 415

35.-Composition of Some Suceulent Vegetables as Compared with Milk.... 419

36.-Composition of the Carrot and the Loss of Nutrients when Boiled..... 421

37.-Percentage Composition of Carrot, Onion, Beet and Other Root Vegetables

Compared with Each Other and with Bread................. 424

38. -Dasheen Plant at Brookville, Florida..................... 426

39.-An Eleven-Pound Hill of Dasheen Corms and Tubers, with Soil and Roots .

Removed, in Actual Position of Growth................. 427

40.-Dasheen Cormels, or "Tubers" .......................... 427

41.-Composition and Fuel Value of the Tomato................. 437

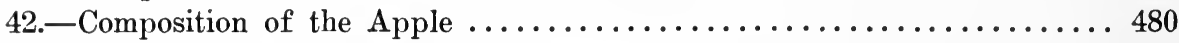

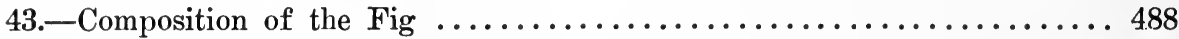

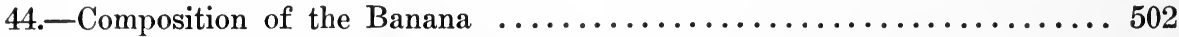

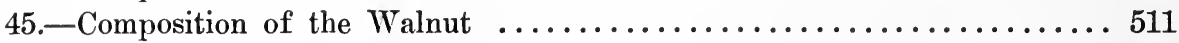

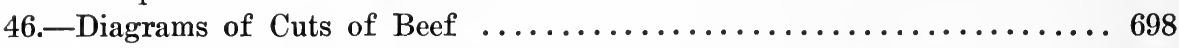

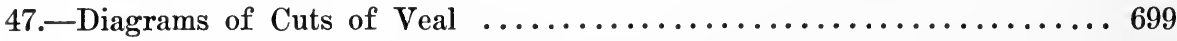

48.-Diagrams of Cuts of Lamb and Mutton .................... 700

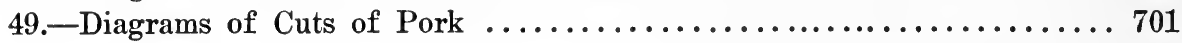




\title{
DIETOTHERAPY
}

\author{
VOLUME I
}

\section{CHEMISTRY AND PHYSIOLOGY OF DIGESTION CLASSIFICATION AND ANALYSIS OF FOODS}

\section{CHAPTER I}

\section{THE EVOLUTION OF MAN'S DIET}

Adam-the father of mankind-came into life fasting, and the newborn babe comes into the world crying and is calmed only at its mother's breast. Eating is a necessity which has led to cookery-an art that has rendered the most important service to society, for it has brought into play the application of fire by which man has subjugated Nature.

Diet Epochs: Precookery Period; Precibicultural Cookery Period; Cibicultural Period.

Changes in Bodily Structure and Function due to Evolution: Modifications due to Diet; Modifications due to Evolution from an Arboreal Ancestor; Teeth, Digestive Organs, Mammary Glands.

Summary of Dietary Influence upon Man's Evolution.

\section{GENERAL INTRODUCTION}

The evolution of man's diet is part of his general evolution, and diet has had considerable influence on this evolution. A work on nutrition and dieteties, therefore, should deal with the changes of man's diet from early times, in so far as this knowledge may be of value for the prevention of disease, and may afford the physician an intelligent insight into the many and diverse disorders which proceed from the consumption of unsuitable food. This will be the object of the following résumé of the chief facts known concerning the evolution of man's diet.

In so far as diet is concerned, the mammalia may be divided into three classes: the carnivora, the herbivora, and the frugivora. 
As the name implies, the carnivora are flesh eaters solely. Since a meat diet is concentrated to a high degree, the capacity of the digestive system of the carnivora is, accordingly, small in proportion to the body weight.

On the other hand the herbivora, which maintain life by eating grasses, leaves, and the like, must eat large quantities in order to obtain sufficient nutriment. Their food is bulky, the reverse of concentrated, and their digestive system is of capacious character. They eat no animal food. The horse, ox and rabbit are examples of the herbivora.

The frugivora, to which group man belongs, also include the more intelligent of the animals, for example, the squirrel, rat, monkey, lemur and ape. Not only have these animals more acute and superior reasoning faculties than herbivora, but owing to their prehensile powers, they are better adapted bodily to select their food. They exhibit their superiority by their cleverness in obtaining food in more concentrated forms; consequently their digestive apparatus is much less bulky. Agile in brain and limb, they are able to procure animal food which, according to Dr. Harry Campbell(1), is "of all foods the most nutritious." Squirrels eat eggs in addition to nuts, and several members of the monkey tribe, as well as the great apes, not only consume fruits, but also small birds, eggs, lizards, grubs, insects and honey. West African monkeys are fond of shellfish and oysters. Probably our Pliocene ancestors lived upon the same sort of food.

One condition may be deduced from a study of the evolution of man and of his diet: namely, that in the early stages of alteration of food and habits he must have been accustomed to a congenial climate and an abundance of the food. The climate suited to the race in its infancy was tropical or semitropical and the food of primeval man was easy to obtain. Nan was then an arboreal creature.

DIET OF PRIMATES BELOW MAN.-In considering the evolution of man's diet as a phase of the evolution of man, it will be apposite to discuss the diet of those animals nearest to man, from anatomical and physiological points of view as well as habits. Such animals and man are known to zoölogists as coming under the order Primates, and include the lemur-like animals and the Anthropoidea or manlike apes.

It appears likely that the first Primate originated in North America. The great group of monkeys also appeared in the Eocene era of North America, and later, in South America. Scott Elliott(2) has pointed out that one of the South American apes enjoys the name of Homunculus patagonicus. According to Macnamara, even at and before the beginning 
of the Miocene period certain apes had no less than 170 structural characters in common with man; the giant apes of the early Miocene perion had 150 of these common characters, annming to over 300 in the midMiocene chimpanze-like form. Among the species of anthropoid apes now extant, the great tailless apes, including the gorilla, the chimpanzee and the gibbon, are the most similar to the human species. The monkeys are likewise members of this family. The baboons are the highest representatives of these and the marmosets the lowest. Nuttall has shown that, tested by the blood precipitin test, the great apes are the most closely allied to man, the baboons standing next, while the lemuroids give no indication of biood relationship.

It is more than likely that our Pliocene ancestors ate very much the same kind of food as the lemurs, the anthropoid apes and the forest pygmies of the present day. With respect to the diet of monkeys, in the main it is frugivorous, but partly animal, as was the diet of prehistoric man in his early stages. "Their animal food comprises birds, birds' eggs, miee, lizards, frogs, shellfish, grubs, scorpions, centipedes and insects"(1). Honey is eaten by some of the baboons, and indeed honey appears to have been essentially a simian food and was a valuable source of nutriment to our early forebears. Gum constitutes an article of diet of the baboons and of other monkeys. The regetable foods of the monkeys include fruit, seeds, roots, tender shoots and leaves.

There is a certain general similarity between men and monkeys, both anatomically and in dietetic inclinations.

Ordinarily in his quest for food the monkey exhibits a certain degree of intelligence, a high degree, judged from the standard of the lower animals. Baboons will dig up roots and lift up stones in the search for insects, which seems to indicate that the early use of their hands is an hereditary trait which they have handed down to man. Moreover, some monkeys fight in the same way as primitive man by hurling stones and other missiles at their enemies; baboons throw stones for the same purpose; while evidence goes to show that pitehed battles occur among certain species of langurs for the possession of feeding grounds, a fruitful and, perhaps, the most common cause of war among men through all the ages(3). A great number of observers have reported that in the early Spanish days in South America the Mreetes monkey used to defend itself by throwing stones. Wafer and Yres d'Erreux have reported that they saw monkeys break oyster shells and crack fruit with stones. 
The great apes feed, on the whole, in the same way as the monkeys. They are chiefly frugivorous, subsisting also on a vegetable diet in concentrated forms, and are animal feeders to a small extent, when vegetable food is difficult to procure. In addition to the forms of vegetable food eaten by monkeys, the great apes will, in stress of circumstances, devour rats, mice and other small animals and even birds. There appears to be no record of their consuming shellfish, nor is there evidence that they eat honey, but in view of the fact that monkeys appreciate both shellfish and honey, it would seem quite within the nature of things that the great apes should also do so on occasion.

To sum up the diet of the animals most closely allied to man as represented by that of the monkey and great apes, we find that it consists mainly of concentrated vegetable foods and of highly concentrated anjmal foods taken in much smaller quantities. Much of the food of the primates below man is, from its character, unsuitable for human consumption, showing that the evolution of man progressed pari passu with his diet.

The Food of Evolving Man.-The food of the evolving man was mainly of a vegetable nature. He could obtain but little animal food, chiefly in the form of fish, birds and birds' eggs, shellfish, lizards, snakes, frogs, grubs, worms, snails, insects and caterpillars. But, notwithstanding the fact that it was extremely difficult for our prehistoric ancestor to procure animal food, it must yet be borne in mind that the food supplied by the vegetable kingdom was inadequate for his subsistence. He had a very limited choice; the vegetables from which he could choose were woefully lacking in nutritive properties. Seeds supplied the most important constituent of his diet, because they contained the largest amount of protein. Under this heading are included fruits, seeds contained in a brightly colored, fleshy envelope. When the fruit is ripe the majority of these envelopes consist for the most part of dilute solutions of sugar and salts, which furnish little energy. The inner portion, the seeds, unless thoroughly masticated, are indigestible to the mammalia.

Roots formed a staple of the diet of primitive man, owing to the comparative ease with which they could be secured. Many of these roots afforded scant nourishment, their nutrient value depending chiefly upon the richness of their starch content. The fleshy roots were the only ones of value, and their value was in more or less exact relation to their richness in starch.

ROOT FOOD OF THE NORTH AMERICAN INDIANS.-In this connection it is both interesting and instructive to note that the North American Indians largely used roots as food. Plants of the lily family furnished 
the most abundant and useful root food of the Indians throughout the Western Hemisphere. The Eskimos of Kowakar ate roots of the wild parsnip, which they secured from the caches in the nests of field mice. The Indians of Cape Flattery ate camas bulbs, as well as equisetum roots, and roots of fern, grass, water plants, clover, cinquefoil and eelgrass. Equisetum tubers and eelgrass roots were eaten raw; other roots were boiled by means of hot stones or baked in pit ovens. Camas was a staple root food from the Wasatch Mountains in Utah, northward and westward. It was an article of widespread commerce, influenced the migration of tribes, and might have become in time the basis of primitive agriculture, notably in the valley of Columbia River. Leiberg said, "Every meadow was a camas field." The plant was so plentiful in many places that it is no exaggeration to say that in the Upper St. Mary basin more than half of the total herbaceous vegetation in the lowlands was composed of this one species. The Skitswish people congregated here in the summer to dig camas and to hunt deer. The root was dug with a sharp pointed stick. In part of this area, the kouse root, second only in importance, was dug in April and May, before camas was in season. This root is the racine blanche of the Canadian voyageurs. It was pounded and made into thin cakes a foot wide and three feet long.

The tubers of the arrowhead plant were widely used in the Northwest for food. The Chippewa and Atlantic Coast Indians also made use of them. The roots of the cat-tail and bur reed were eaten by the Klamath of Oregon, who used also the roots of carum, calochortus and valerian. The Nez Perces of Idaho also ate balsam root.

The pomme blanche, Indian turnip, or prairie potato, was prized by tribes living on high plains from the Saskatchewan to Louisiana and Texas. The Sioux varied their diet with roots of the Indian turnip, two kinds of water lily, the water grass and the ground nut. To these may be added the tuber of milkweed and the root of the Jerusalem artichoke eaten by the Dakotas of St. Croix River. Other tribes of the plain gathered esculent roots to eke out their food supply, among them the immense roots of the wild potato. The Miami, Shawnee and other tribes of the Middle West ate the "man of the earth" and the Jerusalem artichoke. As a result of the universal habit among Californian tribes, especially the Paiute, of gathering food roots, the name "Diggers" was applied to them by the early settlers.

The esculent roots growing in great variety in California were a considerable addition to the Indian larder. Among the plants thus utilized were the brake, tule, calochortus, camas and various lilies. Calochortus 
bulbs, called wild sago, were eaten also by the tribes of Utah and Arizona. The bulbs were starchy and palatable, and it is said that the Mormons during their first few years in Utah consumed this root extensively. In the Southwest few edible roots are found. The Hopi, Zuni, and other tribes eat the tubers of the wild potato. The Pinia, Hopi, and other Arizona tribes habitually chewed the roots of certain plants having sweet or mucilaginous properties. The Seminole of Florida possessed a valuable plant called coontie, the bulbous starchy root of which was converted into flour. Although the use of edible roots by the Indians was general, they nowhere practiced root cultivation, even in its incipient stages.

SUPPOSED DIET OF PRIMITIVE MAN.-Some writers and most poets have depicted in glowing words the happy lot of early man. This Utopian view pictures him as having lived in a lovely warm climate, in which nature exhibited herself in the utmost luxuriance. $\mathrm{He}$ dwelt in a land "flowing with milk and honey," metaphorically speaking, with no need to exert himself to obtain his daily bread. A profusion of products of the vegetable world surrounded him on all sides and he merely had to lift up his hand to gather the most delicious food imaginable. The reality was far from this Utopian conception, which was a product of a vivid or fevered imagination. The food which he was able to obtain easily was scarcely worth the gathering, and in order to satisfy the pangs of hunger and to sustain existence, he was compelled to put himself to much trouble and to undergo many dangers. This is known from the fact that certain races, whose mode of life approximates most closely that of the primitive dwellers on earth, have the greatest difficulty in eking out a miserable existence. The impossibility of modern civilized man leading a vigorous life on vegetable food alone is also shown by the experiences of those who, despite the vastly improved methods of preparing and enhancing the nutritive value of such food, are unable even to subsist on a vegetable diet solely.

THE INFLUENCE OF CULTIVATION ON NUTRITIVE PROPERTIES OF VEGETABLES.-One can hardly conceive to how great an extent cultivation has increased the nutritive value of the products of the vegetable kingdom. Fruits which grow wild are seldom highly nutritious. In their natural state, as a rule, they are small, shriveled and acrid, and, as a source of energy and nutriment, almost a negligible quantity. A striking evidence of this deterioration is afforded when a cultivated fruit, as the apple, is allowed to revert to a wild state. It will not be long before the formerly luscious, sweet tasting fruit becomes a meager, hard, sour and disagreeable article of diet. The truth is that fruits and vegetables, as sup- 
plied to the modern markets, are highly finished products of civilization, as Campbell puts it, "Dating back into an impenetrable past and searcely to be identified with their wild and barely elible congeners." Wild fruits afford but a scant and inadequate supply of nourishment to man, and it may be accepted as an axiom that frults of every description owe their present state of perfection to centuries of the most careful cultivation.

FACTORS WHICH HAVE DETERMINED THE CHOICE OF FOOD.The food of an evolving species is neressarily determined and regnlated by enviromment, that is by the floral and fauna of the locality in which it lives, by the attractiveness of certain kinds of food and by the ability to procure such food. The kind of food available is almost wholly a question of climate and need not be discussed here. With regard to a man's predilection for certain kinds of food, it is a fact, as Campbell has pointed out, that the tendency of every animal is to seek food of the most concentrated and of the most digestible and palatable kind. Of vegetable foods, seeds and roots best fulfill these requirements. The ideal vegetable food is that which contains the most starch, sugar, proteins and fats and the least indigestible cellulose and other unpalatable ingredients. Such regetable foods are most nutritive and agreeable, and consequently the most popular, and offer a sufficient explanation why, in the course of his evolution, man has discarded certain products of the vegetable world from his dietary. However, according to Campbell, of all natural food, animal tissue is at once the most concentrated and, by those possessed of the proper digestive organs, the most easily digested. Given favoring cirenmstances, all animals tend to become carnivorous. The reverse is scarcely ever the case.

Palatability of food varies with the species. Force of habit necessarily wields a certain amount of influence. A food to which an animal has become accustomed by generations of use becomes the natural dict, and even highly cultivated man is influenced in the same direction. A Scotchman "swears by" oatmeal, a Japanese by rice, an Italian by spaghetti, and an Englishman or an Australian by beef or mutton. Man's tendency to favor concentrated, digestible and nicely flavored food in preference to the coarse, bulky, sour and indigestible food that is consumed by the primates below him is strikingly shown by the manner in which he has cultivated his foodstuffs. Among highly cultivated races with whom cooking has become a fine art, this tendeney may have been carried to excess and the pendulum has swung too far in the opposite direction, so that too much delicately flarored and predigested food is eaten. This criticism applies more to the preparation of food, especially cereal foods, 
than to its cultivation. For many and obvious reasons, coarse cerealsthose which are not highly milled-are better on the whole than the smooth decorticated preparations.

The ability to secure the wished for food is one of the most important factors in the evolution of man's diet. Intelligence and bodily equipment count for much in the successful quest. A stupid animal with weak physical powers must be content with a bulky, unpalatable, monotonous food supply; whereas, to a large extent, an agile, acute animal, like the fox, is able to procure a diet to its taste.

SUMMARY.-The evolution of man's diet has been influenced chiefly by the above considerations. We have seen that the diet of the great apes and monkeys is mainly a coarse food, mostly vegetable but also partly animal. The configuration of the digestive organs of many of these animals is an evidence that they are descended from animals with large ceca and shows that these ancestors consumed a much more bulky diet. The tendency of the evolving primate then is to abandon the herbivorous for a frugivorous diet and to eat some flesh.

\section{DIET EPOCHS}

The plan of this chapter dealing with the evolution of man's diet is arranged in a similar manner to the chapter on the same subject contributed by that very able medical writer, Dr. Harry Campbell(1), but before discussing the diet epochs, it may not be out of place to make some remarks on the evolution of man.

Evolution of Man.-It has been suggested by Scott Elliott that the primates had a common Eocene ancestor whose descendents had adopted four distinct and different modes of life. "One group remained nocturnal, fruit and insect eaters who lived in trees; these are now represented by the lemurs. Others, now monkeys, went about in trcops, feeding by day upon nuts, fruits and birds' eggs. A third group had specialized on the lines which led to the modern gibbon, orang, gorilla and chimpanzee; they were animals of the tropical jungle with powerful jaws and muscles, as well as with sufficient strength and ferocity to keep at bay any ordinary enemy. These also lived in trees."

"The question is, was there a fourth group which contained our special ancestor. If so, it seems likely that he lived also more or less in the branches, and there is some anatomical evidence which points to this conclusion. If he used eoliths, he must have hunted in the daytime; he may 
have frequented those woods which were near the seashore or on the margin of great lakes, since suitable stones for eoliths are more numerous by far on the shores of seas or lakes than in dense forests." Moreover, if he lived on oysters and shellfish, eoliths would be invaluable. It is held by, some that these eoliths or flints of various ages which have been struck or chipped in an unusual way were the handiwork of IIomosimius precursor, the scientific name for Oligocene man. This hypothetical man as well as the flints he is supposed to have shaped are but interesting speculations. The more common belief which rests on the most secure foundation is that which traces the ascent of man by a series of evolutionary processes from a primate.

SHAPE AND DEVELOPMENT OF THE SKULL.- "The most remarkable of all the differences between man and his presumably nearest of kin in the animal world lies in the shape and extraordinary development of the skull'(1). Although this matter has no direct bearing on the evolution of man's diet, it has a certain indirect interest. As Campbell has shown in discussing the diet epochs of man, it should be borne in mind that his dietetic career has been signalized by three great advances, each of which has markedly augmented his supply of food. These advances have been made possible by his increase in brain power, and a convenient mode of denoting these successive grades in man's evolution from his simian ancestors is by reference to his cranial capacity. Proceeding then on the assumption that the great apes are man's common ancestors, and the cranial capacity of the great apes 300 c.c., and assuming that the capacity of the average European of today is 1,500 c.c., or striking out noughts, from 3 to 15. By this method of computation Campbell traces the ascent of man from the great ape thus: a third, fourth and fifth grade in the simian period; a sixth, seventh, eighth and ninth grade in the homosimian period; and a tenth, eleventh, twelfth, thirteenth, fourteenth and fifteenth grade in the period where we designate the animal as "man." This method of classification is simple and provides an easy means of following the dietetic progress of evolving man. According to this grading, the first important dietetic advance occurred, say at the tenth grade, when the hunting and fishing stage was entered upon. The second advance took place soon after the eleventh stage, when he began to prepare his vegetable food in various ways, the grand climax being reached when by the employment of cookery he was able to convert innutritious into nutritious food, thereby adding to his supply of vegetable food and opening the way to the cultivation of grain and roots, which would be of little use without the aid of cooking. 
The third and in many respects the greatest advance came when he commenced to cultivate plants and to breed animals. At this period he also learned to store food - a measure which in these days by the aid of refrigeration has been brought to perfection as well as to abuse.

\section{PRECOOKERY EPOCH}

The simian period, the homosimian period and the early hunting period may be termed the precookery epoch, or, the epoch from the ape stage to the invention of cookery. Then came the precibicultural cookery epoch, the epoch from the invention of cookery to the introduction of agriculture and the breeding of animals for food, and lastly the cibicultural epoch, from the time man began to produce his food artificially to the present time.

The Simian Period.-Descendants of animals of herbivorous habits, the primates, became frugivorous. Assuming that man is of simian origin, and consequently that our simian precursors were akin to the great apes, deductions drawn from a study of the food of the primates are of value in discussing the evolution of man. Since authorities have shown that the diet of the great apes is similar to that of the lowest order of men, forest pygmies, living under like conditions at the present time, the supposition that man has a simian ancestry is largely borne out from the viewpoint of diet.

The Homosimian Period.-The homosimian period witnessed the upward trend of the simian precursor of man. His intelligence was developing, quickened no doubt by stress of adverse circumstances. Although his food still consisted to a great extent of raw vegetables, he gradually became more of a flesh eater. As yet, however, lacking the appliances of the chase except of a primitive nature, he had, as a rule, to be content with fish and the smaller animals. These he was able to secure by the exercise of a brain more agile than the other animals, and by the aid of his highly developed physical powers. The addition of even this small amount of animal food marked an important phase of man's dietetic and general evolution, for he gradually came to discard the coarser and more indigestible kinds of vegetable foods.

THE EARLY HUNTING PERIOD.-The early hunting period signified another definite step in advance, for, with the employment of weapons and means for hunting animals and catching fish, the quantity and choice of foods were greatly enlarged. Up to this time the larger animals were more 
or less beyond his reach, although doubtless throughout most of the homosimian period he was a skillful hunter and had fashioned weapons and other implements with which to supply himself with a certain amount of animal food.

Earimest Weapons of Man.-Whether the earliest weapons of man were of flint or other stone is a mooted question. It is certain that the flint weapons are the only ones that have been found, but this does not prove that these were the only weapons employed. Taking into account the fact that the homosimians were forest dwellers, it appears plausible that they used wood-bamboo in particular-for their weapons of the chase. Obviously these wooden weapons conld not be handed down.

By a stretch of imagination one might fancy that our Pliocene ancestor, in that part of his evolution just before he became a man, could hurl stones with accuraey, could crack shellfish or hard fruits with a stone, and twine ereepers or twigs together with which to make snares or other contrivances for increasing his store of provisions. But this would, perhaps, be erediting him with too high a grade of intelligence. If we wished to carry this supposition further we might imagine that if his brain had been capable of conceiving the idea, he could have made a rude club, split off a bamboo splinter, shaped a stone, and so on. But, as he had not reached the level of intelligence of the most primitive "human," all these ideas were impossible both of conception and execution.

So far, however, as the early homosimian is concerned, it is not beyond the bounds of reason to imagine that he did make weapons of an extremely rude and primitive kind, scrapers and coups de poings and various implements of wood. Indeed, it may be taken for granted that the early homosimian possessed intelligence sufficient to conceive and the patience to make weapons and implements by the aid of which he occasionally sueceeded in killing or ensnaring large animals or catching fish, and that the true early hunting period commenced when, with the development of brain power, he was able to invent and devise special weapons and appliances for hunting and fishing, such as are employed by the most backward extant precibiculturists. These special weapons were probably made of wood. The Tasmanians had spears which they conld throw sixty vards with surprising accuracy and force. They also possessed formidable clubs, wooden chisels and the like. Stone implements are by no means characteristic of most prgmy tribes, and are difficult to obtain in forest countries where there is no flint. The most attractive supposition then is that the weapons used in the early hunting period were mainly of wood, stone and shell, and rescmbled in many respects the implements 
employed for the same purpose by certain primitive races of the present day.

To a limited extent the life of the North American Indian may be cited as an example of the manner in which our homosimian ancestors lived. When the homosimian became an expert hunter his diet became more animalized and, perhaps, he ate more flesh than vegetable food; the North American Indian before the coming of the white man was a hunter and largely a meat eater.

Although the dietetic and other customs of the Indian have been greatly changed by contact with the white man and his so-called civilization, yet he is by heredity a nomad and a hunter. The capture of animals devolved upon the man; the preparation of food upon the woman. She often added vegetables to the diet. When the precibicultural cookery period is discussed the diet of the Indians will be considered at length.

DIET OF THE HOMOSIMIAN.-To proceed with the discussion of the diet of the homosimian in the early hunting period: it is assumed on sufficiently clear evidence that the homosimian was more carnivorous than vegetarian. His intelligence and the pressure of circumstances impelled him to invent appliances to procure animal food in large quantities. The present-day precibiculturist, as the North American Indian for example, eats about equal parts of animal and vegetable food. But if he did not know how to cook, and thus make the vegetable world contribute largely to his sustenance, he would perforce be more carnivorous. With this analogy before us, it is fair to conclude that the homosimian of the early hunting period was more a flesh eater than a vegetarian.

LATER HUNTING PERIOD.-Many of our early ancestors were "mighty hunters before the Lord." They esteemed delicacies when they could obtain them, as has been proved by the fact that in the Grotto of the Rhinoceros near Schwarzfeld, about 1,000 bones of the cave bear have been found. These were split to extract the marrow, and also showed the marks of fire. At San Ciro near Palermo, there is evidence that they feasted habitually on hippopotami as is shown by the remains of some 2,000 of these animals (Scott Elliott).

The weapons of the homosimian continued to improve and his skill to increase, so that he was able to migrate to other lands-a necessity, in fact, as the supply of wild animals in the regions he had long occupied was insufficient to provide him with food. The hunting instincts together with the need for food gave the stimulus to our homosimian forefathers to travel and were potent factors in the population of the earth. The question of the food supply rather than the climate was the cause of man's 
spreading himself over the earth. But for many thousand years he could be no more than a lonely hunter as the Fuegan, the Tasmanian, the Bushman or the Veddah. Purely hunting savages can increase in numbers to a very slight extent only. Lord Avebury, better known as Sir John Libbock, gave 6,471 acres as the area required for a single red Indian living almost wholly on wild animals.

\section{PRECIBICULTURAL COOKERY PERIOD}

The discovery of cookery, by means of which the supply of vegetable food was immensely augmented and bettered, was a long step forward. The domestication of animals and the cultivation of plants were also very important advances. With these steps taken, man rapidly increased, multiplied and inhabited the earth. Cooking preceded the cultivation of vegetable plants, and its effect was to increase and improve the supply of vegetable food. Before the invention of cookery man had to laboriously masticate his food to obtain all the nutriment contained therein. Consequently our ancestors in the precookery period were compelled to use their jaws and teeth in the most strenuous manner, with the result that the starch taken into the stomach was thoroughly masticated. Further, as the starch content of the coarse vegetables, eaten before cookery was invented or plants cultivated, was small most of it was digested in the form of dextrin and maltose in the mouth, and little passed into the stomach as crude dextrin. Campbell has drawn attention to this important point that, until the invention of cookery the stomach of evolving man had but little acquaintance with undigested starch.

Early Preparation of Food.-Before the era of cookery, it appears probable that other means were used to prepare his vegetable food and render it more palatable and digestible-by sun drying, grinding, burying and maceration-all methods used by primitive races of the present time.

PRESERVATIVE METHODS.-Among the Iroquois and other eastern tribes vegetable foodstuffs were preserved by drying; among the less sedentary tribes, they were strung or tied in bundles for facility of transportation or storage. The preservation of maize, mesquite beans, acorns, etc., gave rise to granaries and other storage devices. In order to preserve animal food it was often dried or frozen. Dried meat was sometimes pulverized and mixed with berries. Fruits were pulped and dried for preservation. Tubers were frequently stored in the ground. The Virginian tribes preserved tubers for winter use in this way. 


\section{The Development of Cookery}

The Systematic Use of Fire.-The aid of artificial heat opened up a new vista, so that many vegetables which in their raw state were unpalatable and highiy indigestible were, by the agency of fire, converted into nutritious articles of diet. How to make a fire was one of the greatest discoveries made by our simian ancestors. The various ways in which fire may be made have been described by other authors, perhaps most fully in Mason's "Origin of Invention." Wood friction was the most common mode. The use of fire in cooking food was indeed epoch-making, for, as the art of cookery improved, man was less dependent on hunting for his food. The supply of vegetables increased in proportion to the advances in the art of cookery, and the hunter was able to release himself, to some extent, from the chase, and devote a considerable part of his time to other pursuits. In the course of time one-half or more of his dietary consisted of vegetable food.

The Discovery of Cooking.-Cookery is the art which has rendered the most important service to humanity, for it has brought into play the application of fire, by the use of which man has subjugated nature. In all probability cookery is nearly as old as fire. It is almost certain that one of the earliest uses to which man put heat by fire was to cook his food. The antiquity of fire-making, of cookery, are matters of conjecture. At first, the cooking of food was done in a haphazard fashion. Cookery could not be termed an art nor could a period be referred to as the cookery period until it was applied systematically to both flesh and vegetables.

Cooking rendered the indigestible cellulose content of raw vegetables more digestible, and improved the digestibility of the starch. At the same time, less mastication was required, and gradually the power of digesting the more indigestible and unpalatable raw vegetables was lost entirely. The most backward peoples now living cook their food, and that they have done so for ages, seems to be demonstrated by the fact that although widely separated by race and distance, the means they employ for this purpose are very similar. All evidence points to the fact that the methods of cooking now practiced by the most primitive races, as the native Australians, Californians, Pygmies and Andamanese, were handed down from the earliest times, probably from those times when cookery was first practiced, and began to take its place as one of the arts.

The Evolution of Cookery.-It may be assumed that as sonn as man discovered how to make a fire, instinct impelled him to apply it to food, first to dry it, then to cook it by placing it on hot embers. 
Fire Applied to Meat.-Flesh thus prepared was found to taste better; it was more wholesome, and was more ansily masticated. 'The essence of the meat becoming fluid gave a sarory flavor which rendered it more gratifying to the palate. It was quickly discovered that this method possessed some disagreeable drawbaks. Meat grilled on hot embers both burns and soils, while regetable food will burn too readily. Neat was then in all likelihood stuck on skewers, which were placed on stones raised to a sufficient height to prevent contact with the embers. Thus was the gridiron evolved.

EVIDENCES OF COOKING OF MFAT AMONG PRIMITIVE MEN-CReference has been made to the discovery of the remains of hippopotami at San Ciro near Palermo, which had been killed and eaten by the Neanderthal race - a race which probably included the later stages of the River Drift man and the early stages of the Cave Man of English anthropologists. (1) Judging from the remains found at San Ciro, "it seems likely that they grilled their meat orer a fire, and sometimes boiled it, for certain stones found in some caves seem to have been used as pot boilers. Perhaps a hollow was dug in the care, or near it, and a skin, filled with the flesh and water, placed over the hollow. Then stones heated red-hot were dropped into the water to make it boil. This theory is uncertain, for it involves the assumption that they possessed a ressel in which water could be carried. It is true that water might have been carried in skins, but it would have been difficult; therefore it is unlikely that they boiled their game. Moreover, it is not a usual form of cooking among races who live in much the same manner at present." It appears certain that this Neanderthal race used iron pyrites and flint to strike a light. It was no doubt the custom of all primitive people, to whom it was a task of infinite patience and toil, and who were dependent upon the fire continually burning in their eaves for protection from wild beasts, for warmth and for cooking. The Neanderthal race were essentially meat eaters and big game eaters, for no small bones were in their caves, only those of the mammoth, rhinoceros, cave bear, the urus, deer and bison.

It is important always to bear in mind that, although animal food is not so difficult to cook, raw meat wals and is often used. In this form it is not unpalatable, and is more easily digested. While the comnective tissue is softened by cooking and muscular fibers loosened, proteins are coagulated and, on the whole, most cooked meat tries the organs of digestion as much or more than meat in a raw state. Perhaps the warmth imparted to food by the process of cooking is a slight aid to digestion, and man at the present time has become acenstomed by genera- 
tions of use to cooked meat, which is a point in its favor. Early man was carnivorous by heredity and had not acquired the taste for cooked meat. Raw meat is assimilable and is eaten nowadays with gusto by some savage tribes. Some raw meats are even more palatable than cooked, and many highly civilized persons, notably the Germans and other European peoples, eat considerable quantities of raw meat, especially pork.

Raw oysters and other shellfish are esteemed delicacies by the most civilized of people. Raw ham is largely consumed by Germans and other European peoples. Raw meat is given to consumptives as a part of treatment and is eaten by them with avidity. It is not the intention to argue that raw meat is better adapted, from the point of view of health, to civilized people than cooked meat, but rather to show that raw meat was in the precibicultural period the common diet of man, and that even after the discovery of cooking, meat was for a long time eaten raw.

COOKING OF VEGETABLES.-The point on which it is intended to lay stress is that whereas animal food may be consumed in a raw state, vegetable food almost invariably requires the agency of fire to render it fit for human digestion. This is a truth of great significance in the evolution of man and in the evolution of man's diet. By the aid of cooking, the stiff cellulose content of vegetables is rendered easily digestible, and the starch is more accessible to the salivary and other digestive fluids. Hence the use of cooked foods has altered man's organs of digestion and has played a part in his evolution.

The Underground Oven.-While it was a comparatively simple matter to devise means to cook meat, it was altogether different when the cooking of vegetables was in question. This was solved by the invention of the underground oven. A hole was dug in the ground into which the food was placed and a fire was then made over or around it. The principle of this method is applied in various ways at the present time in out of the way parts of the world, and it can be asserted with emphasis that it is a most excellent way of preparing food for human consumption.

The most advanced mode of underground oven-cooking is by heated stones. Alternate layers of hot stones and food are placed in the oven, and covered with matting, leaves or grass. This is a baking system. More frequently, the oven is lined with some vegetable substance, which may also be employed to separate the layers of food and stones. Steam is generated, and the eatables are most efficiently steamed. Both of these methods are admirable, and better in some respects than any of the modern civilized ways. Most of those who have eaten food prepared after this fashion are loud in its praise, and declare that it is superior in its 
results to those attained by the most scientific and artistic French chef. The method is now practiced at the modern clam bake.

BOILING OF WATER.-How to boil water was for long an insurmountable obstacle to our prehistoric forefathers. The boiling of water as an ordinary branch of cooking is a discovery of comparatively recent origin, when the antiquity of the human species is taken into consideration. Natural hot-water springs and pools exist in some parts of the world. Those in New Zealand are the most extensive and eertainly the best known. Such opportunities no doubt were not neglected; the Maoris of the present day use the boiling pools of New Zealand for cooking purposes. Again, stones were hollowed out by some of the more ingenious early savages, but this method involved a great deal of hard work, and also the possession of certain implements which only the most hardy, adaptable and intelligent of the cave men were able to manufacture, and therefore was not widely employed. As a matter of fact, there are tribes yet existing who do not know how to boil food. The Fuegans, the Bushmen and the Australian aborigines are all said to be unacquainted with this method, emphasizing the fact that boiling as a means of cooking was discovered, in the manner described above, long after baking or steaming. The Greeks at the time in which Homer wrote were not very highly skilled in the art of cookery. His description of how Achilles received three noble Greeks, one of whom was a king, shows that their manner of feasting was rude and unrefined. The meat-pork, mutton and goats' flesh -was grilled in a brazen vase over a blazing fire; the only other food served was bread and the beverage, wine. It has been observed that Homer never refers to boiled meat in any of his poems. The Egyptians, at the period in which Homer lived, were the most civilized people and were further advanced in cookery than any of the contemporary races. Even the Hebrews, owing to their sojourn in Egypt, had made more progress in the art of cookery than the Greeks. They had cooking utensils which they placed on the fire; they boiled a good deal of their food, and it was in vessels made for the purpose of boiling that the wily Jacob prepared from red lentils the mess of pottage with which he maneuvered the unsuspicious Esau out of his birthright.

The great obstacle to the boiling of water which was encountered by early man, was the lack of vessels which would resist the action of fire. The introduction of pottery, or was it of metal vessels, revolutionized every detail of the entire science or art of cooking. No true cooking was known until cooking pots came into general use. Where roasting on a rough grill would be possible, a kind of spatchcock might be ised. 
How, then, did man boil water prior to the discovery of earthern or metal vessels? This question is impossible to answer except by an intelligent surmise. In the first place, the remains of prehistoric times must be searched. But these sources of information cannot be relied upon to any extent, because most of the appliances were probably made of easily destructible material which would have utterly disappeared in a relatively short space of time. Hollowed stones were employed by the most hardy and practical of our savage ancestors for this purpose, but these were not in common use.

For holding water primitive man no doubt used the shells of shellfish and egg shells of birds like the auk and other immense birds which inhabited the earth at different early periods of man's evolution before the

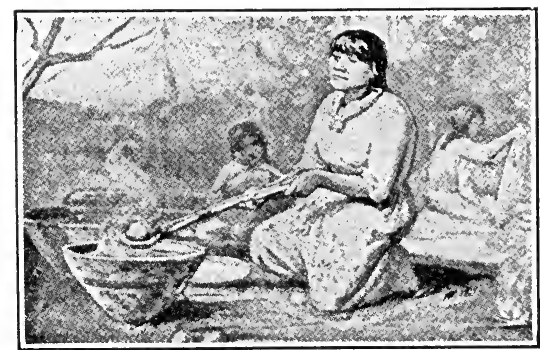

Fig. 1.-Stone-boiling. Liftivg the Hot Stones into the Food Basket; California Indians. (Holmes.) (Courtesy of Smithsonian Institute.) making of pottery or metal vessels. The bamboo 'cane also was utilized, and there is little doubt that in the latter part of his hunting stage man learned to make vessels of skin and of plaited rushes. The only way of boiling food, especially meat, would be to stretch a hide over a hole in the ground, fill it with water, and then heat stones red hot and drop them in until the water boiled. Any non-fireproof, water-tight vessel might be used in a similar way. Of course, this operation is extremely tedious and would hardly be likely to commend itself to the hunter. It may be taken for granted that the hunter did not, as a rule, boil his food, and that boiling meat and vegetables did not come into general use until the invention of the art of making pottery or of forging metal had been consummated.

The customs of existing precibiculturists must be looked into in order to obtain a likely solution of the problem as to how food was boiled before the age of pottery. The method of dropping heated stones into a water-tight vesşel made of skin, bamboo or plaited rushes, is still in use among such ex-

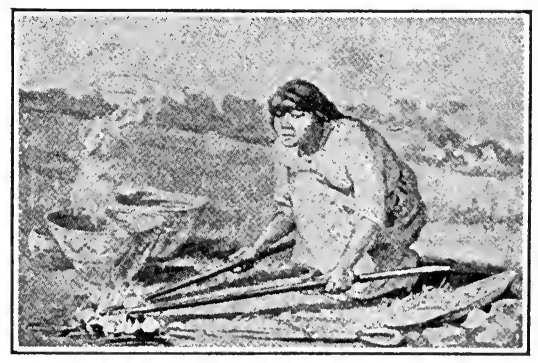

Fig. 2.-Stone- Boiling. Removing the Stones from the BoIling Basket; California Indans. (Holmes.) (Courtesy of Smithsonian Institute.) 
tant primitive people as the (alifornian Indians, the liskimo and the Andamanese. The methods of cooking among the meat-eating Indian tribes of this continent were broiling, roasting and boiling. The last named process, known as "stone boiling," was done in plaited rush baskets. The tribes whose diet was approximately vegetarian praticed all these methods, and the vessels most widely employed were constructed from closely plaited rushes.

Utilization of the Discover of Potrem.-It is not definitely known whether the first cooking pot for boiling fluids was made of metal or earth. Camplell say's that pottery which is of quite recent introduction was not employed by the precibiculturists. It is mnknown to presentday precibieulturists, and belongs to the cibicultural period. This anthority undoubtedly refers to "recent introduction" in a relative sense, the sense in which the vast antiquity of the world and of man is considered, for he conjectures that the eibieultural period began a mere matter of some 30,000 years ago.

How and where the first earthern pot was made is a mystery and must remain a mystery. We know that the art of making adobe bricks is of hoary antiquity, but aceording to many authorities that of molding clay into vessels is yet more ancient. Scott Elliott hypothesizes as follows with regard to this discovery, which was pregnant with far-reaching effects in the evolution of man's diet:

It is possible that a woman once took a basket to the riverside to bring home the fish that she hoped to catch. Laying it accidentally in the mud, the outside became plastered with slime. When the fish were taken home she may have noticed that some water remained in the basket. So she was led to experiment and perhaps carefully plastered the inside with mud and then burnt off the basket.

It may then have been the natural euriosity of woman, handed down to her from her original progenitor (we had almost said Eve, although to a believer in the Darwinian theory of the evolution of man, this would be a rank scientific heresy), to which we owe this epoch-making discovery of pottery. To earry this ingenious hypothesis to its legitimate conelusion, it may be inferred that the mud with which the basket was plastered was potter's clay. In any event, ever since that hypothetical but extremely likely happening, the handling of pots and pans has been severely left to the weaker sex. It may be further remarked that in savage communities, at least in most of snch communities, it is the woman who makes the pots. It may be stated here, although the question is not particularly relevant to the matter in hand, that the earliest record of glass vessels seems to have been in Egrpt about 4000 B. C. 
Application of Art of Boiling Water to Cookery.-When the boiling of fluids became not only possible but easy, cookery made a great advance. It was chiefly employed in the culinary preparation of vegetable products. Boiling softens their consistency and thus allows them to be more readily masticated. It loosens their intercellular structure, and, in consequence, facilitates the penetration of digestive juices into their substance. The action of boiling on the starch granule, the constituent which enters most largely into the composition of vegetable food, is most essential to good digestion. It causes the granule to swell and its outer envelope to burst. The digestive fluids are therefore permitted to come into direct contact with the central part of the starch granule.

COOKING AMONG THE AMERICAN INDIANS.-With the discovery of vessels which resisted the action of fire, the art of cookery advanced by leaps and bounds. Among the Pueblo Indians, cooking is carried to a remarkable degree of proficiency, approaching in variety of methods the art among civilized peoples. Most Indian tribes have long known how to prepare savory and nourishing dishes, some of which have been adopted by civilized people. From the Indians have been derived ash cake, hoe cake, succotash, hominy and samp.

The preparation of maize as food involved almost numberless processes, varying with the tribes. In general, when maize reached the edible stage, the ears were roasted in pit ovens, and, after the feasting, the surplus of roasted ears was dried for further use. The matured grain was milled or parched, the meal entering into various mushes, cakes, pones, wafers and other bread. The grain was soaked in lye obtained from wood ashes to remove the horny envelope, and was then boiled and known as hominy. This was often dried, parched and ground, repparched and reground, making a concentrated food of great nourishing power in small bulk, and was consumed dry or in water as a gruel.

Pinole, which consists of ground parched corn, formed the favorite food of the Southwest Indian tribes. The fermentation of corn to make beer was not generally practiced among the American Indians, and it is doubtful if the process was known in America before its introduction by the white man. The Iroquois and other eastern tribes cooked maize with beans, meat or vegetables. The Pueblos added wood-ash lye to their "paper bread," and prepared their bread and mushes with meat, greens or oily seeds and nuts, besides using condiments, especially chile.

Infusions of leaves, roots, etc., of various herbs were drunk by the Indians as medicine, but there is no record that they drank any stimu- 
lating beverage such as tea or coffee. Drinks made from fruit, as eider from manzanita berries, and a beverage made from cactus fruit by the Pina and neighboring tribes of Arizona, are the Indian fermented drinks best known.

METHODS USED BY OTHER PRIMITTVE PEOPLES-Many of the modes of cooking meat which prevailed, and are still customary among primitive peoples, are excellent. In a recently published work of fiction written by the late Jack London is a description of the manner in which a native of one of the British Solomon Islands cooked a pigeon. Upon a clear burning fire of wood he placed many stones. He then wrapped a plump wood pigeon in leaves and surrounded it with heated stones and finally covered both pigeon and stones with earth. When after a time he removed the pigeon and stripped from it the scorched wrappings of leaves, it gave forth a scent so savory as to set the nostrils quivering. Gypsies generally use this style of cooking. A very delicious dish - an epicurean delicacy -is a fat hedgehog, which is covered with clay and then placed in the hot embers of a wood fire for some time. When the hedgehog is removed from the fire and the caked clay is scraped off, it brings away with it the quills of the animal. The meat is found to be done to a nicety, greatly resembling that of a suckling pig. Similar methods of cooking are employed by primitive people now extant.

The Food of Precibiculturists.-Reference has been made in a general way to the diet of people who lived or are now living to all intents and purposes in much the same manner as our precursors lived. Some of these peoples, more backward than the others, live in a way similar to our homosimian progenitors. The measurements, contours and markings of the skulls of native Australians, Tasmanians, some Eskimos and a few members of other existing primitive races differ but little from those of apes, orang-outangs and of very early man. They live in a state of nature, go naked or nearly so. Their knowledge of everything is of the most elementary character; they know nothing of the arts, and their main concern is to satisfy the cravings of their appetites. The aborigines of Australia, the Californian Indians, the Bushmen of South Africa, the Veddahs of Ceylon and the Hairy Ainus are the most conspicuous examples extant of men and women following a mode of life almost identical with many of our earliest ancestors, while other races more advanced in civilization still retain many of the primitive habits.

The diet of our far-away progenitors has been discussed more or less fully, and it will be interesting to trace the connection between their dietetic habits and those of the races referred to above. 
THE DIET OF THE NORTH AMERICAN INDIANS.-But before doing this, the food of the Indians of this continent before their range of land had been restricted will be considered. In general, in the northern portion of the continent, the diet was three-fourths animal food; in the southern part, it was three-fourths vegetable, while among the tribes of the coast, mountains, lakes and plains, it varied according to the food supply. The absence of dairy food limited the natural increase of population. The food supply changed with the seasons, causing the diet at different periods of the year to vary in its ratio of animal to vegetable constituents. Dièt was also regulated or modified by religious customs. For example, the Apache and Navajo would not eat fish or the flesh of bear or beaver, and other tribes possessed taboo or totemic animals which though useful for food were not eaten.

In inhospitable regions, inland from the Texas coast, in the sixteenth century, the natives subsisted on whatever they could find. Cabez de Vaca wrote of the Yquazas:

Their support is chiefly roots, which require roasting two days; many are very bitter. Occasionally they take deer, and at times fish, but the quantity is so small and the famine so great that they eat spiders and the eggs of ants, worms, lizards, salamanders, snakes and vipers; and they eat earth and wood. They save the bones of the fishes they consume, of snakes, and other animals, that they may beat them together and eat the powder.

Almost the same may be said of the Maidu of California, who, in addition to consuming every edible product, eat badgers, skunks, wildcats and mountain lions, practically all birds except the buzzard, yellowjacket larvæ, grasshoppers, locusts and crickets, and even salmon bones and deer vertebræ.

Vegetable food comprised a vast array of the products of plant life, of which roots and seeds were the most valuable. The most important food plant possessed by the Indians was maize, which formed and still forms their principal means of subsistence. Uncultivated plants, as seeds, roots and flowers of grasses and other plants, or parts of plants used for flavoring, etc., also entered into the dietary. In numberless cases wild plants have preserved tribes from starvation. In the southwest of the continent, cactus and yucca fruits, mesquite beans and the agave were most important elements of the food supply. As in Mexico, the roasted fleshy leaves and leaf matrix of the agave were prized as sweet, nourishing food. Tuckaho and other fungi were used for food by the eastern Indians. The north Pacific tribes made much use of the sweet inner 
bark of the hemlock and spruce. Salt was tabooed by the Onondaga, and lye substituted by some of the sonthem Indians. Chile, which is of Mexican origin, beeame known thronghont the Sonthwest, and saffron, an introduced plant, is still in use there to flavor and color food. Thronghout New England and southeast Canada sugar was produced by the evaporation of the maple sap. In the Southeast it was derived from the willow and agave. In some localities clay was eaten, either alone or mixed with food or taken in conjunction with wild potatoes to mitigate the griping effects of the acrid tuber.

In general, buffalo, the deer family and fish were the animals most useful for food. Some woodland tribes depended on deer, while the coast and river tribes usually made special use of fish and other products of lakes and rivers. The porcupine is said to have been the chief food animal of the Montagnais. All the edible portions of the animal were put to use. In many cases both animal and vegetable substances advaneed toward putrefaction were preferred, as salmon eggrs which were stored in sand by the Alaskans, and immature corn in the ear which the Hurons are said to have soaked in water until it became putrid, when soup was made of it.

The description of the manner in which these Indians were accustomed to procure their food supply, before their hunting grounds were taken from them and the buffaloes disappeared, has been introduced because it referred to the

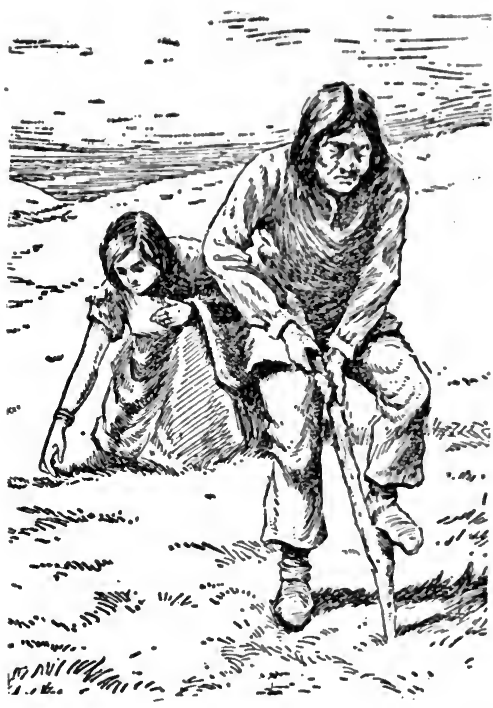

Fig. 3.-Pueblo Indiaxs Plantisg Cons. (Courtesy of Smithsonian Institute.)

original inhabitants of the land, and because the food of some of the tribes was similar to that now eaten by existing primitive people. With few exceptions, the Indians of North America and Canada were of a higher type than the Australians, Bushmen of South Afriea and the Veddahs, but some, notably the Maidu of California, may be placest in the same category. Moreover, according to some authorities, it wals in North America that the very first primate originated, and perhaps. although this may be considered a far-fetched view, the Indian is mdoubtedly the descendant of the North American primate. 
DIET OF BACKWARD PRECIBICULTURISTS.-In a summary of the diet of the most backward of existing precibicultural people, which is practically the same as that of our remote hunting ancestors, it may be said that "all is game that comes to their net"-large animals, when they can be caught or killed; and when these are not available, the smallest and most humble specimens of the animal world are not despised, such as grubs, worms, scorpions, grasshoppers, centipedes, crickets, locusts and hoc omnia genera. White ants are considered a delicacy, while as mentioned before, frogs, toads, lizards and snakes are consumed with the greatest appreciation. The Veddah pygmies of Ceylon up to a short time ago lived in rock shelters and caves and subsisted on honey, grubs, bats, pythons, lizards and an occasional larger animal.

Human Flesh. - Some of the extant savage tribes are cannibals, but cannibalism is more of an incident than a custom, for reasons into which it would be superfluous to enter. A strong suspicion of cannibalism rests upon the Neanderthaler, but judging from the evidence of remains, cannibalism was uncommon among early races, and all evidence is against the theory that they ate one another habitually. Big game is the food of choice, and many of those races who inhabit the immense forests and other inaccessible parts of the world are uncanny in their skill in tracking, entrapping and killing animals even of the largest size.

BIG Game.-Big game supplies the bulk of the animal food supply of the extant precibiculturists. The Andamanese or Semangs of the Malay Peninsula have the hunting instinct so abnormally developed that they are able to track a snake by smell and are quite extraordinary hunters of big game. It is related that when they see elephants ascending a hill, small parties of two or three will lie in wait armed with splinters of bamboo, which have been hardened in the fire and tipped with poison. The elephant descends the hill slowly, the Semang steals behind it and seizing his opportunity, drives the poisoned splinter into the sole of the elephant's foot. These same men are also said to kill the rhinoceros by placing tiny strips of poisoned bamboo in the jungle path frequented by game. They are amazingly clever in the manufacture of snares, nooses and traps of all kinds. Like their simian precursors, they make use of the almost endless varieties of creepers with which the jungle abounds, some of which rival steel in elasticity and strength, while others may be compared with the finest wire for flexibility and toughness(4).

The mode of life of the pygmies is nearer to that of the living anthropoid apes than in the case of any other group of mankind. They were and are still, to some extent, the neighbors of elephants, rhinoceri, hip- 
popotami, as well as of the anthropoid apes. Indeed, they represent the earliest type of lone hunters of the jungle, inhabiting their depths on inaccessible and remote hills. The native $\Lambda$ ustralians who live inland are also expert hunters, but are not so acute of brain as the pygmies. Nevertheless, they manage to subsist mainly on the kangaroos and other marsupials which they ensnare or kill.

Fish Foon.-The Eskimos depend for their food supply chiefly on the seal, walrus and whale; the Fuegans live mainly on seal and porpoises; other tribes, inhabiting the vicinity of the sea, catch turtles, swordfish, salmon and other fish to augment their limited larder. In this connection, it is interesting to note that a harpoon, identical in make and composition to that employed by men many thousand years ago, is used at the present time by the Eskimo for seal, and the Andamanese for spearing turtle. Similar harpoons are used by the $\Lambda$ merican Indians, Ainus, Kurile Islanders and Yahgans. Polybius has described an exactly similar method of fishing for swordfish as in use during his day in the Mediterranean, that is, from 135 to 50 B. C.(5).

All maritime tribes, whether living on the shores of oceans or seas, or inhabiting the neighborhood of lakes or rivers, subsist largely on fish which they eatch and eat in the same manner as in prehistoric times. There is some difference of opinion as to whether the races referred to at the beginning of this section eat flesh raw or cooked. Some authorities assert that, contrary to popular belief, the Indians, as a rule, prefer cooked food, and that the Eskimos, whose name signifies "eaters of raw flesh," eat uncooked meat only when absence of fuel prohibits cooking, or as a side dish. Campbell states that the Eskimo never hesitates to devour frozen flesh raw, and considers the raw viscera of the ptarmigan a great delicacy. Even when these primitive people cook food it is only subjected to heat for a short time and is seldom more than partially cooked. Sun drying is largely resorted to in the case of insects, flesh food and fish by primitive people, after which process it is stored. The Boers of South Africa sun dry meat, which is known as biltong.

Vegetable Foons.-It has been sufficiently emphasized that roots formed the staple aliment of precibiculturists, and that to women fell the lot of digging this food.

Small Seeds.-Payne holds that the cultivation of cereals pared the way to civilization, but the truth is rather that it was to no one form of food to which civilization may be ascribed. The cereals are easily the most important products of the regetable world, owing to their nutritive properties and to the fact that they can readily be preserved by storage 
and other means; on the other hand, it must not be forgotten that there are other vegetable foods which are highly nutritious, among which the pulses occupy a foremost rank. It has also been pointed out that of the small seeds, the grass seeds were the most important, for it was owing to these seeds that the cultivation of cereals was initiated. Whatever may have brought about the begimnings of cultivation, it is enlightening to find that many primitive people, who lived chiefly on seeds and fruit, never discovered how to improve the wild, rudimentary seeds and fruits by cultivation. "This is the case with the Luiseno Indians, who divided up the land among the various families, and lived on the seeds of wild oats, clover, sage and chenopodium as well as on acorns, berries and bulbs, but planted nothing." The Kivakiuti Indians in North America collected berries and roots, drying them for use in winter, and eating them with fish oil(3). "The Australian women regularly collected wild rice, millet and leguminous seeds, which they ground into a sort of meal. In Selangore, Malaya, the natives were accustomed at certain seasons to go to those parts of the jungle where there were many fruit trees. They ate fruit in small shelters erected for the purpose. Having noticed that there were more young trees near these huts, they made fresh shelters in various places, and even went so far as to clear away the jungle around the young trees, but they never planted a single tree"(4). There are several primitive races now extant who do not cultivate the land and others who only cultivate it slightly. They collect the seeds of various grasses which they store and eat, but go no further.

Larger Seeds and Nuts.-The acorn, cactus, watermelon and so on were largely consumed by the precibiculturists. Acorns, wherever the oak tree flourishes, were a favorite food of the early European races as they are still of some of the primitive people of the earth. In the brushwood of the temperate climes and on river sides, besides the acorn will be found hazel-nut, hawthorn, walnut and edible chestnut.

Fruits and Berries.-Many luscious fruits and berries were and still are eaten. Among the fruits in tropical or semitropical climates, the banana and breadfruit are the most nutritious and agreeable to the taste. Ancestral forms of both of these fruits were flourishing as far back as the Eocene period. If it were not for the banana and the breadfruit, many of the precibiculturists of the present day, notably those of the Pacific Islands, would be forced to starve or learn to work. The banana is one of the most nutritious foods, because of its considerable carbohydrate and small protein content, and also because it can be made into flour and cooked as bread. It is closely followed by the fig, the grape and the date, 
the last named constituting the staple diot of the $\Lambda$ rab races. Green vegetables are eaten by the native Australians and by the Californians, especially clover in the spring.

Honey.-The antiquity of honey is not known; there is nothing to show whether the honey ant, termites and the honey bee existed in the Eocene period, but it is known that in the Pliocene period, in Mesopotamia, for example, honey was eaten by the lemurs, anthropoid apes, and by our precursors. The Anstralian athrigines are large consumers of honey. In fact, wherever the climate is propitions and the honey makers ean live, honey is a favorite article of diet of primitive people.

Condiments. - The subject of condinents will be exhaustively considered in this volume, ${ }^{1}$ and the matter perhaps has no influential bearing on the evolution of man's diet. Nevertheless, the question of rendering food which is naturally insipid and mupalatable, appetizing, by the addition of savory substances known as condiments, has from certain points of view a relation to dietary evolution.

Appetizing food, even while it is still in the mouth, and before entering the stomach, excites the secretion of the gastric and pancreatic juices and that of the saliva, so that a food that is mupalatable and indigestible may be readily digestible if it is rendered appetizing by the agency of a condiment. The Hindoo adds curry to his tasteless rice and the Spaniard onions to his bread. For a similar reason, condiments are added to palatable food in order to heighten its appetizing qualities, as for instance, mustard, caper sauce, apple jelly and last but not least, salt, for salt is essentially a condiment, since the daily food ingested by the civilized man provides sufficient sodium salts for the body needs, although such food is not salty to the taste.

The action of salt as a condiment deserves further study (sce Chapter XI of this Volume) because the development of flaror, which the addition of salt induces, is due to increased osmotic action. The addition of salt conspires to produce an isotonic fluid with more rapid traveling activities, stimulating salivary flow and subsequently the secretion of the gastric fluid. The evidence in favor of the use of salt and of other condiments is that the palatability of food is increased, and probably also its absorption value. It must be borne in mind that saliva digests starchy material and stimulates the secretion of gastric juice, which stimulates the intestine when the gastric juice enters the duodenum. An enzyme is produced in the mucons membrane to which Bayliss and Starling have

1 Chapter XVII. 
given the name of secretin. This in turn is absorbed and carried by the blood to the pancreas, to which it acts as a stimulant and causes it to secrete an active digestive juice. It is therefore a desirable object to increase the flow of the saliva by means of condiments added to otherwise unpalatable food.

Man used condiments ages ago, probably when he first became gregarious. He did this first by coction, not long after he had learned the art of roasting flesh. He found that such meat was palatable and easily digested on account of its sodium chlorid content. He then learned the habit of smearing his cooked vegetables with drippings of fat from the roasted meat. Salt was the condiment next employed, and for many centuries, condiments too numerous almost to name have been used.

Precibiculturists as Botanists.-But the use of this wide variety of foods came about after centuries of small advances. "Necessity is a hard master, but whoever fully graduates in this school has thoroughly learned his lesson." This saying applies with great force to the precibiculturists in their search for and preparation of food. With them it was a case of the survival of the fittest, for those who did not learn which vegetables or plants were good to eat or how to prepare them in the best way, did not survive. By generations of this striving with nature to wrest from her a living, these people developed a marvelous instinct as to which plant was nutritious and which poisonous, and this instinct has been handed down to the present generation of primitive men. This "handing down" from generation to generation may also be rightly termed the reedducation of each generation in the judicious selection and preparation of vegetable foods. Knowledge of this character acquired through enormous toil and pain is one not likely to be lost.

All the precibiculturists are practical and sound botanists, and they not only have learned to choose plants best adapted to nourish them, but also how to prepare these natural products in the most effective and suitable manner possible. They are versed in the best modes of gathering and hulling the wild cereals, how to dry, grind and store berries and roots, and to make biscuits and cakes, and they are able to distinguish between a poisonous and innocuous plant with unerring accuracy. The pygmies were the very first race to acquire a thorough knowledge of botany and to realize its importance. If a pygmy is of the opinion that a fruit may be poisonous, he will soak it for two or three days, and then give it to one of his dogs, and if the animal does not become ill, he will eat it himself. Even from unpleasant tasting and poisonous vegetable substances pygmies will prepare wholesome and palatable foods by maceration 
and the application of heat. It is well known that many $A$ meriean tribes are excellent botanists, and on occasions, good herbalist doctors. As striking evidence of their knowledge of herbs, Raffour(5) states that the very first botanic garden in which medical herbs were grown for the use of medical students and their teachers seems to have been in Mexico.

The Beverages of Precibicultural Man.-The beverages used by ancient races are- $(a)$ water, $(b)$ milk, $(c)$ oil, $(d)$ the juices of fruits and sap of trees, $(e)$ fermented liquors, $(f)$ distilled liquors, $(g)$ tea infusion, $(h)$ coffee infusion, (i) chocolate and broths. Blood was oceasionally used as a beverage in days long past. The Huns are said to have been in the habit of drinking the blood of their horses, and it is also stated that the Ostjaks of the Obi valley were very fond of reindeer and bear blood, which they drank while warm. The blood of human vietims was at one time drunk by some camnibals and savage warriors.

WATER.-Water is the natural drink of the races who have advanced little in development. The animal or man who drinks only to quench his thirst, does so with the means by which this aim ean be most effeetually attained. It was an instinct with primeval man, as with the rest of the brute ereation, to assuage his thirst with water, which is still an instinct with the precibieulturist. It is true that many of them rapidly develop a taste for alcohol, but this is an acquired taste, an abnormal appetite. However, in their wild state they know nothing of fermented beverages, which belong more or less essentially to the agricultural period.

Water is the main and universal drink of precibiculturists, and the water which they use for drinking purposes is procured from lake, pool, spring or stream. In dry, sandy countries, in lands in which droughts are long continued and frequent, as in parts of Australia, the aborigines have been known to dig wells to a depth of several feet. But this is very seldom done, for two reasons: first, because it entails too much hard work when they lack the appliances requisite for digging; second, because most primitive people are nomads, and whenever possible choose sites for an eneampment where water is easily available. Furthermore, on account of the wandering habits of precibieulturists, and also because they travel in small numbers, the water they drink is, for the most part, free from contamination and infected matter, and therefore water-borne diseases are practically unknown to them.

Primitive man, in the majority of instances, drinks in the same manner as his ancestor, the anthropoid ape. He bends down and applies his mouth directly to the liquid and sucks it up, or he may make use of h:s hands as a receptacle. Mr. Hillier, quoted by Camphell, says that certain 
Australian tribes employ a method of drinking which may be described as "hand lapping." The water is shot with remarkable accuracy from one hand into the mouth, which is held from twelve to eighteen inches above the pool, the hand traveling to within about six inches of the mouth. Drinking vessels of ariy description are only quite occasionally used. It is an interesting fact, and one which may be recommended to the attention of the medical profession, that, like the lower animals, primitive man seldom, if ever, drinks with his meals.

But although it is probably blind instinct which prompts primitive peoples not to drink with their meals, not the knowledge that the habit is not conducive to good health, they are not entirely ignorant of the fact that water possesses medicinal properties. Some savage races, notably the native Australians, drink large quantities of water for the relief of dyspepsia. It is possible that the imbibing of considerable quantities of hot water, which was prescribed by many physicians not long ago in the treatment of indigestion, may have had its origin in the practice of these savage tribes. The cold bath is also occasionally recommended by those versed in medical lore among primitive people. The Fuegans, when suffering from certain complaints of a feverish character, in the endeavor to promote perspiration, imbibed copious draughts of water, presumably hot, and the northern California Indians employ a 'Turkish bath to open the pores of the skin freely, with the view of relieving or curing various infections.

MILK.-The ancients - by these we mean the Greeks, Romans and perhaps the Egyptians-did not drink animal milk to any extent as a beverage, but converted it into cheese. Dogs' and cows' milk was used; the milk of the former is not much used nowadays, but the milk of the cow, ewe, goat and ass in Europe and America, of the buffalo in Africa, of the camel in Persia, of the mare in Tartary, of the reindeer in Lapland, of the llama and vicuna in South America, and of the yak in the Pamirs and Tibet, has been and is still used largely for drinking purposes, as well as for making cheese and butter.

OIL.-Oil was and is still used by some of the northern races, although more with the view of maintaining their animal heat than as a beverage. The drinking of oil dates back to the period when man first lived in Arctic regions. It was an instinct with him, as much as drinking water to quench thirst was with the savage. The amount of oil and blubber ingested each day by an Eskimo is prodigious. However, all people who live in very cold climates imbibe oil and oleaginous food as necessities. It is related that after Napoleon was finally beaten, and there was a large 
gathering of allied troops in London to celebrate this event, the Siberian Cossacks, who were among these troops, swarmed around the street lamps, which at that time were lighted by mins of oil, and eagerly consumed the oil contained therein. Also not long after this peaceful incursion of the Cossacks from the Don, London experienced a dearth of tallow candles.

JUICES OF FRUITS.-It is reasonalile to suppose that the cocoanut flourished countless ages ago. Indeed, palm trees are known to have existed in the Eocene age. This being the case, there can be little doubt that the abundant juice of the cocoanut furnished milk even before agriculture and the domestication of animals was practiced. This milk was without doubt the most ancient of lacoteal thuids, and was used by the men of those times to quench thirst when cool water was not accessible, in the same manner as the primitive races of such regions employ this juice at the present time.

It may also be assumed that in tropical and warm climates our ancestors took advantage of the juices of some of the fruits and employed them as cooling beverages.

FERMENTED LIQUORS.-With regard to the drinking of alcohol in any form among primitive men, little, perhaps none, was consumed. The same may be asserted of existing precibiculturists, but with a certain amount of reserve.

Aceording to Giradin, the Arancanians before having had relations with other nations, made the fermented drink, now called chica, of maize. The Chinese almost from time immemorial have drunk a liquor made from rice fermentation. Beer is supposed to have been invented in 1996 B. C. Herodotus and other historians state that beer was the most common drink among the Egyptians, who called it helt. From the results of an investigation as to the use of fermented drinks by prehistoric peoples, M. G. de Mortillet concludes that the lake dwellings of Clairvanx in the Jura, and of Switzerland, show that the neolithic people of Central Europe had a wine made from raspberries and mulberries, and the dwellings of Bourget in Savoy and various stations in the Alps appear to testify that the use of this wine continued through the Bronze Age. On the southern slope of the Alps, the relies of the dwellings built between the prehistoric and protohistoric ages reveal the use of another fermented liquor prepared from the dogwood. Traces of the use of grape wine are found in the terra mares of the plain of the Po, going as far back as the earliest Bronze Age(13).

The precibiculturists of the present time make some artificial drinks 
on a small scale. The native Australians make a beverage by dissolving manna, a sweet substance which exudes from the leaves of certain gum trees, and gum acacia in water. Reference has already been made to a kind of cider made from manzanita berries by the California Indians. Referring to this beverage, Campbell does not seem to regard it as an alcoholic beverage, although he calls it a liquor. He says, "The precibiculturists are wholly ignorant of the art of making alcohol, and that discovery belongs to the agricultural period." It undoubtedly is true, in the main, that the ancient precibiculturists were probably entirely ignorant of how to make alcohol. I). Charles Rice(16) in a private letter referred to by an anonymous author said that while he supposed it was quite possible that the Hindoos knew distilled spirits quite early, it has been found that we cannot go back beyond about 910 A. D. for any positive evidence. The precibiculturists who live at the present time are for the most part ignorant of that art, but not entirely so. Further valuable information with respect to the history of distillation is given by Dr. C. E. Pellew(15) and Babcock(14).

\section{CIBICULTURAL EPOCH}

The discovery or invention of cookery, especially of that branch which rendered the boiling of liquids feasible, was the first and perhaps the most important factor in the evolution of man's diet. The introduction of agriculture and the domestication of animals led to a further advance. Whether or not agriculture preceded the domestication of animals is of small consequence. Scott Elliott(2) seems inclined to think that domestication of animals was brought about first, while Campbell is of the opinion that agriculture had its beginning before the herdsman came into being. Campbell says that it is certain that in the New World, at any rate, plants were cultivated before animals were domesticated. Scott Elliott and most writers on prehistoric times regard Asia as the original home of the human species.

Domestication of Animals.-The taming and subjection of wild animals was an immense advance in civilization. From remains it appears probable that almost all our domestic animals were first brought under human control in Asia. The dog was the first animal to be domesticated, but as he was not eaten, except under unusual circumstances, it will be unnecessary to consider the manner in which his progenitor, the wolf, was subdued and trained. The reindeer affords a good example of the way in 
which animals are domesticated. 'The Tschuktchi, a tribe who live in a cold and inhospitable part of northeastern $A$ sia, possess half wild herds of these animals. They are only half tamed and are liable to stampede at any time. These tribesmen have faint ideas of breeding, but the animals are only used for food and clothing. The Lapps have herds of reindeer, which are much more domesticated; these animals supply them with flesh and clothing, milk and cheese, and in addition do draught work.

Cows seem to have been first domesticated some twelve thousand years ago, probably at Anan in Turkestan. The history of the sheep is even more difficult to trace, but the goat is said to be descended from the wild species of Asia Minor and the Grecian Islands. Swine flesh as a food was of greater importance in prehistoric times than now. In Cyesar's time, pork with milk was the main diet of the Celts and their hams had a wide reputation in the Roman world. The history of the common hog resembles in most respects that of other animals. The greater part of our modern breeds are descended from the almost universally distributed wild boar.

Introduction of Agriculture.-Campbell puts the commencement of the agricultural period at 30,000 years ago, and if this conjecture is correct, then that period began some thousands of years before the domestication of animals.

It is certain, however, that both of these forward steps greatly multiplied man's opportunities to ascend in the scale of development, and solidified his position as the undisputed ruler of the animal kingdom. Before these times he was compelled to spend most of his time hunting for food. His brain power was encouraged to develop in one direction only. When he was able to cultivate the greater part of his food supply, and raise animals of many kinds as well as build vessels to eatch fish, his position was assured. He was no longer at the mercy of the elements or of chance, but could train them in many and diverse directions. Diet, therefore, has had a preponderating influence upon the evolution of man, and he has ascended largely by means of this evolution. Again, so long as cooking, in all its branches, was unknown; cultivation of plants undiscovered and domestication of animals not practiced; man was unable to rise much above the level of brute creation.

At first, agriculture was carried on in a desultory manner. The ground was not actually eultivated, but areas of virgin soil were utilized for raising crops and then abandoned for some other location of a like character. Man was still more the hunter than the farmer; the habits of generations could not be given up at once, and for a long period he hunted 
and fished and lived chiefly on flesh. At best, his methods of cultivation were elementary.

As agriculture developed, he began to obtain the bulk of his animal food from domesticated animals and fishing, and his vegetable food was supplied chiefly by his farming activities, although he still ate small amounts of uncultivated vegetable food. His progress in the methods of cultivating land and of breeding animals was necessarily slow. Certain races of men were better adapted for what may be termed stationary agriculture than others. To the long-headed Mediterranean races may be credited the beginnings of agriculture, and to the brachycephalic type of mankind, inhabitants of Asia, may be attributed the domestication' of animals.

STATIONARY AGRICULTURE.- It is a fascinating study to try to trace the origin of any happening which has conduced to the betterment of the race, and naturally the question of the beginnings of stationary agriculture are of supreme interest. At best, it is largely guess work and the nearest guess as to the date of the first harvest is between $15000 \mathrm{~B}$. C. and 10000 B. C. A few thousand years, when considering the evolution of man's diet, is of no especial moment. Campbell puts the commencement of stationary agriculture at 15,000 years ago. Our cultivated plants should supply some sort of an explanation of this puzzle. If most of them are found wild in one district, the likelihood is that the first harvest field was in this section. However, it is obvious that there must have been two centers, one of which was in the Old World and the other in the New World. According to Herodotus, at the time the pyramids were built in Chaldea, 5000 B. C., onions, leek, garlic, carrot, parsnip, turnip, beet and lettuce were cultivated, while wheat, barley, rye, oats and rice had been used for 5,000 years.

Early Agriculture in America.-In America, in Mexico and Peru, about the same time, agriculture, including methods of manuring, irrigation, was as well understood as in Egypt or Mesopotamia. Of the American plants the following are the most important: maize, scarlet runner and vegetable marrow, which appear to be natives of Mexico or Central America. Constantin and Bois (6) found in Peruvian tombs at Ancon four kinds of maize. Ground nut, manioc, potato, canavali, kidney bean, phaseolus lunatus and tomato came from Peru or Chile. In fact, the Jerusalem artichoke is the only American plant which has not been traced to Mexico or Peru.

Indeed, an American work dealing with the relation of the development of agriculture, to the evolution of man's diet, would not be complete 
without a summary of early American agriculture, and of the mode in which the aborigines of this continent raised their crops.

It is erroneous to believe that when Anerical was first discovered by the white man, the Indian inhabitants were mere hunters. Of conrse, they depended largely upon the bison for their animal food, but according to the records of the early discoverers, a considerable proportion of the Indians from the border of the western plains to the $\Lambda$ tlantic dwelt in settled villages and cultivated the soil. De Soto found all the tribes that he visited, from the Florida peninsula to the western part of Arkansas, cultivating maize and other food plants. The earliest voyagers found tho same thing true along the Atlantic shore from Florida to Massachusetts. Capt. John Smith and his Jamestown Colony depended at first for subsistence largely upon the products of Indian cultivation. Jaeques Cartier had the same experience, while Champlain and La Salle found Indians in the parts of the continent through which they traveled, cultivating and subsisting on maize. "Indian corn, the great American cereal," said Brinton( (7), "was found in cultivation from the southern extremity of Chile to the 50th parallel of N. latitude." Du Pratz(8) remarked, "All the nations who inhabit from the sea as far as the Illinois, and even further, carefully eultivate the maize corn, which they make their principal subsistence."

The great length of the period during which maize had been in enltivation previous to the discovery of America is proved by its differentiation into varieties and by the fact that charred corn and impressions of corn on burnt clay have been found in the tombs and in the ruins of prehistoric Pueblos in the Sonthwest. Delaware traditions and proofs found among the remains of the oldest mounds also show that the Indians must have been tillers of the soil in very early times.

Not only are we indebted to the Indians for the maize itself, but also the methods of planting, storing and using it. Bancroft(9) says that "from the earliest information we have of the Pueblo Indians, they are known to have been tillers of the soil, and though the implements used and their methods of cultivation were both simple and primitive, cotton, corn, and wheat after its introduction, beans, with many varieties of fruit, were raised in abundance." It has been mentioned that the very early inhabitants of Mexico eomprehended the art of eultivating the soil by means of irrigation and manuring. The same so far as irrigation is concerned may be said regarding the Indians of New Mexico and Arizona. Hodge(10) sars, "In the valleys of the Salado and Gila, in South Arizona, however, casual observation is suffieient to demonstrate that the 
ancient inhabitants engaged in agriculture by artificial irrigation to a vast extent."

There is evidence also to show that the early Indians used fertilizers. The Plymouth colonists were told by the Indians to add fish to the old grounds (Bradford, 11). The implements they employed in cultivating the ground are described as "wooden howes" and "spades made of hardwood." Mention is also made of shells used as digging implements. Certain stone implements found in vast numbers are generally conceded to have been used in breaking up the soil.

Primitive Milling.- It will be in place to refer briefly to the primitive ways of grinding corn. In Chile within recent years, Scott Elliott(2) has witnessed threshing of corn by driving a herd of brood mares round and round in a circle, and in so doing hammering out the corn with their hoofs. In Palestine oxen were used for the same purpose. It is possible that at first corn was simply steeped in water and not ground at all(12).

The first mill was obviously any convenient flat rock, upon which the ears of corn were spread and crushed and bruised by a stone. The quern was the most effective early appliance for grinding grain into meal or flour, and consists of two circular stones, the lower firmly placed in a wooden frame. Through the upper stone is pierced a small hole, in which a short stick is tightly fixed. A woman turns this stick in the same way as a millstone and thus grinds the grain. Such mills date back to the Copper Age, and have survived up to recent times in civilized countries.

But to return to the general discussion on the development of agriculture, it is evident that the establishment of a system of stationary agriculture meant the establishment of what we know as civilization. So long as man was wholly or mainly concerned in searching for and preparing food, his aims were wholly materialistic, for he could not give the time to any other employment. After the domestication of animals, the culti vation of the land and the practice of cooking had been placed on a sound basis, man was comparatively free to launch out in new fields of endeavor. By the planting of the first seed or by the placing in the ground of the first kernel, the possibilities for human development were immeasurably advanced. Crops yielded twenty or thirty fold in a good fertile soil, therefore sufficient food for a large family could be raised on a small area.

INFLUENCE OF AGRICULTURE UPON CIVILIZATION.-This state of affairs rendered possible the forming of communities where men could permanently enjoy the society of their fellow men. By such means a new type of man was evolved, and instead of being the bond-servant of nature, 
he became in some degree its master. As cultivation improved, it was found that only a small proportion of the population was required to raise crops, fruits and cattle, and the remainder were released to use their brains and brawn in other channels.

First villages sprang up, then towns and cities. Industrialism was initiated, the arts had their disciples, and finally that complex division of labor and of occupations which marks the social progress known as modern civilization was gradually evolved. All this wonderful progress was due to the cultivator of the soil and the breeder and rearer of domesticated animals termed the farmer. The farmer who tills the soil and raises flocks and herds, and the fisherman who reaps the harvest of the seas, are still the most necessary members of the community, for by the labor of the farmer and fisherman, especially the farmer, sufficient food is produced to maintain a vast population whose energies are released for specialized work. Consequently, up to a certain point diet has played the principal part in the evolution of man.

Relation of Climate to Diet.-But although agriculture, man's own invention, has varied and amplified the food supply, it is necessary to emphasize the natural features which affect diet. A direct relation exists between climate and the consumption of food. In cold climates, exercise and cold sharpen the appetite, and therefore more food is consumed. On the other hand, in a warm climate leading to a state of inactivity, there is less inclination to eat.

Not only is there a correspondence between the amount of food ingested and the inclination for taking it, but probably, from the exercise of instinct supplemented by experience, the nature of the food selected, in different climes, is found to vary, and to constitute that which is most in conformity with what is needed. Moreover, the various climates produce in a large degree the kind of food best suited to keep the inhabitants in health. Vegetables which produce carbohydrates will not grow in very cold climates, and, even if they could be grown, they could not be consumed in sufficient quantities to yield the necessary amount of heat. The dwellers in the arctic regions consume prodigious amounts of heat-generating material, fatty matter procured from the bodies of seals and whales which abound in that part of the world. Conversely, the inhabitants of the torrid zone subsist chiefly on vegetable products highly charged with carbohydrate material in place of fat. The vegetables and fruits which grow in the tropics are exactly adapted to the bodily needs of the inhabitants. The succulent fruits and vegetables upon which the natives of very hot countries prefer to feed, contain little carbon, whereas, 
the oil and blubber which enter largely into the diet of those who live in the extreme north, contain a very large proportion of carbon.

A temperate climate lends itself more to an omnivorous diet, something between the two extremes of far north and far south. Custom in such climates has led to the selection of a mixed diet, which furnishes the combination of the two heat-producing principles. The diet should be made to conform to the principle of adaptability to the particular requirement existing. It should be pointed out that in discussing the question of the evolution of man's diet, the dwellers in the temperate climates are almost invariably referred to. Most of what has been said does not apply at all, or only partly, to the inhabitants of the aretic regions and of the tropics.

In order to give emphasis to these statements, it will be of interest to quote from various authors describing the kind of food consumed by the inhabitants of different parts of the globe.

Lubbock(17) reports that "the Eskimos are mainly an animal-feeding people, and their food consists of reindeer, musk-ox, walrus, seals, birds and salmon. They will, however, eat any kind of animal food, and are fond of fat and marrow."

Simmond(18) says: "The choicest dish of the Greenlanders is the flesh of the reindeer. But as these animals have now become extremely scarce, they are indebted to the sea for their permanent sustenanceseals, fish and sea fowl. The heads and fins of the seal are preserved under the grass in summer, and in winter a whole seal is frequently buried under the snow. The flesh, half frozen, half putrid, in which state the Greenlanders term it mikiak, is eaten with the keenest appetite."

Mackenzie(19) says: "The diet of the Icelanders consists almost solely of animal food, of which fish, either fresh or dried, forms by far the largest proportion. During the summer they have milk or butter in considerable abundance; but of bread and every other vegetable food, there is the utmost scarcity. As an effect of these circumstances, cutaneous diseases are exceedingly frequent. Scurvy and leprosy are common in the island. Scurvy is observed to occur with the greatest frequency at those periods when there has been a deficiency of food among the inhabitants or when the snow and frost of the winter succeed immediately to a wet autumnal season. For its cure, a vegetable diet is employed, in as far as the circumstances of the Icelanders will allow of such means."

Wrangell(20) writes that "the food of the Jakuts of northern Siberia consists of sour cow's milk and mare's milk, and of beef and horseflesh. They boil their meat, but never roast or bake it, and bread is unknown 
among them. Fat is their greatest delicacy. In general, they regard quantity more than quality in their food. They grate the inner bark of the larch, or sometimes of the fir, and mix it with fish, a little meal and milk, or by preference with fat, and make it into a sort of broth. They prepare from eow's milk what is called the Jakut butter. It is more like a kind of cheese or eurd, and has a sourish taste; it is not very rich and is a good article of food eaten alone."

F. B. Head (21) says: "The Indians of whom I heard the most wre those who inhabit the vast unknown plains of the Pampas and who pass their lives on horseback. In spite of the climate, which is burning hot in summer and freezing in winter, they have neither bread, fruit nor vegetables, but subsist entirely on the flesh of their mares." Head said of himself that when he had been riding aeross the Pampas for three or four months and had lived on beef and water, he found himself in a condition which he could only deseribe by saying that he felt no exertion could kill him(22). Referring to the Gauchos of the Pampas he stated: "These people live entirely on roast beef, with a little salt, scarcely ever tasting farinaceous or other vegetable food, and their sole beverage is mate, or Paraguay tea, without sugar."

It is said of the Otaheite Islanders (23), "Their common diet is made up of at least nine-tenths of vegetable food."

In China any kind of food is eaten, while in Japan a multiplicity of food is found. In all parts of the Far East, rice is the staple of diet.

Aceording to Johnston(24), the Abyssinians eat the flesh of animals raw when they desire to enjoy themselves partieularly.

Simmond(18) says that "the principal diet of the Kaffir is milk, which he eats rather than drinks, in a sour and eurdled state. One good meal a day taken in the evening, consisting of the curdled milk and a little millet, is all that he requires, and with this he is strong, vigorous and robust."

It would seem from a perusal of the observations of the travelers quoted above with regard to the diet of people in various climes, that no hard and fast rule ean be laid down as to the kind of food to be eaten. Still in a broad way the statement may be reiterated that instinct and experience are generally the best guides as to the form of food hest adapted to the individual. Animal food is mainly indieated for cold climates, vegetable food for the tropics, and a mixed diet for the temperate zone. Food adapted to the inhabitants is, as a rule, that which can be procured in the neighborhood. 
Seasonal Variation of Diet.-The change of seasons exerts some influence on the diet of man. Before agriculture, domestication of animals and cooking came to pass, the influence thus exerted was greater. This is shown by the diet of the primitive races of the present day, which is almost entirely regulated by the seasonal occurrence of vegetable and animal foods. Among civilized communities independence of and indifference to the seasons have been brought about by the elaborate and effective means which have been devised for preserving, storing, and to a less extent for artificially producing food.

Among modern communities an article of food is never out of season. Food of every description, which can be raised and brought to maturity in one or other part of the world, is, owing to the facilities for rapid transit on sea and land, and more especially to the perfection of the methods of preservation and storage, conveyed at any season of the year to the very doors of those who can afford to pay for it. All kinds of food, even highly perishable vegetable foods, are available at all seasons. Although this system has its advantages, unfortunately it lends itself to abuse. Speculators have been quick to seize upon the opportunities afforded for making money at the expense of the pockets and health of the community. Also when food material is preserved and stored for a long period, the continued freezing deteriorates the quality of the food and this system becomes a menace to health. Animal food preserved for a protracted period is not nearly so nourishing as fresh meat, and when preserved too long may be absolutely injurious. However, preservation of food when properly employed is a great boon to the race.

\section{CHANGES IN BODILY STRUCTURE AND FUNCTION DUE TO EVOLUTION}

\section{MODIFICATIONS DUE TO VARIATION OF DIET}

It is self-evident that changes in function and structure have accompanied or followed evolutionary dietetic progress. The faculty of digesting both animal and vegetable food has varied in the periods of man's evolutionary progress. So far as animal food is concerned, this faculty waxed and waned in proportion to the quantity consumed during the various diet epochs, and was most in evidence when man depended chiefly upon animal food for his subsistence.

The capacity of men of those times to digest immense quantities of food material may be surmised from the fact that certain peoples of the 
present era consume and digest enormous amounts of animal food. Of these the Eskimos, who perhaps may be regarded as being in the same stage of evolution as the men of the early hunting period, are the most conspicuous examples. It appears certain that the capacity of the Eskimo to digest animal food greatly exceeds that of the ordinary eivilized individual; and it seems even more certain that the capacity in this direction of the man of the early hunting period was still greater.

Our ancestors of the simian stage possessed the power to digest coarse vegetable foods to an extent unknown to the present day inhabitants of the earth. Like the apes, to which they were very nearly akin in those days, their jaws and teeth were formed to masticate cellulose, and their digestive organs were of a character to deal effectively with it and the other constituents of the vegetables, which they were compelled to eat in order to live. Also, and this is an important point, since cookery has done away with the necessity for the prolonged mastication of vegetable food which was naturally accompanied by excitation of the salivary glands, it may be taken for granted that the salivary glands of primitive man possessed more amylolytic power than those of neo-man, who, owing to the softness of his food, masticates little. The development of agriculture and the advance of cookery have had the effect of greatly diminishing the consumption of raw vegetables; consequently the power of digesting this form of food has waned until, at the present time, very few uncultivated vegetable foods are eaten raw, with the exception of a few of the cultivated varieties of fruits. Further modifications in the digestive organs were brought about by an increase in the supply of sugar and starch. The cultivation of sugar canes and other sugar-producing plants increased man's previous supply of sugar immensely, and the ability to extract sugar from the cane, and especially from the beet root, augmented it beyond conception. Long ago cookery and agriculture added to the quantity of starchy material available for food, and in recent years cookery has added to the supply of soluble saccharids. As always, in utilizing this additional food supply, man's digestive organs have become more tolerant of starch and sugar.

Natural selection has played the great part in all these adaptations. Those who could not adapt themselves to this kind of food were weeded out in infancy, and a type of the human species has been, and is being evolved, whose digestive organs are able to cope with very large amounts of starch and sugar. The great personal adaptability of man to the various kinds of food must be taken into consideration. Of the animals the frugivorous mixed feeding type is the most adaptable to diet, Man has 
evolved from this frugivorous stage to that of the most omnivorous of animals, and this readiness of adaptation to almost any form of diet is a significant feature of his evolution. Some persons have individual idiosyncrasies to certain kinds of food, which are probably atavistic in character. This hypothesis may explain, in some degree, the distaste exhibited towards animal food by numerous persons.

\section{MODIFICATIONS DUE TO EVOLUTION FROM AN ARBOREAL ANCESTOR}

Professor F. Wood Jones, in the early part of 1917, gave a series of lectures before the Royal College of Surgeons of England, in which he analyzed the various features of the human body which must be attributed to an arboreal lineage. All are familiar with the manner in which the mammalian body has been modified and adapted to changing conditions. Those which live in water have been closely studied, and their structural adaptations investigated by John Hunter, Knox, Turner, Struthers and others. It follows that an arboreal existence has had a profound influence on the structure of the body, but this seems to have escaped the attention of, or has been neglected by, the anatomist, despite the universal opinion of all serious students that man is the descendant of an arboreal stock.

Professor Jones emphasizes the point that the effect of this descent is still plainly evident in the structure of certain human limbs and organs. He pointed out particularly the limbs, the organs and functions of which will be discussed later; but his observations and analyses were of so fascinating and instructive a character that no excuse is needed for giving here a condensed account of his lectures.

The professor asked the question, Why is it that the arm and hand of man and of man's congeners retain so many primitive structural features-features which are sought for in vain in the higher order of mammals, but found paralleled in the very lowest mammals and in reptiles and in amphibia? The answer is to be found in the various functional phases in the evolution of limbs. In the lowest land-living forms of vertebrate animals, limbs are purely propelling organs, and are incapable of sustained support of the body. When the limbs become capable of sustained support, as in mammals with hoofs and claws, they become profoundly altered in structure, and lose their primitive characteristics. In tree-living animals, however, the primitive features are retained, for in climbing, the limbs must still serve as propelling rather than as supporting organs. 
Professor Jones drew the following deduction, a most important point in the evolution of man, that the elimbing stock, the primates, mnst have been evolved at the very dawn of the mammalian type of animal, otherwise these primitive features of the limbs conld not have been retained.

Stress was laid on the adaptation of the hand and foot for grasping purposes in climbing animals. It was shown that it was because the hand could grasp, that it was able to replace functions which are performed by the jaws and teeth of other mammals. 'The retrogression of the jaws, the crowding of the teeth, the coming forward of the eyes, and binocular vision, are direct results of an exchange of function from jaws to head. The climbing and grasping habit has led directly to the carrying and nursing of the young. The climbing habit brought about an alteration of the uterus and the production of only single offspring at a birth, for an actively climbing mother could not protect and carry more.

In terrestrial mammals, smell is the dominant sense; the brain is built up round the olfactory centers. In tree-climbers, scent glands disappear; the sense of smell loses its acuity; the eye, the ear and touch become the master senses; the parts of the brain connected with these sense organs undergo a corresponding development; the human brain can be ouserved being built up stage by stage, as the various primate forms are traced towards the human end of the phylum.

Changes in the Digestive 0rgans.-It must always be borne in mind in tracing the evolution of diet that the organs of digestion in animals adapt themselves to the food to which they are accustomed. Hence our progenitors, preceding the early hunting period, had developed digestive organs which could deal with the coarse, dense, cellulose-containing vegetables which comprised their food. Man, in his simian stage, had organs of digestion, assimilation and excretion very similar to those of his immediate animal progenitors. With the introduction of meat diet as a result of his prowess in hunting, the organs of digestion were further modified to handle both animal and regetable diet. Through the discovery of the art of cooking, man has now become omnivorous, or nearly. so, which has resulted in a subsequent modification of the digestive system.

The structural changes in the digestive system of evolving man, due to alterations and modifications of diet, are considerable. But these functional changes have not produced such great structural changes as might have been expected.

The erect posture and gait had more to do with the alteration of the entire skeleton than any other cause. Standing and walking had a great influence upon the digestive organs, although there is a general resem- 
blance between the digestive organs of man and the great apes. When compared with other animals, the size of man's stomach is quite extraordinarily small, and supplies the most obvious reason why his food must be of a concentrated character.

In the simian period, the Liliputian dimensions of his stomach must have been a serious disadvantage, although it is likely that for some time after he had been wont to walk upright, his stomach was more capacious by far than in the man of today. When, however, he was a wandering hunter, his stomach must have been of a reasonably small size, as a large paunch would have greatly militated against his success in the chase. An early hunter with a too generous waist line would have been an anachronism. The gorilla, using all four feet to support his weight, is able to retain an enormous abdomen, but the upright habit of our ancestors forbade this. One of the most marked anatomical differences in the digestive organs of man and the great apes is in the valvulce conniventes of the small intestine, which, in the apes, are only rudimentary. Again, a notable difference is that the stomach of the ape and his kin is more muscular, making it better adapted to deal with the coarse vegetable food which constitutes the principal part of their diet.

Campbell suggests that it seems probable that a type of individual is being evolved capable of coping with an excess of soft food. At present: a goodly part of the bowel, notably the large intestine, is rendered superfluous and may be the most prominent factor in the causation of that form of intestinal toxemia known as intestinal stasis. Among the factors that bring about intestinal stasis in infancy, Sir Arbuthnot Lane includes unsuitable diet and too frequent feeding, which causes an abnormal distention of the intestine. In later life, according to Lane's theory, the condition is produced or aggravated by the habitual assumption of the crect posture, which causes delay of fecal matter in reaching the large bowel or cesspool of the gastro-intestinal tract, or, as best described, the "general drainage system of the body." The resulting pressure and strain may produce distinct changes, and these alterations may take the form of evolutionary bands, which are practically without blood supply. There is no intention to enter into the question of intestinal stasis, but the matter is referred to in order to point out that Metchnikoff, Lane, Bainbridge, Murray, Leslie and others have considered unsuitable feeding and overfeeding when young, and the erect posture in later life, as a contributary cause not exactly of structural changes which are handed down, but mechanical changes in the alimentary tract, which produce disorders and diseases. 
The Evolution of the Teeth.-In the evolution of man's diet the teeth, naturally, play a prominent rôle. The teeth of primates are shaped in the best and most convenient manner for dealing with the diet which these animals have to subsist upon. In the early days, the teeth of man were stronger and lasted much longer because the vegetable food, which was the staple of diet, needed abundant elnewing and thus kept the teeth in exercise. Atrophy of the alveolar process was then probably unknown. Before dealing with the degeneration of the teeth of man, it may be well to compare them with the teeth of very early man and of some other primates.

If the mature gorilla skull is eompared with that of an adult human being, two differences are especially marked. The forward projection of the face is enormously massive in the adult male gorilla, the lower jaw is heavy and the molar teeth are very large, adapted for coarser and more vigorous work than those of man. When man stood erect and when the teeth ceased to be used for aggressive purposes or as prehensile organs, the skull began to change in shape, and the greatest effect of these changes was manifested in the jawbone (inferior maxilla). After a time, man commenced to develop a chin. At first, as in the Ice Age, the chin was very small, the jawbone massive and the teeth very large. Just after the Ice Age, another race is found with a magnificent chin, but the jawbone is still massive and teeth large. So long as man had to break up the cellulose framework of his vegetable food by his teeth, it followed as a matter of course, that his teeth must be massive and strong.

The human canine tooth is nearest to the earliest type of tooth. "Our incisors," aceording to Scott Elliott, "do not differ to any great extent from very early forms. The premolars and molars exhibit the remains of the primitive three-peaked arrangement. The first simple conelike tooth developed two or three cones or peaks, two on the outside in the upper, and two on the inside in the lower jaw. The resulting triangles of three peaks gave the teeth the exact shape required for a perfect shear and were most admirably adapted to tear flesh from the bones or to crush the beetles and grasshoppers, which were a part of the diet of all the early primates. The carnivora still preserve this trituberculate type because they still have need of adequate means for tearing flesh from bones, but the primates below man and man himself evolved crushing teeth, and consequently the basal part of the tooth, the plane, out of which the peaks rose, expanded into cusps. Even the Eocene lemurs, such as Miacis, show this development." Chimpanzees and other apes have five and even six cusps, and when man ate the same coarse vegetable food with 
a large cellulose content as these apes, he, too, had the same number of cusps. Indeed, the fifth cusp is still present in Tasmanian and Negro teeth, but has disappeared in modern Parisians and in many persons whose ancestors have been accustomed for generations to eat cooked food which required little or no mastication.

It is a law of nature that any organ of the body which is not used, atrophies and finally disappears, and this law is well exemplified in the evolution of the teeth of man. The teeth of certain primeval men, as shown by their skeletons, resemble those of some existing primitive races in that they are large and much worn and exhibit signs of laborious mastication. While the evolution of diet may have been to man's benefit or may have added to his comfort and pleasure, it is certain that his teeth have not been improved. The evolution of his teeth has been a deterioration. A writer has referred to the romance of the teeth; a more apt expression would have been the tragedy of the teeth, for with the invention of the cooking pot, degeneration set in, and the evolution of the teeth proceeded in conformity with the nature of the task required of them.

Before the introduction of cookery, total absence of teeth was almost unknown, for most vegetable food in the raw state required strenuous mastication; hence man rarely, if ever, was toothless. His teeth were ground down to the very gums by long and vigorous chewing of thick and coarse vegetable substances.

With the advent of cookery all this was changed. Man was no longer so entirely dependent upon the soundness and sharpness of his teeth nor upon the strength of his jawbone, because cooking rendered the hard, indigestible cellulose fibers of some kinds of vegetable food soft and pliable, so that but a small amount of work was placed upon the teeth. Cookery, to use a somewhat vulgar expression, "cut both ways." It had its great advantages and countervailing drawbacks. By primitive agriculture the supply of soft vegetable food was increased to an almost unlimited extent, and cooking rendered it yet softer. But although these two agencies combined, made man less dependent on his teeth, at the same time, through disuse or insufficient use, they indirectly brought about a change in the form of the jaw and teeth, with a tendency in the latter to decay.

As agriculture progressed, further reducing the sellulose constituents of vegetable food, and grinding and other artificial means for performing this service came into common use, chewing was in some measure no longer the chief function of the jaws and teeth. Accordingly, these grew smaller, altered considerably in type, and the teeth frequently decayed.

The condition of the jaw and teeth did not reach their acme of de- 
terioration until the neo-agricultural period was far advaneed-that is, until the present time. Nowadays, because food is so soft, mastication is to a great extent unnecessiry; consequently the teeth are growing smaller and weaker. The third molar is "practically always degenerate," and not infrequently absent. The jaw, also, does not grow to its pristine or even to what may be termed its normal size. In fact, the teeth which have diminished in size cannot find room in the diminutive jaw to take up their natural anatomical positions. This deterioration, accompanied by a tendency to decay, has of recent years gone on apace.

Dietary dental diseases are now extremely prevalent among the most civilized or among those living under the most highly civilized conditions, as is also dyspepsia, largely due to improper mastication. Nowhere is so much soft pap food eaten and consequently so little mastication and insalivation required as in America. In fact, eereals and many other foods in this country are offered for sale partially predigested; they neither give the teeth work, nor do they excite the salivary glands or the digestive functions to activity. May not this be a chief reason for the prevalence of digestive troubles and for the dental caries, pyorrhea alveolaris and other diseases of the teeth among Americans? It is true that the teeth of Americans compare favorably with those of the inhabitants of other countries, but this is due to art and not to nature. The American dentist is the most ingenious and, on the whole, the most efficient in the world. But his numbers, his skill and his prosperity all show that his services are continually in demand, and that he has gained his proficiency chiefly because he has been given every opportunity to keep in constant practice. Moreover, since the conditions which are kringing about the degeneration and deterioration of the teeth and the subsequent disorders of the digestive system are growing steadily more prevalent, the future in this respect is threatening.

SUMMARY OF THE EVOLUTION OF THE TEETH AND DIGESTIVE SYSTEM.-The situation may be summed up as follows: The teeth of the primates closest to man, and of very early man himself, were sounder than at the present time because they were kept in constant use. With the coming of agriculture and cookery, the teeth lost a good deal of their importance. Before this time they were absolutely essential to life: after this period, although it might be extremely inconvenient and prejudicial to a good state of health to be without teeth, they were not absolutely essential. As time went on, teeth lost more and more of their importance as a means of sustaining life until, at the present time. food is so prepared and cooked that the teeth are not called upon to exert any strenuous 
action. Grinding mastication is unknown. Generally speaking, our food, including meat, is soft; consequently the teeth tend to decay, from lack of exercise and from other causes, at an early age. Therefore, it is true that although we have gained much by agriculture and cookery, we have lost much.

We now eat a large amount of food which is not good for us, simply because it is agreeable and can be eaten without mastication; we eat too much food and a considerable quantity of unsuitable food. Our teeth go, and we suffer from indigestion, especially from that form known as intestinal stasis. No kind of food predisposes to and causes intestinal stasis to such an extent as soft, partially digested, unmasticated food. The outstanding features of the existing dietary is the concentration of diet, and the soft forms of food ingested. These lead to constipation and indiges. tion, the curse, it may almost be said, of modern life and especially of life in cities. Overeating is also encouraged. Moreover, if this sort of soft diet is indulged in for any length of time, the digestive organs deteriorate like the teeth from lack of use, and a thoroughly vicious circle is established.

Changes in the Mammary Function Due to the Artificial Feeding of Children.-The artificial feeding of children will be mentioned here, but as the subject of bringing up infants on the bottle is adequately considered in Volume III, ${ }^{1}$ it will be superfluous to dwell on the matter at length. In the precibicultural period, and among precibiculturists now extant, the theory of the survival of the fittest is an actuality. In former times, if a mother could not suckle her child, it was inevitably doomed to death. If a mother died during childbirth, the infant was deliberately destroyed. Consequently, by the elimination of those unfit to bring up children, the women remaining were in every respect admirably adapted for the purpose. After the domestication of lactating animals, mothers who for one cause or another were unable to nurse their children could rear them by artificial feeding. A beginning was thus made of the lowering of the standard of mammary function, which has now approached a serious condition. The civilized woman of the present day is less well equipped by far than her primitive sister, so far as her maternal functions are concerned.

A distaste to or even aversion to the nursing of children is also becoming more and more evident among all classes of society. In view of these facts it appears within the bounds of reason to foresee a time when the mammary function will atrophy and the majority of women will be physically incapable of feeding their progeny at the breast.

1 Chapter XXV. 


\section{GENERAL SUMMARY}

The chief fact taught by an investigation of man's dietetic past is that food has been a most important factor in the evolution of man. Three events mark the dietary influence on this evolution-the discovery of cooking, the advent of the agricultural era, and the domestication of animals. All of these innovations, by profoundly influencing the diet of man, have changed his manner of life in all respects. In fact, food brought about the ascent of man to a certain level upon which his present lofty position has been built.

While civilization, based upon the results of cookery and cultivation, has been a blessing to mankind, it hals not been an unmixed blessing regarded from the standpoint of health. In early times, the food of our ancestors was such that much of it required vigorous mastication, with the consequence that little starch was taken into the stomach in a crude form. At the present time, the reverse is the case; a very large amount of practically pure starch is ingested, and owing to its soft consistency and the consequent lack of mastication and insalivation, slips down into the stomach in a state totally unprepared for digestion, giving rise to various disorders and to malnutrition. This condition is particularly true in the case of infants. The supply of sugar has also increased and is eaten to an inordinate extent. This, taken in connection with the augmented consumption of vegetable food, gives rise to the conclusion that the present generation is likely to suffer from the undue consumption of both starch and sugar.

No dogmatic statement can be made as to the relative values of animal and vegetable food as articles of diet. Since men have lived in good health as vegetarians or nearly vegetarians, and also solely upon meat, these examples do not prove the point. Climate has a great influence on the nature of a diet; occupation is a factor that must be considered, and heredity is not a wholly negligible quantity. In a general way, it may be said that animal food appeases hunger more thoroughly than a vegetable diet, and satisfies it for a longer time. It gives more stay to the stomach and has a more stimulating effect upon the system generally. In spite of the fact that man is descended from the ape, and that the ape is more frugivorous by far than carnivorous, the fact remains that the small size of man's stomach, due possibly to his erect posture, demands a concentrated diet, and this diet would seem to be best supplied by meat. Cookery affects the relative values of animal and vegetable foods in oppo- 
site ways, with regard to mastication. Cooking coagulates the albumen of animal tissues, hardening it so that mastication may be necessary; cooking of vegetables does away with the need for mastication. It cannot even be argued that either animal or vegetable food is the natural diet of man, for while his ape ancestors did not eat much flesh, at one time of his early career as a human, man was more carnivorous than frugivorous. The present conformation of his jaws and teeth, the result of an evolutionary process, does not single him out as especially adapted for a vegetable or an animal diet. Whatever primitive man may have been considered from the dietetic standpoint, he is now a mixed feeder in temperate climates. Descending from ancestors whose diet for long ages has varied in the temperate zone, man would naturally find a varied diet best suited to his needs and to his taste. His anatomical history also shows that his digestive system is highly adaptable to these variations, and is capable of being modified to almost any extent.

His adaptability affords an explanation of why he has fallen into the routine of the existing civilized mode of diet. Eating food of soft consistency, which is the universal habit, has had and is having an injurious effect upon his jaws and teeth, upon his salivary secretions, and upon his digestive system. He should revert to some extent to the food of his simian ancestors-raw vegetables and fruit-which would afford plenty of exercise to his masticatory, salivary and digestive organs. A simple diet is in the main the ideal one. If he continues to eat soft, cooked foods - and it does not seem very likely that he will not-then in the course of time it may be expected that a type of person will be evolved capable of dealing with the quantity and kind of food which our ultra refined civilization has decreed that we shall consume.

Perhaps it is possible that we have come to the end of our progress in the direction of diet, and that the human race will be the better for going back to the simple diet of our ancestors. It must be borne in mind that extreme luxury in diet has been noted more than once in the history of the world-with the Persians and Romans, for example. Afterwards a period of comparative simplicity has ensued, until a climax has been again reached.

The acme of dietary excellence was attained not long after the age of agriculture, cooking, and domestication of animals came in. Since then the increase of population, industrialism and other concomitants of advanced civilization have made further dietetic changes necessary. At the present time, the situation must be met in the best ways possible. The chief object of this chapter has been to point out and lay stress upon the 
fact that man's evolution has been greatly dependent upon the evolution of his diet, and it is to be hoped that this object has been fairly well attained.

\section{REFERENCES}

1. Campbeit, Harry. Sutherland's System of I)iet.

2. Scotr Eliliott. Prehistoric Man.

3. Holmes. Convolution of Animal Intelligence.

4. Skent and Brafiden. Pagan Races of the Malay Peninsula.

5. Tozer. History and Geography.

6. Constantin and Bois. Rev. Gen. Bot.

7. Brinton. Myths of the New World, 1868.

8. Du Pratz. Hist. La., 1763.

9. Bancroft. Nat. Rac., 1882.

10. Hodge. Am. Anthrop., 1893.

11. Bradford. Hist. Plym. Plant., Mass. Hist. Soc. Coll., 1856.

12. Fisciner. Arch. f. Anthrop., 1909.

13. Popular Science Monthly. April, 1898.

14. BABcock. Historical Notes on Aleohol.

15. Pellew, Dr. C. E. Appleton's Popular Science Monthly, June and July, 1893.

16. Rice, Ciras. Dining and Its Amenities.

17. Luвbоск. Pre-Historic Times, 1869.

18. Simmond. Curiosities of Food, 1859.

19. Mackenzie. Travels in Iceland, 1811.

20. Wrangell. Expedition to the Polar Sea, 1844.

21. Head, F. B. Journeys Across the Pampas, 1828.

22. Hesd. Odontological Society's Transactions, ii, New Series.

23. Cook. First Voyage. Hawkesworth's Voyages, Vol. ii.

24. Johnston. Travels in Abyssinia, 1844. 



\section{CHAPTER II}

\section{CHEMISTRY AND PHYSIOLOGY OF DIGESTION}

\section{CHEMICAL CONSTITUENTS OF THE BODY AND OF FOOD}

Chemical Elements in the Human Body.

Organic Compounds: Fats, Ca'rbohydrates, Proteins, Albumins; Proximate Principles.

Inorganic Compounds: Water, Acids, Salts.

Scientific Classification of Foods: Nitrogenous, Non-nitrogenous.

Tests to Determine Food Value: Chemical, Physical, Physiological, Economic.

Of the eighty-three elements known to the chemist but twenty are found in the body. They are: carbon, hydrogen, nitrogen, oxygen, sulphur, phosphorus, fluorin, chlorin, iodin, silicon, sodium, potassium, calcium, ammonium, magnesium, lithium, iron and occasionally manganese, copper and lead. These elements are rarely found in the pure state, being present in the form of chemical compounds which, as they occur in the structure of the various tissues, are very complex in arrangement. These compounds are comparatively unstable, and are readily converted in the body, or changed into other forms, which may be easily shown by chemical analysis.

The elements of both animal and vegetable foods are derived from the earth, air and water. We know that animal life could not subsist upon inorganic substances nor derive nutriment from them alone, notwithstanding the great importance ascribed to the inorganic materials for the vital processes of the human body.

Other combinations of chemical derivatives are also required, which come under the head of plant and animal life, and are known as organic substances. All food is composed of many combinations of these simpler chemical elements, which, for the most part, must be subjected to alterations in the body itself by digestion, before they are ready for assimilation by the tissues. Nutrition of the body, therefore, involves several distinct metabolic processes, viz. :

I. The secretion of digestive fluids and their physiological action upon food in the alimentary tract.

II. The absorption of food ingredients when digested into the lymphatic and circulatory systems. 
III. The assimilation of the absorbed nutrition products by the tissues.

IV. The elimination of the waste material.

Elements and Their Compounds.-The analysis given below will show the relative predominance of the elements of which the human body is composed.

Elementary Composition of the Human Body

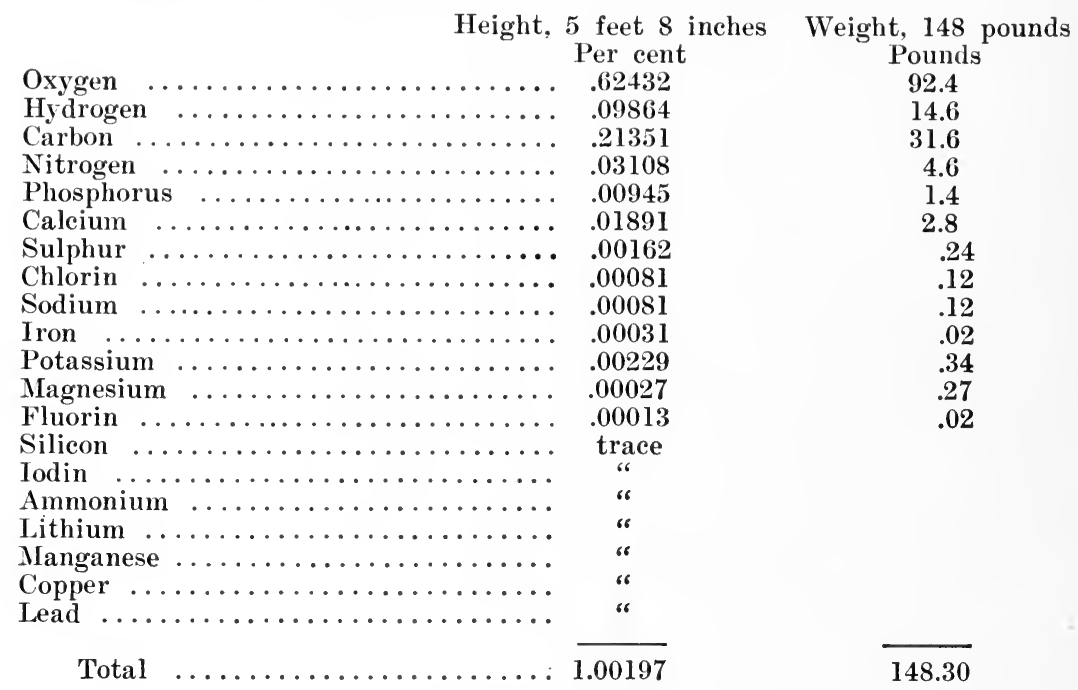

All these elements are derived from the food plus the oxygen, either inhaled from the air or liberated within the body as a molecule of oxygen, when food particles are broken down.

Oxygen, hydrogen, and carbon are the three principal elements of the human body (as well as in all our foodstuffs), being the great force producers of the body, and at the same time the tissue builders.

Nitrogen, when present, is capable of acting in a dual capacity; it either accommodates itself to the process of cell and tissue formation, or is broken down from the completed molecule and thrown off when muscular energy is manifested or when cellular disintegration occurs.

Foodstuffs, to play an important part in tissue production, and at the same time stimulate bone formation, must contain sulphur, phosphorus, iron, sodium, potassium, and calcium phosphate. If these elements and compounds are deficient in the food of a growing infant, softening of the bones will follow. Bone cells contain 50 per cent calcium phosphate, and this element is absolutely necessary for normal osseous development.

Food without iron salts will cause a change of the hemoglobin content of 
the red blood cells and a diminished oxidation, resulting in anemia. The potash salts, especially potassium carbonate and chlorid, if absent or found in insufficient quantities, lead to senrey-which condition is aggravated by the use of common table salt, sodium chlorid. $\Lambda$ diet of salt meat and bread, excluding potatoes, fresh fruit, and vegetables, will produce scurvy.

Sodium chlorid is an important constituent directly concerned in nutrition. Its absence interferes with many of the functions of the body, such as absorption, and materially alters the density and reactions of the different fluids.

PROXIMATE PRINCIPLES.-Chemical elements are rarely found in a pure state, but are present in diverse combinations, or, as they are sometimes termed, "proximate principles," which may be divided into the following groups: (1) mineral, or inorganic compounds; (2) organic compounds, or compounds of carbon. The organic compounds may again be divided very conveniently into two groups: the nitrogenous and nonnitrogenous compounds. The inorganic compounds. comprise water and the various acids; for example, the hydrochloric acid of the gastric juice and numerous salts.

Since the same elements in varying proportions are to be found in both foodstuffs and the human body, the various compounds of these elements may be termed "proximate principles." As pointed out by physiologists, "proximate principles" are chemical compounds of which the body is composed and into which it is theoretically, but not analytically, separable without chemical change. They may be classified as follows:

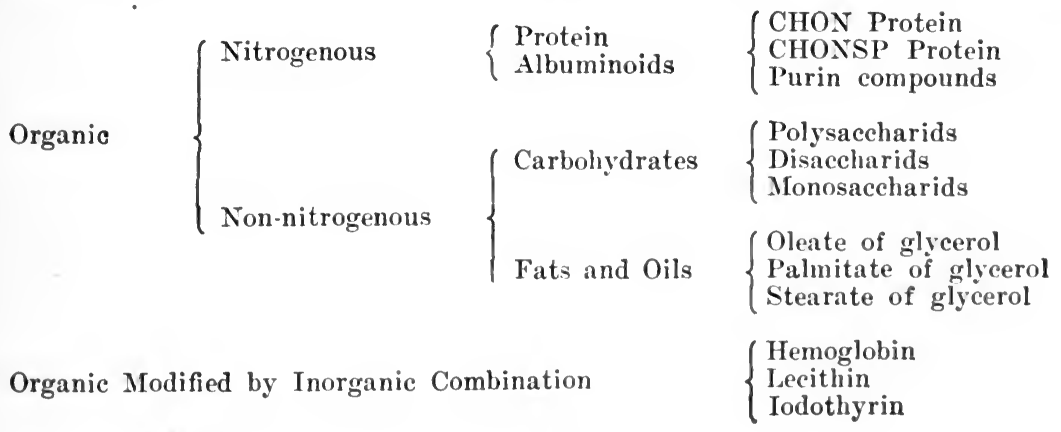

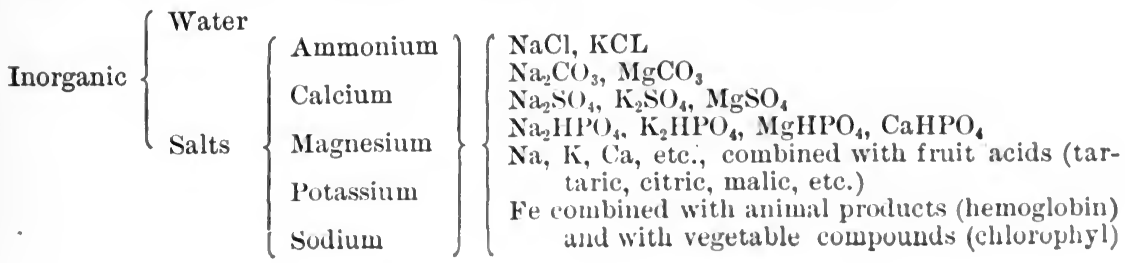


All of these elements are present, yet all are not of equal importance, nor do they occur in the same proportions. Among the inorganic group, water and the salts are preëminent. Among the organic group, protein, fats and carbohydrates are most numerous.

Inorganic compounds act medicinally and aid in the formation of inorganic constituents of bone, and in osmoses. Oxygen is regularly introduced into the body in large amounts both as an essential constituent of organic foods and as an element by respiration. In the latter form, probably by the assistance of enzymes, it oxidizes all forms of organic components of the body, acting, as a rule, destructively rather than constructively. Most of the other elements (excluding corrosive action) might be administered in the elemental state, and would sooner or later form inorganic or organic combinations while in the alimentary tract. We know that iron in its elemental form can be assimilated as such, though not as readily as from organic compounds. In most instances, all the elements give better physiological results when administered as salts or as organic compounds.

Scientific Food Classification.-Of the chemical classification of foods the one advocated by Baron von Liebig is the simplest and best. He was the first to suggest a real scientific division, viz.: (a) Nitrogenous, (b) Non-nitrogenous.

"Each of these classes contains food materials derived from both the animal and vegetable kingdoms, although the majority of the animal substances belong to the nitrogenous, and the majority of vegetable substances to the non-nitrogenous group.

(a) von Liebig regarded the nitrogenous group as containing plastic elements-i.e., they are essentially tissue builders or flesh formers. Nitrogenous foods are sometimes called azotized foods or albuminoids-that is, substances resembling albumin. They consist chiefly of the four elements, carbon, oxygen, hydrogen and nitrogen, to which a small proportion of sulphur and phosphorus is usually joined. The proteins and their immediate derivatives constitute practically all of the nitrogenous material involved in the processes of nutrition. They are fermentable, and under some conditions will putrefy. This group comprises all forms of animal food, except fats and glycogen. It includes, therefore, albumins and gelatins. Its chief representatives are milk, eggs, crustaceans, fish, flesh and fowl. It also contains such nitrogenous substances as occur in the vegetable kingdom, or vegetable albuminoids.

(b) The second or non-nitrogenous group von Liebig called respiratory or calorifacient foods, because their function in the body is to 
furnish fuel or maintain animal heat. Since this original classification was suggested, it has been established that the non-nitrogenous elements supply energy as force, manifested through muscular action; hence they are also called force producers, in distinction from the nitrogenous tissue formers." (1)

The non-nitrogenous group contains only the three elements, oxygen, hydrogen and carbon, together with varions salts found in both animal and vegetable foods. This group comprises all varieties of vegetables, fruits, cereals, starches, sugars and gums, the fats and oils, which are derived both from the animal and vegetable kingdom, and organic acids. Meat, vegetables, and the starch molecules of cereals contain a certain proportion of nitrogenous material which is chiefly found as an outside envelope for protection, affording firmness of resistance to the softer pulp within. This material contains "vitamins," essential for the maintenance of health.

Animal food is not strictly nitrogenous because of the fact that it contains fat and glycogen, while on the other hand, regetable food is not absolutely non-nitrogenous since it contains albuminoids and other forms of protein. Yet this classification is a very convenient and simple one, and its general acceptance has met the approval of most writers on chemical and physiological subjects.

It is therefore permissible to classify the nutritive constituents of food, in accordance with their functions in the body as follows:

TISSUE FORMERS

Protein

Mineral matter

Waters
WORK AND IIEAT PRODLCERS

Protein

Albuminoids

Carbohydrates

Fats

Mineral matter

Water

This is a convenient distinction to adopt, but it will be observed that proteins are able to fulfill both functions of a food, as force producers and heat givers. "It is this physiologieal omnipotence which gives to proteins their vast importance in the diet, and justifies the prond title of 'preeminence,' which the name implies. Without protein, life is impossible. sinee the breaking down of tissues must be replaced. With protein plus water, and the mineral salts, life can be healthily maintained for a longr period of time, as is proven by the experience of savage tribes, Indians 
of the Pampas, who live year in and year out on practically nothing but lean meat and water." (2)

Tests of Food Value.-Such being the use of foods.in the body, the question arises: how is one to judge of their relative value? By what precedent or authority is one to decide whether any special article of diet is good for food or contains food value? The answer is to be given only after submitting the food under consideration to the following tests:

I. Chemical.- What percentage of each nutritive constituent does the food contain?

II. Physical.-How much potential energy is it capable of yielding? III. Physiological.-How does it behave in the stomach and intestines? Is it easily digested and to what extent absorbed?

IV. Economic.-Are the nutritive constituents which the food contains obtained at a reasonable cost? (See Fig. 4, page 59.)

THE CHEMICAL TEST.-Chemical analysis reveals the quantity of each nutritive constituent (protein, fat, carbohydrate) in one hundred parts of foodstuffs. From this information we can arrive at a conclusion as to the exact value of a food as a source of building material or energy. In subsequent chapters the percentage composition of all the chief articles of food will be recorded in detail.

THE PHYSICAL TEST.-Lavoisier was the first to demonstrate the precise changes which food underwent in the body. He proved that the changes were essentially due to oxidation resulting from the combustion of certain foodstuffs. This combustion may be taken as a measure to determine the value of a certain food as a source of energy for heat and work, which are convertible terms. The question may arise in the minds of some as to whether these results, which may hold good for laboratory experiments, are equally true for combustion in the body. "This suspicion is strengthened when one remembers that many of the waste products of metabolism, such as urea, are by no means completely oxidized. The body does not reduce all its fuel to ashes; some of it is only charred."(3) Rubner and other careful observers have shown conclusively that if allowance is made for these incompletely oxidized products, combustion, that is, the amount of energy liberated within the body, is precisely the same as the equivalent laboratory experiments.

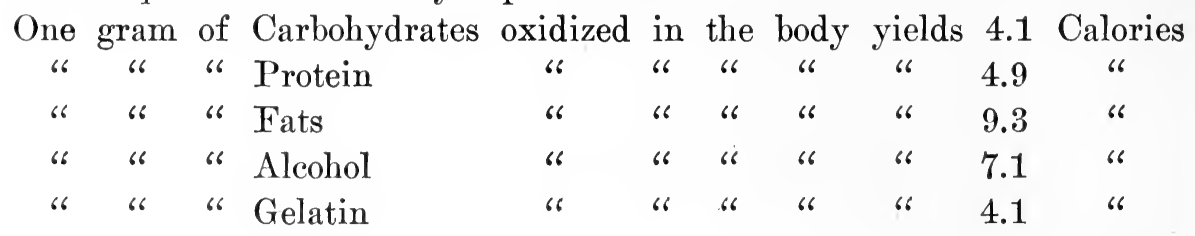


FAT.

CARBOHYORATES.

FUEL VALUE.

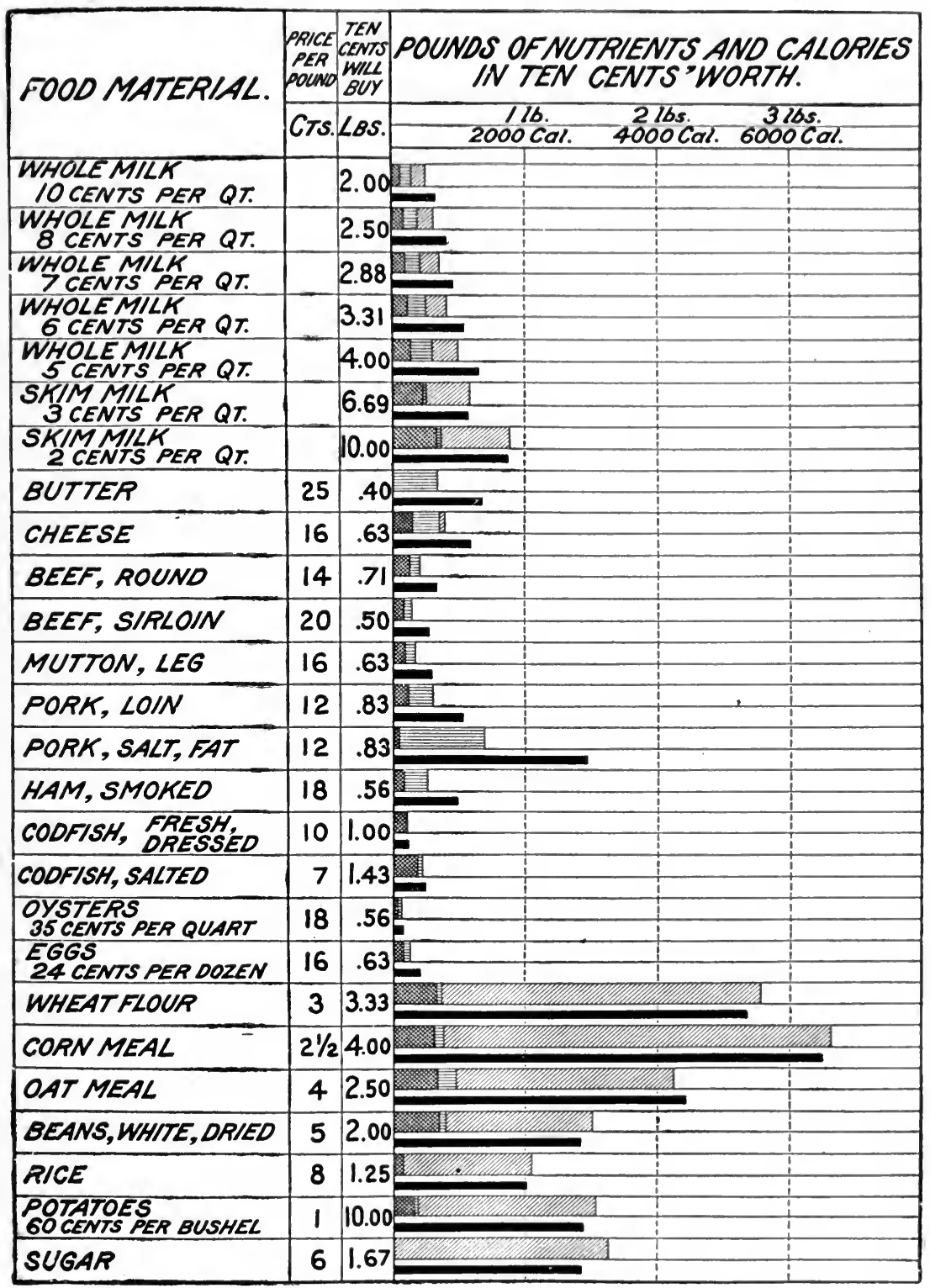

Fig. 4.-Chart Illustrating the Pecuxiary Ecoxom of Various Meats, Milk AND OTHER Foods. (Amount of actual mutrients obtained in different foods for an outlay of 10 cents at certain assumed prices per pound.) (Farmers' Bulletin 363, U. S. Department of Agriculture.) 
These figures represent the average calorie of the nutritive constituents as contained in an ordinary mixed diet, and often allowance has been made for the defective absorption and for the excretion of imperfectly oxidized residues by the kidney. They may therefore be accepted as an indication of the true worth to the body of the different nutrient constituents as sources of potential energy required for the normal individual.

THE PHYSIOLOGICAL TEST.-This test alone is not sufficient to determine a wholesome food, which not only should contain a considerable proportion of protein, fat and carbohydrate, but should be capable of yielding energy on oxidation and at the same time be of such nature as to be readily digested in the stomach and easily assimilated. Such substances as sawdust, petroleum or cattle-hoof parings might pass the chemical and physical tests and still be useless as a food, because they cannot be digested or absorbed. For these reasons the digestibility of food in the stomach and intestines must be taken into consideration before venturing an opinion as to its value in a diet.

THE ECONOMIC TEST.-Having determined the richness of a food in nutritive derivatives, the amount of energy which it is capable of yielding, and the readiness with which it can be digested, assimilated and absorbed, there is still an important question to determine-whether the nutriment which it yields is obtained at a reasonable cost. For this an economic test is required, which is furnished by applying a knowledge of the caloric method, to determine how much energy (in calories) and how much building material (in protein) one can procure for a particular sum, when invested in the food under consideration.

The question of the "high cost of living" has become one of momentous importance in this country during the past decade; therefore the economic value of foods is of special importance to the student, physician and dietitian. Often it is necessary to see that the diet of a patient is enriched in special directions, most commonly, perhaps, in fat or protein. It is useless to recommend to a poor man chicken, duck and cream, which he cannot afford to buy. It is worth while, however, to know that these elements can be furnished economically by buying the cheaper grades of foods, such as skim milk, fish, cheese, beans, peas and the cheaper cuts of meat, since these furnish the desired quantity of protein. Economical forms of fat may be had in margarine and pork drippings, which are within the reach of all.

It must be remembered that the cost of living takes about 50 per cent of a laborer's wages, and that the poorer a man is the greater is his proportionate expenditure for food. 
Another point which concerns the economy of food values is the waste and cost of cooking. Of avoidable waste there is no need of complaint; but of unavoidable waste there is room for discussion. Much of the food "as purchased" (see Chapter XIX, Food Analysis) is not in edible form, such as the skin and skeleton of fish, the bone of meat and some parts of green vegetables. In the ordinary cuts of butchers' meats, the waste is safely calculated at 15 per cent; in fish the waste may be as high as 70 per cent, which must be taken into account in buying food. The cost of cookery is an economic question exceedingly difficult to estimate (see Volume II, Chapter I), as this question depends upon the cook. The general value of the results will be seriously impaired by careless handling.

It will be observed that it is by no means an easy matter to pronounce an opinion as to the caloric value of a food or arrive at an intelligent conclusion offhand in estimating its fuel value. Each test must be applied in turn, as it is only upon the foods which stand a satisfactory scrutiny of all tests, that a favorable opinion can be rendered. In other words, a food is only to be adjudged good when it contains an ample proportion of nutritive material readily digested, easily assimilated, and rapidly absorbed, at a reasonable cost.

\section{REFERENCES}

1. Thompson. Practical Dietetics, p. 5.

2. Hutchinson. Food and Dieteties, 1907, p.5。

3. - Ibid., p. 8. 



\title{
CHAPTER III
}

\section{CHEMISTRY AND PHYSIOLOGY OF THE PROXIMATE PRINCIPLES OF FOOD}

\author{
E. E. SMitif, Pif.D., M.D.
}

\begin{abstract}
Vitamines; Hormones; Enzymes.
Proteins: Protein Amino-acids; Simple Proteins-Albumins, Globulins, etc.; Conjugated Proteins-Chromoproteins, Glycoproteins, etc.; Derived Proteins-Proteins, Metaproteins, Coagulated Proteins, Peptones, Peptids, etc.; Nuclein and Purin Bases.

Carbohydrates: Monosaccharids-Pentoses, Dextrose, Levulose or Fruit Sugar, etc.; Disaccharids-Saccharose, Maltose, Lactose; Trisaccharids-Melitose, etc.; Tetrasaccharids-Stachyose, etc.; Polysaccharids-Starch, Dextrin, Glycogen, Cellulose, etc.

Hydrocarbons: Terpenes; Alcohols-Glycerol; Aldehyds; Acids-Organic;

Esters-Volatile Esters, Oils, Fats, Waxes, Phospho-esters, etc.

Pigments.

Inorganic Salts.

Water.
\end{abstract}

In Chapter II we studied the chemical elements of the body and of foods. We learned that all material things of the universe are composed of eighty more or less simple elements, namely, substances incapable of being divided into different or simpler substances. They exist in innumerable combinations, as compound substances, or compounds as we call them, that make up all known material things. We learned that the body and foods are thus made up of definite chemical units, so that the ultimate composition is expressed in terms of the simple elements-carbon, hydrogen, oxygen, nitrogen, sulphur, phosphorus, etc. In animals and vegetables these elements exist combined to form chemical compounds-e.g., albumin, gelatin, fat, sugar, starch-these are termed proximate principles. Generally, several of these exist together, making up the complicated materials of a simple structure, though there may be storage of particular proximate principles, as of albumin in white of egg or starch in 
particular proximate principles, as of albumin in white of egg, starch in seeds. The proximate composition is the composition expressed in terms of such proximate principles, which for convenience are arranged in five groups, the "five food principles":

Proteins

Carbohydrates

Hydrocarbons
Inorganic Salts

Water

In addition we have accessory food constituents:

Vitamines

Lipoids

In the vegetable kingdom proximate principles are built up from the elements or from simple compounds. To the animal body they are supplied as food. Hence, in order that the nutrition of the body may proceed normally, the food should contain these principles in certain quantities and proportions. A proper diet for man is one containing proximate principles of certain kinds and in certain proportions, the value depending not alone upon essential constituents, but also upon various accessory principles that combine to make the food fully adapted to the needs of the body.

Vitamines.-Besides the classical "Five Food Principles" just enumerated, mention must be made of certain substances of unknown nature termed "vitamines," that are essential to body nourishment. The qualities of food are in many ways determined by the nature of the known carbohydrates, the proteins, the fats and the mineral salts. These proximate principles play an important part in supplying energy and repairing tissue waste, furnishing the materials for construction and use of the body. Yet the vitamines, occurring apparently in very small quantities, are also of vital importance. While as yet opinion is not unanimous in regard to their nature, it seems probable that they contain basic nitrogen, and that they are of such importance that their absence produces certain diseases aptly called deficiency diseases.

Among these is beri-beri, a nervous affection supposedly caused by a diet composed largely or exclusively of rice from which the bran has been removed by polishing, thus depriving the rice of its vitamines. Likewise pellagra, a disturbance of the peripheral and central nervous system, occurring generally among those partaking largely of maize and having a very restricted diet, may point to vitamine deficiency, although this view was not entirely borne out by the findings of the Pellagra Commission, 1914. Again, scurvy, a disease of malnutrition which may be cured by a diet of anti-scorbutic foods, such as limes, lemons and oranges, may prove to be caused by vitamine deficiency. 
Vitamines, or other substances the nature of which is quite obscure, seem likewise essential to growth and maintenance of normal nutrition. Animals may be maintained for a very considerable length of time on ehemical mixtures of the "five principles," but eventually these unknown substances contained in milk fat, and in certain other foods, become necessary or normal nourishment and growth cease. However, it is possible and even probable that these unknown substances differ from the true vitamines, the absence of which causes the deficiency diseases.

Hormones.-Mention should be made of "hormones" (see Chapter VI), substances of physiological rather than food interest, since they are formed and exert their action in the living body. Examples are the gastrin, formed in the stomach, which rouses to activity the gastric-secretory processes, and secretin, an active secretory hormone of the intestine. These substances are probably basic and are heat stable. They are not contained in food but are formed in the body.

Enzymes (See Chapter VI).- - The catalyzers of the body, by whose action various chemical reactions are hastened, are likewise of physiological rather than immediate food interest, though they play an all-important part in the transformation which food undergoes in the body. Their occurrence in food is ordinarily merely incidental.

\section{PROTEINS}

The proteins include all the organized nitrogenous substances which oecur in animal or vegetable tissues, excepting the nitrogenous fats(1). They contain an average of 16 per cent nitrogen; hence the protein substances are usually estimated by multiplying the quantity of the nitrogen by the factor 6.25 .

Proteins are necessary constituents of all animal and vegetable cells; therefore, they are an indispensable principle of our diet. In fact, they are the actual vehicles of life, and upon their properties the very possibility of life depends.

Proteins are colloidal substances whose molecules are exceedingly large, it being estimated that the molecular weight of individual proteins is $10,000-15,000$ or even more. Bunge recognized that they never occur pure in nature, but are combined with mineral substances. Moreover, it is known that mineral matter is essential to the physiological activity of protein, a fact which emphasizes the interrelation of the proximate principles of the living cell.

It is not strange that proteins combine with mineral substances, since 


\begin{tabular}{|c|c|}
\hline . & 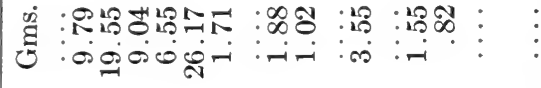 \\
\hline 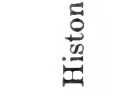 & 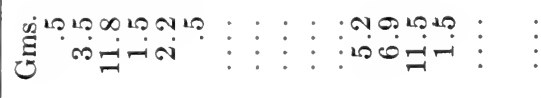 \\
\hline$\stackrel{\Xi}{\mathscr{E}}$ & 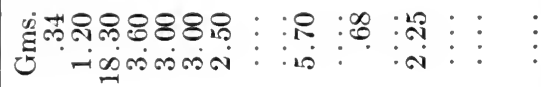 \\
\hline$\frac{\Xi}{\underbrace{}_{3}}$ & 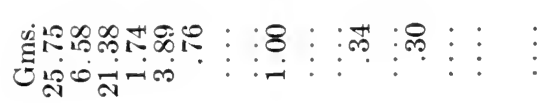 \\
\hline 吾 & 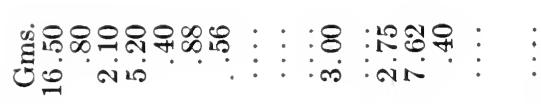 \\
\hline 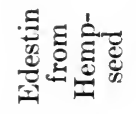 & 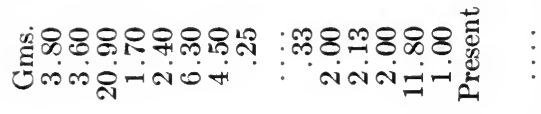 \\
\hline 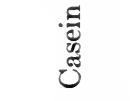 & 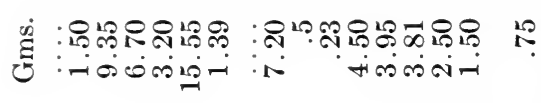 \\
\hline 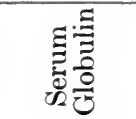 & 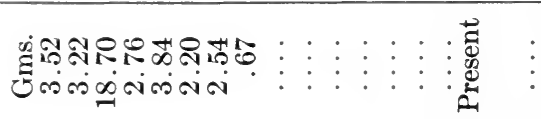 \\
\hline 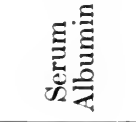 & 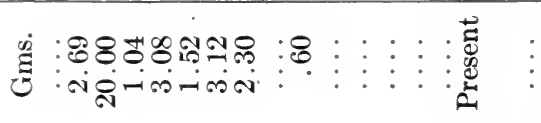 \\
\hline 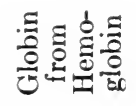 & 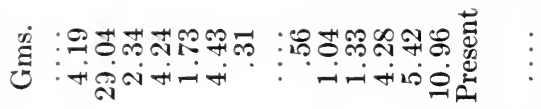 \\
\hline$\stackrel{\Xi}{\frac{0}{2}}$ & 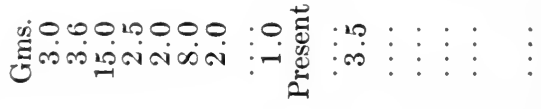 \\
\hline 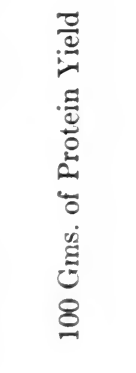 & 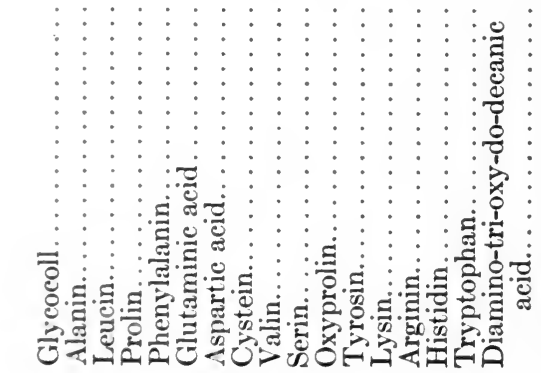 \\
\hline
\end{tabular}


they themselves have both acid and basic properties. This is attributable to the fact that they are combinations of amino-acids. Some twenty or more of these acids have been isolated from proteins in which they aro linked together in various combinations, forming complicated chains or networks, in this way making up the giant protein molecule.

Protein Amino-acids.-Abderhalden estimates that the number of the possible combinations of twenty known protein amino-acids(2), in which each individual amino-acid is present once and only once, is represented by a number composed of thirteen digits. With this possibility, it is easy to comprehend how different classes of proteins present differences in internal structure, even though by ordinary methods they are regarded as identical. Proteins of different animals may present less evident differences. Such differences have in recent times been demonstrated biologically in proteins heretofore regarded as identical. That is to say, the very proteins which perform identical functions in different animals are not themselves identical, but differ from genus to genus, from species to species; and the more widely separated from each other in the evolutionary scheme the greater the differences of such proteins. The effect of this conception upon physiological thought has been and must continue to be far reaching.

The part played by the amino-acids is most interesting and instructive, and an endeavor will be made to further elucidate this phase of the question. Before dealing more closely with the amino-acids, it will be pertinent to discuss their nature. Since all the known disintegration products of the simple proteins belong to the class of the amino-acids, it may be of use to point out some of their distinguishing features.

An amino-acid is derived from an organic acid by the replacing of one atom of hydrogen by the amino group $\mathrm{NH}_{2}$. Thus from the acids,
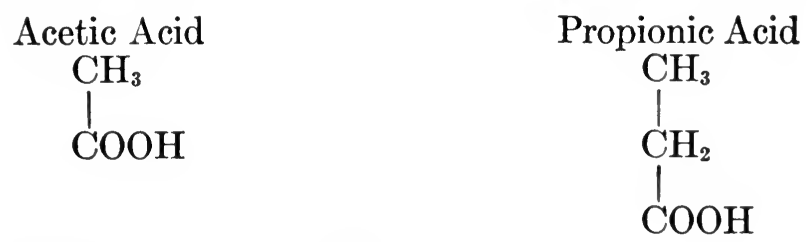

we may obtain the mono-amino-acids,

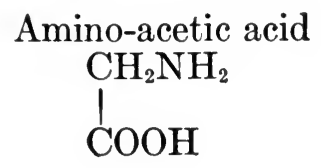

Alanin or $\alpha$-aminopropionic acid $\mathrm{CH}_{3}$

CH. $\mathrm{NH}_{2}$ 
It will be noticed that in the fatty acids with more than two atoms of carbon the position of the $\mathrm{NH}_{2}$ group may be varied. Thus instead of alanin we may have another aminopropionic acid, namely:

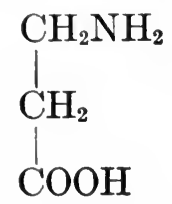

This acid would be referred to as $\beta$-aminopropionic acid, alanin being $\boldsymbol{\alpha}$-aminopropionic acid. This nomenclature is always employed to distinguish the position of the $\mathrm{NH}_{2}$ group, so that we may have monoamino-acids, $\alpha, \beta, \gamma, \delta, \epsilon$, etc. Practically all the amino-acids which occur as constituents of the protoplasm molecule belong to the $\alpha$ group.

On inspection of the formula of glycin it is evident that only one isomer of this body is possible. In alanin, however, the carbon atom to which $\mathrm{NH}_{2}$ is attached is asymmetric, since its four combining affinities are each attached to different groups, thus:<smiles>CC(N)C(=O)O</smiles>

In this case, therefore, there is a possibility of stereo-isomerism, and alanin must have an influence on polarized light. If the compound<smiles>CC(N)C(=O)O</smiles>

is dextrorotatory, then its stereo-isomer

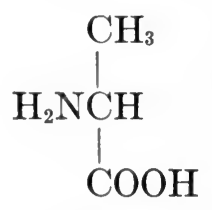

will be levorotatory and it will be possible to obtain a racemic modification without any influence on polarized light by mixing equal molecules of these isomeric forms. All the amino-acids derived from proteins are 
optically active, whereas those obtained by synthesis are inactive, and special means have to be devised in order to obtain from the artificially formed racemic amino-acid either the l- or d-amino-acid.

If more than one hydrogen atom in an organic acid be replaced by $\mathrm{NH}_{2}$ we obtain diamino- and triamino-acids. Thus ornithin obtained by the splitting up of arginin, one of the commonest disintegration products of protein, is an $a \delta$ diaminovalerianic acid,

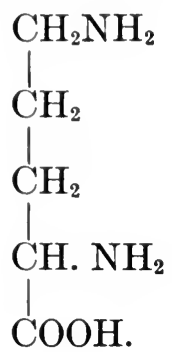

The presence in the amino-acids of the basic radical $\mathrm{NH}_{2}$ and of the acid group $\mathrm{COOH}$ lends to these bodies a double character. In themselves devoid of strong chemical qualities, possessing neither acid nor alkaline reaction, they are able in the presence of strong acids or bases to act either as base or acid. When in solution by themselves it is possible that there is an actual closing of the ring by a soluble union between the $\mathrm{NH}_{2}$ group and the $\mathrm{COOH}$ group, so that, e.g., the formula of glycin may be<smiles>C1NOO1</smiles>

When such a neutral compound is treated with acid, this bond is loosed and we have the salt of the amino-acid. Thus, with hydrochloric acid, glycin forms glycin hydrochlorate,

\section{$\mathrm{CH}_{2} \mathrm{NH}_{2} \mathrm{HCl}$ $\mathrm{COOH}$}

a salt which still possesses an acid group and which is, therefore, capable of combining with ethyl to form the hydrochlorate of the ester of the amino-acid, thus :<smiles>CCOC(=O)CNC(Cl)Cl</smiles> 
With bases, the amino-acids form salt-like compounds such as potassium amino-acetate,

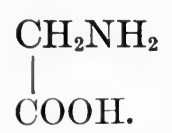

With neutral salts crystalline compounds may also be formed. With sodium chlorid glycin will form the double salt $\mathrm{C}_{2} \mathrm{H}_{5} \mathrm{NO}_{2} \mathrm{NaCl}$.

Not only do the amino-acids form compounds with salts, but they also combine with one another. This power of combination greatly increases the difficulty of separating the constituents from a mixture of aminoacids. Amino-acids which singly are extremely insoluble are readily soluble in the presence of other amino-acids. On account of the dual nature of the amino-acid molecule, these substances act as feeble conductors of the electric current, i.e., as electrolytes.

METHODS OF SEPARATING AMINO-ACIDS.-By the hydrolysis of protein by means of acid or of trypsin, a complex mixture of amino-acids is obtained(3). From this mixture certain amino-acids are separated with ease. Thus, tyrosin, which is extremely insoluble, crystallizes out on concentrating the fluid, and further concentration leads to the separation of leucin. The other acids which keep each other mutually in solution are, however, very difficult to isolate. Fischer was the first to devise a general method for their separation.

The Disintegration Products of the Proteins.-By Fischer's method among the substances isolated from proteins are the following:

Fatty Series.

(1) Mono-amino-acids (Monobasic).

Glycin or Glycocoll. This, the simplest member of the group, is amino-acetic acid,

\section{$\mathrm{CH}_{2} \mathrm{NH}_{2}$ ! $\mathrm{COH}$}

which occurs in considerable quantities among the disintegration products of gelatin and to a less extent among those derived from certain of the other proteins.

Alanin is an $\boldsymbol{\alpha}$-amino-propionic acid,

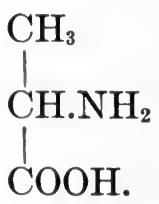


It is optically active, the alanin derived from protein being dextrorota. tory.

Closely allied to alanin is the amino-acid serin which was first obtained by the hydrolysis of silk and has since been found as a constituent of a large number of proteins. Its formula is:

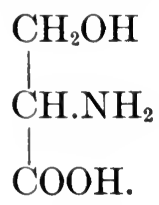

It is an amino-oxypropionic acid. Its special interest lies in the fact that it was one of the first of the amino-oxyacids to be isolated, and it is possible in these acids that we must seek the intermediate stages between carbohydrates and proteins.

Aminovalerianic acid has the formula:

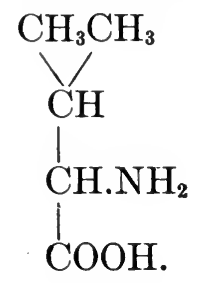

It occurs only in small quantities in the protein molecule.

Leucin, one of the oldest known members of the group of amino-acids, is obtained in large quantities from the disintegration of nearly all the animal proteins, of which in some cases it may form as much as 20 per cent. It has the formula:

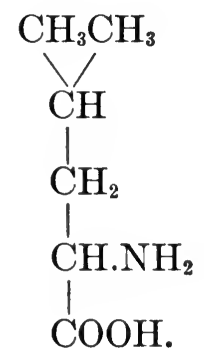

It is an amino-isobutyl acid. On evaporating a tryptic digest of protein, impure leucin erystallizes out in the form of imperfect crystals, the socalled leucin cones.

There are also mono-amino derivatives of dibasic acids, diamino-acids, 
amino-acids containing an aromatic nucleus, amino-acids of heterocyclic compounds, sulphur-containing amino-acids.

Thus all the proximate constituents of simple proteins, as far as is known, are amino-acids. Of these the acids mentioned in the table, page 66 , have been isolated.

These results show that all the proteins contain a very considerable proportion of the total number of amino-acids which have as yet been isolated from acid digests of proteins. The differences in various proteins cannot therefore be determined by qualitative differences in their constituent molecules, but must depend on the relative amounts of the amino-acids which are present and on their arrangement in the whole molecule.

Deaminization.-This process involves the splitting off of an $\mathrm{NH}_{2}$ group from an amino-acid as ammonia, and its replacement by $\mathrm{H}$ or $\mathrm{OH}$. Many tissues of the body appear to have this power. In most cases the nature of the change in the remaining moiety of the molecule has not yet been ascertained. If, for instance, some amino-acid, such as glycin, alanin or leucin, be added to a mass of liver cells, ammonia is set free in proportion to the amount of amino-acid which was added. The ammonia, therefore, is assumed to be derived from the amino-acid.

Certain investigations of Neubauer tend to show that deaminization is accompanied in the first place by oxidation, so that the first intermediate product formed is not an oxyacid but a ketonic acid. A second atom of oxygen is then taken up, and carbon dioxid is split off, with the production of the next lower acid of the series.

However, it would be superfluous to elaborate further the principle of deaminization. It will be sufficient to restate the hypothesis that practically all the proteins of the body are absorbed by the blood stream, removed from it by the tissue cells and dealt with either for the purpose of assimilation into protoplasm, or for the discharge as waste material by the kidney. Deaminization is essential to bring about the end. The arguments in support of this line of reasoning are as follows: In the first place there has been the discovery of erepsin, which assists the pancreatic juice in cleaving proteins into their simple crystalline products; in the second place, there are the experiments of Loewi and Abderhalden and of others which have shown that animals maintain their nitrogenous equilibrium and health when fed exclusively upon these simple materials; thirdly, there are the experiments of Schryver, of Leathes and of Howell, who have shown that the non-protein nitrogenous constituents of the blood and liver increase after the taking of a protein meal; and they have been 
sucessful in the difficult task of detecting in the blood stream some of the individual amino-acids. Lastly, there has been the discovery of Vernon and others, of intracellular enzymes in the various tissues which render the cells capable of dealing with these substances which reach them via the blood and lymph.

Chemical Classification of Proteins.-The present chemical classification of proteins (see table on page 75) is based upon gross differences in structure, differences in solubility, etc., and does not recognize the subtle differences just described that have been demonstrated by biological methods. Nevertheless, the chemical classification is helpful and important. Native proteins are divided into simple and compound. The former include albumins, which are apparently soluble in water alone and are less easily precipitated than most proteins; and globulins, which require the presence of neutral salt to keep them in solution. While at one time it was thought that these made up a considerable amount of the cytoplasm of the cells, it is now recognized that they form a relatively insignificant part, the chief mass of the protein substances consisting of the more complex compound proteins, the albumins and globulins being nutritive materials for the cells or destruction products in the chemical transformations of the protoplasm.

ACTION OF PROTEINS.-The recent work of Abderhalden and the study of cytolysins afford evidence that the proteins of the liver, spleen, pancreas, and possibly other organs have their special peculiarities. Each kind of foodstuff, and indeed each individual protein fraction, follows its own special metabolic path. Moreover, there are paths for fats and paths for carbohydrates, and it is evident that even dextrose and levulose are dealt with in different manners, for a patient whose power of burning dextrose is grossly impaired, might deal with levulose with far better success. In the same way the power of catabolizing a single protein fraction might be lacking in an individual who was able to dispose of other protein fractions in a normal manner. It is believed that these changes are wrought by specialized enzymes, many, if not all, of which are capable of reversed action.

The most prominent compound protein of the cell is nucleoprotein, a compound of simple protein with nucleic acid; this latter being a phosphoric acid compound of purin bases, pyrimidins and sugar. In the cell, nucleoprotein exists in the acid condition in the chromatin structure of the nucleus, while in the cytoplasm the acid is quite saturated with protein.

The solution of a protein is in some respects hardly more than a sus- 
pension, so that relatively slight changes suffice to throw it out. Thus, many proteins may undergo changes whereby they lose their solubility and become inert masses. This state of "coagulation" may be brought about outside the body in the presence of water by the action of heat, of chemicals or of enzymes; it also may occur spontaneously within the body probably from enzyme action when the life of the tissue is extinguished. Certain natural changes are thus explained, such as coagulation of blood and rigor mortis.

DIGESTION OF PROTEINs.-The digestion of proteins, that is to say their preparation in alimentation for absorption, has loug been a matter of investigation. The change is at first one of hydration and cleavage whereby soluble and slightly diffusible products are formed, namely, proteoses and peptones, and it was long thought that it was in this form that proteins were absorbed. It is now believed that the end accomplished by protein digestion is the breaking down of the complex protein molecule into its simple constituent amino-acids, or at least into relatively simple combinations of amino-acids, by which change the protein character is entirely lost. According to this conception, the reconstruction of the proteins in the organism starts from the simple amino-acid fractions, a view that furnishes an adequate explanation of how the transformation of the foreign food proteins into proteins that are specific for the individual organism, or at least for the species, is accomplished.

The protein breakdown in digestion is brought about by enzymes of the digestive juices. The reconstruction of tissue proteins after absorption is likewise accomplished by enzymes which are now working in a reverse direction, taking the simple blocks liberated by the digestive processes and recombining them into structures, that is to say protein molecules, of the nature that constitutes the particular tissues of the individual. There is thus the explanation of individuality in chemical composition as in structural morphology. Applied to germ plasm, it is readily seen how this conception bears upon the problem of hereditary transmissions.

Fischer has thrown much light on the structure of proteins by the experimental joining of amino-acids into combinations, so-called peptids, of greater or less complexity. Molecules have thus been synthesized that present many of the characters of native proteins.

The mechanism by which the regulation of the intricate metabolic changes are maintained, and the work of the regulating mechanism in the animal body, are made manifest in a variety of different ways. Thus we know that internal secretions are implements rather than originators of 
control. The hormones are themselves but chemical products of certain specialized cells, and the activities of the glands which produce them are under the control of the vegetative nervous system which transmits to them impulses in response to the chemical demands of the tissues.

Thus we ses that proteins are of very complex constitation, occurring in both animal and vegetable foods, and that chemically they may be regarded as peptids or combinations of amino-acids and their derivatives. They are colorless, odorless, in general tasteless, non-volatile and of varying degrees of solubility; they are putrefiable and readily undergo chemical change under the influence of the digestive ferments.

\section{Proteins, as Classified by American Biochemists(4)}

I Simple Proteins
A Albumins
B Globulins
C Glutelins
D Prolamins
E Albuminoids
F Histones
G Protamins

II Conjugated Proteins

A Chromoproteins

B Glyco- or glucoproteins

C Phosphoproteins

D Nucleoproteins

E Lecithoproteins
III Derived Proteins

A Primary Protein Derivatives a Proteans

b Metaproteins

c Coagulated proteins

B Secondary Protein Derivatives
a Proteoses
b Peptones
c Peptids

SIMPLE PROTEINS.-These are native proteins that apparently are made up entirely of amino-acids, or at least contain no distinct moiety capable of being split off as such.

Coagulable proteins are the typical simple proteins. They are the albumins and globulins and occur together in most tissues and fluids of animals, as also in various parts of plants, especially fruits and seeds. They are changed into insoluble modifications when they are heated to boiling in a very slightly acid solution. They are built up of a rather large proportion of mono-amino-acids, in distinction to histon and especially protamin, in which the diamino-acids are conspicuous. Moreover, the mono-amino-acids include at least eight varieties. The important chemical distinction is that while albumins are soluble in water, globulins are only soluble in dilute salt solutions. Further, albumins are less, readily salted out of solution than are globulins.

Albumiss.-Albumins are widely distributed. The molecule is highly complex and within certain limits varies greatly in different organs and conditions. The chief examples of albumins are serum albumin, egg albumin, myo-albumin, lactalbumin, vegetable albumin. The serumalbumin of the blood serum, plasma, lymph and other tissue fluids is probably a mixture of two albumins, from one of which amino-sugar was obtained by Langstein. 


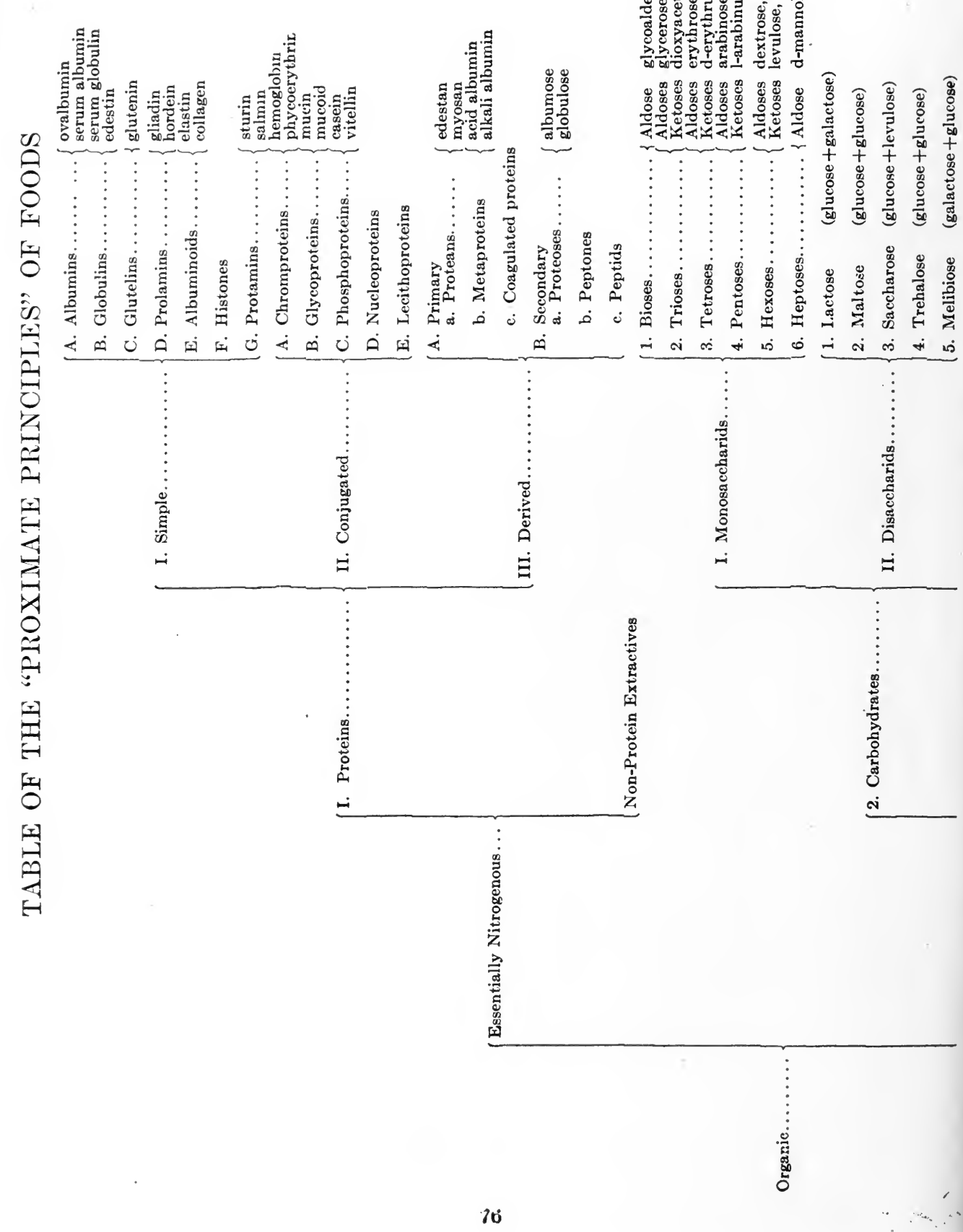



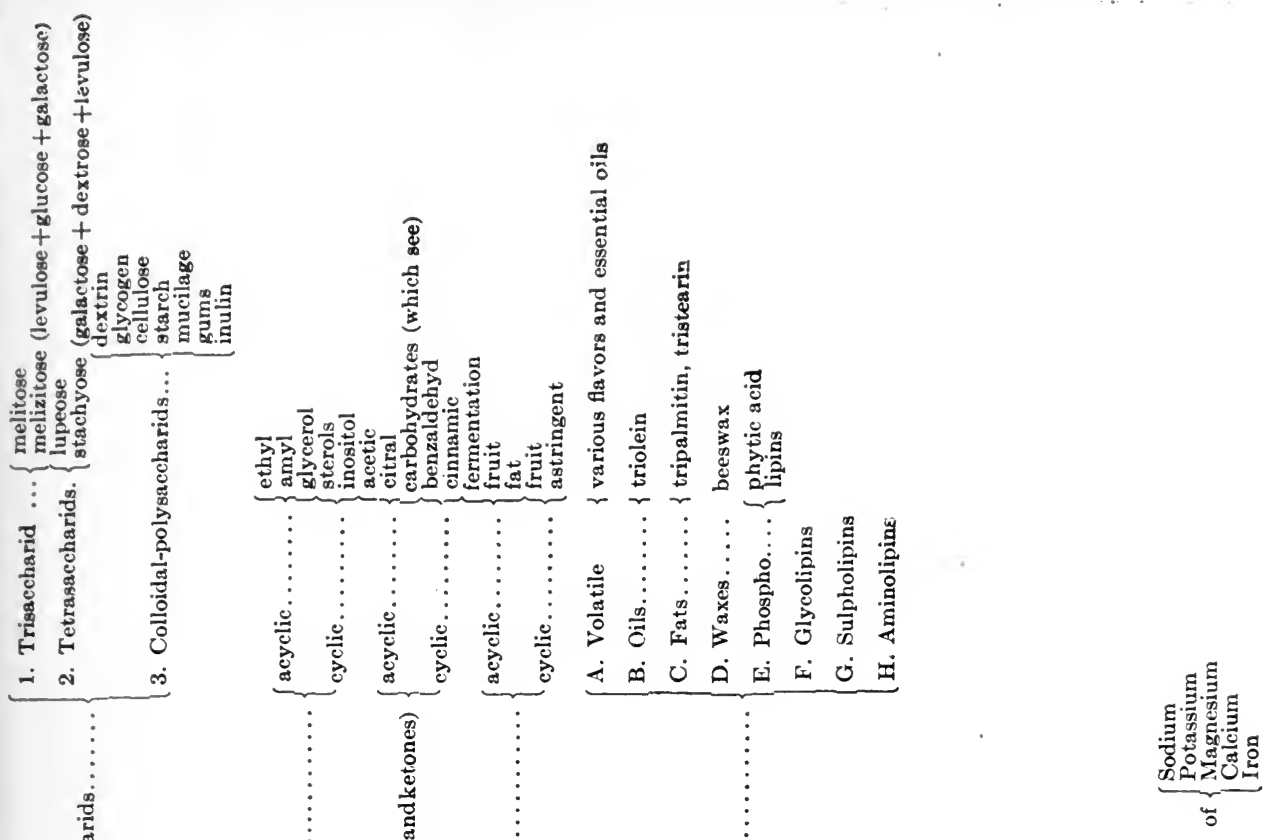

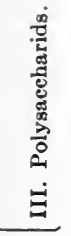
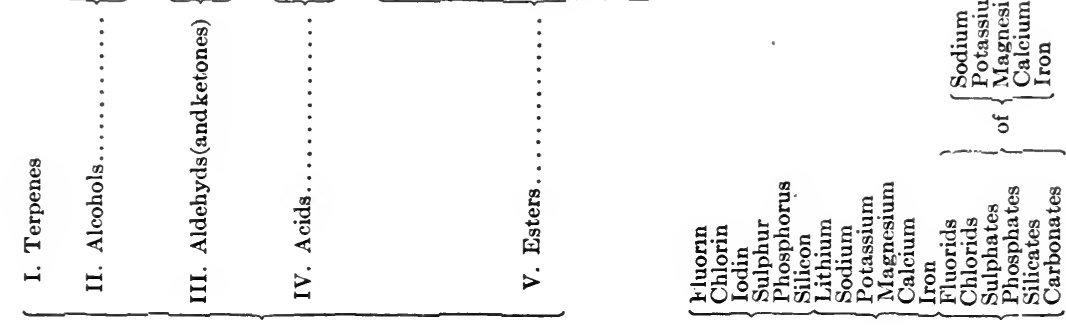

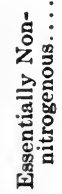

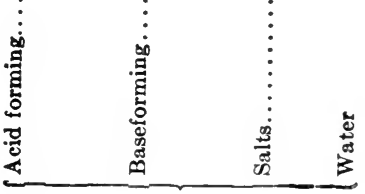


Globuliss.-Globulins are quite abundant and may be present with an appreciable amount of sodium chlorid. The chief examples are serumglobulin, paraglobulin, myoglobulin, myosinogen (myosin), fibrinogen (fibrin), vegetable myosin, legumin or vegetable casein, vitellin, etc. While albumins are only sparingly present among vegetable proteins, the globulins are common. Serumglobulin, paraglobulin, or fibrinoplastin is abundantly present in blood serum, plasma, lymph, red blood corpuscles, leucocytes, and also probably in the cells of many tissues. Fibrinogen occurs in blood, lymph, chyle and certain transudates, and possibly is formed from a destruction of leucocytes. Vitellin is the globulin of egg yolk, which is not precipitated by sodium chlorid.

In the pea, horse bean, lentil and vetch the globulin legumin is abundant; in the first three mentioned, vicilin is also present. These seeds contain small quantities of the albumin, legumelin.

In the oil seeds (nuts), globulins are the principal protein, as excelsin in Brazil nuts and edestin in hempseed. When properly separated from solution, many of these proteins present a crystalline form.

The chief protein constituents of the seeds of cereals form a distinct group not represented in other plants nor in animals. In wheat these are gliadin, belonging to the prolamins, and glutenin, a glutelin. The gluten of dough is a mixture of gliadin and glutenin in roughly equal proportions in which the gliadin forms a sticky mass with water and binds together the particles of glutenin.

Glutelins.-Glutenin is insoluble in water and salt solutions, but soluble in dilute acid or alkali. It gives most of the general reactions for proteins.

Prolamins.-Prolamins, of which gliadin is an example, are insoluble in water and in absolute alcohol, but dissolve in alcohol of 80 per cent. They give most of the general reactions for proteins. Besides their peculiar solubility, they differ in composition from other proteins in that they contain a large amount of prolin and also amido groups, hence the designation prolamins. There is also a large amount of glutamic acid. Zein of maize and hordein of barley are other prolamins.

Albuminoids.-Albuminoids, designated scleroproteins in the English classification, constitute the chief protein constituents of the supporting tissues of the animal body, in marked distinction to plants in which these tissues are carbohydrate in nature (cellulose, etc.). However, chitin, which makes up the hard parts of the arthropoda and is usually designated an albuminoid, is believed to be a polymerized mono-acetyl 
glueosamin and is thus chemically related to the carbohydrates. Its relation to the glycoproteins is indicated below. The keratins, the albuminoid basis of hair, nails, feathers, horn, epidermis, etc., are ordinarily incapable of digestion and so present no food interest. Elastin, the chief constituent of elastic tissue, is very resistant. While under some circumstanees it is easily digested by pepsin and is said to be actually digested in $\operatorname{dogs}_{\mathrm{s}}$, it is believed to be only partially digested by human beings. Collagen, which forms the most abundant nitrogenous constituent of the ground substance of connective tissue of bone and of cartilage, is converted into gelatin by boiling with water and is thus of considerable food interest. The aromatic amino-acids do not enter into the composition of this protein, so that it is sometimes referred to as an incomplete protein. On this account it does not fulfill the protein requirements of the body, though in conjunction with complete proteins it reduces the quantity of the latter which is necessary for sustenance. It is also on account of the absence of aromatic amino-acids that under bacterial growth it does not undergo putrid decomposition, which fact renders it of great service when this process is to be avoided in alimentation. Chondro-albuminoid of cartilage and osseo-albuminoid of bone are present in relatively small amounts and are so resistant that they probably yield little or no protein nourishment to the body.

Histons.-Histons are basic proteins occupying a place midway between protamin and typical protein, and in some instances, at least, seem to be intermediate products in the formation of protamin. On hydrolysis they yield a larger proportion of arginin than albumins and globulins, but less than protamins. Examples are the histons from blood corpuscles and from thymus, as well as from the unripe testicles of fish. Globin, the protein moiety of the conjugated protein hemoglobin, has been considered to be a histon. However, in its properties it has many points of difference, most important of which is that while 29 per cent of its nitrogen is in the form of diamino-acids, the chief acid is histidin, not arginin.

Protamins.-Protamins, sometimes ealled basic proteins, are the simplest of all proteins, and probably form the base or nucleus of all typical protein. Prominent examples of protamins are salmin and sturin, obtained from the corresponding fish sperm in which they are present as salts of nucleic acid. They differ from the more familiar proteins, being composed chiefly of diamino-acids, and especially arginin, and seem to be derived from the diamino-acid portion of muscle protein during growth in the spawning season. 
CONJUGATED PROTEINS.-These are composed of a protein moiety in conjunction with a so-called prosthetic group, usually acid in nature, which determines the class to which they belong.

Cinomoproteins.-Chromoproteins have prosthetic groups that are colored. The iron-containing hematin of hemoglobin is a familiar example. Chlorophyll, whose composition is not yet known, probably belongs to this class, as do the crystalline conjugated proteins, phycoerythrin and phycocyan, closely associated with chlorophyll in plants. That chlorophyll contains a prosthetic group similar to hematin is suggested by the fact that, like hematin, on decomposition it yields pyrrol derivatives. However, it contains no iron, but, instead, magnesium.

Glyco- or Glucoproteins.-These are characterized by having prosthetic groups that are carbohydrates. The group in most cases is glucosamin or a polysaccharid composed of glucosamin units, such as chondroitic acid. The particular examples are the mucins and mucoids, the former yielding slimy or gummy solutions while the latter do not. Mucins occur in saliva, the prosthetic group making up 36.9 per cent of the salivary mucin and 26 per cent of the submaxillary. This radical is probably in part and perhaps wholly glucosamin. Moreover, it is probably a monoacetyl hexosamin, which fact relates it to chitin, which is a polymer of an acetylated glucosamin. The carbohydrate group separated from mucin by boiling with alkali, the animal gum of Landwehr, has a reducing action only after hydrolysis, which further relates it to chitin and to chondroitic acid. This latter in the prosthetic group of mucoids, whether chondromucoid, tendomucoid or osseomucoid substances, occurs in the corresponding tissues. Chondroitic acid is the sulphuric acid compound of chondroitin which on decomposition yields acetic acid, glycuronic acid and glucosamin. It is the formation from the prosthetic group by hydrolysis of these carbohydrate radicals that justifies the classification of the mucins and mucoids as glucoproteins.

Phospioproteins.- These are of considerable importance in food chemistry because being present in milk, in the eggs of birds and frogs and fish they constitute the greater part of the protein present in the foodstuffs of young mammals and of embryo birds. They contain phosphorus, but their prosthetic group has not been identified; hence they are regarded as simple proteins in the English classification. They were formerly called nucleo-albumins, but they yield neither nucleic acid, purins nor pyramidins on hydrolytic decomposition. Casein of milk, termed caseinogen by the English, is the most familiar example, while vitellin of egg yolk, occurring in loose combination with lecithin, is another. It is the 
casein of milk that separates as a curd under the enzyme action of rennin. The presence of calcium salts is essential to this process.

Nucleoprotens. - They are characterized by the prosthetic group nucleic acid. In typical nucleoproteins this is a combination of orthophosphoric acid with (a) a carbohydrate, either a hexose or pentose, which in turn is combined in part with $(b)$ the purin bases guanin and adenin and in part with $(c)$ two of the three pyramidin bases, cytasin, thymin and uracyl. A single grouping of a phosphoric acid, carbohydrate and purin or pyramidin base, is called a mononucleotid. Nucleic acid is a tetranucleotid, in which two are purin and two pyrimidin. The carbohydrate and purin or pyrimidin combination is a nucleosid. When nucleoproteins are hydrolyzed through the action of pepsin-hydrochloric acid, the action does not proceed to complete hydrolysis, but part of the protein remains combined with the nucleic acid as an insoluble compound termed nuclein. Since nueleoproteins are regularly important constituents of cell nuclei and occur as well, though with a lesser proportion of nucleic acid, in the cytoplasm, it will be appreciated why cellular food is the source of exogenous purins, and that a purin-free diet may not include these nucleoprotein-containing tissues.

\section{Purin BoDies}

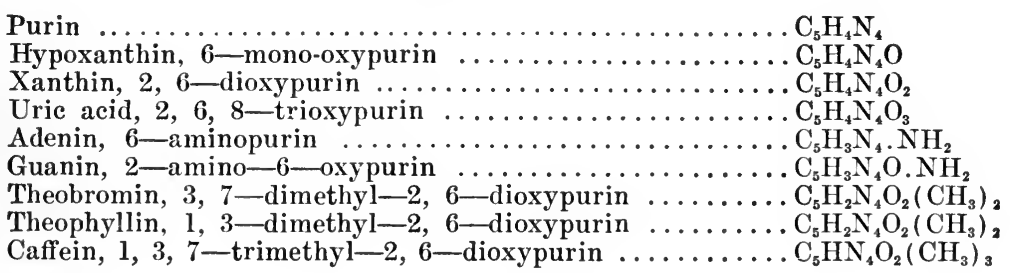

These compounds are closely related in chemical structure and are found more or less closely associated in both animals and plants. They have the following heterocyclic ring structure; for convenience the positions are given fixed numbers:

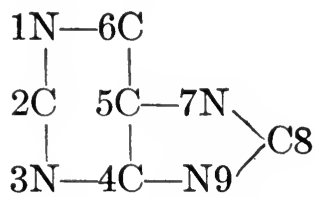

In purin, hydrogen enters into the $2,6,7$ and 8 positions. In the various purin bodies, the particular groups enter into the positions indicated in the names designated above. In the various organs of the body, 
enzymes tend to transform the purin bodies to other members of the group. Thus, guanase hydrolyzes guanin with the formation of ammonia and xanthin; adenase hydrolyzes adenin into ammonia and hypoxanthin; hypoxanthin passes by oxidation into xanthin, which, in turn, through the agency of xanthinoxidase is transformed into uric acid. Finally, the uricolytic enzymes transform uric acid into allantoin, though this destructive power seems to have been largely or wholly lost in human beings.

Guanin and adenin preëxist in nucleic acid. Among the products of hydrolysis, xanthin and hypoxanthin are apt to be produced. Such change may also be brought about by the enzymes in the tissues.

Caffein is the familiar constituent of coffee beans ( $0.8-1.7$ per cent), cocoa beans $(0.1-0.8$ per cent), cocoanuts ( 1.2 per cent), and tea leaves $(2-5$ per cent). Two and one-half to 5 per cent is present in guarana, the roasted fruit of Paullinia, which is eaten in South America. Theobromin is present to the extent of $1.5-2.4$ per cent in cocoa beans and in smaller amounts in Kolo nuts and tea leaves. It is not present in coffee beans. Theophyllin has been isolated from the extracts of tea.

Pyrimidin Bases

Pyrimidin $\ldots \ldots \ldots \ldots \ldots \ldots \ldots \ldots \ldots \ldots \ldots \ldots \mathrm{C}_{4} \mathrm{H}_{4} \mathrm{~N}_{2}$

Uracil, 2,6 -dioxypyrmidin $\ldots \ldots \ldots \ldots \ldots \ldots \ldots \mathrm{C}_{4} \mathrm{H}_{4} \mathrm{~N}_{2} \mathrm{O}_{2}$

Cytosin, 6 -amino-2-oxy pyrimidin $\ldots \ldots \ldots \ldots \ldots \ldots \ldots \ldots \mathrm{C}_{4} \mathrm{H}_{3} \mathrm{~N}_{2} \mathrm{O} \cdot \mathrm{NH}_{3}$

Thymin, 5-methyl-2, 6-dioxypyrimidin ............... $\mathrm{C}_{4} \mathrm{H}_{3} \mathrm{~N}_{2} \mathrm{O}_{2} . \mathrm{CH}_{3}$

These are heterocyclic compounds presenting the following structure:

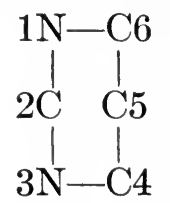

Because this ring is a portion of the purin structure, it has been suggested that the pyramidins are purin decomposition products, but such proves not to be the case. At least two of them preëxist in nucleic acid, but it is probable that uracil is formed from cytosin during the hydrolysis.

Lecitmoproterns.-Lecithoproteins have lecithin or a phospholipin as the prosthetic group. Their existence in cytoplasm is probable but they have not yet been isolated. The globulin vitellin is believed to exist in egg yolk either wholly or in part as lecithovitellin; likewise, a lecithoprotein has been described as present in the gastric mucosa.

DERIVED PROTEINS.- These are the transformed proteins, including proteins that have undergone decomposition, or synthesized compounds resembling such products. 
Primary Protein Derivatives are certain transformed proteins that have not been changed to the state of hydrolytic decomposition.

Proteans.- These are the first products of the action of acids, enzymes or water. They are insoluble in water.

Metaproteins.-The proteins in this group are formed by the further action of acid or alkalies and include acid albumin and alkali albumin.

Congulated Proteins.-These are the insoluble modifications produced by the action of heat and alcohol. The coagulated egg white is a familiar example.

Secondary Protein Derivatives present varying stages of hydrolytic decomposition.

Proteoses.-These proteins are soluble in water, not coagulated by heat and precipitated by saturation of their solution with ammonium sulphate. The individual members are designated by their particular name, e.g., albumoses, globuloses, gelatoses, etc.

Peptones.-These products of further hydrolysis are soluble, noncoagulable by heat and are not precipitated by saturation of their solution with ammonium sulphate. They are somewhat more diffusible and give the biuret reaction, though with a decidedly more pinkish hue than the native proteins or even the proteoses.

PePtids.-These are relatively simple compounds of the amino-acids, either products of hydrolytic decomposition or of synthetic origin, whose exact composition is known. The amino-acids combine through the amino and carboxyl groups. Peptids may or may not give the biuret reaction. They are designated di-, tri-, tetra-, penta-peptids, etc., according to the number of amino-acids that enter into their composition. Where this is large, the designation polypeptid is employed.

NITROgEnous EXTRACTIVES.-More or less closely related to the amino-acids of proteins are certain nitrogenous substances that are frequently found associated with them and which, together with nonprotein amino-acids, go to make up what were formerly known as nitrogenous extractives.

Amids.-These, found in both animals and plants, are derivatives of the fatty acids in which the hydroxyl of one or more carboxyl group is replaced by an amino $\left(\mathrm{NH}_{2}\right)$ group. Thus asparagin of plants is an amid of aspartic acid.

Betarn.-This compound, which occurs in both animals and plants, is a trimethylamin derivative of acetic acid.

Goanidin.- - These derivatives, notably methylguanidin of meat, the 
diamino-acid arginin and creatin, a constituent of meat, are of wide occurrence. These substances must all be recogniized as food constituents in small quantities.

\section{CARBOHYDRATES}

Of the constituents of an ordinary mixed diet, the carbohydrates are usually the most abundant, and, from the standpoint of cost, the most economical. They are found more especially in the various vegetable substances and are of exceedingly varied structure and composition, as a rule containing in the molecule 6 atoms of carbon (or a multiple of 6 ) in combination with hydrogen and oxygen in the proportion to form water as shown in the following formulæ, grape sugar $\mathrm{C}_{6} \mathrm{H}_{12} \mathrm{O}_{6}$, cane sugar, $\mathrm{C}_{12} \mathrm{H}_{22} \mathrm{O}_{11}$, etc.

The carbohydrates include the sugars which are aldehyd or ketone alcohols having the following common properties: (a) they have a sweet taste, (b) optically active, (c) may or may not reduce alkalin metallic solutions, $(d)$ and yield characteristic crystalline compounds with phenylhydrazin.

Classification of Carbohydrates.-Those containing multiples of three carbon atoms are fermentable by yeast, and yield alcohol. Others when heated with strong acids yield characteristic derivatives, i.e., the pentoses yield furfurol; the hexoses yield levulinic acid. We recognize the following classification according to whether one, two or more sugar molecules enter into the formation of the molecule: Monosaccharids, Disaccharids, Polysaccharids.

THE MONOSACCHARIDS.-Under this classification belong the grape sugar group, comprising those which cannot be split by hydrolysis into sugars of lower molecule weight. They are white, odorless, sweet, crystallizable substances, readily soluble in water, sparingly soluble in alcohol, insoluble in ether. Like all aldehyds and ketones they are easily oxidized, acting as reducing agents. They are unaffected by digestive enzymes, and if not attacked by bacteria in the digestive tract, they are absorbed and enter the blood current unchanged. In order to show in its name that a substance belongs to the carbohydrates, the ending ose is used to distinguish these bodies from the members of other groups. According to the number of carbon atoms present, the monosaccharids are again subdivided into classes called, viz.:

Trioses $\mathrm{C}_{3} \mathrm{H}_{6} \mathrm{O}_{3}$ - glycerose an alcoholic aldehyd.

Tetroses $\mathrm{C}_{4} \mathrm{H}_{8} \mathrm{O}_{4}$ - erythrose. 
Pentoses $\mathrm{C}_{5} \mathrm{H}_{10} \mathrm{O}_{5}$ - arabinose, ribose, rhamnose and xylose.

Hexoses $\mathrm{C}_{6} \mathrm{H}_{12} \mathrm{O}_{6}$-dextrose, fructose, galactose, sorbinose.

Heptoses $\mathrm{C}_{7} \mathrm{H}_{14} \mathrm{O}_{7}$-mannoheptose, fructoheptose, glucoheptose.

Octoses $\mathrm{C}_{8} \mathrm{H}_{16} \mathrm{O}_{8}$-mannoctose, glucoctose.

Nonoses $\mathrm{C}_{9} \mathrm{H}_{18} \mathrm{O}_{9}$-mannonose, glucononose.

The monosaccharids are converted into corresponding alcohols by nascent hydrogen, and conversely, the alcohols into monosaccharids by the loss of hydrogen. The more abundant ones are readily susceptible to alcoholic fermentation and are utilized for the production of glycogen in the animal body and in the maintenance of the normal glucose content of the $\operatorname{blood}(5)$.

Pentoses.-These substances, $\mathrm{C}_{5} \mathrm{H}_{10} \mathrm{O}_{5}$, occur in many foods and vegetables as complex carbohydrates known as pentosans. When taken into the body pentosans are split off by hydrolytic cleavage, and pentose is excreted in the urine; considerable pentosans are found in the urine of persons addicted to the use of morphin. Pentoses are of great impcrtance, as they are constituents of certain nucleic acids and are contained in the nuclei and cytoplasm of cells(6). As pentosans they are widely distributed throughout the vegetable kingdom, where, particularly as xylan and arabin, they form a considerable proportion of the building material for the human economy. Pentosans are found in the juice of a large variety of green plants, being more abundant in the morning than in the evening. They occur to a considerable extent in the seeds of cereals and legumins, straws, grasses, etc. Water-free cassava contains 3.96 per cent, and eleven kinds of gum reveal its presence. They are not very digestible. The pentoses are converted into furfurol during the manufacture of alcohol. Experiments have been made to ascertain if the pentoses might be taken in diabetes as a substitute for other sugars; the results have shown that although the pentoses are soluble, they are not readily digested or assimilated by human beings, and that the portion which is absorbed readily passes into the urine.

Hexoses.-These substances, $\mathrm{C}_{6} \mathrm{H}_{12} \mathrm{O}_{6}$, are the most important of the aldoses and ketoses, both from a practical and physiological standpoint. The chief examples are dextrose and levulose, but there are two groups: (a) aldoses comprise dextrose, mannose, galactose, gulose, formose, acrose, talose; (b) ketoses comprise levulose and sorbinose.

Dextrose or glucose is also called "grape sugar" and "diabetic sugar." This is physiologically the most important sugar occurring in an impure state in sweet fruits, such as grapes, also in seeds, roots and honey. It is 
also obtained from other carbohydrates by hydrolysis either by acids or enzymes, and thus becomes the principal form of the carbohydrate after the food enters into the animal economy. In the animal economy of a healthy individual, the glucose of the blood is constantly being burned and replaced. In diabetes, the system loses to a greater or less degree the power to burn glucose; it then accumulates in excessive amounts in the blood, from which it escapes through the kidneys. A temporary loss of glucose in the urine may occur as the result of feeding large quantities of sugar at a time. This condition is known as alimentary glycosuria. Under ordinary circumstances in a healthy individual any surplus of glucose absorbed from the digestive tract is converted into glycogen and stored in the liver.

Levulose, fructose, $\mathrm{C}_{6} \mathrm{H}_{12} \mathrm{O}_{6}$, or fruit sugar, occurs with glucose in sweet fruits and honey. It resembles glucose in most of its chemical and physical properties, but does not crystallize from an aqueous solution. It may, however, be obtained in white silky needles from an alcoholic solution. It is met with generally as a thick syrup, is about as sweet as cane sugar and turns the plane of polarized light to the left; it is formed together with glucose by the action of dilute mineral acids or ferments on cane sugar(7). Fructose may occur in normal blood, but probably only in insignificant quantities. It serves, like glucose, for the production of glycogen; and the fructose which enters the body either through being eaten as such or as the result of the digestion of cane sugar is mainly changed to glycogen on reaching the liver, so that it does not enter largely into the blood or the general circulation. It may be readily understood, however, that fructose should be converted in the liver into glycogen, which on hydrolysis yields glucose.

The sugar of fruit is usually an admixture of dextrose and levulose, and is called invert-sugar. It is uncrystallizable and forms granular masses in dried fruit-it consists of 4 parts of levulose and 3 parts of hydrated dextrose, some of which arise by inversion of saccharose.

Galactose, $\mathrm{C}_{6} \mathrm{H}_{12} \mathrm{O}_{6}$, is not found free in nature, but results together with glucose from the hydrolysis of milk sugar, either by acids or by digestive enzymes, and appears to have the same power as glucose and fructose to promote the formation of glycogen in the animal body. It is also formed together with dextrose when gum arabic is boiled with dilute sulphuric acid. Galactose does not ferment with yeast. The anhydrids of galactose, known as galactans, occur quite widely distributed in plant products. The galactans of certain legumes are found to be readily digested. 
Sorbinose is the sugar in the fruit of the service tree and mountain ash, and appears to arise from the hydrolysis of a glucosid or, according to Freund, from the oxidation of a gelatinous substance in service fruit(8).

Inosite, $\mathrm{C}_{6} \mathrm{H}_{12} \mathrm{O}_{6}$ (muscle-sugar), is classed with the carbohydrates on account of its sweet taste, its readiness to undergo lactic and butyric fermentation, and the identity of its molecular formula with that of the hexoses. It occurs somewhat abundantly in umripe beans and peas, and sparingly in the liquid of muscular tissue; traces are found in urine, the quantity increasing in certain diseases. It does not ferment with yeast and is optically inactive.

Glucosamin, $\mathrm{C}_{6} \mathrm{H}_{13} \mathrm{NO}_{5}$, is an amino-sugar. It is derived from one of the hexoses, probably dextrose or mannose, being an intermediate substance between the glucoses and amino-acids. It is to be regarded as a bridge between carbohydrates and proteins in the development process of matter. It has been obtained from glucoproteins, such as mucin, and also from chitin, the shells of lobsters, crabs, and other invertebrates.

DISACCHARIDS.-Disaccharids, $\mathrm{C}_{12} \mathrm{H}_{22} \mathrm{O}_{11}$, form the cane sugar group(9). They are also called bioses, di-hexoses and sucroses. The chief members of the group include:

Saccharose

Lactose

Maltose cane sugar

milk sugar

malt sugar

They differ from monosaccharids by not fermenting directly and by not forming ozazones, and are sparingly soluble in alcohol. They are important constituents of food and are changed to monosaccharids during the digestive process. In reality they are condensed glucoses formed by two molecules of any of the grape sugar group becoming joined together with the loss of a molecule of water. They are capable of hydrolytic cleavage into two molecules of monosaccharid.

Saccharose, $\mathrm{C}_{12} \mathrm{H}_{22} \mathrm{O}_{11}$, is the chief member of the cane sugar group, and is more largely used for domestic sweetening than any other substance. Chemically, it is a combination of the monosaccharids dextrose and levulose. It is very widely distributed throughout the vegetable kingdom in the juice of plants and fruits, but is especially abundant in the stalk of sugar cane, sugar-millet, roots of beet, carrot, and other vegetables. Many of the common fruits and vegetables contain notable amounts of sucrose. Sucrose is said to constitute at least half the solid matter of pineapples. As a food it occupies a very high position, as will 
be seen by referring to Chapter XV, Sugar, Spices and Condiments. Physiologists have found an enzyme called invertase in the intestinal secretions which hydrolyzes cane sugar; the slight amount of hydrolysis which takes place in the stomach is believed to be due simply to the presence of hydroçhloric acid.

Maltose, $\mathrm{C}_{12} \mathrm{H}_{22} \mathrm{O}_{11}$, is obtained by the action of diastase on starch. Diastase is an enzyme formed during the germination of various seeds (rye, wheat, barley, etc.), and it is for this reason that grain used for alcoholic liquors is converted into malt. It allows germination to proceed, during which process diastase is formed, which acts upon the starch to convert it into maltose and dextrin. Maltose is also formed as an intermediate product when starch is hydrolyzed by boiling with dilute mineral acids, as in the manufacture of commercial glucose. In animal digestion maltose is formed by the action of the ptyalin of the saliva or the amylopsin of the pancreatic juice upon starch or dextrin. The maltose splitting enzyme of the intestinal juice readily hydrolyzes maltose to glucose. It also occurs in leaves of plants as a product of assimilation. It forms as much as 51 per cent of the dry matter of malt. In the process of digestion of starch in the alimentary canal maltose is formed, but the blood of the mesenteric vessels contains only dextrose, wherefore, it must be still further split before it is assimilated either previous to its absorption by the enzyme maltase in the succus entericus, or in its absorption in the cells of its intestinal mucosa. Therefore, it is not likely that any maltose as such is absorbed from the digestive tract under ordinary conditions, though the possibility cannot be denied that such absorption may occur and that maltose may play a part in the normal carbohydrate metabolism. Abderhalden(10) found that when he injected maltose into the blood it appeared to be utilized to better advantage than either lactose or sucrose. $\mathrm{He}$ found that it could be obtained from glycogen by the action of diastatic enzymes in much the same way as from starch and dextrin.

Lactose, $\mathrm{C}_{12} \mathrm{H}_{22} \mathrm{O}_{11}$, saccharum lactis, or milk sugar, is found almost exclusively in milk of the mammalia. It is obtained by freeing milk from easein and fat, and evaporating the remaining liquid to a small bulk, when the milk sugar crystallizes on cooling. It may also be obtained by hydrolysis of certain carbohydrates and other vegetable substances by enzymes or acids. It is a combination of dextrose and galactose, and can be split into these monosaccharids. When hydrolyzed either by heating with acids or by the lactase of the intestinal juice, each molecule of lactose yields one molecule of glucose and one of galactose. In normal digestion probably none of the lactose eaten is absorbed as such, for 
lactose injected into the blood is eliminated quickly and almost completely through the kidneys, but large quantities of lactose can be taken by the mouth without any such loss.

TRISACCHARIDS.- Under this heading are classified the raftinose group of sugars, $\mathrm{C}_{18} \mathrm{H}_{32} \mathrm{O}_{16}$, formed by the linking together of three molecules of the monosaceharids, with the loss of water. The chief members of this group are, viz.:

Melitose, which oceurs in manna and beet root molasses

Melizitose, a sugar forming 20 per cent "honey dew."

Melitose occurs in Australian manna and is a combination of one molecule each of dextrose, levulose and galactose, into which it can be separated by hydrolysis.

Melizitose is a sugar which forms 20 per cent of "honey dew" secreted on the leaves of various trees and also occurs in larehmanna.

Tetrasacchamids.-Stachyose, $\mathrm{C}_{24} \mathrm{H}_{42} \mathrm{O}_{20}$, is a very sweet sugar. It is a dextrorotatory, and ean be hydrolyzed into dextrose, levulose and galactose. It is obtained in abundanee from the tubers of Stachys tuberifera, which is made up of from 14 to 19 per cent. Further information pertaining to roots and tubers will be found in Chapter XI.

COLLOIDAL POLYSACCHARIDS.-Under this classifieation belongs the amylose group which consist of carbohydrates with more than three molecules of monosaccharids or hexoses linked together into a condensation product. They are all uncrystallizable, nondiffusible and insoluble in alcohol; some dissolve in water, others swell and become gelatinous, while a few are unchanged. The members of this group which are of the greatest importance in nutrition are:

$\begin{array}{ll}\text { Stareh } & \text { Malto Dextrin } \\ \text { Dextrin } & \text { Cellulose } \\ \text { Glycogen } & \text { Inulin } \\ \text { Lichenin } & \text { Pectose bodies }\end{array}$

On hydrolysis polysaccharids split forming dextrins, disaccharids and monosacharids; their general composition is indicated by $\left(\mathrm{C}_{6} \mathrm{H}_{10} \mathrm{O}_{5}\right)_{n}$, which means that the molecules are made up of an unknown multiple of $\left(\mathrm{C}_{6} \mathrm{H}_{10} \mathrm{O}_{5}\right)$, the constitution being unknown.

Starch, $\left(\mathrm{C}_{6} \mathrm{H}_{12} \mathrm{O}_{5}\right)_{n}$, which is very widely distributed in the vegetable kingdom, is found chiefly in the seeds of cereals and leguminose, as well as in the roots, stems and seeds of nearly all plants. It is of great importance as a constituent of many food materials, and as the source of dextrin, maltose and commereial glucose, and many fermentation products. 
Starch is found stored in the seeds, roots, tubers, bulbs, and sometimes in the stems and leaves of plants. It constitutes nearly three-quarters of the solid matter of the ordinary cereal grains and at least three-fourths of the solids of mature potatoes. Starch occurs in distinct unchanged granules which differ in structure and size so that in most cases the source of starch may be determined, as different plants furnish different forms and sizes of granules. Starch granules are scarcely affected by cold water; on warming they absorb water and swell, finally passing into a condition of colloidal solution or "starch paste.' If cereal flour be made into a dough, the softened mass may now be rubbed on a sieve under a current of cold water which washes out the starch, while cellular fibrous matter remains on the sieve; the starch deposits slowly from the washings, and is further purified by treating it with water containing a small amount of caustic alkali. Starch forms white, amorphous, tasteless masses, which are peculiarly slippery to the touch and easily converted into a powder; it is insoluble in cold water, alcohol and ether; when boiled with water it yields a white jelly which cannot be broken up as a true solution, but is a suspension of the swollen starch particles. When treated with hydrochloric acid in strength of from 7 to 10 per cent, in cold water or very moderate heat more or less hydration occurs with the production of soluble starch. On further hydration, starch gives, first, mixtures of dextrin and maltose, and finally glucose only as an end product. When brought into contact with the saliva, the starch of foods is hydrolyzed by the ptyalin with the formation of dextrin and maltose; a similar hydrolysis is effected by amylopsin, the starch-splitting enzyme of the paricreatic juice.

Dextrin, $\left(\mathrm{C}_{6} \mathrm{H}_{10} \mathrm{O}_{5}\right)_{\mathrm{n}}$, is formed by the hydrolysis of starch. Small amounts of dextrin are found in resting and larger amounts in germinating cereals. Malt is made by seeping barley in water until it germinates, and then drying it. During acid hydrolysis, dextrin is formed as an intermediate product between starch and maltose. Dextrin is a colorless or slightly yellowish, amorphous powder resembling gum-arabic in some respects; it is soluble in water, does not reduce alkaline copper solution, and the erythrodextrin is colored light wine red by iodin. It is extensively used in mucilage as a substitute for gum-arabic. According to one observer, the complete hydrolysis of dextrin yields glucose as the sole product.

Glycogen, $\left(\mathrm{C}_{6} \mathrm{H}_{10} \mathrm{O}_{5}\right)_{\mathrm{n}}$, or animal starch, is found exclusively in animals. It occurs in the liver, the white blood corpuscles, in many embryonic tissues, and in muscular tissue. In addition to its occurrence in ani- 
mals, it takes the place of starch as reserve carbohydrate in fungi and other forms of plant life not provided with chlorophyll apparatus. Pure glycogen is a white, starch-like, amorphous substance insoluble in alcohol. It forms an opalescent solution with water, gives a port wine color with iodin, and by hydrolysis is converted into glucose.

Glycogen occurs in the lower as well as in the higher animals, and in all parts of the body, but is especially abundant in the liver, where it is found deposited in the cell substance but not in the nucleus. It is distinguished from starch by the property of swelling up and being apparently dissolved in cold water. The solution, however, is never clear, but is opalescent and indiffusible. In this respect it resembles the gummy colloid carbohydrates, such as dextrin, arabin and bassorin. It is, however, more complex than the dextrin, as the latter is obtainable by the decomposition of glycogen. The storage of glycogen in the body is promoted by rest as well as by liberal feeding. The stored glycogen is used up rapidly during active muscular work. The amount of glycogen in the liver depends to a great extent upon the condition of nutrition of the animal.

Lichenin, $\left(\mathrm{C}_{6} \mathrm{H}_{10} \mathrm{O}_{5}\right)_{n}+\mathrm{H}_{2} \mathrm{O}$, is a peculiar starch found only in Iceland moss and algæ. It is not soluble in cold water, but, like ordinary starch, it swells up in hot water, and forms a jelly on cooling. It is impervious to diastatic ferments, such as ptyalin and amylopsin; but it yields dextrose when boiled with dilute acids.

Maltodextrins exist in malted cereals and other food substances, being produced from starch by the action of malt enzyme. Maltodextrins are more soluble in alcohol than dextrin, and they have an apparent composition of maltose, 34.6 per cent, and dextrin, 65.4 per cent. Maltodextrin is very slowly diffusible, but passes through a septum unaltered. According to Herzfeld, the maltodextrins are intermediate substances between achroödextrin and maltose, the latter being fermentable by ordinary yeast, while the maltodextrins are not fermented by it.

Cellulose, $\left(\mathrm{C}_{6} \mathrm{H}_{10} \mathrm{O}_{5}\right)_{n}$, is a carbohydrate or a group of carbohydrates of complex character. It constitutes the fundamental material of which the cellular membrane of vegetables is built up, and forms, therefore, the largest portion of the solid parts of every plant; it is well adapted to this purpose on account of its insolubility in water and most other solvents, and its tough and flexible nature. Some parts of vegetable matter, for instance, cotton, hemp and flax, are nearly pure cellulose. Cellulose is insoluble in water, ether, alcohol and dilute acids and alkalies, but dissolves in an ammoniacal solution of cupric oxid. In the alimentary 
canal of man it resists the action of ptyalin and amylopsin, but undergoes partial decomposition under the influence of bacterial enzymes with the production of methane and carbon dioxid.

Inulin $\left(\mathrm{C}_{36} \mathrm{H}_{62} \mathrm{O}_{31}\right)$ is a starch-like substance in solution in the sap sap of many plants, but especially in tubers of dahlia, Jerusalem artichoke and potato, roots of chicory, dandelion and lichens. It is obtainable from these sources as a white powder consisting of spheroidal crystals, soluble in hot water, sparingly soluble in cold water. It stands in the same relation to levulose as starch does to dextrose. Inulin is not readily acted upon by the enzymes; diastase has little influence over it; ptyalin and amylopsin do not convert it into sugar; it is, however, converted into sugar by the action of dilute acids and is probably digested. Although inulin is readily hydrolyzed to levulose by acids, it is not attacked by the saliva or pancreatic juice. Sandmeyer(11), after feeding 80 grams of inulin to a diabetic dog, recovered 46 grams in the feces, and Mendel and Nakaseko(12) found that little if any glycogen resulted from feeding inulin to a rabbit. Mendel and Mitchell(13) injected inulin in the peritoneum of a rabbit and recovered most of it in the urine.

Pectose Bodies are found in most fruits, in a few roots, and in some vegeta'oles. They are peculiar substances which under certain conditions cause fruit juices to gelatinize. Their constitution and composition cannot very well be ascertained because they cannot be separated from the associated cellulose without disorganizing them or changing their substance. The subject has been treated at some length in Chapters XI and XIII, to which the reader is referred. Pectose is insoluble in water, alcohol and ether, but it is converted by the digestive juices and acids into pectin, which is soluble in water. Pectin is the chief substance in fruit and vegetable jellies. The nutritive value of pectin and pectose bodies is probably about the same as that of starch. The pectins are considered by some authorities to bear the same relation to pentoses as dextrins do to hexoses.

\section{HYDROCARBONS}

Hydrocarbon derivatives of various kinds occur in foodstuffs. They contain carbon, hydrogen, usually some oxygen, but ordinarily no nitrogen, phosphorus or sulphur as essential ingredients, though, as we shall see, they enter into various combinations with compounds of these elements. The amount of oxygen in the fats which make up an important portion of this group is relatively small, leaving their combining capacity with oxygen high. This fact gives them a fuel value double that of 
either proteins or carbohydrates and enables them to supply a correspondingly large energy value to the animal economy.

Classification of Hydrocarbons.-Hydrocarbon derivatives form the bulk of fat, butter, suet, oils and other fatty substances. While carbohydrates are chemically hydrocarbon derivatives, their distinetive chemical composition and their physiological importance render it convenient to deseribe them as a distinct group.

TERPENES.-Relatively few of the compounds of carbon and hydrogen without oxygen appear in foods. Among the volatile or essential oils, however, are found a number of terpenes of the composition $\mathrm{C}_{10} \mathrm{H}_{16}$. These include $d$-limonene, in lemon, kümmel (caraway), dill and celery; $a$ - and $g$-terpinenes in cardamon; phellandrene in fennel; carvone in kümmel and dill; and camphene in ginger.

ALCOHOLS. - When one or more of the $\mathrm{H}$ atoms of the hydrocarbon molecule is replaced by $\mathrm{OH}$ radicals, we have an alcohol, the particular alcohol being determined by the nature of the original hydrocarbon, as well as the number and position of the replacing hydroxyls. Ethyl alcohol $\left(\mathrm{C}_{2} \mathrm{H}_{5} \mathrm{OH}\right)$ occurs in small quantities in muscle and other organic substances, but is chiefly the product of alcoholic fermentation of sugars.

It has been well said that the chief effect of food is nutritive, while the most important action of ethyl alcohol is pharmacodynamic. Nevertheless, alcohol so resembles food in its nutritive effects and is so commonly ingested as a dietary ingredient and as a beverage, that we must include it here. Whether it is in fact a food depends upon the definition of food. Under the definition laid down by the Federal Food and Drugs Act, June 30, 1906, it is so classified. Aside from ethyl alcohol we must mention the higher alcohols which are more toxic the higher we ascend in the series. Fusel oil includes propyl, butyl, amyl and hexyl alcohols and is a common accompaniment of ethyl alcohol when the sugar used for fermentation is derived from starch. Amylic alcohol is an important constituent of the oil of mustard and horseradish.

Triatomic Alconols.-Glycerin is a triatomic alcohol which, being joined to fatty acids, forms neutral fats such as stearin, olein, etc. Glycerin is a product in the digestion of fat and a by-product in the manufacture of soap. There is no satisfactory evidence of the value of glycerin as a foodstuff, but there is evidence to show that any excess of glycerin, which is consumed for therapeutic purposes, is not utilized in the system, but is decomposed into propionic and formic acids.

Cyclic Alconols.-This classification includes the sterols. These, in general, belong to the terpene group, are solid at ordinary temperature 
and yield terpenic acids on oxidation. They include cholesterol, isocholesterol, stercorin (koprosterin), phytosterol, cetyl alcohol, myricyl alcohol, etc. Menthol may well be included in this group. In all probability some of the cholesterol of food is absorbed, but whether it is of service to the body is not clear. Since herbivora contain cholesterol, not phytosterol which they ingest, it seems that the body has the capacity of forming its own cholesterol, leaving it uncertain whether that absorbed from food furnishes any of the body supply.

Inositol, a hydroxy-derivative of hexahydrobenzene, is included with the cyclic alcohols as a matter of convenience and is mentioned because it is found in heart muscle.

ALDEHYDS.-Acetic aldehyd occurs in new spirits, especially when distillation is intermittent. Citrol, an acylic terpene of the formula $\mathrm{C}_{9} \mathrm{H}_{15} . \mathrm{CHO}$, is of food interest because of its presence in the oil of citrous fruits, such as lemon, lime, orange, etc. Cyclic aldehyds are found in essential oils, as cimnanic aldehyd in oil of cinnamon. Furfurol and possibly other aldehyds of this type appear in pot-still spirits, being formed by the action of the fire (and possibly also by the acid) on the pentose of the woody fiber and gum contained in the husks, etc., suspended in the mash. They do not exist, except possibly in the minutest traces, in "patent spirits," which is a point of distinction. Benzaldehyd is formed from the glucosid amygdalin in bitter almonds, in cherry laurel and in fruit kernels. Vanillin, the active constituent of the vanilla bean, is methyl protocatechuic aldehyd.

ORGANIC ACIDS.-Organic acids arise by oxidation from both simple and complex compounds of carbon and hydrogen. Those derived from the alaphatic series, formula $\mathrm{C}_{\mathrm{n}} \mathrm{H}_{2^{\mathrm{n}}+2}$, have the general formula $\mathrm{C}_{\mathrm{n}} \mathrm{H}_{2^{n}} \mathrm{O}_{2}$; those derived from the olefins, $\mathrm{C}_{n} \mathrm{H}_{2 \mathrm{n}}$, have the general formula $\mathrm{C}_{\mathrm{n}} \mathrm{H}_{2^{\mathrm{n}}-{ }_{2}} \mathrm{O}_{2}$. A list of the usual acids follows:

\begin{tabular}{|c|c|}
\hline \multicolumn{2}{|c|}{$\mathrm{CnH}_{2} \mathrm{n}+{ }_{1} \mathbf{C O O H}$} \\
\hline Formic & $\mathrm{HCOOH}$ \\
\hline Acetic & $\mathrm{CH}_{3} \mathrm{COOH}$ \\
\hline Propionic & $\mathrm{C}_{2} \mathrm{H}_{5} \mathrm{COOH}$ \\
\hline Butyric & $\mathrm{C}_{3} \mathrm{H}_{7} \mathrm{COOH}$ \\
\hline Valeric & $\mathrm{C}_{4} \mathrm{H}_{9} \mathrm{COOH}$ \\
\hline Caproic & $\mathrm{C}_{5} \mathrm{H}_{11} \mathrm{COOH}_{1}$ \\
\hline Caprylic & $\mathrm{C}_{7} \mathrm{H}_{15} \mathrm{COOH}_{1}$ \\
\hline Capric & $\mathrm{C}_{9} \mathrm{H}_{19} \mathrm{COOH}_{1}$ \\
\hline Lauric & $\mathrm{C}_{11} \mathrm{H}_{23} \mathrm{COOH}$ \\
\hline Myristic & $\mathrm{C}_{13} \mathrm{H}_{27} \mathrm{COOH}$ \\
\hline Palmitic & $\mathrm{C}_{15} \mathrm{H}_{31} \mathrm{COOH}$ \\
\hline Stearic & $\mathrm{C}_{17} \mathrm{H}_{35} \mathrm{COOH}$ \\
\hline \multicolumn{2}{|c|}{$\mathrm{CnH} \mathrm{H}_{2} \mathrm{n}-1 \mathbf{C O O H}$} \\
\hline $\begin{array}{l}\text { Olelc } \\
\text { Erucic }\end{array}$ & $\begin{array}{l}\mathrm{C}_{17} \mathrm{H}_{33} \mathrm{COOH} \\
\mathrm{C}_{21} \mathrm{H}_{41} \mathrm{COOH}\end{array}$ \\
\hline
\end{tabular}

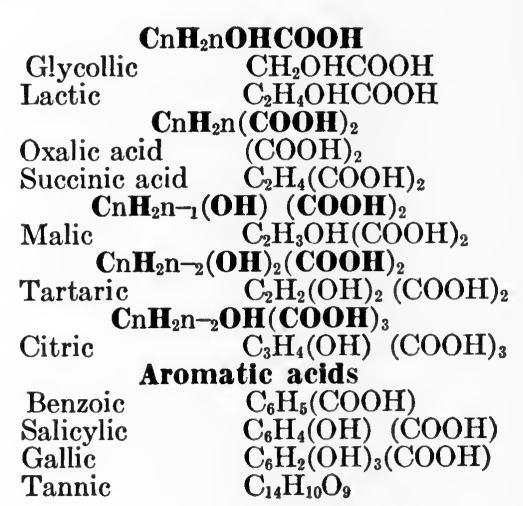


Organic acids are found as constituents of various foodstuffs. Some of these acids are formed by fermentation. Others are present in fruits, and in the process of ripening are progressively utilized in the formation of ethers, aldehyds and carbohydrates. Others are combined to form salts of potassium, sodium, calcium, and are mingled with their phosphates, sulphates and carbonates.

Formic Acidoecurs in small proportions in honey. It is miscible with water and alcohol, possesses a pungent odor and piquant taste. It decomposes carbonates and forms salts called formates.

Acetic Acid oceurs in combination with alcohols in the esters of essential oils in many plants and is formed in the fermentation of many substances by the enzyme of mycoderma acetic, as in the manufacture of vinegar, which is diseussed in the chapter on beverages and stimulants. It forms salts or acetates with sodium, potassium and other metals. The acetates occur normally in certain vegetable juices.

Butyric Acid is formed by the fermentation of lactic acid, a process known as butyric fermentation, and to some extent by the putrefaction of proteins. It exists as butyrin in butter to the extent of 6 per cent, but was not obtained in a recent investigation by distillation in vacuo, for which reason it has been suggested that its oceurrence is due to decomposition of protein matter remaining in the butter. The acid possesses a pungent and disagreeable smell.

Glycollic Acid oceurs in unripe fruits as the result of the oxidation of acetic acid and is in turn converted into glycollic aldehyd, which forms carbohydrates by polymerization.

Lactic Acid oceurs in many plant juices. It is formed from sugar by what is known as lactic fermentation, which causes the presence of this acid in sour liquids and many sour fermented substances, as in sauerkraut, etc. It arises in consequence of the fermentation of lactose, as in the souring of milk in cheese-making, and ripening of cream; from the fermentation of various sugars, starch and othe: substances in the presence of nitrogenous animal matter. It is a thick, sour, hydroscopic, colorless, strongly acid liquid and mixes in all proportions with water and alcohol.

Oxalic Acid is widely distributed throughout the vegetable kingdom either as oxalic acid or oxalate. In the chapter on vegetable foods will be found a table giving the percentage of oxalic acids in a great many fruits and vegetables. It is formed from the oxidation of many substances such as glycerol, glucose, sucrose, alcohol and fats. It is also of considerable physiological interest in its origin and destination. When 
ingested in food, it circulates into the animal tissues either as a free acid or salt. It undergoes oxidation to carbon dioxid and water. It is a question, however, whether the oxalic acid taken into the food is all excreted as carbon dioxid and water, or whether any of it is normally excreted unchanged.

Succinic Acid is a normal constituent in unripe fruits, especially in grapes, lettuce and other vegetables, and occurs in some animal secretions. It likewise is formed in the bacterial decomposition of carbohydrates and proteins, and as one of the metabolic products of yeast during alcoholic fermentation of sugar.

Malic Acid occurs in the juices of many fruits, as apples, currants, cherries, grapes, pineapples, blackberries, etc. It may be extracted from these fruits or it can be prepared synthetically. In combination with bases as malates, it occurs in sweet cherries, apples, rhubarb, gooseberries, grapes and strawberries.

Tartaric Acid occurs in the vegetable kingdom, especially in grapes, and some other fruits, largely as acid potassium tartrate. During the latter stages of the fermentation of grape-juice a considerable quantity of "argol" or crude cream of tartar is deposited, since it is no longer soluble in the alcohol-containing liquid.

Citric Acid occurs in the free state in many fruits, especially in lemons and tomatoes. It also occurs as citrates in lemons, limes, oranges, quinces, currants, gooseberries, strawberries, raspberries, cherries, cranberries, and other sour fruits. Citric acid is also constantly present in the milk of man and other mammals. Citric acid is absorbed from the alimentary canal and partly decomposed and excreted by the kidneys as sodium carbonate.

Benzoic Acid occurs as the free acid in cranberries and some other fruits.

Salicylic Acid is reported to occur as a methyl-ester in currants, cherries, plums, grapes, crabapples, strawberries, blackberries, raspberries, mulberries, peaches, apricots, pineapples and oranges.

Gallic Acid is widely distributed in vegetables, especially in the form of compounds of tannins with glucosids. It occurs in tea leaves, nutgalls, claret, etc.

Tannic Acid occurs in gallnuts and in all kinds of bark, in coffee, tea, etc. All tannins are amorphous and possess strongly astringent properties. Some are probably ester compounds of gallic acid with glucose.

The acids of oils and fats will be described under their esters.

ESTERS.-Chemically these are combinations of alcohol and acid and 
may be viewed as salts of the acids in which the alcohol radical occupies the position of the metal or base of inorganic salts.

The Volatile Esters. - These include some of the most delicate substances, such as fruit essences and flavors; also some of the essential oils which give odor, flavor and pungency to plants, flowers and seeds. Of the volatile esters, or compound ethers, which also are used for artificial flavors, we may mention ethyl acctate, amyl acetate (pear oil), ethyl butyrate (pincapple oil), amyl butyrate, ethyl valcrate, amyl valerate (apple oil), ethyl caprate (enanthic ether) (grape oil, wine oil, cognac oil), ethyl pelargonate (quince oil), ethyl benzoate, methyl salicylate (wintergreen oil, birch oil), and ethyl salicylate.

Most imitation flavors are a mixture of such esters made synthetically. Thus, an imitation raspberry flavor may contain ethyl acetate 5 parts, amyl acetate 1 part, ethyl butyrate 1 part, amyl butyrate 1 part, ethyl benzoate 1 part. Such mixtures as these constitute the flavors of many imitation beverages. Among the natural esters are also to be mentioned allyl sulphid, which gives the odor to garlic; and allyl isothiocyanate, a constituent of black mustard seeds, known as oil of mustard.

Oils and Fats.- These constituents are very extensively distributed throughout both the animal and vegetable kingdoms.

Fats exist as a definite group of chemical compounds. The name applies equally to the solid and liquid fats. However, for convenience we will refer to fats that are liquid at $20^{\circ} \mathrm{C}$. as "fatty oil" or "oils," sometimes called "fixed oils" in contradistinction to volatile or essential oils. All the fats are practically insoluble in water, and all except those of the castor oil group are sparingly soluble in cold alcohol, but dissolve readily in petroleum ether and mix in all proportions with light petroleum oil. All pure fats are colorless, tasteless and odorless substances, which absorb on paper, forming a permanent grease spot. The taste and color of fats are frequently due to foreign substances, often produced by slight decomposition which has taken place in the fat.

The fatty bodies are found sparingly in seeds, fruits, and sometimes in the leaves and roots of plants; abundantly in all animal tissues and organs, especially in bone marrow, subcutaneous and intermuscular tissues, around the various organs, and in the omentum of the abdominal cavity.

All true fats are esters of the triatomic alcohol glycerin $\mathrm{C}_{3} \mathrm{H}_{5}(\mathrm{OH})_{3}$, in which the three hydrogen atoms of the hydroxyl are replaced by three univalent radicals of the higher members of the fatty acids, whose composition has been indicated above. Thus palmitic acid exists in the fat 
ester tripalmatin, $\mathrm{C}_{3} \mathrm{H}_{5}\left(\mathrm{OC}_{15} \mathrm{H}_{31} \mathrm{CO}\right)_{3}$, stearic acid in tristearin, $\mathrm{C}_{3} \mathrm{H}_{5}\left(\mathrm{OC}_{17} \mathrm{H}_{35} \mathrm{CO}\right)_{3}$, and oleic acid in triolein, $\mathrm{C}_{3} \mathrm{H}_{5}\left(\mathrm{OC}_{17} \mathrm{H}_{33} \mathrm{CO}\right)_{3}$, these being the glycerids that make up the bulk of animal fats. The acids higher in the acid series yield triglycerids that are harder and with a higher melting point.

Mixed triglycerids, that is, compounds of different acids with the same molecule of glycerin, have been separated from natural products. Thus, from mutton and beef fat a distearopalmitin, a dipalmitostearin and a dipalmito-olein have been separated; also similar mixed glycerids from olive oil. From butter the mixed triglycerid oleopalmitobutyrin has been obtained, and from cocoa butter mixed triglycerids of oleic and palmitic with stearic or myristic acids, respectively.

Natural fat contains more than a single glycerid. In lard and tallow the glycerids are chiefly those of stearic and palmitic acid, but some olein is also present. Thus, cooling lard to the point of crystallization and expressing the mother liquid yields lard oil, consisting largely of triolein. Also from beef tallow oleo oil is similarly obtained and constitutes the oleomargarin of artificial butter. Natural fats are not pure glyceride, but hold in solution sterols such as cholesterol, phospholipins such as lecithin, and other constituents in small amounts.

Animal fat consists both of fat absorbed from the food ingested, and also of that formed from carbohydrates and from proteins of the food. The character of the fat of warm-blooded animals appears to vary with its position in the body. One observer concludes from experiments with pigs "that the thick layer of subcutaneous fat on the back, where it was not thoroughly warmed by the blood and therefore had an average temperature considerably below that of the interior of the body, was richer in unsaturated compounds, and had a lower melting point than the fat of the body as a whole; while the fat from animals which has been grown in a warm room or which had been heavily jacketed so that the skin was not exposed to the air, contained nearly the same composition as in the interior of the body."

Fat from herbivora as a rule is much harder than fat from carnivorous animals, and land animals have a harder fat than the marine animals, and as a rule all warm-blooded animals possess fats which are decidedly harder than those found in fish. Butter fat differs from body fat in containing fat acids of lower molecular weight, especially those fairly characteristic of butter.

The acids entering into the formation of glycerin esters of oils and fats present the following features: 
Caproic acid occurs as a glycerid to the extent of about 1.2 per cent in butter, and also in cocoanut and palmnut oils.

Caprylic and capric acids are in the glycerids of cow's and goat's milk, and also of cocoanut and palm oil.

Lauric acid abounds as a glycerid or fat in the seeds of the spice bush. It is sparingly present in butter, cocoanut fat, palm fat and some other vegetable oils.

Myristic acid is obtained from nutmeg butter, cocoanut oil, and occlirs in traces in butter, lard, wool-fat and cod-liver oil.

Palmitic acid occurs abundantly in most fats, both animal and vegetable, including many fatty oils. It is also found in several waxes, for instance, beeswax and spermaceti. The general properties of palmitic acid are nearly identical with those of stearic acid, but it has a lower melting point.

Stearic acid occurs as a glycerid most abundantly in the solid fats, chiefly tallow, and especially in vegetable fats having high melting points, such as shea butter and cocoa butter. It is hard, white, somewhat glossy, solid, without odor or taste.

Salts of the various acids described may be found by saponification of the fats with caustic alkali. These constitute the soaps. The alkali palmitates and stearates are soluble in water, but on dilution of their solution undergo hydrolytic dissociation. It is the liberation of alkali by this action that gives to these soaps their particular cleaning value. In the presence of calcium and magnesium salts in water (hard waters), the formation of the insoluble calcium and magnesium soaps occurs and the cleansing action of the soaps is not realized.

Hypogeic acid occurs in peanut and in maize oil as a glycerid. Its isomere, palmitoleic acid, forms about 6 per cent of the acids of cod-liver oil. These are unsaturated acids, and accordingly their glycerids are not as hard as the corresponding saturated compounds. Like oleic glycerids, at ordinary temperature they are oils.

Oleic acid is unsaturated, in virtue of which it is oxidized more readily than the corresponding saturated acids. It also readily forms addition products. It is a constituent of most fats, especially of fat oils, and as a rule is in larger quantities than any other fatty acid. Olive oil, for instance, is mainly oleate of glycerin. Pure oleic acid is colorless and odorless, insoluble in water, and soluble in alcohol to a greater extent than the saturated acids. It crystallizes near the freezing point.

Erucic acid has been found to be present in cod-liver oil.

WAXES. - These are esters of sterols and fatty acids, the natural wax 
frequently containing more or less free sterols. They contain no glycerids. Beeswax, carnauba wax, spermaceti and sperm oil are familiar examples. They saponify with difficulty and have little food value.

Esters of cholesterol and isocholesterol occur in certain fats of animal origin, but they have been little studied. They are believed to exist in wool-fat, while a silicic ester has been found in the feathers of birds.

Phospho Esters.-Phytic acid. This is a phosphoric acid ester of i-inositol and occurs in the outer covering of various cereals, usually as the calcium and magnesium salts, known by the name phytin. It is this substance which gives to whole cereals their laxative action quite as much or more than the mere mechanical or frictional effect of the bran. The presence of sufficient phytin in food does much to prevent the development of the constipation habit. It is not a lipin.

Phospholipins.-These are esters that on hydrolysis yield both phosphoric and fatty acids. The most important substances, from the point of view of food, are the lecithins. These are glycerids in which two of the hydroxyl hydrogens are replaced with fatty acid radicals, and the third with phosphoric acid, which in turn has one free acid hydroxyl and has the hydrogen of the third replaced by the base cholin. It will be seen that in this complicated structure different lecithins exist according to the nature of the fatty acids entering into the composition.

Lecithins are important ingredients of egg yolk, and, indeed, occur in every living cell. These substances play an important part, together with certain sterols, in determining the physical processes of cells, thus contributing in an important way to vital phenomena; and they are further concerned in the phenomena of immunity, so they are of considerable importance in the dietary. Other phospholipins are cephalin of brain tissue, cuorin of beef-heart, sphingomyelin of brain tissue, and jecorin of liver.

Glycolipins.-These substances, also termed cerebrosids, yield on hydrolysis fatty acids and a carbohydrate, generally glucose or galactose. They contain nitrogen but no phosphorus. Cerebrin of nerve tissue is a familiar example. They are, of course, of particular physiological value to the function of animal tissues in which they exist, but it is not known that they add to food value or are of any food importance other than their small energy equivalent.

Sulpholipins.-These are fatty substances that yield on hydrolysis fatty acids and sulphuric acid; the term is applied to little understood substances of brain tissue. It is not known that they have any particular food value. 
Aminolipins.-These substances contain aminonitrogen and fatty acids but no phosphorus. Krinosin and bregenin are names applied to substances of this nature obtained from brain tissue, but their exact composition and their physiological or possible food importance remain to be investigated.

The terpenes, sterols, fatty acids, volatile esters, oils, fats, waxes, and the various lipins above indicated have been grouped under the term lipoids, on account of their solubility in alcohol-ether and their greasy feel and insolubility in water. Owing to the evident unsuitability of this term, the name lipins has been recently proposed. While this grouping is convenient, the properties enumerated do not afford any fundamental basis for classification, and the grouping based upon chemical structure as employed in this chapter, we believe is on the whole to be preferred.

It is, of course, recognized that any classification of substances that present so many structural features as the organic foodstuffs is somewhat arbitrary, since the same substance will present features that justify its inclusion under more than one head. If this is kept in mind and it is recalled that the position of particular substances may be on this account to some extent optional, much confusion will be avoided.

\section{PIGMENTS}

We have not attempted to include the food pigments in the scheme of classification, since their diversity of composition would compel us to distribute them rather widely. However, hemoglobin is mentioned under the chromoproteins and it is suggested that chlorophyll is closely related to it. The work of Willstätter and his pupils confirms the close analogy between hemoglobin and chlorophyll, though differences are found in details. Four pigments are found in the chloroplasts of the leaf:

$\begin{array}{ll}\text { Chlorophyll }(a) & \mathrm{C}_{55} \mathrm{H}_{72} \mathrm{O}_{5} \mathrm{~N}_{4} \mathrm{Mg} \\ \text { Chlorophyll }(b) & \mathrm{C}_{55} \mathrm{H}_{70} \mathrm{O}_{6} \mathrm{~N}_{4} \mathrm{Mg} \\ \text { Carotin } & \mathrm{C}_{40} \mathrm{H}_{56} \\ \text { Xanthophyll } & \mathrm{C}_{40} \mathrm{H}_{56} \mathrm{O}_{2}\end{array}$

To this may be added lycopin, a pigment which is isomeric with carotin of the tomato.

The former term anthroxanthins has been recently reapplied to pigments, usually called flavones and xanthones, that constitute the yellow pigments of plants. Of these, apigenin occurs in parsley and celery in 
the form of the glucosid, apiin, and quercitin is present in the skin of onions.

Closely related are the anthocyans, red, violet and blue pigments of blossoms and fruits. Chemically, these are glucosids. The pigments of cranberry and blue grapes belong to this class.

In the animal kingdom the yellow or orange-red pigments are grouped under the term lipochromes. These, however, are closely related to the vegetable pigments. Thus lutein of egg yolk is isomeric with xantho phyll. The yellow pigment of butter fat is mainly carotin, though xanthophyll is also present. These pigments are taken up from the food of these animals, the cow eating the green grass, absorbing the carotin and xanthuphyll, holding the former by its combination with albumin in the blood serum while the latter is eliminated through the bile, the carotin together with a little xanthophyll eventually finding its way into the milk.

\section{INORGANIC SALT'}

Foodstuffs contain a notable quantity of mineral matter which remains as ash when the foodstuff is burnt. It is to be understood, however, that within the vegetable and animal tissues the salts are to a considerable extent in some form of association with the organic constituents, such as loose protein salt combinations or existing as a part of the organic constituents, as suiphur and phosphorus of the protein molecule and bases combined with organic acids. The ash, therefore, does not adequately indicate the food contents of saline matter simply as such. These very associations indicate how valuable the ash constituents are to the system and hence what actual importance they are in the dietary.

Eight elements, namely, sodium, potassium, magnesium, calcium, iron, chlorin, sulphur and phosphorus, remain either wholly or in part in the ash of foodstuffs. Of these, sodium and chlorin exist in the food largely as sodium chlorid. By the use of salt it seems that the variety of food products that may be eaten is extended. Potassium occurs in animal food largely as phosphate and in vegetables in organic combination. Magnesium and calcium occur in both animal and vegetable food both in organic combination and as phosphates. Sulphur in food is found very largely as a constituent of organic compounds, especially certain proteins, as egg albumin, myosin of muscle, and gliadin, although sulphates are found, particularly in certain waters. Phosphorus occurs as phosphates and in a considerable variety of organic combinations of which we have 
elsewhere noted nucleic acid of the cell nucleoproteins, phytin or bran and lecithins of cellular tissue in generil and the tissues of the nervous system in particular. Iron is an important constituent of food, appearing chiefly in organie combinations. Milk contains iron, but in insuffieient amounts for a growing body, while it is relatively abundant in lean beef, eggs, oatmeal, whole wheat, beans, cablage, spinach and some other foods. The average dietary contains from 12 to 19 milligrams per person per day.

An important phase of the inorganic foodstuffs is the balance of acidforming and base-forming elements in the dietary. This is determined by calculating the equivalent in acid of the chlorin, sulphur and phosphorus of the diet and the equivalent in alkali of the sodium, potassium, magnesium and calcium; the excess of acid or alkali indicating whether the food is an acid-forming or a base-forming diet. Acid-forming foods are meats and eggs and to a lesser extent grains, while base-forming foods are the vegetables. A diet in which the acid-forming elements predominate is less desirable than one in which there is a balance or even a predominance of base-forming elements.

\section{WATER}

For the value of water and its uses in human economy, ste Chapter $X$; for the value of water as a beverage and its various classifications, see this Volume, Chapter XVI, Beverages and Stimulants.

\section{REFERENCES}

1. Mann. Chemistry of the Proteins, 1906.

2. Abderinalden. Text-book of Physiological Chemistry, Lectures 2 to $13,1908$.

3. Shermax. Chemistry of Food and Nutrition, 1914.

4. American Physiological Society and American Society of Biological Chemists.

5. Bailey. Source and Chemistry of Foods.

6. Bunge. Text-book of Organic Chemistry.

7. Srmox, Wr. Manual of Chemistry.

8. Chemical News, 1891, ii, 260.

9. Tibbles, WM. Origin and Manufacture of Foods.

10. Abderhalden. Text-book of Physiological Chemistry. 
11. Sandmeyer. Ztschr. f. Biol., 1895, N. F. xiii, 32.

12. Mendel and Nakaseko. Am. J. Physiol., 1900, iv, 246.

13. Mendel and Mitchell. Am. J. Physiol., 1905, iv, 245.

\section{BIBLIOGRAPHY}

Armstrong. The Simple Carbohydrates and the Glucosids.

Atwater. Methods and Results of Investigations on the Chemistry and Economy of Food.

Cathcart. The Physiology of Protein Metabolism, 1912.

Chittenden. The Nutrition of Man.

Cohen. Organic Chemistry, 1907.

Dakin. Oxidations and Reductions in the Animal Body, 1912.

—. J. Biol. Chem., 1913, xiv, 321.

Fischer. Untersuchungen über Aminosäuren, Polypeptide und Proteine, 1906.

Folin. Am. J. Physiol., 1905, xiii, 45.

Intermediary Protein Metabolism, J. Am. M. Ass., 1914, lxiii, 823.

Hammarsiten. Text-book of Physiological Chemistry, 6th American Edition, 1911.

Holleman. Text-book of Organic Chemistry, 3rd English Edition, 1910.

Howeld. Text-book of Physiology.

Kossel. The Chemical Composition of the Cell, The Harvey Lectures, 1911-1912.

- The Proteins, Johns Hopkins Hosp. Bull., 1912, xxiii, 65.

Lewnowitsch. Chemical Technology and Analysis of Oils, Fats, and Waxes.

Liebig. Complete Works on Chemistry, 1856.

- Theorien des Eiweisstoffwechsels nebst einigen praktischen

Konsequenzen derselben, Ergebn. d. Physiol., 1911, xi, 418.

Lusk. Elements of the Science of Nutrition.

J. Am. Chem. Soc., 1910, xxxii, 671.

-. Phlorhizin Glycosuria, Ergebn. d. Physiol., 1912, xii, 315.

Mann. Chemistry of the Proteids, 1906.

Mendel. Nutrition and Growth, Harvey Lectures, 1914-15.

J. Am. M. Ass., 1915, lxiv, 1539. 
Osbonne. The Vegetable Proteins, 1909.

Die Pflanzenproteine. Ergebn. d. Physiol., 1910, x, 47 to 215 .

Chemistry of the Proteins, The Harvey Lectures, 1910-1911. and Mendel. Feeding Experiments with Isolated Food Substances.

Plimmer. Chemical Constitution of the Proteins, 1908.

Ross. Laboratory Handbook of Dietetics.

Shermax. Chemistry of Food and Nutrition.

Stiles. Nutritional Physiology.

Van Slyke. The Proteins, New York M. J., 1912, August 10 and 17, xevi, 257; 329 . 



\section{CHAPTER IV}

\section{DESCRIPTION AND FUNCTIONS OF THE DIGESTIVE ORGANS}

S. W. S. Tons, Pr.G., M.D.

The Alimentary Tract: Mouth-Palate, Teeth; Pharynx; Esophagus; Stomach; Duodenum; Small Intestine; Large Intestine.

Digestive Glands: Salivary Glands-Parotid, Submaxillary, Sublingual; Pancreatic Gland; The Spleen; The Liver; The Gall-bladder.

Primarily, digestion has for its aim the separation of the elements of growth and repair from the aliments and their preparation for absorption into the circulation. The process is very complex, and is both mechanical and chemical; it is accomplished mainly through the action of certain soluble ferments known as enzymes.

Digestion is an essential factor in the life of every form of animal organism, no matter how low we descend in the zoölogical scale. Some form of digestion is essential in all, since they must be able to take from their environment those elements that are requisite for their maintenance. They must give off those substances termed waste products that are no longer fit for use, for only by this exchange of elements outside of their own organisms are they able to live, grow, and reproduce their kind.

In the higher grades of animal life, as in the articulata, the number of organs concerned in the process of digestion is increased, and in direct ratio the various stages and acts in the whole process are multiplied. In their bodies is a long tube-like canal, in some parts much folded on itself, containing along its course, both inside and out, numerous glands which pour out secretions into the canal to aid in the process of digestion. At the beginning of this tube there is an apparatus for crushing or grinding the solid parts of food. Closely associated with this apparatus are the terminal or absorbing structures of the system of blood-and-chyle vessels 
which assimilate and absorb the digested food products, thus permitting them to circulate throughout the entire body, carrying energy and nutrition to every part of the organism.

In the vertebrata are found modifications and many forms of development dependent upon the class of animal, and even in mammalia there are distinct differences, as the animal may belong to one of the following classes-insectivorous, carnivorous, herbivorous, or omnivorous.

\section{THE DIGESTIVE APPARATUS OF MAN}

Man is the highest in the scale of mammals. He is omnivorous, and his digestive apparatus is adapted to disintegrate and prepare for digestion, assimilation and absorption all kinds of food. In man the digestive apparatus, termed the alimentary tract, includes the mouth, teeth, stomach, duodenum, the small and large intestine and the glands of the alimentary system.

\section{THE ALIMENTARY TRACT}

The alimentary tract in man is a convoluted tube beginning at the mouth and ending with the anus, composed of mucous membrane, muscular tissue and serous membrane. The first lines the canal throughout its entire length, giving to the interior its characteristic smoothness and redness. In this lining membrane, in the submucosa, are located some of the glands whose secretion aids digestion. The alimentary canal measures from thirty to thirty-two feet in length and may be divided into several parts; (a) the mouth, including the teeth, (b) the pharynx, (c) esophagus, (d) stomach, (e) duodenum, (f) jejunum, (g) ileum, (h) colon, (i) anus.

The Mouth.-The mouth is an oral cavity situated at the beginning of the alimentary tract. This cavity is formed by the lips in front, the pharynx behind, and the cheeks at the sides. The roof of the mouth is formed by the hard palate; below is the floor of the mouth upon which rests the tongue. The cavity of the mouth, excepting the teeth, is everywhere invested with a highly vascular mucous membrane, composed largely of squamous epithelium. Conical papillæ are for the larger part very minute and concealed beneath the epithelium. The lips are separated by an oval fissure. They are composed of various muscles converging to and surrounding the oval fissure. The cheeks have a corresponding composition, the principal muscles being the buccinators. 
Beneath the mucous membranes of the cheeks and lips there are a number of racemose glands, communicating with the mouth through their respective ducts. In the lips they are called labial glands; in the cheeks buecal glands. Their function is to secrete mucus and an enzyme.

THE PALATE.-There are two parts of the palate- a hard and a soft. The hard palate is deeply vaulted and lined with smooth mucous membrane, except anteriorly, where it is roughened by a series of transverse

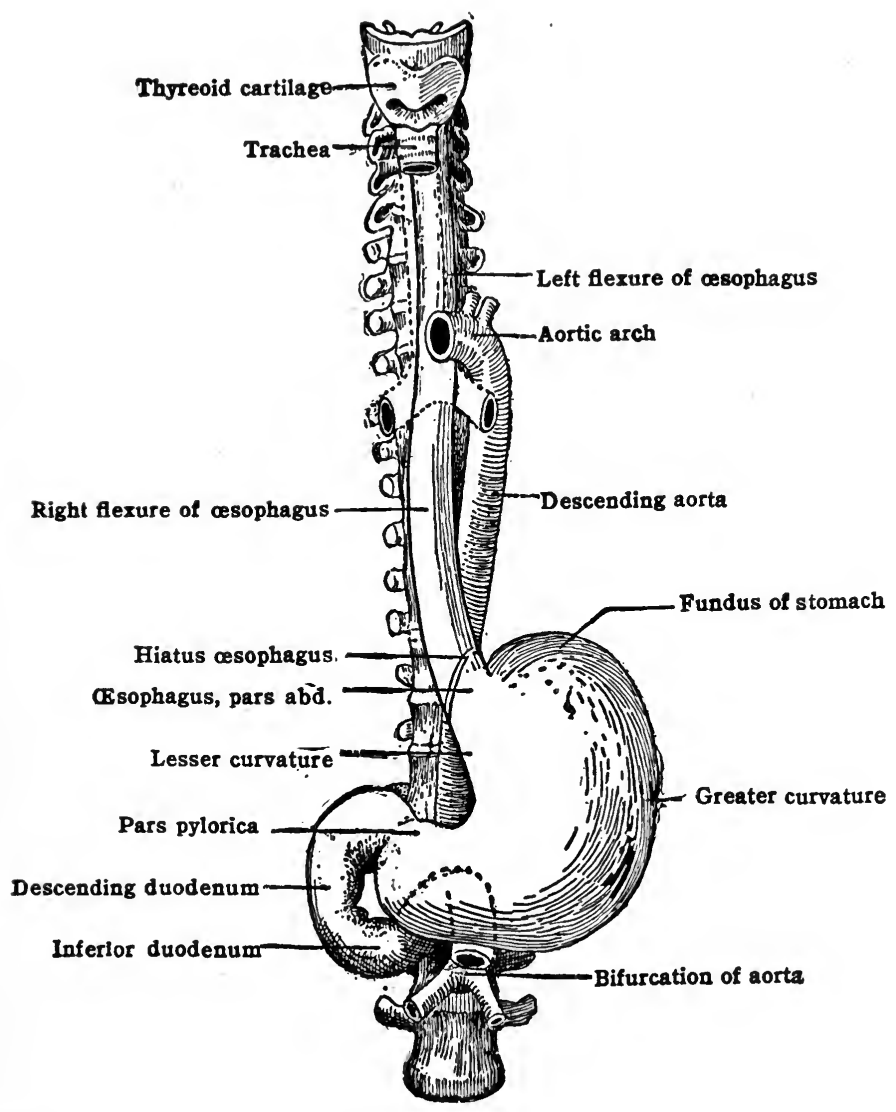

Fig. 5.-Esophagus, Curvatures of the Stomach and the Situation of the Pars Pylorica, the Descending and Inferior Duodenum.

ridges. The soft palate is a reduplication of the mucous membrane enclosing a fibromuscular layer, containing racemose glands. The soft palate hangs obliquely from the posterior portion of the hard palate and forms a freely movable partition between the mouth and the posterior nasal orifices. 
THE TEETH.- The teeth, in form, structure and number, vary in different animals; this is markedly shown in the carnivora and herbivora. Among mammalia, and particularly. in man, the teeth are developed in two sets; (1) called the temporary or milk teeth, 20 in number, 10 in the upper and 10 in the lower jaw; (2) the second set or permanent teeth, 32 in number, 16 in each jaw, viz: 4 incisors, 2 canines, 4 bicuspids and 6 molars. The main body of a tooth is composed of dentine, a hard substance resembling bone, physically and chemically. This encloses the pulp cavity and gives shape to the tooth. It consists of about 28 parts of organic matter and 72 parts of earthy material. The surface of a tooth is covered with enamel, the hardest of all organized substances known. It consists of 3 parts of organic matter and 97 of earthy matter, principally calcium phosphate.

The Pharynx.-The pharynx is a funnel-like cavity, running from the base of the skull to the level of the fifth cervical vertebra, where it ends in the esophagus. There are 7 openings communicating with the

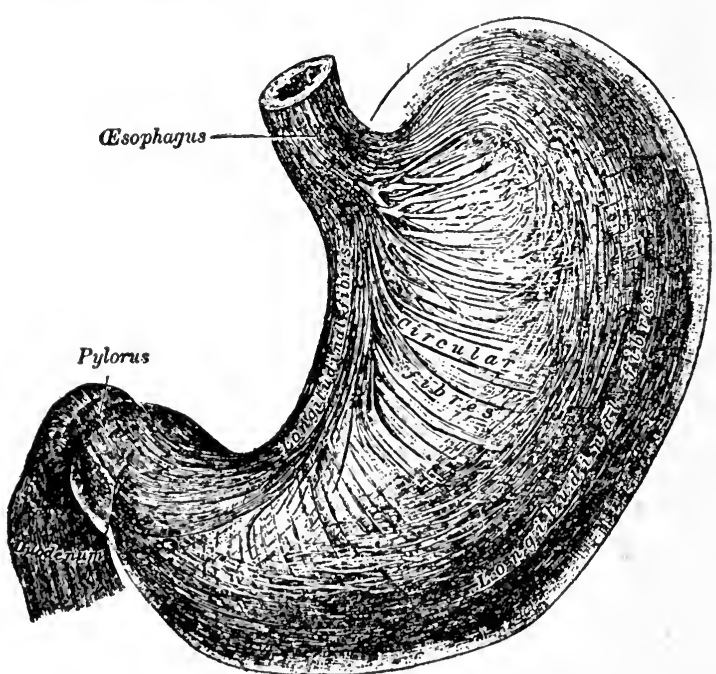

Fig. 6.-The Normal Stomach. This illustration (from Gray's "Anatomy"), though too short in its long axis, is a fairly good diagrammatic outline of the normal stomach. That part of the stomach above where the esophagus enters is almost always filled with gas when the stomach is viewed on the fluoroscopic screen. The relative lengths of the curvatures, the shape and position of the pars pylorica, the pyloric sphincter and the dilated first portion of the duodenum, which forms the cap, are fairly well represented. pharynx; the 2 posterior nares; the 2 eustachian tubes, the mouth and the esophagus. The walls of the pharynx are musculomembranous. The interior is lined with a soft, red, mucous membrane containing many glands.

The Esophagus. - The esophagus is a continuation of the digestive tract, of which the pharynx is the upper part. It is 9 inches long, an inch in diameter, and extends from the lower end of the pharynx to the cardiac end of the stomach (Fig. 6). The esophagus is a nearly straight canal, narrowest at its commencement and gradually enlarges. It has three coats: an outside muscular, a 
fibrous, and an inner or mucous coat. 'The inner eoat contains minute papillie and is covered by squamous epithelium.

The Stomach.-The stomach is a pyriform dilatation of the alimentary canal and forms a pouch, lying in the epigastric and hypogastric regions, about five-sixtlhs being in the median line. It is approximately twelve inches long, four in vertical diameter, and somewhat less anteroposteriorly, weighing about five ounces and holding normally from five to eight pints. It has two orifices, cardia and pylorus; two surfaces, anterior and posterior; and two borders, the greater and lesser curvatures (Fig. 8). Its large end is called the fundus, the small end the portio pylorica. In this organ some of the most important chemical changes in the food take place; it is here converted into a grayish brown soup-like mass. From the stomach the food passes into the small intestine, where the nutrient materials are separated from

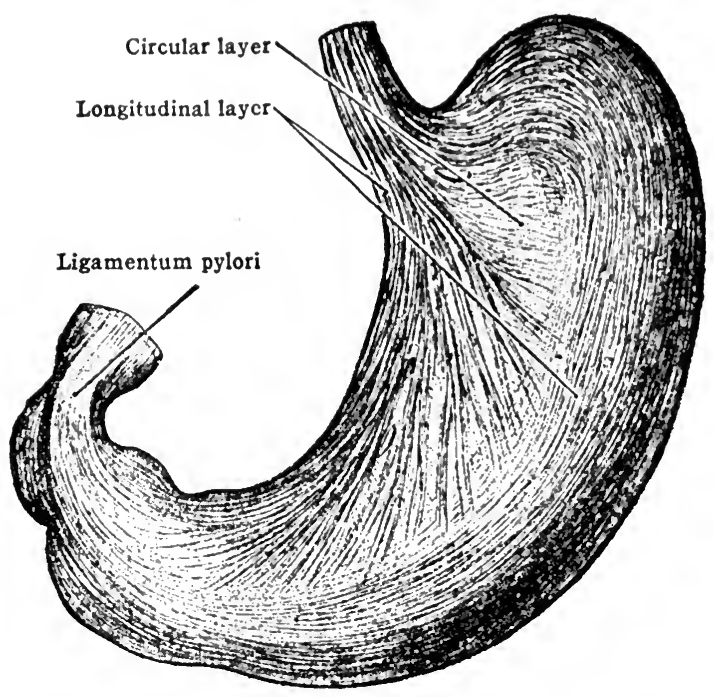

Fig. 7.-The Longitudinal Fibers of the MuScllature of the Stomacil. (Morris' "Human Anatomy.")

the waste residue, the latter passing on into the large intestine to be expelled from the body (Fig. 9).

The stomach and the large and small intestines are located below the diaphragm in the abdominal and pelvic cavities, differing from that part of the digestive tube above the diaphragm, which is practically a straight tube, while the intestine is much folded and convoluted.

The Small Intestine.-The small intestine is about twenty-five feet long; the short first or upper portion is the duodenum, the next two-fifths form the jejunum, and the rest the ileum. The wall of the gut is very thin, and is composed of four layers or coats. The serous coat (external) is peritoneum, and surrounds the jejunum and ileum completely, except along its narrow mesenteric border. The muscular coat consists of two layers; externally longitudinal fihers and internally circular fibers, the latter being three times the thicker. The submucous coat consists largely 


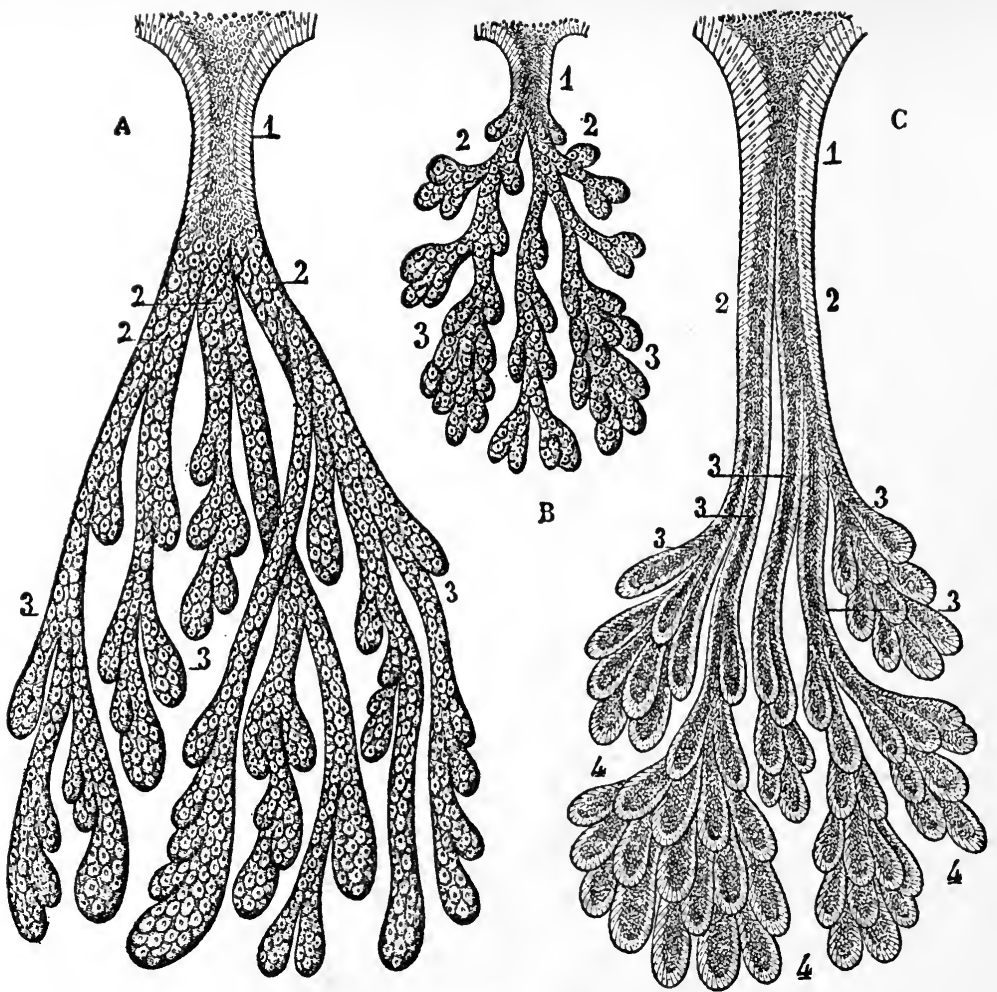

Fig. 8.-Orifices of the Peptic Glands of the Stomach. (Flint's "Physiology.") A-Peptic gland from the middle portion of the stomach: 1, excretory canal; 2, 2, 2, the three principal branches of the gland; 3, 3, 3, secondary branches filled with rounded cells.

B-Peptic gland from the pyloric portion: 1 , excretory canal; 2,2 , the two principal branches; 3,3 , terminal culs-de-sac.

C-Mucous gland from the pyloric portion: 1, excretory canal; 2,2 , the two branches; $3,3,3,3,3$, secondary branches; $4,4,4$, small, terminal racemose glands.

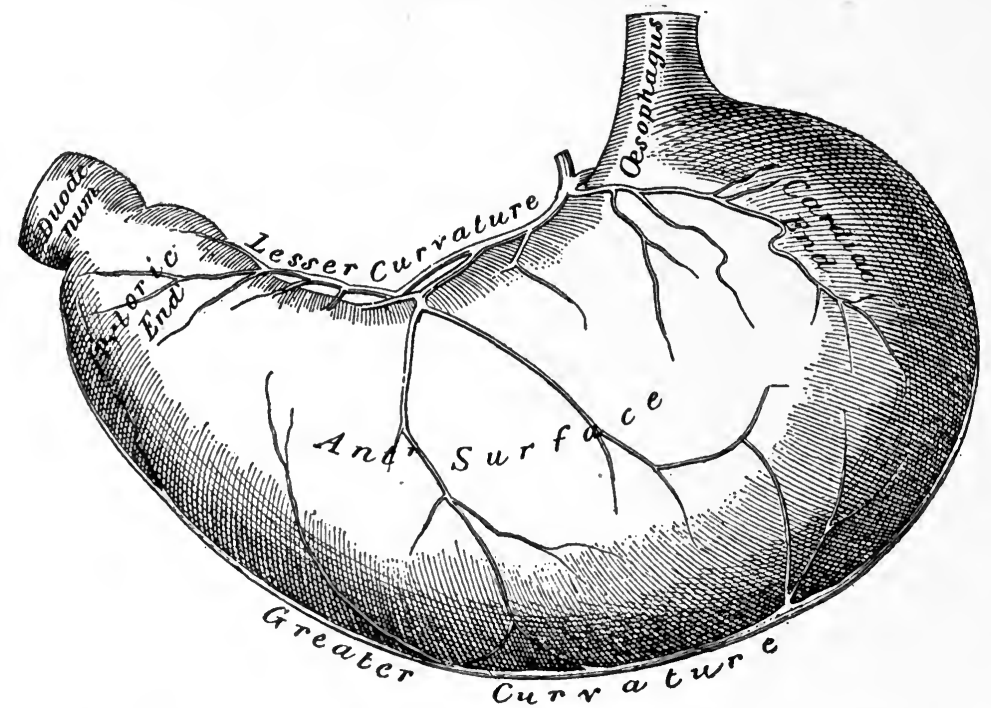

Fig. 9.-The Greater and Lesser Curvatures of the Stomach.

(Morris" "Human Anatomy.") 
of areolar tissue and is more closely connected with the muscular coat; in it are found the lymphaties, blood vessels and nerve plexuses.

THE DuODEnum.-The duoderium is an inverted U-shaped tube, ten or twelve inches long and from an inch and a half to two inches in diameter. It begins at the pyloric end of the stomach and describes a loop ending at the duodeno-jejunal angle, where it becomes the jejunum. In direction it follows one of three types: (1) angular or circular, peculiar to infants less than seven years old, in which the terminal part rises as high as the origin; (2) and (3) U-shaped or V-shaped, found in adults. The first portion, known as the hepatic curvature, is about an inch and a half long, movable at its origin, but firmly fixed at its end. The hepatic curvature is on the level of the upper edge of the body of the first lumbar vertebra; its general direction is upward and to the right and backward, being nearly horizontal and transverse when the stomach is empty, but $\mathrm{n}$ e a r ly anteroposterior when it is full. It passes under the quadrate lobe of the liver and neck of the gall bladder, where it bends downward, be-

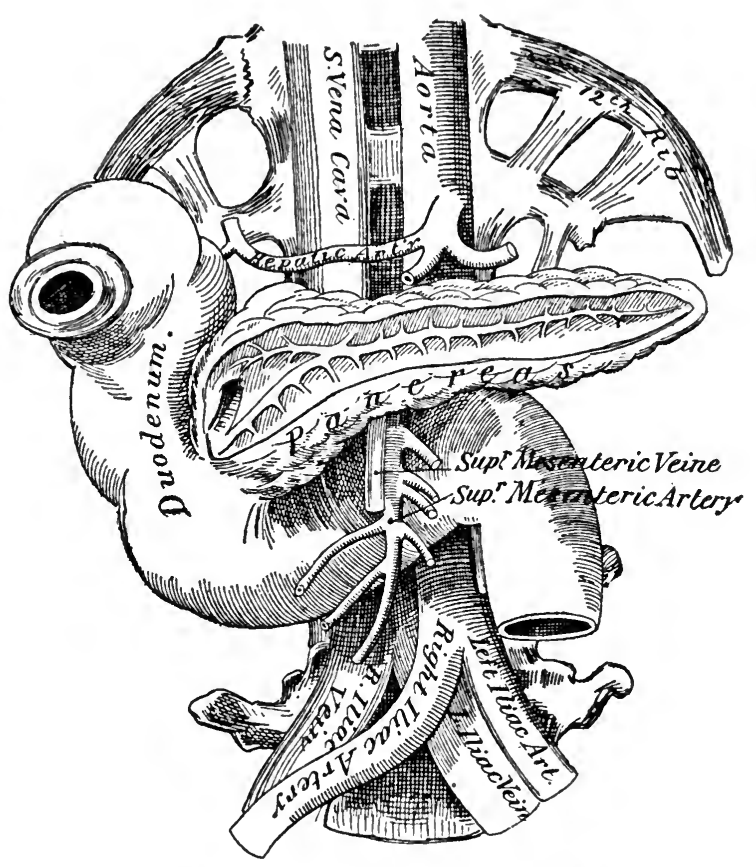

Fig. 10.-The Duodenum in its Anatomical RelaTions. (Allan's “Anatomy.”) coming the second or descending portion, which lies to the right of the first two or three lumbar vertebræ, then crosses the fourth lumbar vertebra. It lies to the left of the spinal column, but in front of the great vessels. The duodenum is held in place by its peritoneum and ligaments, but chiefly by the ducts-from the gall bladder and pancreas, together with its arteries and their fibronervous investments-and by the muscle of Treitz.

The Large Intestine.-The large intestine is five or six feet long and extends from the end of the ileum (cecum) to the anus; its capacity is 
about four quarts and its diameter varies from one inch to two and a half inches. It is differentiated from the small intestine by its larger size,

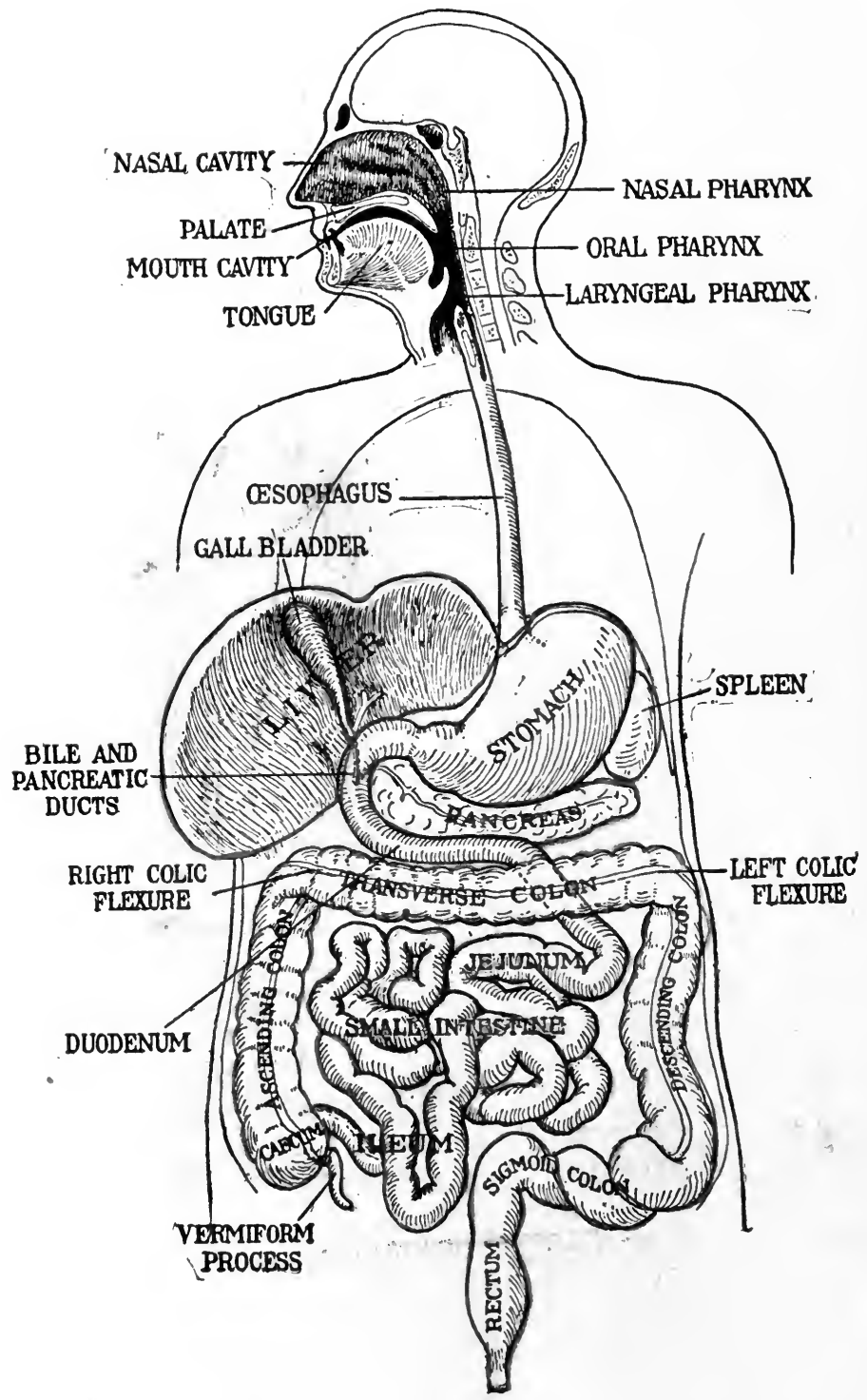

Fig. 11.-Difagam of the Alimentary Canal, Stomach, Liver, Pancreas and. tire Large Ixtestine. (Morris' "Human Anatomy.")

sacular form, the presence of the appendices epiploicæ, and by the longitudinal muscular bands. It begins in the right iliac fossa and passes 
upward to the under surface of the right lobe of the liver; this part is eight inches long and is known as the ascending colon. Here it bends (hepatic flexure) sharply forward and to the left to become the transverse colon. 'This portion is about twenty inches long. From the hepatic flexure it passes transversely to the left in an arch whose convexity is downward and forward, and ends in a sharp bend downward, making what is known as the splenic flexure. The descending colon, eight and a half inches long, begins here, and becomes the sigmoid flexure at the crest of the ilium. The sigmoid colon begins at the upper crest of the ilium and passes down into the left iliac fossa and ends at the brim of the pelvis, becoming the rectum. The rectum passes down on the posterior wall of the pelvus and bends backward around the coecyx to end at the anus. Its total length is about eight inches.

The large intestine has four coats; the serous coat is external, and is formed by peritoneum. The muscular coat is next, consisting of two layers of fibers; externally the fibers run lengthwise of the gut. The next layer is formed of the circular constricting transverse bands or tenia coli. The submucous coat is next and also has a bed for the mucosa. It consists of areolar tissue, and contains blood vessels, nerves and lymphaties. The mucous coat is the internal lining membrane of the gut.

The mucous coat is thick and red at the upper part of the gut, but paler and thinner below; on its outer surface is the muscularis mucosæ, a layer of unstriped muscle fibers. The inner surface presents a shaggy appearance, owing to the presence of the intestinal villi. In its different parts are found villi, valvulæ conniventes, lymph follicles and true glands.

\section{DIGESTIVE GLANDS}

Outside of the intestinal canal, but connected with it, are a number of glands emptying their secretions into the canal by small ducts; the larger of these glands are the salivary, opening into the mouth, and the liver and pancreas, opening into the first fold of the small intestine.

The true intestinal glands are of two kinds: Lieberkiuhn's follicles or crypts are small tubes formed everywhere in the mucous membrane. Bruno's (or duodenal) glands are small, compound, tubular glands found usually in the submucosa, and limited to the duodenum and upper part of the jejunum. They are possibly a continuation of the more highly speeialized pyloric glands.

The intestinal lymph follicles occur in two forms as follows: the Solitary Glands, resembling lymph nodes, found chiefly in the lower ileum; 
they are small, whitish in color, or very vascular and filled with lymph corpuscles. Each is surrounded by the crypts of Lieberkïhn. The Peyer's patches are aggregations of solitary glands which make up the circular or oval patches, between twenty or thirty in number, an inch and a half to two inches wide, and from a half to four inches long. They are largest and most numerous in the lower two-thirds of the ileum.

Although digestion in its entirety, as it occurs in the alimentary canal, is in its nature very complex, yet there are three natural divisions of the process based upon the changes as they occur in the (a) mouth, (b) in the stomach and (c) in the intestines respectively.

For the sake of a clearer understanding of the physiological changes and alterations in foodstuffs, whether mechanical or chemical, it will be well to refer briefly to the anatomy of the organs of the different parts of the digestive tube, explaining the function they fulfill in the process of digestion. The fact must not be lost sight of, that these divisions of the digestive system are arbitrary and that no sharp line can be drawn a the various stages, since all parts, structures and functions work in harmony and have one common goal-the dissolving of the food so that it can be absorbed into the circulation.

Glandular Organs of Digestive Tract.-The most important glandular organs of the digestive tract are as follows:

I. The salivary glands:

parotid, submaxillary, sublingual.

II. The pancreatic gland.

III. The spleen.

IV. The liver.

THE SALIVARY GLANDS.-The largest of the salivary glands is the (a) parotid, weighing from a half an ounce to one ounce. It is named from its position near the ear, lying just below and in front of this organ. It extends upward as far as the zygoma, downward as far as the angle of the lower jaw, and inward between the ramus of the jaw and the mastoid process. The duct of the parotid, called Stensen's duct, has the diameter of a crow-quill, is two inches in length, and runs forward across the masseter muscle to open in the mouth opposite the second molar tooth.

(b) The submaxillary gland weighs about two drams, and is separated from the parotid by a layer of deep cervical fascia. It lies beneath the mylohyoid muscle, below the digastric muscle, and is covered by the sub- 
cutaneous cervical muscle and skin. It is about one-third the size of the parotid, and its duct (Wharton's) is about two inches in length. The duct opens on the side of the lingual frenum, under the tip of the tongue.

(c) The sublingual gland, the smallest of the three, is almond-shaped and weighs about a dram. It lies under the mucous membrane and at the side of the frenum linguæ in a depression on the inner side of the lower jaw elose to the symphysis. This gland has from eighteen to twenty ducts, called Rivinian ducts, opening separately on either side of the frenum. Two or more of these unite to form the duct of Bartholin, which then joins Wharton's duct.

THE PANCREATIC GLAND.-The pancreatic gland-the pancreas-is a long gland of a reddish cream color, situated behind the stomach. It resembles somewhat in structure the parotid gland, though softer, is about six inches long, an inch to one and a half inches wide, and half an inch to an inch thick. It lies transversely a $\mathrm{cross}$ the posterior abdominal wall at the level of the first $\mathrm{l} \mathrm{u} \mathrm{m} \mathrm{b} \mathrm{a} \mathrm{r}$ vertebra, stretching from the duodenum to the spleen, and is divided into a head, neck, body and tail. The duct of Wirsung, or the pancreatic duct, the size of a goose-quill, runs the entire length of the gland.

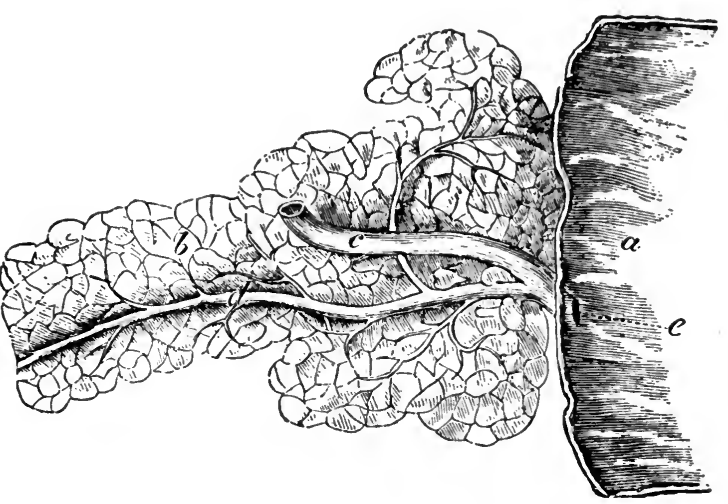

Fig. 12.-The Duodenum Opened, Showing the Valvule Conniventes, and The Opening of the Common Bile Duct. The duct of the pancreas is also represented in greater part of its course. $a$, duodenum; $b$, pancreas; $c$, common bile duct; $d$, pancreatic duct; $e$, opening of the common duct in the intestine.

Upon leaving the pancreas, the duct penetrates the wall of the duodenum to unite with the common bile duct, about three inches from the pylorus.

The pancreas is an acinotubular gland, resembling the salivary glands. Indeed, it has frequently been called the abdominal salivary gland. The lobes are composed of convoluted ducts which terminate in alveoli or sacs which unite with other tubules and communicate with the main duct. The secretory cells of the pancreas are large and rounded. They possess an outer portion which is nearly or quite homogencous, staining readily with dyes; and an inner portion, very granular, which 
does not stain easily. When the pancreatic gland is inactive, its cells are heavily charged with granules. When active, the cells swell and press outward against the basement membrane; later they diminish in size as the granules pass out through the now opened lumen and so leave a large clear zone. The presence of these numerous small granules marks the presence, in the cells, of a zymogen, termed trypsinogen, which is the precursor of trypsin, the active digestive ferment of the pancreatic juice.

THE SPLEEN.- The spleen is the largest ductless gland and lies obliquely in the left hypochondrium between the fundus of the stomach and the diaphragm; above and to the left of the kidney and above the splenic flexure of the colon, and opposite (with its long axis nearly parallel to) the ninth, tenth and eleventh ribs. In shape it is half-ovoid. Its consistency is comparatively soft, and its color is purplish. It is five inches in length, four inches in breadth, and from one to two and a half inches in thickness. Just what rôle the spleen plays in metabolism is as yet undetermined. It is supposed by some workers to originate the leukocytes, and this manufacture reaches a pronounced activity when the organ is hypertrophied, as in leukocythemia. The spleen, from its power to dilate, serves as a reservoir of blood for the portal system, especially for the blood vessels of the stomach. Many of the purin bodies are found in the spleen, as xanthin, hypoxanthin and uric acid. Jones of Baltimore has shown that the spleen contains a digestive fermient adenase, the ferment which converts adenin into hypoxanthin. Ott, in his text-book on physiology, says he has demonstrated experimentally that an extract made from the spleen when injected into an animal will excite active peristaltic movements.

THE LIVER.- The liver is the largest gland in the body. Its shape is ovoidal or that of a triangular prism, with its long diameter transverse. Its convex surface is against the diaphragm; its concave surface is in contact with the stomach and right kidney. It is held in place by the left and right lateral ligaments, together with the suspensory ligament. The organ weighs from three to four pounds, and is a dark reddish-brown. It is composed of five lobes, five fissures and five ligaments. The right. portion of the liver is much larger than the left. It is also thicker and extends lower in the abdomen and higher in the thorax. The liver has been termed the storehouse for the human body. Its excretory apparatus includes the bile canaliculi and ducts, hepatic and cystic duets, gall-blad- der and common bile duct. The bile canaliculi begin between the liver cells and unite into larger ducts, which finally unite into two main ducts for the right and left lobes respectively; they emerge at the transverse 
fissure. The hepatic duct is formed by the union of the right and left bile ducts at the right end of the transverse fissure. Then, descending in the right margin of the lesser omentum, in front of the vena cava and to the right of the hepatic artery, it joins the cystie duet, forming the common bile duct.

THE GALL-BLADDER.-The gall-bladder is pear-shaped, three or four inches long and over an inch wide; it presents a fundus, body and neck, and acts as a natural reservoir for storage of bile. The hepatic duct by joining the eystic duet forms the common bile duct known as the ductus communis choledocus. This is the largest of the three, and is three inches long with the diameter of a goose-quill. It joins the panereatic duct, and empties its secretions into the duodenum through a common opening. The composition of human bile is approximately as follows:

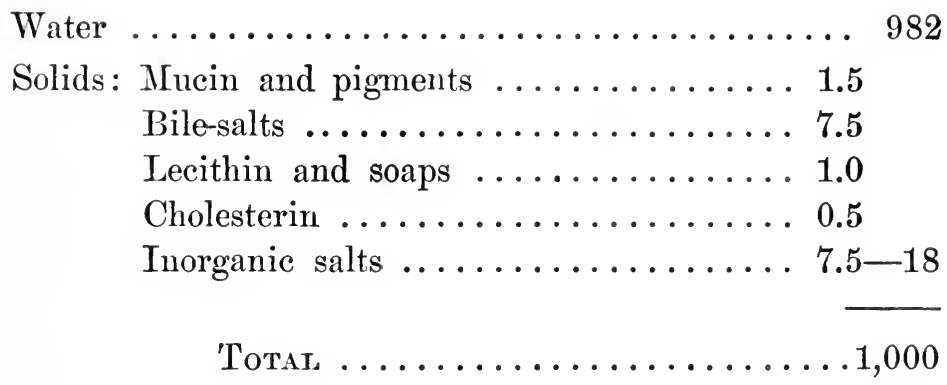

The normal color of bile is due to two bile-pigments: bilimubin and biliverdin, which give a range of color from reddish-brown to grass-green. Bile does not contain either bilirubin or biliverdin in a free state, but combinations of these two substances: as salts, bilirubinates, and biliverdinates of the alkalies.

THE USES OF BILE IN THE INTESTINES.-During the fasting state not a drop of bile enters the intestine. Meat extractives, fat and the products of digestion of egg albumin set up a free excretion of the fluid. The presence of bile in the intestine stimulates the active excretion of the pancreatic enzymes, especially the fat-splitting ones, the action of which is increased fifty per cent.

Bile is principally an excrementitious waste from the liver. It aids in the emulsification of fats and contributes to their solution by saponification brought about by the alkalies of the biliary fluid. Another property of this excrementitious biliary fluid is a regulator of intestinal 
putrefaction and due to its power of dissolving cholesterol serves as an excretory vehicle for ridding the body of toxins and metallic poisons.

Bile renders the chyme alkaline, and aids the action of the pancreatic juice which is most effective as a digestive agent in an alkaline medium. It also favors absorption, by its alkalinity permitting of more ready osmosis. 


\title{
MECHANICAL AND CHEMICAL PROCESSES OF DIGESTION IN THE ALIMENTARY CANAL
}

\begin{abstract}
Mastication.
Insalivation: Stimulation and Action of Enzymes in the Mouth. Deglutition.

Nerve Action in Digestive Processes.

Secretion and Action of Digestive Juices: Saliva; Juices of the Stomach and Intestine-Secretion, Quality and Quantity of Secretion, Correlation of Functions by Chemical Action of Juices.

Functions of the Stomach: The Stomach as a Reservoir; Maceration of Food in the Stomach-Movements of the Stomach, Action of the Pylorus; Sterilization of Food; Regulation of Temperature; Absorption of Food.
\end{abstract}

To make food of use in the body it must be digested, and the process of digestion is a very complicated one. It has been said that digestion is augmented by good food skillfully prepared, pleasant to look upon, inviting to the taste and smell, ingested in comfortable surroundings among pleasing, cheerful companions. Under adverse conditions, pure food improperly prepared will cause digestive disturbances.

Mastication of Food.-Mastication of food is a voluntary act whereby the food is ground up by the teeth, aided by the tongue, palate, cheeks and lips. The bulk of the work is accomplished by the biting and grinding movements of the lower teeth against the upper.

From the peculiar articulation of the lower jaw with the skull, it is capable of performing three primary movements, together with combinations of same: upward and downward, side to side, forward and backward. The muscles concerned in these movements are the masseter, temporal, and internal pterygoids which raise the jaw. The inferior maxillary division of the fifth nerve innervates them. The depression of the lower jaw is brought about mainly through the action of the digastrics. The side to side movements are produced by the separate action of the external pterygoids. Their united contraction permits the 
forward and backward movement of the lower mandible. The up and down biting movement is necessary for the front teeth; the side to side motion is a necessary process of chewing. The tongue and cheeks act like the hopper of a mill and force the food between the grinding facets until it is properly comminuted for swallowing.

Mastication is of prime importance when solid and fibrous foods are eaten, to prepare them by comminution for the fermentative action of the various digestive fluids. When foods are improperly masticated, severe forms of dyspepsia are likely to follow.

"The time consumed in mastication," says Cannon, "varies with the appetite, with the age, the demands of business, the quantity of food in the mouth, and especially with the nature of the food-whether gummy, moist or dry, crisp or tough(1). The amount of mastication given to any food is related to the readiness with which a mass is comminuted, insalivated and formed into a bolus, and is not related to the degree of salivary digestion. For this reason soft, starchy food is little chewed, whereas hard or dry food, which is usually not starchy in nature, requires much chewing to be ready for swallowing"(2).

The secretion of saliva, which softens the hard particles in food, is promoted by the movements of the jaws in chewing the food. Ptyalin, a constituent of saliva, starts the digestion of starches. The weight of a bolus of food in the mouth when ready to be swallowed varies in man between 3.5 and 6.5 grams, and of this, 1.5 grams will be saliva(3). The mass suitable for normal mastication has an average volume of about 5 c.c. Not all animals chew the food as finely as man commonly chews it. The dog, eat, and other carnivorous animals swallow pieces of meat so large that the esophagus seems to have difficulty in accommodating them, and yet these animals seem to have no instinct to divide their food into smaller and more readily manipulated fragments. It would seem, therefore, that nature intended meats to be bolted. The large lumps are merely moved about the mouth of carnivorous animals until they are coated with saliva and are then forced backwards into the gullet. In man, also, the food may be swallowed in such haste that it is barely covered with the saliva which usually lubricates the passage of food through the esophagus. Masses of food from 10 to 12 millimeters in diameter may thus enter the stomach with scant evidence that the teeth have in any way affected them. The ability to bolt food in unbroken masses can doubtless be cultivated.

The thorough comminution of food into fine fragments and the process of mixing it thoroughly with saliva so that it might be suffi- 
ciently moist to be swallowed were formerly considered the most important results of mastication. Recent researches have revealed less obvious results. According to Pavlov and Camnon, the voluntary act of chewing has been found to have much significance for the proper initiation of gastric digestion. "During mastication substances of pleasant taste are brought in contact with the gustatory organs of the tongue and cheeks, and odors released from the separated food rise to the olfactory region of the nose. 'Through the pleasurable sensations aroused by these stimuli the gastric juice is reflexly started flowing in preparation for gastric digestion. Not only in laboratory animals, but also in human beings, this remote effect of pleasurable sensation in the taking of the food has been demonstrated" (t). Hornborg(5) and other research students report cases of gastric fistulæ in children in which the secretion of gastric juice was observed when agreeable food was chewed, whereas the chewing of indifferent material was without influence. Pavlov and Edkins have definitely proved by experimentation that this initial "psychic juice" may be a prime condition for continuance of gastric secretion. According to Cannon(6), another remote effect which may $\mathrm{result}$ from the chewing of agreeable food is the development in the stomach of a condition of tonic contraction-a state of sustained shortening of the circular muscles which nicely adapts the capacity of the organ to the contents, whatever amount is swallowed. The churning movement of the stomach mixes the food with the gastric juice and pushes the chyme onward into the

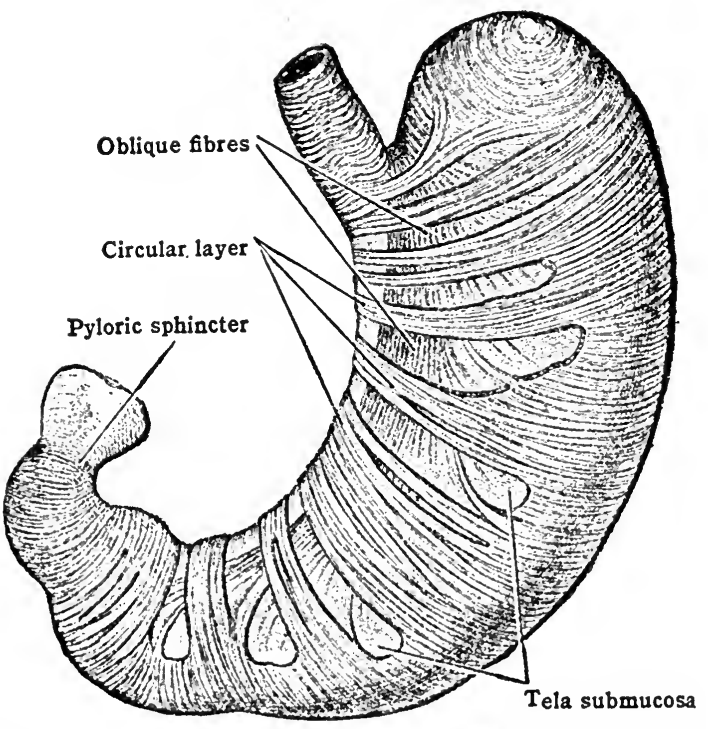

Fig. 13.-Circular Fibers of the Musculature of Tile Stomach.

duodenum. This movement is dependent on the tension developed in the muscular wall as a result of its tonic state.

Insalivation.-Insalivation is a separate and distinct act, performed during mastication, whereby the food is mixed with the secretions of the salivary glands. By this means, the dry, hard portions of food are 
moistened and softened, the better to fit them for swallowing; at the same time the mucous membrane is moistened and lubricated, allowing free movement of the food during the chewing or grinding act. A fever patient attempting to swallow a dry cracker affords an ample illustration of the mechanical value of saliva during the act of mastication.

Saliva is a mixed secretion, a slightly alkaline, viscid and frothy fluid. It is derived from the parotid, sublingual and submaxillary salivary glands and the mucous glands of the oral cavity. Among the formed elements are epithelial cells, salivary corpuscles and bacteria. The presence of mucin is responsible for its stringy and turbid consistency. Saliva has a specific gravity of 1.002 to 1.006 .

STIMULATION AND ACTION OF ENZYMES DURING INSALIVATION.The function of the saliva in the process of digestion has of late received considerable attention at the hands of physiological chemists. Maxwell(7), writing from the physiological laboratory of Melbourne University, suggests that colloidal starch solutions might absorb pepsin in the same way as charcoal and other powders, and hence inhibit the activity of this enzyme. On the other hand, saliva, by hydrolyzing starch, might prevent this absorption of pepsin by the colloidal carbohydrate, serving thus as a material aid to digestion. Maxwell's experiments support this view. He finds that peptic digestion is delayed in the presence of colloidal starch solutions through absorption of the enzyme.

Between the amylodextrin and erythrodextrin stage in the disruption of the starch molecule the absorption of pepsin is lost. Unboiled starch does not hinder the action of pepsin; this is a significant fact in connection with the dietetics of herbivora. Further, cooked farinaceous foods, as rice, potato, bread and porridge, inhibit peptic digestion if not first subjected to salivary digestion. It seems clear, therefore, that ptyalin in human saliva plays a considerable part in aiding gastric digestion by hydrolyzing colloidal starch, which otherwise would absorb pepsin. These observations are of great interest, as they may throw light on the value of active malt extracts and malted foods in dietetics, and particularly in the feeding of infants. It certainly seems an odd physiological fact, as Maxwell points out, that an enzyme should be secreted in the mouth only to be presently destroyed in the stomach, and furthermore, that a more efficient diastase is present in the secretion of the pancreas. The experiments, too, would appear to afford further evidence of the undesirability of the presence of unaltered starch in the infant's diet.

The term "ase" is applied to an enzyme of colloidal structure and is 
suffixed to the name of the substance upon which the enzyme exerts its specific action. Accordingly the word amylase denotes a starch splitting enzyme, while a fat splitting enzyme is known as a lipase. Invertase, found in the small intestine, splits saccharose into glucose and fructose. Moreover, the large intestine contains the Bacillus coli communis which splits up lactose. Lipase or steapsin converts fats into fatty acid and glycerin.

The proteoses are intermediate products between native proteins and peptones. They are only slightly diffusible; they are not coagulated by heat, but can be precipitated. A characteristic of their precipitation is that they can be dissolved by heating, but reappear when the solution cools. They are all soluble in weak salt solutions or dilute acids or alkalies. They are slightly diffusible through animal membranes.

The proteases break up proteins and convert them into peptones and the peptones into amino-acids. The proteases are pepsin, trypsin, erepsin and enterokinase.

According to Ott(8), the stereo-isomeric form of an enzyme is responsible for the manner in which it hydrolyzes the sugar Alpha-methylglucosid and Beta-methylglucosid which are products of glucose and methyl-alcohol. If these two compounds are tested by the enzyme of yeast only the Alpha modification is hydrolyzed, while the Beta modification remains in statu quo. Hence, as Emil Fischer has stated, there must be a special "key to each lock," the ferment being the lock, and its substrate the key. For if the key does not fit exactly to the lock no reaction is possible. The process of hydrolysis is quickened by the working in unison of the ferments.

Temperature greatly influences the amylolytic action of saliva. A low temperature checks or completely arrests its action, while an increase of temperature greatly accelerates its activity. However, after $40^{\circ} \mathrm{C}$, which is considered the optimum point, has been reached, a further rise of temperature becomes injurious. The action of saliva is physical and chemical. Its physical action has been discussed. To ptyalin is due its chemical or amylolytic action, for ptyalin belongs to the amylolytic or starch splitting enzymes. When mastication or insalivation of food is going on, the starch is first split into dextrin and maltose, while the dextrin is subsequently converted into maltose; erythrodextrin is acted upon more quickly than the other kind of dextrin termed achroödextrin. The conversion of erythrodextrin into maltose gives a red color reaction with iodin; if achroödextrin is used no color with iodin results.

The amylolytic action of saliva is most effective at about the tem- 
perature of the body; its action most thorough in a neutral medium. Alkali presert in a small amount does not deter its action to any appreciablc extent, but a relatively very small quantity of free acid will absolutely inhibit its action. It may be stated that the normal condition of the mouth is, to a slight extent, alkaline or neutral. Swallowed saliva converts starch into sugar in the stomach and this process continues for a certain time, the time ranging perhaps from fifteen to twenty minutes. The transformation then ceases, owing to the fact that the amylolytic action of ptyalin of the saliva is stopped by the hydrochloric acid secreted by the peptic glands of the stomach. The acid which is at first poured out nentralizes the alkalinity of the saliva which is combining with the protein of the food. When free acid appears in excess, as has been said before, ptyalin is destroyed and the amylolytic action is arrested altogether. Recent researches have proved that the transforming continues in the stomach for some time after its entry, the time ranging from fifteen to thirty minutes-that is, until (a) the alkalinity of the saliva has been neutralized and $(b)$ until a trace of free hydrochloric acid remains in excess. Free hydrochloric acid does not occur in the stomach until about three-fourths of an hour after a meal.

The researches of Pavlov have made clear several mooted points. He has demonetrated by practical experiments on the submaxillary ducts of the dog that the secretion of saliva is a reflex action. He found that the sight of food, its smell, the chewing of meat or acid, or even the introduction of sand into the mouth, caused such a reflex action as "the mouth to water." Similar experiments on the parotid secretion gave very different results. These showed that the parotid reacts to some extent when dry meat or bread is offered or placed in the mouth. Dry food in the form of meat powder was found to stimulate a free flow of parotid secretion in a hundred $\operatorname{dog} \mathrm{s}$, while moist food excited but little secretion of saliva. 'The importance of the psychical element with respect to the secretion is shown by observation of the gastric juices, as is also the arlaptive capacity of the secretory process to the character of the food masticated and to the requirements of the animal.

Deglutition.-Swallowing occurs in the pharynx and esophagus. Here the masticated mouthful is formed into a large moist bolus. The symmetrical contraction of the musculature of these parts aids in the rapid passage of the food downward into the stomach. This act is usually said to comprise three stages.

In the first stage, in which the act is voluntary and usually unconscious, the masticated food passes between the tongue and palate and is 
foreed backward through the fauces to the entrance of the pharynx. The second act of swallowing is the most complicated, because the food must pass the posterior opening of the nasal cavity and the upper opening of the larynx withont entering these orifices. The three constrictors by their contractions are the chief means by which the necessary motive power for the execution of the act is supplied. Thus the temporary closure of the nasal and laryngeal openings is effected. The elevation of the soft palate and uvula in combination with the contraction of the posterior pillars of the fances occlude the nasal openings; the contraction of the aryteno-epiglottic folds performing a similar service for the laryngeal opening. In the third act an undulatory or peristaltic contraction of the esophagus occurs. The second and third acts of deglutition are involuntary. The movement through the esophagus is termed peristaltic or vermicular.

From the anatomical description of the organs of digestion given in the preceding chapter, and from what has been said above, it would appear that the act of swallowing of solid and of liquid foods is muscular and not governed by the law of gravity. Many animals drink "up-hill," so to speak, and some jugglers can drink when standing on their heads. The fact is well known that a thirsty hunter will lie flat on his stomach, head down, with his mouth in the water of a stream many inches lower than his stomach and satisfactorily quench his thirst.

On the other hand, Cannon(9) agrees with the conclusions aimed at by Kronecker and Meltzer as the result of their observations. These were to the effect that water, holding bismuth of subnitrate in suspension, was drunk by the subject and at each swallowing the liquid was projected rapidly through the pharynx and well down into the thoracic esophagus before being lost to view.

Hertz, quoted by Camnon, has recorded that he was able, in fourteen normal persons, to trace the passage of bismuth salt, suspended in milk, all the way to the stomach. After having been "shot rapidly down the greater part of the esophagus," the food was forced slowly into the stomach. Hertz went on to say that in the head-down position fluids ascended the esophagus at approximately one-third the rate of their descent in the upright position. So far as food is concerned, few will be found to disagree with the conclusion of Cannon "that the act of swallowing varies in different animals and with different consistencies of food." With regard to the swallowing of liquids, the suggestion of Meltzer, with which Cannon agrees, appears to meet the situation. That is whether liquids invariably descend at a rapid rate depends on the amount swallowed, the 
force of the swallowing movement and the degree of contraction of the gullet.

The act of swallowing inhibits the vagus center, for deglutition increases the pulse rate. The influence upon the heart beat is dependent upon neither the amount, character, nor temperature of the food swallowed; it is influenced only by the reflex act and the consummation of other acts. Likewise, it also exerts an inhibitory influence upon respiration. This is very evident during rapid drinking, in an animal with a tracheotomy tube.

Nerve Action in Digestive Processes.-The reflex center for the salivary secretion is situated in the medulla oblongata, near the origin of the ninth and seventh cranial nerves. The afferent nerves are the nerves of taste-the chorda tympani and the glossopharyngeal and sensory branches of the trigeminus; the efferent nerves are the auriculotemporal and chorda tympani.

Marckwald(10), referred to by Cannon, is of the opinion that the part of the nervous system to which the afferent impulses travel is placed in the floor of the fourth ventricle, above the center of respiration. Howell points out that "it is assumed that there is a special nerve center, the swallowing or deglutition center, which has been located in the medulla at the level of the origin of the vagi." However, this writer is somewhat skeptical as to the definite existence of such a center. If we agree with Marckwald and others that the center of deglutition is in the medulla, and there are many and strong points in favor of the theory, we may also assume with Cannon "that from this center the motor impulses pass out, which, distributed by a variety of nerves, produce the remarkably rapid and orderly sequence of movements that give the bolus its initial push and continue it on its course."

The motor fibers concerned in this perfectly coördinated and complex mechanism comprise the hypoglossal, the trigeminal, the glossopharyngeal, the vagus and spinal accessory.

Wassilieff(11) made an observation upon himself to determine the most sensitive areas for inducing a deglutition reflex and to ascertain, if possible, the location of special spots in the mouth and pharynx. Wassilieff "swallowed a small sponge moistened in cocain solution and immediately withdrew the sponge by means of a thread attached to it. He found that his ability to swallow was for some minutes entirely lost, and the saliva which was abundantly secreted had to be expectorated." Many observers have endeavored to determine the exact area or areas in the pharyngeal membrane from which the sensory impulses liberating the 
reflex usually start. Kahn is of the opinion that the location of the most effective areas from whose stimulation the reflex may be produced varies in different animals. The conclusions reached as the result of these experiments were that, under normal conditions of ingesting food, the "sensitive spot" can be stimulated either by liquid, buceal contents flowing back upon it when involuntary swallowing oceurs, or by the more or less solid food masses being voluntarily pushed over the base of the tongue and back into the pharynx.

Two mechanisms are necessary to control the course of a bolus of food along the gullet; one requires only a single afferent impulse to start it, the other consists of a succession of reflexes, each provided with an afferent path, leading to a motor discharge; thus the bolus by its very presence causes a contraction which forces it downward towards the stomach. This aceessory mechanism depends on the integrity of the esophageal tube, and has been called the lower reflex mechanism, and its activity secondary peristalsis (12).

Secretion and Action of the Digestive Juices.-We are indebted to Pavlov(13) and Beaumont for original researches into the physiology of the digestive process. It was the former who established the fact of psychic secretion, which we now know to be a most important factor in digestion. It was Beaumont who established the fact that gentle exercise aided the digestive process.

SALIVA.-The process of digestion really begins as soon as the food enters the mouth, and comes in contact with the first digestive fluid-. saliva, which exerts a mechanical chemical action, moistening and softening the food to render easier the task of swallowing it in the form of a bolus. Under insalivation the action of the enzymes found in the saliva have already been carefully discussed. The chemical changes occurring in the mouth during digestion are well worth further careful study. As already stated, the chief aim of digestion in the animal economy is the reduction of the ingested food substances into a soluble and absorbable condition so that they can pass through the intestinal mucosa after terminal digestion has completed the breaking down of the protein and carbohydrate molecules with the saponification of the fats, ready to replace the cellular waste throughout the body.

The salivary juice also has the power to break up materials, as starches, into maltose, a form of sugar. The active transforming principle in saliva is an unorganized ferment or enzyme, to which the name ptyalin has been given. The conversion of starch into dextrin and maltose by the saliva is known as the amylolytic action. Its action is by 
mere contact, as no appreciable change in quality or character is noted in it after its functions are performed, and so active is it that it is able to convert two thousand times its own weight of starch into dextrin and maltose.

Juices of the Stomacil and Intestines.-Secretion.-The first stimulus of gastric secretion originates in the mouth, causing a flow of gastric juice in the stomach; while the furtherance of the flow depends upon the action of what are known as secretagogues.

Howell(14) holds that there are three steps in the mechanism of the secretion of gastric juice: (a) psychical secretion; $(b)$ secretion from secretagogues contained in the food; $(c)$ secretion from secretagogues contained in the products of digestion. Other physiologists hold to the opinion that the secretagogues, whether present in food or formed during digestion, act upon the pyloric mucous membrane, stimulating the production of a substance which they designate as gastrin, and that this substance, after absorption into the blood, is carried to the gastric glands, stimulating them to greater secretion.

Until recent years it was held that the secretion of the gastric juice was chiefly brought about by the mechanical stimulation of the mucous membrane of the stomach by the particles of food introduced into it. The elaborate and ingenious experiments of Pavlov(15), however, have shown that this is an error and that the chief factors concerned in bringing about the secretion of gastric juice are psychical and chemical, and that the mechanical action plays quite a secondary part, if indeed any part at all.

It was shown later, however, independently by Popielski-a pupil of Pavlov-that the injection of acid into a loop of small intestine was followed by secretion of pancreatic juice even after the section of both vagi and destruction of the sympathetic ganglion at the back of the abdominal cavity.

Bayliss and Starling, experimenting along these lines, found that a secretion of juice was produced, even when the acid was introduced in a loop of the intestine entirely free from any possible nervous cornections with the rest of the body. It was evident, therefore, that the stimulus or message from the intestine to the pancreas which causes secretion of the latter must be carried, not by the nervous system, but by the blood stream. After repeated experimentation Starling was convinced that something must be produced in the epithelial cells of the gut under the influence of acid, and that this product of the epithelial cells was absorbed in the blood stream and was the active agent in exciting 
the pancreas. He secured several duodeni from pigs, the mucous surfaces of which were severely scraped and the scrapings pounded with dilute hydrochloric acid. After filtering, he injected the filtrate, produeing a copious flow of pancreatic juice. This chemical messenger, or hormone, he called secretin.

Quality and Quantity of Secretion.-Certain foods contain substances that apparently have the power to augment the secretion of gastric juice -for example, meat extract and meat juices. The various foods also produce gastric secretion of varying digestive qualities; for instance, that produced by bread is less in quantity but of greater digestive power than that produced by meat. The power of producing secretion is entirely wanting in the white of egg. The gastric juice produced by psychic stimulation is always of the same quality. Water constitutes the largest proportion of gastric juice and the daily secretion of gastric juice amounts to one-tenth of the weight of the body. There is little solid matter in the gastric juice of man and animals, considering the very large amount of work done by solid materials in the digestive processes. Of the solids present, about one-half is composed of inorganic salts; the remaining portion comprises the organic ferment, or enzyme, present in gastric juice-pepsin.

A normal gastric secretion, according to Howell, is a clear, thin, almost colorless liquid with a strong acid reaction and a characteristic odor. Starling, however, says the gastric juice taken from' a fasting animal is a pure specimen. This is quite elear, strongly acid and without smell. When free from admixture with food, the acid of gastric juice is entirely hydrochloric. Human gastric juice contains probably about 0.2 per cent of the hydrochloric acid. The presence of this acid is essential to digestion, because pepsin, the active enzyme of the gastric juice, requires an acid medium in which to act. It further contains one, and possibly two, enzymes, renin and lipase. Lactic acid occurs or may occur. According to Ott, "during digestion, lactic, acetic, butyric, and other acids are often present, due to putrefactive changes and the presence of bacteria."

The following analysis of the composition of gastric juice is accepted:

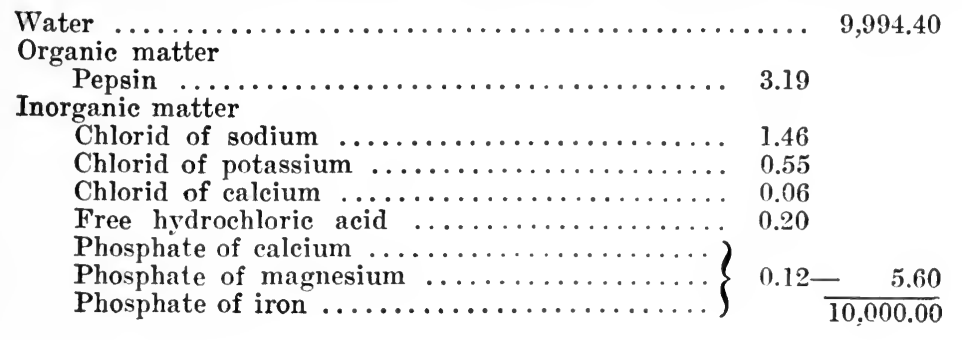


No reliable estimates of the exact quantity of gastric juice or, in fact, of any of the digestive fluids are obtainable and the best approximate estimates vary greatly, according to different authorities. The quantity of gastric juice is sometimes estimated by the amount of pepsin and acid which, outside of the body, are required to digest any measured bulk of food.

Lethby, in carrying out experiments along this line, estimated that in a twenty-four hour period the human stomach secreted 14.11 pounds of gastric juice and 0.44 pound of pancreatic juice. Competent physiologists regard this estimate as wholly fallacious, for the pancreatic juice is much more active than the gastric juice, having ten times the work to do, and the pancreatic gland cells outnumber the gastric cells. Moreover, we know that in the entire human body there are about fourteen pounds of blood, and it does not seem reasonable that a quantity of secretion equal to the whole volume of blood should be formed by a single organ, the stomach. If this were so it would require very rapid reabsorption from the stomach, otherwise it would be a continuously overflowing reservoir.

Correlation of Functions by Chemical Action of Juices.According to Starling(16) a very striking correlation exists between the activities of the body effected by chemical means. The strongly acid chyme enters the first part of the duodenum. The epithelial cells in the mucous membrane, stimulated by the acid, immediately produce a certain amount of "secretin," which is carried by the blood stream to the cells of the pancreas and excite there the secretion of strongly alkaline pancreatic juice. Starling points out that as soon as sufficient juice has been secreted to neutralize the acid chyme, both the formation of secretin and the further secretion of pancreatic juice comes to an end. So long as the stomach contains food, the process is renewed by virtue of the local reflex mechanism which we have alluded to and which will be explained in greater detail in this chapter. So long as the contents of the duodenum are acid, the pylorus remains firmly closed; as soon as these are neutralized the pylorus relaxes and allows the entrance of a further portion of chyme. Thus the secretion of secretin continues afresh, and the whole chain of processes goes on uninterruptedly until the stomach is empty and all the chyme has passed into the intestine.

In studying the process of gastric digestion we have learned that, (a) the chief object of digestion in the mouth is to protect and assist the stomach, and $(b)$ that the function of the stomach is to protect the intestine. Observations upon the results of complete removal of the 
stomach in animals as well as in man have shown that its coöperation with the other organs of digestion cannot be regarded as completely essential to the perfect digestion and absorption of an ordinary mixed diet, provided the food be administered in a suitable form.

Functions of the Stomach.-The stomach serves to perform five important functions:

To act as a receptacle for the chymification of food.

To churn the chymitied food to a semithuid consistency.

To partially sterilize the macerated pultaceous mass.

To regulate the temperature of the stomach contents.

'To bring about some slight degree of absorption.

THE STOMACH AS A RESERVOIR.- As a reservoir the stomach is indispensable, for it allows of the digestion and storing of a considerable quantity of food at a time. That is, it renders meals possible, obviously a great practical convenience. At this point the question of the length of the intervals between meals arises. Hutchison asks: "Is it better to partake of several small meals or to consume one's daily supply of food at one sitting?" He answers that undoubtedly several small meals are far preferable to one or two very large meals and goes on to point out the "one meal a day man" is at a disadvantage, because he is apt in this way to so overburden the mechanical powers of the stomach that some of the constituents of the food are partially wasted; the assimilative powers of the tissues being overworked to keep pace with the flood of nutriment which reaches them at the same time. The chief danger, then, of eating too much at a meal lies in overtaxing the digestive powers of the stomach. In the second place, the habit of eating large quantities of food at a meal is apt to cause dilatation of the organ.

Hutchison emphasizes the fact that in the case of persons of feeble digestive powers the limitation of the quantity of food digested is of even greater importance. For them little and often should be the golden rule.

The same author draws attention to the fact that there is evidence to show that more food is wasted by being used at once than when it is spread over considerable time. "The waste chiefly affects the proteins, which are the most rapidly digested of the constituents of the food, and is partly due to defective absorption and increased opportunity for intestinal putrefaction. Ranke, for instance, found that if he ate 1,800 grams of meat at one time, the loss by the bowel amounted to 12 per cent, but if he ate this same amount in three meals the waste 
was only 5 per cent. The loss of protein must be attributed in part to defective assimilation." The meal hours vary greatly in different parts of the same comntry, depending largely upon convenience and habits in regard to work; but it is conceded that it is best to have dimner, the principal meal of the day, at the end of the day's work, so that comparative repose may be enjoyed after it. As a matter of actual observation, Voit found that 50 per cent of the day's protein, 61 per cent of its fat, and 3:- per cent of its carbohydrate was taken at dinner.

MACERATION OF FOOD in THE STOMACH. - The second function of the stomach is to macerate the food to a semifluid form. This is partially accomplished by the solvent action of the gastric juice, and partly by the mechanical movements of the stomach walls. In studying the movements of the stomach one must distinguish quite sharply between the cardiac and pyloric ends of the organ. There is no doubt that this distinction is not grasped as clearly as it should be. The two ends are distinct, both anatomically and functionally. The cardiac end secretes both pepsin and hydrochloric acid, the pyloric end pepsin alone; the former has but feeble motive power; the movements of the latter are frequent and powerful.

The experiments of Beaumont(17) confirm the above statement. According to this investigator the result of his experiments upon a human stomach as stated by $\operatorname{Ott}(8)$ was to ascertain that a very feeble peristaltic condition begins at the cardiac orifice, and proceeds towards the pylorus by way of the greater curvature, for only along it is any movement apparent. The wave grows stronger until the special band separating the antrum from the fundus is reached, when the contraction becomes so strong that the stomach presents an hour-glass appearance. Immediately the entire antrum contracts at one time as a unit; so that, if the contents are properly acted upon by the gastric secretion, they are propelled by this movement through the pylorus into the duodenum.

Movemexts of the Stomacin.- With regard to the movements of the strmach it must be borne in mind that the stomach not only acts as a reseroir, but, as Cannon has pointed out, is also the seat of important preparatory stages of digestion. In fact, the movements of the stomach are hest studied by Cannon's method of direct observation of the movements in a living unanesthetized animal by means of the Röntgen rays. Of conrse, to entirely comprehend the movements of the stomach one must he familiar with the anatomy of the organ. Cannon quotes from a paper on the subject ontributed by Cunningham to the Transactions of the Roynal Soriety of Edinburgh in 1906. In 1898, Williams and 
Cannon made observations on the changes of form of the normal human stomach during digestion. "They found that whilo early in the process of gastric digestion, when the subject was standing, the greater curvature might reach several centimeters below the umbilicus-the pylorus being then considerably below this level-in the later stages, as the stomach shortens, the pylorus becomes the lowest point. The changes suggested that the contraction of the longitudinal and oblique fibers between the two fixed points - cardiac and pylorus-resulted in a tendency for the lumen to take a more nearly straight course between the two orifices."

That the normal stomach is a reservoir with the pyloric outlet its lowest point, is held by some. This view is in keeping with a conception that has prevailed among surgeons who assume that, with the relative positions of the stomach and pyloric outlet

Fig. 14.-Series of Radiograpits Showixg The DLASTOLE A.ND Systole in the MechaNical Movemexts of the Stomacir. (Morris' "Human Anatomy.")

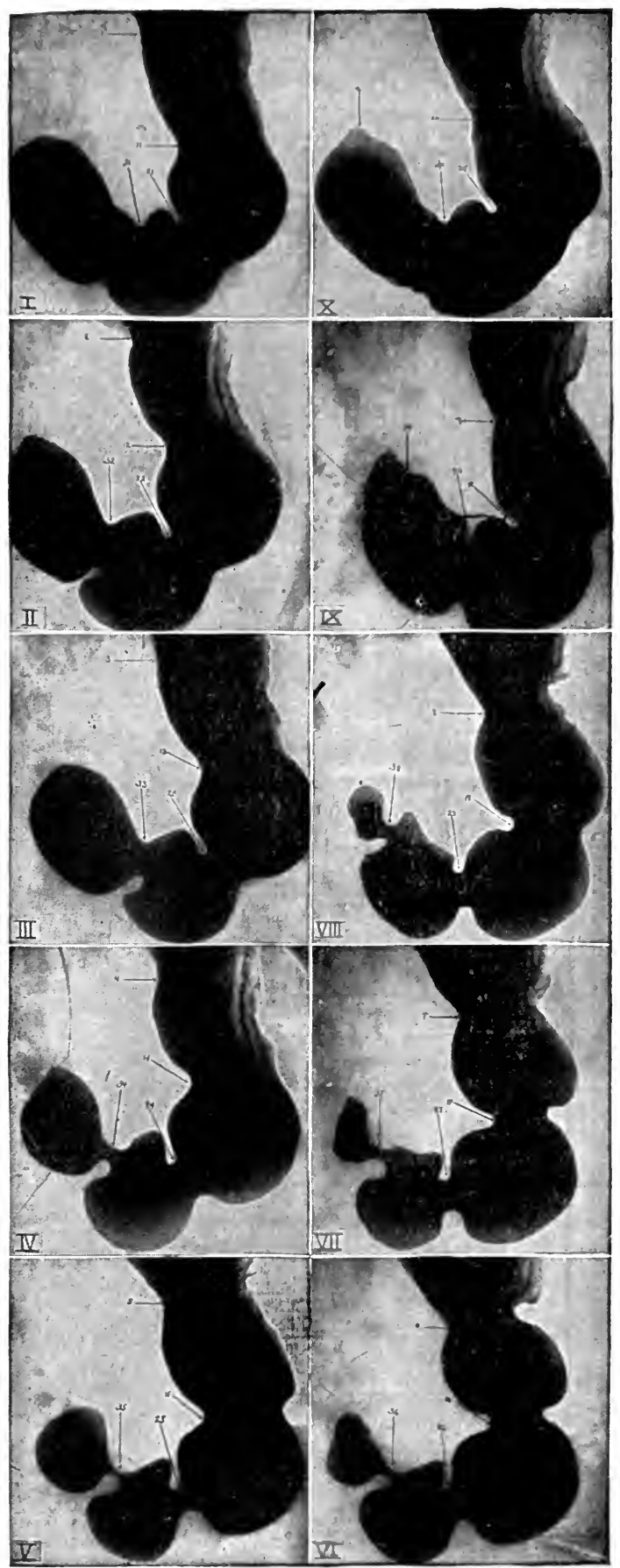


as stated above, the stomach is emptied by gravity drainage. Cannon contends that this view is fallacious, pointing out in support of his assertion that in the "obviously normal stomach of the dog or cat the pylorus is at nearly the highest point when the animal is in the standing position, and that the so-called 'normal' human stomach could remain satisfactory for gravity drainage only so long as a person held the upright position or lay on his right side." Hence the theory that the emptying of the stomach is regulated by gravity may be considered erroneous.

It has been mentioned that observation of these movements is rendered possible by the use of the x-ray. This is known as Cannon's method. Bread and milk, mixed with a quantity of bismuth subnitrate or bismuth oxychlorid, is given to a cat in such a way as to make the shape of the stomach visible. When the stomach of a cat, which has just taken such a meal, is examined by this method, the whole of the food is seen to be lying in the fundus. The "transverse band" marks it off from the pyloric portion. As digestion proceeds, the change of form in the pyloric portion is relatively slight. The first region to decrease in size is that part of the body of the stomach over which these waves are passing. As food is discharged into the intestine, the circular muscle of this middle region of the stomach contracts tonically until a tube is formed, with the full cardiac pouch at the upper end and the active pyloric portion at the other. Along the tube shallow peristaltic waves still continue. At this point the radiating fibers at the cardiac end begin to squeeze the contents into the tubular portion. This process, accompanied by a slight shortening of the tube, continues until the shadow cast by the contents is almost obliterated. The waves of constriction moving along the tubular portion press the food onward as fast as they receive it from the contracting cardiac pouch, and when the pouch is at last emptied they sweep the contents of the tube into the vestibule. There the operation is continued by deeper constrictions, until finally nothing but a slight trace of food is to be seen in the cardiac end. The changes in the human stomach, as revealed by $\mathrm{x}$-ray and post-mortem examinations, are very similar to these.

Regarding gastric peristalsis, two views have long been held. One is that the stomach is completely divided at the transverse band by each recurrent wave; the vestibule then contracts simultaneously in all parts in a systolic manner. The other and newer view is that the waves sweep from their origin to the pylorus, and do not partition the stomach into two chambers. 
Cannon presents and examines the evidence for and against these views, and after a careful analysis of these arguments, sums the subject up thus: he acknowledges that the evidence does definitely prove that the circular muscle at the commencement of the pyloric portion would be capable of powerfully contracting and completely dividing the gastric lumen; but he argues that what the stomach might be capable of doing is no proof of normal functioning, and after carefully weighing the evidence and judging from his own observations he concludes that no complete division of the stomach at the transverse band normally exists, and that when it does occur it is produced as the result of unnatural stimulation.

Stress is laid by Cannon on the importance of a correct conception of the movements of the pyloric portion because of its significance for our understanding of the functions of this part of the stomach. "If the transverse band completely closes the lumen, and the vestibule then undergoes a systolic contraction, the function of this portion must be mainly one of expelling the food into the duodenum. On the other hand, if the waves sweep without interruption over this region, deepening as they go, they may have two functions-that of expelling the food if the pylorus opens, and that of mixing the food with the gastric juice if the pylorus remains closel." Cannon also believes that we are justified in concluding that the restibule has a more important function than that of merely expelling gastric contents into the intestine. Ewald is of the opinion that the plain fact- "that the pyloric portion secretes a strong digestive fluid-proves it to be an important part for the peptonizing portion of the stomach."

Pyloric Action.-It will be apropos to introduce here the manner in which the pyloric portion performs this function. Cannon holds that absorption is concerned with the function of the churning action in the vestibule brought about by the activity of the vestibular mucosa aroused by the presence of acid, peptone or sugar solutions. While water is not absorbed in the stomach, glucose in concentrated solutions and proteins which have been exposed to gastric digestion may be absorbed in considerable amount. Owing to the fact that the mucosa of the restibule has many less glands than the mucosa of the cardiac end, the absorption that occurs in the stomach probably takes place in the vestibule, for the epithelial surface there is most favorable to the process. Also gastric digestion is there most advanced and consequently the food is most ready for passage through the mucosa. Moreover, in the vestibule the mechanical conditions favor absorption, for the reason that the digested food is repeatedly brought into very close contact with the mucous lining. 
In ease the pylorus does not relax before an approaching wave, the food camnot escape and is squeczed back into a fluid, contractile pouch, forming an axial reflex stream towards the eardiac end. Cannon, at a meeting of the Boston Society of Medical Sciences, May 20, 1902, demonstrated a method of showing the churning action of the stomach and the antivities of other parts of the alimentary canal by means of the roetrope. He is inclined to agree with the older writers on physiology who attributed to the pylorus a selective action. According to their views, the region of the sphincter was supposed to possess a peculiar sensitiveness which eaused it to prevent the passage of undigested material into the duodenum. More modern investigators-Hofmeister, Sichut\%, and Moritz-have denied the existence of any such function, and have asserted that antiperistaltic waves carried solid particles from near the exit of the stomach back to the cardiac end. However, from ohservations made by Cannon, it appears that the old writers were correct, for the action at the pylorus as viewed by him was similar to that described in the older works on physiology.

So far as he was alle to judge "there was no antiperistalsis and the sphincter scparating the fluids from the solids caused the solids to remain and undergo a tireless rubbing. The presence in themselves of peristaltic waves on the right half of the stomach and their absence from the left half indicate two separate parts of the stomach." The evidence now before us-and Cannon emphasizes this point-shows that these two parts have distinct functions. The left half is a reservoir in which the food is not mixed with the gastric secretion. "From this side the contents are slowly pressed ont into the active half." The peristaltic waves coursing over the right half mix the food with the gastric juice, expose it to the mucosa of the vestibule for absorption and for the continuance of gastric secretion, churn the unbroken particles of food until they are tritirated and, finally, expel the chyme into the duodenum.

With regard to the opening of the pylorus, Starling(18) states that "this depends not only on intragastric events, but also on the condition of the dundenum." It has been shown by Serdjukow "that the pylorus remains firmly closed so long as the contents of the duodenum are acid. If alkaline fluid is introduced into the stomach, this is rapidly passed into the duodenum. If at the same time, however, some acid is introduced into the duodenum by means of a duodenal fistula, the pylorus remains firmly closed and no fluid passes into the duodenum until the acid which was placed there has been nentralized by the secretion of pancreatic juice and sucens entericus." From this fact Starling premises that we have 
probably in the walls of the alimentary canal at local nervous mechanism for the movements of the pylorie sphincter, which maly be played on by impulses starting either in the stonach or in the duodenum, probably by the contact of acid with the mueous membrane. Inereasing acidity on the side of the stomach causes relaxation of the orifice, whereas acidity on the duodenal side causes contraction of the pyloric sphincter. Starling confesses that the exact parts played in this mechanism by the local system and by the central nervous system respectively have not yet been thoroughly interpreted, although there is no doubt that these movements may proceed independently of any connection with the central nervous system.

Cannon has confirmed, by numerous observations, the conclusions reached as the result of his first obscrvations on the stomach, namely, that in normal conditions gastric peristaltic waves are continuously running, so long as food remains in the organ.

As to the appearance of gastric peristalsis, it may be noted that this part of the stomach movements has received but little attention. In the experiments of Hedbloom and Cannon(19), "the feeding of acid food was attended by especially deep and rapid peristaltic waves, while the feeding of fatty food which inhibits gastric secretion was usually attended by relatively shallow gastric waves. Although there is this evidence of concomitant variation of acid gastric contents and peristalsis, according to Cannon's views, it is not proof that the waves are the result of an acid stimulation. He is disposed to beliere that the causal relation does not exist between secretion and peristalsis, but between those two and a common antecedent factor." So far as the movements of the stomach are concerned these points stand out somewhat prominently: first, the stomach is not merely a reservoir, but is in itself a place of active digestion; second, it is not emptied by gravity drainage; and third, the stomach is only completely divided at the transverse band when unnatural stimulation is exercised. It may be pointed out that the cardiac sac is an active reservoir which presses out its contents little by little as the churning mechanism in the pyloric end is ready to receive it.

There is a good deal yet to be learned concerning the movements of the stomach and, perhaps, especially with regard to gastric digestion. Opinions of investigators by no means coincide on this point, or rather, it might be more correct to say, with regard to certain details. On the whole, the views of Cannon are regarded as most worthy of respect because he was a pioneer in methods of observing the stomach movements 
with accuracy. It has not been the intention of the author to deal with the movements of the stomach exhaustively or very closely, but rather to discuss the matter in a broad way, drawing attention to points which he has considered of the greatest importance and to the opinions of the best known authorities.

STERILIZATION OF FOOD.- "Another function of the stomach is that of partially stcrilizing the food by the antiseptic action of the hydrochloric acid and the gastric juice. This action, however, is not a powerful one and some organisms, such as those that form acids, seem to escape it altogether. There is reason to believe that the same is true of at least some of the commoner pathogenic organisms-notably the tubercle bacillus." Hutchison further states:

"The sterilizing power of the stomach must vary greatly according to the period of digestion and the nature of the food. It probably reaches its maximum towards the later period of digestion when hydrochloric acid is present in the free state, while it is much less, or even absent altogether, in the earlier stages when all the hydrochloric acid is in a combined form. Food rich in protein, by fixing the hydrochloric acid, must greatly lessen the germicidal power of the gastric juice. Over the growth of organisms in the intestine the stomach seems powerless to exert any control. Even in cases in which the secretion of hydrochloric acid is entirely arrested, or in which the stomach has been completely removed, no increase in the amount of intestinal putrefaction was found to occur."

REGULATION OF TEMPERATURE.-The stomach exercises the function of regulating the temperature of food and drink, thus serving as a protector of the intestine, which appears to be more seriously affected by extremes of temperature than the stomach itself.

The activity of the peristaltic movements of the stomach may be controlled by chemical messengers, hormones, in the circulation, although the temperature of the ternary food elements may also either inhibit or augment gastric peristalsis. Even mere mechanical contact seems to exercise some little stimulating effect. Hot food is more agreeable and stimulates the frequency and vigor of gastric peristalsis; cold food excites gastric activity much less.

The local effects of extremes of temperature in the stomach are very much the same, whether the extreme be one of heat or of cold. In each case there is danger of exciting gastric catarrh. Very hot foods seem to be specially dangerous in stomach bleedings-e.g., ulcer; and some anthrities say that the speeial liability of cooks to suffer from gastric 
ulcer is to be attributed to their constantly tasting very hot foods. On the other hand, it is claimed that very warm fluids may relieve pain in the stomach by abolishing pyloric spasm.

ABSORPTION OF FOOD.-Hutchison points out that the powers of absorption of the stomach are notorionsly and surprisingly small. This may be a provision of nature designed for the protection of the body. The stomach, in addition to its digestive functions, acts as a testing laboratory for food, as, owing to its extremely deficient absorptive powers, it has time to neutralize or to reject injurious substances before they can enter the blood. Alcohol is the substance which the stomach absorbs most readily, a fact which partially explains its stimulating action. Most of the anthorities on the subject are of the opinion that the process of absorption by the stomach is rather of the character of a physical osmosis than it is in the case of the intestine. A large quantity of secretion is poured out during the process, which Hutchison suggests may account for the fact that a mixture of alcohol and sugar, such as is found in sweet wines and some malt liquors, may cause "acidity" of the stomach.

The question of absorption, from its physiological standpoint as well as its practical bearing on dietetic treatment of disease, will be fully considered in Volume III of this work.

\section{REFERENCES}

1. Cannon, W. B. The Mechanical Processes of Digestion.

2. Fermi. Arch. f. Physiol., 1901, 98.

3. Gaudenz. Arch. f. Hyg., 1901, xxxix, 231.

4. Pavlov, Ivan Petrovich. The Work of the Digestive Glands, London, 1902, 50.

5. Hornborg. Skandin. Arch. f. Physiol., 1904.

6. Cannon. The Mechanical Factors of Digestion, Edward Arnold, London, 1911.

7. Maxwell. Bio-Chem. J., Liverp.

8. Отт, I. Text-book of Physiology.

9. Cannon, W. B. The Mechanical Factors of Digestion.

10. Marckwald. Ztschr. f. Biol., 1889, xxv, 46.

11. WassiliefF. Ztschr. f. Biol., 18s8, xxiv, 39-40.

12. Meltzer. Proc. Soc. Exper. Biol. \& Med., New York, 1907.

13. Pavlov, Ivan Petrovicir. The Work of Digestive Glands, translation by Thompson, London, 1902; Ergebn. d. Physiol., 190t, Part I; Arch. internat. de physiol., 1904, i, 119 ; Am. J. Physs., 1906, xvii, 142. 
14. Howris, IT. H. Text-book of Physiology.

15. Paviov. I) Ar Arbeit der Verdaumgsdrüsen, Wiesbaden, 1898, 6. (Parlov's chief results have been confirmed, in the case of the human subject, by Schuler's article, "In wie weit stimmen die Experimente von Pavlov am Hunde mit den Befunden am normalen menschlichen Magen überein?" Deut. Arch. f. klin. Med., 1901, lxxi, 111.)

16. Starlixg. Recent Advanees in the Physiology of Digestion, Chicago, 1906, 132.

17. Bealnont. Physiology of Digestion, Plattsburgh, 1833, 110.

18. Starling. Principles of Human Physiology.

19. Henbloom and Canvon. Am. J. M. Sc., 1909, exxxviii, 518.

\section{BIBLIOGRAPHY}

Bayliss and Starling. J. Physiol., 1899, xxiv, 103, 142; ibid., 1901, xxvi, 127, 134; ibid., 1902, xxviii, 325 ; Centralb. f. Physiol., $1901, \mathrm{xv}, 682$.

Bealmont. Physiology of Digestion, Plattsburgh, 1833, 110, 115.

Caxyon, W. B. The Mechanical Factors of Digestion.

The Correlation of the Digestive Functions, Boston M. \& S. J., 1910, elxii, 97.

Am. J. Physiol., 1898, i, 367, 374, 377, 379; ibid., 1902, vi, 262 ; ibid., 1902, vii, 22 ; ibid., 1903, viii, 21, 22 ; ibid., 1904, xii, 392, 393; ibid., 1905, xiv, 344; ibid., 1906.

- and DAy. Am. J. Physiol., 1903, ix, 396.

and Hedrloom. Am. J. M. Sc., 1909, cxxxviii, 518. and Moser. Am. J. Physiol., 1898, i, 440.

Chittenden, Meniele, and Jackson. Am. J. Physiol., 1898, i, 207. Enkixs. J. Physiol., 1906, xxxiv, 133.

Ellifabercier and Golimscimint. Ztschr. f. physiol. Chem., 1886, $x, 384$.

Eutenberrek and Hofmeister. Arch. f. wissensch. u. prakt. Thierh., 1882, viii; 188., ix; 1884, x, 6; and 1886, xii, 126.

Eillotet. J. Physiol., 1904, xxxi, 157. and Parclay-Smitil. J. Physiol., 1904, xxxi, 272.

EWali and Boss. Arch. f. path. Anat, 1885, ci, 365.

FYкMAx. Arch. f. d. ges. Physiol., 1903, xcix, 521.

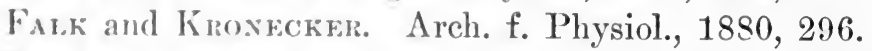

Fiscuere and Amperindiden. Ztschr. f. physiol. Chem., 1903, xl, 216. 
Henderson. Am. J. Physiol., 1909, xxiv, 71.

Honvorg. Skandin. Arch. f. Physiol., 1904, xv, 248.

Keitr. Sys. of Med., 1907, iii, 860 .

Kunne, W. Lehrb. d. physiol. Chem., Ieipzig, 1868, 53.

Lang. Ztschr. f. physiol. Chem., 1905, xlvi, 225.

London and Sulina. Ztschr. f. physiol. Chem., 1905, xlvi, 215.

MacFadyen, Nencki, and Sieber. J. Anat. and Physiol., 1891, xxv, 393.

May. J. Physiol., 1904, xxxi, 270.

McClure and Deree. Johns Hopkins Hosp. Bul., 473, 1907, xviii.

Mering. Verhandl. d. Cong. f. innere Med., 1897, xv, 433.

Mueller. Arch. f. d. ges. Physiol., 1907, cxvi, 253.

Munk. Centralbl. f. Physiol., 1902, xvi, 33.

Openchowsiri. Centralbl. f. Physiol., 1899, iii, 4.

Oser. Ztschr. f. klin. Med., 1892, xx, 288. (He states that vagus stimulation completely closes the open pylorus.)

Pavlov. The Work of the Digestive Glands, London, 1902, 50, 97, 103 ;

Fermi, Arch. f. Physiol., Suppl., 1901, 76.

- Am. J. Physiol., 1902, vi, 36-100.

Schrff. Physiologie de la Digestion, Florence and Turin, 1867, ii, 326. Sherrington. Schafer's Text-book of Physiology, Edinburgh and London, 1900, ii, S51.

Starling. Recent Advances in the Physiology of Digestion, Chicago, 1906, 132.

- Schafer's Text-book of Physiology, Edinburgh and London, 1900 , ii, 329 .

Tobler. Ztschr. f. physiol. Chem., 1905, xlv, 195.

Volkmanx. Wagner's Handwörterb. d. Phýsiol., 1844, ii, 586.

Wrlliams. The Roentgen Rays in Medicine and Surgery, New York, 1901, 360, 365, 370 . 


\title{
CHAP'TER VI
}

\section{THE PHYSIOLOGY OF EN\%Y IIS AND HORMONES AS AP- PLIED IN THE PR()(LSS OF DIGESTION}

\author{
Arthur W. Weysse, Pir.D., M.D.
}

\begin{abstract}
Ferments.
Nature of Enzymatic Processes: Specific Action; Temperature Control; Reversibility.

Classification of Enzymes: Proteolytic enzymes-Trypsin, Pepsin; Amylolytic enzymes-Amylopsin; Fat-splitting enzymes-Lipase; Sugarsplitting enzymes-Invertase, Lactase; Peptolytic enzymes-Erepsin; Coagulating enzymes; Oxidizing enzymes; Hormones-Secretin, Gastrin.
\end{abstract}

Gastric Digestion.

As pointed out in the previous chapter, the digestion of food takes place through a number of complex chemical changes brought about in the alimentary canal by the action of certain unorganized ferments referred to physiologically as enzymes. These chemical changes give rise to alterations in the physical properties of food. The two combined permit the assimilation of the true food substances with the rejection of the waste products as refuse. Enzymes are products of protoplasmic changes; they are complex substances, the exact nature of which has not been determined.

Ferments.-The term fermentation was applied first to the change of sugar into alcohol and carbonic acid by the agency of yeast. A common definition of a ferment is that of a body which when added to a chemical system is capable of bringing about changes in that system, without either imparting energy to the reaction, being consumed itself or having any share in the formation of the end products.

According to Starling, minimum quantities of ferment can induce chemical changes involving almost indefinite quantities of other sub- 
stances, the only result of increasing the quantity of ferment being to quicken the rate of change. Since ferments are effective in minimum doses, they occur in living tissues in minute quantities, and it is due partly to this fact that up to the present time it has proved impossible to procure any preparation of a ferment which could be regarded as a pure substance. Moreover, the difficulty of isolating them is increased by the fact that all of them are colloidal or semi-colloidal in character, and consequently present the tendency common to all colloids of adhering to other colloidal matter as well as to surfaces such as those presented by a precipitate.

Referring again to the term fermentation, it may be pointed out that the evolution of carbonic acid causes frothing and bubbling, hence the name fermentation; yeast, the agency which brings this about, was denominated the "ferment."

APPLICATION TO THE "GERM THEORY."-It is interesting in this connection to note that the "germ theory" of disease offer's an explanation of the origin of infectious diseases by considering that the change in the system is of the nature of fermentation, enzyme action produced by microbes. Infection is caused by the direct conveyance of living pathogenic microörganisms or their products from individual to individual.

It is only within recent times that it has been known how chemical changes were effected by the germ action. It is, however, now a matter of common knowledge that they do so by producing agents of a chemical nature which are termed enzymes. Pasteur showed in his now classical researches that the activity of living organisms was the eause of fermentative action, that is, in the former sense of the word, alcoholic, acid, and putrefactive, and he demonstrated the point just touched upon that many diseases are likewise due to the activity of minute living organisms.

Nature of Enzymatic Processes.-It has been shown that there is no essential difference between the activity of living, or organized, and nonliving, or unorganized, ferments. As Howell points out, the so-called organized ferments probably produce their effects not by virtue of their specific life metabolism, but by the manufacture within their substance of specific enzymes. If this conclusion can be accepted, then the general explanation of fermentation is to be sought in the nature of the enzymatic processes. 'The usual standpoint nowadays from which the mode of action of enzymes is regarded is that advocated chiefly by Ostwald. He assumes that the enzyme actions are similar to those of catalysis. A catalyzer may be defined as a substance which alters the velocity of a reaction, but does not initiate it. The subject of enzymic action is so nearly analogous to 
that of inorganic catalytics that the general opinion considers the former action a catalytic one.

Already, although perhaps it may seem somewhat like putting the cart before the horse, the catalytic theory appears to have most of the weight of evidence on its side. Nevertheless it may still be termed a theory.

ACTION OF Exz'MES. - According to Starling, it may be concluded that in the action of enzrines on the food substances, whether fat, carbohydrate or protein, an essential factor is the combination of the enzyme with the substrate, the substance upon which the enzyme acts. Only that part of the substrate which is thus combined with the enzyme can be regarded as the active mass and as undergoing the hydrolytic change. What is the nature of this combination? Enzymes, which are all of a colloid or semicolloid character, cannot be dealt with in the same way as the catalysts of definite chemical composition, such as molybdic acid or nitrous oxid. In many cases the substrate, e.g., starch or protein, is also colloidal, and the combination therefore falls into the class of combinations between colloids. In this way we have an interaction between two substances in which the absorption by the surfaces of the molecules of one or both substances plays an important part, although this absorption is itself determined or modified by the chemical configuration of the molecules. In the opinion of Starling, therefore, the combining of ferments with their substrates belongs to that special class of interactions not entirely chemical and not entirely physical, but depending for their existence on a cooperation of both chemical and phrsical factors. The combinations formed may be denominated as absorption compounds.

Enzymes are active and inactive. A large number of enzymes exist inactive within the cell, and even when contained in secretions are still inactive. Other enzymes are in a constant state of preparedness for immediate action: The inactive ones are spurred into activity by substances known as activators or co-enzymes. The essential facts regarding enzyme action may be tabulated in the following way:

\begin{tabular}{|c|c|c|c|}
\hline Living Cell & Enzyme Produced & Substrate & $\begin{array}{c}\text { Products of the } \\
\text { Action }\end{array}$ \\
\hline & & & $\begin{array}{l}\text { Aleohol and carbon } \\
\text { dioxid }\end{array}$ \\
\hline Salivary cell & Ptyalin & Cooked starch & Dextrin and maltose \\
\hline Gastric cell & Pepsin & Protein & $\begin{array}{l}\text { Proteoses, peptones } \\
\text { and amino-acids }\end{array}$ \\
\hline
\end{tabular}


Classification of Enzrmes According to Their Activity.-The enzymes which play a part in the digestion and absorption of food may be grouped somewhat roughly as follows:

(a) Proteolytic enzymes, those which, acting upon proteins, split them into proteoses, peptones and polypeptids, and finally into aminoacids. Examples in animals are pepsin, of the gastric, and trypsin, of the pancreatic, juice. In plants a like enzyme exists: bromelin in the pineapple and, finally, papain in the pawpaw.

(b) Amylolytic enzymes, those which convert starches (polysaccharids) into sugar with intermediate dextrin. Thus, ptyalin found in the saliva of animals is an example, while the diastase of vegetable seeds is the corresponding enzyme in plant life.

(c) Lipolytic enzymes, or fat-splitting enzymes, those which split neutral fat into glycerol and fatty acids. Lipase found in the pancreatic juice is an example from the animal species. Many seeds contain enzymes of a similar nature.

(d) Sugar-splitting or inverting enzymes, those which convert disaccharids into monosaccharids. Examples are invertase of yeast cells and invertase of the intestinal juice, which convert sucrose (cane sugar) into equal parts, glucose and fructose, otherwise known as dextrose and levulose. Invertase is also found in the small intestine. Other enzymes split the monosaccharids by hydrolysis.

(e) Peptolytic enzymes, those which split proteoses and peptones into polypeptids and amino-acids. An example is trypsin of the intestinal juice.

(f) Coagulating enzymes, those which convert soluble into insoluble proteins. Thrombin, which converts the soluble protein fibrinogen into. fibrin and rennin, the milk-curdling ferment, are examples of the coagulating ferments.

(g) Oxidizing ferments or oxidizing enzymes, those which produce oxidation and are mainly found as intracellular enzymes.

The following list is by no means complete, but includes most of the more important enzymes, the existence of which has been definitely established in the human body. It will be observed that the majority of them are involved in the processes of digestion in the alimentary canal. This preponderance of enzymes concerned in the digestive and absorptive processes is merely due to the fact that more is known regarding digestion than about other chemical processes which take place within the cells of the body. Some of these individual enzymes will be considered later, 
PARTIAL LIST OF THE ENZYMES CONCERNED IN THE PROCESSES OF DIGESTION AND NUTRITION 1

Act on Carbohydrates $\left\{\begin{array}{c}\begin{array}{c}\text { Enzyas } \\ \text { Ptyalin (salivary dia } \\ \text { Amylase (pancreatic } \\ \text { (diastase) } \\ \text { Iiver glyeogenase } \\ \text { (diastase) }\end{array} \\ \text { Invertase (suerase) } \\ \text { Maltase } \\ \text { Lactase } \\ \text { Glycolytic (?) }\end{array}\right.$

Act on Fats........ \{ Lipse (steapsin)

Act on Proteins..... $\left\{\begin{array}{l}\text { Pepsin } \\ \text { Trypsin } \\ \text { Erepsin } \\ \text { Group of autolytic enzymes }\end{array}\right.$

Nucleases

Deaminizing Enzymes. $\left\{\begin{array}{l}\text { Guanase } \\ \text { Adenase } \\ \text { Deaminase (?) }\end{array}\right.$

Oxidase

Reductase

\section{Catalase}

Arginase

Act on Proteins..... $\left\{\begin{array}{l}\text { Secretin } \\ \text { Gastrin }\end{array}\right.$

1 Howell, W. H. "Text-book of Physiology."
Where Chistry Found

Salivary secretion

Pancreatic mecretion

Liver

Muscles

Small intestine

Sinall intestine, salivary and pancreatic secretion

Small intestine

Muscles (?)

Pancreatic secretion, fat, Splits neutral fats into fatty tissues, blood, etc.

Gastric juice

Pancreatic juice

Small intestine

Tissues gencrally Pancreas, spleen, thy-
mus, etc.

Thymus, adrenals, pancreas

Spleen, pancreas, liver

Tissues generally

Lungs, liver, muscles, etc.

Tissues genes ally

Many tissues

Liver, spleen

Duodenum Pyloric mucous mer.s-
brane
Acrion

Converts starch into sugar (maltose)

Converts starch into sugur (maltose)

Converts glycogen into dextrose

Converts glycogen into dextrose

Converts cane sugar into dextrose and levulose

Converts maltose into dextrose

Converts lactose into dextrose and galactose

Splits and oxidizes dextrose

acids and glyceriu

Converts protein into peptones and proteoses

Splits proteins into their eonstituent amino-acids

Splits peptones and proteoses into their constituent amino-acids

Splits proteins into nitrogenous bases and aminobodies

Splits nucleic acid with formation of purin bases, etc.

Converts guanin into xanthin by splitting off an $\mathrm{NH}_{2}$ group as ammonia $\left(\mathrm{NH}_{3}\right)$

Converts adenin to hypoxanthin by splitting off an $\mathrm{NH}_{2}$ group as ammonia $\left(\mathrm{NH}_{3}\right)$

Splits off the $\mathrm{NH}_{2}$ group from the amino-acids with the formation of non-nitrogenous organic acids

Causes oxidation of organic substances, as in the conversion of hypoxanthin to xanthin and of xanthin to uric acid

Causes reduction or deoxidation as, for example. the reduction of oxyhemoglobin to hemoglobin

Decomposes hydrogen peroxid

Splits arginin with production of urea and ornithin (diaminovalerianic acid)

Stimulant to panereatic secretion

Stimulant to gastric glands 
but for the present the question of the enzymes will be only dealt with in a general way.

Specific Action of Exzrans.-According to Halliburton, the specific action of enzymes is as a rule remarkably definite and narrow. The hydrolysis of the three principal disaccharids, cane sugar, lactose and maltose, is effected by three separate enzymes, none of which will hydrolyze the remaining two sugars. For example, arginin is split by arginase into ornithin and urea, but arginase will then act on arginin alone. As Halliburton has pointed out, the simile of the "lock and key," first introduced by Emil Fischer, will enable us partly to comprehend this action. There must be a speeial key to each lock; in a similar way the chemical configuration of an enzyme must be in certain respects related to the configuration of the substrate to allow it to enter and unlock its parts so that they are loosened from one another.

Temperature.- Halliburton has drawn attention to the optimum temperature of enzyme action which is as follows. He states that, "With the rising of the temperature the velocity of the action increases, until a temperature is reached at which the activity is greatest. Most enzymes act best at $40^{\circ} \mathrm{C}$., but there are exeeptions. For instance, malt diastase acts best at $60^{\circ} \mathrm{C}$. Beyond the optimum temperature a further rise inhibits activity, until a temperature is reached which destroys the enzyme. This fatal temperature, as a rule, is in the neighborhood of $50^{\circ} \mathrm{C}$. The effect of a rise of temperature is complex. At the beginning of the action between certain limits, the law of Arrhenius is followed, that is, a rise of $10^{\circ}$ doubles or even trebles the velocity of the action of the enzyme, as it acts upon other chemical reactions. But as the temperature rises, the velocity of disintegration of the enzyme also increases. The optimum temperature is that at which the enzyme work is best done-a temperature at which the accelerating effect is strong enough to finish the reaction quickly, and the retarding effect due to enzyme destruction is not so great as to neutralize the accelerating effect." An enzyme is practically inexhaustible. He further states that a small amount of enzyme will act on an unlimited amount of substrate, provided sufficient time be given, and provided also that the products of action be removed. The enzyme appears to take a share in intermediate reactions, and there is evidenee that in some stages it combines with the substrate; subsequently, however, when the substrate breaks up into simpler materials, the enzyme is liberated unchanged, and is ready to act in a similar manner on a fresh quantity of substrate.

Revirsibitity-A very important part of enzyme aetion is its re- 
versibility. It is well known that under favorable conditions many chemical reactions are reversible. If, for eximple, as pointed out by Starling, maltaso obtained from yeast, or from the so-called takadiastase, be added to a solution of maltose, the latter is hydrolyzed to glucose. The process of hydrolysis stops short of complete inversion at a point varying with the concentration of the sugar solution. Thus in a 10 per cent solution of maltose, inversion proceeds until as per cent of the maltose is converted into dextrose, whereas in a 40 per cent solution the change stops short when 85 per cent sugar has undergone inversion. Croft Hill showed that if the maltase was added to a $40 \mathrm{per}$ cent solution of dextrose, a change took place in the reverse direction, which proceeded until 85 per cent of the glucose was left. "This phenomenon is due to the fact that two reactions are always taking place in opposite directions. Simultaneously. with the splitting up, the synthetical reaction begins and synthesis or building up increases in proportion as the splitting of the compound advances. 'The velocity of the splitting process decreases at the same rate as the velocity of the synthetic process increases. At a certain point both have the same velocity, and therefore no further change occurs in the mixture when this condition of equilibrium is reached. This rule may be expressed by writing the chemical equation connected by a double arrow instead of the sign of equation.

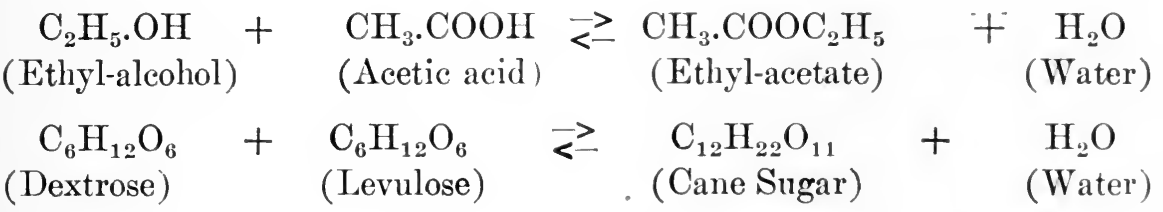

“This phenomenon is termed 'reversibility', and as mentioned previously was first demonstrated by Croft Hill in his experiments with cane sugar and invertase."

Howell has pointed out and emphasized the carefully conducted experiments of Kastle and Loewenhart, who have obtained an excellent example of this double effect in experiments upon lipase, the enzyme which in the body acts upon the neutral fats, converting them into fatty acids and glycerin, a process which takes place as a usual, if not necessary, step in the digestion and absorption of fats. These investigators employed a simple ester analogous to the fats, ethyl-butyrate, and demonstrated the fact that lipase caused not only a hydrolysis of this substance into ethyl-alcohol and butrric acid. but also a synthesis of the two last named substances into ethrl-butyrate and water. Consequently, the reac- 
tion effected by the lipase is reversible and as a chemical equation may be expressed as follows:

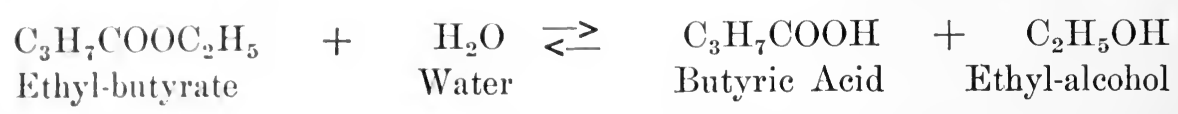

Howell thinks that lipase is capable probably of exerting a similar reversible reaction on the fats in the body. Acting on the assumption that such is the case, it is possible to explain not only the digestion of fats, but also their formation in the tissues and their absorption from the tissues during starvation. 'That is, according to the conditions of concentration, etc., one and the same enzyme may cause a splitting up of the neutral fat into fatty acids and glycerin or a storing up of neutral fat by the synthesis of fatty acid and glycerin. Arguing from the results of experiments, it would therefore appear that fat may be stored, to a certain point, or if the conditions are altered, that the fat which is in the tissues may be changed into the fatty acids and glycerin and be oxidized in the body as food.

As Halliburton shows, in intracellular action, this reversibility of enzymatic action is a factor of importance, for the same enzyme can, in the presence of different proportions of the substrate and its cleavage products, both tie the knot in anabolism and untie it in katabolism. It should also be noted that hydrolytic actions are isothermic, that is, the total energy of the products is equal to that of the substance broken up.

A similar reversibility has been exhibited by some of the other enzymes of the body. In fact, what Halliburton aptly terms the simpler logarithmic law of enzyme action has been demonstrated for the majority of enzymes, invertase, trypsin, erepsin, etc. Also the effect in a given time is directly proportional to the quantity of enzyme present. Pepsin, however, is an exception to this so-called logarithmic law of enzyme action, a fact to which Schultz first drew attention in 1885 . It was discovered by this investigator that peptic activity is proportional to the square root of the amount of pepsin present.

Action of Specific Enzymes.-As mentioned before, it would be impossible and even unnecessary in a work of this nature to discuss at length each and every enzyme or ferment, therefore only some of the more important involved in the processes of digestion and absorption will be briefly described.

Trypsin.-Of the proteolytic enzymes, those which act on proteins, trypsin is of the greatest moment. Corvisart was the first to point out the digestive action of pancreatic juice on proteins, but it was reserved for 
Kuhne to subject the action of the extracts of the gland to a thorough investigation. Finally it was demonstrated that panereatic juice as secreted is free from proteolytic effects, and that this power can only be developed by bringing about some change in the juice itself, a conversion of trypsinogen into trypsin. Under normal conditions this change is induced immediately by the action of a substance, enterokinase, after the juice enters the gut. According to Starling, the pancreatic juice thereby acquires a proteolytic activity superior to that of any other digestive juice, so that the proteins of the food undergo a very thorongh disintegration. "Trypsin acts in an alkaline medium; pepsin, the gastric enzyme, in an acid medim. Trypsin acts more rapidly than pepsin, and more powerfully upon certain proteins which are difficult of digestion in gastric juice. Acting on solid proteins, such as fibrin, it eats them away from the surface to the interior." Trypsin acts further than pepsin, and rapidly splits up the proteose and peptone which have left the stomach into simpler substances, the polypeptids. In their turn the polypeptids are resolved into their constituents, amino-acids. In addition there is a certain amount of ammonia, when once the peptone stage is passed, and the products of further cleavage no longer give the biuret reaction. Accordingly, they are frequently termed abiuretic. Two important differences are to be noted between trypsin and pepsin: trypsin is by far the more powerful and rapid catalyst; pepsin cannot cleave polypeptids into amino-acids as trypsin can. They both work together in normal conditions in perfect harmony. The preliminary action of pepsin is beneficial, as trypsin cleavage occurs more readily after pepsin has acted on a protein.

Pepsin.-Although a typical proteolytic enzyme, pepsin is distinguished from the others in that it acts on acid media only. The combined action of pepsin and hydrochloric acid results in peptic digestion. The effects of its action are mainly exhibited on the protein of the food. Temperature has an influence on its action, low temperature retarding and a high temperature increasing it. Pepsin may be extracted from the gastric mucous membrane by a variety of methods.

But while trypsin and pepsin are the direct activators of digestion and absorption of proteins in the intestine, these must be activated or brought into action by some other agent or agents. It was believed up to a comparatively short while ago that it was solely due to the acid reflex that the pancreatic gland was spurred into action.

- The Hormones: Secretin and Gastrin.-Bayliss and Starling and their co-workers state that the activation of the pancreas is not due to an 
acid, which reflexly inhibits the secretion of the pancreas, but is induced by some unknown substance acting either through the circulation or by reflexly stimulating the nerve centers, and thus producing an increase in the flow of pancreatic juice. Pavlov(1) was the first to suggest this theory as the result of experiments made by himself and co-workers; but he was uncertain whether this activating agent wielded its power through the medium of the nervous system or through the blood stream. To Bayliss and Starling belongs the honor of clearing up this matter and of demonstrating by careful investigations that the stimulus or message from the intestine to the pancreas which accelerates the secretion of the latter must be carried, not by the nervous system, but by the blood stream. Therefore the messenger is a chemical one and was termed by the discoverers "secretin" or "pancreatic secretin" to differentiate it from other possible members of the same class. The general appellation for such chemical messengers is hormone, from the Greek, óp $\mu a ́ v \epsilon \iota$, to excite.

As Bereridge has pointed out(2), chemically no proof has as yet been adduced to show exactly what secretin is. It is not a ferment but a protein substance of low molecular weight, the activity of which is greatly impaired by boiling. Secretin exerts a distinct physiological action upon the pancreas, augmenting its secretions. This action is not a reflex one, as for instance stimulating the nerve supply by a chemical irritation, but a direct one conveyed through the blood stream. In all probability it acts upon the secretory cell itself. In addition to stimulating into activity the pancreatic gland, secretin possesses other functions. These functions have heen demonstrated by Delezenne and Frouin, working at the Pasteur Institute in Paris. They were able to show that secretin is capable of exerting a physiological action which undoubtedly increases the supply of succus entericus. Finally it remained for Hallion to show that secretin possessed the property of increasing the peristalsis of the small and the large intestines.

Starling(3) lays down the following eharacteristics of hormones if they are to fulfill the part of chemical messengers.

(a) In the first place, they must not be antigens, i.e., their injection into the blood stream must not evoke the production of an antibody. If this were the case, the hormone on entering the blood stream would meet its antibody and would be unable to exert any effect upon the appropriate reacting organ. Practically all the complex colloid bodies allied to the proteins, e.g., ferments, egg albumin, peptone and sera of different animals, when injected into the blood stream cause the production of a corresponding antibody. The hormones must be simpler in character than 
such substances and probably have a precise and comparatively simple chemical or molecular constitution.

(b) Since they must be carried by the blood stream to the reacting organ they must in most cases be susceptible to easy passage through the walls of the blood ressels if they are to excite a reaction within a fairly short space of time.

(c) As a rule, the chemical messenger must excite a state of activity in response to a change in some other part of the body. When the primary change passes away, the action of the hormone should also disappear. On this account it is necessary that the hormone should either be susceptible of easy destruction by oxidation or otherwise in the fluids of the body, or be readily exereted so that its action may not be continued indefinitely.

As stated, it is more than likely that hormones are the activating agents which impel all secreting glands to perform their normal functions.

In 1906 Edkins expressed the belief that a hormone excited gastric secretion in the same way that secretin acted upon the pancreatic gland. This investigator showed that decoctions of the pyloric mucous membrane, made by boiling in water, acid or peptone solutions, when injected into the blood cause a marked secretion of gastric juice. These substances when injected alone into the blood cause no such effect, and decoctions of the mucous membrane of the fundic end of the stomach are without action on the gastric secretion. He therefore suggested that the secretogogues, whether preformed in the food or formed during digestion, act upon the pyloric mucous membrane and form a substance which he terms gastrin or gastric secretin, and that this substance after absorption into the blood is carried to the gastric glands and stimulates them to secre$\operatorname{tion}(4)$.

Howell, in commenting upon the chemical action of the hormones, points out that, leaving aside for the moment the way in which the secretogogues excite the secretion, it is important to emphasize the fact that in the normal secretion of gastric juice, that is to say, in the secretion which takes place during an ordinary meal, a distinction must be made between a nervous secretion due to the action of the secretory fibers in the vagus and a chemical secretion due to the chemical stimulation of the secretogogues or of the hormones produced by them. The same authority further points out that "the researches of Pavlor and his fellow workers seem also to indicate that the quantity and properties of the secretion vary with the character of the food. The quantity of the secretion varies, also, other conditions being the same, with the amount of food to be 
digested. The apparatus is adjusted in this respect to work economically. Different kinds of food produce secretions varying not only as regards quantity but also in their acidity and digestive action. The secretion produced by bread, though less in quantity than that caused by meat, possesses a greater digestive action. On a given diet the secretion assumes certain characteristics, and Pavlov is convinced that further work will disclose the fact that the secretion of the stomach is not caused normally by general stimuli all affecting it alike, but by specific stimuli contained in the food or produced during digestion, whose action is of such a kind that it arouses reflexly the secretion best adapted to the food ingested."

With regard, then, to the secondary secretion of gastric juice, Pavlov and Popeilski were of the opinion that it was excited by a local stimulation of the reflex nervous apparatus in the gastric wall. Edkins came to the conclusion that it was caused by a chemical mechanism produced in this manner. The pyloric mucous membrane is acted upon by the first products of digestion, thereby producing in the membrane a substance which, absorbed into the blood stream and conveyed to all the glands of the stomach, excites them to secretory activity; hence the hormone, gastrin. This point has been referred to already, but it is of such importance that it seems wise to lay especial stress upon it again. A phase of the question to which attention is drawn by Starling(4) is that gastrin (i.e., the gastric hormone) is produced in that portion of the stomach in which the process of absorption is most pronounced.

Two factors, therefore, enter into the production and excitation of the flow of normal gastric secretion. The most important is of nervous origin, and the second, which has just been discussed, is of chemical origin. It has not been decided yet whether gastrin is secreted in the pyloric mucous membrane only, or whether its production goes on in the lower gut. Recent researches appear to uphold the belief that the distribution of gastrin is uniform throughout the gastric mucosa. It is said to have been found in small concentrations in the duodenum; and it has been said that its presence has been demonstrated, although with some difficulty, in the esophagus.

The problem of gastric digestion has greatly occupied the attention of research physiologists. Keeton and Koch hold the view that gastrin causes a true gastric flow rather than a simple vasomotor response. Experiments appear to show that this view is logical. These investigators also conclude that gastrin is of a chemical nature different from that of pancreatic secretin and that it is a specific substance.

There is yet a great deal to be learned concerning the hormones. In 
fact, knowledge regarding them and their action is still in its infancy and the results recorded from the various investigations may seem somewhat inchoate and confusing to the practical man. However, a foundation has been laid upon which may be and probably will be built a superstructure of amazing proportions. It would seem to have been proven conclusively that pancreatic secretin is the activator of the pancreatic gland and that its action is chemical. Surely this is a beginning which opens a vista of immense possibilities not only for successful treatment but for the prevention of various chronic diseases. According to Starling(3), secretin (a) increases pancreatic secretions if true organic changes have not occurred, $(b)$ aids protein digestion, $(c)$ stimulates a low urea output, $(d)$ exerts no favorable action in the digestion or breaking down of the carbohydrate molecule, and $(e)$ increases peristalsis.

Amylase.-Of the amylolytic enzymes, amylase contained in the pancreatic juice may be taken as the most conspicuous example. This enzyme converts starch into maltose more rapidly than the other enzymes perform their several duties. Amylase will even act on unboiled starch. The absence of the enzyme in the pancreatic juice of infants is an indication that milk, and not starch, is their natural diet.

Lipase.-Of the fat-splitting enzymes lipase contained in the pancreatic juice splits fats into glycerol and fatty acids. The fatty acids unite with the alkaline bases present to form soaps. Halliburton points out that "when a glycerin extract of pancreas is filtered the filtrate has no lipoclastic action and the material deposited on the filter is also inactive; but on mixing it with the inactive filtrate once more, a strongly lipoclastic material is obtained. In this fashion lipase may be separated into two fractions: the material on the filter is inactive lipase; the material in the filtrate is its co-enzyme which is not destroyed by boiling. The salts of the bile also stir to action the inactive lipase, which explains the fact that bile exerts an action in fat-splitting. Because of its alkaline properties pancreatic juice assists in the emulsification of fats. It likewise possesses the power of liberating fatty acids, which form soaps with the alkali present." It is held by some that the presence of protein in the pancreatic juice renders it especially adapted to the purpose of emulsification, but we cannot agree with this teaching.

Invertase.-Of the sugar-splitting enzymes invertase may be taken as a type. As mentioned previously, the inverting enzymes capable of converting the disaccharids into the monosaccharids are three in number. As a matter of fact, it is the succus entericus which possesses this power, but it owes it to three cnzymes; invertase which inverts cane sugar or 
rather converts cane sugar into dextrose and levulose; maltase which converts maltose into dextrose; and lactase which acts upon lactose, converting. milk sugar into dextrose and galactose. This inverting action is necessary to prepare the carbohydrate food for nutritive purposes.

Interaction of the Exzymes in tire Succus Entericus.-The in. testinal juice and its action were up to a few years ago, comparatively speaking, a terra incognita. It was known that the enzymes referred to possessed the above mentioned powers, but beyond this it was a blank. Since then more light has been thrown upon the subject and it is now frcely recognized that the succus entericus is a juice of the first importance. As Pavlov has demonstrated, one of its main actions is to reinforce and intensify the proteolytic power of the pancreatic juice. A mixture of pancreatic and intestinal juice is remarkably powerful. If, as Starling has shown, secretin is administered to a fasting animal, the juice secreted having no food to act on will produce erosion and inflammation of the intestinal walls. Dixon's and Hamil's work has greatly elucidated the question of the mechanism of pancreatic secretion. As Halliburton shows, according to these investigators, there are in the pancreas three precursors of enzymes, to wit, protrypsinogen, proamylase and prolipase. Secretin combines chemically or at any rate acts chemically on all three; it liberates amylase and lipase from their precursors and these two active enzymes pass into the pancreatic juice. Further, it sets trypsinogen free from protrypsinogen, and trypsinogen passes into the juice, and lastly trypsinogen is converted into the active enzyme trypsin by the enterokinase of the succus entericus.

How then does enterokinase perform its activating functions? It may be explained by the fact that it is capable of transforming the zymogen, trypsinogen, into the powerful enzyme trypsin. J. Mellanby and Wooley explain how this is brought about, thus: trypsinogen is a complex consisting of trypsin united to a protein moiety, and, so long as the enzyme is combined in this way, it is inactive. Enterokinase is the proteolytic enzyme which absorbs and then digests this protein moiety, thus liberating the trypsin. Otto Cohnheim made another discovery with respect to succus entericus. The juice has no action on native proteins such as fibrin and white of egg, but it does act on proteoses and peptones. Cohnheim termed the enzyme to which this is due erepsin. The discovery has been confirmed by other observers, but it has also been found that erepsin or a similar enzyme is present in most of the tissues, and, according to Vernon, it is most abundant in the kidney. 
Gastric Digestion.-The problem of gastrie digestion has greatly occ11pied the studious attention of research physiologists for several decales. Especial interest has been taken and numerons investigations have been made to determine the extent and manner of the participation of the stomach in the essential processes of digestion and the rôle played by the intestinal tract in this all-important function. It is now believed by many that the stomach is unimportant as a digestive organ, and that its main, if not only, purpose is to serve as a receptacle for the masticated foodstuffs. It is argned that the small intestine, on account of the various juices which are poured into it, is easily capable of acting as the digestive agent of the entire body.

The wonderful digestive properties of the body have been amply demonstrated experimentally by excising the stomachs of $\operatorname{dogs}$ and by uniting the esophagus with the small intestine. This radical operation in no way impaired the activity of their digestive functions. It is even stated that dogs which had undergone this operation were able to digest putrefying meats without the aid of the antiseptic action of the gastric juice. At any rate, recent physiological investigations have proven that the digestion in the stomach is by no means so complete as was formerly thought. However, the stomach in its capacity is a digestive organ and does perform at least one important function, that of partially digesting protein. The small intestine can not only digest protein, but also fats, starches and sugars. The stomach does the preliminary work of warming, maceration and chymification of the food, and thus relieves the small intestine of a good deal of work in the final processes of digestion. (See Volume I, Chapter V.)

Summary.-The paramount importance of enzymes and hormones in the physiology of digestion and absorption is now completely evident. Indeed, so far as intestinal digestion and absorption are concerned, the enzymes stimulated by the hormones are doubtless the main factors. When the work of these internal secretions becomes impeded the entire machinery of the alimentary tract gets out of order and disease and ill health are the result.

\section{REFERENCES}

1. Pavlov, Ivan Petrovich. The Work of Digestive Glands, translated by Thompson, 1902 .

2. Beveridge. N. Y. Med. J., vol. ci, June 26, 1915.

3. Starling. Text-book of Physiology.

4. Howell, W. H. Text-book of Physiology. 


\section{BIBLIOGRAPHY}

Atwater. Principles of Nutrition and Nutritive Value of Foods. Farmer's Bull. 142, U. S. Dep. Agric.

- and Bryate. The Chemical Composition of American Food Materials. Bull. 28, Revised, Off. exper. stations, U. S. Dep. Agric.

Bayliss. The Nature of Enzyme Action, 1908.

BrEDIG. Die Elemente der chemischen Kinetik, mit besonderer Berücksichtigung der Katalyse und der Fermentwirkung. Ergebn. d. Physiol., i, 134-212.

Conen. Organic Chemistry, 1907, chap. ix.

Green. Soluble Ferments and Fermentation, 1904.

Howell. Text-book of Physiology.

Hutcuison. Food and Dietetics, 1907.

KönıG. Chemie der menschlichen Nahrungs- und Genussmittel.

LEACH. Food Inspection and Analysis, 2nd ed., 1909.

Oppexheimer. Ferments and Their Actions, 1901.

OTr. Text-book of Physiology.

Starling. Text-book of Physiology.

Verson. Intracellular Enzymes, 1908.

Wiley. Foods and Their Adulteration, 1907. 


\title{
CHAP'TER VII
}

\section{PHYSIOLOGY OF ABSORPTION}

\author{
John C. Hemmeter, M.D., Pir.I., Sc.D., LL.D.
}

\begin{abstract}
Absorptive Powers of the Digestive Organs: Absorption in the Stomach; Absorption in the Small Intestine; Absorption in the Large Intestine; Absorption in the Rectum.

Absorption of Food: Absorption of Fats; Absorption of Carbohydrates; Absorption of Proteins-Amino-acids.

Rôle of White Corpuscles.

Diffusion; Dialysis and Osmosis.
\end{abstract}

In previous chapters the chemical and physical processes, by which the food taken into the digestive apparatus is gradually transformed into such chemical substances as are suitable to become integral constituents of the body, have been described.

These transformations constitute what is usually referred to as "digestion," and the average practitioner thinks no further of this process. But it is clear that the significance of the digestive process for the welfare of the organism does not depend so much upon what is ingested nor upon what is digested as upon the quality, quantity and chemical constitution of the end products of digestion that are permitted to enter that large cell state, designated as the living body. The study of absorption, therefore, is more essential to a correct understanding of human dietetics than the chemistry of digestion.

Quantity and Quality of Food Ingested.-An important factor to be taken into consideration is the quantity and quality of food that is ingested. Excesses of food are as injurious as unsuitable food. The object of the dietitian should be to ascertain the character and quantity of food best adapted to conserve the physical powers and mental faculties of the individual and to instruct him to partake of such food with due discretion. By following this path diseases may be avoided and happy and healthy old age reached. 
Physiological Test.-What then constitutes a food régime which will go far to ward off ill health and be an important factor in the conservation of the phrsical and mental capacities at their highest point? In order that a food should supply the necessary energy or driving power, as well as sustaining power, Hutchison, when discussing the ternary food elements, points out that "it is not enough that it should contain a considerable proportion of protein, carbohydrates and fat, and should be capable of yielding energy on oxidation." The caloric value of a food is of the utmost moment, but food must also be of such a nature that it can be easily digested in the stomach and more or less completely absorbed into the blood. $A$ great many substances might readily pass the chemical and physical tests and yet be of no value as food if they could not be digested and absorbed. Hence, the manner in which food behaves in the stomach and intestine must be taken into consideration before any opinion can be pronounced upon its value as an article of diet.

This then may be termed the physiological test. The expression di. gestibility is employed in a different sense by the physiologist, by the layman and, indeed, by the physician. When the physiologist applies the term "indigestible" to an article of diet, he means that such food is imperfectly absorbed into the blood. To avoid confusion, however, we will adhere to the popular usage of the expression "digestibility," and employ the term "absorbability," as suggested by Hutchison, to indicate the ease with which the constituents of a food ean pass from the stomach and intestine into the circulation.

The ease with which food is or is not absorbed is a fairly accurate criterion of its value. If it is absorbed with difficulty it is not a suitable food. A number of experiments have been carried out in recent years with the view to ascertaining the degree to which the different constituents of various foodstuffs are absorbed into the blood and lymph. The majority of these were conducted in Europe. A few have been done in this country.

The following table, from researches by Rubner and Atwater, summarizes the results in round numbers.

The mode of experiment consists in analyzing the food to be investigated, and then, from an examination of the feces, aseertaining the proportions of its protein, carbohydrate and fat which escape absorption. An analysis of this kind does not reveal accurately the proportion of nitrogen and fat of the feces which is derived from other sources than the frod ingested. However, the important point is this: by some diets more nitrogen and fat are excreted from the body than by others. Irre- 
Percentage of Protein, Fat axd Camonymbates ansomili) from Dry Substaxces in VABIOL'S fools

\begin{tabular}{|c|c|c|c|c|}
\hline & $\begin{array}{c}\text { Dry } \\
\text { Substanee }\end{array}$ & Protein & Fit & Carbohydrates \\
\hline 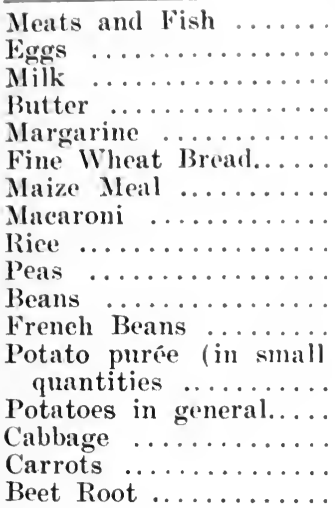 & $\begin{array}{l}95 \\
\ddot{9} \mathrm{i} \\
\ldots \\
9 \overline{95} \\
93 \\
95 \\
96 \\
99 \\
82 \\
85\end{array}$ & $\begin{array}{c}\text { Practically all } \\
\text { Practically all } \\
\text { ss to } 100 \\
\ldots \\
\text { sio } \\
8900 \\
89 \\
81 \\
81 \\
821 \\
70 \\
\cdots \\
801 \\
70 \\
813 \\
61 \\
72\end{array}$ & $\begin{array}{c}79 \text { to } 92 \\
9(6 \\
93 \text { to } 98 \\
98 \\
96 \\
? \\
? \\
? \\
? \\
? \\
\cdots \\
\cdots \\
\ldots \\
\cdots \\
\cdots \\
\because \\
?\end{array}$ & $\begin{array}{c}\cdots \\
? \\
\cdots \\
99 \\
99 \\
97 \\
97 \frac{1}{3} \\
99 \\
96 \frac{1}{2} \\
? \\
\cdots \\
\text { Practically all } \\
92 \frac{1}{2} \\
84 \frac{1}{2} \\
82 \\
82\end{array}$ \\
\hline
\end{tabular}

spective of the souree, loss to the body is equally indicated. Therefore, each constituent of the food material should be considered separately. But before going into this phase of the subject the question of food absorption will be considered at greater length.

Digestion means that food material is converted into an absorbable form. If foods are not absorbed, they cannot be assimilated and thus become in fact an integral part of the body, nor ean their products be utilized for body energy. It follows then that digested food must diminish in quantity as it passes along the alimentary tract, and that the fees contain only the undigested or indigestible residue.

\section{ABSORPTIVE POWERS OF THE DIGESTIVE ORGANS}

\section{ABSORPTION IN THE STOMACH}

Absorption of food in the month and esophagus is very slight, if any, owing to the fact that the epithelium is thick and that the food passes quickly through these parts. In the stomach, absorption is also slight. It is possible that there may be absorption of the following substances: water; salts, sugars and dextrins that may have been ingested as such; the proteoses and peptones formed in the peptic digestion of proteins or albuminoids. In addition absorption of soluble or liquid substances, drugs, alcohol, etc., may occur. The most recent observations seem to show that alcohol is 
absorbed to some extent. It was formerly assumed without definite proof, that the stomach absorbed easily such things as water, salts, sugars and peptones. Nevertheless, actual experiments made under conditions as nearly normal as possible have demonstrated that absorption in the stomach does not readily take place, at least not with the ease that it takes place in the intestine.

Experiments Showing the Actual Course of Digestion.-Methods of various kinds have been employed in such experiments, but the classical one and that most productive of results was the establishment of a fistula immediately beyond the pylorus. When a fistula in this situation has been made, food may be given to the animal and the contents of the stomach extracted and cxamined as it passes out through the pyloric opening.

In a series of papers published by London a few years ago and referred to by Starling, the course of digestion for various kinds of meals was observed in $\operatorname{dogs}$ which had been provided with fistulæ in one of the following places: (a) gastric fistulæ (into the fundus of the stomach); (b) pyloric fistulæ (on the duodenal side of the pylorus); (c) duodenal fistula (on the duodenal side of the pylorus; $(d)$ duodenal fistulæ (about one foot below the pylorus); $(e)$ jejunal fistulæ (about the middle of the small intestine); $(f)$ ileum fistulæ (just below the cecum). A meal composed of 200 grams of bread which the animal ate and swallowed, mixed with saliva, was used for the experiment. Previous to the arrival of the food in the stomach, the psychic secretion of gastric juice had been started by the vagi; the food hormones and gastric hormones continued the secretion and formed a series of special experiments in which the average 200 grams of bread were found to excite the secretion of 20 grams of saliva, about 10 grams of mucus from the coats of the stomach and about 315 grams of gastric juice.

COURSE IN THE STOMACH.-According to London's researches, quoted by Starling, "the secretion of gastric juice was continuous during the entire time that the food remained in the stomach. In the animal with a pyloric fistula, one or two minutes after the meal had been given, a few drops of alkaline fluid were extruded from the opening. From three to eight minutes after the conclusion of the meal small quantities of clear acid gastric juice were repeatedly extruded. The first admixture of the food with the outflow from the fistula occurred at eight or twelve minutes after the completion of the meal, and after this time the pylorus continued to open at regular intervals of ten to forty seconds, discharging each time a small amount of fluid composed of par- 
ticles of undigested bread mixed with gastric juice. One and a half hours later the pylorus began to open less regularly and the fluid became of a more pasty consistence, devoid of lumps of undigested bread. In the fourth, fifth and sixth hours after the meal, the pylorus opened only

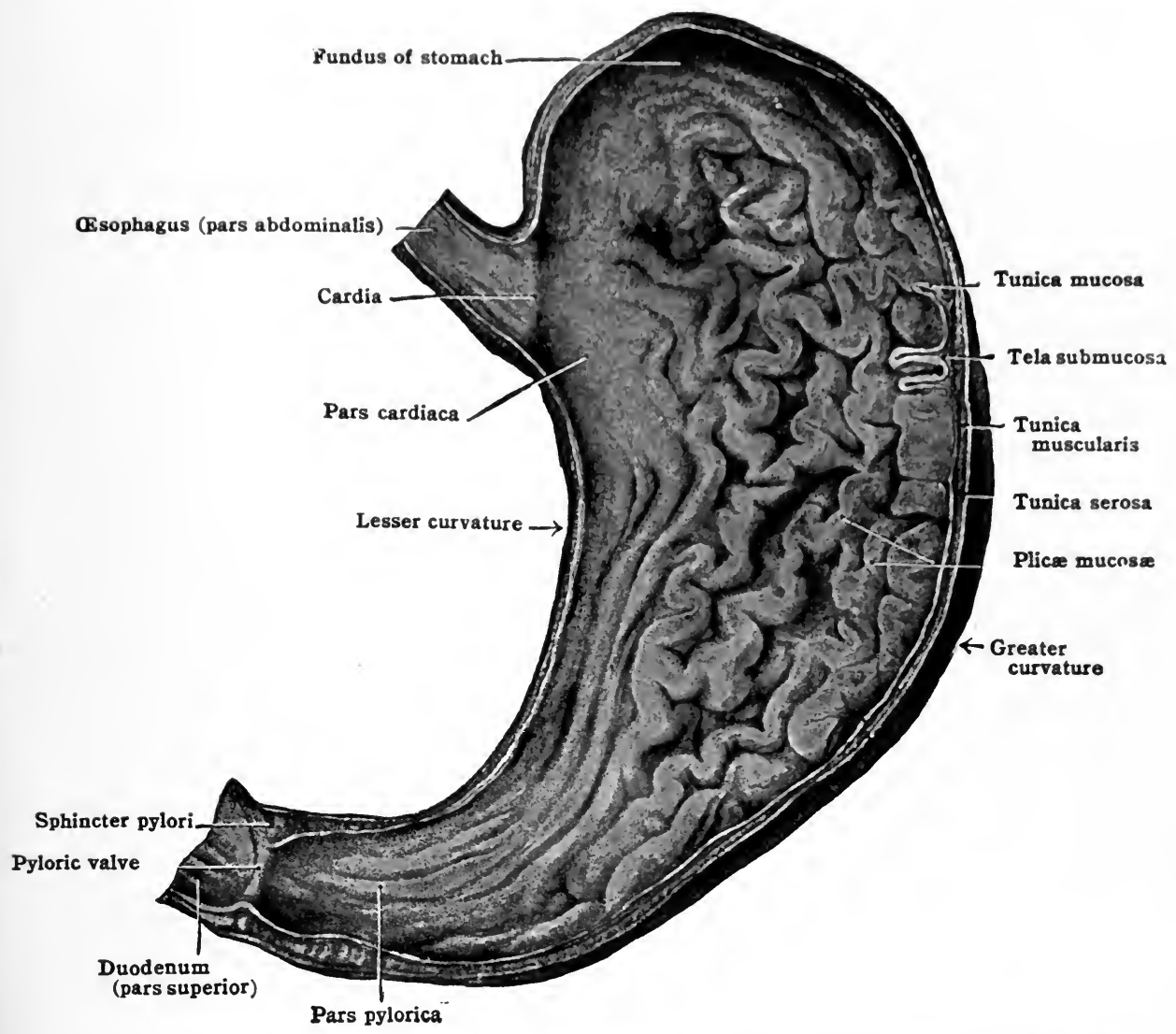

Fig. 15.-View of the Interior of the Stomach. The tunica mucosa, tunica muscularis, tunica serosa, tela submucosa and plicæ mucosæ. (Allen's "Anatomy.")

once every two or three minutes, and towards the end of this period, the fluid extruded was clear. The following table shows the percentage of food ingested which left the stomach at the end of each hour after the meal:

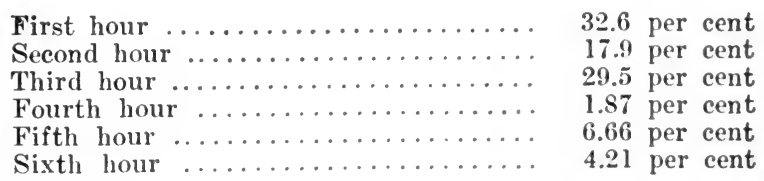


The large proportion of the ingested food leaving the stomach during the first two or three hours can hardly be regarded as normal. Since in these experiments there was a free outflow from the pylorus and the food was not allowed to enter the duodenum, the local reflex evoked by the presence of acid in the duodenum was absent. The gastric contents obtained in this way were analyzed in order to find what changes had been wrought upon the food by the gastric juice. It was found that 32 per cent of the breal had been brought into solution. This solution had affected the proteins more than the carbohydrates. Thus 67 per cent of the proteins had been brought into soluble form, consisting chiefly of albumoses and peptones. No amino-acids were found. Only 25 per cent of the starch of the bread had been rendered soluble, and of this, 21 per cent was in the form of dextrin and 4 per cent in the form of sugar. Tobler, who worked with exact physiologic conditions, found that 20 to 30 per cent of the nitrogen of meat is absorbed from the stomach(1).

DUODENAL DIGESTION.- "The influence exerted by the pancreatic juice, bile and succus entericus, poured out on the food in the duodenum, was studied by analysis of the intestinal contents leaving the intestine through a fistula, either at the lower end of the duodenum, in the jejunum, or in the ileum. From the duodenal fistula the expulsion of food occurred at repeated intervals, but in a somewhat irregular fashion. Its movements were determined partly by the contractions of the stomach and partly by those of the duodenal wall. Usually a large gush was followed by a series of small gushes. Although only a foot intervened between the duodenal and the pyloric fistulæ, a great difference was observed in the character of the intestinal contents obtained in the two cases. The outflow from the duodenum, being mixed with the pancreatic juice and the bile, was yellow in color and increased in amount. With a meal of 200 grams there was secreted on the average 130 grams of bile and 140 grams of pancreatic juice. During the passage of the meal through the duodenum the carbohydrates of the food underwent considerable changes, so that even one foot below the pylorus we found that one-half to three-fifths of the carbohydrates had been converted into dextrin and sugar. A further digestion of the proteins also took place, amounting to about one-tenth of the whole protein taken with the food. On deducting the amount of juices which had been added to the food, it was found that even over this short length of intestine absorption of about one-sixth of the ingested food had taken place-about one-fourth of the carbohydrates and about one-eighth of the proteins.

IOWER INTESTINAL DIGESTION.- "In a dog with a fistula about the 
middle of its small intestine, the ontflow began six to fifteen minutes after the meal, and lasted six or seven hours. The outflow was by small gushes repeated at intervals of five to ten seconds, separated by intervals of one to five minutes, during which nothing appeared at the orifice of the cannula. The material obtained was quite different from that which flowed from the duodenal fistula; the pasty eonsistency had disappeared and the material formed a frothy, orange-yellow, jelly-like mass with practically no trace of undigested bread."

Digestion IN THE ILEUM.- "From a fistula in the ileum the outflow occurred at long intervals of three to fifteen minutes, was much scantier" than that obtained from the jejunal fistula, and consisted of a thick jelly-like, orange-colored mass. Both proteins and carbohydrates were entirely digested, and in the case of the former the chief products of digestion consisted of amino-acids. 'Thus in one experiment, after four large meals of 500 grams of meat each had been given in order to obtain sufficient quantity for analysis, 175 grams of soluble substances were ol,tained. From this were isolated tyrosin, leucin, alinin, aspartic acid, lysin, and traces of arginin and histidin."

DIGESTION IN THE CECUM.-- "From a fistula in the cecum there was no outflow until four or five hours after the meal had been taken. The material from the gut was then expelled in fecal-like masses at long intervals of one-half to one hour. The regular outflow lasted for about six hours. The reaction of the contents was strongly alkaline, with no food particles, and the material contained merely debris of cells, with small traces of sugar, dextrin and maltered starch. The absorption of the foodstuffs was practically complete by the time the food had reached the lower end of the small intestine."

The foregoing account of investigations to determine the actual course of digestion and absorption is somewhat premature, as it treats of the small intestine as well as of the stomach. Still although anticipating the trend of this chapter, it introduces the whole question of absorption from the point of view of experimental research.

Absorption of Water.-To revert again to absorption in the stomach in particular, experiments have shown that water when taken alone is practically unabsorbed in the stomach. It has been demonstrated that as soon as water is introduced into the stomach it commences to pass into the intestine, being forced out in a series of spurts by the contractions of the stomach. Within a comparatively short time practically all the water can be recovered in this way, very little having heen absorbed. J. von Mering was the first to prove experimentally that water is not absorbed 
from the stomach. Starling in his "Human Physiology" accepts the fact that the absorption of water in the stomach may be regarded as nil. Although from this viscus, alcohol and possibly peptone and sugar may be absorbed to a slight extent, water or saline fluids introduced into it are passed through the pylorus either without change or are increased by the secretion of fluid from the gastric glands. Howell holds that alcohol is absorbed readily from the stomach and Hutchison, Chittenden, Mendel and other's are in agreement with the view. Starling and Hallihurton, however, state that alcohol may be absorbed by the stomach to a slight extent.

Absorption of Salts.-The question of the absorption of salts from the stomach has not been thoroughly investigated. Brandl is authority for the statement that sodium iodid is absorbed very slowly and that dilute solutions of it are not absorbed at all. Its absorption becomes important only when its solutions reach a concentration of three per cent or more. Howell is of the opinion that this result, if applicable to all the soluble inorganic salts, would indicate that under ordinary conditions they are practically not absorbed in the stomach, since it may be supposed that they are not normally swallowed in solutions as concentrated as 3 per cent. Solutions of strychnin are absorbed with difficulty from the stomach, as compared with the intestines, rectum, or even the pharynx. It is said that the absorption of sodium iodid is greatly facilitated by the use of condiments-such as mustard, pepper or alcohol-which act either by causing a greater hyperemia of the mucous membrane or perhaps by directly stimulating the epithelial cells. Salts do not appear to be absorbed in the stomach unless present in great concentrations such as do not occur in normal diets.

Absorption of Sugar and Peptones.-Although the absorption of sugars and peptones in the stomach is accomplished with difficulty, experiments by the more recent methods have shown conclusively that sugars and peptones may be so absorbed. In the course of the investigations different forms of sugar-dextrose, lactose, saccharose (cane sugar), maltose and dextrin-were tested with the result that it was found they were all susceptible of absorption; but the more concentrated the solutions the greater was the absorption. Brandl has reported that dextrose and peptone are not sensibly absorbed until the concentration has reached 5 per cent. With these substances also the ingestion of condiments or of alcohol in(reases distinctly the absorptive processes in the stomach. Examination of the mucous membrane of a stomach in full digestion shows that it contains albumoses (Glaessner) - a fact that indicates some absorption. Di- 
rect examination of the stomach eontents demonstrates that the products of peptic action beyond the albumose stage-namely, the peptones, peptids and amino-bodies-are absorbed. (n the whole, however, it wonld seem that sugars and peptones are absorbed with difficulty in the stomach.

Absorption of Fat.--So far as is known at present, fats are only absorbed after they have reached the small intestine and mainly by the agency of the lymphatic vessels. Fats must be emulsified and saponified before they can be absorbed, and, as said before, the process is not undergone until the small intestine is reached. Accordingly, fats undergo no digestive changes in the stomach except when eaten in the emulsified form, as in milk. It is probable that the gastric fat hydrolysis deseribed by Volhard was due to a liapase as it regurgitates from the duodenum.

There is a histologic reason for the incapability of the stomach to function as an organ of ahsorption. The oxyntic, parietal cells and the chief central cells of the peptic ducts stand so closely packed in the greater part of this organ that little epithelium is left for absorption. Only in the pyloric antrum are there surface cells in sufficient number to effect absorption. It is believed by some that the process of absorption by the stomach is much more in the nature of a mere physical osmosis and dialysis than is the case in the intestine, and that the process is accompanied by the pouring out of a good deal of secretion. Perhaps it is in this way that a mixture of alcohol and sugar such as is found in sweet wines and some malt liquors may cause acidity.

\section{ABSORPTION IN THE SMALL INTESTINE}

The small intestine, with the folds and villi that inerease its surface, is the main place for absorption. The superficial area of the small intestine, if it were flat, would be about 115 square meters. By the presence of the villi this is increased about 42 square meters. Absorption begins in the duodenum, and the products of digestion have largely disappeared by the time the intestinal contents reach the ilcocecal valve at the commencement of the large intestine.

Absorption of Saline Solutions and Water.-Absorption takes place very rapidly in the small intestine and naturally the chief absorption of water and saline fluids occurs in the viscus. A striking example of this fact is afforded by the production of dilatation of the stomach with stenosis of the pyloric orifice by water-starration of the body. While this condition can frequently be relieved by introducing water subentaneously or by the rectal route, water given by the mouth only increases 
the dilatation and does not quench the intense thirst of the patient. The explanation of this is that the water administered subcutaneously or by

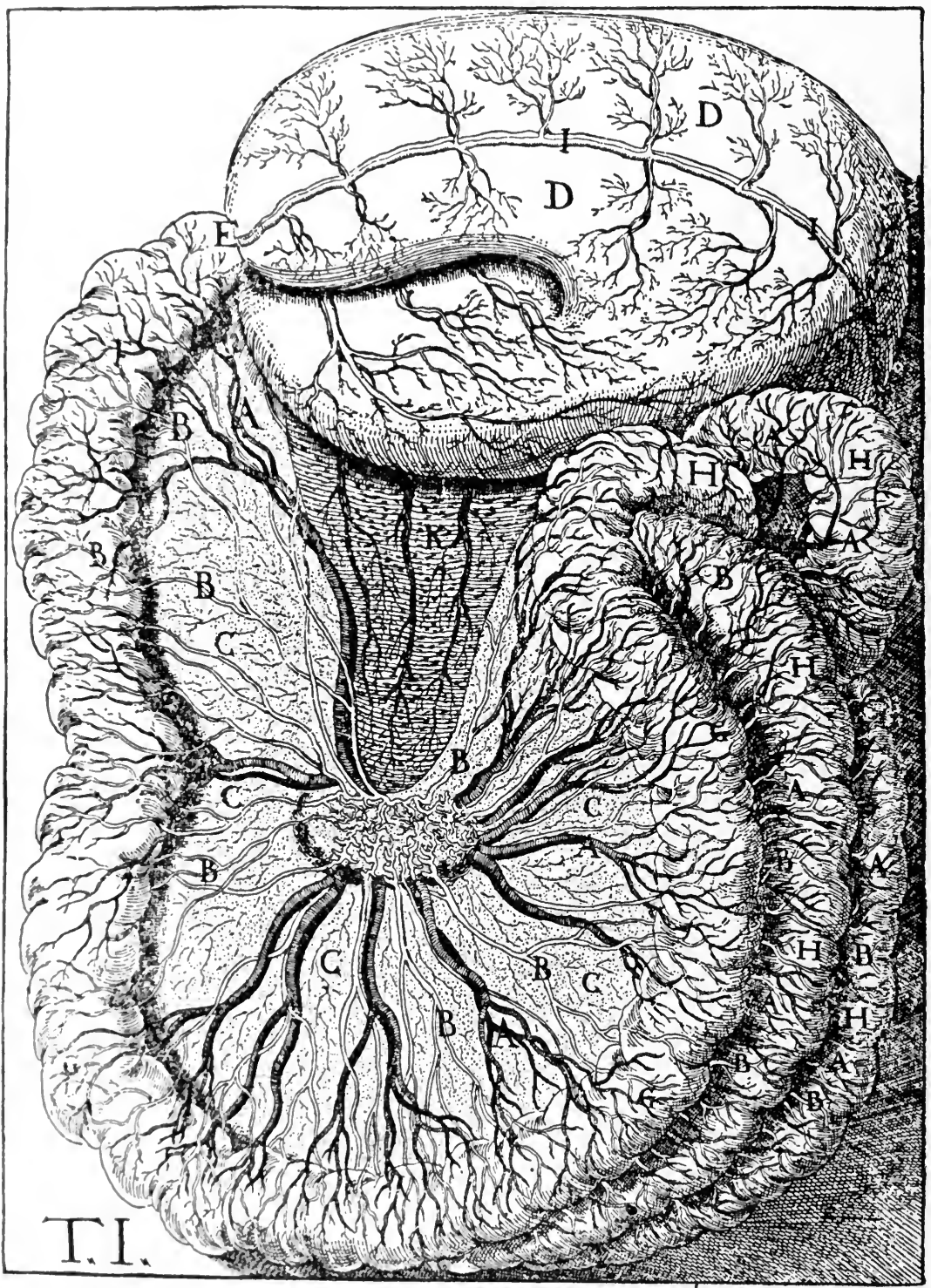

İI6, 16.-Stomach, Intestines and Mesentery; Vessels axd Lacteals, A, mesentoric artories and veins; $\mathrm{B}$, lacteals; $\mathrm{C}$, mesentery; $\mathrm{D}$, stomach; $\mathrm{E}$, pylorus; $\mathrm{F}$, luodenum; (i, jejunum; H, ileum; I, artery of Fundus; K, omentum. (Flint's "hysiology."

the rectum reaches the parts of the body where absorption is possible; Whereis. if introduced into the stomach, it must get into the intestine 
before it is absorbed. It must be borne in mind that almost all the water taken by the month is absorbed in the small intestine, and that but a very small quantity remains to be absorbed in the large intestine, and, as said before, the amount absorbed in the stomach is so small as to be almost a negligible qumtity. Thus the point may be again emphasized that in the absorption of water the small intestine is not only the chief agent, but practically the sole means by which water taken by the mouth is absorbed.

COCRSE OF WATER IN THE STSTEN-INTROHATHOX.-Water is introduced into the body by three methods-by drinking, hy eating foods which contain water, by receiving water into the system through oxidation of the lydrogen of food substances-for example, the end products of carbohydrate metabolism, $\mathrm{CO}_{2}$ and $\mathrm{H}_{2} \mathrm{O}$.

The problem of exactly how absorption in the small intestine is brought about is one that has not been wholly solved and during recent years physiologists have investigated the subject very elosely.

It is known that the mucous membrane of the small intestine absorbs rapidly, but the means whereby this process is effected still remains, to a great extent, an unsettled physiologieal problem.

Howell has drawn attention to the faet that physiologists were wont to assume that absorption took place exclusively through the central lacteals of the villi, hence these vessels were described as the absorbents. It is now known that the digested and resynthesized fats are absorbed by way of the lacteals, but that the other products of digestion are absorbed mainly through the blood ressels and therefore enter the portal system and pass through the liver before reaching the general circulation.

The mechanism of absorption, as now understood, and as stated by the foremost physiologists, will be somewhat briefly described.

LYMPIATIC ABSORPTION.-First, the mechanism of absorption of water will be entered into. The villi, of course, are the processes concerned in the absorption that goes on in the small intestine, and in lymphatie absorption it is the lacteals of the villi that do the work. The villi are main organs of absorption. It is said that the total number of villi in the whole of the small intestine may be eomputed at four to five million; owing to the fact that the villi project, each square centimeter of the intestine gains abont twenty-three times in area. The villi then are special structures for ahsorption purposes situated on the mucous membrane of the small intestine (it may be termed a basement membrane); they project as finger-like processes, presenting a striated basilar border on the side towards the lumen of the intestine. Each villus is 
made up of loose lymphoid tissue containing leucocytes, and is covered with and separated from the gut by columnar epithelial cells. It contains in its interior a plexus of blood capillaries and some commencing lymphatic or lacteal ressels, placed in a central position. One of these, situated in the middle of the villus, is known as the central lacteal. The central lacteal and lymphatics which are in proximity to it are located superficially to the muscularis mucosæ. These possess no valves. Thuse in the deeper plexus are provided with an abundance of valves. Fluid, therefore, can flow in one direction only from the superficial lacteals to the deeper plexus. Unstriated museular fibers pass up through the villus and are partly adherent to the outer surface of the central lacteal and partly by their extremities to the membrane covering the surface of the villus. When these muscles contract, the central lacteal is emptied into the deep plexus of the lymphatics, whence it is unable to return, and the contraction of these fibers may also cause a flow into the central lacteal. It has been demonstrated repeatedly by experiments on dogs that the formation of lymph is constantly going on in the alimentary tract, even when at rest.

ABSORPTION BY CAPILLARY BLOOD VESSELS OF THE VILLUS.-The capillary blood vessels supply the other means by which the small intestine is enabled to exercise its great absorbent properties. The villi have a dense network of blood capillaries immediately underneath their epithelial covering. All the blood capillaries of the intestinal tract are radicals of the portal vein, while the lacteal ducts are radicals of the abdominal lymphatics. There are some difficulties in the way of a clear and cogent explanation of absorption by these blood vessels. However, it has been shown that salt solutions introduced into the small intestine are absorbed rapidly. This rapid absorption does not produce a corresponding rapid rate of inerease of lymph flow from the thoracic duct. Conversely, when large amounts of fluids are absorbed an actual diminution of the solids of the plasma may be eaused. Consequently, there is justification for the belief that the dense network of blood capillaries underneath their epithelial covering are the agents solely responsible for the absorption.

For a long time the theory that osmosis provided a sufficient explanation of all the phenomena of absorption was generally aceepted, mainly perhaps hecause it was such a delightfully easy mode of getting over the difficulty. Acording to Dr. Julius Pohlmann, writing in the Reference Irandbonk of the Medical Sciences, 1913, the work assigned to the cells of the different parts of the digestive tract concerned in absorption 
is first to keep themselves in good condition. Secondly, to pick out from the contents of the tract such substances as the body wants and pass them into the circulation. It is safo to assert that normal absorption is a

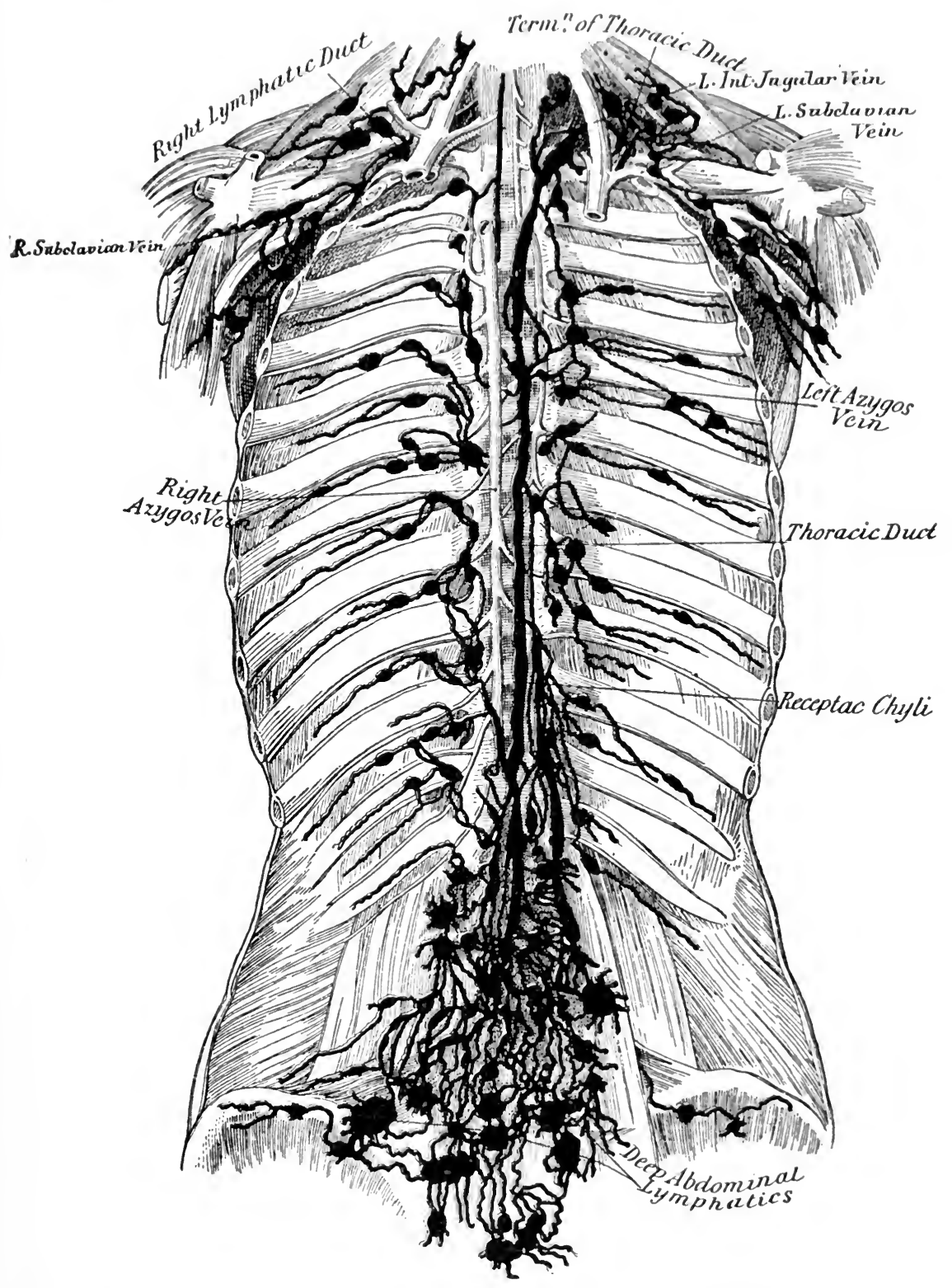

Fig, 17.-Lymphatics of the Trusk. Ixcludigg the Thoracic Duct. 
living, not a mechanical, act, and that osmosis, as a factor in these phonomena, must not alone be taken into account. However, the question of osmosis will be considered at some length in a later part of this chapter. The villi, therefore, in conjunction with the blood capillaries lying under the basement membrane of the villus, are the main factors promoting absorption of water and saline fluids in the small intestine.

Regarding the absorption of food in the small intestine, Howell records observations made by Macfadden, Nencki and Sieber upon a patient with a fistula at the end of the small intestine. In a patient in this condition food begins to pass into the large intestine in from two to five and a quarter hours after eating and it requires nine or more hour's before the last of the meal has passed the ileocecal valve. This estimate includes the time in the stomach. During this passage absorption of the digested products takes place almost completely. This, however, does not necessarily signify that all individuals require this length of time for complete digestion, as observations made by the radiograph ofttimes indicate that it may be reduced by over seven hours. After referring to the point as to whether the known physical laws of diffusion, osmosis, dialysis and imbibition are sufficient to effect the absorption or whether some unknown activities of the living epithelial cells are responsible for the process, Howell concludes that absorption as it actually takes place is not governed simply by known physical laws. The villi, then, in conjunction with the blood capillaries lying under the basement membrane of the villus, are the main factors promoting absorption in the small intestine. Pohlmann puts the absorbing power of the small intestine at about equal to the task of taking up the quantity of fluid formed by the action of the digestive ferments plus the quantity of fluids secreted by the pancreas, liver and intestinal glands, and thus, as these quantities combined do not represent the total amount of fluid present, the contents of the small intestine remain fluid throughout its entire length.

\section{ABSORPTION IN THE LARGE INTESTINE}

Experiments on dogs have demonstrated that after the contents of the small intestine have passed the ileocecal valve, they still contain an amount of unabsorbed food. It is a matter of common knowledge that the material remains for a long time in the large intestine, and seeing that this contains the digestive enzymes received in the duodenum it may be taken as proven that the digestive and absorptive processes continue in the large intestine. Halliburton states that absorption in 
the large intestine, mainly of water, occurs, but to a less extent than in the small intestine. Starling holds that as an absorbing organ the human large intestine is of little importance.

Absorption of Water-An interesting feature of the large intestine is the marked absorption of water therein. It has been shown that water is absorbed in large quantities in the small intestine, but this is due to osmosis or secretion. As Howell states, the absorption of water in the large intestine is not compensated by secretion; the material loses water rapidly while in the ascending colon, and before it reaches the descending colon it has acquired the consistency of the feces.

Halliburton says that foods such as water and soluble salts are absorbed unchanged, and it has been calculated from observations on fistulæ in man that about 500 c.c. of water pass the ileocecal valve during the twenty-four hours and of these 400 c.c. or thereabouts are absorbed in the large intestine. Starling and Halliburton regard the absorptive powers of the large intestine as slight, except with regard to water and salt solution. Howell thinks that absorption continues in the large intestine, while Pohlmann refers to the well-known high absorbing powers of the large intestine. There is little doubt, however, that absorption is very considerably slower in the large than in the small intestine. This fact appears to have been shown by observations made with regard to the absorption results from feeding by the rectum.

It is, however, well known that salts and water are freely absorbed from the large intestine, and the advantages claimed for rectal feeding may be largely due to these ingredients. Langdon Brown, whose views on the subject were published in the proceedings of the British Royal Society of Medicine, points out that the body can stand deprivation of food for a considerable time if salts and water are supplied. W. Pasteur advocated the administration of $10 \mathrm{oz}$. enemata of plain water at a temperature of $100^{\circ} \mathrm{F}$. every four or six hours. He claimed that the results were as good as with the nutrient enemata.

As to the absorption of protein as evidenced by the results of rectal feeding, Voit and Bauer found it advisable to add sodium chlorid to assist absorption of albumin protein, though Ewald and Czerny dispute this conclusion. Leube stated that he had been able to maintain life for six months on a mixture of meat and pancreas. Edsall and Miller, using milk and eggs with pancreatic extract, found that from 40 to 47 per cent were absorbed. Sharkey, using milk and powdered casein, found an absorption of 50 to 75 per cent. These figures seem to indicate that protein is absorbed with considerable freedom from the large intestine. 
langdon Brown thinks there is an important fallacy in these tests, because they are based on the amount of protein which could be recovered from the bowel on washing it out. It is notoriously difficult, however, to remove the bowel contents completely in this way, and in any event some of the protein which disappears may have been reduced by putrefactive changes into a form in which it has no nutritional value. According to Boyd, absorption of protein material in the large intestine seems to depend more on the patient's individual capacity than on the amount given. Normally carbohydrates are absorbed as dextrose by the bowel, and this form of food appears to be the most fully utilized in the large intestine. Starling has stated that the isolated large intestine of man is able to absorb only about six grams of dextrose per hour and about 80 c.c. of water. On the other hand, that dextrose is definitely absorbed from the bowel is proved by the following facts: Reach found that the respiratory quotient was raised by rectal feeding of dextrose, a sure sign that this was being utilized by the tissues, and the acidosis of delayed chloroform poisoning or of inanition in esophageal stricture has been reduced or abolished by this procedure. It is well known that acidosis is produced quickly by deprivation of carbohydrates, and it is just as well known that the assimilation of carbohydrates rapidly abolishes the condition.

With regard to the absorption of fats from the large intestine, opinion seems to be greatly divided. It must be borne in mind that even the finest emulsion of fat is only absorbed by the action of a fat-splitting ferment. In a normal state of the body the pancreatic juice supplies this ferment and in its absence reliance must be placed upon bacterial decomposition. Of course the ferment can be provided by liquor pancreatitis, but it does not follow then that absorption will be satisfactory.

Langdon Brown refers to observations made by Munk and Rosenstein on a patient with a fistula of the thoracic duct. He was first put on a diet very poor in fat, and the enemata of fat and salt were given. In one experiment 3.7 per cent and in another 5.5 per cent were absorbed. Boyd thinks that a considerable amount of fat may be absorbed from the large intestine, while Langdon Brown expresses himself as skeptical with regard to the absorption of fat from the bowel. Both he and Starling are of the opinion that the disappearance of proteins, emulsified fats and boiled starch, that is, when such disappearance from the large intestine is gennine, is due largely to the action of bacteria and as a reliable testimony to the absorptive powers of the large intestine carries little weight. Pohlmann characterizes the absorbing power of the large intestine 
as not limited to substances prepared by the action of the digestive fluids, but holds that it can absorb undigested food, such as white of egg, although it is probable that even here there is a splitting up of the protein molecule into smaller molecules before absorption takes place. Therefore he asserts that mutrient enemata based ироn the knowledge have saved many lives. The opinions of eminent physiologists diverge considerably with respect to the absorptive powers of the large intestine. The whole matter is in a somewhat confused state. It is, however, likely that the powers of absorption of the large intestine have been unduly minimized by some physiologists. The fact must not be lost sight of that in the small intestine the villi are especially adapted for absorptive purposes, and that in the large intestine there are no villi. In the large intestine there are some solitary glands which perform as much absorptive work as can be expected from their limited number, but in the opinion of Pohlmann the mucous membrane of the large intestine is an important factor in absorption.

As an excretory organ the large intestine of carnivora and civilized man plays a prominent rôle and perhaps its main value lies rather in its excretory functions than in its absorptive powers.

\section{ABSORPTION OF FOOD}

Now that the absorptive powers of the alimentary tract and the means or most probable means by which this process is accomplished have been considered, the next obvious subject for discussion is the absorption of the various kinds of foodstuffs. The substances to be absorbed are peptones, glucose and emulsified fats - the products of digestion; in addition to water and various salts. It may be stated in a general way that foods such as water and soluble salts are absorbed unchanged. On the other hand, the organic foods are changed considerably. As pointed out previously, absorption oceurs mainly through the blood vessels by way of the portal tributaries, and through the lymphatic vessels or lacteals. Speaking broadly, the proteins and carboliydrates are absorbed by the blood capillaries of the villi and the fats by the lacteals.

Halliburton, in common with all modern phrsiologists, does not attribute to known phrsical laws a complete explanation of the absorption of food material in the body. It has been definitely proven that diffusion and osmosis occur in the intestine, but this does not mean that absorption proceeds solely from mechanical action. Such action plays a 
part, but in all likelihood a small part, in the absorption that goes on in a healthy human being.

Much has yet to be learned regarding absorption, and as mentioned before the energy that controls absorption is doubtless some form of imbibition. Halliburton lays stress on the fact that a marked feature during absorption is the increased activity of the lymphocytes which lie beneath the epithelium; the number of these cells increases conspicuously. The surmise has therefore been advanced that these cells share in the work of transporting absorbed materials.

\section{ABSORPTION OF FATS}

Theories of Fat Absorption.-The manner in which the fats are absorbed has long been a stumbling block to physiologists and numerous theories have been brought forward to explain the mode of fat absorption. According to most recent views set forth by Howell, the emulsified neutral fat is either ingested directly by the epithelial cells, the fat droplets enter between the epithelial cells in the so-called cement substance, the fat droplets are ingested by leukocytes that lie between the epithelial cells or, lastly, that the fat is first split into fatty acid and glycerol and is absorbed in the epithelial cells in these forms. The last theory is that most greatly favored. While allowing that during digestion the epithelial cells contain fat droplets, Howell is of the opinion that these droplets are formed in situ by a synthesis of the absorbed glycerol and fatty acids. Even granting that the fat is absorbed in solution as fatty acids and glycerol, Howell still thinks that the mechanism of fat absorption remains unexplained. The most favored theory of the mechanism of fat absorption, restated clearly, is that the emulsified fats are split into fatty acids and glycerol which are taken up by the epithelial cells and passed into the stroma of the villi, there to be reconverted into minute fat globules.

Halliburton points out that in explaining the mechanism of fat absorption, the difficulty was to show how the fat first entered the columnar epithelium. Munk and, later, Moore and Lockwood, have demonstrated conclusively that fat is completely broken down. in the intestine into glycerol and fatty acids. Preliminary emulsification is advantageous for the formation of these substances, but not essential. According to Halliburton, then, not only is fat entirely absorbed as glycerol and fatty acids, but the latter, in great measure, are first converted into soaps; that is, compounds of the fatty acids and alkalis. As Pohlmann remarks, it is a moot point as to whether fatty acids and glycerol pass directly 
into the lymph channels which traverse the villus and finally unite to form the lacteal, or whether the lymphocytes, so abundantly found in the stroma, carry the small fat globules from the epithelial cells directly into the lacteal.

Munk found ont that the soap componnds of the fatty acids and alkalis pass realily through the striated borders of the intestinal epithelial cells; and these cells perform the synthetic act of building them into fat once more, the fat so formed appearing in the form of small globules, surrounding or becoming mixed with the protoplasmic granules that are ordinarily present. Munk also discovered as a result of his investigations that on feeding an animal on fatty acids the chyle contains fat, showing that the necessary glycerol must have been formed by protoplasmic activity during absorption.

A chapter dealing with absorption of foodstuffs would be obviously incomplete without reference to the views of Starling, and attention may be drawn here to certain of that distinguished physiologist's statements concerning the absorption of fat. Arguing from the postulate that the fats eaten by an animal in excess of its daily requirements are stored up in the body in the form in which they are ingested, and that each cell of the body probably possesses in itself the mechanism for the utilization of these neutral fats and for effecting in them the various changes involved in the successive stages of their disintegration and oxidation through which they are finally converted to $\mathrm{CO}_{2}$ and water, Starling contends that the problem of fat absorption is ultimately one of the simplest with which we have to deal. It merely involves the transference of the neutral fat of the food to the circulating fluids in such a form that it can be carried by them to the place where it is required for the metabolism of the body or where it may be stored up as a reserve substance. Wherever it is present in health fat should be regarded as food reserve, whether in the subcutaneous or intramuscular tissue, within the bones, or the cells of the cartilage, or of glandular, organs. In its wide distribution fat in the animal tissues may be compared to that of starch in the vegetable kingdom, though the glycogen of liver and muscle bears the closer resemblance. Yet fat and starch are physiologically interchangeable.

It may be further stated that after the removal of storage fat, its utilization, according to the hypothesis of Leathes, is brought about through the agency of the liver, in which such fat is transformed by a process of "desaturation" into fat-like bodies or lipoids, which are thence distributed in a utilizable form to the important organs of the body, 
including, of course, the liver itself. There is no space in this chapter to discuss at any length the elaborate and carefully-thought-out presentation of Starling's views. Among other salient points to which reference is made is the description by Briicke of the muscular mechanism of absorption. This mechanism was commented on in an earlier part of the chapter when considering the manner in which absorption by the small intestine was carried out; namely, that repeated contractions of the muscle fibers of the villus would tend to empty the spaces into the central lacteal, and this in turn into the submucous plexus of lymphatics, so that the lymph in the spaces is constantly renewed and passes laden with absorbed fat particles into the valved lymphatics of the mesentery. Starling thinks it probable that the muscular mechanism of absorption plays an important part in the absorption of fat, although it is difficult to furnish any experimental proof of the manner in which this mechanism works.

An extremely important part is played by the bile as well as by the pancreatic juice in the process of absorption of fats. Bile aids the digestion of fat, the bile salts acting in the same way as the co-enzyme of pancreatic lipase. Bile is also a solvent of fatty acids and Halliburton suggests that it probably assists fat absorption by reducing the surface tension of the intestinal contents. Membranes moistened with bile allow fatty materials to pass through them more readily than would be otherwise the case.

Aceording to Moore and Lockwood, quoted by Howell, the reason that the bile salts aid the absorption of the split fats is probably because the bile salts dissolve the fatty acids readily and then bring them into contact in soluble form with the epithelial cells. If the intestine be deprived of its bile contents by drainage by means of a fistula from the gall bladder or duet, a great deal of the fatty food is not absorbed and can be found in the feces. It is easy by direet observation to prove that the lymphatic ressels take up the greater part of the fat ingested. To demonstrate this it is only necessary to examine the lymphatics of the intestine of an animal after the administration of a meal rich in fats. These vessels are distended with milky chyle, while, according to Starling, the same fluid is found filling the cisterna lymphatica magna (receptaculum chyli) and the thoracic duct. It has been conclusively shown that a part, probably the greater part, of the fat absorbed from the intestine is conveyed thence by the lymphatic vessels to the venous circulation by which it is distributed to the various tissues of the body. It has not been determined as yet how it leaves the blood stream. 
But many experiments have shown that some of the fat which is absorbed does not travel by the way of the lymphatics and the thoracic duet. In fact, after deducting the anount of fat that escapes absorption and is lost in the feces, the amomnt that may be recovered from the thoracic duct is less than that taken in the food.

Frank, referred to by Howell, has advanced the theory that some of the fat is absorbed directly by the blood vessels of the villi. The portion thus absorbed enters the portal vein and passes through the liver before reatehing the general circulation. The liver holds back more or less of the fat taking this route, as it is found that during absorption the liver cells show an accumblation of fat droplets in their interior. Starling says that it is not known what happens to the fat that is not taken up by the lymphatics and holds that it is difficult to imagine that "any large proportion of this lost fraction is absorbed into the blood stream in the form of soaps," pointing out that Munk has shown soaps injected into the blood act as potent poisons. Emphasis may be laid upon the point that if absorption is active, the meshes of the villus contain a number of free fat granules and the leukocytes in these meshes are also generally found full of these granules.

Function of the Leukocytes. - Zawarykin and Schafer, referred to by Starling, impute an importance to the leukocytes in the transference of the granules from epithelial cells to the central lacteal. It was supposed that the leukocytes took up the fat granules extruded by the epithelial cells at the base of the villi and thence found their way into the central lacteal, where they broke down, in this manner furnishing the molecular basis of the chyle as well as its protein constituents. Heiderhain was strongly opposed to the view and pointed out that many of the granules staining darkly with osmic acid were not necessarily fat and that the number of leukocytes within the villi were hardly sufficient to account for the amount of material observed. Reuter is of the opinion that the epithelial cells take up fat in a dissolved condition through the striated border, and deposit it as granules of neutral fat in the inner portion of the protoplasm. From here the fat is passed on by the protoplasm by the side of the nucleus and extruded in the form of very fine granules in the deeper parts of the interepithelial clefts, which thus function as true excretory organs for the epithelial cells.

The view is still held that the fats are taken up by the epithelial cells from the intestine as fine particles of neutral fat, the chief use of the pancreatic juice being to aid the formation of an emulsion of fat in the intestines. Starling does not agree with this conception of the manner 
in which fats are absorbed and thinks there is little doubt they are absorbed and dissolved in the bile either as soap or fatty acids; he states the objections to the former theory at some length, the chief of which is that bile does not dissolve neutral fats, but does exercise a strong solvent action on fatty acids and on all kinds of soaps. Therefore, fats to be fully absorbed must be broken up into fatty acids and soaps. It has been demonstrated by experiment that if bile be cut off by occlusion of the bile duct or by means of a biliary fistula, that only a small proportion of the fat is absorbed; the larger unabsorbed portion is mostly found in the feces. This supplies conclusive evidence that the presence of bile in the intestine is essential for the normal absorption of fat. Ligature of the pancreatic duct also interferes with absorption. In all likelihood this result is due to the absence of the ferment of the pancreatic juice or lipase from the intestine.

Extent of Fat Absorption.-It is interesting to note that the amount of fat that may be absorbed from the intestines varies with the nature of the fat. Howell points out that experiments show that the more fluid fats, such as olive oil, are absorbed more completely, that is, less is lost in the feces, than in the case of the more solid fats. Comparative experiments have given such results as the following: olive oil, absorption 97.7 per cent; goose and pork fat, 97.5 per cent; mutton fat, 90 to 92.5 per cent; spermaceti, 15 per cent. The amount of fat that may be lost in the feces varies also with other conditions. If, for instance, an excess is taken with the foods, or if the bile flow is diminished or suppressed, the percentage in the feces is increased. The usual amount of fat allowed in dietaries is from 100 to 120 grams daily.

Hutchison has this to say regarding the absorbability of fat, that one generalization can be made with a fair amount of certainty. The lower the melting point of the fat, the more completely is it absorbed, due to the fact that a fat which is fluid at the body temperature is more easily taken up into the blood than one which remains more or less solid. The following are illustrative examples:

$\begin{array}{ccc}\text { Fat } & \begin{array}{c}\text { Melting } \\ \text { Pont }\end{array} & \begin{array}{c}\text { Percentage } \\ \text { Unabsorbed }\end{array} \\ \text { Putter } \ldots \ldots \ldots \ldots \ldots & 37^{\circ} \mathrm{C} . & 21 / 2 \\ \text { Bacon } \ldots \ldots \ldots \ldots \ldots \ldots & 48^{\circ} \mathrm{C} . & 8 \\ \text { Mutton fat } \ldots \ldots \ldots \ldots & 52^{\circ} \mathrm{C} . & 10\end{array}$

The total amount of fat which ean be absorbed in one day is also a matter of some interest. It has been found by experiment that 150 grams, 
about $51 / 2$ ounces, can be absorbed without appreciable loss. Above this point the waste increases considerably, but even when twice that quantity is taken the loss is less than 45 per cent. 'The practical deduction from these facts would seem to be that one need have no hesitation in ordering a patient, say a diabetic, to consume one quarter of a pound of butter every day. There is no likelihood of this quantity surpassing the absorptive powers of the intestine.

\section{Summary}

The processes involved in digestion and absorption of fat may be summed up as follows: hydrolytic cleavage of the neutral fats into fatty acids and glycerol is initial to absorption and combustion. In this process the gastric juice, the pancreatic juice and the succus entericus are all concerned. Also in those hydrolytic cleavages, in the velocity in which they occur in the body, the lipolytic action of the pancreatic juice and succus entericus is greatly aided and reinforced by the synergetic action of bile. Moore has shown that the solvent action of the bile is mainly owing to the bile salts and the presence therein of lecithin and cholesterin. The action of these strengthens the activity of the pancreatic juice, dissolves the fatty acids readily, and brings them in soluble form into contact with the epithelial cells. This lipolytic action forms glycerol, also fatty acids and soaps, in accordance with the acid or alkaline reaction of the medium. The alkaline soaps being soluble in water, the soaps of magnesium or calcium in bile and free fatty acids being soluble in bile acids, the fat is reduced to a condition rendering it soluble in the contents of the intestine, whatever their action may be. The fatty constituents are then taken up by the cells of the intestinal mucosa and synthesis takes place. Cleavage of the soaps ensues, fatty acids are set free, and after ridding themselves of water and combining with glycerol, form neutral fats which take the shape of small globules, becoming mixed with or surrounded by protoplasmic granules. As explained in an earlier part of the chapter, by active excretion these are pushed into the intercellular clefts and into the spaces of the villus; they are then expelled by the contractions of the muscle fibers of the villus into the central lacteal and finally to the thoracic duct by way of the mesenteric lymphatics. Sixty per cent of the fat absorbed is accounted for in this manner. As to how the remaining 40 per cent is dealt with in the body there is no accurate means of finding out. It may enter the blood stream or it may be broken down in the tissues. At any rate, as Starling states, 
"under normal circumstances the ntilization of fat is almost complete. By the time the intestinal contents have arrived at the lower end of the ileum 95 per cent of the fat has been absorbed." Vaughan Harley found that the removal of the whole intestine did not affect fat absorption.

Bayliss briefly summarizes the process of fat absorption as follows:

Fats are hydrolyzed in the small intestine by the pancreatic juice and absorbed as glycerol and fatty acids, the latter for the most part in solution in bile. In the epithelium of the villi they are resynthesized to neutral fats, which pass into the lymph of the lacteal system and thence to the blood in a freely emulsified state.

In a broad way this concise description is sufficient, but it hardly explains all that is known concerning the absorption of fat in the body. In order to gain an accurate view of the present situation, so far as the opinions of authorities founded upon careful research are concerned, the description given here almost in full may be submitted for earnest consideration.

\section{ABSORPTION OF CARBOHYDRATES}

There is no doubt that the carbohydrates are more completely absorbed than any other nutrient material. For the most part carbohydrate food is absorbed as simple sugars, monosaccharids. All the sugar ingested finds its way into the circulation, and starch is only detected in the feces when eaten in a form notoriously difficult of digestion-green vegetables, or masses of coarse food, for instance. Vegetable food yields a much larger percentage of indigestible residue than animal food, and is in itself much less easily digested owing to the fact that it is more or less enclosed in cellulose, which is difficult to bring into solution, while animal food is free. In addition, vegetable food, as a rule, is less easily absorbed, and, as it contains usually a less percentage of nitrogen, a much larger quantity is needed to furnish a certain amount of this element than in the case of animal food. Comparatively little sugar is absorbed in the stomach, and, as said before, the small intestine is the main absorbing organ for all classes of foodstuffs. Practically the whole of the carbohydrate constituents has been absorbed by the time the food has reached the ileocecal valve. However, views as to the absorptive powers of the stomach have changed and are changing considerably as the result of modern experiments. Pohlmann, referred to previously, draws attention to the fact that although the stomach has no specialized organs of absorption, its whole mucous membrane may, under certain conditions, absorb some materials digested, such as peptones and glucose. So fi: as the absorptive powers of the stomach are concerned, neither of the 
extreme views taken is corret. It is not merely a temporary receptacle for food, but can absorb peptones and glucose to a limited extent. It certainly does not possess the great absorptive properties that were formerly attributed to it. On the other hand, some absorption of the carbohydrates takes place in the stomach; dextrose, lactose, maltose, and sacharose and even dextrin may be alosorbed by the mucous nembrane of the stomach, and the more concentrated the solutions the more marked is the absorption. Glucose is absorbed mostly in the small and to some extent in the large intestine.

Cane sugar and milk sugar are inverted in the small intestine by invertase and lactase, the first being converted to dextrose and levulose, the second to dextrose and galactose. Both of these are converted from disacharids to monosaccharids before absorption. If an excess of these substances be taken they are partly absorbed without being inverted to simple sugar, and may be eliminated in the urine. The greater part of our carbohydrate food is eaten in the form of starch and the time required for the digestion and inversion of the starch involves a slower and more complete process of absorption.

Course of Carbohydrates in the System.-On hydrolysis, saccharose yields dextrose plus levulose; maltose yields dextrose plus galactose. The process of hydrolysis takes place along the enteric tract, so that all disaccharids ingested as food are absorbed in the blood stream as monosaccharids.

As the result of numerous experiments it is generally held by physiologists that the carbohydrates pass into the body by the route of vessels of the portal system. As a seemingly convincing proof of the statement it may be mentioned that no more sugar is detected in lymph from the thoracic duct than is contained in arterial blood taken at the same time. On the other hand, an increased percentage of sugar in the portal blood during the absorption of a large carbohydrate meal has been observed by several investigators. An abundant quantity of carbohydrate food may be digested and absorbed in the course of a day and all of this may be found in the blood in the form of dextrose which enters the portal vein and is distributed to the liver. This food which enters the blond as dextrose is stored up in the liver as glycogen, a store of carbohydrate held in reserve for the future needs of the body. By this means the amount of sugar in the general circulation is kept quite constant, according to Howell about 0.15. However, when a very large amount of carbohydrate food has been eaten it happens occasionally that the liver is unable to perform its functions of removing the excess completely. The 
condition known as hyperglycemia may be brought about by an increased amount of sugar above the normal in the general circulation. The excess may be excreted in the urine and the condition denominated "alimentary glycosuria" will ensue.

Starch may be eaten in greatly larger amounts than sugar and the percentage of sugar in the blood will not be raised thereby beyond the normal level. This is accounted for by the digestion of starch and sugar, that is, so far as is known concerning this matter. Dextrose is absorbed as such without being subjected to digestive processes, and cane sugar only requires conversion into dextrose and levulose before absorption. The action of ptyalin or amylase, and inversion subsequently by maltase, is needed before starch can be absorbed, and therefore, as pointed out previously, its absorption will be slower by far than that of the sugars. During this period, in the words of Howell, "The entire quantity of blood in the body is passed through the mesenteric arteries over and over again, and it is probable that even in the portal vein the quantity of sugar at any one moment rises but little above the normal level, and this small excess is held back by the liver cells, so that the systemic circulation is protected from becoming hyperglycemic.

The behavior of the intestinal wall to the absorption of disaccharids and monosaccharids is a question of interest. According to Starling, some of the carbohydrates of food are colloidal and indiffusible. How these substances, with respect to the mechanism of the process, pass across the intestinal wall may be explained in the same way as the absorption of water and salts. But the behavior of the intestinal wall enters into the problem to some extent, for it is relatively impermeable to the disaccharids as compared with the monosaccharids.

The absorption of certain disaccharids, especially of cane sugar and lactose, on account of the relative impermeability of the intestinal walls, proceeds more slowly by far from the intestine than that of the monosaccharids, the process of absorption being always dependent upon hydrolysis. This is no doubt the reason why large, even immense, amounts of cane sugar can be taken with impunity without causing the appearance of cane sugar in the blood or urine, while the ingestion of a comparatively small quantity of dextrose may bring about glycosuria. The mechanism of the absorption of the carbohydrates still requires a good deal of elucidation, especially perhaps as regards the behavior of the intestinal wall to sugar, and to nonassimilable artificial sugars in particular. However, with regard to the course of the carbohydrates 
in the system it may be definitely stated that they pass into the body by way of the vessels of the portal system.

FERMENTATION OF CARBOHYDRATES.-The various carbohydrates taken in the diet can be broken down by the fermentation in the alimentary canal into various acids, such as acetic, lactic and butyric acid, as well as the volatile fatty acids. $\Lambda$ certain amount of carbonic acid and alcohol are also formed during this fermentation. In connection with that condition known as auto-intoxication, these facts are interesting. Beyond giving a certain amount of discomfort to the patient by the distention of the intestines, carbonic acid formed in fermentation cannot be considered as toxic, and the alcohol in all cases is probably so small in amount that it can hardly have any effect on the organism. Marsh gas has also been demonstrated in the gases of the alimentary tract, but little is known of its toxic eiriects in the quantities which could thus be formed. The acid products of the carbohydrate and the fat fermentation have a certain amount of significance, since the acid reaction of the feces, when it occurs in disease, is due to these products of fermentation, the normal stools being alkaline. Apparently all these acids are easily absorbed into the general circulation, and are as rapidly oxidized under ordinary conditions. In cases of excessive formation of these acids, or where there is an excessive absorption from the alimentary tract, it may be that the quantities in the circulation are too great to be rapidly broken up; in such cases they are found in the urine, and may have some toxic significance. The condition of increased intestinal fermentation of fat and carbohydrates is most commonly present in children, and is frequently accompanied by vomiting or diarrhea, undoubtedly due to the action of fatty acids as irritants. Where this condition persists, anemia is found, which may result in increased destruction of red blood corpuscles caused by oleic acid.

The acids, when not broken down in the blood stream, may contribute to acidosis by fixing some of the alkali of the blood. In the consideration of the absorption of carbohydrates, the significance of the absorption of acids in the production of disease is a very important point. This leads to the consideration of auto-intoxication from the intestines. 'It is doubtful whether such a process occurs as long as intestinal digestion proceeds normally. As far as the fermentative products of carbohydrates and fats - the gas $\mathrm{CO}_{2} \mathrm{H}$ and the volatile fatty acids (lactic, butyric and acetic)are concerned, they are either harmless or produced from foods in such minute quantities that an effect on the remote organs and tissues has not been satisfactorily demonstrated. 
The theory of Czerny and Keller, that these end products of fermentation could lead to acidosis (especially in children) in spite of the demonstration of increased amounts of $\mathrm{NH}_{3}$ in the urine, cannot yet be regarded as sufficiently well founded.

Borger and Teuchiya's investigations lead them to a different view in explanation of the anemias of gastro-intestinal origin. They assume that lipoid substances exist in the intestinal mucosa which are capable of exerting hemolytic effects. It must not be overlooked that many human beings habitually ingest more of the organic acids in their regular food thin the most exact chemical determinations have discovered to be present normally in weighed amounts of intestinal chyme. Before attributing pathologic effects to the much smaller amounts of these substances produced in normal digestion, one should realize how much vinegar (acetic acid) is taken into the gastro-intestinal tract in the form of pickles, catsup, pickled fruits, condiments and salads; how much lactic acid in buttermilk, etc.

\section{PROTEIN ABSORPTION}

Manner of Absorption.-The views of physiologists, as to the manner in which protein is absorbed, have undergone a remarkable change since the question has been carefully and scientifically investigated. This revolution of ideas has been particularly manifested with regard to the form in which protein is absorbed from the alimentary canal and to its fate after absorption. There is, however, but little difference of opinion as to the channel by which it obtains entry into the circulation. Most of the experimental work recorded shows that the digested proteins are absorbed by the blood vessels of the villi, although, according to Mendel, excessive feeding of protein may result in absorption through the lymphatics also. All physiologists interested in the investigation of the lymph flow from the thoracic duct are satisfied that the variations in the amount of lymph bear no relation to the condition of the animal's digestion.

The accepted belief that protein is entirely absorbed by the medium of the blood ressels rests mainly upon two facts: (a) Schmidt-Mulheim demonstrated that if the thoracic duct and right lymphatic duct are ligated, so that the lymphatic circulation is shut off, an animal will absorb and metabolize the usual amount of protein, as is shown by the urea excreted during the period. This experiment proves that the absorption of proteins is not interfered with as the result of ligature of the thoracic duct. The conclusion, consequently, seems to be that the products of 
protein digestion are taken up by the epithelial cells and by these passed on into the blood vessels. (b) Munk has shown that if a fistula of the thoracic duct be established and the total lymph flow from the intestines be collected during the period of absorption of a protein diet, it will be found that there is no increase in the fuantity of lymph or in its protein contents. These two facts appear to demonstrate that the avenue by which protein reaches the circulation is by way of the blood vessels.

Accompanying Changes of Villus and Epithelium.-Various observers have described certain structural changes in the villi during the absorption of a protein meal. According to Starling, in nearly every case there is marked increase in the number of mitotic figures in the epithelium lining the follicles of Lieberkuhn. With regard to an increase of leukocytes in the villi during the absorption of protein, there is some difference of opinion. Hofmeister states that such is the case, and he believed leukocytes exerted an important function in the absorption of protein. Heidenhain ascribed but little importance to this occurrence, maintaining that in all animals such increase was constant, that the amount of absorption taking place was not influenced to any extent thereby, and that, so far as the total absorption was concerned, it was a wholly inadequate explanation. Other observers, however, have noticed changes in the epithelium after protein digestion. Reuter has described these changes, and has propounded the theory that these signify that proteins are taken up in a dissolved form and converted into coagulable proteins. The evidence is not sufficient to place the theory on a sound basis.

Form of Protein Absorbed.-According to Halliburton, it is possible for the alimentary canal to absorb soluble protein in an unchanged condition. For instance, after eating a large number of eggs, egg albumin is found in the urine. The authority argues from this that patients fed per rectum derive some nourishment from protein food, although proteolytic enzymes are absent from that part of the intestine. Such occurrences are exceptional and are merely illustrations of the fact that under unusual conditions the digestive system can rise to the occasion and perform unusual feats contrary to the normal course of events. According to Halliburton, the food proteins are broken up into their constituent amino-acids and in this form are absorbed. Howell holds that the form in which protein is absorbed and circulates in the blood has not been satisfactorily determined. Physiologists are agreed that, under normal conditions, the proteins of the food are resolved by the action of the gastric juice into alhumoses and peptones while in the stomach. Another step in the process of hydration takes place in the 
stomach when the trypsin of the pancreatic juice conducts the proteins through the stage of secondary albumoses and peptones and converts them into amino-acids and polypeptids. Erepsin of the intestinal wall exerts an action on the albumoses and peptones produced by gastric digestion, which also has the result of converting these into amino-acids and polypeptids. Finally, by the action of the digestive juices the proteins are reduced to a mixture of amino-acids and polypeptids which undergo no further disintegration.

EXTENT OF REDUCTION BEFORE ABSORPTION.-It is important to determine to how great an extent the proteins are reduced to their ultimate hydration products before absorption. Evidence has been adduced that protein may be absorbed by the small intestine without having undergone any hydration whatever. Friedländer made a series of experiments in which the absorptions of various proteins were compared after their introduction into loops of the small intestine which had been previously washed free from ferment. He found that during a period of four hours 21 per cent of the proteins of white of egg or blood scrum was absorbed. Of alkali-albumin which had been introduced into the loops during the same period, 69 per cent was absorbed; per contra, when syntonin and casein were introduced into the intestine, no absorption of any description was observed.

FOREIGN PROTEINS.-Our knowledge is by no means definite as to the manner in which unchanged protein reaches the blood stream. Foreign protein, when introduced into the blood stream, may produce poisonous effects and bring about conditions of disease. It is found that in the majority of cases, however great an amount of protein is administered in soluble form, none of it appears in the urine. As noted previously, Halliburton has alluded to the occurrence and Aescoli has observed that if the white of egg is administered in large amounts, albumin may be found in the urine.

Relation to Infant's Diet.-It has been demonstrated that at the birth of an animal and during the first few days of life the cellular lining of the alimentary canal is permeable to foreign proteins, whereas later on in life any protein which is taken up unchanged from the gut does not arrive in the same unchanged condition in the blood stream. The protein hodies in the colostrum-according to Starling, colostrum contains about 3 per cent of protein-the sole food of infants for the first week or so of life, pass into the intestine practically unchanged. If soluble proteins are introduced into the stomach of the infant, a certain proportion will be absorbed; if these are foreign, as, for instance, those 
contained in cow's milk or in the white of egg, they will excite biochemical reaction, and, in the opinion of Dr. Eric Pritchard, will lead to the production of specific precipitation in the blood. Consequently they will not subserve the functions of ordinary nutrition, and are thus not only useless but may be actually dangerous. It is often elaimed, and seems to have been proved to a very limited extent, that a certain amount of protein, such as white of egg or lacto-globulin, can be absorbed into the circulation from the intestinal tract without being broken down into its component amino-acids by panereatic digestion. While this may be so, it is known that foreign protein, if absorbed, can only act as foreign bodies, which are of no nutritive value to the organism. On the other hand, if proteins, as, for example, those contained in the colostrum of the child's mother, are introduced into the system of the infant and happen to be identical with its own specific circulating proteins, the case is quite different; such proteins are not foreign bodies and are available immediately for the purpose of nutrition. Pritchard further points out that these facts have an important bearing on maternal feeding. The colostrum of a wet nurse does not contain exactly the same proteins as the colostrum of the mother, and consequently is not so well suited to the requirements of the infant. It may then be safer to feed the newborn babe with the colostrum of a wet nurse than with the milk of some foreign species of animal, as the cow, but there are dangers attaching to the procedure and wet nursing should not be attempted during the first few days of life. The fact must be emphasized that the main purpose of digestion and absorption is not so much to effect the solution of solid articles of food as to split up foreign materials into their component elements. Foreign proteins are split up by the processes of gastric and intestinal digestion into their constituent amino-acids and from these new proteins are built up by synthetic processes on an entirely new architectural plan, and of a type which is suited to the specific requirements of the individual in whom they circulate.

Pritchard then lays down the dictum, "The whole question of the resolution of foreign proteins into their component elements or aminoacids is of immense importance in infant dietetics, for unless foreign proteins can be so resolved in the processes of digestion they cannot be utilized for the purpose of synthetically compounding the specific proteins, which are essential for the nutrition of the growing baby."

Lastly, these conclusions may be made that it is quite useless, or even dangerous, to supply the newborn infant with any variety of foreign protein unless or until the digestive functions have been established. 
It is possible, thinks Pritchard, that a great number of the troubles of digestion and nutrition in infants and young children may be traced to the improper administration of cow's milk before the gastric and pancreatic functions have been developed.

The chief protein of cow's milk is caseinogen, belonging to the class of phosphoproteins. Though young infants possess at first no powers of digestion, these are soon acquired by proper training, always provided that the food is suitable. Caseinogen, the protein of milk, is acted upon by the ferment remnin in the stomach and converted into an insoluble casein. It is acted upon further by lactic acid, or by hydrochloric acid and pepsin, and, like all proteins, is converted into albumoses and peptoses. These, to be utilized for nutritional purposes, must be broken down still further into amino-acids by the processes of pancreatic digestion.

However, a very important point made by Pritchard is not to strain the digestive and absorptive powers of an infant too greatly by giving it cow's milk in any form until the digestive functions have been sufficiently developed to deal with this kind of food. It may be weeks or even months before the gastric or intestinal functions become thus developed. Pritchard, therefore, is of the opinion that if an infant cannot digest or break up foreign food into those elementary fragments out of which it can synthesize its own specific nutritive material, we ought wholly or in part to perform its digestive functions for it. In other words, we ought to predigest any artificial food which is given to the newborn baby.

Causation of Protein Poisoning and Auto-intoxication.-Without unduly digressing from the subject in hand, the question of poisons derived from proteins which may be found in the alimentary canal and which may possibly enter the circulation, may be considered here with advantage. The proteoses and simpler products, when injected directly into the circulation, can be eliminated rapidly by the kidneys, but are apparently toxic, since they tend to exert a lymphagogue effect, inhibiting the coagulation of the blood. They also cause a fall in arterial pressure and a febrile reaction. Large doses in animals may even cause death. In cases of ulceration or other lesions of the alimentary canal, it is conceivable that the protenses and end-products of protein digestion may reach the general circulation, and-if the quantity absorbed is larger than the liver can deal with-their presence may explain many of the toxic symptoms which are periodically observed.

Albumosuria is known to occur when any considerable amount of tissue or extensive exudate is being autolyzed and absorbed. The products 
thus formed, reaching the general circulation, are readily eliminated in the urine. In children and in elderly people the epithelial cells of the alimentary canal are apparently thin, which may explain the fact that toxic attacks are more frequently observed among them. After a too copious protein diet probably no actually abrormal products are formed in the intestines, but, since the wall of the bowel has become permeable to the normal end-products of protein digestion, a greater amount may reach the circulation than can be grappled with by the organism. Accordingly, the albumosuria occurring in childhood and old age may be due in some cases to the arrival of these proteoses in the general circulation from the bowel itself.

It is alleged that toxic substances from a protein diet may be absorbed into the circulation and produce that condition known as alimentary toxemia or auto-intoxication. Harley states that among other products formed from protein in the alimentary canal and absorbed into the circulation, the sulphur of the protein can readily form sulphuretted hydrogen when there is putrefaction going on. Under pathological conditions, such as catarrh of the intestines, or when large quantities of protein have been taken in the diet, large amounts may be formed in the intestines. According to Senator, sulphuretted hydrogen, when absorbed into the blood, may be held responsible for various symptoms which vary from simple headache to absolute collapse. Herter has demonstrated the toxic effects of sulphuretted hydrogen when given to dogs per rectum. Cyanosis has been described by Stockvis and Talma and is considered to be due to the presence of methemoglobin in the blood, while Van der Bergh has apparently demonstrated the presence of sulphemoglobin. In 1886 it became a clinical practice to treat phthisic patients with large colon injections of $\mathrm{H}_{2} \mathrm{~S}$ (Bergeron). Cyanosis and other toxic effects described by Herter resulted. Harley thinks that it is difficult to determine to how great an extent one may consider sulphuretted hydrogen responsible for the symptoms occurring when this substance is demonstrated as present in the alimentary canal, as he has found it generally accompanied with some increase of indican in the urine. In those cases in which he had an opportunity of making a more complete metabolic analysis, indcl, skatol, phenol and cresol were also increased in the stools. He has found that when sulphuretted hydrogen is very markedly increased, or when the sulphuretted hydrogen is persistently found on analysis of the feces, the headaches often complained of by these people seem to be constant and accompanied with greater depression.

There are many other substances, derived from the protein by putre- 
faction in the alimentary canal, which can be isolated and which, under certain instances-such as when the wall of the intestine is thin or abraded - may be absorbed into the blood stream and give rise to autointoxication. Alien proteins may be toxic and are sometimes highly so. The normal processes of digestion break down the foreign protein into somewhat simpler, though still complex, atom groups, which, after absorption, are carried to the liver. It is the function of the latter to reconstitute the protein in a form adapted for human needs. One of the primary functions of the liver is to act as a shield against the toxicity of foreign proteins, and there is evidence that when by the formation of an Eck's fistula this function is eliminated, serious toxic results occur. In short, auto-intoxication caused by the absorption of alien proteins into the circulation may be traced to a defect in the liver, which, if functioning properly, ought to shield the body from their effects.

NORMAL FORMS OF PROTEIN WHEN ABSORBED.-In a normal condition, the absorption of unchanged proteins is a matter of little significance, regarded from the standpoint of the assimilation of protein as a whole. Practically all the proteins of food ingested by man are either insoluble or cooking has made them insoluble. Absorption, then, cannot take place until these proteins are rendered soluble. This end, as well as hydration, is reached by the action of the gastric and pancreatic juices. It is the chief object of these ferments to bring about this result.

Kuhne and Schmidt Mülheim both knew of the production of aminoacids as a result of the process of digestion, and yet they regarded their production as evidence of a waste of material.

Albumoses and Peptones.-Physiologists for many years were somewhat at sea as to what happened to the albumoses and peptones, which are soluble and diffusible, after they had been taken up by the absorbing membrane of the alimentary canal. They do not enter the blood stream as such. That they do not seems to have been proved by experiment and observations. Hofmeister and Neumeister concluded otherwise, and Salvioli made experiments in the same direction, which were interpreted as follows: that the result of the observations pointed to a regeneration in the intestinal wall of coagulable protein from the albumose and peptone taken from the intestines. The debated question, then, was whether the views of Hofmeister were correct in ascribing to the lenkocytes of the villi the greater part of the regeneration, or whether such regeneration might rather be attributed to the epithelial cells of the mucous membrane.

In analyzing these experiments, Starling records his opinion that 
the experiments did not justify the conclusion reached, but merely showed that the albumoses and peptones disappeared. Starling draws attention to the fact that Conheim repeated the experiments of Hofmeister in order to put their conclusions to the test. Conheim found that while the statement was aceurate that peptone and Ringer's fluid applied to intestinal mucous membrane together caused the disappearance of albumose and peptone, this was not owing to a regeneration of coagulable protein, as claimed by Neumeister, but because hydrolysis was advanced by the erepsin of the mucous membrane, the albumoses and peptones being by this action converted into the ultimate product of protein hydrolysis. Kutscher and Seemann, as the result of experimental work, came to similar conclusions. They demonstrated that at any time after a protein meal the end-products, especially leucin, tyrosin, lysin and arginin, were to be found in the contents of the small intestine. Cathcart and Leathes repeated Salvioli's experiment and came to conclusions greatly at variance with those of Salvioli. It was found by them that the artificial circulation, though sufficient to maintain the activity of the muscular wall of the intestine, as proven by the peristaltic movements, was insufficient to keep the mucous membrane alive. An hour's experimental work showed that the loop contained a mass of epithelial cells mixed with the products of the action of erepsin on the introduced peptone solution. In none of the experiments was there any decrease in the amount of incoagulable protein, and the processes of absorption had been brought to a standstill by the desquamation.

Amino-acids, Resulting from Hydrolysis of Complex Proteins. - The experiments of Cathcart and Leathes considerably changed the attitude of physiologists with regard to the problem of protein absorption. These experiments tended to prove that protein, in whatever form introduced, underwent hydrolysis in the gut before entering the blood stream.

To Emil Fischer's brilliant investigations and to other organic chemists of the same school we owe the possession of more exact knowledge concerning the molecular constitution of protein bodies than we possessed but a few years ago. It is known, for instance, that complex bodies of that nature consist of long chains of relatively simple atomic-complexes, fatty acids and amino-acids linked or combined together in ester groupings.

The exact chemical constitution of the amino-acids which are thus synthesized is also known. It has been discovered that while all the proteins when hydrolyzed yield the same kinds of amino-acids, there is 
a creat deal of difference in the relative amounts of these amino-acids contained in different proteins. At least twenty separate and independent amino-acids have been isolated by chemical tests and have been recognized as taking part in the composition of the various protein bodies. It is easy enough to separate the various forms of proteins into groups or classes, as serum albumins, globulins, nucleo-albumins, caseinogens, albumoses, peptones or collagens. However, there are slight specific differences in the "make-up" of each representative of each class, and, according to Pritchard, these specific differences unquestionably depend on the number and the grouping of the component amino-acids. The serumalbumins or globulins of no two animals are exactly alike from the biochemical standpoint. This is evidenced by the fact that if the serum of a horse is transfused into the blood stream of a human being, it acts like a foreign body and leads to the production of specific precipitins.

Two deductions are set down by Starling with regard to the relation of amino-acids to protein absorption. The first is that "the energy of the protein as evolved in the body lies not in the coupling of the aminoacids with one another, or indeed in the coupling of the nitrogen to the carbon, but, as in the case of other foodstuffs, in the carbon itself. The energy is derived from the combustion of the carbon in the molecule under the influence of the oxidizing processes of the body into carbon dioxid. Certain experiments seem to show that the theory has much in its favor. The sccond deduction made by Starling is "that while a certain proportion of the proteins of the food may be absorbed unchanged, a larger proportion by far is taken up as albumoses and peptones or amino-acids." Halliburton states "that when protein material is subjected to hydrolysis in the alimentary canal, it is finally resolved into the numerous amino-acids of which it is built. But before the ultimate stage is reached it is split into substances of progressively diminishing molecular size, which still retain many of the protein characters."

The product may be classified in order of formation as follows: (1) Metaproteins; (2) Proteoses; (3) Peptones; (4) Polypeptids; (5) Amino-acids.

According to a very large number of physiologists, perhaps the majority of them, practically all the protein of the body is presented to the alimentary canal for absorption and for passing into the blood stream in the form of amino-acids.

Amixo-acins and-Peptins vs. Bloon Protein.-Alonzo E. Taylor, in his very excellent text-hook on "Digestion and Metabolism," concludes that the problem of resorption of the products of digestion resolves itself 
into two possibilities. Either the amino-acids and peptids are resorbed unchanged and transported to the tissnes in that state for utilization or as far as is needed by the cells; or blood protein is formed in the intestinal wall by synthesis, and the blood protein carried to the cells for utilization. To attempt to oecupy a mildlle ground-that only so much protein is synthesized in the intestine as may be needed in the tissues, the excess of amino-acids deaminated there and the products carried to the liver to be converted into sugar and urea-is only to confuse the situation. Should all the amino-acids be built lack into protein in the intestinal wall when only a fraction thereof will be needed by the tissues? How should the intestinal wall know how much sinthesized protein will be needed by the tissues? Either there is total synthesis, except for superfluous aminoacids, or there is no synthesis in the intestinal wall. 'To Taylor, sound reasoning favors the theory of synthesis of protein from amino-acids in the intestinal wall. The deviation and utilization of the blood proteins are incomprehensible on any other hypothesis.

Reasoning from the above hypothesis, Taylor thinks it probable that the products of the digestion of protein, whatever the type, are resorbed in the form of peptids and amino-acids. When these have passed through the free surface of the epithelial cells of the intestinal mucosa and have been incorporated with the protoplasm of the cells, what occurs? The older view was that they were transported in this state to the liver; there to be largely converted into protein, the remainder to be burned. It was, of course, recognized that these end-products might pass through the liver and be utilized directly in other tissues of the body; but the larger utilization was localized in the liver. For this view, held generally for many years, there was no direct evidence; it simply appeared to be the natural inference.

Taylor somewhat discredits the views held by Starling and the most recent investigators-that practically all the protein of the body is presented to the absorbing mechanisms of the alimentary canal for absorption and for passing on into the circulating fluids. He points out that the positive chemical demonstration of amino-acids in the portal blood or in the general circulation with the Eok fistula, or in the normal circulation, has never been accomplished. Within recent vears, moreover, the investigations with the Eck fistula have shown that the results of this operation properly performed have been greatly exaggerated, and the dependence of the symptoms upon the amount of protein in the dict greatly overrated.

Indirect evidence and general considerations seem to lead to the view that the synthesis of protein from the end-products of digestion occurs 
in the protoplasm of the epithelial cells of the intestine. Howell concludes that under normal conditions the protein of the food is split into its constituent amino-acids by the successive action of the pepsin, trypsin and probably erepsin. It seems probable, or even certain, judging from the results of experiments, that during the digestion of proteins aminoacids are taken up by the blood flowing from the intestines. It is only recently that methods have been devised for the purpose of recognizing amino-acids in such fluids as blood. Alanin and valin have been obtained from the blood in crystalline form and histidin has been recognized by its reaction. Van Slyke and Meyer have shown that in the blood of dogs amino-acids are constantly present in small amounts, and that after a meal this concentration is definitely increased.

In the light of recent work it may be supposed that the normal course of events in regard to the absorption of proteins is as follows: the digested proteins are absorbed as amino-acids and distributed to the tissues by means of the blood. The tissues select and store certain of these bodies, and probably in each organ subsequent use is made of them to build up new tissue or to repair the wastes of metabolism. There is probably no especial form of circulating protein which serves as a pabulum for tissue repair and growth, but the amino-acids themselves constitute the form in which nitrogen food is presented to the different tissues, just as dextrose constitutes the circulatory form of carbohydrate food. Each tissue, from the amino-acids offered to it, builds up its own form of protein, and the amino-acids not used for this synthesis may be deaminized and then employed for energy purposes. There is evidence that in the liver especially many of the amino-acids arising from the digested food undergo deaminization, the nitrogen being eliminated as urea. During starvation the amino-acid content of the blood is maintained probably because the tissues themselves or some of them undergo self-digestion or autolysis, and thus furnish food material for the active tissues.

Leathes, Howell, and later Folin, have succeeded in demonstrating that during absorption the non-protein-that is, the amino-acid nitrogen of the blood-increases, and, as Halliburton points out, we have now a rational explanation of why it is that the organism can construct the proteins peculiar to itself and maintain its chemical individuality, although the food taken varies so widely in composition. Halliburton describes the absorption of protein by this ingenious metaphor: If a man wants to build a house from the bricks of another house previously built, he naturally takes the latter to pieces first, uses the bricks most suitable for his purpose, and arranges them in a new way. The Germans have recently 
coined the expression "Bausteine," or building stones, for the final products of proteolysis with the same underlying idea. This idea explains why we speak of the amino-acids as the final cleavage products of protein digestion. These fragments are rearranged by the tissue cells into tissue protein, which is different arehitecturally from the food protein. However, enough has been written to expound and explain the latest views. Although the opinions here set down are those which carry the most weight, since they are the outcome of the careful and painstaking investigations of scientists who have specialized in the question of ford absorption, yet the problem is by no means completely solved. Most of the salient facts are known, but there are still weak links in the chain. Starling's views are widely held by the majority of investigators, in spite of some differences of opinion, namely, that proteins are practically entirely converted into amino-acids and absorbed as such in the small intestine.

These amino-acids-recently termed the units, or "Bausteine"-form the component parts of the protein molecule, and, as pointed out in Chapter II, it is known that they are the ultimate products of hydrolysis of proteins by acids or by the actions of certain ferments. The amino-acids have one peculiar characteristic: they all contain the basic radical $\mathrm{NH}_{2}$ in their formula, which is graphically outlined in Volume I, Chapter II, explaining the chemistry of the amino-acids.

Course of the Amino-acids in the System.-The amino-acids are apparently absorbed by the intestinal epithelium, and observations made during a condition of starvation appear to show that the normal protein requirements of the body, or of the active tissues, are met at the expense of the less active tissues. As Halliburton points out, the body is remarkable for its economical use of the tissue proteins, and quite a small quantity relatively is used up in our daily activities, so that repair is necessary only to the same small extent. The theory that the amino-acids were decomposed in the intestinal wall into ammonia and non-nitrogenous residues, as well as the theory that the amino-acids are at once synthesized into blood proteins, ean be finally disposed of as incorrect.

Van Slyke, in discussing the "Present Significance of the Aminoacids in the Physiology of Digestion," has shown experimentally that the amino-acid concentration in the portal blood shortly after a meal may be double the normal concentration of these acids in the blood. And the vividiffusion experiments of Abel, Rowntree and Turner have proved the presence of several of these acids in the circulating blood of dogs. It has been proved, therefore, that amino-acids are absorbed and circulate in the 
blood as such, and recent, experiments at the laboratory of the Rockefeller Institute have shown that peptids and albumoses are not absorbed from the intestine. Practically all the nitrogen derived from ingested and digested proteins is found in the portal blood stream in the form of ultimate amino-acids.

Van Slyke's recent investigations qualify him to write authoritatively concerning the ultimate fate of the amino-acids after they have entered the blood stream. His analyses of tissues of dogs after intravenous injections of known amounts of amino-acids have shown that the several organs and tissues promptly remove all excess above the normal coneentration. The liver is the first and most aetive organ in this function of removal, but the muscles, the kidneys, and other organs also remove eonsiderable amounts. The removal by these several organs and tissues does not follow any physical or chemical law, for the acids are not found in the tissues, in even loose chemical combination, and are not present in a concentration equal to their coneentration in the circulating blood.

Having traced the amino-acids from their original formation by hydrolysis of food proteins, through the intestinal wall, into the eirculation and out of the eirculation, into the tissues, we must determine their ultimate fate. It has been shown that the greater portion of the daily intake of protein nitrogen is eliminated within twenty-four hours in the form of urea. It is evident, therefore, that the amino-acids find but temporary lodgment in the tissues by which they are absorbed and are, for the most part, rapidly destroyed and excreted. It is probable the liver is the most active organ, both in the absorption and in the destruction or preparation of the amino-acids for elimination or for storage as reserve protein. By experiment it was shown that the liver does not store aminoacids to any appreciable extent, but converts almost all of the amino-acids reaching it into urea as fast as they arrive. It is probable, however, that the liver is not the only tissue capable of converting them into urea, but it is certain that it is the most active normally. The liver does not wait until the tissues of the body have been saturated with amino-acids after a protein meal before destroying them, but begins their destruction at once as they reach it after absorption, and within a very few minutes after the ingestion of meat. Whether or not the liver destroys all of the amino-acids which reach it, and whether it converts a certain proportion of them into reserve protein which it stores, are points which have not yet been proved, and upon which we cannot therefore speak.

A considerable store of free amino-acids is always to be found in the muscles and other tissues, and this cannot be reduced in amount even by prolonged fasting. Chemical incorporation of the amino-acids into reserve or tissue protein does not take place rapidly after absorption of the acids from the blood stream. So far, we know but little as to which of 
the amino-acids can be synthesized by man and which must be taken already formed from his food. It is known, however, that lysin, tryptophan, cystein, and probably tyrosin, are essential and must be obtained already formed. We know, further, that the higher mimals can synthesize some of the simpler amino-arids, such as glycocoll.

The amino-acids which are not incorporated into the body are broken down by splitting of the amino-gromp with the formation of ammonia and a hydroxyl acid. The ammonia is converted into urea and eliminated. The fatty acid left is, in the case of half of the amino-acids, then converted into glucose.

Lusk points out that the amino-icids alre alsorbed by the blood, as first indicated by the work of Howell, "The Science of Nutrition," American Journal of Physiolyg: 1!nofi, page 27:3, who dialyzed dogs' blood both before and after giving meit, and in the latter instance recovered more material on adding naphthalene sulphochlorid to the diffusate than in the former. The precipitate, however, being an oil, its quantity could not be measured accurately. Folin and Denis made experiments on animals, the results of which indicate that absorbed amino-acids circulate in the blood stream, are retained in the muscle tissue, and that after an hour urea rises in the blood in response to the increased production of urea in the tissues. They found no increase in the quantity of urea or of ammonia in the blood of the portal vein after introducing glycocoll or alanin into a loop of the intestine, and by the experiment demonstrated that the amino-acids were absorbed unchanged without deamination, which would have involved ammonia or urea production. Lusk, in summarizing the pros and cons of a discussion regarding the course of the amino-acids in the blood, is of the opinion that "it becomes clear that though the body is built up of proteins which are aggregates of amino-acids, these same amino-acids occur free in only minimal amounts, 4 parts in 100,000 in hlood, for example, and 40 to 80 parts in 100,000 of muscle. These small amounts are constantly present, and apparently are the precursors of urea. After giving meat in large quantity the amino-acid concentration rises in the blood, but not in the tissues, for in the tissues the amino-acids are either destroyed with the production of urea or they are reconstructed into body protein, thus becoming 'deposit protein.' Then starvation takes place it is obvious that the quantity of protein destroyed may depend upon the protein condition of the cells themselves, and that in the presence of much 'deposit protein' this may be metabolized in large quantity during the first few days, as is indicated by a high nitrogen elimination in the urine." 
Starling holds that although the experimental proof of the conclusion that the blood carries the protein from the alimentary canal by means of amino-acids is beset with many difficulties, there is a prior reason to believe that such is the case. Experiments in this direction are somewhat confusing. Starling, therefore, submits three possible processes which may take place.

At the present time it is impossible to decide with any certainty as to which of these views of the fate of the ingested protein is correct. It is possible that all three processes may take place:

(a) A proportion of the protein may be built up in the cells lining the alimentary canal to form blood protein, so that this organ would have to be regarded as an important blood-forming organ.

(b) Another portion, representing the amount required to replace the tissue waste of the body, is absorbed into the blood stream as amino-acids, in which form it is carried to the tissues and reintegrated into the protein characteristic of each tissue.

(c) A third portion, probably the major portion of the protein, does not reach the tissues at all as a nitrogenous compound, but undergoes deaminization in the intestinal wall, the nitrogen being carried rapidly to the liver and converted into urea and then excreted by the kidneys, while the non-nitrogenous moiety is carried to the tissues, to which it serves as a ready and important source of energy.

Some of the matters discussed in the foregoing paragraphs reiterate the views of the most prominent authorities on the question of food absorption, but it is emphasized in this manner in order to drive home the fact that the modern theory of the absorption of food rests mainly upon the supposition that this process is one with which the amino-acids are chiefly concerned. As to the exact manner in which the amino-acids act, definite knowledge is lacking, but the recent investigations of the leaders of research in this direction tend to prove that they pursue the course which has been already clearly stated - that proteins are split by the digestive juices into their constituent amino-acids, and that these substances pass as such into the blood stream. 


\section{THE ROLE OF THE WHITE BLOOD CORPUSCLES IN}

\section{THE ABSORPTION OF FOOD}

When food is in the course of absorption the leukocytes accumulate in the nucous membrane of the gut. After a meal has been absorbed they are found in the blood in very large quantities. Schäfer describes them as loading themselves with fat and carrying the fat to the chyle where the fat is set free by the dissolution of the leukocyte.

Leukocytosis is said to be most pronounced during the digestion of proteins. These leukocytes that ingest bacteria are termed "phagocytes." The "phagocytosis theory of Metehnikoff" assumes that the functions of the leukocytes is to ingest foreign particles, including bacteria with which they come into contact, in the manner that the ameboid leukocytes are known to do. 'This function was the foundation for Wright's opsonic theory, which was to the effect that the power of the leukocytes to ingest bacteria depends upon the presence in the plasma of certain substances to which the name of opsonin was given, which render the bacteria in such a state that they are particularly susceptible or sensitive to attacks by the leukocytes. Howell states that they also aid in the absorption of fats from the intestine. They aid in the absorption of peptones from the intestine. They take part in the process of blood coagulation. They are held to maintain the normal protein composition of the blood plasma.

Howell further comments "that the blood proteins are peculiar, and they are not formed directly from the digested food. It is possible that the leukocytes, which are the only phagocytic cells in the body, aid in keeping up the normal supply of proteins. From this standpoint they might be regarded, in fact, as unicellular glands, the products of their metabolism serving to maintain the normal composition of the blood plasma. When the products of digestion of proteins are in the capillary tubes the leukocytes are chemotactic towards them, and as they exhibit the same tendency towards decomposing tissue, Hofmeister has suggested that most of the proteins are absorbed by uniting with the leukocyte body. Decomposition of the whole or part of the cell is supposed to set them free. As the agreement among physiologists appears to be general that proteins are absorbed as amino-acids, and enter the blood stream as such, and, moreover, when the rapidity and volume of absorption and the relatively small number of leukocytes found in the blood are considered, this theory will hardly bear close analysis. Howerer, there are still some indications that blood proteins may be formed by leukocytes and that they busy 
themselves in securing sufficient protein to supply the needs of the blood tissue alone.

Perhaps most writers on physiology have reached the conclusion that the work of the leukocytes is limited to the removal of dead or injured tissue. At any rate, much further investigation is called for before any positive statement is made concerning the rôle of the leukocytes during absorption.

\section{OSMOSIS, DIALYSIS AND DIFFUSION}

At one time certain known physical and chemical energies were considered to be sufficient to explain the facts of absorption, namely, osmosis, dialysis, diffusion, and imbibition, which consists in the passage of fluid under pressure through a membrane. These were thought to be the principal means of absorbing food material. These factors undoubtedly play an important rôle in the passage of solutions through the alimentary mucous membrane and the walls of the blood vessels. The part which the physical factors play is probably most pronounced in the absorption of water and crystalloids. The nature of the fluid within the digestive tract, and the movements of the walls of the stomach and intestines by means of which the material to be absorbed is brought into intimate contact with the absorbing membrane, are additional factors which influence absorption.

But before dealing with this phase of the question it may be as well to define the terms diffusion, dialysis and osmosis.

Definition of the Terms.-According to Howell, "When two gases are brought into contact a hemogeneous mixture of the two is soon formed. This interpenetration of gases is spoken of as diffusion, and is due to the continual movement of the gaseous molecules to and fro within the limits of the confining space. So also when two miscible liquids or solutions are brought into contact a diffusion occurs for a similar reason, the movements of the molecules finally effecting a hemogeneous mixture. If the two liquids happen to be separated by a membrane, diffusion will still occur, provided the membrane is permeable to the liquid molecules, and in time the liquids on the two sides will be mixtures having a uniform composition. Not only water molecules, but the molecules of many substances in solution, such as sugar, may pass to and fro through membranes so that two liquids separated from each other by an intervening membrane and originally unlike in composition, may finally; by the act of diffusion, come to have the same composition." Dialysis refers more 
strictly to the passage of substances dissolved in water through animal membranes-osmosis, to the passage of water alone.

"In the body we deal with aqueous solutions of various substances that are separated from each other by living membranes, such as the walls of the blood capillaries or of the alimentary canal. The laws of diffusion through membranes are of importance in explaining the passage of water and dissolved substances through these living septa. In aqueous solutions, such as are found in the body, the movements of the molecules of water, as well as of the substances in solution, must be taken into account. These latter may have different degrees of diffusibility as compared with one another or with the water molecules, and it frequently happens that a membrane which is permeable to water molecules is less permeable or even impermeable to the molecules of the substances in solution. For this reason the diffusion stream of water and of the dissolved substances may be differentiated to a greater or less extent." In recent years it has become customary to limit the term osmosis to the stream of water molecules passing through a membrane, while the term dialysis or diffusion is applied to the passage of the molecules of the substances in solution. The osmotic stream of water under varying conditions is especially important.

Osmotic Pressure.-In comnection with this process it is necessary to define the term osmotic pressure as applied to solutions. A perfectly satisfactory explanation of the nature of osmotic pressure has not yet been furnished. According to Halliburton, "The following simple explanation is the best. Suppose we have a solution of sugar separated by a semipermeable membrane from water; that is, the membrane is permeable to water molecules, but not to sugar molecules. The streams of water from the two sides will then be unequal; on one side we have water molecules striking against the membrane in what we may call normal numbers, while on the other side both water molecules and sugar molecules are striking against it. On this side, therefore, the sugar molecules take up a certain amount of room, and do not allow the water molecules to get to the membrane; the membrane is, as it were, screened against the water by the sugar, therefore, fewer water molecules will get through from the screened to the unscreened side and vice versa-in other words, the osmotic stream of water is greater from the unscreened water side to the screened water side than it is in the reverse direction. The more sugar molecules that are present, the greater will be their screening action; thus we see that the osmotic pressure is proportional to the number of sugar molecules in the concentration of the solution." According to Van't Hoff's hypothesis the osmotic pressure is equal to that which the dissolved sub- 
stance would exert if it occupied the same space in the form of a gas. The nature of the substance makes no difference; it is only the number of molecules in it which causes osmotic pressure to vary.

PRESSURE EXERTED BY CRYSTALLOIDS.-From Halliburton's researches concerning osmosis, dialysis and diffusion he thinks, "The osmotic pressure exerted by crystalloids is very considerable, but their ready diffusibility limits their influence on the flow of water in the body. Thus if a strong solution of salt is injected into the blood, the first effect will be the setting up of an osmotic stream from the tissues to the blood. The salt, however, will soon diffuse out into the tissues, and will then exert osmotic pressure in the opposite direction. Moreover, both effects will be but temporary, because excess of salt is soon eliminated by the excreting organs."

OSMOTIC PRESSURE OF PROTEINS.-It has been generally assumed that proteins, the most abundant and important constituents of the blood, exert little or no osmotic pressure. According to Starling, they have a small osmotic pressure. As Halliburton points out, if this be so, even a slight pressure is of importance, for proteins, unlike salt, do not diffuse readily, and their effect therefore remains as an almost permanent factor in the blood. Starling places the osmotic pressure of the proteins of the blood as equal to $30 \mathrm{~mm}$. of mercury. Halliburton is of the opinion "that from the theoretical standpoint we would find it difficult to imagine that a pure protein can exert more than a minimal osmotic pressure. It is made up of such huge molecules that, even when the proteins are present to the extent of 7 to 8 per cent as they are in blood-plasma, there are comparatively few protein molecules present, and these are in a state of colloidal solution, not true solution. Still by means of this weak but constant pressure it is possible to explain the fact that an isotonic or even a hypertonic solution of a diffusible crystalloid may be completely absorbed from the peritoneal cavity into the blood. The pressure observed may be due to saline materials, from which it is difficult to separate proteins. The functional activity of the tissue elements is accompanied by the breaking down of their protein constituents into such simple materials as urea, and its precursors, sulphates and phosphates. These materials pass into the lymph, and increase its molecular concentration and its osmotic pressure; thus water is attracted from the blood to the lymph, and so the volume of lymph rises and its flow increases. On the other hand, as these substances accumulate in the lymph they will in time attain there a greater concentration than in the blood, and so they will diffuse towards the blood, by which they are carried to the organs of excretion. However, 
this difficulty exists. The proteins which are most important for the nutrition of the tissues are practically indiffusible. 'Therefore, it must be assumed that their presence in the lymph is due to filtration from the blood." The plasma in the capillaries is under a somewhat higher pressure than the lymph in the tissues, and this tends to squeere the constituents of the blood, including the proteins, through the capillary walls. Waymouth Reid finds that absolutely pure proteins exert no osmotic pressure; the pressure observed is due to saline and other materials from which it is difficult to disentangle the proteins. Imbibition is the absorption of fluid by a solid body without resultant chemical changes in either. All colloids are subject to imbibition, which in many cases is impossible to distinguish from the processes of solution.

As noticed before, the processes of osmosis and diffusion are most important from the physiological standpoint. There are aqueous solutions of various substances in the body separated from one another by membranes: the endothelial walls of the capillaries separating the blood from the lymph; the epithelial walls of the kidney tubules separating the blood and lymph from the urine; epithelium in all secreting glands; and lastly the wall of the alimentary canal separating the digested food from the blood vessels and lacteals. Hence, in problems such as lymph formation, the formation of urine and other excretions and secretions, and absorption of food, the laws which regulate the movements both of water and substances which are held in solution by water must be taken into account.

Filtration.-Osmosis is not the only force at work. Filtration must be considered-that is, the forcible passage of materials through membranes, due to differences of mechanical pressure. That osmosis is not sufficient to account for the absorption of food is clearly shown by the fact which Reid has pointed out, namely, that if the living epithelium of the intestine is removed, absorption comes very nearly to a standstill, although from the purely physical standpoint removal of the thick columnar epithelium would increase the facilities for osmosis and filtration.

Consequently, mechanical and physical factors supply no wholly adequate explanation of the observed facts of the absorption of food. There is some hitherto unexplained factor bound up in the characteristics of the living protoplasm of the epithelial cells themselves. If isotonic blood serum be introduced into the intestine the salts and water are at once absorbed, also the albumins, but more slowly. When this occurs the osmotic conditions are in balance and the pressure is greater on the side of the blood vessels so that absorption takes place with the actual expenditure 
of encrey. The really important fact remains that the absorption through a living membrane is influenced by the membrane in ways that as yet have not been thoroughly made plain. This is the factor that determines the different rate of absorption and the so-called selective absorption in various regions of the alimentary canal.

The object of this chapter is to show as far as possible how absorption of food in the body is carried on. No absolutely definite conclusion has been reached on this point, but the majority of those who have been engaged in physiological investigations and observations are of the opinion that it is a living and not a mechanical action. In a healthy body the skin as an organ of absorption may be excluded as a negligible quantity. The views of authorities on physiology have been largely drawn upon.

\section{BIBLIOGRAPHY}

Abierialnen. Text-book of Physiological Chemistry.

Cannox. The Movements of the Stomach Studied by Means of the Roentgen Rays, Am. J. Physiol., 1, 259. The Movements of the Intestines Studied by Means of the Roentgen Rays. Am. J. Physiol., 6, 261. Salivary Digestion in the Stomach, Am. J. Physiol., 9, 396.

- The Passage of Different Foodstuffs from the Stomach and through the Small Intestine. Am. J. Physiol., 12, 387. The Acid Control of the Pylorus, Am. J. Physiol., 20, 283.

Cintteninex. The Nutrition of Man, chaps. 1 and 2.

Fischer. Physiology of Alimentation, 1907.

Folix. A Theory of Protein Metabolism, Am. J. Physiol., 13, 117-138.

Gerinarits. Ueber Darmfäulniss-Ergebnisse der Physiologie, 3, I, 107154,1904 .

Hammarstex. Text-book of Physiological Chemistry.

Heister. Chemical Pathology, 1902. Bacterial Infections of the Digestive Tract, 1907.

Howell. Text-book of Physiology, 2nd ed., 1907.

- Téxt-hook of Physiology, chaps. 47 and 48.

Lusk. The Fate of the Amino Acids in the Organism, J. Am. Chem. Soc., 32, 671-680, 1910.

Oppexinemas. Handbuch der Biochemie, vol. iii, part 2, 1909. Pavioy. The Work of the Digestive Glands, 1910.

Schaffil. Text-book of Physiology, 1898. 


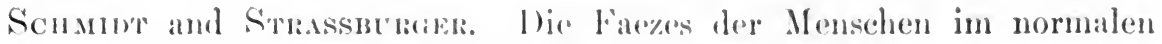
und krankhaften \%ustande, žnd ed., 1905.

Stalidaci. Recent Adrances in the Phrsinlogy of Digestion, 1907.

Von Noonbex. Metabolism and P'ractical Medicine, vol. i, pp. 64, 127, 153-16s. 



\title{
CHAP'TER VIII
}

\section{BACTERIAL DECOMPOSITICN OF FOOD IN THE GASTRO- IN'TESTINAL TRAC'I' IUURING THE PROCESS OF DIGESTION 1}

\author{
Arthur I. Kendall, B.S., Ph.D., Dr.P.H. \\ Experimental Observations of Bacterial Metabolism: Relation to Human \\ Metabolism. \\ Nature of Bacterial Metabolism; Anabolic and Catabolic Activity; Spe- \\ cificity of Microbic Action; Influence of Utilizable Carbohydrates \\ upon the Formation of Proteolytic Enzymes. \\ Gastro-intestinal Bacteriology: In Normal Infants; Adolescents; Adults. \\ Regional Bacteriology.
}

Experiments to Determine the Nature of Bacterial Activity.-Direct observations relating to bacterial decomposition of food in the gastro-intestinal tract are few in number and, for the most part, these observations have been but incidental details in studies of material obtained from natural or artificially produced fistulæ in the human being or the experimental animal. As a general rule such material is small in amount, difficult to obtain and not collected primarily for bacteriological purposes. It is obviously impossible to reproduce experimentally, at the present time at least, those complex intestinal conditions in which alimentary enzymes, bacterial symbioses and antibioses, absorption of products of digestion and of bacterial excretion and other factors mutually react as in a normal digestive system. Relatively simple observations in vitro, where intestinal organisms are grown in the products formed from the digestion of mixtures of proteins and carbohydrates and fats by gastro-intestinal enzymes, are unrecorded.

It will be seen, therefore, that available evidence relating to the bacterial decomposition of foods in the gastro-intestinal tract must be largely circumstantial; it is drawn chiefly from two sources,-first, the changes induced in sterile foods by various extracts of the gastro-intestinal tracts

$1 \mathrm{~A}$ bibliography covering the subject matter presented herein will be found in Kendall's "Bacteriology, General, Pathological and Intestinal," published by Lea and Febiger, 1916. 
of different animals containing enzymes in varying states of activity, and second, the changes induced by different types of bacteria in various foods ordinarily sterile. It is frankly admitted that there are inherent fallacies in generalizations drawn from experiments of this kind which must be considered and evaluated before their relation to the living organism is computed. Nevertheless certain outstanding features of the general problem appear to be so well substantiated that they can be regarded tentatively as fixed points around which concomitant complex and individual details may be ultimately grouped.

A dynamic aequaintance with the underlying principles governing microbic activity in the gastro-intestinal tract and of the relation of this activity to the economy of the host, can hardly be realized from a purely botanical consideration of the various species of microörganisms that may be detected in the alimentary contents. If, on the contrary, intestinal microbes be regarded, as indeed they are, as "living chemical reagents," an important avenue of approach to the problem is opened, because these bacteria in the last analysis are digestive systems working within a digestive system. In other words, bacteria are important from the viewpoint of "what they do rather than what they are." What bacteria are, is a problem in protistology; what bacteria $d o$, is clearly a record of those activities which collectively comprise their metabolism.

Certain fundamental characteristics are discernible in the metabolism of host and microbe alike;- - digestion, through which potential fond is prepared for assimilation; the ultimate intracellular utilization of foods thus prepared; and assimilation for the growth and repair of the tissues and for conversion into energy to maintain the activities of the organism. Bacteria within the alimentary canal of a host perform their entire metabolic activities there, whereas only the digestive phase of the metabolism of the host takes place within this restricted field; the intracorporeal utilization of assimilated digestion products by the host is normally beyond the range of microbic activity, although the latter may at times exert a distinct influence upon the process.

Relation of Bacterial Activity to Food Metabolism.-In general, therefore, bacterial activity in the intestinal tract (which may be more correctly termed "bacterial development" and "bacterial metabolism") takes place at the expense of food in the process of digestion by the host. If the products of bacterial growth within the gastro-intestinal tract are innocuous for the host, a slight diminution in the total food ingested results; if the products of this microbic activity, as, for example, lactic acid, are utilizable by the host after assimilation from the alimentary canal, the 
loss to the host is minimal. In the latter case the loss is limited practically to the actual elements which enter into the substance of the bacterial bodies and waste therefrom.' 'This slight loss is more than compensated for probably through the formation of lactic acid within the alimentary canal by normal intestinal bacteria. The presence of lactic acid would create conditions which would be more or less inimical to the development of extraneous microbes whose activities might be in opposition to the well-being of the host. The development of adventitions types of bacteria within the alimentary canal may affect the host adversely, not so much by a reduction of food leading to partial starvation, as by the formation of products of metabolism which even in small amounts may immediately or mediately create conditions leading to the arrest of the normal digestive processes becaluse of greatly inereased peristalsis, or to the rapid or slow poisoning of the host.

It is important to realize that the products of metabolism even of the same organism are, or may be, greatly influenced by the nature of the diet of the host. The diet of the host, of course, contributes largely to the normal nutritional environment of intestinal organisms in the last analysis. In referring thus to the diet of the host, it is tacitly understood that differences in the rate of digestion and assimilation of the various components of the diet, the integrity of various gastro-intestinal enzymes and the proper progressive movement of food through the alimentary canal, are ancillary factors which collectively influence the nutritional environment of intestinal microbes.

The normal digestive processes in the alimentary canal as the food proceeds from the mouth to the anus result in a progressive simplification of those complex organic compounds, proteins, carbohydrates and fats which comprise the food of the host to simpler compounds through hydrolytic cleavages initiated by the various proteolytic, amylolytic and lipolytic enzymes of the gastro-intestinal tract. It may be confidently anticipated, therefore, that the normal resident bacterial population at a given level will consist largely of organisms which can utilize the average pabulum at a particular site more advantageously than their fellows, as well as bacteria which have been transported mechanically in the intestinal contents from higher levels. Experience has shown that the lower levels of the intestinal tract, at least to the transverse colon, exhibit a greater density of bacterial types than higher levels. This is partly due to a

1 It has been conservatively estimated that a normal healthy adult on a normal diet eliminates daily about thirty-nine trillion bacteria in the feces. About 0.5 gram nitrogen is contained in the dried bodies of these lacteria. 
greater intensity of microbic development at lower levels, and to the acquisition of organisms which are mechanically transported from higher levels. The fecal mass resting in the rectum, therefore, contains representatives of the entire intestinal fecal flora; a great majority of these are either dead or of low viability. This rather general reduction in viability is due to the relative desiccation of the feces, the accumulation of waste products and the generally unfavorable character of the medium.

It is worthy of note that the bacterial flora at a given level may be unhomogeneous; experience has shown that the bacteria of the alimentary canal, which are in contact with the intestinal wall, may differ rather markedly in type from the flora in the center of the intestinal contents at the same level. It is not improbable that mechanical protection afforded by the depths of the folds of the walls of the intestinal canal from the general progressive downward movement of the mass in the alimentary canal, permits of a relative stagnation in this area. A careful study of this highly important phenomenon is yet to be made.

\section{THE NATURE OF BACTERIAL METABOLISM}

Phases of Bacterial Activity.-Two quite distinct phases may be detected in the life history of a bacterial cell; an anabolic or constructive phase (protoplastic) which comprises the phenomena of growth and maintenance of structure (including the replacement of losses incidental to the formation and excretion of soluble enzymes, the production of capsules, etc.) and a catabolic or vegetative phase (protoclastic) during which the mature organism reacts chemically with its nutritive environment in such a manner as to provide the energy necessary for the performance of its various normal functions. Chronologically, the anabolic phase, as a whole, precedes the catabolic phase, although the two may appear to overlap somewhat. The prominent features of the metabolism of bacteria may be summarized as follows:

1. The structural phase or anabolic phase is essentially the phenomena associated with the preparation, assimilation and intracellular transformation of organic substances, among which amino-acids in various degrees of complex combinations are prominent, into the cytoplasm of the cell, its appendages, secretions and enzymes.

2. The energy phase or catabolic phase which comprises the preparation, assimilation and internal transformation of organic substances to furnish the forces requisite to maintain the vegetative activities of the 
mature cell; the latter substances, unlike those required for structure, need not be nitrogenous.

The metabolism of the bacterial cell, therefore, consists in general of the preparation, assimilation and internal utilization or transformation of nutrient substances for the construction and support of the organism.

PRELIMINARY TRANSFORMATIONS.-'The nature of the preliminary transformations which various types of nutrient substances undergo, varies greatly with different kinds of organisms; some bacteria, as, for example, Bacillus protens, the spirillum of Asiatic cholera and Bacillus pyocyaneus, growing in protein media that contain no utilizable carbohydrates, ${ }^{1}$ secrete soluble (exo) proteolytic enzymes. 'These exo-enzymes effect a non-specific hydrolytic cleavage of the various proteins or protein derivatives to simpler compounds which are then assimilable. The mechanics of secretion of these soluble proteolytic enzymes and their action are in general analogous to the secretion of pepsin or trypsin in the human alimentary canal. Many anaërobic bacteria (1) secrete exo-enzymes which are far more active under favorable conditions than the exo-enzymes of aërobic bacteria which have been studied to date(2). A sharp distinction must be drawn between the non-specific cleavage of protein by these exo-enzymes and the substances arising from the intracellular utilization of these products of cleavage by the bacterial cell after they are assimilated. Deaminization is a feature of the latter phase, but it is no more associated with the former than it is with the action of pepsin or trypsin in the alimentary canal of man. The non-specificity of the simpler products of hydrolytic cleavage of various proteins by the exoproteolytic bacterial enzymes is in striking contrast to the specificity of products resulting from the intracellular digestion of these products of hydrolysis; the former (before assimilation by the microbe) are analogous to those formed by enzyme action within the intestinal tract of man, the latter (transformed intracellularly by the microbe) are specific for the organism, and they may be imocuous to the host, harmful or even acutely toxic. The extent to which soluble, bacterial proteolytic enzymes may be a factor in the economy of the alimentary tract of man is as yet unanswered. In addition to these soluble, non-specific, proteolytic enzymes, certain types of bacteria secrete soluble carbohydrolytic enzymes, which effect a cleav-. age of polysaccharids or in some instances even bioses to simpler com-

1 The effect of utilizable carbohydrate in suppressing the formation of these exoproteolytic enzymes, at least in an active state, is worthy of note. Space does not permit of a discussion here. 
pounds(3), and soluble lipolytic enzymes and esterases(4). The latter split fats or esters into their component parts.

FINAL TRANSFORMATIONS.-The final transformations which nutrient substances undergo within the body of the bacterial cell (after preliminary extracellular hydrolytic cleavage and assimilation) bear the same general relation to the life of the microbe that the utilization of nutrient substances which pass from the intestinal tract to the tissues bears to the life of man.

Specificity of Microbe Action.-This brief discussion of the more general phenomena of bacterial nutrition is an essential introduction to the real problem of the formation and elimination of the waste products arising from bacterial metabolism. In the final analysis it is the waste from this internal utilization of proteins, fats, carbohydrates, or their derivatives, that is important in evaluating the function of the specific microbe in nature, since specificity of action upon the environment determines the dynamic individuality of unicellular organisms. The specificity of microbic action furthermore is associated with the catabolic rather than the anabolic phase of metabolism, as the following considerations will indicate.

The weight of a single bacterial cell is very little indeed; an ordinary bacillus, as, for example, B. coli, weighs about $0.000,000,0016$ milligrams. It follows that the actual amount of material required to build such a complete cell, even with a liberal allowance for waste, is extremely small. In spite of the minuteness of bacterial cells, however, many kinds effect a rapid and material transformation of their nutritive environment. This disproportion between the chemical activity of the organism and its size is partly attributable to the relatively large surface area of the cell in proportion to its volume. In general, a parallelism exists between the surface area and energy requirements rather than between the volume and energy requirements in living things; such a parallelism would afford a possible explanation of this phenomenon in bacteria. Thus a million spherical organisms, each one micron in diameter (assuming the specific gravity to be 1.030 , which is very nearly correct), would weigh about 0.00054 milligrams, while their combined surface area would be approximately 3.1416 square millimetres. The ratio of energy to weight is, therefore, very large indeed. Such reasoning must not be regarded as more than suggestive, however, because bacteria of approximately equal size vary greatly in the nature and extent of their energy transformations. Thus Bacillus typhosus and Bacillus proteus are about equal in volume and surface area, but the latter exceeds the former many times in the extent of its chemical activity. Generally speaking, pathogenic 
Lacteria are decidedly less active chemically than saprophytic organisms.

From a chemical standpoint, the structural phase of bacterial growth and activity appears to be largely a series of syntheses. Relatively simple derivatives of proteins, carbohydrates (and probably fats) are transformed through reactions, in which condensations and reductions are prominent, into those complex proteins, fats and carbohydrates (together with salts) which collectively comprise the mature bacterial cell. Many of these syutheses are probably hydrogenic in character, that is, two or more simpler molecules unite to form one of greater complexity, with a coincident elimination of hydrogen and oxygen in the proportions to form water. Thus:

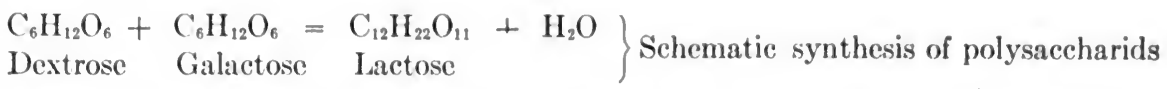

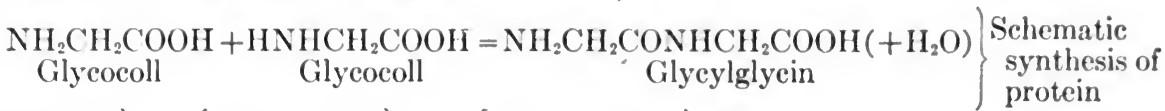

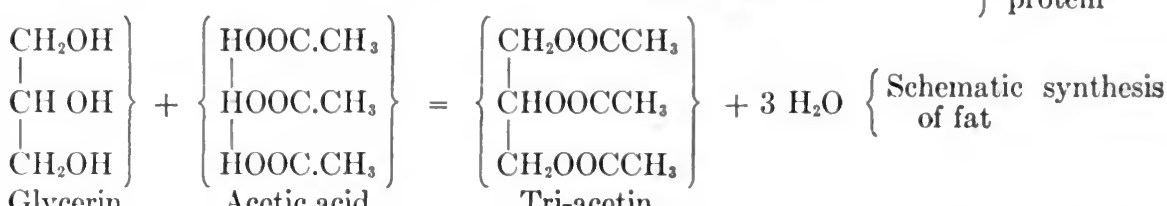
Glycerin Acetic acid Tri-acetin

NECESSITY of NITROGENous DIET-Again, bacteria like all living things are nitrogenous bodies, hence they need nitrogen-containing substances in their dietary. In other words, bacteria camnot thrive in a nonnitrogenous environment, but the form in which nitrogen must be united with other elements to be utilizable for structural purposes varies with the kind of organism under consideration. It is worthy of note that the state of aggregation of nitrogenous compounds in the alimentary canal of man varies from great complexity in the proteins as taken into the mouth to relative simplicity as intestinal digestion proceeds. It is not difficult to conceive of a succession of intestinal organisms from above downwards whose nitrogenous requirements are correspondingly graded.

PREPARATION AND UTILIZATION OF ENERGY.-The energy or vegetative phase of bacterial activity, like the energy phase of other living things, is largely a series of oxidizations of carbon and hydrogen. Nitrogen plays but little part in the process, because the oxidization of this element appears to yield little or no energy to a great majority of bacteria. When proteins or protein derivatives are utilized for energy by ordinary bacteria, therefore, the elimination of nitrogen as ammonia (deaminization) is usually a concomitant phenomenon to the partial or complete oxidization of the carbon and the hydrogen moieties of the protein or 
protein derivatives for energy requirements. ${ }^{1}$ It is not surprising to find that certain carbohydrates, which contain no nitrogen and in which the carbon is already in a state of partial oxidization, are more readily utilized for energy than protein derivatives. In the latter, the carbon is in combination with hydrogen alone, except for the carboxyl group. Furthermore, utilization of amino-acids for fuel appears to presuppose the elimination of the amino-nitrogen as ammonia, in order that the reactions yielding energy may go on. This sparing action of carbohydrate for protein, in relation to the production of energy, is well known in the economy of the human body, as well as in bacteria, as is evidenced by the wellknown expression that "carbohydrate spares body protein."

Utilization of Protein Derivatives.-A series of reactions indicative of some of the more important changes in protein derivatives incidental to their preparation and utilization for energy, appears to be fairly definitely established, and inasmuch as they illustrate the probable mode of formation of products of importance in the gastro-intestinal tract, they are appended:

1. $\mathrm{RCH}_{2} \mathrm{CHNH}_{2} \mathrm{COOH}+\mathrm{H}_{2}=\mathrm{RCH}_{2} \mathrm{CH}_{2} \mathrm{COOH}=\mathrm{NH}_{3}$ - Reductive deaminization of an amino-acid to a fatty acid with the same number of carbon atoms.

2. $\mathrm{RCH}_{2} \mathrm{CHNH}_{2} \mathrm{COOH}+\mathrm{H}_{2} \mathrm{O}=\mathrm{RCH}_{2} \mathrm{CHOHCOOH}+\mathrm{NH}_{3}-$ Hydrolytic deaminization of amino-acid to an oxyacid with the same number of carbon atoms. (Illustrates the possible formation of lactic acid from protein.)

3. $\mathrm{RCH}_{2} \mathrm{CHNH}_{2} \mathrm{COOH}+\mathrm{O}=\mathrm{RCH}_{2} \mathrm{COCOOH}+\mathrm{NH}_{3}$ - Oxidative deaminization of amino-acid to a Keto acid with the same number of carbon atoms.

4. $\mathrm{RCH}_{2} \mathrm{CHNH}_{2} \mathrm{COOH} \rightarrow \mathrm{RCH}_{2} \mathrm{CHNH}_{2}+\mathrm{CO}_{2}$-Carboxylic decomposition of amino-acid to primary amin with one less carbon atom.

The formation of beta-iminazolylethylamin from histidin, of cadaverin from lysin, and of putresein from ornithin are excellent instances of this carboxylic decomposition resulting in the formation of a primary amin.

5. $\mathrm{RCH}_{2} \mathrm{CH}_{2} \mathrm{COOH} \rightarrow \mathrm{RCH}_{2} \mathrm{CH}_{3}+\mathrm{CO}_{2}$ - Carboxylic decomposition of fatty acid-(Compare Reaction No. 1) to a compound with one less carbon atom.

6. $\mathrm{RCH}_{2} \mathrm{CH}_{2} \mathrm{COOH}+3 \mathrm{O}=\mathrm{RCH}_{2} \mathrm{COOH}+\mathrm{CO}_{2}+\mathrm{H}_{2} \mathrm{O}$ - Carboxylic decomposition of fatty acid to a fatty acid containing one less carbon atom.

Illustrations-Formation of indol from tryptophan.-Indol is a substance found in the human intestinal tract in varying amounts; it is pro-

1 A precisely analogous deaminization takes place in the animal body when a predominatingly protein diet is administered. The increase in the output of urea in this case has its origin largely in intracorporeal deaminization, the ammonia resulting therefrom being transformed to urea prior to its elimination. The ammonia which results from the deaminization of protein derivatives within the bacteria cell (and which is excreted as such, since bacteria, so far as is known, are unprovided with livers) is justly to be regarded as "bacterial urea." 
duced from the mother substance, tryptophan (an amino-acid found in proteins), by the action of Bacillus coli, Bacillus protens and certain other intestinal microbes. The exact process is not known, but the steps indicated may be regarded as possible:

A<smiles>NCCCCCCCCC(=O)O</smiles>

Tryptophan

B<smiles>CCNC1CCCCC1CC</smiles>

$\mathrm{c}$<smiles>CNC1CCCCC1CCC(=O)O</smiles>

D<smiles>CCC1CCCCC1N</smiles>

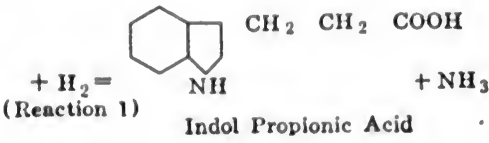

$+30=\bigcirc_{\mathrm{NH}}^{\mathrm{CH}_{2}} \stackrel{\mathrm{COOH}}{+ \text { Reaction } 6)}+\mathrm{CO}_{2}+\mathrm{H}_{2} \mathrm{O}$

Indol Acetic Acid

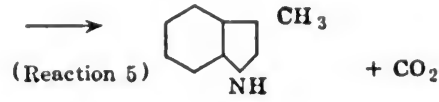

Skatol

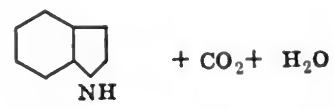

Indol

Indol is not utilizable for energy (or structure probably) by those bacteria which are responsible for its production from tryptophan. The energy that is available in the latter compound appears to be the alanin radical, $\mathrm{CH}_{3} \mathrm{CHNH}_{2} \mathrm{COOH}$, whieh, when added to indol in the beta position, forms tryptophan. The human body likewise can hardly utilize indol for structure or for energy; however, when indol as such is absorbed from the intestinal tract, it is changed to indoxyl in the liver and excreted in the urine as a potassium sulphonate derivative known as indican, thus:

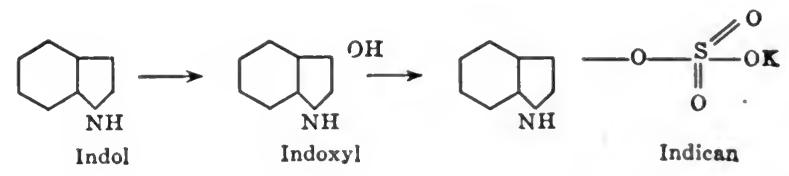

Formation of Phenol and Paracresol from Tyrosin.-Similarly tyrosin is acted upon by Bacillus coli and other organisms, ultimately utilizing the alanin radical of the tyrosin molecule for energy, leaving a residue of paracresol (or phenol) which is not a source of energy either to bacteria or to the human body. When paracresol or phenol is absorbed 
from the alimentary tract, it is transformed (detoxicated) in the liver and excreted as an ethereal sulphate in the urine. The hypothetical steps in the formation of paracresol and of phenol follow:

A<smiles>OC1CCCCC1</smiles>

$\begin{array}{rr}\mathrm{CH}_{2} & \mathrm{CHNH}_{2} \\ & \text { Tyrosin }\end{array}$

B<smiles>CCCCCCCCCCC(=O)O</smiles>

c<smiles>O=C(O)C1CCC(O)CC1</smiles>

D<smiles>CC1CCCCC1</smiles>

$$
+\mathrm{H}_{2}=
$$

(Reaction 1)
(Reaction 5)<smiles>CCC1CCCCC1</smiles>

Para-oxyphenylpropionic Acid

Para-oxyphenylacetic Acid<smiles>C[C@H]1CCCC(O)C1</smiles>

Paracresol<smiles>O=C(O)C(=O)O</smiles>

FORMATION OF BETA-IMINAZOLYLETHYLAMIN FROM HISTIDIN<smiles>NC(Cc1cnc[nH]1)C(=O)O</smiles>

Histidin<smiles>NCCc1cnc[nH]1</smiles>

Beta-iminazolylethylamin

\section{FORMATION OF CADAVERIN FROM LYSIN}<smiles>CC(N)CCCCN</smiles>

Lysin

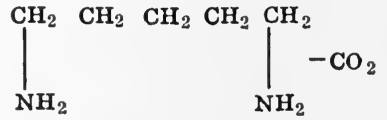

Cadaverin

FORMATION OF PUTRESCIN FROM ORNITHIN<smiles>NCCCC(N)CCCCCCCCCCC(=O)O</smiles> 


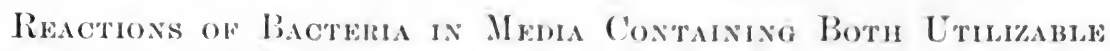
Nitrogexols Sibstances (Protrins and Protean Derivatives) and Carbonrusatres.-The foregoing observations indicate that proteins or protein derivatives may be utilized by hacteria both for their structural requirements and for their energy. Inasmuch as bacteria in common with all living things are nitrogenous organisms, at least some nitrogenous substance is necessary for their structure; the energy, on the contrary, appears to be a phase characterized by the oxidization of earbon and hydrogen. Nitrogen, as it exists in the amino-acids and protein moleculeamino-nitrogen-not only is not a source of energy to the ordinary types of saprophytic, parasitic and pathogenic bacteria, but it is even removed (deaminization) prior to the utilization of the carbon and hydrogen of this group of nitrogenous substances by transformation into energy. In this sense deaminization is a very good measure of the rate of utilization of proteins and protein derivatives when they are oxidized for energy by the bacteria.

Action of Carbohydrates in Media.-The addition of ntilizable carbohydrates to nitrogenous media for bacterial cultures exercises a very profound influence upon the character and physiological effects of the products formed. Of the carbohydrates, those containing six carbon atoms are most commonly adaptable to bacterial needs; bioses and polysaccharids appear to be commonly hydrolyzed to hexoses prior to assimilation.

The products resulting from the utilization of carbohydrates (for energy) are quite commonly acids, particularly lactic and to a lesser degree acetic and formic acids. Those bacteria which produce gas during the fermentation of carbohydrates are said to decompose formic acid, through the activity of a special enzyme, formiase, to carbon dioxid and hydrogen. According to this hypothesis, the typhoid bacillus, which does not produce appreciable amounts of gas from the simple sugars, does not produce this enzyme; the paratyphoid bacillus and Bacillus coli, on the contrary, do produce formiase.

Space does not permit of an intimate discussion of the great difference in the nature and extent of the products resulting from the utilization of carbohydrates and proteins respectively for the energy requirements of bacteria. A few typical illustrations, however, will indicate the paramount importance of the subject in a discussion of the effects of microbic growth and development in the gastro-intestinal tract.

Certain bacteria, as Bacillus protens, the spirillum of Asiatic cholera, Bacillus mesentericus and many anaërobes, produce soluble proteolytic enzymes which are extracellular and liquefy or peptonize a variety of 
proteins. These exo-enzymes are produced in an active state only in media free from utilizable carbohydrates(2). Bacillus diphtheriæ and Bacillus tetani produce extremely potent toxins when grown in appropriate protein media free from carbohydrates. Bacillus coli, Bacillus proteus, the spirillum of Asiatic cholera and other organisms form indol in protein media (provided, of course, tryptophan either alone or in combination is present); no indol is formed by them in similar media containing utilizable carbohydrates. Even the composition of the bacterial cell itself is materially influenced by the presence or absence of utilizable carbohydrates; in media containing the latter, in addition to protein derivatives, nearly twenty per cent less of nitrogen occurs in the organisms than is the case when they are grown in carbohydrate-free media which is of the same composition and reaction otherwise. The part played by fats and by lipoidal substances in general in bacterial metabolism is not well understood at the present time.

To summarize,- - soluble proteolytic enzymes, soluble toxins, putrefactive products such as indol and other conspicuous and distinctive evidences of the decomposition of proteins or protein derivatives, characteristic of various specific bacteria grown in carbohydrate-free media, are not produced when the same organisms are grown in the same nitrogenous media to which are added utilizable carbohydrates. The carbohydrate, in other words, protects the protein constituents of the media from bacterial breakdown in a manner analogous to that in the animal body where "carbohydrate spares body protein." The products arising from the utilization of carbohydrate (for energy) are chiefly organic acids irrespective of the organism under consideration. ${ }^{1}$ Thus Bacillus diphtheriæ, Bacillus coli, the spirillum of Asiatic cholera, Bacillus typhosus and many other bacteria form qualitatively about the same kind of acid products from the fermentation of utilizable carbohydrates that the Bulgarian bacillus and other so-called sour milk bacilli produce in corresponding media. This is true, of course, only as long as carbohydrate in utilizable form is continually available; if the supply of carbohydrate fails, the bacteria at once turn of necessity to protein or protein derivatives for their energy and again form their characteristic products, as toxin, indol, etc.

Summary.-The important generalization which develops from a consideration of these facts may. be stated thus: a large group of bacteria, comprising a great majority of well-known saprophytic, parasitic and pathogenic forms, can utilize carbohydrate for their energy requirements

1 Exception is made of bacteria, as B. alcaligenes, which do not appear to utilize carbohydrates. The group of obligately carnivorous bacteria, however, is quite limited. 
and of necessity require protein or protein derivatives for their structural needs; these bacteria produce varying amounts of relatively simple acid substances such as lactic, formic, acetic and butyric acid as conspicuous but not distinctive products when they are grown in nitrogenous media containing utilizable carbohydrate. The same organisms, grown in the same nitrogenous media in the absence of utilizable carbohydrate, produce the various nitrogenous substances indicated above, which are the conspicuous and specific products of their metabolism. In other words, many pathogenic and saprophytic bacteria prodnce substances which are potentially akin to buttermilk from the fermentation of utilizable carbohydrates; the decomposition of proteins in the absence of utilizable carbohydrates, on the contrary, leads to the formation of the specific and frequently injurious substances as indol, toxins, etc., which largely determine the specificity of the action of these bacteria in a practical way.

This striking relation of the products of bacterial metabolism to the nutritive environment is significant in any discussion of the products arising from the growth of bacteria in the gastro-intestinal tract. Indeed, an interpretation of the effects upon the host of normal and abnormal bacterial development within his alimentary canal depends, in the last analysis, largely upon an intimate knowledge of this phenomenon.

\section{GASTRO-INTESTINAL BACTERIOLOGY OF NORMAL INFANTS, ADOLESCENTS AND ADULTS}

A discussion of gastro-intestinal bacteriology must be prefaced by a consideration of those factors which play a prominent part in evaluating the results sought for.

It is self-evident that at one time or another an indefinite variety of microbes must reach the alimentary canal, since our food and all else that enters the mouth may carry organisms from many sources. Among these heterogeneous microbes will be a variable number that run the gauntlet of oral and gastric digestion and reach the intestines in a viable state. Here they enter into competition with the normal intestinal types. Generally speaking, the result of this competition will be either the gradual or rapid elimination of the intruder, or its establishment at some level where its adaptability to intestinal conditions transiently or permanently approaches or exceeds that of previously established organisms. Repeated invasion may succeed even if a single invasion does not result in colonization; seasonal distribution of microbes in foods or water may lead to seasonal variations in the intestinal flora. 
It is important to realize that a sample of intestinal contents planted on artificial media may and very often does fail to furnish descendants of the viable types in numbers proportionate to those present in the sample as it originally existed; many adventitious types accidentally present in the intestinal contents (which are not, strictly speaking, normal inhabitants of the alimentary canal) grow under such artificial conditions with a rapidity which completely overwhelms the normal forms.

\section{GASTRO-INTESTINAL BACTERIA IN INFANTS}

This disproportion between the growth of normal and adventitious bacteria in artificial cultivations of material taken from the intestinal tracts of infants is momentous. Failure to recognize the change in intestinal environment which is produced by artificial media has led many observers into the serious error of emphasizing the variety of intestinal microbes in the normal infant, whereas, in reality, the relative homogeneity of the normal infantile flora is both chemically and morphologically the significant circumstance. The importance of this relative homogeneity in the chemical and morphological study of the intestinal flora of the normal nursling possesses more than scholastic importance; the direct relationship between diet and flora is particularly well exemplified at this stage of the development of the individual. Escherich(5) recognized the limitations of cultural methods in studying intestinal bacteriology and clearly pointed out the pitfalls three decades ago. Bessau(6) and especially those who have attempted to amplify his rather extensive compilation of bacterial "species" of gastro-intestinal origin have very naturally missed the main issue by following a mass of unrelated and uncoördinated details. A sweeping assertion of this kind requires proof. Fortunately impressive evidence in favor of this view is readily obtained. The fecal flora of a normal nursling, as Escherich pointed out long ago, is composed of rather long, slender, Gram-positive bacilli, together with much smaller numbers of Gram-negative rods, and cocci, when viewed under the microscope. ${ }^{1}$ It is obvious that such an examination, properly made, will be a definite graphic image of a small proportion of the fecal flora. Artificial cultivation from the very same specimen will result in almost exclusive growths of Gram-negative rods and cocci; the Gram-positive forms do not appear at all, or at best in isolated instances. Fortunately the use of very

1 A similar examination of a "hanging drop" preparation of the actual living intestinal bacteria presents a precisely similar picture aside from the tinctorial differentia. tion which the stained specimen exhibits. 
specialized methods permits of the cultivation of the Gram-positive rods in approximately their proper numerical relation to the Gram-negative rods and coeci, as shown by the stained specimens, thus indicating that observations based upon the ordinary methods of cultivation camnot be regarded as reliable in a discussion of the intestinal bacteria in a broad way.

The gastro-intestinal tract of the newly born infant is sterile, but adventitious bacteria appear after a few hours. These come largely through the mouth, although some may conceivably enter through the anus from the bath water. 'This initial flora of varied composition soon gives way to a fairly definite and lasting one which is characterized morphologically by a dominance of rather long, thin, Gram-positive rods together with a smaller number of Gram-negative rods and cocei ; small but variable numbers of short, thick Gram-positive bacilli, some of which contain central or polar spores; and relatively thin Gram-negative rods of medium length. Chemically these organisms growing in a medium closely duplicating that of the normal intestinal contents exhibit a rather remarkable monotony of products formed; these products, so far as available evidence collected from appropriate experiments shows, are largely acid in character. Prominent among these acid products are lactic and acetic acids, together with smaller amounts of other lower products and derivatives of the fatty acid series. Broadly speaking, there is a somewhat remarkable parallelism between the monotonous diet of the nursling (breast milk, which is practically sterile at the time of administration); the monotonous flora evidenced by appropriate, direct microscopical examination and cultural methods; and the monotony of substances formed by the flora, chiefly acid in nature and closely related in their general properties.

BACTERIOLOGY IN ADOLESCENTS AND ADULTS.-As the nursling grows, the necessity of adding to the nowmal sterile dict of breast milk becomes urgent, and experience shows that this transitional period is frequently characterized by nutritional disturbances. During this interval, there is a change in the nature and composition of the food; this change is essentially an increase in the protein constituents, and a relative diminution in the proportion of carbohydrate and fat. In addition, the ingestion of various kinds of miroörganisms becomes a factor, inasmuch as the new regimen is rarely sterile. This change in diet is closely followed by pronounced changes in the prominent types of bacteria of the intestinal flora-a decided increase of the Gram-negative bacteria of the colon group at the expense of the Gram-positive members of the bifidus-acidophilus group; the appearance of small numbers of spore-forming bacilli of various types; 
and increased numbers of spherical organisms and of bacteria which are more proteolytic than those considered above. This process of replacement which accompanies a change in regimen usually reaches a state of comparative stability during adolescence and, depending somewhat upon individual dietary habits, persists throughout life. Accompanying this change in diet there is a concomitant substitution of products of microbic activity for the acid products indicative of the carbohydrate fermentation which is characteristic of the activity of the normal nursling flora.

In the large intestines these products are varied in character, largely, however, those resulting from the decomposition of protein derivatives. The antecedent causes for this striking change are: first, a relative deficiency in the proportion of carbohydrate to protein in the diet; second, a practically continuous influx of various types of bacteria in the varied regimen of the individual. Among these bacteria are organisms that are particularly adaptable to intestinal conditions, as they prevail under the new regimen, as, for example, Bacillus coli. These organisms are more plastic in their dietary requirements, thriving equally well in the presence or relative absence of carbohydrate. These-types are in distinct contrast to the obligately fermentative organisms so characteristic of the intestinal flora of the normal nursling, where the diet is monotonously replete in carbohydrate. It is worthy of note that starches and other slowly hydrolyzed carbohydrates probably have a relatively minimal action in augmenting the available supply, because the products of hydrolysis, never great in amount at a given time, are absorbed practically as fast as formed. The duodenum, on the contrary, frequently contains considerable amounts of carbohydrate, and in general putrefaction is relatively at a low ebb at this level. Bacteriologically considered, this striking microbic response to a definite change in regimen is the most noteworthy and significant indication of the change from the nursling stage to that of the adolescent.

A brief survey of the distribution of microörganisms at various levels of the alimentary canal of the adult will illustrate at least the more general features of the relation of microbic activity to the nature of the products formed.

\section{REGIONAL BACTERIOLOGY}

Bacteria of the mouth, so far as the normal flora is concerned, are usually of little importance in the decomposition of food, although the production of dental caries, and a subsequent disturbance of the digestive 
processes, in part at least attributable to this factor, may justly be regarded as within the scope of this ficld; also an occasional sporadic diarrhea reasonably aseribed to a discharge of considerable numbers of streptococci or allied organisms from oral abscesses through the stomach into the intestines, may likewise fall within the province of this subject, al. though these are considered more properly from the viewpoint of pathology.

The stomach under normal conditions is quite free from microorganisms. Conditions that lead to achlorhydria may and frequently do lead to lactic acid fermentation within the stomach, and partial occlusion of the pylorus may lead to stagnation of the gastric contents and various local types of fermentation or putrefaction.

The upper parts of the small intestine, which ordinarily exhibit a decided fluctuation in the amount of material, contain considerable numbers of bacteria at the height of duodenal digestion, and comparatively few organisms when the interdigestive period is reached. The greater part of the bacteria which appear during the digestive period are transported mechanically to lower levels with the duodenal contents. The actual number of types of bacteria found in the duodenal contents may appear to be considerable. Many appear to be swept into the duodenum from the stomach. The varieties which grow more luxuriantly in the duodenum, however, are relatively few in number. Their activities, depending somewhat upon the relative amounts of proteins and carbohydrates, are expended chiefly upon the sugars and upon the intermediate products of protein digestion, as the albumoses and peptones. Ordinarily the products formed appear to be comparatively small in amount and innocuous. The relatively feeble development of bacteria at this level, and the somewhat intermittent character of their growth due to the ebb and flow of food at this point, are in harmony with this view. Vincent and others have shown, however, that occlusion of a loop of intestine at this level may lead to the production of substances of unknown nature and origin, which are very poisonous for the organism under these conditions. At the lower levels of the small intestine, where the passage of food is more nearly continuous, bacterial development and bacterial activity in the chemical sense are decidedly greater than at the higher levels. The products formed are partly determined by the rapidity of passage of food to the level under consideration, a slow movement being attended by increased hydrolysis of proteins, fats and carbohydrates and a differential rate of absorption from the tract in favor of the latter substances. When the carbohydrate moiety is reduced to nil, the protein residue is vigorously 
attacked by the bacteria present, and a variety of products, among which indol, phenolic bodies as cresols and phenols, $\mathrm{H}_{2} \mathrm{~S}$ and $\mathrm{NH}_{3}$, and rarely products like beta-iminazolylethylamin, which even in very small amounts may have a material pressor effect upon blood pressure, may be found. It is worthy of note that these products of protein putrefaction are not produced when the normal intestinal flora at this level is growing in a medium containing carbohydrate.

Bacterial activity in the alimentary canal is most intense in the cecum and ascending branch of the large intestine. The relatively slow movement of the feces, the abundance of unassimilated food, the accumulation of organisms from higher levels, and the relative absence of products of bacterial activity inimical to their unrestrained development, all tend to create conditions favoring luxuriant growth of these microbes. Here again the products formed depend in considerable measure upon the relative proportions of protein derivatives, fats and carbohydrates. If the former predominate, intense putrefactive changes, resulting in the formation of putrefaction products similar to those mentioned above, take place; if the latter are present, even in relatively small amounts, putrefactive activities are reduced to a minimum.

The desiccation of the fecal mass as it passes through the lower levels of the large intestine causes a rather abrupt decrease in bacterial activity; the fecal mass as it is voided is estimated to be made up of nearly fifty per cent of bacteria. Probably over eighty per cent of these are either dead or so reduced in viability that they fail to develop in artificial media.

It would be difficult indeed to prepare a detailed statement of the effects of various abnormal conditions in the intestinal tract upon the products of bacterial development in the intestinal contents. In general, diarrhea, hastening the passage of food, tends to flood the lower levels of the tract with bacteria from above, thus causing abnormal extension downwards of the activities of bacteria normally found in upper levels. (Diarrheas in the upper levels may not necessarily be accompanied by correspondingly rapid peristalsis at lower levels.) This rapidity of passage naturally tends to reduce somewhat the amount of bacterial activity at a given level, but the reduction is probably slight.

Stasis of the intestinal contents, particularly above the ileocecal valve, usually causes an extension upwards of bacteria normally found at lower levels. This is probably due in part to the gradual digestion of the food by the intestinal enzymes at higher levels corresponding in actual hydrolytic cleavage to compounds normally found at lower levels. Those bacteria which are best adapted to the new conditions grow by extension to 
the upper lavers of the traet where the dietary enviroment is most suited for their development. There is a decided tembeney towards a differential loss of carbohydrate by assimilation under such ionditions, becanse carbohydrates (of the sugar sories at least) appear to be more quickly diffusible than protein derivatives. Lnder these onditions the differential aceumulation of protein tends to increase the putrefantive products.

C'athartics and so-called intestinal antisepties do not appear to decrease the balcterial population materially exeept as they promote rapidity of peristalsis and consequent mechanical voiding of those organisms thus removed. 'The reduction is usually transient and may be followed by a greater bacterial proliferation.

There is no sharp line of demarcation between a normal and an abnormal bacteriological flora in the alinentary canal. An overgrowth of normal flora leading in general to ahnormal putrefaction or fermentation may cause as much discomfort or even danger to life as the purely exogenous infections. This phase of the problem, however, is beyond the scope of the subject under immediate discussion.

\section{REFERENCES}

1. Kexdall, Artuur I. Unpublished observations.

2. - and Walker. J. Infect. Dis., 1915, xvii, 442.

3. $\quad$ and Lewis. Unpublished note.

4. —, DAY and WALKer. J. Infect. Dis., 1914, 451.

5. Eschericu. Darmbakterien des Sänglings, Stuttgart, 1856.

6. Bessac. Referred to in 'Tobler's Allgemeine Pathologie und Physiologie der Ernährung und des Stoffwechsels im Kindesalter.

\section{BIBLIOGRAPHY}

Bienstock. Areh. f. Hyrg., 1899, vol. xxxvi, p. 335.

Hebler. Tntersuchungen über pathogene Anaëroben. Jena, 1908.

Herter and Kevdall. J. Biol. Chem., 1908, vol. v, p. 293.

Jungano et Distaso. Tes Anä̈robies, Paris, 1910.

Kendalt. J. Biol. Chem., 1909, vol. vi, p. 499.

—. Boston M. \& S. T., 1910, vol. clxiii, p. 398.

Ibid., 1911, vol. clxiv, p. $28 s$.

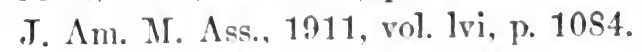


Kexpall.. J. Med. Research, 1911, vol. xxiv, p. 411.

Ibid., 1911, vol. xxv, p. 117.

, DAY and WAlker. J. Am. Chem. Soc.

- and Smith. Boston M. \& S. J., 1911, vol. clxv, p. 306.

Meтcinikoff. Prolongation of Life, 1908.

Rante. J. Infect. Dis., 1914, vol. xv, p. 141.

Rettger. Centralb. f. Bakteriol., 1914, vol. lxiii, p. 362.

Roteri and Kendall. Am. J. Dis. Child., 1911, vol. ii, p. 30. 


\title{
('HAP'TEL IX
}

\section{GENERAL CLASSIFITIOA OF FOODS}

\author{
Necessity of Nitrogenous Foods: Nitrogen Cycle; Plants, Animals, Man, \\ Bacteria. \\ Definition of Food. \\ Working Basis of Classification: Inorganic-Water, Salts; Organic- \\ Animal Foods, Vegetable Forde. \\ Foodstuffs: Combinations; Chief lilements; Accessory Substances- \\ Vitamines.
}

Man is an omnivorous animal, deriving his food from both the animal and regetable kingdoms. The elements of all foods are derived from the inorganic earth, air and water. and every quarter of the globe contributes its portion to the food of civilized man.

Nitrogenous Foods.-The elements which enter into the eomposition of the human body are precisely the sime as those which compose the strueture of the lower animals and the various plants of the regetable kingdom. Like all other animals, human beings are mable to assimilate these elements in their inorganic condition, and therefore the principal elements must be orgunized before they can be of use to the body as a food. This is bronght about through the animals which derive their sustenance from the regetables which they consume; the vegetables, in turn, derive them at first hand from the earth, air and water. This is a law of nature. Nitrogen chemieally pure camot he assimilated by animals. They must obtain this important and indispensable element of life through the vegetable kingdom either directly or indirectly, for there is no other possible way to obtain it in a form ready for assimilation. We are therefore at the merey of the regetable kingdom for our supply of nitrogen, without which life in any form is impossible.

The amount of nitrogen required daily by an adult varies according, to eireumstances, but it averages about 20 grams. The mechanism of the human economy undergoes unceasing changes, owing to wear and repair of the structures which consist mainly of nitrogenous elements: so constantly is this change going on that no part of the body remains 
the same after six or seven years. The materials for the growth and repair of the tissues are derived from the flesh-forming principles of the food. All animals obtain their nitrogen from plants, and the plants in turn derive it from the soil, partly from ammonia and its salts and partly from nitrites and nitrates, and a little from the air.

The foodstuffs of animals are, therefore, complex substances built up by the vegetable kingdom usually for its own use. For instance, the cereals are simply seeds of cultivated grasses. The legumes are the seeds of the cultivated members of the leguminosæ. Nuts are the seeds of certain trees and shrubs. Nature in her wisdom grew these and other seeds for the propagation of new plants, but they are gathered by man for food, and eaten by animals the world over. The herbivorous animals crop and browse the tender green herbage of plants, thus living upon plant tissues direct. The carnivorous animals, cannibalistic in taste and habit, kill other animals and consume them for food. Thus the carnivorous animals subsist directly upon animal tissue, and get their nourishment indirectly from the vegetable kingdom.

Definition of Food.-A food is any substance which will supply the material needs of the body. The material needs must be supplied by foods that are both constructive and energy-producing. The constructive need of the body calls for material for growth and repair, while the energy need must have fuel-producing foods, whose oxidation furnishes the heat which maintains body temperature, and the energy-motor, glandular, or nervous-peculiar to the active tissues of the human economy.

Purpose of Eating.- It has been tersely said that we should "eat to live and not live to eat." The statement that far more people die from eating too much than too little is not far from the truth, and yet food is a necessary requirement of all organisms for their development and growth, to supply them with heat and energy, to keep them in a state of efficiency and to make good the losses resulting from wear and tear of the mechanism. The Romans had a very appropriate proverb covering this point which ran, "Omne quod est nimium, vertitur in vitum"-_Everything in excess becomes a vice." It is surprising to know upon how little food animals and human beings can exist and remain in good health. In fact, the foundations of certain diseases are laid in excessive eating. This is emphasized by the writer who said, "We Americans dig our graves with our teeth."

Classification of Foods.-The object of food classification is to obtain a working basis of subdivision, and the less complex this is made the 
better. The simplest chemical classification is that taught by Baron von liebig and referred to in ('hapter l. Foods may also be classified in various ways, aceording to (a) their physical properties, (b) their source, (c) their composition, and (d) the rible which they perform in the animal body. Under the first heading foods may be classitied as solid, semisolid, liquid, or as fibrous, gelatinoms, starchy, oleaginous and albuminoms. Some use the classiticntion of "complete" foods, such as eggs and milk, which in a single article comprise all the necessary ingredients and elements to support life, and "incomplete" foods which are only capable of maintaining life for a short time.

Another classification is that of Prout, who grouped foods as ( $a$ ) aqueous, $(b)$ saccharine, $(c)$ oleaginous, and $(d)$ albuminous. Liebig's classification was $(a)$ nitrogenous and $(b)$ non-nitrogrenous foods. Foods may also be elassed according to their sonree, animal or vegetable. Animal foods consist of meats, fish, fowl, egrgs, milk and its products, animal fats and gelatin. Vegetable foods are subdivided into cereals, vegetables proper, fruits, nuts, sugars and vegetable oils.

For convenience, simplicity and accuracy, the following classification is adopted in this work:

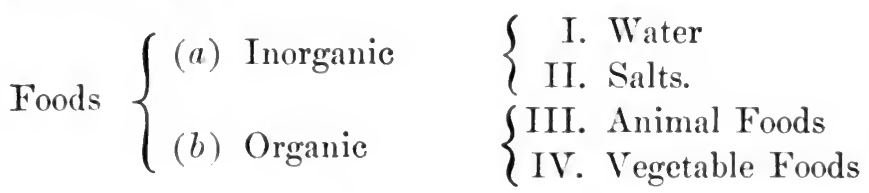

The above classification seems to be the most satisfactory, as it is in harmony with the chemical composition and dietetic use of the several foods.

Foodstuffs.-Foodstuffs-food materials-are usually taken in combination by man to sustain life. Starch, sugar, fat, protein and certain mineral salts are foodstuffs. Bread, for instance, is a combination of all of these foodstuffs, and perhaps for this reason it has been termed "the staff of life," since it supports the needs of the corporeal body. Certain foods are composed of only one foodstuff, for example, cane sugar, olive oil, egg albumin and corn starch.

Constructive foodstuffs are principally derived from animal foods, the most important constituents of which are proteins, without which life is impossible. They (constructive foodstuffs) contain nitrogen, carbon, hydrogen, oxygen, sulphur, and some contain phosphorus and iron. The starches, fats and sugals contain no nitrogen, sulphur or phosphates, but are rich in carbon. 
All foods are in reality mixtures of foodstuffs, as bread, for instance, is a combination of all the foodstufts. Milk has been termed a complete food, as it contains all- the elements (sugar, fat, protein, salts and water) necessary to sustain life. Fresh vegetables usually represent combinations of sugar or starch, or both, with a cellulose matrix. Fruits, again, represent mixtures of sugar solutions with vegetable acids, and mineral salts, contained in a cellulose matrix.

ELEMENTS OF FOOD.-The chief elements of foodstuffs are made up of proteins, fats, carbohydrates and salts. By referring to the table in Chapter III, illustrating the proximate principles of food, we shall see that foods contain something more than albumin, globulin, glutelin, casein, stearin, palmitin, olein, sugar, starch and dextrin.

Vitamines.-Quite a number of food materials contain an infinitesimal but very important percentage of "accessory substances," which have recently been found to be very essential for the normal development and health of the organism. Clinical experimentation has established the fact that when these substances are excluded from foodstuffs, the body suffers, with the ultimate development of some type of deficiency disease. Just what these substances are, and the rôle they enact in the body metabolism, is at present the subject of research and investigation. In nutrition, they play a rôle which might be likened to that of the hormones in cellular activity or the opsonins and other antibodies in the infections.

This much is known concerning these substances: they possess curative properties, they are not protein, carbohydrate, fat, or inorganic salt. They are nitrogenous bodies of definite chemical composition-first isolated and described by Casimir Funk(1), for which he gives the formula $\mathrm{C}_{17} \mathrm{H}_{20} \mathrm{~N}_{2} \mathrm{O}_{7}$, and to this he gives the name of vitamines.

These remarkable substances exist in exceedingly minute quantities, and may act like enzymes catalytically, changing a large amount of food. It is an established fact that when people are fed on a monotonous diet for a long time-principally upon rice foods, corn meal, white wheat bread, pickled meat and canned foods-that their body nutrition suffers, and certain diseases are liable to be developed. In the past, it was thought that these diseases were due to the absence of acids or fresh fruits and vegetables, but it is now believed that these diseases are due in a large measure to the absence of vitamines, and that they are cured by the administration of substances which contain them.

The labor of Osborne, Mendel, Hopkins(2), McCollum and Davis(3), Funk and others shows that there is a specific growth-pro- 
ducing vitamine in fresh milk, egras, meat, yeast, meat extract, yeast extract, in growing grain, and in all grains which have not been deprived of their pericarp (wheat, outs, barley, red rice and corn), and in the substances which have been removed from them (wheat bran, rice bran, corn bran, the germ of wheat and other cereals), and in all rapidly growing green vegetables.

Funk and his followers have isolated other vitamines which may with propriety be called "curative," found in eggs, meat, fish, bran, cereals, legumes, fresh vegetables and yeast. The value of these substances has been shown by ill effects resulting from the ahsence of fresh foods and the benefieial effects which follow their use.

Recent experimentation has shown that most fresh animal and vegetable juices contain minute quantities of vitamines. They are of definite, organic, chemical eomposition, easily destroyed by exposure to heat, and soon perish if the foods containing them are preserved by drying. Their precise chemical composition has not been worked out in definite detail, but they are known to be derivatives of nuclein and nucleic acids. Prof. Leonard Hill, in discussing their importance in the dietary, says, "Foods contain a number of vitamines, and white bread does not contain those vitamines. In the milling process the outer layers of the wheat berry are removed and the vitamines taken away. That does not matter to people who get meat and eggs and vegetables. But it does matter to people whose principal diet is bread. If one saw children having tea and white bread with a smear of jelly, called jam, there would be no vitamines in that. If whole meal bread or black bread were substituted, they would have vitamines." Professor Hill, in further discussing this subject, says that in the processes of milling or canning these are often destroyed or removed, as when rice is polished, or in the preparation of white flour. When foods are stewed and the liquids thrown away, vitamines, being soluble, may be lost. Boiling diminishes the rice vitamines, but those in whole wheat flour are not destroyed by baking. The addition of a very little raw milk to white bread gives the necessary vitamines.

Condensed milk and canned foods have to be sterilized as a part of the process to secure preservation. The heat necessary for sterilizing foods deprives them to a greater or less extent of their vitamines, so that when one gets an abundance of milk, eggs, etc., with white bread, the ration is fairly well balanced; but the poorer classes, among whom white bread forms the principal part of the dietary, with perhaps a little oleomargarin and tea added, fare badly and are undernourished and subject to the deficiency diseases. 


\section{REFERENCES}

1. Funk, Casmir. The Probable Rôle of Vitamines in the Digestion and Application of Food, Pub. Proc. Physiol. Soc., Dec. 13, 1913.

2. Osborne, Mendel and Hopkins. Feeding Experiments Illustrating the Importance of Accessory Factors in Normal Dietary, J. Physiol., 1912.

3. McCollum and Davis. The Necessity for Certain Lipins in Diet during Growth, Bio-Chem. J., 1913.

\section{BIBLIOGRAPHY}

Amperhaldex. Text-book of Physiological Chemistry, Lectures 2 to 13, 1908.

Attrield. Chemistry.

Gangee. Physiological Chemistry.

Halliburton. Physiology.

Hammarstex. Text-book of Physiological Chemistry, 6th American ed., 1911.

Hartley. On the Nature of the Fat Contained in the Liver, Kidney and Heart, J. Physiol., 1909, vol. xxxviii, 353-374.

H九wk. Practical Physiological Chemistry, 2nd ed., 1909.

Holdeman. Text-book of Organic Chemistry, 3rd ed. (English), 1910. Manx. Chemistry of the Proteids, 1906.

Osborne. The Vegetable Proteins, 1909.

Power. Human Physiology.

Roscoe and Schlorlemmer. Chemistry.

Scmryver. The General Character of the Proteins, 1909.

VINe. Botany.

WAтt. Dictionary of Chemistry. 


\section{CHAP'TER $\mathrm{X}$}

\section{WATER IN 'THE BOHY' AND IN FOOISS}

The greatest influence on health is exerted by those things which we most freely and frequently require for our existence, and this is especially true of water and air. (Aristotle.)

Composition of Water.

Physical and Chemical Properties: Color, odor, taste.

Substances in Suspension and Solution: Organic Matter-Sewage Pollutions, Ammonia, Nitrites and Nitrates, Bacteria; Chlorin and Chlorids.

Sources of water supply: Rain water; surface water; ground water; spring, well and river water.

The uses of water in the body: Eliminative Function; Function as Food; Aid to Digestion: Diuretic and Diaphoretic.

General Considerations.-Absolutely pure water, composed wholly of hydrogen and oxygen, as represented by the symbol $\mathrm{H}_{2} \mathrm{O}$, is never found in nature and is never seen except in small amounts as a laboratory curiosity. Broadly speaking, pure water signifies wholesomeness and suitability for drinking purposes and for use in the preparation of food. The term also implies freedom from pathogenic bacteria and other harmful ingredients. In nature, all water contains more or less gases and solid substances in solution and suspension; provided that these are not present in such amounts as to be injurious, and that bacteria dangerous to health are absent, the term "pure water" is appropriate.

Although water is essentially an article of diet, yet it cannot be technically classed as a food. From the remotest antiquity the highest ralue has been placed upon an abundant supply of pure water. In ancient times, places where good water was abundant became the centers of population. Great expenditures of labor, time and treasure were made to carry it to places where it was not naturally plentiful. The Appian aqueduct carrying water to Rome is said to have been constructed about 312 B.c. Eighteen other Roman aqueducts were built at various times until 
as late as the year 226 A.D. The great aqueduct commenced by Emperor Caius and completed by Claudius, according to Pliny, cost 350,000,000 sesterces, or translated into American currency, $\$ 12,700,000$.

\section{COMPOSITION OF WATER}

As late as the beginning of the nineteenth century water was regarded as an elementary substance. Cavendish in 1781 discovered that when an electric current was passed through a mixture of two parts of hydrogen and one part of oxygen, these gases combined to form water. Since that time water has been made in the laboratory synthetically and separated into its elements by analytical methods.

From a sanitary viewpoint, water is either good or bad. Water is commonly referred to as pure or impure-wholesome or unwholesome. However, in the present state of our knowledge(1), it is not possible to draw any sharp line of distinction. A normal water is free from any direct or indirect pollution by waste products from human life or industries. Under this classification water may differ widely in color, taste, odor and composition, and may be unsuited for household consumption.

Physical and Chemical Properties of Water.-Water is a clear, transparent, tasteless and odorless fluid, colorless in small quantities, pale blue through a deep column. At a standard barometric pressure of $76^{\circ} \mathrm{mm}$., or 29,922 inches, water boils at $100^{\circ} \mathrm{C}$. or $212^{\circ} \mathrm{F}$, and freezes at $0^{\circ} \mathrm{C}$. It is practically incompressible, having the greatest density at $4^{\circ} \mathrm{C}$. When water freezes it expands almost 9 per cent of its volume, and therefore acquires a specific gravity less than that of unfrozen water in which it floats. Water is the most remarkable solvent known. Few substances are not acted upon by it to some extent. It takes up all known gases, its solvent power increasing in proportion to the fall in temperature and the rise in pressure.

APPEARANCE.-Pure water is clear, bright and sparkling in proportion to the air and $\mathrm{CO}_{2}$ dissolved in it. However, brilliancy of appearance is not conclusive evidence of purity as some badly contaminated waters show remarkable brightness. Turbidity in water signifies that organic and mineral matters are in suspension; the former may be dead vegetable or animal substances or microscopic living plants and animals. Turbidity of a milky or opalescent nature is commonly due to infinitesimal particles of clay which remain in suspension for a long time. Sewage in solution may also present this appearance. 
COLOR.- Water in its pure state is colorless. Surface waters may derive color from contact with grasses, leaves and woody matters in general. The reaction of water is slightly acid, but most potable waters are faintly alkaline to delicate indicators owing to minute amounts of alkaline carbonates in suspension.

ODOR.-As previously stated, pure water is odorless, but good surface waters containing coloring matters have more or less odor, which is especially brought out by heating. If due to vegetable matter, it may remain after long boiling, but if due to dissolved gases, it rapidly disappears on being heated. Water sometimes contains sulphuretted hydrogen from reduction of sulphates by bacterial action, and sometimes mixtures of products of organic decomposition which suggests the gas. Odors in water do not always indicate danger to health. As in the case of color, absence of odor must not be accepted as an indication of purity, since dangerous waters may often be inodorous.

TASTE.-Pure water has no taste. Whatever taste may be detected is due to dissolved gases. This is most evident when aërated water is heated to the boiling point, allowed to cool and the taste compared with the unboiled water. Saline matters impart no distinct taste unless present in large amounts. The only substance which imparts taste when it is present in small quantities is iron. Organic matter in solution, unless present in large quantities, imparts little taste to the water. Water containing only slight coloring matter may seem to have a distinct taste, but it should be mentioned that the senses of taste and smell are often unconsciously influenced by the sense of sight. Often water with both odor and taste may give no impression of either if drunk in the dark.

Substances in Suspension and Solution-NITROGEN AND OXYGEN.Substances normally found in water are $(a)$ gases in solution, $(b)$ organic matters in solution and in suspension, $(c)$ mineral matter in suspension. The gases of first importance are those found in the air. Water contains no air as such; only its constituents, oxygen and nitrogen, are dissolved by water, not, however, in the same proportions in which they exist in the atmosphere. In salt water the variations in the proportions are less restricted. The dissolved oxygen is, however, the important element. One hundred volumes of water at $15^{\circ} \mathrm{C}$. will dissolve nearly three volumes of oxygen (2.99), and at $20^{\circ} \mathrm{C}$., 2.80 volumes, but boiling increases its solvent properties. The quantity of oxygen in solution is fairly constant in waters of uniform composition freely exposed to the atmosphere; but when exposed to sewage. contamination and other oxidizable matters, the oxygen content diminishes in proportion to the per- 
centage of the sewage content. This progressive diminution is due to the constant access of organic matter, which undergoes oxidation at the expense of the dissolved oxygen. Water from deep wells is very commonly free from dissolved oxygen, because it is abstracted by compounds of iron or manganese, organic matters and other substances. Spring water contains more dissolved oxygen than water from any other source (see directions for making tea or coffee by aërating hydrant water with the atmosphere, Volume I, Chapter XVI). The presence in water of considerable dissolved oxygen, derived from the atmosphere, leads to beneficial changes in the organic matter present. On the other hand, a diminished oxygen content permits the development of low forms of vegetable life which frequently give rise to unpleasant tastes and odors. Their growth is inhibited by a large degree of aëration, and these disagreeable effects are thereby prevented.

CARBON DIOXID.-The carbon dioxid contained in water is derived largely from the atmosphere, and from the soil where it is present in abundance. The percentage of $\mathrm{CO}_{2}$ in water depends upon the character of the soil and the extent of oxidation of organic matter occurring in the interstices; the amount is also regulated to some extent by the percentage carried in by rain and dust. It is present in greatest amounts at great depths, and may constitute almost the entire amount of dissolved gases. It is alleged that sea water contains about 10 times as much $\mathrm{CO}_{2}$ as the entire atmosphere(2).

ORGANIC MATTER.-The organic matters in water are of both animal and vegetable origin, and consist of organisms and products of organic life resulting from disintegration and decomposition. The animal matters include living and dead organisms and dissolved and suspended products of animal life and decay, such as albuminous substances, urea and tissues. The vegetable organisms include species of numerous microscopic plants, which under certain conditions act beneficially by absorbing the products of organic decomposition for their growth, but which may, under favorable conditions, cause much annoyance by over-abundant growth, disintegration and decay. The organic matters-animal and vegetable-which are of prime importance to the physician consist of carbon, hydrogen, oxygen, nitrogen and, in many cases, small amounts of phosphorus and sulphur.

The inception, progress and completion of the process of decomposition is due to bacterial activity, wherein the carbon combines with oxygen to form carbon dioxid, and the hydrogen unites, in part, with nitrogen, liberating ammonia. The presence of the latter in water always 
indicates that the process of decomposition is under way. In its turn the ammonia is converted eventually into nitric acid, which unites with bases to form nitrates.

Ammonia.-Ammonia in water is of importance from the standpoint of sanitation. It most often occurs in the form of hydrate, but oceasionally as a chlorid or carbonate. If, on boiling, the salts deconpose and the ammonia escapes in the steam, it is referred to as free ammonia. The most direct source of ammonia in water is rain water. The showers bring it down from the atmosphere in varying amounts, according to location. Under ordinary conditions the ammonia in surface waters after conversion to nitrates is absorbed very rapidly by growing vegetation, and the more active the conversion and growth, the greater the appropriation on the part of growing vegetation.

If free ammonia exists in water to any marked extent, it may be measured directly by using the Nessler reagent. If the amount is comparatively small, as is usually the case, the ammonia must first be concentrated by distillation and condensation. Ammonia is always characteristic of sewage pollution, the oxidation of which yields it in abundance under conditions which do not permit it to be rapidly oxidized into nitric acid. Ammonia in drinking water produces, per se, no harmful effects. The amount present, however, is of more or less importance. In clean and properly stored rain water it is of little moment; in other waters it is usually evidence of the decomposition of organic matter. Its content in potable water is not large, and on account of oxidation and absorption by growing vegetation, it does not accumulate, even in sewage-polluted waters.

Nitrites.-Nitrites in water are regarded as a special danger signal, the presence of which indicates that active putrefaction of nitrogenous organic matter is under way as a result of bacterial activity, and their presence, therefore, at once suggests organic pollution. Small amounts of nitrites in water may be derived from the air by absorption, or by the cleansing action of rain showers. In some instances they may be due to water coming in contact with metallic surfaces, brick work and new masonry with nitrites in solution. But in the largest majority of instances the presence of nitrites may be traced to sewage contamination. Nitrites are present only in small amounts, since they are rapidly oxidized to the higher and more stable nitrates, which represent the final stage of complete oxidation. Nitrates do not undergo further change and, being permanent in character, accumulate in the water unless withdrawn by vegetable life or reduced. 
Nitrates.-Nitrates in water, like ammonia, are not in any way harmful in the amounts usually present in potable waters. They only represent what was once organic nitrogen, but now rendered harmless by being completely mineralized. The presence in water of nitrites is of far greater importance than that of nitrates; the presence of the former means that fermentative changes are in active progress, and that oxidization is not complete.

CHLORINS AND CHLORIDS.-Sodium chlorid is a normal constituent of all waters. Rain water takes it up from the air in small traces, particularly near the sea coast. The amount of chlorin normally present in water depends principally on location and other conditions. An increase over the normal is always indicative of pollution, mostly due to the presence of urine. Chlorin increases directly with the population; the amount present is also influenced very greatly by proximity to the ocean, since the air above the sea necessarily contains more chlorin than the air inland. For instance, a polluted water may have its organic nitrogen converted into nitrates, and these in turn may be absorbed by vegetable growth; it may be clear, colorless, odorless and palatable, free from pathogenic bacteria, and in every way suitable for drinking purposes, but, nevertheless, the chlorin remains as a mute witness of remote or passed pollution. The percolation of sea water into wells near the ocean renders the water hard, salty and undesirable for domestic use. Magnesium chlorid also renders water unsuitable for use in boilers. Wells driven near the sea frequently become mixed with sea water, particularly if the quantity drawn is sufficient to cause suction. When this happens it may be a difficult problem to operate the well without drawing in sea water. This sea water question has been more scientifically studied in Holland than elsewhere.

BACTERIa.-Bacteria in water may be of the harmless and beneficial kinds, depending upon dead organic matter for sustenance, thereby bringing about its complete conversion into simple chemical substances. Practically all natural waters contain bacteria-rain water, surface water, water of rivers and lakes and ocean water. The number and variety of the bacteria vary greatly in different places and under different conditions. Bacteria are washed into the water from the soil and from almost every conceivable source. The excretions from animals pollute waters with enormous numbers of microörganisms, but infection from certain species of bacteria found in the intestinal tract of man makes water most dangerous for consumption. The bacterial content of surface waters varies with conditions which favor or retard growth and accessions. Sun- 
shine, influx of food material or of substances inimical to bacterial life, sedimentation and growth of higher organisms act for or against increase. Matters suspended in the current of a flowing stream carry down with them the bacteria that have gathered upon them or have been entangled by contact. 'The diminution of their number by this means is more marked in sluggish streams and still waters than in rapidly flowing brooks, rivulets and large water courses. The growth of algae and other aquatic plants causes diminution to a greater or less degree by appropriating the nutrient materials upon which they subsist, and possibly through other influences yet unknown. Certain bacteria whose natural habitat is the intestinal canal of man and animals find their way into surface waters and pollute them. These forms are pathogenic. Probably they do not increase in water, but retain their virulence in undiminished degree for definite periods of time, and then tend to become modified in this respect and rapidly to disappear. Cholera germs have been found in the Seine river in an active state after seven days and in ordinary drinking water for as long as twenty days. Typhoid bacilli remain virulent for longer or shorter periods; they have been found in very pure water after more than seven weeks, while in badly polluted water their life is very short.

Bushner(3) has shown that the rays of the sun kill cultures of typhoid bacillus at a depth of five feet in about four and one-half hours, while at double that depth their effects are practically nil. It is true that this organism survives longer in cold than in hot weather. A probable explanation is that in warm weather the conditions may be more unfavorable to the destruction of the organism than in cold weather.

Concerning the Bacillus coli communis, Kruse(4) in 1894 asserted that this organism is so ubiquitous that it cannot be regarded as characteristic of sewage, and in this position he has received the support of a number of other investigators who have succeeded in isolating the organism from waters examined. In spite of the fact that numerous investigators have found the organism where it could not be traced directly to fecal pollution, the Committee of the American Public Health Association(5), on carefully examining this subject in all its phases, reports that the preponderance of evidence suggests that their mere presence rather than their number should be the criterion of recent sewage pollution. Clark and Goge(6), as a result of the examination of some 16,000 samples of water and more than 2,000 specimens of shellfish, sea water, ice, milk, dust and excrement, conclude that the colon bacillus occurs more frequently in sewage than all other hacteria. 
Sources of Water.-We can safely assert that all water comes to us from the aqueous vapor condensed in the form of rain or snow. Of this a certain percentage returns to the atmosphere by evaporation( 7 ); the balance collects upon the surface of the earth or soaks into the ground. Some of it flows off in the direction of lakes, ponds or rivers. The sources of water may, therefore, be said to be $(a)$ rain water, $(b)$ surface water, (c) ground water, including springs and wells. This classification is a convenient one, but there is no sharp line of demarcation between rain, surface and ground water. Rain water, once it falls, becomes surface water, and surface water quickly passes into the earth, becoming ground water. Ground water in time becomes spring and well water.

ICE AND SNOW WATER.-In freezing water becomes purer, losing a large portion of its saline content. Even the calcium carbonate and sulphate content is materially lessened after freezing. Thus ice water may be tolerably pure, but the air being expelled it is heavy and non-aërated. Snow water contains the salts of rain water; rather less ammonia is present, however, and the percentage of carbonic acid and air is infinitesimally small.

Upland surface water most nearly approaches rain water in all its characteristics. The dissolved matters are present in greater volume, the percentage depending somewhat upon the soil over which the water flows, and therefore it is customary to subdivide this class of water according to the geological character of the ground from which the upland water is obtained. Upland water does not contain any considerable amount of dissolved matters unless they be derived from calcareous strata. The organic substances present are chiefly vegetable. The chlorin content is low and the water soft.

SPRING AND WELL WATER.-Rain falling on the earth is partly absorbed and partly evaporated into the atmosphere, the relative amounts varying with the configuration and density of the ground, and with the circumstances impeding or favoring evaporation, such as temperature, movements of the air, etc. Springs are merely local outeroppings of the water table and are subject to variations in the volume of outflow. During a drouth the flow of water from a spring may cease altogether because of a fall in the level of the ground water; this may also happen in the case of springs located at the foot of hills or mountains. The laity look upon spring water as the purest from nature's water fountain, but they share with other waters the same chanees of becoming polluted. Wells may be classed as dug, driven and bored; again, they are sometimes 
classified according to depth. A well 50 feet or less is termed shallow, and 100 feet or more, deep.

RIVER WATER. - River water comes from a variety of sources, and is even more complex in its eonstitution than spring water. The Schuylkill River rises in the anthraeite coal regions of Pennsylvania and, receiving much refuse mine matter, becomes impregnated with iron salts and free mineral acids, which render it quite unsuitable for domestic or manufacturing purposes. In its course of abont 100 miles it traverses an extensive limestone district and receives several large streams heavily charged with calcinm carbonate. River water is also influenced by seasons and by ciremustances conneeted with seasons, such as the melting of snow, freshets and floods. Even samples of water taken on opposite banks of a river may vary in composition.

Drinking Water-DISTILLATION-Distillation is now largely used, and affords an easy way of securing safe, potable water; besides, boiling effectively frees the water from its impurities. On board ships distillation of sea water is resorted to in order to free it from salts and to render it. fit for drinking purposes( 8 ). Although the water thus obtained is pure, yet all the gases have been driven off from it by the boiling; it is of course unpalatable, and by some supposed to be indigestible. It may be aërated by allowing it to slowly trickle down through a long column of wood charcoal, or by filtration through animal charcoal or other porous substances.

CHEMICAL AND BACTERIOLOGICAL ANALYSIS.-The chemical and bacteriological analyses of drinking water are of great value. Chemical analysis will reveal the presence of organic and mineral impurity, such as accompanies infectious matters from the intestines and bladder. Though it cannot give grounds for a positive assertion that the use of water thus polluted will inevitably canse disease, it can and does point out possible danger. Bacteriological analysis differentiates between pathogenic and non-pathogenic contamination. Only rarely, however, does it serve to point out danger in advance.

According to Professor Frankland, who has had a large experience in the(9) detection of specific pathogenic bacteria in drinking water:

Their detection is now known to be practically impossible, and the seareh for such bacteria is, in general, only earried on in deference to the speeial request of the layman, the uninitiated, or the hopelessly ignorant, since it cannot be repeated often enough; so that any feeling of secur ity which may be gathered from an unsuccessful search for pathogenie bacteria is wholly illusory, and in the highest degree dangerous. By far the most important service which has been rendered by bae- 
teriology is the means which it affords of controlling the efficiency of filtration and other purification processes. The slightest irregularity or defect in the process of filtration is at once laid bare. Bacteriological purity of well water can also be satisfactorily controlled.

Horrocks (10), who has had a large experience in this particular field, says :

If a considerable time has elapsed since the occurrence of pollution, the bacteriological detection of same, especially when waters of great original purity are concerned, becomes more and more difficult ... it is, therefore, evident that a bacteriological examination has its limits of usefulness, and a slavish adherence to it under all conditions, combined with neglect of the hints to be obtained by ehemical means, may lead to a perfectly erroneous judgment. Still, there is one branch of hygienic study in which bacteriology must always reign supreme; it is now acknowledged on all sides that the working of sand filters for public water supplies cannot be properly kept under control except by appealing to bacteriological methods of examination.

Mayer(11) claims to have isolated typhoid bacilli from well water, and Jackson found, by the use of lactose bile media, that he was able to isolate the typhoid bacillus (a) from Grass River, a source of water supply for Canton, New York; $(b)$ from a pond or stream used as a private water supply at Hastings-on-the-Hudson; and $(c)$ from two points on the Hudson River. Nevertheless, it is very rare that the isolation of the typhoid organisms from suspected water supplies is ever accomplished.

With this data before us, it may be safely said that neither chemical nor bacteriological analysis is infallible. Each method has its uses, and each may be helped by the other. The value of either lies largely in the skill of the investigator in correctly interpreting the results of his findings. This requires as much knowledge as the minutiæ of the examination itself.

Below we append a table of qualitative tests for the chemical examination of water:

Table Showiyg Reagents Necessary for Qualitative Examination of Water 1

\begin{tabular}{|c|c|c|}
\hline $\begin{array}{l}\text { Substance sought } \\
\text { for }\end{array}$ & $\begin{array}{l}\text { Reagents to be used, and } \\
\text { effects }\end{array}$ & Remarks \\
\hline Reaction & $\begin{array}{l}\text { Litmus and turmeric pa- } \\
\text { pers; usual red or } \\
\text { brown reactions }\end{array}$ & $\begin{array}{l}\text { Usually neutral. If acid, and acidity } \\
\text { disappears on boiling, it is due to car- } \\
\text { bonic acid. If alkaline, and alkalinity } \\
\text { disappears on boiling, to ammonia } \\
\text { (rare); if permanently alkaline, to } \\
\text { sodium carbonate }\end{array}$ \\
\hline Lime & $\begin{array}{l}\text { Oxalate of Ammonium } \\
\text { White precipitate }\end{array}$ & $\begin{array}{l}\text { Six grains per gallon ( } 9 \text { per } 100,000) \\
\text { give turbidity: sixteen grains }(23 \text { per } \\
100,000) \text { considerable precipitate }\end{array}$ \\
\hline
\end{tabular}

1 Notter and Firth in "Treatise on Hygiene." 


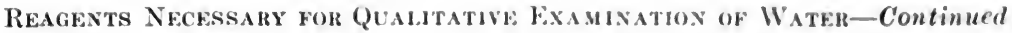

\begin{tabular}{|c|c|c|}
\hline $\begin{array}{l}\text { Substance sought } \\
\text { for }\end{array}$ & $\begin{array}{c}\text { Roagents to be used, and } \\
\text { eflects }\end{array}$ & Remarks \\
\hline Chlorin & $\begin{array}{l}\text { Nitrate of Silver and di- } \\
\text { lute nitric acid } \\
\text { White precipitate, becom- } \\
\text { ing lead color }\end{array}$ & $\begin{array}{l}\text { One grain per gallon (1.4 per } 100,000) \\
\text { gives a laze; four grains per gallon } \\
(6 \text { per } 100,000) \text { give a marked turbi- } \\
\text { dity ten grains (14 per } 100,000) \text { a } \\
\text { considerable precipitate }\end{array}$ \\
\hline Sulphuric acid. & $\begin{array}{l}\text { Chlorid of Barium and } \\
\text { dilute hydrochloric } \\
\text { acid } \\
\text { White precipitate }\end{array}$ & $\begin{array}{l}\text { One und a half grains ( } 2 \text { per } 100,000) \text { of } \\
\text { sulphate gives no precipitate until } \\
\text { after standing; three grains ( } 4 \text { per } \\
100,000) \text { give an immediate haze, and, } \\
\text { after a time, a slight precipitate }\end{array}$ \\
\hline Nitric acid & $\begin{array}{l}\text { Brucin solution and pure } \\
\text { sulphuric acid } \\
\text { A pink and yellow zone }\end{array}$ & $\begin{array}{l}\text { The sulphuric acid should be poured } \\
\text { gently down to form a layer under the } \\
\text { mixed water and brucin solution; half a } \\
\text { grain of nitric acid per gallon ( }=0.7 \\
\text { per } 100,000 \text { ) gives a marked pink and } \\
\text { yellow zone; or, as recommended by } \\
\text { Nicholson, } 2 \text { c.c. of the water may be } \\
\text { evaporated to dryness, a drop of pure } \\
\text { sulphuric acid and a minute crystal of } \\
\text { brucin be dropped in; } 0.01 \text { grain per } \\
\text { gallon ( } 0.0143 \text { per } 100,000 \text { ) can be } \\
\text { easily detected }\end{array}$ \\
\hline Ammonia & $\begin{array}{l}\text { Nessler's solution } \\
\text { A yellow color or a yel- } \\
\text { low brown precipitate }\end{array}$ & $\begin{array}{l}\text { If in small quantity, several inches in } \\
\text { deptl of water should be lonked down } \\
\text { through on a white ground }\end{array}$ \\
\hline Iron & $\begin{array}{l}\text { Red and yellow prus- } \\
\text { siates of potash and } \\
\text { dilute } \mathrm{HCl} \\
\text { Blue color }\end{array}$ & $\begin{array}{l}\text { The red for ferrous and the yellow for } \\
\text { ferric salts }\end{array}$ \\
\hline Hydrogen sulphid & $\begin{array}{l}\text { A salt of lead } \\
\text { Black precipitate }\end{array}$ & $\begin{array}{l}\text { When the water is heated the smell of } \\
\text { hydrogen sulphid may be perceptible }\end{array}$ \\
\hline Lead or copper & $\begin{array}{l}\text { Ammonium s u l p h id } \\
\text { Dark color, not cleared } \\
\text { up by } \mathrm{HCl}\end{array}$ & $\begin{array}{l}\text { Place some water ( } 100 \text { c.c.) in a white } \\
\text { dish, and stir up witl a rod dipped in } \\
\text { ammonium sulphid; wait till color } \\
\text { produced, then add a drop or two of } \\
\text { hydrochloric acid. If the color dis- } \\
\text { appenrs, it is due to iron; if not, to } \\
\text { lead or copper }\end{array}$ \\
\hline Lead & $\begin{array}{l}\text { Small crystals of potas- } \\
\text { sium bichromate give a } \\
\text { turbidity }\end{array}$ & $\begin{array}{l}\text { One-tenth grain per gallon gives an im- } \\
\text { mediate turbidity; one-twentieth grain } \\
\text { per gallon after one minute; one- } \\
\text { fiftieth grain per gallon after half an } \\
\text { hour }\end{array}$ \\
\hline Zinc & $\begin{array}{l}\text { Render water slightly } \\
\text { ammoniacal; boil; fil- } \\
\text { ter; a few drops of } \\
\text { potassium ferrocyanid } \\
\text { give a haze to white } \\
\text { precipitate } \\
\text { Hydrogen sulphid gives } \\
\text { a while precipitate }\end{array}$ & $\begin{array}{l}\text { The filtrate must be quite clear before } \\
\text { the ferrocyanid is added } \\
\text { This reaction is not available if iron be } \\
\text { present or if the water be acid or } \\
\text { alkaline }\end{array}$ \\
\hline
\end{tabular}




\section{THE USES OF WATER IN THE HUMAN SYSTEM}

Eliminative Function.-It was once taught that increased consumption of water was accompanied by an increased waste of nitrogenous tissues, but this erroneous belief is no longer given credence. Any increased excretion of nitrogen with a free consumption of water does not entail an increased breaking down of body substance, only a washing or flushing out of the tissues with the elimination of waste matters loitering in them.

This important eliminative function of water is one of great therapeutic value. It indicates the necessity for a generous supply of water at all times and places, in such diseased conditions as gout, diabetes, continued fevers, and in cases where the excretory power of the kidneys is retarded by disease.

Function as Food.-Of the inorganic substances water may well be taken up first in our discussion, because about sixty-six and two-thirds per cent of the weight of the body is made up of water. The importance of water as a true food is at once apparent from this statement. Water is absolutely essential for the physiological performance of every bodily function, and each living cell of the body requires water for a continuation of its life processes.

About four and a haif pints of water are given off from the body daily in the various excreta and exhalations. About one-sixth of this loss is replenished by the combination of oxygen and hydrogen in the tissues. The remainder is replaced most conveniently from foods, beverages, and lastly from the drinking of water in a pure state when it retains all of its solvent properties. If one reckons that about half of the whole weight of solid food taken consists of water, then the amount required to be added to the diet in an actually fluid form varies from four to six glasses, depending somewhat upon the season, amount and variety of food and exercise taken. The age, sex and size of the individual are factors to be considered in the total daily consumption of water. In very warm weather, under exceedingly strenuous exercise, great quantities of water will be lost in the form of perspiration, that would not be lost on a cold day and must be compensated for.

As previously stated, the nature of the diet has an important influence on the amount of water consumed. On this point some interesting observations have been recorded by Voit as contained in the following table . 
Winter C'onsumed

1.151 grams
$7(i 0)$ grams
6.46 grams
1.238 grams

Water in Feees

212 grams

25) grams

li) grams

10 grums

Aid in Digestion. - Water plays an important rîle in the digestion of foods. While the water of digestion is most frequently taken during meals, it ought to be largely secreted by the salivary glands during the process of masticating the food. In order that the glands may secrete freely and copionsly bathe the bolus of food before swallowing, one should drink freely water, milk or other beverage an hour after each meal. Water is also of use during the process of absorption of the digested foods. It is in the small intestine that water is chiefly absorbed. Only a very small amomt is absorbed by the stomach and a trifling anount possibly in the month. Water absorbed in the intestine is rapidly passed into the limphaties and carried into the circulation, of which it makes up about ninety per cent of the circulating fluid of the body. From the circulation the water is removed by sending it through the kidneys into the bladder, making space in the circnlatory apparatus for the entrance of more fluid from the alimentary tract. This use of water in digestion makes possible the easy distribution of food materials from the point where they are alsorbed to the various parts of the body where they are assimilated by the tissues. It is well to remember that ninety-five and one-half per cent of the salira and gastric juice and ninety-eight per cent of the pancreatic juice is water.

NECESSITY OF WATER-One may do without organic foods for many days, or even weeks, but twenty-four hours without water will cause one to experience a thirst which soon becomes a torturing madness. After a day or so this thirst merges into a suffering which dethrones the mind.

Continued deprivation of water causes the blood, by virtue of its self-regulating power, to withhold fluid from the kidneys and digestive glands. As a result the digestive secretions become more concentrated and more intense in reaction and greatly diminished in amount. The mucous surfaces become dry and parched, especially in the mouth, which is the first part of the organism to suffer because of the passage of the air and the consequent evaporation. The diminution and altered strength of the digestive secretions greatly interfere with and lessen their normal action upon the ingested food. The peristaltic movement of food in the stomach and intestines is retarded and the absorption of fluid through the walls of the alimentary canal is lessened and nutrition retarded. The 
muscles and other structures dry up and diminish in volume and emaciation is rapid.

Diuretic and Diaphoretic Function.-Water is a diuretic and diaphoretic. In conditions where it cannot be retained by the stomach it may be advantageously administered by the use of a rectal tube. All the water so administered will be absorbed if the rectum has been previously evacuated and washed ont. A half or even a pint of salt solution may be introduced subcutaneously, where it will be promptly absorbed and quite rapidly eliminated. This method of flushing the kidneys is often resorted to in certain diseased conditions where rapid elimination through the kidneys is desired.

Recent experiments by Falck (Archiv für Physiologie) have shown that if the water of the diet be reduced twenty-seven per cent there is unmistakable evidence that the blood becomes more concentrated and that the solids of the plasma rise from $4,800,000$ to $5,580,000$ per cubio millimeter, and the specific gravity of the blood serum from 1027.4 to 1033.4. At the same time, the arterial tension and volume of the pulse is diminished as the blood becomes more concentrated. This is the usual result when water is restricted. Water passes from the tissues into the circulation to make good the deficiency. The tissues, therefore, become dryer. Hence in cardiac dropsy where the tissues become water-logged good results may be secured by restricting the amount of fluid in the diet. The tissues then will drain themselves into the blood vessels.

One or two tumblerfuls of cold water taken on an empty stomach in the morning on arising favors the evacuation of the bowels. The water, moreover, is quickly absorbed and temporarily increases the fulness of the blood vessels, which promotes intestinal secretion and intestinal activity. Increased activity of the bowel is explained in this way rather than by the idea that the water itself reaches the colon and flushes out its contents.

The temperature of drinking water is a matter of some importance. Iced water will stimulate a more rapid and greater secretion of gastric juice, but iced water in excess is injurious, as it lessens the motility of the stomach, and should not be taken when one is overheated. Hot water has a very beneficial effect on an irritated stomach, as in some forms of gastritis.

Pure water is by far the safest of all beverages. A moderate amount of water, drunk slowly at the end of each meal, is a valuable aid to digestion, since it stimulates contractions of the stomach, dispersing wind, or diluting any undue acidity, and thereby promoting digestion. A 
tumbler full of warm or preferably hot water taken just before a meal removes mucus and refreshes the gastric mucous membrane. Taken three or four hours after a meal, it assists in the final stages of gastric digestion, dilutes any undue acidity, and frequently leads to the eructation of gas. Thin persons may encourage their appetite by drinking frequent sips of water during a meal. They eat more by its aid. The water, by its ease of absorption, fills out the intercellular spaces, increasing the bulk and weight of the body and improving the general condition.

Water taken in moderate quantities acts as a diluent of the blood, as a solvent of waste material, promotes metabolic changes and assists in the excretion of waste substances.

In diseases of the kidney water is of great value, by flushing these organs, dissolving and washing the waste materials of metabolism and thereby assisting in the prevention or cure of gout, rheumatism, gravel, liver and other diseases.

The uses of water are summarized by Thompson somewhat as follows:

1. It acts as a diluent of the blood.

2. It acts as a solvent of waste material.

3. It promotes metabolic changes.

4. It assists in the excretion of waste substances.

5. It serves as a distributor of body heat.

6. It regulates body temperature through the physiological process of absorption and evaporation.

7. It forms the chief ingredient of all the fluids of the body and maintains their proper degree of solution.

8. It furnishes in the blood and lymph a fluid medium by which food may be taken to remote parts of the body.

9 . By moistening the various mucous and serous membranes of the body it prevents friction and the uncomfortable symptoms. which would result from their drying.

\section{REFERENCES}

In the preparation of this section the author has derived much help and drawn largely from the following published works, particularly from Practical Hygiene by Harrington; Preventive Medicine and Hygiene by M. J. Rosenau; Treatise on Hygiene by Notter and Firth; Text-book of Physiology by Isaac Ott; Text-book of Physiology by. W. H. Howell, etc. 
1. Harrington, Cirarles H. Practical Hygiene, 5th revised ed.

2. Rosenau, Milton J. Preventive Medicine and Hygiene, 2nd ed., p. 796.

3. Businer. Centrlbl. f. Bakteriol. u. Parasitenk., xi, p. 781.

4. Kreuse. Ztsehr. f. Hyg. und Infectionskrankh., xvii, p. 1.

5. —. Public Health Reports, xxix, p. 356.

6. Clakke and Goge. Public Health Reports, xxix, 386.

¡. Rosenau, Milton J. Preventive Medicine and Hygiene, 2nd ed.

8. Notter and FirTh. Treatise on Hygiene.

9. Frankland, Prof. Percy. J. of the San. Inst., Oct., 1899, 393.

10. Horrocks, W. H. Bacteriological Examination of Water, London, 1901, 3.

11. Mayer, G. Centrlbl. f. Hyg. u. Infectionskrankh., 1899, xxi, 133.

\section{BIBLIOGRAPHY}

Dox, T., and Cursholm, J. Modern Method of Water Purification, 2nd ed., New York, 1913, Longmans, Green \& Co.

Hazex, A. Clean Water and How to Get It, New York, 1907, Wiley \& Sons.

Mason, W. P. Water Supply, 3rd ed., New York, 1902, Wiley \& Sons. Prescott, S. C., and Winslow, C. E. A. Elements of Water Bacteriology, 3rd ed., New York, 1913, Wiley \& Sons.

Report of the Committee of the American Public Health Ass'n. Standard Methods of Water Analysis, 2nd ed., 1912.

Savage, W. G. The Bacteriological Examination of Water Supplies, Philadelphia, 1906, Blakiston's Son \& Co.

Thresh, J. C. The Examination of Waters and Water Supplies, 2nd ed., Philadelphia, 1914, Blakiston's Son \& Co.

Turnenure, F. E., and Russelt, H. L. Publie Water Supplies, New York, 1907, Wiley \& Sons.

Winple, G. C. The Microscopy of Drinking Water, 3rd ed., New York, 1914, Wiley \& Sons.

For typical and composite analysis, see

Annual Reports of the Massachusetts State Board of Health.

Bulletin of the Illinois State Board of Health. The Municipal Water Supplies of Illinois, Tune, 1908, iv, 6.

Bulletins of the United States Geological Survey Water Supply Papers. Some Working Analysis. 
Clarke. The Data of Geochemistry, ('hemistry and Physics, 54, U. S. Geological Survey, 1908, Bull. No. 3:30, Series E.

Davies. On the Connection between Milk Supply and Disease, Providence Med. J., 1889.

Deacon. The Constant Supply and Waste of Water, J. Soe. Arts, 1882, xxx, 738.

De Raxce. Water Supply of England and Wales, London, 1882.

Downes, A. I)iphtheria Communicated by Drinking Vessels, San. Rec., 1879-80, xi, 51.

- Enteric Fever Cansed by an Overflow of Non-enteric Sewage into a Well, Lancet, $\Lambda_{\text {pril }} 27,1572$.

Drown. Interpretation of the Chemical Analysis of Water, Report on Water and Sewage to the Massachusetts State Board of Health, 1890.

Dunbar. Ueber den Typhus Bacillus und den Bacterium coli communis, Ztschr. f. Hygiene, 1892, xii, 485.

Dipuit. Etudes sur le mouvement des eaux, Paris, 1875.

Ekix. Potable Water, London, 1890.

Evaxs. Our Homes, Cassell \& Co., London, 1883, 807, 809.

Fansing. On Hydraulic and Water Supply Engineering, New York, 1889.

Farlow. Supplement to First Annual Report of State Board of ITealth, Mass., 1877, p. 143.

Farr. Report on the Cholera Epidemic of 1866 in England, Supplement to the 29th Annual Report of the Registrar-General, 1868.

Field. Pollution of Well Water from Cemeteries, Trans. San. Inst., viii, 254.

Flugge. Micro-organisms, New Syd. Soc., London, 1890.

Fraxkel. Ueber den Bakteriengehalt des Eisens, Ztschr. f. Hyg., Bd. I. Franklanin, E. Water Analysis for Sanitary Purposes, London, 1880.

Franklaxn, P. Third Report to the Royal Society Water Research Committee, November, 1894.

Multiplication of Micro-organisms, Proc. Roy. Soc., London, 1886 .

Supply, J. Chem. Industries, 1887.

Hygienic Value of the Bacteriological Examination of Water, Trans. Internat. Cong. Hyg. \& Demog., London, 1891.

Experiments on the Vitality and Virulence of Sporiferous Anthrax in Potable Water, London, 1894. 
Freundenreicil. Ueber die Durchlässigkeit der Chamberländschen Filter für Bakterien, Centralbl. f. Bakteriol, 1892, vii, 240.

Fuller. Differentiation of the Bacillus of Typhoid Fever, Rep. State Board of Health, Mass., 1891.

Gıвв. Pollution of Cisterns by Sewage, Brit. Med. J., Oct., 1870.

Gors. Diarrhœa Caused by Impure Water, Army Med. Rep., v, 428.

Graxge. On Analysis of Water, Ann. de chim. et phys., xiv, 364.

Greenbow. Diarrhœa Caused by Water Which Had Absorbed Sewer

Gases, 2nd Report Med. Off. of the Priv. Council, 1860, 153.

Guxtuer. Cholera in Saxony or Die Indische Cholera in Sachsen im Jahre 1865, 125 .

Harvey. Food, Water, and Air, London, 1872, 68.

Hawsiey. Report of the Rivers Pollution Commissioners, vi, 233.

Hirscir. Geographical and Historical Pathology, translated by C. Creighton, M.D., 1886, iii, 340-343.

Hochstetter. Ueber Mikro-organismen im künstlichen Selterswasser, Arbeiten aus dem Kais. Gesundheitsamt, ii.

Leffund and Beam. Examination of Water for Sanitary and Technical Purposes, London, 1895.

Musgrave and Clega. Bull. 18, Bur. Gov. Lab., P. I., No. 93.

Niciols, A. H. The Contamination of Drinking Water with Impure Ice, Seventh Ann. Rep., S. B. H., Mass., 1876, p. 467.

Parkes, L. C. Moorland Waters, Trans. Chem. Soc., 1899, lxxv, p. 196. Prescott, S. C., and Winsiow, C.-E. A. Elements of Water Bacteriology, 3rd ed., pub. by Wiley \& Son, New York, 1913.

Russeld, H. L. Public Water Supplies, New York, Wiley \& Son, 1907. Savage, W. G. The Bacteriological Examination of Water Supplies, pub. by Blakiston's Son \& Co., Philadelphia, 1906.

Sedrewick and Wixslow. Experiments on the Effects of Freezing and Other Low Temperatures on the Viability of the Typhoid Bacillus, Amer. Acad. Arts and Sci., Aug., 1902, vol. xii, No. 5.

Thresir, J. C. The Examination of Waters and Water Supplies, 2nd ed., pub. by Blakiston's Son \& Co., Philadelphia, 1906.

Wrimple, G. C. The Microscopy of Drinking Water, 3rd ed., pub. by, Wiley \& Son, New York, 1914.

Whitelegge, A. B. Hygiene and Public Health.

Wood, Harot. B. The Economic Value of Protecting Water Supplies, J. Am. Med. Assn., Oct. 2, 1909, p. 1093. 


\title{
CHAP'TER XI
}

\section{THE MINERAL CONTENT OF THE BODY AND OF FOODS}

\begin{abstract}
General Considerations: The Importance of the Mineral Salts; Mineral Matter Contained in the Excretions; Mineral Content of Organs.

Utilization of Mineral Substances: Form of Mineral Content in Body; Function in Body as Regulators of Osmosis; The Metabolism of the Inorganic Salts; The Various Uses of the Mineral Salts.

Mineral Content of Foods; Calcium ; Magnesium; Iron; Sodium and Potassium; Phosphorus; Sulphur; Chlorin; Iodin; Fluorin; Silica; Bromin; Oxalic Acid; Manganese.
\end{abstract}

\section{GENERAL CONSIDERATIONS}

Importance of Mineral Salts.-The human body contains about seven pounds of mineral matter, of which five-sixths is in the bones. It is obvious from this that the mineral ingredients of the diet are important as building material for the human economy and are, therefore, to be regarded as foods. The principal minerals required in the food are sodium, potassium, calcium, magnesium, iron, with phosphorus, chlorin, sulphur, and traces of silica, fluorin, iodin and others.

The mineral salts are indeed so necessary for maintaining the general metabolic balance of the body, that death would ensue within thirty days if the supply were stopped, even if all the other constituents of a normal diet were provided.

The inorganic salts of the food are important as tissue builders, but of no consequence as sources of heat or energy because the salts in the foods enter the body in a form too highly oxidized to be capable of yielding any heat to the body tissues.

The mineral salts are quite essential to nerve and muscle reaction, and it is due, directly, to their action that a well-balanced osmotic pressure is maintained. Their action favors absorption by increasing endosmosis of the tissues, thereby assisting metabolic processes. 
The metabolism of salts of the body plays a constructive part in the physiology of nutrition, and disturbances of this salt metabolism may be the cause of disease. Indeed Bunge has shown that the nitrogenous products of metabolism cannot be eliminated from the body unless mineral salts are present.

The normal human body contains about 200 grams of sodium chlorid. The body requires daily about ten grams of this element and something like 12 grams is excreted daily through the urine, sweat, feces and tears.

A practical illustration of the value of salt to animal life is observed by the regularity with which wild animals travel, sometimes great distances, to the so-called "salt licks." It is also interesting to note that among animals the herbivora require salt in their food, while the carnivora do not. Domestic animals will allow themselves to be caught for the sake of a handful of common salt. Whenever a high tax has been imposed on salt and its use restricted, the bealth of the people has suffered. In writing on this subject Bunge says: "Most vegetables are rich in potassium, which is ultimately eliminated in the form of mineral salts, largely as sulphate. Potassium sulphate in the blood reacts to some extent with sodium chlorid, forming potassium chlorid and sodium sulphate, both of which are rapidly eliminated by the kidneys. Hence the greater the amount of potash in the food, the greater the loss of sodium and chlorin from the blood, and the greater the necessity for salt to keep up the normal sodium chlorid content of the body."

Bunge also believes that while man might live without the addition of salt to the food, even on a diet largely vegetarian, nevertheless, without salt he would soon experience a disinclination to eat much of the vegetables rich in potassium, such as potatoes, so that the use of salt tends to enable us to utilize a more varied selection of the earth's food products. Excessive use of salts probably acts injuriously by overstimulating the digestive tract, and may overtax the organs concerned in its elimination and thereby cause untoward symptoms. Under certain conditions even small amounts may be excreted in such quantity in the urine that they cannot be held in suspension and as a consequence are deposited in the urinary tract and cause the formation of concretions- "stones."

Mineral Matter Contained in Excretions.-The average amounts of the various mineral compounds excreted in the urine, feces and sweat are shown by the following table worked out by Gautier and other physiologists : 
Mineral Matter Contained in the Urine, Feces, and Sweat of Man (Gautier, after Bischoff, Voit, Wehsarg, Magnier, and Lapicque)

\begin{tabular}{|c|c|c|c|}
\hline & $\begin{array}{l}\text { Urine of } \\
24 \text { hours }\end{array}$ & $\begin{array}{c}\text { Fecal } \\
\text { material of } \\
24 \text { hours }\end{array}$ & $\begin{array}{l}\text { Sweat of } \\
24 \text { hours }\end{array}$ \\
\hline Water. & $\begin{array}{c}\text { Grams } \\
1220-1350\end{array}$ & $\begin{array}{c}\text { Grams } \\
100-119\end{array}$ & $\begin{array}{c}\text { Grams } \\
750-850\end{array}$ \\
\hline Saline material. & $17.3-22$ & $4.35-6$ & $1.6-2.4$ \\
\hline These salts comprise: & & & \\
\hline Chlorin .......... & $4.9-7.2$ & $0.015-0.035$ & 1.12 \\
\hline Phosphoric anhydrid $\left(\mathrm{P}_{2} \mathrm{O}_{5}\right)$ (pentoxid). & $1.6-3$ & $0.76-0.82$ & Traces \\
\hline Sulphuric anhydrid $\left(\mathrm{SO}_{3}\right)$ (trioxid) ...... & $1.4-2.26$ & $0.06-0.17$ & 0.005 \\
\hline Silicic anhydrid $\left(\mathrm{SiO}_{2}\right)$ (dioxid). . & $0.003-0.004$ & $0.17-0.35$ & 0.005 \\
\hline Carbonic anhydrid $\left(\mathrm{CO}_{2}\right)$ (dioxid). & $0.003-0.004$ & 0.05 & 0.005 \\
\hline Potassium oxid $\left(\mathrm{K}_{2} \mathrm{O}\right) \ldots \ldots \ldots$ & $1.6-3.1$ & $0.75-0.30$ & 0.178 \\
\hline Sodium oxid $\left(\mathrm{Na}_{2} \mathrm{O}\right) \ldots$ & $4.16-5.9$ & $0.25-0.35$ & 0.80 \\
\hline Calcium oxid $(\mathrm{CaO})$. & $0.24-0.36$ & $0.65-0.70$ & Traces \\
\hline Magnesium oxid (MgO). & $0.56-0.36$ & $0.65-0.70$ & Traces \\
\hline Ferric Oxid $\left(\mathrm{Fe}_{2} \mathrm{O}_{3}\right) \ldots$. & $0.004-0.013$ & $0.023-0.04$ & Traces \\
\hline
\end{tabular}

Mineral Content of Organs.-The following table shows the mineral content of specific organs:
Mineral Matter Contained in the Principal Organs-for 1,000 Parts of the Fresh Organs (Gautier)

\begin{tabular}{|c|c|c|c|c|c|c|c|}
\hline \multirow{2}{*}{$\begin{array}{l}\text { Mineral mat- } \\
\text { ter per } 1000 \\
\text { grams of } \\
\text { fresh sub- } \\
\text { stance }\end{array}$} & \multirow{2}{*}{$\begin{array}{l}\text { Muscles } \\
\text { of } \\
\text { Mammals }\end{array}$} & \multirow{2}{*}{$\begin{array}{c}\text { Nervous } \\
\text { Tissue }\end{array}$} & \multirow{2}{*}{ Bone } & \multirow{2}{*}{ Liver } & \multicolumn{2}{|c|}{$\begin{array}{c}\text { IN } 1,000 \text { PaRts of } \\
\text { BLOOD }\end{array}$} & \multirow{2}{*}{ Lymph } \\
\hline & & & & & $\begin{array}{l}\text { Cor- } \\
\text { puscles }\end{array}$ & Plasma & \\
\hline & Grams & Grams & Gra & $\mathrm{ms}$ & $\mathrm{Gr}$ & Grams & Grams \\
\hline Chlo & $\begin{array}{c}9-12 \\
0.5-0.7\end{array}$ & $\begin{array}{l}2-17 \\
0.4\end{array}$ & $\mid \begin{array}{c}620-690 \\
06-0.7\end{array}$ & $\begin{array}{c}9 \text { to } 11 \\
025-0.42\end{array}$ & 6.5 to 0.0 & $1.17-4$ & $\begin{array}{l}7.47 \\
3.08\end{array}$ \\
\hline $\mathrm{P}_{2} \mathrm{O}_{5}$. & $3.4-5$ & $0.85-1.4$ & $196-247$ & $5.02-4.27$ & $0.69-0.65$ & $0.71-2.2$ & 0.18 \\
\hline $\mathrm{SO}_{3}$ & 2.2 & 0.14 & 0.20 & 0.09-0.092 & $0.69-0.65$ & $0.71-2.2$ & 0.09 \\
\hline $\mathrm{SiO}_{2}$ & 2.2 & 0.14 & 0.20 & $0.027-0.018$ & $0.69-0.65$ & $0.71-2.2$ & 0.09 \\
\hline $\mathrm{K}_{2} \mathrm{O}$. & $3-3.9$ & $0.71-2.12$ & 0.20 & $2.52-3.47$ & $1.6-1.4$ & $0.15-0.20$ & 0.16 \\
\hline $\mathrm{Na}_{2} \mathrm{O}$. & $0.4-0.7$ & $0.75-1.3$ & 0.20 & $1.45-1.13$ & $0.24-0.65$ & $1.66-1.9$ & 3.07 \\
\hline $\mathrm{CaO}$. & $0.9-0.18$ & 0.03 & $270-500 \mid$ & $0.36-0.03$ & $0.19-0.25$ & $0.06-0.08$ & 0.15 \\
\hline MgO. & 0.4 & $0.065-0.75$ & $4-6$ & $0.02-0.007$ & 0.07 & $0.02-0.05$ & \\
\hline & $0.03-0.02$ & $0.04-0.12$ & $4-6$ & $0.27-0.17$ & 0.77 & 0.006 & 0.15 \\
\hline & $0.03-0.02$ & $0.21-0.33$ & $3.2-4.5$ & $0.27-0.17$ & 0.77 & 0.006 & 0.50 \\
\hline
\end{tabular}


Bunge in his admirable work has tabulated the composition of some of the commoner food materials in respect to the salt content which is shown in the following table:

Salt Content in 100 Parts by Weight of Dried Substance (Bunge)

$\begin{array}{llcccccc} & \mathrm{K}_{2} \mathrm{O} & \mathrm{Na}_{2} \mathrm{O} & \mathrm{CaO} & \mathrm{MgO} & \mathrm{F}_{2} \mathrm{O}_{3} & \mathrm{P}_{2} \mathrm{OS} & \mathrm{Cl} \\ \text { Beef } \ldots \ldots \ldots \ldots \ldots \ldots \ldots & 1.66 & 0.32 & 0.029 & 0.152 & 0.02 & 1.83 & 0.28 \\ \text { Wheat } \ldots \ldots \ldots \ldots \ldots \ldots & 0.62 & 0.06 & 0.065 & 0.24 & 0.026 & 0.94 & \text { ? } \\ \text { Potatoes } \ldots \ldots \ldots \ldots \ldots & 2.28 & 0.11 & 0.100 & 0.19 & 0.042 & 0.64 & 0.13 \\ \text { White of } \mathrm{egg} \ldots \ldots \ldots \ldots & 1.44 & 1.45 & 0.130 & 0.13 & 0.026 & 0.20 & 1.32 \\ \text { Peas } \ldots \ldots \ldots \ldots \ldots \ldots & 1.13 & 0.03 & 0.137 & 0.22 & 0.024 & 0.99 & \text { ? } \\ \text { Human milk } \ldots \ldots \ldots \ldots & 0.58 & 0.17 & 0.243 & 0.05 & 0.003 & 0.35 & 0.32 \\ \text { Milk of egg } \ldots \ldots \ldots \ldots \ldots & 0.27 & 0.17 & 0.380 & 0.06 & 0.040 & 1.90 & 0.35 \\ \text { Cow's milk } \ldots \ldots \ldots \ldots \ldots & 1.67 & 1.05 & 1.510 & 0.20 & 0.003 & 1.86 & 1.60\end{array}$

We now understand the great importance of, and the absolute necessity for, the mineral salts in our foodstuffs. We cannot know how much of these substances is required for healthy nutrition in as precise a manner as we can calculate the need for carbon or for nitrogen. This is because many of the waste mineral matters of the body are excreted by the intestine, and we have no exact means of calculating just the proportion which escapes absorption, and how much has been excreted from the blood after playing a part in metabolism. It is safe, however, to assert that the amount of mineral matter in an ordinary, well-balanced diet is quite sufficient for all the needs of the body.

The mineral salts required daily for the average adult, showing a daily requirement of about 24 grams of the inorganic salts, and their combination with certain acids, are summarized by Gautier as follows:

BASES

\begin{tabular}{|c|c|c|c|c|}
\hline & Grams & & & Grams \\
\hline $\mathrm{K}_{2} \mathrm{O}$ & 3.22 & $\mathrm{P}_{2} \mathrm{O}_{5}$ & & 3.9 \\
\hline $\mathrm{Na}_{2} \mathrm{O}$ & 7.70 & $\mathrm{SO}_{3}$ & & 2.03 \\
\hline $\mathrm{aO}$. & 1.47 & $\mathrm{SO}_{2}$ & & 0.25 \\
\hline$g \mathrm{O}$ & 0.56 & $\mathrm{Cl} \ldots$ & & 8.50 \\
\hline $\mathrm{e}_{2} \mathrm{O}_{3}$ & 0.04 & $\mathrm{CO}_{2}$ & & 0.05 \\
\hline
\end{tabular}

Many, if not indeed most, of the various mineral constituents which enter into a well-balanced diet are in a state of organic combination. Thus we find calcium and phosphorus organically combined in milk, iron in 
the yolk of eggs and in meat, magnesium in bread, sulphur in the protein-containing foods, and so on.

It has been ascertained from analyses of himman milk that an infant requires about five grains of lime daily. The adult, owing to cessation of the growth of the bones, requires less. Insufficient lime in an infant's diet leads to softening of the bones; but it must be remembered that though an element of rickets, this softening is not really the root of the disease, for it is too well known that an infant may suffer from the disease even though there may be an actual excess of lime salts in the food. On the other hand, in old age, various pathological conditions have been ascribed to the excessive consumption of calcium in the food. It must be admitted, however, that there is but little real evidence for such views. It is also questionable whether the intestine ever absorbs more of any mineral substance than the tissues actually require, and even if there is a tendency to the accumulation of such substances in any particular situation, the fault is possibly due to some local tissue change rather than to any undue increase of absorption.

There is a lowered calcium excretion in many diseased conditions, among which may be mentioned pleural effusion, delirium tremens and pneumonia. On the other hand, in osteomalacia, the calcium balance is disturbed and more is excreted than is taken into the body. In myositis ossificans, the amount of calcium excreted in the urine is lower than normal. There is also a retention of lime salts in arthritis deformans.

\section{UTILIZATION OF MINERAL SUBSTANCES}

Form of Mineral Salts in the Body.-The mineral constituents of the body are found not only in combination with the organic constituents, but also partly in solution-in the fluids of the organism. The method of determining the condition of the mineral constituents of any substance consists in dissolving out the inorganic salts, burning the organic part remaining, and then estimating the inorganic material in the ash. In the human body, for instance, the ash content of the mineral matter, including the bones, which are rich in calcium, is about 4.3 to 4.4 per cent of the body weight. The bones, however, in the adult contain most of this ash (five-sixths). The soft tissues, like the muscles, constitute about 0.6 to 0.8 per cent of the moist weight.

Organic bodies subjected to high degrees of heat with the access of air, liberate and set free the mineral matter. The same process takes place 
when foods are oxidized in the tissues of the body. The liberated mineral substances form new combinations, chiefly inorganic salts. The inorganic salts formed in the body in this manner are largely excreted in the urine and other excretions, or they may be retained and recombine with freshly absorbed organic food materials from the digestive system. The latter view is upheld by Forster(1); if correct, it would appear that a constant supply of salts in the food is unnecessary, or, at any rate, that the necessary amount is small.

According to Hammarsten(2), man needs very little mineral matter, and this in general is to be obtained from the daily food, since the latter usually contains a greater quantity than is required by the human body. The daily excretion of mineral matter is not an index of the require: ments of the body for its mineral constituents. Finally, this investigator holds that since the mineral salts are a part of the ingested food they must be excreted when they cease to be of use to the organism. In the present state of our knowledge, however, these statements cannot be accepted without reserve, for further investigation is necessary to determine the definite requirements of the human body for its mineral constituents. But it has been demonstrated that the organism cannot exist on food that contains no mineral matter.

Numerous laboratory experiments have been made upon growing rats fed upon artificial diets(3). These have shown that if the necessary proteins, fats and carbohydrates are supplied, but the inorganic salts omitted, the animal promptly loses weight and dies.

It is known at the present time that life cannot be maintained on foods deficient in inorganic salts. It is also recognized by research workers that something more is essential for the maintenance, growth and well-being of man than protein, fat and carbohydrate. Unless food contains sufficient mineral matter, no matter how well balanced the ration may be, in the ternary food elements, nor how large quantities are ingested, nor how high the caloric value, there will be malnutrition. In Forster's experiments, dogs and pigeons fed on demineralized food died earlier than those that were entirely deprived of food. In these animals disturbance of the functions of various organs, especially the muscles and nerves, was noted before death occurred. From this he concluded that the full-grown animal requires a considerable quantity of inorganic salts. Bunge also held to the theory that the constant renewal of the inorganic. portion of our body was not necessary, and that when the body once reached maturity, it would last indefinitely. Unfortunately this is not so. The following table, taken from Tibbles, graphically shows the per- 
centage present in the various parts and organs of the body of the principal inorganic salts:

Composition of Ash-Percentages

\begin{tabular}{|c|c|c|c|c|}
\hline & $\begin{array}{c}\text { Bone } \\
\text { (Heintz) }\end{array}$ & $\begin{array}{r}\text { Muscle } \\
\text { (Staffel) }\end{array}$ & $\begin{array}{c}\text { Liver } \\
\text { (Oidtmann) }\end{array}$ & $\begin{array}{c}\text { Spleen } \\
\text { (Oidtmann) }\end{array}$ \\
\hline 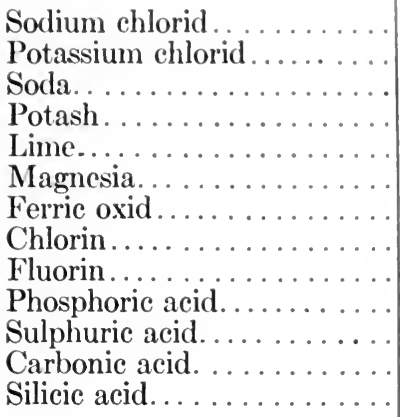 & $\begin{array}{c}\ldots \\
\ldots \\
\ldots \\
37.58 \\
1.22 \\
\ldots \\
\cdots \\
1.66 \\
53.31 \\
\ldots .47 \\
\ldots\end{array}$ & $\begin{array}{r}10.59 \\
2.35 \\
34.40 \\
1.99 \\
1.45 \\
\cdots \\
\cdots \\
48.13 \\
\cdots \\
\cdots .81\end{array}$ & $\begin{array}{r}\cdots \\
14.33 \\
25.23 \\
3.61 \\
.20 \\
2.74 \\
2.58 \\
\ldots 0.18 \\
.92 \\
. .27\end{array}$ & $\begin{array}{r}\cdots \\
44.33 \\
9.60 \\
7.48 \\
.49 \\
7.28 \\
.54 \\
27.10 \\
2.54 \\
\ldots \\
.17\end{array}$ \\
\hline
\end{tabular}

Composition of Ash-Percentages

\begin{tabular}{|c|c|c|c|c|}
\hline & $\begin{array}{c}\text { Brain } \\
\text { (Breed) }\end{array}$ & $\begin{array}{c}\text { Blood } \\
\text { (Verdell) }\end{array}$ & $\begin{array}{c}\text { Lymph } \\
\text { (Dahnhardt) }\end{array}$ & $\begin{array}{c}\text { Milk } \\
\text { (Wilderstein) }\end{array}$ \\
\hline 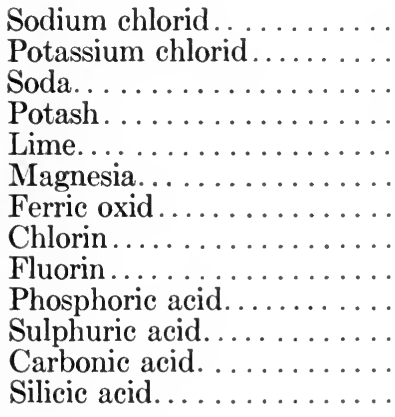 & $\begin{array}{r}4.74 \\
10.69 \\
34.42 \\
.72 \\
1.23 \\
\ldots \\
\ldots \\
\ldots 0.18 \\
.92 \\
\ldots \\
.27\end{array}$ & $\begin{array}{r}58.81 \\
4.15 \\
11.97 \\
1.76 \\
1.12 \\
8.37 \\
\cdots \\
10.23 \\
1.67 \\
1.19 \\
\ldots\end{array}$ & $\begin{array}{r}74.48 \\
10.35 \\
3.25 \\
.97 \\
.26 \\
.05 \\
\ldots \ldots \\
1.09 \\
1.09 \\
8.20 \\
.42\end{array}$ & $\begin{array}{r}10.73 \\
26.33 \\
21.44 \\
18.78 \\
.87 \\
.10 \\
\ldots \\
19.00 \\
2.64 \\
\ldots \ldots\end{array}$ \\
\hline
\end{tabular}

The ash of the body consists of chlorids, phosphates, sulphates, carbonates, fluorids, and silicates of potassium, sodium, calcium, magnesium and iron; iodin occurs also in the thyroid gland. In the body fluids the principal inorganic salts are sodium chlorid, sodium carbonate, sodium phosphate, potassium and calcium chlorid and phosphate. In the chapter dealing with organic foodstuffs, stress is laid upon their value as sources 
of energy as well as their function in the repair of and in constructing tissue. The mineral salts are of importance as tissue builders. Their chemical changes taking place in the body are not attended by any liberation of heat or energy-at least, not of enough importance to be considered here. This does not mean that they do not exercise important functions in the human economy.

Function of Salts in the Body.--In studying the subject of osmosis and diffusion, we learned that they maintain the normal composition of the body fluids by regulating the osmotic pressure, and so playing an important rôle in the control of the flow of water to and from the tissues. For the body consists largely of water, which is an essential element for the removal of effete products arising from the various processes of metabolism, cell growth and disintegration.

According to Howell(4) these inorganic salts constitute an essential part of the composition of all living matter. They are an integral part of the structure of the living molecule, and are vitally necessary to its normal reactions or irritability. "Even the proteins of the body fluids contain definite amounts of ash, and if this ash is removed, their properties are seriously altered, as is shown by the fact that ash-free native proteins lose their property of coagulation by heat. 'The globulins are precipitated from their solutions when the salts are removed." The special importance of the calcium salts in the curdling of milk receives attention in the section dealing with this foodstuff. The action of the salts of iron in the production of hemoglobin has received attention elsewhere. It is an accepted fact that all the salts of the body possess no nutritive value.

Year by year our conception of the metabolism of the mineral constituents of the body broadens and "the time will doubtless come when the special importance of the potassium, sodium, calcium and magnesium will be understood as well, at least, as we now understand the significance of iron, and quite possibly this knowledge will find a direct therapeutic application, just as in the case of iron" (5).

According to the teachings of Bunge the proteins contain from 0.5 to 1.5 per cent of sulphur, which during metabolism is transformed into sulphuric acid. Under normal metabolic conditions, the sulphuric acid arising in this manner combines with the inorganic salts contained in animal or vegetable foods. The acid, being neutralized, is removed from the body by the organs of excretion. If there are no salts or bases at hand to neutralize the acid so evolved, it seizes upon the salts or bases of the body tissues, and, as has been picturesquely said, it wrenches from their places the bricks of the structure, thus bringing about a catabolic destruction of 
the organism. 'This statement may be met by a deseription of the protective agency of the organism in its ability to split off ammonia from the nitrogenous organic compounds, thus neutralizing the injurious effect of free acids. But this power has its limitations. Furthermore, it is not certain that ammonia is always present in these special cells from which the sulphuric acid originates to start its catabolic process(6). Lunin writing on this subject coincides with the views of Bunge. In a series of experiments he fed animals on practically an ash-free diet, adding only enough sodium carbonate to nentralize acidity. They were kept viable twice as long as the control animals subsisting on the same food, minus the sodium carbonate. Sodium chlorid did not answer the same purpose, nor did the carbonate of the same base indefinitely prolong life, death eventually resulting from the want of the proper inorganic salts in the food. The haphazard addition of mineral substances to the ration will not satisfy the' system. Animals fed with normal milk will live, but the same animals will die when given an artificial milk even though it contains the exact percentage of casein, fat, sugar and the salts of milk. The reason is not explainable, though it is probable that the mineral constituents of normal milk are chemically combined with its inorganic constituents. It is known that the ions of inorganic materials enter into combination with protein. We may assume, too, that at least some of the inorganic constituents of foodstuffs form with organic substances a loose combination, thus influencing the assimilation and value of the latter.

Sodium chlorid, calcium and the ferrugenons salts are of special importance to the organism. Sodium chlorid occupies a peculiar place among the inorganic constituents of our diet, and according to Howell(7) it is the only one which we deliberately add to our food. The other inorganic material is taken unconsciously in our diet-but although sodium chlorid exists also in our food in relatively large quantities, we purposely add more. Bunge has pointed out "that among men and animals the desire for salt is limited, for the most part, to those who partake largely of vegetable food. This writer also calls attention to the fact that in the use of a strictly animal diet, craving for salt is not felt. In the use of vegetable diet, on the other hand, the craving for salt becomes so marked as to constitute a serious inconvenience when for any reason it cannot be added to the diet. It may be that this longing for salt by vegetarians is governed by the high percentage of potassium salts in all vegetables, the potassium salts reacting with sodium chlorid during the process of digestion. For, as Howell says, potassium sulphate added to the blood reacts with sodium chlorid, resulting in the formation of 
potassium chlorid and sodium sulphate. These two salts, except in negligible quantities, being foreign to the blood, will be excreted by the kidneys, thus the blood will lose some of its sodium chlorid(8).

The subject of salt-poor and salt-free diets is discussed at length in the following volume of this work. ${ }^{1}$ It cannot be doubted but that we habitually, under ordinary conditions, use sodium chlorid in much larger amounts than is necessary to maintain the normal sodium chlorid content of the blood. Its universal use, as a condiment by all classes, unconscionsly leads to the habit of using it in excess of normal requirements. The continnous ingestion of excessive quantities of sodium chlorid will eventually produce a condition of anasarca, owing to the fact that the physiological action of the salt increases osmotic pressure in the tissues. Likewise in conditions of edema or of "water-logged" conditions the restriction of table salt from the foods will give a contrary result and aid in the restoration of the parts to a normal condition, so far as the water in the tissues is concerned.

The importance of the calcium salts has been clearly demonstrated by feeding experiments. Howell concludes that when young dogs are given a diet poor in calcium salts, they fall into a condition closely resembling rickets in children, owing to deficient growth of the bones. Pigeons when fed on a calcium-free diet, soon exhibit a condition of atrophy and fragility of the bones due in all probability to the lack of calcium in the food. As in the case of other food materials, there must be maintained a calcium metabolism in the body. There is some evidence that the calcium content of the body increases with age, as the bones are exceedingly brittle in the aged, and become more fragile and more liable to break than in youth, and furthermore, in advanced life elasticity of the arteries diminishes as the calcium salts are deposited in their walls.

The ferruginous salts are constantly necessary for the production of new hemoglobin; the requisite amount is supplied normally in our food in which they exist in organic combination. (See analysis of iron content of various foods in a subsequent page of this chapter.)

The uses of the mineral salts derived from food have been summarized by Thompson as follows:

1. To regulate the specific gravity of the blood and other fluids of the body.

2. To regulate the chemical reaction of the blood and the various secretions and excretions.

1 Volume II, chapter on Scientific Feeding. 
3. To preserve the tissues from disorganization and putrefaction.

4. To control the rate of absorption by osmosis.

5. 'Jo enter into the permanent composition of certain structures, especially the bones and teeth.

6. 'To enable the blood to hold certain materials in solution.

7. To serve special purposes, such, for example, as the influence of sodium chlorid on hydrochloric acid formation, and that of lime salts in favoring coagulation of the blood.

\section{MINERAL CONTENT IN FOODS}

Calcium.-We will now pass on to the consideration of the amount and kind of mineral salts met with in different artieles of food and will first take up calcium, because it is one of the important salts of the body. The following table by Hoobler(9) shows the calcium percentage in the following foods:

\section{Calcium-containing Foods with Content Estmated as CaO}

Fruits, 30 to 7 per cent.-Citron, oranges, pineapples, figs, pears, eherries, olives. Berries, 14 to 8 per cent.-Strawberries, gooseberries, currants, huckleberries. Nuts, 9 to 8 per cent.-Almonds, walnuts.

Cereals, 8 to 7 per cent.-Oatmeal, cornmeal, wheat flour.

Vegetables, 27 to 5 per cent.-Savoy eabbage, eauliflower, onions, lettuce, radishes, celery, cabbage, endive, spinach, asparagus, earrots, kohlrabi, turnips, rhubarb, artichokes, pumpkin, lentils, cucumbers, tomatoes, beans.

Milk, eggs, chcese, 35 to 8 per cent.-Cheese, milk, egg yolks, eggs.

Meat and fish, 18 to 7 per cent.-Oysters, salmon, pickerel, pork.

Magnesium.-We will next consider magnesium, which is usually present in foodstuffs in about the same proportion as calcium. There are, however, exceptions to the rule. In milk, for instance, magnesium is less, while in meats it is rather more abundant than calcium, and in bread there is actually five times as much of the former as the latter. The following table from Hoobler gives the magnesium content of the following foods.

\section{Magnesium-containing Foods with Content Estimated as MgO}

Fruits, 8 to 5 per cent.-Apples, pineapples, oranges, figs, pears, eitron, cherries, plums.

Berries, 6 to 5 per cent.-Currants, huckleberries, gooseberries. Nuts, 18 to 6 per cent.-Almonds, walnuts, chestnuts, cocoanuts. 
Vegetables, 9 to 5 per cent.-Tomatoes, sugar beets, peas, cauliflower, kohlrabi, lettuce, spinach, celery, carrots, onions.

Cereals, 16 to 5 per cent.-Corn, cornmeal, wheat, wheat flour, barley, meal, buckwheat, rice, rice flour, rye flour, oatmeal, rolled oats, graham bread.

Meats and fish, 9 to 5 per cent.-Salmon, pork.

Iron.-Iron, although one of the most widely distributed elements, occurs in the uncombined state only in small quantities, and as such is of no use in organic nature. It occurs in the earth in combination with oxygen, and is taken up by plants as an inorganic oxid. There are two forms : ferric oxid, which is a weak base, unable to fix carbonic acid; and ferrous oxid, a strong base which forms neutral salts with all acids. Iron is of extreme value as a carrier of oxygen, especially in organic life. It is concerned in the production of chlorophyll; without it the plant becomes pale and etiolated. As a part of vegetables it is consumed by animals and utilized in the construction of hematogens (iron-containing com-: pounds of nucleo-albumin) and hemoglobin (the oxygen carrier of the blood).

The most important inorganic salt to which the dietitian needs to give special attention is iron. This substance is absolutely essential in the making of rich red blood. In certain diseased conditions it sometimes happens that more iron is excreted from the body than is assimilated from the food. This disturbed metabolism is the result of some disturbance of nutrition either in the digestion, the absorption or the assimilation; but whatever the disturbance is, the blood-making organs do not receive the necessary amount of iron. The blood becomes nearly destitute of hemoglobin; the pallor of the patient becomes extreme, until it reaches a condition of waxy etiolation.

It is difficult to give precise figures as to the amount of iron present in different articles of diet. In animal foods it depends very largely on whether the animal was bled, or not, when killed. In vegetable foods it varies very greatly with the amount of iron in the soil.

Another source of iron is to be found in the chlorophyll or green pigment of plants and vegetables, usually served in the menu in the form of greens, as spinach, turnip tops, celery, cabbage and chard. It is interesting to note in passing that the highly colored, deep red meat of the better cuts of steak or mutton, or the breast of wild game, as well as the highly colored plant green, owes this coloring to a pigment rich in iron. The dietitian seeks this pigment to bring back to the blanched cheek of his anemic patient the ruddy flush of health, which is maintained by a blood rich in iron. 
The following table of Bonssinganett showing the percentage of iron in various food materials is approximately correct:

\section{Iron in Fresh Substances}
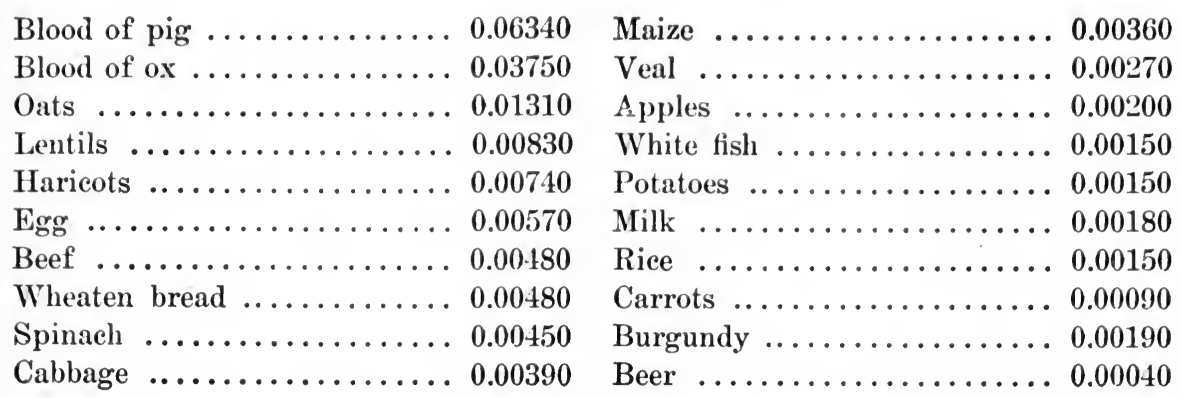

Bunge gives the following order of foods containing iron, the ash of spinach containing most, and milk least: spinach, 0.045 ; yolk of egg, 0.04 ; beef, 0.02 ; apples, 0.02 ; lentils, strawberries, white beans, peas, 0.024 ; egg-white, 0.026 ; wheat, 0.026 ; potato, milk, 0.003 per cent. Stockmann estimates that the average adult diet contains 10 milligrams of iron per diem. One pint of milk contains 2.2 milligrams of iron; 100 grams of oatmeal contain 3.1 milligrams of iron; 300 grams of fine bread contain 1.8 milligrams of iron; 280 grams of common bread contain 1.1 milligrams of iron, and 120 grams of beefsteak contain 4.7 milligrams of iron.

Among animal foods, therefore, there is most iron in beef and yolk of egg, and least in milk. Oatmeal and lentils are the vegetables which contain most iron; but spinach, strawberries, white beans, peas, potatoes and apples contain a good deal. Food is the chief and only natural source of iron in the animal world. It should be noted here that iron contained in hemoglobin and its derivatives is very sparingly absorbed. It is all the more necessary to point this out as hemoglobin preparations are being advocated in the treatment of anemia.

It is possible that the habitual consumption of foods which are poor in iron may eventually lead to anemia, though it is difficult to conceive a diet that would not contain the small amount of this element required daily. Verdell and Subbotin declare, however, that the ash of the blood of dogs fed on meat contained much more iron than that of animals nourished on bread. Hoesslein has shown that if young animals receive only as much 
iron as adults they become anemic. The table from Hoobler gives the percentage of iron contained in the following foods:

\section{Iron-containing Foods with Content Estimated as $\mathrm{Fe}_{2} \mathrm{O}_{3}$}

Fruits, 2 to 1 per cent.-Figs, pineapples, apples, pears, plums.

Berries, 5 to 1 per cent.-Strawberries, gooseberries, huckleberries.

Nuts, 1.8 to 1.3 per cent.-Cocoanuts, walnuts.

Cereals, 2 to 1 per cent.-Rye, flour, barley meal, barley flour, rice, buekwheat flour, cornmeal, eorn flour, rice flour, wheat, wheat flour, graham flour.

Vegetables, 5.3 to 1 per cent.-Lettuce, onions, asparagus, spinach, endive, kohlrabi, pumpkins, artichokes, tomatoes, lentils, black radishes, celery, rhubarb, potatoes, mushrooms, beets.

Bulletin No. 185, Experiment Station, United States Department of Agriculture, shows the amount of iron contained in the following foods:

Proportion of Iron in Food Materials

\begin{tabular}{|c|c|c|c|}
\hline Food material & $\begin{array}{l}\text { Per cent } \\
\text { of iron }\end{array}$ & Food material & $\begin{array}{l}\text { Per cent } \\
\text { of iron }\end{array}$ \\
\hline 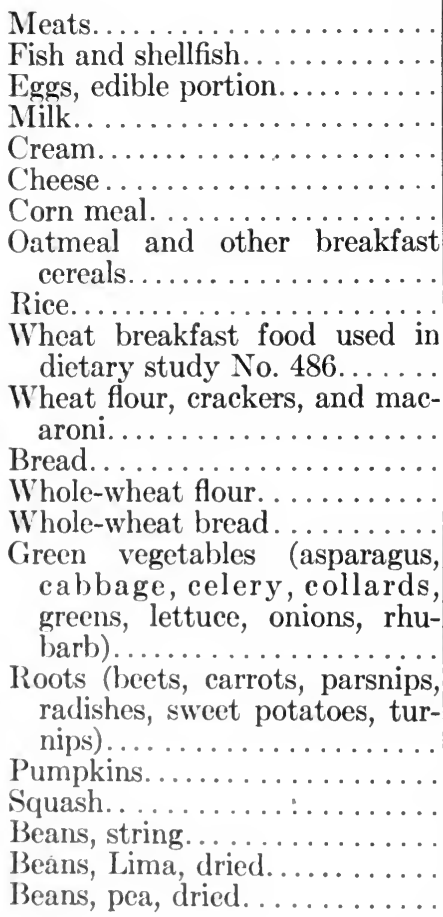 & $\begin{array}{c}(1) \\
(1) \\
0.0030 \\
.0024 \\
.0002 \\
.0015 \\
.00115 \\
\\
.0036 \\
.0008 \\
.0057 \\
\\
.0015 \\
.0010 \\
.0020 \\
.0013\end{array}$ & 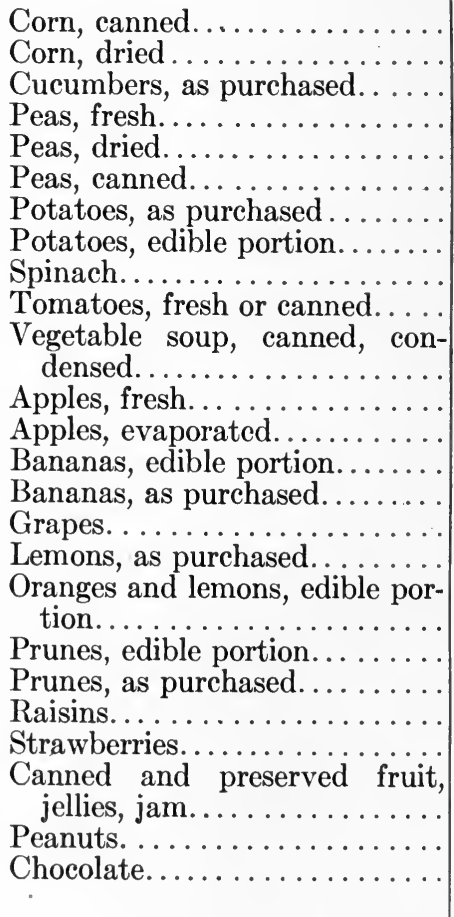 & $\begin{array}{l}0.0007 \\
.0029 \\
.0001 \\
.0015 \\
.0056 \\
.0008 \\
.0010 \\
.00125 \\
.0030 \\
.0004 \\
\\
.0005 \\
.0003 \\
.0014 \\
.0008 \\
.0005 \\
.0013 \\
.0001 \\
\\
.0002 \\
.0029 \\
.0025 \\
.0036 \\
.0009 \\
.0003 \\
.0020 \\
.0020\end{array}$ \\
\hline
\end{tabular}

1. In meats 0.015 gram iron per 100 grams protein, and in fish and shellfish 0.005 gram iron per 100 grams protein. 
Milligrams of Iron in 100 Grams of Dried Substance (Bunge)

\begin{tabular}{|c|c|c|c|}
\hline Blood serum. & 0 & Black cherries, without stones.. & 7.2 \\
\hline White of hen's eggs. & Trace & 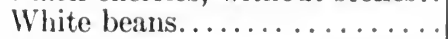 & 8.3 \\
\hline Rice. . & $1.0-20$ & ('arrots. & 8.6 \\
\hline Pearl barley. & $1.4-1.5$ & Wheat bran... & 8.8 \\
\hline Wheat flour (sifted). & 1.6 & Strawberries.............. & $8.6-9.3$ \\
\hline Cows' milk. . & 2.3 & Linseed. . & 9.5 \\
\hline Human milk. & $2.3-3.1$ & Unpeeled almonds. & 9.5 \\
\hline Dogs' milk... & 3.2 & Red cherries, without stones... & 10 \\
\hline Figs. . & 3.7 & Brown skinned hazel nuts...... & 13 \\
\hline Raspberries. . & 3.9 & Apples.................. & 13 \\
\hline Hazel-nut kernels... & 4.3 & Dandelion leaves. . . . . . . . . & 14 \\
\hline Barley........... & 4.5 & Cabbage (outer green leaves)... & 17 \\
\hline Cabbage (inside yellow leaves). & 4.5 & 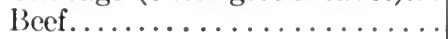 & 17 \\
\hline${ } \ldots \ldots \ldots \ldots \ldots \ldots$ & 4.9 & Asparagus... & 20 \\
\hline Peeled almonds. . & 4.9 & Yolk of egg....... & $10-24$ \\
\hline Wheat........... & 5.5 & Spinach.. & 33-39 \\
\hline Bilberries... & 5.7 & Pigs' blood........ . & 226 \\
\hline Potatoes..... & 6.4 & Hematogen...... & 290 \\
\hline Peas....... & $6.2-6.6$ & Hemaglobin................ & 340 \\
\hline
\end{tabular}

Sodium and Potassium.-The sodium and potassium salts will be considered together. The former is required in the body for the proper constitution of its fluids, the latter for the construction of cells, especially of the red blood cells and the muscles. In fact young animals deprived of potassium do not develop good muscles.

The vegetable group is richest in potassium; animal foods contain a larger amount of the sodium. Bunge gives the following table of proportions :

To one equivalent of sodium there is: in yolk of egg, 1 equivalent of potassium; in milk, 0.8 to 6 equivalents of potassium; in veal, 4 equivalents of potassium; in wheat, 12 to 24 equivalents of potassium; in potatoes, 31 to 42 equivalents of potassium; in peas, 44 to 50 equivalents of potassium.

Early physiologists and clinicians taught that a deficiency of potash salts was the main cause of scurvy. This is now discredited. However, potash is useful not alone for its action as an element, but for the vegetable acids with which it is combined, and which, by oxidation, assist in maintaining a proper degree of alkalinity of the blood. Green vegetables and wholesome fruits are a valuable source of these salts.

Sodium is taken chiefly in the form of sodium chlorid, common table salt. The amount of sodium chlorid contained in natural form in ordinary foods is quite sufficient for health. On the other hand there is no proof that an extra addition of salt in the form of a condiment is in any 
way injurious. We do not yet know whether the addition of salt to food is of benefit or not.

If sodium chlorid be entirely eliminated from the diet, the secretion of hydrochloric acid is lessened, or even arrested. Upon this basis it has been proposed to limit the use of salt in hyperacidity, and hyperchlorhydria of the stomach. Concerning the action of salt upon the general processes of nutrition of the body, the latest and most conclusive experiments of Straub show that any action salt may have is in the direction of lessening nitrogenous waste, provided enough water is supplied at the same time.

The craving for salt as an addition to the diet is strongest among vegetarians, which is ingeniously explained on the lines that the larger proportion of potassium in vegetable food would tend to drive all the sodium out of the body where the latter was not constantly reinforced by addition of salt to the food.

The following tables from Hoobler give the percentage content of sodium and potassium found in various foods:

\section{Sodium-containing Foods with Content Estimated as $\mathrm{Na}_{2} \mathrm{O}$}

Fruits, 26 to 7 per cent.-Apples, oranges, apricots, pineapples, pears, olives.

Berries, 28 to 9 per cent.-Strawberries, gooseberries.

Cereals, 40 to 14 per cent.-Macaroni, barley, flour, brown bread, white bread, graham bread.

Vegetables, 48 to 7 per cent.-Blood beets, spinach, carrots, pumpkin, radishes, asparagus, tomatoes, lentils, endive, cauliflower, turnips, sugar beets, artichokes, lettuce, Savoy cabbage.

Milk, eggs, cheese, 31 to 8 per cent.-Egg whites, eggs, milk.

Meats and fish, 30 to 8 per cent.-Oysters, pickerel, salmon.

\section{Potassium-containing Foods with Content Estimated as $\mathrm{K}_{2} \mathrm{O}$}

Fruits, 81 to 35 per cent.-Olives, plums, apricots, figs, pears, cherries, pineapples, eitron, oranges, apples.

Berries, 57 to 21 per cent.-Huckleberries, currants, gooseberries, strawberries.

Nuts, 56 to 28 per cent.-Chestnuts, cocoanuts, walnuts, almonds.

Cereals, 38 to 14 per cent.-Rye flour, wheat flour, eracked wheat, rolled oats, cornmeal, cornmeal flour, hominy, barley flour, barley meal, oatmeal, buckwheat flour, oatmeal flour, rice flour, graham bread.

Vegetables, 60 to 16 per cent.-Potatoes, rhubarb, cucumbers, mushrooms, cabbage, turnips, celery, beans, peas, tomatoes, endive, lettuce, carrots, kohlrabi, lentils, radishes, Savoy cabbage, onions, artichokes, asparagus, cauliflower, pumpkins, blood beets, spinach.

Milk, eggs, cheese, 31 to 13 per cent.-Egg whites, milk, eggs, cheese.

Meats and fish, 48 to 24 per cent.-Beef, pork, veal, salmon, pickerel. 
Phospnorus.-This element is present in large quantities in the human body. Voit concludes that a man weighing 154 pounds should have 1,400 grams in the bones, 130 grams in the muscles, and 12 grams in the brain and nerves. Phosphorus is also present in the body fluids, and enters into the composition of all cell nuclei. One would naturally expect, therefore, that wherever growth is active, much phosphorus is required in the food, and it is not surprising to find that the development of young animals which are deprived of it is seriously impaired. Hence the great importance of furnishing a plentiful supply of foods containing phosphorus in the dietary of the growing child.

Organic phosphorus is present in all the cellular elements of foodin the yolk of egg, sweetbread, fish roe and in the germ of cereals and legumes. The amount of phosphorus in various foods, reckoned as phosphoric acid, is shown in the following tables(10):

Per Cent of $\mathrm{P}_{2} \mathrm{O}_{5}$ in Fresh foods

Animal

Vegetable

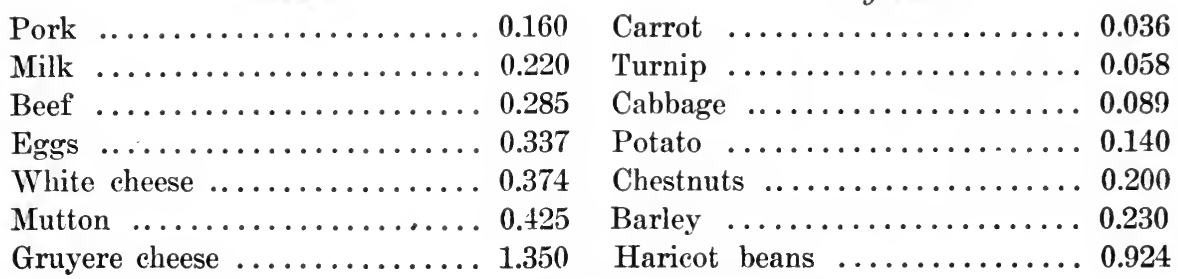

Per Cent of $\mathrm{P}_{2} \mathrm{O}_{5}$ in Water-free Substance

Wheat flour ........................ 0.357

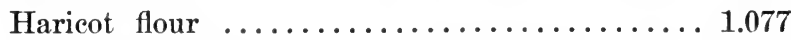

Camembert cheese $\ldots \ldots \ldots \ldots \ldots \ldots \ldots \ldots \ldots . \ldots \ldots$

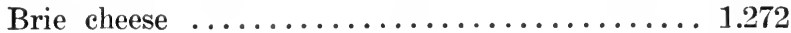

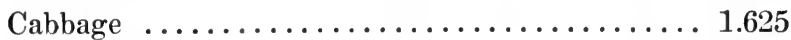

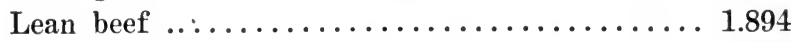

Gruyere cheese ..................... 2.475

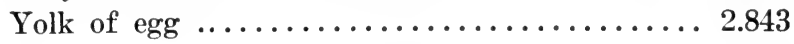

The phosphorus contained in foods is, for the most part, present in an organic form of combination, sometimes of a very complex sort. It is also present in inorganic form as phosphates of the alkalies or alkaline earths, in the form of organic derivatives of phosphoric acid and phosphates, etc., and in the form of phosphorized proteins, as nucleo-albumins, etc. The organic forms are more valuable, since they contribute to the growth and repair of tissues. Examples of these are the chemical substances nuclein, lecithin, glycerophosphoric acid, and phosphocarnic acid, all of which are probably valuable dietetic sources of the element. 
The following table from Hoobler gives the percentage of phosphorus contained in the following foods:

\section{Phosphorus-containing Foods with Content Estimated as $\mathrm{P}_{2} \mathrm{O}_{5}$}

Fruits, 15 to 12 per cent.-Pears, apples, citron, cherries, plums, apricots, oranges, figs.

Berries, 20 to 13 per cent.-Gooseberries, currants, huckleberries, strawberries.

Nuts, 43 to 18 per cent.-Almonds, cocoanuts, chestnuts.

Cereals, 54 to 17 per cent.-Rice flour, rice, wheat flour, buckwheat flour, oatmeal, oatmeal flour, barley meal, barley flour, rye flour, cornmeal, cornmeal flour, rolled oats, pearl barley, macaroni, brown bread, white bread.

Vegetables, 41 to 10 per cent.-Black radishes, artichokes, beans, peas, lentils, pumpkins, kohlrabi, cauliflower, asparagus, potato, cabbage, Savoy cabbage, mushrooms, onions, rhubarb, cucumbers, turnips, celery, carrots, sugar beets, radishes, spinach.

Milk, eggs, cheese, 65 to 26 per cent.-Egg yolk, eggs, cheese, milk.

Meats and fish, 48 to 20 per cent.-Veal, pickerel, pork, beef, oysters, salmon.

Sulphur.-Sulphur is present in the food almost entirely in a state of organic combination, chiefly in proteins. The amount present in different proteins varies considerably as shown in the following tabular analysis of dry proteins(11):

Per cent Sulphur

In dried egg white ......... 1.80 per cent

In syntonin $\ldots \ldots \ldots \ldots \ldots \ldots \ldots 1.80$ per cent

In albumin of wheat........ 1.55 per cent

In albumin of peas ......... 0.40 per cent

In gluten $\ldots \ldots \ldots \ldots \ldots \ldots .0 .70$ per cent

Four-fifths of the sulphur taken into the body is oxidized and excreted in the urine, either as sulphates or phenol sulphates; the remainder enters into compounds of more complex composition. About, one gram of sulphur is excreted daily by a healthy adult.

Physiologists can tell us nothing of the advantages or otherwise of an increase or diminution of sulphur in the food. The table below from Hoobler contains the percentages of sulphur in the following list of foodstuffs:

\section{Sulphur-containing Foods with Content Estinated as $\mathrm{SO}_{3}$}

Fruits, 6 per cent.-Apples, pears.

Berries, 6 per cent.-Gooseberries.

Cereals, 14 to 13 per cent.-White bread, brown bread.

Vegetables, 30 to 5 per cent.-Black radishes, mushrooms, cauliflower, turnips, kohlrabi, cabbage, spinach, carrots, cucumbers, potatoes, asparagus, onions, celery, endive, artichokes. 
Chlorin is taken into the system almost entirely in the form of sodium chlorid or common salt. Except ats a source of hydrochlorie acid, but little is known of its uses in the body. 'The behavior of the chlorids in some acute fevers would suggest that they may perform some special rôle in metabolism. The following table from Hoobler gives the chlorin pereentage in the list of foods enumerated below:

\section{Chlorin-containing Fools wili Content Estimated as $\mathrm{Cl}$}

Fruits, 10 per cent.-Pineapples.

Nuts, 14 per cent.-Cocoanuts.

Cereals, 30 to 5 per cent.-White breaul, brown bread, macaroni, oatmeal.

Vegetables, 16 to 5 per cent.-Celery, potatoes, cucumbers, radishes, Savoy eabbage, lettuce, asparagus, tomatoes, ('abbage, spinach, beets, rhubarb, turnips, kohlrabi, earrots.

Milk, eggs, cheese, 28 to 7 per cent.-Egg whites, milk, eggs, cheese.

Meats and fish, 21 to 5 per cent.-Salmon, oysters, pickerel.

Iodin.-Iodin is present in small quantities in fish. In the human being it is found in the thyroid gland. The significance of its presence in food is quite obscure, though it may prove to be of utility to the dietary. Gautier gives the following tables showing the iodin content of various foods :

Iodin per Kilogray of Fresh Material

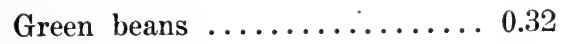

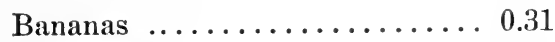

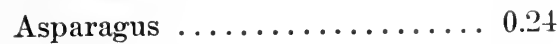

Garlic ..................... 0.21

White cabbage $\ldots \ldots \ldots \ldots \ldots . \ldots .21$

Mushrooms ............. 0.172

Strawberries ............. 0.17

Rice ................. 0.17

Carrots .................... 0.134

Sorrel .................. 0.12

Leeks .................. 0.12

Iodin per Kilogray in Some Animal Foods

Gray shrimp ............ 5.91

Crabs ................. 1.82

Lobster ............... 1.78

Smoked herring .......... 1.57

Fresh salmon ............ 1.40

Roach ................ 1.38

Oysters $\ldots \ldots \ldots \ldots \ldots \ldots \ldots . \ldots 1.32$
Green peas ........... 0.80

Tomatoes .............. 0.23

Grapes .............. 0.02-00

Artichokes ............. 0.017

Pears ................. 0.017

White dried beans ......... 0.014

Lettuce ................ 0.012

Potatoes ................ 0.01

Oatmeal ............... 0.009

Wheat flour ............. 0.007

Bread ................ 0.000

Breme .................. 1.25

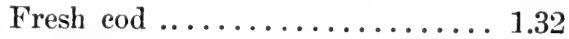

Archovies ............... 0.95

Tunny, fresh ............. 0.88

Eel .................. 0.80

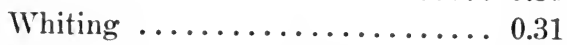

Trout ................ 0.08 
Fluorin and Silica.-Fluorin and silica are present in the body in small quantities, chiefly in the teeth and bones. Vegetable foods, and especially the cereals, are their most abundant source in the diet.

Bromin.-Bromin is present in the nuclear proteins, and is excreted in the sweat. Foods containing iodin also have this element in combination. Fluorin is present in drinking water.

0xalic Acid.-While not strictly speaking a mineral substance, oxalic acid may be conveniently considered here, for it is usually present in the diet in the form of oxalate of lime. Esbach gives the following table of the amount of oxalic acid in different articles of food:

Per 1,000

Black tea infused 5 minutes..... 2.060

Cocoa-powder ............ 3.520 to 4.500

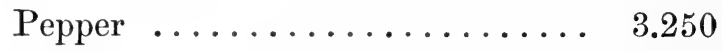

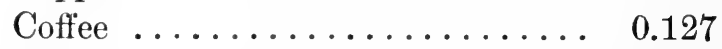

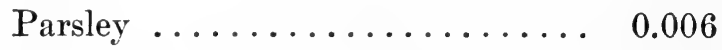

Haricots ................. 0.312

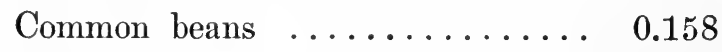

Potatoes ............... 0.046

Good bread .............. 0.047

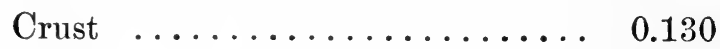

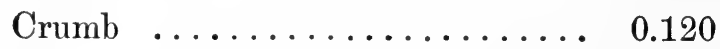

Buckwheat flour ........... 0.171

Barley meal .............. 0.039

Maize flour ............. 0.033

Sorrel .............. 2.740 to 3.630

Spinach ............. 1.910 to 3.270

Rhubarb .............. 2.466

Brussels sprouts ........... 0.020

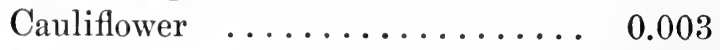

Beetroot ............... 0.390

French beans ............ 0.060 to 0.212

Salsifies ............. 0.070

Tomatoes .............. 0.002 to 0.052

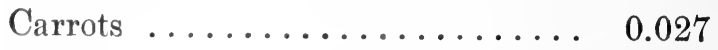

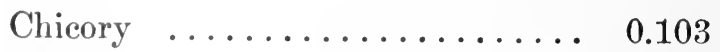

Endive .............. 0.017

Lettuce ............... 0.016

Dried figs ............ 0.270 


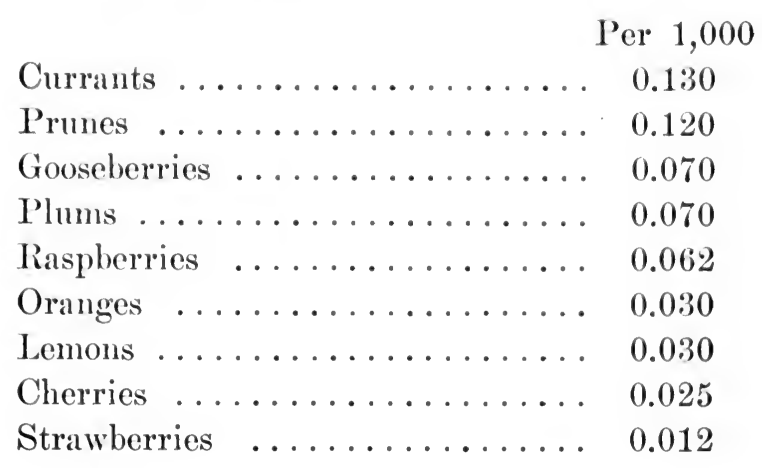

It will be observed from study of this table that oxalic acid oceurs in relatively large amounts in tea, coffee, spinach, rhubarb, sorrel and pepper. Tomatoes are sometimes claimed to be rich in it, but it would appear that this is an error, since the sour taste is due to citric acid. A diet of animal foods diminishes oxalic acid, owing to its low content in animal foods. There seems to be little doubt but that the consumption of foods rich in oxalic acid may be the cause of oxalate calculi.

Manganese.-Manganese is found in the body in minute quantities, and small amounts are detected in some food materials. The ash of legumes, asparagus, cauliflower, lettuce, grapes and various grains contain varying amounts of this element.

Generally speaking, fruits and nuts contain the least quantity of salts, meats rank next, after them vegetables, and pulses and cereals contain most of all.

\section{REFERENCES}

1. Forster. Physiology.

2. Hammarsten. Physiological Chemistry, page 634 .

3. Osborn and Mendel. J. Biol. Chem., 1912, xiii, 233.

4. Howell, W. H. Text-book of Physiology, 6th ed., page 921.

5. Albu and Newbera. Physiologie und Pathologie des Mineralstoffwechsels, 1906.

6. Bunge. Physiological and Pathologieal Chemistry, pages 87-88.

7. Howell, W. H. Text-book of Physiologs, 6th ed., page 922.

8. Bunge. Physiologie der Menschen, 1901, ii, 103.

9. Hoobler. Arch. Pediat., March, 1912.

10. Tibbles. Foods, Origin and Manufacture.

11. Richet. Dictionary of Physiology. 


\section{BIBLIOGRAPHY}

Abderhalden. Physiological Chemistry, chap. 16.

Albu and Newberg. Physiologie und Pathologie des Mineralstoffwechsels, 1906.

Bunge. Physiological and Pathological Chemistry, chaps. 7 and 8.

Forbes. The Mineral Elements in Animal Nutrition, 1909, Bull. 201, Ohio Experiment Station.

Specific Effects of Rations on the Development of Swine, 1910, Bull. 213, Ohio Experiment Station.

The Balance between Inorganic Acids and Bases in Animal Nutrition, 1909, Bull. 207, Ohio Experiment Station.

Hart, McCollum and Fuller. The Rôle of Inorganic Phosphorus in the Nutrition of Animals, 1909, Research Bull. INo. 1, Wisconsin Experiment Station.

and Humpirey. The Rôle of the Ash Constituents of Wheat Bran in the Metabolism of Herbivora, 1909, Research Bull. No. 5, Wisconsin Experiment Station.

Henderson. Das Gleichgewicht zwischen Basen und Säuren im thierischen Organismus, Ergebnisse der Physiologie, 1909, 8, 254325 .

Jordan, Hart and Patten. Metabolism and Physiological Effects of Phosphorus Compounds of Wheat and Bran, Technical Bull. No. 1, New York State Experiment Station; also Am. J. Physiol., 1906, 16, 268.

Osborne. Sulphur in Protein Bodies, J. Am. Chem. Soc., 24, 140.

Shermax, Mettler and Sixclair. Calcium, Magnesium and Phosphorus in Food and Nutrition, Bull. 227, Office of Experiment Stations, U. S. Dept. Agric.

and Sinclatr. The Balance of Acid-forming and Base-forming Elements in Food, J. Biol. Chem., 1907, 3, 307. 


\section{CHAPTER XII}

\section{ANIMAL ANI) FISH FOODS}

E. H. S. Bailey, Ph.D.

Blessed art thou, $O$ land, when thy King is the son of Nobles, and thy Princes iat in due season, for strength, and not for drunkenness.-Ecclesiastes x, 16-17.

\footnotetext{
Meats; Meat Extracts; Gelatin and Gelatin Foods; Animal Viscera as Food; Domestic and Wild Fowl; Fish and Shellfish; Milk and Milk Products; Eggs.
}

\section{MEATS}

Importance of Meat.-Meat is one of the most important foods, and affords, in general, more concentrated and readily available nourishment than vegetable substances, and is the chief source of our protein supply. Fats, carbohydrates, water and mineral salts are other constituents of various meats. This class of food is easily digested, either cooked or in the raw state, after thorough mastication. Meat mixes readily with all other foods and leaves but a small residue in the intestinal canal.

COMPOSITION OF MEAT.-On close inspection, a piece of boiled meat will be found to be made up of bands of muscle fibers held together by connective tissue. These muscle fibers may be short, as in the breast of a chicken, or they may be much longer, as in the leg of a crab; the shorter they are, the more tender and easily digested the meat is. Meat should always be carved at right angles to the long axis of the fibers. It is then masticated with greater ease. The contents of the muscle fibers are more readily brought into contact with the grinding surface of the molars, the taste and flavor are increased and the digestive juices stimnlated, facilitating the process of digestion. 
Fat.-The walls of the muscle fibers consist of an albuminoid substance, elastin, while the connective tissue which holds them together is composed chiefly of a material called "collagen," which yields gelatin on boiling. Imbedded in the connective tissue between the fibers is a variable amount of fat. It is almost entirely absent in most kinds of game and in the breast of chicken. On the other hand, in pork and fattened mutton, in swimming birds (such as the duck and goose, which require a large store of fat both to lighten the body as well as a source of animal heat), the amount of fat may be large. A large amount of fat tends to diminish the digestibility of meat; apparently the fat forms a kind of waterproof coating around the muscle fibers, hindering their rapid disintegration in the gastric juice.

Under ordinary conditions meat contains muscle tissue, connective tissue, blood vessels, nerves and lymphaties, together with a varying amount of fat. The greater the amount of fat there is in the meat, the less water and nitrogenous matter does it contain, and vice versa.

Muscle Tissue.-As we have already learned, muscle tissue is made up of minute thread-like cells that lie side by side and are so small that the individual cells may be seen only by the microscope. In the living animals the contents of these muscle cells are soft and tender. After death a change takes place in the muscle substance, which causes it to become rigid. This hardening of the muscle is known as rigor mortis, or death stiffening. It is due to myosin, which has the property of clotting after death. Meat in this condition is tough. If tenderness is desired the meat should be immediately cooked after the animal is killed, before this condition of rigor mortis has had time to set in. If, however, the animal is allowed to hang for a time, this rigor passes off. Its disappearance is due to a resolution of the myosin by the development of sarcolactic acid and acid phosphates in the tissues, as well as to a partial digestion of it by traces of pepsin, which all muscle fiber contains. This process must be regarded, however, as an early stage of putrefaction, and, as is well known, if meat is allowed to hang for some time it becomes high.

Acins. - The acids which develop in meat after the disappearance of rigor mortis aid the gelatinization (which occurs in boiling) of the connective tissue, and also improve its flavor by changing the rather insipid taste, which characterizes very fresh meat, to one more palatable. Animals which have undergone very great muscular exercise immediately before killing develop a considerable quantity of these acids, hence the flesh of hunted animals is of a superior flavor. Another means of pro- 
ducing these effects artificially is by soaking the meat in vinegar and water for a short time. This improves the flavor of fresh meat, as well as its tenderness. It is on this same theory that the use of vinegar favors the digestibility of the hard muscles of the crab and lobster.

Musche Juice.-The contents of the microscopic muscle fibers consist of water, holding in solution, proteins, salts and substances known as meat extractives, the whole constituting muscle juice. The younger the animal the more water does its flesh contain, and likewise the lower its nutritive value. This is explained by the saying that "calf meat is half meat."

Mineral Substances.-We learned when studying mineral salts that the red coloring matter of the meat was due to the presence of hemoglobin, which varies greatly in different kinds of meat. Its greatest importance is that it contains iron. In the small blood vessels of animals which have bled to death, hemoglobin may be found much diminished in amount or altogether removed.

The chief mineral substances found in the juice of meat are phosphoric acid and potash. Meat is one of the principal sources of these valuable building materials in the diet. When these are not supplied in sufficient amount, the muscles become flabby and poorly developed.

Accessory Substances-Vitamines.-Besides protein, fat and mineral substances, fresh meat contains certain accessory substances which are of importance to the animal organism. Cured and dried meats are deficient in these substances. Casimir Funk described them first and gave them the name vitamines. The leading investigators are of the opinion that meat vitamines are contained in the plasma or muscle juice, and that they form the preventative and curative agents in raw meat and raw meat juice. No doubt the efficacy of raw meat juice as a curative agent in tuberculosis lies in the vitamines of the muscle plasma. This curative property is not due to proteins, for it has been shown that muscle plasma contains very little nitrogen. Whatever the organic principle may be, it is destroyed by prolonged cooking, for neither cooked meat nor cooked meat juice possesses the therapentical effects of raw meat juice. The destruction of vitamines by heat depends on the height of the temperature to which the meat is subjected. It is generally believed that a temperature of $120^{\circ} \mathrm{C}$. destroys vitamines, but at this temperature the interior. of a cut of meat weighing 5 or 6 pounds never reaches more than $60^{\circ} \mathrm{C}$. during ordinary cooking. The vitamines contained in the meat juice of fresh meat are a protection against scurvy and beri-beri. 
Grijns(1) was an early worker in this field, and his conclusions are that the vitamines of meat are destroyed when heated to $120^{\circ} \mathrm{C}$. It was due to his research that the deficiency theory of beri-beri was adopted. He believes that the disease breaks out when this substance, necessary for the metabolism of the nervous system, is lacking in the food. Grijns avers the condition frequently alluded to as nitrogen starvation may exist even when the vitamines are abundant, and has no relation whatever to the condition that Funk refers to as deficiency diseases. Yet individuals in a condition of nitrogen starvation are likely to suffer from deficiency of vitamines and therefore furnish a large percentage of cases of scurvy, beri-beri and pellagra. They are cured by any food containing vitamines. Their nitrogen defect is not relieved unless proteins are also administered. It is believed that a diet defective in vitamines weakens our acquired immunity to tuberculosis and that the rich diet prescribed of late years cures by reason of the excess of vitamines, rather than solely by the nitrogen administered.

Extractives.-The principal substances contained in a solution of meat juice are the extractives. They are so called because they may be extracted from meat by boiling it in water. We shall have much to learn about these extractives later on, but it may be stated here that their exact chemical nature is not definitely known, neither have they any nutritive value. They are of importance only because they give the agreeable and characteristic taste to meat. Meat from which these extractives have been removed by prolonged boiling becomes flavorless and insipid.

The flesh of adult animals is richer in extractives, has a richer flavor than the flesh of those which are immature. This explains why we eat lamb with mint sauce and add spices to veal. The influence of feeding and pasturage is well illustrated by all forms of game. The flesh of wild rabbits, which eat aromatic herbs, for instance, has a much finer flavor than that of rabbits fed in captivity. For this same reason a portion of wild turkey or wild duck is admitted to be a more tasty morsel than the flesh of birds reared in a farmyard. Everyone knows the fishy taste of sea birds, and that mutton raised in the hills is superior to its turnip fed substitutes.

Chemical Composition of Meat.-The chemical composition of meat varies somewhat with the particular cut and the degree to which it has been fattened. The ordinary butcher's meat does not consist entirely of edible matter. In an average piece of meat the waste may be safely reckoned at fifteen per cent of the whole and the proportions of the constituents of the edible part are about as follows (König) : 


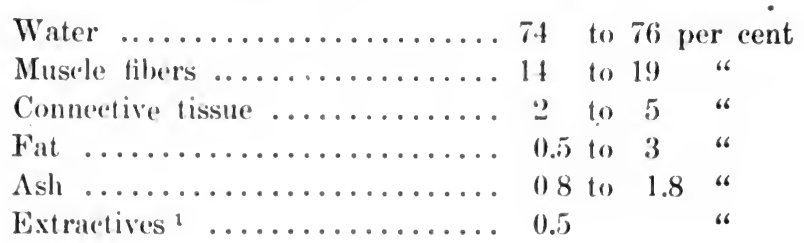

Other analyses represent the proportions of the chemical substances present, thus:

100 Parts of Lean Beef without Visible Fat (Voit)

Protein ................ 19.27

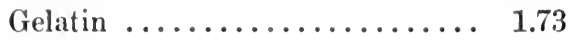

Fat .................... 0.90

Extractives ............. 1.89

Ash .................... 1.30

Water ................... 74.91
100 Parts of Dry Substance (Rubner)

Syntonin, myosin, and gelatin... 68.9

Hemoglobin and serum albumin. 9.57

Musele albumin ........... 3.16

Extractives ................ 13.68

Ash ................... 4.69

The effects of fattening are shown in the following table, in which the composition of lean, medium and very fat beef is stated in round numbers:

\begin{tabular}{|c|c|c|c|c|}
\hline & \multicolumn{3}{|c|}{ Nitrogeneous } & \\
\hline & Water & Matter & Fat & Ash \\
\hline Lean........... & 76.5 & 21 & 1.5 & 1 \\
\hline Medium ........... & 73 & 20.5 & 5.5 & 1 \\
\hline Very fat $\ldots . . . \ldots$. & 53 & 17 & 29 & 1 \\
\hline
\end{tabular}

Note the high percentage of water in meat as compared with the other constituents, the weight of the water contained is three times that of the nutritive parts. In other words, each pound of meat consists of threequarters pound of water and one-quarter pound of nutritive material. The meat from young animals contains the highest percentage of water. Another interesting point shown by the above table is the relation between water and fat. These constituents vary in inverse ratio, the more fat there is, the less water is present. To sum up: fat replaces water in muscular tissue, the protein elements being unaffected. Therefore, by the fattening process the nutritive value of the meat is absolutely increased. The above analyses refer especially to beef; the composition

1 "Nitrogenous matter" is the figure obtained by multiplying the amount of nitrogen in 100 parts by 6.25 ; i.e., it is assumed that it is all protein. In reality, 15 per eent of the total nitrogen is present in the form of extractives, the amount of which can be calculated by multiplying their nitrogen by 3.12 . 
of the other commoner sorts of meat and some varieties of game may be graphically represented as follows: ${ }^{1}$

ANALYSIS OF MEATS

\begin{tabular}{|c|c|c|c|c|}
\hline VARIETY OF Meats & Water & $\begin{array}{l}\text { Protein and } \\
\text { Gelatin }\end{array}$ & Fat & $\begin{array}{l}\text { Mineral } \\
\text { Matter }\end{array}$ \\
\hline 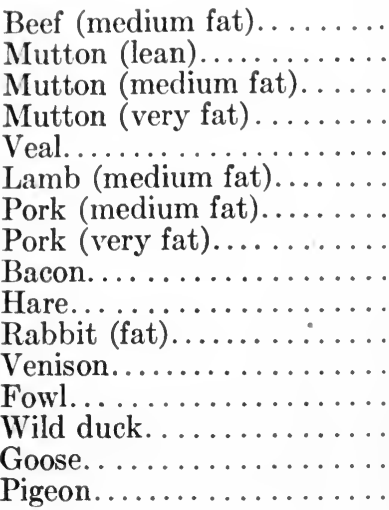 & $\begin{array}{l}77.5 \\
75 \\
65.2 \\
46 \\
71 \\
63 \\
60.9 \\
44.4 \\
22.3 \\
74 \\
66.8 \\
75.7 \\
70.0 \\
70.8 \\
37.0 \\
75.1\end{array}$ & $\begin{array}{l}19 \\
18 \\
14.5 \\
10.2 \\
17 \\
18.5 \\
12.3 \\
9.7 \\
8.1 \\
22.3 \\
21.4 \\
19.7 \\
23.3 \\
22 \\
14.9 \\
22\end{array}$ & $\begin{array}{r}1.4 \\
5.7 \\
19.5 \\
43.2 \\
11 \\
16.5 \\
26.2 \\
45.5 \\
65.2 \\
1.1 \\
9.7 \\
1.9 \\
3.1 \\
3 \\
45.6 \\
1.0\end{array}$ & $\begin{array}{l}1.4 \\
1.3 \\
0.8 \\
0.6 \\
1 \\
1.1 \\
0.6 \\
0.4 \\
4.4 \\
1.1 \\
1.1 \\
1.1 \\
1.0 \\
1.0 \\
0.3 \\
1.0\end{array}$ \\
\hline
\end{tabular}

\section{COMPARATIVE COST OF NUTRIENTS AND ENERGY IN THE} MEATS AND FISH

\begin{tabular}{|c|c|c|c|c|}
\hline FOOD & $\begin{array}{c}\text { Price } \\
\text { per pound }\end{array}$ & $\begin{array}{l}\text { Cost of } \\
1 \text { pound } \\
\text { protein }\end{array}$ & $\begin{array}{l}\text { Cost of } \\
1,000 \text { units } \\
\text { of energy }\end{array}$ & $\begin{array}{l}\text { Energy } \\
\text { units for } \\
10 \text { cents }\end{array}$ \\
\hline 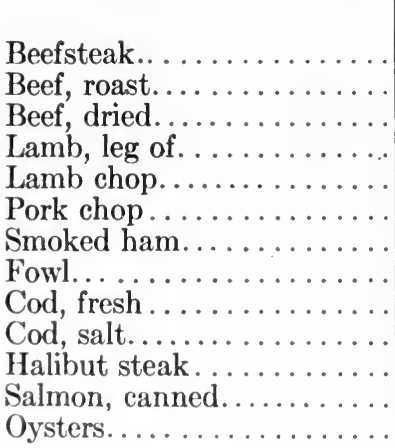 & $\begin{array}{c}\text { Cents } \\
20 \\
16 \\
25 \\
20 \\
22 \\
20 \\
22 \\
20 \\
10 \\
7 \\
18 \\
12 \\
18\end{array}$ & $\begin{array}{c}\text { Dollars } \\
1.28 \\
.87 \\
.98 \\
1.37 \\
1.72 \\
1.60 \\
1.60 \\
1.65 \\
.93 \\
.45 \\
1.22 \\
.57 \\
3.10\end{array}$ & $\begin{array}{c}\text { Cents } \\
20 \\
18 \\
32 \\
22 \\
17 \\
15 \\
13 \\
16 \\
46 \\
22 \\
38 \\
13 \\
80\end{array}$ & $\begin{array}{c}\text { Calories }^{2} \\
515 \\
560 \\
315 \\
445 \\
890 \\
1,035 \\
735 \\
820 \\
220 \\
465 \\
265 \\
760 \\
125\end{array}$ \\
\hline
\end{tabular}

VARIETIES OF ANIMAL FLESH-BEEF.-The flesh from fat young animals is tender, while the meat from old and lean animals is tough.

1 Most of the analyses from which the diagram is constructed are by Honig and Stutzer. The analysis of lamb is from Atwater, that of bacon from Church.

2 See Chapter XIX. 
This is explained by the fact that in the older animal the connective tissue becomes progressively more and more dense. The older the animal, the more work its muscles have had to perform and therefore the thicker and denser the walls of its muscle fibers.

For this reason old work oxen do not make tender beef nor do old milch cows, for both age and muscular work have a bearing on the tenderness of beef. Therefore the choicest animals for food are naturally young ones. An ox from three to five years old, which has been kept plump and fat on good pasturage, supplies the choicest beef, bright red in color and rich in hemoglobin. It is a well-known fact that the flesh of animals, which have roamed the field and forest in search of food, is of finer flavor than that of stall-fed animals or those confined to limited enclosed areas.

The quality of beef is influenced by various factors, such as age, sex, food and breeding. The most agreeable to the taste is heifer beef. Bull beef, which is of a very dark red color, is usually dry and tough, requiring a long time for cooking. Although not very agreeable to the palate, it is preferable to cow beef for making beef tea. Cow beef is of a lighter shade. It is not specially agreeable. As to breeding, the small breeds yield meat far sweeter than that of large breeds. The influence of age varies with the breed, the small breed when about three years old yielding excellent meat, while the flesh of the larger breeds is more palatable when these animals are mature, i.e., when four or five years old. Care must be taken not to slaughter cows that are too young. Veal is at its best when the calf is about two and one-half months of age. When too young, the meat does not compare with beef in wholesomeness. Even at its prime, veal requires a long period for digestion. It is not a very nutritious food, for, when taken from very young animals whose muscular fiber has not had time for development, the meat is inclined to flabbiness, nor does it contain the juices so essential to flavor and nutrition(2). The butchering of calves less than two and one-half to three months of age is prohibited by law in certain states. The former prejudice against the use of very young veal is lessening, due to recent research which seems to indicate that the flesh may be just as easily digested as that of more mature calves or even beef. It is by no means a suitable food for the sick or invalid, as it is hard to digest and often causes diarrhea, with symptoms which indicate the absorption of albuminoses or proteoses into the system.

Mutron.-Mutton is the flesh of the sheep. The domestic sheep, of which there are several varieties, is a grazing and cud-chewing animal. 
Sheep are useful animals to man. Clothing is made from the wool, and the flesh is an agreeable article of diet, perhaps more often eaten than any other meat. It is a first favorite on account of its flavor, digestibility and wholesomeness.

Sheep are best for food at the age of two to three years. The flesh of the wether (castrated male) is in perfection at three to four years. It is by far sweeter and more digestible than ewe mutton, which is at its best at not more than two years old.

There are many varieties of sheep. The difference in the quality of the flesh as food, shown by its flavor and tenderness, depends largely upon the variety. Equally important are the pastures and breeding grounds. The muscle fiber of mutton is finer than that of beef and carries more fat. Mutton fat contains a larger proportion of glycerids and of stearic acid, which make it more compact but no less digestible than the fat of beef.

Iaмв.-Lamb is the flesh of a sheep killed at twelve to fourteen weeks of age. The tissues of young animals contain a larger amount of moisture and are more apt to decompose than those of more mature animals which are closer grained and drier. The freshness of lamb may be determined by brightness of the eye and dilatation of the pupil, by muscular rigidity and by firmness of the kidneys. These signs indicate wholesomeness, freshness and death at the hands of the butcher.

GonT.-Goat meat as a food is not used extensively in the United States, but we venture the opinion that a great deal of what is sold on the New York markets as "spring lamb" is nothing more nor less than Canadian goat. The goat is about the size of the sheep and subsists on the scanty and coarser pasturage of hilly or mountainous regions. It is valuable for its milk, its skins and its flesh, which is used as food by those who live in mountainous regions. The flesh, with the exception of the Angora goat, is not as palatable as that of the sheep.

Venison.-Venison is the flesh of the deer, which are ruminant animals, existing in many parts of the world. The flesh is dark in color, wholesome and delicious. A barbecued saddle of venison is the most savory of meats. Unless obtained from a young animal, when it is tender and highly flavored, venison is apt to be difficult of digestion. It should be avoided by dyspeptics.

The process of barbecuing or roasting of meats was worked out and perfected in the days when pains were taken not to spoil good meat with poor cooking. In those days a saddle of venison, a haunch of mutton or a stuffed turkey were not baked to insipidity in an oven meant for other 
purposes, but they were carefully turned about on an iron spit over a bed of red hot coals. The rich aroma was preserved by constant basting.

Ponk.-Pork is the flesh of the hog. It is eaten fresh, salted, smoked, or cured as bacon, ham and sausage. The fat of pork is lard, a soft neutral, white, fatty substance, which contains olein, stearin and palmitin. Hog fat or lard is the most important representative of the hydrocarbons in our foodstuffs.

The young pig roasted is a dainty dish and highly prized by epicures. The animal should not be more than five or six weeks old. There is no meaty flavor better than that of the crisp, tawny, well-watehed and not over-roasted crackling. Pork is the most indigestible of all meats, owing to the large percentage of fats that it contains. This fat consists chiefly of the glycerids of palmitic and oleic acids and may be present in the proportion of 37 per cent or more. Although many believe that pork is not as desirable as some other meats, it is very extensively used the world over. When hogs are raised under sanitary conditions upon good wholesome food, there is less objection to the use of the meat than when they are fattened in filthy surroundings and fed on brewers' slops, swill or other refuse. The best grade of pork with the choicest flavor is from young hogs about one year old that fatten upon the mast from forest trees and are then confined and fed on grain for six weeks. Hogs fattened in this way have firm flesh of a decided gamy flavor.

HAM AND BACON.-Ham and bacon are more easily digested than fresh pork. Baeon is used largely as an army ration. Broiled crisp, thin slices of bacon are easily digested. The fat of bacon seems to be of a granular form, which is not difficult to digest and it can often be eaten with impunity by persons to whom other forms of fat are intolerable. For this reason bacon is an invaluable aid in feeding delicate children and diabetic or phthisical patients in whose diet the free use of fat is indicated.

Ham contains in 100 parts 29 per cent of albuminates, 33 per cent of fat and a salt content of between 8 and 11 per cent. In Germany ham is much prescribed in invalid dietaries, but in England and America it is seldom so prescribed. Bauer, in Dietary of the Sick, says, "The flesh of the hog seems to be better adapted for smoking than that of other animals and long experience compels us to recognize smoked ham as one of the most wholesome forms of meat. Whether boiled or eaten raw it seems, as a rule, to be more easily digested by weak organs than almost any other."

Ham is easy of digestion when thoroughly boiled, cut in thin slices 
and served cold. For invalids it should never be fried. The best hams offered for sale in this country are from small animals, the sugar-cured hams weighing from 10 to 12 pounds being preferable. The finest flavored hams offered on the markets in the United States are cured in Virginia and North Carolina. They are famous and are known as the "Smithfield" hams.

Horseflesir.-Horseflesh is rarely used for food in the United States and not at all in England. In France, Germany and some other European countries it is used more or less extensively.

HaRe AND RABrit.-The meat of these two animals is quite similar; both live entirely upon vegetable matter. The flesh of the former is dark and dry in comparison with the latter, which is in some respects superior, being more savory and of higher flavor. The rabbit occurs both wild and domesticated.

RAccoon.-The raccoon is a small carnivorous animal about the size of a large house cat. In the late summer and early fall this animal shows a special fondness for ripening corn; at this season, also, frogs, crayfish and wild oysters form a part of the raccoon's food, imparting to the flesh a peculiar gamy flavor. The hunting of raccoons, usually done with dogs, is one of the favorite southern sports. The flesh, dark and juicy, is highly prized as a game food by the southern negro.

Opossum.-The opossum belongs to the marsupial family of mammalia. It is insectivorous, carnivorous and herbivorous. The flesh of the opossum is a dainty dish, highly prized by epicures. The animal, after being caught, should be confined and fattened on wholesome food for from four to six weeks, then slaughtered like a pig, dressed and roasted whole. Its flesh is not as dark as pork; contains considerable fat and is very tasty and juicy.

\section{GENERAL SUMMARY}

It is generally conceded that the flesh of animals which roam in search of food is of finer flavor and more toothsome than the flesh of domestic animals which are confined. Mutton is the most tender of butchers' meats. Beef, of firmer texture, is somewhat tougher and not so readily digested. Pork is the most difficult of all to digest, due to the saturation of its fibers with fat and frequently to fatty degeneration when the hog is overfed. Chicken, pheasant, rabbit, etc., are the most easily digested, largely due to the absence of fat from their tissue.

The flesh of mature animals contains more meat or protein than that of the young, the male more than the female and the well fed more than' 
the poorly fed animals. Castration greatly improves the flavor of the meat of the male and the flesh is also more tender. Every day the testes are allowed to remain in an animal intended for food injures the quality, delicacy and flavor of the flesh of a male animal. Even the flesh of the female is improved by spaying. The flesh of an animal which is not castrated or spayed until after puberty retains a certain coarseness and strong flavor. A notable example of the effects of castration in birds is seen in caponized fowls, the flesh of which is tender and juicy.

\section{MEAT EXTRACTS}

Beef Extract.-There are numerous meat preparations, both liquid and solid, offered for sale, the idea being to furnish a concentrated and easily digested food. Baron von Liebig was the pioneer in making beef extract. He chopped up fresh beef very fine and heated it under pressure with a little water. The extract was filtered and evaporated in vacuum. The product was a golden brown liquid with a strong, agreeable meaty odor. He calculated 34 pounds of good beef would yield one ponnd of extract, and this would make 70 pints of beef tea, each pint representing the strength of $1 / 2$ pound of beef extract. Beef extracts are, therefore, really concentrated bouillons that are to be diluted before being taken. The table on page 288, taken from Chittenden, gives the percentage composition of a few beef products.

It must be admitted that we have only meager information as to the chemical properties of extractives of meat. Most of them are basic substances, a few are amids. Creatin, xanthin, carmin and the peculiar and interesting substance, carnic acid, which is very similar to "antipeptone," are a few of the better known component parts.

NUTRITIVE VALUE OF MEAT EXTRACTS.-These substances are somewhat related to protein, but under no conditions are they of any use as tissue builders. Liebig himself once said, "Meat extract cannot make us strong, but it makes us aware of our strength." If meat extracts are taken dissolved in hot water and the solution slowly sipped, they produce a stimulating effect on the circulation. There is no proof that the extractives of meat act as brain stimulants in the same way as tea and coffee do, but there is positive evidence that they remove the apparent effects of muscular fatigne. This, perhaps, explains the beneficial action often noticed after administering beef extracts.

Hutchison(3), in speaking of the meat extractives, says:

The recent experiments of Pavlov have shown that they are the most powerful exciters of gastric secretion that we possess. They are thus eminently calculated 
to rouse appetite, and aid digestion of any food with which they may be taken This is indeed their true rôle, both in health and disease. They are flavoring agents, and their proper place is in the kitchen and not at the bedside.

The meat from which the extractives have been removed is tasteless and difficult to digest. The small quantity of nutrient material in beef extract may be of value in some cases, where it is of great importance to have a little nutriment, even if the amount is very small, which can be readily absorbed.

CONSTITUENTS OF MEAT EXTRACTS.-In the preceding pages directions were outlined for making beef extracts, and their basic substances, creatin and creatinin, described. Besides these there is found leucin, tyrosin, xanthin, hypoxanthin and adenin. Kutscher(4) has recently isolated various other bodies from meat, i.e., ignotin, novain, carnitin, oblitin, vitiatin, etc. Besides the above constituents of meat and meat extracts, the researches of Casimir Funk and Grijns have demonstrated the presence of certain accessory bodies which they call vitamines, elsewhere fully dealt with.

\section{PERCENTAGE COMPOSITION OF BEEF PRODUCTS (ANALYZED 1891)}

\begin{tabular}{|c|c|c|c|c|c|c|c|c|c|}
\hline Constituents & 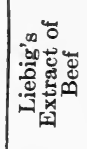 & 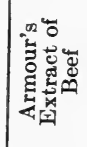 & 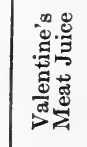 & 焉 & 壱 & 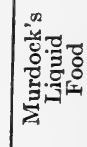 & 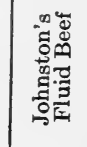 & 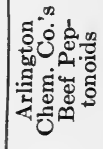 & 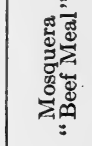 \\
\hline Water (at $110^{\circ} \mathrm{C}$.) & 20.06 & 14.03 & 60.31 & 57.88 & 81.09 & 83.09 & 39.58 & 6.80 & 6.68 \\
\hline Solid matter (at $110^{\circ} \mathrm{C}$.) & 79.94 & 85.97 & 36.69 & 42.12 & 18.91 & 16.01 & 60.42 & 03.20 & 93.32 \\
\hline Soluble in water. . . . . . & 79.94 & 85.97 & 36.69 & 42.12 & 18.91 & 16.01 & 50.40 & 48.12 & 31.26 \\
\hline Insoluble in Water. & & & & & & & 10.02 & 45.06 & 62.06 \\
\hline Inorganic constituents.. & 24.04 & 28.29 & 11.30 & 17.52 & 1.02 & 0.66 & 13.52 & 5.08 & 4.23 \\
\hline Phosphoric acid $\left(\mathrm{P}_{2} \mathrm{O}_{5}\right)$ & 9.13 & 7.28 & 4.00 & 3.94 & 0.03 & 0.09 & 3.91 & 1.40 & 1.71 \\
\hline Fat, ether extractives.. & 0.91 & 1.27 & 0.78 & 0.85 & 1.49 & 0.27 & 1.29 & 2.95 & 13.60 \\
\hline Soluble in $80 \%$ alcohol & 55.72 & 67.92 & 29.15 & 35.08 & 1.49 & 0.27 & 34.10 & 2.95 & 13.60 \\
\hline 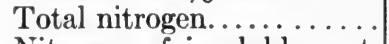 & 9.52 & 8.80 & 2.68 & 3.25 & 2.43 & 2.29 & 7.38 & 4.42 & 12.36 \\
\hline Nitrogen of insoluble mat- & ? & & $2<0$ & 205 & (2) & חק ת & 140 & ת & \\
\hline Insoluble protein matter... & 9.52 & $\begin{array}{l}. .00 \\
8.80\end{array}$ & $\begin{array}{l}2.08 \\
2.68\end{array}$ & $\begin{array}{l}3.25 \\
3.25\end{array}$ & $\begin{array}{l}2.43 \\
2.43\end{array}$ & $\begin{array}{l}2.29 \\
2.29\end{array}$ & $\begin{array}{l}1.46 \\
9.12\end{array}$ & $\begin{array}{r}3.25 \\
2030\end{array}$ & $\begin{array}{r}7.65 \\
47.81\end{array}$ \\
\hline $\begin{array}{l}\text { Soluble albumin (coagula- } \\
\text { tive by heat)............ }\end{array}$ & 0.06 & 0.68 & 0.55 & 0.47 & 13.98 & 14.29 & & & \\
\hline Soluble albumoses... & . & & $\cdots$ & $\cdots$ & & & & 5.44 & 11.09 \\
\hline Peptone. . . . . . . . . . & & & $\therefore$ & & & & & 1.87 & 18.34 \\
\hline $\begin{array}{l}\text { Total protein matter avail- } \\
\text { able as nutriment....... }\end{array}$ & 0.06 & 0.68 & $0.55^{\circ}$ & 0.47 & 13.98 & 14.29 & 9.12 & 27.61 & 77.24 \\
\hline $\begin{array}{l}\text { Nutritive value as com- } \\
\text { pared with fresh lean beef } \\
\text { (lean beef, 100)........ }\end{array}$ & 0.30 & 3.15 & 2.80 & 2.40 & 72.40 & 74.00 & 47.20 & 143.00 & 400.00 \\
\hline
\end{tabular}


CANNED MEATS.-It has been shown that some canned foods can only be preserved by sterilization at a temperature of $248^{\circ} \mathrm{F}$. for not less than 60 minutes. This degree of heat would certainly destroy vitamines. Perfectly fresh meat shows an acid reaction; pickled meat, due to chemicals used in the process, shows an alkaline reaction. The Bacillus putrificus coli is present in the colon of animals and contaminates all meats. The spores of this bacillus are killed by exposure to a temperature of $224^{\circ} \mathrm{F}$. for 15 minutes; $230^{\circ} \mathrm{F}$. for 10 minutes; $240^{\circ} \mathrm{F}$. for 5 minutes. In the process of canning meats, if these temperatures are not maintained, the meat in the interior of the can is not sterilized. This gives the bacilli an opportunity to develop and decompose proteins and other organic compounds. The sulphur generated by decomposed proteins forms a sulphid of iron which blackens the tin, while the generated gas may cause the end of the can to be "blown" or "swollen."

BEEF JUICE.-Beef juice consists of the fluid substance contained in the muscle fibers. These products are prepared by subjecting the meat to strong pressure, and are subsequently concentrated by evaporation in vacuum. The use of heat is painstakingly avoided, as it would coagulate the soluble proteins contained in the juice. Reliable beef juice must be manufactured by the cold process, and have salt or another harmless preservative added to prevent putrefaction after manufacture.

RAW BEEF JUICE.-Raw beef juice may be made at home with an ordinary lemon squeezer. If sufficient pressure is exerted the juice will exude as it would from an orange. Perhaps the best method is to chop the meat very fine, add cold water and let it stand in a cool place. The soluble proteins and other constituents are gradually dissolved out and are obtained by squeezing the pulp in muslin.

The table on page 290, taken from Hutchison, shows the composition of raw beef juice obtained by different methods.

Use of RAw BeEF JuICE.-Fresh beef juice is serviceable for feeding the sick in many severe cases of gastric disorders, in typhoid fever and in the diet of infants at the begimning of the second year. It is much to be preferred to any of the foregoing beef extracts and other preparations.

BEEF TEA.-Beef tea can be readily prepared for domestic use. Allow meat, finely chopped and with a little salt added, to stand in cold water for half an hour, then heat it for some time in a double boiler at a temperature always below $160^{\circ} \mathrm{F}$. Pour off liquid and press the meat to remove as much of the remaining juice as possible.

Preparation of Beef.-If it is desired to prepare a beef tea which 


\section{COMPOSITION OF NATURAL RAW BEEF JUICE}

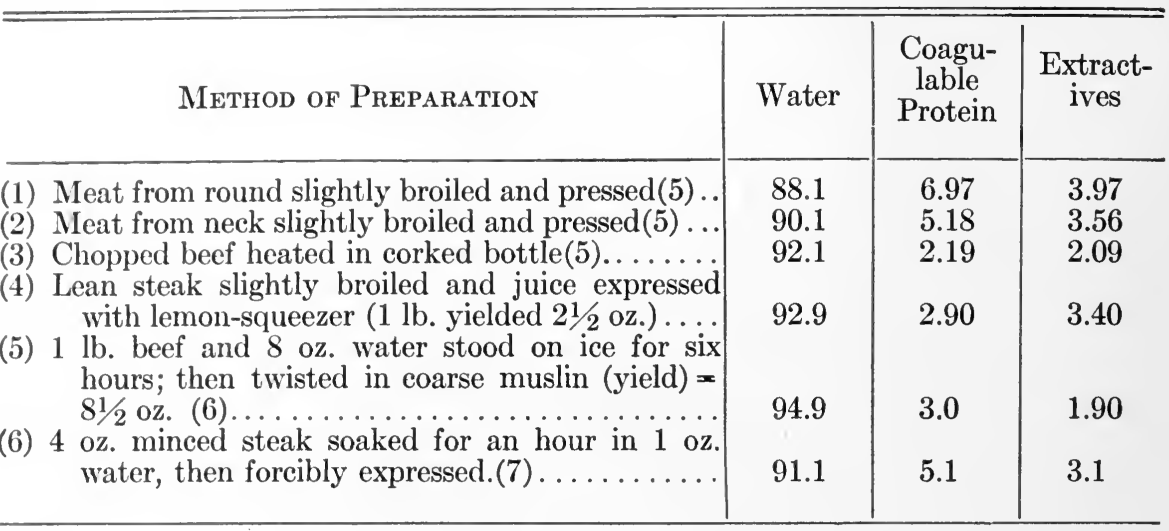

will contain real nutriment, Hutchison advises that one should proceed in the following way:

Procure some good lean beef, trim off with a knife any gristle or fat adhering to it and then scrape the meat thoroughly with the back of the knife so as to tear it into shreds. In this way, all the fibers of the meat are removed from the connective tissue which holds them together. It is these fibers which contain the most nourishing part of the meat. Having placed the fragments of the meat in a jar, add water and mix thoroughly. How much water should be added is a matter of taste. Obviously, if a small quantity of water is taken, the beef tea will be stronger than if much is used. As a rule, one pint of cold water to one pound of beef is the proportion recommended. If the mixture is now set aside in the cold for some time, most of the soluble proteins of the meat will be dissolved along with the extractives and salts. A little salt is sometimes added to the water under the belief that its solvent powers are thereby inereased. It is doubtful, however, whether such is really the ease. By the end of half an hour or so of standing in the cold, the preparation is practically a more or less dilute raw beef juice.

The jar should now be tightly covered, placed in a saucepan of water and gradually heated. The temperature for at least the first hour should be kept below the coagulating point $\left(167^{\circ} \mathrm{F}\right.$.). From time to time the mixture should be stirred with a fork and the lumps of meat squeezed against the sides of the jar. During this time any remaining soluble protein is dissolved out. At the end of the hour the tea must be cooked, i.e., its raw appearance and taste taken away by heating it to above the point at which the red coloring matter coagulates. The simplest plan is to bring it to a boil and then remove it from the fire immediately. Prolonged boiling must be avoided, as it tends to render the coagulated protein indigestible. The beef juice should then be poured from the residue of beef, not strained. ${ }^{1}$ When this has been done, the residue should be squeezed

1 The nutritive value of the preparation can be immensely increased by grating down the residue of the meat into fine particles and adding these to the tea. This, however, is not always permissible. 
very hard with the back of a spoon through a coarse strainer or sieve and the juice which eomes out added to the tea. The latter may then be set aside to cool. When cold, it will be found to have settled into two layers: a lower layer composed of floculent partieles and an upper layer of brown fluid. The fat on the top should be removed with a heated spoon.

Attention must now be directed to the two layers in the beef tea. The lower, floceulent one consists of the nutritive part of the preparation, namely, the protein. It has been coagulated, by bringing the tea to the boiling point, but the coagulation has oceurred in the form of very fine light particles. Had the tea been passed through a fine strainer or through muslin, as is sometimes recommended, these particles would have been kept back and the value of the tea proportionately lessened. The upper or fluid layer corresponds to what is the whole tea, when the latter is imperfectly prepared; in other words, it consists of a solution of the extractives and salts of the meat.

Albuminoid Material in Beff Tea. - It must be admitted that the total quantity of albuminoid material which can be obtained in the manner above described is very small, but in febrile states it is good for the patient to ingest large quantitics of water and there can be no objection to a part of the fluid being taken in the shape of beef tea. When patients suffer from great thirst they soon become tired of swallowing, and it is then well to give nitrogenous food in some concentrated form. In wasting fevers, albuminoid and gelatinous fluids aid in sustaining strength and relieve exhaustion. For this purpose beef tea and beef essence are valuable. It may be improved by adding a crushed cracker, a little butter, salt, sago or chocolate.

Prepared Beff Teas.-In earlier times nearly all beef tea was prepared by the housewife; now, however, numerous preparations are manufactured, some of which offer good substitutes for the domestic article. The following table from Hutchison gives the composition of a few of these prepared beef teas:

$\begin{array}{lccc} & \begin{array}{c}\text { Fibrous } \\ \text { Beef Tea } \\ \text { (Brand's) }\end{array} & \begin{array}{c}\text { Strong } \\ \text { Beef Tea } \\ \text { (Mason's) }\end{array} & \begin{array}{c}\text { Vril Albuminous } \\ \text { Beef Tea } \\ \text { (Bovril Co.) }\end{array} \\ \text { Water } \ldots \ldots \ldots \ldots \ldots \ldots \ldots \ldots & 83.21 & 89.02 & 84.00 \\ \text { Extractives } \ldots \ldots \ldots \ldots \ldots \ldots \ldots & 4.52 & 2.47 & 4.17 \\ \text { Proteins } \ldots \ldots \ldots \ldots \ldots \ldots \ldots & 11.40 & 6.86 & 10.17 \\ \text { Mineral matter } \ldots \ldots \ldots \ldots \ldots & 0.86 & 1.65 & 1.66\end{array}$

BEEF BOUILLON_-Beef bouillon is prepared by cutting meat into small bits, heating it slowly in water for some minutes and then suddenly bringing it to the boiling point. The fluid so produced has a very acceptable flavor and contains very little nutriment, other than the meat 
extractives and salts and some slight amount of gelatin. Bouillons increase the flow of saliva and can be rendered more nutritious by adding an egg. Bouillon cubes often contain from 50 to 72 per cent of common salt.

MEAT POWDERS.-Meat powders, such as Mosquera's beef meal, Somatose and "Beef meal," are tolerated by some stomachs and have the advantage of being less disagreeable than some home-made beef preparations. Meat powders are manufactured from dried lean beef reduced to a powder. It is a highly concentrated food and an excellent product for those who go beyond the reach of fresh food, or who need to carry their sustenance in a small bulk.

BEEF PEPTONES.-Beef peptones consist of digested or partly digested meat containing albuminose and peptones. These products are useful in cases of feeble stomach digestion and in other forms of illness. The following table from Tibbles shows that some of these preparations contain very little albuminose and peptone, but a considerable quantity of extractives of the same character as those in beef extracts. They have slight nutritive value:

PERCENTAGE COMPOSITION OF PEPTONE PREPARATIONS

\begin{tabular}{|c|c|c|c|c|c|c|c|c|c|c|}
\hline "NAME & 离 & 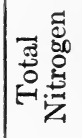 & 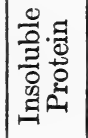 & 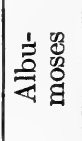 & 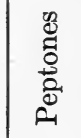 & 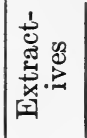 & 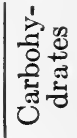 & E्ञ & $\frac{\sqrt{n}}{4}$ & Authority \\
\hline Antweiler's peptone. & 6.92 & 12.85 & 3.22 & 14.54 & 60.15 & 1.74 & & .54 & 13.31 & Kör \\
\hline Armour's peptone wine. & 83.00 & & & 3.00 & 3.00 & 12.90 & & & 1.10 & Hutchison \\
\hline $\begin{array}{r}\text { Benger's peptonized beef } \\
\text { jelly } \ldots \ldots \ldots \ldots \ldots \ldots\end{array}$ & 89.68 & 1.55 & & 2.41 & 4.75 & 2.27 & & & .89 & Köl \\
\hline Brand's essence of beef & 89.19 & 1.48 & 2.25 & & 6.05 & .15 & & & 1.31 & Stu \\
\hline Brand's beef peptc & 84.60 & & & 7.00 & & & & & 1.40 & Hutehis \\
\hline $\begin{array}{r}\text { Carnrick's peptonoids } \\
\text { (liquid) } \ldots \ldots \ldots \ldots \ldots\end{array}$ & 5.5 & & & & & & & & 5.20 & \\
\hline Carnrick's peptonoids & 0.00 & & & & & & & & 0.20 & \\
\hline $\begin{array}{l}\text { (solid)....... } \\
\text { Darby's fluid mea }\end{array}$ & 6.75 & 10.49 & 56.25 & & 6.93 & .10 & 13.41 & 10.67 & 5.50 & Stutzer \\
\hline arby's fluid mea & 25.71 & 8.06 & & & 30.60 & 43 & & & 13.50 & Kö \\
\hline Fairchild & $\begin{array}{l}78.45 \\
81.00\end{array}$ & & & 12.15 & 3.00 & $\left|\begin{array}{c}4.32 \\
15.00^{2}\end{array}\right|$ & & & $\begin{array}{l}2.54 \\
1.00\end{array}$ & \\
\hline Kemmerick's peptone. & 20.95 & 9.72 & 7.86 & 14.56 & 32.57 & 6.16 & & & 18.24 & Stu \\
\hline Koch & 40.16 & 7.80 & 1.42 & 15.96 & 16.83 & 15.96 & & .79 & 6.89 & König \\
\hline Mosquera's beef & & & 48.00 & 29.00 & & $13.00^{3}$ & & & & \\
\hline $\begin{array}{l}\text { Murdoch's fluid meat.., } \\
\text { Savory and Moore's }\end{array}$ & 83.61 & 2.29 & & 12.91 & .23 & 1.87 & & & .56 & Stutzer \\
\hline & 27.01 & 8.76 & & 5.43 & 2.66 & 7.47 & & & 12.10 & Stutz \\
\hline Sor & 14.24 & & 25.23 & 33.96 & 3.06 & 2.62 & & & 5.30 & Tankard \\
\hline Val & 59.07 & 2.50 & & 1.81 & 4.87 & 22.73 & & & 11.52 & Kör \\
\hline Peptonized milk. & 87.50 & & 2.24 & 1.76 & & Trace & 4.50 & 4.00 & .72 & Tibbles \\
\hline
\end{tabular}

1 Chiefly sugar.

2 Mostly sugar.

3 Mostly fat. 


\section{GELATIN}

Preparation of Gelatin.-Gelatin, another meat product which of late years has come into common use, is prepared from bone, tendons, horns, hoofs and hides by boiling under pressure. The potential energy of this product is calculated to be even more than that of some fats and albuminates and yet in the body it is very inferior in the production of energy. It camnot, therefore, take the place of proteins for growth and repair and must be regarded solely as an albumin sparer. Neither can it replace albumin, the loss of which still goes on to some extent even when gelatin is eaten in large quantities. Homemade meat jellies may be made by taking any meat in which there is a large proportion of connective tissue. Put the meat in a pot with cold water, slowly bring to a boil and let it simmer for six or seven hours. This slow cooking of the comnective tissue gelatinizes it. When cooled the gelatin may be separated from the fat, bones and lean meat. This home-made meat jelly possesses a pleasant flavor and is relished as an invalid diet. It is used in the body very much like the carbohydrates and fats, i.e., not as a tissue builder but as a fuel food. In this it acts differently from other fuel foods. The waste materials resulting from its oxidation are similar to the waste materials from the oxidation of protein and must therefore be eliminated by the kidneys. Calf's-foot jelly, calf's-head jelly, hog's-head jelly, if not made too rich by added ingredients, are suitable for invalid diet, especially when flavored with sherry or Rhine wine.

ANALYSIS AND FUEL VALUES OF GELATIN.-The following table from Bulletin No. 28, U. S. Dept. of Agriculture, shows the analysis and fuel value of gelatin and jelly preparations:

COMPOSITION OF GELATIN

\begin{tabular}{|c|c|c|c|c|c|c|}
\hline & \multicolumn{5}{|c|}{ Nutrients, Per Cent } & \multirow{2}{*}{$\begin{array}{c}\text { Calories } \\
\text { per } \\
\text { pound }\end{array}$} \\
\hline & Water & Protein & Fat & $\begin{array}{l}\text { Carbohy- } \\
\text { drates }\end{array}$ & Ash & \\
\hline Gelatin. . & 13.6 & 91.4 & 0.1 & . & 2.1 & 1,705 \\
\hline Isinglass & 19.0 & 89.3 & 1.6 & & 2.0 & 1,730 \\
\hline Calf's-foot jelly & 77.6 & 4.3 & $\ldots$ & 17.4 & 0.7 & 405 \\
\hline
\end{tabular}

DIGESTIBILITY OF JELLIES.-Jellies are easily digested, complete peptonization occurring in one hour. Jelly stimulates the flow of gastric juice, but at the same time fixes a good deal of acid. It is for this reason a useful food in hyperacidity. 
PUREST FORM OF GELATIN.-The purest form of gelatin is isinglass, a substance obtained from the swim bladder of fish, especially the sturgeon. Chemically it is richer than ordinary gelatin, as is shown in the table above.

CHIEF PECULIARITY OF GELATIN.-The chief pecularity of gelatin is that it dissolves in boiling water and settles into a jelly when cool. It is remarkable how weak a solution is capable of setting. Even when one per cent is present the solution sets.

\section{ANIMAL VISCERA AS FOOD}

Definition of Animal Viscera.-Animal viscera are certain organs other than flesh, that are sometimes used for food. Some of the viscera are quite digestible, although none is equal to or as nutritious as good meat. The sweetbreads and thyroid gland are delicacies which an invalid may have.

COMPOSITION AND DESCRIPTION OF VISCERA.-The general composition of these articles is shown in the following table compiled by Hutchison, from Atwater and from our own findings:

COMPOSITION OF ANIMAL VISCERA

\begin{tabular}{|c|c|c|c|c|c|}
\hline MarRow & Water & $\begin{array}{l}\text { Nitrog- } \\
\text { enous } \\
\text { matter }\end{array}$ & Fat & $\begin{array}{c}\text { Carbohy- } \\
\text { drates }\end{array}$ & Ash \\
\hline 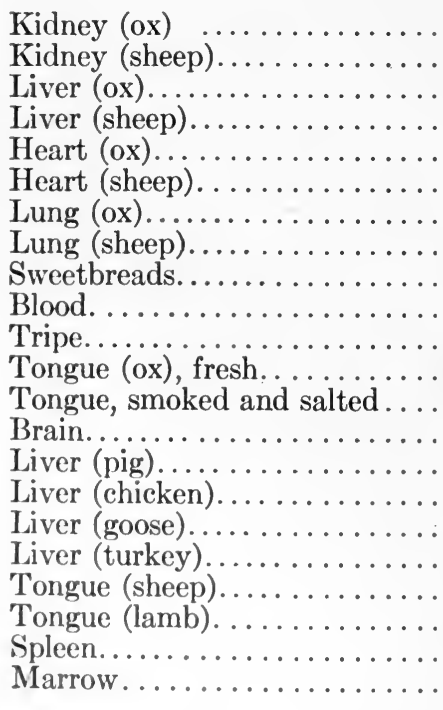 & $\begin{array}{l}76.7 \\
78.7 \\
71.2 \\
61.2 \\
62.2 \\
69.5 \\
79.7 \\
75.9 \\
70.9 \\
80.8 \\
74.6 \\
63.8 \\
35.7 \\
80.6 \\
71.2 \\
69.3 \\
62.6 \\
69.6 \\
47.6 \\
67.4 \\
69.0 \\
8.56\end{array}$ & $\begin{array}{r}16.9 \\
16.8 \\
20.7 \\
23.1 \\
16.0 \\
17.0 \\
16.1 \\
20.2 \\
16.8 \\
18.1 \\
16.4 \\
17.1 \\
24.3 \\
8.8 \\
21.3 \\
22.4 \\
16.6 \\
22.9 \\
24.4 \\
13.9 \\
17.5 \\
1.87\end{array}$ & $\begin{array}{r}4.8 \\
3.2 \\
4.5 \\
9.0 \\
20.4 \\
12.6 \\
3.2 \\
2.8 \\
12.1 \\
0.2 \\
18.5 \\
18.1 \\
31.6 \\
9.3 \\
4.5 \\
4.2 \\
15.9 \\
5.2 \\
24.0 \\
17.8 \\
12.00 \\
88.04\end{array}$ & $\begin{array}{c}0.4 \\
\ldots .0 \\
1.5 \\
5.0 \\
\ldots \\
\ldots \\
\ldots \\
\ldots \\
\ldots \\
\ldots \\
\ldots \\
\ldots \\
\ldots \\
\ldots \\
1.4 \\
2.4 \\
3.7 \\
0.6 \\
0.6 \\
0.6 \\
0.6 \\
0.6\end{array}$ & $\begin{array}{l}1.20 \\
1.30 \\
1.60 \\
1.70 \\
1.00 \\
0.90 \\
1.00 \\
1.20 \\
1.60 \\
0.85 \\
0.50 \\
1.00 \\
8.50 \\
1.10 \\
1.4 \\
1.7 \\
1.2 \\
1.7 \\
4.8 \\
0.5 \\
1.5 \\
1.53\end{array}$ \\
\hline
\end{tabular}

Kidneys. - The kidneys are indigestible, chiefly by reason of the closeness of their texture. The nitrogenous extractives or meat bases are 
urea, uric acid, creatin, purin bases. If cooked too long they become very hard and tough.

Luver. - The liver is more often eaten perhaps than any other organ. Calf's liver is the best flavored and most tender variety. When liver is boiled in water a liguid is obtained containing nucleoproteins, which has been termed ferratin. It also yields important nitrogenons extractives. 'Tender liver is more easily digested than kidney and is fairly nutritious. Liver should never be allowed to diabetics. The Scotch people understand the art of cooking liver. It is chopped very fine and mixed with oatmeal in making the national dish, "Maggis."

HEArT.-The heart is sometimes used as a food, but the meat is hard, tough and stringy, containing but little nutrition.

LuxGs.-Lungs of animals are not regularly used for food, though they are sometimes eaten in prisons.

Sweetblizads. - Sweetbreads are either the thymus gland, sometimes called "neck" or "throat" sweetbread, or the pancreas, called the "belly sweetbread." These two sets of glands, both very similar in composition, consist of a mass of cells held together by loose connective tissue; they are very rich in nuclein and nucleoprotein, but poor in albumin and globulin. They are rich in the salts of calcium and magnesium, potassium and phosphates. The sweetbread is a useful adjunct to the invalid dietary; it is very tender, has an agreeable flavor, is easily digested. Butchers often substitute the pancreas or "belly sweetbread" for the better thymus or neek sweetbread. The former may be recognized as being larger and coarser than the "neck sweetbread." The "belly sweetbread" is harder to digest.

BLoov.-Blood as a food is chiefly used in the form of black puddings, which contain rice and other ingredients sterilized by boiling. This compound is nutritions, and if eaten while fresh is quite free from danger.

Tripe.-Tripe is the name of the stomach and intestines of the ox or hog after being properly cleaned and cooked by prolonged boiling. It consists largely of involuntary muscular fibers. The chief protein is globulin. It contains five times as much nucleoprotein as striated muscular tissue. It also contains a small amount of glycogen, sareolactic acid and mineral salts, in which sodium is in excess of the potassium. When properly prepared, while somewhat flavorless, it is easy to digest and must be regarded as a suitable food, especially in cases where purins are not wanted.

Toxgue.-The tongues of oxen and sheep are used as food, and a 
large industry is carried on by canning these organs, which sell as potted meat. Tongue consists of muscle fibers, which are fairly free from connective tissue.

Brans. - The brain of animals is not very commonly eaten as a food. The substances which make up the complex composition of the brain tissue are varied and of great importance when the organ is regarded as a foodstuff. Hammarsten gives the following composition of the brain:

\section{COMPOSITION OF BRAIN}

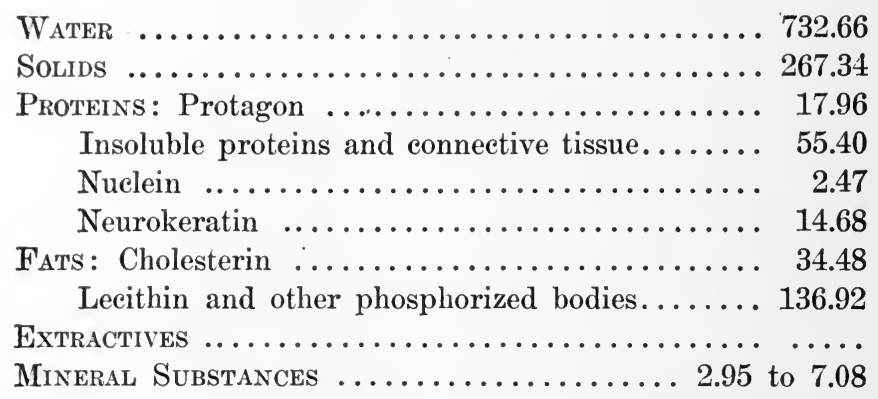

In the class of proteins are found albumin, globulin, nucleo-albumin (phosphoprotein), nucleoprotein, and lecithalbumins, i.e., compounds of lecithin, albumin and phosphoprotein. Adrenin and guanin are derived from the nucleoproteins. Nuclein is found in large proportion in the gray matter, and neurokeratin in the neuroglia. Lecithin, either alone or combined with albumin or fatty acids, is found in both the gray and the white brain matter. Cholesterin, either alone or combined, is found in greater quantities in the white matter. The fatty acids exist in combination with lecithin, cholesterin and protagon.

It might be inferred that brain is a very proper food for persons whose occupation is chiefly intellectual, but observations do not confirm this supposition.

\section{DOMESTIC AND WILD FOWLS}

DOMESTIC FOWLS: ENUMERATION AND DESCRIPTION.-Poultry or barnyard fowls include the following varieties of domestic birds: chicken. turkey, peacock, duck, goose, guinea fowl and pigeon. Generally speaking, the flesh of all birds is edible. Occasionally the flesh of some birds is rendered poisonous by foods which they eat; thus, the pheasants and partridges of America, especially the former, who eat the buds of the calmia latifolia, are considered poisonous in the winter and spring.

Cirmcken.-Chicken is among the most digestible of all meats, whether cooked by broiling, by roasting or by boiling. The white meat 
is more casily digested than the dark. Even a ryphoid convalescent may eat a small piece of chicken breast with impunity. A convalescent recovering from any severe illness may be allowed chicken days before it would be safe to order beef or mutton. Chicken broth is almost universally liked, and when served with rice and an egg forms a tempting and tasty invalid food.

There are many varieties of the domesticated chicken. Some are prized for their tendency to grow large and fatten rapidly, others for their egg-producing qualities. In temperate regions the chickens lay best in the spring and early summer. "Spring" clickens are ready for the table at two to four months old. Older chickens are killed all the year round.

The flesh of the mature cock is too tough and too highly flavored to be palatable and is only fit for stewing. Young cockerels, however, are killed and sent to the market as spring chickens. The older cockerels are caponized(8), i.e., castrated, after which they grow to a good size and fatten readily. The white meat develops more than in ordinary fowls, while they retain the tenderness and sweetness of a spring chicken. The French have practiced spaying of hens to a small extent. Such birds they call poulards. While it is admitted that they fatten more readily than ordinary hens, it is questionable whether the flesh of the poulard is better or finer flavored than that of the ordinary hen.

Turkey.-The turkey (9) is a native of North America. Raleigh's first emigrants to the New World found this "grand" bird roaming the forests of eastern North Carolina. There are many varieties, but the two principal breeds are the American Bronze and the White Holland. Both are large species, sometimes reaching a weight of forty to fortyfive pounds. The turkey is highly esteemed for the excellence of its flesh and its large size. Turkey chickens are not much in demand. They are thin and scraggy; when two or three months old they weigh from 2 to $31 / 2$ pounds and are sold as broilers. Turkey meat when properly fattened and cooked is tender, delicate and nourishing and of most excellent flavor. The flesh is grayish white, free from excessive fat, and therefore much to be preferred to that of the goose.

Peafowl.-This bird belongs to the pheasant family and is the common peacock of Great Britain and America. The peacock has a larger amount of flesh in proportion to bone than most fowls. Young peahens are as delicate and toothsome as pheasants, but mature ones are dry and not as tasty as the flesh of the young pheasant. The older peacock is not held in high esteem for its flesh but only for its ornamental plumage. 
Ducks avi Gerse.-Ducks and geese are indigestible, unless young and tender. There are several varieties of the former, weighing from two

DUCK $\angle E G$ AND SECOND NOINT EDIBLE POATION
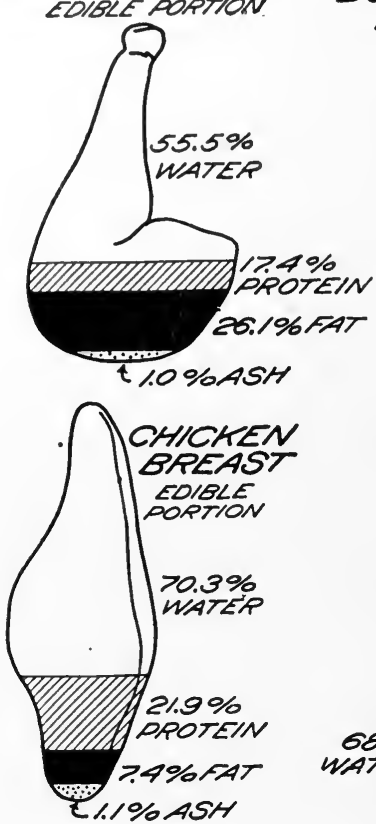

DUCK BAEAST EOIBLE PORTION

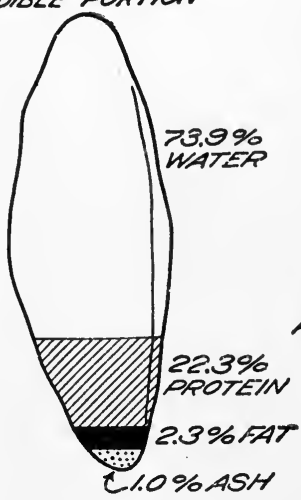

WHOLE CHICHEN EDIBLE POATION

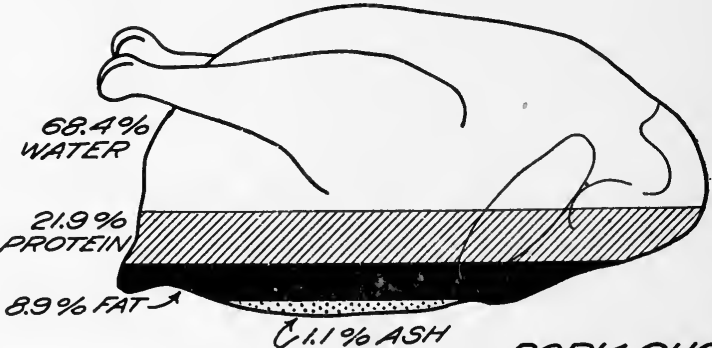

$8.9 \%$ FAT

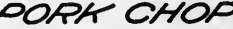
EDIBLE PORTION

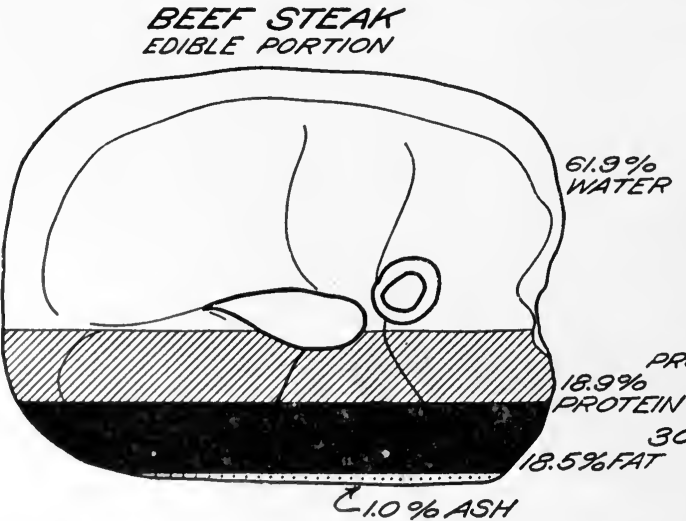
$16.6 \%$

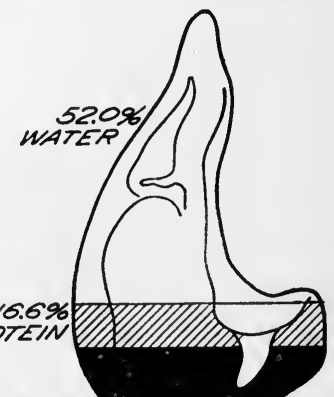
0.1\% FAT

$10 \% .45 H$

Fig. 18. - Chemical Composition of Poultry in Comparison with Steak and Chop. (Bull. 467, U. S. Dept. Agric.) 
to seven pounds. The flesh of the duck is dark and juicy and not as hard to digest as the goose flesh. There are several varieties of geese, some weighing from 24 to 38 pomnds. (Goose flesh is highly prized in Germany, where it is eaten in every conceivable form. Goose fat is eaten by orthodox Hebrews. They consider it an excellent constituent for many dishes.

Pâte de Foie Gras is made ly fattening geese in such a manner as to indue fatty infiltration of the liver. This has long been an industry in France and Germany. These livers sometimes develop to an enormous size, weighing two to three pounds.

Gunes Fowls. - Guinea fowls are domesticated Afriean pheasants. Their flesh is tender and very well flavored. The hens are preferred for the table. Both the flesh and the eggrs are considered a delicacy. The young caponized birds have flesh like that of the partridge and the older ones like that of the pheasant. The meat is dark but highly nutritious.

PIGEoxs.-Pigeons are more sought after as a food in Europe than in Americal. They are classed among the domestic white-fleshed birds. The young birds, squabs, are best for eating. The cultivation of squabs is quite an active industry in this comtry, because the demand exceds the supply. The squab is a delicacy for both the invalid and epicure. The adult pigeon is not so well flavored and requires long cooking to make it palatable.

WILD FOWL.-Some birds, such as wild turkeys, geese and ducks, pigeons, quail, partridge, snipe, grouse, woodcock, pheasants, rice birds and prairie chickens, when "high" are preferred by many persons to the domestic fowls.

The wild turkey, goose and duck are like the domesticated birds of the same species. The avalable energy of the edible portions is about the same as in domesticated birds. The flavor, however, of the wild birds is better.

The meat of game birds, like that of all wild animals, is rather harsh and tough and their fat more strongly flavored. The flesh of the smaller game birds, as quail, partridge, snipe, grouse, woodeock and rice birds is considered a delicacy; the meat of the breast is best adapted for invalids.

DANGER OF "HANGING" GAME-The habit of hanging game until it gets high is quite objectionable and decidedly unhygienic. When it is hung up for this purpose and allowed to beeme malodorous, putrefaction is already well under way. This process of decay not only rapidly leads to decomposition and the development of toxins, but is a genuine hotbed for microörganisms, which may anne gastric troubles and enteric dis- 
orders. Such practices, which are bound to endanger the health even of the most robust, should be condemned.

High game, on account of the toxic substances it contains, is even dangerous to the circulatory system; the toxins contract the small blood vessels and thereby put extra work upon the heart. For this reason, in critical cases of cardiac affection and high blood pressure and in Bright's disease, it should not be eaten.

When meat is stale or game high it is positive evidence that putrefactive changes have taken place by bacterial action, whereby certain alkaloidal substances of the nature of ptomains and leucomains of an exceedingly poisonous nature are formed. When such food is ingested and absorbed, serions and even fatal results often follow.

Analyses of Meat.-For analyses, comparative nutritive and fuel values of butchers' meats, consult Volume I, Chapter XIX, page 693. For analyses, comparative nutrition and fuel value of poultry and game, consult Volume I, Chapter XIX.

\section{FISH AND SHELLFISH}

Fish.-The flesh of fish is another important source of protein food. It is, as a rule, delicate and tender. Fish possesses a peculiar flavor common to all fish, but different from the meat flavor of mammals and birds. Fish flesh is less stimulating and sustaining and not so satisfying as that of birds and mammals. Fish is abundant in both salt and fresh water and has always been a favorite food. It forms the staple protein food of a large number of the earth's inhabitants. The Japanese live almost entirely on fish and rarely, if ever, eat meat. The inhabitants of distant islands, as well as the residents of the metropolitan centers, have learned the value of fish as a cheap and wholesome source of nourishment. In fact, in many countries fish is used exclusively as a nitrogenous food. The readiness with which the flesh of fish undergoes decomposition changes makes it necessary to use this food fresh from the water, or to subject it to some method of preservation, either salting, drying, smoking or refrigeration. All methods of preserving fish modify its flavor and detract from its nutritive value.

For different varieties of fish, their chemical composition, their nutritive value, consult tables on fish, Volume I, Chapter XIX.

FISH AS SEASONABLE FOOD.-All fish are best in season, as out of season they lose their flavor, their nutritive value is lessened, and in some species an offensive odor is developed, due largely to the food on which they subsist or other causes. Fish are in best condition for eating 
just before spawning; after this period they become thin and unfit for food. The popular fallacies that because fish have a large percentage of phosphorus they therefore constitute a gond "hiran forml" amd that they possess aphrodisiac properties, are erroneons theories. It is now well known that many fish contan less of this element than meat.

MOST DIGLSTBBL: Fish.-The most digestible tish are sole, whiting, butter fish, bluefish, codfish, whitefish. flounder, bass, momentain trout, fresh haddock, red snapper, perch, shad and smell. Pavy says, "Of all fish, the whiting may be regarded as the most delicate, tender, easy of digestion and least likely to disagree with digestion."

Fisir as Ixvalin Foon.-Fish having white flesh constitute an excellent food for invalids and convalescents. Fish intended for the sick should be eooked by broiling or boiling (not frying).

The exact chemical composition of cooked fish, of the more common varieties, is shown in the following analysis by Miss Katherine Willians, published in the Journal of the Chemical society, I.XXI, page 649:

ANALYSIS OF COOKED (BOILED) FISH AS SERVED AT TABLE

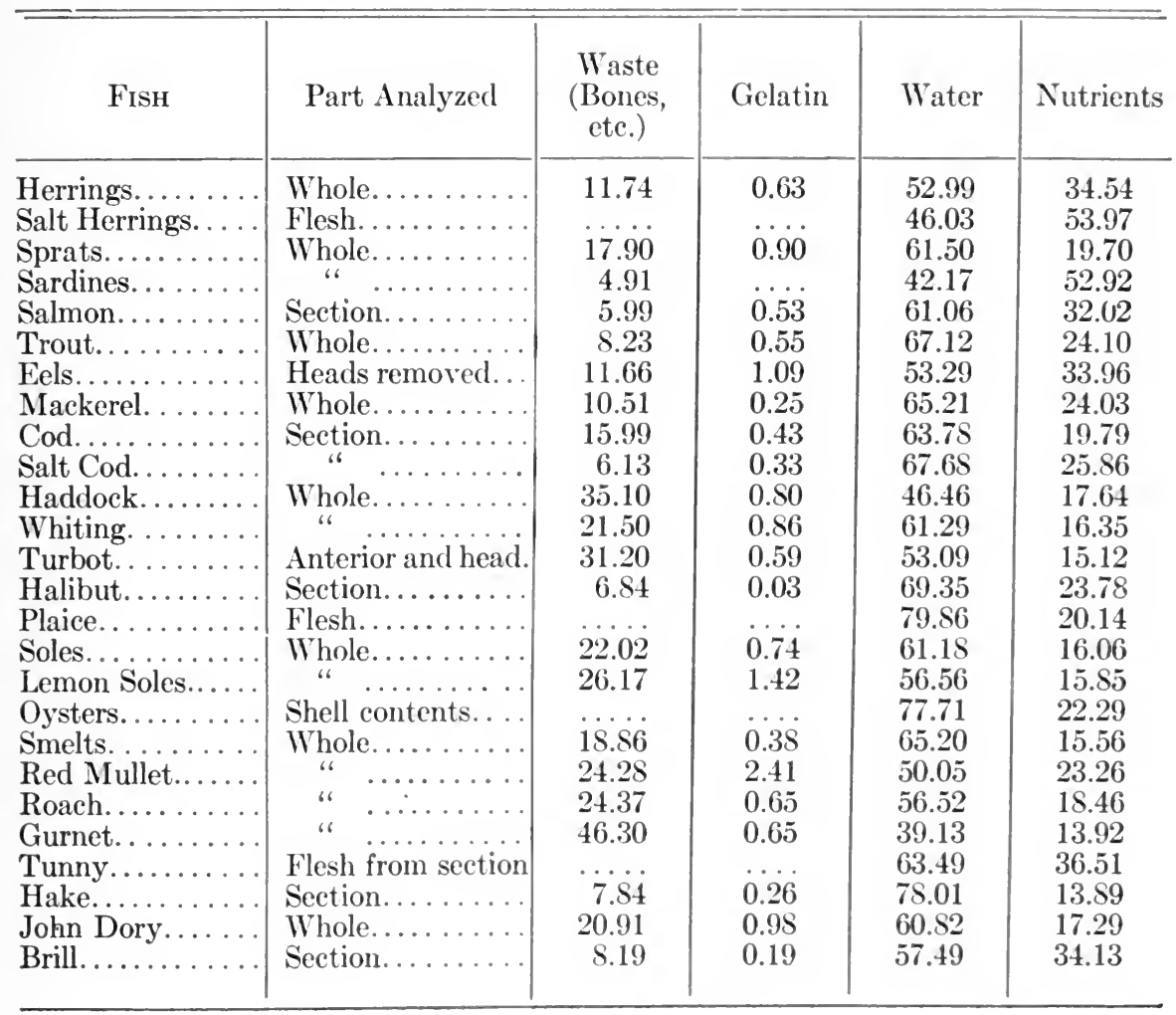




\section{ANALYSIS OF COOKED FISH}

\begin{tabular}{|c|c|c|c|c|c|c|}
\hline \multirow{2}{*}{ Fish } & \multirow{2}{*}{$\begin{array}{c}\text { Water } \\
\text { in } \\
\text { Flesh }\end{array}$} & \multirow{2}{*}{$\begin{array}{c}\text { Reducing } \\
\text { Substances } \\
\text { in Dry } \\
\text { Matter as } \\
\text { Glucose }\end{array}$} & \multirow{2}{*}{$\begin{array}{l}\text { Ash in } \\
\text { Dry } \\
\text { Sub- } \\
\text { stance }\end{array}$} & \multicolumn{3}{|c|}{ Solids in Dry Substances } \\
\hline & & & & N. & Fat & Protein \\
\hline Herrings. . . . . & 60.54 & & 5.56 & 11.11 & 25.25 & 67.07 \\
\hline Salt Herrings. & 46.03 & 17.59 & 19.69 & 7.12 & 21.90 & 38.88 \\
\hline Sprats...... & 75.77 & 9.88 & 6.42 & 9.26 & 27.37 & 57.94 \\
\hline Sardines..... & 44.35 & & 12.03 & 8.54 & 33.49 & 55.44 \\
\hline Salmon...... & 65.32 & 14.89 & 4.94 & 10.70 & 29.43 & 56.65 \\
\hline Trout........ & 73.58 & 4.68 & 6.60 & 11.96 & 8.84 & 80.00 \\
\hline Eels. . & 61.08 & 8.91 & 2.11 & 7.36 & 44.68 & 42.88 \\
\hline Mackerel..... & 73.13 & 13.93 & 4.07 & 10.46 & 25.73 & 62.32 \\
\hline Cod. . & 76.32 & 6.67 & 3.31 & 15.30 & 1.15 & 91.55 \\
\hline Salt Cod...... & 72.35 & 7.14 & 14.26 & 12.41 & 0.94 & 76.06 \\
\hline Haddock..... & 72.37 & 13.15 & 3.28 & 13.11 & 1.29 & 79.57 \\
\hline Whiting. ..... & 78.78 & 17.54 & 1.92 & 13.28 & 1.86 & 79.55 \\
\hline Turbot....... & 77.84 & 11.81 & 2.41 & 13.76 & 4.75 & 84.71 \\
\hline Halibut. . & 74.47 & & 4.11 & 13.32 & 15.81 & 76.67 \\
\hline Plaice... & 77.86 & 11.56 & 4.06 & 13.02 & 9.84 & 75.16 \\
\hline Soles... & 79.20 & 11.87 & 3.47 & 14.00 & 1.71 & 86.71 \\
\hline Lemon Soles.. & 78.11 & 14.80 & 4.42 & 11.04 & 12.96 & 69.88 \\
\hline Oysters. . . . . . & 77.71 & 18.32 & 12.16 & 11.85 & 7.77 & 65.42 \\
\hline Smelts. . & 80.73 & 2.17 & 4.73 & 11.61 & 9.76 & 82.59 \\
\hline Red Mullet... & 68.26 & 9.79 & 5.42 & 11.59 & 24.52 & 66.26 \\
\hline Roach....... & 75.37 & 6.28 & 1.08 & 13.03 & 15.03 & 79.14 \\
\hline Gurnet....... & 73.77 & 14.77 & 3.53 & 14.24 & 1.81 & 89.16 \\
\hline Tunny....... & 63.49 & & 5.52 & 10.55 & 30.68 & 66.08 \\
\hline Hake. . & 84.88 & 13.64 & 3.90 & 12.86 & 5.67 & 81.36 \\
\hline John Dory . . . & 77.89 & 14.29 & 3.06 & 13.32 & 8.52 & 79.53 \\
\hline Brill..... & 62.74 & $\ldots$ & 4.42 & 15.49 & 1.62 & 93.95 \\
\hline
\end{tabular}

FISH AND DISEASE.-It is a well known fact that the flesh of birds which live largely upon a fish diet have a peculiar fishy odor. It is also said that people who subsist largely upon a fish diet have a peculiar rancid odor. Some skin diseases may be caused and others aggravated by a prolonged fish diet. The impression that fish eating produces a tendency to leprosy is not, in the opinion of the authors, well founded, for leprosy often occurs in places where fish is not a common article of food and even in places where fish is difficult to obtain.

USE OF FISH AS FOOD IN COAST COUNTRIES.-In all countries which have extensive coasts, fish is an important article of diet. From the earliest times the Greeks and Romans highly esteemed fish as food and 
even placed extravagant value upon certain varietics as a nitrogenous food. The inhabitants of the British Istes, aceorling to Tibbles, "have always had an abundance of fish and have eaten of the best varieties. The Briton of today who desires light and nourishing food has plenty of fish on the table, most of which is a valuable sonrce of nitrogen and phosphorus and casy of digestion."

Fist ix America.-Reliable information collected by the U. S. Fish Commission places the total weight of fish produced anmally in America at $2,169,000,000$ pounds and its value at $\$ 58,000,000$. The greater part of this is eonsumed in the United States, although a considerable quantity is eamned for export. This estimate does not include the hundreds of thousands of pounds canght by sportsmen.

TREATMENT OF FISH FOR PRESERVATION.- Fish should be killed the moment they are taken from the water, for when allowed to die by slow degrees, in or out of the water, they undergo decomposition more quickly than if killed at once. The preservation of fresh fish during transportation to market is best attained by chilling or freezing. Recent observations have demonstrated the fact that when meat is stored at $32^{\circ} \mathrm{F}$., the activity of the mieroörganisms is checked. The action of certain ferments normally present in meat, however, is not ehecked and this explains why meat may undergo a ripening in cold storage without deeaying. The deductions reached with regard to fish are that, although a temperature of $32^{\circ} \mathrm{F}$. effectually checks the action of mieroörganisms and hinders putrefaction, yet the enzymes normally present in the flesh of fish act prejudicially and produce bodies emitting unpleasant odors, so that, although the fish is not actually decayed, it is far from tasty and palatable(10).

VALUE OF FISH ROE.-Fish roe ordinarily possesses very little nutritive value and serves principally as a relish. Shad roe, thoroughly cooked, is very nutritions. Sturgeon roe, or caviare, which is principally used as an "appetizer," is difficult of digestion, especially when old, black or slightly rancid. Good caviare should be of a gravish color and the separate eggs easily perceived. The proteins of fish roe contain a good deal of nuclein. Fatty fish is contra-indicated in all cases of dyspepsia, arthritis, obesity, Bright's disease and cardiac ailments. To the list may be added liver complaints, uremia and gout.

Composition of Fisil and Meat.- The following table, from Tibbles' "Foods and Their Manufacture," shows the comparative ralue of fish and meat: 


\section{COMPARATIVE VALUE OF FISH AND MEAT}

\begin{tabular}{|c|c|c|c|c|c|c|c|}
\hline \multirow{2}{*}{ Variety } & \multirow{2}{*}{ Refuse } & \multicolumn{2}{|c|}{$\begin{array}{l}\text { NuTRIENTS, } \\
\text { PER CENT }\end{array}$} & \multirow{2}{*}{$\begin{array}{c}\text { Calories } \\
\text { per } \\
\text { pound }\end{array}$} & \multirow{2}{*}{$\begin{array}{l}\text { Cost } \\
\text { per } \\
\text { pound }\end{array}$} & \multirow{2}{*}{$\begin{array}{l}\text { Cost of } \\
\text { Protein } \\
\text { per } \\
\text { pound }\end{array}$} & \multirow{2}{*}{$\begin{array}{c}\text { Cost of } \\
1,000 \\
\text { Calories } \\
\text { of energy }\end{array}$} \\
\hline & & Protein & Fat & & & & \\
\hline Codfish Steak. & 9.2 & 17.0 & .5 & 327 & 12 & .71 & 38 \\
\hline Bluefish...... & 48.6 & 10.0 & .6 & 204 & 12 & 1.20 & 58 \\
\hline Halibut. & 17.7 & 15.3 & 4.0 & 454 & 18 & 1.18 & 40 \\
\hline Codfish (salt dried) & 24.9 & 19.0 & .4 & 363 & 7 & .44 & 23 \\
\hline Mackerel. . . . . . . . & 19.7 & 13.9 & 21.4 & 1,107 & 10 & .61 & 10 \\
\hline Salmon (canned)... & 14.2 & 19.5 & 7.5 & 658 & 12 & .62 & 18 \\
\hline Beef: Sirloin steak. & $\ldots$ & 25.0 & 3.5 & 615 & 20 & 1.52 & 21 \\
\hline Round...... & & 24.6 & 4.5 & 605 & 14 & .74 & 16 \\
\hline Mutton chop...... & 13.0 & 16.0 & 33.0 & 1,695 & 20 & 1.48 & 14 \\
\hline Pork: Loin. ........ & $\ldots$ & 20.3 & 19.0 & 1,180 & 12 & .90 & 10 \\
\hline Smoked ham & & 19.8 & 20.8 & 1,245 & 22 & 1.55 & 14 \\
\hline
\end{tabular}

Shellfish or Sea Foods.-Shellfish or sea foods most commonly used for food may be divided into two groups-crustaceans and mollusks.

CRUST ACEANS.- The crustaceans include the lobster, crab and shrimp. These animals, when alive, are greenish in color, but on boiling turn a bright red. It is the skeleton that turns red, as the animal meat is on the inside of the shell or armor.

Lobster.-The lobster varies in length from ten to fifteen inches and is found abundantly along the New England coast. They are esteemed as a rich and nourishing aliment when fresh, but are dangerous when out of scason or when not cooked alive. They are highly poisonous to some persons, even when fresh and properly served. They may excite nausea, vomiting and even gastro-enteritis, especially if eaten with other foods. In other individuals they sometimes cause urticaria and aggravate existing skin affections.

Chemical Axalysis of Shellfisir.-For the chemical analysis of shellfish consult Volume I, Chapter XIX.

Crabs.-There are several species of erabs, including the hard and soft shell crabs, along the Atlantic and Pacific shores of America. The most highly appreciated crab is found along the middle and southern Atlantic shores. The flesh of the crab is neither so delicate nor so digestible as that of the lobster. The soft shell crabs are those which are caught just after shedding. The hard shell erabs are sea scavengers, and when not thoroughly cleaned or imperfectly cooked may be poisonous 
from contamination with putrid matter, although their own flesh may be wholesome.

Snkmps, Prawes axn Carmotre-C Shrimps are abundant all along the sandy shores of America. Prawns are somewhat larger and inhabit the deeper waters near land in the vicinity of rocks. Carmotes are larger shrimps, common in Mediterranean waters. 'They are all tasty morsels, with a fair amomt of mutrition. The flesh of shrimps and prawns is less dangerous than that of lobster and crabs. It is more delicate and rather rich in mineral matter. Moreover, they are eatable without sance or other bothersome additions.

TunTtes.-Turtles, inhabiting both fresh and salt water, are important foods. The green turtle, sometimes weighing hundreds of pounds, is used chiefly for making green turtle soup, which is a highly esteemed luxury as well as a stimulating, nutritious food. The fresh-water tortoises constitute a large family, of which the chicken tortoise is most esteemed, its flesh having the flavor of chicken. It is mutritious and a highly prized luxury.

Terrapin.-The diamond back terrapin is cultivated for the markets in the regions of the Chesapeake Bay, Charleston, S. C., and Savannah, Ga. The flesh is liked by epicures for its digestibility and agreeable flavor.

Frogs' Legs.-Frogs' legs are now a standard food on the market. The hindquarters are the desirable portions. They are in best season in the autumn and winter. The flesh has an extremely delicate flavor, tastes something like chicken and is easily digested.

MoLLUSKs.-Mollusks include oysters, clams, mussels, scallops and - snails.

Oysters-Tineir Food Value and Celture.-Oysters are grown in shallow salt waters in numerous localities throughout the temperate zone. They thrive best near the mouths of rivers where the water is brackish. Raw oysters are very digestible. When properly cooked oysters are often recommended as a food for the invalid. There are many varieties of oysters on the market, but the most appreciated are the Blue points, from the Long Island waters; the Lynhavens, from Chesapeake Bay; Rockaway oysters, from Rockaway, on Long Island, and the shrewsbury, from the New Jersey coast.

The oyster has never fully come into its own, possibly because of prejudice and partly because the people of the interior have not been able until recently to get it at its best. The average quality of oysters has been greatly improved during recent years as a result of oyster culture, 
which sprang from the demand on the part of the luxurious few in the larger cities for "fancy" oysters.

It can be truly said today that oysters are very sanitary and better than ever before and that there is as good a guarantee of their wholesomeness as there is of milk, strawberries or fresh vegetables not usually cooked before consumption. If oysters are cooked there is a double guarantee.

The United States and many municipal governments have realized the advisability of supervision and inspeetion, and there is now exercised

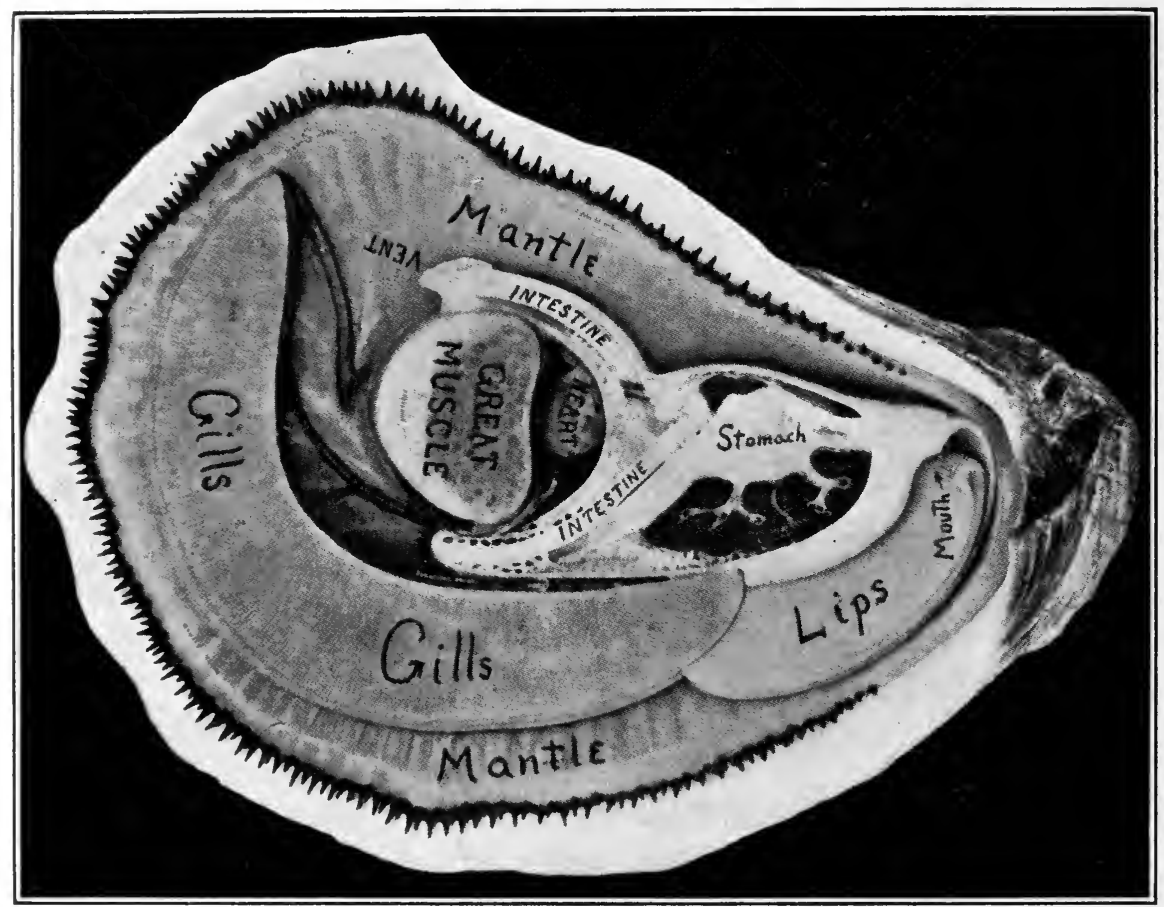

Fig. 19.-Correct ANatomy of the Oyster. This photograph was taken by Dr. Hugh Smith, who says: "It is an astonishing biological fact that in some species of oyster each sex is represented by a different individual, as in the oyster of the Atlantic coast of North America; while in other species, both sexes are united in one individual-the male stage alternating with the female, as in the common oyster of the Atlantic coast of Europe."

close scrutiny of the sourees of oysters which are offered on the markets. Oyster culture has gradually developed in the United States until at the present time nearly half of the oysters produced in the country and about two-thirds of the total value of the product are derived from artifieial beds, privately owned or leased by the states. Beginning in shoal waters 
along shore, the oyster growers have extended their operations into the deep open waters of Long Island Somd, the ('hesapeake Bay, and to every coastwise state from Massachusetts to Texas and from Washington to lower ('alifornia. The few small boats first employed, propelled by sails or oars, have given place to fleets of motor boats and steamers. In 1911 oyster planters spread $17,000,000$ bushels of young oysters, shells and gravel over their 500,000 acres of oyster farms and harvested a crop of $15,000,000$ bushels of oysters worth approximately $\$ 10,000,000$.

Clams.-Clams, like oysters, are found along the coast, and are most commonly used at the seashore. In composition they are very similar to the oyster. There are three principal varieties, the soft, hard and little neck clams. All are used for food. The soft clam is the favorite for "clam bakes," the little necks are eaten raw, like oysters, while the hard clam is used for broth or chowder. They have a pleasant flavor and their nutritive value is well established, but they are not as easily digested as oysters.

Scallops.- Seallops belong to the oyster family and are obtained along the New England coast. They are in season from September to March. The flesh of the scallop is very nutritious. Their use is contraindicated in diabetes, since they contain much glycogen.

Mussels.-Mussels are bivalve mollusks. The common mussel is to be found in both salt and fresh water. Although used as food to a considerable extent, they do not, like oysters, form a dainty dish. Economically they are of more value for the pearls found in them than for their flesh.

Srails.- Snails deserve mention, as in some countries they are consumed as food in great quantities. They are hard, tough and indigestible, and must be made appetizing by the use of spiey eondiments. They are unfit for the sick-room and have nothing in their favor for the hale and hearty.

\section{MILK AND MILK PRODUCTS}

Milk.-Milk is the secretion of the mammary gland and is confined to the mammatia. It is intended for the nourishment of the young animal whose mother secretes the fluid and contains all the ingredients needed for complete nourishment in just the right proportion which science and experience show should be contained in a well balaneed ration.

Milk contains proteins, which furnish the building material for the wear and tear of the body; fats and carbohydrates, which are the fuel to keep the body warm and furnish it with energy and power to do its work, 
and the necessary amount of water required by the body, all combined with the inorganic salts, without which life cannot continue.

COMPOSITION OF MILK.-The composition of milk has been studied possibly more than that of any other food product. As a result, a large amount of reliable information is available. Milk is an opaque fluid, containing fat, 4 per cent; casein and various other proteins, 4 per cent; milk sugar, 4.5 per cent; mineral salts, 0.6 per cent; and water, 87 per cent. These are not filtered from the blood by the mammary gland, for milk sugar and casein do not exist in the blood. They are products of metabolism in the cells of the gland itself. These cells are rich in proteins and nucleoproteins, one of the latter yielding pentose and guanin.

Casers.-Casein arises by the union of the nucleic acid from the cell nucleus and serum albumin, thereby forming a nucleo-albumin, or, according to more recent classifications, a phosphoprotein.

FAT.-Fat is a normal constituent of the protoplasm of cells. During the period of lactation the cells undergo a rapid fatty metamorphosis and the globules of milk are derived in this manner, being liberated by a destruction of cells. It is an unsettled question whether the fat of milk is set free, but it is probable that fats which have been assimilated from food are taken up by the cells. It is known that cattle secrete more fat than is contained in the food which they consume and it is evident, therefore, that it is produced by the metabolism of proteins and carbohydrates.

MILK Sugar.-Neither is the origin of milk sugar clearly understood. We know that lactose is a disaccharid consisting of a molecule of dextrose and galactose, probably formed in the glands by a synthetic process. A large number of vegetables contain both these sugars. Physiology teaches us that the animal body is capable of transforming one kind of carbohydrate into another and we believe that some of the lactose may arise from the transformation of dextrose into galactose.

Salts ani Suspended Matter.-The salts are derived from the blood. The suspended matter is milk fat and a small proportion of casein in particies too fine to be arrested, except by stone filtration.

Comparison of Milk.-The following table, taken principally from König, gives the comparison of the milk of different animals.

A study of the above comparative table shows woman's milk to be richer in sugar, but poorer in protein, than cows' milk, yet the fuel value is about the same. Dogs' milk appears to be the richest, whereas that of the mare is exceedingly poor. Not only is there a wide variation in the milk of different animals, but cows' milk, as we all know, is subject to 
COMPARATIVE: COMPOSITION OF MILK OF VARIOUS ANIMALS

\begin{tabular}{|c|c|c|c|c|c|c|c|c|c|}
\hline \multirow[b]{2}{*}{$\begin{array}{l}\text { Kind of } \\
\text { Milk }\end{array}$} & \multirow[b]{2}{*}{ Water } & \multirow[b]{2}{*}{$\begin{array}{l}\text { Total } \\
\text { Solids }\end{array}$} & \multirow[b]{2}{*}{ Catsein } & \multicolumn{4}{|c|}{ Protein } & \multirow[b]{2}{*}{$\begin{array}{c}\text { Mineral } \\
\text { Matters } \\
(\text { Ash })\end{array}$} & \multirow[b]{2}{*}{$\begin{array}{l}\text { Fuel } \\
\text { Value } \\
\text { per } \\
\text { pound }\end{array}$} \\
\hline & & & & $\underset{\text { min }}{\text { Albu- }}$ & $\begin{array}{l}\text { Total } \\
\text { Pro- } \\
\text { tein }\end{array}$ & lat & $\mid \begin{array}{c}\text { Carbo- } \\
\text { hydrates } \\
\text { (Milk } \\
\text { Sugar) }\end{array}$ & & \\
\hline & $\%$ & $\%$ & $\%$ & $\%$ & $\%$ & $\%$ & $\%$ & $\%$ & Calories \\
\hline Woman. & 87.4 & 12.6 & 1.0 & 1.3 & 2.3 & 3.8 & 6.2 & 0.3 & 319 \\
\hline Cow. & 57.2 & 12.8 & 3.0 & 0.5 & 3.5 & 3.7 & 4.9 & 0.7 & 313 \\
\hline Dog. & 75.4 & 24.6 & 6.1 & 5.1 & 11.2 & 9.6 & 3.1 & 0.7 & 671 \\
\hline Ewe. & 80.8 & 19.2 & 5.0 & 1.5 & 6.5 & 6.9 & 4.9 & 0.9 & 503 \\
\hline Buffalo. . & 81.4 & 18.6 & 5.8 & 0.3 & 6.1 & 7.5 & 4.1 & 0.9 & 506 \\
\hline Cat.... & $\$ 2.1$ & 17.9 & 3.1 & 6.0 & 9.1 & 3.3 & 4.9 & 0.6 & 400 \\
\hline Goat. & 85.7 & 14.3 & 3.2 & 1.1 & 4.3 & 4.8 & 4.4 & 0.8 & 365 \\
\hline Llama. & S6.5 & 13.5 & 3.0 & 0.9 & 3.9 & 3.2 & 5.6 & 0.8 & 312 \\
\hline Ass.... & 89.6 & 10.4 & 0.7 & 1.6 & 2.3 & 1.6 & 6.0 & 0.5 & 222 \\
\hline Mare... & 91.5 & 8.5 & 1.2 & 0.1 & 1.3 & 1.2 & 5.7 . & 0.3 & 180 \\
\hline
\end{tabular}

great variations in the pereentage composition of its eomponent parts. As a rule, a young eow produces better milk than an old one and a well fed animal with free pasturage yields richer milk than one poorly fed, or one well fed and confined in a stall.

THE FOOD VALUE OF MILK.- Unless otherwise stated our present studies refer to cows' milk. Federal government experts estimate that about sixteen per cent of the ordinary American diet consists of milk or milk products. These figures attest the value of milk and the very important place it has in the diet even for adults. The milk of the cow, therefore, is a very important foodstuff, being of a superior nutritive character. It is adaptable for combination with a large variety of other articles of food.

Milk Not a Perfect Food.-The statement, without qualifieation, that milk is a perfect food is somewhat misleading, for while it may be a perfect aliment for the suckling, it does not necessarily meet all the demands of the adult. Besides milk contains more protein than is required by an adult. Again, it is rather too dilute a food for adult consumption, as it would require from four to five quarts daily to furnish sufficient nourishment, which would be about equal to six ounces of bread or threefourths of a pound of beef. While it is quite true that it eontains all the required elements for growth and development of the young mammal, yet it lacks certain preperties which would make it suitable as a well balaneed ration for the adult individual. It may be said, however, that it is too perfect a food for ordinary adult consumption, as every particle of it is assimilated, leaving no indigestible residue necessary for the normal action of the alimentary canal. 
Organic and Irorganic Constituente of Mrlk.-The chief organic and inorganic constituents of milk arld their percentages are graphically shown in the schemes of Van Slyke(11) and Babcock, Bulletin No. 41, Hygienic Laboratory:

\section{VAN SLYKE}

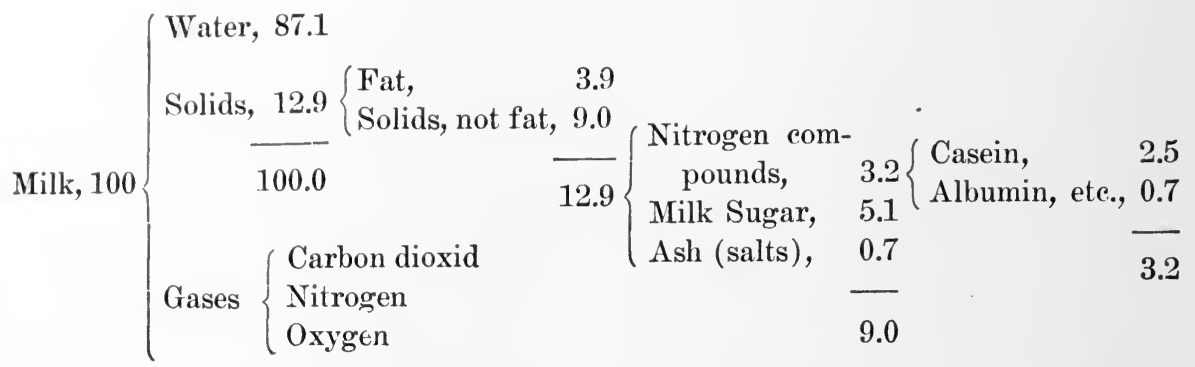

By this it will be seen that the average percentages of food elements in cows' milk is more nearly fat 4 , proteins 3.5 and carbohydrates 5 , than the $4,4,4$ percentages usually calculated, in top milk formulas, or even $4,3.5$ and 4.5 , as often followed.

DIGESTION OF MILK.-Digestion of milk in the stomach is not accomplished as quickly as might be supposed. While milk is a fluid outside of the body, yet, when it enters the stomach, it is immediately coagulated by the hydrochloric acid and rennin of the gastric juice. These curds or coagula set into a hard clot formed by the precipitation of casein and a portion of the fat that has become entangled in the curd. Since the gastric juice is an acid fluid, it is surprising at first thought that curdling does not take place instead of clotting. That this does not happen can be explained by the fact that the alkaline salts of the milk neutralize the acid first secreted by the stomach, and gives the rennin time to act before the mixture has become acid in reaction.

Milk Clots.-These clots vary in size and consistence, depending somewhat on the quantity and dilution of the milk ingested. The casein is soon converted into some form of peptone and the fat is again set free. The albuminous covering of the fat globules is dissolved, coalesces and forms drops, in which shape it passes into the duodenum. A portion of the water and inorganic salts is absorbed by the stomach.

After the clot of casein has once formed in the stomach it shrinks into a hard leathery mass, which offers great resistance to the digestive efforts of the organ. If the milk merely curdled, the act of digestion would be less difficult, for the particles of precipitated casein would be digested 


\section{$\mathrm{BABCOCK}$}

Milk, 100

Butter fat, 3.6

Glyeerids of insoluble and non-volatile acids

Olein

Palmitin

Stearin

Myristin

Butin (trace)

Glycerids of soluble and volatile acids... 0.3

$$
\begin{aligned}
& \text { Butyrin } \\
& \text { Caproin } \\
& \text { Caprylin (trace) }
\end{aligned}
$$

Milk Serum, 96.4

Containing nitrogen

Casein .................. 3.0

Albumin $\ldots \ldots \ldots \ldots \ldots \ldots .6 .6$

Lactoglobulin ............. 0.2

Galactin ..............

Fibrin (trace) ............ 3.8

Milk Sugar $\ldots \ldots \ldots \ldots \ldots \ldots \ldots \ldots . \ldots . . \ldots$

Citric acid

Potassium oxid

Sodium oxid ............. 0.070

Calcium oxid

Magnesium oxid

Iron oxid

Sulphur trioxid 0.001

Phosphoric pentoxid 0.027

Chlorin

with comparative ease. This is one of the reasons why buttermilk is more easily digested than ordinary milk.

The density of the clot which milk forms in the stomach depends, on the one hand, upon the amount of casein and lime salts which it contains, 
and, on the other hand, upon the degree of acidity of the gastric juice. The richer the milk is in casein and lime salts, and the more acid the gastric juice, the tougher is the clot. By reducing the proportion of these different factors, therefore, the clotting of the milk can either be prevented altogether or made to take place in such a way that the clot is not of great toughness and density.

Boiling Diluents to Prevent Clotting.-Boiling lessens the digestibility of the milk, causing the precipitate to be finer and in a more flocculent condition. The mere dilution of milk with water lessens the percentage proportion of lime salts and casein, making it more easily digested. The dilution must, however, be at least half and half if any great benefit is to be obtained from it. Lime water, as a diluent, is by far more efficacious than ordinary water. Burley water is a favorite diluent, and while it has in itself no greater power of preventing clotting than ordinary water, it seems to some extent, by its slight degree of viscidity, to prevent the clot from shrinking into such a hard mass.

ABSORPTION OF MILK.-Absorption of milk yields from 400 to 450 calories per pint according to its quality. The protein, fat and carbohydrate content is almost completely absorbed. Rubner in his observations on the absorption of milk arrived at the following conclusions: if four pints of milk be absorbed daily, the loss of dry substance amounts to only 5.7 to 7.8 per cent. If six pints be consumed, the loss amounts to 10.2 to 11.16 per cent. Wait (Bul. No. 35, U. S. Dept. Agriculture) found the absorption of milk to be more complete as a mixed food than when taken alone:

Milk Digested as Exclusive Food

Protein 92.1 per cent Carbohydrates
86.3 per cent
Milk Digested as Bread and Milk 97.1 per cent 98.7 per cent

The absorption of milk takes place after it leaves the stomach. Milk, like soup and a few other articles of diet, seems to produce a secretion of gastric juice independently of reflex nervous influences. It is, therefore, as sure to be digested if poured into the stomach through a tube, as if slowly swallowed in the ordinary way. As soon as it leaves the stomach and is poured into the duodenum, its digestion is completed by the pancreatic juice. This digestive ferment from the pancreatic gland is alkalin in reaction and acts very powerfully on milk, much more so than the acid gastric juice. The casein of milk is the best absorbed of all proteins, 
while the fat of milk enters the blood quite as readily as that of beef. It has been demonstrated that the fat of airated milk is absorbed more readily than that of milk which has not been so treated. It is an interesting and remarkable fact that milk is much better absorbed by young children than by adults. In the case of balies, the absorption is even more complete. The possible explanation for this may be a greater demand for the lime salts by the infant and a more complete absorption of the mineral constituents of the milk, which react favorably on the absorption of fat of the milk. Unabsorbed lime salts are apt to form insoluble soapy compounds with fat and so hinder its absorption. The comparative absorption of raw and boiled milk has been the subject of a good deal of experimental investigation. One observer found that dogs did not absorb the casein of boiled milk quite so well as that of raw milk, while the absorption of fat was the same in both cases.

Bollixg of MILK.-The bad effects of boiled milk have been strikingly indicated by an interesting observation made upon calves by Jensen, quoted by Czerny and Keller in Des Kindes Ernïhrung: "A feeding of boiled milk to calves as the first meal will, in most cases, call forth a severe, and, sometimes even, hemorrhagic diarrhea, which as a rule ends in death and presents the same picture both pathologically and bacteriologically as the typical acute dysentery of calves. This observation was first made at several farms where there had been no severe diarrheal troubles, until, with the introduction of tubercular testing, the custom arose of feeding the calves from birth on boiled milk. Between eighty and ninety per cent of the calves thus fed died."

Taking the whole of the evidence, the conclusion seems to be justified that just as boiling does not appreciably diminish the digestibility of milk in the human stomach, so it does not to any important extent interfere with its absorption in the intestine.

There is no question but that milk is absorbed in the intestine with far less expenditure of energy than any other food, and again, milk seems to exercise a restraining influence upon putrefactive processes in the intestine. There is reason to believe that much of the value of milk diet and "milk cures" is the diminished absorption of putrefactive products from the intestine.

PERFECT FOOD.-It is frequently alleged that milk is a perfect food. This claim can only he justified, according to Hutchison, in the case of any food when it fulfils the following conditions:

"(a) It must contain all the mutritive constituents required by the body: proteins, fats, carbohydrates, mineral matter and water. 
"(b) It must contain these in their proper relative proportions.

"(c) It must contain the total amount of nourishment required daily in a moderate compass.

"(d) The nutritive elements must be capable of easy absorption and yet leave a certain bulk of unabsorbed matter to act as intestinal ballast.

"(e) It must be obtainable at a moderate cost."

When compared by weight and cost with other articles of food, the food value of milk is found to be reasonable, yet when the ordinary portions usually served are considered, the high worth of milk is clearly shown.

The food value of one-half pint of milk equals approximately two. large eggs, a large serving of lean meat, or two moderate sized potatoes. It is commonly stated that one quart of milk is about equal in food value to any one of the following (Rosenau) :

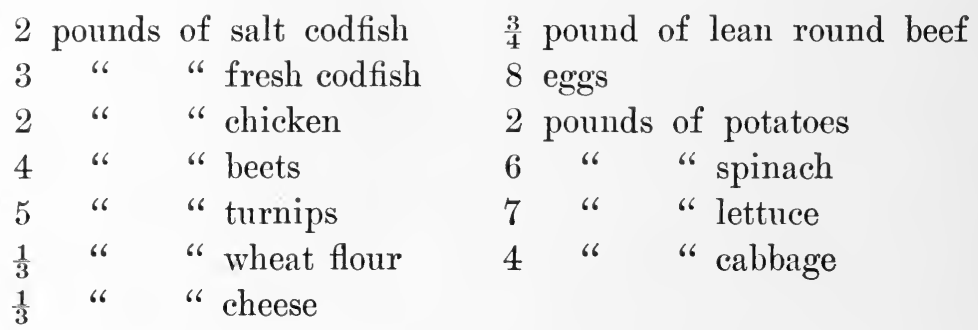

These comparisons are misleading in a way, for we cannot consider foods alone upon their total caloric value, since digestibility and assimilation as well as the chemical composition and fuel value must be carefully taken into consideration. The table on the following page gives instructive comparisons between the fuel value and cost of milk and a few other standard foods. ${ }^{1}$

Milk Not a Perfect Food.-The claim that milk is a perfect food has already been discussed, but we will again briefly refer to this point. There is no question but that milk contains all the nutritive constituents required by the body, but it is too rich in protein and fat, and too poor in carbohydrates, to be a perfect food. The requisite 3,000 calories of daily energy would require about 8 pints of milk, which would furnish 140 grams of protein when 125 is all that is necessary. Again, milk is too expensive to be a perfect food. Compare table above for actual cost of milk and other foods. Foods."

1 Rosenau's Table on “Comparative Analysis and Energy Value of Milk and Other 
COMPARISON OF FUEL, VALCE ANI) COST OF FOODS

\begin{tabular}{|c|c|c|c|c|c|c|c|c|}
\hline \multirow[b]{2}{*}{ Kinil of FoOd } & \multirow{2}{*}{$\begin{array}{l}\text { Price } \\
\text { per } \\
\text { pound }\end{array}$} & \multirow{2}{*}{$\begin{array}{c}\text { Cost } \\
\text { of } 1 \mathrm{lb} \text {. } \\
\text { Protein }\end{array}$} & \multirow{2}{*}{$\begin{array}{c}\text { C'ost } \\
\text { per } 100 \\
\text { Calories }\end{array}$} & \multicolumn{5}{|c|}{ Amount for 10 Cents } \\
\hline & & & & $\begin{array}{c}\text { Weight, } \\
\text { lbs. }\end{array}$ & $\begin{array}{c}\text { Protein, } \\
\text { lbs. }\end{array}$ & $\begin{array}{l}\text { Fat, } \\
\text { libs. }\end{array}$ & $\begin{array}{l}\text { Carbohy- } \\
\text { drates, } \\
\text { lbs. }\end{array}$ & $\begin{array}{c}\text { Energy } \\
\text { Calo- } \\
\text { ries }\end{array}$ \\
\hline Beef. & $\$ 0.25$ & $\$ 1.60$ & $\$ 0.25$ & .40 & .06 & $.06 j$ & & 410 \\
\hline Oysters. & .25 & 4.30 & 1.11 & .40 & .02 & & .01 & 90 \\
\hline Butter. . & .20 & 20.00 & .06 & .50 & .01 & .40 & $\ldots$ & 1,705 \\
\hline Eggs... & .24 & 2.09 & .39 & .42 & .05 & .04 & & 260 \\
\hline Milk. . & .035 & 1.09 & .11 & 2.85 & .09 & .11 & .14 & 8S.) \\
\hline Cheese. & .16 & .64 & $.0 \mathrm{~S}$ & .63 & .16 & .20 & .02 & $1,18.5$ \\
\hline Oatmeal. & .04 & .29 & .02 & 2.50 & .34 & .16 & 1.66 & 4,500 \\
\hline Wheat bread & .06 & .77 & .05 & 1.67 & .13 & .02 & .87 & 2,000 \\
\hline Beans, dry. & .05 & .29 & .03 & 2.00 & .35 & .03 & 1.16 & 3,040 \\
\hline Potatoes. & .015 & 1.00 & .05 & 6.67 & .10 & .01 & .93 & 1,970 \\
\hline Sugar... & .06 & $\ldots$ & .03 & 1.67 & $\ldots$ & ... & 1.67 & 2,920 \\
\hline
\end{tabular}

Advantages of Milk.-The tendency to regard milk as a beverage rather than as a food is to be deplored. This is a great mistake, in the correction of which the author camot do better than quote an extract from the valuable publication on Milk as a Food, issued by the U. S. Dept. of Agriculture, Washington, 1). C. The following extract states suceinctly the advantages which are obtained from the liberal use of milk as a food:

A very interesting experiment was reeently made at the University of Maine, in co-operation with this department, in which the effect of a limited and an unlimited amount of milk was tried at the University boarding-house or "commons." From these studies the following eonelusions were drawn: (a) The dietaries in which milk was more abundantly supplied were somewhat less costly than the others and at the same time were fully as acceptable; $(b)$ the inereased consumption of milk had the effeet of materially increasing the proportion of protein in the diet; $(c)$ the milk actually supplied the place of other food materials, and did not, as many suppose, simply furnish an additional amount of food without diminishing the quantity of other materials; $(d)$ the results indieate that milk should not be regarded as a luxury, but as an eeonomical artiele of diet which families of moderate income may freely purehase as a probable means of improving the character of the diet and of cheapening the cost of the supply of animal foods.

FLridity.-One advantage of milk as a food is that, being fluid, it is easily swallowed. This is of considerable importance in the case of weakened or debilitated patients. Again, the quantity administered can be very simply regulated and measured. Its liquid state also permits it to 
be used as a substitute for beverages. It can be used at meals instead of water, as a means of increasing the amount of nourishment. Milk is a valuable adjunct where a stuffing diet is prescribed.

Advantages in Disease.-The large amount of water contained in milk serves to quench thirst as well as, at the same time, to supply suitable nourishment to fever patients. On account of this same property milk may act as a diuretic, a function which is of great moment in the dietetic handling of certain forms of heart disease accompanied with dropsy.

The high percentage of water as one of the component parts of milk is no serious drawback to milk as a food in most cases of illness. A convalescent patient quietly at rest in a warm bed requires much less nourishment than an active man and will often gain weight on three or four pints of milk per day, notwithstanding the fact that twice this quantity is needed by a healthy adult.

As an article of diet in disease milk occupies an unique position. It can be safely said that no other article of food is of so much value, or can take its place. The use of milk in the dietetic treatment of various diseases will be considered at length in subsequent chapters.

ACCESSORY SUBSTANCES OR VITAMINES OF MILK.-Besides casein, albumin, protein, fat and other constituents, milk contains certain accessory substances too minute for analysis, yet quite necessary for nutrition and growth. Hopkins(12) reported the results of his feeding experiments, illustrating the necessity for certain accessory substances in normal dietaries, which he called vitamines. In the feeding experiments he put a number of young rats on a diet of casein, fat, carbohydrates and salts. To another group he allowed the same ration plus a minute quantity of fresh cows' milk. The amounts of food consumed by the two groups were practically identical. The first class of rats did not appear to thrive; the second class grew normally; so the small addition of fresh cows' milk made up a deficiency wanting in the diet of the first class. Just what is the nature of the substances in fresh milk, which so markedly affected the growth of the rats of the second class, is not yet known.

Boiling milk destroys its vitamines. The addition of peroxid of hydrogen as a preservative to milk also destroys its vitamines and deprives the milk of its antiscorbutic properties.

Importance of Vitamines.-If a nursing mother suffers from a deficiency disease like beri-beri, the child will also develop the disease because the mother's milk is deprived of its vitamines. Andrews(13) says: 
Half the mortality of Manila consists of intants under one year of age; and half the infants who die show some sign of beri-bori. As three-fourths of the infants are breast fod, there is an undeniable relationslip between the milk and the absence of growth, development and sound health. Manila infants fed by a healthy mother, or with fresh eow's' milk, do not develop beri-beri, but grow normally. 'This shows that the milk of healthy women contains vitamines; that of unhealthy women does not. Beri-beri is also cured by feeding the infants with fresh cows' milk or other substances which are proved to contain vitamines.

Osborne and Mendel(14) conducted experiments in feeding animals with isolated proteins and discovered their deficiency as a food material. 'They fed rats with this material: fat, sugar, stareh and salts. 'The fact that the animals failed to grow was evident that the food was deficient and they smpplemented a dict with a preparation of protein-free milk. This contained the milk sugar, salts and unknown components of milk. Rats which were under-nourished and had failed to grow on the former diet, at once resmmed their growth on this diet and in due time reproduced their kind. The rats which were under-nourished and showed marked symptoms of decline on the isolated proteins, revived so rapidly on protein-free milk that the improvement was little short of marvellous. It was concluded by the investigators that there are in milk traces of essential compounds which promote growth, and these compounds in milk are called vitamines.

Where Vitanines Are to be Found: Cuemical Nature.-Further observations are recorded by Osborne, Mendel, Ferry and Wakeman(15). They severally concluded that the vitamines of milk are to be found in the butter-fat fraction, but that at present their chemical nature is unknown. In the first place, in the experimental work of Osborne and Mendel, it was found that perfectly normal growth was obtained when any one of a large number of proteins was used alone with the protein-free milk. Among those that have given this result may be mentioned casein, edestin, excelsin, glutamin, lactalbumin, egg albumin, egg vitellin, globulins from cucumber and cotton seed, and corn glutelin. Not only did each of these proteins when fed alone with the protein-free milk give the normal curve of growth, but after completion of growth, the normal body weight was maintained throughout the normal period of life of the rat, which is approximately 1,000 days. Mlso reproduction and lactation took place in these animals in a perfectly normal manner. Certain proteins, however, when fed alone with the protein-free milk, failed to accomplish one or more of these results. The four most conspicuous examples of this class are the gliadin of wheat, the hordein of barley, the zein 
of corn and gelatin. The insufficiency of gelatin in meeting the nitrogenous demands of the diet is of course well known and led dietitians to create for it the special class of albuminoids, although physiological chemists have for several years recognized that, chemically, gelatin is a true protein and have so classified it in common with the other proteins of skeletal tissue.

Casimir Funk fed chickens on casein, fat, carbohydrate and salts. The fowls ceased to grow and developed polyneuritis, which he called the beri-beri of birds. After which clinical investigation he arrived at the conclusion that this disease in chickens was due to the absence of vitamines in the food. He demonstrated this by feeding a coop of chickens on ordinary food and they grew normally. He then fed a coop of chickens with polished rice; they ceased to grow and in time developed beri-beri and died quickly. He then fed another coop of chickens on unpolished rice; these birds also ceased to grow, but did not develop beriberi. Another coop of chickens were fed on unpolished rice and yeast. They grew slowly. His conclusions from these observations is that normal food contains a growth vitamine, but it is not the same as in the beriberi vitamine. For further information see Volume III, chapter on "Diet in Deficiency Diseases.".

CERTIFIED MILK.- Certified milk is the very best, the very freshest, the very cleanest, the very purest and the very safest raw milk that it is possible to produce. It is a product which has been drawn from tested cows, and handled and marketed in a most painstakingly careful manner-according to rules and regulations formulated by the proper authorities of the community where it is sold and as originally taught by the late Dr. Henry L. Coit, of Newark, N. J., the pioneer in producing certified milk and the prime organizer of the American Association of Medical Milk Commissions, through whose influence valuable legislation for pure milk has been promulgated in a few states, as New York, New Jersey, Ohio, Massachusetts and Kentucky. Certified milk, except in these states (certified, as originally used), means nothing, as it may be certified by interested parties. Certified milk should be of uniform composition and of the highest quality, obtained by cleanly methods, from healthy cows, under special sanitary precautions prescribed by a medical milk commission. The production of certified milk represents the highest ideals in milk dairying.

New York Menical Society Regulations.-The regulations of the milk commission of the Medical Society of the County of New York require that there shall be less than 30,000 organisms of all kinds per 
cubic centimeter in certified milk. It must average 4 per cent of butter fat and must be sold on the day it reaches the city. Certified milk is often found to contain only 8,000 hacteria to the cubic centimeter while an ordinary milk may contain as many as 50,000 or more(16). In Boston, New York, Philadelphia and other large centers of population the amount of certified milk sold is less thin one per cent of the total supply.

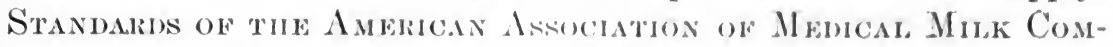
missions. - The "American Association of Medical Milk Commissions" has just published Methods and s'tundurds for the Distribution of C'ertified Milk:(17). "These standards represent, the highest quality of milk possible to produce. It is the ideal to which all milk production should aim. The rules laid down in this publication are given herewith, representing the highest ideals in dairy practice:

\section{REQUIREMENTS}

Gexeral Regr heneNTS

"( a) Certified milk shall be produced by a trustworthy dairyman in accordance with a code of requirements preseribed by a medical milk commission. The dairyman shall enter into a legal contract with the commission, in which he shall agree to comply with all its requirements.

" $(b)$ Certified milk shall be obtained from healthy, tubereulin tested cows under veterinary inspection; all persons who directly or indirectly come in contact with the milk shall he under medical supervision and the milk itself shall be subjected to periodical bacteriological, chemical and other tests.

" $(c)$ Certified milk should be free from harmful germs and shall contain relatively few of the common lacteria. It should not contain more than 10,000 bacteria per cubic centimeter; this average should be based upon bacteriological examinations covering a period of ninety days, and the counts should be made at least once a week during this time.

" $(d)$ Certified milk must be bottlerl at the point of production, rapidly chilled, kept cold and delivered promptly to the consumer. After it is once chilled, the temperature of certified milk should at no time go above $45^{\circ} \mathrm{F}$, or below $32^{\circ} \mathrm{F}$.

" $(e)$ Certified milk shall be normal milk; that is, neither heated, frozen nor altered in any way except strained and cooled.

" $(f)$ Certified milk shall he of miform quality and contain not less than 3.8 per cent, nor more than 4.2 per cent, of fat, unless it is labeled otherwise, in which case it shall not vary more than 0.2 per cent from the amount stated on the label. 
" $(g)$ Certified milk shall not be subjected to the action of heat; shall not be subjected to the action of any preservative whatever except cold; shall not be subjected to the action of light, electricity, pressure, or any special force or ageney of any kind for any purpose; no substance of any lind shall be added to the milk for any purpose; and no part of the milk shall be removed.

\section{Special Conditions}

"Pastures or paddocks to which cows have access shall be:

"(a) Free from marsh or stagnant pools.

“(b) Crossed by no stream which might easily become dangerously contaminated.

"(c) At sufficient distance from offensive conditions to suffer no bad effect from them.

"(d) Free from plants which affect the quality of the milk deleteriously."

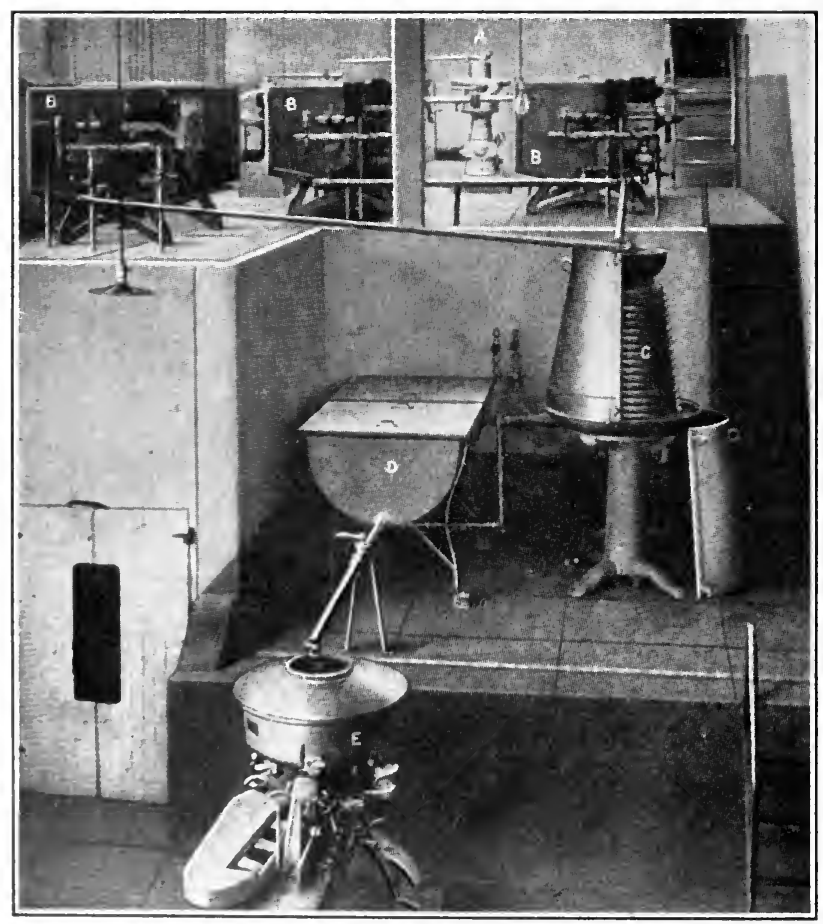

Fig. 20.-Interior of a Complete Milk Plant. The illustration shows (a) milk clarifier, (b) pasteurizing and milk holding tanks, (c) milk cooler, (d) storage tanks for cold milk, (e) bottle filling and capping machine.
PASTEURIZED Milk. - Pasteurized milk was first advised in 1886 by Soxhlet, who lauded the procedure, describing an apparatus for pasteurizing milk in the home. Pasteurized milk, at best, only means heated milk, and does not necessarily mean clean or good milk. On the other hand, it often means bad milk. Unfortunately the pasteurization of milk lulls one into a false feeling of security in regard to it as a food for infants. Pasteurization kills all pathogenic bac- 
teria and from 98 to 99 per cent of the other bacteria. After pasteurization there is less inhibition to bacterial growth than in raw milk. Pasteurized milk will not keep more than three or four days, for the acid-forming bacteria are still present, nor can a guarantee be given that the taste will not change.

Borlen Mrk. - The boiling of milk produces partial fixation of the calcium phosphate and the precipitation of mangesinm salts. This boiling also precipitates the citric alcid of milk to a tri-calcium-citrate and the soluble albumins are completely precipitated. The boiling is kept up for thirty minutes at a temperature of $140^{\circ}$ to $150^{\circ} \mathrm{F}$, which eliminates any danger, direct or indirect, from bacterial action.

There is another method for the preservation of milk which is of considerable interest. The milk is first heated to $150^{\circ} \mathrm{F}$. and then aërated with a mixtme of oxygen and carbonic gas. Then the milk is again twice heated to a temperature of $150^{\circ}$ F., each time for a.

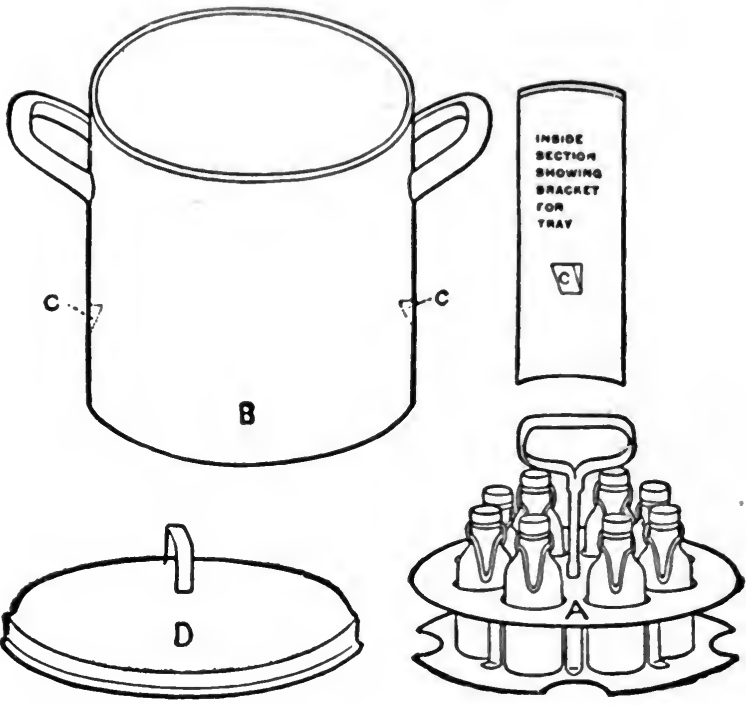

Fig. 21.-Strac's Home Pasteurizer. (Courtesy of the New York Health Department.) period of thirty minutes. Milk so treated keeps quite good for an indefinite period and shows no alteration in taste.

Home Pasteurization.-Milk may be satisfactorily pasteurized in the home by the use of a Freeman or Strans pasteurizer. This simplifies the procedure and at the same time secures perfect pasteurization of the milk. Imperfect pasteurization is worse than none, for the reason that it gives a false sense of security while the danger of further contamination of the milk remains.

The home pastemrizer devised by Mr. Nathan Strans is a modifieation of the Freeman pastemrizel and is shown in the accompanying illustration. Straus gives the following directions for using the lome pasteurizer : 
Emphasis is laid on the fact that only fresh, clean milk, which has been kept cold, should be used.

"Atter" the bottles have been thoroughly cleaned they are placed in the tray ( 1 ) and filled to the neck. The corks or patented stoppers are then put on without fastening them tightly.

"The pot (B) is now placed on the wooden surface of the table or floor and filled to the supports (C) with boiling water.

"Place the tray (A) with filled bottles into the pot (B) so that the bottom of the tray rests on the supports (C) and put cover (D) on quickly.

"After the bottles have been warmed up by the steam for five minutes, remove the cover quickly, turn the tray so that it drops into the water, replace the cover immediately. This manipulation is to be made as rapidly as possible to avoid loss of heat. Thus it remains for twenty-five minutes.

"Now take the tray out of the water and fasten the corks or stoppers airtight. Cool the bottles with cold water and ice as quickly as possible and keep them at this low temperature until cold.

"Use the milk from the bottles and do not pour it into another vessel.

"The milk must not be used for children later than twenty-four hours after pasteurization."

The attempt is frequently made to pasteurize milk in the home by simply placing the bottles of milk in a pot of water and boiling for a variable length of time and finally cooling. If the bottles were completely submerged in water, or if the bottle had a reasonably well fitting cover, the process might be fairly satisfactory in the hands of a competent nurse, but as usually done the necks of the bottles bob about above the surface of the water and the top layers of the milk escape the proper heating, more especially if the eontents of the bottles are not well shaken before eommencing, as the top layers of thick cream wonld prevent circulation in the liquid.

General Sumpary of Pasteurization.-Rosenan(18), after considering the sulject of pasteurization at great length, concludes as follows:

\section{Pasteurization means "parboiling."}

The heat kills the harmful germs, too often found in milk, such as produce tubereulosis, typhoid, diphtheria, searlet fever and the summer complaints of infants.

Pasteurization is not ideal, but at best only a temporary expedient; it is the simplest, cheapest and least objectionable method of rendering infected milk reasonably safe. 
It has only one object-to destroy germus. 'There can be no more objection to pastenrized milk for the use of adults and children over two years of age than there ean be to the broiling of a beefsteak.

Babies should have mother's milk, for which there is no adequate substitute. If mother's milk is not available they are entitled to the very best and freshest cow's milk obtainable. Whether such baby's milk is to be moditied, pasteurized or otherwise treatcold is a question for the attending phrsician to decide in each individual case. Pauteurized milk is just as digestible and just as nutritious as raw milk. The correct temperature to heat the milk is $140^{\circ} \mathrm{F}$. for 20 minutes. Higher heat or longer time is not newessary. Anything less is not effective, and gives a false sense of security. P'astenrization should never be used as a redemption process, nor as a preservative, nor to atone for filth, nor to make good milk out of bad milk. All that pasteurization of milk does is to destroy certain of the dangerous germs in milk.

All milk, that cannot be certified as clean, fresh and safe, should be pasteurized. Pasteurization should always be done under the supervision of the health officer. It is too important a measure to leave to the caprice of individuals. The bottle should bear a label with the time, temperature and date of pasteurization. Pure milk is always better than a puritied milk, but until the milk is safe, the only protection is through pasteurization which will prevent sickness and save lives.

STERILIZATION OF MILK.-Sterilization of milk consists in boiling the milk for from five to twenty minutes. This destroys all bacteria and their spores. At the same time, howerer, the power of the milk to inhibit their growth is destroyed and any contamination will be followed by a marked increase of the number of bacteria in a few hours. The bacteriology of milk has been the subject of an enormous amount of research during recent years, but space is too limited to deal with the subject extensively hers. (See Bulletin No. 25, L. S. Dept. of Agriculture.) We can safely assert that the aecusation, that milk is not an infrequent cause of disease, has been satisfactorily proven.

Milk as it comes from the udder of a perfectly clean cow may be safely regarded as a sterile fluid; not only is it sterile, it even seems to be possessed of feeble germicidal properties. These ideal conditions are impossible to maintain after the milk reaches the milk pail.

Process of Sterilizatiox.-There are so many eonditions favoring contamination that it is difficult to produce a milk without it literally swarming with bacteria. Ronghly speaking, the mieroörganisms met with in milk are: (a) those which produce souring: (b) the pathogenic bacteria. The former are probably harmless, the latter are bearers of disease. The disease germs are mne easily destroyed than those which produce souring. A temperature of $165^{\circ} \mathrm{F}$. for a few minutes is sufficient to destroy them. If the milk is to be preserved for a long time this 
is not sufficient and the temperature must be raised to $230^{\circ} \mathrm{F}$. and kept there for some time. This is the process of sterilization. The chemical (hanges produced by sterilization are very marked. Czerny and Keller enumerate them as follows:

(1) The milk sugar is caramelized under the formation of acid (lactic acid).

(2) The coagulated casein and albumin are brought by the acid to an early precipitable condition.

(3) The rennet action on milk is very much impaired through the fact that the calcium salts are in part rendered insoluble.

(4) The milk gases, especially carbonic acid, are expelled.

(5) The ferment action of the milk is destroyed.

(6) The fat in part separates from its emulsified state.

( 7 ) The lecithin is split up and the more organic phosphorous combinations of the milk are more or less changed into inorganic.

(8) Boiled milk undergoes putrefaction, raw milk does not.

(9) The taste of the milk is disagreeably changed.

(10) The antiseptic and antitoxic properties of the milk are lost.

(11) Hydrogen sulphid is recognizable if the milk is boiled longer than five minutes.

DESICCATED MILK.-Desiccated milk is easily made by the Just-Hatmaker process, which consists of passing a thin layer of ordinary milk be. tween two steam-heated cylinders revolving in opposite directions and having a surface temperature of $212^{\circ} \mathrm{F}$. This process dries the milk in about thirty minutes and completely desiccates the milk to a fine soluble powder which merely requires the addition of water to bring it back again to ordinary milk. The powder so prepared contains all the solids of the original milk in a sterile and soluble form, and consequently is of the highest nutritive value. (See Volume II, chapter "Dehydrated Foods.") There is every reason to predict that desiccated milk will be in great demand in the future.

Metions of Desiccating Milk.-Another method of making desiccated milk is as follows: The milk is placed in a tank heated by a water jacket; heated air is driven through the liquid until it is reduced to condensed milk. It is then transferred to a rolling drum and more hot air driven through it until it is of a semi-solid consistency. The mass is now reduced to small lumps and passed through a sieve to make it granular. The next step consists of reducing the granules to a fine powder.

Probably the best method of desiccating milk is a process of spraying the fresh milk into a warm vacuum chamber where the mist is almost immediately deprived of its water and the resulting powder falls to the floor of the oven. Just as in the Hatmaker process, the proper quantity 
of water added to this powder produces a mixture closely resembling ordinary milk. This last process yields a desincated milk which will keep in all climates and at the same time be complotely soluble in water.

Use of Desiccaten Muk.-Desicrated milk is an article of great utility, especially when fresh milk is unobtainable or when from some peculiar idiosprerasy sick persons are unable to retain fresh milk. It is extensively used as a food for infants and enters into the composition of varions proprietary foods.

Composition of Imicented Mak.-The following table from Tibbles, with additions, gives the composition of dried milk preparations with mutrient percentages:

CCMPOSITION OF CASEIN AND DRIED MILK PREPARATIONS, NUTRIENTS, PER CENT

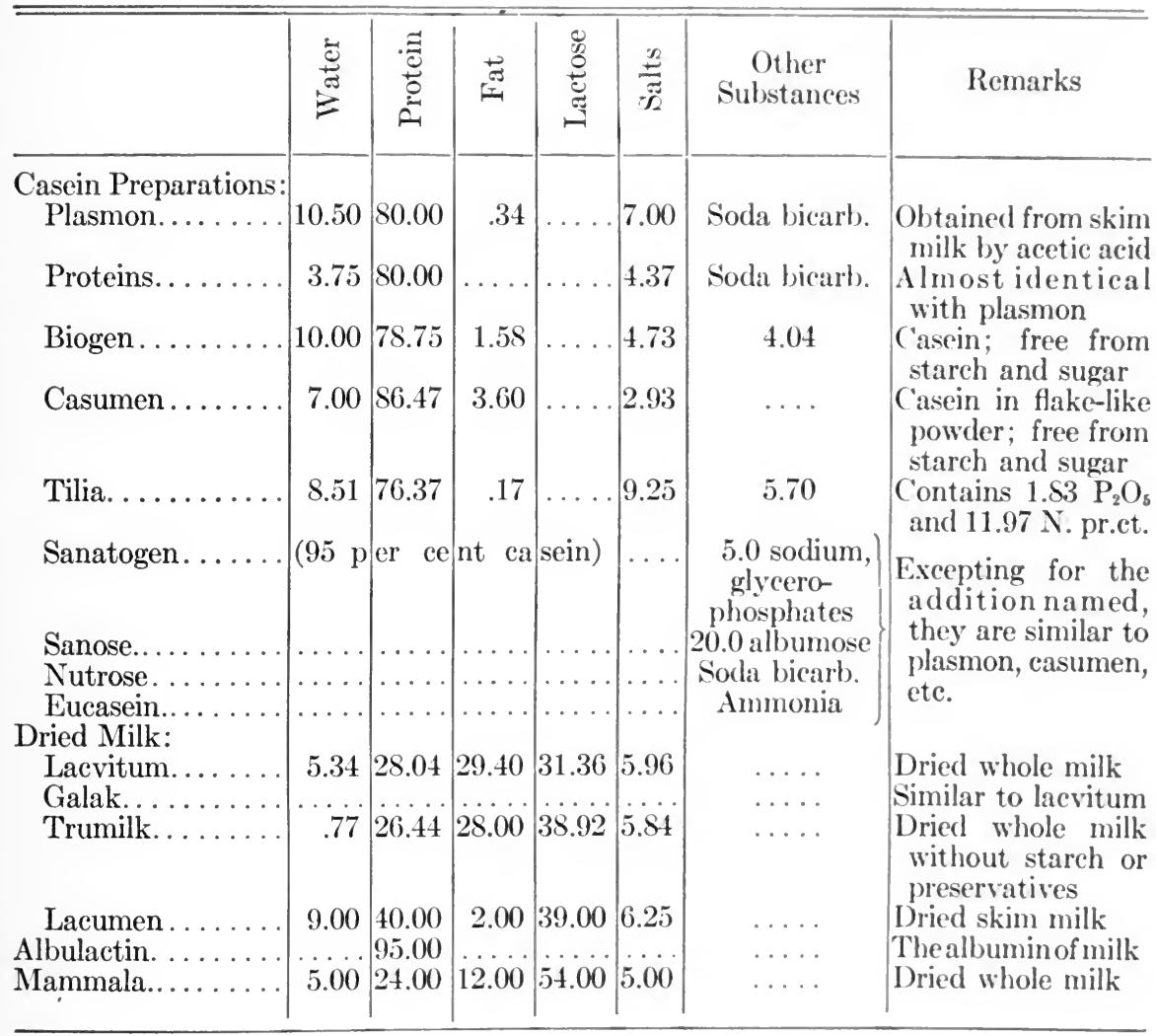

MODIFIED MILK-By careful examination of the comparative analyses given in König's table on page 309, it will he seen that human milk is not as rich in solids as cows' milk, and althongh it contains an equal 
amount of fat, there is more sugar and less protein. In human milk onehalf of the protein content consists of albumin, while in cows' milk only one-fifth of the protein consists of albumin.

Cows' milk is intended to develop the digestive tract of the calf for its future task of digesting tough and fibrous food, while human milk is intended to develop the digestive tract of the infant for its future work of digesting food of an entirely different physical character.

Cow's milk in the human stomach curdles into large, tough, leathery masses and is much harder to digest than the coagula of human milk. Furthermore, the fat globules are much smaller in human milk than in cows' milk.

Cows' milk contains more nitrogenous material, but less fat and much less sugar than woman's milk. Undue attention has been given to the organic constituents of milk and too little to the mineral contents. Cows' milk contains twice as much phosphorus as woman's milk. When eows' milk is substituted for woman's milk, chlorid of sodium should be added. The salts of calcium are present in greater proportions in cows' milk, but this difference can be safely neglected, as nature permits of a more generous variation in the feeding of infants than do laboratory tyrants. Woman's milk and cows' milk differ in specific gravity and reaction. There are, therefore, many points of difference between the two kinds of milk. In infant feeding especially an effort should be made to imitate human milk as much as possible by modifying cows' milk.

Ingredients Used in Modification.-The ingredients most commonly used to modify cows' milk are cream, containing 16 per cent of butter fat, skimmed milk (from the separator), milk sugar and starch, usually barley water. These should always be mixed according to the formula prescribed by a physician. The proportion of each ingredient depends upon the age and condition of the child. Since cream is usually rich in microörganisms, infants often thrive as well or better when cream is omitted from the modified formula. The aim to have uppermost in modifying milk is to bring the proteins and mineral constituents to the right proportion by dilution with water; to add lactose to increase the sugar and finally cream to increase the fat. ${ }^{1}$

VARIATION IN COMPOSITION OF MILK.-No other foodstuff except milk shows such a marked variation except meat. The greatest variation in the component parts of milk is shown in the butter fat. The proteins and sugars are more constant. The variation in composition of pure

1 Recent experiments on mice show that sucrose produces less disturhance than lactose. 
milk is due to many and varying factors. Certain breeds of cows as the Chamel Island breods produce a milk rich in fat. (5 per cent.) The Holstein breed furnishes a milk poor in butter fat. (3i per cent.) Young cows generally yield a richer milk than older ones. A well fed cow gives more and richer milk than a poorly fod animal. Again the quantity of milk is more readily infuenced by the amount and character of the food than are the relative proportions of fat, protein and milk sugar. The flow of milk is usually greatest soon after calving. As the period of lactation advances, the amomnt of milk uradually grows less, while the milk grows richer in solids. It is generilly (onsidered that cows which give a large quantity, yield milk poor in quality, but this is not always the case. It is possible to have a large yield and at the same time have milk of a superior quality.

Timbles' Table on time Composition of Various Milks.-The following table from Tibbles throws light on this point. The table shows a difference of 3 per cent in total solids, 2.15 per cent of fat between the highest and lowest. This table also shows the variation in the vield of milk, as well as the difference in the composition of various breeds of eows :

COMPOSITION OF MILK

\begin{tabular}{|c|c|c|c|c|c|c|c|c|c|c|}
\hline Breed of Cattle & 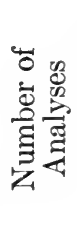 & 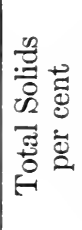 & 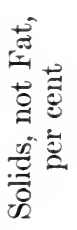 & 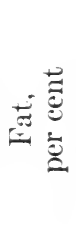 & 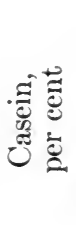 & 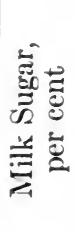 & 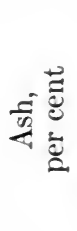 & 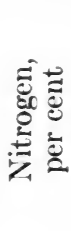 & 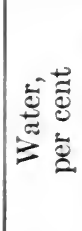 & 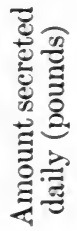 \\
\hline Jersey & 238 & 15.40 & 9.80 & 5.61 & 3.91 & 5.15 & .743 & $.61 \mathrm{~S}$ & 86.40 & 14.07 \\
\hline Guernsey. & 112 & 14.60 & 9.46 & 5.12 & 3.61 & 5.11 & .753 & .570 & 85.39 & 16.00 \\
\hline Devon. . & 72 & 13.77 & 9.60 & 4.15 & 3.76 & 5.07 & .760 & .595 & 86.36 & 12.65 \\
\hline Ayrshire & 252 & 13.06 & 9.35 & 3.57 & 3.43 & 5.33 & $.69 \mathrm{~s}$ & .543 & 86.95 & 18.40 \\
\hline ican Holdernes & 124 & 12.63 & $9.0 \mathrm{~s}$ & 3.55 & 3.39 & 5.01 & $.69 \mathrm{~S}$ & .535 & 87.37 & 13.40 \\
\hline Holstein Friesian. & 132 & 12.39 & 9.07 & 3.46 & 3.39 & 4.84 & .735 & .540 & $\$ 7.62$ & 22.65 \\
\hline
\end{tabular}

FRACTIONAL COMPOSITION OF MILK

\begin{tabular}{|c|c|c|c|c|c|c|c|c|c|c|}
\hline \multirow{2}{*}{. } & \multicolumn{6}{|c|}{ Stages of Milking } & \multirow{2}{*}{$\begin{array}{l}\text { First } \\
\text { Milk }\end{array}$} & \multirow{2}{*}{$\begin{array}{l}\text { Strip- } \\
\text { ping }\end{array}$} & \multirow{2}{*}{$\begin{array}{l}\text { First } \\
\text { quart }\end{array}$} & \multirow{2}{*}{$\begin{array}{l}\text { Last } \\
\text { quart }\end{array}$} \\
\hline & First & Second & Third & Fourth & Fifth & Sixth & & & & \\
\hline $\begin{array}{l}\text { Total solids. . . . } \\
\text { Fat. . . . . . . . } \\
\text { Solids, not fat.. }\end{array}$ & $\begin{array}{r}10.47 \\
1.70 \\
8.77\end{array}$ & $\begin{array}{r}10.77 \\
1.76 \\
8.99\end{array}$ & $\begin{array}{r}10.85 \\
2.10 \\
8.75\end{array}$ & $\begin{array}{r}11.23 \\
2.54 \\
5.69\end{array}$ & $\begin{array}{r}11.63 \\
3.14 \\
8.49\end{array}$ & $\begin{array}{r}12.67 \\
4.09 \\
8.59\end{array}$ & $\begin{array}{r}13.15 \\
1.32 \\
11.33\end{array}$ & $\begin{array}{r}28.81 \\
9.63 \\
19.18\end{array}$ & $\begin{array}{r}12.04 \\
1.22 \\
10.82\end{array}$ & $\begin{array}{r}25.72 \\
8.48 \\
17.24\end{array}$ \\
\hline
\end{tabular}


NUTRIENTS AND ENERGY IN THE MILK FOODS

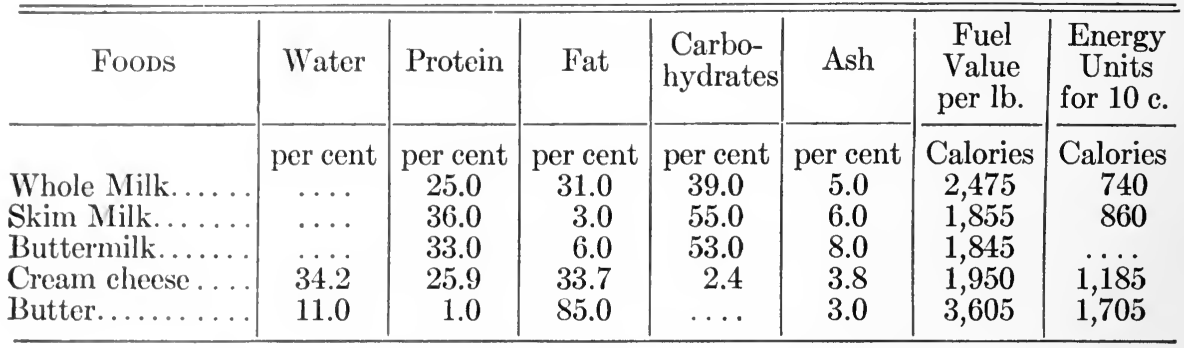

BACTERIAL CONTENT OF MILK.-Milk is rendered impure by adulteration with water, addition of materials to increase the specific gravity, preservatives, dirt and bacteria. The number of bacteria in a given sample of milk is evidence to a limited extent of the quality and purity of the milk. But the kind and quantity of bacteria present is of greater importance. Milk numbering 100,000 bacteria to the cubic centimeter is certainly not fit to use in nourishing an infant. A count below 10,000 is desirable.

Classes of Bacteria.-The bacteria of milk are divided into two classes, pathogenic and non-pathogenic. The former group includes such organisms as the tubercle bacillus, the typhoid bacillus and the diphtheria bacillus. Milk containing these organisms is a direct source of danger to the child or individual who drinks it, hence their presence is absolutely detrimental to health and should positively be prevented in all milk supplied to infants. Rosenau (Bul. No. 42, Hygienic Laboratory) has determined that a temperature of $140^{\circ} \mathrm{F}$., maintained for twenty minutes, will destroy these and other pathogenic bacteria. The pathogenic bacteria, the staphylococci, streptococci, do not appear to be a source of great danger in milk. Lactic acid bacilli, etc., are a source of danger, however, not because of their direct action upon the human organism but because of their decomposing action on the milk itself, which renders it unfit for use. Immediately after milking, the number of bacteria varies from none to $10,000,000$ in a cubic e.c. of milk. They begin to multiply as soon as the milk reaches the milk pail, and continue to do so with the most marvelous rapidity. Miguel found that milk brought to his laboratory had bacteria as follows:

Bacteria in Milk

Immediately after milking . . . . . 9, 9,000 per c.c.

One hour after milking......... 31,750 " "

Nine hours after milking........ 120,000 " "

Twenty-four hours after milking....5,600,000 “ " 
Percentage composition and fucl value of milk, milk products, and some other foods.

(The constltuents are expressed in per cent, the fuel values in calorfes per pound.)

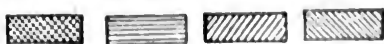

Protein. Fats. Carbo- Minnral hydrates. matters.

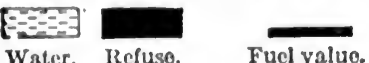

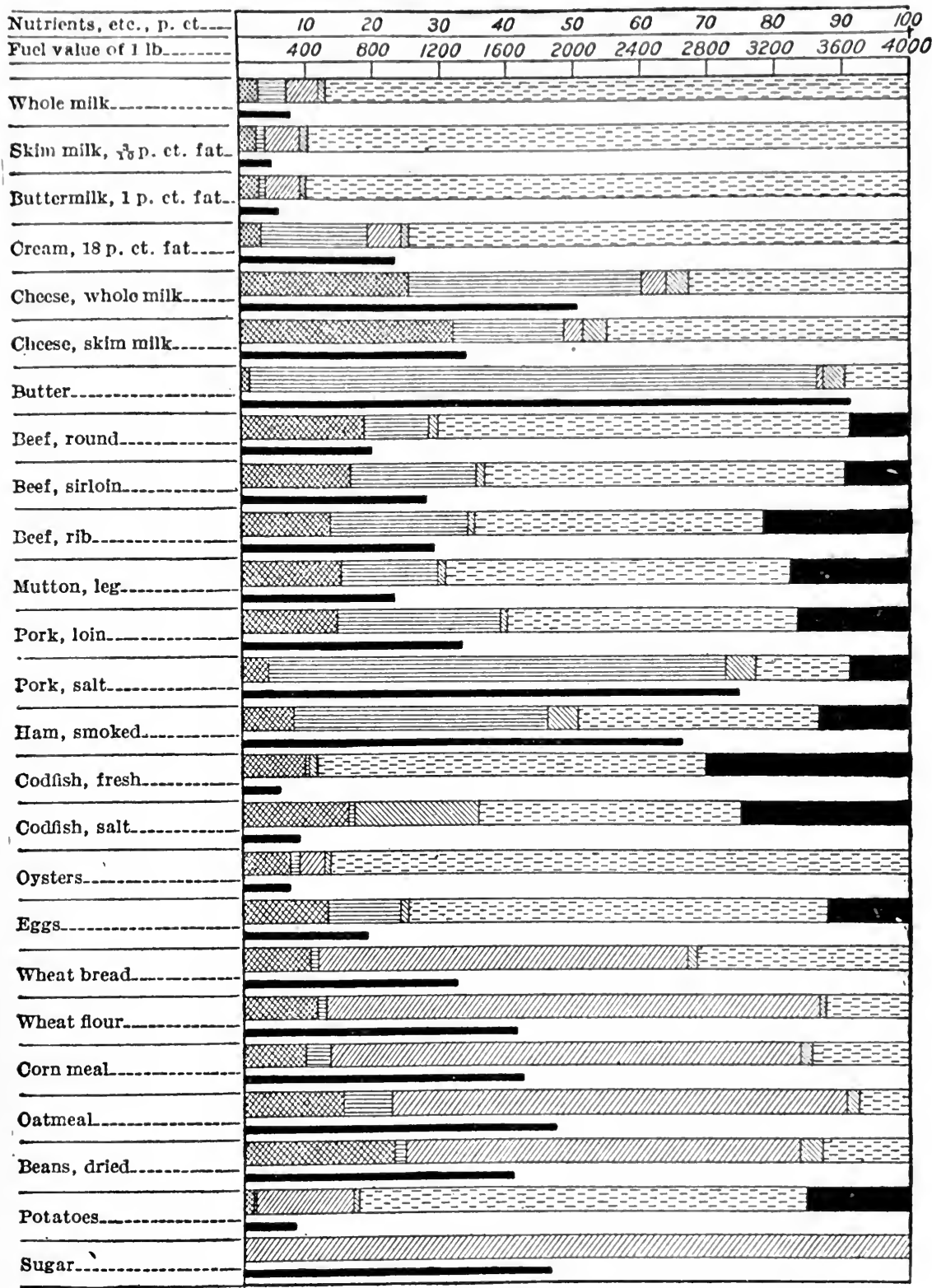

Fig. 22.-Percentage Composition of Foods. (Bull. 363, U. S. Dept. Agric.) 
Tibbles believes this to be a common experience and a moderate estimate of the bacteria in milk, for other observers have recorded 60,000 to 100,000 per c.c. immediately after milking and from 2,000,000 to 6,000 ,000 in six hours. The temperature at which the milk is kept influences the development of these bacteria considerably. Conff found that a sample of milk kept in a eold cupboard for four days had only 10,000 bacteria per e.e.; but a sample of the same milk left in a warm room for only one hour had 1,000,000 bacteria per c.c. The rate of inerease of the bacteria in milk kept at $12.5^{\circ}$ C. $\left(54.5^{\circ}\right.$ F.) and at $34^{\circ}$ C. $\left(93^{\circ}\right.$ F.) was estimated by Conff and is given in the following table:

\section{MULTIPLICATION OF BACTERIA IN MILK}

\begin{tabular}{|c|c|c|}
\hline Time since Milking & Tẹmperature $12.5^{\circ} \mathrm{C}$. & Temperature $34^{\circ} \mathrm{C}$. \\
\hline $\begin{array}{ll}1 & \text { hour } \\
2 & \text { hours } \\
3 & \text { " } \\
4 & \text { " } \\
5 & \text { " } \\
6 & \text { " }\end{array}$ & \begin{aligned} & \multicolumn{2}{c}{ nil } \\
& 4-fold \\
& 6 “" \\
& 8 “" \\
& 26 “، \\
& 435 “" \end{aligned} & $\begin{array}{rc}7.5 \text {-fold } \\
23 & \text { "، } \\
64 & \text { " } \\
215 & \text { " } \\
1,830 & \text { "، } \\
3,800 & \text { " }\end{array}$ \\
\hline
\end{tabular}

However, the actual number of bacteria in milk is of little importance, so long: as they are not pathogenic. Still some species of bacteria are of great value to the dairyman and are by no means injurious if consumed with the milk. This refers to the rapidly developing group of lactic acid bacteria and others which are of considerable importance in cheese and butter making.

Solrce of Milk Bacteria.-The source of bacteria is of interest as normal milk from a healthy cow is considered practically sterile. It is possible that small wounds, cracks or fissures on the teats may lead to bacterial invasion; also germs may invade the mouths of the teats, so that the first milk drawn is infected. It is possible also for later drawn milk to be infected by bacteria extending up the milk ducts, or invading the deeper portions of the gland even to the alveoli.

There are various other sources of bacteria, such as dust that may settle on the milk; again hairs from the cow's hide or bits of dirt or manure rich in bacteria may be flicked into the milk pail by the switching of the cow's tail. The hands of the milker and the milk utensils are fruitful sourees of bacteria. It has been shown that the bacteria increase with each handling of the milk, whether this be pouring the 
milk from one eontainer to another, straining, stirring, or any one of the routine measures common in the care of milk. 'The ordinary farmer does not know that the common fly earries with him an average population of from 5.50 to $155,000,000$ hacteria. $A$ fly dropping into the milk introduces into it not only objectionable parasites, but also quite possibly pathogenic organisms. It can be seen from the above outline how essential to localth is the most painstaking and intelligent care of milk.

MacConkey, who has made a detailed study of many samples of milk, has found in some of these abont thirty-six varieties of the Bacillus coli and Bacilhus enteriditis sporagenes. In others he discovered the Staphylococen pyogenes aureus and the Staphylococeus albus. The existence in the milk of the first two varieties alfords proof of the presence of either cow dung or human feces. As the Bacillus enteriditis does not multiply in milk, its presence is evidence of original pollution. In case of the presence of streptococei in milk, inflammation of the udder or teats is to be inferred. The drinking of milk so contaminated is not infrequently followed by an epidenic of sore throat.

CHANGES IN MILK.-The first change that takes place in milk after being strained and set aside is the separation of the fats as cream, which rises more readily if the milk is kept at a low temperature. The second ehange is souring, which is hastened by warmth and by storing in unclean vessels or filthy surroundings.

The Souring of MiLk.-Although the reaction of milk when freshly drawn is slightly alkalin (amphoteric), with a specific gravity of from 1.029 to 1.033 , the reaction soon changes, becoming more and more acid as the milk gets older, due to exposure to the air and to the transformas tion of the milk sugar $\left(\mathrm{C}_{12} \mathrm{H}_{22} \mathrm{O}_{11}\right)$ into lactic acid $\left(\mathrm{C}_{3} \mathrm{H}_{6} \mathrm{O}_{2}\right)$. In the course of time the development of lactic acid is so great that the milk will coagulate on boiling. The coagulation results in the formation of a solid mass of casein which slowly contracts so tightly as to force out a greenish yellow fluid, whey. Huppe was the first to describe the lactic acid bacillus. According to his teaching it develops rapidly and multiplies freely at a temperature between $50^{\circ}$ and $113^{\circ} \mathrm{F}$. The production of lactic acid from milk sugar is effected by quite a number of microorganisms, including bacilli, micrococci, streptococei and other bacteria.

Bitter MrLk.-Bitter milk is the result of the cow's feeding on such herbs as lupin, wormwood, turnips, cabbage, etc. A bitter taste, which develops in the milk some hours after it is drawn, is due to certain baeteria in the milk. When milk putrefies it is usually referred to as the 
alkaline fermentation of milk. Such milk has a bitter taste and a slimy curd. The principal cases of putrefaction in such milk are due to sporebearing bacilli belonging to the hay bacillus group.

Slimy or Ropy Mlikk.-The cause of so-called slimy or ropy milk is the presence of the Bacillus lactis viscose, which brings about fermentation. This very resistant organism is introduced into milk through the water supply. Once infected by this microbe, a dairy must have the most careful attention before the source of contamination can be banished. Experiments with ropy milk have shown in some instances the attaimment of such a degree of viscosity that a thread of the milk could be stretched to a length of ten feet. Although in Norway slimy milk is considered a delicacy, it is held in this country to be most undesirable.

Colonen Milk. - Various changes in the color of milk are not uncommon. Red milk may be due to blood. A reddish tint in milk may also result from feeding cows on plants containing much red pigment, such as madder root. Again a red color will also be produced by the Bacillus erythrogenus, which is without sanitary significance.

Milk Flavor.-Flavors in milk vary from time to time, due largely to the food the cow eats. Wild onions even in very small quantities markedly affect the flavor of the milk. This effect may last for some days. It is also well known that the flavor of milk is readily affected by turnips, garlic, mouldy hay, damaged ensilage and distillery waste. Cows are usually good botanists and rarely eat wild onions, garlic, etc., but they cannot always be relied upon, so far as food is concerned. Cows grazing in pastures where poisonous herbs and weeds grow are liable to feed upon these objectionable plants, the poisonous odors of which pass into the milk. Herds producing certified milk are not allowed to graze at large.

It is generally held that the milk from cows fed upon mouldy grain and damaged ensilage will cause gastro-enteric disorders in persons who partake of the milk. It is well known that mother's milk contains certain protective antibodies. Infants reared on mother's milk are supposed to have more resistance to certain diseases than infants raised on cow's milk.

PRODICTION OF CLEAN MILK.-The production of clean milk is a comparatively simple matter, but it requires painstaking care and constant supervision and is best undertaken by persons trained in dairying. The first consideration is a healthy cow which must be kept clean and fed upon good, wholesome, nutritious food. The entire herd should be semiannually tested for tuberculosis and no cow should be added to the herd 
which has not successfully passed the tuberculin test within the preceding three months. Long hair on the udder and surrounding parts should be removed. The cows should be well groomed an hour before milking. The udder and surrounding parts should be thoroughly washed with clean water and elean cloths just before milking. No employee suffering with a sore throat or any infections or contagious disease should be allowed about the stables or dairy building. 'The stables should be clean, light and airy. No dogs, hogs, fowls or other animals should be allowed about the cow barn. Nothing that would tend to stir up dust, such as sweeping, should be allowed. The water supply should be absolutely pure. The drainage of the cow barn floors should be perfect and the daily removal of waste should be "arefully attended to. The milkers should wear clean clothes and their hands should be scrupulously clean and kept dry while milking. The milk pails and other vessels should be scalded with boiling water before use. While engaged in handling milk no employee should use tobaceo or intoxicating liquors. They should also keep their hands away from the mouth and nose.

THE HANDLING AND CARE OF MILK.-In order to produce clean, wholesome milk, the main question is cleanliness of barns, of cows, of attendants, healthy cows and good, wholesome food. The question of handling is reduced to cleanliness of milk vessels and protection of the milk from contamination by dust and dirt and to keeping the milk cool. The milk should be immediately cooled after milking and kept cool until used. This can best be accomplished by using some of the modern milk coolers.

According to the Creamery Journal, the best method of preserving milk in hot weather is as follows:

When the milk is drawn from the cow, it should at once be cooled down by means of a circular capillary cooler in which there is cold water or brine. The best temperature to attain is $38^{\circ} \mathrm{F}$., obtained by means of the refrigerator or ice. The latter method is expensive and the treatment can only be done in a large dairy. When the proper temperature is reached the milk is ready for the road. Upon arrival in town it should be pasteurized by heating it to $140^{\circ} \mathrm{F}$. for twenty minutes and then promptly placed in hottles which have been washed and dried. The bottles should be closed by a stopper and cooled to $38^{\circ} \mathrm{F}$. by water or in a cold room before being sent out to the consumer.

TRANSPORTATION OF MILK.-At no time between the cooling of the milk and its delivery should its temperature be allowed to go much below the freezing point, $32^{\circ} \mathrm{F}$. The dispensing of milk from open cans in 
shops or wagons should not be allowed. The safest method of marketing milk is in bottles sealed from dust and contamination.

ADULTERATION OF MILK.-Adulteration of milk is accomplished in many ways, usually $(a)$ by adding water, $(b)$ by removing the cream without the addition of water, $(c)$ by adding preservatives. The adding of water was formerly detected by the use of the lactometer, an instrument for determining the specific gravity of milk. The instrument sinks to a definite point in pure milk of a specified temperature. However, the lactometer is not of much use if the cream has been removed. If the cream is removed it can be detected by the Babcock tester, a simple instrument; it is a centrifugal machine, containing a bottle with a long neck graduated to show percentages of fat. Machines of this type are in use at all dairies and milk factories.

The Use of Preservatives.-The use of preservatives is often resorted to, to prevent the souring of milk. Sodium bicarbonate (ordinary baking soda) was formerly used to neutralize the lactic acid; more recently boric acid, peroxid of hydrogen and formalin have been used as preservatives. The addition of any preservative to milk cannot be too strongly condemned. The practice is rightly forbidden in many cities and states. A food of such great importance, frequently the sole dependence for the nourishment of infants and invalids, should be kept free from adulteration.

\section{MILK PRODUCTS}

SKIM MILK.-Skim milk is that milk which remains after removal of the cream by hand or machine. It contains the proteins and carbohydrates of the milk and is an excellent food substance. In reality, it is whole milk deprived of its fat. It still contains the valuable proteins, a little fat, the milk sugar and most of the mineral salts. When the fat is removed by hand the milk is put aside to "set," for the cream to rise. During this period the milk undergoes changes, owing to the development of bacteria, which more or less impair its freshness. As a result, hand-skimmed milk is not so desirable and is usually fed to pigs and poultry.

However, with the improved centrifugal separators the fat can be removed immediately after it is drawn, leaving a skim milk-a food of no mean value, which can be used in cooking as a substitute for whole milk. Skim milk is of course not a suitable food for infants.

Composition of Skim Milk.-The amounts of fat in hand-skimmed 
milk and separator-skimmed milk are graphically given in the table below, from Tibbles:

COMPOSITION OF SKIM MILK, PERCENTAGES

\begin{tabular}{|c|c|c|}
\hline & Hand skimmed & Machine skimmed \\
\hline 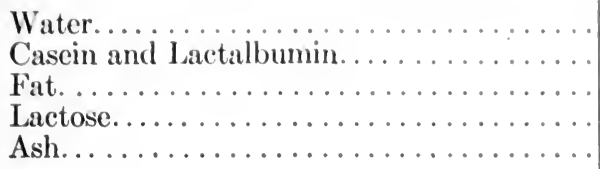 & $\begin{array}{r}89.73 \\
3.95 \\
.89 \\
4.62 \\
.81\end{array}$ & $\begin{array}{r}90.25 \\
4.02 \\
.25 \\
4.65 \\
.85\end{array}$ \\
\hline
\end{tabular}

CREAM.-When milk is allowed to stand in shallow pans for some hours in a cool place, at a temperature of about $60^{\circ} \mathrm{F}$., the fat globules and some little adhering substance rise to the surface and give us what in

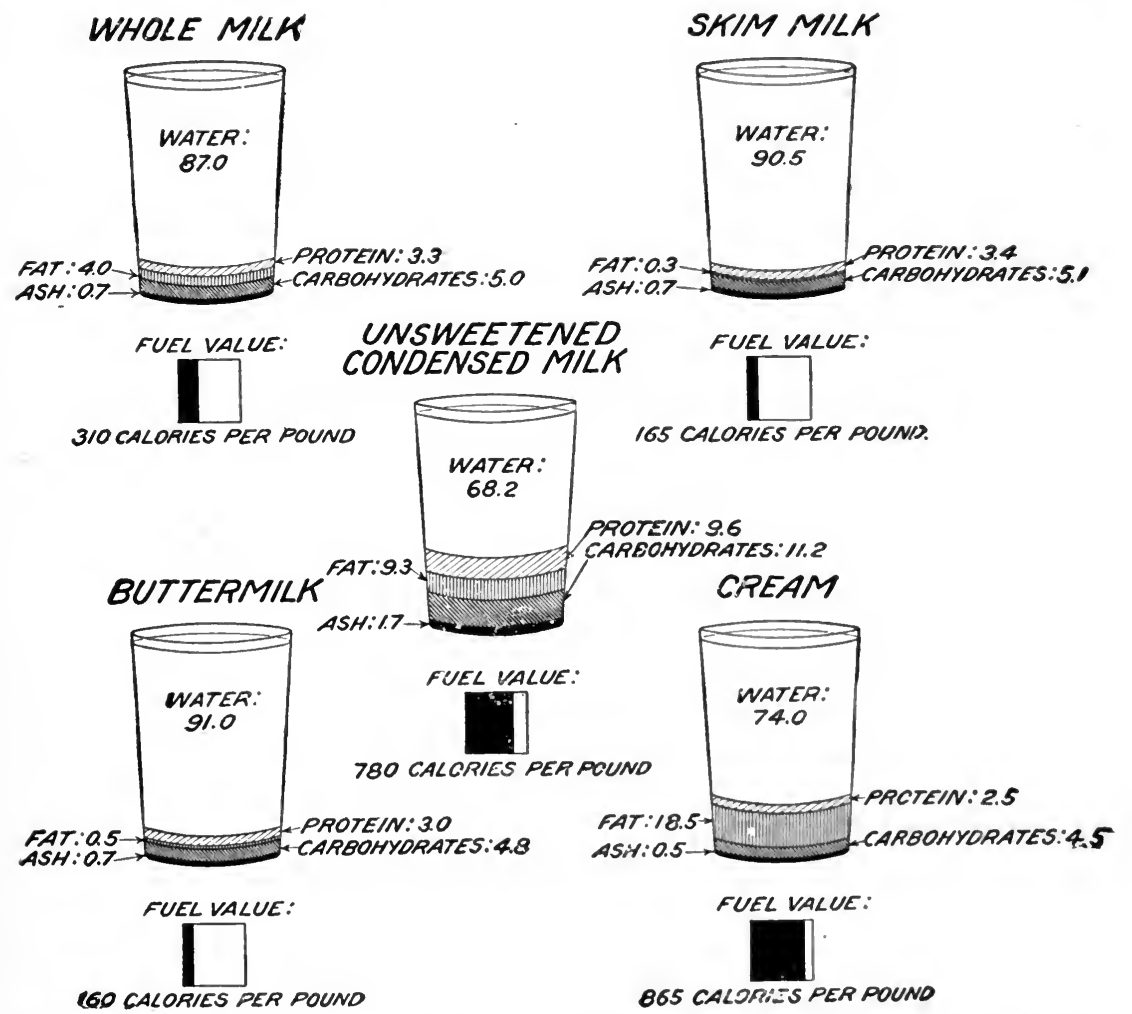

Fig. 23.-Percentage Conposition and Fuel Value Per Pound of Whole Milk axd Some MiLK Products. The constituents are expressed in per cent and the fuel values in calories per pound. (Bull. No. 363, U. S. Dept. Agric.) 
dairying is termed cream, which in reality is butter fat. This fat is in the form of an emulsion; that is, the small fat globules do not coalesce to make a clear, oily liquid, due to some special viscosity of the liquid. One reason for this is believed to be the fact that each fat droplet in milk is surrounded by an albuminous envelope. So long as this envelope is intact, the emulsion is secure; but as soon as this is broken by agitation, or softened and dissolved during the process of souring, the fat droplets readily rum together and destroy the emulsion. For this reason it is much easier to make butier from cream that is "ripe" or partly fermented.

Devorsmine Cream.-Devonshire cream is a cream product sometimes termed clotted cream and is very popular in Great Britain. It is made by allowing pans of milk to stand undisturbed in a cool place until cream rises and then scalding, care being taken not to disturb the cream on top of the milk. When this is properly done and the pans allowed to cool, the cream may be taken off in a thick, clotted condition ready for use. It has a peculiar, nutty flavor, which most persons relish.

Comparative Analysis of Mit.k and Milk Products.-The comparative analysis of milk and milk products is graphically expressed in the following table from Hall on "Nutrition and Dieteties":

\section{MILK AND MILK PRODUCTS}

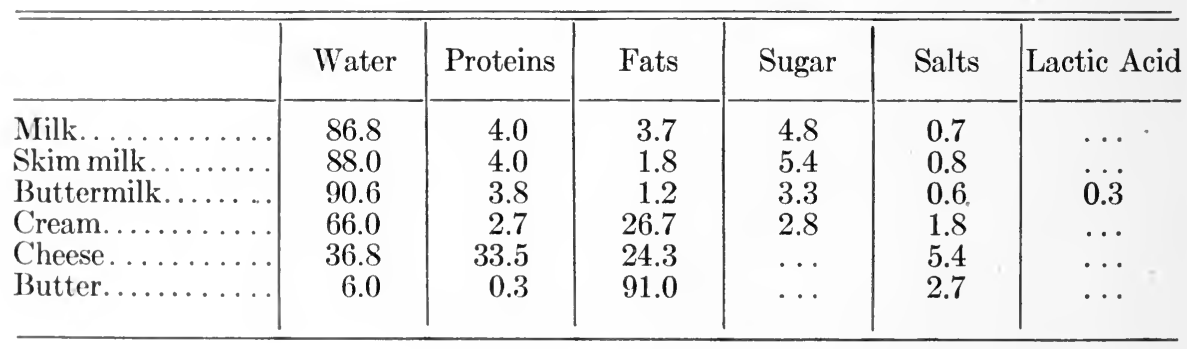

BUTTERMLL-_Buttermilk differs from whole milk and from skim milk. It contains very little fat. It is as rich in protein (casein) as milk, and since this is in a finely divided condition, buttermilk is quite readily digested. Buttermilk contains very nearly as much milk sugar as whole milk, as the loss due to lactic acid fermentation is very small. The presence of lactic acid in buttermilk makes it an excellent diet in the treatment of certain diseases. Buttermilk is often used as a beverage and has practically the same food value as skim milk. It is easily digested and very nutritious. An ordinary glass contains about as much 
nourishment as two onnces of bread, a good sized potato, or a half pint of oysters. To many individuals luttermilk is quite as palatable, or even more so, than whole or skim milk, but some find the sour taste uninviting. Its cascin forms a more flaky "urel than that of ordinary milk. Buttermilk is frequently fed to babies, especially in Holland, and is especially valuable when the protein of ordinary milk interferes with the digestive process.

Use of Butrermik.-The general use of buttermilk in this country is rapidly increasing, so much so that it is frequently made from whole milk by inoculating it with lactic acid bacilli. This is a pleasant, wholesome, nutritions drink much in vogue at the present time. It contains the casein of the milk in a finely coagulable form, has a pleasant acrid taste and contains lactic acid lavilli and the fat of the whole milk. It is nseful in feeding invalids, especially those suffering from certain forms of gastric and intestinal disorders.

Axalysis of Buttemink.-Ordinary buttermilk, aceording to Wiley, shows the following analysis:

\begin{tabular}{|c|c|c|}
\hline . & $\begin{array}{l}\text { From Sweet } \\
\text { Cream }\end{array}$ & $\begin{array}{l}\text { From Sour } \\
\text { Cream }\end{array}$ \\
\hline Water & 89.74 & 90.93 \\
\hline Fat. & 1.21 & 0.31 \\
\hline Milk Sugar ............ & 4.98 & 4.58 \\
\hline Protein $\ldots \ldots \ldots \ldots \ldots$ & 3.28 & 3.37 \\
\hline Ash $\ldots . \ldots$. & 0.79 & 0.81 \\
\hline Acidity $\ldots \ldots \ldots \ldots \ldots$ & $\ldots$ & 0.80 \\
\hline
\end{tabular}

WHEY.-Just as buttermilk represents the residue of milk from butter making, so whey represents what is left from cheese making. It consists mainly of water, milk sugar and mineral matters. Whey is decidedly less nutritious than skim milk or buttermilk, but is occasionally useful as a mild laxative drink for invalids. The so-called whey cure is a means of treatment sometimes resorted to in continental Europe in cases of dyrspepsia, especially when occurring in gourmands. Its range of usefulness is much the same as the grape cure. As in the grape cure, large allowance must be made for the favorable influence of the open air and exercise which form a part of the regimen.

Home-made Whey.- Whey may be made at home by cooking sweet milk with some acid material, such as vinegar, lemon juice, sour wine or 
cream of tartar, or even with sour milk. Such whey differs but little in composition from regular cheese whey. "Fresh curds and whey" is an old-fashioned dish still used to some extent, though less common than it was when cheese making was regularly carried on as a home industry.

According to Hutchison, whey has the following composition:

\begin{tabular}{|c|c|c|c|}
\hline Water & 93.64 & per & reen \\
\hline Protein . . & 0.82 & 6 & . \\
\hline Fat & 0.24 & "6 & \\
\hline Sugar & 4.65 & “ & \\
\hline Mineral Matter ... & 0.65 & 6 & \\
\hline
\end{tabular}

BONNYCLABBER.-Bonnyclabber is soured milk, in which the curd and whey are served in the same dish and usually eaten with the addition of sugar. Curds and whey and junket are milk, coagulated by the addition of remet. Sometimes the whey is removed and used as a food for invalids and children.

JUNKET. A favorite dish for invalids and for general use is prepared by adding remet to milk and allowing it to stand undisturbed until it thickens or coagulates - that is, until the casein is precipitated. If the process is carefully carried out, a thick, custard-like product results. If, however, it is stirred, the casein readily breaks up and separates from the whey. There are a number of preparations of rennet on the market designed especially for making junket, all of them giving satisfactory results.

KUMISS.-Kumiss is a milk preparation of considerable antiquity. Books written early in the thirteenth century hint of its existence almost as far back as the dawn of Christianity. Kumiss is made by fermenting mare's milk. The home of kumiss is in the steppes of European Russia and of central and southwestern Asia. It is made by tribes of nomadic Tartars from the milk of the hardy mares of the steppes. They add special yeast ferments to the milk, which liberate carbon dioxid, which gives to kumiss its sparkling or effervescent qualities. The flavor differs with the process of manufacture. This beverage contains from one to two per cent of alcohol and less than one per cent of lactic acid. The casein is somewhat modified during the process of fermentation.

KEPHIR - Kephir(19) is, as it were, a spurious kumiss and was first produced in the Cancasus Mountains from cow's milk, fermented with 
kephir grains ${ }^{1}$ which contain a special ferment. The mode of preparation is somewhat as follow's: Cow's or goat's milk is put into a container and coagulated with a picce of calf's or sheep's stomach. The container is agitated from time to time, more milk being added as the former coagnlates. In the process of time, yellowish bodies of a seed-like character and about the size of a small pea are formed in the mass. These small bodies are the result of the fungus-like kephir grains which were originally added to the milk and which are essential for the production of the beverage. When ready to make kephir one of these small grains is soaked in a small quantity of milk until it swells up or is "ripe." The ripened grain is then put into the milk, previously warmed, which is to be fermented. Lactic and alcoholic fermentation begins in a few hours and is allowed to proceed from one to three days. Kephir, as previously stated, is not kumiss. It may be regarded as bearing much the same relation to kumiss as margarin does to butter. Kephir contains nearly two per cent alcohol and probably has, for all practical purposes, the same nutritive qualities and value as kumiss, but it is not genuine kumiss.

Double Fermentation in Kumiss and Kephir.-A double fermentation takes place during the brewing of kumiss and kephir. The sugar of milk is partly converted into lactic acid by lactic fermentation. In part a vinous fermentation takes place similar to that which occurs in the making of wine.

The lactic fermentation begins first and lasts longer. It is the aim of the kumiss maker to retard the lactic fermentation as much as possible and to promote the vinous fermentation.

It has been found that mare's milk is a much better medium for this double fermentation than is the milk of the cow, and this is so, oddly enough, for the very reasons which make mare's milk a poorer food than cow's milk. Mare's milk contains less casein and fat than cow's milk, but has more sugar. The sugar of mare's milk lends itself more readily to lactic acid fermentation than the sugar of cow's milk does. That cow's milk is richer in fats is a disadvantage to the process of fermentation,

1 Kephir grains resemble little fragments of cauliflower. Their fermentative power appears to be entirely due to the saccharomyces mycoderma. In addition to this, they contain lactic acid producing organisms. The so-called bacterium dispora Caucasica, which they contain, does not appear to play any essential rôle in the process, unless. perhaps, it helps to liquefy the precipitated caseinogen. For a full account of the history of kephir and mode of preparation see "Le Kephir," by Padwyssotsky (Paris: C. Naud, 1902). This monograph contains a full bibliography. 
since there is apt to be produced from it small quantities of butyric acid, which is extremely irritating to the stomach.

Hutchison's description of the chemical changes taking place in milk during the process of double fermentation is worth consideration. Part of the sugar is changed by the lactic ferment into lactic acid. A very little of the protein is eaten up by the vinous ferment; and simultaneously this ferment acting on the sugar creates from the latter a small quantity of alcohol and a large quantity of carbonic acid gas. Through this process the milk sours and becomes efferrescent with a small alcoholic content. Moreover, the lactic acid precipitates the casein in flocculi just as in the ordinary souring of milk.

A most important factor in the process of making kumiss is the necessity of constant stirring. By this agency, oxygen is given access to the liquid, and in addition the precipitated casein is broken up by this agitation into very minute particles(20). To this condition of the casein is due in large part the ease with which this beverage can be digested. In the process of fermentation at. least a small proportion of the casein seems to be changed into soluble products by means of what may be termed spontaneous (21) digestion, for it is known that a little peptone exists in ordinary kephir.

The maker of kumiss is familiar with the gradual nature of the fermentation processes. Even after the liquid has been fermenting for twelve hours, the kumiss still lacks the agreeable twang; it is still weak and has just turned. But after the lapse of twenty-four hours, or even longer, nearly all of the sugar has been changed, and the appetizing kumiss, thin, sour, with lively effervescence, has been evolved. After reaching this stage, kumiss can be stored for indefinite periods and can be relied upon not to change to any appreciable extent.

YOGHOORT.-Yoghoort (or Janert lactic acid bacteria), which is found in the market as a material for making a milk beverage, consists of three hacteria, viz.: Bacillus bulgaricus, which produces lactic acid, a lactic acid streptococcus and Bacteria lactii acid guntheri. Skim milk is boiled or pasteurized, cooked and inoculated with these bacteria and allowed to stand for some time in a warm place to facilitate their growth. Later it is cooled and will keep for some time on ice.

Composition of Yoghorort.-The composition of yoghoort is:

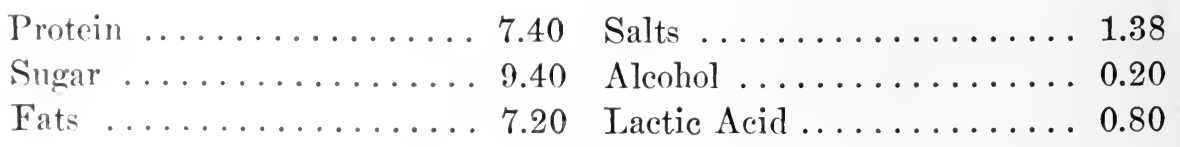


Yoghoort is rery digestible, inasmuch as the casein and albumin contained therein are rendered soluble as peptones and albumoses, and the lime salts are in solution to the extent of bis per cent.

It has been claimed by Metehnikoff that the great age attained by the Bulgarian peasants is due, in part, to the long and continued use of sour milk products.

MATZOON-Matzoon is another: sour milk product, introduced into this country from Armenia. This product is fermented by lactic acid fermentation and enriched by the addition of cream.

LEBEN OR YAOURT.-Leben or yaourt is the product of milk coagulated by moya, a special ferment. The following process is used: The desired quantity of eow's milk is boiled down to one-half its volume. After being cooled to $113^{\circ} \mathrm{F}$, the moya ferment is added. The container is kept at a miform temperature of about $6 \mathrm{~S}^{\circ} \mathrm{F}$. for from eight to ten hours. During this time it should be protected from draughts. At the end of this period the fluid is cooled and is then ready for use. In consistence it is thick and creamy, having masses of coagulated casein. It is agreeably acid to the taste and many people find it a most desirable food.

BUTTER.-Butter is an animal food of very great importance. It is the most easily digested and assimilated of all animal foods. The reason why it is so easily digested is because its melting point is low as compared with other animal fats. It is an exceedingly valuable food and a source of fuel value in debilitating diseases such as phthisis, diabetes, etc. The trophodynamic and trophotherapentic value of butter is fully considered in Volume I, Chapter XIV. The production of butter in the United States, according to Census in 1909 , was $1,994,650,610$ pounds, valued at $\$ 422,861,790$.

CHEESE.-Cheese is a very ancient form of food. In fact, its origin and mode of manufacture are lost in the mists of antiquity. Cheese as a foodstuff was used by the Israelites, Greeks and Romans thousands of years prior to the Christian era. Back and beyond these early days the stomach of various animals was, and in some countries still is, used as a container for the storage and transport of liquids. It is within the bounds of a possibility that the discovery of cheese was an accident arising out of the storage of milk in stomachs which were too fresh or were not properly freed of mucous membrane containing rennin. A small piece of vell or rennet (which is contained in the fourth stomach of the calf) about one and one-half inches in diameter is said to coagulate enough milk to make sixty pounds of cheese. 
The Making of Cheese.- - It will be unnecessary to repeat here all that has been said in the preceding pages concerning the action of rennin upon milk. Cheese making, however, depends upon the activity of rennin, chrmosin or labferment, as the enzyme is frequently called. A milk rich in fat requires more rennet than a poor milk. An excess of rennet
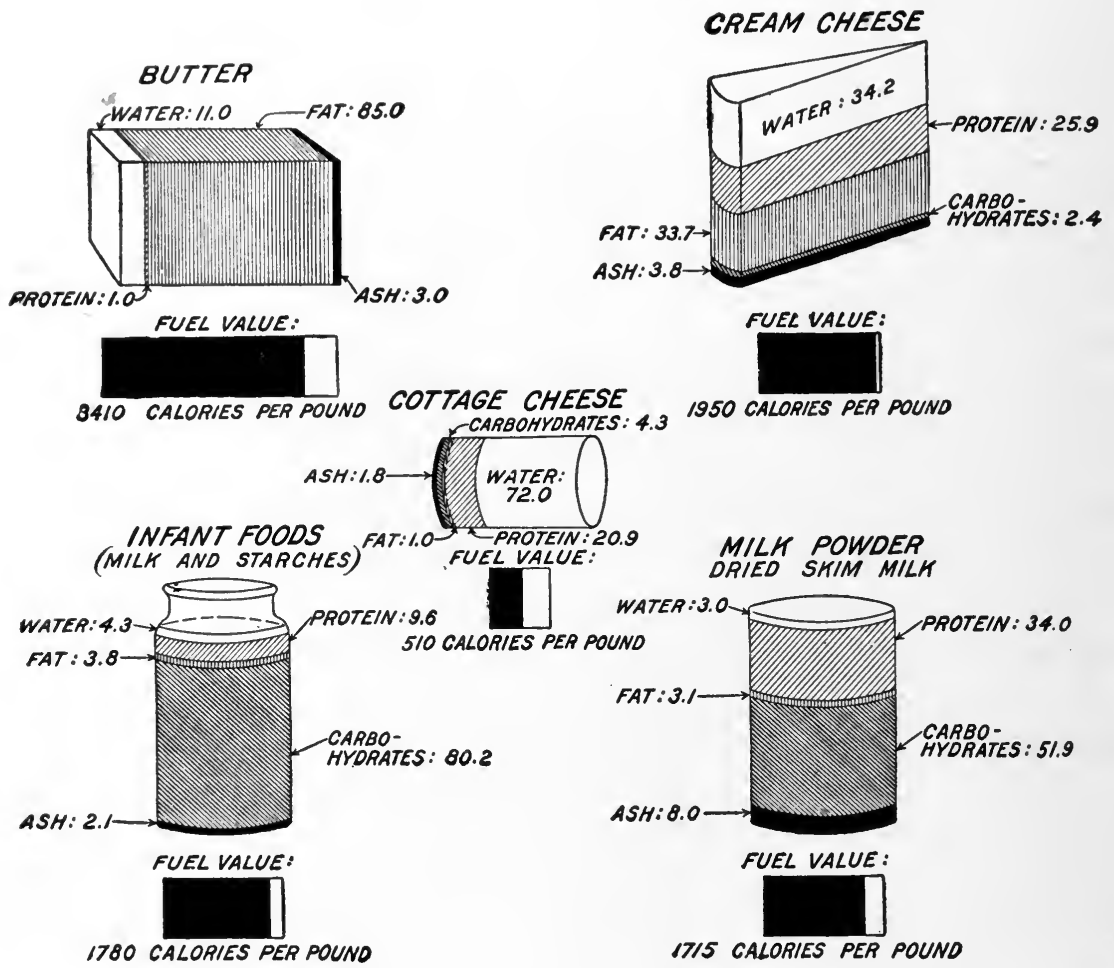

Fig. 24.-Percentage Composition and Fuel Value Per Pound of Butter, Cheese and Other Milk Products. The constituents are expressed in per cent, the fuel values in calories per pound. (Bull. No. 363, U. S. Dept. Agric.)

causes the curd to be less adhesive, tougher and drier, communicating an unpleasant flavor and delays the ripening of the cheese.

Cheese is manufactured through the precipitation by the rennet of the casein and cream of milk as a curd. It may be made from the milk of any animal, but fresh cow's milk is chiefly used.

The precipitate contains most of the casein and fat, besides some milk sugar, sodium chlorid, alkalin and earthy phosphates. The whey or liquid is strained off; the curd is pressed into shapers in moulds and the 
cheeses are frequently turned over at stated periods to facilitate the complete drainage of the whey so that the moistmre may be evenly distributed and gradually evalporated.

In the ordinary process of cheese making in the United States, the casein is coagnlated by the addition of remet to fresh cow's milk brought to a temperature of alout $1066^{\circ} \mathrm{F}$. 'The batch, while still warm, is beaten with a mechanical stirrer to break the chunks of the eurd into small pieces. It is then transferred to cloths often contained in monlds, and when pressure is applied the whey is squeced ont in a press.

When the cheese has become solid it is removed from the moulds, stored in well aired rooms and allowed to season while the flavor develops under the action of bacteria. During the process of ripening, the flavor is greatly improved and there is also an increased solubility of the proteins with the formation of aromatic compounds.

Milks must be ripened before the rennet will aet. This is brought about by an addition of a certain amount of lactic acid which later assists in the ripening of the cheese. Some cheese experts claim that the fat test is not a good basis upon which to purchase milk for cheese factories as the cheese-making value of milk depends largely upon the amount of casein; but it has been shown that milk which is high in fat is also, as a rule, high in casein.

Varieties of Chefses-Soft Chenses.-Cheeses are made soft or hard according to temperature and pressure used in their manufacture. Soft cheeses are made by precipitating the curd at a low temperature and using very slight pressure in the after treatment.

Good examples of soft cheese are:

English cream cheese, which contains 50 to 70 per cent of fat and 20 to 30 per cent casein.

Cottage cheese (pot cheese, green cheese) is the simplest form of cheese. It consists simply of a fresh coagulum of the milk, made with or without the addition of cream and forms a very nutritious and palatable food. Composition water, 40 per cent; protein, 25 per cent; fat, 28 per cent; sugar, 2.5 per cent; ash, 5 per cent.

Neufchâtel has about 41 per cent fat and 17.5 casein.

Camembert is a soft cheese of a buttery consistency covered with a reddish brown mould which is usually associated with excellence of flavor and texture. The composition of this variety of cheese is as follows: Water, 48 per cent: casein, 25 per cent : fat, 21 per cent, and miner:ıl matter, about 5 per cent. 
Brie is a French cheese, quite similar to Camembert in its consistency and composition. It has a strong odor suggestive of decomposition.

Limburger was first made in Belgium. Most of this variety sold in the United States is made in New York and Wisconsin. It has a very disagreeable putrefactive odor. It has the following composition: Casein, 25 per cent; fat, 34 per cent; water, 35 per cent; sugar, ash, etc., 5 per cent.

Hard Cunesses.-Hard cheeses are made by precipitating the casein at a high temperature, $106^{\circ} \mathrm{F}$, and subjecting the cheese to greater pressure in the after treatment. There are many varieties of hard cheese. A good sample is Stilton, made from new milk with cream added. This variety shows, upon analysis, casein, 20 to 35 per cent; fat, 42 to 45 per cent. It is similar to ripened Roquefort in food value and composition.

Cheddar is a hard cheese made from the entire milk. It contains casein, 27 per cent, and fat, 25 per cent. It was first made at Cheddar, England. The successive steps in making this cheese are: setting, cutting, heating, cheddaring, grinding, salting, pressing and curing. This cheese is ripened at a temperature of $70^{\circ} \mathrm{F}$., requiring from four to six weeks. When made from whole milk it is called full cream cheese. If part of the cream is removed it is termed Cheddar cheese. Our American factory cheese is of the English Cheddar type. American cheese made from whole milk contains casein, 20 to 36 per cent; fat, 20 to 35 per cent.

Gorgonzola is an excellent Italian cheese manufactured in the north of Italy. It has a rich, pungent flavor. It is streaked with white, bluish veins, from the mold penicillium glaucum, which penetrates the mass. Gorgonzola contains about 26 per cent of casein; the same amount of fat.

Roquefort is a peculiar hard cheese made from the milk of ewes and contains about 85 per cent casein and 2 to 3 per cent of fat. A great change takes place during the process of ripening, which occurs in cold cellars where it is kept for some eight to ten weeks-the fat percentage increases to 32 per cent and the casein diminishes to 43 per cent.

Fresh, Cooked and Skim-milk Cheeses.-The average fresh cheese contains about the same ratio of protein and fat as are found in milk. More than one-fourth is protein and one-third fat.

Comparative Food Value of Cheeses.-For the purpose of showing the comparative food value of different varieties of cheese, we give the table of analysis prepared by Pearmain, Chattoway and Moor: ${ }^{1}$

1 The Analyst, July, 1894, p. 146. 
THE COMPOSITION OF' CHEESL, PERCLNTAGES

\begin{tabular}{|c|c|c|c|c|c|c|c|}
\hline Name & Water & Nitrogen & Casein & Fat. & Ash & $\begin{array}{l}\text { Valenta } \\
\text { Test } \\
\text { C.C. in }\end{array}$ & $\begin{array}{l}\text { Reichert } \\
\text { C.C. }{ }^{N}\end{array}$ \\
\hline English Cheddar. & 333.5 & 4.20 & 26.7 & 30.5 & 4.1 & 31.0 & 26.4 \\
\hline Canadian Cheddar. & 33.3 & 4.34 & 27.6 & 30.6 & 3.6 & 41.5 & 24.0 \\
\hline American Cheddar. & 29.5 & 4.76 & 20.3 & 33.9 & 2.7 & 47.5 & 26.2 \\
\hline Gorgonzola. & 40.3 & 4.36 & 27.7 & 26.1 & 5.3 & 26.5 & 22.1 \\
\hline Corgonzola.. & $\{33.9$ & 4.06 & 25.8 & $26 i .7$ & 4.6 & 25.0 & 23.6 \\
\hline Duteh. & $\int 11.8$ & 5.11 & 32.5 & 10.6 & 6.3 & 40.0 & 27.0 \\
\hline & $\{37.6$ & 4.58 & 29.1 & 22.5 & 6.5 & 49.0 & 23.0 \\
\hline Gruyere. . & 28.2 & 4.93 & 31.3 & 28.6 & 4.7 & 37.5 & 30.0 \\
\hline & 35.7 & 4.49 & 28.7 & 31.8 & 3.7 & 41.0 & 31.1 \\
\hline Stilton.. & 19.4 & 4.73 & 21.1 & 42.2 & 2.6 & 38.5 & 29.0 \\
\hline & 21.2 & 4.14 & 36.3 & 4.5 .8 & 2.9 & 45.5 & 32.0 \\
\hline Cheshire. & 31.6 & $\begin{array}{l}4.03 \\
4.16\end{array}$ & 25.7 & 31.3 & 4.2 & 43.0 & 31.6 \\
\hline & 33.1 & $\begin{array}{l}4.16 \\
4.99\end{array}$ & 26.5 & $\begin{array}{l}35.3 \\
23.5\end{array}$ & $\begin{array}{l}4.4 \\
5.0\end{array}$ & $\begin{array}{l}47.0 \\
380\end{array}$ & $\begin{array}{l}31.8 \\
314\end{array}$ \\
\hline Double Gloucester. . & 37.4 & 4.50 & 28.3 & 28.1 & 4.6 & 41.0 & 32.3 \\
\hline & 47.9 & 3.43 & 21.8 & 41.9 & 4.7 & 32.0 & 31.0 \\
\hline Camembe & 43.4 & 3.83 & 24.4 & 22.6 & 3.8 & 33.0 & 35.0 \\
\hline Parmesan.......... & & & & & & & \\
\hline $\begin{array}{l}\text { Roquefort........... } \\
\text { Double Cream..... }\end{array}$ & $\begin{array}{l}29.6 \\
57.6\end{array}$ & $\begin{array}{l}4.45 \\
3.14\end{array}$ & $\begin{array}{l}28.3 \\
19.0\end{array}$ & $\begin{array}{l}30.3 \\
39.3\end{array}$ & $\begin{array}{l}6.8 \\
3.4\end{array}$ & $\begin{array}{l}19.0 \\
40.0\end{array}$ & $\begin{array}{l}36.8 \\
31.3\end{array}$ \\
\hline & 63.1 & 2.76 & 17.9 & 6.5 & 1.4 & 41.0 & 29.0 \\
\hline Bondon............ & 39.5 & 1.48 & 9.4 & 24.4 & .7 & 42.0 & 29.4 \\
\hline Cheddar, average. . . & 33.5 & 4.30 & 27.4 & 29.0 & 4.0 & $\ldots$ & 25.9 \\
\hline American, average. . & 27.5 & 4.60 & 29.7 & 30.4 & 4.5 & $\ldots$ & $\ldots$ \\
\hline
\end{tabular}

Cooked cheeses (Emmenthal or Gruyere, ordinarily known in this country as Swiss cheese, Parmesan) are excellent foods.

\begin{tabular}{|c|c|c|c|c|c|}
\hline & Albumin & Fats & Carbohydrates & Ash & Calories \\
\hline & 28.37 & $2 S .49$ & 1.43 & 3.69 & 400 \\
\hline ar & 39.34 & 18.97 & 1.95 & 4.72 & 357 \\
\hline
\end{tabular}

The percentage of albumin is exceptionally high, which makes these varieties the most nitrogenous foods known, meats and regetables being outdistanced. Fats are very abundant, for which reason the food value of the Emmenthal variety, being made of whole milk, exceeds that of the Parmesan.

Skim-milk cheeses are made from skimmed milk, or a mixture of whole and skimmed milk. There is no legal standard for such cheeses, although they contain less fat than cheese made from whole milk. The difference is not so great when partly skimmed milk is used. In Edam, Gloucester or Cheshire cheese the fat in a ripened cheese amounts to 25 or 30 per cent. Cheese made from machine skimmed milk may contain no more than 5 per cent fat. Such cheese is usually dry and tough or crumbly, instead of being soft, smooth and velvety to the feel. The table 
of analysis by Bell shows the proportion of contents of various substances not contained in the foregoing table, e.g., lactic acid, fatty acids and common salt :

COMPOSITION OF CHEESE, PERCENTAGES

\begin{tabular}{|c|c|c|c|c|c|c|c|c|c|c|}
\hline \multirow{2}{*}{ VARIETY } & \multirow{2}{*}{$\stackrel{\vec{\Phi}}{=}$} & \multirow{2}{*}{$\vec{\pi}$} & \multirow{2}{*}{ 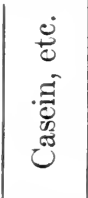 } & \multirow{2}{*}{ 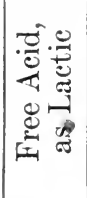 } & \multirow{2}{*}{$\frac{\overrightarrow{7}}{4}$} & \multirow{2}{*}{ 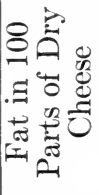 } & \multirow{2}{*}{ 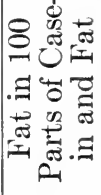 } & \multirow{2}{*}{ 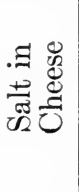 } & \multicolumn{2}{|c|}{$\begin{array}{l}\text { FATTY AcIDS } \\
\text { IN THE FAT }\end{array}$} \\
\hline & & & & & & & & & $\begin{array}{l}\text { Solu- } \\
\text { ble }\end{array}$ & $\begin{array}{l}\text { Insol- } \\
\text { uble }\end{array}$ \\
\hline Stilton. & 23.57 & 39.13 & 32.35 & 1.24 & 3.51 & 51 & 52.50 & .67 & 4.42 & 88.96 \\
\hline Ame & 28.63 & 38.24 & 29.64 & & 4.49 & 53.57 & 52.12 & .72 & 4.26 & 89.65 \\
\hline American Pale. & 31.55 & 35.93 & 28.83 & 0.27 & 3.42 & 52.49 & 53.34 & 0.82 & 4.81 & 88.49 \\
\hline Roquefort & 32.26 & 34.38 & 27.16 & 1.32 & 4.88 & 50.75 & 54.24 & 3.04 & 4.91 & 88.70 \\
\hline Gorgonzola & 31.85 & 34.34 & 27.88 & 1.35 & 4.58 & 20.39 & 53.09 & 2.11 & 4.40 & 89.18 \\
\hline Cheddar (medium) & 35.60 & 31.57 & 28.16 & .45 & 4.22 & 49.02 & 50.49 & 1.43 & 4.55 & 88.75 \\
\hline Gruyere..... & 33.66 & 30.69 & 30.67 & .27 & 4.71 & 46.26 & 47.07 & .81 & 4.41 & 88.97 \\
\hline Cheshire & 37.11 & 30.58 & 26.93 & .86 & 4.42 & 48.78 & 50.84 & 1.69 & 5.55 & 87.76 \\
\hline Gloucester & 35.75 & 28.35 & 31.10 & .31 & 4.49 & 44.12 & 45.24 & 1.28 & 6.68 & 86.89 \\
\hline Dutch. & 41.30 & 22.78 & 28.25 & .57 & 7.10 & 38.50 & 42.41 & 4.45 & 5.84 & 87.58 \\
\hline
\end{tabular}

Flavor of Cinessfis.-The flavoring of cheese depends largely upon the particular species of germ which has found access to it during the process of ripening, each particular variety producing definite chemical bodies which impart to it its peculiar characteristies. It is well known that by the employment of a variety of yeasts, an equal variety of wines can be made from the same kind of grapes. The bouquet and character of the resulting wines differ widely. Turning to account the principle analogous to that made use of by wine makers, the manufacturers of cheese will in future doubtless discard their old-fashioned rules. Hutchison writes that various European countries, including England, have already instituted the new régime.

This would best be carried on by means of a laboratory equipment for each factory. Then, instead of a special cheese coning from a certain locality, Brie, Neufchatel, Limburger, Gorgonzola and other varieties will all come from the same factory, the characteristic taste and odor of each variety depending upon the individual culture that produces them. It can be easily imagined that cheeses not now in the market may in the future be made by the elaboration of this method.

Gexerat Cinemistry of Cheese.-Whether Dr. Hutchison's forecast will ever be verified or not, there is little doubt that the gross chemistry of cheese will ever be much altered. After a careful study of the tables showing analyses and composition, we conclude that cheese is a food compound consisting essentially of protein and fat, and one will not be 
far wrong in estimating cheese as mo-third water, one-third fat and onethird nitrogenous matter. There is considerable mineral matter present in cheese, consisting principally of tho salts of lime. In some cheeses wo find a small anomut of milk sugars.

The nitrogenous matter consists prineipally of proteins, but by no means entirely so. Stutyer estimates the following different forms in which nitrogen ocenrs in ('amembert:

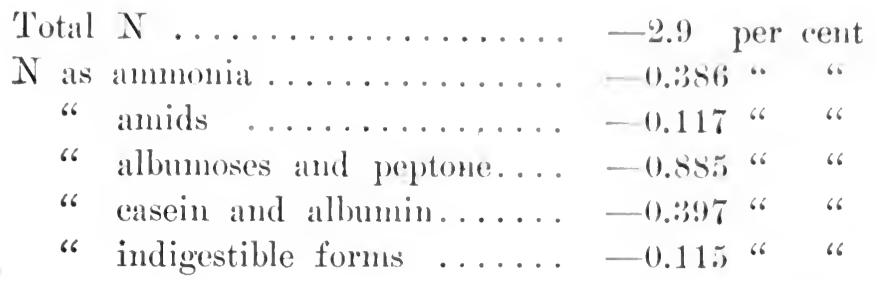

The exact proportions of these different nitrogenous bodies will vary considerably in different eheeses, but it is well to note the large amount of non-protein nitrogen present, which must be allowed for in an estimate of the mutritive value of cheese.

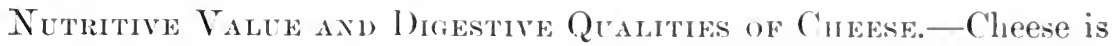
a most valuable storage food, rich in flesh-forming and energr-producing material. In fact, it is so rich in nitrogen and fat that a meal of bread and cheese supplies the needs of the system as well as an elaborate meal from soup to muts. Cheese is a highly mutritions foodstuff. An infiltration of cheese with the fat which it contains must always render it an article of diet not easily digested, for the fat forms a water-proof coating which prevents the contact of the digestive juices with the casein. There are many people with delieate stomachs who cannot digest cheese at all. It is, on the other hand, a most valuable diet for people who lead an active outdoor life, or those whose digestive organs are healthy. With others, especially those who lead sedentary lives, a small piece of cheese at the end of a meal acts as a stimulant to the digestive organs, calling forth the muscular activity of the stomach, stimulating an inereased flow of the gastric juice; to this extent it is an aid to digestion. To individuals who suffer from digestive disorders cheese is an enemy like any other indigestible article of food, and should be rigidly avoided.

Another reason, probably, for the disagreeable effects which cheese is apt to produce in the stomach is that, in the process of ripening, small quantities of fatty acids are produced, which are always very irritating. The stomach is the only digestive organ where difficulty is experieneed. Once in the intestine, it is absorbed as easily and completely as meat. 
For ease of digestion, cheese should be well chewed before being swallowed. It is a well-known fact that a hard morsel of food is more easily pulverized than a soft one, and for this reason a hard piece of cheese is more easily digested than a moist piece. The best way to serve Cheddar and American cheese is to cook it with macaroni or some carbohydrate food which will facilitate its proper mastication and prompt digestion. Williams, on the "Chemistry of Cookery," alludes to the chemistry of casein and the solubility of its compounds with alkalies, averring that the bicarbonate of potash seems to combine with the casein of the cheese, bringing the latter into a soluble state. The amount of bicarbonate of potash which will cover a dime is sufficient to dissolve a quarter of a pound of cheese, if the latter be first chopped into fragments. By adding milk and eggs to the grated or chopped cheese, with which the bicarbonate of potash has been added, a very savory and highly nutritious and easily digested pudding can be prepared.

There can be no doubt of the high nutritive value of cheese when one recalls that a pound of Cheddar cheese represents the total casein and most of the fat of a gallon of milk. We have already learned that cheese contains moisture one-third, nitrogenous matter one-third and fat onethird, in fairly equal proportions. The amount of moisture in lean beef is two-thirds, the balance being protein and fat, the former largely predominating. Beef, as will readily be seen, contains less than half as much nourishment as the same weight of cheese. Williams fathers the assertion that from a caloric point of view 20 pounds of cheese contains as much nutriment as a sheep's carcass of 60 pounds.

The fuel or caloric value of cheese as a foodstuff is high. A pound yields fully 2,000 calories of energy, which is more than three times the fucl value of a pound of moderately lean beef. Besides, a pound of cheese can be purchased at one-third the cost of three pounds of beef, which is its nutritive equivalent.

Use of Cheese in the Invalin Diet.-Cheese has its place even in the sick room. It renders good service in all cases requiring a strong concentrated nutriment, as in tuberculosis, neurasthenia, diabetes, convalescence, etc. By its savory, piquant flavor it lends itself charmingly as a means of modifying the milk diet in an acceptable and effective manner, except in Bright's disease and cardiac disturbances.

In dyspepsia, especially in the hyposthenic form, in enteritis and in enterocolitis, the easy assimilation of a certain quantity of the soft unsalted cheeses and their peptogenic and antiputrefactive elements is of decided value from a dietotherapeutic viewpoint. 
Subuection to Movids-Resulting Fiavor.-The types of cheese represented by the Cheshire, Canudian, American, English C'heddar, are subject to the action of certain yeast moulds and fungous growths, the nature and intensity of behavior of which vary with each particular brand. Their casein content is partially peptonized and partly transformed into a series of products more or less noxious, such as leucin, tyrosin, amino-acids and ammonia, whence they derive their odors and savory qualities that give each cheese its peculiar taste. Thus modified, cheese preserves the qualities of its peptogenic and assimilable substances, i.e., diastase, secreted by the yeast, seems to continue within the intestines, aiding the digestion of casein, and thereby losing completely its character of an antifermentative and slightly toxic food. Such cheeses are not advisable as a food in dyspepsia, enterocolitis, arthritis, heart and liver troubles and in Bright's disease.

Manufacture of Cineses in America.-Of the cheeses manufactured in the United States, at least three-fourths are the ordinary American cheese, while among other varieties are the types of foreign brands, such as Neufchâtel, Stilton, ete. New York and Wiseonsin together produce three-fourths of the entire output of this country. The 1909 census shows that not less than $320,532,000$ pounds of cheese is made yearly in the United States. In 1910 Canada exported 186,000,000 pounds.

\section{EGGS AND EGG PRODUCTS}

Varieties of Edible Eggs.-Eggs of birds are used for food in all parts of the world, and so far as is known, the eggs of every species of bird may be safely consumed for food. The eggs of domesticated birds are used for food to a very great extent, especially those of the barnyard fowls: chicken, guinea foul, ducks, turkeys and geese. Pheasants and guinea hens' eggs are considered a delicacy. Turkey eggs are as mild as hens' eggs. The guinea fowl's egg is smaller but more delicate than the hen's egg. Goose eggs are well flavored. Duck eggs are very rich and both are heavy and oily. The eggs of wild birds, such as the woodeock, plover and partridge, are especially sought after.

Besides the eggs of fowls and wild birds previously mentioned, the eggs of the turtle and terrapin are prized as a food as well as the eggs of fish. Shad roe, especially, and the eggs of the sturgeon, preserved in salt and known as cariare, are considered a delicaey in some countries (see page 303). As may be assumed, the eggs of the heron and other sea fowl have a fishy taste. 

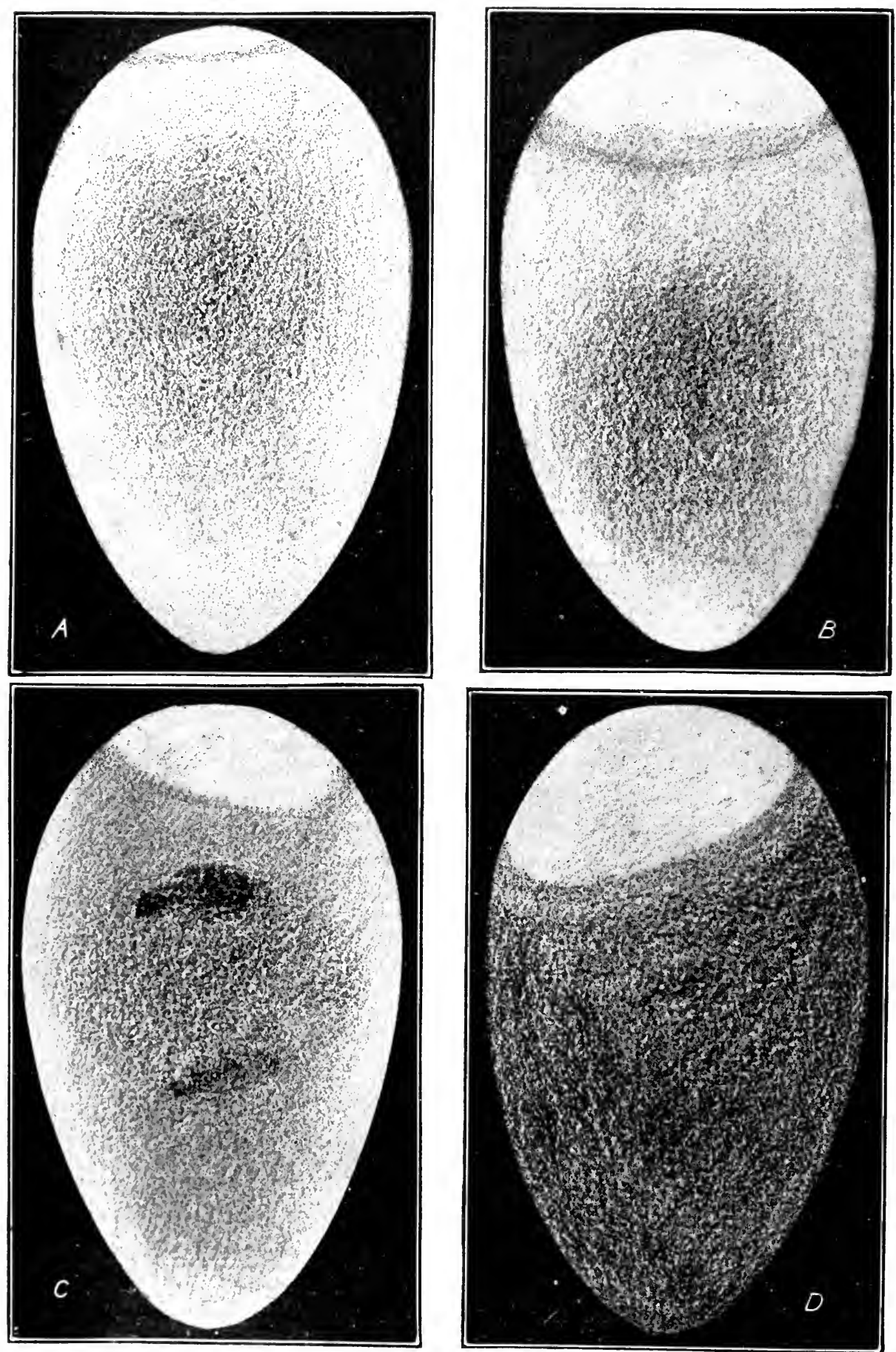

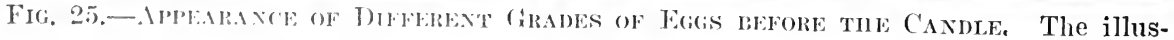

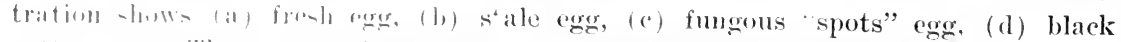

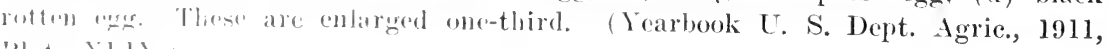
I'late stol 
Eggrs, like milk, form a complete food, that is, they contain the proper proportion of each of the fundamental food elements necessary to sustain and preserve life. Liggrs and milk are the only examples of a complete food furnished by the animal kinglom.

COMPOSITION OF EGGS.-Hens' egres are more largely consumed than those of other barnyard fowls and for this reason they will be referred to as the "type" under discussion. A hen's egg of average size weighs about two ounces, the weight being distributed as follows: the shell 11 parts, the white 58 parts, and the yolk 30 parts. The following table taken from Langworthy $(22)$ shows the composition of the eggs of various fowls, both eooked and raw, and of white- and brown-shelled eggs, etc.

AVERAGE COMPOSITION OF EGGS

\begin{tabular}{|c|c|c|c|c|c|c|c|c|}
\hline & \multirow[b]{2}{*}{ Refuse } & \multirow[b]{2}{*}{ Water } & \multirow[b]{2}{*}{$\begin{array}{l}\text { Pro- } \\
\text { tein }\end{array}$} & \multirow[b]{2}{*}{ Fat } & \multirow[b]{2}{*}{$\begin{array}{l}\text { Car- } \\
\text { bohy- } \\
\text { drates }\end{array}$} & \multirow[b]{2}{*}{ Ash } & \multicolumn{2}{|c|}{ Fuel Value } \\
\hline & & & & & & & $\begin{array}{l}\text { Calo- } \\
\text { ries } \\
\text { per } \\
\text { pound }\end{array}$ & $\begin{array}{c}\text { Calo- } \\
\text { ries } \\
\text { per } 100 \\
\text { grams }\end{array}$ \\
\hline Hen: & Per ct. & Per ct. & Per ct. & Per ct. & Per et. & Per ct. & & \\
\hline Whole egg as purchased. & 11.2 & 65.5 & 11.9 & 9.30 & $\ldots$ & 0.9 & 635 & 141 \\
\hline Whole egg, edible portion & $\ldots$ & 73.7 & 13.4 & 10.50 & $\ldots$. & 1.0 & 720 & 160 \\
\hline White.............. & $\ldots$ & 86.2 & 12.3 & 0.20 & $\ldots$. & 0.6 & 250 & 55 \\
\hline Yolk............... . . & $\ldots$ & 49.5 & 15.7 & 33.30 & $\ldots$ & 1.1 & 1750 & 378 \\
\hline portion .............. & . & 73.3 & 13.2 & 12.00 & $\ldots$ & 0.8 & 765 & 170 \\
\hline $\begin{array}{c}\text { White-shelled eggs as } \\
\text { purchased............ }\end{array}$ & 10.7 & 65.6 & 11.8 & 10.80 & .. & 0.6 & 675 & 150 \\
\hline $\begin{array}{l}\text { Brown-shelled eggs as } \\
\text { purchased........... } \\
\text { Duck: }\end{array}$ & 10.9 & 64.8 & 11.9 & 11.20 & & 0.7 & 695 & 154 \\
\hline Whole egg as purchased. & 13.7 & 60.8 & 12.1 & 12.50 & . & 0.8 & 750 & 166 \\
\hline Whole egg, edible portion & $\ldots$ & 70.5 & 13.3 & 14.50 & & 1.0 & 860 & 191 \\
\hline 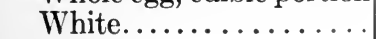 & $\ldots$ & 87.0 & 11.1 & 0.03 & & 0.8 & 210 & 46 \\
\hline Yolk...... & & 45.8 & 16.8 & 36.20 & $\ldots$ & 1.2 & 1840 & 408 \\
\hline Goose: & & & & & & & & \\
\hline Whole egg as purchased. & 14.2 & 57.7 & 12.9 & 12.30 & . & 0.9 & 760 & 164 \\
\hline Whole egg, edible portion & $\ldots$ & 69.5 & 13.8 & 14.40 & . & 1.0 & $\delta 65$ & 142 \\
\hline 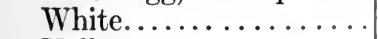 & $\ldots$ & 86.3 & 11.6 & 0.02 & $\ldots$ & 0.8 & 215 & 47 \\
\hline Yolk......... & $\ldots$ & 44.1 & 17.3 & 36.20 & $\ldots$ & 1.3 & 1850 & 411 \\
\hline Turkey: & & & & & & & & \\
\hline Whole egg as purchased. & 13.8 & 63.5 & 12.2 & 9.70 & $\ldots$ & 0.8 & 635 & 141 \\
\hline Whole egg, edible portion & $\ldots$ & 73.7 & 13.4 & 11.20 & $\ldots$ & 0.9 & 720 & 160 \\
\hline White................. & ... & 86.3 & 11.5 & $\begin{array}{r}0.03 \\
3200\end{array}$ & $\cdots$ & 0.8 & 215 & $\begin{array}{r}47 \\
380\end{array}$ \\
\hline $\begin{array}{l}\text { Yolk....... } \\
\text { Guinea Fowl: }\end{array}$ & & 48.3 & 17.4 & 32.90 & & 1.2 & 1610 & 380 \\
\hline Whole egg as purchased. & 16.9 & 60.5 & 11.9 & 9.90 & $\ldots$ & 0.8 & 640 & 142 \\
\hline Whole egg, edible portion & $\ldots$ & 72.8 & 13.5 & 12.00 & $\cdots$ & 0.9 & 755 & 167 \\
\hline White............. & $\ldots$ & 86.6 & 11.6 & 0.03 & $\ldots$ & 0.8 & 215 & 47 \\
\hline Yolk...... & $\cdots$ & 49.7 & 16.7 & 31.80 & $\ldots$ & 1.2 & 1655 & 367 \\
\hline
\end{tabular}


Winte of EGG.-A study of the above table will show that the egg consists mainly of protein and fat, besides water and some mineral matter. The white of the egg consists of a solution of protein shut up in the interior of millions of cells. When the whites of eggs are beaten up, the walls of these cells are destroyed and the protein escapes. The digestibility of the egg white is increased thereby, in proportion as these cell walls are destroyed, since they offer a slight hindrance to the digestibility of the protein which they envelop. The protein of egg white is called egg albumin, but it would be an error to consider it a single substance, since it is a mixture of different proteins, some of which are compounds containing a carbohydrate group in their molecules(23). This has some

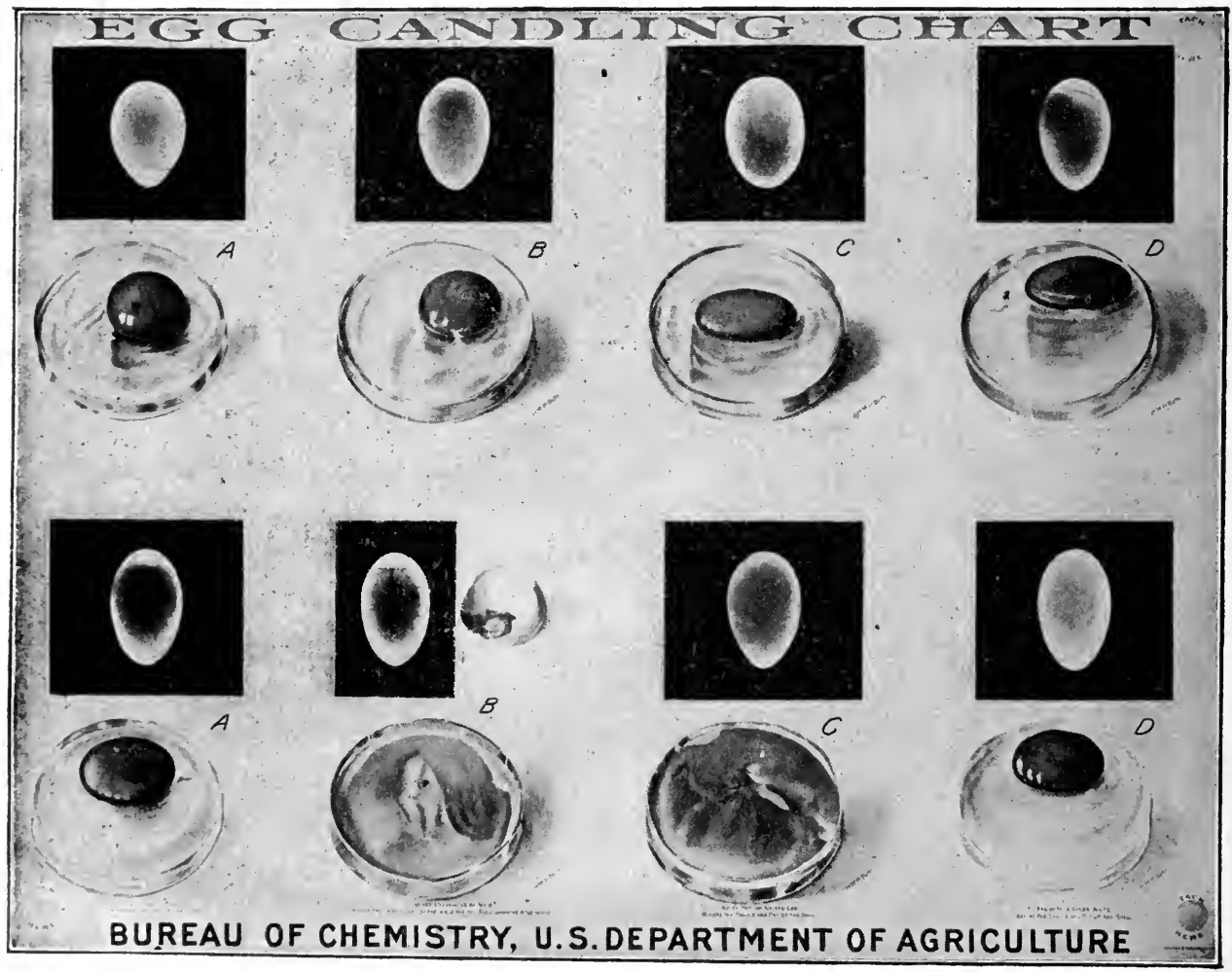

Fig. 26.-Wiint tire Candle Sirows.-Upper-(a) fresh egg, before the candle and out of the shell; (b) slightly stale egg, showing evidence of incubation, before the candle and out of the shell; (c) stale egg, showing a settled, flattened yolk and a thin white, before the candle and out of the shell; (d) egg with yolk beginning to alliere to shell, before the candle and out of the shell.

Lower-(a) egrg showing blood ring, before the candle and out of the shell; (b) cracked egg invaded by mold, before the candle and out of the shell; (c) white rot or addled egg, before the candle and out of the shell; (d) egg with a green white, before the candle and out of the shell. 
bearing on the use of egrgs as a food in dialuetice, which will be cnosidered in the dietotherapy of this malady. ${ }^{1}$

Youk of Eati.-The yolk of the egg is the storehouse of nutriment for the young chick and has a different composition from the white. It contains less water and more solid matter of which fat predominates.

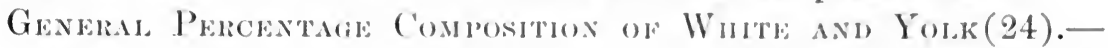
The general composition of the white and yolk is graphically contrasted in the following table ${ }^{2}$ from Kïnig:

PERCENTAGE (OMPOSITION OF THE WHITE ANI) YOLK OF AN GGG

\begin{tabular}{|c|c|c|c|c|c|}
\hline & Water & Protein & Fat & $\begin{array}{l}\text { Other } \\
\text { Non Nitrogenous } \\
\text { Matter }\end{array}$ & $\begin{array}{l}\text { Mineral } \\
\text { Matter }\end{array}$ \\
\hline $\begin{array}{l}\text { White.... . . . . } \\
\text { Yolk....... }\end{array}$ & $\begin{array}{l}85.7 \\
50.9\end{array}$ & $\begin{array}{l}12.6 \\
16.2\end{array}$ & $\begin{array}{r}0.25 \\
31.75\end{array}$ & 0.13 & $\begin{array}{l}0.59 \\
1.09\end{array}$ \\
\hline
\end{tabular}

It will be readily observed that the yolk of the exg is the most nourishing.

In discussing the composition of eggs, Power (Human Physiology) gives a separate analysis for each part.

The white consists of albumin, 13 per cent; globulin, 0.134 ; salts, etc., 0.766; water, 86. The yolk contains vitellin (protein), 14.0 per cent; fat and lecithin, 30 ; nuclein, 1.5; cholesterin, 1.75 ; salts and coloring matter, 0.75 ; water, 52 . The average egg contains about 0.045 per cent of phosphorus; the white has only 0.031 ; the yolk 1.279 per cent in vitellin, lecithin, nuclein, phosphates and glycerophosphates.

According to König one hundred parts of the ash of the white and yolk of egg have the following composition, viz.:

\begin{tabular}{|c|c|c|}
\hline Composition & Yolk & White \\
\hline Potassium ... & 9.29 & 31.41 \\
\hline Sodium $\ldots \ldots \ldots \ldots \ldots \ldots$ & 5.87 & 31.57 \\
\hline Lime $\ldots . . . \ldots \ldots \ldots \ldots \ldots$ & 13.04 & 2.78 \\
\hline Magnesium .......... & 2.13 & 2.79 \\
\hline Oxid of Iron $\ldots . . . \ldots \ldots .$. & 1.65 & 0.57 \\
\hline Phosphoric Acid ............ & 65.46 & 4.41 \\
\hline Sulphuric Acid $\ldots \ldots \ldots \ldots \ldots$ & $\ldots$ & 2.12 \\
\hline Fluorin $\ldots \ldots \ldots \ldots \ldots \ldots$ & 0.86 & 1.06 \\
\hline Chlorin $\ldots \ldots \ldots \ldots \ldots \ldots$ & 1.95 & 28.82 \\
\hline
\end{tabular}

1 There are apparently four different proteins in egg white-Or-albumin. conalbumin, ovomucin, and ovomucoid. The ov-albumin makes up the greater part of the white. Ovomucin and oromucoid are glyeoproteins and are only present in small amounts.

2 For more recent analyses. which, however, do not differ essentially from the above, see a paper by Lebbin on the Nutritive Value of Egggs in the Therap. Nonatshefte, November, 1901. 
The yolk of the egg contains phosphorus in an organic state; the same is true of iron. It also has an abundance of calcium, more than any other food except milk. The great richness of the yolk in fat, together with phosphorus, iron and lime salts, makes it a peculiarly valuable food for young infants, particularly those suffering from rickets and malnutrition, for it is just these very compounds which such a child needs.

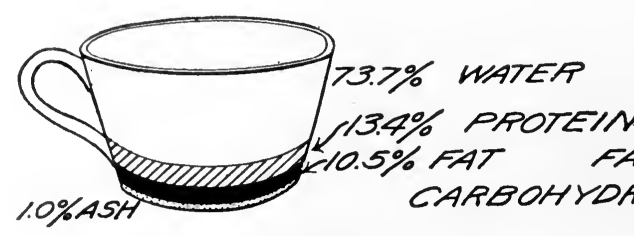

WHOLEEGG

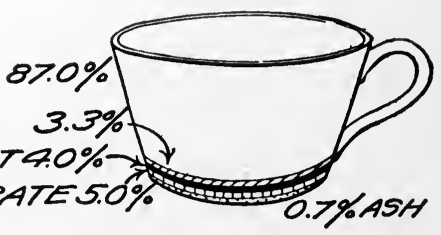

MILK

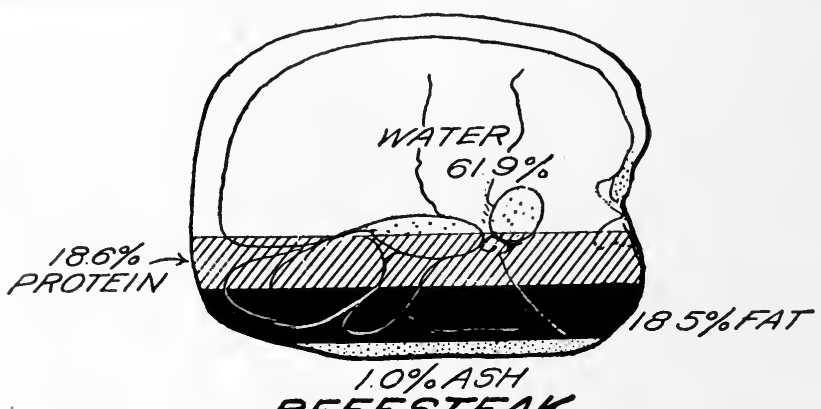

BEEFSTEAK

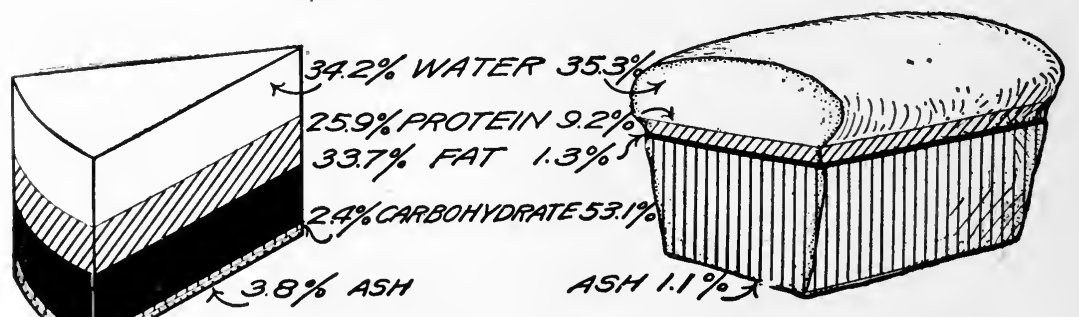

WHITE BPEAD

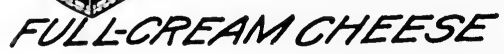

Fig. 27.-Chemical Composition of Eggs as Compared with Milk, Beefsteak, Cream Cheese axd White Bread. (Bull. 471, U. S. Dept. Agric.)

Eggs contain no free purin or purin-yielding substances and are therefore a valuable dietetic adjunct where a purin-free diet is to be recommended in gout.

There is no difference in the composition of eggs with a brown and eggs with a white shell. There is positively no ground for the belief that the former(25) are richer than the latter. 


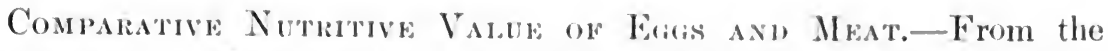
analysis table by Langworthy, it will be seen at a glance that eggrs eontain almost the same total of nutritive matter as meat, but at the same time they are relatively richer in fat and poorer in protein. Eggos are admirably adapted to chemically supplement a food rich in carbohydrate, of a fair protein content, but poor in fat. Such a ford is found in rice and many of the cereals. The addition of egigs to these in the form of puddings makes a well-balanced complete food.

DIGESTIBILITY OF EGGS.-The digestibility of eggs in the stomach depends largely upon the manner of cooking and the form in which they are ingested. In point of mutriment and digestibility, egrgs rank very high indeed, yet it does not follow that they are good for everybody; on the contrary, some persons cannot digest them and they cause bilionsness in another elass. The digestibility depends largely upon the cooking. Raw eggs are not so easily digested as when the white albumin is slightly coagulated. Some experiments have been conducted upon a healthy man to throw light upon this subject. Penzoldt(2i) ordered two eggs cooked in different ways and portions of the stomach eontents were withdrawn at intervals and examined, with results given below taken from Hutchison, "Foods."

2 eggs lightly boiled have left the stomach in........ $13 / 4$ hours

" raw have left the stomach $i n \ldots \ldots \ldots \ldots \ldots \ldots 21 / 4$ "

" poached-5 grams of butter have left the stomach in. . 21/2 "

" hard boiled have left the stomach in.......... 3 "

" as an omelette have left the stomach in........ 3

This experiment of Penzoldt carries a convincing argument. It is surprising to find that slightly boiled eggs are more quickly disposed of by the stomach than raw eggs, but one must not jump at the conclusion that lightly boiled eggs are better suited to the stomach requiring rest than raw eggs; as a matter of fact, it is a question whether raw eggs are digested at all in the stomach, or are passed on to and through the duodenum to a large extent unehanged. Busch in "Virchow's Archives" reported the case of a woman who as the result of disease had an opening in the intestine a few inches from where the small intestine joins the duodenum. He found that when a raw egg was given by the mouth more than half of it eseaped by this opening mehanged.

Cookrng of EgGs.-Eggs may be cooked in a great variety of ways, but in general the simplest methods of cooking are the best. If an egg is boiled two minutes the albumin next to the shell will be coagulated 
while the yolk will remain fluid. If it is boiled three minutes it will be termed soft boiled; if boiled ten minutes it is hard boiled. The eustom of some cooks of plunging an ègg into boiling water and allowing it to remain for three minutes is not to be recommended. Eggs are much more evenly cooked if put into a vessel of boiling water (three eggs to a quart), covered and allowed to stand (not over a source of heat) for five minutes. The eggs will then be found soft boiled. A fried egg is hardest of all to digest, the undigestibility being increased by the frying in fat. Raw eggs are laxative. Hard boiled eggs are constipating.

A poached egg, or one which is boiled until the white is just set, is easiest of digestion. The digestibility of an egg diminishes in proportion to the hardness to which it is cooked. To properly poach an egg, a small quantity of vinegar should be added to the salt water in which they are cooked, in order to assist in the coagulation of the albumin, thereby preventing loss.

ENERGY PROPERTIES OF EGGS.-The analysis by Langworthy, quoted on a previous page, graphically shows the chemical elements of an egg and demonstrates that their nutritive value is due almost entirely to protein and fat. One egg contains enough of these to yield seventy calories of energy, equal in fuel value to half a tumbler of good milk or one and onehalf ounces of fat meat. The absence of carbohydrates prevents eggs from being a complete food, therefore the combination of ham and eggs, both lacking in sugar and starch, is not a well-balanced ration; but French toast or egg on toast are much nearer to a satisfactory food.

PRESERVATION OF EGGS.-The preservation of eggs by cold storage will be found under "Cold Storage." See Volume II, chapter on "The Preservation of Foods."

EGG PRODUCTS.-There are only a few artificial egg preparations.

Ova.-Ova consists of eggs dried at a low temperature so that they are capable of being redissolved. The compound consists of solids, 90.5 per cent, and ash, 4.1 per cent. It is put up in packets, each representing one egg.

Desiccaten EgGs.-Desiccated eggs are prepared by spreading the eggs over the surface of a slowly revolving cylinder heated with a current of warm air. The semi-liquid eggs can be dried in vacuum. From the standpoint of wholesomeness and healthfulness there is no objection to desiceated eggs if made from fresh, wholesome eggs. The product is used largely by bakers and has the advantage of keeping, under conditions where fresh eggs are not available.

EgG Substitutes.-Egg substitutes are manufactured from the 
casein and albumin of milk mixed with flour to form a paste or powder. These substitutes are used chicfly by confectioners. Some of the egg substitutes are made from commercial alhmmin, which is obtained from the blood of slanghtered animals. When collected, the albumin is precipitated, washed and refined. It is a fair substitute for the white of an egg, but as it contains no cellular membanue, such as oceur in eggs, it does not, when beaten, make a good form.
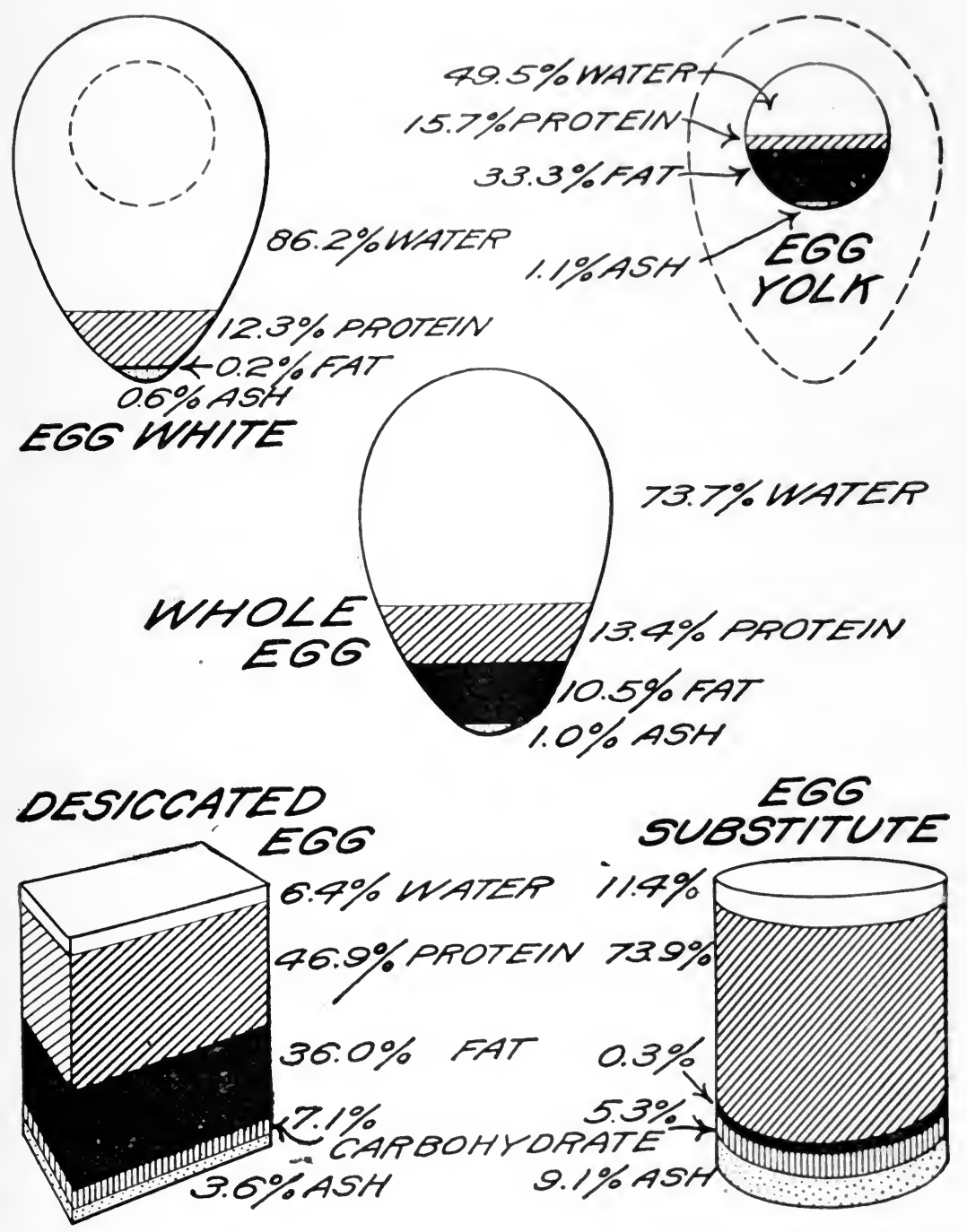

Fig. 28.-Chemical Compositiox of Whorl dig, Fig White. Ega lolk. Desiccaten

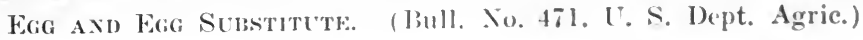


Casein is also used by confectioners as a substitute for eggs. It is precipitated from skim milk, by acetic acid; dried, washed and powdered. A solution of casein can be whipped into a foam like the white of an egg, but it does not make a stiff foam and consequently has little aërating power.

Pidan-Chinese Preserved Eggs. - The Chinese and other Oriental people preserve eggs, not necessarily to keep them unchanged, but to make various new substances-a process analogous to the production of cheese from milk. The products have been little studied and the literature on the subject is therefore limited. The following changes have been shown to take place during the formation of pidan from fresh ducks' eggs: (a) water in large quantities has been transferred from the white to the yolk, and water has been lost from the white to the outside; $(b)$ the ash and the alkalinity of ash have increased in a way similar to that of other eggs preserved in alkali; $(c)$ the ether extract has decreased and its acidity become high; $(d)$ both total and lecithin phosphorus have decreased; $(e)$ the non-coagulable nitrogen has increased and also the ammoniacal nitrogen, the latter to an extraordinary degree, and the aminonitrogen is high. From these changes the conclusion is drawn that decomposition of the egg protein and of the phospholipoids has taken place. The production of pidan from the fresh eggs is probably brought about through the agency of the alkali, bacteria and enzymes.

Recently the Department of Home Economics of the University of Chicago conducted an extensive research into the merits of this method of preserving eggs. According to extensive examination conducted by Blunt and Wang(27), "pidan is made on a factory scale from ducks' eggs. The latter are kept in an infusion of black tea, lime, salt and wood ashes, obviously an alkaline solution, for nearly half a year, much as eggs are preserved in solutions of sodium silicate in this country. They are then drained and coated with rice hulls, whereupon they are ready for the market. The taste of the pidan is characteristic and the odor markedly ammoniacal. There is a tendency for uninformed persons to class such products unreservedly with what are commonly termed rotten eggs. This may not be justifiable. Pidan has no odor of hydrogen sulphid and we are assured does not closely resemble so-called decomposed eggs. Noteworthy chemical changes do, however, attend the long storage process in the formation of pidan. The Chicago investigators state that water in large quantities has been transferred from the white to the yolk and water has been lost from the white to the ontside. The ash and the alkalinity of ash have increased in a way similar to that of other eggs preserved in 
alkali. The ether extract has derreased and its acidity is high. Both total and lecithin phosphorus have decreased."

\section{REFERENCLS}

1. Wetselder and Grimen. Gen. Tydsch. voor Nederl. Indie, 1901, xli, p. 270 .

2. Bandir, E. H. S. Source and (hemistry of Foods, lilakiston, Plinia., J. of A. M. A. Assn., vol. lx, p. 83t.

Fisir. Am. Vet. Rev., 41, p. $17 \mathrm{~s}$.

3. Hutchison. Foods and Dietetics, p. 9:3.

4. Kurscher, F. Ztschr. Nah. Genussmittel, x, 528.

5. U. S. Dep. Agric., Bull. 21, p. 96.

6. Holt. Diseases of Children, 1599, p. 153.

7. Chendee. Artificial Feeding of Infants, 2nd ed., p. 115.

8. U. S. Dep. Agric., Farmers' Bull. 452.

9. Fitcir. Some Neglected History of North Carolina.

10. Bailer, E. H. S. Source, Chemistry and Use of Food Products.

11. Van Slyke, Lecius L., Chemist of N. Y. Agric. Exper. Sta. (Average analysis of cow's milk based on 5,552 analyses of American cow's milk.)

12. Hopkins, F. Gowland. Paper read before the Royal Soc. Med., October, 1913.

13. Annrews. J. Trop. Med., 1913, p. 370.

14. Osborne and Mennex. Science, 1911, pp. 722-730.

15. - Ferry and Wakmanan. J. Biol. Chem., 1913.

16. Bailey, E. H. S. Source and Chemistry of Foods.

17. Am. Assn. Med. Milk Com., Pub. Health Rep., vol. xxvii, No. 24.

18. Roserau, M. J. On the Milk Question.

19. Rothischild. L'Allaitement, Par., 1898.

Struve, H. Nature, xxx, 216 (from Dentsche chem. Gesellsch. zu Berl., 1884).

20. Hutchisox. Food and Sanitation, May 22, 1897.

21. —. Food and Sanitation, May 27, 1597. (Acid albumir, albumose and peptone.)

22. Laxgworthy. T. S. Dep. Agric., Farmers' Bull. 128.

23. Eichirolz. J. Phýsiol., 1898, xxiii, 163.

U. S. Dep. Agric., Farmers' Bull. 12s.

24. Langwonthy, C. F. Eggos and Their Uses as Food, U. S. Dep. Agric., Farmers' Bull. 128.

25. Ibid. 
26. Penzoldt. Deut. Arch. f. klin. Med.

27. Buunt, Katilarine, and Wang, C. C. Chinese Preserved EggsPidan, J. Biol. Chem., 1916, 28, 125. Abstr. J. A. M. A., Jan. 6, 1917, p. 66, Ed. J. A. M. A., Feb. 10, 1917.

\section{BIBLIOGRAPHY}

\section{Meats}

Atwater and Bryant. The Composition of American Food Materials, U. S. Dep. Agric., Off. Exper. Sta., Bull. 28, revised.

Emmett and Grindley. A Preliminary Study of the Effect of Cold Storage upon Beef and Poultry, J. of Indust. \& Engin. Chem., 1909, vol. i, pp. 413-436, 580-597.

Grindley. Studies of the Effect of Different Methods of Cooking upon the Thoroughness and Ease of Digestion of Meat, U. S. Dep. Agric., Off. Exper. Sta., Bull. 193, 1907.

Leighton and Douglas. The Meat Industry and Meat Inspection.

Roвents. Annual Production of Animals for Food and Per Capita Consumption of Meat in the U. S., U. S. Dep. Agric., Bur. of Animal Indust., 22nd Annual Report, 1905, pp. 277-290.

Trowbridge and Grindley. Proteins of Beef Flesh, J. Am. Chem. Soc., 1906, vol. xxviii, pp. 469-505.

Wilder. The Modern Packing House.

Wiley and Bigelow. Preserved Meats, U. S. Dep. Agric., Bur. Chem., Bull. 13, Part 10.

\section{Poultry and Game}

Atwater and Bryant. The Composition of American Food Materials, U. S. Dep. Agric., Off. Exper. Sta., Bull. 28, revised.

Milier. Experiments on the Digestibility of Fish and Poultry, Storrs (Conn.) Agric. Exper. Sta., Seventeenth Annual Report, 1905, pp. 116-142.

Pennixgton. Studies of Poultry from the Farm to the Consumer, U. S. Dep. Agric., Bur. Chem., Circular 64, 1910.

The Hygienic and Economic Results of Refrigeration in the Conservation of Poultry and Eggs, Am. J. Pub. Health, 1913, rol. ii, pp. 840-848.

The Handling of Dressed Poultry a Thousand Miles from the Market, U. S. Dep. Agric., Yearbook for 1912, pp. 285, 292, 1913. 
Tinbles. Foods; Their Origin, Composition and Manufacture.

Wilex, ET AL. A Preliminary Study of the Effects of Cold Storage on Eggrs, Quail and Chickens, U. S. Dep. Agric., Bur. Chem., Bull. $115,190 \mathrm{~s}$.

\section{Fish and Shellfish}

Gorham. Sanitary Regulation of the Oyster Industry, Am. J. Pub. Health, 1912, vol. ii, pp. $7 \%, 85$.

Laxgwokthy. Fish as Food, U. S. Dep. Agrice, Farmers' Bull. 85, revised.

Millakd. Salmon Fishing in Pacitic Waters, Outlook for February, 1910, pp. 171-181.

Mrlaxer. Digestibility of Fish and Poultry, Storrs (Comn.) Agric. Exper. Sta., Seventeenth Anmual Report, 1905, pp. 116-142.

Surtr. Oysters; The World's Most Valuable Water Crop. National Geographic Magazine, vol. xxiv, 1913, pp. 257-281.

A Study of the Influence of Cold-Storage Temperatures upon the Chemical Composition and Nutritive Value of Fish, Biochemical Bull., 1913, vol. iii, pp. 54-68.

Stiles. Sewage-Polluted Oysters as a Cause of Typhoid and Other Gastro-Intestinal Disturbances, U. S. Dep. Agric., Bur. Chem., Bull. 156, 1912.

The Value of the Shellfish Industry and the Protection of Oysters from Sewage Contamination, U. S. Dep. Agric., Yearbook for 1910, pp. 371-378.

The Bacteriological Examinations of Shucked and Shell Ossters, J. Am. Pub. Health Assn., 1911, vol. i, pp. 623-631.

\section{Milk and Milk Products}

Cort. The Origin, General Plan and Scope of the Medical Milk Commission, Proc. of the Am. Assn. of Medical Milk Commissions, 1905, vol. i, pp. 10-17.

Com. Exper. Station, Bacteria in Milk and Its Products.

Exget. Yoghoort or Sour Milk and Its Method of Manufacture, Molkerei-Zeitung, 1908, vol. xxii, pp. 1461-1463.

Fanmixgtox and Woll. Testing Milk and Its Products.

Fitcir. Modified Cows' Milk as a Substitute Food in Infant Feeding, Pediatrics, October, 1912. 
Heinemanx. Lactic Acid as an Agent to Reduce Intestinal Putrefaction, J. Am. Med. Assn., 1909, vol. xxv, pp. 372-376.

Herschell. On the Use of Selected Lactic Acid Bacilli and Soured Milk in the Treatment of Some Forms of Chronic Ill-Health, Lancet, 1908, vol. clxxv, pp. 371-374.

Herter. On the Therapentic Action of Fermented Milk, Popular Science Monthly, 1909, vol. lxxiv, pp. 31-42.

Leacir. Food Inspection and Analysis.

Luerssen and Kunn. Yoghoort, the Bulgarian Sour Milk, Centralblatt für Bakteriologie, Parasitenkunde und Infectionskrankheiten, 1908, ii Abtheil., vol. xx, pp. 234-248.

Metchnikoff. The Utility of Lactic Microbes with Explanation of the Author's Views on Longevity, Century Magazine, 1909, vol. lxxix, pp. 53-58.

Rosenau. Milk in Its Relation to the Public Health, U. S. Pub. Health Service, Hygienc Lab., Bull. 56.

The Milk Question.

Savage. Milk and the Public Health.

Stanislaus. Kefir and Its Preparation, Am. J. Pharm., 1908, vol. lxxx, pp. $20-26$.

Van Slyke. Modern Methods of Testing Milk and Milk Products.

Conditions Affecting the Proportions of Fat and Proteins in Cows' Milk, J. Am. Chem. Soc., 1908, vol. xxx, pp. 1166-1186.

\section{Cheese}

Doane. The Cold Curing of American Cheese (with digest of previous work on the subject), U. S. Dep. Agric., Bureau Animal Indust., Bull. 85, 1906.

Development of Lactic Acid in Cheddar Cheese Making, U. S. Dep. Agric., Bureau Animal Indust., Bull. 110, 1908.

and Lawson. Varieties of Cheese: Descriptions and Analyses, U. S. Dep. Agric., Bureau Animal Indust., Bull. 105.

Issajefr. Directions for Making Camembert Type of Cheese, U. S. Dep. Agric., Bureau Animal Indust., Bull. 98, 1907.

Langworthy and Hunt. Cheese and Its Economical Uses in the Diet, U. S. Dep. Agric., Farmers' Bull. 487.

Rogers. The Relation of Bacteria to the Flavors of Cheddar Cheese, U. S. Dep. Agric., Bureau Animal Indust., Bull. 62, 1904. 
Russell and Hastrosas. A Swiss Cheese lrouble Caused by a GasEorming least, Wisconsin Agric. Exper. Sta., Bull. 128, 1905. Thom. Fungi in (heese Ripening; ('anembert and lioquefort (with bibliography), U. S. Dej. Agric, Bureau Animal Indust., Bull. 82, 1906 .

VAN SLYKE and HART. Conditions Affecting Chemical Changes in Cheese Ripening, New lonk State Agric. Exper. Sta., Bull. 236, $19(0) 3$.

and Prmbow. The Scioner and Practice of Cheese-making. , Sartu and Hakt. Lixpriments in Curing Cheese at Different Temperatures, New lonk State Agric. Exper. Sta., Bull. $234,190 \%$.

Wasmburs. Principles and Pracide of Ice-cream Making, Vermont Agrie. Exper. Stal., Bull. 15\%.

Wrexy. Foods and Their Adulterations.

\section{E'ggs}

Berger. Preservation of Eggs, J. Indust. and Engin. Chem., 1911, vol. iii, pp. $493-495$.

Hastings. The Eigg Trade of the United States, U. S. Dep. Agric., Bureau Animal Indust., ('ircular 140, 1909.

Lamox. The Handling and Marketing of Eggs, U. S. Dep. Agric., Yearbook for 1911, pp. 46i -478 .

Langwortuy. Egge and Their Uses as Food, U. S. Dep. Agric,, Farmers' Bull. 128.

Osborse and Campielu. Proteins of Fgg Yolk and Egg White, J. Am. Chem. Society, 1900, vol. xxii, pp. 413-450.

Pennixgton and Pincer. The Effect of the Present Method of Handling Eggs on the Industry and on the Product, U. S. Dep. Agric., Yearbook for 1!10, pp. 461-476.

Slocur. Marketing Eggs Through the Creamery, U. S. Dep. Agric., Bureau Animal Indust., 26th Annual Rep., 1909, pp. 239-246.

Taylor. The Prices of Farm Products, Wisconsin Agric. Exper. Station, Bull. 209.

Tibbles. Foods; Their Origin, Composition and Manufacture.

Wiley, Pfoxisgtox, Stiles, Hownd and Cook. Effects of Cold Storage on Fogrs, Quail and Chickens, U. S. Dep. Agric., Bureau Chem., Bull. 115, 1908. 



\title{
CIIAP'TER XIII
}

\author{
VEGE'TABLE FOOIOS
}

And God said, Behold, I have given you every herb bearing seed, which is upon the face of the earth, and every tree, in the which is the fruit of a tree yielding seed, to you it shall be for meat.-Genesis 1, 29.

\footnotetext{
General Considerations: Chemical Characteristies of Vegetables; Food Value of Vegretable Foods; Nutritive Substances in Vougetables: Carbohydrates, Fats, etc.; Digestion and Absorption of Vegetable Foods. Varieties of Vegetable Foods: Cereals: Wheat (Flour, Bread), Rice, Corn, Oats, Rye, Barley, Millet, etc.; Breakfast Foorls; Roots and Tube:s: Potatoes, Bects, Carrots, etc.; Green Vegetables: Cabbage, Spinach, Lettuce, Celery, etc.; Dried Legumes or Pulses: Beans, Peas, etc.; Fungi, Lichens and Algæ.
}

\section{GENERAL CONSIDERATIONS}

We come now to the study of that large and varied class of foodstuffs which we obtain from the vegetable kingdom. In the beginning it will be profitable to consider, in a general way, the chemical composition, digestibility and nutritive value of vegetable foods in general, comparing them in these respects, as well as in their economic aspects, with foods derived from the animal kingdom. Then we shall take up a detailed study of the different groups of vegetable foods, as well as the proximate chemical and physiological principles composing the substance of regetable tissues which are isomeric with similar principles in animal tissue in such form as to be readily assimilable by the human organism.

Chemical Characteristics of Vegetable Foods.-Chemically considered, vegetable foods are strikingly different from animal foods. Vegetable foods have a large pereentage of carbohydrates in eomparison to the high protein and fat content of animal foods. This peculiarity differentiates them, for animal foods, with few exceptions, such as milk, contain little or no carbohydrate. Richness in sugar and stareh is the characteristic, then, of vegetable foods; abundance of protein and fat that of foods derived from the animal kingdom. 
CONSTITUENTS OF VEGETABLE FOODS VS. THOSE OF HUMAN BODY.A comparison of the chemical elements in vegetable substances and those in the human body shows them to be quite similar, if not the same. All plants upon examination will be found to contain carbon $(a)$ derived from the air by the aid of chlorophyll; hydrogen $(b)$ absorbed as water, ammonia, or other compounds; oxygen $(c)$ in combination, as carbonic acid, water and many salts; nitrogen $(d)$ in the proteins and salts absorbed chiefly in the form of nitrates and ammonia compounds; sulphur (e), a constituent of the proteins and other tissues, is derived from the sulphates in the soil; phosphorus $(f)$, mainly in the proteins, but also in seeds and other vegetable tissues, is obtained from the phosphates of the soil; iron $(g)$ is the substance which gives the green color to plants and seeds. It is derived as a salt from the soil, and is absolutely necessary for the formation of chlorophyll; potassium $(h)$ salts, derived from the soil, are abundant in all plants which are rich in carbohydrates, such as sugar and starch, also in the green parts of plants; sodium $(i)$ is found abundantly in all plants; calcium $(j)$ and magnesium $(k)$ salts are also important constituents necessary for the normal growth of plant life; silicon $(l)$ is found in the cell walls of various fibrous tissues, being taken up from the soil in the form of silica; iodin $(m)$ and bromin $(n)$ occur in marine plants. They are accidental constituents and of no physiological value; lithium $(o)$ is found in tobacco; zinc $(p)$, copper $(q)$ and boron $(r)$ in other plants in small but appreciable quantities.

INORGANIC SUBSTANCES IN VEGETABLE FOODS.-The inorganic substances found in vegetable life consist chiefly of chlorids, sulphates and carbonates of iron, silicon, magnesia, lime, soda and potash. The following table, quoted from Vine's botany, gives an example of the inorganic constituents, showing the percentage amount in 1,000 parts of dry, solid matter in the vegetable foods enumerated therein:

TABLE SHOWING PERCENTAGE OF INORGANIC CONSTITUENTS IN VEGETABLE FOODS

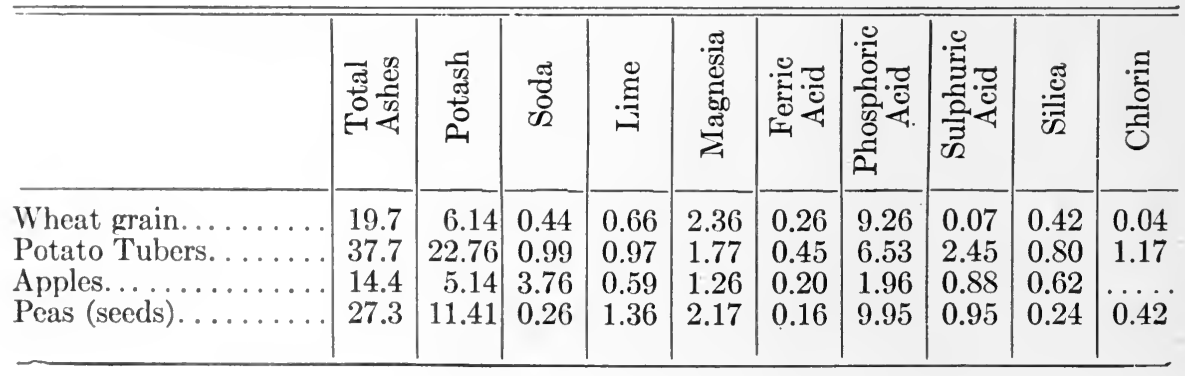


ORGANIC SLBSTANCES IN VEGETABLE FOODS- The organic constituents of plants, as in animals, are composed of cells which have a cell wall consisting of cellulose $\mathrm{C}_{4} \mathrm{H}_{10} \mathrm{O}_{5}$, a carbolydrate substance surrounding the cell contents. The cell contents are composed of living and non-living substances. 'The succulent parts of plants, as the leaves, fruit, seeds and stems, compose the living tissues, containing a fuantity of living protoplasm; a viscid substance of a tenacious character and protein nature. The non-protoplasmic or non-living contents of plant cells consist of sap, starch grains, protein gramules, sugars, fats, oils, salts and water, which are of great importance as elements of our foods.

FOOD VALUE OF VEGETABLES VS. MEAT.-Vegetable foods, while possessing an abundance of carbohydrates, also contain a certain amount of proteins and fats; while the seeds of the leguminous plants are rich in protein, certain of the edible nuts are rich in fats. Vegetable foods as a whole, more than the animal foods, contain representatives of all three groups-protein, fat and carbohydrates-of nutritive substances. In consideration of this fact, the vegetable kingdom must be looked upon with more favor as a source of human food supply than the animal kingdom, and if one were to select the one or the other for an exclusive dietary, it would be the part of wisdom to patronize the green grocer and the miller rather than the butcher and fishmonger. It is possible to subsist on vegetables alone, whereas it would be a hardship to live for any lengthy period of time on an exclusive meat diet. The better plan, however, is to partake of a well-balanced diet obtained from the resources of both the animal and regetable kingdoms.

NUTRITIVE SUBSTANCES OF VEGETABLE FOODS.-In studying the nutritive substances of vegetable foods we will first take up the carbohydrates, already mentioned, as the source of sugar and starch.

Carbonydrates. - Sugar is the circulating carbohydrate, starch the stored-up energy of plant life. When a plant, from good seasons or fertile earth, manufactures more carbohydrate than is required, it stores the surplus in the shape of starch, to be drawn upon in case of necessity. If not used by the plant to maintain its life, some of this surplus is converted into sugar by help of the ferment diastase and again circulates throughout the plant. Sugar, therefore, is the soluble form of carbohydrate; starch is the carbohydrate in reserve, like the glycogen of the liver energy in storage.

The liver is referred to as the "storehouse" of the human economy, and the carbohydrate in reserve in plants is precisely an analogous 


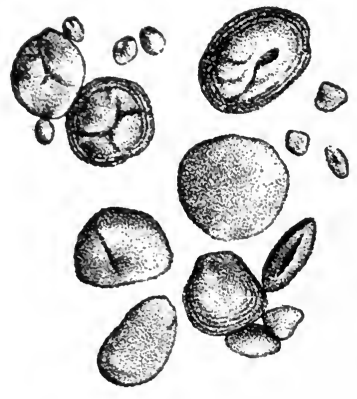

WHEAT
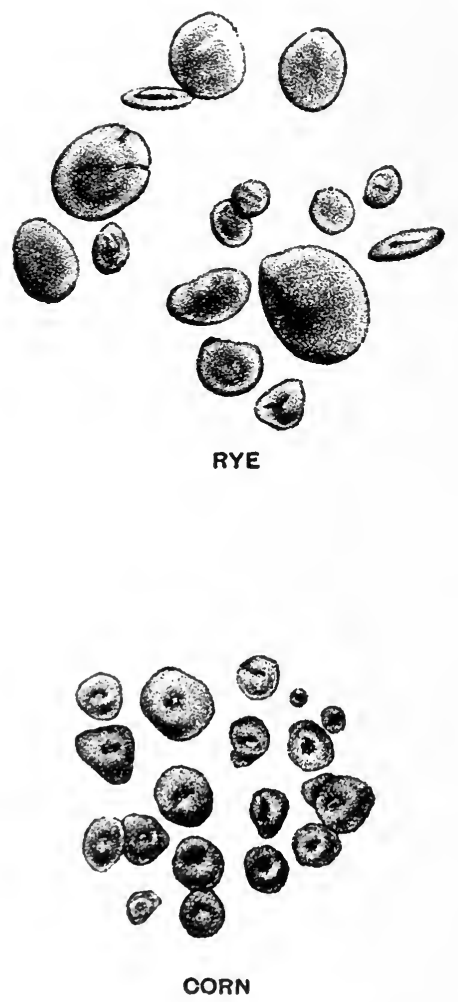

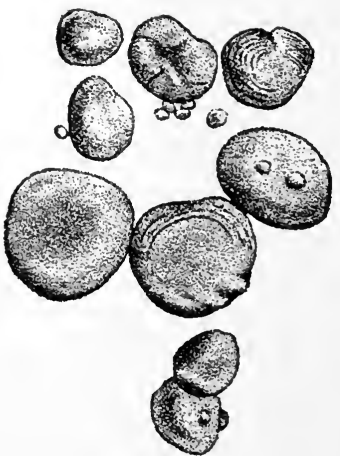

BARLEY

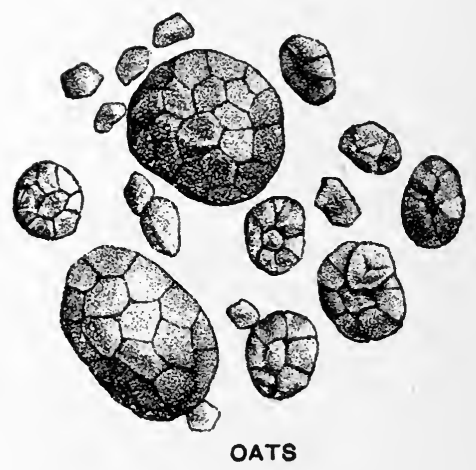

STARCH GRANULES, MAGNIFIED.

Fig. 29.-Cereal Starcil Granules. (Bull. No. 13, U. S. Dept. Agric., Div. Chem.) 
process. All the starch in the fools we eat must first bo converted into sugar or dextrin before it can circulate throngh our bodies and be available as energy. Starch is a more concentrated form of carbohydrate than sugar and packs into smaller bulk. The granules are very minute, and can only be viewed with a microsone. When so examined they will be found to have various shapes, round, oval or polyhedral, depending on the variety of plant from which the starch is derived. These minute starch grains, surrounded by a protecting envelope of cellulose, are not affected by cold water, otherwise in continned rainy weather the starch would be washed away and the plant die of starvation. Boiling water, on the other hand, causes the starch to swell, rupturing the cellulose coverings, and the true starch escapes between the layers of cellulose and forms with the water a colloid, which every laundress understands and appreciates.

During the process of cooking vegetables the starch granules are ruptured, broken up and brought into a colloid state so as to be more easily attacked by the digestive juices. As a result, they are more readily converted into sugar than when ingested in their raw and unruptured state. When starch is subjected to dry heat, say at abont $300^{\circ} \mathrm{F}$., it is converted into soluble starch and dextrin. The caramel-like crust of a loaf of bread, for example, is carbohydrate converted into soluble starch and dextrin.

We learned when studying meat that the nutritive ingredients (proteins) were contained in minute tubes held together by fine connective tissue bands, which on boiling yield gelatin. In the study of regetable foods we also find that the chief nutrient ingredient (starch) is held in a vast number of minute compartments or cells, surrounded by a protecting covering of cellulose, which is especially characterized by its extraordinary insolubility. It is not affected by either hot or cold water and only gives way when boiled in a dilute acid. Owing to the peculiar insolubility of cellulose it is readily seen that this cell wall must present a formidable barrier to the free penetration of the mutritive ingredients by the digestive juices, which is of momentous importance to the normal process of digestion.

Besides starch and cellulose there is another and interesting group of carbohydrates met with in vegetable foods, referred to by some writers as pectin, by others under the general term pectose bodies. Their constitution and composition camnot very readily he ascertained beanse they cannot be separated from the associated cellulose without disorganizing them or changing their substance. Pectose bodies are found in most 
fruits and sparingly in some vegetables. These bodies impart to fruits the power of forming jelly when boiled, the pectose being converted into pectin, which is the chief substance in fruit and vegetable jellies. They appear to be converted into a special kind of sugar (pentose), which is not easily assimilated by the human organism. ${ }^{1}$

The most important group of carbohydrates met with in vegetable foods are the sugars, which we have casually referred to already; but since they merit a more detailed consideration, they were taken up at length in Chapter III and are mentioned in Chapter II.

Proteins.- The nitrogenous substances contained in vegetable foods, like those found in meats, are proteins, therefore vegetable foods may be divided into those which contain protein and those which do not. The vegetable proteins belong almost entirely to the globulin class. It should be remembered that vegetable foods are poorer in nucleoproteins than animal foods. Vegetable proteins are poorer in carbon and richer in fat than animal proteins; both varieties are readily coagulable by heat, which renders them less digestible.

The digestibility of animal foods is lessened by cooking, because they are composed largely of protein. On the other hand, cooking increases the digestibility of vegetable foods, since the latter contain, as a rule, very little protein, with an abundance of starch, which cooking prepares for ease in digestion.

Inferior Substances.-Vegetable foods, like animal foods, contain a number of nitrogenous substances inferior to proteins. They are in no sense comparable to the albuminoids, found so abundantly in the animal kingdom. On the other hand, extractives are well represented, belonging to a group of chemical substances called amids.

FATs.-Fats found in vegetables are of a negligible quantity, other than that in chemical composition they are similar to animal fats. As a rule, they are of a more oily consistency (olein), and have less of the more solid components (stearin and palmitin) than the animal fat. This

1 Some of these bodies appear to be of the nature of dextrins, while others, perhaps, stand nearer to starch. It might be well to restrict the term "pectins" to the former group; they probably bear the same relation to the pentoses, or sugars with five carbon atoms, that dextrin does to the six-carbon-atom sugar, dextrose. The other group may be spoken of as pentosans. The sugars to which they give rise are also found in many ripe fruits and are certainly not easily assimilated by the cells of the body. They are apt to appear in the urine if the fruits containing them are eaten in excess. (Hutchison.) 
difference increases rather than diminishes their digestibility, while their nutritive or fuel value is on a parity with the more solid animal fats.

Watro axi Maxis. Sarts. We have new considered a!l the constituents of vegetable foods exeept water and certain mineral salts. Water is present in large quantity; in some vegetables the percentage is as high as 78 to 90 per cont. This superabundance of water is one of the essential properties of certain vegetables and is largely responsible for the low nutritive value of many of them when empared with their bulk. Such vegetables when cooked become even more watery, and so their last state is worse than the first. On the contrary, just the opposite is the case with animal foods.

The mineral constituents of vegetable foods are numerous and important as we found when studying the Mineral salts in the Body and in Foods in Chapter XI, and to which further reference will be made when the different groups of vegetables are separately considered. The mineral ingredients of vegetable foods unite with the organic acids to form bases. These when burnt up, either outside or inside the body, yield alkaline salts, which are turned to therapeutic account in those who are suffering from calcareous deposits.

Digestion and Absorption of Vegetable Foods.-The digestion and absorption of vegetable foods have already been considered at length in Chapters V, VI and VII. As a class, regetable foods like peas, beans and beets, are not to any appreciable extent acted upon by the gastric juice, because starch, their chief ingredient, is entirely maffected in an acid medium. We learned in Chapters VI and VII that the digestion of starch began in the mouth by the action of the ptyalin of the saliva and was continued in the duodenum, where the reaction was again alkaline from the admixture of the bile and pancreatic secretions. Only vegetables which are particularly rich in protein, such as the pulses, are chemically acted upon in the stomach. The reduction of the bulky vegetable masses into a fine state of subdivision entails a large amount of mechanical effort on the part of the stomach in passing the food through the pylorus into the small intestine. As a consequence, since animal foods require more chemical action on the part of the gastric juice and less mechanical work on the part of the stomach, the former instead of the latter are suggested for persons of enfeebled digestive power.

Many writers hold that vegetable foods are not as readily digested and absorbed in the intestine as animal foods; the table on the next page is taken from Voit, and will show the percentages of absorption in the foods enumerated: 
RELATIVE ABSORPTION OF SOME ANIMAL AND VEGETABLE FOODS

Food

Dry Substance not Absorbed

Dry Substance

White Bread .......... 4 per cent

Food not Absorbed

\begin{tabular}{|c|c|}
\hline Macaroni $\ldots \ldots \ldots \ldots$ & 4 \\
\hline Rice $\ldots \ldots \ldots \ldots \ldots \ldots$. & 4 \\
\hline Meat $\ldots \ldots \ldots \ldots \ldots \ldots$ & $4 \frac{1}{2}$ \\
\hline $\operatorname{Eggs} \ldots \ldots \ldots \ldots \ldots$ & $4 \frac{1}{2}$ \\
\hline Maize $\ldots \ldots \ldots \ldots \ldots \ldots$ & 7 \\
\hline
\end{tabular}

Milk ............. 9 per cent

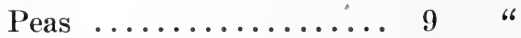

Potatoes .............. 11

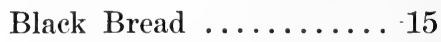

Cabbage ...........................

Turnips ........... 20

FACTORS CONCERNED IN DIGESTIBILITY AND ABSORPTION.-Digestibility and absorption of vegetable foods in the intestine are governed by two factors: first, the bulk, and second, the amount of cellulose which they contain. If the former be small and the latter scanty, digestion is very complete, as will be observed from a glance at the above table, where bread, macaroni and rice were almost completely digested and absorbed.

Digestion and Absorption of Bulky Vegetable Foons-The contrary is the case where the food is bulky and full of cellulose. The majority of regetable foods correspond more or less to this description, hence the dictum "vegetable foods are not so completely digested as animal foods." When we stop to consider that four-fitths of the weight of green vegetables and fruits is due to water, and that even the drier vegetables, such as legumes, take up three times their weight of water in the process of cooking, it will be readily seen that vegetable foods must be bulky out of proportion to their nutritive value. This bulkiness of vegetable foods retards digestion $(a)$ by hindering the free admixture of the digestive juices with the food mass, thereby lessening the conversion of the nutrient constituents for ease of absorption; $(b)$ the bulky mass in the intestine stimulates contractions, which hasten the contents along, allowing less time for absorption.

Cellulose as a Factor in Digestion and Absorption of VegeTABLE Foons. - Another obstacle to digestion and absorption of vegetable foods in the alimentary canal is the presence of cellulose and the formidable barrier which it presents to digestion. (Reference has already been made to cellulose and its extraordinary insolubility pointed out.) Indeed, it is only when the plant is very young and tender that it is at all possible for cellulose to be successfully attacked by the digestive apparatus of man or other carnivorous animals.

While the insolubility of cellulose presents barriers to the digestive process, it serves a valuable purpose to the human economy by adding 
to the bulkiness of the muicldy mass which regetable foods form in the intestine and thereby stimulates the movements of the bowel. For this reason foods rich in cellulose, surh as whole wheat bread, fruits and green regetables, are prescribed as uscful adjuvants in the dietetic treatment of those who suffer from shugish actions of the bowels.

A moderate amount of collulose in the dietary of healthy persons is advisable for its stimulating action on the alimentary canal. Strictly eamivoroms animals have little nor for it, while in the herbivora, owing to their long and sluggish intestiue, its presence is a necessity.

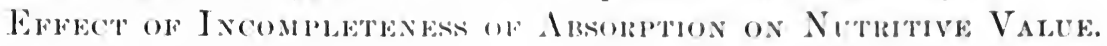
-The incompleteness of absorption, characteristic of most vegetable foods, affects in different measures their varied nutritive elements. 'The vegetable fats, such as cocoa butter and olive oil, seem to be as readily absorbed as butter and cod liver oil. Starch and sugar are readily digested and carried into the circulation almost to the last atom. It is only when enormous quantities of green regetables or other carbohydrates of the legmminous variety are ingested that undigested starch is found in the excreta of healthy persons. It is a well-known physiological fact that a larger amount of nitrogen is excleted by the bowel on a vegetable diet than when animal foods are ingested. Just why vegetable protein should be less completely absorbed than the other nutritive constituents of vegetable foods is hard to explain. The following table from Hutchison gives a résumé of a series of experiments carried out on healthy individuals, showing the percentage of protein which escaped in the excreta, the loss of protein from meat being remarkably less than the protein waste from vegetable foods:

\section{RELATIVE ABSORPTION OF PROTEIN IN VARIOUS FOODS}

Diet

Protein not

Meat Absorbed

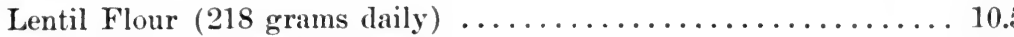

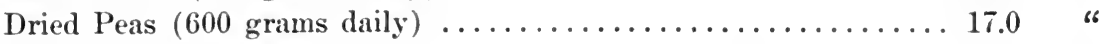

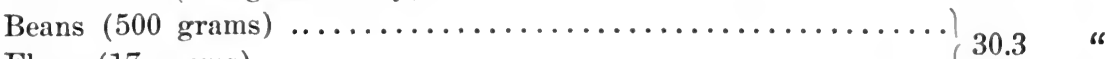

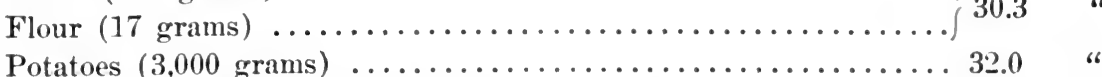

Carrots and Fat $(412$ grams dried) $\ldots \ldots \ldots \ldots \ldots \ldots \ldots \ldots \ldots \ldots \ldots . \ldots \ldots$ "

Lentils (250 grams, simply soaked and boiled till soft) ....... 40.0 "

It is difficult to account for the large amount of vegetable protein which escapes in the excreta. Doubtless, the effects of cooking are less favorable to the digestion and absorption of vegetable protein than to that 
of starch. The effects of heat and moisture cause the starch grains to swell, rupture and burst through the cell walls composed of cellulose which enclose them, but this same heat and moisture cause the protein in the vegetable cells to coagulate and shrink away from its wall of cellulose and in this way, possibly, remain unruptured.

Some authorities hold that the large amount of nitrogen found in the intestinal excreta on a vegetable diet does not come from unabsorbed protein, but rather from the residue of the digestive juices. Reasoning on this analogy, it will be seen that vegetable foods must require a more thorough admixture and a larger amount of digestive juices for their breaking down than is required by animal foods. This explanation, plausible at least in part, does not satisfactorily explain why more nitrogen is lost from the bowel on a vegetable than on an animal diet.

The Nutritive Value of Vegetable Foods.-After considering the chemical constituents of vegetable foods-the proteins, carbohydrates and fats - severally and collectively, we may safely assert that they are equal in fuel value to the corresponding food elements obtained from the animal kingdom. We have already learned that vegetable protein contains a smaller amount of carbon than animal protein and, according to some investigators, the former is therefore of less nutritive value than the latter. The high energy value of starch and sugar is without question. They are fuel foods, and have no nutritive value as tissue formers. Vegetable fats, such as olive oil and cocoa butter, which form a large part of the diet of the inhabitants of some of the southern European countries, are also fuel foods. Fats to some extent are tissue formers of high nutritive value.

PROTEIN VALUE: THE VEGETARIAN QUESTION.-After all is said and done, there remains the fact that the vegetarian question is a question of protein alone. Protein may be obtained from either the animal or vegetable kingdom. Shall we eat our protein in an animal or vegetable form, taking it for granted that the vegetable foods are relatively poorer in this element than the animal foods? Typical examples of both kingdoms will show beyond question that even the fattest meats contain more protein than the most nitrogenous forms of vegetable foods.

It is therefore beyond question that vegetable foods, unless eaten in very large quantities, will not yield a sufficiency of protein for the wear and tear of the human body. This brings us to the question: how much protein does a healthy man require in his food daily?

This most important and momentous question will be elaborated on in Volume II, in the chapter on "Protein and Nutrition." 


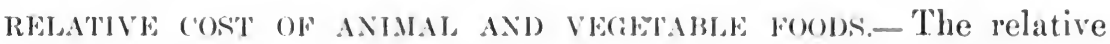
cost of animal and vegetable foods is an economic question in which the vegetarian has the hest of the argument. Althongh sneculent vegetables are expensive, there is no douht that cereals are cheap. 'Then, too, while the nutritive substances in vegetables are not quite so abundant as in animal foods, vet vegetables play an important part in the nomrishment of the body, due in part to their attractive flavor, their freshness and the variety they add to the dietary. P'ersomal experiment at the market will show that one dollar expended for bread, peas or potatoes yields a far larger anount of fuel for the body than a dollar invested in eggs, fish, beef, or even in cheese and milk, which are comparatively cheap animal foods.

\section{VARIETIES OF VEGETABLE FOODS}

For convenience of description, we will consider vegetable foods in the following order:

Cereals :

Wheat (Flour, Bread), ete.

Breakfast Foods.

Roots and 'Tubers.

Green Vegetables.

Dried Legumes or Pulses.

Fungi, Lichens and Alga.

\section{CEREALS}

Cereals.-Cereals belong to a type of grasses of the natural order Graminaciae. They are cultivated at the present time in all parts of the world, but it is questionable whether the cereals so much esteemed at the present day have been evolved by natural selection and cultivation from wild grasses now known, or whether they are distinct species, having their origin in grasses which no longer exist. The term cereal dates back to mythological times. The goddess Ceres is supposed to have been the first to cultivate these wild grasses and gather their seed for food. We gather from the Holy Writ the fact that cereal had been ased as a foodstuff many centuries before Joseph, under Pharaoh, secured his famous "corner on wheat" and for seven years monopolized the grain market of the world. In fact. we may safely say that man's nise of cereals as a foodstuff antedates history and that its origin is lost in the mists of antiquity. 
Among the (grass) cereals, wheat, rice, corn, oats, rye, barley and millet are the most important, and are named in the order of their importance. Other cereals, although not grasses, may be mentioned here as buckwheat and quinoa. As a rule, these grains are ground into meal or flour. However, rice and barley are usually offered in the markets with the hulls removed, though rice flour and barley meal are also used to a limited extent.

COMPOSITION OF FLOUR AND CEREALS.-The following analysis, taken from Lawes and Gilbert and quoted by Tibbles(1), shows the relative percentage composition of flours made from the principal cereals:

COMPOSITION OF FLOUR AND OF CEREALS

\begin{tabular}{|c|c|c|c|c|c|c|}
\hline & Old Wheat & Barley & Oats & Rye & Corn & Rice \\
\hline Water. & 10.00 & 12.0 & 10.06 & 10.50 & 11.5 & 12.40 \\
\hline Starch. & 70.00 & 52.7 & 52.23 & 70.10 & 67.30 & 76.00 \\
\hline Fat... & 1.75 & 2.6 & 4.33 & 1.50 & 5.25 & 0.40 \\
\hline Cellulose. & 2.40 & 11.5 & 12.05 & 2.10 & 1.75 & 0.40 \\
\hline Gum and Sugar.... & 1.85 & 4.2 & 5.7 & 1.60 & 3.00 & 1.40 \\
\hline Protein........... & 12.25 & 13.2 & 12.5 & 12.25 & 10.00 & 6.90 \\
\hline 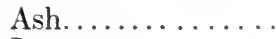 & 1.75 & 2.8 & 3.46 & 1.90 & .5 & .50 \\
\hline Loss, etc.. & 0.0 & 1.0 & 0.2 & 0.5 & 0.7 & .4 \\
\hline
\end{tabular}

WHEAT.- Wheat is by all odds the most important cereal used in American and European countries, where it occupies the same position as a dietetic article that rice fulfills among Oriental peoples. It grows readily, producing beantiful crops throughout the temperate zone, where the active peoples of the earth reside. Its origin as a foodstuff is unknown, but profane history tells us of its cultivation by the ancient Egyptians and Chinese. It was grown in Mesopotamia 2,000 years B. C. The present varieties of wheat are, no doubt, the result of careful selection extending for centuries back. Possibly, the modern wheat may be derived from a wild plant, some varieties of which, improved by cultivation, are still found. Wheat as we know it today was introduced into Britain by the Romans. The wheat crop of the United States in 1915 was 1,011,280,000 bushels.

Elements of the Component Parts of Wheat Grains.-The grain of wheat consists of various parts arranged in concentric layers. Since these are important from a dietetic point of view, we shall briefly consider the elements forming the component parts of the grain. The wheat berry has an external covering or skin, an internal substance or kernel and a germ. The external covering, skin or hull, consists of five 
layers, (a) epicarp, (b) mesocarp, (c) cndocarp, (d) testa, and (e) cerealin encelope. The first three of these layers form the bran, to which are added the hralin and cerealin coats. The testa is the true envelope covering the grain. It consists of long, narrow cells, containing the coloring matter which distinguishes red wheat from white wheat. The cerealin layer or envelope consists of a single layer of polygonal cells immediately beneath the testa. It contains aleuron grains enclosing cells containing vitamines. The vitamines are complex crystalline substances belonging to a chemical group hitherto unkuown.

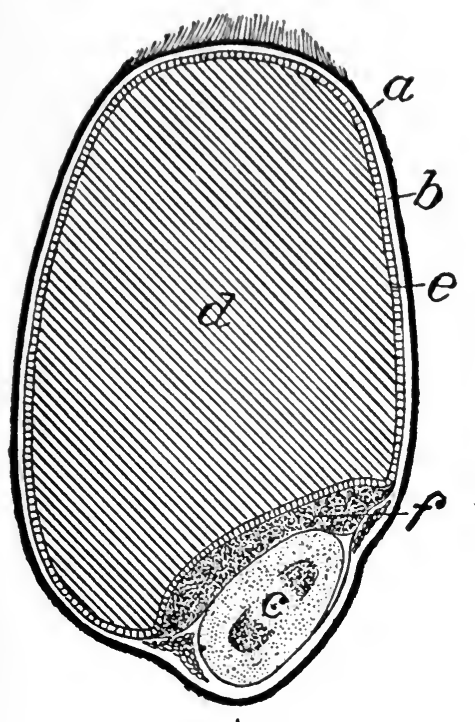

A

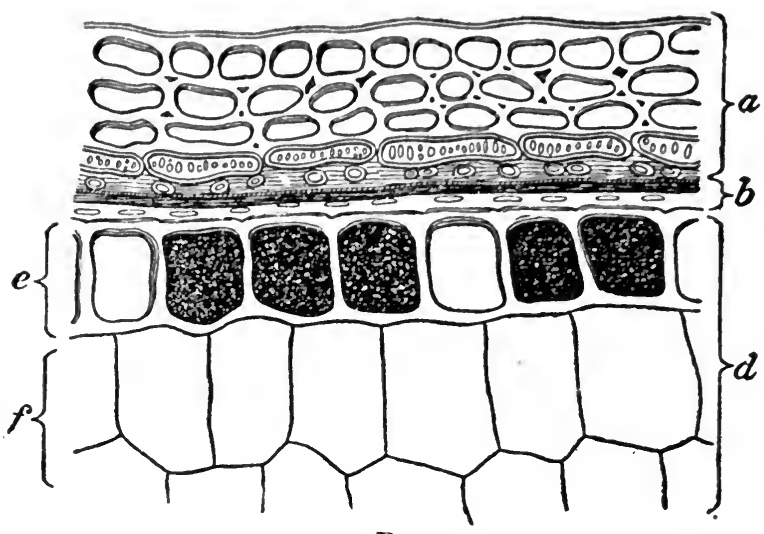

B

Fig. 30.-Diagramatic Section of a Grain of Wheat. A.- (a) skin and testa, (b) membrane, (c) embryo, (d) flour cells, (e) cereal or aleurone layer, (f) scutellum.

B.-Cellular structure of the grain; (a) skin and testa, (b) membrane, (d) endosperm, (e) starch cells. (Bull. No. 295, U. S. Dept. Agric.)

The average composition of whole wheat, according to Wiley, is as follows :

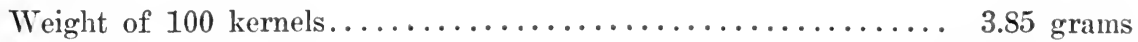

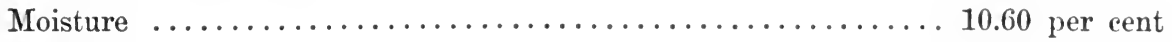

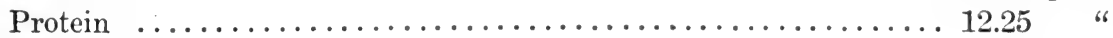

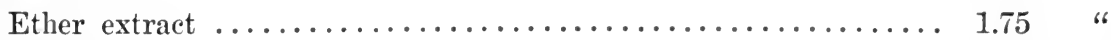

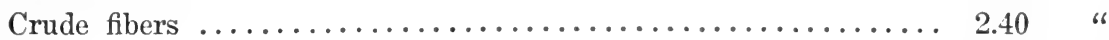

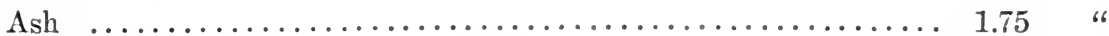

Carbohydrates other than crude fiber.............. 71.25

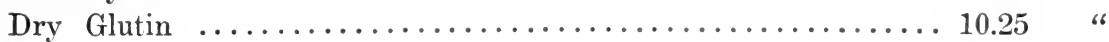

Moist Glutin .......................... " 
Importance of Vitamines.-Vitamines are essential for growth development and life. They are of vital importance to the thyroid and other ductless glands. Vitamines occur in plants, and more especially in their seeds, in whole wheat, whole corn, unpolished rice, fresh tomatoes, fresh legumes, most fresh fruits and their juices. Yeast is also rich in vitamines. Human milk, cow's milk, butter, cheese, eggs and beef contain vitamines. So far as is known at present, animals are incapable of producing vitamines, but they obtain them by feeding on plants containing them.

The cerealin layer is really the outer portion of the endosperm or kernel, which contains the starch. Its cells are rich in fat, containing amorphous protein granules, which are believed to exert an influence upon the process of leavening, more or less deleterious to the quality of the bread. The fat in this layer also tends to become rancid and gives a bad flavor to flour, especially when it has been ground for a long while. These facts are considered a sufficient reason for the removal of the cerealin layer with bran.

According to some investigators, the amount of bran varies from 13 to 38 per cent of the entire grain, according to the quality. In blasted grain it is very high, but in grain of an average quality the bran percentage usually runs about $131 \%$ per cent of the total weight.

The internal substance of the wheat berry referred to as the kernel contains the endosperm, and forms about 85 per cent of the total substance of the wheat berry. It is this portion which is ground into flour. It contains a large number of compartments filled with starch grains, soluble and insoluble protein, a nitrogenous substance called gluten, some sugars and salts. The walls of these compartments are made up of cellulose.

The germ, or embryo, represents about $1 \frac{1}{2}$ per cent of the whole grain. The germ is composed of cells which are rich in enzymes that aid in the transformation of the insoluble starch and protein and change ihe endosperm into sugars, dextrins and amids. The nitrogenous matters or proteins of the wheat berry vary from 10 to 14 per cent. The germ of the wheat berry is particularly rich in nitrogen.

Gluten.-The term gluten is an expression used to designate the proteins, glutenin and gliadin, of wheat. It is obtained by kneading flour into a paste with water and afterward washing away the starch with a rumning stream. The remuant remaining is gluten. It is a yellowishgray or grayish-brown substance, very elastic and adhesive, insoluble in water and in saliva, and tasteless. 
Gluten does not exist as such in wheat or flomr but is formed when the flour is mixed with water ont of two proteins, gliudin and glutenin, which together comprise all the protein of the wheat berry except 1.5 per cent (as worked out hy () shorme in the table below from thibbles):

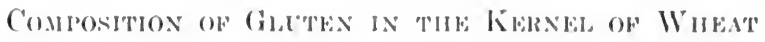

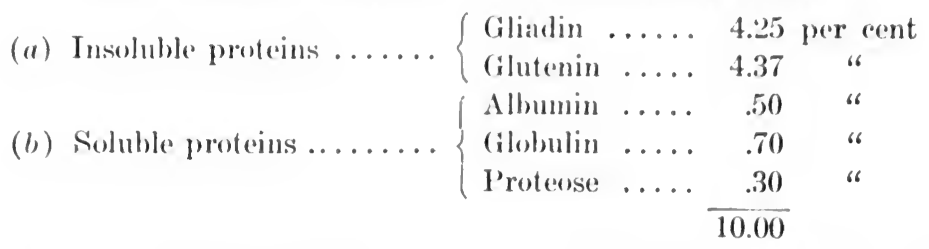

Gliadin, an albuminoid substance, is soluble in dilute acids, alkalies, 70 per cent alcohol, and slightly soluble in a solution of sodium chlorid. It gives to glnten its property of tenacious elasticity. Cilutenin is not dissolved in either alcohol or saline solution, but yiclds to dilute acids and alkalies. It is not a single or simple substance, but, aceording to Mann, a combination of gluten fibrin and gluten casein.

Conposition of Whent Grain.-The following tables, given by Professor Church, graphically portray the proportion and composition of the bran, endosperm and germ of wheat grains:

A-COMPOSITION OF THE PARTS OF WHEAT GRAIN, PERCENTAGES

\begin{tabular}{l|c|c|c|c|c|c|c}
\hline \hline & $\begin{array}{c}\text { Proportion } \\
\text { of Grain }\end{array}$ & Water & $\begin{array}{c}\text { Nitrog- } \\
\text { enous }\end{array}$ & Fat & $\begin{array}{c}\text { Starch and } \\
\text { Sugar }\end{array}$ & $\begin{array}{c}\text { Cellu- } \\
\text { lose }\end{array}$ & $\begin{array}{c}\text { Mineral } \\
\text { Matter }\end{array}$ \\
\hline Bran........ & 13.5 & 12.5 & 16.4 & 3.5 & 43.6 & 18.0 & 6.0 \\
Endosperm . & 55.0 & 13.0 & 10.5 & .8 & 74.3 & .7 & .7 \\
Germ....... & 1.5 & 12.5 & 35.7 & 13.1 & 31.2 & 1.2 & 5.7 \\
\hline
\end{tabular}

B-COMPOSITION OF ENTIRE WHEAT GRAIN, PERCENTAGES

\begin{tabular}{|c|c|c|c|c|c|c|c|c|c|}
\hline & \multirow{2}{*}{$\begin{array}{l}\text { Pro- } \\
\text { por- } \\
\text { tion of } \\
\text { Whole } \\
\text { Berry }\end{array}$} & \multirow{2}{*}{$\begin{array}{c}\text { Mois- } \\
\text { ture }\end{array}$} & \multirow{2}{*}{$\begin{array}{c}\mathrm{Ni}- \\
\text { trog- } \\
\text { enous } \\
\text { Mat- } \\
\text { ter }\end{array}$} & \multicolumn{3}{|c|}{ CARbohydrate } & \multirow{2}{*}{ Fat } & \multirow{2}{*}{$\begin{array}{l}\text { Lig- } \\
\text { nin } \\
\text { or } \\
\text { Fiber }\end{array}$} & \multirow{2}{*}{$\begin{array}{c}\text { Min- } \\
\text { eral } \\
\text { Mat- } \\
\text { ter }\end{array}$} \\
\hline & & & & Sugar & Starch & $\begin{array}{l}\text { Cellu- } \\
\text { lose }\end{array}$ & & & \\
\hline 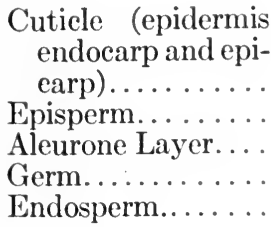 & $\begin{array}{r}4.2 \\
1.1 \\
8.2 \\
1.5 \\
85.0\end{array}$ & $\begin{array}{r}.475 \\
.131 \\
1.115 \\
.173 \\
11.050\end{array}$ & $\begin{array}{r}.362 \\
.178 \\
2.048 \\
.538 \\
8.925\end{array}$ & $\begin{array}{r}.332 \\
1.506\end{array}$ & 61.635 & $\begin{array}{r}3.997 \\
.144 \\
.590\end{array}$ & $\begin{array}{l}.745 \\
.157 \\
.680\end{array}$ & $\begin{array}{c}3.309 \\
\cdots \ldots \\
\cdots \ldots \\
\cdots \ldots \\
\cdots \cdots\end{array}$ & $\begin{array}{l}.080 \\
.060 \\
.452 \\
.070 \\
.590\end{array}$ \\
\hline Total...... & 100.0 & 12.944 & 12.051 & $1.83 S$ & $62.35 \mathrm{~S}$ & 4.731 & 1.615 & 1.615 & 1.252 \\
\hline
\end{tabular}


The percentages of the composition of the entire wheat grain are given in Table B, from Tibbles, showing more fully the proportion of constituents which is contributed by each part in the formation of the entire grain. It will be noticed by studying these tables that the germ is characterized by the protein and fat, the endosperm by an abundance of starch, and the bran by a preponderance of mineral matter and cellulose. It should be added that the germ is further peculiar in both its protein and its carbohydrate contents, chiefly present in a soluble form.

FLOUR.-Flour is made by grinding the grain of various cereals. No doubt from eating the green heads of wheat, man came gradually to store the dried grain for winter use. It is within the bounds of possibility that in time he was not long in perceiving that he might reduce the work of his teeth by triturating or beating the grains of wheat between two stones. There are to be found in archeological collections rounded pieces of sandstone which were evidently used for breaking up the seeds of grasses and grain used by man for food; not by rubbing or rotary motion: but by pounding with a roundended stone the seeds laid out upon a flat stone. There are said to be still in Ireland and other places rocks which give evidence of being used for that purpose.

Methons of Making Flour.-From the primitive methods of powdering wheat upon a flat stone with mortar-like depression came the quern or handmill, formerly used in the British Isles. This may be roughly described as an inverted mortar with a hole in the center, closely fitted over a stationary stone (pestle), which had grooves cut on its rounded surface. The grain was poured in through a small hole in the top of the quern just referred to. The next advance in grinding grain was the buhr millstone, which consists of a fixed nether millstone upon which the upper millstone is made to revolve. The motive power from the earliest times was furnished by slaves, cattle and water. After watermills came windmills, then steam and electricity.

The modern process of milling wheat is done by crushing the clean dried berry between steel rollers. This is termed the patent roller process. In the old method of milling wheat, the bran was removed but the germ was left, the meal or flour consisting of the products of the germ and endosperm together. In the elaborate process of the modern roller mill, however, the germ also is removed. It is found that the oil which is contained so abundantly in the germ is apt to become rancid, spoiling the flour. The soluble proteins which are present in that part of the grain are apt to act upon the starch of the flour, converting part of it into soluble forms, dextrins and sugar. These darken in color in the 
oven and detract from the appearance of the bread. During the process of milling, to which the whole grain is subjected, its component parts are broken up and various milling products produced. The outer coat yields bran, fine pollards and middlings, which represent different fragments of it from without inward. The germ is removed as refuse, while the flour is derived solely from the endosperm, or center of the wheat grain.

To such flour is applied the term straight run. The yield is about seventy per cent of the weight of the original grain. By mechanical processes this is further subdivided into patents and a large quantity of bakers' or household grades. 'The former is derived from the central part of the endosperm, and as prepared from ordinary wheat is rather poor in protein but rich in stareh.

Household flour is subdivided further into $(a)$ second patents, or whites; $(b)$ first households; $(c)$ second households, or "seconds."

Relative Composition of Flours. - The following table, from Bulletin No. 13, Division of Chemistry, United States Department of Agriculture, shows the relative composition of various grades of flours and milling products manufactured in America:

ANALYSES OF WHEAT AND THE PRODUCTS OF ROLLER MILLING

\begin{tabular}{|c|c|c|c|c|c|c|}
\hline & \multirow[b]{2}{*}{ Water } & \multirow{2}{*}{$\begin{array}{l}\text { Pro- } \\
\text { teid }\end{array}$} & \multirow[b]{2}{*}{ Fat } & \multicolumn{2}{|c|}{ Carbohydrates } & \multirow{2}{*}{ Ash } \\
\hline & & & & $\begin{array}{l}\text { Starch, } \\
\text { etc. }\end{array}$ & $\begin{array}{c}\text { Crude } \\
\text { Fiber }\end{array}$ & \\
\hline & $\%$ & $\%$ & $\%$ & $\%$ & $\%$ & $\%$ \\
\hline $\begin{array}{l}\text { Wheat as it enters the mill..... } \\
\text { First break. . . . . . . . . . . }\end{array}$ & $\begin{array}{l}9.66 \\
8.23\end{array}$ & $\begin{array}{l}14.18 \\
14.18\end{array}$ & $\begin{array}{l}2.61 \\
2.68\end{array}$ & $\begin{array}{l}69.94 \\
71.56\end{array}$ & $\begin{array}{l}1.70 \\
1.62\end{array}$ & $\begin{array}{l}1.91 \\
1.73\end{array}$ \\
\hline 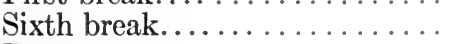 & 7.66 & 16.28 & 5.34 & 59.42 & 5.60 & 5.68 \\
\hline Bran................ & 10.91 & 16.28 & 5.03 & 56.21 & 5.98 & 5.59 \\
\hline Tailings from reduction No. 5 . . & 12.12 & 16.63 & 3.85 & 63.93 & 1.18 & 2.29 \\
\hline Second Germ............. & 8.75 & 33.25 & 15.61 & 35.19 & 1.75 & 5.45 \\
\hline Entire Wheat Flour. . . . . . . . & 11.4 & 13.8 & 1.9 & 71.0 & 0.9 & 1.9 \\
\hline 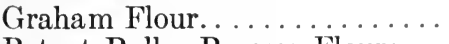 & 11.3 & 13.3 & 2.2 & 70.5 & 0.6 & 1.8 \\
\hline \multicolumn{7}{|l|}{ Patent Roller Process Flour: } \\
\hline Bakers' grade.............. & 11.9 & 13.3 & 1.5 & 72.0 & 0.7 & 0.6 \\
\hline Family and straight grade... & 12.8 & 10.8 & 1.1 & 74.6 & 0.2 & 0.5 \\
\hline High grade............... & 12.4 & 11.2 & 1.0 & 74.7 & 0.2 & 0.5 \\
\hline Low grade..... & 12.0 & 14.0 & 1.9 & 70.4 & 0.8 & 0.9 \\
\hline
\end{tabular}

The Flour Best for Food.-From what has been said concerning flour and the various analyses of different grades of flour, it may be readily understood that "whole wheat flour," "household flour" and "patent flour" have a superiority over the so-called "patent roller flour" both 
for digestibility and availability for bread making. Dr. Hamill(2) examined the evidence published with regard to the nutritive value of various kinds of flour and arrived at the following conclusions-"that whole wheat flour, both stone ground and so-called 'standard,' or eighty per cent flour, contains less available protein than patent or standard patent flour:" He says "there is a difference in entire wheat flour and eighty per cent flour owing to the presence of small particles of bran and the germ of wheat, which contain additional constituents and possess a value of their own in nutrition. Among the component constituents are phosphorus containing organic compounds and other substances, which may prove to be of importance in nutrition."

Tibbles(3) believes that a vast difference exists in the effect on animals of entire wheat meal flour and ordinary wheat flour. This difference, he holds, is neither due to protein nor phosphates, but he alleges that it has been shown that the value of different parts of the grain for nutritive purposes eannot be determined merely by an estimation of the protein, fat and carbohydrates. The entire wheat grain when it leaves the harvest contains all of the elements necessary for the growth and development of a wheat plant, and there is nothing in the wheat berry which is not of use for the proper growth of the young sprout. Various feeding experiments have been conducted to determine the value of whole wheat flour and standard or patent flour. Hill and Flack(4) have conducted a series of experiments with rats fed on whole wheat flour, standard flour and Hovis flour(5). The rats grew normally on whole wheat flour and produced young; but another cage of rats fed on white flour did not thrive and failed to produce young or, when they did, the young did not thrive. It was shown by Tibbles that the nutrition of rats fed on white flour was likely to suffer from the absence of cellulose, this element being necessary for the nutrition of animals possessing a long intestinal canal. Dogs fed exclusively on bread baked from patent roller flour die within eighteen to twenty-five days, whereas dogs fed exclusively on whole wheat flour at the end of thirty days were hearty and thriving. Edie and Simpson(6) fed eages of pigeons on white bread, whole wheat bread and standard bread. Those fed with standard bread maintained their weight, paired and laid eggs; those fed with white bread immediately began to lose weight and manifested illness, developing polyneuritis, the beri-beri of fowls. Some of the latter died, others were eured and recovered their weight and fitness when fed on whole grain or whole grain and yeast.

As a result of these experiments it was concluded that the outer por- 
tions of the grain of wheat which were romoved in the milling process included substances which are necessary for growth, maintenance of mitrition and even life itself. These substances are important both for the growing and adult animal. The milling of wheat, then, is a question of national importance. The flom from which the bread was made that nourished our sturdy forefathers was not made in a patent roller process mill but was ground on an old-fashioned buhr millstone. The finished flour contained all of the starch and cereal salts that nature grew into the wheat berry. An old English anthor in writing on this subject says: "Whatever mixtmes of grain or qualities of bread might be the food of some of our ancestors, the common standard of bread from Alfred the Great's time down to the time of Queen Anme was three-fourths of the wheat which represented all of the flour." The writer says that all went well for eight hundred years, but in the time of Queen Anne it was thought proper to have three sorts of bread, "so that instead of flour for bread, and bran that remained, assize bread beeame a mystery, and we no longer knew what we were eating." Tibbles( 7$)$, in summing up this writer's views, says:

The miller divided the flour, but in the attempt to prepare one for white, another for wheaten and the third for household bread, the inferior kind became disagreeable to the taste of those accustomed to finer bread. The inferior bread contained the pollard and fine bran, which few people chose to eat if they could obtain the finer kind, and so the people, rejecting what they ealled "brown" bread, took to the wheaten, which they called "white" bread, and from that day to the present the greatest attention has been paid to the production of the finest and whitest bread. But to obtain the finest flour and whitest bread it has become necessary to remove all the bran and the germ. By so doing, however, the miller and baker have impoverished the flour and bread of some of the most important constituents of the wheat grain, viz., the vitamines, enzymes, activators, aminoacids and lipoids, which only exist in the germ and subpericarpal layers of the bran of wheat. The removal of these substances does not matter very mueh in the ease of well-to-do families, where fresh milk, animal foods and vegetables containing vitamines are constantly a part of the daily diet. But it matters greatly to the children of the poor, whose chief diet is white bread.

Whole Wheat Flour. - Whole wheat flour is the product of the entire wheat grain as it leaves the harvest field and contains absolutely everything within the epidermis of the wheat berry-the whole ghten, the germ with its rieh protein and oils and all of the salts and all of the starches. Whole wheat flour is the most perfeet wheat produet that the ingenuity of man has devised. It is practically wheat meal containing all the proteins, fat, carbohydrates and minerals which nature grew in 
the wheat berry. No sieves, bolters or dressers are used in its manufacture. The presence of bran prevents the product from being very fine, consequently many coarse particles of bran and unpulverized kernel can be detected in the finished product. Ordinary white flour produced by the patent roller process contains 44 per cent of mineral matter, while whole wheat flour contains 1.75 . per cent mineral matter.

BREAD.-Bread, ordinarily made from a mixture of "whites" and "households," is derived most commonly from a blend of different wheats. The best blends for this country are made up from admixtures of hard winter wheat with white spring wheat. The advantage of blending is that the deficiencies of one kind of gluten are made up for by the excesses of another. Ghuten is a composite substance, and since some wheats are richer in some constituents and other wheats in others, by suitable blending a flour can be produced, which is not only "strong," but has also a good color and flavor.

Historical Tracings of Bread Making.-Bread making is an ancient art, and, like the origin of grinding grain, antedates history. ChingNong, 1998 B. c., is reputed to have been the first who taught men (the Chinese) the art of husbandry and the science of making bread from wheat. The Greeks attributed the discovery of bread making to the god Pan, but bread was in use among the Chaldeans and Egyptians before the Greek gods had their inception. Its earliest form was probably unleavened bread, consisting of bannocks, made from bruised and broken cereals, mixed with water or water and oil.

In the days of the patriarch Abraham cakes were made which were thought to be a fit offering for the angels. His wife Sarah mixed flour and water together, kneaded it and baked bread, using the hearth for an oven and hot ashes for heat. Prior to the bondage of the Israelites in Egypt baking had become a highly perfected art. The Egyptians used several varieties of flour and made cakes of many kinds and shapes.

According to profane history, one of the most important of servants in the service of Pharaoh during Joseph's régime was a professional baker. The staple product of the country seems to have been a cereal (corn in the British sense, not maize, Indian or American corn), which Joseph gathered and stored away during the seven years of plenty and sold during the seven years of famine.

From Egypt the art of baking spread to Greece, thence to Rome, where the bakers formed a guild or a kind of trades union. In Europe, however, the art of baking antedated the knowledge of the Egyptians, for excavations made in Switzerland at the site of the prehistoric lake 
dwellings not only revealed grinding stones for milling purposes but also revealed evidence of the baking art in the presence of charred loaves of bread. It would seem that not infrequently these pile dwellings, like those of modern min, would eatch fire. The charred bread, still retaining the form of the grains, cooking utensils, ete, would drop from the burning building and sink to the bottom of the lake, to remain a mute but sure witness to the customs of those remote days, for charcoal is not susceptible of decay and is practically everlasting when once burned.

The cakes were rombl, an inch or an inch and a half thick, flat or slightly concave on the bottom, giving evidence of having been baked by placing them on heated rocks and covering them with hot ashes. The material of which the loaves were made was not flour or meal as we understand the terms, but grains of cereal broken up into larger and smaller particles.

Process of Home Baknga.-Bread is the most widely used product of wheat and is made in many different forms and varieties. As made in the home, bread is usually prepared by mixing yeast with a flour hatter and leaving it to ferment for several hours. During this process alcohol and carbonic acid gas are produced which make the mass vesicular and cause the dough to "rise." Gluten, a mixture of proteins, has the peculiar property of becoming viscid when mixed with water. The yeast causes a liberation of gas that blows up the viscid mass, which yet possesses sufficient coherence to remain in the form of a honeycomb or sponge. Without this coherence, light bread could not be made. The manufacture of good bread depends largely upon whether the flour contains a fair percentage of gluten or not. It is the proportion of gluten rather than starch which determines the character of the bread, and the character of the gluten is even more important than its proportion. The right proportions of glutenin and gliadin, the component parts of gluten, affect the stability of the latter, so necessary for the production of a porous spongy bread that will retain its moisture. In the making of bread, alcohol forms in the sponge or dough, incident to the yeast fermentation.

Sour Bread.- In the process of baking, the alcohol is almost entirely driven off and the yeast germs killed. If the bread be not thoroughly baked some of the alcohol may be retained in the loaf and the life of the yeast may not be completely destroyed. This will cause the bread to sour when it is a day or two old.

Hот Bread. - While it is true that hot bread forms larger doughy masses in the stomach than stale bread and resists the action of the 
digestive juices a little longer, yet in healthy persons the digestive process is not materially prolonged. A well-baked loaf should have a botton, top, side and end crust which is hard and resonant, while the crumb is elastic and spongy. Such a loaf when stale and slightly dried should be prescribed for dyspeptics, because it crumbles into fine particles and is more easily mixed with the salivary juices during mastication. Hot bread can be made without the aid of yeast; its "rising" properties are conferred upon it by the chemical action of soda or baking powder.

Bread Leaveners.-Bicarbonate of soda is an alkali. If great care is not used, some of it will remain unneutralized on account of the insufficient acid in the product. In making biscuit, cream of tartar and bicarbonate of soda are usually used, in the proportion of two and one-quarter level teaspoonsful of cream of tartar and one level teaspoonful of soda to one pint of flour. During the kneading and baking a chemical reaction takes place, and Rochelle salt is the product which is left in the batch of biscuits to the amount of two and one-half teaspoonsful. Rochelle salt and many other chemicals in food are not food, cannot be used by the body, and must be eliminated. This puts extra and uncalled-for work upon the organs of elimination, especially those whose function it is to destroy poisons. When soda is used with milk, sodium lactate is left in the bread; when combined with vinegar or molasses, sodium acetate is left behind. All these chemicals interfere with digestion and with the life processes of the body, and affect chiefly those who are not vigorous and who, from their vecations, are kept indoors.

Alum is also used as a leavener in bread making. It lessens the nutritive value of the bread by converting the phosphates into aluminum phosphate. In excess, this is a prolific source of dyspepsia and constipation.

A Ërated Bread.-Aërated bread is made without the aid of yeast. By this means fermentation is avoided and some of the starch saved. Such bread is usually made by machinery, no human hand ever touching the flour, dough or finished loaf. The process is this: "Flour is poured into the machine; the atmospheric air is abstracted and its presence replaced by carbonic acid gas; the dough is made with aërated water; the kneading is done by a machine, which turns out the dough into tins, which are kept moving orer the fire until the loaves are done to a turn." Such bread is light and spongy and has the advantage of cleanliness, besides being free from sources of overfermentation. With the use of aërated bread heartburn, indigestion and flatulence become less frequent. 
Yeast bread, howerer, by reason of its high vitanine content, is more wholesone than ariated breat.

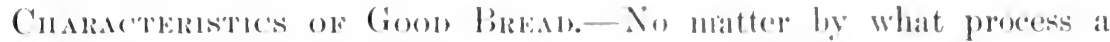
loaf of bread is made, it should possess cortain chatracteristics: (a) it should be well "risen"; $(b)$ it should possess a thin, flinty crust, neither very light nor dark in color, and sufticiently brittle to break easily; (c) the erumb should be elastie, of uniform texture without large holes, and of a smooth and silky "pile"; (d) it should have a sweet nutty flavor and odor; $(e)$ in color it should be neither light nor dark; $(f)$ the erumb shonld be of a ereany whiteness when made from white patent flour.

Digestibility and Amsorption of Breall. - The digestibility of bread has been easually referred to and the notorious indigestibility of new bread pointed out. The more thoronghly bread is chewed and ground into fine particles by the teeth, the more complete will be the transformation of the stareh. It is due to the greater ease with which they can be pulverized by the teeth that dry toast and ordinary stale bread are more easy to digest than newly baked loaves. The dryess of the toast enables the bolus to become more thoroughly insalivated during mastication. As a result, it is readily converted into soluble forms. For this reason the crust of bread is more easily digested than the crumb. From the action of saliva on breadstuffs digestion continues sparingly in the stomach. When it reaches the intestine the final digestion of the stareh and protein takes place and absorption begins. When properly digested bread is almost entirely absorbed.

Some of the most conclusive experiments in the absorption of bread, made from the three following grades of flours, were made by Rubner and are quoted here:

1. Finest white "patent roller"

2. Middle quality "seconds"

3. Whole wheat flour.

The amount of nutrients contained in the loaves made from each grade was as follows:

ABSORBABILITY OF BREAD MADE OF VARIOUS GRADES OF FLOUR

\begin{tabular}{|c|c|c|c|c|}
\hline & Nitrogen & Fat & $\begin{array}{c}\text { Carbo- } \\
\text { hydrates }\end{array}$ & $\begin{array}{l}\text { Mineral } \\
\text { Matter }\end{array}$ \\
\hline No. & 10.20 & 6.69 & 528.8 & 2.39 \\
\hline No. 2 & 13.19 & 5.65 & $50 \pi .9$ & 2.85 \\
\hline No. 3 & 12.45 & 12.65 & 504.5 & 8.54 \\
\hline
\end{tabular}


Bread No. 1 contained 68.5 per cent water; No. 2 had 69.4 per cent; No. 3, 62.4 per cent. The percentages of loss from non-absorption were these:

\begin{tabular}{|c|c|c|c|c|c|c|}
\hline & $\begin{array}{l}\text { Quantity } \\
\text { of Dry } \\
\text { Substance } \\
\text { Eaten }\end{array}$ & $\begin{array}{c}\text { Per cent } \\
\text { Dry } \\
\text { Substance } \\
\text { Lost }\end{array}$ & $\begin{array}{l}\text { Per cent } \\
\text { N. Lost }\end{array}$ & $\begin{array}{l}\text { Per cent } \\
\text { Fat Lost }\end{array}$ & $\begin{array}{c}\text { Per cent } \\
\text { Carbo- } \\
\text { hydrate } \\
\text { Lost }\end{array}$ & $\begin{array}{c}\text { Per cent } \\
\text { Ash } \\
\text { Lost }\end{array}$ \\
\hline No. 1 & . . 615.3 grams & s 4.03 & 20.07 & 44.69 & 1.10 & 19.28 \\
\hline No. 2 & . 6 612.6 "6 & 6.66 & 24.56 & 62.83 & 2.57 & 30.35 \\
\hline No. 3 & . 6 617.1 & 12.23 & 30.47 & 51.14 & 7.37 & 44.98 \\
\hline
\end{tabular}

The absolute losses were:

\begin{tabular}{|c|c|c|c|c|c|}
\hline & $\begin{array}{l}\text { Fresh } \\
\text { Feces }\end{array}$ & Dried & $\mathrm{N}$. & Fat & $\begin{array}{l}\text { Carbo- } \\
\text { hydrates }\end{array}$ \\
\hline No. $1 \ldots \ldots$. & 132.7 & 24.8 & 2.17 & 2.99 & 5.83 \\
\hline No. $2 \ldots . . .$. & 252.8 & 40.8 & 3.24 & 3.55 & 13.10 \\
\hline No. $3 \ldots . . .$. & 217.8 & 75.7 & 3.80 & 6.47 & 37.23 \\
\hline
\end{tabular}

He draws especial attention to the great absolute loss of carbohydrate in the whole wheat bread.

More recent experiments have been unade in this country(8), in which the absorption of bread made from patent and bakers' flour, respectively, was studied, 672 grams (24 ounces) of bread being taken daily. The results were:

\section{ABSORBABILITY OF BREAD FROM BAKERS' AND PATENT FLOUR}

Per cent Digested

\begin{tabular}{|c|c|c|c|c|}
\hline Bread & Dry Matter & Protein & Fat & Carbohydrates \\
\hline "Bakers" " & 94.2 & 91.0 & 94.6 & 96.8 \\
\hline "Patents" & 94.4 & 90.5 & 94.7 & 96.9 \\
\hline
\end{tabular}

No difference was found in this case between the two kinds of bread. In another set of experiments white bread, entire wheat and graham bread were compared, with the following results $(9)$ :

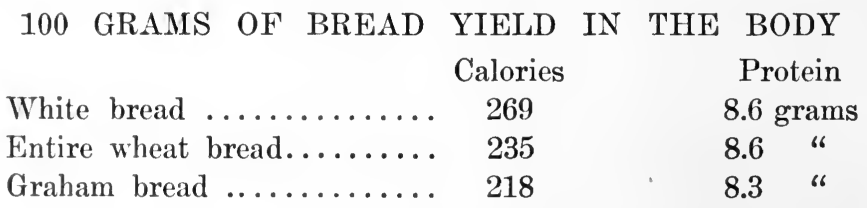

"Taking the results as a whole, it may fairly be concluded that the protein of whole wheat bread is not so well absorbed as that of white bread. Even bread made from decorticated wheat does not offer the advantages often ascribed to it, for exact experiment has shown that it is not much better alsorbed than ordinary whole wheat bread."

Two-thirds of a loaf of bread is made up of gas and the solid part, 
about 30 per cent to 35 per cent by weight, consists of water, so that bread is one of the least watery of regetable foods, relatively much less so than raw meat.

Nurritue Vatue of Brean.- - Taking weight for weight, though by no means bulk for bulk, bread can be regarded as one of the most nutritious of our ordinary foods. It contains most of the chemical constituents necessary for proper nutrition. It yields a large proportion of carbohydrates, a moderate amount, of protein and mineral matter, but searcely any fat. For this reason it camnot be regarded as a perfect food.

From an economic point of view bread is not only the most nutritions but it is also among the cheapest of omr foods, both in regard to the actual weight of nourishment obtained and in regard to the variety of nutrient constituents.

Sawdust axi Woony Fiber Brean.-In Sweden and Norway sawdust is sometimes converted into bread, for which purpose beech or some wood which does not contain turpentine is repeatedly macerated and boiled in water to remove soluble matters and then reduced to powder, heated several times in an oven and ground. In this state it is said to have the smell and taste of corn flour. (Tomlinson's "Cyclopedia of Useful Arts," vol. ii, p. 926.)

Bread has been made in times of famine of a variety of substances; thus, in the years 1629, 1630 and 1693 , very good, wholesome, white bread was made from boiled turnips in England. The moisture was pressed out of the turnips, and they were then kneaded with an equal quantity of wheaten flour. (Beckman's "History of Inventions," vol. i, p. $349,1846$.

During the late siege of Paris the bread served out constituted a very coarse and mixed article. In Sheppard's "Shut Up in Paris," p. 309, it is stated to have been found by analysis to be comprised of one-eighth wheat, four-eighths potatoes, peas, oats and rye, two-eighths water, and the remaining one-eighth straw, hulls of grain and the skins of vegetable products.

During the present European war it is claimed that Germany has resorted to the use of sawdust in hread making. A friend of the author, traveling in Germany and Switzerland in 1916, was presented with a loaf of this bread which was being used as food for the English and Freneh prisoners.

RICE.-Rice is more widely used for food than any other cereal except wheat. It is the staple cereal in Oriental countries, where hundreds of millions of people depend upon it as their chief source of starchy foods. 
Cultivation of Rice.-Rice is grown in low alluvial lands, and requires in the early part of its production that the fields or squares on which it is growing be actually flooded with water. "During germination and growth of the crop, water is allowed to flood the ficld several times; between times the earth is allowed to dry while the young rice is hoed or worked." When rice is threshed it contains a brown husk, which is today removed by a hulling machine. In former days it was removed by means of a large mortar and pestle worked by hand. Until recent years the simple process of hulling rice was considered satisfactory, but a demand for a whiter and a more highly polished rice has brought about the perfection of elaborate machinery, in which, by means of leather belts, the outer layer of the grain is rubbed off, and with it most of the nutritive material of the grain is lost. The practice of polishing rice continues, and as a result the best of this important food is separated, to be used as a food for stock, instead of remaining with the grain to enrich the food of human beings.

Conposition of Rice.-The average composition of rice, as harvested, hulled and polished, is shown in the following table(10):

\section{COMPOSITION OF RICE}

\begin{tabular}{|c|c|c|c|}
\hline & In the Husk & Hulled & Polished \\
\hline Water... & 10.50 & 12.00 & 12.40 \\
\hline Protein............. & 6.80 & 7.20 & 6.90 \\
\hline Fat...... & 1.60 & 2.00 & 0.40 \\
\hline Starch, Sugar and Gum.. & 68.10 & 76.80 & 77.40 \\
\hline Cellulose.............. & 9.00 & 1.00 & 0.40 \\
\hline 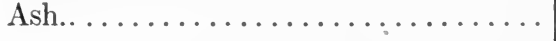 & 4.00 & 1.00 & 0.50 \\
\hline
\end{tabular}

From a study of this analysis it will be seen that rice is poor in proteins ( 6 per cent) and fat, and is, therefore, not a suitable form of food for any individual or nation, unless served with eggs or milk, as in puddings, or with meat, fish or peas, to furnish a well-balanced ration.

Digestion and Absorption of Rice.-Rice is only moderately easy of digestion, but is absorbed with very great completeness in the intestine; indeed, its solid constituents enter the circulation almost as completely as those of meat. This ease of absorption is due to the small amount of cellulose. The fact that rice leaves very little residue in the intestine is of value in certain cases. Its nutritive value is reduced by its deficiency in protein and fat as well as by its impoverished condition due to the process of polishing the grain. 
Polished Rice: Its Ixsurachencr.-The insufficiency of white or polished rice as a food has been studied by physiologists, dietitians and physicians, and the reports of researches along this line are numerous. Kajiura, in collaboration with Rosenheim(11), published the results of their researches concerning the proteins of rice. 'This does not appear to have been as thoronghly accomplished by any previons workers in this field. They established the fact that rice is wholly lacking in protein soluble in alcohol, such as gliudin in wheat and hordein in barley. They were convinced that the lack of such a protein in polished rice might account for its insufficiency as a food. They fed groups of birds on rice plus gluten, rice plus hordein and rice plus calcium carbonate and phosphate. In all cases the birds died after varying lengths of time. Control birds fed on whole barley grew normally and were maintained in a good condition of health. These various observations were not sufficient to prove that the lack of gliadin or hordein was directly accountable for the different effects of barley and polished rice.

Polished rice is rice which, in the process of milling, has been deprived of its husk or shell, pericarp, subpericarpal layers and the germ. From the thresher the rice is sent to the mills in barrels holding about 162 pounds each. From this quantity of rough rice the mills secure 95 pounds of clear rice, 8 pounds of polished rice, 30 pounds of bran and 29 pounds of waste. The rice polish and the rice bran are mixed and sold as a foodstuff under the name of rice food or rice meal. It is very nutritious and is largely employed as a food for pigs. After the process of milling and polishing the end of each grain shows a depression which, in the entire grain, contained the minute yellowish embryo. The removal of these structures leaves a grain composed of cells packed with starch. The substances removed during polishing are driven off by centrifugal force through the meshes of a wire cloth. They form rice polishings, rice bran or meal. This material contains the embryo, the aminoacids, the vitamines and other substances contained in the outer layers of the rice. Fraeser and Stanton(12) carried on a series of investigations and were convinced that the deeper lavers of the pericarp, removed in polishing rice, contain a substance or substances essential to the organism. These results agree with many observations since made on the subject. An alcoholic extract has been made from rice polishings and administered to birds and human beings suffering from beri-beri caused by eating "white rice." This has effected a cure. Simpson, Webster and others(13) confirm the discovery that rice bran and its alcoholic extracts contain substances of a protective and curative nature. Their method of 
securing this curative was by concentrating the extracts under a fan instead of on a water bath, thereby showing that the protective substances are destroyed by moderate heat. Casimir Funk, in a long research at the London Lister Institute, has done a vast amount of work in connection with the "protective substances," to which he gave the name of vitamines. These are nitrogenous substances, probably amins, and highly essential to life. The important truth learned from the researches of these investigators is that we seem here to be dealing with a compound or with compounds which cannot be classified under any of our accepted foodstuff's, protein, fat, carbohydrate or inorganic salts. Small quantities only are needed for health, and the organism may be deprived of them without serious consequences for considerable periods of time. Continued deprivation, however, leads inevitably to death.

CORN.-Corn is a cereal peculiar to this country, unknown until the discovery of America. The progenitor of our Indian corn (according to the Popular Science Monthly) was a plant of the grass family, growing wild on the plateaux of Mexico and Central America thousands of years ago. It was originally, no doubt, a tropical or subtropical plant, but the Indians, though unconscious of the trend of their attempts to extend corn growing, nevertheless succeeded in evolving varieties which would ripen as far north as Canada. The desire to produce corn crops was probably the incentive which led the Indians to abandon nomadic life and to form settlements. After the discovery of America the use of corn and its cultivation spread rapidly to other countries, and it is now very extensively cultivated in all regions of the earth where it will grow.

So generally has it come into use that it now ranks with wheat, rice, rye, barley and oats as one of the food grains of the world, and it may be called the American Indians' gift to modern civilization.

Parts of the Corn Grain.- The grains of corn grow in double rows along a woody cob, from which they are easily shelled when ripe and dry. The seed or grains are not inert but living things, which under favorable circumstances will produce a new plant. Roughly speaking, the seed consists of three main divisions: the skin, the germ and the endosperm. The outer skin composes about six per cent of the entire weight of the grain and serves as a protection to the delicate interior parts. It is made up principally of a tough cellulose or erude fiber, containing some mineral matters embedded in it. The germ in corn is larger than in most cereals and forms, in average corn, about ten per cent by weight of the grain.

The germ contains the embryo, from which a new plant will develop 
under favorable circumstances. The ondosperm constitutes about 84 per cent by weight of the grain and represents the food which the parent plant has stored for the early growth of its offspring. It has been determined by analyses that 51 per cent of the cellulose of the grain is formed in the skin or husk; 65 per cent of the fat and about 16 per cent of the protein are found in the germ; $90 \mathrm{per}$ cent of the starch and 84 per cent of the protein in the endosperm.
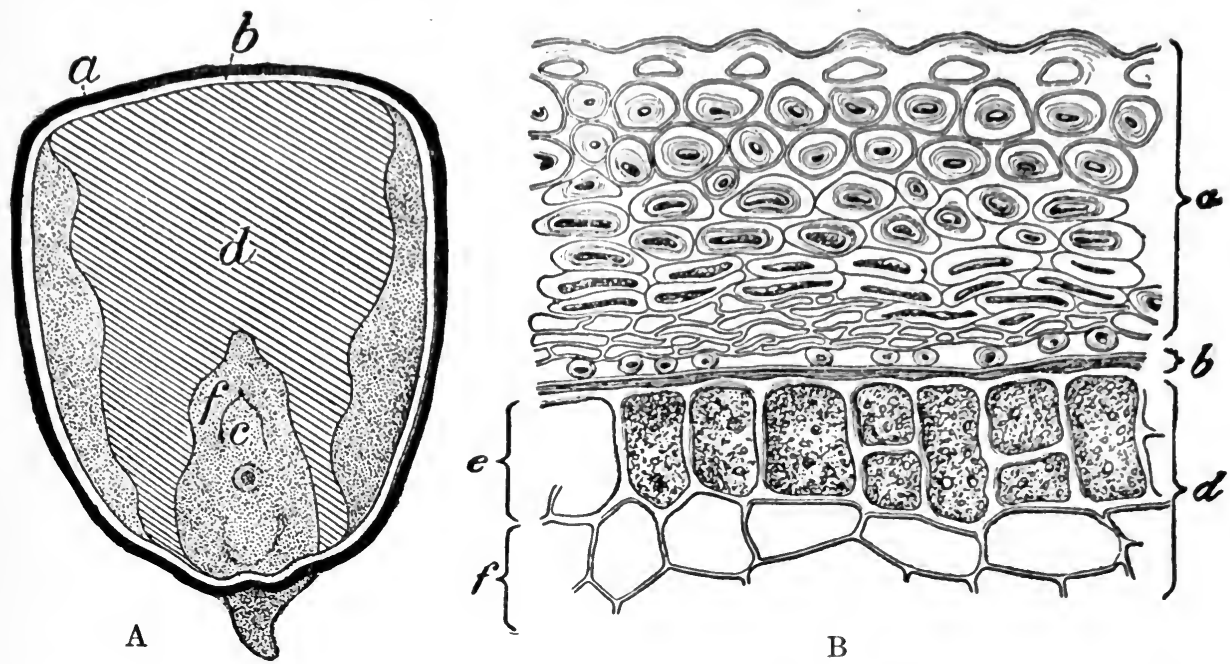

Fig. 31.-Diagramatic Section of a Grais of Cors. A.-(a) skin and testa, (b) membrane, (c) embryo, (d) endosperm, (f) scutellum.

B.-Cellular structure of the grain; (a) skin and testa, (b) membrane, (d) endosperm, (e) starch cells. (Bull. No. 295, U. S. Dept. Agric.)

On the basis of numerous studies it can be stated that the different varieties of corn differ little among themselves in nutritive value, and that when matured and ripened the enrn crops of various parts of the world are practically identical in composition. The fuel value, or, as it is often called, the energy value, is 1,795 calories per pound. This cereal is used to a large extent as a food for both man and animals in various parts of the world. As stated above, corn contains proteins which maintain weight and promote growth and development. The growth of animals fed on corn progresses normally, and it appears that the effective protein is maize glutelin. Osione and Mendel carried ont a series of feeding experiments and found that animals fed on zein, the ehief protein of corn, did not thrive; animals fed on maize glutelin, however, did well. Casimir Funk(14) has come to the conclusion that the pericarp or outer layers of the grain of corn contain vitamines. 
Cons Mruming.-The method of grinding corn meal varies in different countries. The primitive methods of grinding corn on revolving millstones retain in the meal the principal part of the salts, protein, fat and lipoids; this so-called water-ground corn meal was a very nutritious, wholesome product, but the modern methods of milling corn deprive the meal of much of its salts, a considerable proportion of its protein and a large part of its fat and lipoids. The ancient method of milling corn between revolving stones is still prevalent in this country and more particularly in the South. Meal so prepared makes the most palatable bread. Such meal having only the coarse bran removed has nearly the same composition as the entire grain.

Water-ground corn meal has the disadvantage of being hydroscopic, and its higher fat content makes it apt to become musty, especially in the summer months. This makes no difference in the South, where mills are convenient and where one can have fresh water-ground corn meal without trouble. The tendency to become musty is remedied by the modern milling methods, which substitute steel rollers for stones. The rollers flatten the germ without breaking it, thus making it possible to remove it in its entirety. The fat in the germ, when separated, is called corn oil, and is used in many ways in the arts and for culinary purposes. It is also likely to become rancid. The removal of the germ and the kilndrying of the meal lessen the probability of the meal becoming musty and at the same time, on account of the removal of the germ, reduce materially the percentages of fat, cellulose, mineral matter and protein. The water-ground corn meal then contains a larger percentage of vitamines than corn meal made according to the new process.

Analyses of Corn.-Below is a table giving the comparative cost of nutrients and the fuel value from the principal cereal grains:

COMPARATIVE COST OF NUTRIENTS AND ENERGY IN THE GRAINS AND FLOURS

\begin{tabular}{|c|c|c|c|c|}
\hline Food & $\begin{array}{c}\text { Price } \\
\text { per pound }\end{array}$ & $\begin{array}{l}\text { Cost of } \\
1 \text { pound } \\
\text { Protein }\end{array}$ & $\begin{array}{c}\text { Cost of } \\
1,000 \\
\text { Units of } \\
\text { Energy }\end{array}$ & $\begin{array}{l}\text { Energy } \\
\text { Units for } \\
10 \text { cents }\end{array}$ \\
\hline 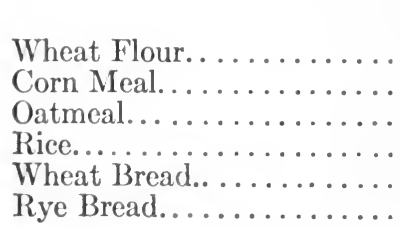 & $\begin{array}{l}\text { Cents } \\
3 \\
21 / 2 \\
4 \\
8 \\
6 \\
5\end{array}$ & $\begin{array}{c}\text { Dollars } \\
.31 \\
.32 \\
.29 \\
1.18 \\
.77 \\
.64\end{array}$ & $\begin{array}{c}\text { Cents } \\
2 \\
2 \\
2 \\
5 \\
5 \\
4\end{array}$ & $\begin{array}{c}\text { Calories } \\
5,440 \\
5,540 \\
4,500 \\
2,025 \\
2,000 \\
2,400\end{array}$ \\
\hline
\end{tabular}


From the preceding table the relative economy of corn meal is apparent. The smaller cost of rye among the breads is also noticeable. However, the relative differences are not great and appetite may well be consulted in choosing between them.

A further analysis of corn, taken from Farmers' Bulletin 298, United States Department of Agriculture, shows the average composition of corn and corn products:

\section{AVERAGE COMPOSITION OF CORN AND CORN PRODUCTS}

\begin{tabular}{|c|c|c|c|c|c|c|c|}
\hline \multirow[b]{2}{*}{ Kind of Material } & \multirow[b]{2}{*}{ Water } & \multirow{2}{*}{$\begin{array}{l}\text { Pro- } \\
\text { tein }\end{array}$} & \multirow[b]{2}{*}{ Fat } & \multicolumn{2}{|c|}{ Carbohydrates } & \multirow{2}{*}{$\begin{array}{l}\text { Min- } \\
\text { eral } \\
\text { Mat- } \\
\text { ters }\end{array}$} & \multirow{2}{*}{$\begin{array}{c}\text { Fuel } \\
\text { Value } \\
\text { per } \\
\text { pound }\end{array}$} \\
\hline & & & & $\begin{array}{c}\text { Stareh, } \\
\text { Sugar, } \\
\text { etc. }\end{array}$ & $\begin{array}{l}\text { Crude } \\
\text { Fiber }\end{array}$ & & \\
\hline & $\%$ & $\%$ & $\%$ & $\%$ & $\%$ & $\%$ & Cal. \\
\hline Corn, whole grain, average... . . & 10.8 & 10.0 & 4.3 & 71.7 & 1.7 & 1.5 & 1,795 \\
\hline Corn with low protein content. & 10.5 & 6.0 & 3.8 & \multicolumn{2}{|c|}{78.5} & 1.2 & 1,685 \\
\hline Corn with high protein content. & 10.5 & 12.9 & 4.4 & \multicolumn{2}{|c|}{70.8} & 1.4 & 1,695 \\
\hline Corn, white.............. & 11.4 & 10.8 & 5.0 & 68.8 & 2.5 & 1.5 & 1,690 \\
\hline Corn, yellow. ...... & 11.9 & 10.7 & 4.8 & 68.9 & 2.2 & 1.5 & 1,690 \\
\hline Sweet Corn (matured) & S. 8 & 11.6 & 8.1 & 66.8 & 2.8 & 1.9 & 1,750 \\
\hline Pop Corn............ & 10.7 & 11.2 & 5.2 & 69.6 & 1.8 & 1.5 & 1,710 \\
\hline Hominy, fine... & 11.0 & 9.4 & .7 & 78.2 & 4 & .3 & 1,810 \\
\hline Samp, coarse... & 10.8 & 8.3 & .5 & 79.4 & .4 & .3 & 1,770 \\
\hline $\begin{array}{l}\text { Corn Meal (whole grain ground), } \\
\text { unbolted........................ }\end{array}$ & 12.0 & 8.7 & 4.7 & 71.1 & 2.2 & 1.3 & 1,850 \\
\hline $\begin{array}{l}\text { Corn Meal (whole grain ground), } \\
\text { bolted.................. }\end{array}$ & 12.0 & 8.9 & 4.9 & 72.0 & 1.2 & 1.0 & 1,765 \\
\hline Corn Meal, granulated ........ & 12.5 & 9.2 & 1.9 & 74.4 & 1.0 & 1.0 & 1,770 \\
\hline $\begin{array}{l}\text { Corn Flour, i.e., finely ground } \\
\text { and bolted eorn............ }\end{array}$ & 12.6 & 7.1 & 1.3 & 77.5 & .9 & .6 & 1,645 \\
\hline Corn Starch... . . . . . . . . & & $\ldots$ & & 90.0 & ... & & 1,675 \\
\hline Liquid Glucose (for table use). & 16.0 & & & 83.5 & $\ldots$ & .5 & 1,120 \\
\hline Corn Oil................ & $\cdots$ & $\ldots$ & 100.0 & $\ldots$ & $\ldots$ & $\ldots$ & 4,040 \\
\hline
\end{tabular}

Fuel Value of Corn.--Chemical analysis shows that corn is high in fuel value, somewhat deficient in protein and mineral matter, slightly below the average for the cereal group. Its energy or fuel value, however, is highest of all the cereals in the list, being approximately 1,800 calories per pound, or about 100 calories above the average. Its high caloric value is dne in part to the percentage of fat, which is 4.3 per cent, while the average of other cereals is 2.5 per cent. 
Normal Crop.-It is estimated by the Department of Agriculture that the normal crop of corn exceeds 3,000,000,000 bushels. There are regions in the South and West in which corn is not only the principal cereal product but also the most important of all articles of diet. In certain sections of this territory, wheat flour is of secondary importance and in some places is used but little.

In many Southern families, even in the cities, corn meal in some form is eaten three times a day and in most families at least once a day. These facts have been given some significance in recent years by those who regard corn as an etiological factor in the production of pellagra(15).

Conn Meal.-Corn meal is the chief product manufactured from maize. In the early days the methods were crude. The Indians ground corn between two flat stones or pounded it to a powder and removed the bran by winnowing in sieves and similar devices. The old process meal was ground on buhr millstones. The new process meal is produced by improved machinery, and the character of the meal is influenced by the amount of the different elements of the grain retained in the finished meal. The difference in chemical variation between whole corn (unbolted) meal old process and corn meal bolted new process is the loss in the latter of about one-eighth of the grain. This loss consists chiefly of the cellulose of the skin. The removal of this material increases the proportion of the other materials present, leaving the new process meal richer in nutrients other than crude fiber than unbolted meal.

Spoiling of Corn Products.-The spoiling of corn products is most common at the season when the whole kernel is ready to germinate and the germ tissue is active. This occurs in the spring, during the germinating season, as a result of moisture and high temperature. A control of these factors offers the hope of checking spoiling. Meal, to be kept through the germinating season, should be kept in cold storage. Water-ground corn meal is likely to spoil, even during the winter months, if it contains an excess of moisture or is stored in a warm place. This is one feature in the manufacture of corn meal which increases the possibility of spoiling(16).

It has long been understood by the miller that the presence of the germ in meal increased the tendency to spoil. Grits keep better than meal from whole corn. Recent examinations made by the Bureau of Chemistry of the United States Department of Agriculture show that, in comparison with whole-kernel meal prepared from corn, degerminated bolted meal, both dried and undried, has better keeping qualities. Meal 
ground from whole grain, even when thoronghly kiln-dried, is likely to develop acidity in so short a time as to demand immediate eonsumption. Meal of this type is of greater mutritive value, is more oily in flavor and more palatable. It shoud be milled locally and in small quantities and consumed at once.

White axn Yeloow Coren Meat. - $\mathrm{A}$ study of the table given on page 395 shows that there is no appreciable difference in the composition of white and yellow corn meal so far as the nutritive value is concerned. The "mutty" flavor of the white and the peculiar flavor of the yellow meal are due to the presence of certain volatile bodies retained in the fat. Hominy, samp and granulated corn meals resemble each other in composition. Such differences as those indicated in the table are no greater than might be expected in a number of individual samples of either food material.

Corn Breans and Pudphas. - Since corn does not contain a true gluten like wheat, it camnot be used for baking ordinary bread with yeast, as the protein of corn is lacking in the quality of tenacity. Corn breads, therefore, though of great variety, fall into three classes: Those "raised" by air beaten into them, those "raised" by baking powder, and those "raised" by soda and sour buttermilk. The granular character of the meal favors the making of the first class; the second elass is made light by the earbon dioxid of the baking powder or through the action of sour milk or soda. The simpler breads, like ash cake, hoe cake, johnny cake, corn dodgers, corn pone, crackling corn bread, are very old types, resembling the bread of the primitive peoples.

Some of the modern methods of preparing eorn meal have resulted in a variety of foods which are both palatable and nutritious, viz.: corn meal muffins, corn meal rolls, soft corn bread, spoon eorn bread and many others.

Corn meal mush, or hasty pudding, is prepared as follows: Place three and one-half times as much water as meal into a double boiler and bring slowly to the boiling point, constantly stirring the mixture. Boil for three or four hours. When served hot with cream and milk it makes a nutritive diet. It is often eaten with syrup, molasses, honey and butter.

Little is known regarding the ehange which takes place in the protein and fat content of corn meal during cooking. but they are doubtless much the same as with other cereal foods. The protein is coagulated by heat and the fat broken down to some extent into simpler bodies. 
The composition of corn breads, Indian pudding or "mush" and other cooked corn products has been worked out by Woods(17) as follows:

COMPOSITION OF COOKED CORN PREPARATIONS, CORN MEAL, AND WHEAT BREAD

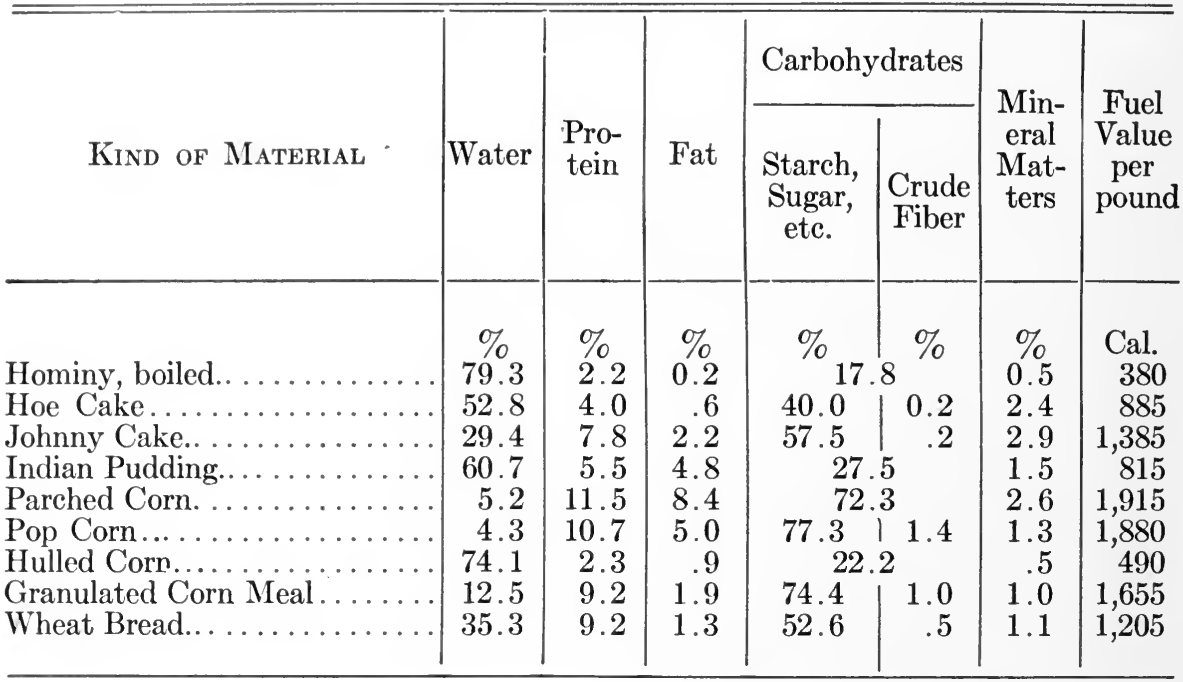

Green Corn.-Green corn furnishes an excellent food product in the milky stage and during the growing season. During this time the kernels are sweet and tender and possess a pleasing flavor. Green corn is gathered from the fields and gardens in July, August and September. In chemical composition and in fuel value it compares favorably with the potato as a food, having 73 per cent water, to 75 per cent in the potato. Sweet corn contains 13.5 per cent starch, 6 per cent sugar and 5 per cent protein. Green corn may be prepared by boiling "on the cob," or it may be cut from the cob and boiled in milk, mixed with snap beans or tomatoes, or boiled with lima beans, making the well-known dish succotash. The green ears in their shucks as they come from the stalk may be roasted in the fire. These are called "roasting ears," and are delicious.

OATS.-Oats were defined by the lexicographer Johnson as "food for horses in England and men in Scotland." A canny Scotchman, reading the definition, remarked: "Hont, mon! there are no such horses as they have in England nor such brawny men as in old Scotland."

In the ordinary process of harvesting and threshing oats the outer husk or hull is not removed, and so oats, unlike other cereals, comes to the market with the chaff still attached. 
Composition of Oxts. - The composition of oats according to the analysis of one thousand samples by Ballard (from Tibbles) and of oatmeal by Dyer, same source, shows the following percentage of the various elements entering into its composition:

\section{COMPOSITION OF OATS ANI OAT PRODUCTS}

\begin{tabular}{|c|c|c|c|c|c|c|}
\hline & Water & Fat & $\begin{array}{l}\text { Nitrog- } \\
\text { enous } \\
\text { Matters }\end{array}$ & $\begin{array}{l}\text { Carbo- } \\
\text { hydrates }\end{array}$ & Cellulose & Ash \\
\hline Oats & 9.8 to 17 & 2.8 to 6.83 & 7.1 to 14.3 & 55.69 to 64.3 & 7.0 to 12.2 & 1.5 to 3.9 \\
\hline Oatmeal, fine... & 8.2 to 9.5 & 8.0 to 12.33 & 12.9 to 18.1 & 54.0 to 6.5 .6 & $\ldots \ldots \ldots$ & 1.7 to 4.0 \\
\hline Oatmeal, coarse & 7.9 to 9.1 & 8.7 to 10.32 & 13.0 to 15.4 & 64.5 to6.5.2 & & 1.7 to 1.9 \\
\hline Crushed Oats.. & 8.1 to 8.9 & 7.5 to 9.3 & 12.6 to 15.1 & 65.2 to 67.0 & & 1.6 to 1.9 \\
\hline
\end{tabular}

From a study of this table it will be noted that oats contain more fat than wheat or barley, and that the protein content is high. The starch grains are small, compressed, faceted and tend to adhere in masses. The value of oatmeal as an energy provider, according to Parkes, may be understood by considering the energy in foot tons of work developed by the complete oxidation of an ounce of the following foods:

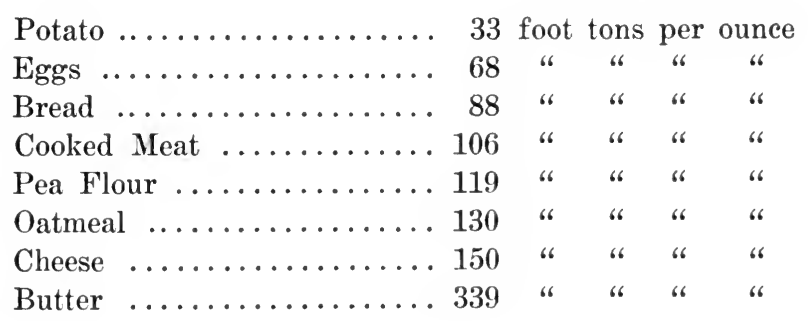

OAtmeal.-Oatmeal, like other cereals, contains valuable cereal salts. The proportion of these ingredients, according to Blythe's analysis, is as follows: In one hundred parts of salts potassium constitutes 17 per cent; sodium, 2.24 per cent; calcium, 2.74 per cent; magnesium, 7.6 per cent; ferric oxid, 0.67 per cent; phosphoric acid, 23.03 per cent; sulphuric acid, 1.36 per cent; silica, 44.73 per cent, and chlorin, 0.58 per cent. Of all grains oats are the richest in phosphates, giving them additional value as a food in cases where phosphates are indicated, as in struma, tuberculosis and rickets. It is one of the most valuable foods we 
possess and ranks very high both as a flesh former and energy producer. At the same time it is one of the most economical of foods.

Oatmeal is rich in heating and fattening principles. With milk, cream or butter it forms an ideal porridge. Its stimulating properties render it a highly useful nutriment for persons engaged in mental work.

In order to be digested with ease, oatmeal should be thoroughly cooked, longer than the thirty or forty minutes usually suggested. Experiments (made at the Minn. Exper. Station, Bull. No. 74, U. S. Dep. Agric.) show that when oatmeal is cooked for four hours or longer the diastase ferment acts on it more readily and as a result it is more easily digested than when cooked for one-half an hour. Since there is no gluten in oatmeal, ordinary bread cannot be made from it. The Scotch people make bread from oatmeal by the aid of fermentation. This produces a bread soft in texture and wholesome. Scotch cakes are made unfermented and are either baked or roasted flat. They are hard to digest. Oatmeal is one of the few vegetable foods which contains appreciable quantities of uric acid formers (purin bodies). Therefore, it will be well to forbid its use in cases of gout.

RYE.-Rye is extensively used for breadmaking in many European countries, especially France, Germany and Russia. It is not a very ancient cereal and was unknown before the Christian era. Rye is grown in the United States and is used mainly as a food for stock and for making whiskey. The rye grain has a structure similar to that of wheat. It is clean and free from husks when threshed.

Component Elements of Rye.-In composition it has the following percentages of its component elements, viz. : water, 8.7 per cent; protein, 11.30 per cent; fat, 1.90 per cent; carbohydrates, 74.50 per cent; cellulose, 1.50 per cent, and ash, 2.10 per cent. The starch is similar to that of wheat flour. The grain is only slightly larger than wheat. The proteins average about 11 per cent of the weight of the flour. Rye bread is usually made from a straight grade of flour, although white, intermediate and dark flours are manufactured. It is estimated that 20 per cent of the protein in rye bread escapes digestion. Rye bread somewhat resembles whole wheat bread in color and texture, but is less nourishing. In Germany the black bread made from rye and known as pumpernickel is the common food for the working people. This is a sour dough bread in which fermentation is started with a piece of dough left over from a previous batch. It is not a very nourishing food as far as protein digestibility is concerned. Sometimes the loss of protein during digestion is as much as 42 per cent as compared with 20 per cent loss in the case of 
white wheat bread. The malted and fermented rye is a common source for the manufacture of alcoholic liquers, more especially in the manufacture of rye whiskey. In Russia the national drink, vodka, is made from rye.

BARLEY-Barley is one of the most aneient of cultivated plants and is chiefly characterized by its richness in mineral matter. It contains more fat than wheat, but is poorer in protein. The percentage of starch varies in different samples from 39) per cent to 57 per cent.

Composition of Bartey.-Aceording to Wynter and Blyth its composition is as follows: water, 15.06 per cent; protein, 11.75 per cent; fat, 1.71 per cent; carbohydrate, 70.9 per cent; fiber, 0.11 per cent, and ash, 0.47 per cent. The prineipal cereal salts in barley are the phosphates of potassium, iron and silicon. The character of barley starch is almost identical with that of wheat. Barley meal was formerly (1626) extensively used for making bread by the peasants or serfs of England. In early times a fairly good bread was produced by the addition of a small amount of wheat flour. This was a common foodstuff of the peasantry down to the reign of Charles I. It was also the principal bread food among the poor population of the mountainous districts of Sweden, Switzerland and Scotland. Since barley contains no gluten it does not make good bread. Barley meal makes an excellent demulcent drink for invalids and children. As a dietetic article in the sick room, barley finds its chief use as barley water, a product which contains but little nutriment as shown by the following analysis by Wynter and Blyth:

\begin{tabular}{|c|c|c|c|}
\hline $\mathrm{Na}$ & 99.27 per cent & Starch & 0.39 per cent \\
\hline$F$ & 0.22 & $\operatorname{ar} \ldots$ & 0.05 \\
\hline Protein & 0.03 & Mineral matter. & 0.03 \\
\hline
\end{tabular}

Peart Barley.-Pearl barley is the whole grain polished by attrition after removal of the husk. II ulled barley looks not unlike rice, and may be used in a similar way, though in this shape its most general use is as an adjunct to soups.

MILLET_-Millet is the smallest of the cereal grains. It is not used as a cereal food for man in the United States, although it is prodnced as a food for stock. It is grown extensively in Africa, India, China, Japan and Korea, where it is made into bread. The millets are an important source of food for man. It is estimated that this cereal is a source of food for one-third the inhabitants of the earth. It is the commonest 
grain food of Africa, where it is the staple diet of the negroes of the upper Nile.

Varieties of Millet.-There are several varieties of the grain. Its cultivation is prehistoric; the evidences of its existence have been found in lake dwellings of the Stone Age. There is evidence that it forned one of the chief foods in China 2700 в. с. Some of the varieties were grown 4,000 years ago by the Greeks and Romans. The principal varieties are: (a) foxtail millet, (b) barnyard millet, (c) broom corn millet, (d) Indian millet, $(e)$ sweet sorghum millet. Mány other varieties are grown in Asia and Africa.

Composition of Millet.-An analysis of millet by Professor Church shows the following:

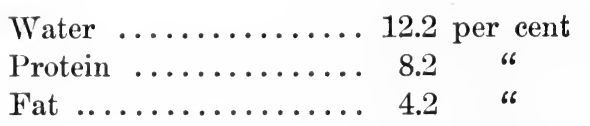

Carbohydrate ........ 70.5 per cent Cellulose ............. 3.1 "

Mineral matter ........ 1.7 "

The starch is similar to that of wheat, but the protein content does not include the whole nitrogen content of the grain. Millet bread is not so good as wheaten bread, but is very nutritious. Its flour makes excellent puddings and is largely used in combination with milk in countries where it is extensively cultivated. As a source of nitrogen it occupies a place second to wheat and rice.

Proso Milcet.-Proso millet is a hardy cereal grain milled like the other cereals. The peculiar agricultural advantage of this cereal is that it is drouth resistant. Proso will grow where the staple small grains which require a moist soil fail. The seed of proso millet, although practically unknown in America as a food for human consumption, is a familiar article of diet in Russia and India. It is said that during the Russian famine of 1890 proso millet bread was for a long time the only food remaining between the peasantry and starvation. The grain can be milled and cooked in the same way as are other cereals. The composition of hulled proso is much like that of patent flour, being even richer in protein. The grain can be used whole, ground like corn meal and thus made into palatable dishes or used as flour. The lack of gluten makes it necessary to combine proso with wheat flour if it is to be converted into a good bread.

A public test of proso as a table cereal was officially made by Nansen(18) at the South Dakota State College of Agriculture early in 1915, so that it has already had an official introduction. From the standpoint of practical agriculture proso deserves consideration because, like kafir corn, it represents a crop which can be produced in a dry season or in arid 
regions where the attempt to raise the more popular cereals is often diseouraging.

KAOLING,- Kaoling is a drouth-resistant grain of the sorghum family, long used in $\Lambda$ frica, India and $\Lambda$ sia(19) as a foodstuff. Kaoling can be grown in any climate where Indian corn is indigenous, and can by careful selection be extended as far north as ('anada on this continent. Specimens of hardy kaoling from China reached America as early as 186,6 but were discarded because they sermed of no value for sugar making. This was the sole use to which the sorghum plant was put at that time. Sorghum seed can be milled; when mixed with gluten-yielding flours kaoling contributes to the production of palatable baked products as does kafir flour, lately exploited as a human food (20). The proso and kaoling flours are the newest cereal flours for hread making in this country. Even cottonseed flour has been used in an attempt to make bread. When ghutinous adjuvants are supplied to cereals poor in them, and when science becomes engaged in the art of bread making, new bakery products are likely to arise.

QUINOA.-Quinoa (ki-no-a) or "petty rice" is the seed of chenopodium quinoa. There are two varieties: one colored, with a green leaf, the other with green leaves and white grain. Both are of American origin and are very ancient. These seeds form one of the staple foods of New Granada, the table lands of Mexico, Chili and Peru, where its cultivation was carried on for many centuries before the Spanish conquest. The plant is an annual herb which grows from four to six feet in height. It will flourish on an elevation 13,000 feet above the sea level. The white grain quinoa is the most farinaceous. The grains are eaten in soup and the flour is made into unleavened cakes.

Composition of Quinon.-The starch gramules are the smallest of any known cereal. The protein percentage is high, with a moderate amount of fat. The ash is said to contain more iron than any other vegetable. The leaves of the green plant are eaten as spinach. Voelcker gives the following composition of quinoa:

COMPOSITION OF QUINOA, NUTRIENTS, PER CENT

\begin{tabular}{|c|c|c|}
\hline & Dry Seeds & Flour \\
\hline Nitrogenous matters & 22.86 & 19 \\
\hline Stareh $\ldots . . . \ldots \ldots \ldots \ldots$ & 58.60 & 60 \\
\hline$\ldots \ldots \ldots$ & 5.74 & 5 \\
\hline Cellulose ........ & 9.74 & .. \\
\hline Water ..... & $\ldots$ & 16 \\
\hline
\end{tabular}


BUCKWHEAT.-Buckwheat is a native grain of Manchuria and Central Siberia. Its cultivation is not ancient, for the Chinese author who first mentioned it lived in the tenth eentury of the Christian era. It was certainly unknown to the aneient Greeks and Romans. Not until the middle ages was it grown in Europe and Russia. Buckwheat is now eultivated extensively in the New England States, New York, Pennsylvania and in New Brunswick. The buckwheat grain is a brown-colored, threesided seed. The flour is dark in eolor and is made by grinding the grain between stones and separating the prineipal part of the hulls by bolting. A finer grade of flour may be produced by the use of more elaborate machinery. Flour made in the old-fashioned way is not so white, but is more nutritious and palatable than the new product.

Use of Buckwhent Flour.-Buckwheat flour is used, especially in Holland and the United States, for pan cakes and griddle cakes. The batter is raised with yeast, for the flour contains enough of a glutinous substance to entrap the bubbles of gas, and is usually allowed to stand over night. The "leaven" left over from one batch will be quite sufficient to start the next. Buckwheat cakes are served hot and eaten with syrup or honey and butter.

Composition of Buckwheat Flour.-Buckwheat flour, according to Atwater, has the following composition: water, 13.9 per cent; protein, 6.4 per cent; fat, 1.2 per cent; carbohydrate, 77.90 per cent, and mineral matter, .60 per cent. This analysis shows it to be a highly nutritious food.

\section{CEREAL BREAKFAST FOODS}

Cereal Breakfast Foods.-During the past twenty years the "hurry up" American breakfast has ereated a demand for a coneentrated form of nourishment easily prepared or ready to serve.

IMPORTANCE OF CEREAL BREAKFAST FOODS.-The eereal breakfast foods commonly used in the United States are manufactured prineipally from wheat, corn, oats, barley and rice, with occasional additions from other sources. In other parts of the world millet, rye, buckwheat, kafir corn and other cereals, cooked into porridge, are extensively used. An idea of the importance of eereal breakfast foods may be obtained from Bulletin No. 13, part ix, p. 1345, United States Department of Agriculture, Bureau of Chemistry. Vegetable foods, including flour, bread and other cereal foods, furnish 55 per cent of the total food; 39 per cent 
of the protein; s per cent of the fat and 95 per cent of the total carbohydrates of the American diet. The percentage amounts which cereal foods alone supplied were:22 per cent of the total food; 31 per cent of the protein; 7 per cent of the fat and 5.5 per cent of the total carbohydratesthat is, about $\sigma^{5}$ pere cent of the vengetable protein, so per cent of the carbohydrates and is per cent of the vegetable fat was supplied by cereals. Their number is legion, and no class of foodstuffs has been more extensively or ingenionsly advertised than the cereal breakfast foods. The majority of these fall into one of three gromps, (a) those which are prepared by simply grinding the grain, (b) those which have been steamed or otherwise partially cooked and then ground or rolled, and $(c)$ those which have been acted upon by malt which induces more or less chemical change in the starch present.

Uncooked ani Partality Cooked Cereals. - The use of cereals as porridge is of special interest, as it was the forerumner of cereal breakfast foods and until recently cereals intended for porridge were simply husked and more or less crushed. Such products refuired long, slow cooking. The earliest of the cereal breakfast foods which came into general use in the United States were of this class. Oats coarsely ground are the most commonly eaten. Uncooked wheat does not scem to be generally used for preparing a breakfast dish, though corn meal porridge and hominy have long been and still are popular. The old-fashioned hulled corn, sometimes called lye hominy, is still a popular dish in some sections of the country. It is prepared by steeping the grains of corn in a solution of lye made by percolating water through wood ashes. This loosens the skin or hull of the grain. When these drop off, the skinned grains are soaked in fresh water, which must be repeatedly changed. This process produces a hominy of a peculiarly attractive and inviting flavor.

When the use of cereal breakfast foods became general the raw products were largely replaced by partially cooked cereals. Of these the socalled raw oats and wheat are typical examples. In these products more or less of the cooking is done at the factory. They are alleged to surpass the simpler or raw products in food value. The manufacture of malted and otherwise specially prepared cereal foods is a later development. The manufacturers claim that they are an improvement over the so-called rolled products.

The Health Department of the City of New York has recently issued a bulletin showing the cost of cereal foods, the price per pound and cost of 1,000 calories, which is included herewith: 
COST OF CEREALS

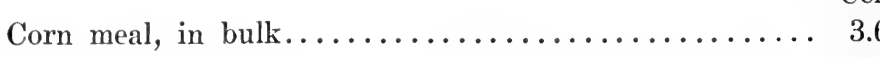

Cost of 1,000

Calories,

Cents

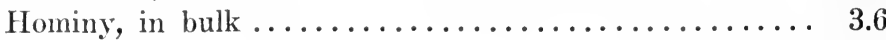

Broken rice, in bulk....................... 3.7

Oatmeal, in bulk............................. 3.8

Samp, in bulk............................. 4.2

Quaker Oats, in package..................... 4.4

Macaroni, in package...................... 4.5

Wheat flour, in bulk..................... 4.6

Malt breakfast food, in package................ 4.8

Pettijohn, in package...................... 5.3

Cream of wheat, in package................. 5.7

Farina, in package........................ 5.9

Cracked wheat, in bulk.................... 5.9

Pearl barley, in package.................... 6.0

Barley flour, in bulk...................... 6.1

Whole rice, in bulk....................... 6.1

Wheatena, in package..................... 8.1

Price per Pound, Cents

6

6

2

8

13

14

12

10

12

10

10

10

10

14

COST OF READY-TO-SERVE CEREALS

Cost of 1,000

Calories,

Cents

Shredded Wheat Biscuit..................... 7.8

Price per

Pound,

Cents

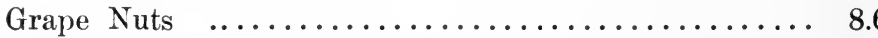

13

Force $\ldots \ldots \ldots \ldots \ldots \ldots \ldots \ldots \ldots \ldots \ldots \ldots, 9.4$

15

Corn Flakes ............................ 11.7

16

Puffed Rice

23.5

20

52

Manufacture of Ready to Eat Cereals.-The "ready to eat" preparations are manufactured in many ways. Some are cooked in water and then dried and erushed; some are made of a mixture of different grains; some have eommon salt, malt, sugar, molasses or other carbohydrate material added; some products have a flake-like appearance, while others have the appearance of dried crumbs. The shredded preparations are made with special machinery which tears the steam-cooked kernels into shreds and deposits them in layers or bundles. Many of the "ready to eat" breakfast cereals are parched or toasted before packing. This gives them a darker color and makes them crisp. In the malted or predigested preparations, malt or some similar enzyme is added during the process of manufacture. This ferment has under eertain eonditions a power of changing starch into various soluble forms such as dextrin and 
maltose. How much of the starch is actually changed in the malted cereals, and whether it is desirable to have it so changed outside of the body, are debatable questions. Some of the cereal foods are prepared by being subjected to dry heat. This is the case with puffed wheat, rice and other products of this class. Brictly speaking, the breakfast cereal foods contain about the same amount of mutriment as the cereals from which they are made.

The following table (taken from Farmers' Bulletin No. 249, Department of Agriculture) shows the arerage composition of the varions sorts of cereal breakfiast foods:

TOTAL NUTRIENTS AND FUEL VALUE OF CEREAL BREAKFAST FOOD

\begin{tabular}{|c|c|c|c|c|c|c|c|}
\hline \multirow[b]{2}{*}{ KIND OF FoOD } & \multirow[b]{2}{*}{ Water } & \multirow[b]{2}{*}{ Protein } & \multirow[b]{2}{*}{ Fat } & \multicolumn{2}{|c|}{ CARBOHYDRATES } & \multirow[b]{2}{*}{ Ash } & \multirow{2}{*}{$\begin{array}{l}\text { Fuel } \\
\text { Value } \\
\text { per } \\
\text { pound }\end{array}$} \\
\hline & & & & $\begin{array}{c}\text { Nitro- } \\
\text { gen- } \\
\text { Free } \\
\text { Extract }\end{array}$ & Fiber & & \\
\hline Oats: & $\%$ & $\%$ & $\%$ & $\%$ & $\%$ & $\%$ & Cals. \\
\hline Whole grain.. & 11.0 & 11.8 & 5.0 & 59.7 & 9.5 & 3.0 & \\
\hline Oatmeal, raw......... & 7.3 & 16.1 & 7.2 & 66.5 & .9 & 1.9 & 1,767 \\
\hline $\begin{array}{l}\text { Rolled oats, steam- } \\
\text { cooked ............. }\end{array}$ & 8.2 & 16.1 & 7.4 & 65.2 & 1.3 & 1.8 & 1,759 \\
\hline Flaked and malted oats. & 7.9 & 16.2 & 5.2 & 66.7 & 1.6 & 2.4 & 1,709 \\
\hline Wheat: & & & & & & & \\
\hline Whole grain....... & 10.5 & 11.9 & 2.1 & 71.9 & 1.8 & 1.8 & \\
\hline Cracked wheat. ...... & 10.1 & 11.1 & 1.7 & 73.8 & 1.7 & 1.6 & 1,501 \\
\hline $\begin{array}{l}\text { Rolled wheat, steam- } \\
\text { cooked } . . . \ldots \ldots \ldots\end{array}$ & 10.6 & 10.2 & 1.8 & 74.1 & 1.8 & 1.5 & 1,541 \\
\hline $\begin{array}{l}\text { Flaked a nd crisped, } \\
\text { ready to eat........... }\end{array}$ & 9.4 & 12.2 & 1.4 & 72.7 & 1.9 & 2.4 & 1,500 \\
\hline $\begin{array}{l}\text { Flaked, crisped a } \mathrm{n} d \\
\text { malted, ready to eat. }\end{array}$ & 9.0 & 12.1 & 1.4 & 73.0 & 1.8 & 2.7 & 1,526 \\
\hline Crumbed and malted. & 5.6 & 12.2 & 1.0 & 77.6 & 1.7 & 1.9 & 1,623 \\
\hline 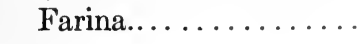 & 10.9 & 11.0 & 1.4 & 75.9 & .4 & & 1,609 \\
\hline Rye: & & & & & & & \\
\hline Whole grain............ & 11.6 & 10.6 & 1.7 & 72.5 & 1.7 & 1.9 & \\
\hline Flaked, to be eaten raw. & 11.1 & 10.0 & 1.4 & 75 & & 1.7 & 1,526 \\
\hline Barley: & & & & & & & \\
\hline $\begin{array}{l}\text { Whole grain............ } \\
\text { Pearled barley... }\end{array}$ & $\begin{array}{l}10.9 \\
11.5\end{array}$ & $\begin{array}{r}12.4 \\
8.5\end{array}$ & $\begin{array}{l}1.8 \\
1.1\end{array}$ & $\begin{array}{l}69.8 \\
77.5\end{array}$ & $\begin{array}{r}2.7 \\
.3\end{array}$ & $\begin{array}{l}2.4 \\
1.1\end{array}$ & 1,514 \\
\hline $\begin{array}{c}\text { Buckwheat: } \\
\text { Flour.... } \\
\text { Farina... }\end{array}$ & $\begin{array}{l}13.6 \\
11.3\end{array}$ & $\begin{array}{l}6.4 \\
3.3\end{array}$ & $\begin{array}{r}1.2 \\
.3\end{array}$ & $\begin{array}{l}77.5 \\
84.6\end{array}$ & .4 & $\begin{array}{l}.9 \\
.4\end{array}$ & $\begin{array}{l}1,471 \\
1,4 S 0\end{array}$ \\
\hline
\end{tabular}


It may be said in defense of the general use of preparea breakfast foods sold in packages that they are cleaner, less liable to accumulate dust and dirt than cereals sold in bulk. On account of the general use of these "easy to prepare" breakfast cereal foods in the United States, the question of economy is to be considered. When you compare the prices of food sold in bulk with the price of the package product, it will be found that the consumer is paying luxury prices for the latter.

The following table from Bailey summarizes the percentages of constitnents contained in some of the more popular advertised American breakfast cereal foods:

TOTAL NUTRIENTS AND FUEL VALUES OF POPULAR BREAKFAST FOODS

\begin{tabular}{|c|c|c|c|c|c|c|}
\hline Name & Moisture & Protein & $\begin{array}{c}\text { Total } \\
\text { Carbo- } \\
\text { hydrates }\end{array}$ & $\begin{array}{l}\text { Crude } \\
\text { Fiber }\end{array}$ & Fat & Ash \\
\hline 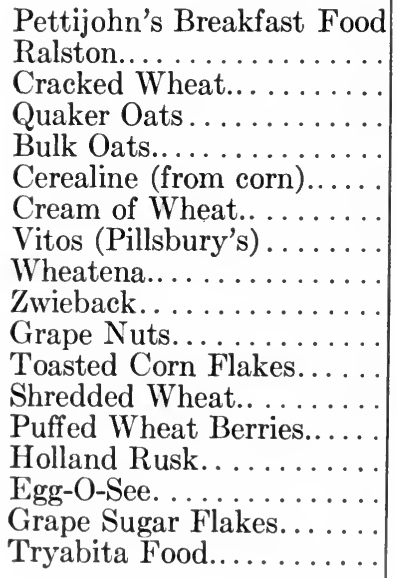 & $\begin{array}{r}7.51 \\
9.72 \\
9.30 \\
7.40 \\
8.07 \\
9.55 \\
10.69 \\
8.74 \\
8.41 \\
10.64 \\
8.00 \\
9.63 \\
9.45 \\
10.19 \\
7.59 \\
8.24 \\
8.13 \\
9.69\end{array}$ & $\begin{array}{r}10.56 \\
15.10 \\
12.60 \\
17.20 \\
17.74 \\
9.90 \\
11.75 \\
12.69 \\
11.50 \\
14.31 \\
12.73 \\
9.21 \\
11.06 \\
13.06 \\
12.44 \\
10.87 \\
10.27 \\
11.81\end{array}$ & $\begin{array}{l}76.96 \\
71.75 \\
74.42 \\
66.65 \\
65.89 \\
78.75 \\
76.17 \\
76.56 \\
75.23 \\
68.87 \\
73.78 \\
78.31 \\
76.41 \\
73.72 \\
72.87 \\
76.15 \\
75.87 \\
72.47\end{array}$ & $\begin{array}{r}2.01 \\
1.55 \\
1.49 \\
1.40 \\
0.99 \\
0.72 \\
76.17 \\
76.56 \\
1.03 \\
4.21 \\
2.02 \\
0.57 \\
76.41 \\
73.72 \\
0.32 \\
1.36 \\
2.28 \\
2.57\end{array}$ & $\begin{array}{l}1.45 \\
1.90 \\
2.22 \\
6.08 \\
6.52 \\
1.24 \\
0.95 \\
0.98 \\
2.10 \\
0.49 \\
1.57 \\
0.54 \\
1.42 \\
1.63 \\
5.88 \\
1.18 \\
1.76 \\
1.08\end{array}$ & $\begin{array}{l}1.52 \\
1.53 \\
1.46 \\
1.67 \\
1.78 \\
0.56 \\
0.64 \\
1.03 \\
1.73 \\
1.48 \\
1.90 \\
1.74 \\
1.66 \\
1.61 \\
0.90 \\
2.12 \\
1.69 \\
2.77\end{array}$ \\
\hline
\end{tabular}

Differences in Composition of Breakfast Foods.-In comparing the chemical composition of different cereal foods it is apparent that while they resemble each other closely (all are rich in carbohydrates), still there are certain differences between them which are quite characteristic; thus corn is characterized by a relatively high proportion of fats; oats are relatively rich in both protein and fat; wheat and rye have a high proportion of protein with a moderate amount of fat, while barley and rice products contain about the average proportions of all the nutritive ingredients. 
Preparen Cereat Foons.-Many of the cereal breakfast foods which are sold mider various names and extravagantly advertised, are artificial preparations of these cereals, in the manufacture of which the cereals are subjected to heat and otherwise treated, so that the preparation undergoes certain changes intended to save labor in cooking and to spare the digestive organs a part of their normal work. The idea of having part of the process performed outside of the body is not a new one. Physicians have used predigested foods of different sorts for their patients for many years. Since the diastase of malt imitates the work of the diastase of the saliva and the pancreas so well, it is the common means of predigesting carbohydrates. It is a grave question, however, as to whether it is good for the human race to have its food partially digested before it is consumed. "It is not beneficial to the teeth to have only soft food to masticate, and on the other hand it cannot be beneficial to the stomach to have constantly such foods to work upon. What the stomach is relieved from doing by choice may later become a matter of necessity." If an athlete does not use his muscles they will soon degenerate, become flabby and unable to do laborious work. In a similar way the stomach which is given labor-saving foods may in time be unable to perform the normal functions of digestion. Therefore a large consumption of the prepared cereal foods should be deprecated, since it is generally believed that the digestive organs, as all other organs of the body, are normally prepared to perform to advantage their several functions. We believe a well man has no more need for predigested food than a sound man has for crutches.

\section{ROOTS AND TUBERS}

Roots and Tubers.-From our study of cereals, we learned that the bulk of the grain furnished a storehouse of nutriment for the use of the young plant. We now turn our attention to the consideration of the roots and tubers which on examination may be regarded in like manner, as reserves of nourishment for the use of the adult plant itself. The reserve nutriment so laid up is almost entirely in the form of carbohydrates, chiefly starch. Protein and fat are only infinitesimally represented. This fact must not he lost sight of in estimating the value of this class of regetable foods. The plants belonging to this group have different habits and are varied in appearance, but from the standpoint of food value their common characteristic of producing underground parts filled with nutritions material, makes it convenient to group them together. In some instances 
it is a true root, such as the beet, in which the plant lays up its store; in others it is an underground stem, as in the case of potatoes, and again it is a bulb, like the onion.

CLASSES OF ROOTS AND TUBERS.-These edible tubers, roots and bulbs naturally divide themselves into three main classes: $(a)$ those in which the plant stores a comparatively large proportion of food in the form of sugar or other soluble carbohydrates, as the yam and sweet potato; (b) those in which the plant stores its food principally in the form of insoluble starch, the most important of the starch-bearing tubers, the white potato, cassava, taro tubers and yantia tubers; $(c)$ the succulent roots containing a large proportion of water, such as beets, carrots, parsnips, turnips, radishes, salsify, horse radish, onions and garlic. The tubers and root vegetables contain from 70 to 90 per cent of water and from 10 to 30 per cent solid material, the greater part of which is some form of carbohydrate. They also contain a small amount of nitrogenous substance and, compared with other vegetables, considerable quantities of mineral matter, especially in the succulent roots.

White Ротато.-The potato, called in different sections white potato, Irish potato, English potato or round potato, was first introduced into England during the reign of Queen Elizabeth. A cargo of this vegetable was carried from Roanoke Island, Colony of North Carolina, to England by one of Sir Walter Raleigh's ships in 1586. The American Indians were cultivating this tuber when the English discovered America(21). In former times the top of the potato blossomed and bore seeds, which produced new varieties. The potato, modified by cultivation, has lost this power of bearing seeds. Now the "eye" of the old tubers is planted to produce a new crop.

Structure.-In structure the potato may be said to be a modified shortened, thickened stem which serves as a storehouse for the reserve material for the new young plant. The outer skin consists of a thick, grayish-brown, corky substance. If a cross section is made of a raw potato, three distinct parts besides the skin may be seen. The outermost known as the cortical layer, which is slightly colored, and denser than other parts of the potato; the interior or fleshy part is made up of two layers known as the inner and outer medullary areas.

Composition.-In composition the potato contains the following percentage of nutrient chemical elements : water, 62.6 per cent; protein, 1.6 per cent; fat, 0.1 per cent; carbohydrates, 22.8 per cent, and mineral matter, 0.8 per cent. The carbohydrates are by far the most abundant of the nutrients, with less than 5 per cent of cellulose. Other carbohydrates of 
the potato are the so-ealled pectose bodies. When the tubers are large and bulky, pectose bodies make up about $t$ per cent of the weight of the tuber. Fat appears in such small quantities that it may practically be ignored in discussing the food value. The proteins are rather scanty as compared with the elements in cereals, and muly about 60 per cent of the total amount present is true protein. 'The non-protein forms of nitrogenous
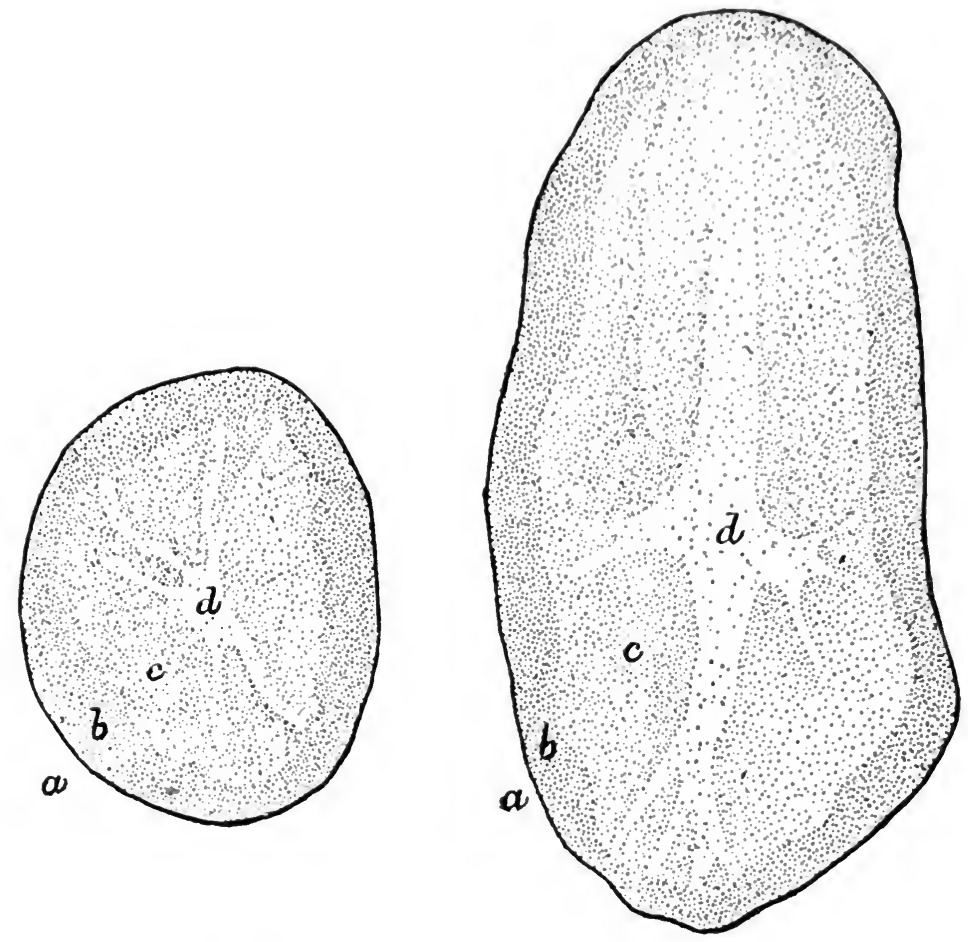

Fig. 32.-Transyerse axd Loxgitudical Sections of the Potato. (a) skin, (b) cortical layer, (c) outer medullary layer, (d) inner medullary area. (Bull. No. 295, U. S. Dept. Agric.)

substances in the potato are asparagin and small quantities of amino-acids occurring more particularly in the juice. The most important mineral matters found in the potato are potash and phosphoric acid compounds. The potato as purchased contains about 20 per cent nutritive matter, while rice contains about $s s$ per cent. In the process of cooking rice water is added, so if we compare four pounds of potatoes with one pound of rice we shall find that they are about equal in nutritive value. Four pounds of potatoes cost about twentr-five cents, while a pound of rice costs abont ten cents, so there is no decided adrantage in the cost of rice over 
potatoes. The potato contains but little iron, calcium and phosphorus, the elements too often lacking in the food of children.

Cooking of Potatoes.-Cooking improves the taste of the potato and at the same time prepares the starch for more complete digestion. The process of cooking breaks up the lamellæ which hold the starch cells together. Thus the action of the saliva on the unbroken cells, swollen by the process of cooking, is facilitated. The granules are rendered permeable by the digestive enzymes, and digestion and absorption readily take place. From numerous tests(22) it has been determined that 8.2 per cent of protein is lost when the

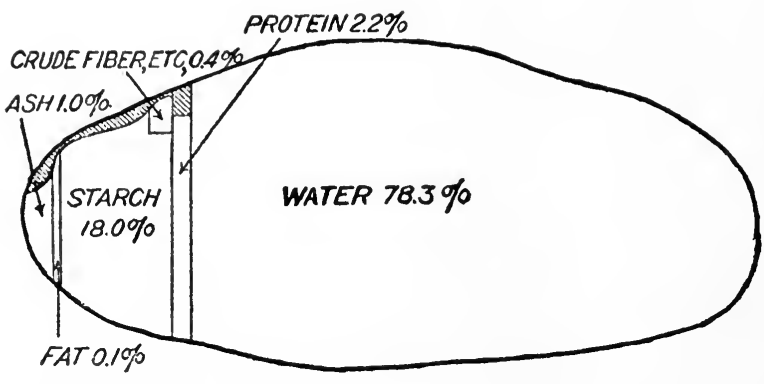

Fig. 33.-Composition of the Potato. The shaded portion represents the average loss of nutrients when boiled. (Bull. No. 295, U. S. Dept. Agric.) peeled potato is plunged directly into boiling water. Whereas, if soaked for several hours before cooking, at least 25 per cent of the protein is wasted. If plunged into cold water and brought to the boiling point, 15.8 per cent of the protein is lost. When potatoes are boiled in their "jackets," the loss is only 1 per cent of protein and a little over 3 per cent of mineral matter.

In a series of tests made it was observed that if the nutritive material was to be retained in potatoes they should be boiled with their "jackets" on, and removed immediately from the water to prevent them from becoming water soaked. In baking potatoes very little of the nutritive elements are lost. The starch is thoroughly cooked, since the temperature necessary for baking is several degrees above the boiling point. Immediately upon its removal from the oven the baked potato should have the skin broken so as to allow the steam to escape and prevent the tuber from becoming soggy. The potato so cooked will be mealy, attractive and in a proper condition to be readily acted on by the digestive enzymes.

Desiccated potatoes are prepared by slicing and drying the contents at not too high temperature. When dry they contain about the same constituents as the fresh potato, minus the water. They are extremely useful for camping parties, or at sea, or whenever it is impracticable to transport fresh potatoes.

Potatoes are by no means a perfectly well-balanced ration. In fact, 
they are not as satisfactory as bread, if one would live on a single food. As ordinarily used in conjunction with meat, milk, eggs and other varieties of food containing fat and protein in proper quantities, they are an extremely raluable food. They rank next to breadstuffs in Europe and America as a source of carbohydrate foods. The potato crop of the United States in 1912 was $420,647,000$ bushels. In addition there were 2,500,000 bushels imported from foreign conntries.

Sweet Potato.- Sweet potatoes are grown largely in North and South America, Spain, Portugal, China and the East and West Indies. In countries where they are most abundantly grown, they provide a large proportion of the food for the natives. The plant belongs to the Morning Glory family; it's botanical name is Ipomoa batatus. It is probably a native of tropical America. The sweet potato grows best in loamy, sandy soil, in a elimate where there are at least four and one-half months without frost. Each year sweet potatoes are hecoming of greater importance as a commercial truck crop in the United States. They rank third in the list of the five greatest vegetable truck crops.

Sweet potatoes do not keep as well as white potatoes and are subject to various diseases : black rot, soft rot, dry rot and white rot. For keeping they require a warm, dry atmosphere. In the South they are kept in pits ont of doors, which must be well ventilated and protected from northwesterly winds. The temperature should be from $50^{\circ}$ to $54^{\circ} \mathrm{F}$. The sweet potato is propagated from "sets" which are grown from the mother potato. In the spring they are bedded in a location which will have protection from north winds. The bed is a manure-heated hotbed and insures quick propagation of the plants.

Varieties of Sweet Potato.-There are many varieties of sweet potatoes, which differ in color, size and other characteristics. In the Southern States the sweet potato plays almost as important a part as a foodstuff as white potatoes do in other parts of the country. The Jersey varieties are very popular; among them are the big stem Jersey, yellow Jersey and red Jersey. These varieties when cooked present a dry, mealy-fleshed substance. In the South the most popular variety belongs to the yam group. This is a moist, fleshy, yellowish colored potato. Among the varieties of this latter group are the Southern Queen, the pumpkin yam, Georgia yam, the Florida yam and the red Bermuda. Of these varieties there are a large number of special strains known under many local names. The Jersey varieties are inclined to grow rather large and are poor keepers, becoming "punky" toward the spring. The Southern varieties are large, thick and blunt at the ends, the color varying from white or light 
cream to an orange yellow. The Southern varieties are the most agreeable as food and are prepared in a variety of ways. They are made into pies, puddings, etc., baked or boiled or candied. The sweet potato is highly prized as an article of food in North and South America, China, and in the East and West Indies. The annual crop in the United States is $50,000,000$ bushels.

Composition.-In composition the sweet potato is unlike the white potato, since it contains sugar. Sweet potatoes are wholesome and possess slightly laxative properties. Owing to their sweet taste they do not form such an appropriate accompaniment to meat as the ordinary potato. The varieties most esteemed for the table by those who eat freely of them are the varieties which contain the largest proportion of sugar. The amount of protein and fat is small. When cooked the carbohydrate consists of from 13 to 18 per cent of starch in granules. The sugar varies from 4 to 10 per cent and is nearly all cane sugar or sucrose. Of 26 samples analyzed by Atwater in the United States Government Laboratories there was found an average of only $21 / 2$ per cent cane sugar and 3.4 per cent invert sugar. The total fermentable matter contained in the sweet potato varies from 23 to 30 per cent. They yield also a corresponding proportion of alcohol and are much used for the production of alcoholic drinks in the Azores.

Digestibility. - No very extensive experiments have been made with the sweet potato to determine its digestibility, except in Japan. Judging from the conclusions arrived at by the Japanese investigations, 98 per cent of the carbohydrates of sweet potatoes are digested. The values for protein were variable, but on the whole were lower in protein than white potatoes. It may be said of sweet potatoes that they are wholesome and well digested by the average man. The distress many persons suffer from eating the dry, mealy varieties is overcome by using large quantities of butter.

Presence of Sugar.-More than twenty-five years ago Stone(23) demonstrated the presence of sucrose or cane sugar in sweet potatoes. This is one of the more complex sugars in which the molecules are so bound that they do not reduce Fehling's solution. On the contrary, later observers have found reducing sugars present.

Interesting experiments have proven that in the tuberous root of the sweet potato, as in the resting storage organs of other plants of temperate regions, starch is transformed into sugar. In most plants the transformation of starch into sugar ceases at a few degrees above the freezing point. The sweet potato is an exception to this rule. Soon after the tuber has 

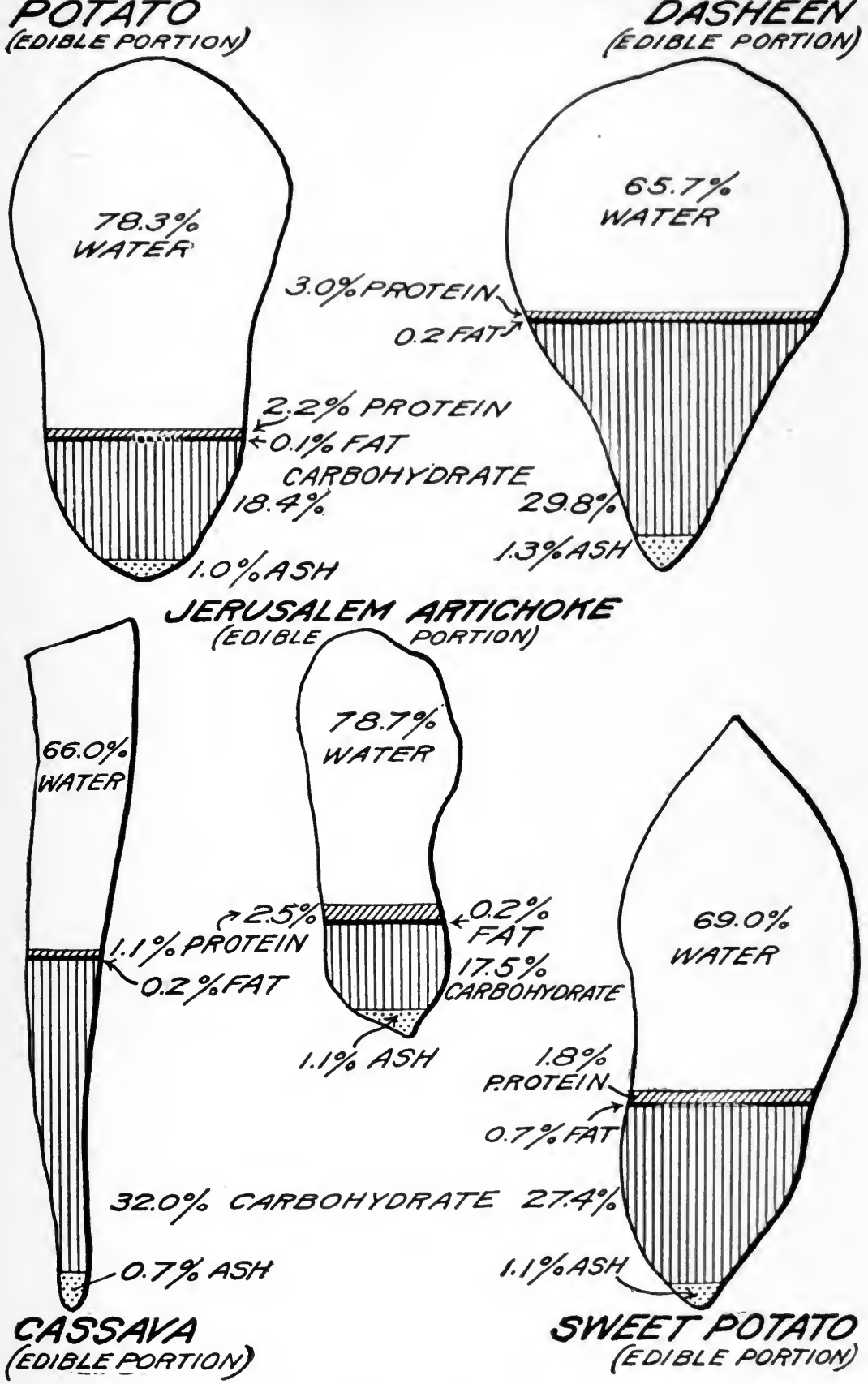

Fig. 34.-Composition of Common Starchy Root Vegetables. These outline figures show diagrammatically the proportion of nutrients present. Plain white indicates water and the differently shaded portions protein, fat, carbohydrates and ash respectively. (Bull. No. 468, U. S. Dept. Agric.) 
been gathered, transformation of starch into sugar takes place at much higher temperatures $\left(86^{\circ} \mathrm{F}\right.$.).

Two competent observers, Hasselbring and Hawkins(24), record another interesting peculiarity of the sweet potato. Except in soft-wooded trees reducing sugars have been observed as the usual and most abundant products of starch transformation in resting storage organs. On the contrary, little reducing sugar results from this transformation in the sweet potato, the principal product being sucrose.

It would be pleasant to believe that all these researches might have a practical, a gastronomic, outcome. At its best and rightly cooked (baked "in its jacket," so that the rich, black, syrupy juice is incrusted wherever the cook's fork has pricked it), this vegetable is a unique delicacy. As it reaches our Northern markets, or at any rate, our Northern tables, however, it is too often dry and insipid.

Composition of Sweet and White Potatoes.-Considering both composition and digestibility it may be said that the nutritive value of the sweet potato is much the same as the white potato, although there are important differences between them. The average composition of sweet potatoes raw and cooked is given in the following table by Langworthy (25):

AVERAGE COMPOSITION OF SWEET AND WHITE POTATO

\begin{tabular}{|c|c|c|c|c|c|c|c|c|}
\hline \multirow{2}{*}{ Kind of Potato } & \multirow{2}{*}{$\begin{array}{l}\text { Ref- } \\
\text { use }\end{array}$} & \multirow[b]{2}{*}{ Water } & \multirow{2}{*}{$\begin{array}{l}\text { Pro- } \\
\text { tein }\end{array}$} & \multirow[b]{2}{*}{ Fat } & \multicolumn{2}{|c|}{$\begin{array}{l}\text { CARBohy- } \\
\text { DRATES }\end{array}$} & \multirow[b]{2}{*}{ Ash } & \multirow{2}{*}{$\begin{array}{c}\text { Fuel } \\
\text { Value } \\
\text { per } \\
\text { pound }\end{array}$} \\
\hline & & & & & $\begin{array}{l}\text { Sugar, } \\
\text { Starch, } \\
\text { etc. }\end{array}$ & $\begin{array}{l}\text { Crude } \\
\text { Fiber }\end{array}$ & & \\
\hline & $\%$ & $\%$ & $\%$ & $\%$ & $\%$ & $\%$ & $\%$ & Cals. \\
\hline 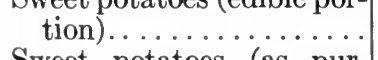 & $\cdots$ & 69.0 & 1.8 & 0.7 & 26.1 & 1.3 & 1.1 & 570 \\
\hline 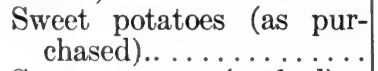 & 20.0 & 55.2 & 1.4 & .6 & 21 & & .9 & 460 \\
\hline Sweet potatoes (cooked). & .. & 51.9 & 3.0 & 2.1 & 42 & & .9 & 925 \\
\hline Sweet potatoes (canned).. & .. & 55.2 & 1.9 & .4 & 40.6 & .8 & 1.1 & 820 \\
\hline $\begin{array}{c}\text { White potatoes (edible por- } \\
\text { tion) } \ldots \ldots \ldots \ldots \ldots \ldots\end{array}$ & . & 78.3 & 2.2 & .1 & 18.0 & .4 & 1.0 & 375 \\
\hline $\begin{array}{l}\text { White potatoes (as pur- } \\
\text { chased)............... }\end{array}$ & 20.0 & 62.6 & 1.8 & .1 & 14 & & .8 & 310 \\
\hline
\end{tabular}

Jerusalem Artichoke.-The Jerusalem artichoke is a tuber of the sunflower family. It was introduced into Europe in 1616. Indigenous 
to Canada and the upper Mississippi Valley, artichokes were cultivated by the American Indians before the discovery of America. Although the tubers contain no starch they possess a considerable amount of sugar, estimated by Wiley at 16.93 per cent. They contain 2 per cent of inulin, which is not very soluble, hut is isomeric with starch; also pectose bodies, 1.3 per cent, which canse them to be mucilaginous when boiled. When boiled in water or milk and eaten with white sance, pepper and salt, they are tasty and nutritious. They may also be cooked with meats and stews, and in various highly seasoned dishes in which condiments connteract the griping tendency of the tuber. They are wholesome, nourishing and fattening, and are recommended by von Noorden in diabetes, since they are better borne than any other carbohrdrate.

Taro Tubers. - Taro tubers have from time immemorial been an important foodstuff for the natives of various countries. They are at present one of the most commonly cultivated tuber crops in the tropies, in Japan, China, Anstria, Hawaiian Islands, Asia, India and Africa. Their cultivation is very ancient. They were grown in China $100 \mathrm{~B}$. c. They contain a large amount of starch, some cane sugar and protein of an albuminoid nature. The roots are tuberous, varying in shape and appearance from a yam to a sweet potato, which they resemble in nutritive value. Although they make a good substitute for them, taro tubers are in no way superior to the more familiar vegetable, the sweet potato. The Hawaiians eat them in the form of a sticky, doughy-like dish, which ferments and is called poi. It is pinkish lavender in color. The taro tuber is said to be a suitable aliment for persons suffering with gastric ailments.

The Yautia.- The yautia botanically is closely related to the taro, though it belongs to a different group. It is a very important starchy food in the West Indies, where it is known by a variety of names, as taniers, cocoes, taye, etc. The cultivated varieties do not produce seed, although they put out abortive blossoms. The plants grow luxurionsly in any moist region free from frost and produce bountiful crops in return for comparatively little labor. In Porto Rico every small farmer has a small plot planted in yautias, and next to sweet potatoes and yams they are the most important native food crop. The vegetable may be prepared like sweet potatoes in a number of appetizing ways. For their chemical composition and fuel value see table on page 418 .

Stachrs.-Stachys is a small perennial belonging to the mint family and produces just below ground a multitude of small white, crisp, edible tubers varving in size from an inch to two and a half inches long and onehalf an inch in thickness, having an irregular corkscrew form. They are 
prepared for the table like other vegetables or may be eaten raw like radishes.

Composition of Starcii-Bearing Roots.-The percentage composition of cassava, taro, yautia, etc., is given in the following table(26) together with that of potatoes for comparison:

\section{AVERAGE COMPOSITION OF SOME TROPICAL STARCH-BEARING ROOTS}

\begin{tabular}{|c|c|c|c|c|c|c|c|}
\hline \multirow{2}{*}{ KIND OF FoOD } & \multirow{2}{*}{ Water } & \multirow{2}{*}{ Protein } & \multirow{2}{*}{ Fat } & \multicolumn{2}{|c|}{$\begin{array}{c}\text { TOTAL CARBO- } \\
\text { HYDRATES }\end{array}$} & \multirow{2}{*}{ Ash } & \multirow{2}{*}{$\begin{array}{l}\text { Fuel } \\
\text { Value } \\
\text { per } \\
\text { pound }\end{array}$} \\
\hline & & & & $\begin{array}{l}\text { Sugar, } \\
\text { Starch, } \\
\text { etc. }\end{array}$ & $\begin{array}{l}\text { Crude } \\
\text { Fiber }\end{array}$ & & \\
\hline Sweet cassaya & $\begin{array}{l}\% \\
66.0\end{array}$ & $\%$ & $\begin{array}{l}\% \\
0.2\end{array}$ & $\begin{array}{c}\% \\
30.2\end{array}$ & $\begin{array}{l}\% \\
1.8\end{array}$ & $\begin{array}{l}\% \\
0.7\end{array}$ & $\begin{array}{c}\text { Calories } \\
610\end{array}$ \\
\hline Cassava starch. & 10.5 & .5 & .1 & \multicolumn{2}{|c|}{88.8} & .1 & 1,625 \\
\hline Cassava bread... & 10.5 & 9.1 & .3 & \multicolumn{2}{|c|}{79.0} & 1.1 & 1,650 \\
\hline Cassava cakes or wafers. . & 10.3 & 1.1 & .2 & 85.2 & 1.6 & 1.6 & 1,670 \\
\hline Taro................. & 70.9 & 1.8 & .2 & 23.2 & .8 & 1.2 & 475 \\
\hline Yams............... & 72.9 & 1.8 & .2 & 23.2 & .6 & .9 & 475 \\
\hline Yautia tubers.... & 70.0 & 2.2 & .2 & 26.1 & .6 & .9 & 535 \\
\hline Artichokes.... & 91.6 & 1.8 & 0.08 & 4.6 & 0.9 & 0.61 & $\ldots$ \\
\hline Stachys.... . . & 78.6 & 2.7 & 0.01 & 17.0 & 0.4 & 1.2 & \\
\hline Potatoes.. & 78.3 & 2.2 & .1 & 18.0 & .4 & 1.0 & 375 \\
\hline
\end{tabular}

COMMON SUCCULENT ROOT VEGETABLES.-There are a number of common succulent root vegetables which resemble each other in so many points that they may be conveniently grouped together for consideration as to their value as nutrient vegetable foods. The following is a list named in the order of their prominence, viz.: beets, carrots, parsnips, turnips, radishes, etc. In some instances the leaves and stems when young and tender are used as pot herbs or "greens."

There are quite a number of these roots, closely resembling one another in general character, grown for the table in European countries and often scen in the United States. With the varieties named above, parsnips, chervil, Spanish salsify and Tettow turnips may be cited as examples. Among the succulent roots used in Oriental countries, but rarely used by the western races, are the following: arrowhead, sacred locust and water chestnut.

Of the bulbs used as foodstuffs in the United States, various members of the onion family are the only ones, which deserve special mention, though lily bulbs of different varieties are eaten by the Chinese. 


\section{LETTUCE}

AS TYPE OF LEAF VEGETABLE.

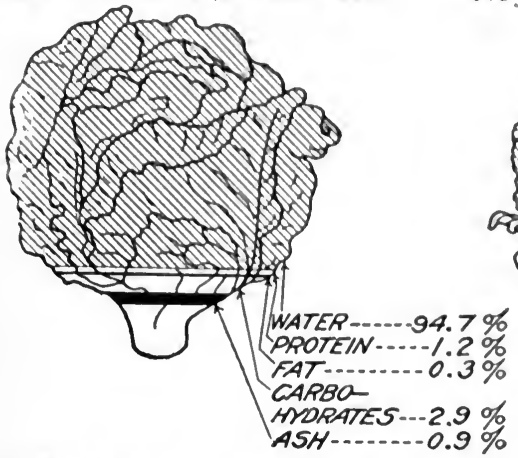

FUEL VALUE PER POUND: 90 CALORIES.
CAULIFLOWEP

AS TYPE OF FLOWER MEAD.

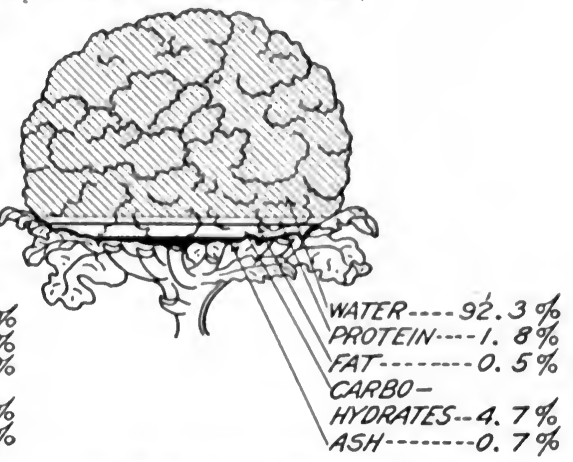

FUEL VALUE PER POUND: 140 CALORIES.

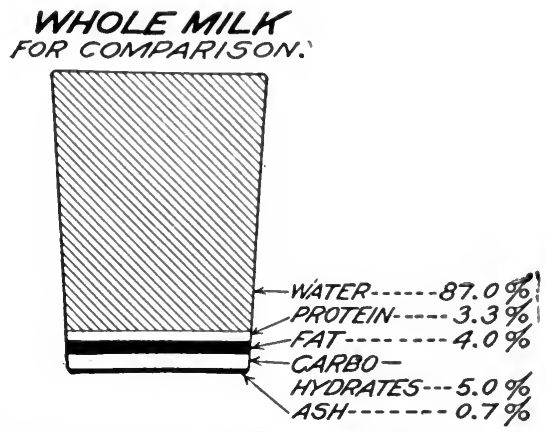

FUEL VALUE PER POUND: 325 CALORIES.

POMPARISON. 
Composition of Succulent Roots.-The following table(27) shows the composition of the nutritive elements of the succulent roots, tubers and bulbs in common use as foodstuffs, as well as the composition of potato, which is included for purposes of comparison:

AVERAGE COMPOSITION OF SUCCULENT ROOTS, TUBERS, AND BULBS

\begin{tabular}{|c|c|c|c|c|c|c|c|c|}
\hline \multirow{2}{*}{ Root, Tuber or Bulb } & \multirow{2}{*}{$\begin{array}{l}\text { Ref- } \\
\text { use }\end{array}$} & \multirow{2}{*}{ Water } & \multirow{2}{*}{$\begin{array}{l}\text { Pro- } \\
\text { tein }\end{array}$} & \multirow{2}{*}{ Fat } & \multicolumn{2}{|c|}{$\begin{array}{c}\text { EdIBle PoR- } \\
\text { TION CARBO- } \\
\text { HYDRATES }\end{array}$} & \multirow{2}{*}{ Ash } & \multirow{2}{*}{$\begin{array}{l}\text { Fuel } \\
\text { Value } \\
\text { per } \\
\text { pound }\end{array}$} \\
\hline & & & & & $\begin{array}{c}\text { Sugar, } \\
\text { Starch, } \\
\text { etc. }\end{array}$ & $\begin{array}{l}\text { Crude } \\
\text { Fiber }\end{array}$ & & \\
\hline & $\%$ & $\%$ & $\%$ & $\%$ & $\%$ & $\%$ & $\%$ & Gals. \\
\hline $\begin{array}{l}\text { Beets, Iresn...... } \\
\text { Beets, cooked... }\end{array}$ & & 88.6 & $\begin{array}{l}1.0 \\
2.3\end{array}$ & $\begin{array}{r}0.1 \\
.1\end{array}$ & \multicolumn{2}{|c|}{7.4} & $\begin{array}{l}1.1 \\
1.6\end{array}$ & $\begin{array}{l}215 \\
185\end{array}$ \\
\hline Celery... . . . . . & 20.0 & 84.1 & 1.5 & .4 & 11.8 & 1.4 & .8 & 285 \\
\hline Carrots, fresh. & 20.0 & 88.2 & 1.1 & .4 & 8.2 & 1.1 & 1.0 & 210 \\
\hline Carrots, desiccated.. & & 3.5 & 7.7 & .6 & \multicolumn{2}{|c|}{80.3} & 4.9 & 1,790 \\
\hline Parsnips. . . . . . . & 20.0 & 83.0 & 1.6 & .5 & 11.0 & 2.5 & 1.4 & 300 \\
\hline Salsify "Oyster Plant". & 24.0 & 85.4 & 4.3 & .3 & 6.8 & 2.0 & 1.2 & 250 \\
\hline Black Salsify........... & 20.0 & 80.4 & 1.0 & .5 & 17.1 & 2.3 & 1.0 & 390 \\
\hline Radishes...... & & 91.8 & 1.3 & .1 & 5.1 & .7 & .1 & 135 \\
\hline Turnips, white........... & 10.0 & 89.5 & 1.3 & .2 & 6.8 & 1.3 & .8 & 160 \\
\hline $\begin{array}{l}\text { Turnips, yellow (ruta-ba- } \\
\text { gas) } \ldots \ldots \ldots \ldots \ldots\end{array}$ & 10.0 & 88.9 & 1.3 & .2 & 7.3 & 1.2 & 1.1 & 185 \\
\hline Kohl-rabi.............. & 20.0 & 91.1 & 2.0 & .1 & 4.2 & 1.3 & 1.3 & 145 \\
\hline Onions.......... & 30.0 & 87.6 & 1.6 & .3 & 9.1 & .8 & .6 & 225 \\
\hline Garlic.... & & 64.7 & 6.8 & .1 & 27.9 & .8 & 1.5 & 650 \\
\hline Potatoes.. & 20.0 & 78.3 & 2.2 & .1 & 18.0 & .4 & 1.0 & 375 \\
\hline Arrowhead Tubers...... & $\ldots$ & 66.88 & 8.42 & 1.22 & 22.19 & .98 & 2.04 & $\ldots$ \\
\hline
\end{tabular}

Nutritive Food Value.-In common with other starchy vegetables this class of foodstuffs contains large quantities of water and consequently has a low nutritive food value. The proportion of protein which it contains is low. Of this small amount not more than a third and frequently not more than a fifth is in a form of albumin or similar compounds. There are sugars, pectose bodies, and, in some cases pentosans. These constitute the reserve material which the plants have stored up instead of the starch characteristic of such roots as the white potato and sweet potato. These succulent vegetables differ from the white and sweet potato in that they possess marked flavors and odors, imparted to them by the small amount of volatile oils which they contain.

The succulent roots, tubers and bulbs, when considered from a standpoint of the nutrient elements, protein, fat and carbohydrates entering 
into their composition, are of much less importance to the diet than the concentrated cereal foods or even the starchy roots and tulers. It may be said of them that they do furnish some nutritive material and are appetizing and generally relished, while furnishing a considerable bulk to the diet, which is an important onsideration from the standpoint of normal digestion. One of the most important functions of these vergetables is the amount of mineral salts needed for the upbuilding and repair of tissue, as well as for inparting alkalinity to the blood, which they supply.

BEETs - Beets are chiefly of vilue for their carbohydrates, consisting of sugar, starch, mueilage and alkaline salts. A glance at the preceding table will give the percentage of their chemical elements. This vegetable when young and tender is used in its entirety. The leaves are boiled for "greens." Of the total nitrogenous miltter a small portion is protein. There are several varieties, varying in color from a light red or vellow to a deep or blackish red. Beets are extensively grown as a food for man and beast. The hoiled roots form an appropriate accompaniment of roast meat. They may also be served cold, cut into slices, made into salads or pickles. They are readily digested by most people. Beets are more nutritious than turnips, parsnips or carrots. Cane sugar (see Volume I, Chapter XVII) constitutes a considerable portion of the carbohydrate content. Some reducing sugar is present. Beets are often served after being boiled and sliced and soaked in vinegar, which assists in softening the fiber and does not interfere with the digestion of the other constituents.

Carrots.-Carrots are grown in many varieties and vary greatly in size, color, flavor and other characteristics. They are a common vegetable all over Europe and Western Asia, where they have been cultivated for more than 2,000

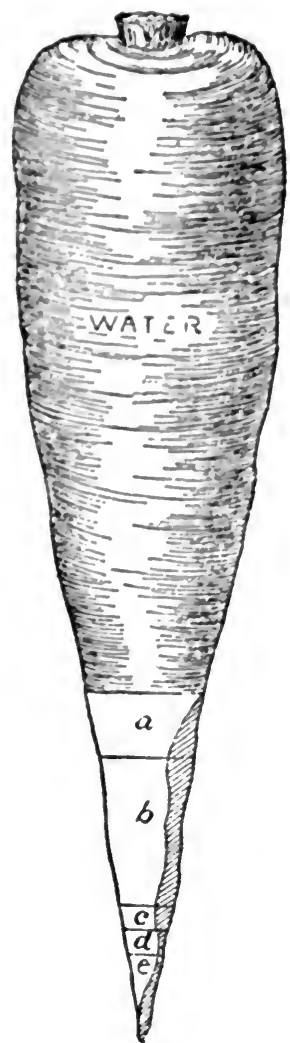

Fig. 36. - CoMPosITION OF THE CARROT A.ND THE Loss OF Nutriexts Whes BoILEd. The illustration shows-(a) fiber, starch, fat, etc., (b) sugar, (c) nonproteid nitrogenous matter, (d) proteid nitrogenous matter, (e) mineral matter. The batched portion represents the loss when medium-sized pieces were boiled. (Bull. No. 295, U. S. Dept. Agric.) 
years. It is alleged by Church that this vegetable was introduced into England during the reign of Queen Elizabeth. Those commonly raised. are of medium size, deep yellow color, tender and have a delicate flavor. Young carrots are more edible and tasty than old ones. When fully matured they tend to become hard and woody. A glance at the table on page 418 shows their composition does not differ materially from other similar roots, carbohydrates constituting the principal nutritive material.

Sugar is the next element of importance; it ranges from 7 per cent or more. The coloring matter of carrots is due to the presence of carotin. This is sometimes extracted with their juice and used for coloring butter. Carrots resemble parsnips in composition, but they are richer in sugar and poorer in starch.

Cooked carrots lose a considerable portion of their nutriment, especially the soluble protein and carbohydrates, of which they retain little more than 4 per cent. It is alleged by a European investigator that when carrots are steamed they become soft more quickly than when cooked in hot water. The loss of nutrient elements is much less by the former method. Carrots are considered a wholesome and valuable addition to the diet, and as a seasoning vegetable they may be cooked in a great variety of ways. When the foliage of carrots is wet it gives off a poisonous substance, perhaps an essential oil, which produces an eczema similar to that produced by poison ivy.

PARsNips.-Parsnips belong to the same botanical order as carrots and resemble them in form and general habit of growth. The flesh of the root, however, is paler, being a light cream color. The flavor is quite distinct and well pronounced. The parsnip root is found wild in the meadows of Great Britain and all over Europe. It was a common garden vegetable among the Romans and probably was cultivated by them more than 2,000 years ago. It figures in the ancient frescos of Pompeii, being mentioned by Dioscorides. In times of scarcity it has been used for making bread. This vegetable may be cooked and served in a variety of ways.

Composition.-In composition parsnips are much like the other roots and tubers, but contain rather high quantities of cellulose. The amount of total nutritive material lost in boiling is not definitely known. The parsnip contains considerable nutritive material of the sugar, starch group and about 80 per cent of water. It is unique in containing more fat than other vegetables of this class. The parsnip is therefore a somewhat better food vegetable than a turnip or carrot. Pectose and cellulose are abundant in parsnips. The carbohydrate content averages from 13 to 14 per cent. It has a strong flavor which is not attractive to many people. An 
excellent wine is made from the roots and also a fermented liquor which yields a spirit resemhling Madeira in thavor. In Great Britain the juice of the parsnip is used for wine and the forment distillation yields a por table spirit.

Tumas.-Turnips are grown in great variety throughont temperate climates. The tumip has been contivated in Greene since the earliest days of history. It grows wild in many comntries. In Rossia it is classed as a luxmre and is sometimes aten raw als a relish. 'The Laphlanders are said to be exeedingly foud of this regertable.

Vurieties.-There are numerons speries. Special varieties of turnip are known as white and yellow turnips and suedes. There is considerable variation in the color, flaror and composition of the turnip. Yellow flesh varieties as a group are common and are distinguished from the white by the name of rutubagas. Solid as the turnip root appears, it contains an average of 89 per eent of water, a trifle more than is found in whole milk. Carbohydrates are the prineipal nutritive material; ghcose, cane sugar, pectose or jelly-yielding bodies, pentosans and crude fiber are the characteristic carbohydrates present. The turnip is best eaten boiled and mashed or male into a purée. They are also used in soups and stews. The turnip contains no starch and is therefore a valuable vegetable in the diet for diabeties. The turnip is considered a wholesome, palatable and useful addition to the diet. In the early spring the tender tops are much prized as greens or turnip salad. These young tender tops when boiled with a hog's jowl make an appetizing, wholesome addition to the dietary.

Radisues.-Radishes are probalbly a development of the wild charlock, which is an annual weed of the old world and has been cultivated in gardens from the earliest historic times. There are a great number of varieties, varying in shape and color: white, yellow, red, black or purple. Some of the roots have a very fine flavor and when young are crisp, juicy and tender, but when old they contain much woody fiber and are difficult to digest.

Composition.-According to analysis contained on page 420 it will be observed that the radish contains even more water than the turnip. The characteristic pungent flavor is due to organic compounds similar to the essential oil of mustard. Radishes are almost always eaten raw and are so sucenlent and tender that they are doubtless rather thoroughly assimilated. Especially when tender they are stimulating to the stomach and produce a flow of saliva and gastric juice, their pungeney and warmth eneouraging appetite. This pungeney of radishes adds to their value as an antiscorbutic. 


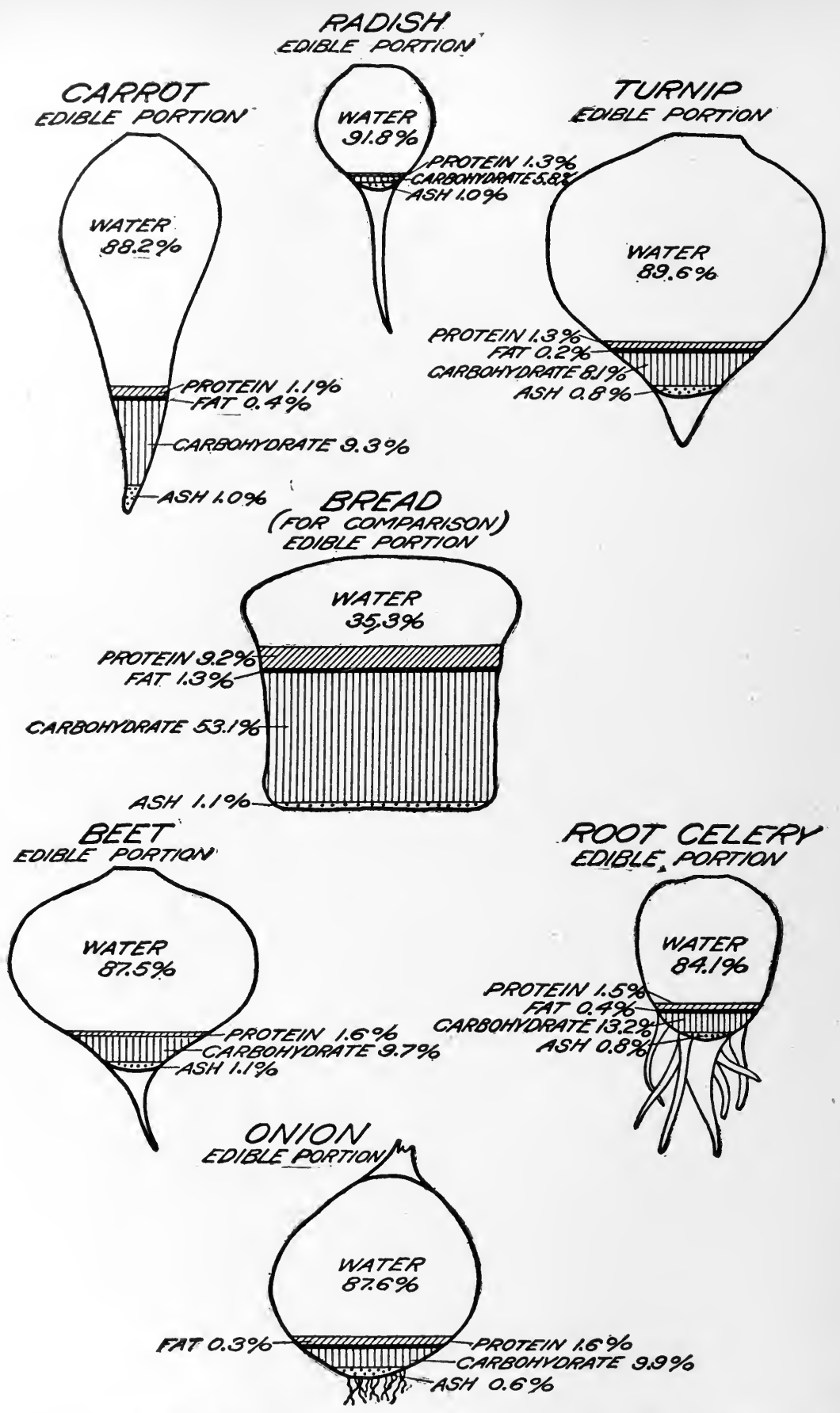

Fig. 37.-Percentage Composition of Carrot, Onion, Beet and Other Root Vegetables Compared with Each Other and with Bread. These outline figures represent diagrammatically the proportion of nutrients present. Plain white indicates water and the differently shaded portions protein, fat, carbohydrates and ash respectively. (Bull. 503, U. S. Dept. Agric.) 
Salsir - Salsify or oyster plant resembles the carrot in appearance. It grows wild in the sonth of Europe and in Algeria. When tender the roots are considered a delicacy similar to asparagus and are eaten with white sance or lemon juice. They have a flavor of oysters which has gained for them the name vegetable oyster. The leaves or tops are eaten as a salad. They may be cooked and served with sauce in the same way as asparagus. The principal carbohydrate stored in black salsify is inulin rather than starch, so that this vegetable is often used in the diet of diabetics.

Horse Ramsu. - Horse radish is the ront of a plant which is a native of Western kurope. It is extensively grown on both sides of the Atlantic. The horse radish has a warm taste and a pungent odor which tends to promote appetite and the secretion of saliva. It increases gastric secretion and motility, thereby acting as a stimulant to the alimentary functions. At the same time it is a carminative and antiseptic all along the intestinal tract. Its antiseptic properties are due to the presence of a volatile oil contained in the root. This oil is obtained by distillation. It is pale vellow and nearly colorless, heavier than water, but very volatile, having a pungent, acrid taste. Horse radish contains a large amount of sulphur in an organized form and is a most valuable antiscorbutic condiment. In addition to its useful qualities already mentioned, it is valuable in the dietotherapy of chronic rheumatism, sciatica and various dropsical conditions.

Konlrabi.-Kohlrabi, or turnip cabbage, represents a curious variety of the turnip and cabbage families in which the reserve material of the plant is stored in a tuber-like enlargement of the stem just above the surface of the soil rather than beneath. While, strictly speaking, it does not belong to the class of roots and tubers, yet it is so similar to them that it is ineluded in this study of succulent roots and tubers. Although it resembles them in flavor, kohlrabi is more delicate than either the turnip or the cabbage. As a vegetable it is at its best in the early summer, when it is young and tender, although it is commonly found in the markets until late antumn. Its chemical composition may be seen in the table on page 420 .

Skirret.-Skirret is a root vegetable grown in Europe, America, Asia, China and other countries. When boiled the roots resemble the parsnip and are eaten with white sance; half boiled they are fried and eaten with pepper and other condiments. This regetable was known to the Romans and Greeks of the middle ages. It contains considerable cane sugar. The roots are sweet after boiling and a fine white sugar can be 
obtained from them. They are esteemed for this property by some people who consider them the finest, whitest and pleasantest roots grown.

Arrownend Tubers.-Arrowhead tubers are common articles of food in some countries. The American Indians called it wappato. The tubers are small, the interior yellow, farinaceous and of the consistency of the potato. The high percentage of protein proves their superiority to potatoes, sweet potatoes and yams. Starch is the most important carbohydrate, although cane sugar is present. Their percentage composition may be studied on page 420 .

Daillias.-Dahlias are more appreciated for their flowers than for their tubers, notwithstanding attempts have been made to introduce this

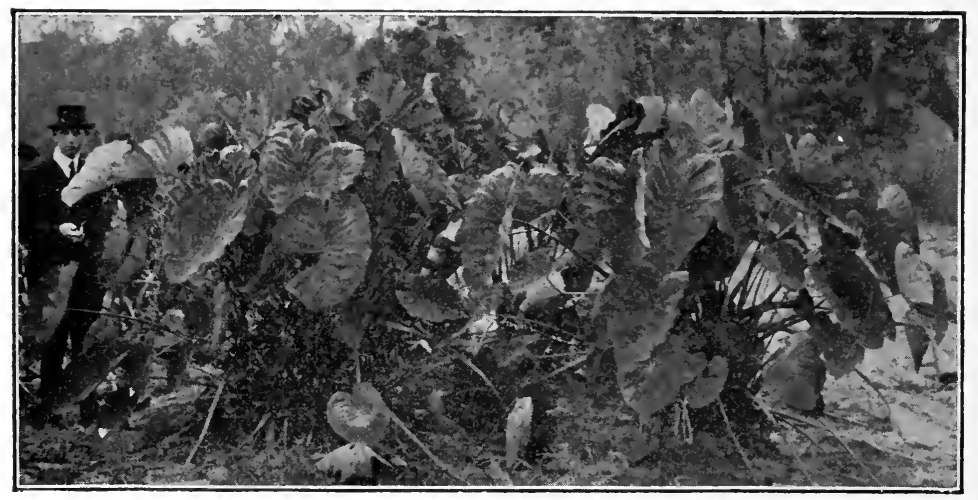

Fig. 38.-Dasheen Plant at Brooksville, Florida. Hills as they appear at the time of harvest, early in November, $7 \frac{1}{2}$ months after planting. One of these hills produced 26 pounds of corms and tubers. A good average yield, however, in rich soil is from 6 to 8 pounds, or 360 to 475 bushels per acre. (Yearbook for 1916, U. S. Dept. Agric.)

tuber as a succulent vegetable food. The tubers are rich in carbohydrate, especially inulin, and contain little or no starch. They are recommended as an addition to the dietary for diabeties.

Water Chestruts.-Water chestnuts grow wild in swampy ground. The tubers are sweet, juicy and resemble the chestnut in flavor. They have a brown skin and white interior.

Upon examination their composition has been found to be as follows: water, 77.29 per cent; protein, 1.53 per cent, including albuminoid, 1.16 per cent; amids, 0.37 per cent; fat, 0.15 per cent; starch, 7.34 per cent; cane sugar, 6.35 per cent; reducing sugar, 1.94 per cent; fiber, 0.94 per cent, and ash, 1.19 per cent. The striking feature is the high proportion of sugars, which gives them a sweet taste and makes them of value as a 


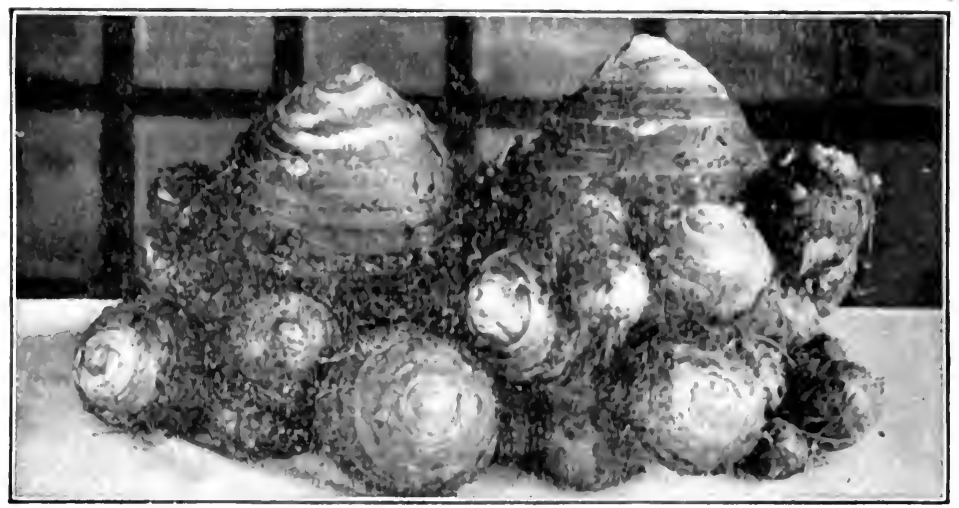

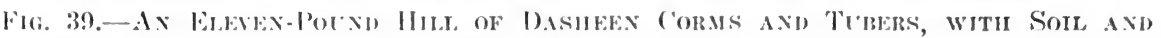

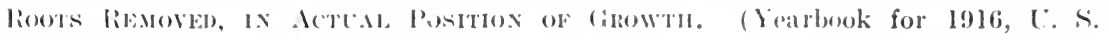
Dept. Igric.)

raw food. 'The protein is principally allumin. The principal element in the ash is manganese. (Analysis hy lianislale in Bull. 6s, L. S. Dept. Invic.)

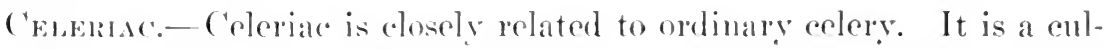
tivated variety, sometimes known as turnip-rooted celery. 'The roots are

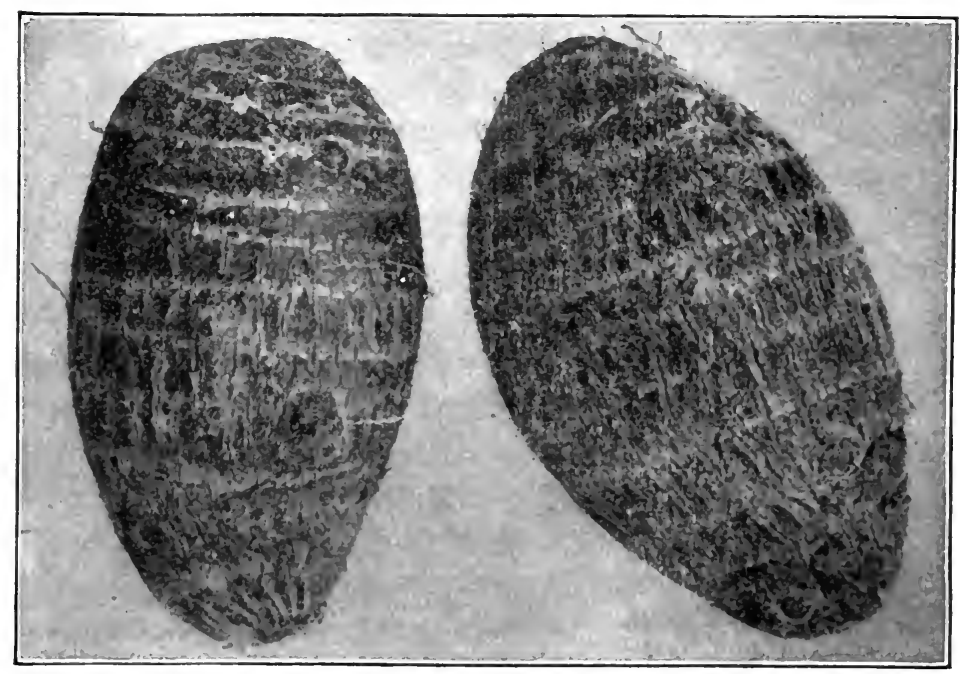

Fig. 40.-Dasinfex Cormers. or "Tiners." Tuhers of the grade here shown are referred to as firsterade tulers and are abont two-thirds natural size. With many. of smaller size or irregular shape, they grow elustered around one or more large corms. Inder proper soil enditions they are of excellent quality and command a much better price than the smaller and irrexularly shaped ones. (Yearbook for 1916. I. S. Drpt. Inric.) 
white, more or less globular in shape and closely resemble turnips in appearance. This vegetable has a pronounced celery flavor and when cooked does not differ greatly from ordinary stewed celery.

As will be seen by consulting Fig. 37, page 424, they have much the same composition as other succulent roots.

DasheEn.-Dasheen is a vegetable of the tuber variety readily grown in semi-tropical climates. It is a staple food for millions of people in tropical countries. They have a flavor when boiled or baked simulating that of boiled chestnuts. Dasheens have been successfully grown in South Carolina and Florida. (See Figs. 39 and 40, page 427.)

Dasheen roots are similar in composition to the potato, but contain more starch and protein.

Lily Bulbs.-Lily bulbs have long been used as articles of food by the Orientals of several Asiatic races. They are more of a delicacy than a standard article of diet. The bulbs are prepared for eating by boiling or they may be slightly roasted and served with sugar. Prepared in this way, they are considered a desirable food for invalids and convalescents. The tuber is nourishing and wholesome, and is believed by the Asiatics to be of value to people suffering from pulmonary complaints.

In composition they contain a small amount of protein, more than that found in potatoes. The chief carbohydrate is starch, but cane sugar is also found. There is an abundance of pectose-like substances.

The Lotus.-The lotus of Asia belongs to the family of water beans and has been used from time immemorial as a food material by the Hindoos, who regard the plant with much veneration. The lotus occupies a prominent place as a food in Japan, China, Indo-China and other Asiatic countries. There are several varieties. The roots consist of yellowish nodular stocks with a firm, reddish, fleshy interior. They contain an abundance of starch, while the amount of nitrogenous material is small, one-half of which is albuminoid. The roots are boiled and eaten like potatoes, pickled in salt and vinegar and eaten with rice, or dried and powdered and added to soups. The lotus has a seed which when dried is eaten as we eat filberts or other nuts. They are also used in soup in China and Japan, while in Egypt they are roasted and ground into meal. The seeds compare favorably with beans and peas, some of which they resemble in flavor. They are equally nutritious.

$\mathrm{S}_{A G O}$.- Sago is the starchy substance obtained from the pith of various palms growing in the tropics, and while not a tuber or root it is included in this section for the sake of convenience. Sago starch is obtained from the sago palm. It is the inner pith. Each tree yields about five hundred 
pounds of this material. The pith is removed by scraping, reduced to a pulp, mixed with cold water and agitated until the starch falls off. The starch gramules of the finished product are sago grains of large and irregular shape, often nearly spherical. The gratin are classed as medium and bullet sago. The latter is used principally for making puddings to which milk, eggs, butter and sugar are added. In fuel value such puddings compare favorably in nutritious value with rice pudding and are equally suitable for food. They are very easily digested and in absorption very little residue is left.

Tapioca.-Tapioca is a species of manioc cassava and is derived from a tuberous root. Its cultivation and use are of great antiguity. The roots of this vegetable grow from ten to twelve inches in length and three to four inches in thickness, usually in clusters of three to eight in number.

They are so similar to cassava in chemical composition and nutritive value that the reader is referred to this vegetable, described on page 418 .

Oxioxs.-Onions, while most commonly used for flavoring purposes, are also used as a food. There are said to be some seventy-eight varieties of onions, many of which are used as vegetable foods. They may be described as bulbs growing under ground; characterized by their strong flavor and odor, due to the presence of allyl sulphid, a characteristic organic compound of sulphur. The common onion in its many varieties is best known and most used in the United States. As with most vegetables, the young and somewhat immature onion is preferred to the fully matured bulbs. The white varieties are milder in flavor than the red and yellow, and are generally preferred as table vegetables.

Onions are succulent and tender and are as thoroughly digested and as freely absorbed as other similar vegetables. They are considered wholesome and have been prized since the earliest times as a valuable addition to the diet. Their peculiar characteristic, sulphur compound, is believed to stimulate the flow of digestive juices and to act as a mild laxative. They impart an unpleasant odor to the breath. Since onions contain no appreciable amount of starch and an infinitesimal amount of sugar, they are usually allowed to diabetics.

Their chemical composition is somewhat similar to other succulent roots, as will be observed by referring to Fig. 37, page 424. They contain rather large quantities of cellulose, more particularly in the outer layers.

Garlic.-Garlic belongs to the onion family and is more of a condiment than a food. Its use stimulates appetite and promotes digestion, expelling flatus. Garlic quickens the circulation, excites the nervous system and acts as a tonic and carminative. In this country it is little eaten. 
save by the foreign population. This is perhaps unfortunate, for if rightly used, garlic undoubtedly adds to the palatability of salads, meats and other dishes.

SHallot.-Shallot is a variety of the onion family and is much esteemed in European countries for its flavoring qualities.

\section{GREEN VEGETABLES}

Green Vegetables.-The leaves of green vegetables consist of a framework of fibro-cellular tissue upon which the chlorophyl-bearing protoplasmic plant cells are spread out to the air and light. This breadth of surface of the green leaves is for the respiration and nutrition of the plant. Since respiration is the chief function of the leaves, they contain only a limited amount of nutriment. Green vegetables are, in no sense, like the roots and tubers, reserve storehouses of nutritive food elements.

COMPOSITION OF GREEN VEGETABLES.-Green vegetables are rather poor in solid material, owing to the fact that water forms a high percentage of their composition. The nitrogenous matters in the leaves of green vegetables do not exceed 2 or 3 per eent, one-half of which is protein. The remainder consists of amids, ammonia salts, including nitrates and other bases. The non-nitrogenous materials include 2.5 per cent of sugars, besides stareh and pentosans, making a total earbohydrate content of 2 to 10 per cent and about 2 per cent of fibro-cellulose.

FOOD VALUE OF GREEN VEGETABLES.-The food value of green vegetables is not very great, as proven by ehemical analysis, which shows them to be defective as a source of nutriment for man. While the value of vegetables to mankind cannot be estimated in terms of protein, fat and carbohydrate, yet aside from the small amount of energy they furnish, their chief importance is not alone the pleasing variety and palatability they add to the dietary, but they are a source of supply of organic acids and mineral salts. These ingredients render green vegetables an absolute necessity for our well-being. Their bulk stimulates peristalsis and maintains a healthy activity of the alimentary tract.

Travelers and sailors who go beyond the reach of fresh green vegetables suffer from scurvy or other signs of ill health, due to the fact that they are deprived of the organic acids and vitamines contained in this class of food. There is no question but that many forms of ill health are fostered if not created by the absence of such vegetables from the dietary of people living both in town and country. "All vegetables contain important salts and mineral matter in the forms of oxalates, eitrates, phosphates and sulphates, besides free organic acids, which play an important rôle in 
our physiological economy." Such salts are just as important a necessity for our blood and secretions as the proteins for renewing our tissue and carbohydrates for producing energy. Tibbles believes that these salts enter the regetables from the earth by way of the vegetable roots, in the form of ions and circulate as ions through the plant fluids and tissues, and that such ionizel salts are the prime sources of the great value of fresh vegetables to the human economy.

Compositiox of Green Vegetables.-The table on page 432, taken partly from Hutchison, gives the composition of the various chemical elements found in green regetables and the energy or fuel value in calories per pound.

A well-balanced dietary contains a liberal allowance of fresh vegetables, such as cabbage, cauliflower, potato, lettuce, tomatoes, celery, turnip, cucumbers, asparagus, ete., or other salads or fruits. One or more of these vegetables should constitute a portion of at least one meal each day. The mineral salts from such vegetables render the blood and urine more alkaline and the indigestible fiber or cellulose by its bulk acts as a stimulant to the movements of the alimentary tract, promotes secretion of the intestinal fluids and thereby counteracts a tendeney toward constipation. Fresh vegetables play an important rôle in the treatment of disease and are of especial value to people who suffer from constipation, liver disease, gout, gravel, rheumatism, diabetes, scurvy, purpura, anemia and various disorders of the integumentary system.

COOKING OF VEGETABLES.-Vegetables may be cooked by boiling, roasting or baking; some are equally palatable cooked either way. In boiling vegetables it is well to advise that they be boiled in soft water, for the reason that when hard water is used, a layer of lime or magnesia salts is deposited upon them, preventing the free penetration of heat into the interior. This delays the process of cooking and often spoils their appearance. Some vegetables lose a considerable part of their nutrient compounds, especially the soluble materials, by being boiled. In these steaming is a better method.

DIGESTIBILITY OF VEGETABLES.-Regarding the digestibility of regetables. much depends upon the amount and character of their cellulose custent. Young and tender vegetables contain very little cellulose. Slow growth, on the other hand, favors the formation of fibrous tissues. Persons in robust health, leading active out-of-donr lives and having normal healthy stomachs, are able to digest vegetables easily, but in aged persons, in those who follow sedentary occupations, in invalids and in roung children, the digestive functions are neither so powerfil nor so energetic. 


\section{COMPOSITION OF GREEN VEGETABLES}

\begin{tabular}{|c|c|c|c|c|c|c|c|}
\hline VEGETABLE & Water & Protein & Fat & $\begin{array}{l}\text { Carbo- } \\
\text { hydrate }\end{array}$ & Ash & Fiber & $\begin{array}{l}\text { Fuel } \\
\text { Value } \\
\text { per } \\
\text { pound }\end{array}$ \\
\hline Cabbage. & $\begin{array}{r}\% \\
896\end{array}$ & $\%$ & $\begin{array}{c}\% \\
040\end{array}$ & $\begin{array}{r}\% \\
58\end{array}$ & $\%$ & $\%$ & Cals. \\
\hline Cabbage, cooked........ & $\begin{array}{l}09.0 \\
97.4\end{array}$ & $\begin{array}{l}1.80 \\
0.60\end{array}$ & $\begin{array}{l}0.40 \\
0.10\end{array}$ & $\begin{array}{l}5.8 \\
0.4\end{array}$ & $\begin{array}{l}1.50 \\
0.13\end{array}$ & $\begin{array}{l}1.10 \\
1.30\end{array}$ & $\begin{array}{l}165 \\
165\end{array}$ \\
\hline Cauliflower.............. & 90.7 & 2.20 & 0.40 & 4.7 & 0.80 & 1.20 & 175 \\
\hline Sea-kale.... & 93.3 & 1.40 & 0.40 & 3.8 & 0.60 & 0.90 & 175 \\
\hline Sea-kale, cooked. & 97.9 & 0.40 & 0.07 & 0.3 & 0.20 & 1.10 & 175 \\
\hline Spinach........ & 90.6 & 2.50 & 0.50 & 3.8 & 1.70 & 0.90 & 120 \\
\hline Vegetable Marrow.... & 94.8 & 0.06 & 0.20 & 2.6 & 0.50 & 1.30 & 120 \\
\hline Vegetable Marrow, cooked. & 99.2 & 0.09 & 0.04 & 0.2 & 0.05 & 0.37 & 120 \\
\hline Brussels Sprouts......... & 93.7 & 1.50 & 0.10 & 3.4 & 1.30 & 0.37 & 95 \\
\hline Tomatoes............... & 91.9 & 1.30 & 0.20 & 5.0 & 0.70 & 1.10 & 105 \\
\hline Tomatoes, cooked......... & 94.0 & 1.00 & 0.20 & 5.0 & 0.70 & 1.50 & 105 \\
\hline Greens............... & 82.9 & 3.80 & 0.90 & 8.9 & 3.50 & 1.50 & 275 \\
\hline Lettuce...... . . & 94.1 & 1.40 & 0.40 & 2.6 & 1.00 & 0.50 & 105 \\
\hline Lettuce, cooked......... . & 97.2 & 0.50 & 0.16 & 0.5 & 0.40 & 0.90 & 105 \\
\hline Leeks. . . & 91.8 & 1.20 & 0.50 & 5.8 & 0.70 & 0.90 & 105 \\
\hline Celery... & 93.4 & 1.40 & 0.10 & 3.3 & 0.90 & 0.90 & 85 \\
\hline Celery, cooked. & 97.0 & 0.30 & 0.06 & 0.8 & 0.50 & 1.00 & 85 \\
\hline Turnip Cabbage.... . . . & 87.1 & 2.60 & 0.20 & 7.1 & 1.50 & 1.30 & 145 \\
\hline Rhubarb. . & 94.6 & 0.70 & 0.70 & 2.3 & 0.60 & 1.10 & 105 \\
\hline Macedoine (tinned)....... & 93.1 & 1.40 & 0.70 & 4.5 & 1.00 & 1.10 & 110 \\
\hline Water Cress............. & 93.1 & 0.70 & 0.50 & 3.7 & 1.30 & 0.10 & 110 \\
\hline Cucumber... & 95.9 & 0.80 & 0.10 & 2.1 & 0.40 & 0.50 & 70 \\
\hline Cucumber, cooked....... & 97.4 & 0.50 & 0.02 & 0.7 & 0.20 & 0.90 & 70 \\
\hline Asparagus............. & 91.7 & 2.20 & 0.20 & 2.9 & 0.90 & 2.10 & 110 \\
\hline Salsify, cooked. & 87.2 & 1.20 & 0.08 & 9.0 & 0.30 & 2.20 & 110 \\
\hline Endive........ & 94.0 & 1.00 & 0.08 & 3.0 & 0.80 & 0.60 & 110 \\
\hline Savoys. . & 87.0 & 3.30 & 0.70 & 6.0 & 1.60 & 1.20 & 110 \\
\hline Red Cabbage............ & 90.0 & 1.80 & 0.19 & 5.8 & 0.70 & 1.20 & 110 \\
\hline Sauerkraut... & 91.0 & 1.40 & 0.70 & 2.9 & 1.70 & 0.90 & 110 \\
\hline Carro & 84.00 & 3.20 & & 7.20 & 2.50 & 3.10 & \\
\hline Colewort or Collards. . . & 87.10 & 4.50 & .60 & 6.30 & 1.20 & & \\
\hline Curly-kale or Greens...... . & 82.90 & 3.80 & .90 & 9.90 & 3.50 & 1.50 & \\
\hline Dandelion leaves......... & 81.40 & 2.40 & 1.00 & 10.60 & 4.60 & & \\
\hline Marigold leaves.......... & 90.00 & 2.00 & $\ldots$ & 3.80 & 1.60 & 2.60 & \\
\hline Parsnip leaves.... & 85.70 & 2.00 & & 6.30 & 2.40 & 2.60 & \\
\hline Turnip Cabbage, Kohl-rabi. & 87.30 & 3.90 & 1.50 & 5.60 & 2.10 & & \\
\hline Turnip-tops..... . & $\begin{array}{l}87.10 \\
86.70\end{array}$ & $\begin{array}{l}2.60 \\
4.20\end{array}$ & $\begin{array}{l}.20 \\
.60\end{array}$ & $\begin{array}{l}7.10 \\
6.30\end{array}$ & $\begin{array}{l}1.70 \\
2.20\end{array}$ & 1.30 & \\
\hline White....... & 88.00 & 2.50 & $\ldots$ & 3.80 & 1.80 & 3.90 & \\
\hline Swede.... . & 86.50 & 3.20 & $\cdots$ & 4.30 & 1.80 & 4.20 & \\
\hline
\end{tabular}

These classes of individuals do not digest all kinds of vegetables well. Their digestion is slower and the motor power of their stomachs more feeble, so that vegetable matter may remain longer in the stomach, causing 
pain or generating flatus, perhaps giving rise to other unpleasant symptoms.

Digestibintity of Cooked Vegetables. - Science has established the fact that a well-balanced diet is composed of the proper combination of animal and vegetable food; nevertheless there are individuals who cannot eat vegetables in their ordinary form after cooking, without suffering from discomfort for a longer or shorter time. For such persons vegetables should be prepared in the form of a purce or served in a consommé. The preparation of vegetable dishes for invalids requires some skill. The cooked vegetable should be placed in a mortar and pounded until reduced to a pulp. It should be rubbed through a sieve to remove the cellular fiber and other refuse. It should then be warmed in a stew pan with a little milk or cream and flavored with pepper and salt. Persons who suffer from indigestion, flatulence, gastric or intestinal disorders will be able to digest most vegetables with impunity if so prepared.

The effect of cooking upon green vegetables reduces largely their present poor stock of mutrients. They gain water and lose part of their carbohydrate and protein content. Much of their mineral matter as well as the principal part of their non-albuminoid, nitrogenous constituents are lost, including the non-protein nitrogen, 30 to 50 per cent of the carbohydrates, 50 per cent of the inorganic salts and at least one-third of the total nutrients. This happens when they are boiled, but not so when stewed or baked.

Digestibility of Raw Vegetabi.es. - Some vegetables are eaten raw, such as celery, lettuce, water cressen, tomatoes, cucumbers, or cabbage made into cold slaw, etc. Usually raw vegetables are prepared by the addition of salt, olive oil, vinegar, pepper and other condiments. When these vegetables can be secured crisp and fresh there is no reason why they should not be thus served; the only caution to be observed is that they should be scrupulously clean and thoroughly masticated. The chewing should be continued until they are reduced to a creamy pulp, when they will be easily taken care of by the digestive system and seldom give rise to any discomfort.

VARIETIES OF VEGETABLES: CABBAGE.-Cabbage belongs to the N. O. of Cruciferce. This plant was probably first cultivated by the Saxons and early Germans. Its cultivation as a foodstuff was begun, probably, before the Aryan invasions. Cabbages are used as food on account of their agreeable flavor and succulent character. They are also important on account of their antiscorbutic properties. They seem to have been evolved by natural or artificial selection from the wild coleworts or collards that grow 
wild on the seashore in many countries. The leaves rising from the root stalk are gathered together to form a compact head, and in this way the light is excluded. They become white from want of chlorophyl and are crisp and tender. Cabbages contain a considerable quantity of sulphur and on this account are apt to cause flatulence. Where digestion is good, however, they are a wholesome vegetable. Cabbage is eaten boiled or raw. After cooking it contains more water than in the green state. When eaten raw the cabbage contains more nutrients than after boiling, since a certain percentage of the mutrients is lost in the water.

By referring to the table on page 432 it will be noted that in composition there will be found some sugar and starch with a rather high constituent of protein. The calcium content should not be overlooked, as it probably gives the cabbage antiscorbutic and bone-building properties.

The varieties of the cabbage family are so similar in composition and food value that we need do no more than mention them. Starting with the simplest form of the cabbage plant, we have the collard. Kale or borecale has two varieties - the "curly kale" and "asparagus kale"; the former is very tender when cooked and of mild flavor; the latter is a dwarf variety, which throws out long shoots. These when properly cooked are as tender and delicious as asparagus.

Cauliflower was known to the Greeks and Romans, but was not much cultivated in Europe until after the sixteenth century. It is the most digestible member of the cabbage family. It is much more delicate in flavor and more digestible than the ordinary cabbage, and is wholesome when boiled and served with a milk sauce. The edible portion consists of the inflorescence altered by cultivation.

Brussels sprouts is a variety of cabbage having blistered leaves. The stem of the plant is covered with small miniature heads of cabbage, which are the edible portion of the plant.

Broccoli sprouts embrace many strains of the cabbage family. The leaves of this variety resemble the cauliflower; they are the part uscd for food.

Seakale is a native of the cliffs of the shores of England. It is a green vegetable with young and tender shoots and is held in special regard by the inhabitants of Great Britain. It has been brought to a high state of perfection by cultivation, and when properly cooked is easy to digest and very nutritious.

Spisach.-Spinach is a green vegetable said to have been cultivated in the ancient empire of the Medes and Persians. It was grown extensively as early as the sixteenth century. There are two varieties of the 
plant, one winter or perpetual spinach having small prickly leaves, the other a smooth leaf rariety having thick, fleshy and crimped leaves. It is of special value as a green vegetable owing to the very small amount of cellulose which it contains.

LETTUCs.-Lettuce is one of the most important of all the succulent. regetables. It was introduced into lingland from Flanders in 1520 . There are many varieties, some of which are spreading and have large sucenlent leaves, while others are drawn together like the cabbage and are very crisp and nearly white in color. There are several species and about one hundred varieties, of which ('os or leaf lettuce from the Island of Cos and cabbage lettuce are the two most important. Lettuce is usually eaten raw as a salad, but is sometimes boiled and eaten as a vegetable. There is very slight food value in letture, although its mineral salts are of use in the processes of metabolism. It is a wholesome, digestible, cooling and agreeable vegetable, chiefly valuable for its juice, which is bland, pellucid, has little taste or smell and is cooling and soothing. The juice is milky and possesses mild soporific properties. W'hen the plant is matured the juice is collected, inspissated and forms lettuce-opium, lactucarium. The principal salts are the oxalate, malate, nitrate and sulphate of potash, chlorid of potash, and phosphates of lime and magnesia, oxids of magnesia, iron and silica. The plant also contains traces of hyoscyamin.

Celerr.-Celery grows wild in damp and marshy places in Europe, Asia and Africa. Its cultivation is very ancient and is spoken of in the Odyssey under the name of selinon. There are about forty varieties and many more sub-varieties. It was brought from England to the United States and gradually has come into common use. At present it is considered a valuable addition to our supply of foods and condiments. The long blanched leaf stalks are the result of cultivation, which with careful selection and development have lost their rank odor and the coarse taste of the wild plant. Some of the varieties of superior quality are large compact plants, crisp and juicy and have a fine nutty flavor. The entire plant, stems and seeds possess stimulating, carminative and diuretic properties. Celery is especially recommended for rheumatics. Its peculiar odoriferous principle is due to an essential oil which is found in very small quantities and regarded by some as of therapentic importance. Celery salt is made by grinding celery seed with sodium chlorid. It is used as a flavoring for soups and salads. Turnip celery has already been considered on page 427 .

RHuBARB.- Rhubarb is a valuable article of dict, rich in regetable salts. It is in season when fruits are scarce. The plant belongs to the 
buckwheat family and is often called pie plant. Rhubarb is used for making pies and sance. The thick petioles or foot stalks of the leaves are used for this purpose. Rhubarb occupies the same place in the dietary as fruit, but is uneatable in its raw state. Wine and other beverages are made from it. Its use as a food or beverage is contra-indicated in persons of a gouty diathesis and those with oxalate of lime, also in some forms of rheumatism, owing to the presence of calcium oxalate in its content. In medicine this plant is appreciated for its slightly laxative action.

Below is appended a table, showing cost per pound and cost of 1,000 calories of some of the common vegetables, from the publication of the Health Department of New York City, 1917:

COST OF VEGETABLES

\begin{tabular}{|c|c|}
\hline Cost of 1,000 & Price per \\
\hline Calories, & Pound, \\
\hline Cents & Cents \\
\hline 20.0 & 2.5 \\
\hline 21.8 & 10.0 \\
\hline 25.8 & 4.0 \\
\hline 27.6 & 5.0 \\
\hline 29.3 & 6.0 \\
\hline 30.0 & 3.3 \\
\hline 39.2 & 10.0 \\
\hline 39.2 & 10.0 \\
\hline 42.9 & 6.0 \\
\hline 50.0 & 8.0 \\
\hline 55.6 & 10.0 \\
\hline 76.2 & 8.0 \\
\hline 89.4 & 7.0 \\
\hline 214.0 & 15.0 \\
\hline
\end{tabular}

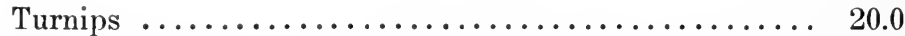

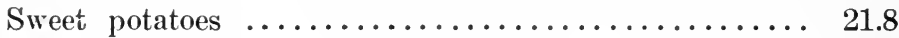

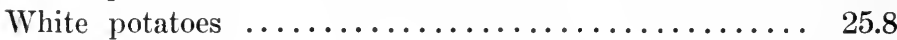

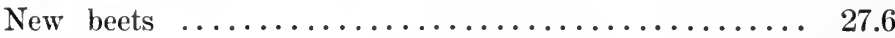

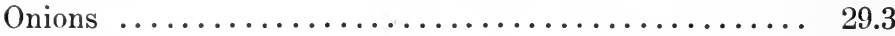

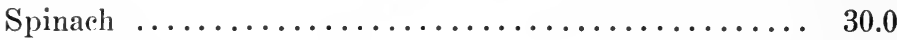

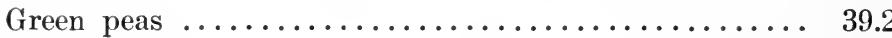

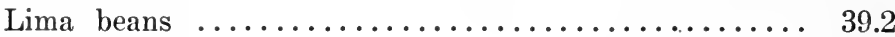

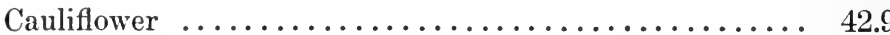

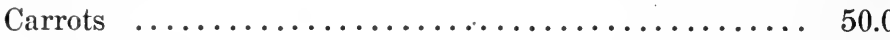

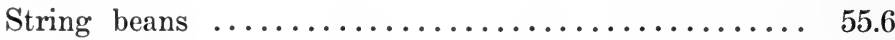

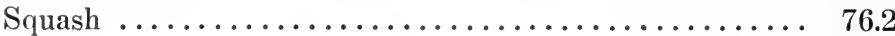

Lettuce $\ldots \ldots \ldots \ldots \ldots \ldots \ldots \ldots \ldots \ldots \ldots \ldots . \ldots \ldots .4$

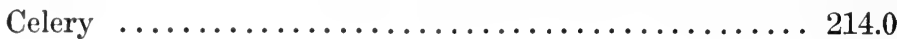

15.0

WATER Cress.-Water cress grows in rivulets, clear ditches and ponds. It is cultivated in Europe, Asia and North Africa. Its origin is obscure, but probably the plant came from Persia. The leaves have a moderately pungent taste and are highly esteemed as a salad, especially for their antiscorbutic properties. There are several varieties of plants called cress. The garden cress, of which there are "curly" and "broad" leaved varieties, is also a valuable antiscorbutic.

Asparagus.-Asparagus, sometimes called sparrow grass, has been prized by epicures from the earliest Roman times. More than four hundred and fifty years ago asparagus was grown and relished in nearly every part of Europe. The plants are best raised in well-drained, fertile soil. 
It is a wholesome and nutritious vegetable and one of the great delicacies of the garden. It is a very early vegetable. Asparagus should be cooked fresh by boiling twenty minutes. When wilted, the flavor is injured. Asparagus contains cellular tissue which encloses a substance similar to sago, besides albumin, or glutin, asparagin, mannite, malic acid, carbonates and phosphates of calcium, and other salts. Its nitrogenous substance is only half protein. The chief non-protein, nitrogenous substance is asparagin, which acts as an aperient and quickly passes out of the system through the urine. Its odor'is characteristic. Asparagus is credited with being of value to persons suffering from nervous affections, palpitation and heart neuroses.

Exnve.-Endive, sometimes called white chickory, is a plant growing wild in all the comtries surroming the Mediterranean sea. The blanched leaves are the portions used, and although they would be acrid and tough if exposed to the air, the blanching makes them crisp and tender. The green tops are eaten as a salad. This vegetable is believed to be of value in the distotherapentic treatment of indigestion.

Articiroke Greens.-Artichoke greens are the immature flower buds of a kind of eultivated thistle, and is a well-known garden plant. It is a native of Southern Europe. The flower head is gathered before the flower expands. The suceulent base together with the central dise and leafy seales furnish a delicious and most delicately flavored vegetable. Artichoke is boiled in plain water or milk and eaten with white sance, pepper and salt, or other condiments. They are diuretie and as they contain no starch may be eaten by diabetics. The active principle of artichoke greens is inulin. The entire plant, as well as the edible portion, contains a bitter juice, which when mixed with an equal quantity of wine, is reputed to be of great service in the relief of dropsical conditions.

Tomatoes.-Tomatoes were formerly grown for ornamental purposes and by the French were termed pomme d'amour. The tomato is a native of America, either Mexico or Peru. It was not extensively grown until after 1850 , when it was introduced into Europe. Tomatoes contain one per cent of protein, very little earbohydrate, including sucrose, dextrose,

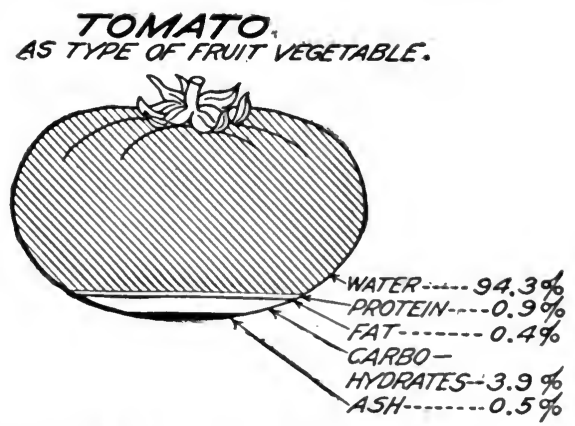

FUEL VALUE PEP POUND: 105 CALORIES.

Fig. 41.-Composition axd Fuel Vaide of the Tomato. (Bull. No. 363. L. S. Dept. Agric.) 
levulose and some resinous matter. They are free from oxalic acid, but contain citric acid. Green tomatoes are used for pickles, chow chow, etc., while the ripe tomato is eaten raw or as a salad. They are used largely in sauces, soup, ketchup, preserves and confectionery. Since much of the nutritive material is in the juice, this should be utilized.

Okra.-Okra or gumbo belongs to the N. O. Malvacece and is of African origin, where its propagation seems to have begun at the beginning of the Christian era. The parts used are the long pyramidal seed pods which are gathered while green. They are boiled and eaten with butter and spices. In the process of cooking no copper, brass or iron vessels should be used, or the pods will be discolored. The young green pods are often stewed and served like asparagus. The young seed pods are mucilaginous in substance and contain pectose, which forms a jelly of the water in which they are cooked. Owing to this special mucilaginous property, okra has become popular with cooks in the South, who use it in preparing chicken gumbo; not only is the soup flavored with this product, but a mucilaginous consistency is imparted to the product.

Chickory.-Chickory is closely related to the endive. The leaves have a rather bitter taste but are used in salads. It grows wild throughout Europe, Africa and Asia. Its cultivation is ancient, for it is mentioned in the writings of both the Greeks and Romans.

Dandelion.-Dandelion leaves, when young and tender, are highly prized as a salad by many people, who regard them much the same as turnip tops, chickory or endive. A wine is also made by fermenting the roots of the plant. Young dandelion leaves form an agreeable accompaniment to pork, veal or duck. They are stomachic, mildly laxative, and indirectly increase the action of the liver and kidneys.

Sorrel.-Sorrel is a common garden vegetable somewhat similar to dandelion and endive. When cooked with the two latter it makes an agreeable accompaniment to veal, pork or duck. This vegetable is stomachic, mildly laxative and is said to increase the activity of the liver and kidneys. It should not be eaten by persons suffering from gout, rheumatism or gravel. Sorrel has an agreeable acrid taste and makes a pleasant inviting addition to salads and sauces.

Oracire.-Orache belongs to the spinach family and is sometimes called winter spinach. It is a native of Tartary, introduced into Europs in 1584. There are several species of this vegetable cultivated for the table. The leaves have a slightly acid flavor, for which they are esteemed. The vegetable is cooked and served the same as spinach. 
Tursu 'Tors. - T'urnip tops or turnip greens are the young and tender leaves of the vegetable turnip. They are highly prized for their inviting flavor. They are carefully picked, washed and boiled with hog's jowl and served hot. They fumish abmudant mineral salts and are of considerable importance in the animal metabolism by furnishing an agreeable variety to the food in the early spring.

OTnE: Grisexs.- (Other greens that may be mentioned here, which are often called "pot herbs," are: bret tops, narrow leafed dock, stinging netlle, Suiss chard, plantuin leares, purslane (lettuce), mustard leaves, poke sprouts, pig weed and chick weed. These greens are nsmally prepared by being boiled in water to which a piece of bacon has been added, and sometimes after being cooked they are chopped fine and served with hard-boiled eggs. Some of these green vegetables are of positive value in the relief of chronic constipation and indigestion and all are highly recommended as furnishing an agreeable addition to the dietary, especially in the early spring, when green vegetables are scarce. 'They stimulate the appetite, distend the alimentary tract and make the blood alkaline which winter foods tend to make acid.

GREEN PEAS AND BEANS.-Green beans, string beans, or snap beans are the whole bean, pod and contents. The crisp succulent pod is tender and luscious after brief boiling and may be served as a side dish with butter or cream sance. The young bean may be boiled with bacon and served as a regular vegetable dish. Young, absolutely fresh string beans can be thoroughly softened in from one to two and a half hours' boiling. There are several edible varieties of beans which are suitable for eating in the young and immature condition. They are of importance in the order mentioned: the kidney bean, the duarf bean, French beans, string beans, stringless beans, snap beans and wax beans. The American Indians were cultivating beans when the white man first came, for we see from the writings of Champlain that the Algonquins planted two varieties of polo beans.

Cinemical Composition of Beans ani Peas.-The chemical composition of green peas and beans is given in the table on next page.(28)

Silelled Beaxs. - At a later stage in their development beans are greatly increased in size at the expense of the pod, the latter becoming thin and leathery. When the beans have reached this stage in their development they should be shelled. The shelled green beans may be prepared and served like green peas.

Shelled beans, which must also be fresh, should not be overcooked, or they will lose their fine flavor and become yellowish brown in color. The 
COMPOSITION OF GREEN PEAS AND BEANS, NUTRITIVE PERCENTAGE

\begin{tabular}{|c|c|c|c|c|c|c|}
\hline Material & Water & Protein & Fat & $\begin{array}{l}\text { Carbo- } \\
\text { hydrates }\end{array}$ & Ash & $\begin{array}{c}\text { Fuel } \\
\text { Value } \\
\text { per } \\
\text { pound }\end{array}$ \\
\hline Fresh Legumes: & $\%$ & $\%$ & $\%$ & $\%$ & $\%$ & Cals. \\
\hline $\begin{array}{l}\text { String Beans............. } \\
\text { Whole pods of Dolichos }\end{array}$ & 89.2 & 2.3 & 0.3 & 7.4 & 0.8 & 195 \\
\hline sesquipedalis.......... & 71.9 & 4.5 & 0.5 & 13.9 & 1.2 & 365 \\
\hline Sugar Peas or String Peas & 81.9 & 3.4 & 0.4 & 13.7 & 0.7 & 335 \\
\hline Shelled Kidney Beans... . & 58.9 & 9.4 & 0.6 & 29.1 & 2.0 & 740 \\
\hline Shelled Lima Beans..... & 68.5 & 7.1 & 0.7 & 22.0 & 1.7 & 570 \\
\hline Shelled Peas........... & 74.6 & 7.0 & 0.5 & 16.9 & 1.0 & 465 \\
\hline Shelled Cow Peas. & 65.9 & 9.4 & 0.6 & 22.7 & 1.4 & 620 \\
\hline
\end{tabular}

addition of butter, after the vegetable is cooked, improves the flavor and greatly increases the food value of the vegetable. The addition of a little cooking soda (bicarbonate) to the water in which beans are cooked enters into combination with the legumin, rendering the beans more digestible.

Broad or Windsor Bean.- The broad or Windsor bean is eaten either in the fresh or dry state. This bean is sometimes referred to as a butter bean and is a very nutritious vegetable, a favorite in the dietary on account of its size and flavor. They are especially sought after in making the well-known North American Indian dish known as succotash.

Green Peas.-Green peas and beans in their unripe and immature state are used extensively as vegetables. This vegetable was known to the Greeks and Romans and was introduced into England by the Aryans. Green peas are frequently referred to as French peas. They are tender and sweet and contain a fair amount of nourishment, which is a forecast of their great value in the matured and ripened state; but they are never of the same nutritive value as the ripe peas. They are, with the exception of the sugar peas, removed from the pod to be cooked, since the tough cellular shells are uneatable. The young peas become soft and tender when boiled, and are more digestible than are the dried peas. They contain a considerable amount of sugar, which greatly improves their flavor.

The dried pea contains more nitrogenous material than the dried bean. The protein of peas consists chiefly of legumin, a globulin not coagulated by heat, and vicilin. 


\section{DRIED LEGUMES OR PULSES}

Dried Legumes or Pulses. -The pulses or seeds of the legumes N. (). Leguminose and their allies contain a large store of nutriment, designed by nature for the use of the plant in its early growth. They have been used as a food from time immemorial by various races and peoples. In fact their origin is lost in the mists of antiquity.

PECULIAR CHARACTERISTIC OF LEGUMES.- It may be interesting to note in passing that a peculiar characteristic of this family of vegetables is that the plants not only furnish a valuable foodstuff for man and animals, but at the same time the roots of the plants have the peculiar property of fertilizing the earth by sending nitrogen into the soil. This is accomplished by the bacteria working in the laboratories of the roots.

These vegetables, beans, peas and lentils, grow rapidly, maturing in from three to four months. They are cultivated both as garden crops and field vegetables. Another advantage of this family of vegetables is that they grow well in most any kind of soil, producing fair crops. This is due largely to the fact that they can avail themselves of a double supply of nitrogen; that which is contained in the soil, as nitrites, nitrates and ammonia, and that which is absorbed from the air through the green leaves (lungs) and carried to the root nodules. These root nodules possess the remarkable power of fixing the free nitrogen of the atmospheric air and passing it on for the use of the plant.

CHIEF NUTRIENT VALUE.-The chief nutrient value of this group of vegetable foods is the richness of its members in nitrogen, in virtue of which fact they have been termed "the poor man's beef." The entire total nitrogen, with the exception of from 3 to 5 per cent, is in the form of protein. The chief protein found in pulses is legumin, sometimes called vegetable casein, owing to its resemblance to the prineipal protein of milk. Legumin unites freely with salts of calcium, resulting in a compound which is not soluble in water. For this reason peas and other pulses do not readily, soften when soaked in water containing lime salts (hard water). This should be remembered when cooking legumes or pulses. In soaking these vegetables it is important to add bicarbonate of soda if the water is hard. Water containing magnesia has no effect upon pulses, nor upon legumin.

ABSORPTION OF LEGUMES.- Since the purchase of protein foods usually adds to the high cost of living, it would seem that in beans, peas and lentils we have a cheap and abundant source of this food element. This is true to a certain extent. They are extensively utilized for this 
purpose. It happens, however, that the protein of the legumes exists in the form of legumin, containing but little albumin, which, according to Voit and others, is hard to digest. Legumin, like the vegetable proteins, is not so well or completely digested as the proteins of animal foods. It is also a fact that this legumin is attacked mainly by the ferments and enzymes in alkaline solutions, principally present in the lower part of the alimentary tract. "On this account beans, peas and lentils are not readily acted upon by the acid gastric juices: Thus 150 grams of lentils in the form of a mash remained in the stomach four hours, and 200 grams of peas in a similar form remained in the stomach four and a quarter hours, an equal weight of French beans remained even longer" (29).

If properly prepared the pulses will be readily absorbed in the intestine. They are more easily digested when soaked over night and boiled with bacon for some five or six hours, placed in a mortar and pounded into a mass; then pressed through a fine sieve and made into a purée. Prepared in this way the protein of the pca or lentil is all taken up, except $S$ or 9 per cent. This shows that the protein of the pulses, if given in a state of fine division, is capable of very good absorption, almost as good indeed as that of gluten when taken in the form of macaroni. Macaroni suffers a loss of 11.2 per cent; gluten ingested in the form of white bread suffers a loss of about 20 per cent; if beans, peas or lentils, on the other hand, are simply boiled soft and eaten with broth, the loss of protein will be about 40 per cent. Therefore it is absolutely necessary to prepare the legume in the finest state of subdivision possible to secure digestion and the greatest possible amount of absorption.

CHEMICAL COMPOSITION: RESUlting UTILIZATION.-The pulses are well supplied with carbohydrates, but very poor in fat (see analysis, page 443). For this reason they should always be boiled with bacon. They are very much improved by being served with sauces containing butter and oil. It is also well to remember that they contain a bitter principle which renders them unpalatable to many persons. Since they contain quantities of purin bodies, larger amounts of uric acid are excreted; they consequently are sometimes forbidden in the dietary of the gonty or rheumatic.

The proportion of water in the soaking and boiling rises from 14 to 73 per cent for beans and for peas from 9.7 to 86.9 per cent. This increase in water means a corresponding increase in the weight and bulk of the food, which must be considered when comparing the relative nutritive values of the pulses and meat. The table on page 443 (analysis by Abel) shows that the nutritive value of beans and peas is high, due to their high protein content. 
COMPOSITION OF DRIED LEGUMES

\begin{tabular}{|c|c|c|c|c|c|c|}
\hline MATERIAL & Water & Protein & liat & $\begin{array}{l}\text { Carbo- } \\
\text { hydrates }\end{array}$ & Ash & $\begin{array}{c}\text { Fuel } \\
\text { value per } \\
\text { pound }\end{array}$ \\
\hline 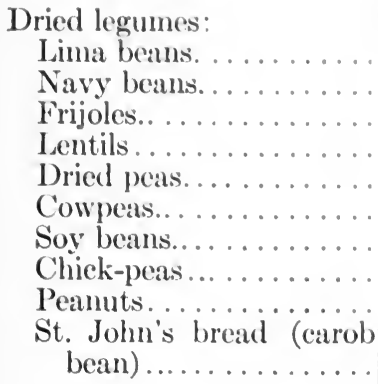 & $\begin{array}{c}\text { Per cent } \\
10.4 \\
12.6 \\
7.5 \\
5.4 \\
9.5 \\
13.0 \\
10.5 \\
14.5 \\
9.2 \\
15.0\end{array}$ & $\begin{array}{c}\text { Per cent } \\
18.1 \\
22.5 \\
21.9 \\
25.7 \\
24.6 \\
21.4 \\
34.0 \\
12.4 \\
25.5\end{array}$ & $\begin{array}{c}\text { Per cent } \\
1.5 \\
1.8 \\
1.3 \\
1.0 \\
1.0 \\
1.4 \\
16.5 \\
6.7 \\
38.6\end{array}$ & $\begin{array}{c}\text { Per cent } \\
65.9 \\
59.6 \\
65.1 \\
59.2 \\
62.0 \\
60.5 \\
33.7 \\
63.3 \\
24.4\end{array}$ & $\begin{array}{c}\text { Per cent } \\
4.1 \\
3.5 \\
4.2 \\
5.7 \\
2.9 \\
3.4 \\
4.7 \\
2.8 \\
2.0\end{array}$ & $\begin{array}{c}\text { Calories } \\
1,625 \\
1,605 \\
1,695 \\
1,620 \\
1,655 \\
1,590 \\
1,970 \\
1,690 \\
2,560 \\
1,565\end{array}$ \\
\hline
\end{tabular}

The nutritive value of the pulses is undoubtedly high. Numerous experiments have been made to determine to what extent the protein of beans, peas and lentils, etc., is actually utilized as a mutrient in the system. It is also a fact that, when combined with other foods, the nutriment is much more completely utilized than when they form the bulk of the meal.

FLATULENCE.-The flatulence that is often attributed to this class of vegetables is probably caused by the decomposition by bacteria of the germ of the bean in the intestine, giving rise to more or less of the hydrocarbon methane $\left(\mathrm{CH}_{4}\right)$. The abundant sulphur in beans and peas evolves sulphuretted hydrogen gas. This also explains the tendency of these regetables to produce flatulence. Beans are richer in sulphur than peas. The ash of the pulses is poorer in phosphorus than that of cereals, but richer in potassium and calcium salts. The legumes contain a very small amount of fat with some cholesterin and lecithin. The carbohydrates are fairly high, but their proportion is smaller than in the cereals, the amount varying from 25 to 60 per cent, including sugar, dextrin and gum. In India the bean is highly esteemed by rich and poor alike. They are even given to the sick, but "alwars with a seasoning of asafotida to prevent flatulence."

VARIETIES OF LEGUMES.-The bean on account of its numerous varieties and the many ways in which it can be prepared for food and because it is so easily grown is one of the most important of the legumes. Beans were cultivated by the North American Indians. It is recorded that the Algonquin Indians cultivated two varieties of pole beans. Snap and string beans may be grown as well as fresh or green beans, which have already been considered. 
Broad Beans.-Broad beans, more commonly known as Windsor beans, are fully an inch in diameter. This particular bean has been cultivated in Europe since prehistoric times. The Greeks were well acquainted with it and it is mentioned in the Iliad. The Hebrews were acquainted with it at least 1000 B.c. The principal variety grown in America and Europe for human food is the Windsor bean, which is eaten while young and tender as a green bean as well as when dried.

Kinney Bean.- The kidney bean is referred to as the French or haricot bean. There are many varieties of this bean which comprise nearly all the kinds of beans which are ripened and dried, such as the white haricot bean, navy bean, red kidney bean. It is thought to be a native of Souts America, introduced into Europe in the sixteenth century. The common haricot bean is a plant of ancient civilization, being found in the remains of Troy as well as in the remains of the lake dwellings of Italy and Switzerland. The sub-varieties are divided into those which include the string and snap or stringless beans eaten in the green state; those which are shelled and eaten while young and tender, and those allowed to mature and then dried.

Lima Beans.-Lima beans consist of a small short pod having flat kidney-shaped seeds and sometimes called sugar bean. It is a favorite shelled, both green and dry, in the United States. There are a number of varieties. The lima bean has been cultivated in American gardens since the beginning of the last century.

Butter Beans.-Butter beans are much used as a food in Southern Europe, India and the United States. They are eaten stewed or baked and have a pleasant flavor. The fat content is high. The beans are of a greenish yellow color, resembling mutton suet.

Bolicoirs Beans.-There are two popular varieties of this group, which differ slightly from the common bean and are known as the hyacinth bean and the asparagus bean.

Soy Bears.- The Soy or Soja bean, while for generations known and much appreciated in Japan, is a comparatively recent production in the United States. In Japan it is a valuable food for man as well as for stock. In the United States it has received little attention for purposes other than the production of forage crops for cattle and swine. It is destined, however, to become a very important agricultural product, both as grain food for man and as forage crop for beasts.

Composition of the Soy Bean.-There are variations in the composition of different varicties of the beans. This bean has a remarkably high per cent of protein and a liberal fat content, as shown by the follow- 
ing analysis. The yellow beans produced in the Inited States have the following analysis:

\begin{tabular}{|c|c|c|c|}
\hline Water & 9.80 & & \\
\hline Protein ......... & 37.13 & “ & “ \\
\hline 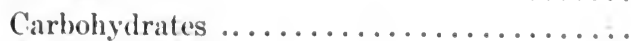 & 24.40 & “ & “ \\
\hline Fat $\ldots \ldots \ldots \ldots \ldots \ldots \ldots \ldots \ldots \ldots \ldots \ldots$ & 18.36 & “ & “ \\
\hline Lecithin & 1.60 & “ & “ \\
\hline Crude fiber ... & 4.47 & “ & “ \\
\hline Ash & 4.30 & “ & “ \\
\hline
\end{tabular}

Riihrah of Baltimore has studied this bean extensively and is of the opinion that soy bean flour contains no starch or reducing sugar, and recommends it as a valuable adjunct in the dictotherapy of diabetes and of great importance in infant feeding.

Preparations Made from Soy Beans.-In the recent war between Russia and Japan soy beans were the ehief foodstuff upon which dependence was placed. The Oriental races generally eat the bean after it has been prepared in more or less cheesy-like foods. The most common of these are natto, tofu, miso, yuba and shoyu. Natto is a sort of cheese, made from the boiled beans packed in rice straw and allowed to ferment. The mass becomes white and mucilaginous by the development of bacteria and the straw flavors the product. Miso is a fermented produet made from the beans, barley and salt. Tof $u$ is made by crushing and boiling the beans and filtering the mass through cloth. . Two per cent of concentrated sea brine is added to this, which, probably on account of the ealeium and magnesium present, precipitates the plant casein, which is then pressed into tablets.

Soy bean suuce, having a pungent and agreeable taste, is also made by fermenting for several months with a special ferment, a mixture of cooked soy beans, roasted with wheat flour and salt. Soy milk is made by boiling the beans and beating to a pulp, when some of the regetable casein passes into solution, resulting in a milky looking solution.

All soy bean products are high in fuel value and supplement very well the rice diet of the natives of China, Japan, Korea and Manchuria, as they furnish both protein and fat, in which the rice is so deficient. Soy bean food products will, no doubt, eventually be largely used for food purposes in the United States, much the same as cottonseed oil has come into extensive use within the past two decades. Soy bean oil is now mixed with cottonseed oil and used as a salad oil. It also forms the basis of the soy sances and condiments used the world over.

Peas: Fiet.d Peas.-The field pea grows wild in Italy in hedges, for- 
ests and mountainous regions. It is probably a progenitor of the garden pea, but the date of its cultivation is unknown. The Canadian field pea is used in its immature condition when about two-thirds grown as a shelled green pea.

Garden Pea.-The garden pea is supposed to have come from Western Asia, but this is doubtful, as it is found in many countries growing wild. It is, however, an ancient food, being found among the remains of the lake dwellings in Savoy and Switzerland. There is no indication, however, of its being cultivated in ancient Egypt or India. Garden peas by cultivation and hybridization have been developed into many varieties. The more popular are those divided into shelling peas and edible podded peas. The latter are called sugar peas and are little known in the United States. The former consists of two varieties, (a) the smooth roundseeded variety and $(b)$ the wrinkled kind, of - which marrowfat peas is the chief. Some of the special strains were mentioned under green peas. There are records of green peas being eaten in the Norman times and later at the time of Henry VIII. The choice varieties of garden peas were brought from Holland.

Chick Pes. - The chick pea has not been found wild, but many species are known in Western Asia which were cultivated by the Greeks in the time of Homer. They are eaten boiled in soup or roasted. In Spain and Oriental countries the leaves of this plant during the hot summer months exude a viscous limpid liquid which on examination, according to Hogg, consists almost entirely of oxalic acid.

Cow Pess.-Cow peas belong properly to the bean group, but the name has long passed into common use, especially in the United States. There are several varieties, as the round lady peas, the mottled and speckled whip-poor-will peas, the black and red peas, the black eye, purple eye and other varieties. These beans were originally brought from India or China, where their use is very common. Considerable quantities are eaten green, shelled like kidney beans. The dry ones are cooked like other beans. They have an agreeable flavor. The plant is indigenous to equatorial Africa.

COMPARISON ON PEAS AND BEANS.-Comparing the analysis of peas with that of beans, it is evident that peas, especially when dried, are even more nitrogenous than beans. Another advantage of the pea over the bean is that the nitrogenous material of the pea is said to exist in the form of proteins. The protein of the pea consists chiefly of legumin globulin, not coagulated by heat and vieilin. The unripe or green peas are more digestible than the dry peas and contain considerable sugar which greatly 
improves their Havor. The field pea is often grown to furnish the split pea of commerce. In preparing these for the market the outer skin is removed, which increases the digestibility of the product.

CANNED PEAS.-Canned peas are a very important addition to the dietary, especially in this country. The peas are collected green and shelled. If the process is well conducted and the peas young and immature, an extremely edible product is available for use throughout the year. It is to be regretted that canned peas are sometimes subject to several methods of adulteration. They are sometimes colored green by the use of the salts of copper. ${ }^{1}$ They are swectened by the use of saccharin. Old or dry peas are sometimes soaked for a long time and then canned and put on the market as fresh green peas.

LENTILS.-Lentils are mentioned in most of the ancient writings and were no doubt among the earliest food cultivated by man. The Bible tells us of their use in Egypt, Asia and Mediterranean countries. The mess of red pottage for which Esau sold his birthright to Jacob was composed largely of red lentils. There is little doubt but that lentils were cultivated in Egypt before history began; at a less remote period, but hardly in historic times, their cultivation appears to have extended east and west into India and Europe. Lentils are consumed by Catholics during Lent in place of meat. Lentil flour or meal is eaten by the Hindoos and other Orientals in addition to rice when engaged in laborious work. The lentil is much richer in protein than either the bean or the pea, and as a rule the smaller varieties are richer in this constituent than the larger. Lentils contain no sulphur and are more digestible and less apt to cause flatulence than either beans or peas.

Composition of the Lentil.-In composition the lentil is one of the most nutritious of all the legumes and contains the highest percentage of protein. According to analysis by Church it contains 25 per cent of albuminoid, 56 per cent of starch, 2 per cent of fat. Its mineral content is particularly high in iron. The favorite method of serving lentil is in the form of a puree and in soups and stews.

\section{FUNGI, LICHENS, ALG压}

Fungi, Lichens, Algæ.-The classification of fungi by various writers is so diverse that we will only attempt to group the families which include the edible varieties. The common classification of edible fungi, as mushrooms, and the inedible ones, as toadstools, is not in accordance with fact,

1 Late Federal legislation has prevented the use of both copper for coloring and saccharin for sweetening. 
since all of the fleshy fungi are toadstools and probably most of them are edible. The poisonous properties of fungi are due to the presence in them of alkaloids. The nature of these differs in different species, so that the symptoms of toadstool poisoning are varied.

EDIBLE FUNGI.-It is erroneous to say that all poisonous fungi are toadstools and that the only edible varieties are mushrooms. Fungi have been used as foodstuffs since the earliest times. They are a low form of vegetation. Fungi contain no chlorophyll as they cannot utilize the carbon dioxid of the air to build up carbohydrates. They form no starch, although glycogen, sometimes called animal starch, is found in truffles, and they take up carbon from previously organized carbon. There are some 10,000 kinds of fungi, of which comparatively few are edible. The three edible varieties most commonly used are mushrooms, truffles and morel. There are several varieties common in the United States(30), among which we will mention (a) orange milk mushroom; (b) French chanterelle; (c) fairy ring champignon; $(d)$ spine mushroom; (e) meadow mushroom; $(f)$ Maned Agaric; $(g)$ Morchella esculenta; $(h)$ Claviria cinera Bull; (i) Claviria rugosa Bull; $(j)$ Boletus edulis Bull; (k). Lycoperdon giganteum puffball; (l) liver fungus(31).

Composition of Edible Fungr.-The chemical composition of some of the more edible fungi is given in the following table [Tibbles(1)]:

THE COMPOSITION OF FUNGI, PERCENTAGES

\begin{tabular}{|c|c|c|c|c|c|c|c|c|c|c|}
\hline & \multirow[b]{2}{*}{ 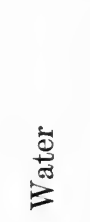 } & \multicolumn{3}{|c|}{ Nitrogen } & \multirow[b]{2}{*}{ 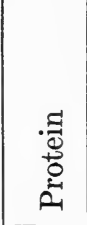 } & \multirow[b]{2}{*}{ 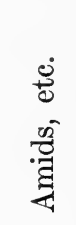 } & \multirow[b]{2}{*}{ 垔 } & \multirow[b]{2}{*}{ 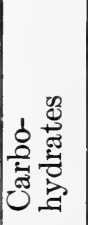 } & \multirow[b]{2}{*}{$\begin{array}{l}0 \\
0 \\
\frac{0}{3} \\
\overline{0} \\
0\end{array}$} & \multirow[b]{2}{*}{$\frac{\pi}{4}$} \\
\hline & & 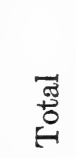 & 当 & 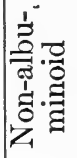 & & & & & & \\
\hline Common Mushroom. . & $\left\{\begin{array}{l}91.30 \\
93.70\end{array}\right.$ & .60 & .36 & .24 & $\begin{array}{l}3.75 \\
2.20\end{array}$ & 1.30 & $\begin{array}{l}.20 \\
.30\end{array}$ & $\begin{array}{l}3.50 \\
1.20\end{array}$ & $\begin{array}{r}.80 \\
1.20\end{array}$ & $\begin{array}{l}.30 \\
.30\end{array}$ \\
\hline $\begin{array}{c}\text { Shaggy or Maned } \\
\text { Mushroom.......... }\end{array}$ & 92.19 & .45 & .15 & .30 & 2.81 & & .26 & 1.40 & .57 & .98 \\
\hline Milky Agaric. ...... & 89.08 & $\ldots$ & $\ldots$ & $\ldots$ & 1.88 & .91 & .54 & 4.49 & .32 & \\
\hline \multirow{2}{*}{$\begin{array}{l}\text { Boletus (Boletus edu- } \\
\text { lis)................ }\end{array}$} & 90.93 & & & & 1.19 & .64 & .64 & 5.09 & .33 & 1.20 \\
\hline & 84.19 & & & & 3.70 & 2.60 & .40 & 4.65 & .74 & \\
\hline $\begin{array}{l}\text { Morel (Morchella es- } \\
\text { culenta)........... }\end{array}$ & $\left\{\begin{array}{l}90.70 \\
89.54 \\
90.00\end{array}\right.$ & .49 & .37 & .12 & $\begin{array}{r}3.49 \\
3.06 \\
4\end{array}$ & $\begin{array}{l}3.59 \\
\ldots \\
40\end{array}$ & $\begin{array}{l}.25 \\
.50 \\
.56\end{array}$ & $\begin{array}{r}.73 \\
1.60 \\
3\end{array}$ & .97 & $\begin{array}{l}1.08 \\
1.36\end{array}$ \\
\hline $\begin{array}{l}\text { Truffles.............. } \\
\text { Black Truffles....... }\end{array}$ & $\begin{array}{l}73.00 \\
72.00\end{array}$ & & & & $\begin{array}{r}6.10 \\
8\end{array}$ & 1.40 & .60 & 6.02 & 6.40 & $\begin{array}{l}2.00 \\
2.07\end{array}$ \\
\hline IVhi & $\{72.34$ & & & & & 96 & .44 & 15. & & 2.10 \\
\hline Beef Stea & 772.50 & & & & 8.91 & 7.52 & .64 & & & \\
\hline parison............. & 62.50 & & & & 19.50 & & 17.00 & & & 1.00 \\
\hline
\end{tabular}


Genemal Consmerations to Obskive.-It is difficult to give specific directions for the recognition of the harmless fungi. Unfortunately some of the most dangerous are found in greatest abundance. There are certain general indications which it is always safe to observe: "All fungi should be avoided when overripe or allucked by slugs. Those that soften readily are usually dangerous, and the same is true of fungi growing in, on or near dunghills, for this plant has a great tendency to absorb poisons from the medium on which it happens to be grouing."

Description of the Enhle Mishroos.-Mushrooms are found in pastures and open spaces. The young fingus consists of a small spherical growth of a white or fawn color growing up from the earth by a solid stem or stalk. As it grows, the cap expands into an umbrella shape, exposing the stalk. The cap varies from one and a half to three inches in diameter. The flesh is white, of brittle texture, delicious odor and flavor, forming a tasty, appetizing and agreeable addition to other food. This mushroom is extensively cultivated and consumed in Great Britain. It is a common article of consumption in France and Germany. It is never poisonous, and if it be remembered that the spores are purple, the gills at first pink and afterwards purple, that there is a permanent eollar or ring about the stalk, and that they are never to be looked for in the woods, few accidents will occur.

Varieties of Edible fungi: The Meadow Mushroom.-Meadow or horse mushroom is similar to the former, but larger, ranging from three to six inches in diameter. It sometimes weighs several pounds. As its name indicates, it grows in meadows and pastures. Some persons prefer it to the common mushroom; it has a stronger flavor, but otherwise there is very little difference. It is preferred in France, where it is considered a delicacy. There are many other edible varieties known, as St. George's mushroom, the oyster mushroom, the snail fungus and blewits, all very similar in composition and much alike in their uses.

The Parasol Mushroom.-The parasol mushroom is much in demand in France, Spain and Italy. There are many varieties, some species growing very large. They produce best in old mushroom beds and fir plantations and are usually crisp and very good and wholesome.

Truffues. - Truffles are subterranean fungi, cultivated extensively in France and Italy. There are about fifty varieties of this fungus. They grow in woods or forests, especially in the vicinity of oaks and nut trees, on fir plantations and inder beech trees. Their derelopment is slow; the mycelium does not prodnce truffles for several years after it begins to grow, but when once they begin they continue for years. Truffles grow 
underground and are of varions sizes, from two to three ounces in weight. In color they are red, white and black; the latter are held in high esteem and have great repute for making gravy, soups, entrées and garnishing dishes. They are used both fresh and dried, and are highly stimulating.

Truftles, owing to their nitrogenous constituents, are highly stimulating and heating. They should be eaten in moderation; their digestion is diffcult and their wholesomeness is not without question.

The Morec. - The morel is a fungus having a hollow stalk and a conical pitted cap. There are various species, growing plentifully in Germany. They are sold in the dry state and used principally for making gravy, ketchup, sances and entrées. In France the term champignon is applied to the morel as well as to mushrooms in general.

Boletus Enulis.-Boletus edulis is an edible fungus very common in the beechwoods of South England. It is grown extensively in Austria and Germany, where it is cut into slices, dried and sold in the shops as a farinaceous food. The pileus grows to the size of from four to six inches in diameter, light brownish color above and white underneath. The flesh is firm when young and softens with age. Nearly all boleti are edible. The soft ones are yellowish white on the under surface of the pileus.

LICHENS.-Lichens grow abundantly in the Arctic regions. Iceland moss is the most important edible lichen. The Laplanders use it as a breadstuff and also boil it with the milk of the reindeer. It contains two carbohydrates: lichenin, moss starch $\left(\mathrm{C}_{6} \mathrm{H}_{10} \mathrm{O}_{5}\right)$, which yields dextrose on hydrolysis, but is not affected by digestion and probably does not form glycogen, a mucilage; and isolichenin, which resembles starch, but on digestion yields only dextrins, no sugar. Bread made from Iceland moss is recommended for diabetics. From the chemical nature of Iceland moss and from its resistance to the process of digestion, also from the small amount of it ever present in jelly, it is safe to say that its nutritive value is not worth consideration.

According to Church's analysis its chemical composition is about as follows: water, 10.0 per cent; proteid, 8.7 per cent; lichen starch, 70.0 per cent; lichen acids, etc., 6.3 per cent; cellulose, 3.5 per cent; mineral matter, 1.5 per cent.

ALGA.-Alga include a variety of fungi seaweeds of which laver, dulse and others are occasionally used for foods. The only one which demands serious consideration here is the Irish or Carraigeen moss which is used both as an ordinary article of diet and as a delicacy for the sick room. It grows abundantly on the rocky shores of Iceland and is usually under the surface of the water, from three-quarter tide to below low water 
mark. There are several species of this seaweed used for food. They are boiled for several hours until reduced to a slimy pulp which is sometimes made into cakes with oatmeal and fried in butter. Other edible alga aro the alaria or murlins of the north coants, which form a welcome addition to the potato diet of the peasants, and the agar agar or Chinese gelatin of the Orient. 'The edible birds' nests which are popular as a food with the Chinese are formed by the swallow from gelatinous seaweeds, which are disgorged by the birds in building their nests.

Agar A iass.-Agar agar, called Bengal isinglass, is a fungi seawed imported from Singapore. It occurs in thin transparent strips which readily dissolve in hot water, forming a gelatinous, tasteless and odorless jelly. The dried seaweed is sometimes called Ceylon moss. Some species of this fungus are favorite additions to soups and for jellies and blancmange.

\section{Summary}

Fungi are difficult of digestion, owing to the large percentage of cellulose in their composition and to the shrinkage and greater compactness which result from the process of cooking. The pain and discomfort which they are apt to produce in the stomach have often been wrongly attributed to poisons. In consequence fungi which are merely indigestible have been classed as inedible. The absorption of fungi is also very imperfect. One observer who consumed large quantities of fresh mushrooms daily found that 19 per cent of the dry substance, 37.7 per cent of the protein, escaped absorption. On the whole, mushrooms and other fungi must be classed with such substances as green vegetables, carrots and black bread as among the wasteful foods. The nutritive value of fungi has been very much overestimated: thus the Patagonians have erroneously described them as "vegetable beefsteaks," which has caused the poorer elasses to use them extensively as a food. Their nitrogenous content is in a form which is useless for the purpose of nutrition, owing to the very imperfect degree to which this element is capable of being absorbed. Further, the carbohydrate content is very uncertain in nutritive value and cannot be regarded as food of any greater value than fresh green vegetables.

\section{REFERENCES}

1. Trbbles. Origin and Manufacture of Foods. Baillière, Tindall and Cox, London. 
2. Hamill. Food Reports, Nos. 11-12, Local Gov. Bd., 1911.

3. Tibbles, William. Food in Health and Disease.

4. Hill and Flack. Brit. Med. J., 1911, vol. i, p: 311 ; vol. ii, September, 1911.

5. McCallum. MeCallum (of Yale) has shown that rats do not thrive and bear young when fed on wheat alone.

6. Edie and Simpson. Brit. Med. J., 1911, vol. i, p. 1151.

7. Tibbles, William. Ibid.

8. U. S. Department of Agricilture, Experimental Station, Bull. 67.

9. Hutchisor. Food and Dietetics.

10. United States Department of Agriculture, Bull. No. 45.

11. Kajiura and Roseninem. Proc. Physiol. Soc., 1908; also J. Physiol., 1908.

12. Fraeser and Stanton. J. Trop. Med. \& Hyg., 1911.

13. Simpson, Webster, et al. Philippine J. Med., 1912.

14. Casimir Funk. J. Physiol., 1913, pp. 389-392.

15. Silver, F. J.; Garrison, P. E. ; and MacNeal, W. J. Pellagra, J. Am. Med. Assn., Jan. 3, 1914, p. 8.

16. Winton, A. L.; Burnet, W. C.; Bormmann, J. H. Information in respect to this problem will be found in the paper: Composition of Corn (Maize) Meal Manufactured by Different Processes and the Influence of Composition on the Keeping Qualities, U. S. Dept. Agric., May 21, 1915, Bull. 215.

17. Woons. U. S. Dept. Agric., Far. Bull. 298.

18. Nansen, N. E. Proso and Kaoling as Table Foods, South Dakota Agric. Exper. Sta., Bull. No. 158, March, 1915.

19. BALL, C. R. The Importance and Improvement of Grain Sorghums, U. S. Dept. Agric., Bureau Plant Industry, Washington, 1911, Bull. 203.

20. United States Department of Agriculture, Farmers' Bulletin No. $559,1913$.

21. Fitci, W. E. Some Neglected History of North Carolina.

22. United States Department of Agriculture, Bull. No. 43.

23. Stone, W. E. Berliner Deutsch. chem. Gesellsch., 1890, xxiii, 1, 1896.

24. Hasselibring, H., and Hawnins, I. A. Physiological Changes in Sweet Potatoes During Storage, J. Agric. Research, January, 1915, p. 331. Ripening and Storage of Certain Foods (editorial), J. Am. Med. Assn., April 3, 1915, p. 165. 
25. Langwortny. U. S. Dept. Agric., Farm. Bull. No. 295.

26. —. Ibid.

27. —. Ibid.

28. U. S. Dept. Agrice, Farmers' Bull. No. 121.

29. Hutcinson. Food and Dietetics, p. 230.

30. Report Microscopist, U. S. Dept. Agric., Cir. No. 13, Div. Botany.

31. Bulletin United States Department of Agriculture. (Principally from this source.)

\section{BIBLIOGRAPHY}

\section{Cereal and Cereal Foods}

Amos. Processes of Flour Manufacture.

Aron and Hocson. Rice as a Food-Nitrogen and Phosphorus Metabolism with Rice and Other Foods, Biochem. Ztschr., 1911, vol. xxxii, pp. 189-203.

Ciramberlain and Vedper. Second Contribution to the Etiology of Beri-beri, Philippine J. Sc., 1912, Series B, vol. vi, pp. 395404 .

and Williams. Third Communication on the Etiology of Beri-beri, Philippine J. Se., 1912, Series B, vol. vii, pp. 39-52.

Dunnington. The Grinding of Cornmeal for Bread, Original Communications, 8th Internat. Cong. Applied Chem., 1912, vol. xviii, pp. 119-127.

Duvalu and Duvald. Shrinkage of Shelled Corn while in Cars in Transit, U. S. Dep. Agric., Bull. 48, 1914, pp. 1-21.

Funk. Chemical Nature of the Substance Which Cures Polyneuritis in Birds Induced by a Diet of Polished Rice, J. Physiol., 1912, vol. xliii, pp. 395-400.

Effect of a Diet of Polished Rice on the Nitrogen and Phosphorus of the Brain, J. Physiol., 1912, vol. xliv, pp. 50-53.

. Substance from Yeast and Certain Foodstuffs Which Prevents Polyneuritis, Brit. Med. J., 1912, ii, p. 787.

Influence of the Milling of Maize on the Chemical and Nutritive Value of Maize Meal, J. Physiol., 1914, vol. xlvii, pp. 389-392.

Grant. The Chemistry of Breadmaking. 
Greig. Rice in Relation to Beri-beri, Scientific Memoirs of the Med. and Sanitary Depts. India, 1911, New Series No. 45, pp. 1-43.

Hunt. The Cereals in America.

The Effects of a Restricted Diet and of Various Diets upon Resistance of Animals to Certain Poisons, Hyg. Lab. of U. S. Pub. Health Service, 1910, Bull. 69.

JAGo. The Technology of Breadmaking.

Laxgwortiy and Hunt. Corn Meal as a Food and Ways of Using It, U. S. Dept. Agric., 1914, Farmers' Bull. 131, p. 565.

Mendel and Fine. Utilization of the Proteins of Barley, J. Biol. Chem., 1911, vol. x, pp. 339-343.

Merrill. Indian Corn as Food for Man, Maine Agric. Exper. Sta., 1906, Bull. 131, pp. 133-145.

Osbionve. The Nutritive Value of the Proteins of Maize, Science, Jan. 31, 1913, vol. xxxvii, pp. 185-191.

. The Proteins of the Wheat Kernel.

Sмгтн. The Sulphur Bleaching of Commercial Oats and Barley, U. S.

Dep. Agric., Burean of Plant Industry, 1911, Circular 74.

Trier. Phosphatids of Oatmeal, Ztschr. f. physiol. Chem., 1914, vol. lxxxvi, pp. 153-173.

Watson. Oatmeal in the Dietary of Children, Brit. Med. J., 1907, pp. 985-986.

Winer. Cereals and Cereal Products, U. S. Dept. Agric., Bur. Chem., Bull. 13, Part 9.

Analyses of Cereals Collected at the World's Columbian Exposition, U. S. Dept. Agric., Bur. Chem., Bull. 45.

\section{Wheat and Flour}

Balley. Minnesota Wheat Investigations, Minn. Agric. Exper. Sta., 1913, Bull. 131.

Lamd and Stalimas. Bleaching of Flour, North Dakota Agric. Exper. Sta., 1906-1907, Bull. 72, pp. 219-235.

Osborxe and Vooriness. The Proteins of Wheat, J. Am. Chem. Soc., 1894, vol. xvi, pp. 524-535.

Sxyder. Wheat and Flour Investigations, Minn. Agric. Exper. Sta., 1904, Bull. 85.

and Woons. Wheat Flour and Bread, U. S. Dep. Agric., Yearbook for 1903, pp. 347-362. 
Teller. The Carbohydrates of Wheat and Wheat Products and Changes in the Same during Development of the (irain, Orig. Communications, Sth Internat. Congress of Applied Chemistry, 1912, vol. xiii, pp. $273-278$.

Thatcher, Olson and Hanlock. Wheat and Flour Investigations, Washington Agric. Exper. Sta., 1911, Bull. 100.

Wood and Harby. Physical State of Ghiten, Proc. Royal Soc. London, 1909, Series B, vol. Ixxxi, pp. 38-43.

\section{Bread Making}

Grainam. Chemistry of Bread-making, London, 1880.

Harcourt and Pundy. Flour and Breadmaking, Ontario Agric. College, Dept. Agric., 1910, Bull. 180.

HrLl. Nutritive Value of White and Standard Bread, Brit. Med. J., 1911, No. 2627, pp. 1068-1069; (discussion) No. 2628, pp. $1151,1911$.

JAGo. Science and Art of Breadmaking, London, 1595.

Kohmax. Salt-rising Bread and Some Comparisons with Bread Made with Yeast, J. Indust. \& Engin. Chem., 1912, vol. iv, pp. 20-30, 100-106.

LADD and BAILEY. Wheat Investigations; Milling, Baking and Chemical Tests, North Dakota Agric. Exper. Sta., 1911, Bull. 89.

Syyder. Studies in Bread and Breadmaking, U. S. Dept. Agric., Office of Exper. Sta., Bulls. 67, 101 and 126.

Wardall. Relation of Yeast to Flavor in Bread, J. Home Economies, 1910, vol. ii, pp. 75-91.

Willard and Swanson. Influence of Certain Substances upon the Baking Qualities of Flour, Kansas Agric. Exper. Sta., 1914, Bull. 190, pp. 237-285.

\section{Vegetables}

Arec. Beans, Peas and Other Legumes as Food, T. S. Dep. Agric., 1900, Farmers' Bull. 121.

Dubors. Analyses of Canned Peas and Beans, T. S. Dep. Agric., Burean Chem., 1910, Circular 5t.

Gilmore. A Study of Quality in Potatoes, Cornell Agric. Exper. Sta., 1905, Bull. 230. 
Hrndhede. The Digestibility of Potatoes, Skandin. Arch. f. Physiol., 1912, vol. xxvii, pp. 277-294.

Langwortiy. Potatoes and Other Root Crops as Food, U. S. Dept. Agric., 1907, Farmers' Bull. 295.

- Green Vegetables and Their Uses in the Diet, U. S. Dept. Agric., Yearbook for 1911, pp. 439-452.

Winterstern and Reuter. The Nitrogenous Constituents of Mushrooms, Centrlbl. f. Bakteriol. u. Parasitenk., ii. Abth., vol. xxxiv, pp. 566-572; Chemical Abstracts, 1912, vol. vi, p. 3279. 


\section{CHAPTER NIV}

\section{FAT'S ANI) OILS}

General Considerations: Fat and ()il substances; Sources of Fats; Chem. ical Characteristies of Fat; Fatty Bodies; Importance of Fats and Oils.

Animal Fats: Varieties: Butter, Lard, Suet, Olem

Vegetable Fats: Value of Vegetable Fats; Absorption of Vegetable Oils; Varieties: Palm Oil, Almond Oil, Peanut Oil, etc.

\section{GENERAL CONSIDERATIONS}

Fats and oils may be divided into two general classes: (a) fixed oils and fats, $(b)$ essential or volatile oils. The former are derived from two sources, i.e., the animal and vegetable kingdoms; the latter are volatile constituents of plants and may be obtained unchanged by the application of heat. They are important constituents of spices and a fuller consideration will be found under the chapter "Spices and Condiments."

Fat and 0il Substances.-Fats and oils contain substances of an extremely varied nature. They are devoid of nitrogen and consist almost entirely of three elements, viz., carbon, hydrogen and oxygen; the latter in small proportion, but so combined that they readily undergo oxidation, during which they give out considerable heat. The sugars and starches contain oxygen and hydrogen in such proportions that when their molecules are split up, water $\left(\mathrm{H}_{2} \mathrm{O}\right)$ is formed. In the group of fats oxygen is present in insufficient quantity to produce water with all of the hydrogen atoms, so that combustion takes place with the liberation of heat. It is the peculiar property of hydrocarbons to unite readily with oxygen, and it is the consequent development of heat that renders them so exceedingly valuable as a source of fuel for the animal economy.

Sources of Fat.-Fat forms the bulk of butter, fat meat, suet, lard, oils and other fatty substances. About one-sixth of the entire body weight is composed of fat, while only about one-quarter of an ounce is contained in the blood. In a prolonged fast or death from starvation ninety per cent of the body fat is consumed. The chief sources of this supply 
of fat in the human body are starches and sugars, but not all, as some of it, as Monk has demonstrated, is undoubtedly derived from fatty food. Many of the fatty substances are important constituents of foods, while others, differing only very slightly in chemical composition, are of value, from a commereial standpoint, in the manufacture of soap, eandles and paint. Fat is a souree of energy, as is evident in the inhabitants of Polar regions, whose aliment is almost entirely fat and oils.

Many of the animal oils, such as whale oil, seal oil and fish oil, are obnoxious to the taste of civilized peoples. For the most part the vegetable oils when properly refined make wholesome, palatable food products. Vegetable oils are derived, principally, from the seeds of plants, extracted by pressing the ground or mashed seeds. Animal fats are secured from animal tissues by a process of "rendering" which consists in placing the fatty substances in a large vessel and applying heat until the fat is melted, so that it can be separated from the animal tissues. The animal tissues containing the greatest proportion of fat are the bone marrow, subcutaneous and intermuscular tissues around the various internal organs and the omentum of the abdominal eavity.

Chemical Characteristics.-Chemically considered, fats are glyceryl esters of fatty acids. The fatty acid radical replaces the $\mathrm{OH}$ in the alcohol molecule (glycerin) and joins the alcohol radical $\mathrm{C}_{3} \mathrm{H}_{5}$ or allyl, which is a trivalent ion, whereby fats are formed. By some authorities fats are considered salts of the higher saturated or unsaturated fatty acids in which the glyceryl acts as the base. Just as nitric acid when acted upon by caustic soda forms water and sodium nitrate, so stearic acid will theoretically combine with glyceryl, produeing glyceryl stearate, that is, ordinary stearin. Stearin is abundant in hard fat; it is a stearopten solid at ordinary temperature.

Fatty Bodies.-Fatty bodies are component parts of the cells of animals and plants, more particularly in animal fat, though to some extent in the seeds of vegetables and fruit. The most common are palmitin, olein and stearin and the most common fatty acids are palmitic, oleic, stearic, butyric, caproic, caprylic, erucic and valeric, but there are others. Fat is formed by their union with glycerin.

FLUID AND SOLID FATTY BODIES.-The three fatty bodies, olein, palmitin and stearin, form the fat of animal tissues. Olein and stearin are in such proportion that the fat remains fluid if kept at the temperature of the human body. The physical condition of fat or oil, i.e., whether it is a solid or a liquid at ordinary temperatures, depends largely upon the proportion of saturated or unsaturated glycerids present. Fats 
predominating in a greater proportion of palmitate and stearate are solid, while those predominating in oleate are liquid.

Recently a process has been commercialized for saturating unsaturated glycerids by merely heating them with hydrogen in the presence of a eatalyptic agent, niclel. Instead of having a white solid similar to tallow, we have a liquid cottonseed oil which is high in glyceryl oleate and low in stearate. This process changes a large portion of the oleate to stearate, thereby solidifying the liquid product.

Importance of Fat.-Fat is the most important representative of the hydrocarbon group of foods; common forms are fat meal, butter, cream, a part of mills and cheese. Fat meat, such as beef, mutton and pork, are important ingredients of our diet. As a rule the fat is so closely associated with the lean that it is taken more or less incidentally along with the proteins of the lean meat. The quantity of fat ingested can be regulated by inspection and more accurately determined by the actual separation and weighing of the fat. Meat fats should be thoroughly cooked in the presence of moisture, if they are to be easily digestible (see Volume II, chapter on Seientific Cooking).

ASSIMILATION OF FATS.-Fats are comparatively easily assimilated. They pass through the mouth and stomach unchanged. During the digestive process the slight framework of the connective tissne of meats and the protoplasm of cells are peptonized. The enclosed fat or oil globules are liberated and later on emulsified and saponified by the action of the mild but copions carbonates in the small intestine, together with the ferment action of lipase (steapsin). The combined action of these digestive agents changes the fat into an emulsion and eventually saponifies it, thus releasing the glycerin of the fat molecule and redneing the fat to soluble components, soap and glycerin. Other portions of the fat are converted into forms of soap by the action of the pancreatic fluid, a solution of which is quite readily absorbed. A large proportion of the digested fat is absorbed by the lacteals and gains an entrance into the blood by way of the thoracic duct. After a full meal the fluid in the lymphatic vessels, of which the thoracic duet is the largest. is milky from the presence of fat. All the fat does not reach the blood in this manner. A large amount is absorbed directly into the blood ressels in the form of the soluble and insoluble soaps which are manufactured in the bowels. Research experiments have proved that 150 grams of fat (about five and one-half ounces) can be easily absorbed and assimilated with only an infinitesimal loss. As a result it will be good practice to preseribe one-quarter of a pound of fat daily for a diabetic. 
On watching the blood stream after a meal fat globules can be observed, but after a time the blood resumes its usual appearance. The white blood cells are said to carry these minute fat globules all over the body, distributing them to the working tissues for the production of heat and energy and other current expenditures. The fat itself is reduced' to carbonic acid and water which are excreted by the skin, lungs and kidneys. When more food is consumed than is necessary for the immediate needs of the body, fat is stored up in the subcutaneous and other cellular tissues. It is a well-known fact that animals often put on more fat than their food contains. Pigs accumulate much more fat in the body and cows give more fat in their milk than exists in the food which they consume. It is therefore assumed that additional fat is derived from the conversion of proteid and carbohydrate elements, which have already been shown to cause an accumulation of fat, when there is greater consumption of them than is necessary.

FAT AS NECESSARY TO HEALTH.-The consumption of fat is required to promote the earlier stages of growth and repair of the organism. There are also many diseased conditions and degenerative changes which are accompanied by increased accumulation of fat in and between the tissues and cells of the body. Therefore it is quite impossible to live very long in perfect health without fatty food. It is equally impossible to live very long upon fatty food alone, since its prolonged use upsets the digestive processes and causes an absolute repugnance for fat.

Dependence of Muscular Action on Fat.-The expenditure of muscular action is more or less intimately dependent upon fat combustion. It was formerly taught that the force of the body was supplied by the oxidation of nitrogenous materials, for instance, fat eaten with food was believed to be deposited again as fat in the tissues. Of recent years this theory has been exploded and the primary value of fatty foods has been established beyond question as a contributing force in saving other tissues, especially the albuminous, from destruction by oxidation; whereas its secondary use is in connection with tissue formation. Fats do form a part of many different tisues of the body, even those of the nervous system.

FATS VS. OILS.-Both fats and oils employed as food serve essentially the same purpose and may, therefore, be grouped together and considered as a class. Their physical properties are identical, although they differ considerably in their melting points. Fatty bodies and fatty acids vary in chemical composition, but after being absorbed they are recognized mainly in one or two simple forms, chiefly as stearin and olein. 
While the varions fats and oils, of both animal and vegetable origin, have the same beneficial effect upon nutrition, there is considerable difference in their fuel value, and in the facility with which one variety or another may be assimilated in individual cases. Animal fats have a higher nutritive power than those derived from the vegetable kingdom, and of the former, liver fat, butter and cream are the most easily digested, assimilated and absorbed of all fats.

The use of fats and oils should be restricted or forbidden in all forms of acute gastro-enteric intestinal disorders, chronic gastritis, dilatution of the stomach, chronic diarrhea, obesity, fatty and waxy liver, gallstones, acne and urticaria.

Economy of Fats and Oils.-Below is given a table showing cost of 1,000 calories and cost per pound of some of the more common fatty food products. Prices were obtained in New York City in the fall of 1917 :

COST OF FATS

\begin{tabular}{|c|c|c|}
\hline & $\begin{array}{c}\text { Cost of } 1,000 \\
\text { Calories, } \\
\text { Cents }\end{array}$ & $\begin{array}{c}\text { Price per } \\
\text { Pound, } \\
\text { Cents }\end{array}$ \\
\hline Cottonseed oil $\ldots \ldots \ldots \ldots \ldots \ldots \ldots$ & 7.3 & 31 \\
\hline Oleomargarin $\ldots \ldots \ldots \ldots \ldots \ldots \ldots$ & 8.5 & 30 \\
\hline Peanut butter $\ldots \ldots \ldots \ldots \ldots \ldots \ldots$ & 8.8 & 25 \\
\hline 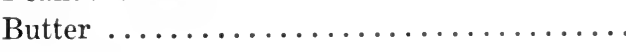 & 11.9 & 43 \\
\hline Olive oil $\ldots \ldots \ldots \ldots \ldots \ldots \ldots \ldots \ldots \ldots \ldots \ldots \ldots \ldots \ldots$ & 12.1 & 51 \\
\hline 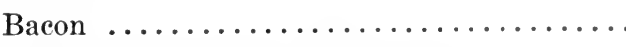 & . 13.8 & 37 \\
\hline Cream (extra heavy, 40 per cent) ....... & . 19.8 & 65 (pint) \\
\hline 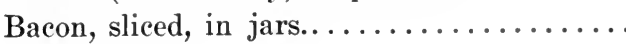 & 22.2 & 65 \\
\hline
\end{tabular}

\section{ANIMAL FATS}

Animal Fats.-Animal fats are obtained from fatty foods, including butter, cream, suet, lard, oleomargarin, the fat of beef, mutton, pork and bacon, bone marrow, pemmican, fish and cod liver oil. Oil is also obtained from the yolk of eggs.

BUTTER.-Butter is one of the most ancient articles of food. It was written of in the. Vedas 2000 to 1400 в.с. It is made by churning whole milk, which canses the fat globules of "ripened" cream to coalesce, breaking up the cmulsion of cream and forming the butter fat into a solid mass. When cream is designed for the manufacture of butter a "ripening" process is required to bring the cream to a suitable condition. No special precautions are necessary where the shallow pan system at a 
low temperature is used, but this system requires time for the cream to "ripen." With the employment of the "separator" the period of time is shortened somewhat. The best butter is made from cream that has ripened in shallow pans from twelve to twenty-four hours and churned at a temperature of between $65^{\circ}$ and $70^{\circ} \mathrm{F}$. In this way butter may be made in twenty to thirty minutes. Standard butter should contain 82.5 per cent of milk fat and not more than 16 per cent water.

Chemical Characteristics of Butter.-From a chemical standpoint, one is impressed by the large content of fatty acids contained in butter fat. The acids butyric, caproie, capric and caprylic are soluble in water. (See table below.)

Butyric acid is present in the proportion of about 7 per cent. The most abundant of the insoluble fatty acids in butter is oleic, olein being present in the proportion of 40 per cent. This fact points to the low melting point $\left(31-34^{\circ}\right.$ C. $)$ of butter, and consequently its ease of digestion and assimilation. For ease of digestion, butter stands at the head of the list of fatty foods. Human fat is also rich in olein and has a lower melting point $\left(25^{\circ}\right.$ C. $)$ than butter. A plausible explanation of the digestibility of butter is the similarity between butter fat and human fat in their proportion of olein.

\section{THE FATTY ACIDS IN 100 GRAMS OF BUTTER FAT}

Analysis by Hehner and Mitchell

Per cent

Stearic Acid .............. 1.83

Distearic Acid ............. 1.00

Oleic ..................... 32.50

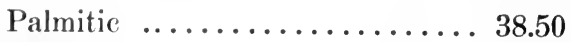

Myristic ............... 8.89

Lauric .................. 2.57

Capric .................. 32

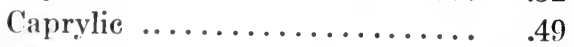

Caproie $\ldots \ldots \ldots \ldots \ldots \ldots \ldots . \ldots . .69$

Butyric ................ 5.45

Total Acids per cent....... $\overline{94.50}$

\section{Analysis by Bell}

Volatile or Soluble:

Butyric Acid ........ 6.13

$\left.\begin{array}{l}\text { Caproie } \ldots \ldots \ldots \ldots \ldots \\ \text { Caprylic } \ldots \ldots \ldots \ldots \ldots \\ \text { Capric } \ldots \ldots \ldots \ldots \ldots\end{array}\right\} 2.09$

Nonvolatile or Insoluble:

Oleic Acid .......... 36.10

Palmitic, Stearic, Lauric and Myristic Acids... 49.46

Total Acids per cent....... 93.78

To the trace of casein found in butter is due the disagreeable raneidity which often develops in butter kept for a while. The casein decomposes 
in time, this proess being hastened by the presenee of water. In order to keep butter sweet indefinitely, it is melted and loiled until all the water is expelled. This product in its melted state is strained through a muslin cloth to separate the cascin. It is then penred into a container, cooled and securely corked, when it will keep sweet indefinitely.

Creamer Butras. - Cremery butter is mate in a creamery from cream obtained by a centrifugating machine or separator. The creamery is supplied every morning with fresh cream from the dairymen or farmers in the surrounding district. This is the chief system in this country as well as in Ifolland, Ireland and other European countries. In England there are many factories in sucesssul operation where the whole milk is received, the cream loing separated at the factory and butter manufactured after the same process as at creameries in this country. The Department of $\Lambda$ grieulture estimates that the yearly butter product of this country aggregates $1,621,796,475$ pounds, valued at $\$ 648,718,590$.

Imitation Creamery Buttek.-Imitation ereamery butter is made by farmers or dairymen on a small scale in the same manner as creamery butter. Such butter is purehased by dealers from the farmers before it is washed, salted, or worked, the dealers having supervision over this part of the butter-making process. Their attention to the details of washing, salting and kneading and mingling together butters from various sources produces a more uniform butter of a superior quality than butters made by individuals.

Dairy ButTer.-Dairy butter is butter, salted, kneaded and packed by the dairyman and sold in print packages. Such butter is usually made by old-fashioned methods, i.e., the cream is ripened in shallow pans, etc. This method produces a pure and wholesome produet.

Factory Butter.-Factory butter is produced from butter sorted into salt and saltless butter and sold by the farmers to factories. It is sent in rolls, baskets or boxes to the factories, where it is washed by a powerful butter working machine and then packed into firkins for the market.

Renovated butter is usually stale, raneid or otherwise unsalable factory butter, derived from many sources. It may he purified by sterilization, clarified, melted down, refined and deprived of deleterious odors and more particularly of its rancid odor.

Causes of Raveidity of Butter.-The eauses of rancidity in butter have frequently been investigated by chemists and bacteriologists. The cause of rancidity of butter and other fats is not thoroughly understood, 
but light, heat and moisture may play a part in the transformation. Recently the causes for the undesirable flavors sometimes present in cold storage butter have been sought by dairymen, storage men and hygienists.

It has been generally supposed that rancidity is due to changes taking place in the fats of which butter is principally composed and that the "off flavors" are merely mild forms of rancidity. After a series of studies on butter which had been prepared under widely varying conditions and stored at $0^{\circ} \mathrm{F}$. for varying lengths of time, Dyer(1) concludes that (a) "the development of undesirable flavors in storage butter is not dependent on an oxidation of the fat itself, but that $(b)$ it is attributable to a slow process of oxidation progressing in the non-fatty constituents of the buttermilk, and that $(c)$ the extent of this change is directly proportional to the amount of acid present in the cream from which the butter has been prepared."

In other words, the buttermilk supplies the substances which decompose during cold storage. This decomposition is proportional to the amount of acid present in the cream before churning. The experiments showed that butter made from sweet cream had a very mild flavor and kept in good condition almost indefinitely in storage, while the butter from highly acid cream had a high flavor and would not keep well. The remedy consists in preventing the cream from ripening too much, i.e., producing too much acid before churning or, if that has occurred, in washing out the buttermilk from the freshly churned butter with fresh water.

Chemical Composition of Butters.-The following tables, taken from Tibbles' "Origin and Manufacture of Foods," will serve to illustrate the chemical composition of various grades and makes of butter:

\section{A-COMPOSITION OF BUTTER-PERCENTAGES}

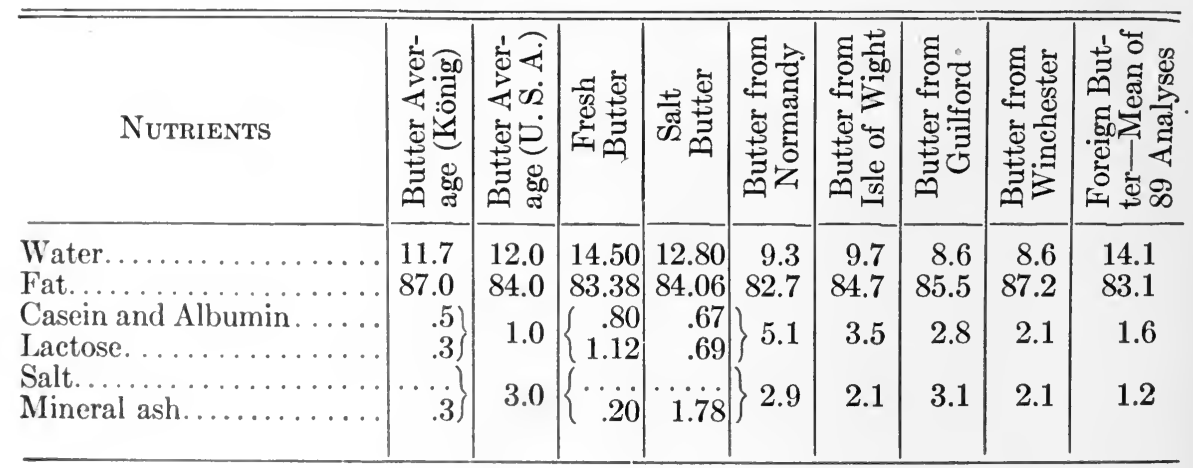




\section{B-COMPOSITION OF BUTTER-PERCENTAGES}

\begin{tabular}{|c|c|c|c|c|c|c|c|c|}
\hline $\begin{array}{l}\text { Samples From } \\
\text { VARIOUS SOURCES }\end{array}$ & Water & Salt & C'urd & $\begin{array}{l}\text { Butter } \\
\text { Fat }\end{array}$ & $\begin{array}{c}\text { Specific } \\
\text { Ciravity } \\
\text { at } 10()^{\circ} \\
\text { F. }\end{array}$ & $\begin{array}{l}\text { Fixed } \\
\text { Acid }\end{array}$ & $\begin{array}{l}\text { Soluble } \\
\text { Acid }\end{array}$ & $\begin{array}{l}\text { Melting } \\
\text { Point }\end{array}$ \\
\hline 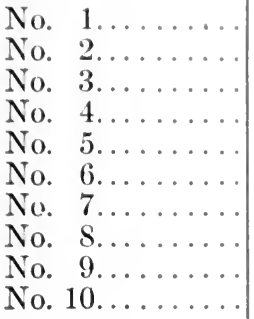 & $\begin{array}{r}7.55 \\
11.71 \\
16.89 \\
16.25 \\
11.42 \\
12.55 \\
12.96 \\
13.40 \\
12.05 \\
14.62\end{array}$ & $\begin{array}{r}1.03 \\
3.60 \\
8.56 \\
3.32 \\
1.29 \\
.80 \\
2.43 \\
1.39 \\
.96 \\
1.48\end{array}$ & $\begin{array}{l}1.15 \\
.95 \\
1.23 \\
1.56 \\
1.12 \\
.74 \\
1.25 \\
2.03 \\
1.95 \\
1.88\end{array}$ & $\begin{array}{l}90.27 \\
83.74 \\
73.32 \\
78.84 \\
86.15 \\
85.82 \\
83.36 \\
83.18 \\
85.04 \\
82.04\end{array}$ & $\begin{array}{l}913.89 \\
911.45 \\
911.48 \\
912.79 \\
910.47 \\
910.20 \\
912.51 \\
911.67 \\
911.04 \\
910.70\end{array}$ & $\begin{array}{l}8.5 .56 \\
88.24 \\
88.22 \\
86.00 \\
88.53 \\
89.00 \\
88.25 \\
88.72 \\
87.51 \\
89.00\end{array}$ & $\begin{array}{l}7.41 \\
5.41 \\
4.64 \\
7.00 \\
8.44 \\
4.57 \\
5.45 \\
5.07 \\
5.28 \\
4.50\end{array}$ & $\begin{array}{l}85.0^{\circ} \mathrm{F} \\
90.0^{\circ} \\
89.5^{\circ} \\
88.5^{\circ} \\
90.0^{\circ} \\
90.0^{\circ} \\
98.0^{\circ} \\
99.0^{\circ} \\
98.0^{\circ} \\
91.0^{\circ} \\
9 .\end{array}$ \\
\hline
\end{tabular}

According to Intchison, the percentage of fat in butter varies within fairly wide limits, but the average is about $\$ 2$ per cent, or twice as much as the amount in cream. "An ounce of butter may therefore be reckoned as the equivalent of four-fifths of an ounce of pure fat." Butter contains twelve to fifteen per cent of water and about two per cent of non-fatty organic matter, casein and milk sugar.

Digestion of Butter.-The value of butter as a source of fat in the dietetic treatment of various diseases is very great. It is so easily digested that it may be ingested freely by those suffering from consumption, dyspepsia of various forms and diabetes. A daily ration of onequarter of a pound may be eaten with impunity, and the nutritive value is great. It is a well-known fact that butter used in cooking not infrequently causes indigestion, doubtless due to the liberation of the fatty acids by the heat.

It has been determined that with the daily ration of one-quarter of a pound the excretion of waste from it does not reach five per cent. No other form of fat is so thoroughly assimilated and this fact should emphasize the dietetic value of butter as compared with cod liver oil and other similar medicinal fats, a large number of which prove indigestible and difficult to assimilate.

LARD.-Lard is hog fat separated by melting from the areolar connective tissue. There are several grades of hog fat. The highest grade is known as leaf lard, which comes from the fat surrounding the kidners. Refined lard is a second grade, and the two lower grades are called 
respectively, steam rendered lard and prime steam lard. Lard is frequently stiffened by the addition of lard stearin. Lard thus treated keeps better in warm climates and is, therefore, more satisfactory. Lard oil is obtained by subjecting lard contained in woolen bags to hydraulic pressure. The expressed oil is chiefly olein, of a pale yellow color and a peculiar bland taste. The principal use of lard from a culinary standpoint is for "shortening," to diminish the adhesiveness of flour in making bread and cakes and for preventing the pastry from being tough.

TALLOW.-Tallow is beef fat obtained from the different tissues of cattle.

SUET.-Suet is mutton fat or that part of the fat surrounding the kidney of the sheep.

OLEOMARGARIN.-Oleomargarin is a compound of beef fat with mutton fat, lard oil, cottonseed oil, peanut oil, corn oil, sesamine oil, cocoanut oil, stearin and other oils and fats, which are ground together by specially designed machinery and subjected to steam heat under pressure. The wholesomeness of the product is regulated by act of Congress. It is a good substitute for butter and is more palatable than poor butter. There is some demand for it as a food product, as 50,000,000 pounds of it are sold annually.

BUTTERINE.-Butterine has largely replaced oleomargarin. It is made in a similar manner, only the ingredients differ in proportion and the leaf lard of the hog is added during the process of manufacture.

BONE MARROW.-Bone marrow is an easily digested and wholesome form of fat which has long been used as a food. The marrow of the young animals, such as the calf and lamb, is supposed to contain more tissue-building elements than the marrow of mature animals. This should be borne in mind, particularly if an anemic or chlorotic patient is to be treated. It is a very soft, rich fat.

PEMMICAN_-Pemmican is made of meat cut in slices and dried in the sun, to which fat, sugar and dried fruit, such as raisins and currants, are added. It is used on long voyages, especially in the Aretic regions, where a fatty diet is essential to produce heat and force.

OTHER FATS.- The fat of a good roast of beef is very nutritious. A very digestible variety of fat is good breakfast bacon, thinly sliced and broiled. This form of crisp fat is often digested by invalids who cannot tolerate other fats. Ham fat and pork fat are usually very digestible, especially when ingested hot.

Prains and liver of animals contain considerable quantities of fat, and when taken as a food furnish fat in an agreeable form. 
FISH FaTs.-The common fish which contain large amounts of fat are the eel, salmon, herring and mackerel. Sardines contain some fat, but no doubt the oil in which they are preserved exceeds the fish oil in fuel value. Many species of fish are ricl: in oil. The Eskimo eats whale blubber (fat). The oil of the shurgen is extensively employed to preserve caviare.

Con Liver Ont.-Cod liver oil is manufactured from the fresh raw livers of the codfish by subjecting them to heary pressure. It is one of the most easily absorbed of all the wils. I ts taste is objectionable to most people. Cod liver oil is much used as at therapentic agent, and the reader is referred to text-books on materia medica and therapeutics for further information on this product.

\section{VEGETABLE FATS AND OILS}

Vegetable Fats and 0ils._Vegetalle fats and rils are derived in greatest abundance from the seeds of plants and are extracted by pressing the crushed seeds. Most of the cold dimn vegetable oils from seeds and fruits are suitable for culinary purposes or for the preservation of foodstuffs. The elimination of all fatty acids from edible oils is a very important process, brought about by the use of alkalies or alkaline earths during the process of manufacture. These oils should not congeal at temperatures near the freezing point. Olive oil does not congeal, but some other oils, such as cottonseed oil and peanut oil, which contain stearin, have to be demargarined to prevent congealing. To prevent this the oils are stored for the winter months in large tanks to allow the stearin to settle or crystallize out. The clear oil may be withdrawn from this, or the stearin may be removed by filtering or by centrifugalization.

VALUE OF VEGETABLE OILS AND FATS.- Vegetable fats and oils are very valuable for the production of heat and energy for the body. Compared with sugar, vegetable fats are about two and a half times as effective and are to be regarded as a very concentrated form of nutriment.

ABSORPTION OF VEGETABLE FATS-L'nless fats and oils are well emulsified and saponified they will be decomposed in the intestines into fatty acids and glycerin, which recombine when passing through the intestinal wall.

Since vegetable oils are readily absorbed after proper emulsification and saponification, they may be ingested in relatively large quantities, and are extremely useful for the diet in the treatment of certain 
diseases. "The principal uses of vegetable oils and animal fats like lard are for "shortening" pastry and for frying foods. Fried foods, however, are difficult to digest, because the material becomes saturated with fat, which acts as a barrier to the free penetration of the digestive enzymes. This prevents ready contact with the carbohydrates and proteins of the food substance. If food is to be cooked in "deep fat," the process used in cooking doughnuts, it is important that the heat should be sufficiently high so that very little of the fat is absorbed.

PERCENTAGE COMPOSITION OF OIL-BEARING VEGETABLES.-The following table, from Professor A. A. Church, contains a list of oil-bearing vegetable products, with the percentage composition present in each:

$\begin{array}{lcccc}\text { Palm Nut (pulp) } & \text { contains } 72 \text { per cent oil } \\ \text { Brazil Nut (seeds) } & \text { " } & 67 & \text { " } & \text { " } \\ \text { Almond (kernels) } & \text { " } & 54 & \text { " } & \text { " } \\ \text { Ground Nut (peanut) } & \text { " } & 52 & \text { " } & \text { " } \\ \text { Sesamé (seeds) } & \text { " } & 51 & \text { " } & \text { " } \\ \text { Poppy (seeds) } & \text { " } & 45 & \text { " } & \text { " } \\ \text { Olive (pulp) } & \text { " } & 39 & \text { " } & \text { " } \\ \text { Olive (kernels) } & \text { " } & 44 & \text { " } & \text { " } \\ \text { Cacao (seeds) } & \text { " } & 44 & \text { " } & \text { " } \\ \text { Cocoanut (meats) } & \text { " } & 36 & \text { " } & \text { " } \\ \text { Hemp (seeds) } & \text { " } & 32 & \text { " } & \text { " } \\ \text { Walnut } & \text { " } & 32 & \text { " } & \text { " } \\ \text { Cotton (seeds) } & \text { " } & 24 & \text { " } & \text { " } \\ \text { Sunflower (seeds) } & \text { " } & 22 & \text { " } & \text { " } \\ \text { Oatmeal } & \text { " } & 10 & \text { " } & \text { " } \\ \text { Corn (maize) } & \text { " } & 5 & \text { " }\end{array}$

This may be supplemented by the following, which are of less commercial importance: rape seed, mustard seed, tomato seed, raisin or grape seed, apricot and peach kernels, which are all of some commercial value. Flaxseed, from which linseed oil is made, is of great commercial importance.

Palm Ort.-Palm oil is obtained by cold pressing the soft part of the fruit of numerous varieties of palm trees in many tropical countries. It is semisolid at ordinary temperatures and has an agreeable taste. Palm oil is extensively used for food purposes. Its chief constituent is palmitin. The palm nut, from the kernels of which palm nut oil is manufactured, is obtained from the same tree. This product is used in the manufacture of butterine and other butter substitutes, and is sold as vege- 
table butter under varions trade-marked nanes. Palm oil or butter is used extensively by the natives in districts where it is produced.

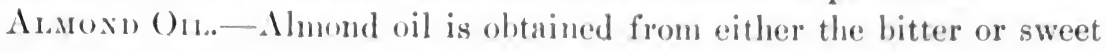
almond. The former contains a greater percentage of oil and is more generally used. 'This almond nut is grown extensively in comntries around the Mlediterranean Sca. Almond oil is sometimes adulterated with cheaper oils made from apricot and peach kernels. Almond oil is of a clear yellow color and a bland tiste.

Peanut On. - Peamut oil is obtained by the cold hydraulic pressing of peamuts. 'The best quality of peanut oil, ealled cold drawn oil, comes from the first pressing. Subsequent pressings and pressing with 'ieat yield oil of a lower grade. The residue left is rich in proteins and starch and is valuable as a stoek food. The principal use of peanut oil is for a salad oil, either alone or mixed with other oils. Recently it has been largely used as an adulterant for olive oil and is itself sometimes adulterated with cottonseed or poppy seed oils. Peanut oil is an excellent substitute for lard in "shortening" or in other culinary uses. It is superior to most oils for the "deep frying" of foods.

Sesame OrL.-Sesame oil is obtained by pressing the seeds of the sesamum orientale, a native plant of southern Asia. The best grades of this oil are a golden yellow, free from any disagreeable taste or odor, and may be used in place of olive oil for salads. Cold drawn sesame oil is considered quite equal to olive oil as a salad oil. It has a slight amber color, a grain-like odor and a pleasing, bland taste.

Porpy SEed OIL.-Poppy seed oil is made from the seeds of the black and white poppies. These are grown extensively in Europe, Turkey, Persia, India, China and Germany, to extract the oil made from the seeds, as well as the inspissated juice of the same, which supplies the opium of the world. The better grades of poppy seed oil are of a light color and have an agreeable taste. This oil is also much used in foreign countries as salad oil.

Olive OrL.-Olive oil is obtained from the pulp and sometimes from the kernels of the olive fruit. The better grade of olives produce from 40 to 60 per cent of oil. It is called virgin oil when taken from the first pressing. The pomace, then taken from the press, reground, mixed with water and repressed, produces a second grade of oil in the process of manufacture. After the high grade oils are extracted, they are further purified by being placed in tanks and washed with water, then allowed to stand until the pulp and gummy material settle to the bottom, when the oil is carefully drawn off. Olive oil is frequently adulterated by the addi- 
tion of cottonseed oil and peanut oil. Rape seed oil and poppy seed oil are frequently used as adulterants of olive oil in Europe. This can be readily detected by chemical analysis. When pure olive oil from the first pressing leaves the press it is of a dark green color from the presence of chlorophyl, but most of this is deposited in the tanks. Olive oil has a peculiar faint odor and a bland, pleasant taste.

Mustard Seed Oil.-Mustard seed oil is produced in Switzerland and Italy and commonly used in those countries as a substitute for olive oil.

Cacao Fat.-Cacao fat or oil of theobroma is one of the few vegetable oils that is solid at ordinary temperatures. It is prepared by pressure of roasted and crushed cacao beans or nibs. This oil is obtained during the manufacture of chocolate. Cacao butter has a pleasant odor and flavor faintly suggestive of chocolate. It is extensively used in pharmacies and in the manufacture of perfumes. On account of its high price it is frequently adulterated with cocoanut oil, palm oil, beeswax and paraffln.

Coconnuts.-Cocoanuts have long been a source of fat. There are several names for the oil made from this nut, dependent upon the country in which it is made. The meat of the cocoanut includes the milk which is gradually absorbed as the nut reaches maturity. The milk is used by the natives in the same way as cow's milk. The oil is obtained from the sun-dried kernels. This is prepared by the natives by boiling the kernels in water and removing the fat by skimming.

Cocoanut oil is semi-solid at ordinary temperatures, keeps well and is free from fatty acids. It is seldom adulterated on account of its cheapness. It is extensively used for culinary purposes. This oil must not be mistaken for salad oil, to which it is inferior. Cocoanut oil is a fat of moderate consistency, nearly as hard as lard, and has an agreeable flavor, pleasant taste and aroma.

Cottonseed Oil.-Cottonseed oil is manufactured from the seed of the cotton plant. The seed is passed through machines which remove the linters, when they are transferred to a shelter where the hull is broken and separated from the kernels in a winnowing machine. The kernels are then crushed between massive steam rollers and put into steamjacketed kettles, where they are cooked, with constant agitation. The mass is then shaped into cakes surrounded by cloth and subjected to from 3,000 to 4,000 pounds hydraulic pressure to the square inch. This process yields about 45 gallons of cottonseed oil from a ton of cottonseed. The 
oil obtained is purified and the residue from the seed is broken up and ground to a meal and put on the market as a stock food. The process of purifying the erude cottonseed oil is an intricate one. Purified cottonseed oil as a food product has become popular in the last decade. It is practically tasteless and odorless and is as wholesome as animal fat. It is admirably adapted to many culinary uses.

Sunflower Senn Ort.-Sunflower seed oil has not been utilized to much extent in the United States, although the seeds contain considerable oil. In some European countries sunflower seeds are eaten as an ordinary food. The plant is extensively cultivated in Russia, Hungary, India and China for food purposes. The oil made from the seeds is palatable and needs no refining to make an excellent salad dressing. The best grade of oil is obtained by cold pressure of the whole seeds.

Cons OrL.-Corn oil is manufactured from the germs of the grains of Indian corn or maize. The germ contains more than 20 per cent of oil, the odor and taste of which are agreeable. This oil is frequently mixed with other vegetable oils and used largely in the manufacture of oleomargarin and lard substitutes. Corn oil is a by-product of starch and glucose factories and contains stearic, palmitic and oleic acids.

RAPE OIL.-Rape oil is made from the rape seed, which produces an excellent oil for culinary purposes. The "cold drawn" oil is of the best quality. The plant is grown extensively all over Europe, also in India and China. Fresh rape seed oil has an agreeable taste and odor, but on long standing it becomes rancid. The oil is frequently adulterated with cheaper oil, such as cottonseed and hemp seed and poppy seed oil.

Mustard Oil.-Mustard oil is an excellent bland oil, sometimes used in place of animal fat for culinary purposes. This oil as extracted by pressure is a by-product in the preparation of mustard as a condiment.

Tomato Seed OiL.-Tomato seed oil is employed especially in Italy as a salad oil.

Apricot Kervel Oil.-Apricot kernel oil and peach kernel oil are both edible oils and important articles of commerce. They are principally used as an adulterant to almond oil.

Soy BEAN OIL.- The soy bean oil contains from 18 to 19 per cent of oil which is of such good quality that it will in time no doubt come into general use.

Linseed Oil.-Linseed oil is manufactured from flaxseed. It is sometimes used as a substitute for olive oil, but is not very digestible. Its principal use from a commercial point of view is in the painter's trade. 


\section{Summary}

The use of fatty foods, fats and oils may be briefly summarized as follows, viz. :

1. They yield force for energy and work.

2. Their consumption supplies heat.

3. They yield more heat than the other classes of food.

4. They accumulate in the body as a storage of reserve force.

5. They furnish protection to many important tissues and organs.

6. They serve to lubricate and make more plastic various structures of the body.

7. They give to the surface of the body rotundity and contour of curve which is in the line of beauty.

\section{REFERENCES}

1. Dyer, D. C. Progressive Oxidation of Cold Storage Butter, J. Agric. Research, 1916, vol. vi, 927.

\section{BIBLIOGRAPHY}

Amberger. Influence of Food on Composition of Butter Fat, Ztschr. $f$. Untersuch. d. Nahrungs- u. Genussmittel, 1907, vol. xiii, pp. 614-621.

Behrend and Wolfs. Butter Fats from Individual Cows, Ztschr. f. Untersuch. d. Nahrungs- u. Genussmittel, 1902, vol. v. pp. 689719.

Browne. A Contribution to the Chemistry of Butter Fat, J. Am. Chem. Soc., 1899, vol. xxi, pp. 612-633, 807-827, 975-994.

Gibbs and Agcaorli. Lard from Wild and Domestic Philippine Hogs and the Changes Effected by Feeding Copra Cake, Philippine J. Sc., 1910, series A, vol. v, p. 33.

KLeIN. The Olive Oil Industry in Portugal, J. f. Landwirtschaft, 19111912, vol. lx, pp. 31-73.

Lindsay, et al. Effect of Feed on Butter Fat, Mass. Agric. Exper. Sta. Rep. for 1908, pp. 66-110; Chemical Abstracts, 1910, vol. iv, p. 1774.

McCollum and Davis. The Necessity of Certain Lipins in the Diet during Growth, J. Biol. Chem., 1913, vol. xv, pp. 167-176. 
Osbone and Mennez. The Influence of Butter Fat on Growth, J. Biol. Chem., 1913, vol. xvi, pp. 423-437. (S'ee also 1914, vol. xvii, pp. 401-408.)

Rogers and Gray. Influence of Acidity of Cream on Flavor of Butter, U. S. Dept. Agric., Burea Animal Indust., 1913, Bull. 114.

Shaw. A New Method for Determining Fat and Salt in Butter, Especially Adapted for Use in Creameries, U. S. Dept. Agric., Bureau Animal Indust., 1912, Cireular 202.

Simmoxs and Mitcheir. Edible Fats and Oils.

Swavixg. Influence of Feeding Cottonseed and Sesame Meal on the Properties of Butter Fat, Ztschr. f. Untersuch. d. Nahrungs- u. Genussmittel, 1903, vol. vi, pp. 97-115.

Tolman and Muxson. Olive Oil and Its Substitutes, U. S. Dept. Agric., Bureau Chem., 1902, Bull. 77.

Walker. Coconuts and Coconut Oil, Philippine J. Sc., 1!06, vol. i, pp. 58-117.

Wessor. Bleaching of Oil with Fuller's Earth, J. Indust. \& Engin. Chem., 1911, vol. iii, p. 126.

The Chemist and the Cottonseed Oil Industry in America, J. Indust. \& Engin. Chem., 1912, vol. iv, pp. 64-65. 



\title{
CHAP'TER XV
}

\section{FRUITS, NUTS ANI) GARDEN FRUITS}

\author{
M. E. JAFFA, M.I.
}

General Considerations: Fruits in Relation to Climate; Classification of Fruits; Chemical Composition of Fruits; Importance of Fruits; Digestion and Absorption of Fruits.

Tree Fruits: Pomaceous, Citrus, Moraceous, Anonaceous, Myrtaceous, Sapotaceous, Anacardiaceous, Ebenaceous, Lcguminous, Palmaceous Fruits and Miscellaneous Tree Fruits.

Ampelidaceous or Vine Fruits: Passifloreous Fruits.

Small Bush Berries.

Herb-like Fruits.

Nuts.

Garden Fruits.

Preservation of Fruits by Cold Storage.

\section{GENERAL CONSIDERATIONS}

Fruits in Relation to Climate.-Edible fruits show the greatest range in form, eolor and appearance, and are found in almost countless varieties the world over. This is more or less nature's index for man's necessity.

That fruits grow in greatest abundance in hot climates and are less profuse in the cold regions of the earth, emphasizes the fact that in warmer climates, fruits and non-stimulating vegetables are better suited for foods, while the more stimulating animal foods are better suited for the inhabitants of the colder climates. This teleological argument favors more fruits and vegetables and less animil foods in the summer and the reverse in the winter months, even in the temperate regions.

The number of kinds of fruit indigenous to the temperate region is very small compared with the great number of varieties in the tropies. Some of the native fruits of the temperate zone still grow wild; but the 
cultivated varieties of apples, pears, plums, strawberries and raspberries and other fruits have been greatly improved by cultivation, in size, taste and appearance. The cultivated varieties of apple are a superior fruit to their original parent, the crabapple, while the delicious cultivated plum shows a great contrast to the parent sloe.

RECENT PROGRESS IN FRUIT TRANSPORTATION.-Though the variety of fruits grown in temperate climates is small, the rapid methods of transportation and storage have placed the superabundance of the tropics and the delicate fruits and vegetables of the whole world within our reach. Apples, pears, plums, oranges, lemons, grapefruit, pineapples, mangoes, sapodillas, mangosteens, persimmons, alligator pears and various other fruits are brought from many parts of the world. Many of these formerly were rarely seen on fruit stands. Now they are never absent.

Classification of Fruits.-The following classification of fruits most cultivated is taken in part from Bailey's(1) "Principles of Fruit Growing." While completeness is not claimed, yet it will serve as an inventory of the more staple fruits grown in the temperate and subtropical climates. For convenience we divide fruits into the following:

\section{CLASS I, TREE FRUITS}

\section{Classification}

VARIETIES

1. Pomaceous Fruits ......... Apple, pear, quince and medlar.

2. Drupaceous Fruits ........ Plum, peach, apricot and cherry.

3. Citrous Fruits ........... Orange, lime, lemon, grapefruit and kumquat.

4. Moraceous Fruits ........ Fig, mulberry and bread fruit.

5. Anonaceous Fruits ....... Sour apple, sugar apple and pawpaw.

6. Myrtaceous Fruits ........ Guava, rose apple and Surinam cherry.

7. Sapotaceous Fruits ........ Sapodilla, marmalade and star apple.

8. Anacardiaceous Fruits..... Mango and Jew plum.

9. Ebenaceous Fruits .........Persimmon and Japan persimmon.

10. Leguminous Fruits ........ St. John's bread and tamarind.

11. Nut Fruits ...........Walnut, butternut, chestnut, pecan, almond, chinquapin, filbert, hickory nut, etc.

12. Palmaceous Fruits ....... Dates and cocoanuts.

13. Miscellaneous Tree Fruits... Olive, pomegranate, alligator pear and Mammee apple.

\section{CLASS II, VINE FRUITS}

14. Ampelidaceous Fruits ....... Fox grape, muscadine, scuppernong.

15. Passifloreous Fruits ...... Granadilla, Passiflora edulis and others. 


\section{CLASS III, SMALL BUSH FRUITS}

16. Bush Fruits ..........Raspberry, blackberry, wineberry, dewberry, currant, gooseberry, June herry, huckleberry. loganberry.

17. Strawberry ............ Common strawberry, wild strawberry, Virginian

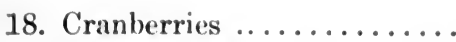
strawberry, Alpine strawberry and others.

19. Herb-like Fruits ........ Banana, pineapple, prickly pear, Barbadoes gooseberry.

Chemical Composition of Fruits.-Fruit contains, besides sugar, salts and organic acids, a vegetable substance called pertin, $\mathrm{C}_{32} \mathrm{H}_{48} \mathrm{O}_{32}$, which has already been described. The nutritive value of fruit depends upon its percentage of sugar. Fruit sugar, or grape sugar, is glueose or dextrose $\mathrm{C}_{6} \mathrm{H}_{12} \mathrm{O}_{6}$. It is found in large quantities in such fruits as grapes, which contain from 10 to 25 per cent; dried figs, 60 to 70 per cent; cherries, 11 per cent; mulberries, 9 per cent; currants, strawberries and whortleberries, each 6 per eent, and raspberries, 4 per eent. Fruit also contains an uncrystallizable invert sugar, levulose, $\mathrm{C}_{6} \mathrm{H}_{12} \mathrm{O}_{6}$. When pure, levulose is a sirup; it exists in combination with dextrose in many fruits and vegetables, notably in grapes, figs, cherries, gooseberries, strawberries, peaches and plums. In dritd fruits the levulose inereases at the expense of the dextrose, which is inverted by means of a ferment or enzyme as in raisins.

ACIDS IN FRUIT.-The organic fruit acids are citrie, malie, acetic, tartaric, oxalic, salicylic and boric acids alone, or combined with bases, to form salts of potassium, sodium, calcium, etc., or they may be commingled with phosphates, carbonates, sulphates and chlorids of such bases in smaller proportion.

Malic acid $\left(\mathrm{H}_{3} \mathrm{C}_{4} \mathrm{H}_{4} \mathrm{O}_{5}\right)$ is present in generous quantity in apples, pears, red and white currants, blackberries and raspberries, quinces, pineapples and eherries. Citric acid $\left(\mathrm{H}_{3} \mathrm{C}_{6} \mathrm{H}_{5} \mathrm{O}_{7}\right)$ is found in lemons, limes, oranges, gooseberries, strawberries and raspberries, and tartaric acid $\left(\mathrm{H}_{2} \mathrm{C}_{4} \mathrm{H}_{4} \mathrm{O}_{6}\right)$ predominates in grapes, though it exists also in other fruits. Salicylic acid is sparingly present, probably in the form of methyl ester, in plums, cherries, currants, grapes, strawberries, raspberries, ete. Boric acid is said to be present in oranges and lemons. The flavor and aroma of fruits are due to the various ethers of the particular variety of fruits.

The above acids are present in varying proportions in fruit juices where they occur usually as acid salts of potassium, sodium or calcium, 
imparting an agreeable flavor to the fruit and adding a wholesome and stimulating variety to the food. The flavor and aroma of the fruit are due to various ethers and essences which have been prepared in imitation in the chemical laboratory by mixing ethereal salts and oils with each other until the odor of every fruit has been imitated.

CARBOHYDRATES.-The carbohydrates, such as cane sugar, grape sugar, fruit sugar, include the principal nutritive constituents. The special kind of sugar present depends upon the stage of ripeness of the fruit, as many chemical changes occur during the ripening and maturing process. The amount of the different sugars and of the acid in various fruits, according to Leach, is about as follows(2):

\section{ACID AND CARBOHYDRATE CONTENT OF FRUITS}

\begin{tabular}{|c|c|c|c|}
\hline & Cane Sugar & Reducing Sugar & Acid \\
\hline$\ldots \ldots \ldots \ldots \ldots \ldots$ & 6.04 & 2.74 & 1.864 \\
\hline 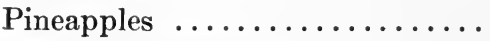 & 11.33 & 1.98 & 0.547 \\
\hline English Cherries $\ldots \ldots \ldots \ldots \ldots$ & 0.00 & 10.00 & 0.661 \\
\hline Lemons $\ldots \ldots \ldots \ldots \ldots \ldots \ldots$ & 0.41 & 1.06 & 4.706 \\
\hline Figs $\ldots \ldots \ldots \ldots \ldots \ldots \ldots \ldots \ldots$ & 0.00 & 11.55 & 0.057 \\
\hline Strawberries ................ & 6.33 & 4.98 & 0.550 \\
\hline Raspberries $\ldots \ldots \ldots \ldots \ldots \ldots$ & 2.01 & 5.22 & 1.380 \\
\hline Gooseberries............. & 0.00 & 6.40 & 1.574 \\
\hline Oranges $\ldots . . . . . . . . . . . .$. & 4.22 & 4.36 & 0.448 \\
\hline Peaches (green) $\ldots \ldots \ldots \ldots \ldots$ & 0.92 & 1.07 & 3.900 \\
\hline Pears (Madeleine) ............ & 0.36 & 8.42 & 0.115 \\
\hline Apples $\ldots \ldots \ldots \ldots \ldots \ldots \ldots \ldots$ & 2.19 & 5.45 & 0.633 \\
\hline Prunes $\ldots \ldots \ldots \ldots \ldots \ldots \ldots \ldots$ & 5.24 & 2.43 & 1.288 \\
\hline Grapes (hothouse) $\ldots \ldots \ldots \ldots \ldots$ & 0.00 & 17.26 & 0.345 \\
\hline Grapes $($ green $) \ldots \ldots \ldots \ldots \ldots$ & 0.00 & 1.60 & 2.485 \\
\hline Bananas...$\ldots \ldots \ldots \ldots \ldots \ldots$ & 20.00 & 20.00 & 0.300 \\
\hline Apples $\ldots \ldots \ldots \ldots \ldots \ldots \ldots \ldots$ & 5.28 & 8.72 & 1.148 \\
\hline
\end{tabular}

VARYING COMPOSITIONS.- The composition of fruits of the same family, even of the same garden or tree, varies. These variations will be referred to in the following paragraphs. The average composition in carbohydrates, protein, fat and inorganic constituents will be found in Chapter XIX_-"Analysis of Foods," to which the reader is referred. The protein and fat content is so small as to be negligible in all calculations on dietetics. Since the starches and sugars of various kinds possess the same nutritive value, this analysis shows the food and fuel value of fruits fairly well. 
Importance of Fruits. - The great importance and therapeutic value of fresh fruits, more particularly for the inhabitants of towns and cities, cannot be too strongly cmphasized. The organic acids in fruit arouse the appetite, and, by increasing the flow of salivat and indirectly the flow of the gastric juice, materially aid digestion. When the fruit first reaches the intestines, its acids increase the acidity of the chyme and stimulate the secretions of the liver and pancreas, the intestinal glands and musculature; their influence upon the blood is peculiar; by combining with a portion of the alkaline salts of the bleod serum the blood is rendered less alkaline, but never acid. The action of the phosphoric acid is to angment the phosphates of the red blood cells; hence fruits are antiscorbutic and of great value in anemia, general debility, and convalescence from acute illness.

Tomatoes, gooseberries and strawberries, on account of the oxalates contained in their chemical content, are of value for persons suffering from amenorrhea, bronchitis and asthma.

Strawberries, raspberries, currants, oranges and blackberries contain salicylic acid and are a valuable addition to the dietary of rheumatics.

Digestion and Absorption of Fruits.-The digestibility of fruit in the stomach and intestine depends largely on the nature of the fruit and its degree of ripeness. Two small apples require about three hours for digestion by the stomach. On the other hand, if the fruit is unripe, the cellulose is greater and digestion will be more difficult. Unripe fruits containing an excess of acids may be irritating to the intestine and are frequently the cause of colic and diarrhea, more especially in young children. On the other hand, in ripe fruits the cellulose and acids excite only gentle stimulation and may be very useful. Owing to their liberal cellulose content and the acid salts contained in fruits they stimulate intestinal activity and relieve constipation.

The absorption of fruits corresponds very closely with the absorption of fresh vegetables. The final stage in the digestion of fruit is the conversion of the fruit acid salts into alkaline salts, chiefly carbonates. They are therefore valuable adjuvants to the diet in scurvy, rheumatism, gout and other diseases of the uric acid diathesis. They increase the secretion of the urine and its alkalinity. Indeed fruits are the most certain agents to render the urine alkaline, to stimulate the kidneys and indirectly the skin, thereby increasing the total excretion of salts and other materials. 


\section{TREE FRUITS}

\section{POMACEOUS FRUITS}

Varieties of Pomaceous Fruits-APPLE.-Apples (Pyrus malus) come under the first class of fruits. They are essentially a fruit of the temperate regions of the earth. Apple trees are indigenous to most parts of the world and thrive wherever the oak grows. All the cultivated varieties of apples have been derived from the crab or wild apple, and its cultivation is prehistoric. Apples were introduced into England by the Romans, who highly appreciated the excellent edible qualities of the fruit.

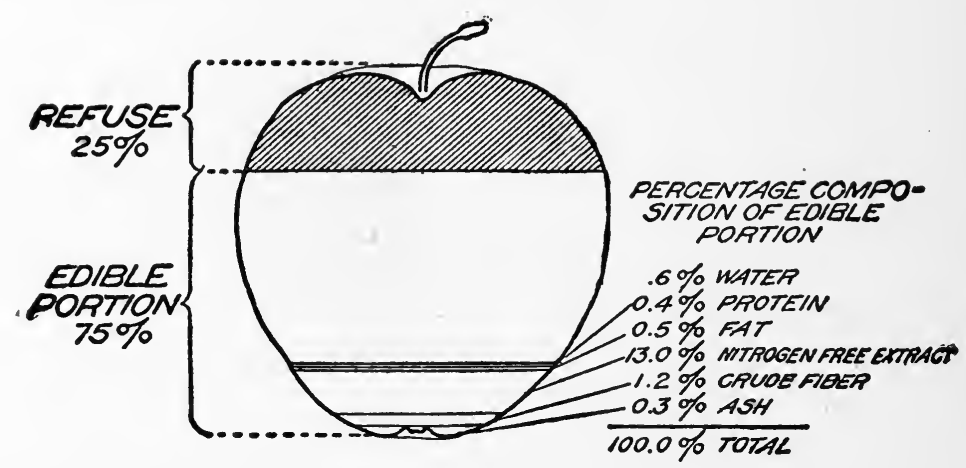

Fig. 42.-Composition of the Apple. (Bull. No. 293, U. S. Dept. Agric.)

Apples for dessert should be characterized by a firm, juicy pulp, piquant flavor, regular form and beautiful coloring. Such apples are the Baldwin, Banana, Bellflower, Ben Davis, Codlin, Faliawater, Hubbardston, None-Such, Greening, King Pippin, Northern Spy, Newtown Pippin, Winesap, Norton Melon, Spitzenburg, Roxbury, Russet, McCrosky and Opalescent apples, Red Astrachan, Yellow Bell Flower and others. Apples for cooking are characterized by the property of forming, by the aid of heat, a jelly-like mushy mass of even consistency, commonly termed apple-sauce.

Chemical Composition of Apples. - The pectin bodies contained in apples are substances which give the fruit juice the property of forming a thick mass or jelly, especially by boiling, in cooking, and often by continued exposure to sunlight. Pectin is present in nearly all fruits, although some are better adapted to jelly making than others. Fruits yield this gelatinous material best by being cooked with water. In the case of berries and very juicy fruits but little water is needed. Pectin is precipitated or thrown out of solution by such substances as alcohol, sugar, 
salt, etc. Therefore hard water should not be used in attempting to make jelly from raw fruit.

Peetin yields reducing sugurs, furfurol and mucic acid in varying quantities. It is now held by the l)epartment of Agriculture (Bulletin 49) that pectin bodies are produced by chemical treatment from a combination of simple carbohydrates. The apple is a much used and highly prized fruit. The dietetic value of apples is very great, especially as an antiscorbutic and laxative when taken on an empty stomach. The trophotherapentic value of this fruit in regulating the constipation of dyspeptics is very great.

Richards gives the following as the average composition of apples: Total solids, 13.65 per cent; ash, $0.28 s$ per cent; acidity expressed as sulphuric acid, 8.73 per cent; cane sugar, 1.5: per cent; crude fiber, 0.96 per cent. Sugar is the most valuable and abundant nutrient present.

Wirolesomeness of $\Lambda_{\text {pples. }}-\Lambda$ pples are a wholesome food either raw or cooked. They exert a mildly aperient action. Dyspeptics should not eat too freely of raw apples, but an abundance of cooked apples is not only pleasant but curative. Individuals of sedentary habits, whose livers are sluggish, will be benefited by the use of ripe apples, which will assist in eliminating noxious matters from the body.

Apple Cider.-Apple cider is a fermented liquor made from the juice of apples and is not inferior to some wines when due attention is paid to the selection of the fruit and its manufacture into eider. It contains the acids and salts of the fruit, the acidity being sometimes increased by the acetous fermentation.

THE PEAR.-The pear is a native of temperate Europe, Asia and Great Britain. All cultivated varieties are derived from the wild pear, with possibly some crossing with the snow pear-so called because it is eaten in the winter-of Austria and Italy. Of the numerous varieties, the most delectable are as follows: Bartlett, Bockworth, Flemish Beauty, Columbia, Kieffer, Lawrence, Manning, Mt. Vernon, Pound, Seckle, Tyson and Winter Nele's. Pears are not so commonly used for food as apples, because they are not so well adapted for cooking Gond ripe pears are a delicious dessert fruit. They are characterized by a saccharin aromatic juice, a soft, pearly, liquid pulp, which readily melts in the mouth in some varieties, principally the summer ones, but is firmer in most winter varieties. The Bartlett and Seckle varieties are especially adapted for canning.

Perry.-Perry is a strong fermented beverige similar to cider, made from the juice of pears. It contains about the same percentage of alcohol. 
In some parts of England pears are grown for this purpose and the beverage is equal to champagne cider.

QUINCE-Quince grows freely wherever apples grow. It was known to the ancient Greeks and Romans and formed an important element in their religious rites and civil ceremonies. It is mentioned by Pliny and Plutarch as a deterrent against evil influences. It was naturalized at an early period in Persia and in the countries surrounding the Mediterranean. There are several varieties of the fruit. It is a handsome yellow pome, a hard, austere fruit, and is not edible in the raw state, but is much used for preserving in marmalades or jelly form. The quince has a fine flavor, which is communicated to any other fruit with which it is cooked.

\section{DRUPACEOUS FRUITS}

Varieties of Drupaceous Fruits-THE PLUM.-The plum belongs to the drupe fruits, which have one or more stones or "pits" surrounded by an edible fleshy layer. Inside the stone or pit is a kernel which is also in some cases edible. There are about a dozen species of this fruit found in the north temperate zone of the globe. They are much used for tarts, jams and jellies. Plums are an agreeable, refreshing fruit containing about the same amount of nutriment as apples and pears; they are apt to cause diarrhea and should therefore be eaten sparingly by weak and delicate persons.

PRUNES.-Prunes are a variety of plums which are largely preserved by drying. They are ovoid in shape, their exterior black and wrinkled, their pulp brownish. They contain a purgative principle which makes them of value as an aperient. They are grown extensively in Spain, France, California and other fruit-growing countries. It is estimated that California produces $150,000,000$ pounds annually. The method of drying and preserving is outlined in the chapter on dehydration in Volume II.

Proper Method of Cooking Dried Fruits.-The proper way to cook prunes or other dried fruit is as follows: wash in warm water to remove any grit; drain; cover with cold water and allow to stand for twelve hours; let simmer slowly until cooked, but do not boil.

DAMSONS.-The damson is a species of prune, of which there are many varieties. It was introduced from Damascus. The fruit grows on a tree not unlike the sloe. It is small and oval, of finer quality than the ordinary plum, and has more astringency. The favorite American varieties are the 
bluish and dark purple damsons, which are excellent for preserves and marmalades.

THE PERSIMMON.-The persimmon (Dinspyros virginiana), or date plum, came originally from ('hina. 'The fruit is sucenlent and of a reddish yellow color when ripe. It contains eight or ten seeds. The green fruit is very astringent, but when ripened after frost it is sweet and palatable. The persimmon grows wild extensively, especially in the Southern states. A beer is made by fermenting the ripe fruit with dried apples and locusts. The American persimmon contains 14.5 per cent of sugars, of which 13.5 per cent is gluense and the rest cane sugar. The pulp of the wholly ripened fruit is sweet and has an inviting flavor. Many excellent varieties of large size are now produced from the American persimmon.

THE PEACH.-The peach is a drupe of the genus prunew, introduced into Europe from Persia. It is extensively eultivated in the semi-tropical regions of Europe, Africa and Asia and in many localities of the United States. The fruit is large and downy, with a kernel which contains a large proportion of amygdalin, which produces prussic acid. There are two sorts, one in which the flesh clings to the stone, and the other in which the ripened flesh freely leaves the stone. The Hlesh of the peach is well flavored, depending upon the presence of a small quantity of hydrocyanic acid and fruit ethers. As peaches ripen, the reducing sugars decrease in quantity while sucrose increases. It is well known that peaches picked before they are ripened and shipped to market in cold storage do not develop that fine peachy flavor which is found in peaches that reach maturity and ripen on the tree.

Peaches are regarded as among the most delicious and valuable of all orchard fruits, for eating raw, for evaporating, preserving or canning. Lemon and orange "clings" and Crawfords are the most popular varieties for canning purposes. The nectarine is a variety of peach having a smooth skin and a reasonably firm pulp. There are two varieties, "freestone" and "clings."

Peacir Braxdy.-Peach brandy is a delicious alcoholic beverage mado from fermented peach juice distilled. The product is very tasty and contains about 50 per cent absolute alcohol.

APRICOTS.-Apricots, of delicious flavor, are cultivated extensively in China, Japan, Syria and California. This fruit belongs to the peach family and grows readily in warm and temperate climates. It is supposed to have its origin in Armenia. It was introduced into England about the sixteenth century. Unlike the peach, the skin of the apricot is not downy. 
Analyses of ripe apricots show saccharose, 3.8 per cent; invert sugar, 2.25 per cent, and dextrose, 0.35 per cent.

THE CHERRY.-The cherry has been improved from the wild cherry of Great Britain and Europe. Its origin appears to have been in the Caucasus of Asia. It is said that when Lucullus returned to Rome after his victory over Mithridates in the province of Pontus, he brought with him to adorn the triumph of his victory a cherry tree laden with fruit. There are more than two hundred and fifty varieties of cherries, some sweet and some sour. This fruit is extensively grown for the market in the United States. Some of the sweet varieties, like the red heart, black heart, white heart and ox heart, are admirably adapted for eating, while the sour cherries, like the Morello, Montmorencies and Dukes, are used for canning and for pies, tarts, brandied cherries and for making "cherry bounce."

The Maraschiro Cherry.-The Maraschino, grown in Italy, is largely used to decorate salads and cocktails. This cherry is prepared by bleaching the fruit in a solution of salt, washing thoroughly and then saturating with sugar or glucose and dyeing red or any desired tint with coal tar dyes and preserving in alcohol. They are sometimes flavored with almond oil. Large quantities of Maraschino cherries are shipped packed in brine to the United States from the province of Dalmatia in Austria. They are processed in this country. No matter where treated, very littlo of the original acids remains in the processed product.

Cherry Brandy.-Cherry brandy is made by expressing the juice of ripe cherries and allowing it to undergo fermentation. It is then distilled, producing a brandy of piquant flavor and taste.

Cherry Bounce.- Cherry bounce is made from sugar and brandy in which cherries have been soaked. This concoction is a tasty, pleasing beverage.

Composition of Cherries.-Cherries are extensively cultivated in the most temperate climates of the earth. Their chief value lies in the fact that they are among the earliest fruit of the season. They contain cellulose, pectose, sugars, protein, acids, ethereal oils and salts and an unfermentable sugar sorbile. The cherry contains more than 20 per cent of solids, considerably more than apples, and 11 per cent of sugars. They are a most delicious, tasty fruit, raw or cooked.

\section{CITROUS FRUITS}

Description and Varieties of Citrous Fruits.-Citrous fruits include a number of botanical species, such as the orange, lemon, lime, mandarin, 
grapefruit, eitron and kumquat. These fruits were indigenous to China and Asia, but were introduced very arly into the countries surrounding the Mediterranean Sea and sulsequently into North America. These fruits are extensively grown in Sonthern California and Florida. They thrive where there is moisture and where the temperature does not fall below $18^{\circ} \mathrm{F}$ or go ahove $95^{\circ} \mathrm{F}$. These fruits are characterized by a thick peel or rind which is not edible, but is used for the production of a volatile oil. The principal acids of these fruits are citric acid $\left(\mathrm{C}_{6} \mathrm{H}_{8} \mathrm{O}_{7} \mathrm{H}_{2} \mathrm{O}\right)$, phosphoric acid $\left(\mathrm{H}_{3} \mathrm{PO}_{4}\right)$ and a little malic acid. The sugars, which are of both the cane and invert varieties, range from 1 to 10 per cent.

THE CITRON.-The citron is the fruit of the citron tree, a native of the warm parts of Asia. The fruit has nine loculi or cells forming a white pulp which is said to be less acid than the lemon. It is seldom eaten raw, being usually preserved. The rind is the part used for confectionery, for instance in crystallized fruit. The citron is thick and spongy and has a fragrant aroma and an inviting taste. This fruit should be distinguished from another fruit, or more properly a variety of watermelon of the same name, which also has a pulp used as a confection. The sweet citron is a hybrid product of the citron and the orange and is a very delicious fruit.

LIMES.-Limes grow in any region where the orange and lemon thrive. They are extensively cultivated in Italy, Florida and the West Indies. The fruit is oval, pale yellow and not suitable for eating. It is even sourer than the lemon. The principal varieties are: $(a)$ the sweet lime, cultivated in gardens; $(b)$ the lemon lime or sweet lemon, cultivated in Leguria; $(c)$ the bergamot lime, grown in Calabria. The juice is expressed and exported; the rind is very fragrant and yields an oil known as "essence of bergamot." Lime juice is not a medicine, but is valuable as an antiscorbutic.

THE LEMON.-The lemon is a native of India, but is cultivated in most warm countries, especially Italy, Spain, Sicily, Florida and California. There are many varieties. Those most in demand are: $(a)$ the Genoa lemon, oval in shape, skin thick and rough, with an abundance of sour juice; $(b)$ the lustrato, or thin-skinned lemon, having a smooth, fragrant rind, delicate pulp, acid juice but agreeable taste and fragrant aroma, grown to perfection only around Rome; $(c)$ the sweet lemon; (d) the citron lemon, having a pulp like an orange, a peel like a lemon, and a rough, warty exterior, grown in Florida and California. This last is one of the most delicate of citrous fruits.

Composition of the Lemon.-When the lemon is allowed to ripen 
on the tree it becomes coarse and of an inferior quality. The choicest fruit, therefore, is picked green when it reaches marketable size. The lemon contains less than one-half of one per cent sugar and over five per cent of citric acid, $\mathrm{H}_{3} \mathrm{C}_{6} \mathrm{H}_{5} \mathrm{O}_{7}$. It is characterized by an essential oil, which is abundantly found in the rather thick rind. The oil of lemon contains citral $\left(\mathrm{C}_{10} \mathrm{H}_{16} \mathrm{O}\right)$, nonylaldehyde, acetylaldehyde, citronal, dextrolimonene, cymen phellandrene and pinem(3). It is obtained by pressure of the fresh rind of ripe lemons by distilling it with water.

The acids of the lemon occur both free and combined with a base, usually potassium. On account of its composition, piquant acidity, low sugar content and the protection due to the hard rind of the fruit, it bears transportation and storage exceedingly well. The lemon is used the world over for flavoring, as a relish and for making cooling, refreshing beverages. Lemonade is an exceedingly piquant, pleasant, refreshing drink suitable for the use of people of a bilious temperament. The alkaline citrates of the juice enter the blood and undergo partial oxidation in the system into carbonic acid and water and partly to carbonates. Essence of lemon, a flavoring extract, is an alcoholic solution of the oil. The best fruit is gathered while still green after reaching a marketable size and allowed to ripen in open sheds. Lemons ripened on the trees are of a coarse quality.

THE ORANGE.-Oranges are cultivated in all the warm countries of the world, in tropical and subtropical islands and archipelagoes. The orange is a globular golden-yellow fruit divided into eight or ten loculi or cells, each filled with a juicy and delicious pulp made up of a mass of oblong vesicles, containing seeds. When ripened on the tree, the orange has an extremely juicy pulp, which is sufficiently tender to be eaten with a spoon. It is one of the most fragrant, delicious and palatable fruits provided by nature; it is not very nutritious, but has valuable antiscorbutic and other salutary properties. Oranges are useful in feverish conditions, illness or convalescence, when fruit is not entirely forbidden.

Composition of the Orange.-The orange contains from 5 to 10 per cent of sugar, a part of which is sucrose or invert sugar. The percentage of acid reckoned as citric acid varies from one to two per cent. The pulp contains about 85 per cent of water; the nutritive value, therefore, of the orange is not very high. It is a valuable fruit from a dietetic standpoint on account of its palatability, its mineral and organic salts and its general salutary influence on other food in the alimentary tract.

Tine Cinef Varieties of Oranges. - The chief varieties of oranges 
are the following: (a) Bitter Seville oranges, not very edible and used largely for marmalade; $(b)$ Sweet or China oranges, distinguished by a smooth, thin skin scarcely separable from the friit. They are the finest edible oranges, excelling all others by the delicacy of the flavor and perfume, and by an abundance of sugary juice; $(c)$ the Portugal orange has a deep color and inviting aroma; $(d)$ the navel orange is a large rounded oval fruit, receiving its appellation from its characteristic appearance. They are sweet, delicions and much prized. The navel orange is grown in the United States, Brazil and other countries; $(e)$ the blood orange is the product of an orange tree grafted upon a pomegranate tree and is characterized by a change in color during ripening. Streaks of red appear in the flesh as the frnit reaches maturity. This grows deeper in color until, when well ripened, the whole fruit, including the skin, is influenced by the coloring; $(f)$ the tangerine orange is a small flat, highly perfumed fruit with agreeably flavored flesh; $(g)$ the Mandarin orange, grown in Italy, Spain and Algeria, has a sweet and edible rind which is often easily separated from the fruit. It is red withont and within and has a fine perfume. The Japanese or Satsuma orange is similar to the Mandarin and tangerine oranges.

The Kumquat. - The kumquat is a dwarf orange about the size of a large plum. The pulp is agreeably acid and the skin aromatic. It is a native of China, but is grown in many other countries.

GRAPEFRUIT AND SHADDOCK.-The grapefruit and shaddock are the largest fruits of the citrus family. They are natives of Southern China and are very popular in the United States. According to some authorities the grapefruit and shaddock are two different varieties or species of citrus. The shaddock, named after Captain Shaddock, who introduced it into England, is the larger of the two. It often weighs ten or twelve pounds. The grapefruit is smaller and has a finer flavor. Grapefruit is now grown extensively in California, Florida and Cuba, and the Isle of Pines. The fruit is more sour than the orange but less sour than the lemon. The Cuban fruit is less acid and devoid of the bitterness which to some extent characterizes the Californian and other varieties. It has come to be regarded as a valuable addition to the American breakfast menu.

\section{MORACEOUS FRUITS}

Varieties of Moraceous Fruits-THF FIG.-The fig, the fruit of the Natural Order of Moracea, is quite different in nature from the apple, orange or other seed-bearing fruit. It has a large receptacle containing 
numerous very small flowers. The ripe carpels, which are called seeds, are imbedded in a saccharated pulp. They are eaten green, while they are fresh, or dried. Figs are very nutritious(4).

The fig has been cultivated from the remotest antiquity, as shown by ancient historic and sacred writings. It is mentioned in the Iliad as growing near Troy, and the sweet fig is mentioned in the Odyssey. Romulus and Remus according to tradition were nursed at the foot of a fig tree. The fig grows chiefly over vast areas of Syria and Persia. There are numerous species, but the most noted is the common fig. This is a native of Persia and adjacent countries.. The quality of preservation by means of drying early revealed its importance as a storage food of great value. It is very prolific, producing three crops each season in the Levant and in

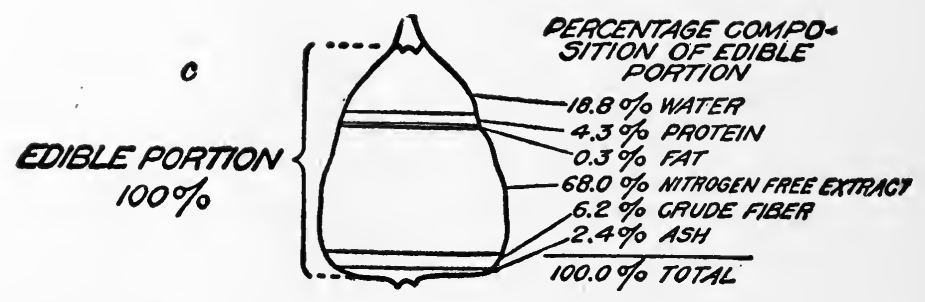

Fig. 43.-Composition of the Fig. (Bull. No. 293, U. S. Dept. Agric.)

Spain. A fig tree in its prime will produce from 100 to 200 pounds of figs at a bearing. The fruit grows to perfection in some southern states and in lower California.

Fertilization of the Fig.-The male and female flowers of the fig grow upon separate trees. Fertilization is brought about by means of insects, notably by the fig wasps. The process is called caprification and has been studied alike by botanists and by entymologists. To fertilize the blossoms of the cultivated fig it is customary in eastern countries to hang upon the fig trees branches of the wild fig-bearing fruit or capri figs. It has been observed that only by so doing can the cultivated fruit reach perfection in development and flavor.

Botanists have found that capri figs or wild goat figs contain the male flowers, while the cultivated figs contain only female flowers. The flowers of the wild fig contain numerous eggs of the fig wasp. This insect when it has escaped from the staminate or male flower with her body covered with pollen, instinctively seeks a place for laying her eggs and finding the Smyrna figs near by, forces her way into the flower-bearing receptacle and thus fertilizes the pistillate flowers-that is, the wasp 
earries the pollen from the male to the female flowers and thereby secures fertilization.

Nutrimext of Drien axn Flisin Fins.-Fresh green figs are a wholesome and agreable fruit. Dried figs are nutritive by virtue of 60 to 70 per cent of sugar. They contain pectoral and have demulcent and laxative properties. If eaten in excess they canse pain, flatulence and diarrhea. As a source of heat and energy they have a very high fuel equivalent. One pound of figs will produce 1,455 heat units or calories of energy. Weight for weight, figs contain more nutrient properties than bread. One-half pint of milk and six ounces of figs make a good meal.

THE MULBERRY-The mulberry consists of a collection of small drupes. It was introduced into England alout the sixteenth century and is now cultivated in most countries of Europe, Asia and America. The fruit is agrceable and succulent. It has a characteristic flavor, is cooling and laxative. The tree is cultivated chiefly for its green leaves, as a food for silkworms. A wine is made from the juice and a vinegar from the wine. The fruit is of a deep red color, has a sweet flavor and piquant acidity. Mulberry and apple juice combined make a cider of port wine color.

BREAD FRUIT.-Bread fruit is a large spurious fruit or sorosis (covered with hooks) like the pineapple. It consists of a somewhat rounded fleshy mass six inches or more in diameter, greenish in color, and contains a white fibrous pulp which becomes yellow and succulent during maturation. The taste of the pulp is somewhat similar to the cabbage. It is roasted before being eaten or made into bread. It is indigenous to Java and Ceylon, whose natives make farorite dishes from it. It has been cultivated from great antiquity. There are many varieties. Bread fruit forms the principal foodstulf of the Malay and South Sea Islands.

\section{ANONACEOUS FRUITS}

Varieties of Anonaceous Fruits-THE SOUR APPLE-The sour apple or sour sop is grown abundantly in Jamaica. It is a large conical or podlike fruit from five to twelve inches long, about two-thirds as broad, tapering at the top to a rounded point. The pod may weigh as much as two pounds. It has a thick greenish-yellow skin, covered with hooks (sorosis). A fibrous core runs through the center surrounded with a white pulp, which is pleasantly acid. It is used for making preserves and bererages, The trees grow wild in the West Indies and South America. 
THE CUSTARD APPLE.- The custard apple is a native of the West Indies, but grows in all tropical countries. It is called bullock's heart in the East Indies. The fruit is the size of a tennis ball, spherical and of a greenish or dark brown color. The peculiarity of the fruit is that the edible pulp forming almost the entire mass is of the consistency of a custard. The pulp tastes like clotted cream and sugar and has a pleasing odor simulating rose water. It surrounds a black seed and the whole is enclosed within a tough skin. It is delicious eaten raw.

SUGAR APPLE.-The sugar apple is a West Indian fruit closely allied to the custard apple. It is heart shaped or ovoid, greenish yellow in color, covered with scales like the pineapple, and has a thick, sweet, luscious pulp. It is also called "sweet sop," and in British Indies "custard apple."

THE PAWPAW.-Pawpaw fruit grows on small trees throughout the eentral United States. In size it resembles a large pear. The pulp has an odor and taste simulating bananas. The pawpaw has not been received with favor as a fruit on account of its peculiar taste. The pulp which surrounds the numerous large seeds is mucilaginous in character. This variety of pawpaw is an entirely different fruit from the tropical fruit of the same name.

THE PAPAW.-The papaw is a native of Central Ameriea and of the East and West Indies. There are male and female papaw trees. The fruit grows on the female tree and reaches the size of a large muskmelon, deep green in color, becoming red as it ripens. The fruit consists of a soft yellow, sweet pulp, which contains numerous black seeds. The ripened fruit has a peculiar flavor. Papaw is eaten raw with salt or boiled as a regetable. When mixed with lime juice it has a flavor resembling apples and is much used as a substitute for them. The juice of the unripe fruit is of a milky acrid character and acts as an efficient vermifuge. The juice also exerts an emmenagogue action, therefore neither the fruit nor the juice can be safely taken by pregnant women. The juice of the leaves contains fibrin, which, with this exception, is only found in the animal kingdom and in certain fungi. It also contains a proteolytic enzyme, papain, which exerts a powerful influence upon proteins. The fruit or its active principle promises to have a wide sphere of usefulness.

Papaw Action on Tough Meats.-An infusion of the leaves will render tender the toughest meats. A gentleman residing in Nueva Gerona, Isle of Pines, West Indies, states that boiling fresh killed beef in water with some of the infusion of papaw leaves will render it very tender in a short while. He also says that an old fowl killed and hung to the limb of a papaw tree overnight will become as tender as a freshly killed young 
capon. The same effect may be obtained by wrapping the dressed fowl or cut of meat in the leaves of the tree. 'The dried extract of the leaves, called papayotin, is used commercially in the prepartion of meat extracts and other prepared foods. This cxtract as well as the fresh fruit is useful in the treatment of gastric disorders, ulcers of tho stomach and duodenum, atony and other disorder's of the gastric mucosa.

\section{MYRTACEOUS FRUITS}

Varieties of Myrtaceous Fruits-THE GUAVA,-The guava is a native of America, growing wild in the West Indies and Central America. There are several varieties. The fruit of the two prineipal ones resembles an apple or pear in shape. 'The common or white guava is a pear-shaped fruit about the size of a temis ball, with a russet colored rind. 'The fruit grows on a small tree of the N. O. Myrtacee. The pulp is pink or white and of a sweet agreeable flavor. The red guava is apple shaped, the pulp is yellowish red, very acid, and is inferior to the white variety. The grava is not eaten raw, but as a jelly. As a marmalade it has a unique flavor. The composition of guava is 20 per cent solid material, including 1 per cent protein; the remainder is ehiefly invert sugar and organic acids.

THE ROSE APPLE--The rose apple is cultivated in the East Indies and all tropical countries for its fruit, which is of the size and shape of a small pear, rose scented and tasting like an apricot. There are several varieties.

THE SURINAM CHERRY.-The Surinam cherry, sometimes called the Barbadoes cherry, is a red fruit the size of a drupe cherry and has an abundant sweet and agreeable juice.

\section{SAPOTACEOUS FRUITS}

Sapotaceous Fruits - THE SAPODILLA-The sapodilla is a drupaceons plant of the West Indies, Central Ameriea and Cuba. It is one of the best tropical fruits of the order of Sapotacece. It is a small brown or greenish fruit resembling in size and shape a bergamot pear. It weighs about two ounces, has a sweet characteristic odor and a soft core which contains five or six brown seeds. "A fully ripened sapodilla," says Discourtalz, "is melting and has the sweet perfume of honey, jasmine and lily of the valley." They are eaten raw and preserved. The fruit is sweeter than the eustard apple. It is about five inches long, covered by a rusty colored skin. The pulp is rery agreeable.

THE MAMMEE SAPOTA.-The Mammee sapota is a native of the West Indies and South Ameriea. It eontains a thick agreeable pulp having the 
flavor and appearance of quince marmalade. The pulp surrounds a single seed, one side of which is attached to the flesh, while the other side is free, smooth and highly polished. The fruit is about five inches long and has a rusty, greenish colored skin.

THE STAR APPLE.-The star apple is a large purple or rose colored drupe of the N. O. Sapotacece. The interior consists of an outer purple portion which is fibrous and not edible. The inner portion is white and glutinous and divided into ten compartments, each containing a seed enclosed in a gelatinous pulp of characteristic flavor.

\section{ANACARDIACEOUS FRUITS}

Varieties of Anacardiaceous Fruits - THE MANGO FRUIT.-Mango fruit is a native of Asia, held in high esteem in tropical climates and cultivated in all Oriental countries. The fruit is flat or kidney shaped, reddish brown or like an apricot in color. It is about the size of an apple and has a most agreeable juice. The mango cuts like an apple but is much more agreeable; the pulp has a pleasant acid taste and sweet, aromatic perfume. It is eaten raw, cooked in pies or tarts, in preserves, jelly and chutney. It is a very welcome addition to the dietary during the summer. The mango is held sacred in India and references to it are interwoven in their folklore writings.

Mango Chutney.-Mango chutney is a well-known sauce imported from India. The mango is now successfully grown in Florida.

\section{EBENACEOUS FRUITS}

Varieties of Ebenaceous Fruits-THE PERSIMMON.-The persimmon or date plum is the fruit of the N. O. Ebenacece. The Japanese variety is the most highly prized, reaching a size of from two to three inches in diameter. It is the most esteemed fruit of the Japanese Empire. There are many varieties grown in China, Japan and India. The Japanese ripen persimmons artificially by placing them in casks, from eight to fifteen days, from which the native beer called saki has been emptied. Persimmons are dried like figs and exported in large quantities from China and Japan. The Japanese persimmon is like a vellow plum in appearancè. When ripened it has a soft, gelatinous pulpy flesh. The American persimmon, according to Atwater, contains 14.5 per cent sugars. The fruit also contains both malic and tannic acids. 


\section{LEGUMINOUS FRUITS}

Varieties of Leguminous Fruits-THE TAMARIND.-The tamarind is the fruit of the N. O. Leguminosee. It is a pod of a leguminous tree, of from one to six inches long, dark brown color, a thin, brittle exterior when dry, and contains a dark, fleshy pulp which is used for both food and medicine. Tamarinds are preserved by placing them in jars with layers of sugar between them, or by pouring boiling syrup over the ripe fruit. They are laxative and refrigerant; an infusion is grateful to patients suffering from fevers and inflammation. The fruit has a sweetish, sour taste. It is said to contain more sugar than the sweetest fruit and more acid than the sourest. Analysis shows 85 per cent solids, 40 per cent reducing sugar and 15 per cent acids.

ST. JOHN'S BREAD.-CSt. John's bread, sometimes called locusts or carob beans, comes originally from Syria and the shores of the Mediterranean. The fruit grows on a large tree of the N. O. Leguminosece. In America the tree sometimes attains an enormous size, three feet in diameter and from sixty to seventy feet in height. The pods sometimes grow ten or twelve inches in length, having as many seeds. When ripe-after frost has bitten them-the seeds are surrounded by a sweet mucilaginous mass of honey-like substance having a pleasing acrid, piquant taste. Tho dried pod contains 50 per cent sugar. Its generic name is derived from John Robin, who introduced it into France about the year 1600. It is much prized as a food for man and beasts in the hotter countries. Its cultivation began in historic times. The Greeks knew and appreciated its food value. The pods of the honey locust are eaten raw and sold in confectioner's shops. A delightful beverage, locust beer, is made by breaking up the dried pods, adding dried American persimmons and dried apples, placing the whole in a barrel and pouring boiling water on the mass and allowing it to undergo fermentation. When three or four days have elapsed, a beautiful port wine colored "beer" is produced, possessing an alluring piquant taste with some "kick" in it.

\section{PALMACEOUS FRUITS}

Varieties of Palmaceous Fruits-DATES-Dates grow in abundance in the region between the Euphrates and the Nile. In Babylonian times, in the fifth century B.C., Herodotus mentions "the dates of Babylon," and Egyptian monuments contain drawings of the fruit and of the tree. The fruit is grown extensively in all Oriental countries. The Persian Gulf region is the center of the date-growing industry of the world. There are said to be no less than $20,000,000$ date-bearing palms in this territory. 
There are many varieties of date trees. It is said that date trees are sometimes prolific for 200 years. The tree is diøcious, i.e., the male and female flowers, the pistillate and staminate, like those of the fig tree, grow on different trees and fertilization is brought about by means of pollen-bearing insects and currents of air. In some countries the growers plant one male tree to every thirty female trees. In times of war, the Arabs destroy the male trees in the enemy territory, in order to cause date famine. The fruit is gathered just before it is ripe, dried in the sun or in ovens, and carefully packed. Dates should be washed before eating, as the Arabs who gather the fruit are not a very cleanly race. The fruit forms an important article of food in the country where it is cultivated and is a considerable source of income to growers. Dates are a wholesome and nutritious fruit. When dried without the pits, they contain about 7 per cent protein, 54 per cent sugar, as levulose, dextrose and some sucrose, and 11 per cent of pectose and gum. It is claimed that half a pound of dates and a half a pint of milk will make a sufficient meal for a person of sedentary habits.

Date Palm Wine.-The date palm is extensively cultivated by the Hindoos for the sap, from which they make palm wine or joggery wine. Each tree is said to yield one hundred and eighty pints of sap, twelve pints of which produce one pint of joggery; four pints of joggery yield one pound of good brown sugar, so that from the annual sap yield about seven pounds of sugar is produced. The palm wine when distilled yields a spirit called tody. The fruit is a source of sugar, honey, spirits and vinegar. The unopened fresh leaf buds are a tender succulent vegetable, which may be prepared and eaten like cabbage.

COCOANUTS.-Cocoanuts are the fruit of the cocoanut palm, grown largely in the East and West Indies, Indo-China, China and Japan. This fruit is a staple food product for the inhabitants in countries where it is grown. Without it the Pacific Islands would be uninhabitable and the natives would die of hunger and thirst. The fleshy part of the fruit is white and tasty, nutritious and wholesome. As the fruit reaches maturity the flesh hardens from the circumference towards the center, and on the inside is the milk which is used like cow's milk. It is a pleasant beverage, milky, sweet and slightly acidulous. For analysis of the component parts of the nut see Volume I, Chapter XIX.

\section{MISCELLANEOUS TREE FRUITS}

OLIVES-Olives are mentioned in the earliest Hebrew writings as one of the trees of the land of Canaan. The Bible records the return of the 
dove bringing an olive branch to Noah in the Ark. The olive is believed to have come originally from Asia. It has been naturalized in Spain, Italy, France, Greece, ('alifornia, C'entral and South America, where it is an important source of income. The tree is a small gnarled evergreen, of which there are numerous varieties, long leared and short leaved. The finest oil is produced from the long leaved variety. The edible olive is picked while young and placed in lye 1 to 2 per cent for some hours, which removes the bitter taste; they are then soaked and washed in fresh water several times, pickled in brines of varying but increasing strength, and finally packed in sterilized brine for shipment. Ripe olives are of more value for food purposes; the green olives for pickles and relishes. The olive contains one of the chief principles of food which the average vegetarian diet lacks-fat-for which they are extremely valuable. Ripe olives are of a purplish black tint. They are wholesome, readily digested, slightly laxative and highly nutritious.

POMEgRaNATE.-Pomegranate fruit is one of the earliest known in the history of the world. It is indigenous to Persia and is grown throughout tropical countries. Mention is made of it in ancient religious and mythological writings. It has been cultivated from time immemorial. It was known to the Greeks of Homeric times and entered into the ceremonies of the ancient Romans. The cultivated varieties, which are scarcely thorny, have coral red wax-like terminal flowers.

The fruit is as large as an orange, with a leathery-like, yellow-tinted, rosy skin. Each of the many seeds is enclosed in a sweet or sub-acid, separate, reddish, edible pulp, surrounded by a thin membrane. The pulp when macerated, mixed with water and honey or sugar, makes a delicions cooling, acidulous beverage. The South Americans macerate the pulp and by a process of fermentation produce a wine called "Aguardiente," which is quite intoxicating. The rind is also used for tanning moroceo leather. The expressed pomegranate juice contains 13.6 per cent sugar and 0.51 per cent of organic acids.

THE ALLIGATOR PEAR.- The alligator pear, or avocado pear, is a fruit of the N. O. Lauracece. It is a native of Mexico and is eultivated in the West Indies and tropical America. It is a pear shaped fruit from four to six inches long, of a green or brownish color, weighing from one to two pounds. It is highly prized as a salad fruit. The pulp, which is of a yellow, buttery consistency, is dipped out with a sponn and is eaten with salt, vinegar and other condiments. It may also be prepared as a soup, to which it imparts an agrecable odor. The fruit is rich in fat, 10 to 20 per cent, and has a starch and sugar content of 6.5 per cent. 
MAMnEe APPLE.-The Mammee apple is grown extensively in South America, Cuba, West Indies, as well as in the United States, where it is highly esteemed. It is a large fruit of a baccate character, two to nine inches in diameter, weighing from eight to twenty ounces. It has an outer brownish yellow, leathery rind and a thinner internal rind closely covering the flesh. The flesh of the Mammee apple is firm, bright yellow, with a sweet aromatic perfume, an acidulous sweetish juice in abundance, a peculiar piquant taste. It can be eaten raw, but is principally used for preserves and marmalades.

\section{AMPELIDACEOUS OR VINE FRUITS}

Varieties of Ampelidaceous Fruits-GRAPES-Grape vines are found growing wild throughout the temperate and parts of the torrid zone of both hemispheres. From these the cultivated varieties of the present day have been propagated. The cultivation of the grape and the making of wine are of the most remote antiquity, as appears from the scripture history of Noah and other Bible characters and from many passages of the most ancient authors, for example, Virgil and Columelia. The grape was probably introduced into the south of France and into Italy by the Phœnicians about 600 years B.c.

There are many varieties of grapes indigenous to America, particularly the Scuppernong, the Catawba, the Isabella, the Concord and the Fox grape, which are all described by the historian of Sir Walter Raleigh's voyages to Carolina in 1584 .

During Colonial times many attempts were made to grow European varieties of grapes in the United States, but the experiment was not a success, owing to various pests and to certain mildews which did not affect the hardy native vines but which infested the foreign importation. The European grapes have a higher sugar content than the American species and are better adapted for wine making, especially champagnes. They. also keep better and make better raisins. The American table grapes, however, are more refreshing and make a better unfermented drink than the imported varieties.

As a fruit, grapes are delicious, nourishing and fattening; in large quantities they are diuretic and of value in the dietetic treatment of constipation and some gastric disorders. The grape cure (see Volume.II, Chapter XVI, on "Cures") consists of eating many pounds of grapes daily. The value of grapes is due especially to the large proportion of sugar. In certain wasting diseases care must be exercised not to eat too freely, 
or diarrhea may be produced, which wonld hasten the end. Sweet grapes, when they do not purge, are excedingly valuable as a food and exert a curative action in bronchitis, gastric and intestinal atony. Even in Bright's disease they may, with favorable climatic conditions, contribute to a restoration of health.

Composition of Grapes.-Grapes contain from 12 to 25 per cent sugar, about 2 per cent non-nitrogenous and 0.6 per cent nitrogenous matter, besides gum and mucus, with salts, chiefly hydropotassic tartrate or "cream of tartar" phosphates, sulphates and chlorids of calcium, magnesium, sodium and potassimn, and traces of iron, aluminium and silica. The acidity of the grape is due to tartaric and malic acids, and depends somewhat upon the period of development and upon the seasons, whether it be good or bad. As ripening proceeds, the malic acid disappears. The sugar of grapes (see analysis, Volume I, Chapter XIX) consists of dextrose or glucose, 12 to 25 per cent, besides levulose or invert sugar and malic and tartaric acid.

Utilization of Grapes.-Grapes are principally utilized in some one of the following ways: (a) for eating; (b) for making raisins; $(c)$ for making grape juice; $(d)$ for making wine; $(e)$ for making brandy. The fruit is readily and safely shipped over long distances if carefully packed in small baskets.

Raisixs.-Raisins are the dried fruit of many varieties of the grape. They are principally produced in Southern Europe, France, Spain, Italy, Greece, Turkey and California. They are sold under various names, as Muscatels, or raisins dried on the vines, which include Malaga and varieties of muscatels and Valencias, or dipped raisins, which include Lexias and Denias from Turkey and California raisins. The Sultana raisins are made from the small seedless grapes of Greece, Turkey and Persia.

In the process of drying the genuine muscatels, ripe white Malagas are used. The stem is partially cut or twisted, to interfere with the circulation of the vine sap, and the fruit is allowed to hang on the vine and dry. The raisins are then ready to pack for shipment withont further treatment. "Dipped" raisins are prepared in the following way: ripe grapes, with the stems twisted, are allowed to hang on the vines for a day to facilitate evaporation. They are then pulled and dried in the sun for another day, rinsed in water and dried in the sun for twenty-four hours; then they are dipped in boiling potash lye, flarored with rosemary and lavender, and covered with a laver of olive oil. This treatment sterilizes the fruit and shortens the period for drying the grape, which is accomplished by exposing them to the sun with frequent turning. When dry they are 
piled in heaps to "sweat." This softens the skins and distributes the moisture more evenly.

Currants.-Currants are the dried fruit of the small black Corinth grape, grown in the Levant and Morea. The grapes are small, round, thick-skinned and seedless. They are plucked when slightly overripe, dried in the sun, afterwards removed from the stalks, cleaned and packed. Currants contain two and one-fourth per cent malic acid and six and seven-tenths per cent of sugar. A wine is made by fermenting the juice and is a very useful beverage in fevers and inflammations.

The important constituents of raisins and currants are sugars-dextrose and levulose -and potassium acid tartrate in the pulp, tannin and fixed oil in the seeds. Raisins and currants are used largely in cooking. Their chief value is in the carbohydrates they contain. They are also a convenient food for pedestrians and travelers, who have long held them in high esteem. Of small compass, they are easily carried and contain much sustaining nutriment. In addition to their demulcent properties they prevent excessive thirst. These fruits possess the protein-sparing properties of carbohydrates. They are demulcent, balsamic and inerease the flow of urine, diminishing the excretion of urea and uric acid. They slightly stimulate the hepatic function and promote the flow of bile.

\section{PASSIFLOREOUS FRUITS}

The granadilla or Passiflora edulis is the fruit of the sweet calabash or apple fruited granadilla. When eaten with wine and sugar, the pulp is agreeable. The common granadilla has a purple pulp which is also very agreeably pleasing to the palate.

\section{SMALL BUSH BERRIES (5)}

Berries consist of a mass of small seeds surrounded by a pulp which is often quite watery, as in the raspberry, although sometimes firm, as in the gooseberry. The juice of berries consists principally of sugars, pectin, mineral salts, acids and flavoring ethers which are frequently highly colored. The pulp is the principal portion of the berry, since the small seeds have no food value. Berries act as an irritant to the alimentary tract and are a frequent cause of constipation when consumed too freely. There is no great improvement in the cultivated over the wild varieties.

Varieties of Berries-THE WHORTLEBERRY.-The whortleberry, blueberry or bilberry, is found growing wild throughout the north temperate 
zone on bushes from one to three feet in height. There are many varieties of related shrubs bearing these berrice, but they are rarely cultivated. The fruits are subacid, moderately astringent, and contain mucilage, sugar, malic and citric acids and an astringent substance which exereises a tonic effect. These berries grow in immense quantities on waste lands all over the Northern United States and in Canada, where they are gathered by the native berry "pickers." 'The fruit bears shipping to distant cities. Some varieties are large and juicy and very palatable. It contains from 76 to 89 per cent of water; 5 per cent sugar; some pectin and from 1 to 1.6 per cent of malic and citric acid.

HUCKLEBERRIES.-Huckleberries may with eare be dried for winter use. They may also be preserved by camning. Some varieties make excellent jellies and jam. Huckleberries are also highly prized for making pies. The big blue huckleherry is similar in composition to the whortleberry; it is larger and less juicy, but not so agreeable nor wholesome.

SERVICE BERRY.-The service berry, also known as the June berry or shad berry, varies in color from red to black. It grows on a medium size tree in the eastern United States as far south as Florida. The service berry is sometimes eaten raw, sometimes used in making sauces. The fruit is largely consumed by birds and squirrels.

ELDERBERRIES,-Elderberries are drupe fruits of the Sambucus Niger. They are chiefly used for making cordials and the "elderberry wine" used in adulterating port wine. The ripe berries are sometimes made into pies.

BARBERRY.-The barberry, of which there are many species, grows wild all over the north temperate zone, in the Andes of South America, and along the Atlantic Coast. The shrub is cultivated chiefly for ornamental purposes. It bears an elongated, red, acid berry, utilized in making pickles and preserves. The fruit possesses astringent properties, an inviting, pleasing taste, grateful and refreshing to the palate.

BLACKBERRY.-The blackberry is borne on second year twigs which spring from the roots of the common bramble briars, growing luxuriantly in wild hedgerows. The cultivated berry is a great improvement over the wild variety, both in size and appearance, but not always in flavor or sweetness. The berries when matured are red, turning black when fully ripened. They are used for making pies, jams, jellies, preserves and wine. They are also dried for winter use. The fresh berries are canned.

Blackberry wine is produced by the fermentation of the berry macerated with sugar. Blackberry brandy is manufactured by distilling the wine. Blackberry cordial is the juice strained and preserved by the addi- 
tion of whiskey or brandy. All three products are of value from a dietetic standpoint.

THE RASPBERRY.-The raspberry is a native of Great Britain and Europe. It grows on a tall, slender briar or bramble thoughout the northern United States from the Atlantic to the Rocky Mountains. It is much improved by cultivation. It has a delicate and agreeable flavor. The two varieties are the red and the white. They contain 0.53 per cent nitrogenous matter; 4 per cent sugar; 1.50 per cent other nitrogenous substances; 1.38 per cent of free acid, and organic salts. They are not as nutritious as strawberries or blackberries. Raspberries are used in cooking and confectionery. Various liqueurs and cordials are made from the juice. The fruit is also used to make raspberry vinegar. They are useful in relaxed conditions of the bowels.

THE CLOUDBERRY,-The cloudberry is a yellow raspberry, and its active principle is diuretic. It has a sub-acid taste somewhat like that of the tamarind. It grows wild on the Atlantic coast, and is cultivated in the interior.

LOGANBERRIES.-Loganberries are the product of a hybridization of the blackberry and raspberry briar and are now cultivated. Some of the fruit is very fine, superior in flavor and taste to either the blackberry or the raspberry. The fruit is large, luscious and reddish black in color. This berry grows very luxuriantly in some of the Western states, more particularly in Montana.

DEWBERRIES.-Dewberries grow wild on a running briar in the southern portion of the United States. They are large succulent drupes, black in color, and covered with a bluish bloom of dew-like appearance. The fruit is sweet but more acidulous than the blackberry, and possesses astringent and tonic properties. Many species are cultivated in the United States. The fruit juice when fermented with sugar makes an excellent wine of some dietetic value. The fresh berries are much prized for pies, tarts, jellies and jams.

THE ROEBUCK BERRY.-The roebuck berry is an edible fruit found in Great Britain, but more abundantly in Russia. It is also an important fruit in Norway, where it is held in high esteem. In Stockholm it is prized as a dainty of the rarest and most delicate kind. In Russia the inhabitants eat the fruit and also make a wine and a distilled spirit from it.

THE GOOSEBERRY.-The gooseberry grows wild in Europe and America. It has been much improved by cultivation. Some of the cultivated 
berries now grow very large. There are many varieties, differing from one another only in size, color and hardiness. 'The American variety of the cultivated fruit is smooth. The gooseberry is sometimes eaten raw, but is more commonly used for making jam, either alone or mixed with other fruit. It contains very little protein and consists largely of invert sugar. Its abundant pectose and acid make it valuable for many culinary purposes. In the process of boiling, all the cane sugar is inverted by the acid present, so it is found as invert sugar in the jam. Gooseberries are a wholesome, agreeable fruit. They are in season when other fruits are scarce.

CURRANTS.-Currants are the fruit of a small shrub tree which grows best in temperate climates in a strong, moist, loamy soil with a northern exposure or partial shade. It has been cultivated from the middle ages and the fruit is used for puddings, pies, wine and jelly. Currant wine made from the fresh berries is a refreshing drink, useful in fevers and inflammations. There are two varieties, red and black. The black wine is better than the red.

The composition of currants includes 6.5 per cent sugars; 0.9 per cent of other non-nitrogenous constituents; 2.25 per cent of free aeid; 4.5 per cent pectose, cellulose and seeds, and .75 per cent salts. The black currant is valuable on account of its medicinal properties. It is diaphoretic and soothing to inflamed mucous surfaces and quenches thirst.

STRAWBERRIES.-The strawberry, unlike most berries, is in reality a sycon, or receptacle, which bears the achenes, or true fruit, upon its outer surface. As it ripens it becomes succulent and its outer surface is beautified with a variety of pleasing tints, varying from a searcely perceptible pink to a blushing dark red. It grows wild over a large area of the semitropical regions of Europe, Asia and America. Its cultivation began in the fifteenth century. The finest cultivated fruit today is a cross between the common Virginia and Chili strawberries. The plant is propagated by "runners," which readily take root. Some varieties are propagated by seeds. The plant requires careful enltivation and is usually mulched with straw before the buds start. Though much eare has been taken to increase the size and improve the appearance of the native strawberry by eultivation, the aroma and flavor of the wild strawberry are superior. The Carolina strawberry was introdueed into English gardens in 1629.

Strawberries contain 90.4 per cent water: 1 per cent protein: 7.4 per eent sugar; 1.4 per cent pectose, and 1.4 per cent of acids, prineipally. malic. The berry is highly esteemed not only for eating as a dessert, but for making jams and preserves. The fresh fruit is most agreeable to 
invalids and convalescents. It is cooling, diuretic and laxative, and is thought to be helpful in gout and in rheumatic affections.

CRANBERRIES.-Cranberries grow in mountainous regions, in peat bogs and in swampy areas in Europe and America. The fruit grows on a low bushy vine, some varieties near the seashore, others in uplands and on mountain tops. The fruit is about double the size of a currant, of a crimson red color, and contains a very acid juice. Analysis shows its composition to be as follows: 2.34 per cent free acids, principally malic and sulphuric, including 0.05 per cent benzoic acid. A liberal amount of pectose makes the cranberry of value in making tarts, jams, jelly, and particularly as a sauce for meats and poultry.

\section{HERB-LIKE FRUITS}

Varieties of Herb-like Fruits-BANANAS.-Bananas, of which there are several varieties, were known and appreciated by the ancient Greeks, Romans and Arabs. They are not mentioned by the Egyptians or He-

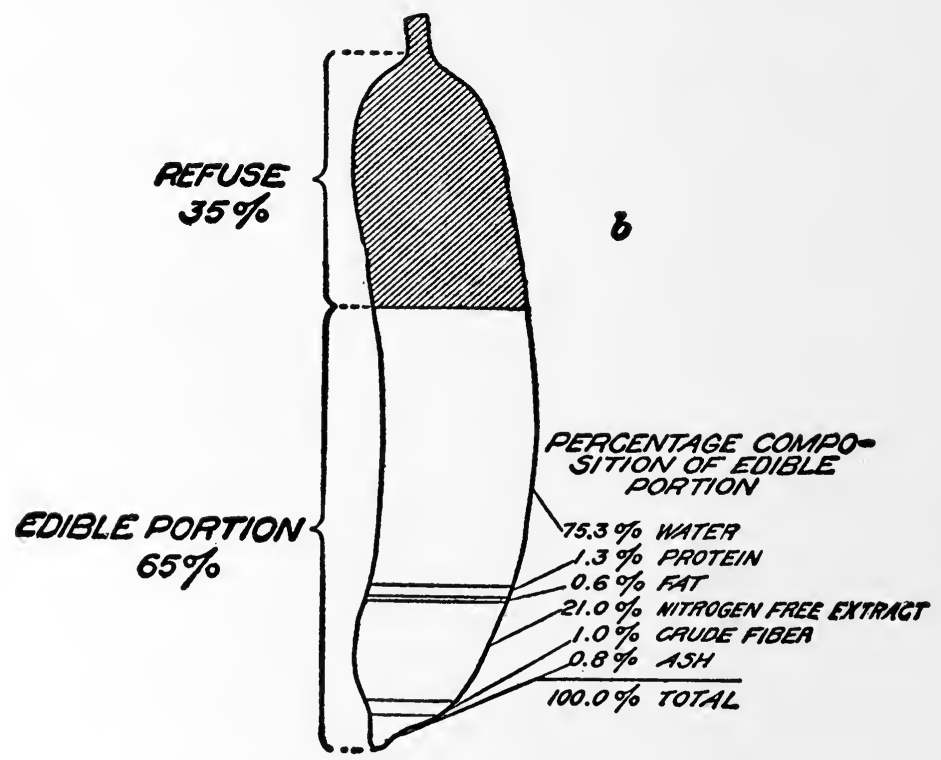

Fig. 44.-Composition of the Banana. (Bull. No. 293, U. S. Dept. Agric.)

brews. The banana is believed to have had its origin in Asia, and from there to have been introduced into America and the East and West Indies. The plants are herbaceous perennials or biennials, which die down after 
fruitage, after which new stalks spring 11 from the old parent roots. The fruit is a herry, withont an endosperm, but has a large perisperm. It is gathered before the fruit is ripe. The plant is a marvel of productiveness; often as many as two hundred bananas grow in one bunch. It is estimated that a greater quantity of food may be produced per acre from the growth of banamas than from wheat, potatues or any other foodstuff. 'The banana is too bulky, however, to serve as the main constituent of a healthy diet. Assuming that an average banana weighs two ounces, it would require about eighty of these to yield the amount of energy daily needed by the human system and nearly double that number to supply the requisite amount of protein. No wonder, then, that in tropical countries where bananas form the principal food staple, the inhabitants become "pot bellied" from ehronic abdominal distention.

There are more than one hundred and fifty varieties of bananas, some red and some yellow. All are used for food. The banana is too well known and appreciated to need much detailed description. The pulp is soft, of delicious and luscions flavor, and contains a goodly portion of nitrogenous and carbohydrate material. They may be eaten raw, or cut in slices and - fried in butter. The pulp is also dried and gromnd into a flour that is used in invalid foods. The flour ean be made into bread upon the addition of wheat flour. Analysis shows the banana to be deficient in fat and protein. The fruit is, however, a food of much value on account of its high carbohydrate content.

THE PINEAPPLE.-The pineapple is indigenous to America. It grows well in Central America, the West Indies and Hawaii. The cultivated form has no seeds. In temperate climates it must be protected by sheds, as is done in Florida. The green fruit is not edible. It is almost caustic in taste and action; but the ripe, soft, luscious, pulpy fruit forms one of the most fragrant and delicious desserts. The juice is very sweet and agreeable. The pineapple contains a proteolytic ferment capable of peptonizing albuminoids, for which reason it is used to a considerable extent in the preparation of varions artificial foods. This proteolytic ferment furnishes a very suitable accompaniment to a repast as an aid to digestion. It is appropriate at the end of a hearty meal. The juice has a therapentic value in bronchitis, attended by a tenacions sputum. The composition of the total solids in the pineapple is 14.17 per cent cane sugar; invert sugar, 11.90 per cent; acids, 0.80 per cent without the skin.

The flavor and odor of the pineapple are due to the essential oils and ethers which are present in small quantities. Camned pineapples are prepared in Singapore, the Bahamas, Hawaii and in Florida. If carefully 
sterilized during the cauning process no sugar is needed. The nutritive value of the fruit depends entirely upon the natural sugars contained in the juice and pulp. The pineapple is a valuable food. It is useful as an aid to digestion, owing to the presence of its proteolytic enzyme bromelin, which is closely related to trypsin. This ferment converts albuminoids into peptonates and proteoses, and exerts its full physiological action in acid, alkaline or neutral media. Wiley found that the sugar content of pineapples was 60 per cent sucrose and 40 per cent invert sugar.

THE PRICKLY PEAR.-The prickly pear, tuna or Indian fig, is the edible fruit of a cactus indigenous to Mexico and southwestern United States. It is much prized by the natives where it grows. The fruit is covered with bunches of fine spines and is of a reddish-yellow, purple color. The outside rind is readily removed and the pulp has a subacid taste suggesting that of the cucumber. It contains about 11 per cent sugar and small quantities of other nutrients. The Mexicans make a fermented spirituous beverage from it called colonche.

\section{NUTS}

Nuts.-Unlike the seeds of cereals, nuts are rich in protein and fat and are highly nutritious. Some nuts have such a high fat and protein content that they are of practically the same food value as meat. Bulk for bulk, dry nuts are among the most nutritive foods which we possess. Hutchison estimates that 100 grams of shelled walnuts, averaging thirty in number, contain as much fat as 2.75 pounds of lean beef, but 2.6 ounces of such beef would equal them in protein; so it would be necessary to consume 700 walnuts daily in order to obtain the requisite amount of protein required by the body.

In many countries nuts have long been used as a food; but until recent years they have been regarded rather as a luxury than as a real food in the United States. If the prices of domestic nuts and the more expensive breakfast foods are compared, it will be found that nuts are not an expensive food. Our native nuts, such as hickory nuts, walnuts, butternuts, chestnuts, hazel nuts and pecan nuts, may be had for the gathering by anyone in the rural districts, and in the shops they may be purchased at reasonable prices. Professor Jaffa of the California Agricuiltural Experiment Station has carefully studied the value of nuts from the point of view of nutrition. He says if the true composition of nuts were more generally appreciated and their appetizing qualities and food value better understood, they would lose their reputation for being indigestible. 
Digestion of Nuts. - Nuts contain a fibrous or cellular stroma surrounding the oily meat or kernel (protein, fat and starch cells), all enclosed in a hard shell. The greater portion of cellulose consumed leaves the body' unchanged therefore the nut requires the most thorough and careful mastication in order that the digestive secretions may readily act upon the really mutritious portion of the mut. Since nuts must pass through the pylorus before they can be digested, a considerable proportion of protein and fat may be lost from nonabsorption, unless they are thoroughly masticated. The fact that nuts are such a concentrated food, with only 3 to 5 per cent water, as compared with meat, which has 50 to 70 per cent water, may serve to explain their indigestibility. No doubt, if proper attention were directed to this point and the proper use of nuts as a food were forcibly emphasized, less unfavorable comment would be heard in regard to them. We should regard muts as a food, just as we look upon sugar as a food, and if we used them as such, in proper quantities and at the right time, they would canse no discomfort.

Although nuts alone do not form a well balanced diet, there are numerous faddists who endeavor to live upon them. Even if they did furnish an ideal well balanced diet, the amomnt of muts in the world is insufficient to suppiy any large proportion of mankind with the quantity necessary for their support. It is true that a diet composed exchusively of fruits and nuts contains a sufficiency of the component nutrients in the right proportion to support life, but experience proves that the protein from a mixed diet is more economically utilized. On this account persons who use nuts in the place of meat should not depend on them alone for a food supply, but should at the same time consume more bulky foods with a low protein and fat content.

Becauso they are hard to digest, cansing indigestion, dyspepsia, heartburn, constipation and other annoying symptoms, many people cannot eat nuts in any form. Nuts should not be eaten by persons with feeble digestive power, nor by those subject to constipation or chronic diarrhea. They are when well masticated suitable foods for the corpulent and for those suffering from Bright's disease and diabetes. In fact diabetics acting under their physicians' advice may partake very freely of walnuts, almonds, Brazil nuts, butternuts, hickory muts and pignolia nuts.

Nuts are, for the most part, heat producing foods, due to their large fat content, and are tissue or energy builders by virtue of their contained protein. It should be remembered that nuts are prone to become rancid in a few months, and their palatability and value is thereby diminished. Various fats and oils are manufactured from nuts (see Chapter XIV, Fats 
and Oils). These are quite as easy to digest as butter, and some of them are used as shortening and are found to be quite economical.

Increased Appreciation of Food Value of Nuts.-From available statistics it appears that in 1905 the total quantity of nuts of various kinds, shelled and unshelled, imported into the United States was, in round numbers, $86,238,000$ pounds. In the same year the California almond crop was $4,200,000$ pounds; the walnut crop was $12,800,000$ pounds, and the peanut yield in three Southern states was $225,000,000$ pounds. These figures augur well for a better appreciation of nuts as a food in our country. The increased demand for nuts is due in the main to two causes, namely, a better appreciation of their appetizing qualities and the numerous ways in which they form a palatable addition to the diet of the average family, and secondly, to their use by the vegetarians and persons of similar belief, who use nuts, and more particularly the peanut, as a substitute for meat and other nitrogenous and fatty foods-a group small in proportion to the total population, but still fairly large numerically.

Varieties of Nuts-ACORNS.-Acorns, the fruit of various species of oak, Quercus, consist of a single seeded oval nut in a fixed cap or cup. They were formerly much used as a human food; now, although in this country they are chiefly used to fatten swine, they are still consumed as food in breadmaking in some parts of the world. They contain a large percentage of carbohydrate and about 14 per cent of extractive matter, including tannin and a bitter principle. In Turkey acorns are buried in the ground, during which time they undergo various changes. It is thought that some enzyme is formed while underground, which causes the bitterness to disappear. When taken from the earth they are sweated, dried and ground into a fine meal to which sugar and spices are added. A beverage called roccabout is made from this mixture for the ladies in the harem.

ALMONDS.-Almonds, the fruit of the Amygdalis communis, are cultivated throughout the countries of the Mediterranean basin, Persia and Palestine and other oriental lands. The almond also flourishes in California and moderately in Florida(6). There are two varieties, the bitter and sweet. Of the sweet almonds the Jordan almond is the best in quality. Its shell is thick and hard, long and narrow; the kernel is flat, rather tough but sweet and covered with a cinnamon-colored cuticle. The almond contains a large percentage of nitrogenous matter and is a noteworthy form of concentrated food. "No man," it has been said, "need starve on a journey when he can fill his waistcoat pocket with almonds."

Bitter Almonds.-Bitter almonds(7) are grown chiefly in Sicily, 
Moroce and Barbary. The pit of the bitter almond, like that of the peach and apricot, contains a glucosid, amy gdalin. The kernels are shorter than the sweet variety and have a bitter taste. When ground to a powder and made into a paste with water, they have a characteristic odor. 'This odor is due to the hydrolization of the glucosid, amygdalin $\left(\mathrm{C}_{20} \mathrm{H}_{27} \mathrm{NO} \mathrm{O}_{11}\right)$, under the influence of an en\%yme, whereby oil of bitter almonds is produced. The bitter almond, while not poisonous when fresh, has a most disagreeable odor, and this, in addition to the fact that one of the products of decomposition is hydrocyanic acid, makes it undesirable as a food.

Green almonds are the young sweet almonds before the shell is formed. They are preserved in sugar, like green apricots. 'The uses of almonds need not be dwelt upon. They are eaten as nuts, used for culinary purposes, ground into flour and made into almond paste cakes, biscuits, bread, marzipan and various other confections.

Almonds contain no starch, the carbohydrate consisting entirely of sugar, gum and fibrocellulose. The absence of starch makes them suitable for the diabetic. The fat content is about 50 per cent and is a bland oil consisting mainly of olein, with a slight amount of palmitin and stearin. Almond oil is of the same nutritive value as olive oil, and much more agreeable to the taste.

THE BEECHNCT.-The beechnut is very abundant in some localities. It consists of small triangular seeds, which have long been known as nutritious foods. The nuts are small and have an agreeable taste, but there is so little meat in the shell that the energy expended in chewing them is scarcely repaid. They furnish foed for hogs, squirrels and birds. They are sometimes consumed by man for food and may be eaten with safety in small quantities. If consumed in exeessive quantities they are said to cause giddiness, delirium and convulsions, as the result of either indigestion or of some noxious principle contained in them. In Silesia the oil is expressed and used as a substitute for butter.

BRAZIL xUTS.-The Brazil nut, known also as the cream nut, a native of Para, Brazil, is now extensively cultivated in Brazil and Guiana. The nut consists of a large oval or round pericarp of thick wood, five cr six inches in diameter, divided into four compartments, each of which encloses from six to eight nuts. Like most other muts they contain a sort of vegetable milk, a considerable amount of nitrogenous material, 66 per cent of fat, a little sugar and 17 per cent protein. The mineral content comprises 1.35 per cent phosphoric acid, 2.35 per cent of silica, lime and potash. 
BREAD NUTS.- Bread nuts, the fruit of the Brosimum alicastrum, are eaten roasted or boiled and are said to be superior to chestnuts both in taste and as a food, being agreeably flavored, easy of digestion and very wholesome.

BUTTER NUTS.- The butter nut, closely related to the walnut, is a native of South America, but is also cultivated in the West Indies. 'The nuts have a fine bland flavor, the kernel is soft, white and fleshy, and as mild as a sweet almond.

CASHEW NUT.-Cashew nut is the fruit of the Anacardium occidentale, sometimes called Maranon fruit. The cashew nut is a native of the West Indies. 'The seed is enclosed in a grayish brown cellular coat that contains an essential oil. If applied to the skin, this oil produces a blister. The ripe fruit and nut are eaten in Brazil and the fermented juice is used to make a wine, called "kajr."

CANDLE NUT.-The candle nut of the tropics is very oily and only after it has been stored for some time and is thoroughly dried, is it edible. If eaten before it is thoroughly dried, the croton oil-like substance which it contains is liable to produce seriolis illness.

CHESTNuTs.-Chestnuts are the fruit of Castanea dentata, which grows wild in the forests of continental Europe. It is not known whether the tree is indigenous to Europe or not. The Romans distinguished eight varieties of chestnuts. It grows readily in the eastern part of the United States. The lumbermen have almost devastated the forests of the trees so that few of the original trees remain. The trees grow to an enormous height and are valuable for lumber. The chestnut forms a wholesome form of concentrated nourishment which is highly esteemed by the inhabitants of many countries, notably those of southern Europe. They are the most important nuts as a source of food, because they contain a large proportion of carbohydrates (starch). They are eaten steamed, boiled, roasted and raw. The French make a dish called galette, composed of chestnut meal, butter, eggs and salt, which is a more satisfactory food than wheat bread and contains the elements of a perfect food in proper proportions. The horse chestuut is only fit for food for the lower animals.

THE CHINQUAPIN.- The chinquapin is a dwarf chestnut of the United States. The tree is usually found in clusters or bunches ranging from six to ten feet in height, the diameter about three inches. The nut develops in a burr very much like the chestnut burr, enclosing a single nut about half the size of a chestunt. The outer hull has a polished black surface; the kernel is white and when seasoned is very much sweeter than the chestnut. 
COCOANUTS-Cocoanuts are the fruit of the C'ocos Nucifera, which is grown largely in the East and West Indies. The meat of the nut is scraped and eaten with rice curries. its composition and other uses have been discussed on page 494, to which the reader is referred.

FILBERTS.-Filberts are the fruit of the Corylus tubulosu, of which there are both wild and cultivated vilrieties in most European countries. The name filbert is a corruption of "full beard" and should be applied only to those varieties in which the husk is fringed and extends beyond the kernel. The nut is of fine flavor, rather long pointed. It is a superior dessert nut, but little inferior to the almond.

GROUND NUTS.-Ground nuts are the fruit of A rachis hypogea, a tuberous root growing in warm comutries, sometimes called "earth chestnut." The muts grow undergromed and are about the size of a hazel nut. When digged and dried they are very sweet and of excellent flavor. 'They form a very nutritious food (see also "Ronts and Tubers," Volume I, Chapter XIII).

HAZEL NUTS.-Hazel muts are the fruit of the Corylus avellana, which is cultivated in the temperate regions of the earth, especially in the Asiatic countries, around the Black Sea. Iarge quantities are exported as filberts from Spain. There are many species. One in particular, called the cob nut, is broad and short but not of the best quality. Dried hazel nut meal contains 65 per cent oil, which is known commercially as "nut oil."

HICKORY NUTS.-Hickory nuts are the finest wild nuts which grow in the United States. These nuts are the most highly esteemed nuts of North America, especially the scaly bark varieties, which are very sweet and highly nutritious. They contain a large proportion of fat and should be eaten in the winter following their growth.

LI-CHI NUTS-_Li-chi nuts are the so-called Chinese nuts. In the strict botanical sense they are not nuts, but fruit protected by a nut shell. They grow extensively in China, but are about the size of a date and are covered with a scaly hard rind. red on one side, green on the other. They contain a delicious pulp of a sweetish subacid taste and raisin-like flavor. The Chinese dry them like prunes for winter use. A few are imported to America.

PARADISE NUTS.-The paradise nut, grown on the Lecythis usitata, resembles the Brazil nut. It has a rough shell, is about the same size, but is not so much curved. It is of finer quality and more delicate texture than the Brazil nut, but as yet has not become common in the markets of the United States. 
PEANUTS.-The peanut, the fruit of the Arachis hypogea, is a leguminous pod and not a nut, strictly speaking, but a legume. ${ }^{1}$ This nut is known under various names, groundnut, pindar and goober. It appears to be of tropieal American origin. Although grown for a long time in the United States, it did not become popular until 1870. They are grown extensively in Virginia, Tennessee and the Carolinas.

The peanut plant grows from the peanut and produces a more or less trailing vine, which has this peculiarity; as the blossom withers, the spike of the ovary pushes into the ground so that the pod develops and the nut is matured under the ground. The annual nut crop is something over 4,000,000 bushels, 75 per cent of which are consumed as roasted peanuts. These are eaten as an adventitious or extra food, but their digestibility and nutritive qualities deserve better recognition. They are rich in oil and protein and make a concentrated ration (see analysis, Volume I, Chapter XIX).

Prepared peanut confectionery, "salted" peanuts, "peanut brittle," are becoming popular. There are various peanut products on the market, including roasted peanuts, salted peanuts, peanut butter, peanut meal and peanut oil. The last is a fixed oil having a sweet taste and is said to be equal to olive oil (see "Fats and Oils," Volume I, Chapter XIV).

PECAN NUT.-The pecan nut, the fruit of Hicoria pecan, is indigenous to the United States. Pecan nuts are highly esteemed and are grown largely in the southern states for American markets. Some of the choice varieties of pecan have originated in southern Indiana, northern Kentucky and southern Virginia and are most successfully grown in these localities. The nut grows on a tree somewhat similar to the hickory tree, but not nearly so large or so tall. The nut is highly valued and commands a good price. Nut cracking factories have been located in pecan growing districts. The kernel is aromatic and resembles the hazel nut in this quality. Its composition is water, 3 per cent; protein, 11 per eent; fat, 71.2 per cent; starch and sugar, 13.3 per cent, and ash, 5 per cent.

PINE NUTS-Pignolia nuts, the fruit of various species of the pine tree, are edible and are consumed largely for food. This nut grows in the pine cone and is shaped somewhat like a bean. It is enclosed within a thin shell of a brownish color. The meat of the pine nut is white and of a rich, delicate flavor without any suggestion of a resinous nature. On analysis pine nuts show 14 per cent protein; 62 per cent fat; 17 per cent

Farmers' Bulletins, Nos. 121, 332, 356, of the United States Department of Agriculture. 
carbohydrates. They are grown extensively in lower California and throughout the Pacific states.

PISTACHo NUTs.-Pistachio muts are the seeds of the Pistachio viru, growing wild and extensively in Syria. The nut is also found in France, Spain, Italy and sicily and to a less extent in Florida and the sonthern States of America. 'The fruit is about the size of an almond, convex on one side and coneave on the other. It is of the drupe family, grows in clusters and has a smooth stono which is easily separated inso two halves at maturity. 'The pulp which surrounds the mut is crimson colored and tender. The kernel is of a greenish color with a white pellicle. It has a sweet, agreeable flavor and an aroma resembling that of almonds. 'The pistachio mut is highly prized on aceount of its greenish color, since usable green pigments are rare in the vegetable world, and for its pleasant flavor. Pistachio nuts are largely used in confectionery and for flavoring ice creams and various dishes for the table.

SAPUCAIA NUTS.-Sapucaia nuts grow in Brazil. 'The seeds of Lecythis allaria are allied to Brazil nuts. 'The fruit consists of a capsule several inches in diameter. When it is ripe the seeds fall out. 'The seeds are nuts of $1 \frac{1}{2}$ to 2 inches, slightly curved and grooved, a light brown color and in shape somewhat like a small cucumber. The shell is soft, the interior mild yellow in color, with a flavor of cream or custard. Sapucaia nuts are eaten raw or roasted. They contain no starch or sugar and are therefore a valuable food for diabetics.
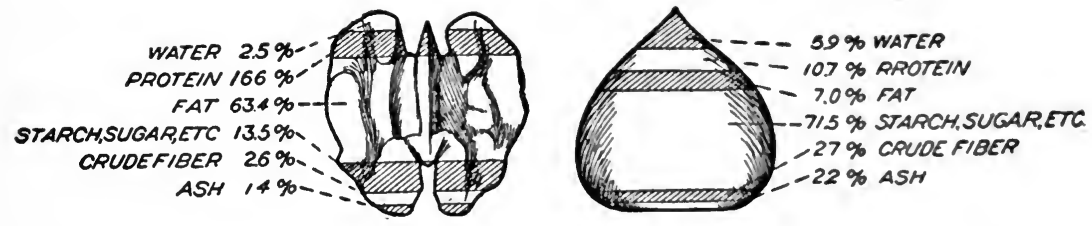

Fig. 45.-Composition of the Walive. (Bull. No. 293, U.S. Dept. Agric.)

THE WALNUT.- The walnut(s) is the fruit of the various species of Juglan. 'The black walnut tree grows wild in the forests of the North American continent. The nuts are edible. The English walnut has been cultivated in England for centuries and is supposed to have originally come from Persia. More recently English walnuts have been successfully grown in California. The walnut is so well known in all countries that it is unnecessary to describe it. It contains about 21 per cent water; 27 per cent protein ; 56 per cent fat: 12 per cent carbohydrates, and about 3 per cent of cellulose and ash. Atwater found upon analysis that the 
ash of walnut kernels had the following composition: $\mathrm{CaO}, 5.6 ; \mathrm{MgO}$, 16.6; $\mathrm{Na}_{2} \mathrm{O}, 1.0 ; \mathrm{K}_{2} \mathrm{O}, 12.7 ; \mathrm{MnO}_{2}, 0.3 ; \mathrm{Fe}_{2} \mathrm{O}_{3}$ and $\mathrm{Al}_{2} \mathrm{O}_{3}, 3.2 ; \mathrm{P}_{2} \mathrm{O}_{5}$, $57.8 ; \mathrm{SO}_{3}, 1.3 ; \mathrm{SiO}_{2}, 0.7$, and $\mathrm{Cl}, 0.7$ per cent.

\section{GARDEN FRUITS}

This class of fruits is raised from seed which is sown annually. The plants are generally vines, and the fruit ripens on the surface earth. All of this class of vegetable fruits are grown for immediate use, with the exception of the pumpkin, which may be kept for months.

Most of the garden fruits come under the order of cucurbitacex, which include the cucumber, vegetable marrow, pumpkin, squash and various other gourds. According to Goff, there are more than fifty varieties of pumpkin, squash and vegetable marrow. The fruits of the cucurbital or gourd family contain very little nutriment of any moment. Atwater has found that the cucumber contains a protein content of only 0.8 per cent, of which but 0.4 per cent was albuminoid; in squash the nitrogenous matter was but 0.6 per cent, including 0.5 per cent protein. The carbohydrates are starch and sugar; the free acid is only 0.2 per cent. These fruits, while of no value as a food product, are useful mainly to break the monotony of the dietary.

Varieties of Garden Fruits-THE CITRON.-The citron, a variety of Citrus vulgaris, a native of tropical countries, is really a small variety of watermelon which has a very thick rind, grows nearly solid and has an insipid taste. The seeds are black and the flesh of the citron is a light cream yellow and not edible raw. It is used for making preserves and candied confections similar to that of the genuine citron (see page 485 ).

CUCUMBER.-Cucumber, the fruit of the Cucumis sativa, is one of a number of the gourd family which is indigenous to southern India and grows luxuriously in most of the warm climates of the world. In fact few garden plants have been known longer to man than the cucumber, if we are to believe De Candolle, who has proven its cultivation for the past four thousand years. This melon fruit came into general use in England about the beginning of the seventeenth century. In Egypt the cucumber is cooked and served in various ways and forms quite an addition to the diet. In the United States and other countries the cucumber is gathered while immature and used for pickling and peeled and sliced for salads. The cucumber contains about 96 per cent water and is hardly worth while from the viewpoint of food value. 
The Guerkin.-Gherkin is a fruit of the cucumber family used largely for pickling. 'This fruit is covered with prickers, which sting the fingers when pulling the fruit from the vine. It is a short, thick fruit, while the cucumber is oblong. 'The gherkin is highly prized for pickles.

EGGPLANT.-Liggplant, the fruit of Solanum melongena, is a native of the East Indies, but is also grown in Europe, America and the West Indies. The fruit is a large, egg-shaped, melon-like fruit, about the size of a cocoanut, sometimes white but more generally of a purple color. It grows on a bush-like vine. The eggplant is eaten raw like a tomato, cut into slices, or it may be broiled or fried.

MELONS.-Melons are the fruit of varieties of Cucumis melo, which have ${ }^{\circ}$ long been cultivated in Eastern countries, probably for more than 2,000 years. According to De Candolle, melon culture dates back to the beginning of the eighth century. $\Lambda$ study of the origin of melons indicates that they were found originally in India and Africa. The Indian varie ties produce a fruit which is sweet, insipid or slightly acid, its surface striped or all of one color. The African type grows wild in Guinea. The odor is that of any fresh melon.

The Muskmelon.-The muskmelon, grown originally in India and Beluchistan before the Christian era, is a yellowish green oval fruit, with a highly flavored sweet pulp. The sub-varieties include: $(a)$ citron muskmelon; (b) cantaloupe muskmelon; $(c)$ nutmeg muskmelon, and $(d)$ pineapple muskmelon, so called from their various physical characters. 'The casaba or winter muskmelon has a faintly vellow, delicate pulp of sweetish taste, somewhat resembling that of a ripe cucumber.

The Rockyford cantaloupe, originally grown under irrigation at Rockyford, Colorado, is noted for its delicious taste and odor. It is now grown from seed all over the southern states. The Shamman is a fruit similar to the muskmelon and is said to be the finest fruit grown in Egypt. Pomegranate, Dudaim or Queen Anne melon is another variety of muskmelon, a native of Persia. It has a variegated color, green and orange, becoming yellowish when fully ripe. It has an insipid pulp, is inedible, but has a most fragrant vinous musk-like odor.

Watermelox.-Watermelon, the fruit of the Citrullus vulgaris, a native of tropical Africa, was extensively cultivated by the ancient Eg.ptians, whence it spread into Asia. It was found, cultivated by the American Indians, by Raleigh when he discovered Roanoke Island in 15s4. The watermelon is a smooth, round, elongated fruit of green color, having a hard green rind which encloses a rose colored pulp of a rich, delicious flavor, and an abundance of watery juice of an inviting sweetish taste for 
which it is highly prized. This fruit comprises a very important part of the food of the natives of Egypt during the hot season. It is much esteemed in India and in America from Chili to Canada. This fruit is cultivated in nearly all tropical and temperate countrics and is very popular with all classes of society. It is delicious served icy cold on a hot summer's day. Its qualities are said to be improved by cutting a hole in the rind and adding a bottle of champagne. It is a valuable commercial crop in the southern states and immense quantities are shipped north during the summer months.

THE PUMPKIN.-The pumpkin is the fruit of the Cucurbita pepo. According to Goff, there are fifty-five varieties of pumpkin, squash and vegetable marrow. He classifies them into: (a) pumpkins and vegetable marrow ; $(b)$ summer and winter squash, and $(c)$ sweet potato pumpkin and cashews. The pumpkin was found growing in the Indians' cornfields when our forefathers came to this country. Although its handsome exterior belied its food and fuel value, nevertheless it has become a popular garden vegetable, and the taste cultivated through necessity at first, has been handed down through generations, until it has become an established favorite for pies and custards.

The pumpkin is usually round, occasionally oblong, weighs from ten to two hundred pounds and is used in a variety of edible dishes. It may be cut up and used in soups, made into pies, or the ripe pumpkin having had the seeds scooped out through an opening made in one end, may be filled with sliced apples, sugar and spices and cooked whole. The pumpkin is highly prized in the New England States for pies and custards. To make the best pies and custards the pumpkin should be cut into long, large slices and baked, then scooped from the rind and sugar and spices added, together with rich milk or cream mixed into a batter.

SQUASH.- Squash, the fruit of the Cucurbita melopepo, sometimes called cymling or summer squash, is thought to be a variety of the common gourd from which the pumpkin also appears to have been derived. Squash is extensively grown in America, the vegetable is flat with prominent angles or ribs at the sides. As a nutrient vegetable the squash amounts to little. It contains only 9 per cent of nutritive material, while the nutritive material of the pumpkin is 5 per cent.

VEGETABLE MARROW.-Vegetable marrow, the fruit of the Cucurbita ovifera, is closely akin to the squash. It is more cultivated in England as a garden vegetable than in the United States. One variety known as custard marrow is a flattened fruit with scalloped edges and is sweeter than the true marrow. The fruit is eaten when quite young. Both squash and 
marrow are boiled, seasoned with butter, salt and pepper and used as at vegetable.

\section{Preservation of Firuits. by C'old sitorage}

'The preservation of ripe fruits by cold storage is a process somewhat similar to that for the preservation of meats, fish, game, eggrs and buter. ete. It should not be forgotten that the life processes go on, although slowly, in fruit, even at a low temperature. The fungi and bacteria are always ready to produce decay and their action is only retarded by a low temperature. The keeping qualities of ripe fruits in cold storage depend upon their ripeness, their somdness and their freedom from bruises. "The modern ecid storage warehouse has its ice plant so arranged that cold brine can be circulated in pipes through the rooms in which the fruit is stored. The temperature may thus be kept at $: 32^{\circ} \mathrm{F}$. or even below, and can be positively controlled. For some varieties of apples a lower tomperature is required than for others. It has been learned from experience that there is a special temperature most satisfaetory for keeping each variety of fruits. Fruits as well as other produce kept in cold storage for a long time deteriorate or "go down" very quickly when removed from the warehouse. This is not the case with fruits which have been stored in cellars, in caves or in "hills" at the temperature of the outside air. Fruit stored in this manner does not deteriorate, when removed to rooms of ordinary temperature, nearly so rapidly as that which has been in cold storage.

\section{REFERENCES}

In the preparation of this section, the author has freely consulted and drawn largely from the following published works: Tibbles' "Foods, Their Origin, Manufacture and Composition"; Bailer's "Principles of Fruit Growing"; "Source, Chemistry and Origin of Food Products."

1. Barley. Principles of Fruit Growing.

2. Leach. Analysis of Fruits, 3rd ed., p. 566.

3. Schim mel. Report, October, 1902 .

4. Tibbless. Origin and Manufacture of Foods.

5. - Ibid.

6. Wrley, H. W. Foods and Their Adulteration.

7. JafFa. Nuts and Their Uses as Food, U. S. Dept. Agric., Farmers' Bull. 332.

8. McClenahax. Development of Fat in the Black Walnut. J. Amer. Chem. Soc., 1913, vol. xxxv, pp. 485-493. 


\section{BIBLIOGRAPHY}

\section{Fruits}

Bantey. Biochemical and Bacteriological Studies on the Banana, J. Am. Chem. Soc., 1912, vol. xxxiv, pp. 1706-1730.

Bertines. Standard for Marmalades, Fruit Juices, and Other Fruit Preserves, Report of Conference of German Food Chemists and Representatives of Manufacturers, Ztschr. f. Untersuch. d. Nahrungs. u. Genussmittel, 1909, vol. xviii, pp. 54-78.

Bıoletri. Olive Cultivation, Oil-Making, Pickling, Calif. Agric. Exper. Sta., Report for the years 1898-1901, part ii, pp. 285-304, 1902 .

Browne. A Chemical Study of the Apple and Its Products, Penn. Dept. Agric., Bull. 58; and J. Amer. Chem. Soc., 1901, vol. xxiii, pp. 869-884.

Chase, Tolman and Munson. Chemical Composition of Some Tropical Fruits and Their Products, U. S. Dept. Agric., Bur. of Chem., 1904, Bull. 87.

Funk. The Nitrogenous Constituents of Lime Juice, Biochem. J., 1913, vol. vii, pp. 81-86.

Gore. Composition of the Scuppernong, Concord and Catawba Grape Juices, J. Indust. \& Engin. Chem., 1909, vol. i, pp. 436-441.

JAfFe. Nutrition Investigations Among Fruitarians, U. S. Dept. Agric., Office of Exper. Sta., 1901, Bull. 107.

Kearney. Date Varieties and Date Culture in Tunis, U. S. Dept. Agric., Bur. of Plant Industry, 1906, Bull. 92.

Langworthy. Raisins, Figs and Other Dried Fruits and Their Use, U. S. Dept. Agric., Yearbook for 1912, pp. 505-522; reprinted at Yearbook Separate, 1913, p. 610.

Use of Fruit as Food, U. S. Dept. Agric., 1907, Farm. Bull. 293.

Murson, Tolman and Howard. Fruits and Fruit Products; Chemical and Microscopical Examination, U. S. Dept. Agric., Bur. Chem., 1905, Bull. 66.

VAN SLyke. Home-made Cider Vinegar, N. Y. Agric. Exper. Sta., 1905, Bull. 258. 
Nuts

Benttie. 'The Peanut, U. S. Dept. Agric., 1911, Farm. Bull. 431.

JaFfa. Nuts and Their Úses as Fond, U. S. Lept. Agric., 1908, Farm. Bull. 332.

McClenahan. The Development of Fat in the Black Walnut, J. Amer. Chem. Soc., 1913, vol. xxxv, pp. 485-49\%.

Youna. A Study of Nuts with special Reference to Microscopic Identification, U. S. Dept. Agric., Bur. Chem., 1912, Bull. 160. 



\title{
CHAP'TER XVI
}

\section{WATERS, BEVERAGES, MAL'T IIQUORS, S'TIMULANTS, WINES, CIDERS AND VINEGARS}

\author{
Waters: Classification of Waters-Potable and Table Waters; Drinking \\ of Water at Meals. \\ Beverages: Varieties of Beverages-Tea, Coffee, Cocon, Chocolate, Kola, \\ Guarana, Coca; Nutritive Value of Beverages; Deleterious Fffects \\ of the Use of Beverages.
}

Malt Liquors: P'reparation of Malt Liquors; Composition of Malt Liquors; Aciion of Malt Liquors on Digestion; Low Alcoholic Bev. erages; Herb Beers.

Stimulants: Consideration of Effects of Alcohol on the Body; Varieties of Alcoholic Drinks-Whiskey, Brandy, Gin, Liqueurs; Conclusions as to the Use of Alcohol.

Wine: Preparation of Wine; Varieties of Wines; Still, Sparkling. Natu. ral Wines, etc.; Effect of Wines on Digestion; Wine as Source of Nutriment; Use of Wines.

Vinegars: Cider and Perry.

\section{WATERS}

Man can live for weeks without food, but he can abstain from water but a few days. In the human organism ( 60 per cent of which is water) water is essential to digestion, assimilation, metabolism and reproduction. In fact no vital process in the body occurs in the absence of water.

Water is an absolute necessity as a solvent. It is constantly being eliminated by the skin, the lungs and the kidners. This loss must be replaced in order to maintain the functions of the body. Fortunately water is the chief constituent of all beverages and enters largely into the composition of solid foods, so that it is an easy matter for man to follow normal inclinations in quenching his thirst.

Physicians have for years encouraged the habit of drinking water. However, the question whether it is wise to drink water at meal time or not, is still a matter of discussion.

"Though many persons are accustomed to drink considerable quantitics of water at meal time with no apparent ill effect, the statement has been 
and still continues to be made that water drunk with meals is injurious. This assertion rests solely on a priori reasoning and not on experiment, but is commonly believed by the general public and by many of the medical profession today." It is commonly stated that water should never be drunk with meals, but an hour after the meal has been eaten; that water drunk while eating "artificially moistens the food, thus hindering the normal and healthful flow of saliva and the other digestive juices; that it dilutes the various juices to an abnormal extent, and that it washes the food elements through the stomach and into the intestines before they have had time to become thoroughly liquefied and digested. The effects of this upon the welfare of the whole organism can only be described as direful." There is no proof that such effects follow the drinking of water with meals. On the contrary, certain experiments show that these effects do not follow.

Pavlov(1) proved that water acts as an excitant of the pancreatic juice. "When 150 c.c. of water is introduced into the stomach of a dog, the pancreas begins to secrete or its flow increases within a few minutes after the water has entered the stomach. Since this amount of water is insufficient to excite the flow of gastric juice, the secretion of pancreatic juice is not secondary to a secretion of the gastric juice, but is a direct result of the presence of water in the stomach.

"In dogs with pancreatic fistulæ, it has been shown that following chemical and psychical stimuli, there is a parallelism between the secretion of gastric juice and pancreatic juice. All kinds of acids are powerful excitants of pancreatic secretion. Large amounts of acid chyme pouring into the small intestine cause increased pancreatic secretion with increased flow of pancreatic juice" (see Volume I, Chapters VI-VII). It has been shown that the biliary secretion is also increased, thus augmenting the digestive processes. "Thus the increased acidity of the gastric contents resulting from the stimulating action of water causes a far more active digestive juice to be poured out upon the chyme when it reaches the intestine. Further, Hawk has shown that increased pancreatic activity follows water drinking with meals, the index being the output of fecal amylase."

It has been taught, in the past, that free consumption of water during meals is apt to retard digestion by diluting gastric juice. This statement is not well grounded, and has led to a tendency on the part of the laity to use an insufficient amount of water and other liquids with the daily diet. Water is itself a slight though unimportant excitant of gastric secretion. Experiments by Fleischer have shown that even in quantities of one pint it does not affect the rapidity of digestion. Even two pints pro- 
duce slight slowing, while it requires three pints to produco any marked effect. Recent investigations seem to indicate that water and other beverages taken in quite large quantities with the food tend to assist digestion rather than retard it. Water shmuln never be drunk to wash down the food. A glass of water before meals flushes out the dibris of the last meal from the stomach, removes the muns and tones up the gastric mucous membrane. Taken three hours aftre meals it assists the final stages of digestion, dilutes acidity and sometimes facilitates the eructation of gas.

In Chapter $\mathrm{X}$ we studied the physiological value of water, its absorp. tion, its diuretic and diaphoretic antions and its various uses. In this chapter we will take up the classitication of waters, the various varieties of mineral waters and their therapentic uses.

Classification of Waters. - Water's are classified as hard or soft, according to the amount of mineral matter which they contain. Rain water, the purest form of natural water, is soft. Hard water contains considerable caleium and magnesium salts. If these salts are in the form of carbonates, the water is referred to as "temporarily hard"; if in the form of sulphates, the water is "permanently hard." The magnesium present in "temporarily hard" water can be precipitated by boiling, which will leave an incrustation on the walls of the ressel. Water which has a particnlarly high content of this mineral substance is not satisfactory for some culinary purposes. For making tea, however, a soft water is preferable, For laundry purposes, on the other hand, hard water is very unsatisfactory, as the soap which is added is used up in precipitating a lime or magnesia soap before a permanent lather will form. When a large amount of water is prescribed for drinking purposes, it should be as soft as possible. Drinking waters are classified, according to the Rivers Pollution Commission, as follows:

$\underline{\text { Wholesome.... }}\left\{\begin{array}{l}\text { 1. Spring Water } \\ \text { 2. Deep Well Water } \\ \text { 3. Upland Surface Waters }\end{array}\right\}$ (Very palatable)?

Suspicious.... $\left\{\begin{array}{l}\text { 4. } \text { 'Stored Rain or Soft Water } \\ 5 \text {. Surface Water from ('ultivated Land }\end{array}\right\}$ (Moderately palatable)

Dangerous... $\left\{\begin{array}{l}6 . \text { River Water to which Sewage gains Access } \\ \text { 7. Shallow Well Water }\end{array}\right\}$ (Paiatable)

Rosenau, in his "Preventive Trelicine and Hygiene," prefers the following simple classification: $(a)$ gond, (b) polluted, (c) infected. This practically corresponds to the classification of the Rivers Pollution Commission. 
POTABLE WATERS.-Potable waters, or those suitable for use as a source of domestic supply and for drinking, may be derived from public or private sources. The advantage of a public supply is that the whole quantity used by the City may be supervised carefully and analyzed frequently, thus insuring its purity and wholesomeness. On isolated farms or in small villages there are always sources of filth near at hand, such as stables, closets, drains, cesspools or hog wallows. Few individuals appreciate the danger of surface water as a source of filth to the water supply. It may percolate through the soil without the slightest purification, or it may rum over the surface and into the well or cistern, carrying with it any germs of disease that may have been in the filth with which it came in contact. Water may be clear, colorless and tasteless, while it contains many impurities and disease bearing germs. Some of the most dangerous waters do not betray their eharacter by their taste, color or appearance.

IMPURITIES OF WATER. - The impurities of water are both mineral and organic. As water percolates through the soil and over the rocks, it dissolves out various mineral substances, which, with the aid of carbon dioxid and other gases, are held in solution. The mineral substances ordinarily found in water include calcium, magnesium, sodium, potassium, iron, aluminium and a few other metals united with such acid ions as chlorin, sulphur and the sulphate, carbonate, nitrate, phosphate and silicate ions. The purification of water is best accomplished by distillation. Soluble impurities may often pass through the filter, so that filtered water is not nearly so reliable as distilled water.

The organic eonstituents of waters are obtained from organic matter and are either vegetable or animal in origin. When water is loaded with organic matter, it is likely to contain the germs of disease. For instance, water may be contaminated with the drainage from eesspools and contain the germs of typhoid fever, cholera or other diseases of this class. The presence of organic matter is a warning to the chemist and the bacteriologist that the water is dangerous and the source of pollution should be ascertained and the water condemned. To guard against impurities consisting largely of organie matter, sources of the water supply should be carefully and rigidly inspected.

TABLE WATERS.-Table waters are comparatively free from mineral matter and should have little or no color, no odor, a pleasant, fresh taste and should contain only a moderate amount of solid matter, eight and onehalf grains per gallon being a good average. Wholesome table waters should contain very little organic matter. What there is should be of vegetable origin, with only a small proportion of chlorids. Some of the 
purest natural waters are found in the Appalachian and Green Monutain regions of the Lnited States, where the rocks are of granite or sandstone, and where there is very little soil through which the water can percolate. Paradise Spring at Brunswick, Me., contains only 0.99 grains of mineral matter per gallon; Poland Spring at Poland, Me., contains :3.76 grains of mineral matter. Both are considered very low in mineral substances.

Table waters are not without therapentic effect. As we have learned in Chapter $\mathrm{X}$, they are powerful solvents used to remove the waste tissues from the body in gonty and rheumatic conditions, in diseases of the liver, kidneys and bladder. Being highly charged with carbonic acid, their bright and sparkling appearance tempts the patient to use them in large quantities withont effort. This class of waters in the United States are derived from the Bladon Springs, Choctaw, Alabama; the Blue Lick, Kentucky; Clarendon, Rutland County, Vermont; the Sweet Chalybeate, Alleghany, Virginia; Adam's Spring, Lake County, California; the Saratoga Vichy, New York, and the Wilhoit Springs, Oregon.

Axalysis or Table Waters.-In table I, taken from Tibbles, will be found analyses of various table waters, showing the constituents in grains per gallon.

MINERAL WATERS.-Mineral waters are classified under the following $\operatorname{heads}(2)$ :

(a) Purgative and Bitter waters

(b) Alkaline waters

(d) Chalybeate waters

(c) Saline waters

(e) Sulphurous waters

(f) Calcic waters

(g) Thermal waters

(a) Purgative or Bitter Waters.-Purgative or bitter waters are characterized by a large proportion of sulphate of sodium and sulphate of magnesium; they also contain various proportions of magnesium chlorid, carbonate and nitrate, calciun, carbonate and sodium chlorid. These waters are aperient by reason of the sulphates. Metabolism is encouraged by the chlorids, and the alkaline salts render them of value in many of the same diseases as are treated by the alkaline waters. These waters are indicated in small doses as stimulants to excite intestinal peristalsis and are also useful in habitual constipation. They are of considerable therapeutic value in the treatment of acute and chronic diseases of the stomach, jaundice, disease of the liver, spleen and kidners: in lithemia and in diseases due to the uric acid diathesis: in lead and other forms of poisoning: in anemia, chlorosis, diseases of the blood and skin; in scrofula, lymphatic 


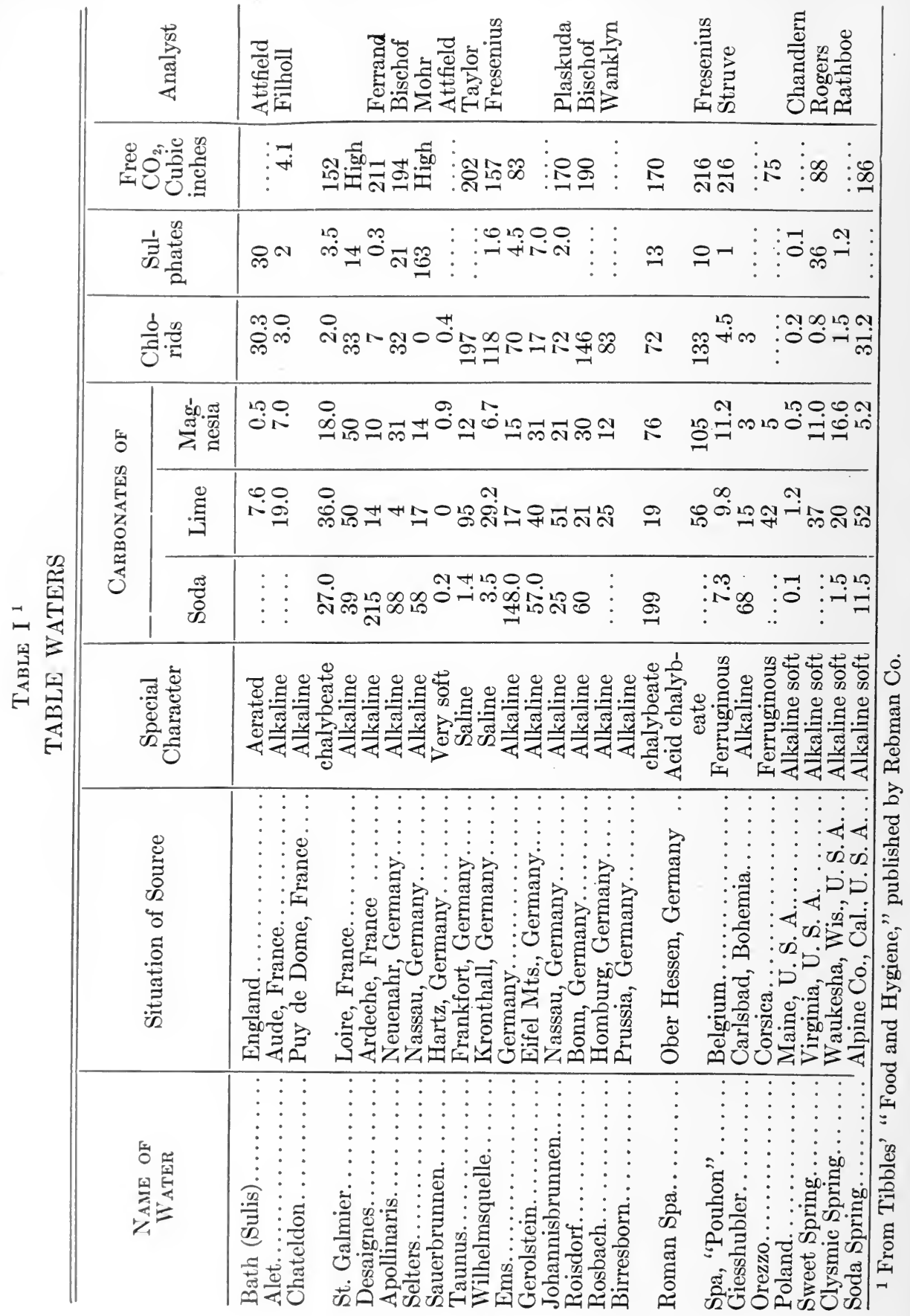


and other enlargements, and in chronic uterine entarrh, lenkorrhea, contgestion or chronic inflammatory disenses of the nterine appendages.

The proper dose of the stronger aperient or purgative waters is usually about a wineglassful, best taken before breakfast and followed by a cup of hot tea, coffee or milk.

Axalysis of Principar Purgative or Bitter Sprisgs.-The principal springs from which this class of waters are obtained, together with their analyses (constituents in grains per gallon), will bo found in Table II. (From Tibbles' "Food and Hygiene.")

(b) Alkalne Waters.-Alkaline waters are divided into: 1 . Simple acidulous, 2. Alkaline acidulous, 3. Alkaline muriated acidulous, 4. Alkaline saline acidulous waters.

1. The simple acidulous alkaline waters contain large quantities of earbon dioxid, which increases peristaltic action of the stomach and intestines. The principal waters of this class come from the Clysmic Spring in Wisconsin, Blne Lick in Kentucky, the Geyser Spring in California, the Manitou Soda Spring in Colorado, and the Carlsbad Spring in Bohemia.

2. The alkaline acidulous waters contain, in addition to carbon dioxid, varying proportions of sodium carbonate. These waters are useful in the treatment of minor gastric disturbances and in catarrhal conditions of the respiratory tract. In moderate quantities they exert a stimulating action upon the gastro-intestiual tract and upon the urinary organs. They dissolve mueus and neutralize the excess of acid in the stomach. These waters are useful in the treatment of constipation, indigestion and deficiency of secretion.

3. The alkaline muriated acidulous waters contain, in addition to carbon dioxid and sodimm carbonate, large quantities of sodium chlorid. These waters exert a markedly solvent action on uric acid, biliary and urinary concretions. They are especially valuable in liquefying the secretion of the respiratory and urinary tracts. This class of waters is useful in the uric acid diathesis, hepatic engorgements, gallstones, hyperacidity of the gastric juice and catarrhs of the stomach and bladder. The Saratoga Vichy is a good example of this trpe of water.

4. The alkaline saline acidulous waters contain sulphate of sodium, bicarbonate and chlorid of sodiun. They are both warm and cold waters. The cold waters when taken in large quantities act as purgatives and at the same time exert marked diuretic effects. The warm waters inhibit urinary secretion and are useful in relieving gastro-intestinal catarrh, gout and catarrhal jaundice, hepatic congestion and urinary concretions. Some 


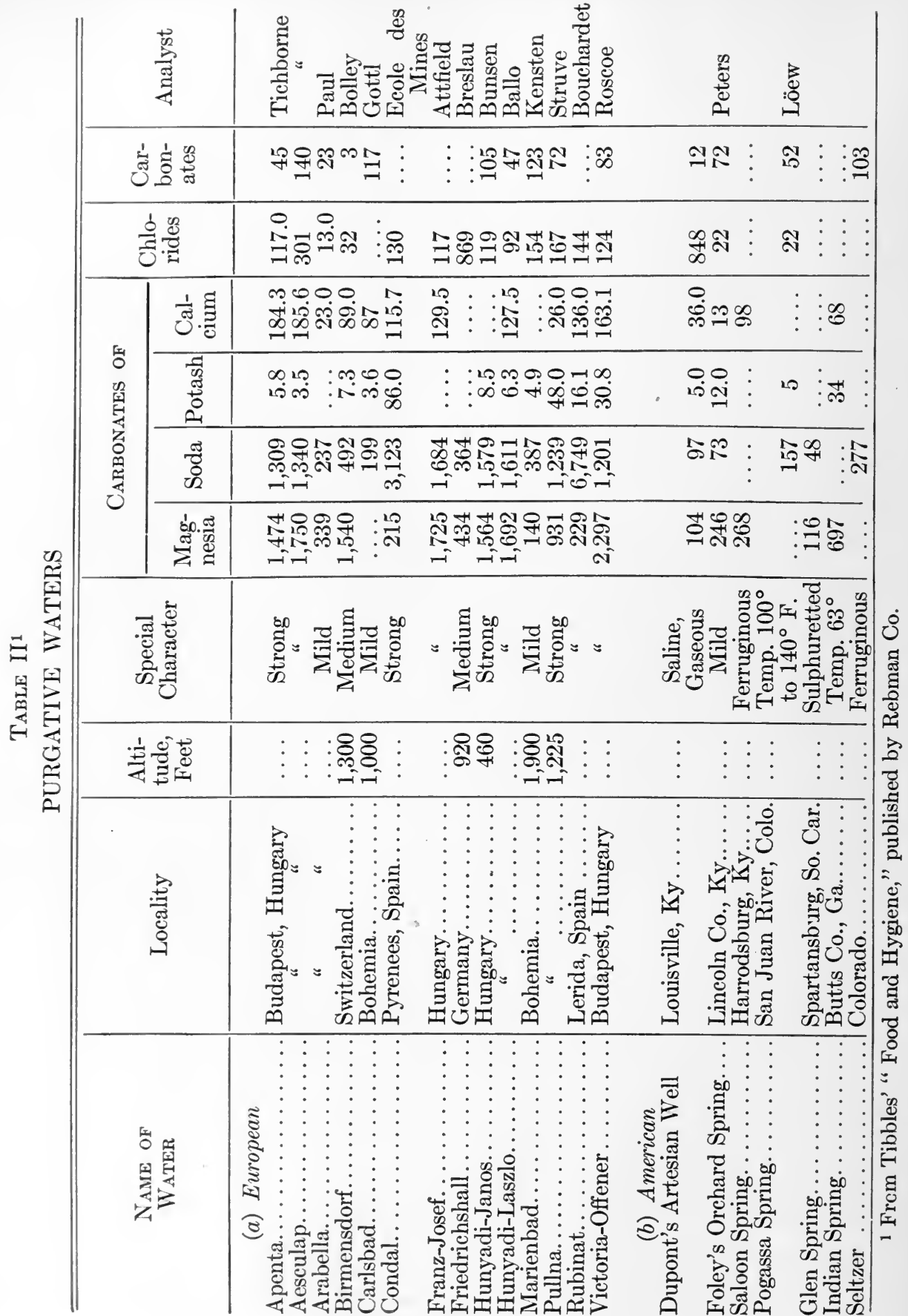


of the principal springs from which these waters are obtained are the Carlsbad and Marienbad in Bohemia, Keyser Spa in California, and Hot Springs in Arizona. In many cases of albuminuria they effect a reduction in the amount of albumin and exert a beneficial influence upon the injured kidneys. In urinary gravel-a sign of retarded metabolismthe alkaline waters have a characteristic effect; the acid reaction of the urine becomes less marked, the deposition of uric aeid ceases, and the urine becomes clear, bỉand and mirritating.

In addition to the alkaline waters given in Table III, on page 529, we enmmerate below, additional springs in the United States supplying alkaline waters(3), viz. :

\section{ALKALINE SPRINGS}

\section{SPRING}

LOCALITY

State

Blount Springs

Alabama

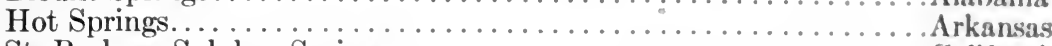

St. Barbara Sulphur Springs.

California

St. Helena Sulphur Springs

Ashley's Spring.

South Carolina

Glen Spring ..........
Nicholls' Spring

Onslow Alum Spring.

Plummer's Arsenic Spring.

Thomson's Spring.

Perry Spring.

Versailles Spring.

Daggy Spring.

Dewdrop Spring

Epsom Spring.

Hawkins' Spring.

Marian Artesian Well

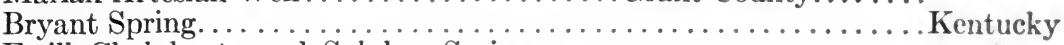

Estill Chalybeate and Sulphur Spring.

Field Spring.

Grove Spring. . .

Howard Spring. .

North Port Mineral Well.

Poland Spring.

Underwood Spring.

Clymnera Spring. .

Hubbardstone's Well.

Leslie's Spring.

Warner Spring. .

Birchdale Spring.

Concord Spring. . .

Jerusalem Spring.

Artesian Well. .

Calo Springs.

Lincoln County........

Pike County

Brown County......

Greencastle County... Indiana

Cherry Hill Springs

Wyandotte County... “

Wayne County...... "

Grant County........

Florida Spring.

Lebanon Spring.

Valley Springs.

Manor Estate.

Iona......

Ingraham.

Albion.

....

.............

New Hampshire

Vinslow

Brown's Mills

Otsego County.

Columbia

Otsego County
Maine

Maryland

Michigan

" "

New Jersey

New York

"

4 
SPRING

LOCALITY

STATE

Yellow Springs .....................Green County........ Ohio

Black Barren.......................Lancaster County.....Pennsylvania

Cresson's Springs. ......................... Cambria County......

Fayette Limestone and Chalybeate Spring. . Bedford County......

McVittey's Satilla Spring................. Huntingdon County..

Minnequa Springs .......................

Rock Springs..............................

Strummel's Lithia Spring. ..............Adam's County.......

Missequoi Spring. ....................Frankland. .........Vermont

Augusta Springs. . ............................... Virginia

Berkeley Springs....................................

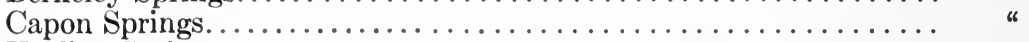

Healing Springs...................................... "

Jordan Springs. ........................................ "

Massanattan Spring.............................. "

Orkneys Spring................................ "

Rawley Spring....................................

Stribbeling's Spring....................................

(c) Saline Waters.-Saline waters are solutions of halogen compounds of the alkalies, commonly distinguished by the presence of large quantities of sodium chlorid. They also comprise solutions of calcium, potassium, lithium and aluminium chlorids, and may contain traces of bromin or iodin.

The simple sodium chlorid waters contain besides the sodium and other chlorids carbon dioxid in large quantities. The sodium chlorid increases the secretion of the mucous membranes, especially in the stomach. Those waters exert a markedly diuretic and laxative effect and are useful in chronic catarrh of the respiratory tract and of the alimentary tract.

The bromin and iodin waters contain bromin and iodin, in addition to the sodium and other chlorids. The bromin occurs in the form of sodium and magnesium bromid; the iodin in the form of magnesium iodid, calcium iodid and sodium iodid. These waters exert a special effect upon the lymphatic system and hasten absorption. They are of value in syphilis and diseases of the glands, as in goiter.

Lithium is often present in the simple sodium chlorid waters and is thought to be valuable in dissolving uric acid. It is questionable if such action occurs, yet these waters are markedly diuretic. Saline waters with a large percentage of lithium are useful in the treatment of gout, renal and urinary concretions. These mineral waters are useful in the so-called uric acid diathesis, gouty rheumatism, whether involving the joints or other parts, in gravel, stone and obesity, in fact in any condition due to defective metabolism. They have proved beneficial in numerous affections, neurasthenia, neuralgia, sciatica, chorea and paralysis; in blood poisoning, as by lead or mercury; in syphilis and in chronic skin dis- 


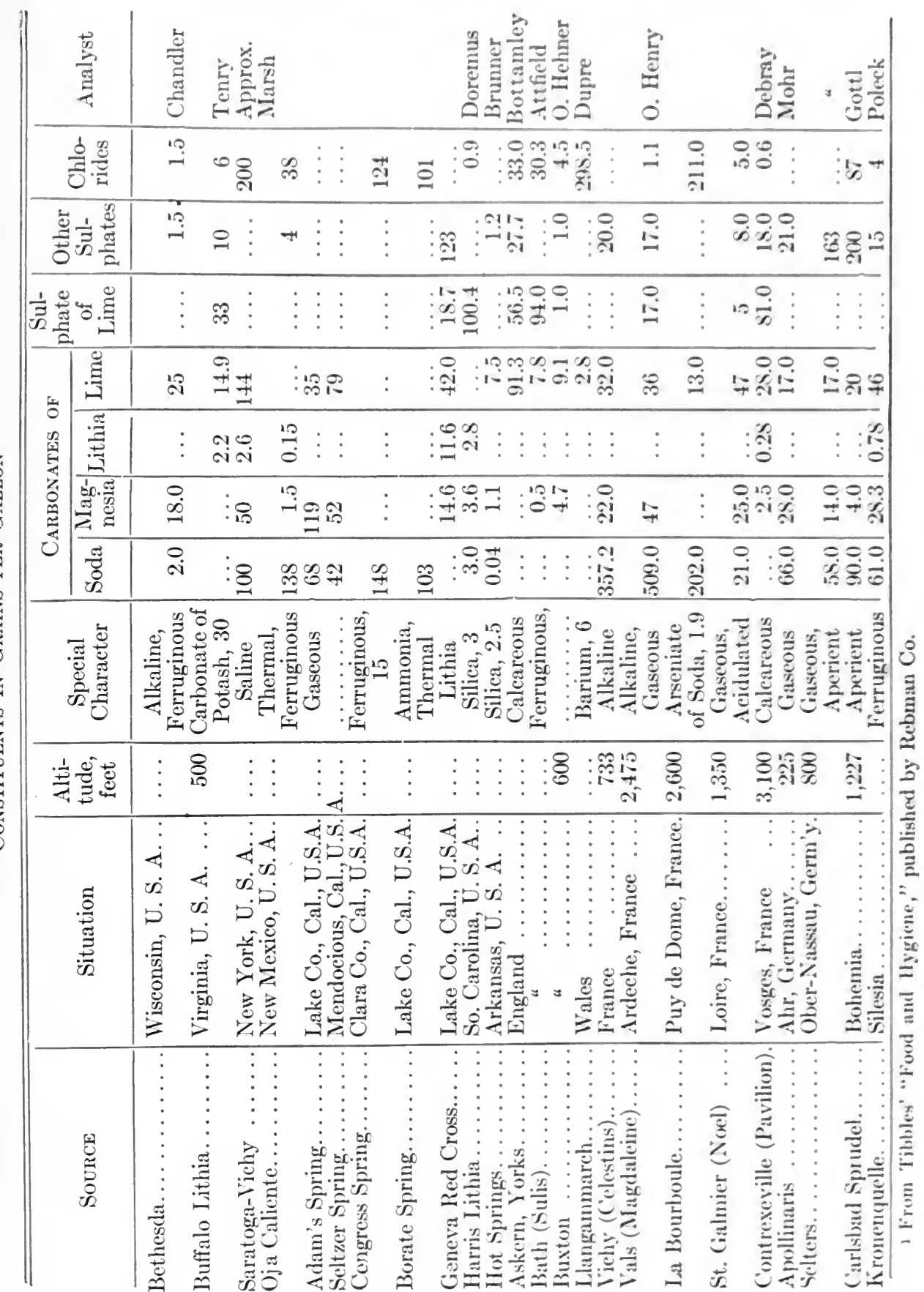


eases. The waters of Nauheim are much used in cardiac disease. The beneficial action of these waters is in great part due to their sodium chlorid content, although the effects of artificial solutions are inferior to those of the natural waters. The latter contain combinations of chlorids of the alkaline earths, and in some of them are large percentages of bromin and iodin; lithium, strontium and iron are found in others. The beneficial action of chlorids when ingested consists largely in the aid they render in the digestion of albumin and starch. They also induce a free, normal action of the alimentary mucous membrane; their absorption takes place quickly; they give the blood some of its most essential constituents, and by means of the circulation they are supplied to all of the body tissues and secreting organs. These properties make them useful in various types of dyspepsia in which secretion is abnormal, in torpidity of the liver and bowels, and in many conditions in which chronic inflammatory exudations exist.

Some of the more important American saline waters with analysis will be found in Table IV(4):

Thermal saline waters come gushing from the earth well heated, and are believed, by many persons, to possess special properties. Besides their internal use, most of the saline waters are used for baths, inhalations, sprays and douches, especially the thermal waters. Robin(5) names the conditions in which brine baths are useful, as: $(a)$ in all abnormal conditions in which nitrogenous excretion or nitrogenous exchange in the organism is decreased; $(b)$ in conditions in which nitrogenous oxidation is diminishing; $(c)$ and finally in conditions in which tissues rich in nitrogen and phosphorus are wasting. The effects of these baths vary with their strength. Baths of three-quarter strength are most beneficial when an increase of nitrogenous exchange or oxidation is not desirable, as in individuals who are losing weight, but this type of bath has little influence over chronic bone affections. Baths of half strength are of use in conditions in which nitrogenous exchange is decreased, as in strumous states, affections of the glands, and disorders of the joints and bones. Baths of full strength have a marked effect on organic changes, and so are valuable in rickets and other bone affections; in some nervous affections, in anemia and in auto-intoxications. By them the production of urea is diminished, but since they cause the oxidation of products of imperfect combustion and poisonous waste matters they are valuable in conditions of obesity, gout and the like. There has been lively conten. tion as to whether waters containing mineral salts when used for bathing produce more beneficial effects than ordinary water used for the same 


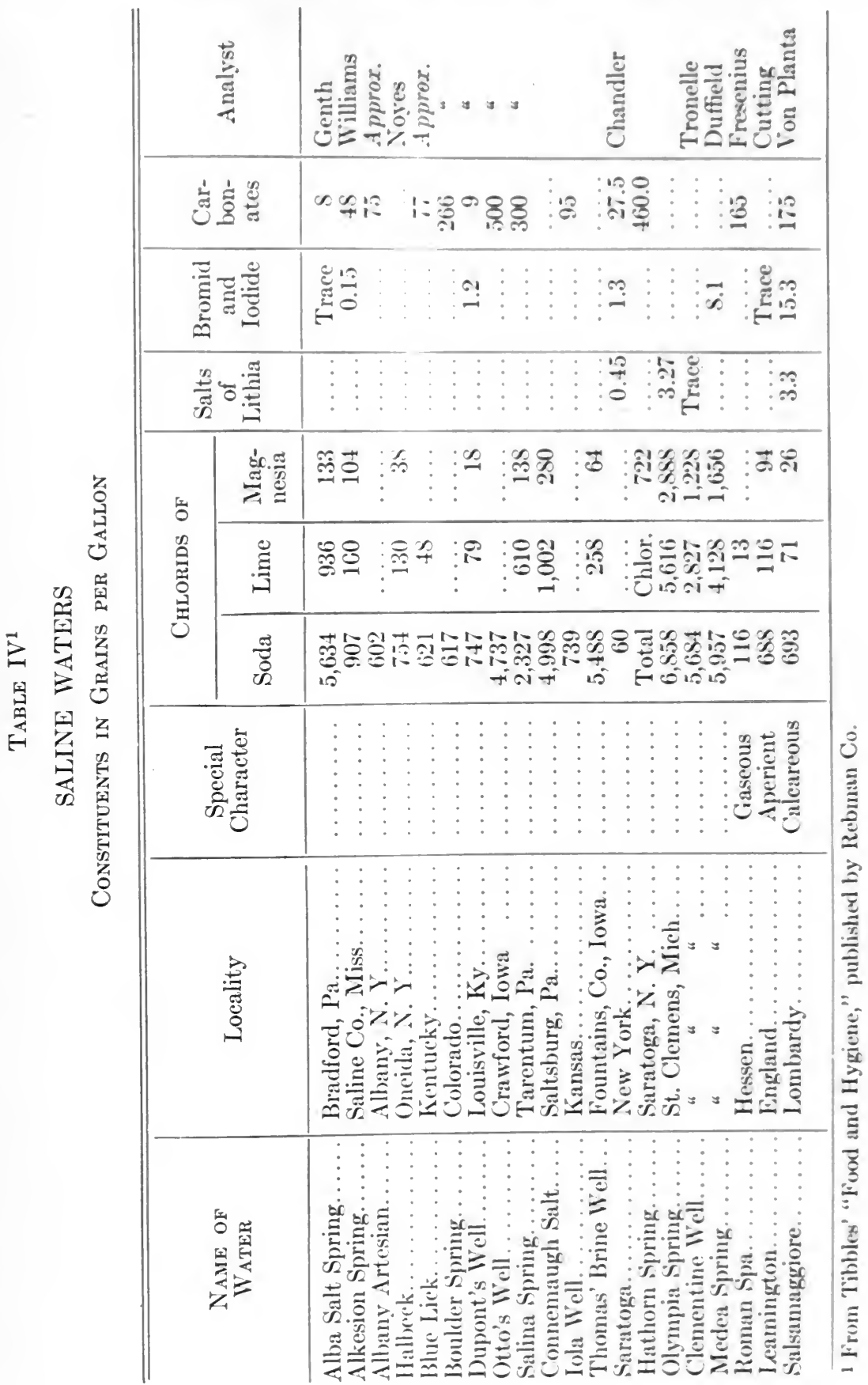


purpose. The accumulated experience of years points to the superiority of the mineral baths, for it has been demonstrated that fine crystals of these salts left on the skin after the bath continue.their beneficial influence.

(d) Cinnlybate and Ferruginous Waters.-Chalybeate and ferruginous waters contain large proportions of iron; they are divided into carbonated iron waters, sulphated iron waters, iron and arsenic waters. The waters containing earbonate of iron also contain large quantities of carbon dioxid. These waters increase the number of the red blood-cells and the amount of hemoglobin. They stimulate the appetite, but are prone to produce constipation. 'They are indicated in chlorosis and in anemia.

Sulphated iron waters contain large percentages of ferrous sulphate, and in addition to the sulphate of sodium, magnesium and ealcium sulphate. Many of these waters also contain arsenie, alum and sulphuric acid in small amounts. These waters are indicated in cases of chronic diarrhea, in anemic children, in chronic gastric conditions, in ulcer of the stomach and in chronic malarial poisoning. They should be prescribed with eaution as they are prone to produce indigestion and nausea. Sulphated iron waters are best taken in small doses.

The iron and arsenic waters contain considerable quantities of arsenic in addition to iron; they are indicated in chlorotic and anemic conditions, in chronic malaria and in neuralgias. They also serve as tonies for the blood and nerves, but if given over too long a period of time they may cause dyspepsia. The indications for the use of these waters are the same as for iron in other forms-debility, anemia, chlorosis and other states of the blood in which the cells are defective in quantity or quality, as for instance in diseases of the female generative organs.

Some of this class of waters also contain the sulphates of soda and magnesia, called the purgative chalybeate waters. These waters are employed in diseases that have shown the beneficial influence of bitter purgative waters. Waters containing alum are very useful in the treatment of chronic catarrh of stomach and intestines, partieularly when diarrhea is present. The alkaiine chalybeate waters are beneficial in disorders of stomach and intestines, in diabetes, Bright's disease, renal stone, and gravel; also in certain diseases of the nervous system, as hysteria. chorea and epilepsy. Saline chalybeates, including the Homburg waters, having tonic and laxative properties, are of value in sluggishness of liver and intestines; in gallstones, hepatic congestion, hemorrhoids, plethora and conditions favored by a life of luxury. Kreuznach 
water and others containing large amounts of chlorids are of use in lymphatic disorders, tubercular affections of glands, joints and bones; in diseases of the nervous system, including paralysis, and in rheumatic and gouty conditions.

In addition to the ferruginous waters given in Table V (Tibbles), we enumerate below other American waters containing from 21 to 25 grains of sulphate of iron to the gallon:

\section{AMERICAN FERRUGINOLS WATERS}

Spring

Kittanning Springs.

Alum Springs.

Alum Springs.

London Alum Water.
LOCALITY

Armstrong.

Bath County.

Bedford County

Campbell County...
State

Pennsylvania

Virginia

"

Other American waters containing oxid of iron are:

Spring Grains Locality State

Congress Spring ................. Santa Clara County..California

River Spring. .................. 4...Este's Park.........Colorado

Oswassee Spring. ................12 . . Shiawassee............ Michigan

Arien Spring................. 5 ...Jackson County. ..... Missouri

Richfield Spring............... 5 ... Otsego County....... New York

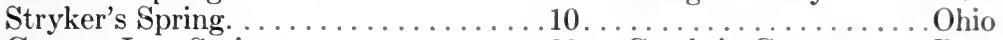

Cresson Iron Spring. .............29 . . Cambria County...... Pennsylvania

Thorpe's Spring .................. 40 ...Hood's County....... Texas

Rock Enon Spring. ............. 14 . . Frederick County.....Virginia

(e) Sulpingous Waters.-Sulphurous waters(6) contain hydrogen sulphid or some other sulphur compound such as sodium, ealcium, magnesium or potassium sulphid. The sulphurous waters are obtained hoth hot and cold; they are especially useful in the treatment of syphilis and chronic lead-poisoning, in hemorrhoidal conditions and congestions of the liver. They are also beneficial in many chronic skin diseases, blood poisons, nervous diseases, chorea, tuberculosis, glandular affections of children and tuberculous diseases of bones and joints, uterine ailments and in respiratory diseases. They are of value in atonic dyspepsia, catarrh of the stomach and hepatic congestion. As a bath or douche, these waters are exceedingly valuable in chronic skin diseases, rheumatism, enlarged or stiffened joints, contracted tendons or muscles. 


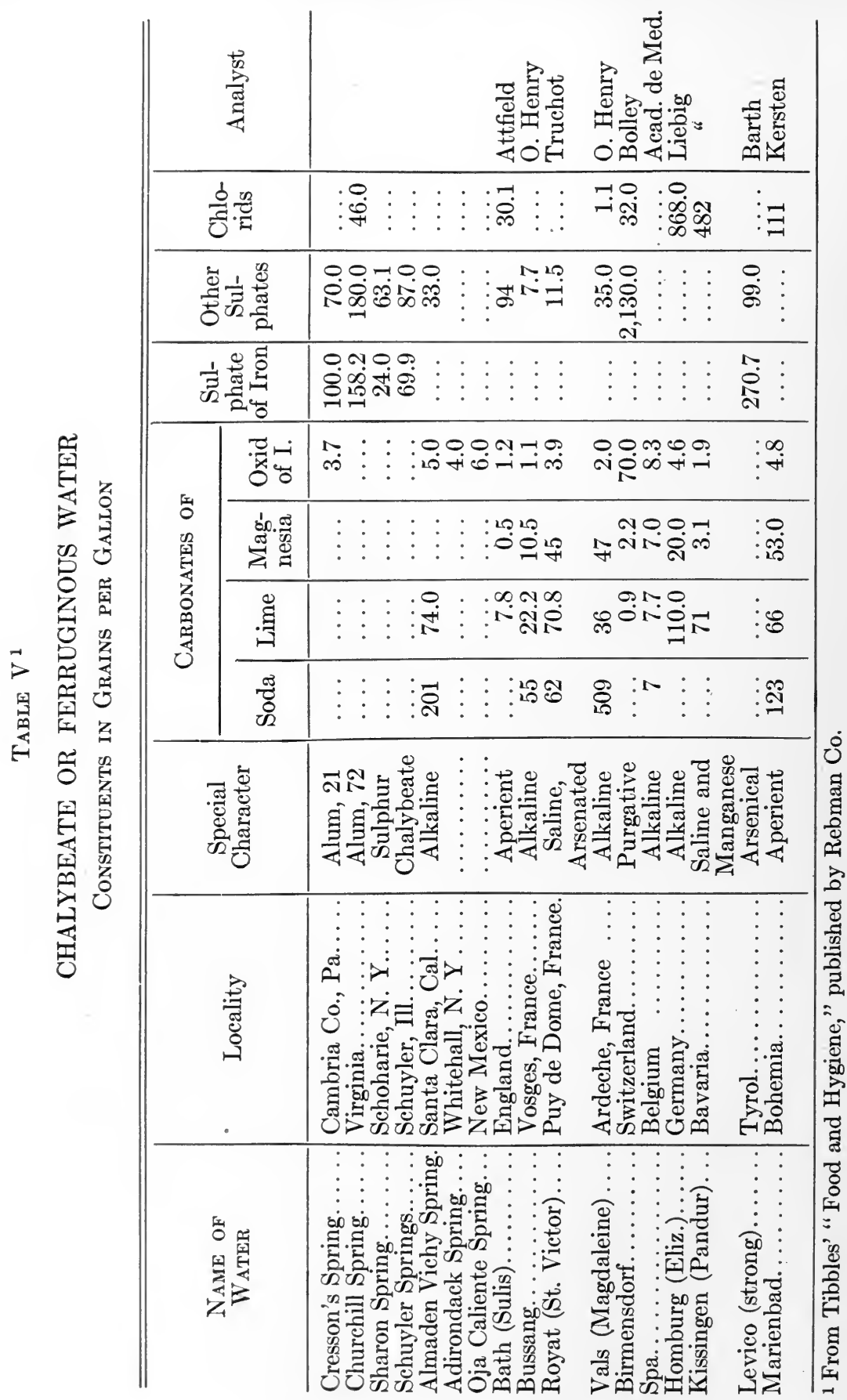


Tho most renowned sulphuretted waters in the United States are found as follows:

\section{Spring}

Valhemosa Spring.

Hot Springs.

Hot Sulphur Springs

Nysa Springs.

Pasa Robels Hot Springs

St. Helena White Sulphur Springs

Manley Springs.

Shorio Springs.

Glenn's Springs

Canon Springs.

Pogassa Hot Springs

Portea Springs. ...

Bladon Springs.

Indian Springs.

French Lick Spring

Indian Springs. .

Lodi Artesian Springs

West Baden Springs.

Blue Lick Springs.

Dremion Springs.

Olympian Springs

De Soto Springs.

White Sulphur Springs.

Alpena Springs.

Ypsilanti Springs

Motesano Springs

St. Louis Springs. .

Sweet Springs.

White Sulphur Springs

Las Vegas Springs.

Avon Spring.

Balston.

Longman's Well.

Richfield Springs. ...

Saratoga Springs.

Sharon Springs.

Delaware Sulphur Spring.

Deschutes Spring.

- Carlisle Spring. .

Minnequa Spring.

Hagers Spring.

Castilian Springs.

Highdate Springs.

Missequoi Springs

Sheldon.

Hot Springs.

Hot Sulphur Springs

Buffalo Springs.

Sulphur Springs

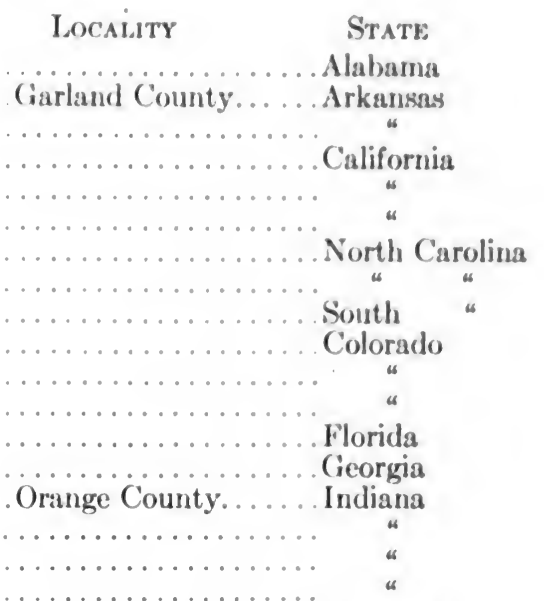

Kentucky

"

Louisiana

Michigan

Missouri

Montana

New Mexico

Livingstone........ New York

Rochester............ " "

44

44

$\omega 4$

Ohio

Oregon

Pennsylvania

Tennessee

Sumner County .....

( $f$ ) Calcic Waters.-Calcic waters are characterized by the presence of large amounts of calcimm and magnesium salts. They diminish the production of acid in the stomach and also lessen the secretion of the 
respiratory, digestive and urinary tracts. They are indicated especially in chronic catarrh of the urinary organs, in uric acid diathesis, gout, glandular tuberculosis and rachitis. These waters should be prescribed at first in small quantities and gradually increased until the flow of urine is markedly increased.

The principal calcic waters are:

SPRING

STATE

Bethesda Spring ...................Wisconsin

Birchdale Spring ................... Vermont

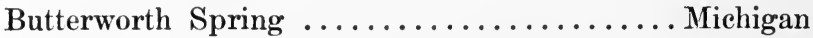

Clarendon Spring ................... Vermont

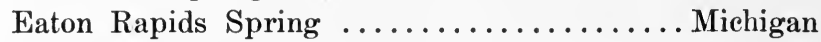

Gettysburg Spring .................... Pennsylvania

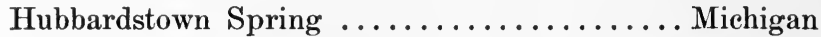

Silurian Spring..$\ldots \ldots \ldots \ldots \ldots \ldots$ Wisconsin

The chemical composition of the most important calcic mineral waters is as follows $(6)$ :

CHEMICAL COMPOSITION OF CALCIC WATERS

\begin{tabular}{|c|c|c|c|}
\hline SPRING & $\begin{array}{l}\text { Calcium } \\
\text { Sulphate }\end{array}$ & $\begin{array}{c}\text { Calcium } \\
\text { Bicarbonate }\end{array}$ & $\begin{array}{l}\text { Calcium } \\
\text { Carbonate }\end{array}$ \\
\hline 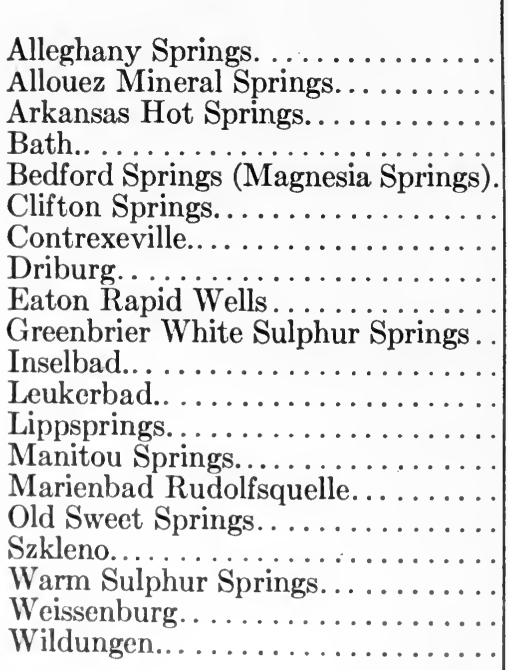 & $\begin{array}{c}\text { Grams } \\
1.80 \\
1.80 \\
1.80 \\
1.50 \\
1.84 \\
1.18 \\
1.10 \\
1.04 \\
0.77-0.94 \\
1.33 \\
\ldots . .42 \\
0.82 \\
0.82 \\
0.82 \\
0.22 \\
0.22 \\
0.24 \\
0.24 \\
2.00\end{array}$ & $\begin{array}{c}\text { Grams } \\
\ldots . .42 \\
0.42 \\
0.42 \\
0.42 \\
0.42 \\
0.45 \\
1.44 \\
1.44 \\
1.44 \\
0.30 \\
0.09 \\
0.41 \\
0.41 \\
0.60 \\
0.60 \\
0.10 \\
0.10 \\
1.27 \\
1.27\end{array}$ & $\begin{array}{c}\text { Grams } \\
0.06 \\
0.47 \\
0.12 \\
0.12 \\
0.12 \\
0.16 \\
0.16 \\
0.16 \\
0.34-0.78 \\
0.12 \\
0.12 \\
0.12 \\
0.12 \\
0.40-1.11 \\
0.40-1.11 \\
0.51 \\
0.51 \\
0.08 \\
0.08 \\
0.08\end{array}$ \\
\hline
\end{tabular}

(g) Therana Waters.-The principal thermal springs in the United States are in Arizona, Arkansas, California, Colorado, Idaho, Michigan, 
New Mexico, Oregon, Utah and Virginia; many of them have alrealy been particularly mentioned. Some of these springs flow from the earth in the neighborhood of old extinct volcanoes; their temperature is very great, from $150^{\circ} \mathrm{F}$. to $195^{\circ} \mathrm{F}$. These waters do not, however, contain any active mineral ingredients. They are rarely used for drinking purposes, but are used mainly for thermal baths. The places where these springs are located are important watering places where baths of the most luxurious and elaborate description are provided. The waters are used in every conceivable form for therapentic purposes. Great curative powers are claimed for these waters in gout and rheumatism in the joints and elsewhere; in nervous disorders, as in nenrasthenia, sciatica, paralysis; in spinal disorders and chronic diseases of bones and joints. The treatment is aided by climatology, trophotherapy, thermotherapy, electrotherapy, massage, Swedish and other gymnastic movements.

Mud Baths. - At some of the watering places, mud baths are very popular. They are prepared by mixing well seasoned earth containing more or less of the mineral substances which make the water of medicinal value. Slime baths consist of the mud from the bottom of a pond or river, which is rubbed over the body before bathing. Each of these methods is supposed to accentuate the action of the water in certain cases. Mud baths are claimed to be useful in chronic rheumatism, gout and the various uterine ailments of women. They are contra-indicated in valvular diseases of the heart and chronic Bright's disease. Carbonic acid baths are indicated in neurasthenia, discases of the reproductive organs and sexual impotency. The principal thermal waters in the United States are to be found in the following locations: Arkansas, Arizona, California, (Buncombe County) North Carolina, (Charleston Artesian) South Carolina, Colorado, (Merriweather) Georgia, Idaho, Michigan, (Volcano) Nebraska, New Mexico, Oregon, Utah, Virginia and West Virginia.

WATER CURES.-In order to obtain the best results from water cures, they should always be carried out at the resorts. Under exceptional circumstances a water cure may be ordered at the patient's home, but the results are never quite so satisfactory as when the patient goes to a watering place. For not only will he have the advantage of the baths and water at the springs, but also in addition, the value of the change of climate, scene, plenty of outdoor exercise and freedom from care and worry.

The methods and the diet at the different institutions vary greatly and for the most part umnecessarily so. In many of these watering places methods are empiric and are not founded on any sound basis. Certain 
foods are forbidden for the most fanciful reasons. Again, the routine and diet at many resorts are alike for all patients, regardless of their ailments. An important factor overlooked at these water-cure resorts is the abuse of drinking water. Patients with weak hearts, chronic nephritis or those suffering from atony or dilatation of the stomach may take a considerable amount of water without overtaxing the excretory organs.

For instructions as to diet in the various diseases, the reader will be referred to Volume III of this work.

Water Drinking.-Hawk(7), in a series of beautiful and convincing experiments, arrived at the conclusion that copious water drinking caused an increased excretion of nitrogen and phosphorus in the urine. The increase in the amount of nitrogen eliminated is due, primarily, to the washing out from the tissues of the urea the nitrogen previously formed, but not removed by the normal processes, and secondarily, to a stimulation of the protein catabolism. The increase in the excretion of phosphorus is due to increased cellular activity and the accompanying catabolism of nucleins, lecithins and other phosphorus-containing bodies.

Strauss(8) says that increased supply of liquids increases the excretion of the products of protein metabolism, but does not hasten the metabolism itself. The excretion of liquids is accompanied by loss of body weight dependent on removal of nitrogen waste, but not on loss of fat.

WATER DRINKING AT MEALS.-Fowler and Hawk(9), continuing their studies on water drinking in the human subject, investigated the effect of the copious ingestion of water with meals. The subject of the experiment was placed on a normal, constant diet and by means of a preliminary period of sufficient length, was brought to a condition of approximate nitrogen equilibrium. At this point one thousand cubic centimeters of water were added to each meal and continued thus through a period of five days. Immediately following this period came a final period of eight days, during which the original normal constant diet was again maintained and the after-effects of the copious water ingestion observed.

Final Conclusions.- In view of their experiments, they regard the current statements respecting the exceedingly harmful influence of water drinking with meals as misleading and arrive at the following conclusions:

The daily drinking of three liters of water with meals, for a period of five days, by a man twenty-two years of age, who was in a condition of nitrogen equilibrium through the ingestion of a uniform diet, produced the following findings:

1. An increase in body weight, aggregating two pounds in five days. 
2. An increased secretion of urinary nitrogen; with excess nitrogen being mainly in the form of urea, ammonia, and ereatin.

3. A decreased excretion of creatinin and the coincident appearance of creatin in the urine. The decreased creatinin outp'st is believed to indicate that the copious water drinking has stimulated protein katabolism. The appearance of creatin is considered evidence that the water has caused a partial muscular disintegration resulting in the release of ereatin, but not profound enough to yield the total nitrogen content of the muscle. The output of creatin is, therefore, out of all proportion to the increase of the excretion of total nitrogen.

4. An increased output of ammonia, which is interpreted as indicating an increased output of gastric juice.

5. A decreased excretion of feces and of fecal nitrogen, the decrease in the excretion of fecal nitrogen being of sufficient magnitude to secure a lowered excretion of both the bacterial and the non-bacterial nitrogen.

6. A decrease in the quantity of bacteria excreted daily.

7. An increase in the percentage of total nitrogen appearing as bacterial nitrogen.

8. A lower ereatinin coeffieient.

9. A more economical utilization of the protein eonstituents of the diet.

10. The general conclusion to be reached as the result of this experiment is to the effect that the drinking of a large amount of water with meals was attended by many desirable and by no undesirable features.

\section{BEVERAGES}

In addition to water, there are a number of beverages that serve not only to meet the physical needs of the human economy, but are also taken for their stimulating effect. These beverages afford the stimulation which is necessary in certain diseased conditions and at the same time take the place of water as a beverage. The habit of imbibing socially for the purpose of conviviality unfortunately leads sometimes to the pernicious habit of taking such drinks to excess.

From time immemorial, the ingenuity of man has supplied mildly stimulating non-intoxicating beverages from various vegetable substances. It is somewhat surprising that people of different nationalities, living at different epochs in and under widely different conditions of civilization, should have felt the necessity for, and appreciated the satisfaction to be derived from, the use of this class of beverages. It is even more remarkable that in the beginning they should have selected the plants for making them that continue in use for the same purpose trday.

The all important eonstituent contained in these beverages is an alkaloid, a nitrogenous substance containing stimulating properties. Tea, coffee and cocoa contain, besides this alkaloid, a rolatile oil which imparts an agreeable odor and taste to the beverage and a considerable amount of an astringent principle related to tannin, which modities the taste besides exerting its specific physiological action. Before describing these 
beverages, it will be instructive to review briefly the history, mode of manufacture and chemistry of each of them, then to consider their uses in the diet and their action on digestion as a whole.

Varieties of Beverages-TEA.-Tea, the leaves of Thea Sinensis, a subtropical plant introduced into Europe by the Dutch East India Company, is believed to have had its origin in Assam and Burmah. The plant grows wild in the mountainous regions which separate India from China. There are authorities who allege that tea was grown in China before 519 A. 1. Reliable authorities state that tea was introduced into Japan in the thirteenth century. Mr. Pepys, writing in his diary in 1660, says, "I sent for a cup of tea, a China drink, of which I had never drunk before." In 1664 the East India Company considered a gift of two pounds of tea to the Queen of England a rare gift. A tea house was established in London in 1657 that sold tea at fifty dollars per pound. Besides China, Japan and Assam, tea is grown in Ceylon, Java and Brazil and for the past ten years tea has been successfully grown in South Carolina. The plant grows best in sub-tropical countries where the rainfall is at least sixty inches or more.

The tea plant when cultivated grows to the height of three or four feet, but if allowed to grow without pruning, it may attain a height of forty or fifty feet. The plants are obtained from seeds and when planted in rows four feet apart and four feet distant, attain in two years a height of two feet. They are cut back to ten inches high and after another year back to fifteen inches high. At three years the mature tree includes a great number of young shoots three feet in height. The plant flushes or sends out shoots four times a year, when the young leaves are ready to pick. The leaves are picked irregularly; some farms pick every fortnight, others only twenty times per year. They are carefully picked with the thumb and forefinger. One hundred pounds of fresh leaves yield about twenty-five pounds of tea.

Green and Black Tea.-Tea is not green or black according to separate species of tea plant, but derives its color from the difference in mode of treatment of the same plant. Green tea is made in Japan by steaming the leaves before they are rolled and dried, while the Chinese wither the leaves in a pan at the temperature of $160^{\circ} \mathrm{F}$. Black tea is obtained by allowing the green leaves to wither in the sun; then they are rolled until they become soft and "mashy," the object being to break up the fibers and cells of the leaf and liberate the constituents, so that they may afterwards be more easily extracted. They are then made into balls and allowed to ferment. 
The process of fermentation oxidizes a certain portion of the tannin in the leaves, converting it into less soluble forms while the essential oil content is increased and a certain amount of bitterness developed. When the fermentation is complete, the leaves are again exposed to the sun and dried in an oven. The main difference, then, between green and black tea lies in the fact that black tea is fermented while the green is not.

Quanity of 'Tea.- The quality of the tea depends somewhat upon the age of the leaves when picked, the younger leaf yielding the best tea. Apart from this cause of variation, teas show marked difference in "body" according to the country and district in which they are produced.

The principal agent that imparts "body" and flavor to tea is oxydase, an enzyme found in the unopened tip-leaf of the young shoot(10), which diminishes with its growth and expansion. The proportion of this enzyme present in a given sample depends in a measure upon the amount of phosphates in the soil. The enzyme increases during the preparation of the tea as the leaf withers. The leaves containing the highest percentage of the enzyme make the most highly flavored tea.

Cinina and Indian Teas. - The most famous China teas are: Congou, Oolong, Formosa, Souchong and Bohea (black teas); Hyson, Twankay and Gunpowder (green teas). India Assam or Assam Pekoe are good teas. A good blend is made of China Assam and Ceylon teas together. China tea, such as Moning Congou, is very suitable for persons with weak digestive organs. The Indian teas, especially those produced in Assam, are very strong. Their astringent properties make them powerful teas, not well suited for brewing alone. They are admirable for blending with milder varieties.

Composition of B Back and Green Tea.--The following table from Bamnister(11) gives the composition of black and green tea:

ANALYSIS OF GREEN AND BLACK TEA

\begin{tabular}{|c|c|c|}
\hline Constituents & Black Tea & Green Tea \\
\hline 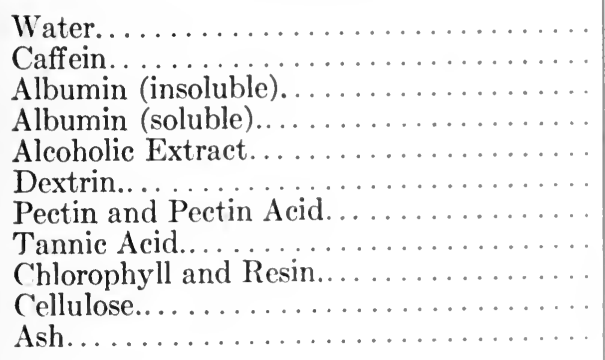 & $\begin{array}{r}8.20 \\
3.24 \\
17.20 \\
0.70 \\
6.79 \\
2.60 \\
2.60 \\
16.40 \\
4.60 \\
34.00 \\
6.27\end{array}$ & $\begin{array}{r}5.96 \\
2.33 \\
16.83 \\
0.80 \\
7.05 \\
0.50 \\
3.22 \\
27.14 \\
4.20 \\
25.90 \\
6.07\end{array}$ \\
\hline
\end{tabular}


It will be observed in studying the above analysis that tea contains practically no nutrient ingredients. Its principal constituents are caffein and tannic acid. Its special aroma is due to a volatile oil. Since tannic acid is detrimental to the process of digestion, tea should be so prepared as to contain the smallest possible amount of tannin and the greatest proportion of caffein obtainable.

Notwithstanding that green and black tea is produced from leaves from the same bush, their composition, as we have seen, is not quite the same. As previously stated, this difference arises from the method of preparation. The amount of tannic or gallo-tannic acid diminishes from 13 per cent in fresh leaves to 10 or 11 per cent in green, and to less than 5 per cent in black; there is an increase in the proportion of volatile oil and amido-nitrogen resulting from the fermentation in the black tea.

These differences are graphically shown in the following analyses by Kozai(12) :

COMPOSITION OF TEA-LEAVES BEFORE AND AFTER PREPARATIONPERCENTAGES

\begin{tabular}{|c|c|c|c|}
\hline Constituents & $\begin{array}{c}\text { Fresh Leaves } \\
\text { before } \\
\text { Treatment }\end{array}$ & $\begin{array}{l}\text { Made into } \\
\text { Green Tea }\end{array}$ & $\begin{array}{l}\text { Made into } \\
\text { Black Tea }\end{array}$ \\
\hline 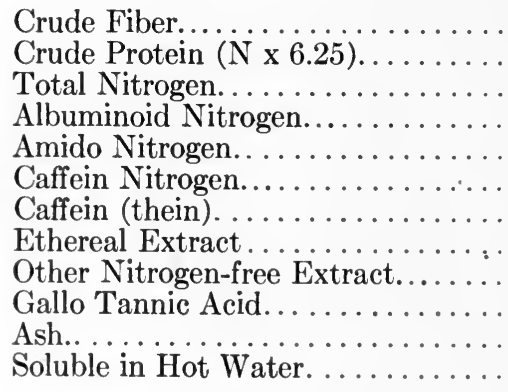 & $\begin{array}{r}10.44 \\
37.33 \\
5.97 \\
4.11 \\
.91 \\
.96 \\
3.30 \\
6.49 \\
27.86 \\
12.91 \\
4.97 \\
50.97\end{array}$ & $\begin{array}{r}10.06 \\
37.43 \\
5.99 \\
3.94 \\
1.13 \\
.93 \\
3.20 \\
5.52 \\
31.43 \\
10.64 \\
4.92 \\
53.74\end{array}$ & $\begin{array}{r}10.07 \\
39.90 \\
6.22 \\
4.11 \\
1.16 \\
.96 \\
3.30 \\
5.82 \\
35.39 \\
4.89 \\
4.93 \\
47.23\end{array}$ \\
\hline
\end{tabular}

The composition of a cup of tea is of far greater practical importance than the leaves from which it is made. In "drawing" a cup of tea, if prolonged heat is used, the percentage of tannic acid will be greater. Tea leaves should therefore be in contact with the hot water only just long enough to extract the volatile oil and some of the caffein. If tea is infused in the usual way, about 25 per cent of the leaf goes into solution. The caffein content is so soluble that it is all practically dissolved out immediately the infusion is begun, which is not the case with tannic acid. There is much less tannic acid after infusing five minutes than after 
infusing fifteen minutes. The following experiment by Hughes(1:3) bears this out:

\begin{tabular}{|c|c|c|}
\hline & $\begin{array}{c}\text { Five Minutes' } \\
\text { Infusion }\end{array}$ & $\begin{array}{c}\text { 'Thirty Minutes' } \\
\text { Infusion }\end{array}$ \\
\hline Assan & 10.35 per cent & 14.76 per cent \\
\hline Ceylon & S.60 " " & 10.88 " \\
\hline China & $7.50 \quad$ " & $9.40 \quad$ " \\
\hline
\end{tabular}

Hutchison conducted a mumber of experiments to determine the quantity of eaffein and tannic acid in an ordinary cup of tea drawn or in. fused in the usual way and arrived at the following conclusions:

CAFFEIN IN TEAS '

\begin{tabular}{|c|c|c|}
\hline TEA & $\begin{array}{l}\text { Caffein in } \\
\text { Grammes } \\
\text { per } 150 \text { c.c. }\end{array}$ & $\begin{array}{l}\text { Grains } \\
\text { per } \\
\text { Teacup }\end{array}$ \\
\hline 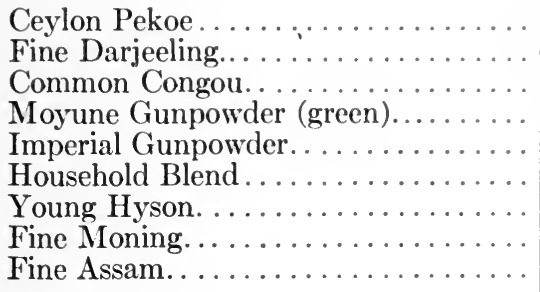 & $\begin{array}{l}0.0787 \\
0.0751 \\
0.0745 \\
0.0645 \\
0.0590 \\
0.0580 \\
0.0547 \\
0.0510 \\
0.0475\end{array}$ & $\begin{array}{l}1.21 \\
1.05 \\
1.14 \\
0.99 \\
0.90 \\
0.89 \\
0.84 \\
0.78 \\
0.73\end{array}$ \\
\hline
\end{tabular}

TANNIN IN TEAS?

\begin{tabular}{|c|c|c|}
\hline TEA & $\begin{array}{l}\text { Tannin as Gallo- } \\
\text { tannic Acid per } \\
150 \text { c.c. of Infusion }\end{array}$ & $\begin{array}{l}\text { Grains } \\
\text { per } \\
\text { Teacup }\end{array}$ \\
\hline 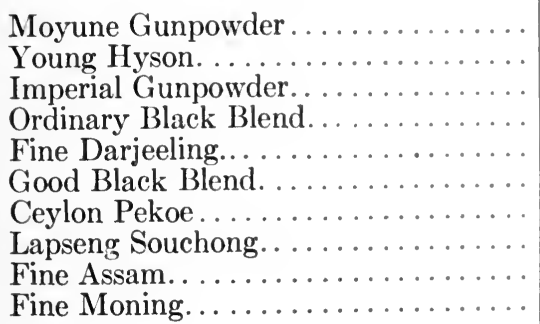 & $\begin{array}{l}0.273 \\
0.242 \\
0.227 \\
0.173 \\
0.168 \\
0.168 \\
0.142 \\
0.087 \\
0.080 \\
0.058\end{array}$ & $\begin{array}{l}4.20 \\
3.72 \\
3.49 \\
2.66 \\
2.55 \\
2.55 \\
2.18 \\
1.33 \\
1.23 \\
0.89\end{array}$ \\
\hline
\end{tabular}

1 Eight grams of dry leaf were infused with 300 c.c. boiling water for five minutes. The caffein was estimated by Allen's method.

2 Eight grams of the dry leaf were infused for five minutes in 300 c.c. of water, and the tannin estimated by Procter's modification of Lowenthal's process. 
Proper Method of Infusing Tea.-In spite of the popularity of tea as a beverage, it is comparatively rare to get a really good cup of tea. For this reason it is thought well to give some suggestions for the proper method of infusing tea, based on the facts as to its chemistry which we have just been considering.

The first point in "drawing" a cup of good tea is, it should be infused, not boiled or stewed, as is often the case. The water is of prime importance; it should not be too hard, as the presence of lime salts will interfere with the extraction of certain constituents of the tea leaf. If the water is hard, add a pinch of bicarbonate of sodium to the teapot. On the other hand, water which is too soft seems to extract an excess of the bitter principle from the leaf.

The Chinese rule is, "Take the water from a running stream; that from the hill springs is best, river water is the next and well water is the worst of all." The point to be emphasized is that the water should be aërated. Prolonged boiling drives out the dissolved air and leaves the liquid flat. Therefore, the water should have been barely brought to the boiling point. It never should be allowed to simmer, as with such water good tea can never be made.

The quantity of tea to be used is a matter of great moment if good tea is desired. Tea tasters recommend forty-three grains of tea to three and one-half ounces of water as the proper proportions. The domestic rule is two teaspoonsful of tea to a pint of boiling water. Allow it to stand for five minutes, when it is ready to pour. The above rules, if followed, will infuse good tea of sufficient strength for most persons, provided the tea is of good quality. If allowed to stand longer, the aroma is spoiled; more tannin, as well as other astringent principles and coloring matter, is extracted; the infusion is made rough and bitter to the taste and unwholesome. Before the tea leaves are placed in the pot, it should be scalded to insure the proper temperature of the water when ready to start the infusion.

Most Europeans add sugar and cream to the tea as it is poured, claiming its deliciousness is increased thereby. This in the eyes of an oriental connoisseur would be considered an outrage. Such a practice is to be condemned on hygienic grounds, as it is known that the albuminous matter of the milk tends to throw down some of the tannic acid of the tea in an insoluble form. Sugar, on the other hand, does not in any way increase and it may detract from the healthfulness of the beverage. It does increase its nutritive value. 
Amount of Tea Consumed,-It is estimated that the amount of tea used in one year per capita in the United States is one pound, while in England it is six pounds and in Australia seven pounds. The consumption of this more or less innocent stimulating beverage increases with the world's population and exceeds $2,500,000,000$ pounds a year. In the year 1912 there was imported into the United States 98,706,241 pounds, nearly one pound for each inhabitant. Tea tasting has become a highly perfected art. Tea blenders employ high-salaried men to determine the flavor, aroma, body and strength of infusions of different varieties of tea.

COFFEE.-Coffee, the fruit of Coffea arabica, natural order of Rubiacea, is a native of Arabia and Abyssinia, but is grown extensively in many tropical countries(14). Coffee has been used in Abysinia from time immemorial, but as a beverage it has been traced to the Persians, who began its use in $875 \mathrm{~A} . \mathrm{D}$.

The genus coffea comprises a number of species, perhaps thirty, but the Coffea arabica is the variety most highly prized and which possesses most valuable properties. The seeds of C'offea mauritiana, prepared in the same way as Coffea arabica, are bitter and slightly emetic.

The Coffea arabica tree, if grown in a wild state, attains a height of fifteen to twenty-five feet, with few branches; in cultivation it is seldom allowed to become more than ten or twelve feet high and is made to assume a sort of pyramidal form, with horizontal branches almost from the ground. The leaves are evergreen and leathery; the flowers are small, fragrant and snow white. The whole appearance of the tree is pleasing. The fruit, when ripe, is a dark, scarlet colored, fleshy berry about the size of a cherry, containing two seeds or beans in each berry. These seeds, commonly termed "coffee beans," are horn-like and hard. A prolific bearing tree will usually produce a pound of coffee beans.

The coffee trees begin to bear when three to five years old and usually' produce good crops for the next twenty years. They are raised from seeds planted in nurseries. When eighteen months old the "slips" are transferred to the coffee plantation in rows eight to ten feet apart and the same distance between. The coffee tree continues flowering for about eight months in the year, so that its beans are of uneven ripeness; in Brazil and the West Indies three gatherings are made annually.

The beans are placed on mats on large floors, especially constructed for the purpose, where they are dried by the sun's rays, being frequently turned to permit the full effect of the heat to reach all sides of the bean. When thoronghly dried they are passed between large rollers to remove 
the dried pulp of the bean and the membrane which encloses the beans themselves, and the coffee is afterwards freed from impurities by winnowing, filled into bags and transferred to seaports for shipment.

The kinds or varieties of coffee best known to commerce are Mocha from Abyssinia; Mysore from East India, Java and Ceylon; Jamaica from West Indies, St. Domingo, Cuba and New Granada. Brazilian coffee comes from Rio Janeiro and Santos and from Colombia.

Mocma Coffee.-The Mocha coffee brews the finest cup of coffee in the world, but it is a question if the genuine Mocha ever reaches either the United States or England. However, a large amount of so-called Mocha, which is not to be compared to the genuine Mocha, comes from Guatemala and other countries. Palgrave(15) says that only a very small portion of the coffee grown in Arabia ever arrives in Europe:

Arabia itself, with Syria and Egypt, consumes two-thirds and the remainder is absorbed by Turkish and Armenian esophagi. Nor do these last get their share of the best or purest. Before reaching the harbors of Jaffa, Beyrouth or Alexandria, the Mochan bales are opened, sifted and resifted, even while in transit. All of the good Mocha coffee beans worth roasting and pounding are carefully picked out by experienced fingers. Only the faulty, flattened, whitish beans go abroad for shipping. So constant is this selecting process that a gradation as regular as the degrees on a map may be observed in Mocha-that is, genuine Yemen-coffee, even within the limits of Arabia itself. As it is transported from mart to mart, it is sifted time after time. As it passes from hand to hand, the genuine Mocha is diminished, and substitution occurs, until that which actually leaves the port, marked "Mocha," for Europe and the West, is often no more like the offspring of the Yemen plant than the logwood preparations of a London fourth-rate wine-seller resemble the pure libations of an Oporto vineyard.

Mrsore Coffee.-The Mysore coffee of East India yields a strong, clean liquor of fine flavor. Much of this grade also comes from Java and Ceylon. Speaking of the East Indian varieties, Palgrave says:

This class supplies almost all the coffee drinkers from Darfah to Basrah and thence to Bagdad and Mosoul; Arabs, Persians, Turks anả Kurds have no other beverage. To one accustomed to what the Yemen supplies, the Indian variety is tolerable, or even agreeable. But for one freshly arrived from Nejed or Kaseem it is hardly potable.

Java Coffee.- Java coffee beans are large and oblong; in color they vary from pale yellow or green to whitish-grey; they produce a strong, clear beverage of smooth flavor and fair body. 
Ceylon Corref.-The Ceylon plantation coffec bean is of a pale greenish tint and yields a clear beverage full-flavored with good borly. This coffee is used largely for blending.

JAMACA Correk- - Janaica coffee from the West Indies has a medium size bean of a greyish-blue color, with shades of bluish-green, yellowish-green, or even yellow, of varions quality. The finest Jamaica Blue Momtain coffee rivals the Mysore plantation product in flavor, body, odor and agreableness of the heverage.

Brazhan Corkek- Brazilian coffee from Rio Janeiro and Santos, South America, is often sold as Mocha and Java. It yields a liquor of good flavor and body. Palgrave says:

American coffee holds, in the opinion of all orientals, the very last rank. The deterioration of this product in the New World from what it is in the Old is no less remarkable than that which oceurs in rice and tea and is of an ambiguous character.

Roasting of Coffee.-In order to prepare a good beverage from the coffee bean it must first be roasted and, as with tea, care is necessary in the application of the requisite heat to develop the coffee flavor. As a preliminary for roasting, all the light materials, such as sticks, dust and chaff, must be removed. After roasting the coffee is drawn upward by a current of air, leaving behind the heary refuse. The roasting may be done in a small way in the kitchen with each pound as purchased, but it is more uniformly done on a large scale by the coffee houses, by means of machinery especially constructed for this purpose. This process requires much skill. If insufficiently roasted, the product will lack aroma and flavor, and if it is over-roasted, the liquor will be bitter and acrid. The usual temperature for roasting coffee is just a little above the boiling point of water. However, each grade of coffee or blend requires different treatment. No definite directions can be given for the process.

During the roasting the berry swells from the formation of gas in the interior. Twelve to twenty per cent of moisture by weight is driven off. There is also a loss of organic matter, including 10 per cent of fat and 21 per cent of caffein. If the coffee is roasted too long, the destruction of caffein is greater and the liquor will have a burnt or acid taste, the cellular elements containing albumin rupture. Sugar is lost by transformation, and some of the starch is transformed into dextrin. The aroma is developed by the production of caffeol. Carbonic, palmitic and acetic acids are driven off together with pryttol, hydroquinon and methylamin. 
Composition of Coffees.-The following table shows graphically the composition of various specimens of coffee:

COMPOSITION OF COFFEE-PERCENTAGES (16)

\begin{tabular}{|c|c|c|c|c|c|c|c|}
\hline & 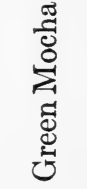 & 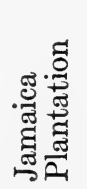 & 总 & 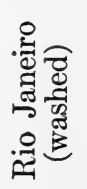 & 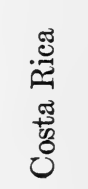 & $\frac{\text { స్ }}{\frac{0}{\sigma]}}$ & 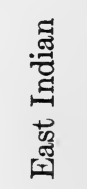 \\
\hline Gum, Sugar, etc. & 22.60 & 25.30 & 23.80 & 27.40 & 20.60 & 25.80 & 24.40 \\
\hline Caffein.......... & .64 & 1.43 & 1.33 & 1.14 & 1.18 & .88 & 1.01 \\
\hline Fat... & 21.79 & 14.76 & 14.87 & 15.97 & 21.12 & 18.80 & 17.00 \\
\hline Tannic, Caffeo-tannic Acid & 23.10 & 22.70 & 20.90 & 20.90 & 21.10 & 20.70 & 19.50 \\
\hline Cellulose.............. & 29.90 & 33.80 & 36.00 & 32.50 & 33.00 & 31.90 & 36.40 \\
\hline Ash. . & 4.10 & 3.80 & 4.00 & 4.50 & 4.90 & 4.30 & .... \\
\hline Potas & 2.13 & 1.87 & ... & $\cdots$ & & & $\ldots$. \\
\hline Phosphoric Acid. . & .42 & .33 & .27 & .51 & .46 & .60 & $\ldots$ \\
\hline
\end{tabular}

The albuminoid, albumin-proteoses, fat and cellulose form the hard portion of the bean and together make a total of half its weight. The mineral salts consist of potassium carbonate, phosphate and smaller quantities of magnesium and calcium.

Caffeone or caffeol $\left(\mathrm{C}_{8} \mathrm{H}_{10} \mathrm{O}_{2}\right)$ imparts a characteristic flavor and aroma to roasted coffee and is its principal aromatic substance. It is formed during the roasting process and is a brown oily liquid, a single drop of which will fill a room with the odor of coffee. A trace gives the characteristic aroma to a quart of water. Being volatile, some of this substance is lost by over-roasting the beans. Caffein $\left(\mathrm{C}_{8} \mathrm{H}_{10} \mathrm{~N}_{4} \mathrm{O}_{2}\right)$ is the substance which contributes to coffee its chief physiological activity. It acts on the brain as a stimulant and is identical with thein in tea. The average proportion in all commercial varieties is only.one-half per cent. This is only one-third of the active principle contained in tea, but coffee contains more body from the presence of dextrin, saccharin and coloring matters than is contained in the corresponding infusion of tea. Hutchison determined that a cupful of good coffee, made from two ounces of freshly roasted and ground coffee to a pint of water, contained nearly two grains of caffein and three and a quarter grains of tannin. He also found a cupful of tea to have from 0.73 to 1.21 grains of caffein and 0.89 to 4.2 grains of tannin. Therefore, a cup of café noir contains more caffein than a cup of tea of the same size, and the caffein in a cup of café au lait corresponds to the amount of caffein in an ordinary cup of tea. 
The table given below from Hutchison(17) gives the composition of coffee before and after roasting:

COMPOSITION OF RAW AND ROASTED COFFEE

\begin{tabular}{|c|c|c|c|c|}
\hline \multirow{2}{*}{ Component Constituents } & \multicolumn{2}{|c|}{ Mocha } & \multicolumn{2}{|c|}{ last Indian } \\
\hline & Raw & Roasted & Raw & Roasted \\
\hline 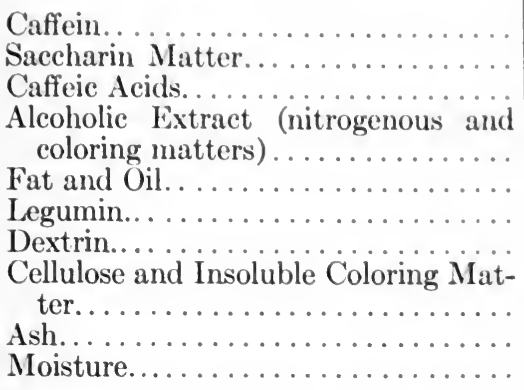 & $\begin{array}{r}1.08 \\
9.55 \\
8.46 \\
\\
6.90 \\
12.60 \\
9.87 \\
0.57 \\
\\
37.95 \\
3.74 \\
8.98\end{array}$ & $\begin{array}{r}0.82 \\
0.43 \\
4.74 \\
14.14 \\
13.59 \\
11.23 \\
1.24 \\
48.62 \\
4.56 \\
0.63\end{array}$ & $\begin{array}{r}1.11 \\
8.90 \\
9.58 \\
\\
4.31 \\
11.81 \\
11.23 \\
0.84 \\
\\
38.6 \\
3.98 \\
9.64\end{array}$ & $\begin{array}{r}1.05 \\
0.41 \\
4.52 \\
\\
12.67 \\
13.41 \\
13.13 \\
1.38 \\
\\
47.42 \\
4.88 \\
1.13\end{array}$ \\
\hline
\end{tabular}

Preparation of Coffee for Dirinking.-With an understanding of the production and handling of the coffee bean, a knowledge of the better varieties and the nature of their chemical constituents, it is evident that in the preparation of the beverage an effort should be made to retain as much as possible of the volatile oil, caffein and nutrient constituents and at the same time to eliminate the tannin.

There are many methods of making coffee. We shall only refer to three, percolation, infusion and decoction. Coffee making is an art. Someone has said the secret of making good coffee is to make it strong and to serve it hot. The author believes that in this country the failure to have good coffee is due to the fact that not enough ground coffee is used and that it is improperly made. Two ounces to the pint is the smallest proportion which will produce anything like good results. It is also important that the coffee should be freshly roasted, for its fragrance is quickly dissipated on keeping. In roasting, if one would secure the best results, the beans should be even in size to insure equal roasting. For this reason, blending should be done after roasting and not before. In order to secure the best coffee it should be roasted in the home, ground while still warm and immediately put into the coffee pot. Care should be taken to see that the coffee grinder is quite clean, for coffee left from 
a previous grinding may spoil the result. The finer the coffee is ground the better.

The water for making coffee should be neither too hard nor too soft. The same general directions pertaining to water as pointed out in tea making, applies also to coffee making.

Percolation is a process in which boiling water is poured over and allowed to percolate through finely ground coffee which dissolves from 11 to 15 per cent of the coffee, instead of 20 per cent as in other methods. This is the French method, and many patterns of percolators have been devised for coffee making.

The Vienna method of percolating coffee is a somewhat similar process, except that steam and hot water pass up through the coffee, which is held in a strainer above the water. This method produces a beverage superior to the French percolated coffee.

In the Southern United States a beverage is produced from coffee called the southern drip, which is made by packing finely ground coffee in the top of a French coffee pot; a little boiling water is poured over this and percolated very slowly through the coffee; then a little more water is poured over it, repeating the operation for five minutes. This process gives a very strong coffee. The black café noir of the French is made by the filtration method. Café au lait is made in the same way and served with hot milk, usually three parts milk to one of coffee.

Infusion is the common method of making coffee in the United States and England. Freshly roasted, finely ground coffee is used in the proportion of one to two ounces to a pint of water. The water should not be too hard. It should be allowed to boil tumultuously for a moment or two before it is poured over the coffee. Then the mixture should be allowed to boil for four or five minutes and should be served as soon as the grounds settle. In order to secure quick settling of coffee grounds, washed eggshells or little egg albumin may be mixed with the coffee or a little cold water may be added to the ground coffee before the process of infusion begins.

If sugar and cream are to be used, they should be placed in the cup before the coffee is poured. If good coffee is to be obtained, the pot should be of tin or aluminium. This should be scalded thoroughly each time before using and the coffee poured into a porcelain or earthenware vessel as soon as it is made. Coffee should never be made in a pot in which the tin, from long use, is corroded. This will injure the flavor of the beverage. It has been found that soft water extracts more of the constituents from the coffee bean than does hard water. 
Decoction is the method employed in making 'lurkish coffee. The requisite amount of ground coffee is placed in a small coffee pot, cold water is added, and this is brought to the boiling point. It is then immediately served without settling. The T'urk takes his coffee without sugar or eream, and drinks the gromuls as well as the liquid. This method is largely used in making coffee in Oriental countries.

Ancteration of Cofres.-Coffee is adulterated chiefly with chickory, but many other substances are used, such as dandelion roots, acorns, wheat, rye, peas, beans, the seeds of lupin, locust beans, dates and figs, also turnips, dandelion cabbages, burnt sugar and other coloring agents, none of which are deleterious but are very poor substitutes for coffee.

Substitutes for Coffee.-Many substances have been used as substitutes for coffee. Sometimes the product offered consists wholly of chickory, or of roasted malt, or of dry and roasted figs. The use of roasted cereals as substitutes for coffee is far less common than formerly.

Coffee Extracts and Essexces.-Coffee extracts and essences are usually concentrated infusions made by digesting coffee and chickory with water in a percolator. The liquid is evaporated in a vacuum and mixed with caramel. A common formula is four parts of coffee, two parts of chickory and one part of caramel. Coffee extract is a convenient form for the rapid preparation of the beverage, but as a rule such liquors lack the pleasing aroma of good coffee.

Axvual Coffee Crop.-The annual coffee erop of the world is about $1,920,000,000$ pounds, valued at over $\$ 200,000,000$. Brazil álone produces 1,200,000,000 pounds. The United States is the greatest consumer of coffee in the world; the average consumption is about twelve pounds per capita each year. In Holland the consumption is fourteen pounds, in Germany six pounds, in Great Britain, Australia and Canada orly one pound.

cocoA.- Cocoa is made from the seeds of Theobroma cacao, natural order of Sterculiacece. The tree is a native of tropical America and grows principally in the warmer parts of Brazil, Guiana and Central America. There are from fifteen to twenty species of the cacao tree, all belonging to tropical America. 'The common cacao tree grows wild in the valleys of the Amazon and Orinoco rivers. Some authorities allege that both the wild and cultivated trees were growing all over that stretch of country from Panama to Guatemala at the time of the discovery of America. 
The knowledge of this tree was brought to Europe in 1519 by Fernando Cortez, who found it growing in Mexico, where its cultivation had been carried on for many centuries. The Mexican name for the plant was "cacao." The name theobroma (food for the gods) was first applied by the botanist Linnæus.

The cacao seeds may be sown in the field or the plants may be first started in the nursery and transplanted to the plantation. When the tree is found growing wild in the forest it is usually in some shaded spot, and in imitation of this habit, on cacao plantations the banana or coral tree is grown at the same time to furnish shade and protection to the cacao. The cacao tree begins bearing after the fifth or sixth year and may continue prolific for fifty years. It grows from twelve to twenty feet in height, with a trunk of five to eight inches in diameter. The blossoms are borne not only on the stems, but also on the thicker branches. The fruit is picked as it ripens, throughout the entire year.

The fruit of the cacao tree is a cucumber-shaped pod somewhat tapering at both ends and corrugated along the sides. It is from seven to twelve inches long and three or more inches in thickness. It contains a pulp in which are embedded a number of beans the size of haricot beans. It is from these beans that cocoa and chocolate are made. The pods are removed from the trees by the aid of pruning knives and piled in heaps under the trees. The cacao beans are placed on platforms in the sun for three or four days, and are turned occasionally to insure thorough drying. They are next transferred to the "sweating house," where a kind of fermentation takes place, the temperature rising to $140^{\circ} \mathrm{F}$.; next they are placed in boxes or barrels, tightly covered with plantain leaves and stored in a close room from four to seven days. Here the fermentation continues developing the aroma and flavor so highly prized in chocolate.

Treatment of Cacao Beans.-A satisfactory beverage cannot be made from tea or coffee until they are subjected to special forms or processes of treatment. So it is necessary, in order to prepare an inviting drink from the cacao beans, to open up their tissues in order to render their constituents more easily capable of emulsion and suspension in water or milk. "Soluble cocoa" prepared by the Dutch method consists in treating the powder from the roasted beans, either with or without the removal of some of the fat, with some alkali such as potassium or sodium carbonate. In the German method ammonia or ammonium carbonate is used. Treatment with an alkali is not favorably looked upon. The United States Department of Agriculture considers the term "soluble" 
as applied to cocoa so treated a misnomer, as no more of the cocoa is made soluble than by any other process.

The fresh beans have a crimson color, a somewhat oily and unpleasant taste. The process of fermentation drives off some of the moisture and $\mathrm{CO}_{2}$; the color changes from crimson to dark brown, and the disagreeable taste and bitter flavor are lost with the development of the aroma and flavor so highly prized by chocolate comoisseurs. The beans are next removed from the boxes or barrels and spread out to be picked over, to remove any adherent pulp or other foreign matter, then spread out on trays and covered with red earth for a day to complete the fermentation. The red earth absorbs any allherent moisture and gives the beans a uniform red color. After the last process, "rubbing," they are spread upon trays and dried in the sun.

The next process is roasting, which further develops the flavor and removes the astringent taste and also permits the ready removal of the shells.

In the after part of the manufacture of cocoa, the beans are roasted either by direct heat over a coke fire, or dried by the indirect heat of superheated high pressure steam; they thus beeme hard and brittle. They are next passed through a machine which cracks the hard, thin skin! or husk. The latter is removed by winnowing. Finally, they are rubbed again and spread on trays to dry in the sun, care being exercised to prevent shriveling.

The shells are called "cacao shells," and in the cheaper shops a beverage is made from these "cacao shells." They contain very little of the cacao substance except the flavor.

When the beans are cracked, the germ is removed. The eracked or broken bean is called "cacao nibs." This is the purest form of cocoa. From these nibs, also, a beverage is produced by prolonged boiling.

Usually the cacao nibs are ground between hot rollers. The heat breaks down the thin walled polygonal cells, dissolves out some of the fat and reduces the mass to a semi-fluid, pasty condition. A considerable part of the fat is now removed by hydraulic pressure; the remainder of the material is run into moulds and forms what is commercially known as "flake cocoa." This differs from the cacao nibs in that it contains very little fat.

Sometimes the cocoa while fresh from the press and in a soft and plastic condition is mixed with starch and sugar and is known, commercially as "Rock Cocoa." Of these numerous varieties of cocoa "Caracas Cocoa" is thought to be the best. 
Composition of Cocons. - The composition of the special varieties of commercial cocoas is given in the table below from Bell:

COMPOSITION OF COMMERCIAL COCOAS-PERCENTAGES

\begin{tabular}{|c|c|c|c|c|c|c|}
\hline & $\begin{array}{c}\text { Fresh } \\
\text { Beans } \\
\text { (Shelled) }\end{array}$ & Nibs & $\begin{array}{l}\text { Flake } \\
\text { Cocoa }\end{array}$ & $\begin{array}{l}\text { Rock } \\
\text { Cocoa }\end{array}$ & $\begin{array}{c}\text { Prepared } \\
\text { Cocoa }\end{array}$ & $\begin{array}{c}\text { Cocoa- } \\
\text { tina. }\end{array}$ \\
\hline $\begin{array}{l}\text { Moisture............ } \\
\text { Fat. ............. } \\
\text { Added starch....... } \\
\text { Added cane sugar.. } \\
\text { Non fatty cocoa... }\end{array}$ & $\begin{array}{c}7.6 \\
49.9 \\
\text { nil } \\
\text { nil } \\
42.5\end{array}$ & $\begin{array}{c}2.6 \\
51.8 \\
\text { nil } \\
\text { nil } \\
45.6\end{array}$ & $\begin{array}{c}5.5 \\
28.2 \\
\text { nil } \\
\text { nil } \\
66.3\end{array}$ & $\begin{array}{r}2.6 \\
22.6 \\
17.6 \\
32.2 \\
24.8\end{array}$ & $\begin{array}{r}5.0 \\
24.9 \\
19.2 \\
23.0 \\
27.9\end{array}$ & $\begin{array}{c}3.5 \\
24.0 \\
\text { nil } \\
\text { nil } \\
72.5\end{array}$ \\
\hline
\end{tabular}

It will be observed that the natural cocoa bean contains from 36 to 55 per cent of fat. A considerable part of this is removed from the prepared cocoas, which only retain from 23 to 33 per cent of fat. The nitrogen content in cocoa varies from 1.75 to 2.24 per cent, equivalent of 11 to 14 per cent protein.

The proportion of theobromin varies from 1.0 to 2.65 per cent and constitutes a little of the non-protein nitrogen. It is the active principle of cocoa and is a dimethylxanthin $\left.\left(\mathrm{C}_{7} \mathrm{H}_{8} \mathrm{~N}_{4} \mathrm{O}_{2}\right)_{2} \mathrm{~N}_{42}\right)$. Its close relation to caffein $\left.\left(\mathrm{C}_{8} \mathrm{H}_{10} \mathrm{~N}_{4} \mathrm{O}_{2}\right)_{3} \mathrm{~N}_{4} \mathrm{O}_{2}\right)$-a trimethylxanthin-is well known. Fifty per cent of the nitrogen content of cacao is held to be amid nitrogen and consequently not available in nutrition.

The following analyses of the chemical constituents of various commercial cocoas are given in the table below by Ridenour(18):

COMPOSITION OF COMMERCIAL VARIETIES OF COCOA-PERCENTAGES Roasted and Unroasted Beans

\begin{tabular}{|c|c|c|c|c|c|c|c|}
\hline Source & Java & $\begin{array}{l}\text { Trini- } \\
\text { dad }\end{array}$ & Ariba & Caracas & $\begin{array}{c}\text { Roasted } \\
\text { Trini- } \\
\text { dad }\end{array}$ & $\begin{array}{l}\text { Roasted } \\
\text { Caracas }\end{array}$ & Bahia \\
\hline Fat or Butter & 45.40 & 43.60 & 43.30 & 36.80 & 41.80 & 37.60 & 42.10 \\
\hline Theobromine.. & 1.16 & 1.16 & .86 & 1.13 & .95 & .76 & 1.08 \\
\hline Albuminoids. . & 9.25 & 11.90 & 10.10 & 10.50 & 12.00 & 12.30 & 7.50 \\
\hline Glucose... . . . . & 1.20 & 1.30 & .42 & 2.70 & 1.40 & 1.70 & 1.00 \\
\hline Saccharose..... & .51 & .32 & 6.37 & 1.50 & .28 & .51 & .51 \\
\hline Starch... & 5.10 & 4.90 & 1.50 & 3.80 & 5.70 & 6.00 & 7.50 \\
\hline Lignin.. & 6.10 & 5.60 & 4.60 & 3.20 & 5.80 & 9.00 & 7.80 \\
\hline Cellulose.... & 13.80 & 13.00 & 14.00 & 16.30 & 19.60 & 11.60 & 13.80 \\
\hline Extractive... & 8.90 & 8.30 & 9.00 & 12.70 & 5.80 & 9.20 & 8.00 \\
\hline Moisture..... & 5.10 & 6.30 & 5.90 & 6.60 & 2.60 & 5.60 & 5.90 \\
\hline Ash........ & 3.30 & 3.60 & 3.70 & 4.30 & 3.70 & 50.0 & 3.60 \\
\hline
\end{tabular}


Stareh in cocoa varies from 1.5 to 7.5 per cent; saccharose from .51 to 6.37 per cent; glucose from 1.20 to 2.70 per cent; cellulose, 11.60 to 16.30 per cent. 'Tammin, the astringent of cocoa, is different from that in tea and coffec. The proportion varies from + to 6.7 per cent, and averages about 5 per cent. The content of mineral matter in cocoa reaches rather a high proportion, amounting to from 2.5 to 4 per cent in the raw and from 3.5) to 5per cent in roasted beans.

Prepared cocoa is by reason of its composition a mutritious food and, while not stimulating, it is much more sustaning than either tea or coffee. However, in its natural condition it is too rich in fat and slightly indigestible. 'The object of the special treatments, roasting and grinding, is to make it more acceptable to the stomach and at the same time to reduce the fat content.

CHOCOLATE- - (hocolate consists of the ground cacao beans "sweated," fermented and roasted in a similar way for the preparation of cocoa; but the "cocoa nibs" are ground in a heated mill and as much of the fat as possible extracted by pressure. The cocoa mass while in this soft plastic condition is mixed with 30 to $60 \mathrm{jer}$ cent of cane sugar, 5 to 10 per cent of sweet almond, 1.0 to 1.5 per cent of vanilla, 0.5 per cent of cinnamon and 0.2 per cent of oil of rloves. The proportion of sugar and flavorings vary to a considerable extent, due to the processes of various manufacturers. This constitutes the differences in chocolate. Various adulterants are added to cocoa, principally sugar and starch in the cheaper grades. In others, cocoa shells are ground up and added to the product, and mineral coloring matter is oreasionally found. Plain chocolate should contain not less than 45 per cent of cocoa fat. If the fat content is below this figure, it means an adulteration.

A delightful nutritious beverage may be prepared from cocoa or chocolate by using either warm water or milk brought to the boiling point and the cocoa or chocolate added, two teaspoonsful to each cup of milk or water, with the addition of a pinch of sodium chlorid for each cup. Two lumps of sugar and cream improve the "body" and flavor. The nutritive value of cocoa is greater than that of tea or coffee. A breakfast cup of cocoa made as alove contains in grams, protein, 3.75 per cent; fat, 4.75 per cent; sugar. 10.01 per cent; starch, 0.50 per cent : theobromin, 0.095 per cent: tamin and dextrin, 3.66 per cent: ash, 0.50 per cent, and has an energy value of 120 to 125 calories. Chocolate, therefore, by reason of its composition is a nutritions, wholesome beverage. While not so stimulating as tea or coffee. it is more sustaining. 
KoLA.-Kola or Goora-nut is the product of Cola acuminata, an African tree of $N$. O. sterculiacex. It forms a stimulating beverage and the nut is highly prized as a nutrient by the natives of Africa, West Indies and Brazil.

Composition of Kola.-The arerage composition of ten varieties of kola $\operatorname{nut}(19)$ is:

\section{AVERAGE ANALYSIS OF KOLA NUT}

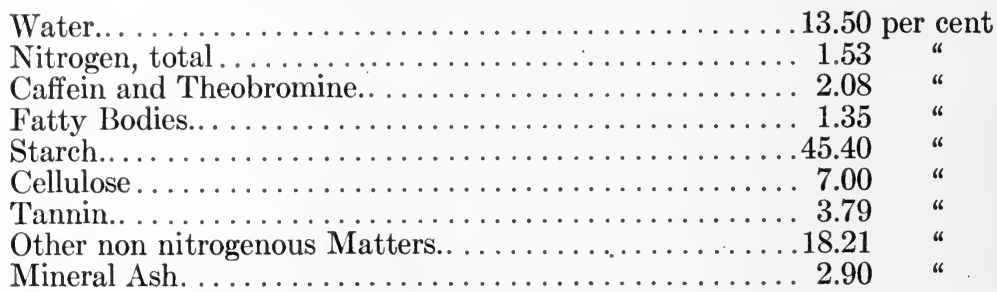

The active principle of this nut is kolanin, a glucosid, developed from fermentation under the influence of an enzyme, lacase. After certain processes the kola nut is converted into a kola powder from which a beverage is made by mixing a teaspoonful of the powder with a little water and stirring to a paste, then adding a half pint of water and boiling for five minutes in an open pan. It is then poured into a jug and allowed to remain for five minutes to clear. The liquor is then poured off and is ready to serve. Its palatability is inereased by the addition of sugar and cream.

Kola increases the power of endurance for mental and physieal strain, or at least it remores the sense of fatigue after such strain. 'Its use permits the body to bear fatigue during prolonged fasting.

GUARANA.-Brazilian cocoa, or guarana, is obtained from the seeds of the Paullinia capana, a tree belonging to the natural order of Sapindacea, which, according to most botanists, ineludes the horse chestnut. The tree grows abundantly in the province of Amazonas, along the banks of the Tapajos, Rio Negro, etc., as well as in Guiana and Venezuela. It is used extensively in Brazil, Guatemala, Costa Rica and other parts of South America as a nerve stimulant and restorative and also as a refreshing beverage. Aceording to late reports, 16,000 pounds are annually exported from the eity of Santarem.

The fruit, which is about the size of a small walnut, contains five or six seeds. These seeds are roasted, and after being pounded, are made into a thick paste with water and formed into round or oblong cakes, 
which are dried in an oven or by the heat of the sun. Thiese are called guarana bread. The cakes are scraped or grated when required for use, and the powder produced has a light brown coler; an odor faintly resembling roasted coffee and a bitter, astringent taste.

Composition of Guarana.-It contains, in addition to empyreumatic oil (developed by the process of roasting) and tannic acid, a substance called guaranin by 'Theodore von Martins, but shown by Dr. Stenhouse to be identical with thein. This alkaloid is stated by Dr. Stenhouse to be present to the extent of 5.07 per cent, or according to the results of the same observer, to the extent of twice the amount contained in good black tea and five times that contained in coffee: the actual figures given for tea being 2.13 per cent, and those for coffee 0.8 to 1.0 per cent. For Paraguay tea the amount mentioned is 1.25 per cent.

The large amount of tanic acid that enters into the composition of guarana gives it marked astringent properties, while, owing to the guaranin it contains, it exerts the same kind of effect on the nervous system as tea and coffee.

Therapeutic Use of Guarana.-Guarana is used in South America to some extent dietetically, but chiefly therapeutically, as a stomachic and febrifuge and as an astringent in catarrhal diarrhea and dysentery. It is either eaten with cassava or chocolate, or taken as a drink in sweetened water. In the United States it is employed as a nervous stimulant and restorative, and attention was directed to it some years ago in France by Dr. Gavrelle, who had held the position of physician to Dom Pedro of Brazil.

Aleohol, it is stated, is the only agent which completely extracts its active principles. Ether and water only do so imperfectly. A watery infusion, therefore, will fail to possess the virtue belonging to guarana.

Guarana appears, according to Gautier, to have enjoyed a high repute in France as a remedy for migraine, or sick headache, and attention has been reeently directed to its employment for this purpose, in England, by Dr. Wilks. Articles upon the subject may be seen in the British Medical Journal for 1872, and another article by Mr. M. C. Cooke is to be found in volume one, third series, of the Pharmaceutical Journal, p. 221. As far as experience goes, it seems that in some cases of sick or nervous headache it is capable of affording the most marked relief, while in others it utterly fails to produce any good effect. Its virtue is, in all probability, due to the guaranin (thein or caffein) it contains, which is, as already remarked, according to the analysis of Stenhouse, present in much larger proportions than in either tea or coffec. 
Employed for the medicinal purpose above referred to, the quantity generally used is about fifteen grains of the powder administered in coffee, water or some suitable vehicle.

COCA.-Coca, the leaves of Erythroxylum coca, N. O. Erythroxylacex, is included here because of the similarity of its action to that of tea, kola, etc. The natives of Peru and Bolivia cultivate this shrub for its leaves. It is a very ancient custom with them to chew coca leaves for their aromatic and stimulating properties. The custom has spread beyond the regions where the shrub is cultivated, so that at present the annual consumption of coca leaves in South America is said by Tibbles to exceed one hundred million pounds.

The physiological action from chewing these leaves places them in the same class as tea, coffee and kola. However, the principal alkaloid of the leaves is different, as they contain cocain $\left(\mathrm{C}_{17} \mathrm{H}_{21} \mathrm{NO}_{4}\right)$ and several other alkaloids of minor importance. The action of this alkaloid is less exciting than the alkaloids of tea or coffee, but its action on the heart is greater. The dry leaves of commerce are by no means so active as the green or freshly dried leaves. The properties are virtually those of cocain with slight astringency and greater stimulation.

Effect of Caffein in Beverages. - The alkaloids of these beverages are caffein in tea, coffee and kola; theobromin in cocoa, and cocain in coca. Caffein is a brain stimulant and acts chiefly upon the nervous and muscular systems. Its action increases reflex excitability and shortens the time occupied in nervous processes. It stimulates the intellect and removes languor and drowsiness. This action is so marked in some persons that they are unable to sleep after drinking a strong cup of coffee at night. Wakefulness and increased quickness to respond to stimuli result in the ability to perform an increased amount of intellectual work. The special action of this alkaloid has given rise to the statement that tea and coffee are the beverages for those engaged in mental work. It is alleged that they stimulate the spirits, incite thought, clear the perceptive faculties and goad the imagination.

The vital centers also share in the stimulation produced by caffein. Following its administration the respiratory movements are deeper and more frequent and the heart beats more forcibly and rapidly. It is an important aid in combating impending paralysis of these centers in cases of coma.

Nutritive Value of Beverages.-Tea and coffee are in no sense foodstuffs. Their constituents yield nothing to the tissues in the way of building material or potential energy. The nutritive value of a beverage 
from either of these products depends largely upon the amomt of cream and sugar which are added. The two humps of sugar which most people add to an ordinary cup of either tea or coffee, weigh :s drams and contuin 11 grams of carbohydrate, which vields 45 calories or units of heat.

DELETERIOUS EFFETS IN USE OF BEVERAGLS-Habit materially weakens the stimulating effects of tea, coffee, etc. At the same time an excess of tea is deleterions in its influence upon the nerrons system. Common symptoms are indigestion, heartburn, flushing of the face, excessive nervousness, irregularity of the heart, palpitation, neuralgia, headache, insomnia, etc. Green tea is more likely to produce this train of symptoms than black. 'The consumption of coffee in excess is not followed by insomnia, but by numbness and loss of power of groups of muscles, pain in the back, etc. The tamnin in these infusions of either tea or coffee has a tendency to disturb digestion.

The influence of these beverages on salivary and gastric digestion is, on the whole, unfavorable. Roberts(20) stated that tea markedly inhibits the conversion of starch into sugar by the saliva, and attributes this result to the action of the tannic acid in the infusion. Robertson(21) confirms the observation of Roberts as regards the detrimental action of tea, and says that coffee exerts a much less detrimental influence and cocoa almost none at all.

The physiological action of tea, coffee and cocoa is due to the volatile oil, alkaloids and tamnin contained in these beverages. The volatile oil is not in the same in each of these substances; neither is their flavor or effects the same.

The oil of tea dilates the blood ressels on the surface. flushes the skin with blood and stimulates the sweat glands to increased activity. Its action warms the body when it is conl by increasing the circulation through the skin; it likewise cools the body when it is warm by causing a radiation of heat from its surface with an increased evaporation of moisture. The volatile oil of coffer produces more or less contraction of the arterioles and capillaries and cools the surface of the body by reducing the circulation through the skin.

\section{MALT LIQUORS (22)}

The manufacture of fermented liquors from malted grain is of great antiquity. The discovery of the art of brewing is accredited to Gambrinus, son of Mareus, King of the Germans, who lived $1730 \mathrm{~B}$. C. Herodotus gives the ancient Egrptians credit for making a fermented 
liquor from barley which was only a little inferior to wine. Two celebrated Egyptians living 500 and 700 years B. c. described ale as the "wine of barley." Isodorus in the fifth century describes the mode of making beer by the ancient Britons, and Ina, King of Wessex, in 680 A. D. found it necessary to formulate regulations for ale booths.

Preparation of Malt Liquors.-Malt liquors are beverages prepared from an infusion of malt and hops; they are commonly called beer, but this is a generic term including ale, beer, stout, porter, etc. There is some confusion in the use of these names, for they have not quite the same meaning in all parts of the country. In some places "ale" is spoken of as a brown beverage, while the darker-black-drinks are termed "beers." For a clearer understanding it might simplify matters to consider "beer" and "ale" as synonymous and to put them in the class of the paler liquors and to speak of the blacker drinks as stouts or porters.

Germination of Malt.- "Malt is obtained by moistening barley and allowing it to germinate in heaps at a moderate and regular temperature. During germination important changes take place: the ferment diastase appears in the grain and acts upon some of the starch, transforming it into dextrin and malt sugar; while part of the proteids, by the action of another ferment, are converted into soluble forms." The green malt is next dried in a kiln, one hundred parts producing about ninety-two parts of dried malt. If the malt is dried at a high temperature the ferments exert a more powerful action in the grain, and as a result the beverage will be dark, while on the other hand, if the drying be effected at a low temperature, the beverage will be a pale color.

WORTING.-After the barley has germinated, sprouted and been dried, it is called malt. The first stage of producing "ale" or "beer" is the grinding or crushing of the grain into a coarse powder, so that the malt can be mashed. This is accomplished through the addition of water, which dissolves and diffuses the saccharin matters out of the malt. The starch is thus gelatinized and a sweet liquor, called wort, is formed. The diastatic, proteolytic and other enzymes are aided in performing their respective functions.

There are numerous malt substitutes which are often added to the wort. They include corn, rice, rye, oats, barley (unmalted), glucose and other sugar bodies. There is sufficient diastase in the malt to change to sugar considerably more starch than is contained in the malt itself, and for this reason these malt substitutes can be used.

BoIling of THE Wort.-The next step in the process is the straining off of the wort from the malt and boiling it with hops. The boiling stops 
any further action of the diastase and extracts from the hops their soluble ingredients. ('hief among these are tamnic acid and certuin resinous acids of bitter taste. Inutehison deseribes hops as "thir cones or strobiles of the Humulus lupulus; they contain 4 per cent of tunnin, 1 to 11 per cent of fragrant volatile oil of an alkaloid called lupulin, a bitter principle, and a large amount of resin"; they also contain a substance called "hopein," the nature of which has not been fully investigated, but it seems to have properties resembling those of morphia.

Coolng of THE Wolit.-The boiled wort is next pumped out and rapidly passed over coolers. It is then ready for the addition of yeast. Great care is taken to employ pure veast, for many of the diseases of beer, as the development of acetic acid poisoning, are due to the contamination of wild yeasts. According to Thatcher, "modern brewers consider careful boiling of the wort an absolute necessity to effect sterilization; but they sometimes neglect to prevent contamination during cooling; yet this is equally necessary, for germs killed by yeast and present as inert matter become food for other germs, which may be introduced during cooling and thus render purification useless."

Fermentation.-After the yeast is added to the wort in vats, the fermentation is allowed to proceed under the proper degree of temperature. Here again much depends upon the degree of temperature employed. Brewers in England favor a high temperature, with the result that most of the sugar is broken up and the resulting beer is rich in alcohol. In Germany, low temperatures are employed; therefore more sugar and dextrin are left in the beer, with a lessening of the alcoholic content. Low fermentation beers also contain more carbonic acid than high fermentation beers, and are therefore better aerated.

After fermentation is completed, the yeast which has been carried to the surface is skimmed off and the beer is allowed to stand in shallow tanks till most of the remaining reast has settled to the bottom. It is now run off into casks, when the second fermentation occurs under the action of the small quantity of yeast still contained in the beer, but it is restrained somewhat by the addition to the cask of an extra quantity of hops; the longer this lasts, the greater is the amount of aleohol produced, and if strong beer is desired, it is left in the cask for some months.

Composition of Malt Liquors.-For the manufacture of bitter pale ale the finest and highest dried malt and hops of the hest quality are used. The alcoholic contents of this beverage is about 6 or 7 per cent. In Senteh ale, 8 or 9 per cent of alcohol and about 10 per cent of malt extract are present. In lager beer there is generally present 4 or 5 per cent of malt 
extract. The fermentation of Bavarian beer is carried on at a low temperature and it contains only 2 or 3 per cent of alcohol. The aroma of this beer is fine, its taste is rather bitter, with an additional characteristic flavor from the containing cask derived largely from the pitch extracted from the wood of which the barrels are made.

The contents of malt liquors has been shown by analysis to consist of from 1 to 10 per cent of alcohol ; from 4 to 15 per cent of dextrin, maltose and cellulose, certain free organic acids, as lactic, gallic, malic and acetic; in general, about two cubic inches of free carbonic acid gas per fluid ounce of liquor; mineral salts derived from the malt and water; and certain vegetable matters from the bitter hops, gentian root and chiretta used in the manufacture of malt liquors. The aromatic and bitter principles employed are harmless when taken in moderation, and usually exert a tonic action on the stomach. They serve to stimulate the appetite, invigorate the system and so act as agents introducing into the body an increased supply of nutriment. This constitutes the chief value of malt liquors.

"PRINING."-A good many brewers are accustomed to "prime" their malt liquors by the addition of some saccharin substance before it is stored in casks. The priming substance used is not always the same, but as a rule it consists of glucose, which produces a "briskness" rather than "sweetness"; or an invert sugar when the property of palate fullness and lusciousness are desired.

FININGS.-Just before barreling, a solution of isinglass in acetic or tartaric acid ("finings") is added to the cask, which soon settles in the form of a precipitate, carrying with it any remaining yeast cells and other impurities. After bottling, the beer becomes "brisker" than it was in the cask, since no gas can escape. Strong beer will keep well in the bottle for eighteen months or longer. High priced ales usually contain more solid matter, have a higher specific gravity and contain more hops than the cheaper grades. A good ordinary bitter ale usually contains from 18 to 19 pounds of solids to the barrel, while an ordinary mild ale carries only 16 or 17 pounds. A good bitter ale may have as much as 22 pounds and Bass ale as much as 23 pounds to the barrel of 36 gallons.

Porter and Stout.-Porter is made with roasted or dark brown malt and contains alcohol 5 to 7 per cent and extract of malt 7 or 8 per cent; stout is a stronger kind of porter. They are manufactured in the same way as beer, with the exception that the malt is first thoroughly roasted in cylinders, much as coffee is. This roasting process produces some caramel to which the dark color of these beverages is mainly due. 


\section{COMPOSITION OF MAIT LIQLORS}

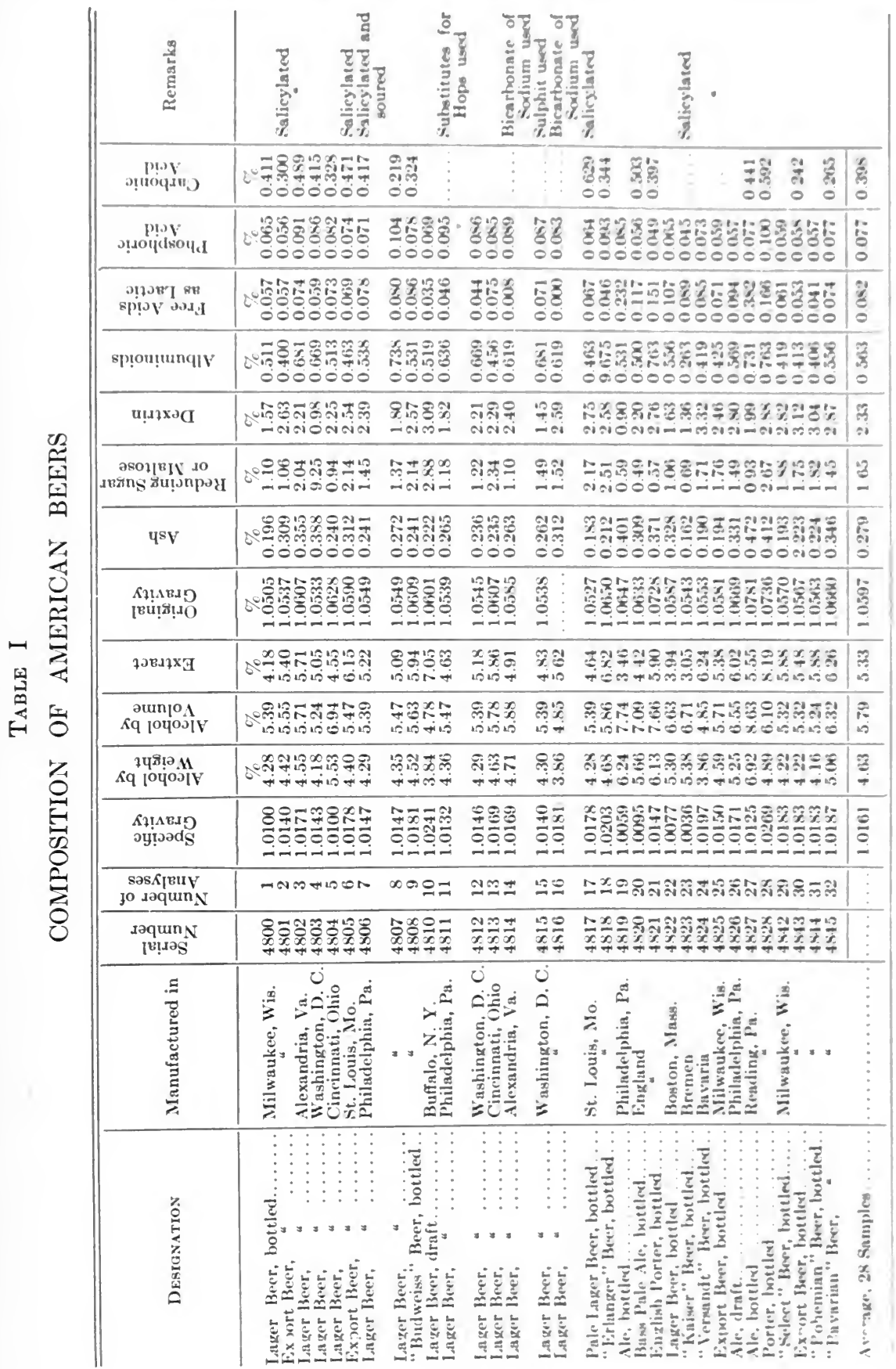


This heating process, by killing the diastase, prevents further production of dextrin and sugar in the "mashing." The proportion of solid matter in the liquor is often increased by the addition of caramel or of invert sugar. German beers are fermented at a lower temperature than English or American beers. They contain more dextrins, also, and secondary fermentation takes place in them to a large extent, with the production of much carbonic acid gas.

The composition of malt liquors has been studied very extensively by Crampton(22) of the U. S. Dept. of Agriculture, Bulletin No. 13, entitled "Fermented Alcoholic Beverages." Crampton, in Table No. I, page 563, gives the analyses of American malt liquors.

The more important constituents of these beverages are alcohol, dextrins, sugar, a small amount of soluble nitrogenous matter and vegetable acids. Tibbles, in his work on "Foods, Their Origin, Composition and Manufacture," gives in Tables II and III analyses of English, German and Bavarian beers, ale and porter, taken from the "Hospital," April 24, 1909 :

TABLE II

COMPOSITION OF MALT LIQUORS-PERCENTAGES

\begin{tabular}{|c|c|c|c|c|c|c|c|c|c|}
\hline & $\frac{\vec{\Phi}}{\frac{\vec{d}}{\pi}}$ & $\begin{array}{l}\overrightarrow{0} \\
\frac{1}{0} \\
\frac{0}{4}\end{array}$ & 氶 & 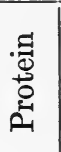 & 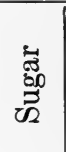 & 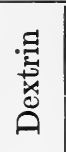 & 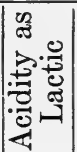 & 员 & Authority \\
\hline English Beer, mild. . & 84.71 & 8.45 & 6.74 & .26 & \multicolumn{2}{|c|}{5.77} & & $\ldots$ & $\begin{array}{l}\text { Lancet, Feb. 16, } \\
1895\end{array}$ \\
\hline English Beer, bitter. & 87.42 & 6.78 & 5.42 & .16 & \multicolumn{2}{|c|}{4.22} & & & \\
\hline English Ale and Porter. & 89.10 & 4.89 & 6.93 & .53 & \multicolumn{2}{|c|}{4.22} & 310 & .31 & Leyden \\
\hline Burton Pale Ale.... & 89.63 & 5.25 & 4.40 & $\ldots$ & $\cdots$ & & & .35 & Chittenden \\
\hline Guinness's Dublin Stout. . & Dorat & 5.50 & 5.42 & $\ldots$ & $\ldots$ & . & & .36 & and Mendel \\
\hline Oatmeal Stout...... & & 6.55 & 8.00 & & & & & .33 & \\
\hline Nourishing Stout. ........ & & 6.24 & 6.30 & $\cdot$ & ・. & $\cdots$ & .900 & .45 & \\
\hline 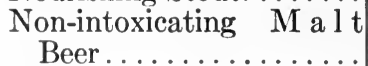 & & 3.07 & 3.14 & & & & & .10 & $\begin{array}{l}\text { Lancet, } 1902,11 . \\
\quad 1265\end{array}$ \\
\hline Pilsener Lager Beer....... . & 91.15 & 3.46 & 4.97 & $\ddot{3} \dot{3}$ & & & .160 & .20 & \\
\hline Bavarian winter Beer..... & 91.81 & 3.21 & 4.99 & .81 & .44 & 2.92 & .116 & .20 & \\
\hline Beer. . & 90.71 & 3.68 & 5.61 & .49 & .87 & 4.39 & .128 & .22 & \\
\hline Munich Bock Beer.. & 88.72 & 4.07 & 7.23 & .71 & .90 & $\ldots$ & .170 & .27 & Leyden \\
\hline Hofbr & & 3.70 & 5.87 & & $\ldots$ & $\ldots$ & $\ldots$ & $\ldots$ & \\
\hline Spa & & 3.23 & 6.61 & & & & 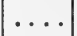 & & \\
\hline Lowenhra & & 4.45 & 7.09 & .57 & 6 & & & .36 & $\begin{array}{l}\text { Lancet, Feb. 16, } \\
1895\end{array}$ \\
\hline Burton Lage & 89.49 & 4.34 & 6.42 & .40 & 2.04 & 3.34 & .120 & .27 & Cameron \\
\hline Danish Beer. & & 2.12 & 6.61 & $\cdots$ & $\ldots$ & & $\ldots$ & .20 & $\begin{array}{l}\text { Lancet, 1909, ii. } \\
\quad 1265\end{array}$ \\
\hline
\end{tabular}




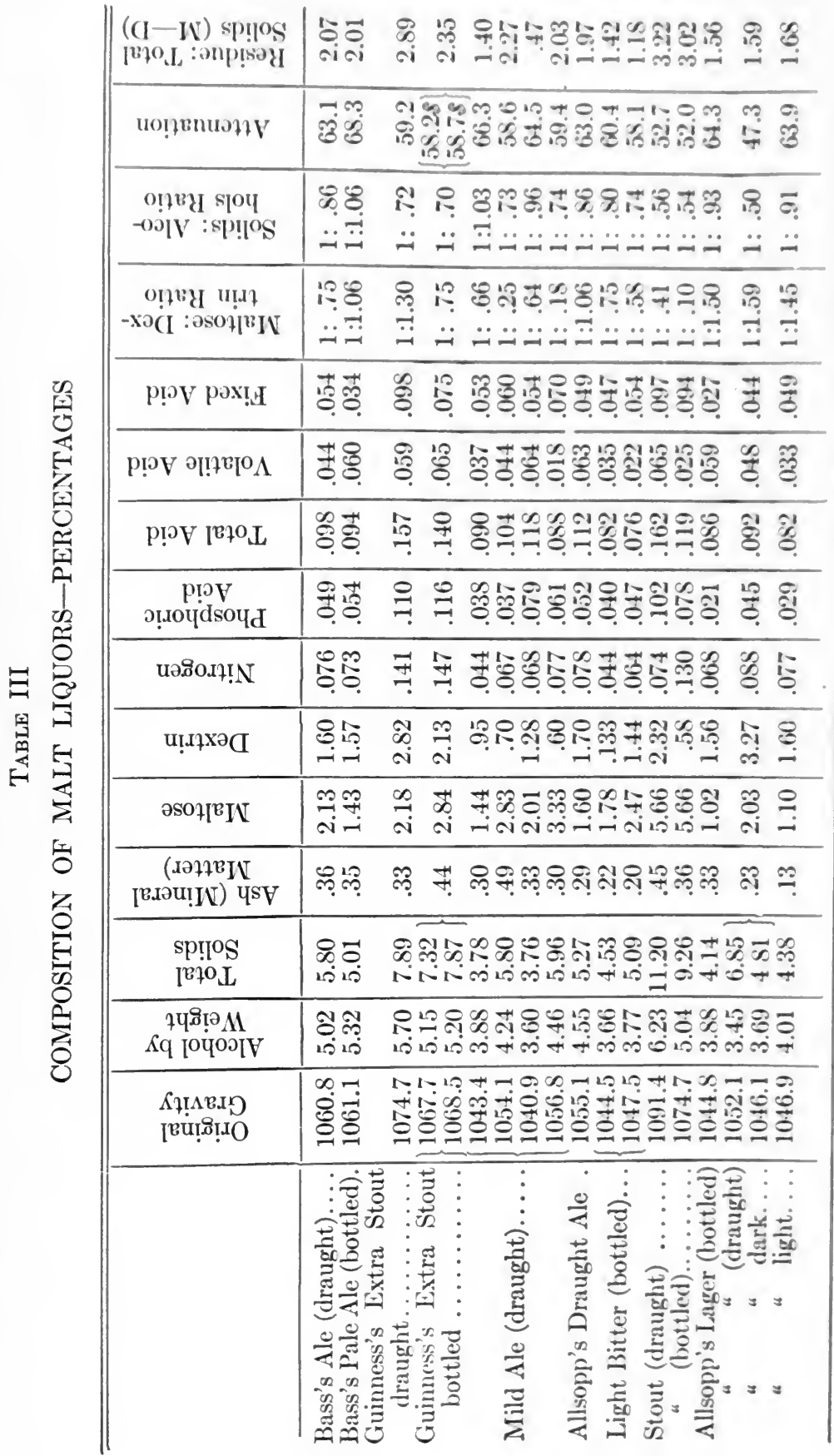


Action of Malt Liquors on Digestion.-The action of malt liquors on digestion has received considerable study. Hutchison is of the opinion that they exert but "little retarding influence on salivary digestion, and any action that they may possess is entirely due to their acidity. Stout is twice as acid as beer, and hence has a greater retarding action on the digestion of starch by the saliva." The hop extract in beer is inclined to induce drowsiness, and by causing a more profuse flow of saliva, rather improves than retards salivary digestion.

Beer, if taken alone, does not remain in the stomach longer than water. If taken on an empty stomach, 200 c.c. will be found to have left the stomach in about one and a half hours. "If taken with food, it delays the chemical processes of digestion more than the mere amount of alcohol which it contains will explain." Hutchison thinks that the extract and salts are the contributing causes. It is probable, however, that a tumblerful of good, brisk beer may actually aid digestion by increasing appetite and stimulating a more abundant secretion of the gastric juice as well as stimulating more active movements of the stomach. In persons of weak digestion, beer is prone to produce biliousness and has a tendency to act as a fat producer. If used in excess it produces obesity and in some cases a permanent dilatation of the stomach. In some individuals, all liquors are prone to give rise to acidity of the stomach. This may be the result of acid fermentation. Again, in other persons, it seems to exert an unfavorable influence on the liver, producing dyspeptic symptoms. It is for these reasons, among others, that beer is not a good beverage for the sedentary individual, unless in very moderate amount.

Stout and porter are popularly believed to be more digestible. "If it be desired to avoid nervousness," says Hutchison, "and to get rid of insomnia, shun tea and coffee and drink stout."

On account of the extractives present, beer contains more nourishment than any other alcoholic beverage. It does not follow from this, however, that beer is to be recommended as an economical food, for, as we have scen, alcohol is to be regarded as a food only in limited amount. According to Hutchison, "five liters of good German beer with 5 per cent of extract should yield 250 grams of earbohydrate ( 1,025 calories), which is half the total required daily, and in addition 100 to 150 grams of alcohol with a fuel value of from 700 to 1,050 calories."

It has been determined by exhaustive study of the effects of malt liquors on the digestive system that, when containing the bitter principle of hops, they act as appetizers, aid digestion and encourage sleep. 
These propertics make them of value in certain forms of dyspepsia and debility, especially when induced hy disease, overexertinn, worry, nenralgia and the like. Therip mutritive value depeinds upon their content of sacharin and allumimoms substanees. Mthomgh the moderate use of alcoholic liquor's may unt be open to very serions wheetion, it has been demonstrated, nevertheless, that all types of work are better aceomplished without the nse of any of these heverages. An excess of malt liquors produces effects similar to those of other forms of alcohol. 'Their tendency to cause obesity is a matter of common knowlerlge, and the check put by them on the oxidation and elimination of the waste matters of the body naturally favors the development of gunty conditions and other disorders which follow the acemmulation in the organism of uric acid and its congeners. It must be remembered also that malt liquors are bulky drinks, and indulgence in them introduces a large anount of fluid into the circulation. The effort to expel this surplus fluid puts an extra strain on the heart, which may be very injurious if that organ is already damaged.

CONSUMPTION OF MALT LIQUORS.-According to the report of the United States Census in 1900, the total consumption of such alcoholic beverages was in excess of 1,332,000,000 gallons. Three years later it had passed the 1,600,000,000 mark. In 1906 it rose to more than 1,500 ,000,000 gallons. In 1907 the total consumption had reached 2,130,000,000 gallons. Startling as these figures are, they are surpassed by the records of European countries. France leads the list with an annual consumption of 35 gallons per capita; Great Britain, in 1903, had a consumption of more than 30 gallons per capita, while in the United States the amount is 20 gallons per capita.

Low Alcoholic Beverages.-Low alcoholic beverages were formerly produced by making a second brew of the grains after sparging. The liquid so produced was fermented separately and vielded a beverage called "small beer" which contained some sacharin material and from 1.25 to 2 per cent alcohol. It was a refreshing heverage, containing just enough aleohol to keep it for a time and puite strong enough to satisfy the craving of many people without producing alcoholism. Such beer might properly be termed "weak lager beer." This variety" of beer unfortunately is not now produced, as the "smalls" are added to the "sweet-wort" and the entire ale is fermented at once.

Genuine malt liquors can he produced of low alcoholic strength (2 per cent alcohol): these are practically non-intoxicating. Such beers are now universally made as a result of prohibition laws. These low alco- 
holic beers have a flavor like that of lager beer and are agreeable. They contain a fair amount of malt extract and are satisfactory.

Herb Beers.--Herb beers are made from a decoction of herbs, nettles and other green or dried herbs, saccharin malt and cane sugar. The liquor is fermented with yeast. Herb beers should not contain more than from 1 to 2 per cent of alcohol.

GINGER BEER.-Ginger beer or stone ginger is made after a variety of formulas. When made on a large scale, the water is boiled in a steam jacket pan; from this it is run into a mash tub with ginger. After the ginger has been infused for one or two hours in a settling vat, the liquid is run off and citric or tartaric acid, sugar or honey are added and the mixture allowed to ferment. The honey gives a peculiar softness to the beverage and hastens fermentation. Gum is sometimes added to give body, and it may be clarified by using isinglass. It is bottled on the fifth day, and becomes well aerated in about ten to fourteen days. It usually contains 0.75 to 1.05 per cent alcohol.

SPRUCE BEER.-Spruce beer is a fermented liquor made from the leaves and small branches of the Norwegian spruce, fir, or from the essence of spruce. There are two kinds of spruce beer, brown and white. The former is made with molasses and the latter with white sugar. The liquid is fermented with yeast. The proportion of alcohol varies from 7 to 16 per cent. Spruce beer is an agreeable and wholesome beverage possessing tonic and antiscorbutic properties.

\section{STIMULANTS(23)}

Stimulant is a term which is used with various meanings when applied to medicinal agents. The definition of the Latin word stimulus is to goad, to whip up, to spur on. Alcoholic preparations, which are true narcotics, are often referred to as "stimulants," and the same expression is employed to designate any agent which excites, even briefly, the organic action of any part of the human system. All excessive stimulation reacts into depression, and most of the agents which stimulate the nerve centers first will depress and finally paralyze them. In many cases the action is one of progressive stimulation primarily and progressive paralysis afterwards, affecting the centers in the inverse order of their development, the highest or latest developed centers being affected first, the lowest or oldest ones last. Generally speaking, stimulants act directly upon either the nervous system or upon the circulatory organs. Alcohol affects the latter more than the former. It is questionable if alcohol may be regarded as a 
nerve stimulant. Brain activity coincident with the udministration of aleohol is no donbt due to an increased thow of blood through the brain rather than any direct action upon the cerehral adls.

Alcohol.-Alcohol is produced by the fermentation of sugar with yeast according to the well-known equation:

$$
\begin{gathered}
\mathrm{C}_{83} \mathrm{H}_{12} \mathrm{O}_{43}=2 \mathrm{C}^{2}+2 \mathrm{O}_{2}+\mathrm{H}_{5} \mathrm{OH} \\
\text { (sugar) (carbonic (alcohol) } \\
\text { acid) }
\end{gathered}
$$

The principal constituent of all alcoholic beverages is ethyl alcohol $\left(\mathrm{C}_{2} \mathrm{H}_{6} \mathrm{O}\right)$, each molecule of which is composed of two atoms of carbon, six atoms of hydrogen and one atom of oxygen. The respective proportions of these ingredients by weight are: carbon 52.17 parts, hydrogen 13.04 parts and oxygen 34.7! parts per hundred. Absolute alcohol is somewhat difficult to procure, since it is hydroscopic and rapidly becomes diluted with water when exposed to a damp atmosphere. lithyl alcohol, $\mathrm{C}_{2} \mathrm{H}_{6} \mathrm{O}$, or ethyl hydroxid, $\mathrm{C}_{2} \mathrm{H}_{5} \mathrm{OH}$, is a transparent, colorless, mobile fluid of pleasant ethereal odor, mixing with water in all proportions. It boils at $78^{\circ} \mathrm{C}$. $\left(172.4^{\circ} \mathrm{F}\right.$.) and burns with a white flame. 'The specific gravity is 0.795 . It is only used for technical'purposes. What is known as pure spirit of wine consists of 93 to 95 per cent of absolute alcohol and 5 to 7 per cent of water. The small proportion of water causes it to burn with a blue flame.

The glucose in fruits when fermented is converted directly into alcohol, whereas the starches in grains and potatoes, etc., are converted into dextrin and maltose. Then by the aid of diastatic ferments, before alcoholic fermentation can take place, they are converted into glucose and after a certain period of fermentation are distilled, producing alcoholic beverages. Glueose, the formula of which is $\mathrm{C}_{6} \mathrm{H}_{12} \mathrm{O}_{6}$, is transformed into alcohol by a process of fermentation, through which each of its complex molecules loses two atoms of carbon, four atoms of oxygen (constituting two molecules of carbon dioxid, $\left.\mathrm{CO}_{2}\right)$, the portion remaining constituting two molecules of alcohol $2 \mathrm{C}_{2} \mathrm{H}_{3} \mathrm{OH}$.

The special characters of different alcoholic beverages depend to a large extent upon the particular kind of sugar and yeast concerned in the fermentation. It is also interesting to know that the process of fermentation as carried on in the mannfacture of alcoholic drinks is not such a simple process as the above equation might induce one to believe. In the process of fermentation and distillation. several by-products, the 
chief of which are methyl alcohol, carbon oxid gas and glycerin, are produced as well as alcohol. The nature and amount of these profoundly influence the character of the resulting beverage. It remains true of all alcoholic drinks that the principal constituent by which they affect the mutrition of the body is due to ethyl alcohol. It is therefore of much. importance to study minutely the eflects of alcohol on the body, for upon the results of such study our opinion as to the value or detriment of alcoholic drinks, both in health and disease, may be correctly estimated.

LOCAL EFFECTS OF ALCOHOL.-The local effects of alcohol are those of a chemical irritant. If its evaporation is prevented, as by covering with a watch glass or a piece of rubber, or if the alcohol is rubbed in, it absorbs water from the tissues and hardens them. It coagulates the albumin of the part, but the coagulum is soon redissolved by the fluids of the tissues. It then dilates the vessels of the derma, producing a sensation of warmth upon the skin. If some strong spirit, such as whisky or brandy, is taken into the mouth, a sensation of burning is preduced, owing to the irritation of the nerve endings, and by and by the mucous membrane becomes somewhat corrugated and whitened by reason of the removal of water from its surface cells and the coagulation of their protoplasm.

Internally, in moderate doses, alcohol acts briefly as. a cerebral, cardiac and general stimulant; in large doses as an anesthetic, intoxicant, deliriant and finally as a narcotic poison and paralyzant of the nerve centers.

EFFECTS OF ALCOHOL UPON THE HEART.-As a cardiac stimulant, alcohol should be given when heart failure is impending. The radial pulse is not always a good indication of the strength of the heart. An incompressible pulse, due to obstruction of contracted arteries, may give the impression of a full, strong pulse, whereas the heart may be very weak. Upon auscultation, however, it can be determined exactly when alcohol should be given. In many cases of fever, only one sound of the heart can be heard, the first sound being so weak as not to be audible. This is a condition where there is great danger of collapse, for the first sound coincides with the systole and in proportion to its feebleness there will be weakness in the systolic contraction. At first the sound may be muffled, and as the contractions become more feeble it can only be heard by a practised ear. On the other hand, the second sound is due to relaxation of the heart. If it relaxes quickly, the sound is more distinct than if gradual, and this clearness of the second sound indicates the beginning of heart failure. Disappearance of the first sound always calls for the administration of alcohol. In cardiac failure accompanying acute 
disease, mlimited quantities of brandy are indicated, but stimulants must be reserved for the actual time of heart failure. Alcohol is of great value for its stimulating eflect upon the spirits in conditions of profound nervous exhanstion where there is great depression. It also produces remarkably soothing eflecets in muscular weakness.

The stimulating action of alcohol upon the heart is similar to that produced by violent musenlar exercise, that is, a greater frequency of contraction with an increased force of the heart beat. The pulse is rapid and very short; consequently the arterial system is dilated and respirations increase. 'This is the main action of alcohol. Just as prolonged violent muscular exercise results in exhanstion, so this rapid action of the heart, produced by constant doses of alcohol, finally leads to cardiac weakness. In diseased conditions, however, when the heart is beating rapidly, but feebly and ineflectually, the administration of alcohol of ten diminishes the frequency of the beats, while at the same time, improves its force and volume. As long as these effects are maintained in a case of acute illness, one is reasonably safe in assuming that alcohol is doing good.

The heart seems to show the stimulating effect of alcohol even hefore the liquid is absorbed, due probably to the action on the gastric nerves which are so closely related to those controlling cardiac action. In certain cases this reflex action is so marked that the heart ceases to beat. This phenomenon is not infrequently observed in the sudden death of heavy drinkers. Among the numerous investigations concerning the effects of alcohol on the circulatory system, those of Parkes and Wallowicz are enlightening. They studied a patient who imbibed daily from one to seven and one-half ounces of rectified spirits with the effect of rise in pulse rate of ten beats to the minute as compared with that in the time when alcohol was withheld. However, in accordance with the observations of other investigators, this cardiac stimulation was succeded by depression in which the beat was not only slower than normal, but also more feeble.

This after-effect of alcohol is most important, for it points to the fact that the temporary stimulation must he followed by depression of the heart's action. Alcohol, it would seem. does not afford nutriment for the heart, but is merely an agent by which this organ is enabled to make temporary use of its rezerve strength. The physician should learn from this data that alcohol must not he given ton early in acute disenses, otherwise before the crisis is past the pitient will have arrived at the state in which further stimulation is impossible. 
"Much has been written on the action of alcohol on the heart and circulation, the results of which, however, are far from uniform. Swientochowski(24) found that after the administration of 25 to 100 c.c. of alcohol of 50 per cent strength the pulse rate is increased, but slows down again a little in two or three minutes, without reaching the normal again, however, for at least half an hour. For an hour after its administration blood pressure is lowered. He found no evidence that it really stimulated the heart, but believes that the latter is depressed by alcohol, as are all vital functions. Dixon(25), on the other hand, concludes from his experiments that the first action of alcohol on the heart is a directly stimulant one. Cabot(26) is convinced from his observations on patients that no effect of alcohol upon the heart to increase blood pressure is demonstrable, although he does not go so far as to infer that it is useless in disease." Abel(27) summarizes the experimental evidence regarding the action of alcohol on the vascular apparatus as follows:

1. Alcohol as such, when introduced into the circulation with the avoidance of local irritation, is not a circulatory "stimulant."

2. Alcohol in moderate quantities-say a pint of wine-has no direct action on the heart itself, either in the way of stimulating or depressing. This statement is based on the results of laboratory experiments extending over short periods of time only, and does not imply that it holds for the steady daily use of alcohol in this quantity.

3. In moderate quantities it has no appreciable effect on the blood-pressure. When a change in this becomes evident it is always in the direction of a fall.

4. By virtue of its local action on mucous membranes and on the brain, alcohol is capable of affecting the several parts of the vascular apparatus in such ways that the term "circulatory stimulant" may be applicable. The most frequent of these indirect effects is a quickening or slowing of the pulse rate. Such indirect influences must not be allowed to hide the true character of alcohol, which is always depressant in kind.

The theory that alcohol is a stimulant has long been held. It was commonly believed to stimulate the action of the heart, the muscular system, the digestive system, and even the mental powers. But recent work goes to prove that instead of acting as a stimulant, alcohol is ultimately depressive in its effects on the body in general, especially in its relation to the higher functions. In other words, alcohol should be grouped with the anesthetics and narcotics.

Effect of Alcoirol upon Temperature.-Another apparent inconsistency in the action of alcohol which is explained by its effects on the blood vessels is its influence on the temperature of the body. Alcohol is in reality a fuel, and by its oxidation produces heat, just as it does in 
a spirit-lamp. By dilating the sirface blond vessels it causes more heat to be given off by radiation than its own combustion produces, so that the net result is that the temperature of the brly is lowered. This only seems to occur in an appreciablo degree, however, when the alcohol is taken in intoxicating doses. On this Atwater remarks:

The theory that the energy yielded by alcohol is lost by the increased heatradiation, like the theories that alcohol is not oxidized in the body, and that it prevents normal oxidation of other material was suggested by observed facts. There exists in the minds of the laity the belief, that drinking whiskey or brandy on a cold day will "keep out the eold," and the deceptive feeling of warmth produced by the flushing of the skin with blood is erroneous. Aleohol does not "keep out the eold," but lets out the heat of the body, and consequently the consumption of spirits is a very bad means of fortifying one's self to meet a low external temperature, as was found out by the Aretic explorers long ago. On the other hand, if one has been exposed to eold and the blood has been driven into the internal viscera, and is stagnating there and is about to produce congestion, the timely administration of alcohol may save the situation by once more bringing about a proper distribution of the blood. The proper time, then, to take alcohol is on coming in. doors when wet or ehilled. Its use should be avoided when going out into a blizzard, or on a elear frosty morning or a cold drizzling rain.

There is no doubt that prolonged over-indulgence in alcohol may cause a vascular paralysis which may become permanent, as one often olserves in the bloated look and purple nose of a drunkard. In subjects of this type, when coming down under an acute illness, the beneficial effects which are hoped to be obtained from the administration of alcohol are no longer manifested. The heart and blood vessels have been so often stimulated that they will cease to respond to this administration and the patient pays the penalty with his life.

EFFECT OF ALCOHOL UPON MUSCULAR ACTIVITY.-'The effect of alcohol on muscular activity has been studied very carefully. The experiments show that alcohol does not increase the capacity of muscular work but distinctly decreases it. Doubtless this assertion may seem contradictory to the observations of recorded experience of some authorities, but the explanation is found in the fact that alcohol really blurs the judgment. As Voit remarks, "it gives not strength, but, at most, the feeling of strength. A man may think he is working faster and better under the influence of alcohol than he would otherwise. hut rigidly conducted experiments do not confirm this opinion." "Both science and the experience of life," says Dr. John .J. Abel, of Johns Hopkins I'niversity(28), "have exploded the theory that alcohol gives any persistent increase of muscular power. The disappearance of this universal error will greatly reduce the 
consumption of alcohol among laboring men. It is well understood by all who control large bodies of men engaged in physical labor that alcohol and effective work are incompatible."

According to Abel, alcohol is not a practicable source of energy in the performance of physical labor, while on the other hand, Professor Atwater is inclined to the view that, when alcohol is burned in the body, the heat generated may be directly utilized in the promotion of muscular activity; but he was very careful to state that his experiments only suggested but did not prove the conclusion.

It makes little difference, from a practical viewpoint, which of these views is correct, since all observers are practically agreed that alcohol in small doses may indeed stimulate muscular activity for a very short period of time (twenty or thirty minutes), when the paralyzing action of the drug becomes effective and the aggregate amount of work performed is found to be less with than without alcohol.

Dr. A. J. Rasanoff of the New York State Hospital at Kings Park, in commenting on experiments carried on by Dr. Schnyder and Professor DuBois, draws the following conclusions:

(a) Unlike an ordinary food, alcohol, when taken in moderate quantity on an empty stomach, has two distinet effects on the muscular system-a strengt_.aning one and a weakening one. During the first brief stage after it is taken, the strengthening effect predominates, the aleohol probably being utilized as a food by the exhausted body. But no sooner is the first stage over than the weakening effeet becomes more prominent, the alcohol probably acting injuriously upon the nervous system.

(b) Moderate amounts of alcohol taken with a meal effect a very considerable lowering of the capacity for doing muscular work. The widespread notion that moderate drinking with meals helps a laborer do his work is false.

EFFECT OF ALCOHOL ON DIGESTION AND SECRETION.-The effect of alcohol on the digestion and secretion is to increase the flow of saliva in the mouth from the stimulating effect of the alcoholic beverage. In small quantitics, alcohol dilates the gastric vessels, reddens the mucous membrane of the stomach, produces a sense of warmth and comfort, stimulates the gastric glands and increases the activity of the gastric movements. This increased flow of the salivary secretion is, however, of very brief duration. Not only is the volume of saliva increased, but also its organic and inorganic constituents.

The effect of alcohol upon the gastric secretion is marked, since the quantity of gastric juice, the amount of acids and the total solids is angmented, not only by the presence of alcoholic beverages in the stomach, 
but also indirectly through the influenere of alcolud absurbed from the intestine. 'This increase in the flow of gastric juice maly possibly connterbalance the greater or lesser retardation of the digestive changes cansed by alcoholic beverages. Alcohol talion moderately, immediately before or during meals, promotes the appertire and assists digestion, lessens the elimination of waste products, aluses a subjective sensation of heat and slightly raises the body temperature.

The most elaborate and significant series of investigations to test the effects of alcohol in this direction were carried out by P'rofessor ('hittenden, of Yale(29), working in association with the "committer of loifty." His results are very definte and convineing, and they corroborate the findings of various other experimenturs, notably those of lioberts in lingland. A summary of his findings ma! he expressed as follows:

Aleohol, taken as proof-spirit or as hrandy or whisky, directly stimulates the flow of the digestive juices, salivary, stomachie, and pancreatic. But if present in sufficient quantity to form more than tive per cent of the gastric contents, it materially interferes with the digestive aletion of the gastrie juice, the formation of which it has just stimulated. Thus one of its effects tends to counteraet the other: and the ultimate result will depend upon such factors as the quantity ingested, the rapidity of its absorption and the quality of the gastric juice itself.

The two antagonistic effects of alcohol on digestion are now pretty well understood. Professor Chittenten hriefly summarizes his conclusions as follows:

The results collectively indicate that the period of gastric digestion does not greatly vary under the influence of aleohol or aleoholic beverages. In some few of the experiments the results indicate il slight acceleration of digestion in the presence of weak alcoholic beverages, while in others strong aleohol retards slightly the rate of digestion. Giving due heed, however, to the avoidable errors which must of necessity attend this kind of experimentation, we believe that the results obtained justify the conclusion that gastric digestion as a whole is not materially modified by the introduction of alcololie fluids with the food. In other words, the unquestionable acceleration of gastrie secretion which follows the ingestion of alcoholic beverages is. as a rule, counterbalanced by the inhibitory effect of the alcoholie fluids upon the chemical process of gastrie digestion, with perhaps at times a tendeney toward preponderaner of inhilitory action.

Still further experiments were (arried on hy. [)r. Sohnyder and Professor DuBois in order to determine the effect of alcohol on a well-nourished organism. Under such conditions, if alcohol possesses some action besides its nutritive effect, a highly momished boly would not make use 
of the nutrition, but might respond to its other action. Whatever such other effect might be, it could be determined as an entity entirely unaffected by any other action. Two of their concluding experiments will now be described:

Experiment No. 4 consisted of the same measurements as in the first three experiments, earried out at about the same hour of the day, but shortly after a good meal without alcohol, the meal consisting of soup, meat, vegetables and bread.

No. 5 consisted in similar measurements, taken shortly after meals during which a moderate quantity of alcohol was consumed. The food was the same as in experiment No. 4; in addition, 300 cubic centimeters of good Bordeaux wine, containing 29.4 grams of alcohol, was consumed in the course of the luncheon. Dr. Schnyder observes that this is about the quantity referred to as "a good glass of wine," considered by many people as a moderate, perfectly harmless, even indispensable drink. The tabulated results of experiments 4 and 5 follow, each figure -as in the first three experiments-being an average from ten different single experiments on ten separate days:

WORK DONE-METER-KILOGRAMS

\begin{tabular}{|c|c|c|c|}
\hline Period No. & 4 (Food only) & $\begin{array}{c}5 \text { (Food and } \\
\text { Alcohol) }\end{array}$ & $\begin{array}{l}\text { Loss of } \\
\text { Efficiency }\end{array}$ \\
\hline 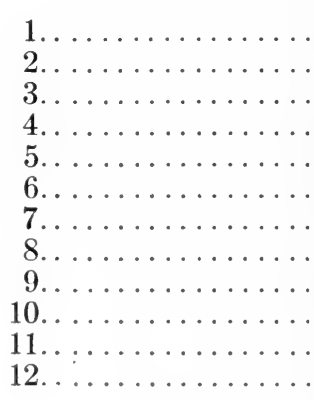 & $\begin{array}{l}7.969 \\
4.418 \\
3.652 \\
3.440 \\
3.245 \\
3.215 \\
3.248 \\
3.223 \\
3.233 \\
3.254 \\
3.322 \\
3.282\end{array}$ & $\begin{array}{l}7.370 \\
3.872 \\
3.373 \\
3.182 \\
3.016 \\
3.136 \\
2.996 \\
3.004 \\
3.076 \\
2.929 \\
2.993 \\
2.922\end{array}$ & \\
\hline $\begin{array}{l}\text { Total of } 12 \text { Periods. . } \\
\text { Total first } 5 \text { " } \\
\text { Total last } 7\end{array}$ & $\begin{array}{l}45.501 \\
22.724 \\
22.777\end{array}$ & $\begin{array}{l}41.869 \\
20.813 \\
21.056\end{array}$ & $\begin{array}{l}8.0 \% \\
8.4 \% \\
7.6 \%\end{array}$ \\
\hline
\end{tabular}

A peculiar fact is shown here: while alcohol is a food, the human body will not use it as such when it has ample supply of other food. Consequently, the weakening influence of alcohol, which is here got at by itself, is seen to be at work continuously. The total loss of efficiency in the twelve periods is 8 per cent; in the last seven periods it is 7.6 per cent; the weakening effect, as might be expected, is really great at first. 
FOOD VALUE OF ALCOHOL-C'lle foed value of alcohol, aceording to Dr. Frederick Petersen, may be smmmarizen in a single sentence. "If alcohol is a food, it is " poison lood." In discussing the subject, P'rofessor Atwater says:

The question as to whether aleohol is a food and whether and in what way it supplies the body with nutriment have been netively diseussed for the last fifty years or more. No one doubts that the continued and exeessive use of aleohol is injurious to body, mind and character. No one questions that in large quantities it is really a poison. The debatable problem is its effects when taken in small or moderate quantities.

Many competent observers have made corroborative experiments proving the depressive effect of alcohol upon the muscular system, the result of the experiments being widely different in character. Atwater, in a remarkable series of experiments, found that the men in his respiratory cabinet were apparently able to perform much less work under the inflinence of alcohol even when administered in small doses than without it. Professor Hodge in a notable series of experiments on dogs furnishes some specific data. He tested very carefully the activity and the resistance to fatigue of dogs that were given alcohol regularly as compared with other $\operatorname{dog}$ in the same kennel that received no alcohol. His results when summed up showed that the spontaneous activities of dogs under the influence of alcohol were 30 per cent less than the dogs in the same kennel under normal conditions. The tests made by Hodge, which proved the effect of effort and fatigne, were in the pursuit and retrieving of a ball thrown repeatedly; the alcoholies developed but little more than half of the efficiency of their companions and the evidence of fatigne was very much greater in these animals. The dogs in question were not acutely intoxicated, but merely suffering from the depressing effects of considerable quantities of alcohol taken day by day. In common parlance, these dogs might be termed "habitual heavy drinkers," except they did not drink the alcohol voluntarily.

"The regulation of the dosage of alcohol," sar's Professor Hodgre. "was to give as large a dose as possible short of producing uoticeable intoxiention." The animals were able to take such doses as this without heroming acutely intoxicated. Snch experiments as these tend to reveal alcohol in its true light, not only proving the negative of alcohol as a muscle stimulant, but in a large measure substantiate the opinion of Dr. Ahel that "alcohol is not a food in the sense in which fats and arbohydrates are 
foods," but it should rather be defined "as an easily oxidizable drug with numerous untoward effects which inevitably appear when a certain minimum dese is exceeded"; it therefore should be classed with the more or less dangerons stimulants and narcoties, such as opium, hasheesh, tobaceo, etc., rather than with truly sustaining foodstuffs.

Alcohol as a Fat-Sparer.-Alcohol may be termed a protoplasm poison or anesthetic which is itself easily burnt up in the body. This is the key to the proper understanding of its action on metabolism. We know from physiological experiments that the greater the quantity of arrbohydrate and fat which is supplied with protein, the less does the latter tend to be wasted in supplying energy and the more of it there is available for the higher purpose of keeping the tissues in repair. The fat and carbohydrate are sacrificed instead of the protein. This is what physiologists mean when they describe fats and carbohydrates as protein sparers. Thus the cells of the body may be regarded as being bathed with lymph containing in solution particles of protein, fat and carbohydrate, and we know from experiments that these are broken down by the cells, protein being more easily destroyed than carbohydrate and lastly fat. If alcohol gets access to the cell and partially paralyzes or anesthetizes it, the cell will lose its power of breaking down these compounc's, such as fat, with which it has, even in a condition of full activity, difficulty in coping. Alcohol then saves fat from combustion; in other words, it is a fat-sparer. Experiments have proved, though with greater difficulty, that alcohol may be able to spare carbohydrates, but this is exceedingly doubtful. This action of alcohol on cellular activity is quite in keeping with what we know of the effects of other cell poisons.

Unquestionably alcohol spares fat and in certain instances carbohydrate. Nevertheless, as in this process, alcohol is itself consumed and heat and energy are generated. Hutchison confirms this statement when he declares that without doubt alcohol should rank as a food. As demonstrated by recent investigations, 7 calories of energy are produced by the complete combustion of 1 gram of alcohol in the organism; that is, the heat value of 131 grains of alcohol equals that of 100 grams of fat; or, in other words, the fuel value of 1 ounce of alcohol and 1 ounce of butter are equivalent (about 200 calories).

Careful study of the work of competent experimenters on the action of alcohol clearly proves that alcohol is not as good a source of heat in the food as fat, for, as we have already seen, by dilating the surface blood ressels, alcohol may canse more heat to be dissipated than it is capable of producing. In addition, the combustion of alcohol takes place 
rapidly, and the resulting loat is quickly dissipated, while heat originat ing from fat is produred far more stowly and equably. Then, too, it has been shown that alcohol in large quantities produces general paralysis of cellular activity, often to such a degree that there is both a diminution of heat production and an increased heat loss, cmoling in a marked lower. ing of the temperature of the body. Aleohol cannot he unquestionably considered as a nseful muscle foud. Even thongh it may be oxidized in muscular tissue so as to yiehl energy, any effect of this nature must be decidedly ofliset by the paralyzing effect of aleohol on nerve cells.

Even granted that alcohol is a fat-sparer and that it exerts an oxidi\% ing effect upon carbohydrate, one is not surprised to learn that its administration neither increases nor diminishes the intake of oxygen or the ontput of earbonic acid. Besides, if the amonnt of fat or carbohydrate in the diet is sufficient for the needs of the body, alcohol is able to supplement them by acting as a source of heat. Atwater, in his famous experiments at the laboratory of the Wesleyan University, found that from oncfifth to one-seventh of the total calories of the diet conld be thus replaced by alcohol. This explains the observation of Hammond, who found that when he added alcohol to a diet on which he was losing weight, the loss was inmediately stopped.

Dr. Henry Smith Willians(30), in discussing Atwater's experiments, succinctly summarizes the following:

It appears that aleolol is a food allied in character to the sugar with which it has close chemical affinity. If taken in small quantities, about 98 per eent of it is burned in the body, and the resulting heat is available for the uses of the body. But to admit that alcohol may serve as a food is not more equivalent to arguing for its use under ordinary conditions than the admission that human flesh may bo nutritious is an argument for the practice of cannilalism.

Professor Atwater cantions the reader that his tables showing the nutritive value of alcohol as compared with other fonds tell only half the truth, because they "leave ont of accomint the action of the alcohol as a drug, which is not exerted by ordinary food." "llhen alcohol is taken in excessive quantities," he continues, "its action as a drug may far more than counterbalance its nutritive effect. Taken habitually in excess it is ruinous to both health and character." II sperifically advises "people in health, and particularly young people." to alstain altogether from alcoholic beverages. Similarly Dr. Nemmann, Professor of Hrgiene in the University of Heidelherg. and ne of the foremost anthorities on the subject, concludes a recent article on the food value of alcohol by declar- 
ing that "from the standpoint of practical hygiene we have only to wish that alcohol should be used as little as possible, because it is an irrational, a very dear, and an equally dangerous foodstuff." Develde, another Continental authority, points out that "it is more economical to feed one's self with fieldfares than with beer or wine."

Further argument along this line is quite needless, because no one seriously pretends to take alcohol in any form merely for its food value. At the very best, no alcoholic beverage has the food value of the grain or fruit from which it is made. Alcoholic beverages owe their popularity to those other and quite different effects which have just been referred to as "drug" effects.

Antsie in physiological memoirs records some striking instances of the uses of alcohol seemingly as a true food. He kept patients alive for many days during acute illness on nothing but large quantities of brandy, and found that they had not emaciated nearly so much as they would have done had they been merely living on their own tissues. This is not surprising, says Hutchison, "for the amount of alcohol (12 ounces of brandy) administered daily is capable of yielding close upon 1,000 calories to the body."

EFFECTS OF ALCOHOL UPON METABOLISM.-The influence of alcohol on metabolism may be briefly summarized: $(a)$ it is burnt up in the body, sparing fat and possibly carbohydrate, but (b) the weight of evidence is against the view that it has any important power of diminishing nitrogenous waste. The combustion of alcohol in the body and its elimination are questions which demand much thought and study. In nonintoxicating doses, very little ( 1 to 3 per cent at most) passes off from the body unchanged, while on the other hand, if the quantity consumed is sufficient to produce intoxication, the amount of alcohol which escapes combustion may be as high as 10 to 12 per cent of the whole dose. Whenever the proportion of alcohol in the circulating medium becomes greater than the cells can rapidly decompose, it exerts a protoplasmic poisonous effect. Those effects are cumulative and soon a condition of cell paralysis is produced, so that the expression "paralytic drunk" has a truer physiological meaning than those who commonly use it suppose.

Impairment of Mental Processes.-The experiments of Kraepelin and Kürz(31) show the marked impairment of various mental processes and the progressive character of such impairment, from the continued repeated moderate use of alcohol. These experiments were originally published in 1900 ; the results of these experiments show a piling up of the destructive effects of alcohol with considerable impairment of the mental faculties. Since the brain cells are particularly susceptible to the 
paralyzing effect of alcohol, the brain naturally exhilits the first effects of an orerdose. The higher centers being the tirst uffected, the paralysis begins in these, passing downward. As the highest cerebral centers are the controlling centers, the carliest exhibition of alcoholic poisoning is loss of control of the intellect, emotions and muscular system. The "driving centers" of the brain, those centers of life upon which depend the cardiac action and respiration, are affected by the paralysis only in an extreme degree of intoxication. The condition of intoxication then develops into coma, which commonly ends in death.

It must not be forgotten that the prolonged and habitual consumption of alcohol, though insufficient in quantity to "produce any of the ontward or visible signs of intoxication, is yet beyond the immediate oxidizing power of the cells and may result in considerable detriment to the tissues." The brain, likewise, in a habitual drinker is especially liable to suffer, probably owing to the fact of its being the most highly organized and delicate tissue of the body. Through the abuse of prolonged chronic alcoholism, the brain beeomes the seat of various degenerative changes which affect the sensory centers more deleteriously than the motor, leading eventually to a blunting of the moral perceptions with a special loss of the sense of integrity. The presence throughout the body of even a small amount of undecomposed alcohol leads to inactivity of chemical energy of the cells, thereby hindering the ordinary metabolic processes leading to chronic diseased conditions. As already pointed ont, alcohol seens to enact the rôle of a fat-sparer in the metabolic process, therefore alcoholism is a common cause of fatty degenerations and a primary factor in many cases of obesity. By hindering the decomposition of carhohydrates, it interferes with the glycogenic function of the liver, favoring some forms of diabetes. There can be no doubt that its continned administration may be a causative factor in that alteration of protein metabolism which seems to be the basis of gout.

EFFECT ON EXCRETORY ORGAXS.-The elimination by the kidners and other organs of excretion of undecomposed alcohol irritates these organs and is a factor in bringing about changes in their structure which may seriously interfere with the normal functions of the affected organs. In this way the habitual consumption of more alcohol than can be decomposed in the body may lead to the production of chronic nephritis. These changes due to chronic alcoholism emphasize the very great importance of ascertaining, if only approximately, just how much alcohol can be so completely oxidized in the hody that there will he none left over to exert the ill effects and injurious influences just enumerated. 
AMOUNT OF ALCOHOL THAT CAN BE COMPLETELY OXIDIZED.As a result of much experimentation, it has been determined that from one to one and one-half fluid ounces of absolute alcohol is the maximum amount which can be completely oxidized in the human system during a period of twenty-four hours, and in such a way that none of its nareotic effects are manifested and no unchanged alcohol appears in the urine (Parkes). It is estimated that this quantity of alcohol would be contained in the following amounts of some of the commoner alcoholic drinks :

Brandy or Whiskey (50 per cent Alcohol) Port, Sherry, and other strong Wines (20

per cent Alcohol)..............

Claret, Hock, Champagne, and other

Weaker Wines (10 per cent Alcohol) 10

Bottled Beer (5 per cent Alcohol)..... 20

\section{2 fluid ounces or 1 glass}

5 " * " $\quad 2 \frac{1}{2}$ glasses

0 " " "equals 1 tumblerful " " " 1 imperial pint

Idiosyncrasy or personal peculiarity of the individual plays a very large part in determining the amount of alcohol which can be consumed by a person without injurious effects upon health. Some persons are able to burn up more alcohol than others. We all have known persons who are able to go on day after day consuming much larger quantities of alcohol than mentioned above without appreciably interfering with their normal condition. Apart from these personal peculiarities of constitution, it must be obvious that surroundings and environment of each individual affect, in a way, the amount of alcohol which can be imbibed within the bounds of safety. Another factor which must influence any ealculation as to the amount of alcohol which can safely be consumed daily is the form, mode and quantity in which the alcohol is taken. It is clear to the careful student that an amount of alcohol which would be harmful if swallowed at one time, may be free from danger if taken in smaller quantities during a twenty-four-hour period.

Varieties of Alcoholic Drinks - WHISKEY.-Whiskey, according to the United States Pharmacopœia, is a spirit obtained from fermented grain by distillation and contains from 46 to 56 per cent by volume of alcohol. It should be free from disagreeable odor and at least two years old. It is quite important to clearly distinguish genuine malt whiskey distilled from malted barley, or a mixture of malted and unmalted barley from a "pot-still," and grain whiskey distilled from unmalted grain, such as barley, oats, corn and wheat, which is prepared in the "patent-still."

MaLT WIISKEY.-Malt whiskey is prepared from malted barley which is carefully dried. Then it is made into a "mash," making a true 
beer. 'The nature of the water used in "mashing" is supposed to have some influence on the character of the finished product, soft water being preferable.

When the fermentation of the "mash" is complete, it is distilled in the old-fashioned "pot-still" heated over an open fire. 'This is a point of some importance, since the direct heat canses some of the sugary substance in the mash to become slightly charred. In this way, among other things, the substance furfurol $\left(\mathrm{C}_{5} \mathrm{H}_{4} \mathrm{O}_{2}\right)$ is produced, the presence of which is one of the chief distinguishing characteristics of "pot-still" whiskey.

Gran Whiskny.-Grain whiskey is made from a mixtmre of grains, rye, com and barley, with just a sufficiency of malt to convert this starch into sugar. Various other substances also are used for its production, such as cane sugar, glucose, molasses, potatoes, tnrnips, beetroot, ete. More important than this distinction, howerer, is the fact that it is distilled in a patent steam still in such a way that the by-products of fermentation (fusel-oil, etc.) are, to a large extent, separated from the ethyl alcohol. The raw product from the patent-still has much less flaror than new malt whiskey, but it has the advantage of being ready for consumption much sooner.

This kind of whiskey is stronger and harsher than malt whiskey and is more eheaply made beeause the cost of malting is saved. Genuine grain whiskey, however, is made from the fermentations and distillations of the wort of grain rye, corn and barley. Kentucky Bourbon whiskey is made by the use of partially malted corn and rye, while the Monongahela whiskey of western Pennsylvania is made from rye with 10 per cent of malt. Scotch and Irish whiskies are made from malted barley mixed with other grains and distilled in the old-fashioned pot-still.

The fresh distilled whiskey, called raw whiskey, is unfit to drink until after it has been aged by storage, allowing various ehemieal changes to take place. The color of gennine whiskey is in part due to the material from which it is made, and in part to the way in which it is stored. The process of maturation consists of certain changes in the spirit attended by softening, with the development of aroma and a deepening of the color. The bouquet depends largely upon the material from which the liquor was obtained and the methods of preparation. 'Thus malt whiskey develops a distinguishable flavor formed in no other whiskey. Whiskey from potatoes has a very faint odor of violets. Pot-still whiskey develops a flavor never found in patent-still whiskey. The proper time for maturation should be from five to eight years. New whiskey contains a varying proportion of the higher alcohols, which are. for ennvenience, 
commonly classed together as "fusel-oil." This term includes the following substances: iso-amyl alcohol, propyl alcohol and normal butyl alcohol. Fusel-oil is injurious to living organisms and speedily poisons small animals. In man it produces rapid intoxication, followed by headache, depression and general nervous indisposition.

Moonshine Whiskey.- "Moonshine" whiskey is a product made in the mountainous sections of the United States from grain, corn, wheat, rye and potatoes by most crude methods without the supervision of the Internal Revenue Department of the United States Government. The preparations of materials used in making "mash" for distillation is usually, cornmeal, 0.8 per cent; rye, 0.1 per cent; malt, 0.1 per cent. This mixture is placed in tubs and scalded with "slop," the refuse from former distillation. After cooling it is raked, or mixed by a stick called a "masher." Water is added and the mass ferments for two or three days. Sweet mash whiskey is made by scalding the mash with water instead of slops, with yeast added to induce fermentation. Sour mash whiskey is made without yeast but with slop. The wort is then heated by steam, and the low wines, called "singlings," are run off from the residue or slop and redistilled. The whiskey is now ready for barrelling. As before stated, new whiskey is unfit for consumption, and after barrelling it should be stored and allowed to ripen for five years. The pot-still is so ancient that the date of its origin is unknown. It is probable that the modern patentstill has been evolved from the primitive stills which even now are used in Ceylon and the Malay Archipelago, where the art of distilling is believed to have originated.

At least two distillations are necessary when the pot-still is used so as to produce a spirit of proof strength, i.e., 50 per cent alcohol, and repeated fractional distillation is required to separate the alcohol from the water and oils, as in the manufacture of spirits of wine. The product of the pot-still is always uniform in character. No matter what is the source of the spirit, it is, as previously stated, a grain spirit and is made from raw grain such as barley, oats, corn or potatoes, etc. The process of malting brings about changes in the grain which are unobtainable by other means. These changes are the source of differences between mature pot-still whiskey made from malt and mature patent-still whiskey made from unmalted grain.

Patent-Still vs. Pot-Still Whiskey.-Various controversies have taken place as to the respective merits of pot-still and patent-still whiskey (32). On the one hand, it is claimed that pot-stilled whiskey alone retains the flavor which is derived from malt and the effects of heat. Just 
as wine depends for its flavor upon the substance used, so does whiskey. Malt whiskey obtained by means of the pot-still retains a rich malty flavor. 'This flavor is distinctly recognimed in prot-still whiskey, but is all. sent from the patent-still product. "Thle main differences in the two varieties of whiskey may be briefly summarized as follows":

(a) Patent-still whiskey contains much less of the by-products of formentation, fusel-oil, etc., than pot-still whiskey and is thercfore a much purer product.

(b) Pot-still whiskey improves with age whilo patent-still whiskey does not improve so much from aging.

(c) Young patent-still whiskey is much safer to drink than young pot-still whiskey, but the latter when fully matured has a fuller and pleasanter flavor than the former.

Most of the commercial whiskies are blends of malt and grain whiskies and are not the product of one distillery. Grain whiskey is often used as a basis of the blend, a certain percentage of malt being added for the purpose of proper flavoring.

BRANDY.-Brandy is the spirit distilled from the fermented juice of grapes and other fruits. It is made in most wine-growing countries, but the best known brandies come from France, Spain, Portugal and Califormia. White wine contains 6 to 8 per cent of alcohol and is generally used for making the best brandy. The wine itself is often harsh and unfit for consumption. The distillation is carried on in the old-fashioned pot-still having a large boiler with a bulbous head which collects the scum and some of the water thrown up in boiling. The distillate is condensed by running through a "worm" surrounded ly cold water. "The process is that of fractional distillation and consists of two distinct distillations. In the first operation the distillate is divided into three parts which are collected separately. The first part contains the crudities of the wine and is returned to the still; the middle running is the best part and is used in the second distillation; and the third part or tailings is mingled with fresh wine to be redistilled. The second part constitutes the brandy, and the tailings are used to make a second grade of brandy."

Apple Brandy.-Apple brandy-cider brandy, applejack-is a distilled liquor made by the distillation of apple cider. It contains the natural organic acids and ethers of the apple which impart to the brandy a peculiar flavor, which is not so agrecalle as that obtained from the distillation of fermented grape juice in making grape brandy. Apple brandy usually contains from 40 to 50 per cent of alcohol. Pench brandy is made by distilling the pomace of ripened peaches by means of the old-fashioned 
"pot-still"; apricot brandy is a similar product. Both varieties have a very pleasing bouquet.

All brandy is a clear, colorless spirit when new, and is only fit for use after remaining in wooden casks for some years. The color then becomes brown from the extractives of the wood and various aromatic ethers, aldehydes and other products. The propyl, butyl and amyl alcohols, originally present and more or less injurious, are decreased by age. Furfurol, which is always present in genuine brandy, rapidly diminishes with age. The percentage of alcohol in all brandies is about 50 per cent.

Fictitious Brandy.-Much of the brandy on the market is a fictitious blend and not a pure distillate of fermented grape juice. It may therefore be termed fictitious brandy. The product is a mixture of neutral, silent or grain spirit (produced by the distillation of rice, rye, corn, beetroot, potatoes, glucose, etc.) colored with prune juice or caramel and flavored with cognac essence. It is a clever imitation, but in such brandies the flavor vanishes immediately it is tasted and leaves a dryness on the tongue. There aro other differences between fictitious and genuine brandy: that made from grain spirit contains no furfurol and no appreciable quantity of higher alcohol or ethers, excepting what are added to it. The color of fictitious brandy is usually deeper than that of the genuine spirit and is due to the addition of prune juice or burnt sugar. It is sometimes "fortified" by adding bitter almond shells or tincture of capsicum. The genuine brandy is not usually diluted excepting by the addition of water to "extend" it and earamel to restore the color of the diluted article.

RUM.-Rum is a spirit distilled directly from sugar cane products in sugar-growing countries and is usually produced by the distillation of fermented molasses obtained in the manufacture of raw sugar. The best qualities, however, are obtained by direct fermentation of the juice of the freshly harvested sugar cane. The spirit contains by-products of fermentation, which impart to rum its characteristic flavor.

Genuine rum is of two distinct types: (a) Jamaica rum and (b) Demerara rum. The former is distilled from liquor having a high original gravity and which undergoes slow fermentation for from ten to twelve days; the latter is distilled from a so-called "wash," having a low original gravity and which ferments rapidly for a period varying from thirty-six to forty-eight hours. In addition to these two, many imitation and mixed rums are sold. They are manufactured from grain spirit and butyrate of ethyl, while burnt sugar is used as a coloring agent. In contrast with this motley assortment of counterfeit preparations, genuine 
rum is that made in Jumaica from fermentend juice of sugar eance, anul is of mequalled quality. In analogons instance is that the characteristic

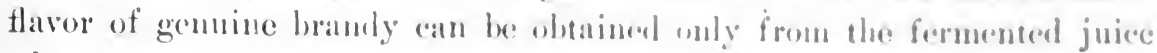
of grapes. The method of distillation and maturation is similar to that used in the manufacture of other spirits, and the process of maturation is much like that taking place in whiskey and brandy. 'This has already" been described.

Rum spirit, like malt whiskey, improves greatly in flavor by the development of ethers in which it is pecollanly rich. 'The product, like old wine, improves with age and usually goes into consumption at about the same alcoholic strength and age as malt whiskey. Rum contains a notable amount of furfurol and is highly arid. "Fine old Jamaiea rum, well matured, is soft to the palate and has a mollow flavor and aroma, dne to the natural combination of ethers and aldehyds." Its alcoholic content is about 70 per cent by volume.

GIN-Gin is a spirit distilled from the mixture of malt, grain and various other substances which give to the liquor sperial properties.

(a) Holland gin is manufactured from a mash of the cereals mentioned, distilled three times in a pot-still, with juniper berries being added to the last distillation. The product is then run off into underground cisterns lined with white tile, where the spirit can be kept without danger of absorbing coloring matter.

(b) Irish gin is made from the same cereals with a combination of aromatic, carminative and diuretic substances derived from angelica root, calamus, cardamon, cassia, cinnamon, coriander, juniper, fennel, grains of paradise, licorice, orris root and other substances.

(c) "Old Tom" gin is a London beverage made by the addition of cane sugar to gin made after the Irish formula.

Much so-called gin is a fictitious product, manufactured out of grain spirit flavored with salt, juniper berries and the oil of turpentine. New or raw gin is as injurious as new malt whiskey or brandy, and andergoes changes somewhat similar to those which have been described in comection with other spirits. In compesition, gin resembles beet spirit more than any other; the ethers and higher alcolonls are comparatively insignificant; the secondary products are therefore small in amount. ITnsweetened and dry gin contains about 45 per cent: the Irish and Holland gins run about 35 to 43 per cent, and the Old 'Tom gin varies from to to 50 per cent of alcohol.

LIQUEURS.-Liquemrs(33) are spiritunu lworages havine a high percentage of alcohol. They are swectenem with sane sugar, while the flavor- 
ing consists of essences, ethers, herbs, which may be aromatic, and in certain instances bitter substances. Originally these spirits were distilled from the fermented liquor derived from herbs, barks, roots and seeds. Now, however, they are offered in the form of tinctures of these articles which have been made with grain spirit, spirits of wine and the like. Laborde, in a communication to the French Academy of Medicine, appearing in the Lancet, 1902 , Volume II, page 49, says:

Liqueurs are now largely made of artificial essences. Genuine vegetable essences are bad enough, but these are not used now. The essences are made of synthetic flavorings, which are more poisonous than the vegetable essences. Synthetic essence of anisette contains a quantity of hydrocyanic acid and the inhalation of the vapor from this essence has been sufficient to eause grave syncope followed by illness lasting several days. Chartreuse essence contains thirteen poisonous substances which bring about serious effects.

Brouardel, in discussing liqueurs in the London Lancet, says: "Liqueurs were formerly distilled from wine holding aromatic substances in solution; they are now simply solutions of essences in rectified alcohol. Like absinthe, they cause drunkenness, loss of sensation and motion and veritable attacks of epilepsy."

Laborde in summing up the harmful influences to the public health from the consumption of liqueurs considers that absinthe and its compounds, chartreuse, gin, noyau, vermouth, vulnerary and Angostura bitters, should be absolutely forbidden to be sold, except for medicinal purposes, and that public authorities onght to forbid the manufacture or sale of these drinks. He asserts that vulnerary contains at least 15 per cent of poisonous substances.

Composition of Liqueurs.-The proportion of alcohol in liqueurs is high, following from 33 to 50 per cent or more by volume. The proportion of the other ingredients is shown in the analysis (on page 589) of some of the most prominent of this class of alcoholic beverages, taken from König and Rupp.

Absintine.-Absinthe is one of the spirituous liqueurs. It contains the essential oils of a number of aromatic herbs having antispasmodic properties. Among these herbs are cloves, cinnamon, wormwood, angelica, marjoram leaves, sweetflag and parsley. They are macerated in a 40 per cent spirit. The greenish-yellow or opalescent color is produced by the chlorophyll of the green leaves of spinach, wormwood, hyssop and veronica. Recently artificial coloring agents have been used in the liqueur. 
THE ALCOHOL CONTENT OF VARIOLS LIQLEURS

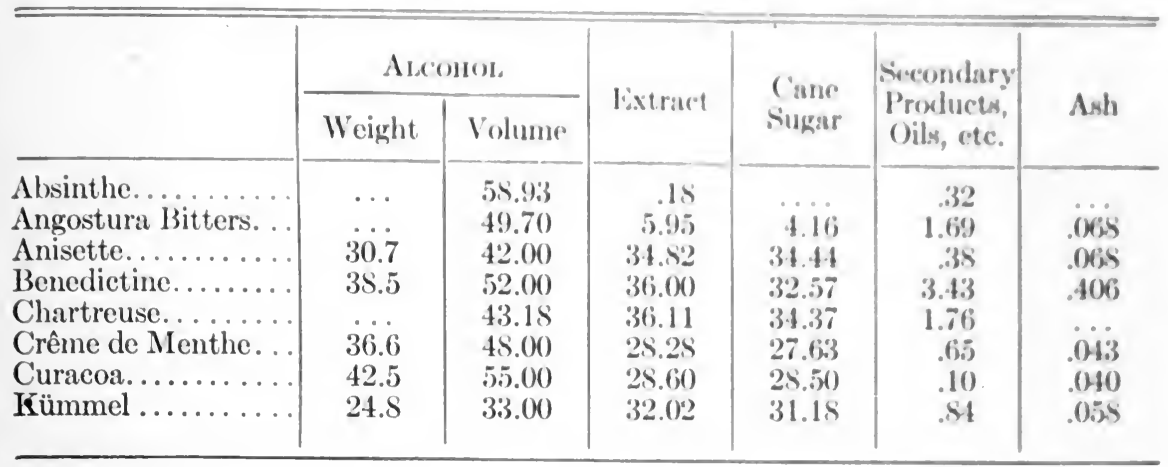

This beverage was first introduced in the French Army in 1844, but is now prohibited. Its consumption produces the customary effects of alcohol exaltation of the nervous system, "quickening of the circulation and increase of appetite due to these bitter principles; but this is followed by a depression which may be profound," leaving deleterious effects on the nervous system such as headache, giddiness and loss of memory, with the subsequent degeneration of mental and moral faculties ultimately leading to extreme depravity. The Federal Government of this country recognizing the danger of absinthe drinking has prohibited its importation and interstate commerce in the United States. The primary physiological effect is one of exaltation to the nervous system, a quickening of the circulation and increase of the appetite and digestion; but is followed by depression which may be profound. Aceording to Mangan (Lancet, I, 739,1887 ), absinthe drunkenness or poisoning is attended by sudden and severe headache and giddiness, delirimm in which hallucinations affecting the special senses predominate, epileptiform attacks, loss of consciousness, and, on recovery, loss of memory; followed by hysterical manifestations.

Angostura Bittens.-Angostura bitters is really a tineture of Angostura bark and various spices slightly sweetened with sugar. It is made largely in Trinidad.

Benedictine.-Benedictine is a liqueur originally made at the Abbey of Fecamp in northern France as early as $1510 \mathrm{hy}$ the Benedictine Monks of the Abbey. It is a strong alcohol flarored with rarious essential oils and herbs. The exact constituents are a trade secret.

Chartrecse.-Chartreuse is made at the Carthusian Abbey near Grenoble, France. Its manufacture furnishes a considerable revenue to 
the monks of the abbey. This liqueur is made from alcohol distilled with angelica, hyssop, nutmeg, peppermint, and sweetened. Like other liqueurs, chartreuse is now made prineipally from volatile oils and essences instead of from herbs and spices.

Crême de Mentue.-Crême de menthe, if genuine, is a liqueur made by distilling a fermented decoction of mint, sage, balm, cinnamon and ginger, sweetened with sugar and colored with chlorophyll. The herbs are macerated with the roots and bark in the alcohol for fourteen days, filtered and sweetened with sugar. Often, however, this liqueur is clearly a tincture sweetened and artificially colored with analine dyes.

Curacon.-Curacoa is a liqueur somewhat simpler than most bever-o ages of this class. It is made in Amsterdam from the peel of bitter oranges imported from the island of Curacoa. The peel is macerated and distilled with spirit sometimes flavored with small quantities of Jamaica rum. It is sweetened with sugar and caramel added to give color.

Kinscinwasser.- Kirschwasser is a liqueur made from crushed cherries grown in the Black Forest. This is a very popular drink among the Germans. It is made by the distillation of crushed fermented cherries. It has the taste and odor of cherry pits and contains about 50 per cent alcohol.

KümmeL.-Kümmel is a liqueur made from a fermented infusion of cumin and coriander seeds sweetened with sugar. It is now made from a tincture of cumin and coriander mixed with brandy and sweetened with sugar.

Maraschino.-Maraschino liqueur is made from small sour Dalmatian cherries from Marasca, Italy. The cherry is crushed together with the pits, mixed with honey, fermented and distilled. The imitation is made from crushed wild cherries, peach pits, cherry leaves, raspberries and nuts. These are macerated for fourteen days in alcohol of 85 per cent strength and sweetened with sugar in the same way as crême de menthe.

MEsD.-Mead is a vinous beverage manufactured from honey by mixing it with hot or boiling water in equal quantities. To the mixture are added certain spices, a portion of ground malt and a piece of toasted bread to aid the process of fermentation. There is no question but that mead formed the favorite beverage of the Northern people for many centuries; it is also frequently mentioned in Ossian.

Mescal.-Mescal is a distilled beverage made by the Apache Indians and other natives of New Mexico from a species of cactus (Maguey) haring heary succulent leaves and turnip-like roots. After roasting, the 
produet is "pulped" between rocks and the juice which exules is allowed to ferment. This is the lager beer of Ilexion, and is known as "pulque." It is held that the injurions effects of this beverage are not 80 much duo to the alcohol contained, as to the products of fermentution. Mescal is fermented in the skins of hogs and cows and is sold from these receptacles.

Metueglan.- Metheglin is a vinoms lipuor extracted from honey. It is made as follows: one part strained honey and three parts boiling water, to which aromatic spices are added. The mixture is poured into a eask and fermentation allowed to promeed in the usual manner. Metheglin has been used as a heverage by primitive peoples from time immemorial. It was known and used by the nations of Sonthern Europe and the barbarons tribes of the more Northern countries. Metheglin was a favorite beverage in England just after the usurpation of William the Conqueror. The English emigrants to the New World brought with them the knowledge of its manufacture, and even today metheglin is still made in rural sections inhabited by the lescendants of the original English. Pliny says it has all the bad qualities of wine and none of the good ones. It has a high alcoholic content, and forms a very seductive and inviting potation, producing an intoxication somewhat simulating that due to absinthe. A reputable physician practicing in upper New York state reports to the author a remarkable case of intoxication, which lasted from Saturday until the following Tueslay, from rather liberal indulgence of this vinous concoction, during which time the subject lost all knowledge of person, place or time.

Ratafin.-Ratafia is a general term applied to a variety of liqueurs and cordials made in the south of France from cherry fruits, spices and herbs, fermented, distilled and subsequently sweetened. It usually contains about 25 per cent of alcohol.

Vermouth.-Vermouth is a liqueur made in France and Italy from white wine which is "fortified" with varions extracts including wormwood, etc., distilled and sweetened with 20 per cent of sugar, then exposed in casks to the direct rays of the sum for some time.

EFfect of Liqueris ox Digestox.-Liqueurs contain a very high percentage of ethyl alcohol, with the admixture of other high grade alcohols such as propylic, butylic, amyiic, ete., and of ethers in varying quantities, by no means negligible. Such liqueurs are the highest grade of spirituous preparations. If the arerage unfortmate man knew the nature of these admixtures that are put into what are given him to drink, he no doubt would be more cautious and reserved in his potations.

Liqueurs taken at the end of a heary meal may perhaps give a fillip 
to digestion and counteract to some extent any retarding influence due to the coffee taken during the meal, but the large quantity of sugar which they contain may in the process of digestion be a prolific cause of acidity.

On the process of digestion, the action of liqueur is practically identical to that of pure alcohol. Liqueurs can only delay digestion by virtue of the alcohol which they contain. In moderate quantities, the influence is probably favorable rather than otherwise, owing to the vegetable bitters which they contain. Their acidity is so slight that they have but small untoward effect on salivary digestion.

\section{CONCLUSIONS AS TO THE USE OF ALCOHOL}

Alcohol is undoubtedly an unnecessary article of diet in normal health, but it can be consumed without harmful effects within certain limits in quantities up to two ounces per day, the maximum amount that can be metabolized by the average individual within twenty-four hours. For some this estimate is too low, while for others even this amount cannot be utilized without unpleasant after-effects.

From the foregoing study of alcohol and its various preparations, we have been able to determine that its use as a food is practically nil; that it can replace, only to a certain extent, a small amount of fat and perhaps also an infinitesimal amount of carbohydrate in the body, while its secondary effects on the nervous and muscular system counteract, to a large extent, the benefits derived from the production of heat and energy by its oxidation.

Clinical experimentation has shown that the consumption of alcohol does not favorably induce sustained muscular effort and that on the other hand it may even do harm by paralyzing the sense of fatigue which is the natural check on excessive exertion. Its use does not stimulate the performance of mental labor, but instead retards mentality unfavorably in the performance of perfectly healthy brain work. Abel in writing on the "Physiological Aspects of the Liquor Problem" says: "He who has mental labor of an exacting kind to perform, and he upon whom great responsibilities devolve, is forced, if he would be at his best, to use alcohol as a restorative agent only at the proper time and place, as he would other pleasures and luxuries in his environment." There can be no question but that even daily moderate drinking reduces considerably the rapidity with which the habitual association of ideas are formed in the mind.

The effect of alcohol is cumulative and increases as time goes on. The idea that alcohol "stimulates" a person to the performance of mental tasks 
is not founded on fact; neither is the widespread notion that its uso helps an artisan in his task corroborated hy tests.

The work of scientific investigntor's has likewise robhed alcohol of its traditiona! glory as a digestive stimulant. While it is granted that alcohol does at first stimulate the digestive organs, yet this effect is connterbalanced by its inhibitory effect upon the chemical process of digestion.

It is the opinion of careful students of the subject that the moderate use (two ounces per day) of alcohol in health is harmless, buc Dr. Murchison on the other haml asserts that (a) "a man in grod health dues not require alcohol and is probably better off without it. Its occasional use will do him no harm; its habitual use, even in moderation, may, and often does, induce disease gradually; $(b)$ there are a large number of individuals in modern society to whom alcohol, even in moderate amount, is a positive poison."

The use of alcohol in disease is a subject on which rolumes have been written. It undoubtedly has a place in disease, but like other poisons and narcotics should be prescribed with caution. Just as the effect of alcohol on the digestion is the test for its ralue in health, so its effects upon the circulation and nervous system are the criterion of its usefulness in most cases of acute disease.

Alcohol may be employed in fevers and other wasting diseases, where, by its oxidation, it limits the destruction of the bodily tissues, reduces the temperature and stimulates the heart and cireulation. A dry brown tongue, restlessness and a feeble, irregular pulse are indications for its use. It is best given in the form of whiskey or brandy in definite quantity, according to the condition of the pulse and heart, the general strength, the height of the fever, the ability to take nourishment and the age and previous habits of the patient. It is not indicated in every case of fever, and many cases will be aggravated by its use.

Armstrong and Greves found $(a)$ it is doing good if the tongue becomes moist, the pulse slower, the breathing more tranquil and the skin moist; (b) it is doing harm if the tongue becomes dry and brown, the pulse quicker, the respirations more rapid and the skin hot and parched. Young children and aged persons bear stimulants well.

Habitual drinkers when coming to the sick bed do not react to stimulation. Alcohol is landed as a check to tissue waste in febrile conditions so marked in prolonged wasting diseases, though we have seen reason to doubt this-at least so far as nitrogenous tissues are involved. There are reasons for the theory that alcohol actually increases the resisting power 
of the body to the poisonous toxins of septic fevers. In some chronic diseases, such as diabetes, alcohol is used advantageously to replace a certain amount of carbohydrate in the diet.

\section{WINE(34)}

Wine is produced by the fermentation of grape juice. The juice is first extracted from the grape by pressing and kept for a few days at ordinary temperature, when it changes into wine, the dextrose and levulose content being transformed into alcohol and carbonic acid gas according to the following equation:

$$
\begin{aligned}
& \mathrm{C}_{6} \mathrm{H}_{12} \mathrm{O}_{6} \\
& \text { Dextrose }
\end{aligned}+\underset{\mathrm{C}_{6} \mathrm{H}_{12} \mathrm{O}_{3}=}{\text { Levulose }}=\underset{\text { Alcohol }}{4 \mathrm{C}_{2} \mathrm{H}_{6} \mathrm{O}}+\underset{\begin{array}{r}
\text { Carbon } \\
\text { dioxid }
\end{array}}{4 \mathrm{CO}_{2}}
$$

The ferment which produces these changes is present in the grapes or their stalks and in the atmosphere of the manufactories. There are a number of factors, such as the character of the grape utilized, its cultivation and the method of manufacturing, that enter into the production of good wines. Wine has been celebrated from time immemorial, as indicated in the writings of ancient peoples, such as the Hebrews, Chaldeans, Greeks and Romans. About the year 2347 B.c. we hear that "Noah planted a vineyard and drank the wine thereof."

Composition of Wine.-Dupré(35), writing on "What is Wine?", gives the constituents of grape juice and the wine manufactured from it. According to his investigations grape juice or "must" contains: ${ }^{1}$

\section{Water}

$\left.\begin{array}{l}\text { Grape Sugar } \\ \text { Fruit Sugar }\end{array}\right\} 10$ to 30 per cent

Malic Acid

Tartaric Acid

Racemic Acid

Albuminous Substances
Vegetable Mucus

Essential Oils

Extractives

Mineral substances

Tannic Acid

Coloring Matters [From the Skins and Fatty Substances $\}$ Kernels

He also found on analysis that wine contains the following:

\section{Water}

$\left.\begin{array}{l}\text { Grape Sugar } \\ \text { Fruit Sugar }\end{array}\right\} 0$ to 6 per cent

Ethylic Alcohol

Propylic Alcohol 5 to 22 per cent

Butylic Alcohol
Ethers of foregoing Alcohols and Acids Glycerin

Aldehyd

Carbonic Acid and Ammonia

Trimethylamin

Oils produced by Fermentation

1 Taken from Popular Science Monthly, vol. vii, by Hutchison, p. 576; Ruhräh, p. 184 . 
Amylic Alcohol

Other higher Alcohols

Malic Acid

Tartaric Acid

Racenic Acid

Succinic Acid

Acetic Acid

Formic Acid

Propionic Acid

Butyric Acid
Alluminous Matter

Vegetable . Mucus

('oloring Matter

Tammic Acid

lixtractives

Mineral Matters, 0.15 to 0.6 per cent

Preparation of Wine.-The wine-making season begins about the middle of Angust and ends the last of September. The juice of the grapes is expressed in a wine press, unipe, deayed or withered fruit being carefully rejected. Great care should be taken in expressing the juice to avoid crushing the grape seeds and stalks; therefore, the old method of pressing out the juice by "treading" is much preforable to the wine-press method. "The 'must,' as the liquor is now called, consints of: 70 to s. per cent of water; 10 to 30 per cent of dextrose and levulose, and tartaric, racemic, malie and tamic acids, albuminous, fatty and mucoid substances, essential oils, mineral and coloring matters." The "must" is run into tanks where fermentation is bronght about by the action of various veasts and other organisms that are present in the juice. The most important of these yeasts is Saccharomyces ellipsoideus, but many other ferments are also present. The fermentation continues from one to several weeks, depending on the character of the "must" and the variety of wine to be made. The liquid is then drawn off from the "lees" and is filtered. clarified and put into bottles or barrels or vats for storage in cool rellars. If the temperature is carefully regulated, a second fermentation takes place, providing enough sugar remains to induce it, and the wine is greatly improved by maturation.

In the manufacture of wines the process of fermentation must be carefully regulated. In still wines the primary fermentation must he allowed to complete itself, or else it must be stopped by the addition of aleohol or preservatives. Thus the formation of earbonic acid gras will be prevented and the following changes will not be noticeable. Sparkling wines demand a different procedure. In champagne, for example, primary fermentation is soon checked so that the succeeding process, i.e., secondary fermentation, may take place in the bottle and impart the sparkles and froth so essential to this type of wine. In certain wines made, from black grapes only the juice is used, the skins being discarded on account of their coloring matter and tannin. "Must" is placed in cellars to ferment. On the deposit of the "lees" the liquid is transferred 
from cask to cask until fermentation is at the right stage. The wine is then clear and bright. Vin brut is natural wine to which no liquor is added. When ready for sale the wine may contain considerable sugar; or again, it may contain very little, and is then known as sec, or dry wine. When the amount of sugar contained is negligible the wine is très sec, or very dry.

Varieties of Wines.-Wines may be classified according to character and composition (36):
(a) Natural Wine
(e) Acid Wines
(b) Strong Dry Wines
(f) Sparkling Wines
(c) Strong Sweet Wines
(g) Perfect Wines
(d) Aromatic Wines
(h) Rough or Astringent Wines

(i) Sophisticated Wines

(a) NATURAL Wine.-Natural wine is made from fresh grapes alone. No spirit is added. In this beverage there should be not less than 7 per cent of alcohol by volume, and not more than 16 per cent. Red wine owes its color to the natural coloring matter contained in the skins of the grapes. However, artificial coloring agents are often used. White wine is made from grape pulp, no skins being used-unless those of white grapes. After the reducing sugar has been extracted, this wine should not contain more than 1.7 per cent of dry extract.

(b) STRONG DRY WINES.-Strong dry wines are those in which the destruction of sugar by fermentation is complete; they are sometimes "fortified" by the aduition of brandy or grain spirit. Examples of this class of wines are port, sherry and Madeira. In cases of fever these wines are sometimes used in place of whiskey. Port contains from 15 to 20 per cent of alcohol; sherry from 15 to 22 per cent, and Madeira about 17 per cent.

(c) STRONG SWEET WINES.-Strong sweet wines are those in which the fermentation is partially completed in the bottle. A sediment is formed and removed and sugar or syrup is added. Varieties of this class are Tokay, Malaga and sweet champagne. They contain from 18 to 22 per cent of alcohol and 3 to 5 per cent of sugar.

(d) AROMATIC WINES.-Aromatic wines are those possessing a superior flavor due to the presence of essential oils. Examples of this class are Moselle, Capri and some of the Rhine wines. Their alcoholic content varies from 10 to 12 per cent. 
(e) ACID WINES.-Acid wines are these in which the distingnishing feature is due to the large quantity of aceid they contain.

(f) SPARKLING WoNks-Sparkling wines are those in which the fermentation is partly completed in the bottle. 'I'hey contain large quantities of earbonic acid gas to which their exhilarating effect is due. During fermentation in the bottle a sedimcnt is formed which is removed and sugar or syrup is then added.

Champagne- Champagne is the chief example of this class of wines. The dryness or sweetness of these wines depends upon the amount of cane sugar and cognac added during the process of manufacture. A dry champagne contains from 1 to 4 per cent of sugar and from 9 to 12 per cent of alcohol. In considering the influence of wine upon nutrition and its effects upon the individual in various diseases, its' constituents must be borne in mind. Champagne having a low specific gravitynearly that of water-is absorbed less readily than spirit. This is a good quality, since the alcohol is more slowly absorbed. Such wine is less dangerous than spirits. Dry champagne is absorbed without change; its bouquet and aroma stimulate taste and appetite and influence nutrition favorably. The aromatic constituents stimulate the glands of the alimentary system and favor the manufacture of blood cells. Wine has a restorative action on those exhausted by fatigue, mental labor, insufficient food or long illness, and in various diseases such as anemia, atony of the digestive organs and general debility. Good champagne can be taken with impunity by gouty or rheumatic patients and is very serviceable in cases of acute illness where there is a tendency to heart failure, in obstinate vomiting and convalescence. It is a valuable remedy in fevers and other wasting diseases, where, by its oxidation, it acts as a food, spares the destruction of the bodily tissues, reduces the temperature, stimulates the heart and circulation. A dry brown tongue, restlessness and a feeble, irregular pulse are the indications for its administration.

(g) PERFECT WINES.-Perfect wines are those defined by Chambers as containing alcohol, water, sugar, ethereal flavors, fruity extractives and acids. Under this classification Burgundy and Bordeanx are the principal varieties. Burgundy contains a rather larger percentage of alcohol and extractive matter; it is therefore said to have considerable "body:" Good Bordeaux wines are thoroughly fermented and together with the Burgundies contain very little sugar; consequently, they are well borne by invalids and are especially used as tonics during convalescence from protracted illness.

(h) ROUGH WINES.-Rough or astringent wines are those containing 
considerable tannic acid, to which they owe their astringent effect. They contain little alcohol and are only of slight value for medicinal purposes.

(i) SOPHISTICATED WINES.-Sophisticated wines, says Tibbles, embrace a large proportion of the wines on the market. Some substance is either added to the "must" before fermentation, or to the wine after fermentation. Wine growers do not consider it illegal or injurious to add the following:

(1) "To the must: cane sugar, concentrated must, eitric, malic, tartaric and sulphurous acids, the acids being subsequently neutralized by pure carbonate of potassium or calcium."

(2) "To the wine: citric, malic, tartaric, tannic and carbonic acids, potassium and calcium carbonates, neutral potassium tartrate, sulphites of sodium and calcium, or pure sulphurous aldehyd."

(3) "To assist clarification: isinglass, gelatin, albumin, pure kaolin, gypsum or sulphate of lime are added."

Composition of Wines.-The chief wines have been studied extensively by W. D. Bigelow of the United States Department of Agriculture(37). The table on page 599 gives the average composition of some American wines.

It will be seen from study of these tables that the chief constituent of all wines is alcohol; but this is not the only ingredient. Wine contains a great number of other bodies in small proportion whose existence is of importance in the formation of the character of the wine(38). There are certain characteristics of wines which cannot be imitated. The alchemist has never been able to produce wine by a combination of water, alcohol, ethers, cream of tartar and other salts, because small amounts of certain substances contained in wines, which exist in the form of ions or dissociated particles, continually act and react upon each other in a manner which cannot be imitated artificially. The propriety of "fortifying" wine is a matter of public health. "Fortification is dangerous to the public health, not only from the quantity, but from the quality of the spirit added to the wine. It also permits subsequent dilution with water." If there is sufficient sugar in the "must," the percentage of alcohol will continue to increase until it reaches 16 per cent, when the alcohol will inhibit the growth of the yeast and fermentation will cease. Wines that contain more than this amount of alcohol are "fortified" by additional alcohol. Some wine growers allege that this is necessary, especially for wines intended for export, and say that the fortification prevents the growth of wild yeast and the consequent deterioration of the wine.

"The aroma and bouquet of wine is due to the combination of higher 


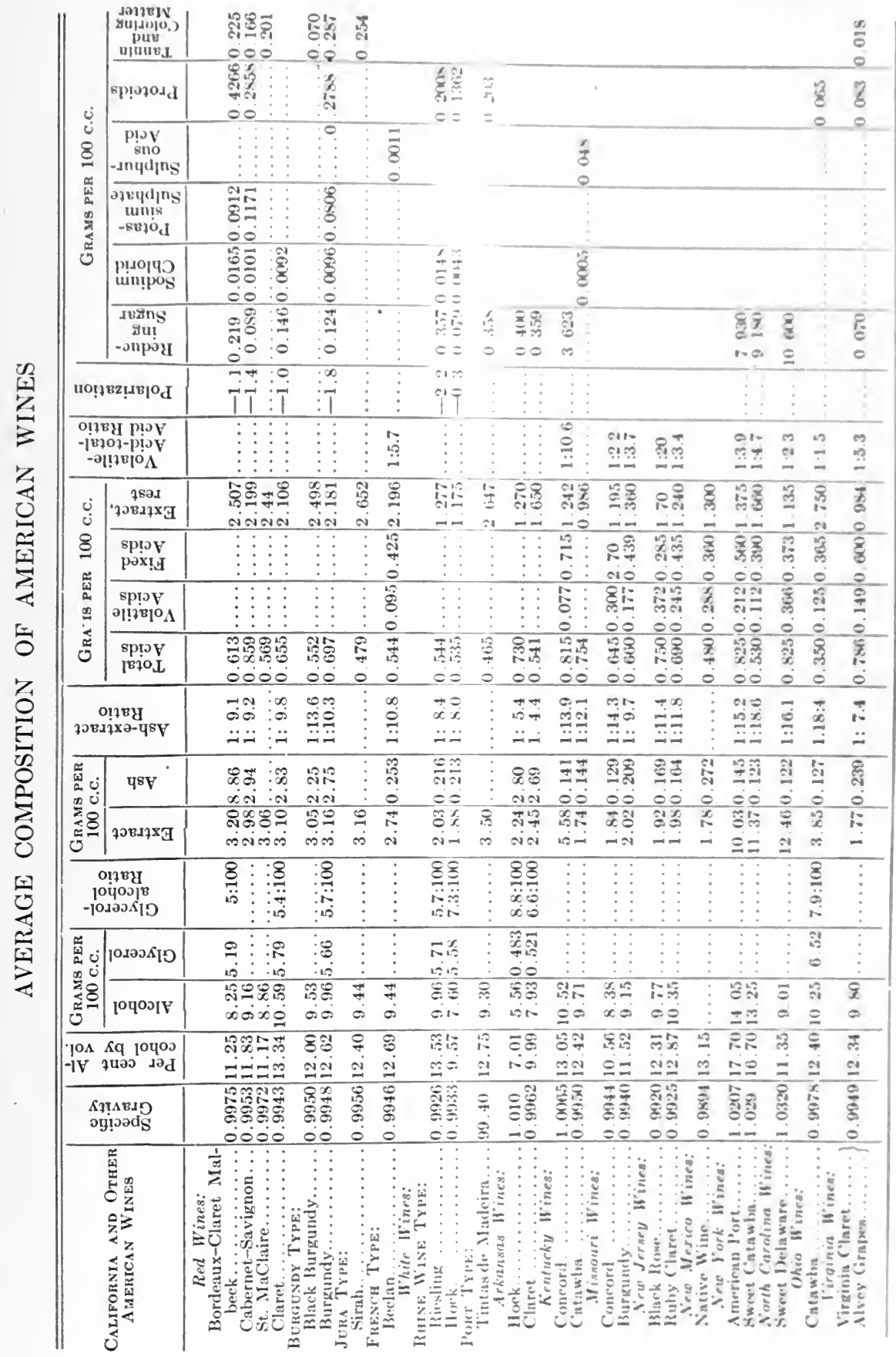


alcohols, aldehydes and ethers, such as caproic, caprylic, acetic, malic, butyric, enanthic and pelargonic. They arise by the oxidation of alcohol or by the action of ferments" (Tibbles).

"The substance enanthin, or enanthic ether, demands special mention. It is derived from a hypothetical fatty acid (enanthic acid) contained in the stones, stalks, skins of the grapes, and in the waxy fat which gives to the grapes their bloom. This acid is not found by itself in wine, but only in the combined or ethereal form. It exists in the proportion one part in every 40,000 of wine. Along with glycerin and succinic acid it is mainly responsible for the peculiar "vinous" smell and taste characteristic of all wines" (Hutchison).

Effect of Wine on Digestion.-'The influence of wine on digestion is no more satisfactory than that of spirituous liquors, wine having a much more powerful inhibitory effect on salivary digestion than spirits. Roberts, writing on this subject, has come to the conclusion that if one per cent of sherry or hock were present in the digesting mixture, the conversion of starch was almost entirely inhibited. This effect of 'wines is entirely due to their activity. It has been shown that claret of 0.75 per cent acidity has a markedly retarding effect on salivary digestion, while the influence of a sherry of 0.54 per cent and a port of 0.42 per cent was very much less.

The experiments conducted by Chittenden confirmed these results. It has been found that if the more acid wines are mixed with vichy water, the acidity is neutralized and the inhibitory effect prevented. As a general rule, the stimulant action of any wine depends chiefly upon its alcoholic content. It is well known that the natural wines contain only about half as much alcohol as the strong or fortified wines, so that two bottles of good claret or hock are about equal, as far as alcohol is concerned, to one bottle of port or sherry. It may therefore be said that fortified wine is about twice as great in stimulating action as that of a natural wine. The more dilute the alcohol is, the more slowly it will be absorbed and the less chance of a large quantity flooding the tissues at one time. It must also be taken into consideration that the ethers and other volatile constituents of wine exert a certain modifying influence upon the action of alcohol; consequently, wines which are rich in these elements may be expected to have a different effect from those which are lacking in these constituents. When all due weight is given to such modifying factors, it is safe to conclude that it is only the weaker or natural wines which are adapted for habitual use as accessories of the diet.

From clinical experimentation, we have already learned that from 
one to two fluid ounces of alcohol is about the amount that can be safely taken during a twenty-four-hour period. A bottle of good claret or hock contains about two fluid ounces of alcohol; therefore, we may conclude that half a bottle daily of such wines is a safe allowance for a sedentary individual and a whole bottle is enough for a man of more active life. The fortified wines, on the other hand, should be reserved as medicines.

Wine as a Source of Nutriment.-- $A s$ a source of nutriment, wine is much inferior to milk. It is estimated that the alcoholic content of ordinary wine yields seven calories per gram and the sugar four calories per gram. Wine, then, will yield from fifteen to forty-five calories per ounce, according to the proportion of alcohol and sugar. Cood natural wines, sound and unsophisticated, are among the best stimulants to digestion. At the same time they form a combination of various principles which invigorate the body and arouse the nutritive and blood-making functions. No changes occur in the stomach other than dilution of the gastric juice. No digestive effort is required, and the wine is absorbed by osmosis. The aroma and bouquet stimulate tasts and appetite, and after ingestion the aromatic substances possibly favor nutrition by stimulating the glands of the alimentary system and the manufacture of red blood cells.

A small proportion of iron in some wines renders them a valuable adjunct to the diet for those who are unable to digest green vegetables or other iron-bearing food. It also renders this kind of wine of value in anemia, chlorosis, general debility and other diseases in which iron is of therapeutic value: A generous wine, therefore, is well adapted to the digestive apparatus and is of value in convalescence from arute illness, in general debility, atony of the digestive organs, and especially for daily use by the inhabitants of cold, damp countries. These effects are not attributed to the alcohol alone, though undoubtedly the alcohol contributes very largely to the effects of the vine; but the special combination of thers, alcohol, aldehydes, etc., is believed to give to wine as a daily beverage a superiority over spirits such as whiskey, brandy or rum. Bouchardat in summing up the question says, "that, with the same proportion of alcohol, wine rich in tannin and astringent principles excites the brain less than strong wines or spirits."

Use of Wines.-It must not he overlooked that the abuse of wine leads to the same evil effects as the abuse of other forms of alcohol. Some wines, especially port and sometimes claret, provoke an attack of gout and, like all other forms of alcohol, may be the means of causing gastric. hepatic, renal, vascular and nervous diseases. In summarizing the points just gone over in this section on the use of wines in health and disease, 
the author feels he can do no better than quote from the conclusions of Antsie(39):

(a) Wines for daily use by healthy adults should not on the average contain more than 10 per cent absolute alcohol (by weight) and 8 to 9 per cent is better.

(b) If wine is used as the daily drink, it is best, as far as may be, to use only one kind at a time and no other form of alcoholic liquid.

(c) Sound natural wines are to be obtained at the best economic advantage from the Bordeaux district; the red wines are to be preferred.

(d) Rhine wines (white) are equally excellent, but more expensive.

(e) Hungarian wines are also in many instances excellent, but they are unequal in quality owing to defects of manufacture.

(f) Greek wines labor under the same defects.

(g) The fortified wines, as a class, develop no proper vinous qualities till they have been for some years in bottles. Sherry, however, is greatly superior to the other wines of this class in the rapidity with which it develops the volatile ethers.

(h) Fortified wines in small quantities, especially sherry, for the reason just named, are the appropriate stimuli of certain kinds of infantile and youthful debility and of the enfeebled nervous system of old persons.

(i) Half a bottle of a natural wine a day for a sedentary and a bottle a day for a vigorous and actively employed adult affords a reasonable and prudent allowance of alcohol. This quantity of wine, either alone or with water, will be enough to satisfy the needs of moderate persons for a beverage at lunch and dinner, the only two meals at which alcohol should, as a rule, be taken.

\section{VINEGARS}

Cider and Perry.-Cider and perry, derived from the juice of the apple and the pear, respectively, may be spoken of here, for they are really to be considered as wines. Cider, indeed, when first made in England in the thirteenth century was always called "wine."

Cider is an alcoholic beverage made by the fermentation of the juice of apples. Perry is made the same way from the juice of pears. The manufacture of cider in England began about 1284, and in Normandy, where it took the place of beer, somewhat earlier. It is no doubt a far more ancient beverage, but of this we have no definite data. "Cider is made late in the autumn from many varieties of apples. The usual criterion for the suitability of the fruit is the specific gravity of the 'must' before fermentation. Good cider cannot be made from juice with a specific gravity below 1.040. 'Must' of this density yields a beverage containing 4.085 per cent of alcohol and 2.688 per cent sugar." Apples which ripen in October are considered best for making good cider. The fruit is gathered and allowed to mellow under cover for a fortnight; it is then 
ground into pulp and left in vats fol' thirty hours. 'The pulp is then pressed and the gallons of liquor run into a clean vat and left there for some days until it has cleared. It is then racked, clarified and the clear, bright liquid run into casks and bument. Perry is made in a very similar way. If a "sparkling" beverage is desired, fermentation is allowed to be completed after bottling. These leverages are mildly alcoholic, containing from 3 to s per cent of alcohol he volume, or much the sane proportion of alcohol as beer. Cider that is botiled before the completion of fermentation is called "champagur vilcr." Vinons fermentation, which is completed in the bottle, produres a "still" dry cider with less heating properties than hock and less acid than Moselle wines.

COMPOSITION OF CIDER-Buth cider and perry contain the stimulating and fragrant ethers found in champagne. These are developed by maturation and become greater with age. Cider also contains malic acid, salts, sugar, albuminoids and extrantives. As a rule, cider is a refreshing, invigorating beverage, possessing dinretic and laxative properties. It is prone to undergo acetic fermentation after a time which renders it unfit for use.

VINEGAR.-Vinegar is an ancient condiment. Its origin is lost in the mists of antiquity. Boaz, a rich citizen of Bethlehem, is represented in the Bible as providing vinegar for his reapers to drink (1312 B.c), a custom which still prevails in Spain and Italy. It is made by the alcoholic and subsequent acetous fermentation of the juice of the apple and contains not less than four grams of acetic acid in 100 cubic centimeters at $20^{\circ} \mathrm{C}$. Although this product is a condiment, it is thought best, while discussing products made from frinits, to deseribe it here and give its action and uses in the chapter deroted to condiments.

The fermentation of vinegar is brought about by the organism known as Mycoderma aceti, and may be indured under proper conditions in weak alcoholic solutions from any source. Besides eider vinegar, there is found on the market wine or grape vinegall, glucose vinegar, malt vinegar and spirit and distilled or grain vinegar. Wood vinegar or acetic acid, which is made by the destructive distillation of wood, may not by law be used in any food produets in the United States.

Vinegar Plant.-The vinegall plant, or "mother of rinegar," is a tough gelatinous substance(40), in appearance somewhat like an animal membrane, and requires for its growth albuminous substances and mineral salts which are always present in wine, beer, ete. If these substances are absent, the vinegar plant has no influence on alcohol, unless sotie alkaline phosphates are added to supply the food elements. This vinegar 


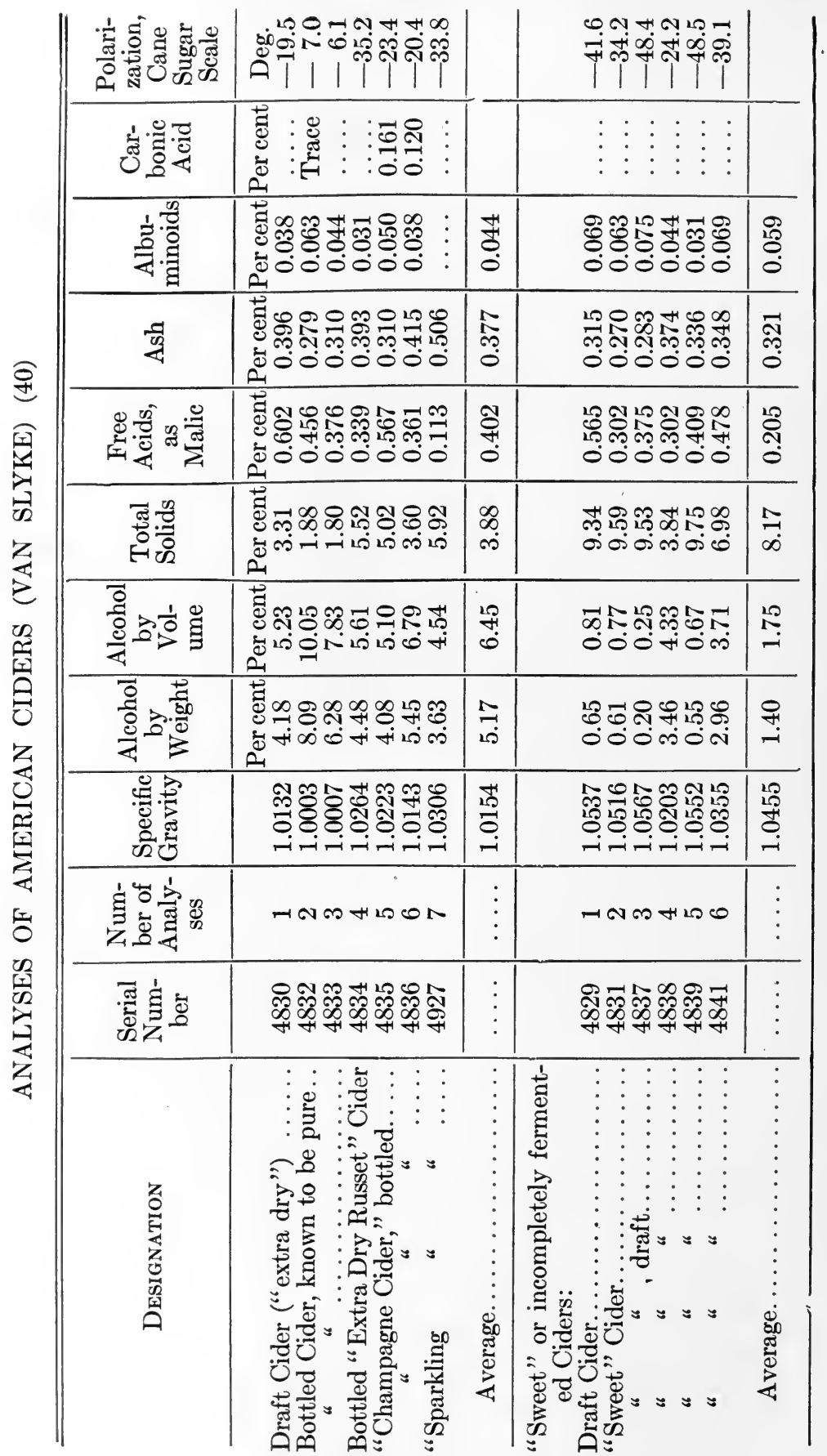


plant appears as a heavy thick scmu in the harrel on the upper surface of the vinegar. 'The conditions necessary for its development elosely' resemble those required for the development of beer yeast. In the manufacture of cider vinegar, according to the old process, the cider is allowed to ferment in the cellar in barrels with open bungholes. The addition of old vinegar or "mother of vinegar" accelerstes this process, which is completed within three to four days. Whereas, without the "mother of vinogar" added, the process requires a much greater time.

Ciner Vinegar.-Cider or apple vinegar is the purest vinegar for table use. It is a product of the alcoholic and subsequent acetous fermentation of apple juice and contains malic acid and various ethers from the fruit. It is levo-rotatory, has a specific gravity $1.01 \%$ to 1.015 and should contain not less than 4.5 per cent ( 4 per cent according to United States regulations), and a maximum of 6 per cent of absolute acetic acid. On evaporation it should yield not less than 1.6 or an average of 3.0 per cent of apple solids; the ash should be not less than 0.25 per cent, and the ash from 100 c.c. of vinegar should contain not less than 10 milligrams of phosphoric acid $\left(\mathrm{P}_{2} \mathrm{O}_{5}\right)$ and require not less than 30 c.c. of a decinormal acid solution to neutralize its alkalinity. Davenport found that the solids are usually 3 per cent and never fall below 2 per cent of apple solids. This residue is a soft, mucilaginons, viscid substance, having the flavor and odor of baked apples, somewhat acid, but not astringent to the taste.

Varieties of Vinegars.-Vinegars are manufactured from various other substances recognized officially by the United States Department of Agriculture Food Inspection Decision 140, Feb. 27, 1912, viz. :

Wine vinegar, grape vinegar, is the product made by the alcoholic and subsequent acetous fermentations of the juice of grapes.

Malt vinegar is the product made by the alcoholic and subsequent acetous fermentations, without distillation, of an infusion of barley malt or cereals whose starch has been converted by malt.

Sugar vinegar is the product made by the alcoholic and subsequent acetous fermentations of solutions of sugar, syrup, molasses or refiner's syrup.

Glucose vinegar is the product made by the alcoholic and subsequent acetous fermentations of dilute distilled alcohol.

Several questions regarding these definitions have been raised, and after investigation the board has reached the following conclusions:

Meaning of the term "vinegar." While the term "rinegar" in its etymological significance suggests nnly sour wine, it has come to have a broader significance in English-speaking countries. In the Cnited States 
it has lost entirely its original meaning and when used without a qualifying word designates only the product secured by the alcoholic and subsequent acetous fermentations of apple juice.

\section{REFERENCES}

In preparing this section, the author has derived much help and drawn largely from the following published works: "Climatology of Mineral Waters of the United States," by Dr. A. N. Bell; "Text Book of Hygiene," by George H. Rohe; Parkes' "Hygiene, Balneology and Ampelotherapy"; articles by Kirsh, Hinsdale and Peals ; Cohen's "Physiological Therapeutics," vol. ix; "The Evolution of Natural Mineral Waters," by Wm. Kirby; "Hygiene and Public Health," by B. A. Whitelegg; "Lead Poisoning by Water," Journal of State Medicine; "Hygiene and Public Health," by L. C. Parkes; "Mud Baths," British Medical Journal; reports from many health resorts in the United States; "Hydrotherapy," by Diffenbach, published by Rebman Company; Tibbles' "Food and Hygiene," published by Rebman; Gould's "Medical Dictionary."

\section{Water}

1. Pavlov, Ivan Petrovitcin and Parastschuk. Ztschr. f. phys. Chemie, 1904, pp. 42, 415.

Burge. Am. J. Physiol., 1912, pp. 29, 330.

2. Cohen. Physiological Therapeutics, vol. ix, p. 416.

3. Shommaker. Practical Therapentics.

4. Tibbles, William. Food and Hygiene.

5. Robin. Bull. Acad. de Méd., 1891, vol. xxi.

6. Cohex. Loc. cit., p. 447.

7. НАwк. Univ. Penn. Med. Bull., 1905, vol. xviii, p. 7.

8. Strauss. Deutsch. med. Wochenschr., Nov. 7, 1912.

9. Fowler and Hawk. J. Exper. Med., 1910, vol. xii, p. 388.

\section{Tea, Coffee and Cocoa}

10. Mann. J. Asiatic Soc., Bengal, 1901.

11. Bannister. Cantor Lectures, $\mathbf{1 8 9 0 .}$

12. Kozar. College of Agriculture, Japan, Bull. No. 7.

13. Hughes. J. Soc. Arts, Jan. 25, 1895.

14. Tibbles, William. The Origin and Manufacture of Foods. 
15. Palgiave. (entral and kiastern Arabia, pl. 1-424.

16. Levisic. Areh. d. Pharm., ser. :3, vol. viii, p. 2!!4.

17. Baxistek. ('antor Lectures, 1s:o).

15. Rinexork. Am. J. Pharm., 1891, p. 207.

19. UfFemaxin. \%tschr. f. ang. ('hem, 1894.

20. Roner's. I)igestion and l)iet, p. 120.

21. Robertson. J. Anat. \& Physiol.

\section{Malt Liquors}

22. In the preparation of this section, the anthor has consulted and drawn largely from the following works: liffront's "linzyme"; Jorgensen's "Alicro-organisms of Fermentation"; Southby"s "Practical Brewing"; Thansing's "Mlt and Beer"; Syke's "Principles and Practice of Brewing"; Moritz and Morris's "Science of Brewing"; Hansen's "Studies in Fermentation"; "Analyses of Ale," by Chittenden and Mendel; American .Journal of Medical Science, 1896; Crampton, "Fermented Alcoholic Beverages," U. S. Dept. of Agric., Bull. 13; Robert's "Digestion and Diet," p. 119.

\section{Stimulants}

23. In preparing this section the anthor has derived much help from the following sources: "Pharmacologic and Phrsiologic Action of Alcohol," by Abel; "Alcohol-How It Affects the Individual and the Community," by Henry Smith Williams, M.I.; "Ihe Influence of Alcoholic Beverages on I)igestion and Secretion," by R. H. Chittenden; "An Experimenta! Inpuiry Regarding the Nutritive Value of Alcohol," by Atwater and Benedict; "Final Experiments on the Elimination of Aleohol from the Body," by Antsie, Practitioner, 1stt; "Study and Stimulants," by A. A. Reade; "The Plyrsiologrical Action of Alcohol," by Sir Lauder Brunton, Practitioner, 1sif: "Foods, Their Origin, Composition and Mannfacture," by William Tibbles; "Sinurce and Chemistry of Foods," by F. H. S. Bailey, Ph.D.; "Food and Dietetics," by Robert Hutchison.

24. Swientochowski. Ztschr. f. klin. Med., 1904, vol. xlvi, p. 284.

25. Dixon. Tr. Brit. Med. Assn., 1904.

26. Савот. Boston Med. \& Surg. J., July 2:3, 1904. 
27. Abex, John J. Physiological Aspects of the Liquor Problem, vol. ii, p. 91, pub. by Houghton Mifflin Co., New York.

28. Pharmacologic and Physiologic Action of Alcohol, Baltimore.

29. Chittenden, R. H. Influence of Alcoholic Beverages upon Digestion and Secretion, Yale.

30. Williams, Henry Smith. Alcohol-How It Affects the Individual and the Community.

31. Kraepelin and Kurz. Kraepelin's Psychologische Arbeiten, 1900, vol. iii.

32. Tibbles, William. The Origin and Manufacture of Foods.

33. - Loc. cit.

\section{Wine}

34. In obtaining material for this section the author acknowledges indebtedness to the following publications: "Composition of American Wines," by W. D. Bigelow, United States Department of Agriculture, Bulletin 59 ; "What is Wine?" by Dupré, Popular Science Review; "On the Uses of Wines in Health and Disease," by Antsie; Report on Sherry Wine, the Lancet, 1898; "A Treatise on Wines," Scientific Library, 1896; "On the Composition of Wines," Bence Jones, 1857; "The Use of Alcoholic Liquors," by Bouchardat, Bulletin 59, United States Department of Agriculture; "On the Use of Wines in Health and Disease," by Antsie; "La Nophistication des Vins," 1884; "Die Chemische Untersuchung und Beurtheilung des Weines," Berlin, 1896.

35. Dupré. Pop. Sc. Rev., vol. vii.

36. Tibbles, Wiliman. The Origin and Manufacture of Foods.

37. Bigelow, W. D. Composition of Amer. Wines, U. S. Dept. Agric., 1900, Bull. 59.

38. Bence, Jones. Composition of Wines, 1857.

39. Antsif. The Uses of Wines in Health and Disease, pub. by Macmillan Co., 1877.

40. Van Slyke. A Study of the Chemistry of Home-made Cider Vinegar, N. Y. Agric. Exper. Sta., 1904, Bull. 258. 


\section{CHAP'TER XVII}

\section{SUGAR, SPICES ANI) ('ONDIMENTS}

Sugars: Sugar Cane; Raw Sugar; Bet Root Sugar; Sorghum Sugar; Maple Sugar; Palm Sugar; Joaf Sugar; (iube Sugar; (iranulated Sugar; Powilered Sugar; Rock Candy, Burnt Sugar or Black Jack; Molasses; Sirup-Sorghum Sirup, Commercial Sirup. Mixed Sirup; Saccharin; Glucose; Confectionery-White Candy, Sugar Drops, Soft Candy, Hard Candy; Honey.

Spices and Condiments: Bay Leaf; Sage; Mace; Spearmint; Sweet Mar. joram ; Sweet Basil ; Summer Savory; Peppermint; Parsley; Tarragon; Wintergreen; Thyme; Cherry Laurel Leaves; Fennel ; Capers; Cloves; Saffron; Cassia; Cimnamon; Turmeric; (iarlic: Ginger: Horseradish; Sassafras; Allspiee; Capsicum; Juniper; Pepper; Va. nilla Bean; Anise Seed; Cardamon; Caraway Seed; Celery Seed; Coriander Seed; Cumin Seed; Tonka Bean; Dill Seed; Fennel Seed; Grains of Paradise; Mustard; Nutmeg; Salt.

Pickles and Salads: Pickles—Cold Slaw, Sauerkraut, Sktshi; Sulads.

\section{SUGAR}

Sugar as an article of diet is of such great importance, both for its pleasant taste and mutritive value, that it is well to devote more than ordinary attention to its consideration. It is conceded that most people eat as much sugar as they can get, and that the consumption of sugar in different countries is, in general, proportionate to the wealth.

Only two plants-the sugar cane and the sugar beet-play an impo:tant part in the world's supply of sugar. The manufacture of sugar from the sap of the maple and palm trees is a relatively small industry when compared with the production of sugar from the sugar cane and sugar beet.

Sugar Cane.-The sugar cane, which is the oldest and best known sugar-producing plant, grows only in tropical and semitropical countries. In appearance it resembles the Indian corn in many ways, and like it. produces a jointed stalk varying from eight to fourteen feet in height. Sugar eane is a native of India, and is frequently mentioned in the writings of the ancient Chinese and in the old sacred books of the Hindoos 
many centuries before Christ. According to Strabo, the historian, the Greek soldiers under the command of Nearchus, an Admiral of Alexander the Great, saw the cane growing in India at the time of the conquest and brought the plant with them on their return 325 B.c. Subsequently it was brought by the merchantmen who traded with Persia and India for spices, perfumes and costly merchandise. The Greek warriors became accustomed to its use during the invasion, and brought back stories of the wonderful reed which yielded a juice "sweeter than honey." The Persians and Arabians introduced the cultivation of sugar cane westward, and we find that sugar was both grown and refined in the valleys of the Tigris and Euphrates in the tenth century A.D. The Crusaders, in 1096, found sugar cane and sugar factories in Syria and Palestine(1), and brought back samples of the product upon their return from the East. The Saracens introduced the cultivation of sugar cane into Sicily, and the Moors into Spain; the Spaniards introduced sugar cane to the New World during their voyages of discovery and colonization (1750). In this way the sugar cane was gradually brought westward from its original home in India, and is now found throughout the entire tropical and semitropical world.

The present leading sugar-cane-producing countries of the world are British India, Cuba, Java and the United States, including Porto Rico, Hawaii and the Philippine Islands.

The nature and origin of sugar were but little understood by the early European consumers. It was supposed to be a form of manna, and was thought to exude from the stem of a plant or tree, and dried like gum "white and brittle." Others supposed it to be a form of "honey made from reeds." The important sources of sugar in nature are the sugar cane, sugar beets, sorghum or Chinese cane, sap of sugar maple trees, date palm trees, sap of ash trees of southern Europe, the bamboo, honey, raisins and milk of mammals.

Several different varieties of sugar enter into the composition of articles of diet, but for practical purposes they may be divided into two groups :

(1) Sucroses or disaccharids $\left(\mathrm{C}_{12} \mathrm{H}_{22} \mathrm{O}_{11}\right)$ (a) Cane sugar-Sucrose

(b) Beet sugar "

(c) Maple sugar "

(d) Malt sugar-Maltose

(e) Milk sugar-Lactose

(2) Glucoses or monosaccharids $\left(\mathrm{C}_{6} \mathrm{H}_{12} \mathrm{O}_{6}\right)(f)$ Grape sugar-Dextrose

(g) Fruit sugar-Levulose

(h) Invert sugar 
'The sugar cane is propagated by planting the seeds from the flowering tops of the previons erop in plowed furrows, and another varicty from euttings, obtained from the joints of the cane stalk. When the sprouts of the young cane appear above ground, they are cultivated in a similar manner to the eorn crop, with the exception that when the rainy season begins, the cane erop is left to grow for varying length of timc, depending on the locality and climatic conditions, etc. In Lonisiana the crop is matured and ready for harvesting in less than a year, while in Hawaii the plant is allowed to go for two years.

The plants blossom or flower when a year old, and in from four to five months after flowering, the canes are completely ripe and contain a sweet viscid juice. They are then ready to be harvested. 'They are cut down close to the gromb and the tops and leaves removed; the stripped stalks are now taken to mills where the juice is expressed by grinding and crushing between revolving cylinders. The cane stalk contains about 85 per cent of juice, but in the usual process of grinding, a little more than 50 per cent is obtained, some of the best mills expressing 60 to 65 per cent; consequently 25 to 30 per cent is left in the refuse called the "begasse." This is dried by passing it over the boilers on conveyors, and is then used for fuel in the furnace. The largest mills at the present time have a capacity of a thousand tons of cane in twenty-four hours. The composition of sugar cane and the juice cbtained from it are given in the following table from Tibbles(1):

COMPOSITION OF SUGAR CANE AND JUICE

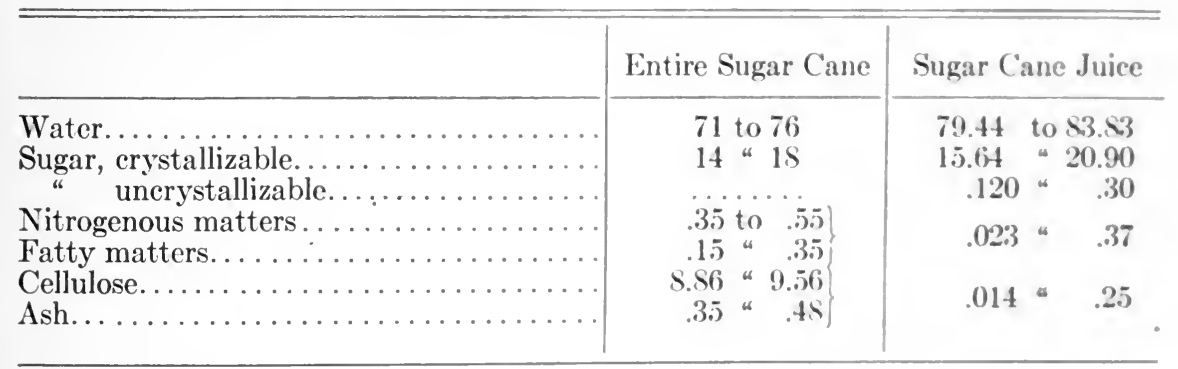

The juice, as obtained from the grinding of the sugar cane stalk, is quite dark colored and turbid, contaning considerable organic matter other than sugar. This is removed by passing through wire sereens to eliminate the coarse fiber. It is then neutralized by lime, which precipitates organic matter and checks formentation. Next it is submitted to the action of sulphurous acid gas, either before or after the addition of lime. 
This process is known as "defecation." The lime neutralizes any of the acid that may be left in the juice and thus prevents some of the sugar from "inverting" or changing into the uncrystallizable invert sugar. It is then subjected to a temperature of $170^{\circ}$ to $180^{\circ} \mathrm{F}$., which coagulates and separates the suspended materials. These rise to the surface as a scum and are removed. The juice is now filtered through bone-black or animal charcoal. The clarified juice obtained by the defecation and filtering process is now evaporated in the so-called "multiple efféct" vacuum pans. After remaining for some time in the first pan it is transferred to the next and afterwards to the next and the next-a series of four pans. Bailey says: "The air in the first pan of the multiple effect is exhausted to such an extent that exhaust steam from the engines and pumps of the factory will, when entering the steam. jacket of the pan, cause the juice, under the partial vacuum, to boil and thus concentrate. The steam arising from the boiling juice of the first pan enters the jacket of the second pan, and as the vacuum of this pan is higher, the temperature of the steam from the first supplies sufficient heat for further evaporation." Tibbles, in describing the crystallization point in the manufacture of sugar, says: "It becomes more concentrated in each pan, and in the fourth reaches the point of crystallization. It is then transferred to the coolers where it is allowed to 'grain' or crystallize, being afterwards put into a cask which has a number of holes in the lower part, temporarily stopped with plugs. When the chief mass is crystallized, the plugs are removed and the liquid residue, or 'molasses,' is drained off; the crystals constitute raw sugar." The above is a more or less succinct description of the imperfect process of manufacturing sugar which has lately been replaced by improved methods, especially by concentrating the juice to the point of crystallization in a vacuum pan and removing the molasses by centrifugalization.

According to the "modern process"(2), after the clarified juice has been evaporated to a sirup, it is run into a steam vacuum "strike pan;" which is a large boiler heated with steam coils, and is connected with an exhaust pump so that a very high vacuum can be maintained; this brings about the "graining or crystallization" of the sugar. When the mass begins to crystallize, additional sirup is allowed to run in from time to time, until the pan is finally filled with the crystalline sugar, mixed with molasses. In this high vacuum the ebullition is violent, and unless the sugar boiler is watchful, some of the sirup will be carried over with the vapor into the condenser; this is called entrailment and is a source of loss in sugar manufacture.

The supervision of the vacuum pan in operation requires mere skill 
than any other operation in the sugar factory; meticulous eare must be exercised, (a) to prevent "entrailment" and (b) to build up the sugar crystals of uniform grain and size. The principal aim of the boiler is to build up these erystals without forming new ones. He controls this process by frequently drawing out samples, and examining them upon a glass, against the light. If very fine new erystals are seen among the old ones, he reduces the vacuum, thus raising the temperature, which promptly dissolves this false grain, as the fine crystalsoure culled. By skillful manipulation, which only comes with long experience, the sugar boiler is able to turn out sugar with erystals of uniform size, as in ordinary granulated sugar.

When the vacuum pan becomes filled with a thick magma of sugar erystals (sugar and molasses) known as "masseruite," it is transferred to a mechanical mixer, which keeps the mass in motion by means of re volving arms. This mixer is situated over a row of centrifugal machines, and when of uniform consistency, it is run into the "centrifugal." This machine was first successfully used for this purpose in 1860. The inner walls of the revolving drum are lined with fine brass meshing, and as the drum revolves, the masse-cuite is whirled against the meshing, which holds the sugar, but allows the molasses to pass through. After spinning at from 1,000 to 1,200 revolutions for a few minutes, until as much of the molasses as possible is removed, the revolving mass is sprayed with a fine spray of water or jet of steam to remove any of the film of molasses which remains adhering to the crystals; the amount of spraying regulates the whiteness of sugar. In Louisiana a very pure, white sugar is produced which has several sprinklings or sprayings of water; the sugar analyzes over 99 per cent pure sucrose, the remainder being mostly moisture.

The centrifugals are stopped when the removal of molasses has reached its limit, and the sugar is passed through the bottom of the drum into a conveyor. Thence it is transferred to the packing room, and after being placed in bags is ready to be shipped. As there is much moisture in the raw sugar from the centrifugal, in certain countries this sugar is put into revolving drums for drying before it is packed in bags. There are two advantages in this drying process: first, the removal of superfluous moisture, the weight of which would increase the cost of transportation; and, second, drying sterilizes the sugar and protects it against the inroads of ferments and bacteria. At this stage salts of tin are sometimes used for clearing the sugar; and now and then ultramarine blue is added to offset the delicate yellow tinge. 
The use of ultramarine is objectionable, as sugars subjected to this process are not fit to be used for certain purposes, for example, in the manufacture of fruit sirups.

The term "first sugar" is applied to that made from the pure cane juice, while the molasses obtained from draining this sugar is known as "first molasses." There is a large sucrose content in the latter, and different methods are employed for obtaining from this as much as will crystallize. A "second sugar" is obtained by reboiling the molasses and washings from the first "masse-cuite" and running the product through the centrifugals. A "third sugar" is the article recovered through process of concentrating the molasses of the "second sugar." Such a molasses may still contain, however, 30 per cent sucrose. There is also present about 30 per cent invert sugar, 8 to 10 per cent of ash, and 8 to 10 per cent of gums, organic acids, amino compounds, etc.

Raw Sugar.-Raw sugar, or musavado, is the product of the crude open-pan process of manufacture(3). These raw sugars are now imported into the United States for refining. The raw sugars come principally from Demerara, Barbadoes, Cuba and Brazil. These sugars contain from 95 to 98 per cent pure sugar. The removal of the remaining impurities is carried out in sugar refineries, usually situated in places where fuel is more abundant than in the tropical countries where the sugar cane is chiefly cultivated. The difference in price between raw and refined sugar is from 0.7 to 0.9 cents per pound, while the cost of refining is estimated at from 0.6 to 0.65 cents per pound, leaving only a small margin of profit to the refineries, so that it is necessary for the operation to be conducted on a large scale in order to make it remunerative.

In the United States the industry is confined practically to very few large establishments in New York, Philadelphia, Boston, New Orleans and San Francisco. In one of the largest of these refineries 13,000 barrels of sugar per day are refined. Nearly all of the sugar, aggregating nearly three million tons, is imported, and only about 700,000 tons are produced in the United States.

Beet Root Sugar.-Beet root sugar was first made by Marggraff, in 1747, and by Archard in 1796. In the early days of the French Revolution, Napoleon was induced to take a great interest in its manufacture because of the prolonged Peninsular War, which seriously interfered with the ordinary supplies of sugar. The industry is commonly considered as dating from about $1810(4)$. The first attempt in this country to produce sugar from sugar beets was made at Alverado in California in the year 1870. 
The cultiration of the sugar beet for its sugar content and purity of the juice does not depend entirely upon the variety planted, but on the soil, elimate, weather and distribution of moisture. For the best sugar output the beet should not be harvested until the coming of the frost, as every day added to the growing season increases the sugar content. The greatest amount of sugar is obtained from beets grown in irrigated regions where there is an abundance of sunshine and where the distribution of water can be regulated. The sugar beet thrives in temperate climates, and the comntries in which the production of sugar from beets is largest are Germany, Austria, Russia, France and the Lnited States-the order indicating the amount of production. The bects of medium size are usually of better quality than the largrer ones.

The composition of the sugar beet and sugar beet juice is given in the following table taken from Browne:

COMPOSITION OF THE SUGAR BEET AND ITS JUICE

\begin{tabular}{|c|c|c|}
\hline & Sugar Beet & Sugar Beet Juice \\
\hline 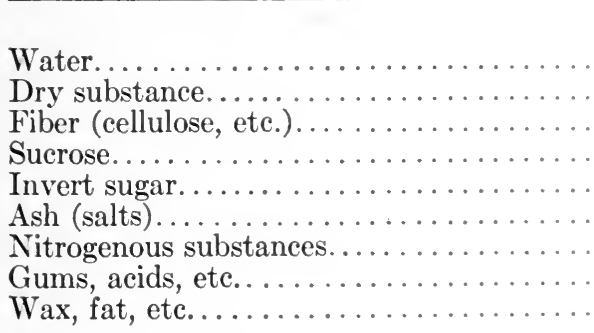 & $\begin{array}{c}\% \\
75-85 \\
15-2.5 \\
4-6 \\
12-16 \\
0.0-0.3 \\
0.8-1.5 \\
1.5-2.5 \\
0.4-0.5 \\
0.2\end{array}$ & $\begin{array}{c}\% \\
7 S-84 \\
16-22 \\
13-17 \\
0.0-0.3 \\
0.6-1.0 \\
0.5-1.5 \\
0.3-0.6\end{array}$ \\
\hline
\end{tabular}

The sugar beet industry in the United States, begun in C'alifornia in 1870 , is still in successful operation at present $(5)$. The beets, after being dug and having their green tops removed, are hauled to the factory; here they are washed to remove dirt, and then passed orer knives which reduce them to fine slicings. The slicings are next earried by a conveyor to the diffusion battery, which consists of a series of tall boiler-shaped cylinder ealled cells. These are comnected by pipes, the outlet from the top of the first cell passing downward into the bottom of the next and so on. Each cell is filled with beet slicings through a large hole at the top, and when full is tightly closed with a gasket fitted cover and clamped into place. Twelve cells connected in series comprise a battery. and when all are filled, warm water at about $80^{\circ} \mathrm{C}$. is passed through the system. The water circulating upwards through the heet slicings removes the sugar 
from each succeeding cell. Heaters are placed between the cells so that the circulating water is constantly kept at an even temperature, aiding the process considerably. As Clausen says, "When the water has made a complete circuit through the twelve cells of the battery, the slicings in the first cell become practically exhausted; this cell is then thrown out of circulation, emptied of exhausted chips, refilled with fresh slicings, and reconnected with the system, while the second cell undergoes replenishing. The process is thus a continuous one; ten cells are always in circulation, while one cell is always being emptied and ono always being refilled."

The diffusion juice as it leaves the last cell of the battery contains from 12 to 15 per cent of sugar, and is ready for clarification. The process consists of the evaporation of the diffused beet juice by heating it with lime, which neutralizes the free acid and assists in coagulating the nitrogenous matter. This process is called "carbonation." The juice is usually treated with sulphur dioxid gas, which bleaches it, but care must be taken that the solution still remains slightly alkaline, to prevent inversion of the sucrose $\left(\mathrm{C}_{12} \mathrm{H}_{22} \mathrm{O}_{11}\right)$. The purified juice is evaporated, as in the case of cane sugar. "The molasses in beet sugar manufacture cannot be used for making second and third sugars, as can the molasses from cane sugar boiling. On this account the molasses is boiled down and treated with lime which precipitates calcium saccharate(6) $\left(\mathrm{C}_{12} \mathrm{H}_{22} \mathrm{O}_{11 \cdot 3} \mathrm{CaO}\right)$, the latter being separated from the solution by filter presses, and the solid cake thus formed is returned to the 'carbonators,' where it is treated with carbon dioxid gas, thus again setting the sugar free." The juice from the second carbonation is again strained through a brass mesh filter, reëvaporated, grained and centrifugalized. These processes are carried out essentially as described in the process for the manufacture of cane sugar.

Comparison of Physical Properties of Raw Cane and Raw Beet Sugars.-There is quite a difference in the physical properties of raw cane sugar and raw beet sugar. Raw cane sugar possesses a fragrant odor and a pleasant taste which many prefer to the refined product, while raw beet sugar has a bitter nauseating taste and a gluish-like odor, not very impelling.

Sorghum Sugar.-Sorghum sugar is obtained from a cereal plant native in India and largely grown as a foodstuff throughout Asia-particularly in China, India and Japan-also in Egypt, and to a less extent in the United States (7). The stalk of this grass, like the Indian corn stalk, grows luxuriantly, with a large jointed stalk, an abundance of long green leaves, and with a large broomeorn-like top or blossom that contains the 
seeds from which the plant is propagated. Like the sugar cano it abounds in a sweet sugary juice, on which account the Americans, when it was first introduced, called it the "Chinese sugar canc:" The amount of sugar in the stalks varies from 8 to 14 per cont of erystallizable sugar and 1.5 per cent of uncrystallizable sugar. The rest is made up chiefly of starch, cellulose, pentosans and mineral substances.

Sorghum sugar is easily made on a small scale, us it can be grown as readily as corn, and is a hardy plant. It grows from Maine to Folorida, being more suitable for cultivation in the United States than the sugar eane. The juice is obtained in the same way as that of the sugar cane. Sorghum sugar can be successfully manufactured on the farm, in a small way, by erushing or grinding the stalk in a small horse-power mill. The juice is evaporated in a series of shallow pans which allow skimming in the earlier stages of boiling. 'The balance of the process is similar to that used in making sugar from sugar cane. Sorghum cane vields a sirup equal to that of the best sugar refineries, and although there is a little difficulty, owing to the presence of starch, the sugar is refined and crystallized as well as that of the sugar cane.

Soon after the Civil War, 1861-65, owing to the scarcity and high price of sugar, sorghum sirup was extensively manufactured throughout the Southern states. In 1879 more than $28,500,000$ gallons were produced. It is a wholesome, palatable sirup and contains 36 per cent sucrose, 27 per cent reducing sugar.

Maple Sugar.-The North American Indians were the first manufacturers of maple sirup(8). All species of the maple tree yield a sweet sap. but the silver maple, red maple and black maple are species best adapted for making sugar. The sap of the tree abounds in sucrose or cane sugar, which is obtained in the following manner: In the early spring, while the cold is still intense, the tree is bored on the south side of its trunk with an auger in two places five inches apart, at a height of about twenty inches from the ground. The holes, one-half inch in diameter, are made obliquely. upwards so that a tube fixed into them directs the sap into a vessel placed below. Sometimes the tube is a piece of elderwood with the pith removed. The sap flows for about six weeks during the warm, sumshiny days and frosty nights of early spring; it is collected each day, strained and boiled at once, never being kept longer than twenty-four hours. It is boiled in open pans or kettles to the point of crystallization and is then poured into moulds, where it sets. "Maple sugar is not usually refined, as that would destroy the peculiar characteristic of the sugar. A good quality of maple sirup weighs 11 pounds to the gallon. The 
sucrose content is 62.6 per cent and invert sugar 1.47 per cent. The maple sugar and sirup industry is principally confined to the following states: New York, Ohio, Pennsylvania, West Virginia and the New England states. In 1909, 4,106,418 gallons of sirup were produced and $14,000,000$ pounds of maple sugar were made. It is prized chiefly for its ethereal substances which produce flavor and aroma." In the early period of the American Colonies, in addition to honey, maple sugar was the chief sweetening substance, and it was very cheap. Under the improved methods of making sugar from the cane and beet, these have largely taken the place of maple sugar. The liquid which drains from the crystals is "maple sirup," which is prized as a table sirup.

An average tree yields about four pounds of sugar in a season, each pound being derived from four to five gallons of sap. The maple sugar is dark brown and has the following composition:

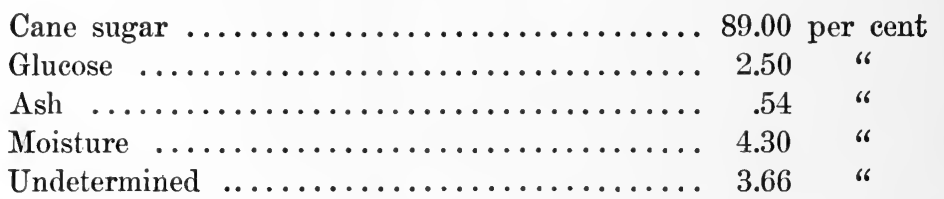

Maple sugar is very easily made: the farmer needs no other machinery than a few pans or kettles in which the sap is concentrated, and the moulds in which the sugar crystallizes while the sirup drains away. The farmer can manufacture 200 or 300 pounds in two or three weeks. It can be made very easily in the modern vacuum-pan and centrifugalizer. The sugar can be refined, and 100 pounds will yield about 83 pounds of refined product. As already indicated, refining is rare, because the demand for the unrefined product is equal to the output, and besides its flavor is destroyed by the refining process.

Palm Sugar.-Palm sugar, also called "date" or "jaggery" sugar, has been used in India from time immemorial, and is consumed throughout the East(9). The juice from which the sugar is made is obtained by incisions in the tree or flower stalk of the palm tree and by the natives is called "tardy." The juice contains a large amount of cane sugar or sucrose. It is readily fermented and forms palm wine, which being distilled yields the spirit known as "arrack." This beverage, which is in common use among the Hindoos and Malays, often contains 50 per cent of absolute alcohol. In sugar making the sap is neutralized by lime, boiled immediately, filtered and clarified as in the making of sugar from the sugar cane juice. Three quarts of sap are necessary to produce one pound of sugar. The sap contains more glucose or invert sugar than 
sugar cane juice does; consequently the product is of low quality and remains as moist or raw sugar. Aecording to Thorpe's "Dictionary of $\lambda_{p}$ plied Chemistry," the composition of pulm sugar is as follows:

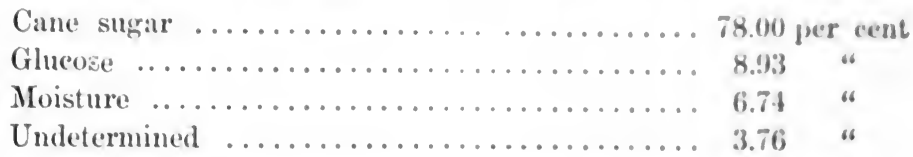

Formerly it was imported in!n kurope in considerable quantities, especially when the sugar ane harvest was porr; but owing to the devel. opments of the beet sugar industry, there is now little demand for palm sugar. It is principally in domand at the present time by brewers and distillers.

Comparison of Production of Singar C'ane, Sugar Beet, Siorghum Cane, Maple Tree Sap and Palm T're's sup.-The foregoing briefly outlines the production of sugar from sllgal cane, sugar beet, sorghum cane, maple tree sap and palm tree sap. I'ntil about 1810 sugar cane furnished practically the world's supply of sugar; since that time the beet sugar industry has developed by le:ıs and bounds, until about 1584, when the amount of production of sugar from the two sources was about the same. By 1859 almost twice as much sugar was made from beets as from cane-largely due to the fact that the sugar industry in Cuba had been almost extinguished by the Spanish-American War. Soon after the restoration of peace in Cuba, the amount of production of sugar from beets and cane again became about alike. It is estimated that the world's production of sugar in the year 1912 and 1913 amounted to $9.175,574$ tons manufactured from sugar cane and $\$, 968,064$ tons manufactured from the sugar beet. The production of sugar by the ten leading countries for the same period of time is given by Browne(10), as follows:

SUGAR PRODUCTION BY COUNTRIES

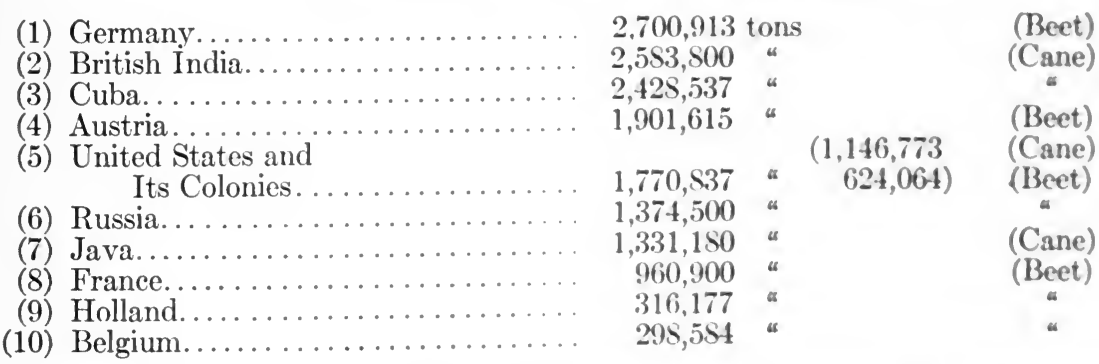

The total amount of sugar consumed in the entinental Tnited States is nearly $4,000,000$ tous or $\$, 000,1700,000$ pounds, or about 85 pounds 
per capita. The value of the sugar consumed in the United States at the present (1917) prevailing war prices is $\$ 72,000,000$.

The following table gives the sugar consumption per capita-all kinds included-and the retail cost per pound to consumers:

CONSUMPTION OF SUGAR PER CAPITA IN LEADING COUNTRIES OF THE WORLD

\begin{tabular}{|c|c|c|}
\hline & $\begin{array}{c}\text { CONSUMPTION PER } \\
\text { CAPITA }\end{array}$ & $\begin{array}{l}\text { Retail Price PER } \\
\text { Pound, } 1911\end{array}$ \\
\hline 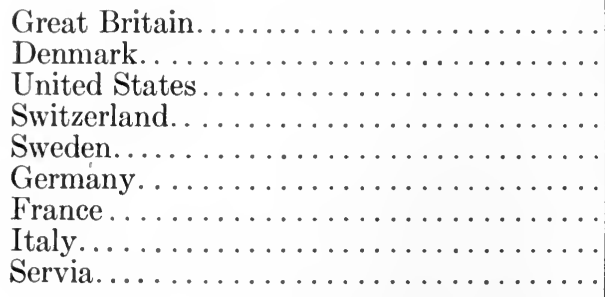 & $\begin{array}{l}91.63 \\
84.23 \\
79.20 \\
76.34 \\
57.98 \\
47.91 \\
42.84 \\
10.10 \\
7.90-7.94\end{array}$ & $\begin{array}{rc}5 & \text { cents } \\
5 & \text { “ } \\
5.69 & \text { “ } \\
5.10 & \text { “ } \\
8.00 & \text { “ } \\
5.90 & \text { “ } \\
5.90 & \text { “ } \\
14.00 & \text { “ } \\
8.70 & \text { “ }\end{array}$ \\
\hline
\end{tabular}

Sugar refining is not absolutely necessary so far as raw cane sugar is concerned, as it has a sweet aromatic taste and can be used without refining for all domestic purposes. The raw beet root sugar, as we have already learned, is not so agreeable; it has a soapy taste and an odor resembling glue which renders refinement essential.

Principles of Sugar Refining.-The first principle in refining sugar consists in washing off as much of the molasses which adheres to the crystals of raw sugar as is practicable; then the crystals are dissolved, purified and decolorized, and the sugar recovered in a purified state by recrystallization. While the process is simple in principle, the large scale upon which it must be carried out and the extreme precautions necessary to guard against apparently small losses if the industry is to be economically successful, require elaborate equipments and constant chemical control which we will not undertake to describe here. Those interested can find an elaborate description of the process in an article by Horne, of Columbia University, published in the School of Mines Quarterly, April, 1911; also an article by Browne, School of Mines Quarterly, 1913, and Davoll, Technical Account and Chemical Control in Sugar Manufacture, Journal of Industrial Chemistry, 1913, vol. v, pp. 231-234.

Loaf Sugar.-According to Tibbles, "Loaf sugar is produced as follows: Masse-cuite of a known density is heated to $187^{\circ} \mathrm{F}$. and poured into moulds; when cold it consists of a mass of fine crystals. The moulds are left for twelve hours until the sugary mass is so thick that there is no 
danger of the crystals settling out and forming an unequal mixture. 'The spigot is then drawn, a wire pushed into the sugar two or three inches deep, and it is left to drain. After twenty-four hours the sirup censes to run, and the surface of the loaf is then hardened by pouring in a highly concentrated simp. In twenty-four hours more the lonves are removed from the moulds; they are then racked for ten to fourteen days in a drying room where the temperature is $120^{\circ} \mathrm{F} . "$

Cube Sugar.-Cube sugar is ent into shape by clippers or machinery. The process for making eube sugar is longer than that used in the manufacture of loaf sugar. Pure white moist refined sugar is mixed with enough sirup to hold the crystals in a mass. This is passed by a hopper into a centrifugal machine. The latter consists of a revolving drum on which are arranged a series of moulds for forming the sugar into cubes. The hopper is above the moulds, and the sugar passes from the hopper to be pressed by a plunger into the moulds. Later the cubes, still moist, are dried in a steam-heated stove.

Granulated Sugar.-Granulated sugar is produced from a sirup at the masse-cuite stage. The liquid is quickly concentrated until it shows a sharp grain, after which it is centrifugalized in order to separate sirup or molasses. Washing removes from the crystals any remaining sirup or débris. The sugar is now ready for the granulating machine. This machine consists of a steam-leated double cylinder arranged at an inclination. Into one end of the cylinder are poured the moist crystals, which, as the machine revolves, fall upon the central heated cylinder. The moisture is carried off by an air current passing through the large cylinder. The inclination of the cylinder causes the sugar to pass down gradually to the lower end, from which it emerges as snow-white crystals. The last step in the process is the sorting of the crystals into (a) large or coffee crystals, (b) medium erystals, i.e., ordinary granulated sugar, and $(c)$ small erystals, or castor sugar.

Powdered Sugar.-Powdered sugar is obtained from the waste made from the cutting of loaf or eube sugar and from the dressings left from granulated sugar. These remnants are reduced to a powder in a disintegrator, and passed through several dressing reels to separate it into various grades of fineness.

Rock Candy.-Rock eandy is the purest form of cane sugar. It is made by dissolving cane sugar and heating to $230^{\circ} \mathrm{F}$. In this solution strings are suspended, and as the solution cools, the sugar eristallizes upon the strings. In order to obtain good crystals, the sugar solution must stand for several days in a warm room, where the cooling takes place 
slowly. Flowers and fruits may be suspended in the sugar solution, and the product is known as "crystal flowers and fruit."

Caramel, Burnt Sugar, or Black Jack.-This is prepared by heating sugar to the temperature of $374^{\circ}$ to $406^{\circ} \mathrm{F}$. In this process the chemical composition of the original sugar remains unchanged, although the properties of the product are entirely transmuted. Caramel is slightly bitter, but gives an agreeable flavor to confectionery. It is extensively used to give a brownish color to food products. Its principal use is that of an adulterant.

Molasses.-Molasses is obtained as a by-product in the manufacture of crystallized sugar. According to the definitions and standards of the Association of Official Agricultural Chemists, "Molasses is the product left after separating the sugar from the masse-cuite, and contains not more than 25 per cent of water and not more than 5 per cent of ash. This standard would practically confine the term molasses as a commercial designation for human food to material of the nature of the "first molasses' of modern sugar manufacture." The "mother liquor," as the chemists call it, from which the sugar has been crystallized, is the molasses. It contains, besides sucrose, some of the uncrystallizable sugar of the original juice and all the "invert sugar" produced in the process of manufacture, besides those of soluble impurities and the mineral salts of the original juice.

Sirup.-Sirup, on the other hand, is the product obtained after the evaporation of the original juice from which no sugar has been removed; as a result, we have sugar cane, sorghum and maple sirup. Of these, maple sirup commands the highest price. In the process of manufacturing cane sugar by the open pan method, the juice is boiled down in open pans or kettles and passed from one to another as it reaches a certain degree of concentration, and finally run into shallow tanks and stirred until it becomes a crystalline mass of sugar and molasses. It is then dumped into hogsheads provided with holes in the bottom, and allowed to drain for some time. The resulting product, called "raw sugar," is put upon the market, and the molasses which runs into cisterns beneath the hogsheads is shipped as "New Orleans molasses." In the manufacture of sugar by the vacuum process, the drippings and workings of the first. masse-cuite are boiled down to make a "second sugar," and the drippings from this boiled to make a third masse-cuite. The "third molasses" necessarily contains all the impurities of a considerable amount of juice. The last molasses according to this process is known as "black strap." It is fermented to make alcohol and used to some extent as a food for mules 
and southern negroes. Open pan sirup, or sugar cane sirup, makes a very satisfactory molasses(11). This simp is made by clarifying and evaporating the sugar cane juice to a consistency in which 25 to 30 prep cent of water remains. Inring the process the scom is carefully removed, and the final sirup is strained. No lime or other chemical is used in the process. Sugar honse molasses is obtained in the process of sugar refuing, and has already been referred to. This molasses is of a much lighter color than the product from the sugar factory (black strap), but contains a very large amomnt of organic substance other than the sugar. It is not a suitable food unless used in small yuantities.

Molasses Produced by the Open Kettle Process of Boiling.-Molasses produced in this way is the most highly appreciated, and is a suitable article of diet in the South, where it can only be obtained, sinces the modern process of sugar making has practically eliminated this open ketuo method from the market. To supply its place, the manufacture of sirup directly from the sugar cane and without the separation of any kind of sugar has come to be practiced extensively in Georgia, Alabama, Florida, Louisiania, Mississippi. This sirup forms a delicious, wholesome and valuable condiment, the use of which is rapidly extending-and owing to its wholesomeness it should become an important food product.

The color of sirup does not by any means foretell its taste or food value. The dark color in some sections is still associated in the minds of many with the flavor of old-fashioned molasses. Molasses of a light color is preferable for the table, and while the light oolnred varieties are very popular, it does not signify that the brown colored sirup is not a good quality.

Difference in Composition between Molasses and Successive Cryeingi:zations of Sugar.-The following table from Wiley(12), entaining the analysis of first, second and third molasses, will illustrate the difference in composition between molasses and successive crystallizations of sugrar:

COMPOSITION OF FIRST, SECOND AND THIRD MOLASSES

\begin{tabular}{|c|c|c|c|}
\hline & $\begin{array}{c}\text { First } \\
\text { Molasses }\end{array}$ & $\begin{array}{l}\text { Second } \\
\text { Molasses }\end{array}$ & $\begin{array}{c}\text { Third } \\
\text { Molusses }\end{array}$ \\
\hline Water. & $\begin{array}{c}c c \\
20.00\end{array}$ & 20.00 & $\begin{array}{c}\% \% \\
2000\end{array}$ \\
\hline Sucrose (cane sugar). & 53.60 & 41.70 & 31.70 \\
\hline Dextrose (glucose)... & 8.76 & 12.20 & 1巨.in \\
\hline Levulose (fructose) . . . . . . . . . . . . & 8.00 & 12.50 & $16 \because 0$ \\
\hline 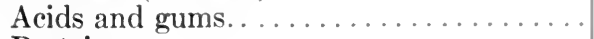 & 4.50 & 6.50 & $\$ .20$ \\
\hline 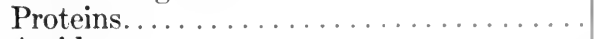 & 0.20 & 0.25 & 0.30 \\
\hline Amids. . & 0.94 & 1.30 & 2.10 \\
\hline$\ldots \ldots \ldots \ldots \ldots \ldots$ & 4.00 & 3.3 .5 & 6.30 \\
\hline
\end{tabular}


SORGHUM .SIRUP.-Sorghum sirup is extensively manufactured in the Middle West, Kentucky, Tennessee, Missouri, Kansas, Texas, Georgia and North and South Carolina, the sorghum cane being grown extensively for the manufacture of sirup for local use. Soon after the Civil War this industry was carried out on an extensive scale, due to the high prices of sugar. In 1879 more sorghum sugar was manufactured in the United States-28,500,000 gallons more than before or since. Sorghum sirup is very easily made on a small scale, as the cane can be grown as readily as corn and is easily crushed in a small mill operated by horse power. The juice obtained is evaporated in a series of shallow pans which allow skimming in the earlier stages of boiling. The sirup is wholesome and nutritious, and on account of its peculiar piquant, pleasing flavor it is very palatable and inviting. It contains about 36 per cent of sucrose and 27 per cent of reducing sugar. The yield of sorghum is from 50 to 100 gallons of sirup per acre.

COMMERCIAL SIRUPS.-Many of the sirups on the market are mixtures of various saccharine products, which contain glucose as their base; and while they may be wholesome, they are not so sweet as sirup made from sugar cane. In making this sirup the glucose is warmed(13), and with it is mixed some maple sirup, brown sugar, refiner's molasses, cane sugar molasses, or sorghum molasses. In many states the manufacturer is required to label this product, naming the percentage of each ingredient in the compound. The chief excuse for the sirups is their cheapness. They are liable to contain an excess of mineral impurities or bleached substances which make them unwholesome. It is beyond question that any such sirup can ever compete in delicacy of flavor or in wholesomeness with pure maple sugar or the open pan sugar cane sirup or plain sorghum sirup.

MIXED SIRUPS.-Mixed sirups contain coloring matter and flavoring substances which distinguish the brown or yellow raw cane sugar from the white refined sugar as it appears in commerce. The characteristic flavor of the raw sugar which is thus left in the sirup in the refining process is preferred by many people to the mere sweetness of sucrose or glucose; however, the refiner's sirup is in demand for mixing with commercial glucose sirup. Other mixed sirups are made from commercial glucose or corn sirup, with refined sugar cane sirup. The product is practically colorless with sorghum sirup made by boiling down the juice of the sorghum cane, or with sirup made by concentrating the juice of the sugar cane without removing any of the sugar. Other mixed simps are thus 
made by mixing either glueose or surose with maple simp. Commereial and mixed sirups differ chiefly from the maple, eane and sorghum sirup in their color. The former ermuls shomlit be so marked that the purchaser may know whether they contain gluose or whether they are true sirups made from cane juice without any of the sugar removed. It should be observed that the ghlucose in the mixed and commercial sirup frequently contains recognizable quantities of sulphuric acid, and if the acid be impure, it may also contain arsenice; there may also be a little sulphuric acid used for bleaching, and the salts are chicfly sulphates and chlorids. The composition of rurions sirups is given in the table helow (14):

\section{THE COMPOSITION OH SIRUPS, PERCENTAGES}

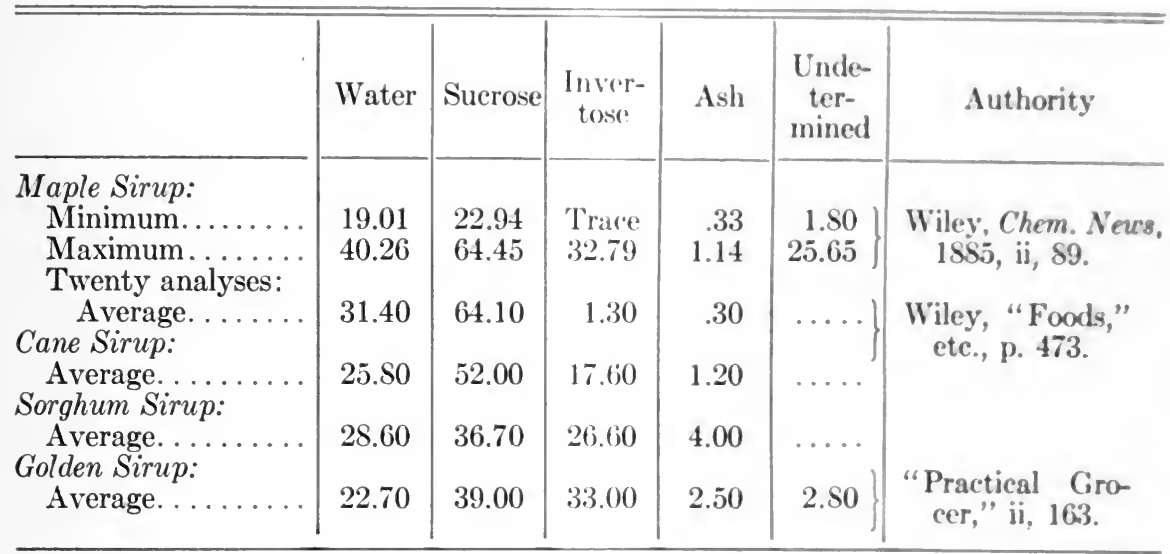

The adulterations to which molasses and sirup are liable have already been referred to (p.622). Ultramarine when added to granulated sugar or sirup is considered an adulteration: so also are the salts of tin, which are indeed poisonous (p. 623). It is considered permissible to add starch, not exceeding 1 per cent, to powdered sugar, so that the latter will retain its pulverulent nature and not berome himpy; but the addition of any mineral substance such as chalk or magnesium for this purpose should not be permitted. Sulphites in any quantity remaining in the sugar sirups or molasses is injurious to health(15).

Saccharin.-Saccharin, $\mathrm{C}_{6} \mathrm{H}_{4} \mathrm{CO}$. $\mathrm{SO}_{2} \mathrm{NH}$, is a white crystalline coal tar product, soluble in 400 times its bulk of cold water. When pure it is 550 times sweeter than cane sugar. It is not a sugar, neither does it possess any nutritive properties, and there seems to be considerable proba- 
bility that if taken continuously for a long period of time, it would be injurious. In the United States its use is not allowed in foods or beverages, and its manufacture is forbidden in Germany and Italy. The Referee Board of Food Inspection, in Decision No. 135, reported to the Secretary of the Treasury, says: "The continued use of saccharin for a long time in quantities over .3 of a gram per day is liable to impair digestion." The addition of saccharin as a substitute for cane sugar or other forms of sugar reduces the food value of the sweetened product and hence lowers its quality. The findings of this Board show that saccharin in food exerts a deleterious effect upon the health of the consumer.

Saccharin is neither a vegetable nor a mineral substance; it is not a condiment, because it does not stimulate; it is not a food, because it does not nourish; it is not a drug, because it possesses no curative properties; it is not a food accessory, because it is a laboratory manufactured chemical. It is sweet, but unlike sugar; it takes away the appetite without appeasing through any nourishing properties.

Glucose-Glucose, properly speaking, is the generic name for the hexoses $\left(\mathrm{C}_{6} \mathrm{H}_{12} \mathrm{O}_{6}\right)$ or six carbon-atom carbohydrates, and more particularly of dextrose, or grape sugar, which occurs in so many plants and fruits. Commercial glucose, according to Bailey, is obtained by boiling starch with acids. "The process depends on the principle of the 'hydrolysis, as it is called, of starch by heat and dilute acid. The manufacture of the starch and its conversion into glucose are more economically conducted in the same factory. In the United States, the starch is manufactured from corn. It is accomplished by steeping the corn until it is softened to loosen the germs from the grain. The meal is ground fine. The next process consists in 'inverting' the starch, and this is accomplished in large copper boilers by the use of about six pounds of hydrochloric acid to 10,000 pounds of $\operatorname{starch}(16)$. After being heated for some time under pressure, it will be found that no starch remains. The free acid is then neutralized with sodium carbonate, and the solution is decolorized by filtering through bone black. It is then passed into vacuum pans and concentrated by methods similar to those employed with cane sugar juice. The concentration is carried to the point of producing a heavy, thick sirup which contains about 35 per cent of dextrose, from 4.6 to 19.3 per cent of maltose, and from 29.8 to 45.3 per cent of dextrin."

Glucose is very extensively used as a constituent of many table sirups, as a sweetening in the manufacture of jams and jellies; it is also used in making artificial honey and as a substitute for malt in brewing. Glucose is deficient in sweetening power as compared to cane sugar. The 
relation is about 8 to 5 . The total amount of glucose and grape sugar produced anmully in the Cuited states is alout one billion pounds, and in this industry no less than fifty million bushels of corn are used. 'This product is the output of a very few factories which control this mann. facture.

There is a great demand for artificial ghucose or sturch sugar, which is produced by a combination of dextrose, maltose, dextrin and unfermentable bodies. Althongh prepared for immediate absorption from the stomach and intestine and for assimilation, ghoose (17) is of little service for flavoring other articles of food, for when so used it is apt to produce flatulent dyspepsia with acid eruetations. If glucose is eaten as a food in the form of candy or otherwise, it overloads the system by being ton promptly absorbed.

Confectionery.-Included under this heading are various products manufactured largely from sugar of one kind or another. Flavoring and often some coloring material are used. In certain instances the latter is developed by cooking. The sweets are "boiled" or "unboiled," according to the method of treating the sugar. In some of these products pure cane sugar alone is used; in others cane sugar and commercial glucose or invert sugar are combined. The desired consistence is attained by boiling or other methods. By dipping fruits and flowers into concentrated cirups the former are preserved entire. By a similar process, nuts and seeds are converted into candy. On account of the variety of materials used in confectionery they are difficult to classify. However, cane sugar or glucose is the basis of all confectionery. Among other materials used are flavors, extracts, coloring matter, gum arabic, milk products, gums, flowers, fruits, caramel and chocolate. In moulding certain kinds of candy, starch is used, a little remaining in the finished product. Rock candy has already been described on page 121. Cane sugar only can be used for making the hest quality of cream candy and bonbons. Starch is used in moulding some varieties of confectionery, and is present in small quantities in the manufactured product.

White Caxdy.-White candy is the product when pure loaf sugar has been used. It consists of 80 per cent of cane sugar and 20 per cent of water of crystallization. Colored sugar candy is made chiefly in Holland, Germany and Belgium, from white or brown sugar.

Sugar Drops.-Sugar drops and small sweets of various kinds are made by evaporating cane sugar sirup down to the crystallizing point until it hardens. 
Soft Candy.-According to Bailey, soft candy is made by heating sugar in water to which cream of tartar and a few drops of acetic acid have been added. This mass is rapidly heated, usually in a copper kettle, until the temperature of $246^{\circ} \mathrm{F}$. is reached, when it is poured on a marble slab and partially cooled. It is then worked with suitable tools until it creams - an operation quite similar in its results to the old-time method of "pulling the candy." This product is used as a basis for the manufacture of cream chocolates and similar confections. It may be warmed and run into moulds of various shapes.

Hard Candy.- "Hard candy," according to Bailey, "is produced by mixing cane sugar, glucose and water, and bringing the mixture to a temperature of $310^{\circ}$ to $330^{\circ} \mathrm{F}$.; then it is poured onto a slab as with soft candy, and the flavor, usually an essential oil, added. In working the batch on the slab, the edges are continually turned in toward the center. After it has been worked and there is a tendency to become 'hard,' it is thrown over a hook placed on the wall, and 'pulled' until it becomes white. The mass is then warmed and suitable portions are taken to a table and rolled by hand to form stick candy."

THE ADULTERATION OF CONFECTIONERY.-This process is being carefully watched by the Department of Agriculture at Washington. A few vegetables and a few animal colors are admitted to be satisfactory, but mineral colors are universally condemned. The aniline coal tar colors, which have lately come into common use for coloring confectionery, have not been looked upon with favor by the Department of Agriculture. The use of glucose bleached by sulphites is another source of danger, and with sugar selling at $\$ 7.60$, and glıcose at $\$ 4.40$ per hundredweight, one can readily understand the temptation of the manufacturer to substitute the latter for the former in the making of confectionery. The use of mineral substances, poisonous colors or flavors or any injurious substance is discouraged by all reputable confectioners in the making of candy. The practice of coating with shellac chocolate or other confectionery is not allowed. It is estimated that more than $\$ 80,000,000$ is spent annually in the United States for confectionery. As an illustration of the demand for confections, it may be stated that during the Spanish-American War, one New York firm(18) shipped over fifty tons of confectionery to the troops in Cuba, Porto Rico and the Philippines.

Honey.-Honey is defined by the Association of Official Agricultural Chemists and by most fond chemists as the nectar and saccharin exuda* tions from the nectariferous glands of plants and flowers gathered into the dilated esophagus of the bee, afterward disgorged, modified and stored 
in the comb by honey bees. Besides its unquestioned food value, honey is a somewhat forgotten remedy for many diseases. Pythagoras claimed that honey prolonged his life for many years, and ancient Greeks attributed many virtues to it. The rery fact that the honey bee subsists entirely on the nectar gathered from flowers and plants, many of which have a medieinal ralue, suggests that honey must contuin many of the virtues which the bee extracts for its fond. Cennine honey is a food like none other; the sugars contaned $i n$ it are directly assimilable. Honey imparts to the hmman economy more firel value than meat or eggs. Thic energy or fuel value of an egg is s:3 calories, while one ounce of honey furnishes 95 calories. The industrims honey bee gathers the nectar from flowers and plants for its daily sulwistence as well as for a future store during the season when there are no flowers. Honey has been used by man for food from the earliest disy of which we have any record. In prehistoric times, it was probably the muly sweetening substance known to mankind. . It has, however, lost much of its importance as a confection since the production of cane sugar on such a large scale. At the present time, whether considered as a delicions article of food or the base of a wholesome vinous beverage, ${ }^{1}$ it is of no mean value as a food product.

Professor Reclam strongly suggests that honey be used more largely instead of ordinary sugar, since the formic acid which it contains prevents fermentation and its accompanying symptoms of flatulence and toxemia. An analysis by Professor Bunge of Basel, Switzerland, shows that, while sugar contains no lime or iron, honey has 6.70 per cent of lime and 1.20 per cent of iron, and as our food is so frequently deficient in these two elements, owing to demineralization-e.g., white patent flours, polished rice, etc.- the desirability of substituting honey for sugar is urgent and obvious.

The glucose and fructose sugar's contained in honey are readily assimilable, while cane sugar must first undergo changes in the alimentary canal before it can be absorbed. Therefore, if cane sugar is not properly digested, it leads to fermentation, acidosis and symptoms of indigestion and subsequent catarrh. As will be seen from the analysis given below by Bunge, honey has a combined 76.10 per cent of grape and fruit sugar, and should be preferred to manuficctured cane sugar whenever possible. A further study of this analysis emphasizes the great value of the organic mineral salts, especially lime and iron. The antiseptic formic acid adds to its value as a health food.

1 See Metheglin described under the heading of Beverages and Stimulants. Chapter XVI. 
The analysis of honey, according to Browne and Bunge(19), is as follows :

Analysis By Browne

\begin{tabular}{|c|c|c|c|}
\hline \multicolumn{4}{|c|}{ Water..............17.70 per cent } \\
\hline Sucrose............ & .1 .90 & $"$ & \\
\hline Fructose (Levulose).. & .40 .50 & “ & \\
\hline Glucose (Dextrose). & .34 .48 & “ & \\
\hline Dextrin. . . & 1.51 & “ & “ \\
\hline Ash. & 0.18 & “ & “ \\
\hline Undetermined. & 3.73 & “ & \\
\hline
\end{tabular}

Analysis By Bunge

Water.................. 14.00 per cent

Sucrose (Cane Sugar)....2.00" "

Fructose (Fruit Sugar)....34.60 " " "

Glucose (Grape Sugar)....41.50 “ "

Calcium............66.70 " "

Ferrum............. 1.20 " "

In some instances genuine honey has been found to contain as much as 8 per cent of sucrose; more than that would usually show that the honey is either abnormal or adulterated. The differences in flavor are largely due to the characteristic ethereal substance found in the nectars of different flowers. Some flowers yield nearly all glucose or dextrose, and others chiefly sucrose. The saccharine matter having been extracted from the nectaries of the flowers by the bee, the sucrose is inverted to glucose by the invert in enzyme in the intestine of the insect, secreted as honey, deposited in the cells of the comb, and sealed over with wax. Honey is either extracted or sold in the comb. Honey in the comb is more delicate and aromatic than that which has been extracted for some time from the comb.

The color, flavor and odor of honey are chiefly due to the foreign substances in it-namely, to the flowers from which the nectar was gathered. It is the possession of these characteristics which causes certain honey to be so highly prized. The honey bee is one of the most valuable of insects on account of cross-pollinating the flowers of various economic plants.

There are a number of instances on record in which several people have been poisoned by eating honey gathered from poisonous flowers. Sometimes such honey causes headache, nausea, and even a kind of intoxication, but fatal illness seldom results. The soldiers of Xenophon, in his "Retreat of the Ten Thousand," were poisoned by honey, which, though it did not act fatally, caused those who ate a small portion of it to become intoxicated, and those who ate it freely to become delirious, and finally exhausted. Honey is a viscid, transparent liquid or soft opaque mass, becoming gradually more opaque with age, crystalline, and of semi-solid consistency; it varies in color from white or pale yellow to yellowishbrown or reddish-brown(20). It has a characteristic odor and sweet taste, is exceedingly nutritive, demulcent and laxative. The quality of honey is much influenced by the character of the flowers visited by the bees. The 
different rarieties are "buckwheat honey", which is of a dark color and has a strong Havor" "white clover honey," which has a reputation of possessing the mest delicate taste: "sour wood honey," which is also much appreciated for its pipuant taste and delicate whitish appearance. Honey made from the flowers of the alfalfa, apple blossoms, golden rod, gum tree and basswood has in calch case its own characteristic thavor. The production of honey in the lnited States, aceording to statistics, shows that California leads in its production. Other important honeg-producing states are New Hampshire, Pennsylvnia and (hho. The average vield per colony-gum or hive, runs from twenty-five to thirty pounds of comb honey.

The ingenuity of man has devised a method of aiding the honey bee in producing greater amounts of honey. Artificial honey combs are now made from paraffin, and are stamped into cells to imitate the original. This enables the bees to devote all their time and energy to the manufacture of honey, instead of wasting time in the manufacture of honey comb. Bee-keepers have long since recognized the saving of time and labor on the part of the bee by supplying the comb ready made.

\section{Digestibility of Sugar}

The first factor which determines the digestibility of sugar is its chemical form. No matter in what form sugar is taken into the stomach, it can only be assimilated as a monosaccharid (dextrose or levulose). We learned in the chapter on absorption that provision is made in the alimentary canal for the conversion, by means of suitable ferments, of all forms of sucrose (disaccharids) into dextrose and levulose. It is of importance. then, from a trophodmamic viewpoint, to consider the sucroses as undigested and the glucoses as predigested sugars. It is readily understood, then, that sweet fruits are important lietetic sources of sugar, for the reason that they contain it in a form which is fit for direct absorption into the circulation. Honey is therefore regarded as a very easily digested saceharine substance. The importance of the inversion which cane sugar undergoes in the manufacture of jams and preserves also becomes clear. For this reason home-made jams and preserves are superior to commercial jams.

Another factor which influences the digestibility of sugar is the degree of concentration of its solution. Strong solutions of sugar produce an irritating effect upon the tissues. I'pon the external skin, they are apt to set up a superficial inflammation. This is emphasized in the 
eczema which is apt to appear in a diabetic from the contact of the sugarladen urine with the skin, and from similar conditions occurring on the arms of grocers' clerks and other persons who frequently handle sugar.

At the Minnesota Experiment Station(21), the digestion of sugar was studied on five healthy men; five ounces per day were consumed as part of a simple mixed diet. The sugar showed a high digestibility, 98.9 per cent of its total energy, on an average, being available to the body. In general, it increased the energy 25 per cent and did not affect the digestibility of the foods with which it was combined. The protein of the ration was more economically used than commonly. The nitrogen retention was increased 25 per cent. It was pointed out in discussing these experiments that the value of sugar in a ration depends upon its judicious use and combination with other foods.

Experiments were carried out by Brandl on a number of dogs, and he "found that 5.7 per cent of sugar produced reddening of the mucous membrane; if the concentration was increased to 10 per cent, the mucous membrane became dark red, while a 20 per cent solution produced pain and great distress." Another investigator, Atchison Robertson(22), in carrying out a series of experiments, injected 250 c.c. of the 20 per cent solution of sugar into the stomach of a patient who was suffering from chronic gastric catarrh. "Shortly afterwards the patient became sick, and vomited a very acid fluid which put his teeth on edge. He also complained of heartburn and flatulence, and of a severe pain in the region of the stomach." Another experiment was an injection of a solution of invert sugar of the same strength, which produced no discomfort. The experiment was repeated with similar results in other cases of dyspepsia, and in every case the invert sugar produced no unpleasant symptoms. Schule found that from two to six lumps of cane sugar, when taken in an ordinary test breakfast, produced no appreciable effect on the digestion, but when the quantity was increased from ten to twenty lumps, considerable delay of digestion ensued, by reason of the great outpouring of mucus in the stomach. In this connection he says "that one can easily take from 80 to 100 grams of sugar at dessert in the form of ices and. sweets, but that a retarding action on digestion of a meal will not infrequently be manifested."

The tendeney of sugar to undergo fermentation affects its behavior in the stomach. The varieties of iermentation likely to occur are:

(a) Alcoholic, resulting in the production of alcohol and acetic acid.

(b) Butyric, with the formation of butyric acid.

(c) Iactic, producing an excess of lactic acid. 
It is interesting to note that different sugars vary in the readiness with which they tend to undergo these different forms of fermentation. Some interesting experiments upon this point lave been made by Robertson(23); according to the results worked out by him, the fermentution to which sugars are liable oceurs in the following order:

\section{TYPES OF FERMENTATIONS OF SUGARS}

\begin{tabular}{|c|c|c|}
\hline I.ACTIC & Buтrне & Aисоноi.ic \\
\hline $\begin{array}{l}\text { Levulose } \\
\text { (most fermentable) } \\
\text { Lactose } \\
\text { Dextrose } \\
\text { Invert Sugar } \\
\text { Cane Sugar } \\
\text { Maltose }\end{array}$ & $\begin{array}{l}\text { Ievulose } \\
\text { (most fermentable) } \\
\text { Maltose } \\
\text { Dextrose } \\
\text { Invert Sugar } \\
\text { Cane Sugar } \\
\text { Lactose }\end{array}$ & $\begin{array}{l}\text { Maltose } \\
\text { (most fernentable) } \\
\text { Invert Sugar } \\
\text { Cane Sugar } \\
\text { Dextrose } \\
\text { Levulose } \\
\text { Lactose }\end{array}$ \\
\hline
\end{tabular}

As the result of his rescarch he draws the following deductions:

(a) In dyspepsia the absorption of carbohydrates is delayed, and therefore all sugars tend to ferment.

(b) In dyspepsia with lactic acid formation, one should avoid dextrose, levulose and invert sugar, and use cane sugar, maltose and lactose in moderate amount.

(c) In butyric fermentation lactose should be preferred.

(d) In alcoholic and acetic fermentation one should forbid invert sugar and levulose and give lactose.

Of all sugars, then, lactose is the least liable to fermentation-which emphasizes the point that a milk diet is desirable in all stomach disorders.

\section{Assimilation of Sugars}

The assimilation of sugars has received considerable study at the hands of physiological chemists and dietitians. As a result it is conceded that after entering the blood it is converted by the liver into glycogen. What becomes of it after that is more or less disputed, but everyone is agreed that glycogen is the form in which sugar is stored in the body, for a time at least. It has been determined. however, by physiological experimentation that all sugars are not capable of being converted into glycogen, and it is only those which can be directly fermented by veast without first being changed into invert sugar. "Of the sugars commonly consumed, cane sugar and lactose are not directly" fermented by 
yeast, and in order that they may be stored up as glycogen, provision has to be made for their previous inversion." This is taken care of, as we have learned from the chapter on absorption, by the production of certain inverting ferments in the intestine which act directly on the sugars. Should these ferments be of feeble activity while the absorptive power of the intestine is great, a portion of the sugar may reach the blood unchanged, and under these conditions be incapable of conversion into glycogen; sugar will then immediately appear in the urine, producing what is ordinarily termed "alimentary glycosuria."

The fact that sugar may have a disturbing influence upon digestion does not mean that the sugar itself is at all likely to escape digestion. "The readiness with which sugar is hydrolyzed by the sugar-splitting enzyme of the intestinal juice, combined with the susceptibility of sugar to the attack of bacteria, makes it unlikely that much sugar will pass through the digestive tract unchanged." Pflüger, who has devoted so much attention to glycogen and other carbohycirates, says, "Undoubtedly sugar in the blood is heavily drawn on during violent exercise; hence the longing for it in a form that can be readily assimilated."

By giving large quantities of lifferent sugars on an empty stomach, and observing whether or not glycosuria results, physiological clemists have been able to determine the precise assimilation limit of each. The results of experimentation along these lines have been carefully worked out, and the following conclusions settled upon. It has been found, therefore, that the maximum quantity which can be consumed at any one time without the overflow of any of the sugar taking place in the urine is as follows:

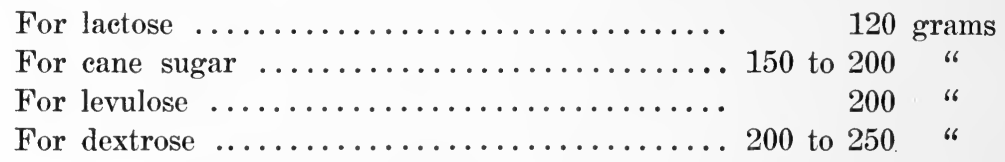

It has been found, therefore, that lactose is the least assimilable of sugars, and this fact is of some particular interest. Experiments have shown, says Hutchison, "that the only sugars capable of direct fermentation are those which contain three carbon atoms or a multiple of that number. Those which contain five, seven or any other number of carbon atoms cannot be converted into glycogen, and accordingly, should they gain access to the blood, are at once excreted in the urine." The pentose group of sugars with five carbon atoms occur with considerable frequency in fruits, and hence pentosuria, as it is termed, is not the infrequent result of the free consumption of such fruits. 
Fuer Value ol siciale as a Food

The fuel value of sugar as a food for the animal body may be considered as the equivalent of starch that has been digested and made ready for absorption. Refined sugar is to be regarded as a pure cryatalline carbohydrate; therefore its food value is high and every gram yields 4.1 calories of energy. An ordinary lump of loaf sugar weighs 5 grams and yields 20 calories of energy. The caloric energy of four such lumps is equal to the carbohydrate of a medium-sized potato. For these reasons, the amount of sugar added to a coup of tea or coffee contributes in no small degree to its supply of energy required by the body daily. One pound of table butter will rield about twice as much energy (:B,600 calories) as a pound of sugar (1,800 calories), but at about ten times the same cost, for sugar is one of the cheapest fuel foods.

Sugar is the most concentrated of all carbohydrate foods. There is no question but that too large quantities of sugar are cousumed in the American enisine. The consumption of sugar per capita in the United States has inereased with leaps and bounds during the past two or three decades. The present per capita consumption of sugar in the leading countries of the world is given by Browne as follows:

\section{PER CAPITA CONSUMPTION OF SUGAR IN VARIOUS COLNTRIES}

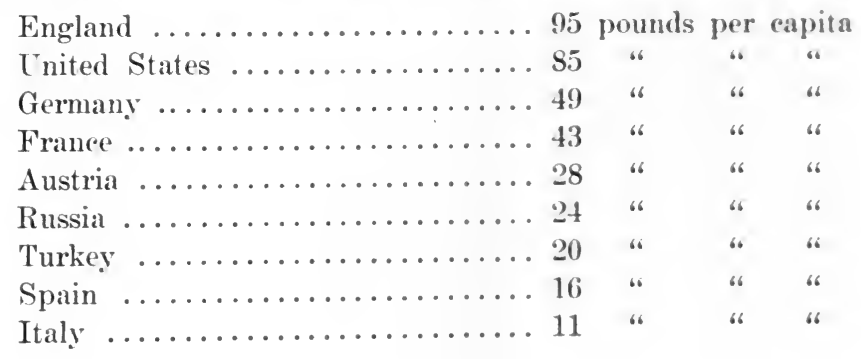

\section{Developanest of the Sigar Indestry}

The development of the sugar industry has had a far-reaching effect on the national health. The tendency during recent years has been to consume more carbohydrate and loss fat, for fat is always an expensive form of food. Sugar. on the other hand, can replace fat as a fuel in the proportion of $21 / 1$ parts of the former to 1 of the latter, but it does not follow on that account that sugar can perform all the functions in the body which are usually fulfilled by fat. The fact must not be lost sight 
of, however, that refined sugar constitutes an extreme case of a one-sided food, its sole nutritive functions being to serve as a fuel, so that the energy requirements of the body are met to a larger and larger extent by the consumption of refined sugar. There is a constantly increasing danger of an unbalanced diet, by making it deficient for the building and repair of the body tissue and for the regulation of physiologic processes.

In our study of the processes of digestion and absorption, we learned that sugar is more rapidly burnt up in the body than fat, and on this account a more efficient protein-sparer than the latter. This rapid oxidation is favored by the ease with which sugar is absorbed, interfering as it does with the complete destruction of proteins. This probably explains the bad effects sometimes observed from the use of sugar in the gouty diathesis (Volume III). It is conceded that sugar possesses undoubted fattening properties. Possibly it may not be transformed into fat, but it spares the body destruction of fat, and part of that in the diet combustion. Whether the fat so formed is as useful as that which can be stored up from the fat in the diet is an unsettled physiological question. The point is one of practical importance in the feeding of convalescents.

We are of the opinion that the moderate cost of sugar has had a favorable influence on the health of growing children, since it furnishes them an ample supply of the body fuel which they so much need. Its sweet, inviting taste has the advantage of being a fuel food that children are not likely to refuse. This is not the case with all fatty foods. Bunge has sounded a warning note in regard to the dangers incidental to the great increase in the dietetic use of sugar. He is of the opinion that where a large quantity of sugar is eaten, the amount of other vegetable foods in the diet is diminished. This may possibly result in a deficiency in the supply of calcium, iron, fluorin and other mineral ingredients of the blood.

\section{Sugar as a Food for Muscular Work}

Sugar as a food for muscular work has been referred to in the chapter on digestion and absorption. We have already learned that the carbohydrates are probably the general source of muscular energy. The sugars, on account of the ease and rapidity of their absorption, are better calculated to fulfill this function than any other member of the carbohydrate group. Brillat-Savarin long ago pointed out an interesting fact that "the English give sugar to their blood horses in order to sustain them in the trials to which they are subjected." To Swiss guides and Arctic explorers the value of chocolate as sarcharine food has long been known. It 
is a fact, says Abel, that the harventor, lumberman and others who do hard work in the open air consume trout quantities of sugar in pie, pudding, doughmuts and molusses, with lenefit. (O) the other hand, people living a sedentary indoor life fimd that large amounts of pie, eake and pudding with highly sweetened prescrvinl fruit, and sugar in large amount on cooked cereals, almost always pombure indigestion.

Masso, in 1s93, performed somm lost experiments to determine tho exact value of sugar as a muscle fool. liy means of an instrument which he called an ergograph, he deternincel that sugar possesses a notable effect in lessening muscular fatigue. Amulure investigator, Vuughan Harley, working under Masso's direction, lertormed the following experiment: He took $17 \%$ ounces of sugar a lay and found that his ability to perform work was increased from lil tu iti per cent. He also demonstrated that "the administration of sugar dolayod the onset of fatigue, and that its effect was rapidly exerted, the maximum influence being reacher in about two hours." Schumbure confirmed these results in regard to extraordinary muscular exertion. Nimilar experiments have been performed by Stowasser, who says, "Whe'n sugar is added to the diet, the ability to perform work is increased, while the fatigne and nitrogenous waste are lessened." The conclusion of these several investigators is that sugar is the most valuable food for persons who have to perform severe muscular effort, especially if they are obliged to do so in a state of exhaustion.

This brief summary shows the use which may be made of sugar when severe work is to be performed, and some of the experimental data which indicate that this use is justified. For a long while the German army has recognized the value of these scientific experiments which they have made practical use of by allowing their men engaged in the autumu maneuvers to have a free allowance of sugar daily in addition to their ordinary rations. It was determined after a trial extending over five weeks that the soldiers who had been supplied with sugar marched better and suffered less from hunger, thirst and fatigne than their comrades who were not supplied with sugar. As a result of the experiments, the anthorities recommended an increase of two ounces of sugar per day to the ration for the German soldiers.

Large quantities of brown and white sugar are used by the natives of India as a common article of diet, heing freely mixed with milk, rice, cheese and other foods. It is also stated that the employers who will not furnish the native laborers with as much sugar as they desire. must expect to lose their workmen. The use of sugar by mountain elimbers is 
well known. The Swiss guide considers lump sugar and highly sweetened chocolate an indispensable part of his outfit.

\section{Misuse of Sugar}

From a gastronomic point of view it would seem that in the Ameriean cuisine possibly too much sugar is used with too many kinds of food, with a consequent loss of variety and piquancy of flavor in different dishes. The nutty flavor of grains in cereal foods and the natural taste of mild fruits are very often concealed by the addition of too much sugar.

\section{SPICES AND CONDIMENTS}

According to the Food and Drugs Act of the United States, the definition of the word food covers all articles used for food, drink, confections or condiments. While it is true that certain of the condiments offer opportunity for food adulteration, still the enforcement of the pure food laws is sufficiently drastic to take care of the situation.

There seems to be some misunderstanding as well as apprehension existing concerning the use of condiments, or as the Germans say, Genussmittel. In its translation the latter term is broader and better since we restrict condiments to spices, like cinnamon, ginger, salt, pepper, etc., which we add to food in the stage of preparation or at the table to improve the taste. Genussmittel in its broader sense embraces all our term implies plus the savory element of the food itself which makes it palatable. The extract of meat, the sugar and dextrin of dry toast, fruit, the dextrin and caffein of coffee developed by roasting, the jellies when taken with meats, are included under this head, also caviare, piccalilli and other kinds of pickles and relishes which excite and stimulate the appetite. Many of these relishes contain sugar, starch and woody fiber also; in some instances, caviare, fat and protein must enter into the sum-total in figuring the caloric value of our food. We think it prudent to treat these appetizers or condiments in the Teutonic sense and to concur, in the present generally accepted view, that they are beneficial adjuvants to the food both in health and disease, since they awaken and intensify the appetite and stimulate the salivary and intestinal glands to secrete the juices necessary for normal digestion. Attention is directed to Volume II, Chapter III (24), in order to emphasize the great importance of the proper preparation of food in cooking, so as to develop the best aroma and flavor which in turn induce through the special senses a more thorough mastication and insalivation of the food. 
Children and young people in sormal health have no need for condiments, as a rule, but in adult life, under varions conditions of living and oceupation, the appetite often thags, and whon ifl or during convalesence with complete loss of appetite, it is necessary (1) tompt the latter. and under these conditions, the use of condinents becomes the sine yua non of treatment.

Spices, condiments and flavoring agents generally, in a restricted sense, while incapable of supplying the body with building material or energy, are nevertheless important acquisitions for the cook, for they are used largely in the culinary art and may" with propriety be termed "food adjunets." Spices and condiments of every kind and description contain aromatic oils and other substances of extremely comples and variable composition, and play an important rôle in increasing the appetite and in aiding the digestive functions; hy exerting a stimulating effect upon either or both the organs of the taste and serretion. By their use otherwise insipid food is made pleasing and palatable, and monotony in the dict is relieved.

Contra-indications.-Their use is contra-indicated in certain gastric disturbances as well as in diseases of the kidneys, in which condition they act as irritants. We believe it is the consensus of opinion of students of sitology that the consumption of spices and condiments in moderation is advantageons as an accessory to the diet, but at the sane time their abuse should be interdicted, as they may serve as a contributing eause of chronice congestion of the liver from hyperemia and chronic gastric eatarrh. When properly used, a flagging appetite is aroused, sluggish gastric secretions accentuated, and movements of the stomach and bowels excited. These properties indicate their use by the middle-aged and otherwise enfeebled persons to give zest and increased pleasure in partaking of food. Sceording to Tibbles(25), healthy individuals with normal digestion do not need them, and they should be witheld from children.

Value of Spices and Condiments._."The aromatic substances contained in spices and condiments are closel:" allied to phenol on the one hand, and to the resins and balsams on the other." They are excellent antiseptics, and by their aromatic and sedative action exert a soothing effect on an irritable stomach and bowels. The sensation of warnth which they exert relieves dyspepsia, cramp, spasms, hiccough. The sime intuene is exerted throughout the intestinal tract. Secretion, ton, is angmented, flatus expelled, and the pain or griping dise to many vegretalule foods prevented. Their mixture with fond serves to exeite the nerves of taste and smell as well as the sense of hunger. thereby direetly angmenting appetite and 
desire for and enjoyment of food. Their use is of great value to persons of jaded appetite, to invalids and convalescents, and no adjustment of the diet in such cases can be regarded as satisfactory which leaves this consideration out of account.

It is thought best for the purpose of the present work to omit a detailed study of the chemistry and composition of the vast number of flavoring agents which enter into diet, but only to consider casually those which are in common use.

Tibbles groups condiments into three classes: stimulating condiments, aromatic spices, sweet herbs; but for the purpose of the present work it is thought wise to classify condiments and spices with reference to the source from which they are obtained.

\section{Sources from Which Condiments are Obtained}
(a) From stems or leaves
(d) From roots or root stocks
(b) From buds or flowers
(e) From immature or ripe fruits
(c) From barks
(f) From seeds

(a) Stems and Leaves.-BAY LEAF.-The bay leaf (Laurus nobilis), or sweet bay as it is commonly called, is used as a condimental substance in food. It is a native of the Mediterranean countries, but grows in sheltered gardens throughout the temperate zone. The leaves have an agreeable odor and an aromatic bitter taste, and are used for flavoring custards, etc. The leaves contain a fixed oil which can be expressed as an essential volatile oil or obtained by distillation. The oil of bay is used in making bay rum. It is obtained from a different plant, the Myrcia acris.

SAGE.-Sage is an ordinary perennial garden herb which grows wild in southern Europe and is cultivated in old-time gardens throughout the United States and other temperate climates. The leaves, which are the official portion, are grayish-green and very aromatic. From these an aromatic oil can be distilled. It possesses slightly tonic, astringent and aromatic properties. The principal use of the sage leaf is in flavoring meat, especially sausage and the "stuffing" of fowls.

MACE.-Mace is obtained from the arillus and reticulated envelope which surrounds the nutmeg. It has a beautiful blood-red color, and closely surrounds and encloses the nutmeg or kernel. The mace contains a notable quantity of fixed oils and resinous matters. Its volatile oil resembles that of nutmeg. It contains a considerable amount of carbohydrate, which behaves like starch, but gives only a red reaction with 
iodin and is ealled an amylodextrin. Maco contains between 20 or 30 per cent of non-rolatile ether extract and atwout: prep rent of total ash, and 0.5 per cent of ash insoluble in hydrechloric acid and 10 per cent of crude fiber. Mace is a stimulant, carminatice and valuable flavoring agent, used in the culinary art. Its excessive use is apt to produce narcotic effects similar to those of eamphor. (See Siutmeg, page 649.)

COMmon mast,-Garden mint is used largely for sances and other eulinary purposes. It has an oil which contains a stearoptene $\left(\mathrm{C}_{10} \mathrm{H}_{30} \mathrm{O}\right)$, also a liquid $\left(\mathrm{C}_{10} \mathrm{I}_{14} \mathrm{O}\right)$ which is isoneric with carvol. This herb is highly prized for its delightful aroma when scientifically blended with well-seasoned brandy in the famous Southern Mint Julep.

SPEARMINT.-Spearmint is the dried leaves and tops of a perennial herb found in most moist places of the northern United States, linrove and Asia. The plant is used extensively in flavoring mint sauce, which is served with mutton and lamb. It somewhat resembles peppermint, but can be readily distinguished from it both by its appearance and odor. The oil of spearmint is largely distilled in this country, the whole plant being used in the process.

SWEFT MARJORAM.-Sweet marjoram is a native plant of North Africa. It is a sweet, fragrant and aromatic herb cultivated in gardens for culinary purposes. The plant is used for medicinal purposes as well as for flavoring. It vields a volatile oil containing 40 per cent terpinene, some terpineol, and small quantities of acetic and other acids. Sweet marjoram extract and marjoram extract are both made from the oil of marjoram.

SWEET BASIL.-Sweet basil is an aromatic herb, native of India and Africa, and is cultivated in gardens throughout the temperate zone. It is a useful aromatic herb for seasoning soups and various dishes. It possesses a peculiar inviting flavor resembling somewhat that of cloves.

SUMMER SAVORY.-Summer Savory is an aromatic herb used for flavoring soups, entrées and other meat dishes. It has a very vungent, aromatic odor and a warm, rather bitter taste. The leaves are sometimes profusely covered with small vesicles containing the oil which gives the herb its aromatic properties.

PePpermat.-Peppermint is found growing in moist places thronghont the temperate zone. It is cultivated extensively in Michigan, Indiana and New York, for the manufacture of the essential oil of peppermint. It is used for flavoring foods, though not extensively, and is used in bererages and confectionery. Menthol is obtained from the oil of peppermint. 
PARSLEY.- Parsley is a native of Sardinia and other European countries. All parts of the plant contain an oil to which its flavor and properties are due. The crude oil is most abundant in the seeds, which contain apiol or apiolin, obtained by boiling the herb with water and cooling. Various parts of the plant are used for medieinal purposes. The main use of parsley, however, is in sauces and for garnishing meat dishes.

TARRAGON.- Tarragon is a plant cultivated for its pungent, aromatic leaves which are used for flavoring soups and for making "tarragon vinegar."

WINTERGREEN.-Wintergreen is a small evergreen herb which grows wild in various sections of the United States. The oil of wintergreen is used extensively as a flavoring for beverages and confectionery. The oil of wintergreen contains methyl salicylate, largely used as a substitute for salicylic acid in medieine.

THYME.-Thyme is a garden plant, native of southern Europe and grown in all countries throughout the temperate zone. There are two varieties-garden thyme and the wild thyme. Both contain the same oil, which gives the fragrance and aroma to the plant, but the cultivated plant contains more than the wild variety. The leaves of this plant are used prineipally in sausage and "stuffing" for fowls. The oil of thyme, which is produced from the leaves by distillation, contains from 25 to 42 per cent of thymol $\left(\mathrm{C}_{10} \mathrm{~K}_{13} \mathrm{O} . \mathrm{H}\right)$, a useful medicinal antiseptic.

Cherry LAUREL LEAVES.- Cherry laurel leaves have a taste and flavor resembling that of bitter almonds; they are used to flavor custards, blanemange and puddings.

FENNEL.-Fennel is a native plant, naturalized in England and the United States. It is used principally for sauces for rich varieties of fish - salmon, mackerel, etc.

The essence of sweet herbs, a favorite condiment with Southern cooks in the days "before the war," is made according to the following formula: Take of thyme, 4 parts; winter savory, 4 parts ; sweet marjoram, 4 parts; sweet basil, 4 parts; grated lemon peel, 2 parts ; celery seeds, 1 part; aleohol, 50 parts; bruise them all, macerate, keep in the alcohol for seven days, and filter. This essence is used largely for flavoring soups, entrées and other culinary preparations.

(b) Buds and Flowers.-Buds and flowers of certain herbs furnish a variety of aromatic substances, highly prized by cooks and chefs.

CAPER.-The eaper bush buds are the unexpanded flowers, of a low trailing herb that grows abundantly along the shores and on the islands of the Mediterranean. The plant begins to bloom in the early sum- 
mer, and the fresh houds are gathered exery morning lefore they expand, and are pickled in strong white vinchar and salt. When the season closes, the buds are assorted according to size and color: the youngest and greenest are considered of the finest quality. Capers add grently to the flaror in the preserving of pickles, their peculiar flavor lecing due to capric acids.

CLOVES.-Cloves are the dricl flower buds of an crergreen tree, native of the Molneca lslands, hut contivated all were the liast Indies, West Indies, East $\Lambda$ frica and Brai:il and other tropical conntries. The trec grows to the height of thirty or forty feet and begins to hear when about six years old. The buds are plucked by hand when they are red and nearly ready to open; they are dried quickly in the sun or log the heat of a wood fire. Cloves contain from 17 to 20 per cent of the volatile oil of cloves and about s pere cent of oleoresin. T'he vil of cloves contains about 90 per cent of engenol $\left(\mathrm{C}_{10} \mathrm{II}_{12}()_{2}\right)$, a phenol-like sulstance. 'The use of cloves in domestic soience is well known. They are employed chiofly for their flaror, but they also possess stimulant, aromatic, antispasmodic and antiseptic properties. They are the ehief representatives of the "aromatic spices."

SAFFRON.-Saffron is the dried stigmas and tops of the stiles of a perennial plant, native of Asia Minor, hut now cultivated in many parts of southern Europe. It is chiefly used in the culinary art to impart color and flavor to food.

Barks.-CASSIA.-Cassia is the imner bark of varions trees, having an odor and flavor somewhat similar to cimmamon. It grows extensively in China, Ceylon and other Oriental countries. Some of this class of barks are thin, and others are thick; the thin barks resemble true cinnamon so closely that they are often used as an adulterant of the latter. It contains a volatile oil similar to the oil of cimmanon. 'The flower buds put on the market from this tree furnish the cassia buds of commerce which are used for flavoring purposes.

CINAAMON-True cimmamon is the inner bark of the true cinnamon tree, native of Cerlon and found all orer India and the islands of the Eastern Archipelago, but chiefly in Ceylon, Borneo, Java, Sumatra and Brazil. The trees are cultivated and the bark is removed and cut longitudinally and laid aside for twenty-four hours, during which time a species of fermentation takes place which facilitates the remoral of the inner epidermis or green part of the bark. The inmer bark is then removed and rolled into long cylinders and dried in the sun. It is then ready for shipment. 
The oil of cinnamon is obtained from flowers, leaves, bark and roots of the cinnamon tree. The finest oil is distilled in China, and is used for making waters and cordials. An artificial (synthetic) cinnamic aldehyd $\left(\mathrm{C}_{6} \mathrm{H}_{5} \mathrm{CH}: \mathrm{CH}-\mathrm{CHO}\right)$, a coal tar product, is sometimes used to replace the genuine oil of cinnamon in the manufacture of flavoring materials. The cinnamon bark can readily be adulterated with cassia and other similar barks. Pure ground cinnamon is more frequently found on the market at the present time than formerly.

Roots or Rootstalks.-TURMERIC.-Turmeric is the rhizome of a perennial plant growing in the eastern countries. The roots are dried and frequently ground before being offered for sale. Turmeric contains a yellow coloring matter, and the powder has a warm aromatic, bitter taste. It is used for coloring and flavoring food products.

GARLIC.-Garlic is a cultivated plant closely related to the onion family. The tops, and especially the bulbs, have a peculiar taste and smell which are quickly communicated to the breath and perspiration of the consumer. This is due to an essential oil usually stated to consist chiefly of allyl sulphid $\left(\mathrm{C}_{3} \mathrm{H}_{5} \mathrm{~S}\right)$, which occurs in many cruciferous plants. The bulbs are used as a condiment in the preparation of entrées, sauces, etc. Garlic provokes the appetite, as well as the muscular and glandular activities of the stomach. "It also possesses stimulant properties, quickens the circulation, excites the nervous system, the skin and kidneys."

GINGER.-Ginger is the creeping rhizome of a plant which is said to be a native of Hindoostan, but is now cultivated in the East and West Indies, and in.fact, in all southern tropical countries. The roots are sufficiently matured when a year old. They are then dug up, trimmed, washed, boiled or scalded with boiling water to prevent germination, and rapidly dried. So prepared they constitute unbleached or black ginger. In this condition they have a grayish wrinkled epidermis with a brown underlayer and a yellowish interior. The epidermis contains a large amount of oleoresin; therefore the black ginger contains more aromatic properties than white or bleached ginger. The latter is prepared from the best selected roots, deprived of their epidermis, decorticated, and carefully dried in the sun-the latter process giving them a beautiful white color. Decorticated ginger roots are smoother and whiter, but less pungent than the black ginger. Preserved ginger is made from the young succulent rhizomes which are washed and boiled in sirup. Some of the roots are afterwards crystallized or candied by drying them in the same way as candied fruits. 
Ginger contains an oleoresin, a volatile oil and uearly 50 per cent of a peculiar starch. 'T'he flavor and pungency are due to the volatile oil and the oleoresin. Ginger possesses valuable carminative properties. It is of considerable value in enfeebled states of the alimentary canal, such as atonic dyspepsia, nausea, vomiting and diarrhea. The stimulant aromatic properties of ginger ale are due to the volatile oil and oleoresin contained in the ginger root.

HORSERADISH.-Dorseradish is the root of a plant which is a native of western Europe and is extensively grown on both sides of the Atlantic. It is so well known as to require little description. It has a warm taste and pungent odor, which promotes appetite and secretion of saliva, increases gastric secretion and motility, thereby stimulating the alimentary functions. At the same time it is a carminative and antiseptic thronghout the alimentary canal. The virtue of the root is contained in a volatile oil which is present, but which is dissipated by drying. The oil is principally a sulphocyanite of butyl $\left(\mathrm{C}_{4} \mathrm{H}_{9} \mathrm{CNS}\right)$. The root may be grated well, and preserved in vinegar for use. Horseradish is valuable as an addition to a diet, containing much salt meat, to prevent scurvy. It is a valuable aid in the digestion of meat and varions acid dishes, and is extensively used with raw oysters. It is one of the most valuable antiscorbutic condiments; of value in chronic rhematism, sciatica, varions dropsical conditions, and as a general stimulant and excitant in systemic and nervous debility.

SASSAFRAS.-Sassafras is obtained from the inner part of the roots of the sassafras tree which grows along the Atlantic coast and the interior of the United States. The root and bark contain a volatile oil used in flavoring beverages and confectionery.

Immature and Ripe Fruits.-ALLSPICE-Allspice is the dried, halfripened fruit of a handsome evergreen tree, attaining a height of thirty feet. It is a native of the Caribbean Islands. It is grown in the West Indies, Mexico and the northern part of South America. It bears fragrant aromatic white flowers. The berries grow rapidly and become moist when ripe and later dry, black and tasteless. The! are, however, picked when green and fully grown, in which condition they have the maximum of flavor. They are dried in the sun, which turns them a reddish brown. They have a fragrant odor resembling a combination of cinnamon, cloves and nutmeg; hence the name allspice. Their taste is warm, aromatic and pungent. They are used in the preparation of fond as an aromatic spice. being possessed of aromatic, stimulant and carminative properties which they communicate to various cordials, ete. They are used for flavoring 
puddings and pies. Besides a volatile oil, they contain a green fixed oil which has a burning aromatic taste somewhat like that of pimiento.

CAPSICUM-CAYENNE PEPPER.-They are the fruit or pods of several species of eapsicum known under various names as pod pepper and red pepper. They vary in size from a small pod to a large pod or berry. Cayenne peppers are hot and the "paprikas" are mild. Capsicum and the pepper derived from it is a diffusible stimulant; it promotes the secretion of gastric and pancreatic juices. As a condiment a small amount is of value in eases of atonic dyspepsia attended with flatulenee, etc. It is of value to alcoholic subjects, and is largely used by the residents of hot elimates to arouse appetite and relieve dyspeptic symptoms generally.

JUNIPER BERRIES.- Juniper berries are the fruit of an evergreen tree very widely distributed over the northern hemisphere; it grows as far north as the Arctic circle. The trees differ greatly in size and shape in different latitudes. The fruit matures during the second season, and is used medicinally and for making aromatic oil. The crushed berry or the oil is used in flavoring gin (see Volume I, Chapter XVI). Juniper berries are about the size of a pea and contain a sweet pulp; when dry they are black and have a sweet-bitterish balsamic flavor. They are stomachic, inerease the appetite, and stimulate digestion; they also stimulate the skin and kidneys to inereased action and give to the urine an odor of violets.

PEPPER.-Pepper is the dried unripe fruit of a perennial plant which is propagated by euttings, and as it grows must be supported by props or other trees. The tree begins to bear three or four years after it is planted and produces two erops a year. Black and white pepper are the fruit of the same tree, but treated in different ways. The pepper plant grows wild in the forests of Malabar and is cultivated throughout India, Siam, Indo-China, Java, Sumatra, the Philippine Islands and the West Indies. The largest quantity of pepper is produced in the region of Singapore.

The berries are gathered before they are ripe, are dried in the sun, and beaten on mats to detach them from the stalks. This constitutes the black pepper of commerce. In the preparation of white pepper the berries are allowed to become fully ripe before they are gathered, and then are permitted to stand until a certain amount of fermentation takes place. This treatment allows some of the pungeney to eseape, retaining a finer flavor and aroma than black pepper. The berries are carefully selected, only the finest being used for this purpose. After fermentation takes place, they are rubbed together by hand to remove the pulp; they are afterwards dried and blanched in the sun. 
One of the most important ingredients in pepper is an alkaloid, piperin $\left(\mathrm{C}_{7} \mathrm{H}_{19} \mathrm{NO}_{33}\right)$. Pepuer also contains an oleorenin and a volatile oil which contribute flavor and pungency to the produrt. Ciround pepper is quite generally used ats a table condiment on varions dishes.

VANILLA BEan. V Vuilla bean is the dried and cured bean of an orchid with thick fleshy leaves, indigenons to Mexien, which grows upon cocoa and other trees, but is also cultivated in the West Indies, Central and Sonth America. The best enred heans are from 20 to 25 centimeters long, drawn ont at the ends and curvend at the base. 'l'hey have a characteristic brown color, waxy feel, and are covered with fine, almost imperceptible crystals of vanillin which has the composition of $\mathrm{C}_{n} \mathrm{H}_{n} \mathrm{C}_{3}$, varying from 1.60 to 2.60 pere cent. They possess a delirions flaven due to the active principle of the alove. It is realily extracted by alcolool and other solvents. The vanilia extract is male in this way and is much used in flavoring ice cream, cakes and for other culinary purposes.

Seeds.-ANise.-Anise is interesting as being one of the earliest arom matics mentioned in literature. It is obtained from an anmual plant, a native of Egypt, and is cultivated in Malta, Italy, Spain, Russia and South America. Anise has aromatic and carminative properties. The seeds have a fragrant odor and a sweet warm aromatic taste dne to the volatile oil which forms 2.5 per cent of the seeds. The oil contains anethol $\left(\mathrm{C}_{6} \mathrm{H}_{12} \mathrm{O}\right)$, a stearoptene. They are much used in cookery, in making spices and cordials and in medicine. The seeds are used for tlavoring many dishes, but the whole plant is aromatic and with it the liqueur anisette de Bordeaux is flavored.

CARDAMON.-Cardamon is a native of Malabar and is grown in the East Indies, Ceylon and Java. The cultivated plants bear fruit in the fourth year and continue to do so for many years. The fruit is gathered in November and dried over a gentle fire, and afterwards the seeds are separated from the calyx by rubbing. The seeds are dark brown, of aromatic odor, warmth and pungency. These properties depend upon a volatile oil which can be obtained by distillation. Cardamon seeds are used in cakes, curries, sauces, cordials and confectionery.

CARAWAY SEED.-Caraway seed is obtained from a plant, a native of Europe, and cultivated extensively in Holland and other conntries. The seeds have an agreable taste. They are aromatic and carminative: are much used as a flavoring agent to give taste and aromatic odor to various dietetic articles. The seed contains an escential oil which has a percentage of earvol $\left(\mathrm{C}_{10} \mathrm{H}_{14} \mathrm{O}\right)$. 
CELERY SEED.-(See Celery, Volume I, Chapter XIII). The seeds of this plant are often used for flavoring purposes and have some medicinal value, exerting a carminative action.

CORIANDER SEEDS.-Coriander seeds are obtained from the coriander plant which grows in Europe. They contain a volatile oil which has a remarkable odor. The seed possesses properties somewhat similar to anise seed, caraway and fennel. The whole of the fresh plant, when crushed, emits a fetid odor, but the dried fruit is very fragrant, and is used in making bread, cakes, confectionery, and for flavoring liqueurs.

THE CUMIN SEED.-The cumin seed possesses similar properties to coriander and caraway, and is much cultivated in Malta and Sicily. It is used largely as a flavoring. In Germany these seeds are frequently mixed in bread and cake, and in Holland they are used to flavor cheese.

THE TONKA BEAN.-The tonka bean is obtained from an almondshaped pod containing a single bean which is shaped like a kidney bean of dark brown color. The active principle of the tonka bean is coumarin $\left(\mathrm{C}_{9} \mathrm{H}_{6} \mathrm{O}_{2}\right)$. It possesses a fragrant odor and a bitter taste. The tonka extract is often used to partly replace vanilla extract.

THE DILL SEED.-The dill seed is a native of Spain, Portugal and southern France and is cultivated in the gardens in Europe and America. In the United States the seeds are used for flavoring, and especially in the preparation of "dill pickle." The flavor is not as agreeable as fennel.

THE FENNEL SEED.-The fennel seed is obtained from the fennel plant, a native of Europe and common in all temperate climates. The seed yields four or five per cent of volatile oil which has a sweet aromatic taste. Fennel seeds are chiefly used to flavor cakes and liqueurs.

GRAINS OF PARADISE.-These are used as a condiment. They possess a pungency similar to that of black pepper, and are used to give a fiery taste to various liquors, such as beer, wine and gin.

MUSTARD.- Mustard is derived from the seeds of Sinapis arvensis, of which there are two varieties, the black and white. Mustard originally grew wild, in waste places, and was known as charlock. At the present time the product on the market is composed of a mixture of the seeds of the black and white cultivated varieties, but charlock seeds are still collected and are used for purposes of adulteration. The plant is an annual, bearing yellow flowers; the seeds may be separated from the pods when ripe by threshing. Mustard contains a fixed oil which is present to the amount of from 20 to 30 per cent. This oil presents in many respects the same general character as rape-seed oil (Volume I, Chapter XIV). 
This may be expressed from the powelered recels after warming. It is a bland oil with very little taste and forms an excellent salad dressing. Much of the tixed oil is frequently monoted before the reeds are prepared as "ground musturd."

The active principle of black mustand is sinigrin ( $\mathrm{KC}_{10} \mathrm{H}_{14} \mathrm{KNS}_{2} \mathrm{O}_{10}$ ), and that of white mustard is simallin $\left({ }^{2} 30 H_{1}, \mathrm{~N}_{4} \mathrm{~S}_{2}\left(\mathrm{O}_{18}\right)\right.$. These are the substances which break up to yield, anmong other products, the volatile oil. The strongest ground musturd is oltained by mixing the two varietice of seeds.

The use of mustard in medicinc, ats a condiment, and to stimulate the appetite are too well known to need repetition here.

NUTMEG.-Nutmeg is the dried sind of the Myristica fragrans, a tree native of the Malay Archipelago, which somewhat resembles the orange tree in appearance. The tree attains at height of about thirty feet and has a large branching head resembling a pear tree in foliage and general appearance. The flowers are insignificant, the males and females being on separate seeds. The plantation of nutmeg trees is cultivated from the seeds, and they begin to produce flcwers in the eighth or ninth year. But as above stated, the sexes are distinct, and the male trees are cut when they are two years old, and the remaining are grafted with cuttings from selected female trees. Only one or two male trees are left in the grove to insure fecundation.

The fruit is round or oval, and resembles a small peach, green at first, yellow when ripened. The fruit is zathered by hand, the pulpy lusk stripped off, and the mace of commerce is detached. The nuts are first sun dried, and then smoked until the kernels are shrivelled and lonse. and the shells are sufficiently brittle to be easily broken. The kernels, nutmegs of commerce, on being removed from the shells, are dipped in lime water two or three times to prevent the depredations of insects, and again dried and divided into grades. The small round ones are considered of finer quality than the large oval nuts.

Nutmeg contains a volatile oil which consists of a terpene, myristicin $\left(\mathrm{C}_{14} \mathrm{H}_{25} \mathrm{O}_{2}\right)$. It also contains a fat called nutmeg butter, which is obtained by applying pressure to the kernels between hot plates; it is of yellowish-brown color and has an arreeable odor. The volatile oil is extracted by distilling powdered nutmegs with water. It is a pale strawcolored liquid, soluble in ether and alcohol, having the pungent taste and odor of nutmegs.

Nutmeg is aromatic, stimulant and stomachic. much used and of great value as a flavoring for various foods and drinks. A very small quantity 
is usually sufficient to flavor any food required by one person. In large doses nutmeg is narcotic, poisoning having occurred from the mastication of nutmegs. This is due to the essential oil.

SALT (Sodium Chlorid, $\mathrm{NaCl}$ ) is a condiment which has been used from time immemorial. It occurs in immense underground deposits in various parts of the earth, forming "rock salt." This is said to be formed by the evaporation of prehistoric seas. These salt rock beds are found in many parts of the world. In the United States these beds occur especially in New York, Michigan, Kansas and Louisiana. They are sometimes near the surface, but often at a depth of one thousand feet or more. The salt is mined by sinking a shaft and working as in a coal mine. The rock salt, if sufficiently pure, is sold as it comes from the mine, or ground and screened. The product is usually 98 to 99 per cent pure. In many places a saturated brine, containing about 25 per cent of sodium chlorid, is formed on the top of the salt beds, as a result of the percolation of water through the earth's strata. These lakes of brine water are often referred to as brine springs. Chlorid of sodium also exists in large proportion in sea water. The method of obtaining salt from these waters is by evaporation. Each gallon of sea water will produce about one-fourth of a pound of salt, and salt is still produced by the solar evaporation of sea or salt water in many countries. Salt made from ocean water is quite impure unless purified by washing and recrystallization.

The evaporation of brine from salt springs is one of the commonest and most satisfactory methods. This evaporation is carried on by solar heat in open pans or heated directly over a fire or heated by steam, or more recently in open pans connected with an exhaust or vacuum pan. The salt is raked from the pans, allowed to drain, and sometimes dried artificially before it is put on the market.

The average composition of common salt is as follows:

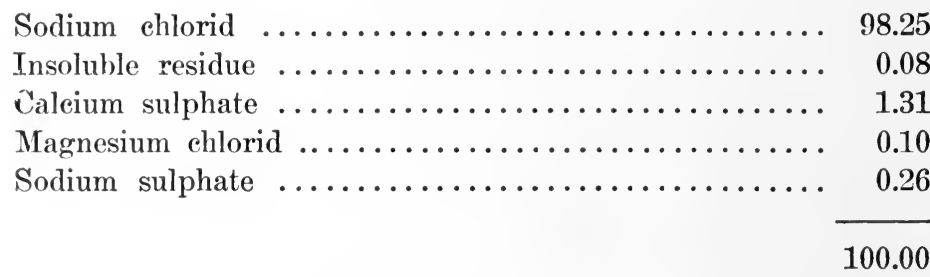

Sodium chlorid, or common table salt, though a true inorganic food, and required in amounts of about 10 grams a day, is often used in larger quantities, 20 grams a day, as a relish. (See Volume I, Chapter XI.) 
It is one of the most important amd uhumbunt of the saline constituents of the aninal organism, existing normally in the lowed, where it kerops the fibrin and allumin in solution. In inflanmation, leeing thus neceded, it accumulates at the seat of the morhid action, disappearing temporarily from the urine; its resppentance therein is considered one of the surest signs of the pationt's improvenent. "In very dilute solution it enables water to dissolve both albumins and globulins, and rembers water non. irritant to the animal tissues and harmless to the red hlond corpusedes." For these purposes the solution emploped is one of 0.0 per ant, known in experimental physiologe as the normal salt solution. In sul,atanoe, however, or in eoncentrated solntion, salt is very irritant to cont surfaces, mucons membrane, muscle and nerve tissnes. Taken into the stomath in quantity, it irritates that organ and induces vomiting. When absorbed in excess of the normal requirements of the body it canses the peculiar nervous irritation expressed by the sense of thirst, and is relieved only by the ingestion of water in sufficient quantity to enable the excess to the dissolved and excreted by the kidneys. It is rapidly absorberi and rapilly excreted; and when consumed in excess it increases tissue change and consequently the excretion of urea and potassinm salts. On the other hand, the excessive ingestion of potassium salts (as in the eases of herbivorous animals and regetarian cranks) increases the excretion of sodimm chlorid by a double decomposition between these salts in the blood, forming potassium chlorid and sodium phosphate, which being foreign to the hood are constantly excreted. In this way, hy a continuous regretable dict, the normal amount of sodium chlorid in the organism may be greatly reduced, and the animal will feel the want of it and will travel hundreds of miles to visit a salt lick. Besides heing emetic when given internally, sodium chlorid also acts as a hemostatic, decreases the seeretion of mucus, is a vermifuge against threadworms, promotes the alsurption of pleuritic serous exudations and of dropsies, and has considerable power as an antiperiodic and an antiseptic.

\section{PICKLES AND SALADS}

Pickles.-Pickles are made from fruits and vegetalules br a procesa of pickling-i.e., immersion in a sulution of salt and vinegar. Cucumbers, artichokes, beets, carrots, gerkins, fin.. peaches, canliflower, onions, pears. string beans, wahnts, capers and nasturtium seeds are all thus picklesl.

The common homschold mothol of pickling is to soak the recectall. for some days in brine: afterward they are subjected to sealding with boil- 
ing water at stated intervals, being put back in the brine between times and finally put up in suitable containers filled with vinegar, to which spices and sugar have been added. Pickles like all vegetables are antiscorbutic, but many of them are difficult to digest, and without good mastication and the stimulation of the stomach by the spices they may prove quite indigestible.

Pickles are often adulterated by the use of the salts of copper to give the pickle a fresh green color. Alum is also a common adulterant, added to the pickled vegetables to make them firm and crisp.

Cold Slaw.-The red cabbage is the favorite cabbage for pickling, but the white cabbage should not be overlooked at a time when salads are scarce. White cabbage hearts chopped fine and mingled with vinegar, salt and oil will supply a salad, "cold slaw," throughout the winter when other materials are scarce.

Sauerkraut.-Sauerkraut is a preparation of cabbage leaves. These are chopped or shredded very fine and packed in casks with salt and weighted down; water is then added until the whole is submerged in the briny solution. After standing for some time the mass undergoes fermentation-during which process the various organic acids of the vegetable impart a flavor which is much prized. This pickled cabbage is a favorite German dish. It is now extensively consumed in the United States.

Sktshi.-One of the Russian national dishes, called sktshi, is made by packing chopped cabbage into barrels with vinegar and salt, and allowing the cabbage to ferment. The product is made into a broth with meat and forms an important part of the daily food of the common people.

Salads.-Salads are composed of vegetables, usually raw, many kinds being mingled together and dressed with condiments, such as vinegar, salad oil and spices. Salads are valuable as a food, mainly for the freshness of the vegetables of which they are composed, for their vitamines and valuable mineral salts, and the iron in connection with the chlorophyll which gives vegetables their green color. Salads are cooling, appetizing and antiscorbutic. Sometimes salads cause indigestion, and because of the indigestible cellulose in them many people require the addition of vinegar to stimulate the process of digestion. The salads most commonly served çonsist of lettuce and one or more of the following: onion, cucumber, endive, cress, radish, tomato, beetroot. Other salad plants are the cardoon, which resembles the artichoke, the leaf stalks of which are blanched like celery, and which is eaten as a vegetable in soup or salad. Some of the following plants or herbs-borage, burnet, coper, 
chevril, mint, nasturtium, parsley, pepper, krass, green peppers and sorrel-have vegetable acids or essential oils which give them a characteristic flavor for making tasty salads.

\section{REFliRLACLS}

In the preparation of this section, the author has Irawn on, freely consulted and derived much help from the following:

1. Thbmes, Whidam. Origin, Composition and Manufacture of Foods.

2. Brown and Brouns. The Chemistry of Sugar Cane and Its Produets in Louisiana, Agric. Exper. Sta., 1907, Bull. 91.

3. Browne. Chemistry of Raw Sugar Production, School of Nines Quarterly, 1911, vol. xxxii, pp. 217-234.

4. Kerpescilatr. Requirements of the Bect Sugar Factory as Compared with the Cane Sugar Establishment, Int. Sugar J., 1911, vol. xiii, pp. 527-593.

5. Clausex. Beet Sugar Manufacture, U. S. Dept. of Agric, Bull. 124.

6. Rogers and Avbert. Industrial Chemistry, p. 663.

7. U. S. Dep. of Agric., Farmers' Bull. No. 47.

S. U. S. Dep. of Agric., Chem. Bull. 134.

9. Tibbles, William. Origin, Composition and Manufacture of Foods.

10. Browne. Hand Book of Sugar Analysis.

11. U. S. Dep. of Ag., Chem. Bull. No. 70 .

12. Wiley, H. W. Foods and Their Adulteration.

13. - Ibid.

14. Tibbles. Origin, Composition and Manufacture of Fonds.

15. Wiley. Foods and Their Adulteration, p. 480.

16. Ricinarns. Food Materials and 'Their Adulterations, p. 92.

17. Thompsox, W. Gilmax. Practical Dietetics.

18. - Ibid.

19. Browne. (Findings based on an estimate of 100 samples.) I'. S. Dept. of Agric., Bull. 110.

20. Kustexaociner. Chemistry of the Formation of Hones, Ztsch. f. Biochem., 1911, vol. xxx. pI. 237-254.

21. Minnesota State Report. 190:3-190t.

22. Robertsox, Atchisox. Digrestion of Sugars in Some Diseased Conditions of the Bodv, Edinb. Med. J. 
23. Robertson. Rate of Fermentation of Sugars, Edinb. Med. J.

24. Fiтch. Scientific Cookery, Food Preparation and Preservation, vol. ii, ch. i.

25. Tibbles, William. Origin, Composition and Manufacture of Foods.

\section{BIBLIOGRAPHY}

Abel. Sugar as Food, U. S. Dept. of Agric., Farmers' Bull. 535.

Baller. Source, Chemistry and Use of Food Products.

Browne. By-products of Sugar Manufacture and Their Utilization, School of Mines Quart., July, 1913.

The Chemistry of Raw Sugar Production, School of Mines Quart., vol. xxxii, 1911, pp. 217-234.

Chemical Analysis and Composition of American Honeys,

U. S. Dept. of Agric., Bur. of Chem., 1908, Bull. 110.

Manufacture of Raw Sugar in the Philippine and Hawaiian Islands, Ibid., 1913.

- The Development of the Sugar Industry, Ibid., April, 1914.

- Handbook of Sugar Analysis.

Browne and Brouin. The Chemistry of the Sugar Cane and Its Products in Louisiana, Agric. Exper. Sta., 1907, Bull. 91.

Bryan. Maple Sap Syrup, U. S. Dept. of Agric., Bur. of Chem., 1910, Bull. 134.

- Composition of Imported Honeys, U. S. Dept. of Agric., Bur. of Chem., 1912, Bull. 154.

Bryant. Composition of Commercial Glucose, Original Communications, Sth Internat. Cong. Applied Chem., 1912, vol. xiii, pp. $47-56$.

Chausen. Beet Sugar Manufacture (translated by Hall and Rolfe).

Cowtes. Suggested Standards for Maple Sugar and Syrup, J. Industr. \& Eingin. Chem., 1909, vol. i, pp. 773-775.

I)erre. Cane Sugar Manufacture.

Cane Sugar Manufacture in the Hawaiian Islands. Orig. Communications, 8th Internat. Cong. Applied Chem., 1912, vol. viii, pp. 7-12.

- Sugar and the Sugar Cane.

Genrlixgs. The World's Cane Sugar Industry, Past and Present. Horxe. The Sugar Industry and Its Relation to the United States, J. Industr. \& Engin. Chem., 1909, vol. i, pp. 3-4. 
Hutchison. Food Dietetics, Fiarmers' Bull. 9\%, U. s. Dept. of Agric., Farmers' Bull. 535, U. S. Dept. of Agric., U. S. Semate Document, 890 .

Koppeschasi. Requirements of the lieet sugar Factory as Compared with the Cane Sugar Establishment, Internat. Sugar J., 1911, vol. xiii, pp. 527, 593.

Richanus. Food Materials and Their Adulteration, Bull. 47\%, U. S. Dept. of Agric., 90.

Rolfe. Notes on Commercial [)extrins, /hid., vol. xiii, pp. 2:37-245, 1912.

Shredded Sugar Cane, J. Industr. \& Engin. Chem., 1910, vol. ii, p. 558.

Sxell and Locknean. Composition of Maple Sugar "Sand," J. Industr. \& Engin. Chem., 1!14, vol. vi, pp. :301-:302.

History, Mamufacture and Analysis of Maple Products, J. Franklin Institute, 1908, vol. clxvi, pp. 249-280, 321-352, 433445.

Walker. The Sugar Industry in the Philippine Islands.

Wiley. Foods and Their Adulteration.

Zerban. Tnvestigations on the Use of Sulphur and Its Combinations in the Sugar House, L. Agric. Exper. Sta., 1908, Bull. 103. 



\title{
CHAP'TER XVIII
}

\section{TOXIC SUBSTANCES (OF FIDBIE FOODS-SOME CONSEQUENT DISEASES}

\author{
IN COLLABORATION WITH
}

A. I. Benenict, A.M., M.I)., F.A.C.P.

\begin{abstract}
Medicinal and Toxic Substances of Edible Foods.
Diseases Caused by Dietetic Errors and Various Fool Poisons: Classi. fication of Dietetic Errors Causing Disense.
\end{abstract}

In a work devoted to the scientific application of the fundamental doctrine of trophotherapy to the general principles of nutrition, there must obviously occur, here and there, an overlapping of pharnacology and toxicology on the one hand and of dietetics on the other-especially with regard to foods derived from the vegetable kingdom.

Tannic acid and certain volatile and essential oils and pigments of more or less positive medicinal properties are found at least in some parts of all plants used as food or food adjuncts.

\section{MEDICINAL AND TOXIC SUBSTANCES OF EDIBLE FOODS}

The principal vegetable foodstuffs in which toxic or medicinal substances are found are as follows:

Abies Nigra, or black spruce, possesses powerful antiscorbutic properties. The American Indians are said to have taught Jacques Cartier the use of this plant, which, according to Cartier, was at that time far superior to any antiscorbutic then known to European physicians.

Aesculus hippocastamum, or horse chestnut, is a possible source of starch, when freed from the bitter medicinal principle.

Acorns contain larger quantities of starch. Which is available for breadmaking after the acorns have been buried underground for a certain period to extract the tamin. 
Asparagus contains an active principle, asparagin $\left(\mathrm{C}_{4} \mathrm{H}_{8} \mathrm{~N}_{2} \mathrm{O}_{3}\right)$, which is a stimulant diuretic and to some extent an arterial and nerve sedative. While contained mainly in the root, it is present to some extent in the stalk. The latter has been recommended as an oxytoxic and emmenagogne, as a nerve sedative and a diuretic in dropsy of various forms and as an aphrodisiac. Asparagin is an active principle, occurring in large rhombic crystals and found in many other plants, as in the shoots of asparagus, vetches, potatoes, licorice, the swcet almond, the root of the locust, etc. It is considered a derivative of succinic acid, and has diuretic properties, besides being a sedative to the circulation. It may be used in ascites, especially in children, in the anasarca of Bright's disease and in gout. It is eliminated in the urine as methyl mercaptan, which has a peculiar disgusting odor. It is excreted very rapidly, being noticeable from one to six hours after ingestion. There is no better test of gastric motility, absorption and renal elimination than the time of appearance and disappearance of the characteristic odor of asparagin.

Bananas, when ripened and especially when cooked, develop a strong odor of amyl nitrite, and occasionally produce mild symptoms of vascular dilatation.

Barberries contain a bitter yellowish alkaloid substance, berberin, which is also found in hydrastis and many other plants. Bitter almond, peach pits, cherry pits, etc., yield hydrocyanic acid from the inner action of the emulsin amygdalin. The latter is not present in sweet almonds. The therapeutic action of this acid is too well known to medical men to be repeated here.

Chamomile, peppermint, catnip, sage, savory, saffron, boneset, and other herbs of this character are often used for making teas. They do not exert any very powerful medicinal action nor have they any nutritive value. They do, however, exert a slight medicinal action in that they are sudorific and more or less sedative to the nervous system.

Coca crythroxylum is the plant from which the alkaloid cocain is derived. It is entirely distinct from caffein. The general use of the plant is as a nerve sedative and stimulant. It is incorporated with a popular drink which is now used as a beverage.

Cratcogus is a species of thorn apple occasionally eaten as a fruit. Aside from the astringent and volatile principles contained in the apple, exaggerated claims have been made by certain practitioners for an extract or tincture made from this apple, which is alleged to be valuable as a heart tonic.

Carrots, parsnips, celery, anise, caraway, dill, coriander and parsley, 
like all other umbellifera, contain volatile oils which are poisonous in sufficient doses. When the follage of arrots is wor, it gives off a proisonous substance, perhaps an essential oil, which exerts an irritating netion upon the skin similar to ec\%ena or to the irritation produced from the poison ivy. Parsnips are considered poisonons if used the second year. The bleaching of celery hy burying in soil, it is elaimed, frees the stalks and leaves of their rolatile oil.

Cucumbers, spuashes and pumplins belong to a family pervaded with a bitter, cathartic principle which may oceasion gastric distress and diarrhea, when an unusual quantity of this prineiple is present. This oeenrs especially if the fruit is over-ripened or a faint fermentative process has begun.

Coffee, tea and cocoa were discussed in the previons chapter on beverages and stimulants and are more or less commonly used as fornd adjurants. They contain definite physiolngical principles, purins, diand tri-methyl xanthin, including tannic acid, which is injurions to health.

Red cabbage contains litmus, so also do many of the pigments of fruits, i.e., such vegetables as the beet, the stem of the red apple, ete. While of no known therapentic or toxic importance, these color reactions may interfere with the examination of stomach contents, and may lead to a false diagnosis of blood, bile and other colored abnormal ingredients of the feces.

Corn, as we learned in Volume I, Chapter XIII, is indigenons to America. Of late years it has been acensed of being the canse of pellagra, probably unjustly, unless as a factor in improperly balanced diet. (See Rye.)

Elderberries, obtained from the elder bush, Sambucus nigra, are often used in the same way as huckleberries. They have an active principle, but in very small quantities. These herries are used to adulterate huckle berries and in the making of elderberry wine.

Grapes, while a delightful fruit, are rich in tartaric acid. 'The skins contain quantities of tamin.

Horseradish, uatercress, mustard, turnip, radish, all contain aromatic sulphur compounds which in large quantities are more or less irritating to the alimentary canal.

Hops, in addition to a small quantity of asparagin, contain also a liquid alkaloid, lupulin and lupulinic acid $\left(\mathrm{C}_{40} \mathrm{H}_{82} \mathrm{O}_{19}\right)$, both of which were mentioned on page 561. when describing the process of brewing. Hops are mildly hypnotic and selative, and are sometimes used as an anaphrodisiac. 
A candy in the shops, sold under the name of Iceland moss, is usually flavored with anise. Besides its use as a nutrient, Iceland moss is of value as a demulcent. It is also considered hemostatic and expectorant.

Lettuce contains a small amount of hyoscyamin $\left(\mathrm{C}_{17} \mathrm{H}_{23} \mathrm{NO}_{4}\right)$ and other active principles. These principles have been referred to by some writers as a mild form of opium.

Licorice is obtained from the root of the glycyrrhiza, a native of Europe and largely cultivated in many other parts. It is slightly demulcent and mildly laxative. Licorice has an agreeable taste and increases the flow of saliva when slowly chewed or sucked. It contains a small amount of sugar, also asparagin and is used as an expectorant. It is much employed in acute bronchitis.

Limes, lemons, oranges, grapefruit, etc., contain antiseptic oils in the skins, while the fruit contains considerable quantities of citric and malic acids.

Manna is a saccharine substance containing various sugars. It is derived from a species of ash tree, oak, larch, flowering ash and the Indian Alhagi plant. It is a legume and possesses laxative as well as nutritive qualities. Manna contains mannotebrose $\left(\mathrm{C}_{24} \mathrm{H}_{42} \mathrm{O}_{21}\right)$, each molecule of which is said to contain two molecules of galactose, one molecule of dextrose and one of levulose.

Mushrooms are described in Volume I, Chapter XIII, page 449, and their danger pointed out. Some varieties of this form of fungi contain several active poisonous substances, of which muscarin $\left(\mathrm{C}_{5} \mathrm{H}_{13} \mathrm{NO}_{2}+\mathrm{H}_{2} \mathrm{O}\right)$ is the chief. Amanitin is found in one variety, while phallin is found in others. Cooks have various tests for detecting these poisons. For instance, if a silver spoon or fork is used to turn the fungi while cooking, the metal will be unaffected by edible fungi; but the acrid juice of poisonous mushrooms will corrode or blacken the silver. None of these tests taken singly is reliable.

Onions and garlic contain allyl sulphid, which is expectorant, antiseptic and somewhat irritating. This active principle may produce intense gastro-enteric irritation if taken in large quantities or in persons having a peculiar idiosyncrasy. Regularly taken in moderate quantities, these regetables seem to be fairly efficient prophylactics in tuberculosis.

Oats belong to the cereal grasses, which constitute the principal fodder of stock animals, while the seeds are a most important food for man. Wood states that the whole family contains but one poisonous or even suspicions genus, lolium. Oats are an aphrodisiac to horses, due to the active principle, avenin, which they contain. This active principle is 
slightly toxic to man, if the use is long continued. Buckwheul, while not a true cereal, contains an active principle which is liable to produce indigestion and skin eruptions.

Pomegranate, as a fruit, was described on page 495. The rind contains the same liquid alkaloid, polletierin $\left(\mathrm{C}_{n} \mathrm{H}_{13} \mathrm{NO}\right)$, as the hark of the root and therefore has powerful anthelmintic properties.

Pumphin sceds are obtained from the pumpkin fruit which is described on page 514, and are useful as an anthelmintic in the treatment of tapeworm. They may also be used as a food.

Potatoes, tomaloes and egg plant all contain mydriatic alkaloids, but not to any appreciable degree in their edible portions. Oceasionally, however, the green parts, even raw petato peelings, may produce mild poisoning. Potato tubers, if young or diseased, are liable to contain an alkaloid solanidin $\left(\mathrm{C}_{26} \mathrm{H}_{41} \mathrm{NO}_{2}\right)$, a glucoside-like combination with sugar, though this particular alkaloid is usually in negligible quantity. Severe, though not fatal, wholesale poisoning from mydriatic alkaloids has been recorded.

May apple belongs to the same genus as the officinal Podophyllum. This apple is occasionally eaten and if liberally ingested, more particnlarly if eaten green, may produce violent eatharsis.

Persimmons, as fruit, have been described on page 483. They are palatable and wholesome after frost, but prior to being "frostbitten" they are disgustingly bitter, astringent, and exert a cathartic action.

Pennyroyal, lavender, sage, hoarhound, thyme, spearmint, peppermint, rosemary, catnip, oceasionally employed for flavoring. belong to the mint family. All of them possess a volatile oil more or less medicinal, but not toxic unless in large quantities.

Pawpaw and pineapple, as fruits, are considered in Volume I, Chapter XV, page 490, and are said to contain digestive ferments similar to trypsin and amylopsin, acting in alkaline or neutral media, as io also the insectivorous plants not used as food. These ferments are not so sensitive to temperature as animal ferments, but are destroyed by boiling.

Rye and corn are subject to smut just before ripening. From the former the fluid extract of ergot is obtained and from the latter ustilago maydis is produced. They are parasitic plants and not themselves used as food, but frequently contaminate the cereals.

Rhubarb, described in Volume I, Chapter XIII, page 435, is a valuable article of diet. Its use as a food or heverage is contra-indicated in per- 
sons of a gouty diathesis owing to the presence of calcium oxalate in its mineral content.

Tomatoes and sorrel contain considerable amounts of oxalates. Oxalic acid poisoning has been reported from the use of rhubarb leaves as greens.

Rice as a foodstuff was considered at length in a previous section. The use of "polished rice" as the principal carbohydrate in the dietary undoubtedly leads to the production of beri-beri, a deficiency disease, which will be considered at length in Volume III, Chapter XVII. The researches of Casimir Funk and others have shown that polished rice is devoid of accessory substances-vitamines.

Slippery elm is obtained from the inner bark of the elm tree and is a valuable demulcent, and nutritive to a slight degree.

Sarsaparilla is obtained from the sarsaparilla root and is commonly used as a flavor for soft drinks. Its medicinal and toxic action is not of sufficient moment to be mentioned.

Sassafras contains an antiseptic volatile oil, not toxic in ordinary doses. The fresh leaves and twigs and the bark of the root are often chewed and the latter is made into a tea.

Tapioca is prepared from the roots of the casava, which was described in Volume I, Chapter XIII. The sap of this plant is poisonous, but it can be removed by washing.

Vanilla is obtained from the vanilla bean; its active principles are irritating to the skin, conjunctiva, alimentary canal and urinary passages. It possesses slight aphrodisiac qualities, but these effects are rare owing to the minute quantity employed in foods.

\section{DISEASES CAUSED BY DIETETIC ERRORS AND VARIOUS FOOD POISONS}

It is a well-known fact that diseases may be caused by taking too little or too much food, or by an improperly balanced dietary-for instance, one which does not contain the proper combination of food elements in correct proportions. Other factors and influences, the precise nature of which are more or less obscure, may also act as etiological factors. Food which contains certain poisons or disease germs or parasites taken into the body with the food may also act as a causative factor. Personal idiosyncrasy to certain foods may occasionally produce illness. Some claim that all food idiosyncrasies are due to anaphylaxis. 
Classification of Dietetic Errors Causing Disease.-Dietetic errors may act as cansative factors in producing a variety of diseased conditions:

(a) Insulficiont linod.

(b) Overeating.

(c) Imperfectly Balanced Diet.

(d) Fools ('ontaining Animal Parasites or Ora.

(e) Foods ('ontanining Ptomains.

(f) Foods ('ontaining Other Poisons.

(g) Adulterated Foods.

(h) Foods Containing Microörganisms.

(i) Wholesome Food against which Personal Idiosynerasy Exists.

(j) Alcohol as a Food and a Poison.

(a) INSUFFICIEXT FOOD.-The diseases arising from the partaking of insufficient food are starvation, malmutrition, marasmus and some forms of anemia, including chlorotic conditions in voung girls who are underfed. Starvation is a condition in which the tissues are not nourished, due to the lack of assimilation of food. A well-balanced ration may be ingested, but defoctive metaholism results in inanition from lack of ability to absorb and develop foree and nutriment from the body. Fxposure to cold accelerates starvation symptoms by reducing the vitality of the body.

(b) OVEREATING.-Overeating, or the taking of improper food, gives rise to a great variety of diseases, especially in individuals who have predisposing hereditary tendeneies to certain maladies. A gourmand may not only partake of too much fool, but of foods which produce more or less irritation of the alimentary tract. This irritation may be the direct cause of disease, as in acute indigestion and inflammatory conditions of the gastro-enteric tract.

Temporary orereating at one or two meals may not produce any serious effect, but when excess in feeding is long eontinued, a variety of ills will sooner or later result, due to overloading of the alimentary canal and to the accumulation of waste matter in the tissues, leading to imperfect oxidation processes. The injurious effects of overeating lead, first, to abnormal fermentation in the alimentary tract with the resulting decomposition of starches, fats, sugars and proteins, leaving end products, particularly of protein digestion, which may be reabsorbed into the circulation, while the former may decompose or pass awa unaltered; but if the end products of protein digestion are aboorled into the blood, it is overwhelmed and the excretory organs overworked. 
Chronic overeating may lead to certain diseases or diatheses, such as obesity, gout, lithemia, oxaluria and the formation of renal, vesical and hepatic calculi. This habit may also produce congestion of the liver, leading to a condition known as "biliousness," in which the stomach and intestines are engorged, the tongue is heavily coated, the bodily secretions are altered in composition, the urine overloaded with urea compounds, the liver congested, and finally the nervous and muscular systems are depressed as a result of the imperfect digestion and absorption in the alimentary tract. This leads to fatigue, lassitude, drowsiness, to physical as well as mental depression. Overeating puts a severe tax upon the digestive system, at the same time exerts a great strain upon the glandular and excretory organs, the liver and kidneys. If the habit is long continued, intestinal auto-intoxication and intestinal stasis are inevitable, resulting in impaired mental and physical efficiency. An overfed boiler soon burns out, its flues become choked with ashes which accumulate faster than they can be removed. Overeating is the commonest dietetic error, especially with the well to do, and analyzing the question in its broadest aspects, we are quite certain that it lays the foundation for more diseases than overdrinking.

(c) IMPERFECTLY BALANCED DIET.-Food in itself may be wholesome, and at the same time it may be injurious to the system because the ingredients are not properly balanced. The diet may produce anemia from lack of meat or other animal or vegetable food sufficiently rich in iron. It may produce scurvy from preponderance of salt meat and fish and lack of fresh fruits and vegetables. Rickets and scrofula arise from errors of infant feeding, such as excess of starchy food and insufficient animal food, together with the necessary salts. Foods too rich in fats may produce acne or eczema. Constipation sometimes is due to food that is highly concentrated or too nutritious, and hence containing too little cellulose and water to stimulate peristalsis adequately. It is the belief of Gübler and other authorities that an exclusively vegetable diet eventually leads to the development of an atheromatous condition of the arteries, on account of the large proportion of mineral salts which thus enter the blood through vegetables; but this evidence is not convincing. It has also been claimed by some authorities that a strictly vegetable diet favors the deposition of mineral salts in different parts of the body as phosphatic stone, gravel and tartar on the teeth. It is almost impossible, however, to select a diet that does not allow, nltimately, the accumulation of calcium salts, especially the phosphate. A diet composed largely of coarse cereals leads to a roughening of the skin. 
There are many facts in nature which indicnte that man from his earliest prehistoric days has been omuivorous, adapting himself to his surroundings and enting, in his primitive condition, whatever his environment afforded and what he could obtain with least resistance and with least expenditure of labor-vegetables when in senson and animal food at other times. This is shown in the proctically unchanged dentition from prehistoric skulls, in the length of the alimentary canal and by the character of the digestive organs and secretions existing at present. A study of the dietetic hahits of the more primitive races of living mankind shows that no arguments can be drawn from them as to the advantages of any particular class of foods.

(d) Foons Contanixi Axima Parasites or Ova.-Quite a number of diseases are communicated to man by means of the parasites or their embryos taken into the stomach with food or drink. In many instances, the source of infection is found in the consumption of raw or imperfectly cooked swine-flesh, other meats used in the manufacture of sausages, and similar preparations which are earelessly handled and come in contact with the viscera of the animals in which parasites or embryos in some intermediate state of development reside. Another possible source of infection, especially by intestinal worm larve, is in the excrement of animals allowed to pollute raw vegetables growing upon the ground. Manure used for fertilizing purposes, spread around the roots of growing vegetables, and the feces of domestic animals infested with worms may contaminate vegetables growing low upon the ground and usually eaten raw, such as celery, cabbage, lettuce, ete. For this reason no domestic animal should be allowed to roam at large in a vegetable garden. We will not take up here the subject of these parasites and their effects upon the human system, as the student may find this subject well covered in text-books on bacteriology.

Varieties of Parasites.--The Ameba coli is a parasite whose life history is not definitely known, but it canses a form of chronic dysentery and is probably taken into the system through drinking water.

Coccidium oriforme probably gaius entrance into the șstem through drinking water, ingestion of green vegretables or from handling domestic pets. Its life history is also obseure. The spores have been found in the liver, pleura and other organs of man.

Trichomonas intestinalis is a small parasite at times found in the stools of man. ${ }^{1}$

1 This parasite has been describerl hy George Dock, Am. J. Med. Sc. vol. exi, p. 1,1896 . 
Distoma hepaticum, or liver fluke, frequently infests the gall-duct or the gall-bladder. The embryos are attached to aquatic plants and are said to be taken in with them or with drinking water. See Volume III, Chapter XIV.

Bitharzia hamatobium, or blood fluke, is found in the urine, and the embryos are probably taken into the body with drinking water, especially in southern Africa and Arabia. See Volume III, Chapter XIV.

The presence of intestinal worms, such as Ascaris lumbricoides, Tenia solium, and other species of cestodes, require no special dietetic care beyond the preventive treatment of avoiding raw or imperfectly cooked flesh and submitting the patient to a period of starvation for twenty-four hours, to completely empty the alimentary tract of food, before an anthelmintic is administered. There are two principal varieties of tapeworms found in man besides four or five others found in the intestines of the lower animals. See Volume III, Chapter XIV.

Tenia solium is a pork tapeworm and is a somewhat rare form. Tenia saginata is the beef tapeworm which is produced through eating raw or underdone beef. Consult Volume III, Chapter XIV.

Tenia cucumerina is a very small tapeworm found in the dog and its embryos occur in the dog louse.

Tenia mediocanellata is a segmented worm having a large square head and four suckers, by which it maintains its hold upon the intestinal mucosa without the aid of hooklets.

The Bothriocephalus latus is a tapeworm found in the north of Europe, but it is occasionally imported into the United States. The larvæ are found in fish.

The Tenia echinococcus is found in the intestines of dogs. Its infection in man occurs from handling dogs or from eating green vegetables, while the Ascaris lumbricoides is a round worm and a common parasite found in man and whose life history is unknown. See Volume III, Chapter XIV.

The Oxyuris vermicularis, or pin-worm, is found in children, from infancy up. It is a small parasite which is believed to enter the system with raw fruit or food, etc. See Volume III, Chapter XIV.

Ankylostomum duodenale is a parasite which has lately attracted some attention. Formerly it was little known in the United States. The embryos of this parasite are probably taken into the system with drinking water and also through the skin. It attacks the upper part of the intestinal tract and causes serere anemia. It is apt to be found in brick- 
makers, miners, dirt caters and hricklayers. The infertion is also called

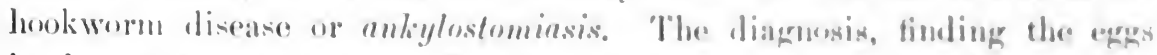
in the excrement, is easy. The treatment is spereitic, fasting for one day, then a salime purge, followed by thyomel. Siec also Volume 111, Chapter XIV.

Filaria sangminis hominis is a parasite found in various parts of the world, and is probahly taken into the system thromph impure water. It camses hematodyluria and produces elephantiasis. (Volume III, Chap. ter $\mathrm{NI} \mathrm{Y}^{r}$.)

Filarin, or Dracunculus medinensis, develops in the eyclops, a small crustacean. The larva are probably taken into the stonach through the medium of drinking water and produce inflammatory conditions of the skin leading to vesicles and ulcers.

Trichocephalus dispar is found in the recum of man, but doues non usually cause any injurious symptoms.

Rhabdonema intestinale, or diarrhen worm, is a small parasite native of Cochin China. It produces tropical diarrhea.

Trichiniasis is a disease cansed by eating the so-called mensly pork. or pork infected with Trichina spiralis. This parasite, one of the nematode worms, is only observed spirally coiled. Infection in mau is caused by the eating of ham and pork from hogs whose bodies contain the parasite. When taken into the intestinal canal, the envelope surrounding the embryo is dissolved and develops into a full-grown trichina in from three to six days. The female produces embryos by the thousands, which are found several weeks later in the voluntary muscles. In Germany, raw pork is eaten with greater frequency perhaps than in other countries. Trichiniasis, therefore, is commoner in that country than in the United States. A temperature of $140^{\circ} \mathrm{F}$. kills the parasite and the only sure way of preventing this disease is the thorough cooking of all pork, ham. or sausage made from swine flesh. The symptoms of this disease are noticed four or five days after eating raw pork or ham. The patient will suffer from severe abdominal eramps, with vomiting and diarrhea. General muscular prostration may also be present, which may or ma! not be followed by chills. In some cases the galstro-intestinal symptoms may not be of sufficient severity to attract attention. There will be severe pain in the invaded muscles, with an increase in temperature of an intermittent or remittent character. If the diaphragm is invaded or the muscles of respiration affected, there will he more or less dyspnea. If the parasites reach the face, jaw and pharrux. mastication and deglutition may be difficult or, later, impossible. There ma! also be noticed 
urticaria and more or less disturbance of the nervous system. Eosinophilia is quite characteristic.

(e) Foods Containing Ptomatys.-Foods containing ptomains are dangerous to life and health, both on account of the living microorganisms and other products. Various forms of food when decomposed, contaminated, or improperly prepared, may produce toxic symptoms. Ptomains and lenkomains are substances of a protein nature which resemble the powerful vegetable alkaloids in their composition and poisonous effects. They are formed in the alimentary canal by the decomposition or putrefaction of nitrogenous foods. Some of these poisonous products are found in animal matter which is undergoing decomposition, such as tyrotoxicon in old cheese and mytilotoxicon in shellfish under certain conditions. They have been found in pork, sausages, potted meat, ice-cream, mouldy bread, oysters, mussels, crabs, lobsters, mackerel, eels and conger eels. Ermenglin(1) says that the toxic ptomains found sometimes in preserved meat, ham, beans, etc., are due to a specific microorganism, the Bacillus botulinus, which secretes a soluble ptomain, called botulin; it is intensely poisonous, but is destroyed at a temperature of $60^{\circ}$ to $70^{\circ} \mathrm{C}$. The bacillus which produces it is destroyed at $85^{\circ} \mathrm{C}$, so that thorough cooking should prevent all danger from this source, provided there is no fresh infection after it is cooked.

The artificial cultivation of microörganisms, has proved that they are capable of forming substances which have distinct physiological actions that are sometimes highly poisonous. Brieger calls these poisonous ptomains, toxins. Many of these microörganisms flourish in beefjuice, milk and various solutions of nitrogenous foods. Conditions are most favorable for the growth and development of toxins in the alimentary canal. When these ptomain poisons are ingested, therefore, they are readily absorbed by the intestinal mucosa. It is probable that ptomain poisoning would occur much more frequently than it does were it not for the fact that the liver acts as a guard at the gateway for the admission of nutritive material for the body and is capable of destroying many poisons which enter into it from the intestines through the branches of the portal vein.

We have instances of the liver acting as a bodyguard to the system. A poisonous snake bite of the surface of the body might prove highly poisonous by immediate absorption of toxic material into the circulation, whereas the poisonous surface, if brought to the mouth and swallowed, causes no harm, for it is absorbed from the alimentary canal and is destroyed by the liver before reaching the nervous system. The same is 
true of putrefying meat, which, in small quantities, may not produce severe gastro-intestinal symptoms or constitutional disturfunues, and yot if inoculated through a cut in the finger mag canse symptoms of a violent septic infection.

The symptoms of ptomain prisoning mag develup in from fiftern to twenty mimutes, or may be delaved as mang hours after the monl. Sometimes the symptoms may be that of a simple urticuria, or there may bo formed large, round or oval swollings or whenls, having a whitish center, pink or red edges, and attended with intolerable itching. In other ennes, there may be simptome of sufforation, extreme muscular wosknesa, forble heat action, purging, cramps of the extremities and other choleric symptoms. Ptomains may be developed from a variety of foods, but the principal sources from which poisoning from time to time oredurs are ment, sausage, fish, mussels, cheese and milk. Crustaces, aml to a less degrees other foods, may develop similar symptoms, even if quite fresh and uncontaminated, due to idiosyncrasy which in turn is often, and according in some authorities, always, to be explained as an anaphylactic phenomena. Such cases may equal or exceed in severity those due to ptomains, but they are usually more prompt in their onset and of shorter duration.

Kreotoxismus.--Kreotoxismus, or meat poisoning, follows the ingestion of decomposed flesh. Diseased raw meats and those partially cooked have given rise to serious symptoms of poisoning. Fien thorough conking of such meats may not always make them safe for food. The flesh of animals that have died of any disease is unfit for human consumption, and the old Mosaic law, "Ye shall not eat anything that lieth of itself" (2). set forth in Deuteronomy, is a good hygienic rule. Ham poisoning sometimes occurs and other meats have been known to produce toxic symptoms. Among these may be mentioned beef, real, pork and fowl, pork pies, ribs of beef, goose-grease, in fact almost every kind and form of canned meats. The practice of placing undrawn prultro in cold storage should be forbidden, instead of required by law, especially if it is kept too long a period of time before removal from cold storage. Gartner"s bacillus, the Bacillus enteritides, is developed in cold storage meats and is thought to be the immediate cause of kreotoxismus.

Botulisurs.-Allantiasis, or sausage poisoning, is probahly due to the employment of improper methods of preparation. It has heen known for more than one hundred years and is now beoming less frequent, ans the causes which give rise to the disease are hecoming better known to sausage makers. Formerly, hood. although decomposed. was often used, and in other instances the sansage was not properly cured. the nutside 
being smoked and rendered harmless, while the center was soft and highly poisonous, due to the specific Bacillus botulinus. Such sausage, the outside of which was eaten while fresh, exhibited no ill effects, while those who partook of the center were made ill.

Von Faber, in 1821(3), "observed sixteen persons who were made sick by eating fresh unsmoked sausage made from the flesh of a pig which had suffered from an abscess on its neck. Five of the patients died. The symptoms were as follows: There were constriction of the throat and difficulty in swallowing, retching, vomiting, colic-like pains, vertigo, hoarseness, dimness of vision and headache. Later on, in severe cases, there was complete exhaustion, and finally paralysis. The eyeballs were retracted; the pupils, which did not respond to light, were sometimes dilated and then contracted, and the upper lids were paralyzed. The tonsils were swollen, but not as in tonsillitis. Liquids which were not irritating could be carried as far as the esophagus, when they were rejected from the mouth and nose with coughing. Solid food could not be swallowed. On the back of the tongue and in the pharynx there was observed a puriform exudate. Obstinate constipation existed in all, while the sphincter ani was paralyzed. Breathing was easy, but all had a croupous cough. The skin was dry and there was incontinence of urine. There was no delirium, the mind remaining clear to the last."

Ichтнутотіsmus.-Ichthyotoxismus, or fish poisoning, may occur under various conditions: (a) certain tish are known to be unfit for food, while others, edible at ordinary times, are poisonous during the spawning season; $(b)$ diseased or decomposed fish, which in its normal condition and when fresh, is edible, when diseased or decomposed may produce toxic symptoms; $(c)$ spoiled canned fish and shellfish are the most frequent causes of fish poisoning; $(d)$ some fish may be infected with bacterial diseases which may cause diseases in man; $(e)$ like other nitrogenous food, fish may be infected with bacteria producing toxins.

Kobert, according to Novy and Vaughan, makes the following classification of poisonous fish:

(a) Fish which are supplied with poison glands connected with barbed fins, with which they wound their enemies, like the poison of snakes. These cause prostration, convulsions, and death in man.

(b) The genus tetrodon, a Japanese fish which has poisonous ovaries. They are less poisonous in winter, when the ovaries are inactive. Kakke, a disease of Japan and other Eastern countries, is believed to be due to the eating of certain varieties of the Scombridce family.

(e) Certain other fish whose flesh and glands are harmless may be dangerous on account of the decomposing substances of corals, etc., on which they feed. 
(d) Poisoning due to ptomains, of which drrep has isolated two. These aro

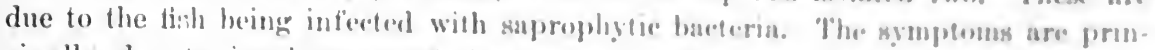
cipally due to involvement of the gastro-intestunal tmot and servous syotemnausea, vomiting, diarrhea, prostration, rashes, ete.

Mrthotoxisans- Mytilotoxismus, or poisonimg from musels or other shelltish, usually results from infection with ptomains developed by microörganisms. The idiosverasy of many prosoms to shellfish poi. soning is well known. 'To such persons the eating of elan broth or raw oysters, erabs or lobsters, may grive rise to violent outbreaks of urticarin or eczema, or the production of headache, mansea, vomiting and purging.

Aceording to Vaughan and Nory, there are three kinds of shellish poisoning:

(a) Where the principal symptoms are gastro-intestinal, and of varying intensity. This form may at times be choleriform (Combe). Death may follow very rapidly-in Coombe's ease it oceurred in two days.

(b) The most frequent form is that in which simptoms are principally norvous, coming on shortly after the mussels are eaten. There is a sensation of heat and itehing; a rash of an urticarial, and sometimes of a vesioular nature, appears. There may be dyspnea and death may result from convulsive tremors or coma. Death has followed from this form in three days.

(c) In the third form the symptoms are those of an intoxication rescmbling alcoholism followed by paralysis and death. Coombe, in 18:7, reported death as early as three hours after eating the mussels and others six or seven hours and still others after longer intervals.

The poison in shellfish is found chiefly in the liver of the bivalve and it is not known whether a certain species is always toxic or whether ordinary mussels become poisonous under special circumstances.

It is a well-known fact, however, that shellfish "tonged" from filthy water are apt to be poisonous. Ovister beds near the outlet of a city" sewer are dangerous for food. Many cases of poisoning have been reported from the eating of oysters taken from the near vicinity uf the outlet of a drain from a public water-eloset. Shellfish that are fresh, that have been taken from clean water and that have been wished with clean water, are generally safe. Trphoid fever has been transmitted through oysters that have imbibed the bacilli from sewage.

Trrotoxismes.-Tyrotoxismus, or cheese poisoning, may result from the ingestion of cheese which apparently presonts no suspicions aspert and which to all appearances is entirely wholesume. Some anthoritics believe that the ill effects resulting from the ingestion of certain cheeses are due to fatty acids. Numerous cases of chese proisning have hern discussed and reported. In 1883 and 1sst the Michigan State Board 
of Health reported some three hundred cases of cheese poisoning. Persons who ate the cheese were attacked and the symptoms varying with the quantity ingested, beginning with vomiting, purging and with watery stools; the tongue, at first white, later red, dry and parched. The patients complained of pain in the region of the stomach. The circulation was feeble, heart's action irregular, and in some cases there was marked cyanosis. Vaughan studied these cases, and as a result claimed that the poisoning was due to twelve different varieties of cheese, most of which came from one factory. The cheese differed but little from ordinary good cheese; but a test with domestic pets proved that dogs and cats would accept the good cheese and reject this particular bad cheese. The poison was isolated as a crystallized, highly toxic substance, which Vaughan called tyrotoxicon. This special ptomain induces vertigo, nausea, vomiting, rigors, chills, severe epigastric pain and marked prostration.

Galactotoxismus.-Galactotoxismus, or milk poisoning, may follow the ingestion of decomposed milk. Newton and Wallace report an interesting series of cases of milk poisoning due to the presence of tyrotoxicon in milk. The milk under observation came from a dairy where the milking was done at noon and at night. It was found that the noon milk was the one that was poisonous. The milk, immediately on being drawn, was placed in cans and promptly delivered to customers in the middle of the day. The heat permitted the growth of bacteria with the formation of toxin. There have been numerous recorded instances where this toxin in milk has produced poisoning. Vaughan and Novy have demonstrated its presence in ice cream and custard. The summer diarrheas of children are doubtless largely due to this form of poisoning.

There is no question but that many diarrheal diseases are caused by milk. This subject is one of great importance, since, during the warm months, 97 per cent of all the cases that occur in children are bottle-fed babies. Only milk, therefore, which is known to be pure and produced under the most watchful and careful observation in its transmission from the cow to the consumer should be allowed the infant as a food. The milk is a sterile fluid when leaving the cow, but if carelessly handled, many cases of diarrhea and death are the result. It is not absolutely known just what bacteria give rise to summer diarrhea. Recent investigators point out the Bacillus dysentericus as an organ most commonly present.

Foot and Mouth Disease(4).-Aphthous fever, epidemic stomatitis, is an infectious disease of animals, most frequently seen in cattle, sheep 
and pigs, and larely observed in dugs, catt and fowls. It is characterized by the presence of vesicles and ukers 11 pun the bucenl mucous membrane, in the clefts abont the feet and upon tho udders. It may ocour in epidemies, when it spreads with great rapidity. The disense was studied as early as 1834 , when three German worinary surgeons drank the milk from infected cows and developed the lisense. Infants and children have contracted the disease by drinking mutanninated milk. The disense can also be transmitted through eating nherse or butter made from the milk of infected cattle, as well as throngh contanct with the contents of the vesicles in the mouths or upon the trits of the disensed animals. Meat from such animals does not appenr to hre infections. No micrö̈rganism has yet been demonstrated to be respmusible for this disease, and while it may be of microbic origin, the speritic canse is probably too small to be visible through the microscope. Animals may be immunized by a vaccine elaborated by Loeftler. The milk from a cow suffering from this dicease is yellowish in color, of a namsens, bitter taste. The contagious principle is destroyed by heat, but the tlesh, milk and milk products of animals with foot-and-mouth disease shmuld not be used for food. Infants may be infected from diseased cows and a connection has been suggested between the aphthous stomatitis of children and foot-and-mouth diseases in cattle.

(f) Foods containixg other poisons-Grain Poisonisg.-It sometimes happens that flesh becomes poisonous from the animal having fed upon some noxious substance previous to being slaughtered; for instance, pigs fed upon garbage may have their tlesh so infected as to canse diarrhea. It is a well-known fact, mentioned in Volume I, Chapter XII, when discussing animal foods, that the flavor and digestibility of game, and even fish, varies much with the season of the year and the consequent nature of the food upon which the animal has been fed.

It is a prevalent notion that oysters are not wholesome food from May 1 until September 1, or in the months which are spelled without the letter "R." This is to a certain degree correct on account of the greater tendency to decomposition in warm weather. It may apply even to the oyster before it is taken from the water. Danger of infection of typhoid would obviously extend well into the winter. In the chapter on "Milk" we mentioned the fact that cow's milk is unwholesome for infant's food when the cow is allowed pasturage in which certain herbs and weeds grow and which if ingested by the cow will entaminate the milk. There are only a few instances of serion illness of alults camsed by eating meat which became poisoned thromgh the animals having eaten noxious 
foods before being slaughtered. There is a case on record in which a large dose of tartar emetic was administered to an ox. The animal died and the meat subsequently was found to contain enough of the substance to poison severely those who ate it.

In Volume I, Chapter XII, "Animal Foods," we pointed out that the reason game sometimes disagrees is on account of the nature of the food upon which the animal has been feeding. This is particularly true of grouse and pheasants in various parts of the country at certain seasons of the year. The laurel buds act as a toxic poison which penetrates the flesh of fowl. Likewise, hares that feed upon the rhododendron are poisonous. Thompson, in his valuable work on "Practical Dietetics," records a curious case of poisoning which occurred in a young ladies' boarding school at Amherst, Mass. In this case the fowl was a roast turkey and the young ladies who partook of the flesh of this fowl showed symptoms of atropin poisoning. It was afterwards ascertained that this bird had been fed largely upon deadly nightshade berries.

Grain poisoning occurs principally from old, overripe grain and mouldy flours which develop poisons from the decomposition of their gluten. The old authors usually refer to three forms of grain poisoning: (a) ergotism; (b) pellagra, and (c) lathyrism. These diseases are found almost exclusively among the squalid and destitute. The effects are principally due to insufficient nourishment combined with the specific poison from the grain. The well to do and properly nourished are practically insusceptible to this disease.

Sitotoxismus.-Sitotoxismus, or ergotism, is produced by a fungus known as Claviceps purpurea which grows upon rye. The history of this disease is interesting. The malady described in the twelfth century as "St. Anthony's fire," 1 was at a later date diagnosed as grain poisoning. It is not the author's intention to take time to describe here the horrible epidemics of grain poisoning which occurred in the middle ages. Within recent years epidemics have occurred in Russia. The symptoms of ergotism may be briefly divided into two groups, one of the gangrenous and the other the convulsive type. In the gangrenous form of ergotism the early symptoms are principally those of vasomotor disturbances, affecting principally the extremities. There will be marked anesthesia, numbness, prickling pain and spasmodic twitching of the muscles, with restricted circulation. In the convulsive variety, the nervous system is profoundly disturbed, with symptoms of lassitude, headache, spasms of the muscles which may be tetanic in character, lasting sometimes through

1 Usually taken to mean erysipelas. 
many days. 'This spasmodic rigidity of the muscles may give place to violent eonvulsions which may become general and fatal. Menul disturbances and symptoms of cord imolvement may supervene. The disease should be differemiated foum ery/hromelalgin, liaynaud's disease, or acrodynia, whose symptoms it simulates. Bottger has given a simple test to detect ergotism in flour. A small quantity of flour is mixed with ether and a few crystals of oxalic acil are adted. The mixture is then boiled and allowed to settle. When clear, if ergot is present, a red tinge will be imparted to the fluid.

Luprososs-Lupinosis, or lathyrism, is a poisoning due to chick. pea vetch, which is sometimes used for the adulteration of the flour of various cereals. Poisoning ocenrs from the menl ground from this chick-pea. The disease was noted first in the seventeenth century, when, during the wheat famine at Allahabad, the inhabitants used this chickpea veteh for food and an epidemic followed. It was observed bo bames Irving. Lupinosis is a rare disease and little is known of its exact nature. The poison seems to affect the extremities, producing stiffness of the joints simulating spastic paraplegia.

Pellagra.-Pollagra, Mayidismus, is a disease of the highest im. portance. It is endemicepidemic in its nature and for nearly two hundred years has been a problem of paramount importance to physicians and publicists in southern Europe. Important legislation has heen enacted, and large expenditures of both money and talent of the highest order have been devoted to the solution of the problem which has proved the greatest menace to public health. This disease has prevailed so extensively where corn is an article of diet that it has been aseribed to a fungus growth upon mouldy corn. But the area of corn consumption is now known to be wider than that of pellagra, and pellagra is found where corn is not an ordinary article of diet. Recent researches, while they have added many facts to our previous knowledge of the disease, have left its exact etiology and nature still mestelerl. The l'nited states was thought to be free from this disease, but within the last ten years it has been reported from all sections, from Maine to Florida and from Virginia to California.

Recent investigations have been made into the etiology and pathologv of pellagra by E. M. Purdue(5). who claims that pellagra is a chronic intoxication cansed br colloidal siliea in drinking water. He asserts that the disease is strictly localized and contrated in zones where the water commonly drunk by the people is in entact with an arevillacenus terrain. According to his theory, pellagra is not dependent upou corn alimenta- 
tion and is not caused by infestation with filariæ. He maintains that it is not a parasitic disease, not transmitted by the "buffalo gnat" nor by stomoxys calcitrans. Purdue's views have not been corroborated by scientific research and are giren herewith to show the views of one who has had a large experience with pellagrins.

From a careful study of the latest literature on the subject, it seems that in conditions where sodium salts are constantly ingested, pellagra is rare, unless the amount ingested is overbalanced by the amount excreted. It appears that this may occur under vegetable diet, in starvation, disease and so on. It also appears that a lack of sodium salts eventually interferes with the excretion of purins, allowing them to accumulate in the blood and to cause irritations similar to those seen in pellagra. Diminution of the sodium salts, we know, reduces the alkalinity of the blood to perhaps the point of acidity, in the excretions at least, and this interferes with the activity of the oxidases in their protective function against invading organisms. The general opinion in Europe is that pellagra advanced with the extensive cultivation of corn and the more general adoption of this new cereal as an article of food. Stelwagon, in his work on skin diseases, says the majority of persons who contract pellagra have lived for years mainly on a vegetable diet.

All pellagrins are vegetarians almost entirely or in greater part. There exist in the carbohydrate foodstuffs toxic substances, or lack of vital substances, which when the foodstuffs (themselves not necessarily spoiled) are consumed over a more or less long period of time produce injurious effects upon the organs of the body. All physicians of large experience in the treatment of pellagra are agreed that the milder cases improve if kept in a hospital at rest and upon a fairly liberal diet, with plenty of fresh meat, fresh vegetables, milk, etc.

The Thompson-McFaddin Pellagra Commission has worked in Spartanburg County, S. C., where practically all pellagrins are cotton-mill hands and conditions are not comparable to other countries where the disease is just as prevalent. Yet they came to these conclusions: $(a)$ the simulium is discredited; $(b)$ animal inoculation and experimental study of intestinal bacteria have not yielded conclusive results; $(c)$ no evidence of inheritance is obtainable; $(d)$ the immediate results of hygienic and dietetic treatment in adults have been good, but after returning to former conditions of environment and living, most of these cases have recurred. The prognosis in children is very much more favorable; $(e)$ occupation has no influence.

Fischer(6), Abderhalden(7), Mendel(8) and Osborne(9) have shown 
the great rariation in composition of profeins in regard to content of various amino acids. ('ertain proteins lanek, or are deficiont in, ecertain amino aeds necessary for growth and maintonace. Oll proteins derived from animal sourees, with the exception of grolutins, seem to he suitubles for human eonsumption, as they contain all the uecessary components in right proportion. Some of the regetable proteins are deficient in this respect, notably the protein of corn, hut as ret it has not been sufficiently proved that corn per se is the offonding or cansative agent.

Funk points out that vitamines are essential for the mantenance of the health. Animal foods and vegetables contain these in varying amounts; meats are especially rich; polished rice is devoid of them. Funk argnes that pellagra is a disease due to the lack of vitamines in the food, analogous to the production of beriberi through the large consumption of polished rice.

By permission of the governor, an experiment was carried ont at the farm of the Mississippi State Penitentiary by Surgeon Joseph Goldberger and Assistant Surgeon G. A. Wheeler. ${ }^{1}$ This experiment was undertaken for the purpose and possibility of producing pellagra in healthy human white adult males by a restricted, one-sided, mainly carbohydrate (cereal) diet. Governor Earl Brewer offered to pardon all the convicts who would volunteer for the experiment. They were assured that they would receive proper care throughout the experiment, should it be necessary. Of the eleven conviets who volunteered for this experiment, six developed a tỵpical dermatitis and mild gastro-intestinal symptoms. The diet given was bountiful and more than sufficient to sustain life. It differed from that given the other convicts merely in the absence of meats, milk, eggs, beans, peas and similar proteid foods. In every other particular the convicts selected for the experiment were treated exactly as were the remaining convicts. They had the same routine work and discipline, the same periods of recreation and the same water to drink. Their quarters were better than those of the other convicts. The diet given them consisted of biscuits, fried mush, grits and brown gravy, sirup, corn bread, cabbage, sweet potatoes, rice, collards and coffee with sugar. This is the usual ration of the poorer classes of the South. All components of the dietary were of the best quality and were properly cooked. As a preliminary, and to determine if the conviets were afflicted with any other disease, they were kept under observation from February 4 to April 9, 1915, two and a half months, on which date the onesided diet was begun.

1 Of the United States Public Hygienic Laboratory. 
Although the occurrence of nervous symptoms and gastro-intestinal disturbances was noted early, it was not until September 12, or about five months after the beginning of the restricted diet, that the skin symptoms so characteristic of pellagra began to develop. These symptoms are considered typical, every precaution being taken to make sure that they were not caused by any other disease. The convicts upon whom the experiment was being made, as well as twenty other convicts who were selected as controls, were kept under continuous medical surveillance. No cases of pellagra developed in camp excepting among those men who were on the restricted diet. In this experiment Drs. Goldberger and Wheeler were able to produce pellagra in six of the prisoners, who were promptly pardoned and afterward restored to health by a liberal diet of fresh animal and leguminous foods, poultry, eggs and milk. The experimenters have therefore drawn the conclusion that pellagra has been caused in at least six of the eleven volunteers as a result of the one-sided diet on which they subsisted.

This announcement by an officer of the Public Health Service(10) offers the first insight as to the cause and cure of pellagra, which has been increasing alarmingly throughout the United States during the past eight years. It is conservatively estimated that 75,000 cases of this disease occurred in the United States during 1915, of which number at least 7,500 died.

We are of the opinion that pellagra is a deficiency disease due in part, if not largely, to the present methods of milling corn. In the olden days the corn was ground on the old-fashioned buhr millstone and very little of the outer husk was removed, but in the present modern methods of milling, the meal is ground fine and passed through a very fine bolting cloth which practically removes all of the pericarp of the grain. Like polished rice, the corn is devitalized; all the vitamines of the grain of corn are removed in the milling. We are of the firm opinion that this plays an important rôle in the causation of pellagra. We will leave the disease as one due to deficiency of vitamines in the foodstuffs.

As a rule, pellagra is chronic, beginning in the spring and subsiding in the summer, but returning with greater severity the following spring. It runs on year after year until the patient succumbs. In adults the symptoms begin with headache, dizziness, ringing in the ears, a burning sensation of the skin, especially in the hands and feet, followed by diarrhea; at the same time a red rash appears on the skin, resembling erysipelas, the red spots being tense and painful, especially when exposed 
to the sun. When the spots disuppenr at the close of sumuer, the skin remains rongh and dry. The tomgue will present a red and dry appear. ance. A burning feeling in the month is complainod of, and more or less pain on swallowing. Soon the nervons system shows signs of involvement, first by ptosis of the eyolids and dilatution of the pupil, and, later, pigmentary changes are observed in the skin, resembling those of Addison's disease.

Actramronsis. - Actinomyeosis is a rare disease due to an infection, not by bacterium, but by a fungus called streplothrior actinomyces. The disease is eomparatively rare in Ameriob. No evidence exists to prove that it has been transmitted through artinles of diet, but eases are recorded where the infection has been traneend in barley sheaths. Prof. IV. H. Thompson(11) reports the case of a firmer who maintained to his physician that the disease in his case was caused from inhalation of musty dust while he was wimnowing oats in his barn. The early symptoms of many cases begin in the lungs and may infect the whole system, including, according to some reports, even the brain. Abscesses may oceur in bone, while others invade such organs as the liver and spleen. When, as is often the case, the mycelimm first lerelops in the month, it may attack the jaw, forming a tumor closely resembling a sarcoma.

Beriberi.-Beriberi, or kakke, is a curious disease which is both epidemic and endemic on the eastern coast of the Asiatic continent. It also prevails among the Chinese in ('alifornia. According to Manson, up to 1883 , "over one-fourth of the entire number of Japanese sailors were affected with this disease. In 1583 there were 236 cases among 5,349 men. The following year a more liberal allowance of nitrogenous food was added to the diet and the following year only 41 cases were reported. In the year 1887 the disease had been completely driven out of the Japanese Navy." It has been firmly established that beriberi is largely confined to countries whose chief food is rice. It is not beyond the possibility, though, that if white hread were used in America to the extent that the Japanese use rice, beriheri would appear in this country. The reduction of beriberi in the Japanese Navy by the addition of meat to the dietary was followed by the discovery that the disease is restricted to people using polished rice as the principal constituent of their diet. The main symptoms of the disease are emaciation, with widespread edema, paralysis, muscular atrophies and contractures of the extremities; sometimes there is a cardiac breakdown. All stages of degeneration are found in the peripheral nerves.

Following the discoveries that beriberi is largely caused by eating pol- 
ished rice, investigators made some experiments by feeding fowls on polished rice exclusively. A fowl fed on this diet shows anorexia and great loss of weight, as much as 45 per cent. After one to six weeks, acute symptoms come on, consisting chiefly of paralysis of the legs and wings. None of these results follow where fowls are fed on unpolished rice as the sole food.

Eykmann, in an exhaustive research on beriberi, has been able to show that the addition of rice polishings (pericarp or rice paste) to the polished rice prevented the appearance of the disease. Finally, a curative substance not a protein, or a carbohydrate, or a fat, or an inorganic salt, was extracted from the rice polishings. Grijns, later, showed that similar curative substances were obtainable from beans, meat and yeast. Finally, Casimir Funk extracted from rice polishings a crystalline curative substance which he calls vitamine. This remarkable substance exists in exceedingly minute quantity and may act like enzymes, catalytically changing a large amount of food. Vitamines are found in the outer layers of grains, but not in the starchy center, thus accounting for beriberi after the use of polished rice and for pellagra in those whose diet is composed largely of finely milled grain meal. These vitamines seem to be destroyed in many corned, picked or dried foods, thus accounting for scurvy. Recent researches have demonstrated the fact that they exist largely in all of the natural foods-milk, eggs, meat—and to a less extent in yeast, fresh fruits and uncooked vegetables, particularly potatoes, whose juice is so effective in scurvy. This subject opens up a new field. Undoubtedly the question of the causation and prevention of beriberi will be settled beyond doubt in the very near future. The reader may be referred to Volume II, Chapter VII, for further information on the subject of vitamines, and also to Volume III, Chapter XVII.

Avitaminoses.-Avitaminoses, according to H. Stassano(12), are diseases resulting from a deficiency of vitamines in the diet. The vitamines are complex crystalline substances belonging to a chemical group hitherto unknown. The nitrogen is not combined in the amin radicle and can be extracted only in part by the Kjeldahl method. The characteristic syndromes of the avitaminoses are classified as follows: $(a)$ the syndrome of degeneration of nerves with paralyses and contractures; (b) the cardiac syndrome with dilatation of the right heart, accompanied by dyspnea, cyanosis and oliguria, and (c) the syndrome of anasarca, hydropericardium, hydrothorax and ascites; all of these three syndromes belong to the group of cases properly called beriberi; $(d)$ the classical syndrome of scorbutus, and $(e)$ the syndrome of pellagra. In all of the 
above conlitions the following articles of dict which are rich in vitanines have been found to be of eurative as woll as of prophylactic value: human milk, fresh cow's milk, butter, cheese, yolk of egg, beef juice, fresh tomatoes, fresh logmmes and sonps containing them, fresh fruits or their juices, the sance of stewed fruits, whole corn of wheat bread, unpolished rice, slightly roasted beef, fresh yeast, extracts and preparations of yeast and cod liver vil.

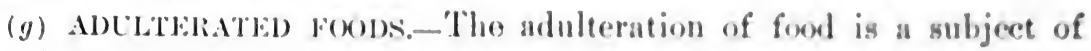
great importance and covers such a wide seope that it can be only cursorily mentioned(1:3) (see Biblingraphy at end of this (hapter). The subject is one of such great importance to the community at large that the Federal Govermment, on .June 30, 1906i, enacted legal restrictions to insure the proper inspection, regulation and sale of foodstuffs. The Federal Food and Drugs Act, usually referred to as "The Pure Food Law," and on which subsequent legislation by most of the states has been largely based, defines the main types of adulteration. Aceording to this law, a food is deemed adulterated:

(a) If any substance has been mixed or packed with it so as to reduce or lower or injuriously affect its quality or strength.

(b) If any substance has been substituted, wholly or in part.

(c) If any valuable constituent has heen wholly or in part abstraeted.

(d) If it be mixed, colored, coated, powdered, or stained in a manner whereby damage or inferiority is concealed.

(e) If it contain any added poisonous or other added deleterious ingredient which may render it injurious to health.

(f) If it consists in whole or in part of a filthy, decomposed, or putrid animal or vegetable substance, or any portion of an animal unfit for food, or if it be the product of a diseased animal or one that has died otherwise than by slaughter.

This law also deems a food to be misbranded: ${ }^{1}$

(a) If it be an imitation of or offered for sale under the distinctive name of another article.

(b) If it be labeled or branded so as to deceive or mislead the purchaser, or purport to be a foreign product when not so, or if the contents slall have been substituted in whole or in part, or if it fail to bear a statement on the label of the quantity or proportion of any narcotic or habit-forming drug which it contains.

(c) If, when sold in package form it fails to hear a corzect statement of weight, measure, or numerical count of its contents: provision being made for reasonable variations and for certain exemptions.

1 sce Food and J)rugs Act, June 30, 1906, as amenderl dugust 23,1812 , for fuller 
(d) If the package containing it or its label shall bear any statement, design, or device which is false or misleading in any particular.

Adulterants.-Among the common food adulterations may be mentioned the following: isinglass adulterated with gelatin; powdered sugar with barium sulphate; mustard with flour and turmeric; distilled colored vinegar sold as cider vinegar; pickles adulterated with iron and copper; oleomargarin sold as butter; ground spices adulterated with cocoanut shells, rice, flour and ashes; water, sugar and tartaric acid sold as lemonade.

Alcoholic beverages are sometimes adulterated with alum, baryta, caustic lime, salts of lead, salicylic acid and various pigments. Wood or methyl alcohol is sometimes substituted for grain or ethyl alcohol. Wood alcohol is a very dangerous adulterant. Blindness and even death have followed its use. A large quantity of ethyl alcohol may be taken day after day without causing death, whereas repeated large doses of methyl alcohol will speedily cause death. Adulterated alcoholic liquors contain fusel oil, tannin, logwood, water, coloring matter and burnt sugar. Various grades of cheap whiskey and brandy are manufactured by unscrupulous rectifiers by mixing alcohol, coloring matter and flavoring extracts. An imitation of gin is frequently made from cheap spirits, turpentine, sugar and water.

The Adulteration of Malt Liquors.-Adulterated beer may contain burnt sugar, licorice, molasses, quassia, coriander and caraway seed, cavenne pepper, soda, salicylic acid, salt, carbonic acid, artificially introduced grains other than barley, glycerin, glucose, tobacco and Cocculus indicus. Crampton detected the presence of salicylic acid in more than 30 per cent of the samples of bottled beer which were brought to him for examination. He did not, however, find salicylic acid in draft beer. Sulphurous acid is one of the oldest preservatives. Its use is forbidden in both France and Germany, where the use of borax is likewise forbidden. In this country, borax and sodium bicarbonate are used in beer to correct acidity caused by careless and improper brewing, as well as to increase the carbonic acid content. Many of the so-called liquid malt extracts are nothing more or less than beers, since they have very little or no diastasic action and possess no special food value, nor do they offer any aid in the digestive processes. Some of this class of malt liquors are adulterated and harmful.

Tine Adulteration of Wine.-Wine is sophisticated by the addition of various substances, usually added as preservatives. Chief among these 
preservatives is salicylic acid. Its use is forbidden in France and Germany. Wine is also adulterated by adding sugar, gummy substances, coloring matters, salicylic acid and mineral acids as preservatives. In the wine-growing districts of France wine is frequently "plustered" by the addition of calcium sulphatc. As pointed out by Crampton, "the sulphuric acid of the lime salts replaces the tartaric acid which is combined with potash and forms an acid sulphate of potash, while the tartaric acid separates out as a tartrate of lime."

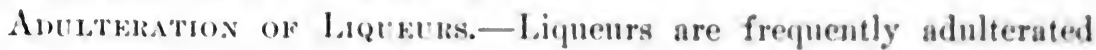
and imitated, so that many of them contain injurions coloring matter. Maraschino and crême de menthe are often colored with anilin dyes and sometimes contain a large amount of coloring matter.

Anvlatiation of Beverages.-The provisions of the present Pure Food Law are so drastic that leas imported into the United States at presert are practically free from adulteration. Tea is usually adulterated by mixing exhausted or foreign leaves with the tea leaves. "Facing" consists in treating the tea leaves with plumbago, indigo, or Prussian blue, the object being to make an inferior tea resemble a better product. The adulteration, while not very injurious, is easily detected (see Tea, page 540 ).

Green and roasted coffee may be imitated. An inferior grade of coffee is frequently branded and sold as a better article. Roasted coffec may be adulterated with earamel, chicory, pea meal, ete. Even coffer berries are artificially made in moulds out of mixtures of starch, molasses, or caramel, chicory, etc. (see Coffee, page 545).

Cocoa is frequently adulterated by the addition of starch, sugar, brick dust, coloring matter and flavoring materials. The cocoa butter may be extracted and tallow or other fats substituted.

Adulteration of Foonsturfs.-Bread, fortunately, is a food product which eannot be very easily adulterated without detection, but the use of inferior flour in breadmaking is well known.

Butter may be adulterated with oleomargarin, lard, cotton-seed oil, beef tallow and olive oil. Butter and oleomargarin have about the same composition and both possess about equal food value. 'The flavor of genuine butter, however, is not to be compared with its substitute. Lard is frequently adulterated with cotton-seed oil and water, but the adulterants are usually harmless.

Olive oil is frequently adulterated with cotton-seed oil; in fact, the latter is often sold as olive oil. Most of the maple syrup sold is made from glucose. Maple syrup is also derived from other sugars artificialiy 
flavored with extracts of hickory bark. Nearly half of the strained honey sold is adulterated with glucose. Genuine comb honey cannot be adulterated, since it cannot be made other than by the honey bee (see Honey, page 628$)$.

Baking powders are adulterated with alum in place of cream of tartar. Canning of Foods.-Canned meat is now put up in large quantities. In many of the large packing houses, often all the meat of the fore quarter and the cheaper cuts of the hind quarter are canned. There is a tendency to use the leaner carcasses for canning, both because the fat beef can be sold at better prices in the fresh state and because the leaner meats are more attractive than the fat meats when canned.

Canning of vegetables is an important and extensive industry in this country. The principle depends on the sterilization of the product by heat and then protecting it in hermetically sealed vessels from coming in contact with the germ-laden atmosphere.

Chemical preservatives are not generally used in the canning of fruits, although they are used in the canning of vegetables. Copper and zinc are used extensively to add color to green peas. Lead, tin and zinc may be present as a result of unintentional contamination. Lead may gain entrance from the solder, which is frequently used in large quantities. Preservatives, such as sulphurous acid, salicylic acid, boric acid, etc., are frequently added to canned foods. Canned products of the United States in 1909 were valued at $\$ 157,101,000$.

Adulteration of jams, jellies and preserves is a subject which should be mentioned at this point. These food products are sometimes adulterated by supplying the deficiency in pectose bodies by the addition of some foreign substance to gelatinize and thus improve the appearance of the product. Agar-agar, gelatin, turnip, vegetable marrow, boiled sago, and similar substances have been used. The use of apple pulp or gooseberry pulp, both of which are rich in pectin, is not so serious an adulteration as the replacement of one fruit juice by another. Another adulteration is the addition of coloring matter, very often an anilin color, to correct any lack of genuine ripe fruit color.

Preservatives.-Preservatives in many countries are forbidden by law. Borax and boric acid are the most frequent combination. These substances, together with sulphurous acid, sulphites and sulphates, salicylic acid, benzoic acid and formaldehyde, are most frequently employed.

It may be safely stated that the addition of any chemical preservative to food is not only undesirable, but more or less injurious. Borax and 
boric acid may, however, find their proper use in preserving ments, such as hams. 'lime and experience has prosed that ineat sprinkled with borax and boric acid does not beconu slimy. The German Government has expressly forbidden the use of smith chemicals on meats. IViley (14) concludes, as a result of his experiments, that boric acid and borax should not be used for this purpose, except whre preservation is a necessity, and that articles containing boric acid w" horax slould be so labelled. "It appears, therefore, that boric acid and horax, when continuously administered in small doses for a long priml, or when given in large doses for a short period, cause disturbances of ilpetite, of digestion and of health."

Harrington(15), in discussing the ill effects of horic acid on the human economy, states that in his opinion luric acid may be the direct eause of subacute and chronic nephritis; therefore it would appear that iadividuals suffering from 13right's disease womld he taking chances in eating fruits preserved with borax or boric acid.

Salicylic acid is widely used as a food preservative, especially in beer, malt extracts, preserved fruit and the like. Its action inhibits digestion and exerts an irritating action num the kidneys and bladder. Food preserved with salicylic acid is highly injurious in cases of Bright's disease.

Formaldelyyd is used to some extent for the preservation of milk. In general, its action as a preservative is both undesirable and dangerous.

Sulphurous acid is used to some extent for preserving wines. It has been used for preserving color in dried fruits.

Sulphite and bisulphate of sodimu are used for preserving all sorts of foods. The latter is largely used for preserving the color of meats, but their use is regarded as more ar less dangerous.

Both tin and lead poisoning may oceur from the prolonged use of preserved meats, vegetables or fruits. These foods are usually preserved in tin cans. The lead derived from the can by the various organie acids upon the solder (which in this comutry is 50 per cent lead) and the tin used for the inside of the can are eventually dissolved by the organic acids in the food.

Copper is frequently added for the purpose of coloring the vegetable or it may gain cntrance to the fonds from the use of copper or brass kettles.

Nickel is used in camning green peas to augment their color, and it may be found in food cooked in nickel ressels. In the latter event the amount is small and may practically he disregarded.

Zinc is found at times in ford, especially in dried apples, particu- 
larly when the same are evaporated on galvanized iron racks. Zinc may also enter the food from certain kinds of solder.

Arsenic may be introduced in the food in various ways. It is found more particularly in malt liquors, such as beer, malt extracts, syrups and foods containing glucose and vinegar.

The following table, compiled by Professor Sharpless(16), gives the articles of food likely to be adulterated, and shows the deleterious, fraudulent and accidental adulterants:

\section{FOODS AND THEIR ADULTERANTS}

\begin{tabular}{|c|c|c|c|}
\hline Articles & $\begin{array}{l}\text { Deleterious } \\
\text { Adulterants }\end{array}$ & $\begin{array}{l}\text { Fraudulent } \\
\text { Adulterants }\end{array}$ & $\begin{array}{l}\text { Accidental } \\
\text { Adulterants }\end{array}$ \\
\hline Arrow-root & & $\begin{array}{l}\text { Other starches which are sub- } \\
\text { stituted in whole or in part } \\
\text { for the genuine article } \\
\text { Water, burnt Sugar }\end{array}$ & \\
\hline Bread. & Sulphate of Alum. & $\begin{array}{l}\text { Flours, other than Wheat, in- } \\
\text { ferior Flour, Potatoes }\end{array}$ & $\begin{array}{l}\text { Ashes from oven, } \\
\text { grit from mill- } \\
\text { stones }\end{array}$ \\
\hline Butter. & & $\begin{array}{l}\text { Water, other Fats, excess of } \\
\text { Salts, Starch }\end{array}$ & \\
\hline $\begin{array}{c}\text { Canned Vegeta- } \\
\text { bles and meat }\end{array}$ & $\begin{array}{c}\text { Salts of Copper, } \\
\text { Lead }\end{array}$ & Excess of Water & $\begin{array}{l}\text { Meat damaged in } \\
\text { the process of }\end{array}$ \\
\hline Cheese. & $\begin{array}{l}\text { Salts of Mercury } \\
\text { in the Rind }\end{array}$ & Oleomargarin & \\
\hline $\begin{array}{l}\text { Candy and Con- } \\
\text { fectionery }\end{array}$ & $\begin{array}{l}\text { Poisonous Colors, } \\
\text { Artificial Es- } \\
\text { sences }\end{array}$ & Grape Sugar & Flour \\
\hline Coffee... & & $\begin{array}{l}\text { Chicory, Peas, Rye, Beans, } \\
\text { Acorns, Chebus-nuts, Al- } \\
\text { mond or other Nut-shells, } \\
\text { Burnt Sugar, Low-grade } \\
\text { Coffees }\end{array}$ & . \\
\hline $\begin{array}{l}\text { Cocoa and Choc- } \\
\text { olate }\end{array}$ & $\begin{array}{l}\text { Oxid of Iron and } \\
\text { other Coloring } \\
\text { Matters }\end{array}$ & $\begin{array}{l}\text { Animal Fats, Starch, Flour } \\
\text { and Sugar }\end{array}$ & \\
\hline Cayenne Pepper.. & Red Lead.. ..... . & $\begin{array}{l}\text { Ground Rice Flour, Salt, Ship- } \\
\text { bread. Indian Meal }\end{array}$ & Oxid of Iron \\
\hline Flour. & Alum... & Ground Rice. . . . . . . . & Grit and sand \\
\hline Ginger & $\cdots \cdots$ & $\begin{array}{l}\text { Turmeric, Cayenne Pepper } \\
\text { Mustard, inferior varieties } \\
\text { of Ginger }\end{array}$ & \\
\hline Gin... & $\begin{array}{c}\text { Alum Salt, Spirit } \\
\text { of Turpentine }\end{array}$ & Water, Sugar & \\
\hline Honey . & & Glucose, Cane-sugar. & $\begin{array}{l}\text { Pollen of various } \\
\text { plants and in- } \\
\text { sects }\end{array}$ \\
\hline
\end{tabular}


FOODS AND THEIR ADULTFRANTS-Continued

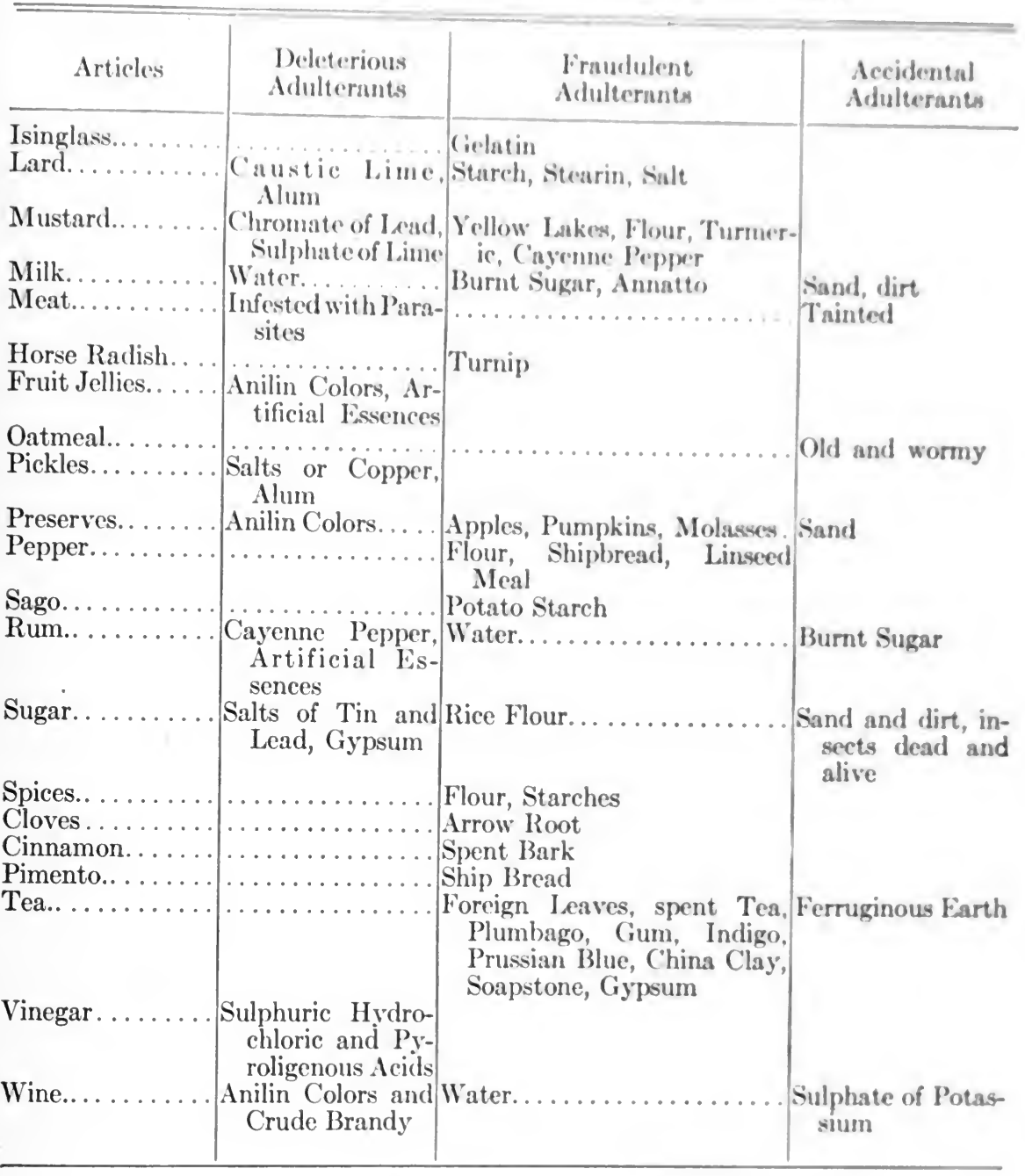

(h) Foods CONTAINing Micro-orgasisus.-During the past decade, careful investigation and research have demonstrated, bevond doubt, the fact that certain foods containing microorganisms are the means of conveying the germs of various infectious diseases.

MrLk.-Milk is an admirable culture medium for a great variety of germs and bacilli, like those of typhoid fever and tuberculosis. These thrive particularly well in milk, due to its abundant and raried protein material which furnishes substances out of which develop powerful toxins 
for absorption. The principal diseases whose germs are capable of being transmitted through milk are tuberculosis, typhoid fever, cholera, diphtheria and scarlet fever. Milk containing these germs is usually produced by careless dairy men. (See section on Milk, Volume I, Chapter XII, for details as to the proper care of milk production.)

Tuberculous mill infection has been a theme which has received much attention of late years. The matter is of special importance in regard to the danger of conveying tuberculosis to infants through raw milk. That this has happened is beyond question. Milk infected with tubercle bacilli, when fed to animals, has been shown to produce primary intestinal and mesenteric tuberculosis, and therefore its danger to infants is apparent. Tubercle bacilli may find their way into the milk from the tuberculous gland or udder. It should be borne in mind, however, that milk from a tuberculous cow, even if it does not cause disease directly, is apt to be poor in quality and undesirable for food. As a means of safeguarding the public, dairy herds are regularly inspected for tuberculosis. When cows are found to be tuberculous they are ordered to be slaughtered. Notwithstanding these precautions, milk is still produced from tuberculous cows, and among infants who live largely upon raw milk, and whose gastric digestion is less vigorous than that of adults, mesenteric tuberculosis is relatively more common.

Tuberculous meat usually proves less virulent than raw milk, for the reason that it is subjected to thorough heat in cooking. This does not kill all the bacilli, however, so that tuberculous meat should not under any circumstances be consumed for food. This fact is now generally appreciated by the public. Meat inspection by federal officers and abattoirs is now much better regulated by law and supervised by local health boards than formerly. As a safeguard, all meat offered for sale should be slaughtered in public abattoirs under competent governmental inspection. Not only should the animals be examined before killing, but the carcass should be carefully inspected after slaughtering.

We have stated elsewhere that meat from animals dead of various acute diseases, although it does not form a wholesome food, is sometimes eaten, and, if well cooked, may be harmless. No part of any animal suffering from the foot-and-mouth disease, rabies, glanders, actinomycosis, anthrax, septicemia, swine plague, sheep or cow pox, pneumonia, trichiniasis or tuberculosis should ever be consumed as food by human beings.

Diarrheal diseases are commonest in the warm months. Ninety-seven per cent of the cases that occur in children are in bottle-fed babies. Where milk is pure and where proper care has been observed in trans- 
mission from the dairg to the consumer, the discuse is rare. These dis. eases may he produced hy toxins genernted in the milk by the bacteria, or by the bacteria themselves introduced into the intentinal tract.

Diphtheria bacilli mag find their way into milk from the milker, who may have the discase in a mild form, or from sulserpuent entunisution. A number of epidenies have been traced to this origin of infected milk.

Scarlet fever epidemics have oceurred as a result of milk infection: they have usually been traced to a case of the disease in a milker's fumily. Kober has tabulated 100 scarlet fever epidemics of milk, traceable chictly to persons employed at the diary, or from infected bottles or milk eans used in families where the disease prevaled or to employees handling milk while suffering from the disease.

Typhoid fever has been traced to infected milk supply, and too much stress cannot be laid on the importance of investiguting dairy farms as a source of typhoid fever epidemies. Kober tabulated 195 epidemics of this disease due to milk infected with the typhoid bacilli.

Infection BY Orstens. - Typhoid fever epidemies have been traced to infected oysters, usually grown very near the outlet of a sewer. In New Haven, some years ago, thirty students were infected with typhoid fever from eating raw oysters supplied by a dealer who made a practice of placing fresh oysters in the river for a few days after receiving them. The report of this epidemic was made by $\operatorname{Conn}(17)$, who found that all the oysters eaten at this college society supper had come from one dealer who had obtained all of them from one ovster grower. At three of these suppers raw oysters were served, and all of the thirty victims who had partaken of the oysters in this condition were attacked by the disease. The oyster grower admitted that his daughte: had been ill of typhoid fever and it had been his habit to place the oysters temporarily in the river at a point near the place where a short drain from his house discharged into the stream. The water hecame infected by the flow of the drain leading from his house. In time the surrounding water became infected by the flow, and when the orsters were taken up the shell outside and inside contained the germs of typhoid. The raw oysters used at the students' dimers contained the trphoid poison. It has been generally believed that typhoid bacilli do not develop in salt water, but circumstantial evidence points strongly to their having existed in the brackish water above described.

Infection BY Files.-Food is frequently infected through the ageney of the common house fly. During the past decade much has heen written on this subject. During the Spanish-American War many thousands of 
men succumbed to typhoid fever transmitted through the agency of the house fly, coming direct from the latrines to the kitchens with their bodies laden with typhoid bacilli. These insects, from their great numbers and incessant activity, are admirably adapted to convey infection. Their numerous feet and capacious intestines, their frequent evacuations and disgusting habits of alighting and feeding upon all matter of refuse, make them an incessant pest. Of late years the sanitary officers of the United States Army have so perfected sanitary regulations that the presence of these pests is almost unknown.

(i) WHOLESOME FOOD AGAINST WHICH PERSONAL IDIOSYNCRASY ExisTs.-Idiosyncrasies are found to exist with some persons in regard to special articles of food which cannot be readily explained. As a rule, if marked, they extend throughout life, but sometimes persons pass through periods when a particular article of food disagrees with them which they had previously been able to eat with impunity. Some individuals will complain that milk makes them bilious, while others cannot eat eggs, while they can take milk. Again, there are persons who believe they cannot take either. Some individuals can eat the white and not the yolk of eggs; again, there are other people who cannot partake of fat in any form. There are persons who acquire a headache whenever they eat butcher's meat in excess. A common idiosyncrasy of diet is met with in persons who cannot partake of shellfish of any kind. An English authority reports the case of a lady patient who throughout her life was unable to drink coffee, of which she was very fond, without bringing on an attack of diarrhea. Such idiosyncrasies are sometimes hereditary and may affect several members of the same family. They are entirely independent of ordinary dyspeptic conditions and may occur in persons who otherwise are able to digest any and all kinds of foods.

(j) ALCOHOL AS A FOOD AND A POISON.-This subject has been most carefully considered in Volume I, Chapter XVI, Beverages and Stimulants, page 519, to which the reader is referred.

\section{REFERENCES}

1. Ermenglin. Am. Drug. \& Pharm. Record.

2. Old Testament: Deuteronomy xiv, 21.

3. Von Faber, Vaughan and Novy. Cellular Toxins.

4. Monr and Rosenau. Origin of a Recent Outbreak of Foot and Mouth Disease, U. S. Dept. Agric., 1909, Bur. Animal Industry, Cir. 147. 
5. E. M. Primle. (Professor of Tropical Diseaseg, Ecelectic Medical University, Lansas (ity, Mo.) Clin. Mred., March, 1915.

6. Fischer. Physiology of Alimentation, 1907.

7. Amminalusi. Text-book Physiological Chemintry.

S. Mranes. Theory of Protein Metalolism, Am. I. Physiolo, 1905.

9. Osbokxis. The Vegetable Proteins, 1909.

10. Weckly Report Inited States Pullic Health Servine, Nor. 12, 1915.

11. Tuompos, W. H. Treatment on Clinical Medicine.

12. Stassaxo, H. La Quinzane Thérapentique.

13. U. S. Dequt. Agric., Bureau of Chemistry, Bull. 151.

14. Wincy. Results of Borax Experiments, U. S. Dept. of Agrice, Bur. of Chem., Circular No. 15.

15. Harrixiton. Am. J. Med. Sce, Sept., 1904.

16. Sumpless. U. S. Wept. of Agric., Dir. of Chem., Bull. 25.

17. Cons. Med. Rec., New York. 



\section{CHAPTliR XIX}

\section{ANALYSIS OF AMERICAN F(ODS-FUET, VALLE PER POUNI ANI PliR PORTION}

\footnotetext{
Meaning of "Protein."

Sources and Methods of Computing Fond Analynis: Hintorical Anpect. Composition of Food Materials: l'ruluins: Fats; Carbohydrates; Anls or Mineral Matter; fuel Matter- Calories per Pound and per lor. tion: Water.

Cuts of Meat: Beef; Lamb; Pork; lial, etc.
}

\section{AVERAGE CHEMICAL COMPOSITION OF AMERICAN FOOD MATERIALS}

Meaning of Protein.-Nitrogenous matter is usually designated "protein." Nominally the total nitrogenous substance of animal and vegotable food materials, exclusive of the so-called nitrogenous fats, is included in this term. Actually it is employed, in common usage, to designate the product of the total nitrogen in a substance by an empirical factor generally expressed as 6.25. The common practice of European and American chemists and physiologists is to multiply the percentage of nitrogen by 6.25 and take the product as representing the total nitrogenous substance.

For many food materials, animal and vegetable, this factor, 6.25, would be nearly correct for proteins. which contain on the arerage not far from 16 per cent of nitrogen, although the nitrogen content of the individual protein is quite varied. The variations in the nitrogen of nonproteins are wider, and they contain on an average more than 16 per cent of nitrogen. It is evident, therefore, that the computation of the total nitrogenous substance in this way is by no means correct. Throughout most of the tables for meats and other animal foods the protein is calculated by subtracting the other ingredients, including water and mineral matter, from 100 per cent. The difference in the two estimates of "protein" is usually less than 1 pur cent of the total meat, and the $\mathrm{N} \times 6.25$ estimate is usually, but not alwars, in excess of tho estimate 
by difference. While this latter method of calculation is by no means absolutely correct, it is nevertheless oftentimes more nearly so than the determination by use of the usual formula, $\mathrm{N} \times 6.25$.

Sources and Methods of Computing Food Analysis Tables.-In the compilation of these tables only edible portions are retained, unless otherwise stated, especially in animal foods. By edible foodstuff is meant the material as ordinarily prepared for cooking, after removal of bones, skin, entrails, peelings, cores, pods, rinds, etc. Thus the edible foodstuff still contains material ordinarily removed by dainty, finicky or fastidious diners, as fat, gristle, etc., of meats, fine skins and other parts of vegetable foods, the under crust of pie, and other materials in foods. This unused material is a physiological waste.

The material for this chapter has been taken largely from the revised work of Atwater and Bryant(1), which represents by far the best compilation extant of analyses of American foods down to 1906 . In abstracting these tables, the minimum, maximum and averages only of edible foods are given, which suffice for the purpose of this -work. For the complete tables the reader is referred to the original report(2).

In the preparation of these tables much care has been exercised to keep the protein, fat and carbohydrate percentages corrected to show true protein and digestible carbohydrate. For meats the $\mathrm{N} \times 6.25$ method of calculation has been followed. Many of the computations as to the protein content of vegetables are slightly excessive, since no actual estimate of protein proper was made. This is of no practical importance, however, because if the protein content is large, as in the legumes, the nonprotein nitrogenous substances are comparatively insignificant; while, if the total nitrogenous constituents are small, the error for any ordinary use of the food is slight in the aggregate.

In amplifying the fuel value of the foods great care has been exercised by the author to estimate the caloric value per hundred grams of the various foods. Realizing the fallacy of exactitude in determining positive fuel values, some license has been taken to state fractions of a per cent in the nearest per cent. It will be realized, therefore, that in using these tables to ascertain the organic nutrients of foodstuffs ingested, only approximate results can be hoped for, hence it will serve every purpose to use average figures and to ignore fractions of a per cent or even the nearest aliquot fraction of the whole.

HISTORICAL ASPECT.-The earliest quantitative analyses of food materials with which we have come in contact are those of potatoes, reported by George Pearson in England in 1795(3). Einhoff(4), in 
1805 , made analyses of potatoes and rye. He attempted to separate the albumin in the latter and in the former, he also deternined several of the constituents of the ash. Other workurs in this tield of researeh. chiefly in the peried from 1540 to 1 stis, have reperted their findinge. Nearly all our detinite knowledge of the eluemical compusition of food materials and their nutritive value, however, has arcumulated within comparatively the past few years. The great advance in the analytical chemistry of foodstuffs was made in 1stit, when Hennelerg and his associates elatorated the so-called "Weende method" for proximate anal. ysis. This method with slight variations is used to-day wherever ford analyses are minle. "The methods folleworl in difforent countries agree so closely that for the last twenty yenrs it has been possible to accept analyses by chemists in different parts of the world and compare them with one another without hesitation" (Atwater and Bryat).

The first analyses by these methods in the United States of which record has been found were at series of analyses of corn in 1869(5). With thanks to the research workers in the Experiment Stations of the United States Department of Agrieulture, who have perhaps led the world in scientific work of this character, we now have a definite knowledge of the chemical composition of foodstuffs, their fuel rahe, and nutritive properties.

Explanation of Terms $(6)$. - The terms used in reporting analyses of foods and feeding stuffs need some explanation. Some of these terms have a technical meaning which is well recognized and understood by scientists, although the dictionaries and similar books of reference have not yet included these terms in their definitions. In other eases the same word has been used by scientists in different ways. The more usual terms are defined and explained below in the sense in which they are employed in this bulletin and other publications of this office:

\section{COMPOSITION OF FOOD MATERIALS}

Ordinary food materials, sueh as meat, fish, eggs, potatoes, whest, ete, consist of:

Refuse.-As the bones of meat and fish, shells of shelltish, skin of potatoes, bran of wheat, etc.

Edible Portion.-As the flesh of meat and fish, the white and yolk of eggs. wheat flour, ste. This edible portion eonsists of water (usully incorporated in the tissue and not visible as such), and nutritive ingredients or nutrients.

The principal kinds of nutritive ingredients are protein, fats, earbohydrates, and ash or mineral matters.

The water and refuse of various foods and the salt of salted meat and fish are 
called nonnutrients. In comparing the values of different food materials for nourishment they are left out of account.

Protein.-This term is used to include nominally the total nitrogenous substance of animal and vegetable food materials, exclusive of the so-called nitrogenous fats. Actually it is employed, in common usage, to designate the product of the total nitrogen by an empirical factor, generally 6.25 .

This total nitrogenous substance consists of a great variety of chemical compounds, conveniently divided into two principal classes, proteids and nonproteids.

The following is taken from Bulletin 28, U. S. Department of Agriculture:

The term proteid, as here employed, includes the simple proteids, e.g., $(a)$ albuminoids, globulins, and their derivatives, such as acid and alkali albumins, coagulated proteids, proteoses, and peptones; $(b)$ the so-called combined or compound proteids; and $(c)$ the so-called gelatinoids (sometimes called "glutinoids") which are characteristic of animal connective tissue.

The term albuminoids has long been used by European and American chemists and physiologists as a collective designation for the substances of the first two groups though many apply it to all three of these groups. Of late a number of investigators and writers have employed it as a special designation for compounds of the third class.

The term nonproteid is here used synonymously with nonalbuminoid, and includes nitrogenous animal and vegetable compounds of simpler constitution than the proteids. The most important animal compounds of this class are the socalled "nitrogenous extractives" of muscular and connective tissue, such as creatin, creatinin, xanthin, hypoxanthin, and allied cleavage products of the proteids, To some of these the term "meat bases" has been applied. The latter, with certain mineral salts (potassium phosphates, ete.), are the most important constituents of beef tea and many commercial "meat extracts."

The nonproteid nitrogenous compounds in vegetable foods consist of amids and amido-acids, of which asparagin and aspartic acid are familiar examples.

The ideal method of analysis of food materials would involve quantitative determinations of the amounts of each of the several kinds or groups of nitrogenous compounds. This, however, is seldom attempted. The common practice is to multiply the percentage of nitrogen by the factor 6.25 and take the product as representing the total nitrogenous substance. For many materials, animal and vegetable, this factor would be nearly correct for the proteids which contain, on the average, not far from 16 per cent of nitrogen, although the nitrogen content of the individual proteids is quite varied. The variations in the nitrogen of the nonproteids are wider, and they contain, on the average, more than 16 per cent of nitrogen. It is evident, therefore, that the computation of the total nitrogenous substance in this way is by no means correct. In the flesh of meats and fish, which contain very little of carbohydrates, the nitrogenous substance is frequently estimated by difference, i. e., by subtracting the ether extract and ash from the total water-free substance. While this method is not always correct, it is oftentimes more nearly so than the determination by use of the usual factor. 
The distinction between protein and proteids is very sharp. The lateer are definite chemical compounds, while the furmer is an entirely arbitrury term used to designate a group which is commonly assmmol to include all of the nitrogenous matter of the food except the nitrogenoms fats.

In the tables herewith the common unage is followed, by which the protein is given as estimated "lye factor." i. c., lobal nitrogen multiphed be 6.20. In the analyses of ments and fish, however, the tigures for protoin "hy difference" are also given. Where the profeid amil monproteid nitrogenous matter has been cstimated in a food material, the propurtuns are indicated in a footnote.

Fats.- Luder fats is included the folal ether extract. Fomiliar examples of fat are fat of meat, fat of nilk (butfer), oil of eorn, olive oil, ete. The ingredionts of the "ether extract" of animal and vencotable foods and fooding stuffs, which it is eustomary to group roughly as fals. include with the true fats various other substances, as fatty acids, lecithins (nilrugenous fats), and chlorophylls.

Carbohydrates.-Carhohydrates aro usually determined by difference. Thry include sugars, starches, cellulose, gums, wooly fiber, etc. In many instancas separate detcrminations of one or morn of these groups have been made. The determinations of "fiber" in vecretable fouds, i. e., substances allied to cartwhy. drates but insoluble in dilute acid and alkali, and somewhat similar to woody fiber, are given in a separate columm. 'The figures in parentheses in the crude. fiber column slow the number of analys's in which the fiber was determinerl. The figures for "total earbolydrates" inclulle the fiber, as well as sugars, starebes, etc. Where the sugars or starches have been determined separately footnotes are added giving the average results.

Ash or Mineral Waters.- Under this head are ineluded phosphates, sulphates, chlorids, and other salts of potassium, solium, magnesium, and other metallic elements. Where analyses of the mincral matters have been found they are added in the form of footnotes. These results usually give the percentage composition of the ash as produced by incineration rather than the proportions in which the different mineral ingredients occur in the food material.

Fuel Value.-By fuel value is meant the number of ealories of heat equivalent to the energy which it is assumed the body would be able to obtain from one pound of a given food material, provided the nutrients of the latter were completely digested. The fuel values of the different food materials are calculated by use of the factors of Rubner, which allow 4.1 ealories for a gram of protein, the same for a gram of carbohydrates, and 9.3 calories per gram of fats. These amounts correspond to 18.6 caluries of energy for each hundredth of a pound of protein and of earbohydrates, and 4.2.2 calories for each hundredth of a pound of fat in the given food material. In the following table the fuel value per pound ${ }^{1}$ has been ealculated by the use of these factors. In these calculations the values of protein by factor have he'n used in all eases with the exception of the salt cod (p. 723) and hens' eggs (p. 725) in which the value of protein by difference was used.

1 The author has amplified these calculations of fuel value by extending the ealorirg per portion for each foodstuff enumeratml. Which it is hoped will make the tables mure valuable and convenient for the student of sitology. 


\section{CUTS OF MEAT}

The methods of eutting sides of beef, veal, mutton, and pork into parts, and the terms used for the different "cuts," as these parts are commonly called,

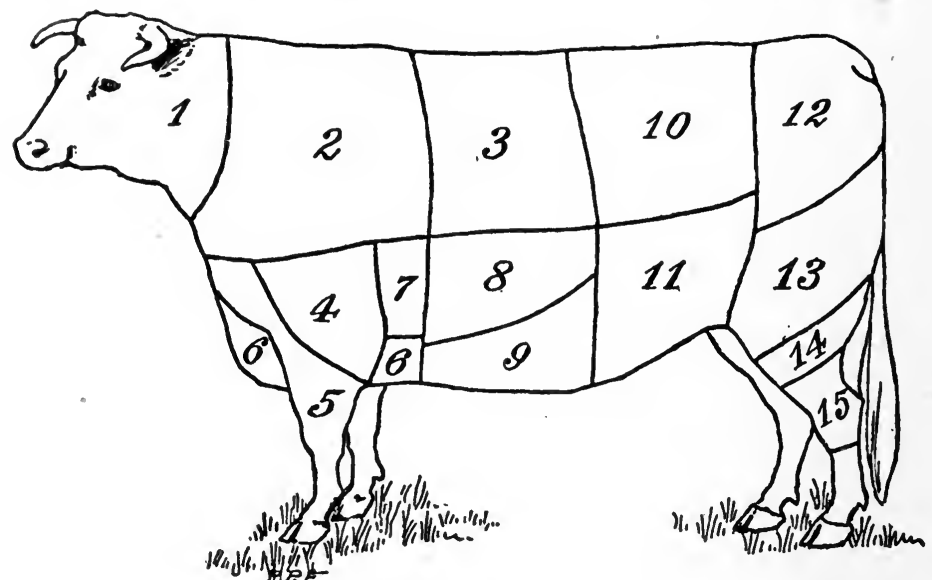

1. Neck.

2. Chuck.

3. Ribs.

4. Shoulder clod.

5. Fore shank.

6. Brisket.

7. Cross ribs.

8. Plate.

9. Navel.

10. Loin.

11. Flank.

12. Rump.

13. Round.

14. Second cut round.

15. Hind shank.

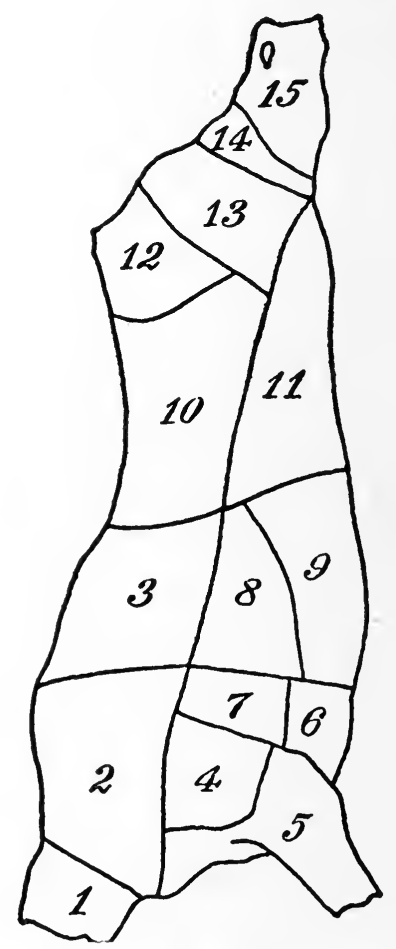

Fig. 46.-Diagrams of Cuts of Beef. (Farmers' Bull. No. 34, U. S. Dept. Agric.)

vary in different localities. The analyses here reported apply to cuts as indicated by the following diagrams. These show the positions of the different euts, both 
in the live animal and in the dressed curcass as found in the morkets. The liness of division between the different cuts will vary slightly, accordung to the usage of the local market, cren where the general mellod of culcing is as here indacated. The numes of the same "uts likewise vary in different parts of the country.

The Cuts of Beef.-The gencral method of culling up a side of berof is illus. trated in Fig. 46, which shows the relative position of tho cuts in the animal and in a dressed side. The neek piece is frequently cut so as 10 include more of the chuck than is represented by the diagrans. The shoulder elod is usually eut with. out bone, while the shoulder (not indicnted in disgram) would include more or less of the shoulder blade and of the uppere cond of the fore shank. Shoulder steak is cut from the dhuck. In many localities the plate is made to include all the parts of the fore quarter designated on the diagrams as brisket, crosa-ribs, plate and navel, and different portions of the plate, us thus cut, are spoken of as the "brisket end of plate" and "navel end of plate." This part of the animal is

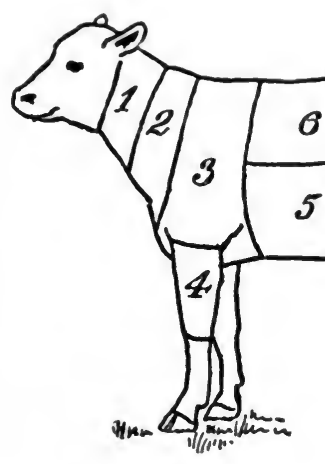

1. Neck.

2. Chuck.

3. Shoulder.

4. Fore shank.

5. Breast.

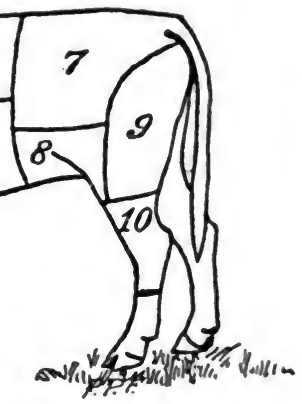

6. Ríbs.

7. Loin.

8. Flank.

9. Leg.

10. Hind shank.

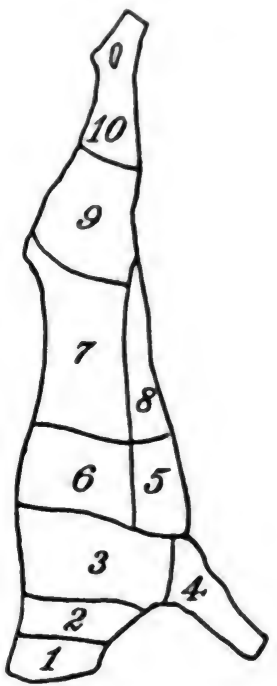

Fig. 47.-Diagrams of Cuts of Veal. (Farmers' Bull. No. 34, U. S. Dept. Agric.)

largely used for corning. The ribs are frequently divided into first, second, and third euts, the last lies nearest the chuck and is slightly less desirable than the first and second. The cluck is sometimes subdivided in a similar manner, the third eut of the chuck being nearest the neck. The names applied to different portions of the loin rary considerably in different loealities. The part nearest the ribs is frequently ealled "small end of loin" or "short steak." The other end of the loin is ealled "hip sirloin" or "sirloin." Between the short steak and the sirloin is a portion generally called the "tenderloin," for :he reason that the real tenderloin, the very tender strip of meat lying inside the loin, is found most fully developerl in this eut. Porterhouse steak is a term most frequenty applied to either the short steak or the tenderloin. It is not uncommon to tind the flank eut sn as to 
include more of the loin than is indicated in the figures, in which case the upper portion is called "flank steak." The larger part of the flank is frequently corned, as is also the case with the rump. In some markets the rump is eut so as to include a portion of the loin, which is then sold as "rump steak." The portion of the round on the inside of the leg is more tender than that on the outside, and is preferred to the latter. As the leg lies upon the butcher's table this inside of the round is usually on the upper, or top side, and is therefore called "top round." Occasionally the plate is called the "rattle."

The Cuts of Veal.-The method of cutting up a side of veal differs considerably from that employed with beef. This is illustrated by Fig. 47, which shows the relative position of the cuts in the animal and in a dressed side. The chuck is much smaller in proportion, and frequently no distinction is made between the chuck and the neck. The chuck is often eut so as to include a portion here desig-

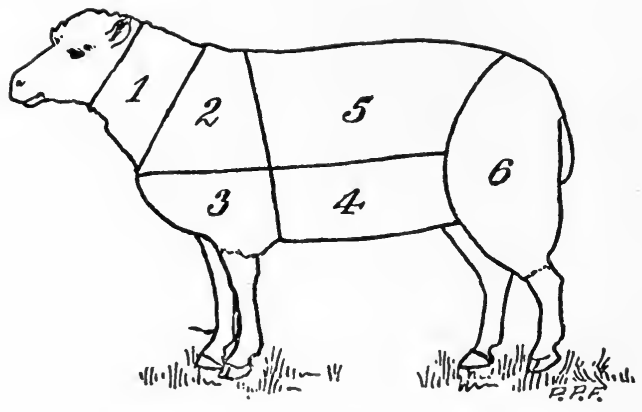

1. Neck.

2. Chuck.

3. Shoulder.

4. Flank.

5. Loin.

6. Leg.

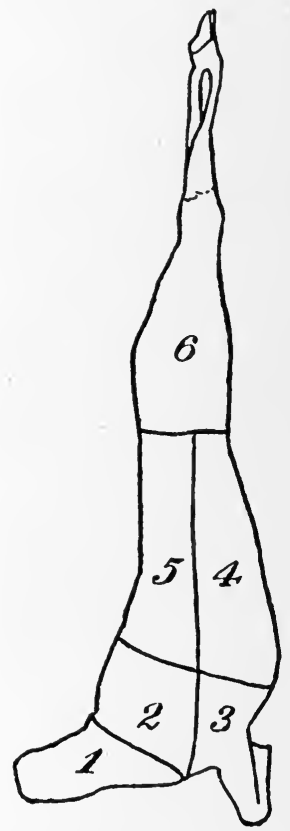

Fig. 48.-Diagrams of Cuts of Lamb and Mutton. (Farmers' Bull. No. 34, U. S. Dept. Agric.)

nated as shoulder, following more nearly the method adopted for subdividing beef. The shoulder of veal as here indicated includes, besides the portion corresponding to the shoulder in beef, the larger part of what is classed as chuck in the adult animal. The under part of the fore quarter, corresponding to the plate in the beef, is often designated as breast of veal. The part of the veal corresponding to the rump of beef is here included with the loin, but is often eut to form part of the leg. In many localities the fore and hind shanks of veal are called the "knuckles." 
The Cuts of Lamb and Mutton.-Fig. Is shows the rolative ponition of the ruts in a dressed side of mutlon or lanh and in a live mimal. The cuts in a side of lamb and mutton number but six, thren in ench quarter. The chuck includes the ribs as far as the end of the shoulder blade, beyond which comes the loin. The flank is made to include all the under mulp of the animal. Some butchen, however, make a larger mumber of euts in the fure quarter, including a portion of the cuts marked "loin" and "churek" in l"ig. 48, to make a cut dessignateel as "rib," and a portion of the "flank" and "shombler" to make a cut designated as "brisket." The term "chops" is ordinarily used to designate portions of rither the loin, ribs, ehuck or shoulder, which are either "ut or "ehopped" by the butcher into pieces suitable for frying or broiling. The churck and ribs are sometimes called the "rack."

The Cuts of Pork. - The method of "utting up a side of pork differs from that employed with other meats. A laren portion of the eareass of a dresued pig
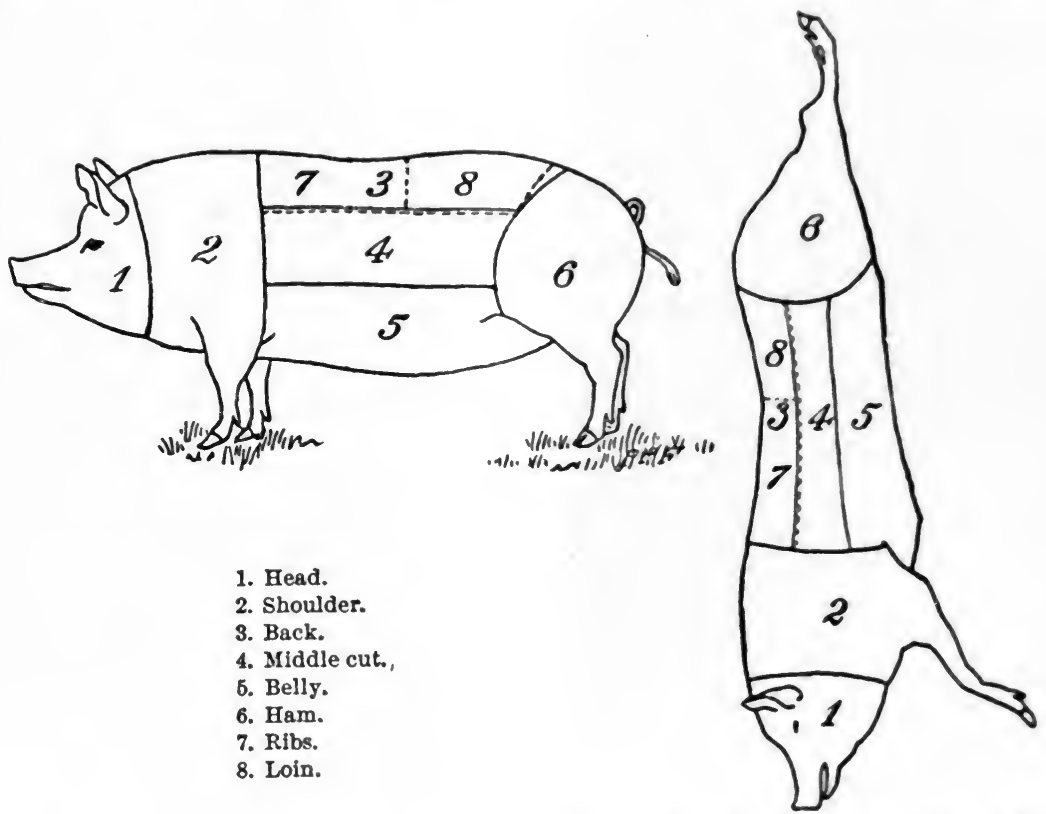

Fig. 49.-Diagrans of ('uts of Pork. (Farmers' Bull. No. 34, U. S. Dept. Agric.)

consists of almost elear fat. This furnishes the euts which are used for "salt pork" and bacon. Fig. 49 illustrates a common method of eutting up pork, showing the relative position of the cuts in the animal and in the dressed side. The cut designated as "back cut" is ulmost clear fat and is used for salting and pickling. The "middle cut" is the portion quite generally used for bacon and for "lean ends" of salt pork. The belly is salted or pickled or may be made into sausages.

Beneath the "back cut" are the ribs and loin, from which are obtained "spareribs," "chops," and roasting pieces, here designated by dotted lines. The hams and shoulders are more frequently curml, but are also sold fresh as pork "steak." The tenderloin proper is a comparatively lean and very small strip of meat lying 
under the bones of the loin and usually weighing a fraction of a pound. Some fat is usually trimmed off from the hams and shoulders which is called "ham and shoulder fat" and is often used for sausages, etc. What is called "leaf lard," at least in some localities, comes from the inside of the back. It is the kidney fat.

As stated above, cuts of meats, as shown in the diagrams herewith, correspond to those of which analyses are reported in the tables given in this chapter, but do not attempt to show the different methods of cutting followed in markets in different parts of the United States. The illustrations and tables which follow are taken from Bulletin No. 28 (Revised Edition), U. S. Department of Agriculture, "The Chemical Composition of American Food Materials," by W. O. Atwater, Ph.D., and H. P. Bryant, M.S.

\section{AVERAGE CHEMICAL COMPOSITION OF AMERICAN FOOD MATERIALS ${ }^{1}$}

\section{ACCORDING TO ATWATER'S AND BRYANT'S CAREFUL WORK ON FOOD ANALYSIS, UNITED STATES DEPARTMENT OF AGRICULTURE, BULLETIN No. 28}

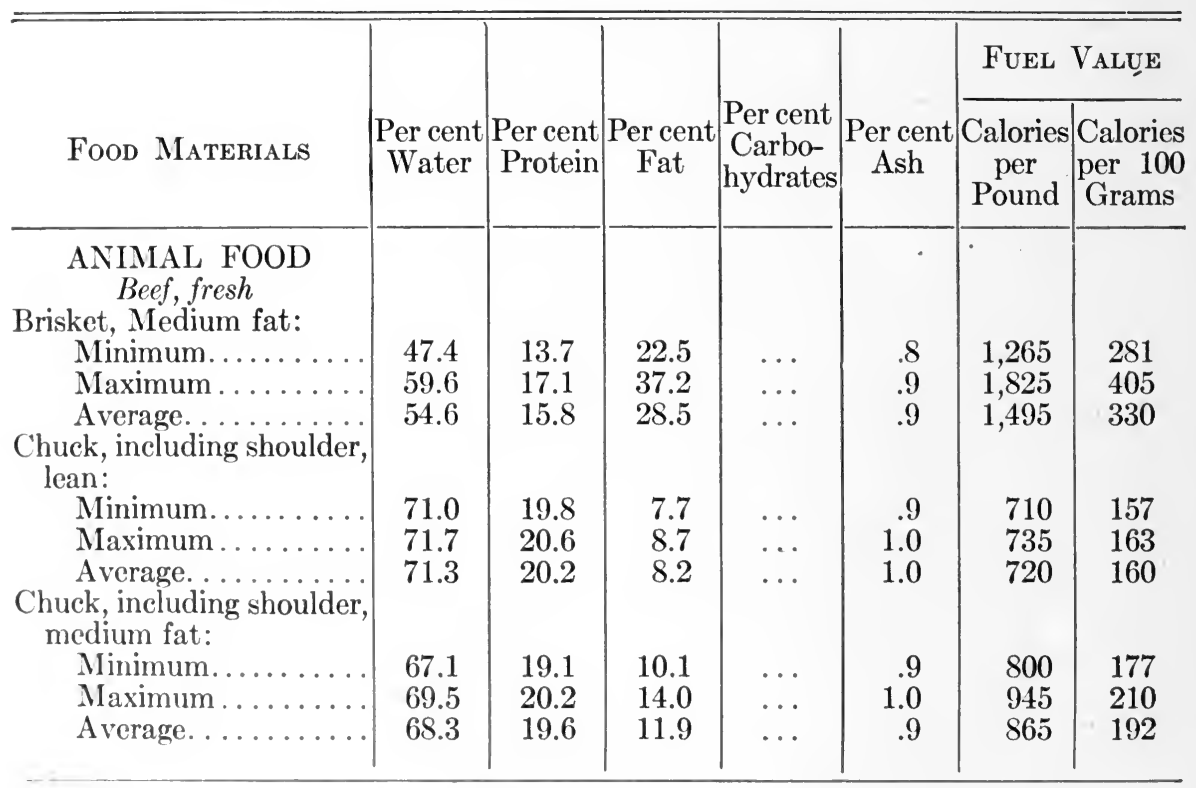

1 I nless otherwise stated, the values in each ease are for the edible portion only. 


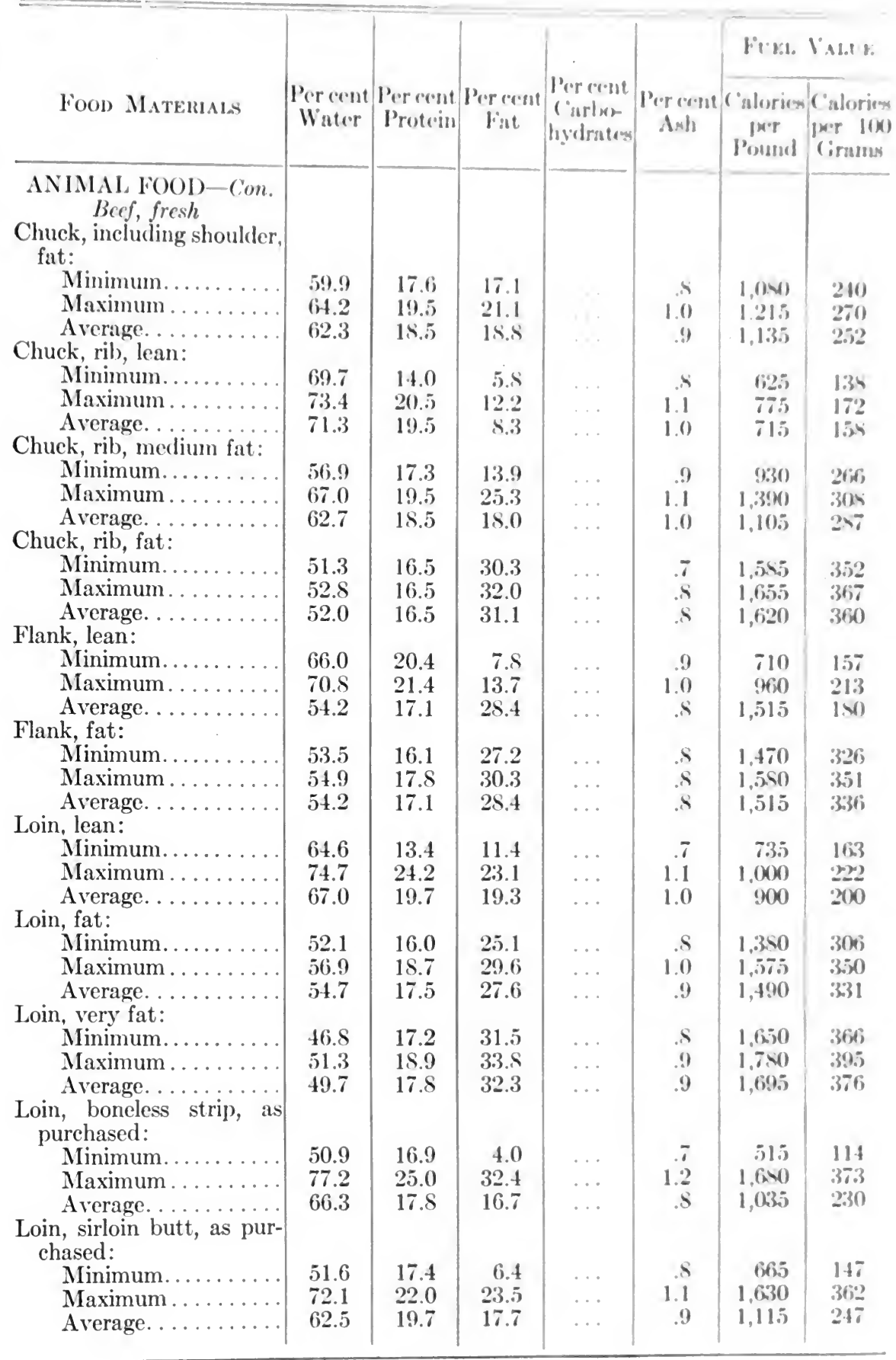




\begin{tabular}{|c|c|c|c|c|c|c|c|}
\hline \multirow[b]{2}{*}{ Food Materials } & \multirow[b]{2}{*}{ 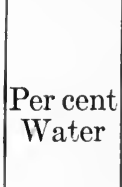 } & \multirow[b]{2}{*}{$\begin{array}{l}\text { Per cent } \\
\text { Protein }\end{array}$} & \multirow[b]{2}{*}{$\begin{array}{l}\text { Per cent } \\
\text { Fat }\end{array}$} & \multirow[b]{2}{*}{$\mid \begin{array}{c}\text { Per cent } \\
\text { Carbo- } \\
\text { hydrates }\end{array}$} & \multirow[b]{2}{*}{$\begin{array}{l}\text { Per cent } \\
\text { Ash }\end{array}$} & \multicolumn{2}{|c|}{ Fuel Value } \\
\hline & & & & & & $\begin{array}{c}\text { Calories } \\
\text { per } \\
\text { Pound }\end{array}$ & $\begin{array}{l}\text { Calories } \\
\text { per } 100 \\
\text { Grams }\end{array}$ \\
\hline $\begin{array}{l}\text { ANIMAL FOOD-Con. } \\
\text { Beef, fresh }\end{array}$ & & & & & & & \\
\hline $\begin{array}{l}\text { Loin, porterhouse steak: } \\
\text { As purchased....... }\end{array}$ & 52.4 & 19.1 & 17.9 & $\cdots$ & .8 & 1,110 & 246 \\
\hline $\begin{array}{l}\text { Loin, sirloin steak: } \\
\text { As purchased. . }\end{array}$ & 54.0 & 16.5 & 16.1 & $\ldots$ & .9 & 985 & 218 \\
\hline Neck, lean: & & & & & & & \\
\hline Minimum........ & 69.3 & 21.3 & 8.0 & $\cdots$ & 1.0 & 735 & 163 \\
\hline Maximum ......... & 71.0 & 21.4 & 8.7 & $\cdots$ & 1.1 & 765 & 170 \\
\hline $\begin{array}{l}\text { Average. .......... } \\
\text { Neck, medium fat: }\end{array}$ & 70.1 & 21.4 & 8.4 & .. & 1.0 & 750 & 166 \\
\hline Minimum........ & 60.5 & 18.9 & 11.5 & $\ldots$ & .8 & 870 & 193 \\
\hline Maximum .... & 67.8 & 22.0 & 19.8 & $\ldots$ & 1.1 & 1,195 & 265 \\
\hline Average. . & 63.4 & 20.1 & 16.5 & $\ldots$ & .9 & 1,070 & 237 \\
\hline Plate, lean: & & & & & & & \\
\hline Minimum........... & 60.8 & 8.9 & 16.5 & $\ldots$ & .4 & 860 & 191 \\
\hline Maximum .......... & 74.5 & 19.1 & 20.8 & $\cdots$ & .9 & 1,230 & 273 \\
\hline Average. ........... & 65.9 & 15.6 & 18.8 & $\ldots$ & .7 & 1,085 & 241 \\
\hline $\begin{array}{l}\text { Plate, medium fat: } \\
\text { Minimum...... }\end{array}$ & 487 & 148 & 232 & & & & \\
\hline Maximum ........ & $\begin{array}{l}48.6 \\
59.9\end{array}$ & $\begin{array}{l}14.8 \\
18.0\end{array}$ & $\begin{array}{l}20.2 \\
35.6\end{array}$ & $\begin{array}{l}\cdots \\
\cdots\end{array}$ & .9 & $\begin{array}{l}1,280 \\
1,780\end{array}$ & $\begin{array}{l}282 \\
395\end{array}$ \\
\hline Average. .......... & 54.4 & 16.5 & 29.1 & $\ldots$ & .8 & 1,535 & 341 \\
\hline $\begin{array}{l}\text { Ribs, lean: } \\
\text { Minimum. }\end{array}$ & 66.0 & 16.5 & 9.8 & $\ldots$ & 8 & 790 & 175 \\
\hline Maximum. & 69.5 & 20.9 & 14.0 & $\cdots$ & 1.1 & 955 & $\begin{array}{l}170 \\
212\end{array}$ \\
\hline Average. . . . . . . & 67.9 & 19.6 & 12.0 & $\ldots$ & 1.0 & 870 & 193 \\
\hline Ribs, fat: & & & & & & & \\
\hline Minimum... & 47.4 & 12.0 & 33.9 & .. & .6 & 1,710 & 380 \\
\hline Maximum .... . & 51.7 & 16.8 & 36.8 & $\ldots$ & .9 & 1,845 & 410 \\
\hline Average. ......... & 48.5 & 15.0 & 35.6 & $\ldots$ & .7 & 1,780 & 395 \\
\hline $\begin{array}{l}\text { rolls, as purchased: } \\
\text { Minimum........... }\end{array}$ & 67.3 & 19.3 & 8.4 & & 0 & 740 & \\
\hline Maximum ........... & 70.5 & $\begin{array}{l}19.0 \\
20.8\end{array}$ & $\begin{array}{l}0.4 \\
13.3\end{array}$ & $\begin{array}{l}\cdots \\
\cdots\end{array}$ & $\begin{array}{r}.9 \\
1.0\end{array}$ & $\begin{array}{l}740 \\
920\end{array}$ & $\begin{array}{l}164 \\
204\end{array}$ \\
\hline Average. ...... & 69.0 & 20.2 & 10.5 & $\cdots$ & 1.0 & 820 & $\begin{array}{l}204 \\
182\end{array}$ \\
\hline Round, lean: & & & & & & & \\
\hline Minimum. . & 65.8 & 18.8 & 5.1 & $\cdots$ & .3 & 565 & 125 \\
\hline Maximum ..... & 73.6 & 24.1 & 10.0 & $\ldots$ & 1.3 & 835 & 185 \\
\hline Average. . . . . . . & 70.0 & 21.3 & 7.9 & $\ldots$ & 1.1 & 730 & 162 \\
\hline Round, fat: & & & & & & & \\
\hline Minimum... & 57.8 & 18.3 & 16.7 & $\cdots$ & .9 & 1,050 & 233 \\
\hline um .... & 64.5 & 21.4 & 22.3 & $\ldots$ & 1.0 & 1,305 & 290 \\
\hline Average. ...... & 60.4 & 19.5 & 19.5 & $\ldots$ & 1.0 & 1,185 & 263 \\
\hline $\begin{array}{l}\text { Round, very fat: } \\
\text { Minimum...... }\end{array}$ & & & & & & & \\
\hline $\begin{array}{l}\text { Minimum...... } \\
\text { Maximum ..... }\end{array}$ & 54.9 & 17.2 & 24.7 & . & .7 & 1,400 & 311 \\
\hline $\begin{array}{l}\text { Maximum . . . . . } \\
\text { Average. . . . . }\end{array}$ & 56.8 & 19.1 & 27.7 & $\cdots$ & .9 & 1,490 & 331 \\
\hline $\begin{array}{l}\text { Average. } \\
\text { Round, second cut: }\end{array}$ & 55.9 & 18.2 & 26.2 & $\ldots$ & .8 & 1,445 & 321 \\
\hline Minimum..... & 69.5 & 20.1 & 8.6 & & 1.0 & 735 & 163 \\
\hline Maximum ..... & 70.0 & 20.7 & 8.6 & $\ldots$ & 1.3 & 745 & 121 \\
\hline Average. ........ & 69.8 & 20.4 & 8.6 & $\ldots$ & 1.1 & 740 & 120 \\
\hline
\end{tabular}




\begin{tabular}{|c|c|c|c|c|c|c|c|}
\hline \multirow[b]{2}{*}{ Food Materials } & \multirow[b]{2}{*}{$\begin{array}{l}\text { Per cent } \\
\text { Water }\end{array}$} & \multirow[b]{2}{*}{$\begin{array}{l}\text { Percent } \\
\text { Protein }\end{array}$} & \multirow[b]{2}{*}{$\begin{array}{c}\text { Prrcent } \\
\text { rat }\end{array}$} & \multirow[b]{2}{*}{$\begin{array}{l}\text { Percent } \\
\text { Carbo- } \\
\text { hydrates }\end{array}$} & \multirow[b]{2}{*}{$\begin{array}{l}\text { Percent } \\
\text { Ash }\end{array}$} & \multicolumn{2}{|c|}{ Fun.t. ValeE: } \\
\hline & & & & & & $\begin{array}{c}\text { Cinlories } \\
\text { puer } \\
\text { Pound }\end{array}$ & $\begin{array}{l}\text { Calorien } \\
\text { per 10 } \\
\text { Ciraums }\end{array}$ \\
\hline $\begin{array}{l}\text { ANIMAL FOOD-Con. } \\
\text { Beef, fresh } \\
\text { Rump, lean: }\end{array}$ & & & & & & & \\
\hline Minimum... & 62.1 & 17.5 & 10.0 & $\cdots$ & .9 & 840 & 186 \\
\hline Maximum ..... & 68.3 & 22.7 & 17.7 & $\ldots$ & 1.1 & 1,170 & 260 \\
\hline Average. ........ & 6.5 .7 & 20.9 & 13.7 & $\ldots$ & 1.0 & 965 & 214 \\
\hline $\begin{array}{c}\text { Rump, medium fat: } \\
\text { Minimum... }\end{array}$ & 524 & 160 & 903 & & 8 & 1.195 & \\
\hline Maximum . . . . . . . & 60.3 & 19.5 & 29.9 & $\cdots$ & 1.0 & 1,575 & $\begin{array}{l}2(3) \\
3 . x)\end{array}$ \\
\hline Average...... & 56.7 & 17.4 & 25.5 & ... & .9 & 1,400 & 311 \\
\hline Rump, fat: & & & & & & & \\
\hline Minimum... . . . . & 43.1 & 14.7 & 33.3 & $\ldots$ & .7 & 1,710 & 350 \\
\hline Maximum ........ & 49.9 & $22 . \overline{1}$ & 39.4 & .. & 1.2 & 1,960 & 430 \\
\hline Average...... & 47.1 & 16.8 & 35.7 & .. & .8 & 1,820 & 404 \\
\hline $\begin{array}{l}\text { Shank, fore, lean: } \\
\text { Minimum... }\end{array}$ & 69.9 & 20.9 & 5.3 & & 9 & 615 & 136 \\
\hline Maximum ..... & 73.2 & 24.4 & 7.9 & $\cdots$ & 1.1 & 735 & 16.3 \\
\hline Average. . ........... & 71.5 & 22.0 & 6.1 & $\cdots$ & 1.0 & 66.5 & 147 \\
\hline Shank, fore, medium fat: & & & & & & & \\
\hline Minimum.......... & 65.5 & 19.9 & 9.9 & $\ldots$ & .9 & 800 & 177 \\
\hline Maximum ........ & 70.0 & 21.0 & 14.2 & $\cdots$ & 1.0 & 970 & 215 \\
\hline $\begin{array}{l}\text { Average } . . . . \ldots \ldots \\
\text { Shank, hind, lean: }\end{array}$ & 67.9 & 20.4 & 11.6 & $\cdots$ & .9 & 570 & 193 \\
\hline Minimum.......... & 71.3 & 20.8 & 4.3 & . & .9 & 590 & 131 \\
\hline Maximum ..... & 73.6 & 23.1 & 7.3 & $\ldots$ & 1.2 & 715 & 155 \\
\hline Average. ............ & 72.5 & 21.9 & 5.4 & $\cdots$ & 1.0 & 635 & 141 \\
\hline $\begin{array}{l}\text { Shank, hind, medium fat: } \\
\text { Minimum.......... }\end{array}$ & & & & & & & \\
\hline $\begin{array}{l}\text { Minimum........... } \\
\text { Maximum ........ }\end{array}$ & 65.3 & 19.0 & 9.6 & $\cdots$ & .5 & 500 & 177 \\
\hline $\begin{array}{l}\text { Maximum ........... } \\
\text { Average. ......... }\end{array}$ & 69.5 & 21.8 & 15.4 & $\cdots$ & 1.0 & 1,005 & 223 \\
\hline Shoulder and elod, lean: & 08.0 & 20.9 & 11.0 & $\cdots$ & .9 & Sis) & 13.3 \\
\hline Minimum......... & 71.4 & 19.2 & 4.7 & $\cdots$ & 1.0 & 5.55 & 123 \\
\hline Maximum ...... & 74.5 & 22.1 & 6.7 & .. & 1.1 & 680 & 151 \\
\hline Average. ....... & 73.1 & 20.4 & 5.4 & $\cdots$ & 1.1 & 605 & 134 \\
\hline Shoulder and clod, fat: & & & & & & & \\
\hline Minimum......... & 56.2 & 18.1 & 15.5 & $\cdots$ & $\begin{array}{r}.9 \\
1.2\end{array}$ & $\begin{array}{l}1,120 \\
1,320\end{array}$ & $\begin{array}{l}245 \\
293\end{array}$ \\
\hline Maximum........ & 62.1 & 21.9 & 21.6 & $\cdots$ & $\begin{array}{l}1.2 \\
1.0\end{array}$ & $\begin{array}{l}1,320 \\
1,200\end{array}$ & $\begin{array}{l}293 \\
266\end{array}$ \\
\hline $\begin{array}{l}\text { Average....... } \\
\text { Forequarter, lean: }\end{array}$ & 00.4 & 19.3 & 19.0 & & & & 200 \\
\hline Minimum... . & 67.5 & 16.5 & 11.4 & $\cdots$ & .7 & $\$ 15$ & 181 \\
\hline Maximum.... & 71.1 & 20.0 & 12.7 & $\cdots$ & .9 & 910 & 202 \\
\hline Average...... & 68.6 & 18.9 & 12.2 & $\cdots$ & .5 & $\$ 65$ & 192 \\
\hline Hindquarter, lean: & & & & & & & \\
\hline Minimum... . . . & 64.6 & 19.3 & 12.2 & $\cdots$ & $\begin{array}{l}1.0 \\
1.0\end{array}$ & $\begin{array}{l}590 \\
990\end{array}$ & $\begin{array}{l}196 \\
220\end{array}$ \\
\hline $\begin{array}{l}\text { Maximum ....... } \\
\text { Average. . . . . . }\end{array}$ & $\begin{array}{l}67.5) \\
66.3\end{array}$ & $\begin{array}{l}20.6 \\
20.0\end{array}$ & $\begin{array}{l}1+.9 \\
13.4\end{array}$ & $\cdots$ & 1.0 & 93.5 & 207 \\
\hline Hindquarter, medium fat: & & & & & & & \\
\hline Minimum........... & 55.7 & 17.2 & 16.8 & $\cdots$ & $\therefore$ & 1,070 & 237 \\
\hline 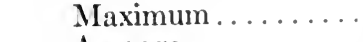 & 63.9 & 19.5 & $\begin{array}{l}26.6 \\
216\end{array}$ & $\cdots$ & $\begin{array}{r}1.0 \\
9\end{array}$ & $\begin{array}{l}1.430 \\
1.250\end{array}$ & $\begin{array}{l}317 \\
277\end{array}$ \\
\hline Average & 59.8 & 15.3 & 21.6 & $\cdots$ & & & 211 \\
\hline
\end{tabular}




\begin{tabular}{|c|c|c|c|c|c|c|c|}
\hline \multirow[b]{2}{*}{ Food Materials } & \multirow[b]{2}{*}{$\begin{array}{c}\text { Per cent } \\
\text { Water }\end{array}$} & \multirow[b]{2}{*}{$\begin{array}{l}\text { Per cent } \\
\text { Protein }\end{array}$} & \multirow[b]{2}{*}{$\begin{array}{l}\text { Per cent } \\
\text { Fat }\end{array}$} & \multirow[b]{2}{*}{$\begin{array}{l}\text { Per cent } \\
\text { Carbo- } \\
\text { hydrates }\end{array}$} & \multirow[b]{2}{*}{$\begin{array}{l}\text { Per cent } \\
\text { Ash }\end{array}$} & \multicolumn{2}{|c|}{ Fuel Value } \\
\hline & & & & & & $\begin{array}{c}\text { Calories } \\
\text { per } \\
\text { Pound }\end{array}$ & $\begin{array}{l}\text { Calories } \\
\text { per } 100 \\
\text { Grams }\end{array}$ \\
\hline $\begin{array}{c}\text { ANIMAL FOOD-Con. } \\
\text { Beef, fresh }\end{array}$ & & & & & & & \\
\hline Sides, lean: & & & & & & & \\
\hline Minimum... . & 66.5 & 17.6 & 12.3 & $\cdots$ & .8 & 905 & 201 \\
\hline $\begin{array}{l}\text { Maximum... } \\
\text { Average. . . . }\end{array}$ & 67.5 & 20.3 & 14.8 & $\cdots$ & $\begin{array}{r}1.0 \\
9\end{array}$ & 950 & 211 \\
\hline $\begin{array}{l}\text { Average. ....... } \\
\text { Sides, medium fat: }\end{array}$ & 67.2 & 19.3 & 13.2 & & & 915 & 203 \\
\hline Minimum...... & 54.8 & 17.2 & 15.7 & $\cdots$ & .8 & 1,020 & 248 \\
\hline $\begin{array}{l}\text { Maximum ........ } \\
\text { Average }\end{array}$ & 64.9 & 19.3 & 27.1 & $\ldots$ & .9 & 1,465 & 325 \\
\hline $\begin{array}{l}\text { Average } \ldots . . . . . . \\
\text { Beef Organs }\end{array}$ & 59.7 & 18.1 & 22.0 & $\cdots$ & .9 & 1,265 & 281 \\
\hline 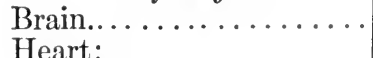 & 80.6 & 8.8 & 9.3 & $\ldots$ & 1.1 & 555 & 123 \\
\hline Minimum........ & 56.5 & 15.7 & 14.6 & $\ldots$ & .9 & 920 & 204 \\
\hline Maximum.... & 68.7 & 16.3 & 26.2 & $\ldots$ & 1.0 & 1,395 & 310 \\
\hline 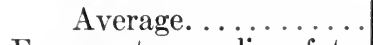 & 62.6 & 16.0 & 20.4 & $\ldots$ & 1.0 & 1,160 & 257 \\
\hline $\begin{array}{c}\text { Forequarter, medium fat: } \\
\text { Minimum.......... }\end{array}$ & & & & & & & \\
\hline 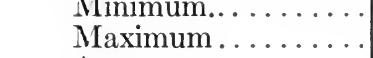 & $\begin{array}{l}54.1 \\
636\end{array}$ & $\begin{array}{l}17.2 \\
19.1\end{array}$ & $\begin{array}{l}17.1 \\
27.6\end{array}$ & $\begin{array}{l}\cdots \\
\cdots\end{array}$ & 1.8 & $\begin{array}{l}1,075 \\
1485\end{array}$ & $\begin{array}{l}238 \\
330\end{array}$ \\
\hline Average. ..... & 60.4 & 17.9 & $21: 4$ & $\ldots$ & .9 & 1,235 & 274 \\
\hline Kidney: & & & & & & & \\
\hline $\begin{array}{l}\text { Minimum... . . } \\
\text { Maximum... }\end{array}$ & $\begin{array}{l}75.7 \\
78.7\end{array}$ & 15.8 & 2.4 & $\cdots$ & 1.1 & 420 & 93 \\
\hline $\begin{array}{l}\text { Maximum ..... } \\
\text { Average. . . . . }\end{array}$ & $\begin{array}{l}78.7 \\
76.7\end{array}$ & $\begin{array}{l}17.1 \\
16.6\end{array}$ & 7.1 & $\ddot{4}$ & $\begin{array}{l}1.3 \\
1.2\end{array}$ & 595 & 132 \\
\hline Beef Liver: & 70.7 & 10.0 & 4.8 & & 1.2 & 520 & \\
\hline Minimum... & 69.5 & 18.1 & 3.3 & 1.0 & 1.3 & 520 & 115 \\
\hline Maximum... & 75.0 & 23.1 & 5.7 & 3.5 & 2.5 & 670 & 148 \\
\hline Average. ....... & 71.2 & 20.4 & 4.5 & 1.7 & 1.6 & 605 & 134 \\
\hline Lungs, as purchased...... & 79.7 & 16.4 & 3.2 & $\ldots$ & 1.0 & 440 & 97 \\
\hline Marrow, as purchased.... & 3.3 & 2.2 & 92.8 & $\ldots$ & 1.3 & 3,955 & 878 \\
\hline Sweetbreads, as purchased & 70.9 & 16.8 & 12.1 & $\ldots$ & 1.6 & 825 & 183 \\
\hline $\begin{array}{c}\text { Suet, as purchased: } \\
\text { Minimum... . . . }\end{array}$ & & & 707 & & & & \\
\hline Maximum........... & $\begin{array}{r}4.0 \\
21.9\end{array}$ & 7.5 & 94.5 & $\cdots$ & .2 & $\begin{array}{l}3,110 \\
4,010\end{array}$ & $\begin{array}{l}091 \\
891\end{array}$ \\
\hline Average........... & 13.7 & 4.7 & 81.8 & $\ldots$ & .3 & 3,540 & 786 \\
\hline Tongue: & & & & & & & \\
\hline Minimum... & 63.5 & 17.0 & .8 & $\cdots$ & .9 & 445 & 98 \\
\hline Maximum......... & 76.2 & 22.2 & 18.0 & $\cdots$ & 1.1 & 1,075 & 238 \\
\hline $\begin{array}{l}\text { Average. } \\
\text { Beef, Cooked }\end{array}$ & 70.8 & 18.9 & 9.2 & $\ldots$ & 1.0 & 740 & 164 \\
\hline $\begin{array}{l}\text { Cut not given, boiled, as } \\
\text { purehased............. }\end{array}$ & 38.1 & 26.2 & 34.9 & & .9 & 2,805 & 623 \\
\hline Minimum......... & 4.5 & 16.3 & 27.7 & $\cdots$ & .7 & 1,660 & 368 \\
\hline Maximum. . & 41.9 & 26.4 & 75.8 & . . & 6.2 & 3,580 & 795 \\
\hline Average. ....... & 23.2 & 21.4 & 51.7 & $\ldots$ & 3.5 & 2,580 & 573 \\
\hline $\begin{array}{l}\text { oast, as purchased: } \\
\text { Minimum........ }\end{array}$ & & & & & & & \\
\hline $\begin{array}{l}\text { Minimum... . . . } \\
\text { Maximum . . . . }\end{array}$ & 38.7 & 15.1 & 19.6 & . & .7 & 1,210 & 268 \\
\hline $\begin{array}{l}\text { Maximul } \\
\text { Average. }\end{array}$ & 59.5 & 29.0 & 41.4 & $\ldots$ & 2.7 & 2,030 & 451 \\
\hline Ay & 48.2 & 22.3 & 28.6 & $\cdots$ & 1.3 & 1,630 & 362 \\
\hline
\end{tabular}




\begin{tabular}{|c|c|c|c|c|c|c|c|}
\hline \multirow[b]{2}{*}{ Food Matemalas } & \multirow[b]{2}{*}{$\begin{array}{l}\text { Percent } \\
\text { Winter }\end{array}$} & \multirow[b]{2}{*}{$\begin{array}{l}\text { Percent } \\
\text { Protein }\end{array}$} & \multirow[b]{2}{*}{$\begin{array}{l}\text { Per cront } \\
\text { lint }\end{array}$} & \multirow[b]{2}{*}{$\begin{array}{l}\text { Percent } \\
\text { ('urlus } \\
\text { hyilrates }\end{array}$} & \multirow[b]{2}{*}{$\begin{array}{c}\text { Perecont } \\
\text { Ants }\end{array}$} & \multicolumn{2}{|c|}{ ICEL VALE: } \\
\hline & & & & & & $\begin{array}{l}\text { ('alorices } \\
\text { Pox.r } \\
\text { Pound }\end{array}$ & $\begin{array}{l}\text { ('aloriox } \\
\text { fxir l(x) } \\
\text { (irame }\end{array}$ \\
\hline $\begin{array}{c}\text { ANIMAL FOOI)-Con. } \\
\text { Berf, cooked }\end{array}$ & & & & & & & \\
\hline $\begin{array}{l}\text { Round stcak fat removed, } \\
\text { as purchased: }\end{array}$ & & & & & & & \\
\hline Minimum............... & 53.5 & 19.4 & 3.3 & 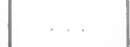 & 1.1 & $61 \%$ & $1: 36$ \\
\hline $\begin{array}{l}\text { Maximın . . . . . . . . . . . . } \\
\text { Average. . . }\end{array}$ & 72.3 & 34.1 & 16.9 & $\ldots$ & 3.1 & $1.1 \% 0$ & 260 \\
\hline $\begin{array}{l}\text { Average. } \\
\text { Sirloin steak, baked, as }\end{array}$ & 63.0 & 27.6 & 7.7 & . & 1.6 & 810 & $1 \times 6$ \\
\hline $\begin{array}{l}\text { purchased......... } \\
\text { Loin steak, tenderloin, } \\
\text { broiled: }\end{array}$ & 6.3 .7 & 23.9 & 10.2 & $\ldots$ & 1.4 & sij & 194 \\
\hline Minimum.......... & 42.7 & 19.8 & 11.8 & $\cdots$ & 1.0 & 925 & $20 i$ \\
\hline Maximum ......... & 64.5 & 26.7 & 35.7 & $\ldots$ & 1.4 & 1,875 & 416 \\
\hline Average. ........... & 54.8 & 23.5 & 20.4 & $\ldots$ & 1.2 & 1,300 & 245 \\
\hline $\begin{array}{l}\text { Sandwich meat, as pur- } \\
\text { chased: }\end{array}$ & & & & & & & \\
\hline Minimum.......... & 56.3 & 27.1 & 8.0 & $\cdots$ & 2.5 & sio & 193 \\
\hline Maximum ......... & 61.2 & 28.6 & 13.6 & $\cdots$ & 3.1 & 1,075 & 235 \\
\hline 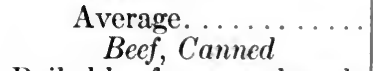 & 58.3 & 28.0 & 11.0 & ... & 2.5 & 985 & 218 \\
\hline Boiled beef, as purchased. & 51.8 & 25.5 & 22.5 & $\cdots$ & 1.3 & 1,425 & 316 \\
\hline $\begin{array}{l}\text { Cheek, ox, as purehased. } \\
\text { Chili - con - carne as pur- }\end{array}$ & 66.1 & 22.2 & S.4 & $\cdots$ & 3.2 & 76.5 & 170 \\
\hline $\begin{array}{l}\text { Chilı - con - carne, as pur- } \\
\text { chased.................. } \\
\text { Collops, minced, as pur- }\end{array}$ & 75.4 & 13.3 & 4.6 & 4.0 & 2.7 & 515 & 114 \\
\hline $\begin{array}{l}\text { conops, minced, as pur- } \\
\text { chased.............. } \\
\text { Corned beef : }\end{array}$ & 72.3 & 17.8 & 6.8 & 1.1 & 1.9 & 640 & 142 \\
\hline Minimum.......... & 43.2 & 20.7 & 11.7 & $\cdots$ & 2.0 & 1,000 & 222 \\
\hline Maximum......... & 58.3 & 35.1 & 31.1 & $\cdots$ & 7.3 & $1,69.5$ & $3 \pi 6$ \\
\hline $\begin{array}{l}\text { Average. . . . . . . } \\
\text { Dried beef, as purchased: }\end{array}$ & 51.8 & 26.3 & 18.7 & $\cdots$ & 4.0 & $1,2 \times 0$ & 24 \\
\hline Minimum .......... & 44.2 & 38.0 & 6.1 & ... & 9.8 & 955 & 292 \\
\hline Maximum......... & 45.3 & 40.4 & 4.8 & $\ldots$ & 12.6 & 965 & 214 \\
\hline Average. ........... & 44.8 & 39.2 & 5.4 & $\cdots$ & 11.2 & 960 & 213 \\
\hline $\begin{array}{l}\text { Luncheon beef, as pur- } \\
\text { chased................... }\end{array}$ & 52.9 & 27.6 & 15.9 & $\cdots$ & 4.8 & $1,1 \times 5$ & 263 \\
\hline $\begin{array}{l}\text { Kidneys, stewed, as pur- } \\
\text { chased: }\end{array}$ & & & & & & & \\
\hline Minimum.......... & 70.9 & 14.6 & 4.9 & & 2.1 & 580 & 122 \\
\hline Maximum......... & 72.9 & 22.1 & 5.4 & 4.3 & 2.5 & 620 & 137 \\
\hline Average. ............ & 71.9 & $1 \mathrm{~S} .4$ & 5.1 & 2.1 & 2.5 & 600 & $13: 3$ \\
\hline Palates, ox, as purchased: & & & 94 & & & & \\
\hline 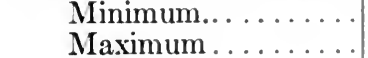 & $\begin{array}{l}69.6 \\
73.1\end{array}$ & $\begin{array}{l}16.4 \\
19.3\end{array}$ & $\begin{array}{r}9.7 \\
10.6\end{array}$ & $\cdots$ & 2.0 & $\begin{array}{l}750 \\
75.5\end{array}$ & $\begin{array}{l}166 \\
167\end{array}$ \\
\hline 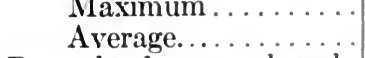 & 71.4 & 17.8 & 10.0 & $\ldots$ & 1.2 & 755 & 167 \\
\hline Roast beef, as purchased: & & & & & & & \\
\hline Minimum.......... & 55.8 & 20.3 & 9.0 & $\cdots$ & 1.2 & 93.5 & 207 \\
\hline $\begin{array}{l}\text { Maximum ..... } \\
\text { Average ..... }\end{array}$ & 62.8 & 29.8 & 23.6 & $\cdots$ & $\begin{array}{l}1.4 \\
1.3\end{array}$ & 1,375 & $\begin{array}{l}305 \\
245\end{array}$ \\
\hline Average...... & 58.9 & 25.9 & 14.5 & & $1.0)$ & $1,10)$. & -2.) \\
\hline
\end{tabular}




\begin{tabular}{|c|c|c|c|c|c|c|c|}
\hline \multirow[b]{2}{*}{ Food Materials } & \multirow[b]{2}{*}{$\begin{array}{l}\text { Per cent } \\
\text { Water }\end{array}$} & \multirow[b]{2}{*}{$\begin{array}{l}\text { Per cent } \\
\text { Protein }\end{array}$} & \multirow[b]{2}{*}{ Per cent } & \multirow[b]{2}{*}{$\mid \begin{array}{c}\text { Per cent } \\
\text { Carbo- } \\
\text { hydrates }\end{array}$} & \multirow[b]{2}{*}{$\begin{array}{c}\text { Per cent } \\
\text { Ash }\end{array}$} & \multicolumn{2}{|c|}{ Fuel Value } \\
\hline & & & & & & $\begin{array}{c}\text { Calories } \\
\text { per } \\
\text { Pound }\end{array}$ & $\mid \begin{array}{c}\text { Calories } \\
\text { per } 100 \\
\text { Grams }\end{array}$ \\
\hline $\begin{array}{l}\text { ANIMAL FOOD-Con. } \\
\text { Bcef, canned }\end{array}$ & & & & & & & \\
\hline Rumpsteak, as purchased. & 56.3 & 24.3 & 18.7 & $\ldots$ & 1.5 & 1,240 & 275 \\
\hline Sweetbreads, as purchased & 69.0 & 20.2 & 9.5 & $\ldots$ & 2.0 & 775 & 172 \\
\hline Tails, ox, as purchased... & 47.7 & 18.5 & 4.5 & $\ldots$ & .8 & 535 & 118 \\
\hline $\begin{array}{l}\text { Tongue, ground, as pur- } \\
\text { chased: }\end{array}$ & & & & & & & \\
\hline Minimum......... & 42.5 & 20.1 & 21.6 & $\ldots$ & 2.9 & 1,305 & 290 \\
\hline Maximum ......... & 54.9 & 23.6 & 32.6 & $\ldots$ & 5.1 & 1,750 & 388 \\
\hline Average........... & 49.9 & 21.4 & 25.1 & $\ldots$ & 4.0 & 1,455 & 323 \\
\hline $\begin{array}{l}\text { Tongue, whole, as pur- } \\
\text { chased: }\end{array}$ & & & & & & & \\
\hline Minimum.......... & 42.4 & 10.8 & 15.7 & $\ldots$ & 3.0 & 865 & 192 \\
\hline Maximum .... & 57.4 & 23.4 & 32.7 & $\ldots$ & 6.3 & 1,725 & 383 \\
\hline Average. . . & 51.3 & 19.5 & 23.2 & $\ldots$ & 4.0 & 1,340 & 297 \\
\hline Tripe, as purchased: & & & & & & & \\
\hline Minimum.......... & 68.9 & 16.5 & 2.6 & $\cdots$ & .4 & 425 & 93 \\
\hline Maximum......... & 80.2 & 17.0 & 14.5 & $\ldots$ & .6 & 920 & 204 \\
\hline Average. .......... & 74.6 & 16.8 & 8.5 & $\cdots$ & .5 & 670 & 148 \\
\hline Beef, corned and pickled & & & & & & & \\
\hline $\begin{array}{l}\text { Brisket, as purchased.... } \\
\text { Flank: }\end{array}$ & 40.0 & 14.4 & 19.4 & $\ldots$ & 4.5 & 1,085 & 241 \\
\hline Minimum........... & 43.2 & 13.1 & 24.9 & $\ldots$ & 2.8 & 1,350 & 300 \\
\hline Maximum . & 56.5 & 16.1 & 51.1 & $\ldots$ & 3.1 & 1,980 & 440 \\
\hline Average. & 49.9 & 14.6 & 33.0 & $\ldots$ & 2.9 & 1,665 & 370 \\
\hline $\begin{array}{l}\text { Plate, as purchased ...... } \\
\text { Rump: }\end{array}$ & 34.3 & 11.7 & 35.8 & $\ldots$ & 4.0 & 1,730 & 384 \\
\hline Minimum.. & 50.2 & 13.3 & 13.0 & & 2.0 & 880 & 195 \\
\hline Maximum . & 65.9 & 17.8 & 30.2 & $\cdots$ & 4.9 & 1,550 & 344 \\
\hline Average. .......... & 58.1 & 15.3 & 23.3 & $\cdots$ & 3.3 & 1,270 & 282 \\
\hline $\begin{array}{l}\text { Extra family beef, as pur- } \\
\text { chased................ }\end{array}$ & 33.1 & 11.1 & 42.3 & $\ldots$ & 3.6 & 1,990 & 442 \\
\hline $\begin{array}{l}\text { Mess beef, salted: } \\
\text { Minimum... . }\end{array}$ & 31.7 & 11.3 & 40.2 & & 4.1 & & 434 \\
\hline Maximum .... & 42.4 & 13.8 & 48.7 & $\cdots$ & $\begin{array}{l}4.1 \\
9.0\end{array}$ & 2,265 & $\begin{array}{l}404 \\
503\end{array}$ \\
\hline Average. . ............. & 37.0 & 12.6 & 44.5 & $\ldots$ & 6.5 & 2,110 & 468 \\
\hline $\begin{array}{l}\text { Corned beef, all analyses, } \\
\text { as purchased. . . . . . . . } \\
\text { Spiced beef, rolled, as pur- }\end{array}$ & 49.2 & 14.3 & 23.8 & & 4.6 & 1,271 & 282 \\
\hline $\begin{array}{l}\text { chased... pickled: } \\
\text { Tongues, }\end{array}$ & 30.0 & 12.0 & 51.4 & & 6.8 & 2,390 & 531 \\
\hline Minimum.. & 50.9 & 8.3 & 15.3 & & 3.1 & 800 & 177 \\
\hline Maximum . & 73.6 & 17.3 & 25.8 & $\because$ & 6.3 & 1,410 & 313 \\
\hline Average. ....... & 62.3 & 12.8 & 20.5 & $\cdots$ & 4.7 & 1,105 & 245 \\
\hline $\begin{array}{c}\text { Tripe, as purchased: } \\
\text { Minimum... . . }\end{array}$ & 840 & & 0 & & & & \\
\hline Maxin & $\begin{array}{l}84.0 \\
91.1\end{array}$ & $\begin{aligned} 7.1 \\
18.6\end{aligned}$ & 1.8 & .4 & $\begin{array}{l}.1 \\
.4\end{array}$ & $\begin{array}{l}185 \\
335\end{array}$ & $\begin{array}{l}41 \\
74\end{array}$ \\
\hline Average. & 86.5 & 11.7 & 1.2 & .2 & .3 & 270 & 60 \\
\hline
\end{tabular}




\begin{tabular}{|c|c|c|c|c|c|c|c|}
\hline \multirow[b]{2}{*}{ Food Materials } & \multirow[b]{2}{*}{$\begin{array}{l}\text { Per cent } \\
\text { Water }\end{array}$} & \multirow[b]{2}{*}{$\begin{array}{l}\text { Per cent } \\
\text { Protcin }\end{array}$} & \multirow[b]{2}{*}{$\begin{array}{l}\text { Percent } \\
\text { liat }\end{array}$} & \multirow[b]{2}{*}{$\begin{array}{l}\text { Percent } \\
\text { Cirlor } \\
\text { hydrates }\end{array}$} & \multirow[b]{2}{*}{$\begin{array}{l}\text { Percent } \\
\text { Ash }\end{array}$} & \multicolumn{2}{|c|}{ Fuser Valer: } \\
\hline & & & & & & $\begin{array}{c}\text { ('sloricx } \\
\text { Juer } \\
\text { Pousud }\end{array}$ & $\begin{array}{l}\text { Colorios } \\
\text { per } 1(x) \\
\text { firams }\end{array}$ \\
\hline $\begin{array}{c}\text { ANIMAL, FOOD-Con. } \\
\text { Beef, dried, etc. }\end{array}$ & & & & & & & \\
\hline $\begin{array}{l}\text { Dried, salted, and smoked: } \\
\text { Minimum }\end{array}$ & & & & & & & \\
\hline $\begin{array}{l}\text { Minimum........... } \\
\text { Maximum........ }\end{array}$ & $\begin{array}{l}24.3 \\
6.5 .4\end{array}$ & 24.4 & 2.5 & & 6.3 & $\therefore, 70$ & 126 \\
\hline Average............. & $\begin{array}{l}\text { (1.). } \\
54.3\end{array}$ & $\begin{array}{l}47.5 \\
30.0\end{array}$ & $\begin{aligned} 11.5 \\
6.5\end{aligned}$ & $\begin{array}{r}2.7 \\
(3) .4\end{array}$ & $\begin{array}{r}16.9 \\
9.1\end{array}$ & $\begin{array}{l}920 \\
810\end{array}$ & $\begin{array}{l}204 \\
1 \times 6\end{array}$ \\
\hline Veal, fresh & & & & & & & \\
\hline Breast, lean: & & & & & & & \\
\hline $\begin{array}{l}\text { Minimum......... } \\
\text { Maximum........... }\end{array}$ & 68.4 & 19.6 & 8.0 & .. & 1.0 & 700 & 155 \\
\hline $\begin{array}{l}\text { Maximum . . . . . . . . . } \\
\text { Average. . }\end{array}$ & 72.2 & 22.9 & 8.0 & $\cdots$ & 1.1 & 76.5 & 170 \\
\hline $\begin{array}{l}\text { Average........... } \\
\text { Breast, medium fat: }\end{array}$ & 70.3 & 21.2 & 8.0 & $\cdots$ & 1.0 & 730 & 162 \\
\hline Minimum........ & 65.1 & 19.1 & 12.0 & $\ldots$ & 1.0 & 870 & 193 \\
\hline Maximum......... & 68.4 & 19.9 & 1.5 .4 & $\ldots$ & 1.0 & 1,010 & 224 \\
\hline Average............ & 66.4 & 19.4 & 13.8 & $\ldots$ & 1.0 & 930 & 206 \\
\hline $\begin{array}{l}\text { Chuck, lean............ } \\
\text { Chuck, medium fat: }\end{array}$ & 76.3 & $\cdots$ & 1.9 & $\ldots$ & 1.2 & 46.5 & 103 \\
\hline Minimum.......... & 71.5 & 19.1 & 5.1 & $\cdots$ & 1.0 & 570 & 126 \\
\hline Maximum........ & 75.4 & 21.1 & 8.5 & $\ldots$ & 1.0 & 715 & 155 \\
\hline Average. ........... & 73.3 & 19.7 & 6.5 & $\ldots$ & 1.0 & 640 & 142 \\
\hline $\begin{array}{l}\text { Flank, medium fat, as pur- } \\
\text { chased: }\end{array}$ & & & & & & & \\
\hline Minimum.......... & 64.4 & 19.4 & 7.8 & $\ldots$ & .9 & 690 & 153 \\
\hline Maximum......... & 72.7 & 21.5 & 15.8 & $\ldots$ & 1.1 & $1,0: 35$ & 230 \\
\hline Average. ........... & 68.9 & 20.5 & 10.4 & $\ldots$ & 1.0 & 820 & 152 \\
\hline $\begin{array}{l}\text { Flank, fat, as purchased.. } \\
\text { Flank, all analyses, as pur- }\end{array}$ & 57.0 & 18.1 & 24.1 & $\ldots$ & .9 & $1,3,5,5$ & 301 \\
\hline $\begin{array}{l}\text { chased................ } \\
\text { Leg, lean: }\end{array}$ & 66.9 & 20.1 & 12.7 & $\cdots$ & 1.0 & 910 & 202 \\
\hline Minimum...... & 71.5 & 20.3 & 1.1 & $\ldots$ & 1.1 & 46.5 & 103 \\
\hline Maximum..... & 75.6 & 22.6 & 6.4 & $\ldots$ & 1.3 & 660 & 146 \\
\hline Average ............ & 73.5 & 21.3 & 4.1 & $\cdots$ & 1.2 & 370 & 126 \\
\hline $\begin{array}{l}\text { medium tat: } \\
\text { Minimum.......... }\end{array}$ & 67.8 & $1 S .2$ & 6.7 & $\ldots$ & 1.0 & $6 \pi 0$ & lis \\
\hline Maximum......... & 72.1 & 21.4 & 11.7 & $\cdots$ & 1.2 & 1,780 & 395 \\
\hline Average. ........... & 70.0 & 20.2 & 9.0 & $\ldots$ & 1.2 & 753 & 166 \\
\hline Leg, cutlets: & & & & & & & \\
\hline Minimum...... & 67.3 & 20.1 & 3.3 & $\cdots$ & 1.0 & 515 & 114 \\
\hline Maximum..... & 75.4 & 20.5 & 10.6 & $\ldots$ & 1.2 & $\mathrm{~S} 30$ & 154 \\
\hline Average. . . . . . . & 70.7 & 20.3 & 7.7 & $\cdots$ & 1.1 & 705 & 156 \\
\hline $\begin{array}{l}\text { n, lean: } \\
\text { Minimum. . }\end{array}$ & 71.3 & 18.8 & 4.5 & $\ldots$ & 1.0 & 565 & 125 \\
\hline Maximum ..... & 75.4 & 21.5 & 6.7 & $\cdots$ & 1.2 & $6 \vee 0$ & 151 \\
\hline Average. ....... & 73.3 & 20.4 & 5.6 & $\ldots$ & 1.2 & $61 \%$ & 136 \\
\hline Loin, medium fat: & & & & & & & \\
\hline Minimum...... & 67.9 & $1 S .3$ & 10.1 & $\cdots$ & 1.0 & 80.5 & 175 \\
\hline Maximum..... & 69.7 & 20.3 & 13.0 & $\ldots$ & 1.1 & 590 & 197 \\
\hline Average... & 69.0 & 19.9 & 10.5 & $\cdots$ & 1.0 & 525 & 153 \\
\hline
\end{tabular}




\begin{tabular}{|c|c|c|c|c|c|c|c|}
\hline \multirow[b]{2}{*}{ Food Materials } & \multirow[b]{2}{*}{$\begin{array}{l}\text { Per cent } \\
\text { Water }\end{array}$} & \multirow[b]{2}{*}{$\begin{array}{r}\text { Per cent } \\
\text { Protein }\end{array}$} & \multirow[b]{2}{*}{$\begin{array}{l}\text { Per cent } \\
\text { Fat }\end{array}$} & \multirow[b]{2}{*}{$\begin{array}{c}\text { Per cent } \\
\text { Carbo- } \\
\text { hydrates }\end{array}$} & \multirow[b]{2}{*}{$\begin{array}{c}\text { Per cent } \\
\text { Ash }\end{array}$} & \multicolumn{2}{|c|}{ Fuel Value } \\
\hline & & & & & & $\begin{array}{c}\text { Calories } \\
\text { per } \\
\text { Pound }\end{array}$ & $\mid \begin{array}{l}\text { Calories } \\
\text { per } 100 \\
\text { Grams }\end{array}$ \\
\hline \multicolumn{8}{|l|}{$\begin{array}{c}\text { ANIMAL FOOD-Con. } \\
\text { Veal, fresh }\end{array}$} \\
\hline \multicolumn{8}{|l|}{ Loin, fat: } \\
\hline 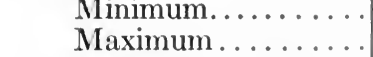 & $\begin{array}{l}61.3 \\
61.9\end{array}$ & $\begin{array}{l}18.0 \\
19.3\end{array}$ & $\begin{array}{l}18.3 \\
19.4\end{array}$ & $\begin{array}{l}\cdots \\
\ldots\end{array}$ & $\begin{array}{l}1.0 \\
1.1\end{array}$ & $\begin{array}{l}1,130 \\
1,155\end{array}$ & $\begin{array}{l}251 \\
256\end{array}$ \\
\hline Average............ & 61.6 & 18.7 & 18.9 & .. & 1.0 & 1,145 & 254 \\
\hline \multicolumn{8}{|l|}{ Neek: . } \\
\hline $\begin{array}{l}\text { Minimum.. } \\
\text { Maximum . }\end{array}$ & 75.8 & $\begin{array}{l}19.9 \\
20.8\end{array}$ & $\begin{array}{l}4.3 \\
9.2\end{array}$ & $\begin{array}{l}\cdots \\
\cdots\end{array}$ & $\begin{array}{r}.9 \\
1.1\end{array}$ & $\begin{array}{l}555 \\
775\end{array}$ & $\begin{array}{l}123 \\
172\end{array}$ \\
\hline Average. ........... & 72.6 & 20.3 & 6.9 & $\ldots$ & 1.0 & 670 & 148 \\
\hline \multicolumn{8}{|l|}{ Rib, medium fat } \\
\hline Maximum... & 75.5 & 21.7 & 9.3 & $\ldots$ & 1.2 & 770 & 171 \\
\hline Average. . . & 72.7 & 20.7 & 6.1 & $\ldots$ & 1.1 & 640 & 142 \\
\hline \multicolumn{8}{|l|}{ Ribs, fat: } \\
\hline $\begin{array}{l}\text { Minimu } \\
\text { Maxim? }\end{array}$ & 50.1 & 16.2 & 11.1 & $\cdots$ & .9 & 840 & 186 \\
\hline $\begin{array}{l}\text { Maximum . } \\
\text { Average. . . }\end{array}$ & $\begin{array}{l}6 \\
6\end{array}$ & $\begin{array}{l}20.0 \\
18.7\end{array}$ & $\begin{array}{l}31.5 \\
19.3\end{array}$ & $\begin{array}{l}\cdots \\
\ldots\end{array}$ & 1.1 & 1,630 & $\begin{array}{l}362 \\
257\end{array}$ \\
\hline Rump, as purchased.... & 43.7 & 13.8 & 11.3 & $\cdots$ & $\begin{array}{r}1.0 \\
.8\end{array}$ & $\begin{array}{c}1,160_{\circ}^{\circ} \\
735\end{array}$ & $\begin{array}{l}258 \\
163\end{array}$ \\
\hline \multicolumn{8}{|l|}{ Shank, fore: } \\
\hline Minimum............... & 72.5 & 19.8 & 4.1 & $\ldots$ & 1.0 & 540 & 120 \\
\hline $\begin{array}{l}\text { Maximum.......... } \\
\text { Average. }\end{array}$ & 75.8 & 21.4 & 6.4 & $\cdots$ & 1.0 & 655 & 145 \\
\hline $\begin{array}{l}\text { Average. ............ } \\
\text { Shank, hind, medium fat: }\end{array}$ & 74.0 & 20.7 & \multicolumn{4}{|c|}{ Shank, hind, medium fat: } & 134 \\
\hline $\begin{array}{l}\text { Shank, nind, medium tat: } \\
\text { Minimum............ }\end{array}$ & 73.4 & 18.9 & 3.0 & . . & .9 & 520 & 115 \\
\hline Maximum......... & 76.2 & 21.6 & 6.7 & $\ldots$ & 1.1 & 635 & 141 \\
\hline Average............ & 74.5 & 20.7 & 4.6 & $\ldots$ & 1.0 & 520 & 128 \\
\hline \multicolumn{8}{|l|}{ Shoulder, lean: } \\
\hline Minimum......... & 71.9 & 20.7 & 3.1 & $\ldots$ & 1.2 & 515 & 114 \\
\hline Maximum......... & 74.9 & 20.7 & 6.2 & $\ldots$ & 1.3 & 635 & 141 \\
\hline Average............. & 73.4 & 20.7 & 4.6 & .. & 1.3 & 520 & 128 \\
\hline \multicolumn{8}{|l|}{$\begin{array}{l}\text { Shoulder and flank, me- } \\
\text { dium fat: }\end{array}$} \\
\hline Minimum..... & 64.7 & 19.3 & 13.5 & $\cdots$ & 1.1 & 945 & 210 \\
\hline Maximum..... & 65.6 & 20.1 & 15.2 & $\cdots$ & 1.2 & 1,000 & 222 \\
\hline \multirow{2}{*}{\multicolumn{7}{|c|}{ Forequarter: }} & 218 \\
\hline & & & & ․ & .8 & 595 & \\
\hline Maximum... & 74.8 & 20.9 & 10.6 & $\ldots$ & 1.1 & 810 & 180 \\
\hline Average...... & 71.7 & 20.0 & 8.0 & .. & .9 & 710 & 157 \\
\hline \multicolumn{8}{|l|}{ Hind quarter: } \\
\hline Minimum... & 68.4 & 19.6 & 5.6 & . & .8 & 620 & 137 \\
\hline Maximum... & 73.8 & 20.8 & 11.2 & $\ldots$ & 1.2 & 835 & 185 \\
\hline Average. ............ & 70.9 & 20.7 & 8.3 & $\cdots$ & 1.0 & 735 & 163 \\
\hline \multicolumn{8}{|l|}{$\begin{array}{l}\text { Side, with kidney, fat, and } \\
\text { tallow: }\end{array}$} \\
\hline Minimum..... & 69.2 & 19.8 & 5.5 & & .9 & 605 & 134 \\
\hline Maximum ..... & 74.3 & 20.7 & 10.3 & $\ldots$ & 1.1 & 805 & 178 \\
\hline Average...... & 71.3 & 20.2 & 8.1 & $\ldots$ & 1.0 & 715 & 158 \\
\hline
\end{tabular}




\begin{tabular}{|c|c|c|c|c|c|c|c|}
\hline \multirow[b]{2}{*}{ Food Materials } & \multirow[b]{2}{*}{$\begin{array}{l}\text { Per cent } \\
\text { Water }\end{array}$} & \multirow[b]{2}{*}{$\begin{array}{l}\text { Per cent } \\
\text { Protein }\end{array}$} & \multirow[b]{2}{*}{$\begin{array}{l}\text { Percent } \\
\text { lint }\end{array}$} & \multirow[b]{2}{*}{$\begin{array}{l}\text { Percent } \\
\text { Ciutlo- } \\
\text { hyidratem }\end{array}$} & \multirow[b]{2}{*}{$\begin{array}{c}\text { Percent } \\
\text { Ash }\end{array}$} & \multicolumn{2}{|c|}{ Fun. Valev: } \\
\hline & & & & & & $\begin{array}{l}\text { Conlorios } \\
\text { per } \\
\text { Pound }\end{array}$ & $\begin{array}{l}\text { Cialorios } \\
\text { per I0x) } \\
\text { Ciraman }\end{array}$ \\
\hline $\begin{array}{c}\text { ANIMAI FOOD-Con. } \\
\text { Veal Organs }\end{array}$ & & & . & & & & \\
\hline $\begin{array}{l}\text { Heart, as purchased...... } \\
\text { Kidneys, as purchased: }\end{array}$ & 73.2 & 16.8 & 9.6 & $\cdots$ & 1.0 & 720 & $1(x)$ \\
\hline Minimum............. & 74.7 & 16.6 & 5.4 & $\ldots$ & 1.3 & 545 & 121 \\
\hline Maximum . . . . . . . & 76.8 & 17.1 & 7.4 & $\cdots$ & 1.4 & 620 & 137 \\
\hline $\begin{array}{l}\text { Average. ......... } \\
\text { Liver, as purchised: }\end{array}$ & 75.8 & 16.9 & 6.4 & .. & 1.3 & 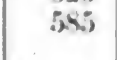 & 130 \\
\hline 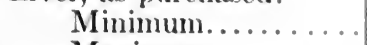 & 72.4 & 18.4 & 4.0 & $\ldots$ & 1.2 & 53.5 & 118 \\
\hline Maximum ........ & 73.7 & 19.6 & 6.6 & ... & 1.3 & 620 & 137 \\
\hline Average. ............ & 73.0 & 19.0 & 5.3 & $\ldots$ & 1.3 & 575 & 127 \\
\hline $\begin{array}{l}\text { Lungs, as purchased. . . } \\
\text { Lamb, fresh }\end{array}$ & 76.8 & 17.1 & 5.0 & $\cdots$ & 1.1 & 530 & 117 \\
\hline $\begin{array}{l}\text { Breast or ehuek, as pur- } \\
\text { chased, ............ } \\
\text { Leg, hind, medium fat: }\end{array}$ & 45.5 & 15.4 & 19.1 & $\ldots$ & .5 & 1,090 & 242 \\
\hline Minimum............ & 63.1 & 18.7 & 15.3 & $\ldots$ & 1.1 & 1,010 & 224 \\
\hline Maximum......... & 64.7 & 19.7 & 17.6 & .. & 1.2 & 1,090 & 242 \\
\hline $\begin{array}{l}\text { Average. . . . . . . . . } \\
\text { Leg hind fat: as pur- }\end{array}$ & 63.9 & 19.2 & $16 . \overline{5}$ & $\cdots$ & 1.1 & 1,055 & 234 \\
\hline $\begin{array}{l}\text { chased................ } \\
\text { Leg, hind, very fat: as }\end{array}$ & 47.3 & 15.8 & 23.7 & $\ldots$ & .8 & 1,295 & 257 \\
\hline $\begin{array}{l}\text { purchased............... } \\
\text { Leg, hind, all analyses: as }\end{array}$ & 48.2 & 16.4 & 28.0 & $\ldots$ &.$s$ & 1,455 & 330 \\
\hline $\begin{array}{l}\text { purchased....... } \\
\text { Leg, free from all visible }\end{array}$ & 50.3 & 16.0 & 19.7 & $\ldots$ & .9 & 1,130 & 251 \\
\hline fat, as purchased...... & 72.3 & 25.3 & 2.7 & $\cdots$ & 1.4 & 555 & 130 \\
\hline $\begin{array}{l}\text { Loin, without kidney and } \\
\text { tallow: }\end{array}$ & & & & & & & \\
\hline $\begin{array}{l}\text { Minimum....... } \\
\text { Maximum ..... }\end{array}$ & 48.6 & 16.9 & 25.1 & $\ldots$ & .8 & $1,4: 20$ & 315 \\
\hline Maximum......... & 54.8 & 20.2 & 35.1 & $\cdots$ & 1.1 & 1,795 & 395 \\
\hline Average........... & 53.1 & 18.7 & 28.3 & $\cdots$ & 1.0 & 1,540 & 342 \\
\hline Neck............ & 56.7 & 17.7 & 24.5 & $\cdots$ & 1.0 & 1,375 & 305 \\
\hline Shoulder............... & 51.8 & 18.1 & 29.7 & $\cdots$ & 1.0 & 1.590 & 353 \\
\hline Forequarter............ & 55.1 & 18.3 & 25.8 & $\ldots$ & 1.0 & 1,430 & 317 \\
\hline Hind quarter............. & 60.9 & 19.6 & 19.1 & .. & 1.0 & 1,170 & 260 \\
\hline $\begin{array}{l}\text { Side, without tallow: } \\
\text { Minimum.......... }\end{array}$ & 56.8 & 17.0 & 21.2 & $\ldots$ & 1.0 & 1.235 & 274 \\
\hline Maximum ........... & 60.0 & 18.9 & 25.7 & $\ldots$ & 1.1 & 1,400 & 311 \\
\hline $\begin{array}{c}\text { Average. .......... } \\
\text { Lamb }, \text { cooked }\end{array}$ & 58.2 & 17.6 & 23.1 & .. & 1.1 & 1,300 & 205 \\
\hline $\begin{array}{l}\text { Chops, broiled: } \\
\text { Minimum...... }\end{array}$ & 43.4 & 19.2 & 24.3 & $\ldots$ & 1.1 & 1,495 & 332 \\
\hline Maximum.... & 50.4 & 25.2 & 34.7 & $\cdots$ & 1.7 & 1.560 & 413 \\
\hline Average........... & 47.6 & 21.7 & 29.9 & $\therefore$ & 1.3 & 1,665 & 370 \\
\hline Leg, roast. . ............. & 67.1 & 19.7 & 12.7 & $\therefore$ & s & 900 & 200 \\
\hline $\begin{array}{c}\text { T o n g u e, spiced and } \\
\text { cooked.................... }\end{array}$ & 67.4 & 13.9 & 17.5 & $\ldots$ &.$j$ & 1,010 & 224 \\
\hline
\end{tabular}




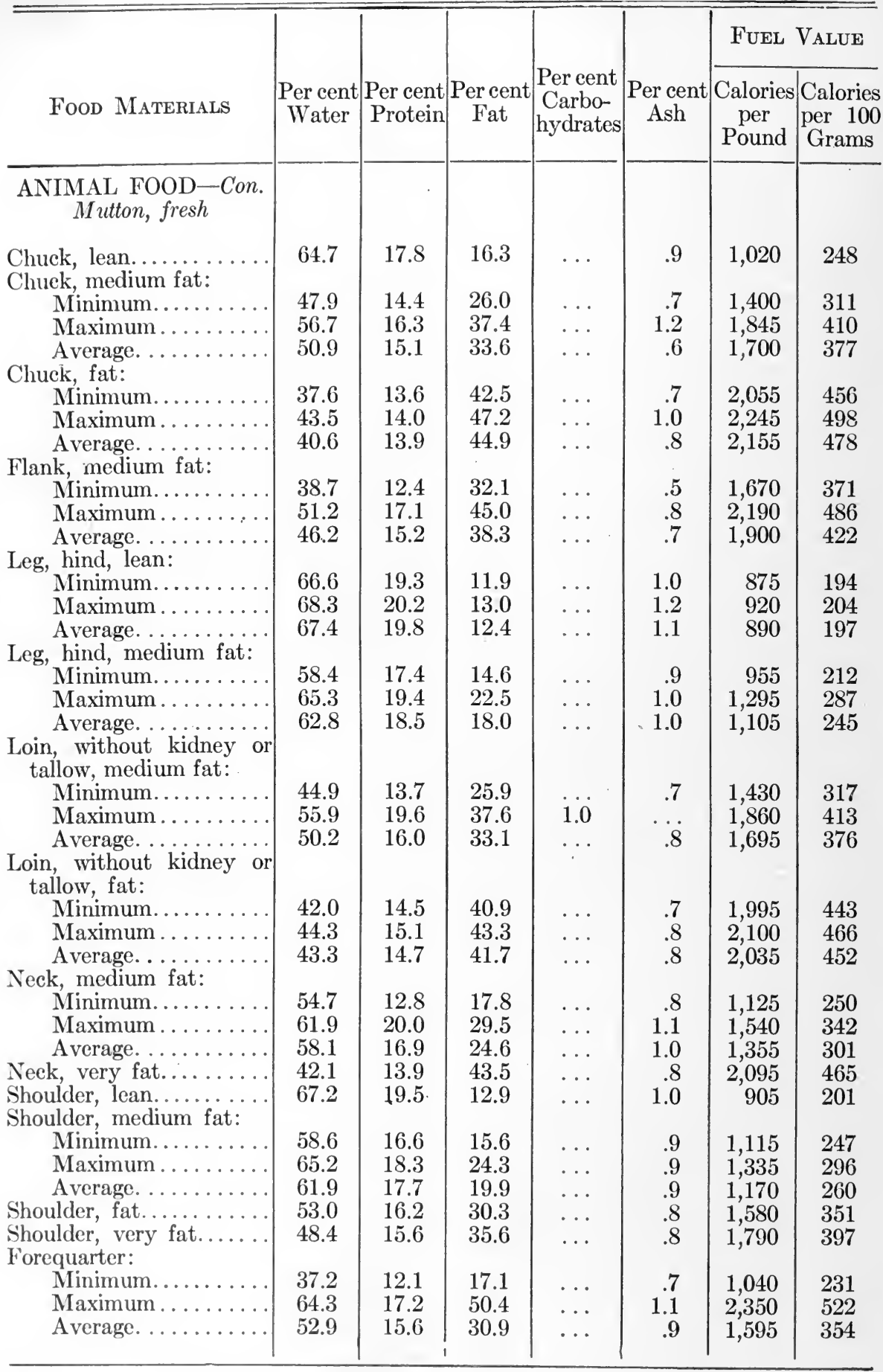




\begin{tabular}{|c|c|c|c|c|c|c|c|}
\hline & & & & & & Fun. & Vaste: \\
\hline Food Materials & $\begin{array}{l}\text { Per eent } \\
\text { Water }\end{array}$ & $\begin{array}{l}\text { Per cent } \\
\text { Protein }\end{array}$ & $\begin{array}{l}\text { Per cent } \\
\text { l'at }\end{array}$ & $\begin{array}{l}\text { Per cent } \\
\text { Carbo- } \\
\text { hydrates }\end{array}$ & $\begin{array}{l}\text { Percent } \\
\text { Axh }\end{array}$ & $\begin{array}{c}\text { Caloriex } \\
\text { per } \\
\text { Pound }\end{array}$ & $\begin{array}{l}\text { Caloriow } \\
\text { yor } 1(x) \\
\text { Ciramus }\end{array}$ \\
\hline $\begin{array}{c}\text { ANIMAL lOOD -Cion. } \\
\text { Mutton, fresh }\end{array}$ & & & & & & & \\
\hline Hindquarter: & & & & & & & \\
\hline Minimum. . & 40.4 & 13.2 & 21.4 & $\ldots$ & (i) & 1,235 & 274 \\
\hline Maximum ........ & (60). 4 & is.2 & 46.1 & ... & 1.0 & 2,190 & INB \\
\hline $\begin{array}{l}\text { Average.......... } \\
\text { Side, ineluding tallow: }\end{array}$ & 54.8 & 16.7 & 23.1 & .. & . & 1,495 & 332 \\
\hline Minimum. . . . . . . & 47.2 & 14.5 & 14.7 & $\ldots$ & .7 & 965 & 214 \\
\hline Maximum.......... & 55.9 & 18.9 & 38.0 & ... & 1.0 & 1,860 & 413 \\
\hline $\begin{array}{l}\text { Average. ............ } \\
\text { Side, not including tallow: }\end{array}$ & 54.2 & 16.3 & 25.9 & $\ldots$ & .9 & 1,520 & 337 \\
\hline Minimum........... & 38.5 & 12.6 & 23.3 & $\ldots$ & .7 & 1,295 & 257 \\
\hline Maximum ... & 58.8 & 17.4 & 48.2 & $\cdots$ & .9 & 2,265 & 503 \\
\hline Average. ........ & 53.6 & 16.2 & 29.8 & ... & s & $1,5(60)$ & 346 \\
\hline $\begin{array}{l}\text { Mutton, cooked } \\
\text { Mutton, leg roast: }\end{array}$ & & & & & & & \\
\hline Minimum........ & 50.8 & 23.3 & 20.5 & $\ldots$ & 1.2 & $1,3 \times 0$ & 306 \\
\hline Maximum........ & 51.0 & 27.8 & 24.6 & $\ldots$ & 1.3 & 1,470 & 326 \\
\hline Average. ........... & 50.9 & 25.0 & 22.6 & $\ldots$ & 1.2 & 1,420 & 315 \\
\hline Heart, as purchased: & & & & & & & \\
\hline Minimum....... . & 67.4 & 15.8 & 11.9 & $\cdots$ & .9 & 795 & 176 \\
\hline Maximum ......... & 71.6 & 18.0 & 13.4 & $\ldots$ & .9 & 890 & 197 \\
\hline Average. .... & 69.5 & 16.9 & 12.6 & $\cdots$ & .9 & 845 & 157 \\
\hline Kidney, as purchased: & & & & & & & \\
\hline Minimum............ & 2.9 & 1.7 & 94.9 & $\ldots$ & .1 & 4,035 & 896 \\
\hline Maximum ......... & 3.9 & 1.8 & 95.8 & $\ldots$ & .1 & 4,075 & 905 \\
\hline $\begin{array}{l}\text { Average. ........ } \\
\text { Liver, as purchased: }\end{array}$ & 3.4 & 1.8 & 95.4 & $\cdots$ & .1 & 4,060 & 902 \\
\hline $\begin{array}{l}\text { Liver, as purehased: } \\
\text { Minimum....... }\end{array}$ & & & & & & & \\
\hline $\begin{array}{l}\text { Minimum....... } \\
\text { Maximum . . . . }\end{array}$ & 52.7 & 23.1 & 4.7 & 2.1 & 1.4 & 645 & 14.3 \\
\hline $\begin{array}{l}\text { Maximum . . . . . . } \\
\text { Average. . . . . }\end{array}$ & 69.8 & 24.2 & 13.2 & 7.9 & 2.0 & 1,155 & 256 \\
\hline $\begin{array}{l}\text { Average. ........ } \\
\text { Lungs, as purchased }\end{array}$ & 61.2 & 23.1 & 9.0 & 5.0 & 1.7 & 905 & 201 \\
\hline $\begin{array}{l}\text { Lungs, as puren } \\
\text { Minimum. . }\end{array}$ & 74.6 & 19.0 & 2.6 & & 1.2 & 475 & 105 \\
\hline Maximum.... & 77.1 & 21.4 & 2.9 & ... & 1.3 & $50 ;$ & 112 \\
\hline Average. ... & 75.9 & 20.2 & 2.5 & ... & 1.2 & 495 & 110 \\
\hline Mutton, canned & & & & & & & \\
\hline Corned, as pure & 45.8 & $2 S . S$ & 22.8 & . & 4.2 & 1,500 & 3333 \\
\hline $\begin{array}{l}\text { Tongue, as purchased.... } \\
\text { Pork, fresh }\end{array}$ & 47.6 & 24.4 & 24.0 & $\ldots$ & 4.5 & 1,465 & 325 \\
\hline $\begin{array}{l}\text { Chuck ribs and shoulder: } \\
\text { Minimum........... }\end{array}$ & 50.3 & 17.2 & 30.4 & & .9 & 1.605 & 3.56 \\
\hline Maximum ......... & 51.9 & 17.3 & 31.9 & $\ldots$ & .9 & 1,665 & 370 \\
\hline Average. . & 51.1 & 17.3 & 31.1 & $\ldots$ & .9 & 1.635 & 363 \\
\hline Flank: & & & & & & & \\
\hline Mir & 56.0 & 17.2 & 19.4 & $\ldots$ & .9 & $1,1 \$ 0$ & 262 \\
\hline Max & 60.7 & 19.5 & 26.9 & $\ldots$ & 1.0 & 1.455 & 323 \\
\hline Average. & 59.0 & 18.5 & 22.2 & $\ldots$ & 1.0 & 1.290 & $2 \times 6$ \\
\hline
\end{tabular}




\begin{tabular}{|c|c|c|c|c|c|c|c|}
\hline \multirow[b]{2}{*}{ Food Materials } & \multirow[b]{2}{*}{$\begin{array}{l}\text { Per cent } \\
\text { Water }\end{array}$} & \multirow[b]{2}{*}{$\begin{array}{l}\text { Per cent } \\
\text { Protein }\end{array}$} & \multirow[b]{2}{*}{$\begin{array}{l}\text { Per cent } \\
\text { Fat }\end{array}$} & \multirow[b]{2}{*}{$\begin{array}{l}\text { Per cent } \\
\text { Carbo- } \\
\text { hydrates }\end{array}$} & \multirow[b]{2}{*}{$\begin{array}{l}\text { Per cent } \\
\text { Ash }\end{array}$} & \multicolumn{2}{|c|}{ Fuel Value } \\
\hline & & & & & & $\begin{array}{c}\text { Calories } \\
\text { per } \\
\text { Pound }\end{array}$ & $\mid \begin{array}{c}\text { Calories } \\
\text { per } 100 \\
\text { Grams }\end{array}$ \\
\hline $\begin{array}{c}\text { ANIMAL FOOD-Con. } \\
\text { Pork, fresh }\end{array}$ & & & & & & & \\
\hline Ham, fresh, lean: & & & & & & & \\
\hline Minimum.... & 55.6 & 19.8 & 13.0 & $\cdots$ & 1.0 & 1,035 & 230 \\
\hline Maximum........ & 64.4 & 30.2 & 15.8 & $\ldots$ & 1.6 & 1,110 & 246 \\
\hline Average. ............ & 60.0 & 25.0 & 14.4 & $\cdots$ & 1.3 & 1,075 & 238 \\
\hline $\begin{array}{l}\text { Iam, fresh, medium fat: } \\
\text { Minimum........... }\end{array}$ & 37.3 & 9.9 & 21.2 & $\ldots$ & .6 & 1,225 & 272 \\
\hline Maximum......... & 60.3 & 20.3 & 39.4 & $\ldots$ & 1.3 & 2,070 & 460 \\
\hline Average.... & 53.9 & 15.3 & 28.9 & $\ldots$ & .8 & 1,505 & 334 \\
\hline Ham, fresh, fat: & & & & & & & \\
\hline $\begin{array}{l}\text { Minimum............ } \\
\text { Maximum......... }\end{array}$ & $\begin{array}{l}30.4 \\
44.3\end{array}$ & $\begin{array}{l}10.7 \\
142\end{array}$ & 43.8 & $\cdots$ & .5 & 2,030 & 451 \\
\hline Average. . . . . . . . . & 38.7 & 12.4 & 50.0 & $\cdots$ & .8 & $\begin{array}{l}2,825 \\
2,345\end{array}$ & $\begin{array}{l}627 \\
521\end{array}$ \\
\hline $\begin{array}{l}\text { Ham, fresh, visible fat } \\
\text { largely removed....... }\end{array}$ & 645 & $10 ?$ & & & & & \\
\hline Head: & 04.2 & 19.2 & 10.2 & $\cdots$ & .9 & 1,040 & 231 \\
\hline Minimum.......... & 38.4 & 11.6 & 34.5 & $\cdots$ & .6 & 1,725 & 383 \\
\hline Maximum......... & 50.5 & 14.5 & 50.5 & $\cdots$ & .8 & 2,350 & 522 \\
\hline $\begin{array}{l}\text { Average. ........... } \\
\text { Head cheese: }\end{array}$ & 45.3 & 13.4 & 41.3 & $\ldots$ & .7 & 1,990 & 442 \\
\hline Minimum...... & 38.1 & 17.4 & 27.4 & $\ldots$ & 3.0 & 1,555 & 345 \\
\hline Maximum......... & 48.1 & 21.5 & 40.5 & $\ldots$ & 3.4 & 2,035 & 452 \\
\hline Average. ........... & 43.3 & 19.5 & 33.8 & $\ldots$ & 3.3 & 1,790 & 397 \\
\hline $\begin{array}{l}\text { Loin (chops), lean....... } \\
\text { Loin (chops), medium fat: }\end{array}$ & 60.3 & 20.3 & 19.0 & $\ldots$ & 1.0 & 1,180 & 262 \\
\hline Minimum.......... & 49.1 & 13.8 & 25.0 & • & .8 & 1,415 & 314 \\
\hline Maximum......... & 55.2 & 19.4 & 35.2 & $\ldots$ & 1.1 & 1,785 & 397 \\
\hline Average........... & 52.0 & 16.6 & 30.1 & $\cdots$ & 1.0 & 1,580 & 351 \\
\hline $\begin{array}{c}\text { Loin (chops), fat: } \\
\text { Minimum }\end{array}$ & & & & & & & \\
\hline Maximum....... & $\begin{array}{l}39.7 \\
46.7\end{array}$ & $\begin{array}{l}11.3 \\
19.3\end{array}$ & $\begin{array}{l}38.8 \\
486\end{array}$ & $\cdots$ & .6 & $\begin{array}{l}1,995 \\
2,260\end{array}$ & 443 \\
\hline Average. .......... & 41.8 & 14.5 & 44.4 & $\cdots$ & .7 & 2,145 & 476 \\
\hline $\begin{array}{l}\text { Loin, tenderloin, as pur- } \\
\text { chased: }\end{array}$ & & & & & & & \\
\hline Minimum.......... & 62.4 & 15.8 & 9.3 & $\ldots$ & .9 & 770 & 171 \\
\hline Maximu & 72.8 & 20.5 & 17.1 & $\ldots$ & 1.2 & 1,100 & 244 \\
\hline Average. . . . . . & 66.5 & 18.9 & 13.0 & $\cdots$ & 1.0 & 900 & 200 \\
\hline Middle euts: & & & & & & & \\
\hline Minimum. & 46.0 & 15.7 & 34.9 & $\ldots$ & .7 & 1,760 & 391 \\
\hline Maximum ..... & 49.4 & 15.7 & 38.8 & $\ldots$ & .8 & 1,925 & 427 \\
\hline Average. & 48.2 & 15.7 & 36.3 & $\ldots$ & .7 & 1,825 & 405 \\
\hline Shoulder: & & & & & & & \\
\hline Minimu & 44.0 & 9.4 & 18.5 & $\cdots$ & .6 & 1,105 & 245 \\
\hline Maximum..... & 63.6 & 17.4 & 49.3 & $\ldots$ & .9 & 2,260 & 502 \\
\hline Average... . & 51.2 & 13.3 & 34.2 & $\cdots$ & .8 & 1,690 & 375 \\
\hline
\end{tabular}




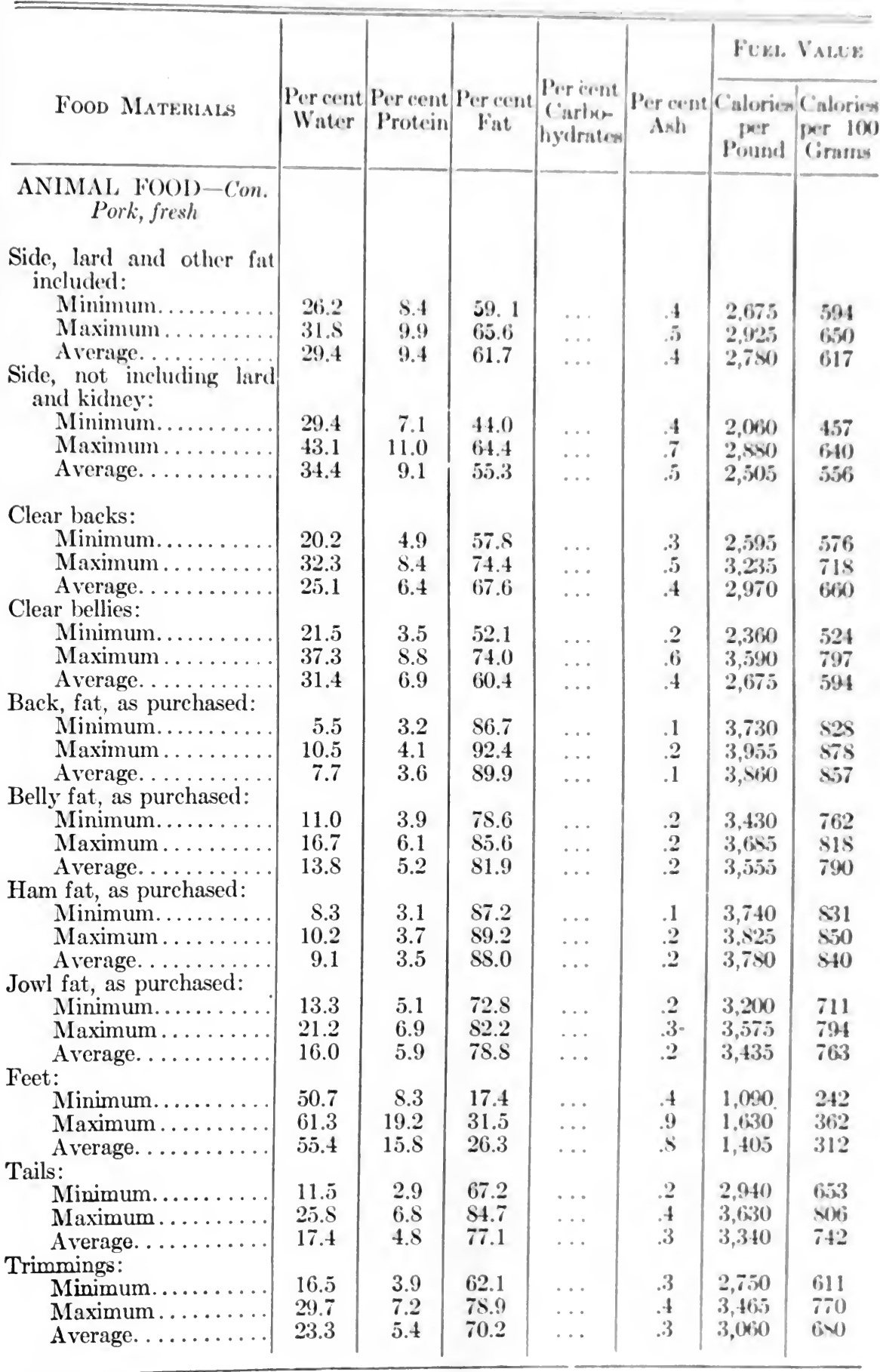




\begin{tabular}{|c|c|c|c|c|c|c|c|}
\hline \multirow[b]{2}{*}{ Food Materials } & \multirow[b]{2}{*}{$\begin{array}{l}\text { Per cent } \\
\text { Water }\end{array}$} & \multirow[b]{2}{*}{$\begin{array}{r}\text { Per cent } \\
\text { Protein }\end{array}$} & \multirow[b]{2}{*}{$\begin{array}{c}\text { Per cent } \\
\text { Fat }\end{array}$} & \multirow[b]{2}{*}{$\mid \begin{array}{c}\text { Per cent } \\
\text { Carbo- } \\
\text { hydrates }\end{array}$} & \multirow[b]{2}{*}{$\begin{array}{l}\text { Per cent } \\
\text { Ash }\end{array}$} & \multicolumn{2}{|c|}{ Fuel Value } \\
\hline & & & & & & $\begin{array}{c}\text { Calories } \\
\text { per } \\
\text { Pound }\end{array}$ & $\begin{array}{l}\text { Calories } \\
\text { per } 100 \\
\text { Grams }\end{array}$ \\
\hline \multicolumn{8}{|l|}{$\begin{array}{l}\text { ANIMAL FOOD-Con. } \\
\text { Pork, organs, etc. }\end{array}$} \\
\hline Brains, as purchased. . . & 75.8 & 11.7 & 10.3 & $\ldots$ & 1.6 & 655 & 145 \\
\hline Heart, as purchased.... & 75.6 & 17.1 & 6.3 & $\cdots$ & 1.0 & 585 & 130 \\
\hline $\begin{array}{l}\text { dneys, as purchased: } \\
\text { Minimum......... }\end{array}$ & 76.1 & 15.2 & 4.1 & $\ldots$ & 1.2 & 455 & 101 \\
\hline Maximum .......... & 79.5 & 15.9 & 5.5 & $\cdots$ & 1.2 & 530 & 117 \\
\hline Average. ... & 77.8 & 15.5 & 4.8 & & 1.2 & 490 & 108 \\
\hline Liver, as purchased. & 4 & 21.3 & 4.5 & 1.4 & 1.4 & 615 & 136 \\
\hline $\begin{array}{l}\text { Lungs, as purchased...... } \\
\text { Marrow, as purchased: }\end{array}$ & 83.3 & 11.9 & 4.0 & $\ldots$ & .9 & 390 & 86 \\
\hline Minimum.......... & 13.2 & 1.5 & 78.4 & $\ldots$ & & 3,360 & 776 \\
\hline Maximum ......... & 16.7 & 3.2 & 84.5 & $\ldots$ & $\ldots$ & 4,095 & 910 \\
\hline Average... & 14.6 & 2.3 & 81.2 & $\cdots$ & $\cdots$ & 3,470 & 771 \\
\hline Skin, as purchased: & & & & & & & \\
\hline Minimum........... & 35.5 & 18.5 & 14.4 & $\cdots$ & .5 & 1,140 & 253 \\
\hline Maximum......... & 55.4 & 33.3 & 35.3 & $\ldots$ & .8 & 1,860 & 413 \\
\hline $\begin{array}{l}\text { Average. ............ } \\
\text { Pork, pickled, salted, and } \\
\text { smoked } \\
\text { Ham, smoked, lean: }\end{array}$ & 46.3 & 26.4 & 22.7 & .. & .6 & 1,450 & 322 \\
\hline 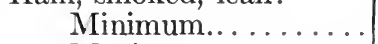 & 49.5 & 19.5 & 17.0 & $\ldots$ & 5.4 & 1,080 & 240 \\
\hline Maximum......... & 57.4 & 20.2 & 24.4 & ... & 5.8 & 1,405 & 312 \\
\hline 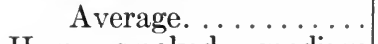 & 53.5 & 19.8 & 20.8 & . . & 5.5 & 1,245 & 276 \\
\hline $\begin{array}{l}\text { Ham, smoked, medium } \\
\text { fat: }\end{array}$ & & & & & & & \\
\hline Minimum.......... & 34.7 & 12.5 & 30.3 & $\cdots$ & 2.7 & 1,690 & 375 \\
\hline Maximum ...... & 45.6 & 22.9 & 44.7 & $\ldots$ & 7.4 & 2,145 & 476 \\
\hline Average. . . . . . & 40.3 & 16.3 & 38.8 & .. & 4.8 & 1,940 & 431 \\
\hline Ham, smoked, fat: & & & & & & & \\
\hline $1 \ldots \ldots \ldots$ & 22.4 & 12.0 & 42.0 & $\cdots$ & .6 & 2,135 & 474 \\
\hline Maximum .......... & 34.9 & 19.5 & 56.8 & $\cdots$ & 6.5 & 2,652 & 589 \\
\hline Average. $\ldots$ so. & 27.9 & 14.8 & 52.3 & $\cdots$ & 3.7 & 2,485 & 552 \\
\hline $\begin{array}{l}\text { Ham, smoked, boiled, as } \\
\text { purchased: } \\
\text { Minimum... }\end{array}$ & & & & & & & \\
\hline 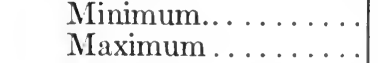 & 39.2 & 18.1 & 7.8 & $\cdots$ & 5.6 & 740 & 164 \\
\hline $\begin{array}{l}\text { Maximum ........... } \\
\text { Average........... }\end{array}$ & 63.4 & 22.2 & 37.0 & $\cdots$ & 6.6 & 1,900 & 122 \\
\hline Ham, smoked, fired, as & & & 22.4 & . & 6.1 & 1,320 & 293 \\
\hline Ham, boneless, raw: & 36.6 & 22.2 & 33.2 & . & 5.8 & 1,815 & 403 \\
\hline Minimum........ & 40.3 & 10.0 & 17.3 & & 4.4 & 1,052 & 233 \\
\hline $\begin{array}{l}\text { Maximum ....... } \\
\text { Average }\end{array}$ & 55.9 & 17.3 & 38.9 & ... & 6.6 & 1,930 & 428 \\
\hline $\begin{array}{l}\text { Average........... } \\
\text { m, luncheon, cooked: }\end{array}$ & 50.1 & 14.9 & 28.5 & $\cdots$ & 6.0 & 1,480 & 328 \\
\hline num.......... & 47.8 & 19.5 & 19.4 & & & 1290 & \\
\hline Maximum ..... & 50.5 & 25.5 & 22.7 & $\cdots$ & 6.7 & 1,320 & $\begin{array}{l}200 \\
293\end{array}$ \\
\hline Average. ... & 49.2 & 22.5 & 21.0 & $\cdots$ & 5.8 & 1,305 & 290 \\
\hline
\end{tabular}




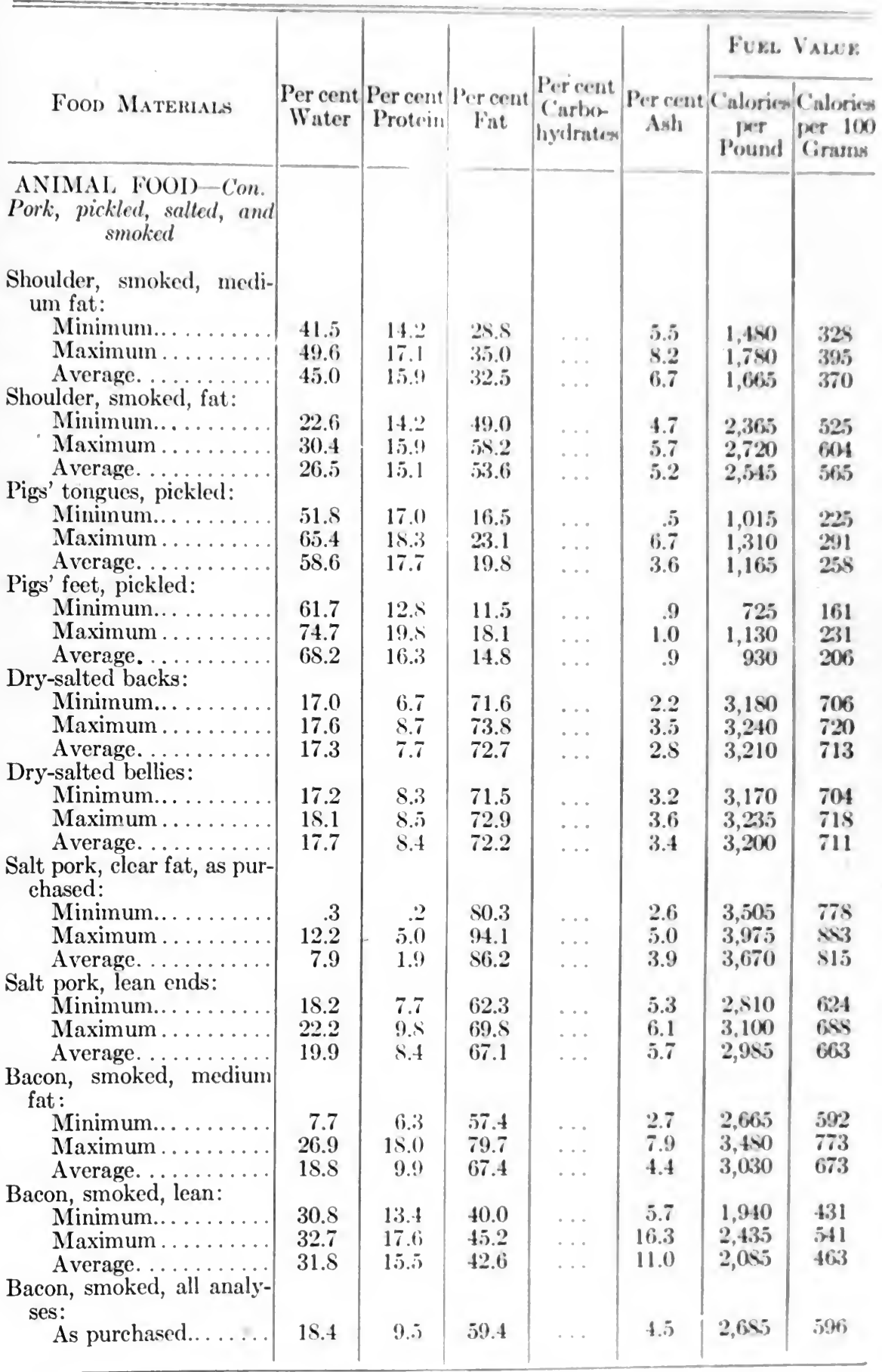




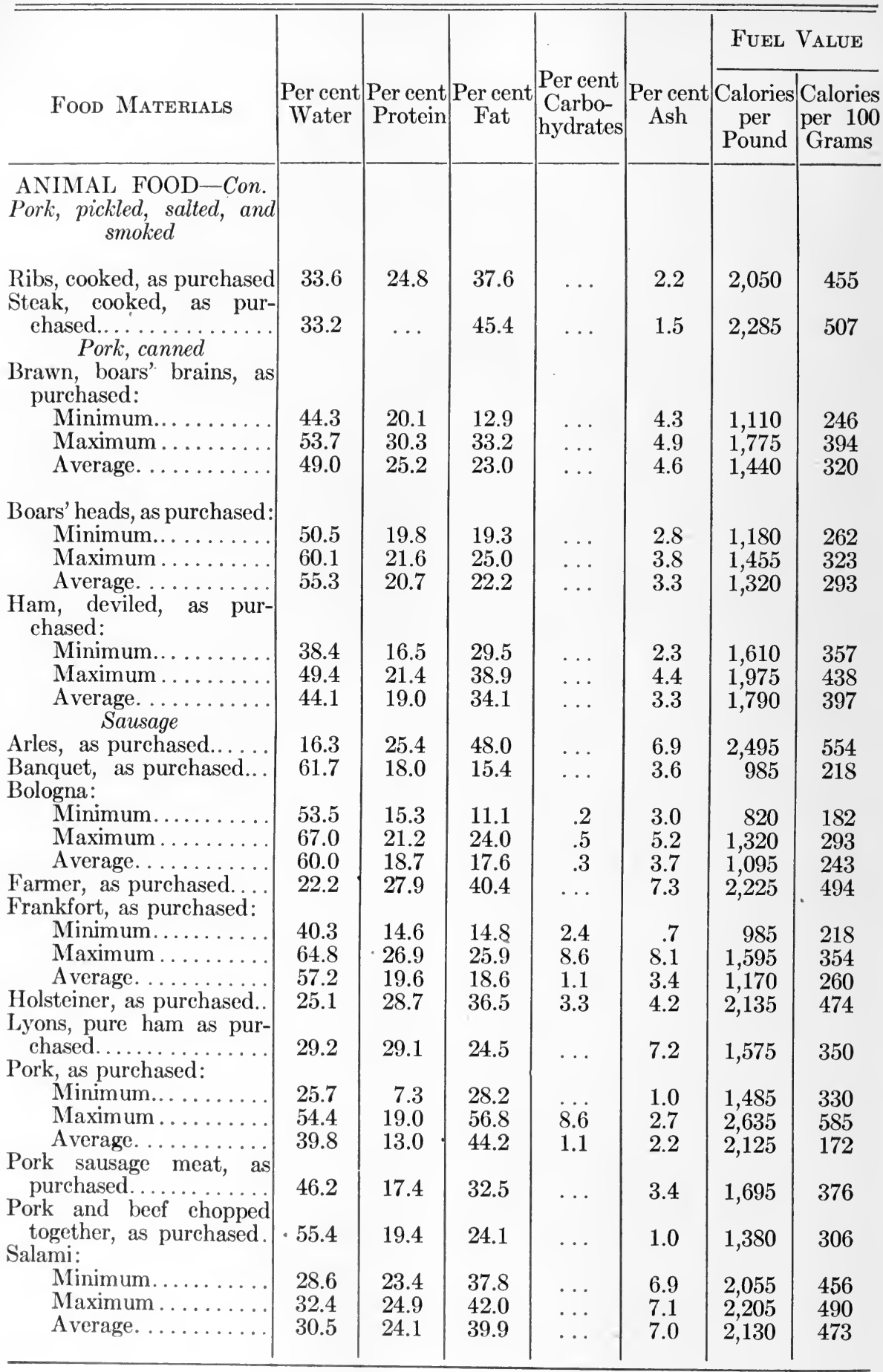




\begin{tabular}{|c|c|c|c|c|c|c|c|}
\hline \multirow[b]{2}{*}{ Food Materials } & \multirow[b]{2}{*}{$\begin{array}{l}\text { Per cent } \\
\text { Water }\end{array}$} & \multirow[b]{2}{*}{$\left|\begin{array}{c}\text { Per cent } \\
\text { Protein }\end{array}\right|$} & \multirow[b]{2}{*}{$\begin{array}{l}\text { Percent } \\
\text { lint }\end{array}$} & \multirow[b]{2}{*}{$\begin{array}{l}\text { Per cent } \\
\text { Carbo- } \\
\text { hydratew }\end{array}$} & \multirow[b]{2}{*}{$\begin{array}{c}\text { Percent } \\
\text { Ash }\end{array}$} & \multicolumn{2}{|c|}{ Fur. Value: } \\
\hline & & & & & & $\begin{array}{l}\text { Calorices } \\
\text { por } \\
\text { Pound }\end{array}$ & $\begin{array}{l}\text { Colorics } \\
\text { per } 1(x) \\
\text { Cirams }\end{array}$ \\
\hline$\underset{\text { Sausage }}{\text { ANIMAL FOOD }}$ & & & & & & & \\
\hline $\begin{array}{l}\text { Summer: } \\
\text { Minimum...... }\end{array}$ & 20.0 & 23.5 & 43.0 & $\ldots$ & 7.3 & 2,290 & 506 \\
\hline Maximum..... & & & 45.7 & & & 2,480 & 3233 \\
\hline Average. . & $2:$ & 26.0 & 44.5 & & 7 & 2,360 & 324 \\
\hline Tongue, as purchased. & & 21 & 33.1 & & 3.2 & 1,770 & 393 \\
\hline $\begin{array}{l}\text { Wienerwurst, as purchased. } \\
\text { Ponitry and Game, fresh }\end{array}$ & 43.9 & 25.0 & 22.1 & 1.6 & 4.4 & 1,455 & $3: 30$ \\
\hline $\begin{array}{c}\text { Chicken, broilers: } \\
\text { Minimum..... }\end{array}$ & 72.2 & 19.0 & 1.6 & & 1.0 & 440 & 97 \\
\hline Maximum.... & & & 4. & & 1.4 & 5.00 & 122 \\
\hline Average. & 74.8 & 21.5 & 2.5 & .. & 1.1 & $50 ;$ & 112 \\
\hline Fowls: & & & & & & & \\
\hline Minimum & 54.1 & 15.5 & 9.7 & $\ldots$ & $\therefore$ & 770 & 171 \\
\hline Maximum. & & 21 & 28.3 & .. & 1.5 & 1,520 & 337 \\
\hline Average. ............ & 63.7 & 19.3 & 16.3 & $\cdots$ & 1.0 & 1,045 & 232 \\
\hline $\begin{array}{l}\text { Goose, young, as pur- } \\
\text { chased............... } \\
\text { Turkey: }\end{array}$ & 38.5 & 13.4 & 29.8 & $\dot{\bullet}$ & .7 & $2,50.5$ & 556 \\
\hline 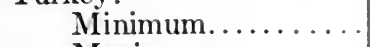 & 49.5 & 19.0 & 8.7 & $\ldots$ & .9 & 830 & 184 \\
\hline Maximum......... & 66.1 & 24.9 & 30.7 & .. & 1.3 & 1,650 & 366 \\
\hline Average. ........... & 55.5 & 21.1 & 22.9 & $\cdots$ & 1.0 & 1,360 & 302 \\
\hline $\begin{array}{l}\text { Chicken gizzard, as pur- } \\
\text { chased............... }\end{array}$ & 72.5 & 24.7 & 1.4 & $\cdots$ & 1.4 & 520 & 115 \\
\hline $\begin{array}{l}\text { Chicken heart, as pur- } \\
\text { chased............... }\end{array}$ & 72.0 & 20.7 & 5.5 & $\cdots$ & 1.4 & 615 & 136 \\
\hline $\begin{array}{c}\text { Chicken liver, as pur- } \\
\text { chased............... }\end{array}$ & 69.3 & 22.4 & 4.2 & 2.4 & 1.7 & 640 & 142 \\
\hline Goose gizzard.......... & 73.8 & 19.6 & 5.8 & & 1.0 & 610 & $\begin{array}{l}135 \\
? 23\end{array}$ \\
\hline Goose liver, as purchased. & 62.6 & 16.6 & 15.9 & 3.7 & 1.2 & $1,0.50$ & 233 \\
\hline $\begin{array}{l}\text { Turkey gizzard, as pur- } \\
\text { chased.............. } \\
\text { Turkey heart, as pur- }\end{array}$ & 62.7 & 20.5 & 14.5 & 1.2 & 1.1 & 1,015 & 225 \\
\hline $\begin{array}{l}\text { Turkey heart, as pur- } \\
\text { chased............... }\end{array}$ & 68.6 & $\begin{array}{l}16.8 \\
22.9\end{array}$ & $\begin{array}{r}13.2 \\
5.2\end{array}$ & & 1.0 & 570 & $\begin{array}{l}193 \\
145\end{array}$ \\
\hline 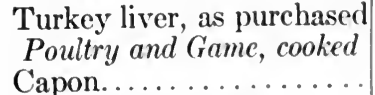 & 69.6 & 22.9 & 5.2 & .6 & 1. & 60.3 & 145 \\
\hline 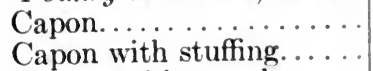 & 59.9 & 2 & 11.5 & 35 & 1.8 & 985 & 215 \\
\hline $\begin{array}{l}\text { vith stuffing. . } \\
\text {, fricasseed.. }\end{array}$ & & & $\begin{array}{l}10 \\
11\end{array}$ & $\begin{array}{l}3.5 \\
2.4\end{array}$ & 1. & Sis.5 & 145 \\
\hline $\begin{array}{l}\text { Chicken, fricasseed... . . } \\
\text { Turkey, roast.......... }\end{array}$ & $\begin{array}{l}67.5 \\
52.0\end{array}$ & $\begin{array}{l}17.6 \\
27.8\end{array}$ & 18.4 & $\cdots$ & 1.2 & 1,295 & 257 \\
\hline $\begin{array}{l}\text { Turkey, roast, light and } \\
\text { dark meat and stuffing. } \\
\text { Poultry and Game, canned }\end{array}$ & 65.0 & 年 & 10.8 & 5.5 & 1.6 & S70 & 193 \\
\hline $\begin{array}{l}\text { Chicken, sandwich, as } \\
\text { purchased.............. }\end{array}$ & 46.9 & 20.5 & 30.0 & . & 2.6 & 1,655 & 367 \\
\hline $\begin{array}{l}\text { Turkey, sandwich, as pur- } \\
\text { chased................ }\end{array}$ & 47.4 & 20.7 & 29.2 & & 2.7 & 1,615 & 3.55 \\
\hline Plover, roast & $\begin{array}{l}57.7 \\
66.9\end{array}$ & $\begin{array}{l}22.4 \\
21.5\end{array}$ & 10.2 & $\begin{array}{l}7.6 \\
1.7\end{array}$ & $\begin{array}{l}2.1 \\
1.6\end{array}$ & $\begin{array}{l}955 \\
775\end{array}$ & $\begin{array}{l}215 \\
172\end{array}$ \\
\hline Q & & 21.5 & 5.0 & & & & 10. \\
\hline
\end{tabular}




\begin{tabular}{|c|c|c|c|c|c|c|c|}
\hline \multirow[b]{2}{*}{ Food Materials } & \multirow[b]{2}{*}{$\begin{array}{l}\text { Per cent } \\
\text { Water }\end{array}$} & \multirow[b]{2}{*}{$\begin{array}{r}\text { Per cent } \\
\text { Protein }\end{array}$} & \multirow[b]{2}{*}{$\begin{array}{l}\text { Per cent } \\
\text { Fat }\end{array}$} & \multirow[b]{2}{*}{$\begin{array}{c}\text { Per cent } \\
\text { Carbo- } \\
\text { hydrates }\end{array}$} & \multirow[b]{2}{*}{$\begin{array}{c}\text { Per cent } \\
\text { Ash }\end{array}$} & \multicolumn{2}{|c|}{ Fuel Value } \\
\hline & & & & & & $\begin{array}{c}\text { Calories } \\
\text { per } \\
\text { Pound }\end{array}$ & $\begin{array}{l}\text { Calories } \\
\text { per } 100 \\
\text { Grams }\end{array}$ \\
\hline $\begin{array}{l}\text { ANIMAL FOOD-Con. } \\
\text { Fish, fresh } \\
\text { Alewife, whole: }\end{array}$ & & & & & & & \\
\hline Minimum............ & 73.0 & 19.0 & 3.8 & $\ldots$ & 1.4 & 515 & 114 \\
\hline Maximum. & 75.9 & 19.7 & 6.0 & $\ldots$ & 1.5 & 620 & 137 \\
\hline Average. ... & 74.4 & 19.4 & 4.9 & $\ldots$ & 1.5 & 570 & 126 \\
\hline Bass, black, whole: & & & & & & & \\
\hline $\begin{array}{l}\text { Minimum........... } \\
\text { Maximum........ }\end{array}$ & 74.8 & 19.4 & 1.0 & $\cdots$ & 1.2 & 405 & 90 \\
\hline $\begin{array}{l}\text { Maximum . . . . . . . . . . . } \\
\text { Average. . . }\end{array}$ & 78.6 & 21.7 & 2.5 & $\ldots$ & 1.2 & 510 & 113 \\
\hline Average. . . . . . . . . . & 76.7 & 20.6 & 1.7 & $\ldots$ & 1.2 & 455 & 101 \\
\hline $\begin{array}{l}\text { Bass, red, whole, as pur- } \\
\text { chased.................. }\end{array}$ & 29.8 & 6.2 & .2 & $\cdots$ & .4 & 125 & 27 \\
\hline $\begin{array}{l}\text { Bass, sea, whole, as pur- } \\
\text { chased............... } \\
\text { Bass, striped whole: }\end{array}$ & 34.8 & 8.7 & .2 & $\cdots$ & .6 & 170 & 37 \\
\hline $\begin{array}{l}\text { Bass, striped, whole: } \\
\text { Minimum............. }\end{array}$ & 75.8 & 17.1 & 1.6 & $\ldots$ & .9 & 405 & 90 \\
\hline Maximum...... & 79.6 & 19.5 & 4.6 & $\ldots$ & 1.4 & 530 & 118 \\
\hline Average. . . . & 77.7 & 18.6 & 2.8 & $\ldots$ & 1.2 & 465 & 103 \\
\hline Blackfish, whole: & & & & & & & \\
\hline Minimum.... & 76.9 & 17.6 & .6 & . & .6 & 350 & 77 \\
\hline Maximum .. . & 81.4 & 19.3 & 2.8 & $\ldots$ & 1.4 & 475. & 105 \\
\hline Average. .... & 79.1 & 18.7 & 1.3 & $\ldots$ & 1.1 & 405 & 90 \\
\hline $\begin{array}{l}\text { Blackfish, entrails re- } \\
\text { moved, as purchased: }\end{array}$ & & & & & & & \\
\hline 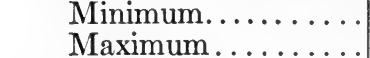 & $\begin{array}{l}33.5 \\
36.4\end{array}$ & $\begin{array}{l}8.0 \\
8.8\end{array}$ & .4 & $\cdots$ & $\begin{array}{l}.4 \\
.6\end{array}$ & 125 & $\begin{array}{l}27 \\
45\end{array}$ \\
\hline Average............... & 35.0 & 8.4 & .5 & $\cdots$ & .0 & 175 & $\begin{array}{l}40 \\
38\end{array}$ \\
\hline $\begin{array}{l}\text { Buffalo fish, entrails re- } \\
\text { moved, as purchased.. }\end{array}$ & 37.3 & 8.5 & 1.1 & $\cdots$ & .6 & 205 & 45 \\
\hline $\begin{array}{l}\text { Butter-fish, whole, as pur- } \\
\text { chased............... }\end{array}$ & 40.1 & 10.3 & 6.3 & & .6 & 460 & 102 \\
\hline Catfish, as purchased.... & 51.7 & 11.6 & 16.6 & $\cdots$ & .7 & 915 & 203 \\
\hline Ciscoe, whole: & & & & & & & \\
\hline Minimum..... & 72.3 & 17.7 & 3.5 & . & .9 & 505 & 112 \\
\hline Maximum..... & 76.1 & 19.3 & 9.2 & $\ldots$ & 1.3 & 715 & 158 \\
\hline Average. ............ & 74.0 & 18.5 & 6.8 & $\cdots$ & 1.1 & 630 & 140 \\
\hline $\begin{array}{l}\text { Ciscoe, entrails removed, } \\
\text { as purchased: }\end{array}$ & & & & & & & \\
\hline $\begin{array}{l}\text { Minimum. . } \\
\text { Maximum. . }\end{array}$ & 62.4 & 15.3 & 7.2 & . & .8 & 615 & 136 \\
\hline $\begin{array}{l}\text { Maximum . . } \\
\text { Average. . . }\end{array}$ & 68.8 & 17.2 & 7.8 & . & 1.0 & 625 & 138 \\
\hline Average. . . . & 65.6 & 16.3 & 7.5 & $\ldots$ & .9 & 620 & 137 \\
\hline $\begin{array}{l}\text { Cod, whole: } \\
\text { Minimum. }\end{array}$ & & & & & & & \\
\hline Minimum... & 80.7 & 15.5 & .3 & $\cdots$ & 1.0 & 300 & 66 \\
\hline $\begin{array}{l}\text { Maximum ... } \\
\text { Average. . . }\end{array}$ & 83.5 & 18.3 & .5 & $\ldots$ & 1.4 & 370 & 82 \\
\hline $\begin{array}{l}\text { Average. ...... } \\
\text { Cod, sections: }\end{array}$ & 82.6 & 16.5 & .4 & $\cdots$ & 1.2 & 325 & 72 \\
\hline Minimum. . & 81.8 & 15.6 & .1 & & .8 & 300 & 66 \\
\hline Maximum . . & 83.5 & 17.7 & .5 & $\ldots$ & 1.0 & 335 & 74 \\
\hline Average. . . . & 82.5 & 16.7 & .3 & $\ldots$ & .9 & 325 & 72 \\
\hline Cod, steaks. ...... & 79.7 & 18.7 & .5 & $\ldots$ & 1.2 & 370 & 82 \\
\hline
\end{tabular}




\begin{tabular}{|c|c|c|c|c|c|c|c|}
\hline \multirow[b]{2}{*}{ Food Materialas } & \multirow[b]{2}{*}{$\begin{array}{l}\text { Per cent } \\
\text { IVister }\end{array}$} & \multirow[b]{2}{*}{$\begin{array}{l}\text { Percent } \\
\text { Protein }\end{array}$} & \multirow[b]{2}{*}{$\begin{array}{l}\text { Percent } \\
\text { lint }\end{array}$} & \multirow[b]{2}{*}{$\begin{array}{l}\text { Percent } \\
\text { Cisurbo- } \\
\text { inyelraicex }\end{array}$} & \multirow[b]{2}{*}{$\begin{array}{c}\text { Percent } \\
\text { Ish }\end{array}$} & \multicolumn{2}{|c|}{ Feve. Valuer. } \\
\hline & & & & & & $\begin{array}{c}\text { Calories } \\
\text { per } \\
\text { Pound }\end{array}$ & $\begin{array}{l}\text { Cislorios } \\
\text { per } 100 \\
\text { Cirmina }\end{array}$ \\
\hline \multicolumn{8}{|l|}{$\begin{array}{c}\text { ANIMAL FOOD-Con. } \\
\text { Fish, fresh }\end{array}$} \\
\hline Cusk, entrails removed... & $\$ 2.0$ & 17.0 & .2 & $\ldots$ & .9 & 325 & 72 \\
\hline $\begin{array}{l}\text { Eels, salt water, head, skin } \\
\text { and entrails removed: }\end{array}$ & & & & 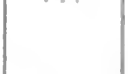 & & (1) & \\
\hline Minimum........... & 69.5 & 17.8 & 7.9 & $\cdots$ & .9 & 665 & 147 \\
\hline $\begin{array}{l}\text { Maximum ........... } \\
\text { Average. }\end{array}$ & 73.4 & 19.3 & 10.3 & $\ldots$ & 1.1 & 795 & 176 \\
\hline $\begin{array}{l}\text { Average. ........... } \\
\text { As purchased: }\end{array}$ & 71.6 & 18.6 & 9.1 & .. & 1.0 & 730 & 162 \\
\hline Minimum....... & 54.9 & 14.4 & 6.4 & $\cdots$ & .7 & 540 & 120 \\
\hline Maximum. & 59.4 & 15.2 & 8.1 & $\ldots$ & .9 & $62 i$ & 138 \\
\hline Average. . & 57.2 & 14.6 & 7.2 & .. & .5 & $i x)$ & 128 \\
\hline \multicolumn{8}{|l|}{ Flounder, whole: } \\
\hline Minimum. . & 83.4 & 13.3 & .4 & $\cdots$ & 1.2 & $2 \times 0$ & 62 \\
\hline Maximum . & 85.0 & 14.9 & .9 & $\cdots$ & 1.3 & 305 & 67 \\
\hline \multirow{2}{*}{\multicolumn{8}{|c|}{$\begin{array}{l}\text { Haddock, entrails re- } \\
\text { moved: }\end{array}$}} \\
\hline & & & & & & & \\
\hline Minimum...... & 80.3 & 16.3 & .1 & $\cdots$ & 1.0 & 315 & 70 \\
\hline Maximum ......... & $\$ 2.6$ & 18.6 & .4 & $\ldots$ & 1.6 & 3.55 & 78 \\
\hline Average........... & $\$ 1.7$ & 17.2 & .3 & $\cdots$ & 1.2 & 3.35 & 74 \\
\hline $\begin{array}{l}\text { Hake, entrails removed, } \\
\text { as purchased. . . . . . . . }\end{array}$ & 39.5 & 7.3 & .3 & $\cdots$ & .5 & 150 & 33 \\
\hline \multicolumn{8}{|l|}{$\begin{array}{l}\text { Halibut, steaks or sec- } \\
\text { tions: }\end{array}$} \\
\hline Minimum.......... & 70.1 & 17.5 & 2.2 & . & .9 & 420 & 93 \\
\hline Maximum.. & 79.2 & 19.7 & 10.6 & $\ldots$ & 1.1 & 790 & 175 \\
\hline Average. ...... & 75.4 & 18.6 & 5.2 & $\cdots$ & 1.0 & 565 & 125 \\
\hline \multicolumn{8}{|l|}{ Herring, whole: } \\
\hline $\begin{array}{l}\text { Minimum. . } \\
\text { Maximum. . }\end{array}$ & 69.0 & 19.1 & 3.2 & $\cdots$ & 1.5 & 505 & 112 \\
\hline $\begin{array}{l}\text { Maximum. . } \\
\text { Average. . . }\end{array}$ & 76. & 19.8 & 11.0 & $\cdots$ & 1.6 & 820 & $1 \leqslant 2$ \\
\hline $\begin{array}{r}\text { Averag } \\
\text { Kingfish, w }\end{array}$ & 79.5 & $\begin{array}{l}19.5 \\
18.9\end{array}$ & $\begin{array}{r}8.1 \\
9\end{array}$ & $\cdots$ & $\begin{array}{l}1.5 \\
1.2\end{array}$ & 660 & 146 \\
\hline $\begin{array}{l}\text { Kingfish, w } \\
\text { Lamprey, v }\end{array}$ & 71.1 & 15.0 & 13.3 & $\cdots$ & 1.2 & 540 & 186 \\
\hline \multicolumn{8}{|l|}{ Mackerel, whole: } \\
\hline Minimum. & 64.0 & 17.5 & 2.2 & .. & 1.0 & 430 & 95 \\
\hline Maximum . & 78.7 & 19.5 & 16.3 & $\ldots$ & 1.5 & 1,045 & 232 \\
\hline Average. ............ & 73.4 & 18.7 & 7.1 & .. & 1.2 & 645 & 143 \\
\hline \multicolumn{7}{|c|}{$\begin{array}{l}\text { Mackerel, entrails re- } \\
\text { moved, as purchased... }\end{array}$} & 81 \\
\hline Mullet, whole. ......... & 74.9 & 19.5 & 4.6 & ... & 1.2 & 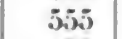 & 123 \\
\hline Muskellunge, whole. . & 76.3 & 20.2 & 2.5 & $\ldots$ & 1.6 & 450 & 106 \\
\hline \multicolumn{8}{|l|}{ Pereh, white, whole: } \\
\hline & 75.6 & 15.0 & 2.5 & $\cdots$ & 1.1 & 490 & 105 \\
\hline Maximum ... & 75.8 & 20.6 & 5.6 & $\ldots$ & 1.3 & 570 & 126 \\
\hline $\begin{array}{l}\text { Average. . . . . . . } \\
\text { Pereh pike }\end{array}$ & 75.7 & 19.3 & 4.0 & $\cdots$ & 1.2 & 530 & 117 \\
\hline 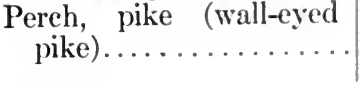 & 79.7 & 15.6 &.$\dot{5}$ & $\cdots$ & 1.4 & 365 & si \\
\hline
\end{tabular}




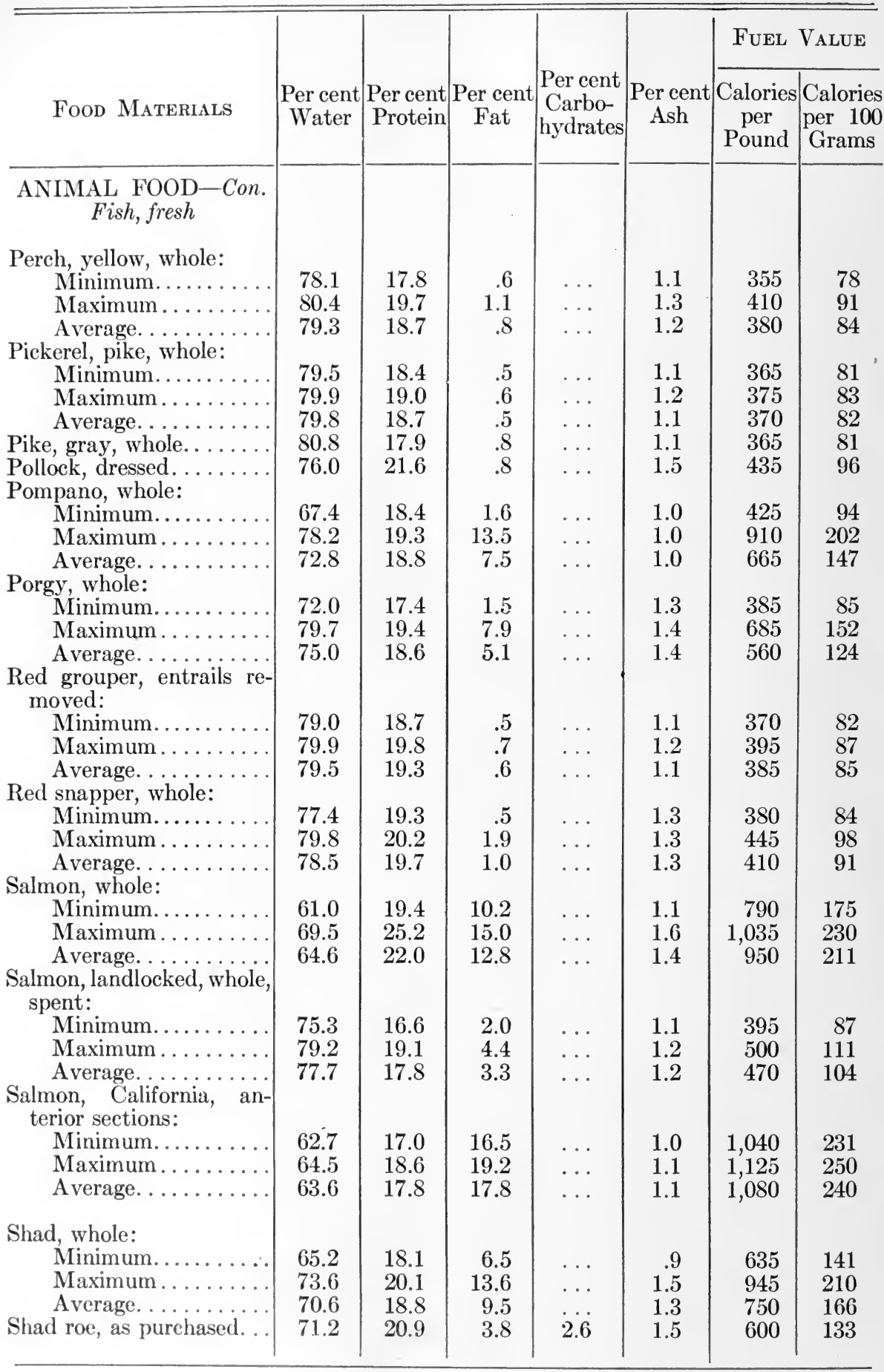




\begin{tabular}{|c|c|c|c|c|c|c|c|}
\hline \multirow[b]{2}{*}{ FoOd Materialas } & \multirow[b]{2}{*}{$\begin{array}{l}\text { Percent } \\
\text { Wnter }\end{array}$} & \multirow[b]{2}{*}{$\begin{array}{l}\text { Percent } \\
\text { Protein }\end{array}$} & \multirow[b]{2}{*}{$\begin{array}{c}\text { Prorenent } \\
\text { lint }\end{array}$} & \multirow[b]{2}{*}{$\begin{array}{l}\text { Percent } \\
\text { Corluo- } \\
\text { hyolrutes }\end{array}$} & \multirow[b]{2}{*}{$\begin{array}{c}\text { Percent } \\
\text { Ash }\end{array}$} & \multicolumn{2}{|c|}{ Fene. Vaber: } \\
\hline & & & & & & $\begin{array}{c}\text { Cinlories } \\
\text { por } \\
\text { Pound }\end{array}$ & 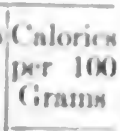 \\
\hline$\underset{\text { Fish, fresh }}{\text { ANIMAL }}$ & & & & & & & \\
\hline Sheepshend, whole: & & & & & & & \\
\hline & 72.0 & 19.1 & .7 & $\cdots$ & 1.1 & 390 & si \\
\hline $\begin{array}{l}\text { Maximum . . . . . . . } \\
\text { Average. . . . }\end{array}$ & 79.1 & 261.15 & 6.7 & .. & 1.3 & 670 & 148 \\
\hline Skate, lobe of body... & $\begin{array}{ll}75.6 \\
89,6\end{array}$ & 20.1 & 3.7 & $\cdots$ & 1.2 & 230 & 117 \\
\hline Smelt, whole: & 82.2 & 15.2 & 1.4 & .. & 1.1 & 40() & 88 \\
\hline Minimum... . & $7 \$ .2$ & 16.5 & 1.6 & $\cdots$ & 1.4 & 355 & 85 \\
\hline Maximum . . . . . & 80.2 & 15.7 & 1.9 & ... & 2.0 & 415 & 92 \\
\hline Average....... & 79.2 & 17.6 & 1.8 & ... & 1.7 & 405 & 90 \\
\hline Spanish mackerel, whole.. & 68.1 & $21 . \overline{1}$ & 9.4 & ... & 1.3 & 79.5 & 176 \\
\hline Sturgeon, anterior seetions & 78.7 & 1s.1 & 1.9 & $\ldots$ & 1.4 & 415 & 92 \\
\hline $\begin{array}{l}\text { Tomeod, whole.......... } \\
\text { Trout, brook, whole: }\end{array}$ & 81.5 & 17.2 & .4 & .. & 1.0 & 33.5 & 71 \\
\hline Minimum........... & 75.8 & 18.6 &.$S$ & . . & 1.0 & 365 & 8.j) \\
\hline Maximum........ & 79.8 & 20.3 & 2.9 & ... & 1.4 & 500 & 111 \\
\hline Average. ........... & 77.8 & 19.2 & 2.1 & $\cdots$ & 1.2 & 445 & as \\
\hline Trout, salmon or lake: & & & & $\ldots$ & & & \\
\hline $\begin{array}{l}\text { Minimum........... } \\
\text { Maximum........ }\end{array}$ & 68.8 & 17.6 & $\begin{aligned} 8.1 \\
12.6\end{aligned}$ & $\cdots$ & 1.0 & 675 & 150 \\
\hline $\begin{array}{l}\text { Maximum . . . . . . . } \\
\text { Average. . . . . . . }\end{array}$ & 72.9 & 17.9 & $\begin{array}{l}12.6 \\
10.3\end{array}$ & $\begin{array}{l}\cdots \\
\cdots\end{array}$ & 1.3 & $\mathrm{Sij0}$ & 191 \\
\hline $\begin{array}{l}\text { Average. . . . . . } \\
\text { Turbot.......... }\end{array}$ & 70.5 & $17 . x$ & 10.3 & $\cdots$ & 1.2 & 76.5 & 170 \\
\hline 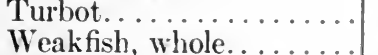 & 71.4 & 14.8 & 14.4 & $\cdots$ & 1.3 & 865 & 196 \\
\hline $\begin{array}{l}\text { Weakfish, whole.......... } \\
\text { Whitefish............. }\end{array}$ & 79.0 & 17.8 & 2.4 & $\cdots$ & 1.2 & 430 & 95 \\
\hline Whitefish............. & 69.8 & 22.9 & 6.5 & $\cdots$ & 1.6 & 700 & 155 \\
\hline Bluefish, cooked.......... & 68.2 & 25.9 & 4.5 & $\ldots$ & 1.2 & 670 & 148 \\
\hline $\begin{array}{l}\text { Spanish mackerel, broiled. } \\
\text { Fish, preserved and canned } \\
\text { Cod, salt: }\end{array}$ & 68.9 & 23.7 & 6.5 & $\cdots$ & 1.4 & 715 & 155 \\
\hline Minimum.......... & 53.5 & 24.9 & .2 & $\ldots$ & 24.4 & 40.5 & 90 \\
\hline Maximum ......... & 53.6 & 25.9 &.$t$ & ... & 25.0 & $4: 20$ & 93 \\
\hline Average............ & 53.5 & 25.4 & .3 & $\cdots$ & 24.7 & 410 & 91 \\
\hline $\begin{array}{l}\text { Cod, salt "boneless": } \\
\text { Minimum... }\end{array}$ & & & & & & & \\
\hline $\begin{array}{l}\text { Minimum........ } \\
\text { Maximum...... }\end{array}$ & 54.4 & 26.3 & .3 & $\cdots$ & 14.9 & 425 & 94 \\
\hline $\begin{array}{l}\text { Maximum ... . } \\
\text { Average. . . . . }\end{array}$ & 55.7 & 28.2 & .3 & $\cdots$ & 23.1 & 5.505 & 123 \\
\hline $\begin{array}{l}\text { Average............. } \\
\text { Haddock, smoked... . . . }\end{array}$ & $\begin{array}{l}55.0 \\
72.5\end{array}$ & $\begin{array}{l}27.3 \\
23.3\end{array}$ & .2 & $\begin{array}{l}\cdots \\
\cdots\end{array}$ & $\begin{array}{r}19.0 \\
3.6\end{array}$ & $\begin{array}{l}49) \\
440\end{array}$ & $\frac{105}{97}$ \\
\hline Halibut, smoked: & & & & & & & 96 \\
\hline Minimum.......... & 47.7 & $18 . j$ & 14.4 & $\cdots$ & 14.9 & 1,000 & 222 \\
\hline Maximum ......... & 5.11 & 23.0 & 15.6 & $\ldots$ & 15.2 & 1,035 & 230 \\
\hline Average. . & 49.4 & 20.7 & 15.0 & $\ldots$ & 15.0 & 1,020 & 226 \\
\hline Herring, smoked... . & 34.6 & 36.9 & 15.5 & & 13.2 & 1,355 & 301 \\
\hline Lamprey, canned........ & 63.3 & 16.9 & 12.2 & 3.6 & 4.0 & $\$ 95$ & 195 \\
\hline $\begin{array}{l}\text { Mackerel, salt, entrails re- } \\
\text { moved........................ }\end{array}$ & 42.2 & 21.1 & 22.6 & $\cdots$ & 13.2 & 1,345 & 298 \\
\hline $\begin{array}{c}\text { Mackerel, salt, canned, as } \\
\text { purchased............. }\end{array}$ & 65.2 & 19.6 & 8.7 & $\cdots$ & 3.2 & 730 & 162 \\
\hline
\end{tabular}




\begin{tabular}{|c|c|c|c|c|c|c|c|}
\hline \multirow[b]{2}{*}{ Food Materials } & \multirow[b]{2}{*}{$\begin{array}{l}\text { Per cent } \\
\text { Water }\end{array}$} & \multirow[b]{2}{*}{$\begin{array}{l}\text { Per cent } \\
\text { Protein }\end{array}$} & \multirow[b]{2}{*}{$\begin{array}{l}\text { Per cent } \\
\text { Fat }\end{array}$} & \multirow[b]{2}{*}{$\mid \begin{array}{c}\text { Per cent } \\
\text { Carbo- } \\
\text { hydrates }\end{array}$} & \multirow[b]{2}{*}{$\begin{array}{c}\text { Per cent } \\
\text { Ash }\end{array}$} & \multicolumn{2}{|c|}{ Fuel Value } \\
\hline & & & & & & $\begin{array}{l}\text { Calories } \\
\text { per } \\
\text { Pound }\end{array}$ & $\begin{array}{l}\text { Calories } \\
\text { per } 100 \\
\text { Grams }\end{array}$ \\
\hline $\begin{array}{l}\text { ANIMAL FOOD-Con. } \\
\text { Fish, preserved and canned }\end{array}$ & & & & & & & \\
\hline $\begin{array}{l}\text { Mackerel, salt, canned in } \\
\quad \text { oil. ...................... }\end{array}$ & 58.3 & 25.4 & 14.1 & $\cdots$ & 4.1 & 1,065 & 236 \\
\hline Mackerel, salt, dressed: & 43.2 & 16.6 & 24.9 & $\cdots$ & 12.0 & 1,345 & 298 \\
\hline Maximum........... & 43.6 & 17.9 & 27.9 & $\ldots$ & 13.8 & 1,485 & 330 \\
\hline Average. . & 43.4 & 17.3 & 26.4 & $\ldots$ & 12.9 & 1,435 & 318 \\
\hline Minogy, pickled, canned.. & 56.5 & 22.0 & 18.6 & .. & 3.0 & 1,195 & 265 \\
\hline 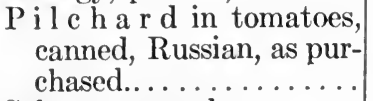 & 52.7 & 27.9 & 15.8 & $\ldots$ & 4.0 & 1,185 & 263 \\
\hline $\begin{array}{l}\text { Salmon, canned: } \\
\text { Minimum.......... }\end{array}$ & & & & & & & \\
\hline $\begin{array}{l}\text { Minimum............ } \\
\text { Maximum ........ }\end{array}$ & $\begin{array}{l}57.5 \\
67.1\end{array}$ & $\begin{array}{l}19.5 \\
24.3\end{array}$ & $\begin{array}{r}5.3 \\
21.5\end{array}$ & $\begin{array}{l}\cdots \\
\cdots\end{array}$ & $\begin{array}{l}1.8 \\
3.5\end{array}$ & $\begin{array}{r}675 \\
1,270\end{array}$ & $\begin{array}{l}150 \\
282\end{array}$ \\
\hline Average. . . . . . & 63.5 & 21.8 & 12.1 & $\cdots$ & 2.6 & 915 & 213 . \\
\hline Sardines, canned: & & & & & & & \\
\hline $\begin{array}{l}\text { Minimum.... } \\
\text { Maximum... }\end{array}$ & 48.2 & 21.2 & 12.7 & $\cdots$ & 5.6 & 1,000 & 222 \\
\hline 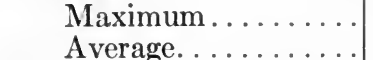 & 56.4 & 24.9 & 26.7 & $\cdots$ & 5.7 & 1,520 & 337 \\
\hline $\begin{array}{l}\text { Average. } \\
\text { Sturgeon, dried, Russian, }\end{array}$ & 52.3 & 23.0 & 19.7 & $\cdots$ & 5.6 & 1,260 & 280 \\
\hline $\begin{array}{l}\text { Sturgeon, dried, Russian, } \\
\text { as purchased ........... }\end{array}$ & 44.1 & 27.8 & 8.4 & $\cdots$ & 6.7 & 870 & 193 \\
\hline Trout, brook........... & 68.4 & 22.3 & 6.1 & ... & 3.7 & 670 & 148 \\
\hline Tunney, as purchased. . : & 72.7 & 21.7 & 4.1 & ... & 1.7 & 575 & 127 \\
\hline $\begin{array}{c}\text { Tunney, canned in oil, } \\
\text { Russian............ } \\
\text { Amphibia }\end{array}$ & 51.3 & 23.8 & 20.0 & .6 & 4.3 & 1,300 & 288 \\
\hline $\begin{array}{l}\text { Frogs' legs: } \\
\text { Minimum }\end{array}$ & & & & & & & \\
\hline $\begin{array}{l}\text { Minimum } \\
\text { Maximum }\end{array}$ & 81.2 & 13.2 & .2 & $\cdots$ & .8 & 255 & 56 \\
\hline $\begin{array}{l}\text { Maximum } \\
\text { Average. . }\end{array}$ & 86.2 & 1 & .2 & $\cdots$ & 1.2 & 355 & 78 \\
\hline $\begin{array}{l}\text { Average......... } \\
\text { As purchased: }\end{array}$ & 83.7 & 15.5 & .2 & $\ldots$ & 1.0 & 295 & 65 \\
\hline Minimum...... & 54.8 & 19.1 & .1 & & .6 & 175 & 38 \\
\hline Maximum..... & 59.1 & 12.0 & .2 & & .8 & 225 & 50 \\
\hline $\begin{array}{l}\text { Average............. } \\
\text { Shell fish, fresh }\end{array}$ & 56.9 & 10.5 & .1 & ... & .7 & 200 & 44 \\
\hline Clams, long, in shell: & & & & & & & \\
\hline Minimum...... & 85.0 & 8.1 & 1.0 & 1.6 & 2.0 & 225 & 50 \\
\hline Maximum ..... & 86.1 & 9.0 & 1.2 & 2.5 & 3.0 & 255 & 56 \\
\hline Average. & 85.8 & 8.6 & 1.0 & 2.0 & 2.6 & 240 & 53 \\
\hline Clams, round, in shell. & 86.2 & 6.5 & .4 & 4.2 & 2.7 & 215 & 47 \\
\hline Crabs, hardshell, whole... & 77.1 & 16.6 & 2.0 & 1.2 & 3.1 & 415 & 92 \\
\hline Crayfish, abdomen, whole. & 81.2 & 16.0 & .5 & 1.0 & 1.3 & 340 & 75 \\
\hline Lobster, whole: & & & & & & & \\
\hline Minimum... & 68.6 & 11.6 & 1.5 & ... & 1.6 & 345 & 76 \\
\hline Maximum. . & 84.3 & 25.4 & 2.5 & .9 & 4.0 & 555 & 123 \\
\hline Average. . & 79.2 & 16.4 & 1.8 & .4 & 2.2 & 390 & 86 \\
\hline Mussels, in shell.... . & 84.2 & 8.7 & 1.1 & 4.1 & 1.9 & 285 & 63 \\
\hline
\end{tabular}




\begin{tabular}{|c|c|c|c|c|c|c|c|}
\hline \multirow[b]{2}{*}{ Food Matrimals } & \multirow[b]{2}{*}{$\begin{array}{l}\text { Percent } \\
\text { Water }\end{array}$} & \multirow[b]{2}{*}{$\begin{array}{l}\text { Percent } \\
\text { Protein }\end{array}$} & \multirow[b]{2}{*}{$\begin{array}{l}\text { Percernt } \\
\text { lint }\end{array}$} & \multirow[b]{2}{*}{$\begin{array}{l}\text { Perecont } \\
\text { Ciarlice- } \\
\text { hydrates }\end{array}$} & \multirow[b]{2}{*}{$\begin{array}{c}\text { Per cent } \\
\text { Anh }\end{array}$} & \multicolumn{2}{|c|}{ FenL VAlde: } \\
\hline & & & & & & $\begin{array}{c}\text { Calorius' } \\
\text { Poer } \\
\text { Pound }\end{array}$ & $\begin{array}{l}\text { Calories } \\
\text { per } 1(x) \\
\text { firams }\end{array}$ \\
\hline $\begin{array}{l}\text { ANIMAL bOOD-Com. } \\
\text { Shellfish, fresh } \\
\text { Oysters, in shell: }\end{array}$ & & & & & & & \\
\hline Minimum........ & S1.7 & 1.2 & .6 & 1.5 & 1.2 & 135 & 30 \\
\hline $\begin{array}{l}\text { Maximum } \ldots \ldots \ldots \\
\text { Average. }\end{array}$ & 91.4 & 10.0 & 1.9 & 6.7 & 2.5 & 370 & 52 \\
\hline $\begin{array}{l}\text { Average } \\
\text { Oysters, solids, as pur- } \\
\text { chased: }\end{array}$ & siti!n & (i.2 & 1.2 & 3.7 & 20 & 235 & 52 \\
\hline Minimum......... & $\because 2.2$ & 4.5 & .5 & 1.5 & .7 & 1335 & 30 \\
\hline Maxilisum ...... & 92.4 & $\therefore 3$ & 1.8 & 6.2 & 2.5 & 325 & 72 \\
\hline $\begin{array}{l}\text { Average. . . . . . . } \\
\text { Seallops, as purchased: }\end{array}$ & 85.3 & 6.6 & 1.3 & 3.3 & 1.1 & 230 & 51 \\
\hline Minimum........... & 77.8 & 14.5 & & 1.1 & 1.3 & $30 i$ & $6 \pi$ \\
\hline Maximum . . . . . . & 82.8 & 15.1 & .3 & 5.6 & 1.5 & 385 & 85 \\
\hline Average. . . . . . . . & 80.3 & $14.5 \mid$ & .1 & 3.4 & 1.4 & 345 & 76 \\
\hline 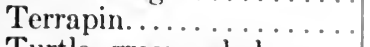 & 74.5 & 21.2 & $3 . \bar{j}$ & $\ldots$ & 1.0 & 545 & 121 \\
\hline $\begin{array}{l}\text { Turtle, green, whole..... } \\
\text { Shellfish, etc., cammed }\end{array}$ & 79.8 & 19.8 & $\therefore$ & $\cdots$ & 1.2 & 390 & 46 \\
\hline $\begin{array}{l}\text { Clams, long, as purchased. } \\
\text { Clams, round, as pur- }\end{array}$ & $\$ 4.5$ & 9.0 & 1.3 & 2.9 & 2.3 & 275 & 61 \\
\hline $\begin{array}{l}\text { Cams, round, as pur- } \\
\text { chased.................. } \\
\text { Crabs, as purchased: }\end{array}$ & 82.9 & $10 . \overline{5}$ & .8 & 3.0 & 2.8 & 263 & 63 \\
\hline Minimum .......... & 78.9 & 15.6 & .8 & .7 & 1.5 & 340 & 33 \\
\hline Maxisstum......... & $\$ 1.0$ & 16.0 & 2.3 & .8 & 2.1 & 410 & 91 \\
\hline $\begin{array}{l}\text { Average.......... } \\
\text { Lobster, as purchased: }\end{array}$ & 80.0 & 15.8 & 1.5 & .7 & 2.0 & 370 & $\$ 2$ \\
\hline Minimum........... & 76.2 & 16.7 &.$\overline{5}$ & j) & 2.1 & 345 & 76 \\
\hline Maximum........ & 79.4 & 19.5 & 1.7 & .6 & 2.8 & 445 & 95 \\
\hline Average. .......... & 77.8 & 18.1 & 1.1 & .5 &.$j$ & 390 & 86 \\
\hline $\begin{array}{l}\text { sters, as purchased: } \\
\text { Minimum........... }\end{array}$ & 78.1 & 7.0 & 2.0 & 2.6 & 1.2 & 240 & 62 \\
\hline Maximum .......... & $\$ 6.0$ & 13.0 & 3.4 & 3.2 & 1.9 & 310 & 65 \\
\hline Average. ............ & 83.4 & 8.8 & 2.4 & 3.9 & 1.5 & 335 & it \\
\hline Shrimp, as purchased.... & 70.8 & 25.4 & 1.0 & .2 & 2.6 & 520 & 115 \\
\hline $\begin{array}{l}\text { Hens', uncooked }{ }^{1} \text { : } \\
\text { Minimum...... }\end{array}$ & 67.2 & 11.6 & 8.6 & & 6 & & \\
\hline Maximum ......... & 75.8 & 16.0 & 15.1 & $\cdots$ & 1.6 & $\begin{array}{l}600 \\
910\end{array}$ & $\begin{array}{l}1+6 \\
202\end{array}$ \\
\hline $\begin{array}{l}\text { Average. .......... } \\
\text { Hens', boiled: }\end{array}$ & 73.7 & 13.4 & 10.5 & $\cdots$ & 1.0 & 720 & 160 \\
\hline Minimum. & 68.6 & 10.0 & 9.1 & $\cdots$ & .6 & 373 & 127 \\
\hline Maximum........ & 79.9 & 15.6 & 14.7 & $\ldots$ & 1.1 & $\Delta \times()$ & 195 \\
\hline Average. .......... & 73.2 & 13.2 & 12.0 & $\cdots$ & .5 & 765 & 170 \\
\hline As purchased......... & 65.0 & 11.7 & 10.7 & $\cdots$ & .7 & 60 & 151 \\
\hline
\end{tabular}

1 Eggs are diflicult of analysis and the discrepancy leetwen the protoin by factar and by difference may be due in part to incomplete determination of nitrogen and fat. It is also probable that the factor 6.25 is not correst for eggs. The value of protein by difference is perhaps the more nearly correct and has been uad in the computation of the fuel value per pound. 


\begin{tabular}{|c|c|c|c|c|c|c|c|}
\hline \multirow[b]{2}{*}{ Food Materials } & \multirow[b]{2}{*}{$\begin{array}{l}\text { Per cent } \\
\text { Water }\end{array}$} & \multirow[b]{2}{*}{$\begin{array}{l}\text { Per cent } \\
\text { Protein }\end{array}$} & \multirow[b]{2}{*}{$\begin{array}{l}\text { Per cent } \\
\text { Fat }\end{array}$} & \multirow[b]{2}{*}{$\begin{array}{l}\text { Per cent } \\
\text { Carbo- } \\
\text { hydrates }\end{array}$} & \multirow[b]{2}{*}{$\begin{array}{l}\text { Per cent } \\
\text { Ash }\end{array}$} & \multicolumn{2}{|c|}{ Fuel Value } \\
\hline & & & & & & $\begin{array}{l}\text { Calories } \\
\text { per } \\
\text { Pound }\end{array}$ & $\begin{array}{l}\text { Calories } \\
\text { per } 100 \\
\text { Grams }\end{array}$ \\
\hline ANIMAL $\underset{\text { Eggs }}{\text { FOOD-Con. }}$ & & & & & & & \\
\hline $\begin{array}{l}\text { Hens', boiled whites: } \\
\text { Minimum............ }\end{array}$ & 83.1 & 11.6 & & • & .4 & 235 & 52 \\
\hline Maximum.............. & 87.1 & 14.8 & 3 & $\ldots$ & 1.0 & 295 & 65 \\
\hline $\begin{array}{l}\text { Average. ....... } \\
\text { Hens', boiled yolks: }\end{array}$ & 86.2 & 12.3 & .2 & $\cdots$ & .6 & 250 & 55 \\
\hline Minimum..... & 48.4 & 15.3 & 32.2 & $\ldots$ & 1.0 & 1,685 & 374 \\
\hline Maximum...... & 50.2 & 16.8 & 34.4 & $\ldots$ & 1.4 & 1,745 & 387 \\
\hline Average. ......... & 49.5 & 15.7 & 33.3 & ... & 1.1 & 1,705 & 378 \\
\hline $\begin{array}{l}\text { Dairy Products, etc. } \\
\text { Butter, as purchased.. }\end{array}$ & 11.0 & 1.0 & 85.0 & & 3.0 & 3,605 & 801 \\
\hline Buttermilk, as purchased. & 91.0 & 3.0 & .5 & 4.8 & 3.7 & 165 & ... \\
\hline $\begin{array}{l}\text { Cheese, American, pale, as } \\
\text { purchased.............. }\end{array}$ & 31.6 & 28.8 & 35.9 & .3 & 3.4 & 2,055 & 456 \\
\hline $\begin{array}{l}\text { Cheese, American, red, as } \\
\text { purchased............. }\end{array}$ & 28.6 & & 38.3 & & 3.5 & 2,165 & 481 \\
\hline $\begin{array}{l}\text { Cheese, Boudon, as pur- } \\
\text { chased................... } \\
\text { Cheese California flat as }\end{array}$ & 55.2 & 15.4 & 20.8 & 1.6 & 7.0 & 1,195 & 265 \\
\hline $\begin{array}{l}\text { purchased............ } \\
\text { Cheese, Chediar, as pur- }\end{array}$ & 34.0 & 24.3 & 33.4 & 4.5 & 3.8 & 1,945 & 432 \\
\hline $\begin{array}{l}\text { chased ................ } \\
\text { Cheese, Cheshire, as pur- }\end{array}$ & 27.4 & 27.7 & 36.8 & 4.1 & 4.0 & 2,145 & 476 \\
\hline $\begin{array}{l}\text { chased............... } \\
\text { Cheese, cottage, as pur- } \\
\text { chased: }\end{array}$ & 37.1 & 26.9 & 30.7 & .9 & 4.4 & 1,810 & 402 \\
\hline Minimum..... & 67.0 & 16.1 & .4 & 3.7 & 1.6 & 435 & 96 \\
\hline Maximum ..... & 77.0 & 25.7 & 1.6 & 4.9 & 2.0 & 585 & 130 \\
\hline Average................. & 72.0 & 20.9 & 1.0 & 4.3 & 1.8 & 510 & 113 \\
\hline $\begin{array}{l}\text { Cheese, Crown brand } \\
\text { cream, as purchased.... }\end{array}$ & 31.4 & 5.2 & 58.0 & 2.2 & 3.2 & 2,585 & 574 \\
\hline $\begin{array}{l}\text { Cheese, Dutch, as pur- } \\
\text { chased: }\end{array}$ & & & - & & & & \\
\hline Minimum...... & 27.6 & . & 16.3 & $\cdots$ & 8.7 & 1,240 & 275 \\
\hline Maximum ..... & 42.7 & & 19.0 & & 11.4 & 1,630 & 362 \\
\hline $\begin{array}{l}\text { Average...... } \\
\text { Cheese, Fromage de Brie. }\end{array}$ & 35.2 & & 17.7 & & 10.0 & 1,435 & 318 \\
\hline as purchased........... & 60.2 & 15.9 & 21.0 & 1.4 & 1.5 & 1,210 & 268 \\
\hline $\begin{array}{l}\text { Cheese, full cream, as pur- } \\
\text { chased: }\end{array}$ & & & & & & & \\
\hline Minimum...... & 27.0 & 17.9 & 24.5 & 1.2 & 2.5 & 1,790 & 397 \\
\hline Maximum... & 44.1 & 37.0 & 44.6 & 4.0 & 4.9 & 2,430 & 540 \\
\hline Average. . . . . . . . . . & 34.2 & 25.9 & 33.7 & 2.4 & 3.8 & 1,950 & 433 \\
\hline $\begin{array}{l}\text { Cheese, imitation full } \\
\text { cream, Ohio, as pur- } \\
\text { chased............. } \\
\text { Cheese, imitation old Eng- }\end{array}$ & 37.9 & & 31.7 & & 4.5 & 1,820 & 404 \\
\hline lish, as purchased ..... & 20.7 & 30.1 & 42.7 & 1.3 & 5.2 & 2,385 & 530 \\
\hline
\end{tabular}




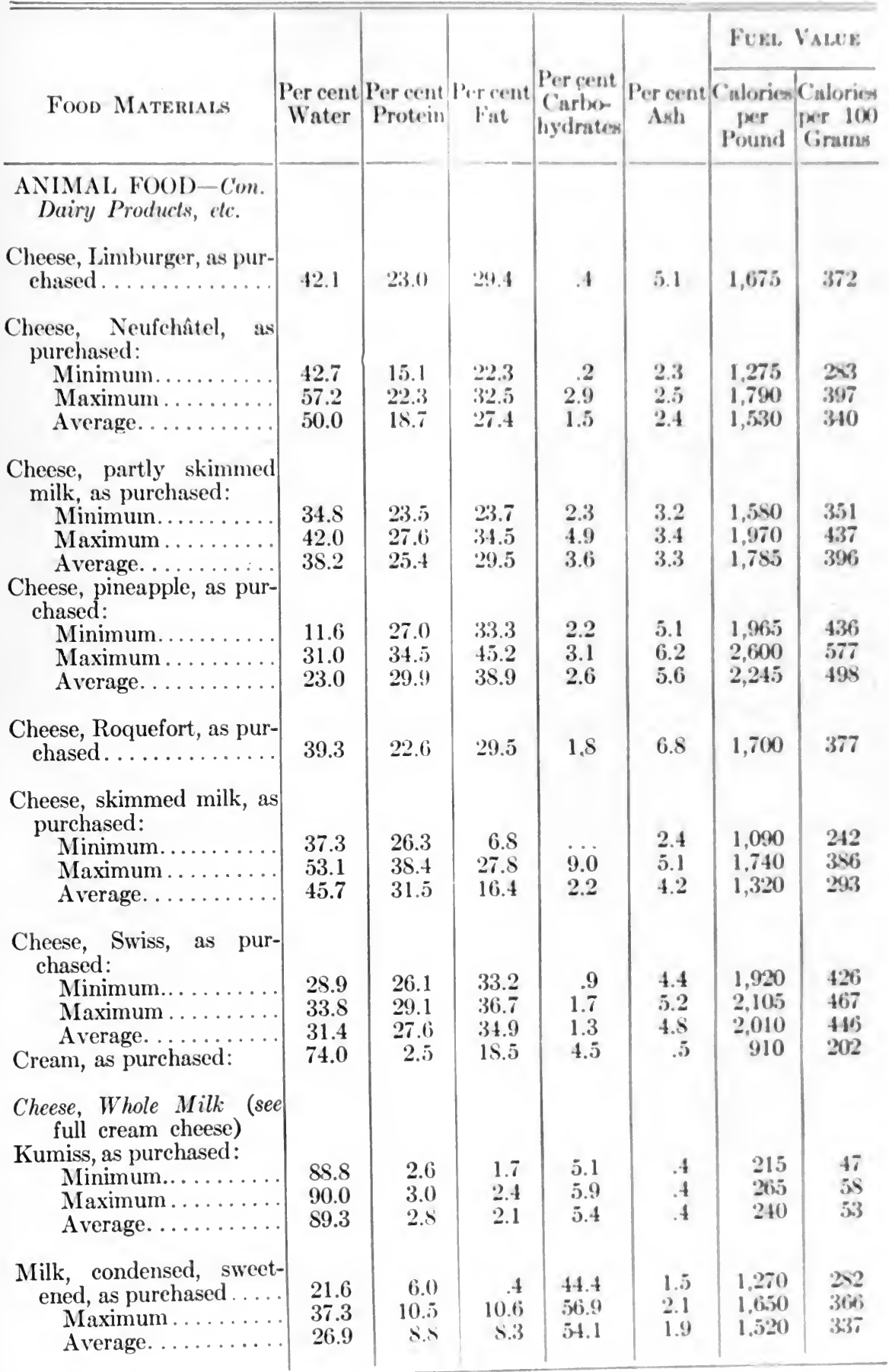




\begin{tabular}{|c|c|c|c|c|c|c|c|}
\hline \multirow[b]{2}{*}{ Food Materials } & \multirow[b]{2}{*}{$\begin{array}{c}\text { Per cent } \\
\text { Water }\end{array}$} & \multirow[b]{2}{*}{$\begin{array}{l}\text { Per cent } \\
\text { Protein }\end{array}$} & \multirow[b]{2}{*}{$\begin{array}{c}\text { Per cent } \\
\text { Fat }\end{array}$} & \multirow[b]{2}{*}{ t $\begin{array}{c}\text { Per cent } \\
\text { Carbo- } \\
\text { hydrates }\end{array}$} & \multirow[b]{2}{*}{$\begin{array}{c}\text { Per cent } \\
\text { Ash }\end{array}$} & \multicolumn{2}{|c|}{ Fuel Value } \\
\hline & & & & & & $\begin{array}{l}\text { Calories } \\
\text { per } \\
\text { Pound }\end{array}$ & $\begin{array}{l}\text { Calories } \\
\text { per } 100 \\
\text { Grams }\end{array}$ \\
\hline $\begin{array}{l}\text { ANIMAL FOOD_Con. } \\
\text { Cheese, Whole Milk (see } \\
\text { full cream cheese) }\end{array}$ & & & & & & & \\
\hline $\begin{array}{l}\text { Milk, condensed, unsweet- } \\
\text { ened, evaporated cream, } \\
\text { as purchased: }\end{array}$ & & & & & & & \\
\hline Minimum.......... & 66.3 & 8.6 & 7.8 & 10.4 & 1.5 & 740 & 164 \\
\hline Maximum......... & 69.6 & 10.5 & 10.4 & 12.2 & 2.1 & 835 & 185 \\
\hline Average........... & 68.2 & 9.6 & 9.3 & 11.2 & 1.7 & 780 & 173 \\
\hline $\begin{array}{l}\text { Milk, skimmed, as pur- } \\
\text { chased............... }\end{array}$ & 90.5 & 3.4 & .3 & 5.1 & .7 & 170 & 37 \\
\hline Milk, whole, as purchased. & 87.0 & 3.3 & 4.0 & 5.0 & .7 & 325 & 72 \\
\hline Whey, as purchased...... & 93.0 & 1.0 & .3 & 5.0 & .7 & 125 & 27 \\
\hline $\begin{array}{c}\text { Miscellaneous } \\
\text { Gelatin, as purchased: }\end{array}$ & & & & & - & & \\
\hline Minimum.......... & 9.6 & 89.3 & $\cdots$ & $\cdots$ & 1.4 & 1,660 & 368 \\
\hline Maximum......... & 15.4 & 97.5 & .4 & $\ldots$ & 4.4 & 1,830 & 406 \\
\hline Average........... & 13.6 & 91.4 & .1 & $\cdots$ & 2.1 & 1,705 & 378 \\
\hline $\begin{array}{l}\text { Calf's foot jelly, as pur- } \\
\text { chased............. }\end{array}$ & 77.6 & 4.3 & $\ldots$ & 17.4 & .7 & 405 & 90 \\
\hline $\begin{array}{l}\text { Isinglass, sturgeon, as pur- } \\
\text { chased.............. }\end{array}$ & 19.0 & 89.3 & 1.6 & $\ldots$ & 2.0 & 1,730 & 384 \\
\hline $\begin{array}{l}\text { Spinal column, sturgeon, } \\
\text { as purchased.......... }\end{array}$ & 17.7 & 59.8 & 17.1 & .8 & 4.6 & 1,850 & 411 \\
\hline Lard, refined, as purchased & $\cdots$ & $\ldots$ & 100.0 & $\ldots$ & $\ldots$ & 4,220 & 937 \\
\hline $\begin{array}{l}\text { Lard, unrefined, as pur- } \\
\text { chased: }\end{array}$ & & & & & & & \\
\hline Minimum...... & 3.1 & 1.7 & 72.0 & $\ldots$ & .1 & 3,895 & 865 \\
\hline Maximum...... & 6.6 & 2.9 & 95.9 & ... & .1 & 4,065 & 903 \\
\hline Average........... & 4.8 & 2.2 & 94.0 & ... & .1 & 4,010 & 891 \\
\hline $\begin{array}{l}\text { Tallow, refined, as pur- } \\
\text { chased.............. }\end{array}$ & $\cdots$ & & 100.0 & & & 4,220 & 937 \\
\hline Cottolene, as purchased.... & $\ldots$ & $\ldots$ & 100.0 & $\ldots$ & $\ldots$ & 4,220 & 937 \\
\hline $\begin{array}{l}\text { Oleomargarin, as pur- } \\
\text { chased............... }\end{array}$ & 9.5 & 1.2 & 83.0 & & 6.3 & 3,525 & 783 \\
\hline Beef juice, as purchased... & 93.0 & 4.9 & .6 & $\ldots$ & 1.5 & 155 & 34 \\
\hline
\end{tabular}


CHEAICAL COMPOSITION OF .MERICAN FOODS T2M

\begin{tabular}{|c|c|c|c|c|c|c|c|c|}
\hline Food Matemalas & $\begin{array}{l}\text { Por } \\
\text { cent } \\
\text { Water }\end{array}$ & $\begin{array}{l}\text { Per } \\
\text { cent } \\
\text { Pro- } \\
\text { tein }\end{array}$ & $\begin{array}{l}\text { Per } \\
\text { rent } \\
\text { Fint }\end{array}$ & $\begin{array}{l}\text { Per } \\
\text { cont } \\
\text { Car- } \\
\text { lushy- } \\
\text { dratess }\end{array}$ & $\begin{array}{l}\text { lerer } \\
\text { cent } \\
\text { bituers }\end{array}$ & $\begin{array}{l}\text { l'er } \\
\text { cont } \\
\text { Anht }\end{array}$ & $\begin{array}{l}\text { Colorios } \\
\text { pure } \\
\text { Pound }\end{array}$ & $\begin{array}{l}\text { Calorios } \\
\text { jer I(x) } \\
\text { (irmanx }\end{array}$ \\
\hline \multicolumn{9}{|l|}{$\begin{array}{l}\text { VEGEETABLE FO(OD) } \\
\text { Flours, Meals, ete. }\end{array}$} \\
\hline $\begin{array}{l}\text { Barley, granulated.... } \\
\text { Barley meal and flour: }\end{array}$ & 10.9 & 7.5 & .9 & $79 . k$ & .7 & .9 & 1,860 & 365 \\
\hline Minimum........ & 9.9 & 9.0 & 1.5 & 70.4 & 5.9 & 1.6 & 1,$533 ;$ & :H \\
\hline Maxim & 13.6 & 12.7 & 3.2 & 74.5 & 7.0 & 3.5 & $1,6,40$ & 373 \\
\hline Average.. & 11.9 & 10.5 & 2.2 & 72.8 & $(3) 6.5$ & 2.6 & 1,640 & 364 \\
\hline \multicolumn{9}{|l|}{ Barley, pearled: } \\
\hline Minimum. & 9.8 & 7.0 & .7 & 77.3 & & .6 & 1,6335 & $36 i 3$ \\
\hline Maxim & 12.9 & 10.1 & 1.5 & 78.1 & & 1.6 & 1,675 & 372 \\
\hline Average...... & 11.5 & 8.5 & 1.1 & 77.8 & (1) .3 & 1.1 & 1,650 & 366 \\
\hline \multicolumn{9}{|l|}{ Buckwheat flour: } \\
\hline Maxim & 17.6 & 10.4 & 2.3 .3 & $\begin{array}{l}71.6 \\
81.5\end{array}$ & .7 & 1.5 & $\begin{array}{l}1,560 \\
1,6.50\end{array}$ & $\begin{array}{l}346 \\
366\end{array}$ \\
\hline Average... . . & 13.6 & 6.4 & 1.2 & 77.9 & (S) .4 & .9 & 1,620 & $3(x)$ \\
\hline \multicolumn{9}{|l|}{$\begin{array}{c}\text { Buckwheat preparations: } \\
\text { Farina and groats: }\end{array}$} \\
\hline Minimum. . & 10.6 & 3.3 & .3 & 83.4 & .1 & .4 & $1,6.50$ & 366 \\
\hline Maxin & 11.2 & 4.8 & .6 & 84.8 & .3 & .6 & $1,66 \%$ & 370 \\
\hline $\mathrm{Av}$ & 10.9 & 4.1 & .4 & 84.1 & .2 & .5 & 1,660 & 365 \\
\hline Maxim & $\begin{array}{r}9.8 \\
13.6\end{array}$ & $\begin{aligned} 5.5 \\
11 .\end{aligned}$ & 1.4 & 77.3 & & $\begin{array}{l}4.4 \\
7.0\end{array}$ & (3) & $\begin{array}{l}3.350 \\
3.55\end{array}$ \\
\hline Average... . & 11.6 & 8.2 & 1.2 & 73.4 & (1) .4 & 5.6 & 1,370 & 348 \\
\hline \multicolumn{9}{|l|}{ Corn flour ${ }^{3}$ : } \\
\hline Min & 13.0 & 8. & 1.8 & 79.6 & 1.2 &.$s$ & 1,665 & 370 \\
\hline Average......... & 12.6 & 7.1 & 1.3 & 78.4 & .9 & .6 & 1,645 & 36.5 \\
\hline \multicolumn{9}{|l|}{ Corn meal, granular": } \\
\hline Maximum. . & $\begin{array}{r}0.0 \\
17.9\end{array}$ & 11. & 5.3 & S0.6 & & 1.9 & 1,720 & 352 \\
\hline Average......... & 12.5 & 9.2 & 1.9 & 75.4 & (1) 1.0 & 1.0 & 1,655 & 367 \\
\hline \multicolumn{9}{|l|}{ Corn meal, unbolted: } \\
\hline $\begin{array}{l}\text { Minimum. . } \\
\text { Maximum. }\end{array}$ & 10.9 & 7.8 & $\begin{array}{l}4.5 \\
5.2\end{array}$ & $\begin{array}{l}71.9 \\
75.4\end{array}$ & & 1.2 & $\begin{array}{l}1,70 \\
1,740\end{array}$ & 386 \\
\hline $\begin{array}{l}\text { Maximum. . } \\
\text { Average.. . . }\end{array}$ & $\begin{array}{l}12.4 \\
11.6\end{array}$ & $\begin{array}{l}9.3 \\
8.4\end{array}$ & $\begin{array}{l}5.2 \\
4.7\end{array}$ & 74.0 & & 1.3 & 1,730 & $\begin{array}{l}380 \\
354\end{array}$ \\
\hline \multicolumn{9}{|l|}{ Corn meal, unbolted: } \\
\hline s purchased: & 9.2 & 6. & 3.5 & 55.7 & & 1.0 & 1,305 & 290 \\
\hline Maximum. . & 10.8 & 8. & 4.5 & 72.2 & & 1.3 & 1,670 & 371 \\
\hline Average.. . & 10.3 & 7.5 & 4.2 & 65.9 & & 1.2 & 1,545 & 343 \\
\hline
\end{tabular}

1 Fiber included.

2 Number of determinations in parentheses.

3 Average of 77 analyses of eorn meal used for fodder gives water 15. protein 50 . fat 3.8 , carbohydrates 68.7 , fiber 1.9 , and ash 1.4 per cent, and fuel value 1.610 calories.

4 The ash of one sample contained 0.185 per cent phowphorus. 


\begin{tabular}{|c|c|c|c|c|c|c|c|c|}
\hline \multirow[b]{2}{*}{ Food Materials } & \multirow{2}{*}{$\begin{array}{c}\text { Per } \\
\text { cent } \\
\text { Water }\end{array}$} & \multirow{2}{*}{$\begin{array}{l}\text { Per } \\
\text { cent } \\
\text { Pro- } \\
\text { tein }\end{array}$} & \multirow{2}{*}{$\begin{array}{l}\text { Per } \\
\text { cent } \\
\text { Fat }\end{array}$} & \multirow{2}{*}{$\begin{array}{c}\text { Per } \\
\text { cent } \\
\text { Car- } \\
\text { bohy- } \\
\text { drates }^{1}\end{array}$} & \multirow{2}{*}{$\begin{array}{l}\text { Per } \\
\text { cent } \\
\text { Fiber }^{2}\end{array}$} & \multirow{2}{*}{$\begin{array}{l}\text { Per } \\
\text { cent } \\
\text { Ash }\end{array}$} & \multicolumn{2}{|c|}{ Fuel Value } \\
\hline & & & & & & & $\begin{array}{c}\text { Calories } \\
\text { per } \\
\text { Pound }\end{array}$ & $\begin{array}{l}\text { Calories } \\
\text { per } 100 \\
\text { Grams }\end{array}$ \\
\hline $\begin{array}{l}\text { VEGETABLE FOOD- } \\
\text { Con. } \\
\text { Flours, Meals, etc. } \\
\text { Pop Corn: }\end{array}$ & & & & & & & & \\
\hline Minimum.......... & 4.1 & 10.3 & 4.7 & 78.6 & 1.3 & 1.3 & 1,870 & 415 \\
\hline Maximum... & 4.4 & 11.1 & 5.4 & 78.7 & 1.4 & 1.4 & 1,880 & 417 \\
\hline Average.. ..... & 4.3 & 10.7 & 5.0 & 78.7 & 1.4 & 1.3 & 1,875 & 416 \\
\hline $\begin{array}{l}\text { Corn preparations: } \\
\text { Cerealine }{ }^{3}:\end{array}$ & & & & & & & & \\
\hline Minimum.... & 9.5 & 9.1 & .9 & 76.6 & .2 & .2 & 1,635 & 363 \\
\hline Maximum. . & 11.0 & 9.9 & 1.3 & 79.2 & .7 & 2.3 & 1,710 & 380 \\
\hline Average... & 10.3 & 9.6 & 1.1 & 78.3 & (4) .4 & .7 & 1,680 & 373 \\
\hline $\begin{array}{l}\text { Hominy: } \\
\text { Minimu }\end{array}$ & 92 & 6.3 & 2 & 773 & & 1 & & \\
\hline Maximum. . & 13.4 & $\begin{array}{l}0.5 \\
9.5\end{array}$ & 1.0 & 81.4 & 1.2 & .7 & $\begin{array}{l}1,610 \\
1,700\end{array}$ & $\begin{array}{l}357 \\
377\end{array}$ \\
\hline Average... . & 11.8 & 8.3 & .6 & 79.0 & $(12) .9$ & .3 & 1,650 & 366 \\
\hline Hominy, cooked... & 79.3 & 2.2 & .2 & 17.8 & $\ldots$ & .5 & 380 & 84 \\
\hline Parched: & & & & & & & & \\
\hline Minimum. . & 4.9 & 11.1 & 8.2 & 71.1 & $\cdots$ & 1.7 & 1,895 & 421 \\
\hline Maximum. . & 5.6 & 11.8 & 8.7 & 73.4 & $\ldots$ & 3.5 & 1,930 & 428 \\
\hline Average... & 5.2 & 11.5 & 8.4 & 72.3 & & 2.6 & 1,915 & 425 \\
\hline Kafir corn........ & 16.8 & 6.6 & 3.8 & 70.6 & 1.1 & 2.2 & 1,595 & 354 \\
\hline $\begin{array}{l}\text { Oatmeal }{ }^{4} \text { : } \\
\text { Minimum. }\end{array}$ & 2.0 & 12.9 & 6.0 & 63.8 & .6 & 1.5 & 1,810 & 402 \\
\hline Maximum... & 8.8 & 20.8 & 8.8 & 70.2 & 1.2 & 2.2 & 1,875 & 416 \\
\hline Average....... & 7.3 & 16.1 & 7.2 & 67.5 & (9) .6 & 1.9 & 1,650 & 366 \\
\hline Oatmeal, boiled... & 84.5 & 2.8 & .5 & 11.5 & $\ldots$ & .7 & 285 & 63 \\
\hline Oatmeal gruel: & & & & & & & & \\
\hline Minimum. . & 87.5 & .9 & .2 & 2.9 & $\ldots$ & .3 & 80 & 17 \\
\hline Maximum... & 95.7 & 1.6 & .5 & 9.6 & $\ldots$ & .8 & 230 & 51 \\
\hline Average.. ... & 91.6 & 1.2 & .4 & 6.3 & $\ldots$ & .5 & 155 & 34 \\
\hline Oatmeal water: & & & & & & & & \\
\hline Minimum. . & 94.0 & .4 & .1 & 1.3 & $\ldots$ & .1 & 35 & 7 \\
\hline Maximum... & 98.1 & .9 & .1 & 4.5 & . & .5 & 105 & 23 \\
\hline Average........... & 96.0 & .7 & .1 & 2.9 & $\cdots$ & .3 & 70 & 15 \\
\hline $\begin{array}{l}\text { Oats, other preparations: } \\
\text { Rolled oats: }\end{array}$ & & & & & & & & \\
\hline Minimum. . & 5.5 & 13.6 & 5.6 & 62.8 & 1.2 & 1.6 & 1,755 & 390 \\
\hline Maximum... . & 11.2 & 19.1 & 8.8 & 70.8 & 1.4 & 4.7 & 1,885 & 418 \\
\hline Average.. ..... & 7.7 & 16.7 & 7.3 & 66.2 & (2) 1.3 & 2.1 & 1,850 & 411 \\
\hline $\begin{array}{l}\text { Miscellaneous: } \\
\text { Minimum. }\end{array}$ & 6.4 & 13.7 & 6.1 & 63.9 & 6 & 13 & 830 & \\
\hline Maximum... & 9.2 & 18.4 & 8.2 & 70.5 & 1.7 & $\begin{array}{l}1.3 \\
1.9\end{array}$ & $\begin{array}{l}1,830 \\
1,890\end{array}$ & $\begin{array}{l}400 \\
420\end{array}$ \\
\hline Average.. . . . & 7.9 & 16.3 & 7.3 & 66.8 & $(20) .9$ & 1.7 & 1,855 & 412 \\
\hline Analyses, average ...... & 7.8 & 16.5 & 7.3 & 66.5 & $(22) 1.0$ & 1.9 & 1,850 & 411 \\
\hline
\end{tabular}

1 Fiber included.

2 Number of determinations in parentheses.

3 The ash of one sample contained 0.192 per cent phosphorus.

4 The ash of one sample contained 0.414 per cent phosphoras. 


\begin{tabular}{|c|c|c|c|c|c|c|c|c|}
\hline \multirow[b]{2}{*}{ Food Matemals } & \multirow[b]{2}{*}{$\begin{array}{c}\text { Per } \\
\text { cent } \\
\text { Water }\end{array}$} & \multirow{2}{*}{$\begin{array}{l}\text { Per } \\
\text { cent } \\
\text { Pro- } \\
\text { tein }\end{array}$} & \multirow[b]{2}{*}{$\begin{array}{l}\text { Prrr } \\
\text { 'ontul } \\
\text { linl }\end{array}$} & \multirow{2}{*}{$\begin{array}{l}\text { P'ur } \\
\text { cente } \\
\text { car- } \\
\text { Inoliy- } \\
\text { drates' }\end{array}$} & \multirow[b]{2}{*}{$\begin{array}{l}\text { Per } \\
\text { rentit } \\
\text { riturts }\end{array}$} & \multirow[b]{2}{*}{$\begin{array}{l}\text { Per } \\
\text { cent } \\
\text { Anh }\end{array}$} & \multicolumn{2}{|c|}{ Fune Vaser: } \\
\hline & & & & & & & $\begin{array}{l}\text { Colorion } \\
\text { pour } \\
\text { Pound }\end{array}$ & $\left\{\begin{array}{l}\text { ('aluric } \\
\text { (irmer 10) }\end{array}\right.$ \\
\hline $\begin{array}{l}\text { VEGETABIS H(OOD) } \\
\text { Con. } \\
\text { Flours, Meals, etc. } \\
\text { Rice: }\end{array}$ & & & & & & & & \\
\hline Minimum. . . . . & 9.1 & 5.9 & 1 & 75.4 & 1 & 2 & 1,600 & $3 \sin$ \\
\hline Maximum. & 14.0 & 11.3 & $i$ & $\$ 1.9$ & 4 & .5 & $1,600)$ & 375 \\
\hline Average... . . & 12.3 & 5.0 & 3 & 79.0 & $(13) .2$ & .1 & 1,6330 & 342 \\
\hline $\begin{array}{l}\text { Rice, boiled: } \\
\qquad \text { Minimum. . . . . . . }\end{array}$ & & & & & & & & \\
\hline $\begin{array}{l}\text { Minimum.......... } \\
\text { Maximum........ }\end{array}$ & 52.7 & 1.6 & & 15.5 & $\cdots$ & 1 & 330 & 73 \\
\hline $\begin{array}{l}\text { Maximum......... } \\
\text { Average......... }\end{array}$ & 52.7 & 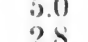 & 1 & 0.9 & $\cdots$ & 3 & 575 & 19 \\
\hline Rice, flaked: & $12 . .0$ & 2.5 & .1 & $2-1.6$ & $\cdots$ & 2 & 510 & 113 \\
\hline Minimum. & 9.4 & 7.5 & .3 & 81.4 & .1 & .3 & 1.650 & $37: 3$ \\
\hline Maximum. . & 9.7 & 8.3 & $\therefore$ & \$2.2 & .2 & .4 & 1,690 & 375 \\
\hline Average..... & 9.5 & 7.9 & .4 & 81.9 & .2 & .3 & 1,645 & 374 \\
\hline $\begin{array}{l}\text { Rice flour: } \\
\text { Minimum. . . }\end{array}$ & & & & & & & & \\
\hline $\begin{array}{l}\text { Minimum. . . } \\
\text { Maximum... }\end{array}$ & $\begin{array}{r}3.7 \\
10.9\end{array}$ & $\begin{array}{r}4.7 \\
12.0\end{array}$ & 10.8 & $\begin{array}{l}58.3 \\
79.2\end{array}$ & $\begin{array}{r}9.1 \\
25.3\end{array}$ & $\begin{array}{r}6.6 \\
10.7\end{array}$ & $\begin{array}{l}1.635 \\
1.765\end{array}$ & $\begin{array}{l}30.3 \\
392\end{array}$ \\
\hline Average... . . & 8.5 & 5.6 & ii. 1 & 68.0 & 16.1 & $\$ .5$ & $1,6 \times 0$ & 373 \\
\hline Rye flour: & & & & & & & & \\
\hline Minimum. & 11.9 & 4.9 & $\therefore$ & 77.6 & .4 & .6 & 1.615 & 325 \\
\hline Maximum. . & 13.6 & 5.8 & 1.3 & 80.2 & j) & .9 & $1,6 i x()$ & 306 \\
\hline Average.... & 12.9 & 6.8 & .9 & 78.7 & (4).4 & .7 & 1,630 & 362 \\
\hline Rye meal............... & 11.4 & 13.6 & $2 .(1)$ & 71.5 & 1.5 & 1.5 & 1,665 & 370 \\
\hline $\begin{array}{l}\text { Wheat flour, California, } \\
\text { fine: }\end{array}$ & & & & & & & & \\
\hline Minimum. ...... & 12.4 & 7.2 & 1.2 & 73.9 & $\ldots$ & .4 & 1,590 & 353 \\
\hline Maximum........ & 15.6 & 3.8 & 1.6 & 77.8 & $\ldots$ &.$j$ & 1.660 & 365 \\
\hline Average........... & 13.8 & 7.9 & 1.4 & 76.4 & $\cdots$ & .5 & 1.625 & 361 \\
\hline $\begin{array}{l}\text { Wheat flour, Califor- } \\
\text { nia: }\end{array}$ & & & & & & & & \\
\hline Minimum... & 6.4 & 12.2 & $1 . \bar{j}$ & 69.5 & .5 & .6 & 1,635 & 363 \\
\hline Maximum... & 13.1 & 14.6 & 2.1 & 77.0 & 1.2 & 1.5 & 1,760 & 391 \\
\hline $\begin{array}{l}\text { Average........ } \\
\text { Wheat flour, gluten: }\end{array}$ & 11.4 & 13.8 & 1.9 & $\cdots$ & (3) $\quad .9$ & 1.0 & 1,675 & 372 \\
\hline $\begin{array}{l}\text { Wheat flour, gluten: } \\
\text { Minimum........ }\end{array}$ & & & & & & & 1,635 & \\
\hline $\begin{array}{l}\text { Minimum.......... } \\
\text { Maximum........ }\end{array}$ & $\begin{array}{l}10.5 \\
13.0\end{array}$ & $\begin{array}{l}12.5 \\
15.0\end{array}$ & 2.4 & 72.8 & .6 & 1.3 & 1,690 & $\begin{array}{l}365 \\
375\end{array}$ \\
\hline 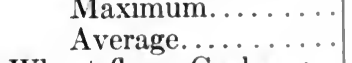 & 12.0 & 14.2 & 1.5 & 71.1 & (1) .6 & .9 & $1,66.5$ & 370 \\
\hline $\begin{array}{l}\text { Wheat flour, Graham: } \\
\text { Minimum. . . . . }\end{array}$ & & & & 66.0 & 1.5 & & 1,615 & \\
\hline $\begin{array}{l}\text { Minimum. ......... } \\
\text { Maximum....... }\end{array}$ & $\begin{array}{r}9.9 \\
137\end{array}$ & $\begin{array}{r}5.5 \\
17.7\end{array}$ & $\begin{array}{l}1.3 \\
3.6\end{array}$ & 75.5 & 2.0 & 2.7 & 1,710 & 350 \\
\hline $\begin{array}{l}\text { Maximum.......... } \\
\text { Average........... }\end{array}$ & $\begin{array}{l}13.6 \\
11.3\end{array}$ & 13.3 & 2.2 & 71.4 & $(3 ; 1.9$ & 1.5 & 1,670 & 371 \\
\hline $\begin{array}{l}\text { Wheat flour, prepared } \\
\text { (self-raising): }\end{array}$ & & & & & & & & \\
\hline 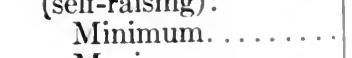 & 8.0 & 8.0 & .6 & 67.4 & .4 & 1.5 & 1,350 & 34 \\
\hline Maximum... & 13.0 & 13.3 & 2.2 & 75.6 & .5 & $i$ & 1.730 & 354 \\
\hline Average.......... & 10.8 & 10.2 & 1.2 & 73.0 & (3) .4 & 4.5 & 1.600 & 325 \\
\hline
\end{tabular}

1 Fiber included.

2 Number of determinations in parentheres. 


\begin{tabular}{|c|c|c|c|c|c|c|c|c|}
\hline Food Materials & $\begin{array}{c}\text { Per } \\
\text { cent } \\
\text { Water }\end{array}$ & $\begin{array}{l}\text { Per } \\
\text { cent } \\
\text { Pro- } \\
\text { tein }\end{array}$ & $\begin{array}{l}\text { Per } \\
\text { cent } \\
\text { Fat }\end{array}$ & $\begin{array}{c}\text { Per } \\
\text { cent } \\
\text { Car- } \\
\text { bohy- } \\
\text { drates }^{1}\end{array}$ & $\begin{array}{c}\text { Per } \\
\text { cent } \\
\text { Fiber }^{2}\end{array}$ & $\begin{array}{l}\text { Per } \\
\text { cent } \\
\text { Ash }\end{array}$ & $\begin{array}{c}\text { Fuel } \\
\text { Calories } \\
\text { per } \\
\text { Pound }\end{array}$ & $\begin{array}{l}\text { Calories } \\
\text { per } 100 \\
\text { Grams }\end{array}$ \\
\hline \multicolumn{9}{|l|}{$\begin{array}{l}\text { VEGETABLE FOOD- } \\
\text { Con. } \\
\text { Flours, Meals, etc. }\end{array}$} \\
\hline \multicolumn{9}{|l|}{$\begin{array}{l}\text { Wheat flour, patent roll- } \\
\text { er process, baker's } \\
\text { grade: }\end{array}$} \\
\hline Minimum........... & 10.1 & 10.3 & .9 & 70.3 & .3 & .3 & 1,640 & 364 \\
\hline Maximum... & 13.3 & 14.9 & 2.0 & 75.5 & 1.5 & .9 & 1,705 & 378 \\
\hline Average........... & 11.9 & 13.3 & 1.5 & 72.7 & (6) .7 & .6 & 1,665 & 370 \\
\hline \multicolumn{9}{|c|}{$\begin{array}{l}\text { Wheat flour, patent roll- } \\
\text { er process, family } \\
\text { and straight grade: }\end{array}$} \\
\hline Minimum. ......... & 10.3 & 9.6 & 1.0 & 72.7 & & .4 & 1,635 & 363 \\
\hline Maximum... & 13.1 & 13.3 & 1.2 & 78.5 & & .6 & 1,680 & 373 \\
\hline Average....... & 11.9 & 10.9 & 1.1 & 75.6 & (1) .1 & .5 & 1,655 & 367 \\
\hline \multicolumn{9}{|l|}{ Winter wheat: } \\
\hline Minimum. ... & 11.7 & 10.8 & 1.0 & 72.1 & .2 & .3 & 1,615 & 358 \\
\hline Maximum.... & 14.0 & 13.7 & 1.3 & 73.7 & .4 & .6 & 1,655 & 367 \\
\hline Average.......... & 13.1 & 12.3 & 1.1 & 73.0 & (4) .3 & .5 & 1,635 & 363 \\
\hline \multicolumn{9}{|l|}{$\begin{array}{l}\text { Wheat flour, patent roll- } \\
\text { er process, grade not } \\
\text { indicated: }\end{array}$} \\
\hline Minimum. ........ & 8.2 & 8.4 & .3 & 70.3 & .1 & .3 & 1,640 & 364 \\
\hline Maximum......... & 13.9 & 14.7 & 1.6 & 80.0 & .3 & .8 & 1,730 & 384 \\
\hline Average........... & 11.5 & 11.4 & 1.0 & 75.6 & $(15) .2$ & .5 & 1,660 & 368 \\
\hline \multirow{2}{*}{\multicolumn{9}{|c|}{$\begin{array}{l}\text { Wheat flour, patent roll- } \\
\text { er process, high } \\
\text { grade: } \\
\text { Spring Wheat: }\end{array}$}} \\
\hline & & & & & & & & \\
\hline $\begin{array}{l}\text { Minimum. . } \\
\text { Maximum... }\end{array}$ & 8.8 & 8.7 & .7 & 71.7 & .1 & .3 & 1,615 & 358 \\
\hline $\begin{array}{l}\text { Maximum.... } \\
\text { Average. }\end{array}$ & 14.3 & 13.8 & 1.9 & 78.1 & .2 & .5 & 1,715 & 381 \\
\hline $\begin{array}{l}\text { Average..... } \\
\text { Winter wheat: }\end{array}$ & 12.3 & 11.7 & 1.1 & 74.5 & (7) .1 & .4 & 1,650 & 366 \\
\hline \multicolumn{9}{|l|}{ Winter wheat: } \\
\hline $\begin{array}{l}\text { Minimum......... } \\
\text { Maximum........ }\end{array}$ & 14.0 & $\begin{array}{r}9.0 \\
14.9\end{array}$ & 1.0 & 75.5 & .2 & . .3 & $\begin{array}{l}1,615 \\
1,645\end{array}$ & $\begin{array}{l}358 \\
365\end{array}$ \\
\hline \multirow{3}{*}{\multicolumn{9}{|c|}{$\begin{array}{l}\text { Average of all analyses } \\
\text { of high and medium } \\
\text { grades and grade not } \\
\text { indieated........... } \\
\text { Wheat flour, patent roll- } \\
\text { er process; low grade: }\end{array}$}} \\
\hline & & & & & & & & \\
\hline & & & & & & & & \\
\hline Minimum......... & 9.3 & 10.0 & .8 & 64.2 & .5 & .5 & 1,645 & 365 \\
\hline Maximum........ & 13.9 & 17.9 & 3.9 & 75.9 & .9 & 2.0 & 1,735 & 385 \\
\hline Average..... . & 12.0 & 14.0 & 1.9 & 71.2 & (7) .8 & .9 & 1,665 & 370 \\
\hline
\end{tabular}

1 Fiber included.

2 Number of determinations in parentheses. 


\begin{tabular}{|c|c|c|c|c|c|c|c|c|}
\hline \multirow[b]{2}{*}{ Food Matrialas } & \multirow{2}{*}{$\begin{array}{l}\text { Per } \\
\text { cent } \\
\text { Water }\end{array}$} & \multirow{2}{*}{$\begin{array}{l}\text { Pror } \\
\text { cont } \\
\text { Prom } \\
\text { trin }\end{array}$} & \multirow{2}{*}{$\begin{array}{l}\text { Per } \\
\text { rent } \\
\text { Fint }\end{array}$} & \multirow{2}{*}{$\begin{array}{l}\text { Por } \\
\text { cent } \\
\text { C'ar- } \\
\text { Inoliy- } \\
\text { Iratcol }\end{array}$} & \multirow{2}{*}{$\begin{array}{l}\text { Per } \\
\text { cent } \\
\text { liluers }\end{array}$} & \multirow{2}{*}{$\begin{array}{l}\text { Per } \\
\text { eerut } \\
\text { Anh }\end{array}$} & \multicolumn{2}{|c|}{ Fuge VAlo: } \\
\hline & & & & & & & $\begin{array}{c}\text { Condorics } \\
\text { per } \\
\text { Pound }\end{array}$ & $\begin{array}{l}\text { Cinloricx } \\
\text { get I(x) } \\
\text { Cirmass }\end{array}$ \\
\hline $\begin{array}{l}\text { VEGETABLE FOOD- } \\
\text { Con. } \\
\text { Flours, Meals, etc. }\end{array}$ & & & & & & & & \\
\hline $\begin{array}{l}\text { Wheat flour, unclassifiod } \\
\text { process, grade not } \\
\text { indicated: } \\
\text { Spring Wheat: }\end{array}$ & & & & & & & & \\
\hline Minimum. & 11.4 & 9.6 & .6 & 73.5 &.$j$ & .4 & 1,610 & 3.37 \\
\hline Maximum.......... & 13.5 & 12.1 & 1.3 & 77.4 & .8 & .9 & 1,650 & 366 \\
\hline $\begin{array}{l}\text { Average........... } \\
\text { Winter wheat: }\end{array}$ & 12.4 & $10 . \bar{j}$ & 1.0 & 75.4 & (3) .5 & .7 & 1,640 & 364 \\
\hline Minimum.... & 9.9 & 9.5 & .4 & 73.2 & .2 & .3 & $1,60 \%$ & 356 \\
\hline Maximum... & 14.4 & 12.5 & 1.5 & 78.2 & .5 & 1.8 & 1,640 & 373 \\
\hline $\begin{array}{r}\text { Average......... } \\
\text { Undesignated: }\end{array}$ & 11.9 & 10.7 & 1.0 & 75.8 & (5) .4 & .6 & 1,650 & 366 \\
\hline Minimum. .... & 6.7 & 8.7 & .6 & 75.3 & .3 & .4 & 1,645 & 365 \\
\hline Maximum... & 11.7 & 11.4 & 1.6 & 82.1 & 1.8 & .9 & 1,760 & 391 \\
\hline Average.......... & 9.4 & 10.4 & 1.2 & 78.4 & (3) .9 & .6 & 1,700 & 377 \\
\hline All analyses, average. . & 11.4 & 10.6 & 1.1 & 76.3 & $(10) .2$ & .6 & $1,6(6 i)$ & 370 \\
\hline $\begin{array}{c}\text { Wheat preparations, } \\
\text { breakfast foods: } \\
\text { Cracked and crushed: }\end{array}$ & & & & & & & & \\
\hline$n . . . \ldots$. & 8.9 & 9.5 & 1.3 & 73.7 & 1.2 & 1.4 & 1,645 & $36 i$ \\
\hline $1 \ldots \ldots \ldots$ & 11.7 & 12.9 & 2.2 & 77.2 & 2.0 & 2.2 & 1,710 & 380 \\
\hline $\begin{array}{l}\text { Average...... } \\
\text { Farina: }\end{array}$ & 10.1 & 11.1 & 1.7 & 75.5 & (7) 1.7 & 1.6 & 1,$65 ;$ & 374 \\
\hline Min & 6.1 & 10.4 & .8 & 74.6 & .2 & .1 & 1,630 & 362 \\
\hline aum........ & 13.2 & 11.7 & 3.5 & 75.5 & .6 & .7 & 1,825 & 405 \\
\hline Average........... & 10.9 & 11.0 & 1.4 & 76.3 & (7) .4 & .4 & 1,655 & 374 \\
\hline Flaked: & & & & & & & & \\
\hline mum. . & 7.9 & 9.7 & 1.1 & 69.7 & 1.3 & 1.2 & 1,640 & 364 \\
\hline$n \ldots$. & 10.1 & 15.6 & 1.5 & 77.8 & 2.2 & 3.3 & 1,705 & 375 \\
\hline Average....... & 8.7 & 13.4 & 1.4 & 74.3 & 1.5 & 2.2 & 1,690 & 373 \\
\hline $\begin{array}{l}\text { Germ } \\
\text { Mir }\end{array}$ & 9.1 & 8.6 & 1.2 & 73.1 & .3 & .5 & $1,66.5$ & 370 \\
\hline Maximum.... & 12.3 & 13.4 & 2.5 & 80.0 & 1.2 & 1.6 & 1,720 & 342 \\
\hline Average..... . & 10.4 & $10 . \bar{j}$ & 2.0 & 76.0 & (S) .9 & 1.1 & 1,695 & 376 \\
\hline Gluten: & & & & & & & & \\
\hline Minimum.... & 6.8 & 12.7 & .7 & 69.2 & .5 & .9 & 1,693 & 376 \\
\hline m.... & 11.1 & 14.4 & 3.3 & ZN.S & 2.5 & 2.0 & 1.730 & 354 \\
\hline $\begin{array}{l}\text { Aver } \\
\text { Miscell }\end{array}$ & 80 & 13.6 & 1.7 & 74.6 & 1.3 & 1.2 & 1,715 & 351 \\
\hline Mini & 3.8 & 10.4 & 1.3 & 70.5 & .5 & .9 & $1,66,5$ & 370 \\
\hline Maximum........ & 11.9 & 16.6 & 4.0 & $\$ 1.0$ & 1.6 & 1.5 & 1,520 & 800 \\
\hline Average..... & 9.4 & 13.1 & 2.1 & 74.1 & (16).9 & 1.3 & 1,710 & 340 \\
\hline
\end{tabular}

1 Fiber included.

2 Number of determinations in parenthems. 


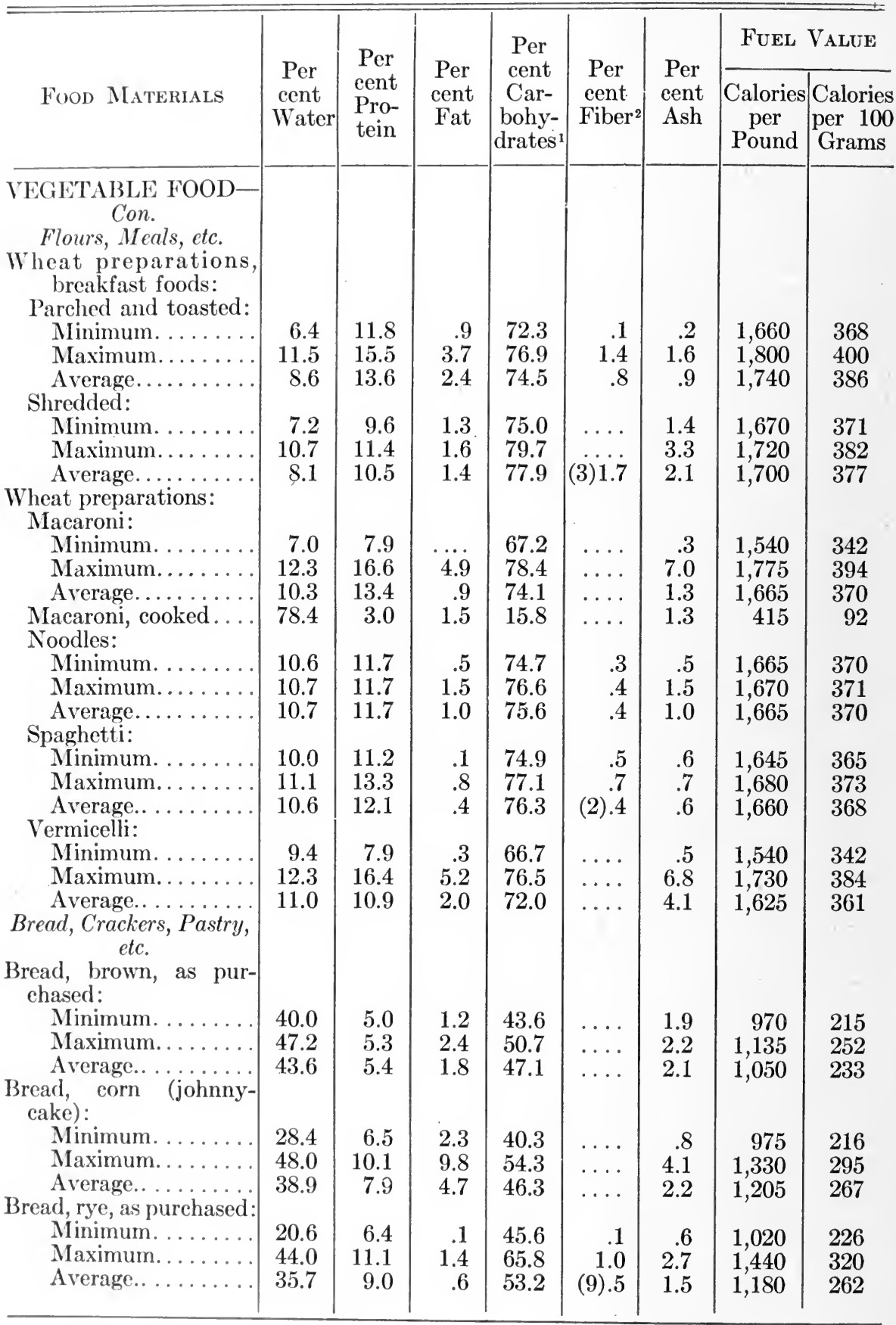

1 Fiber included.

2 Number of determinations in parentheses. 


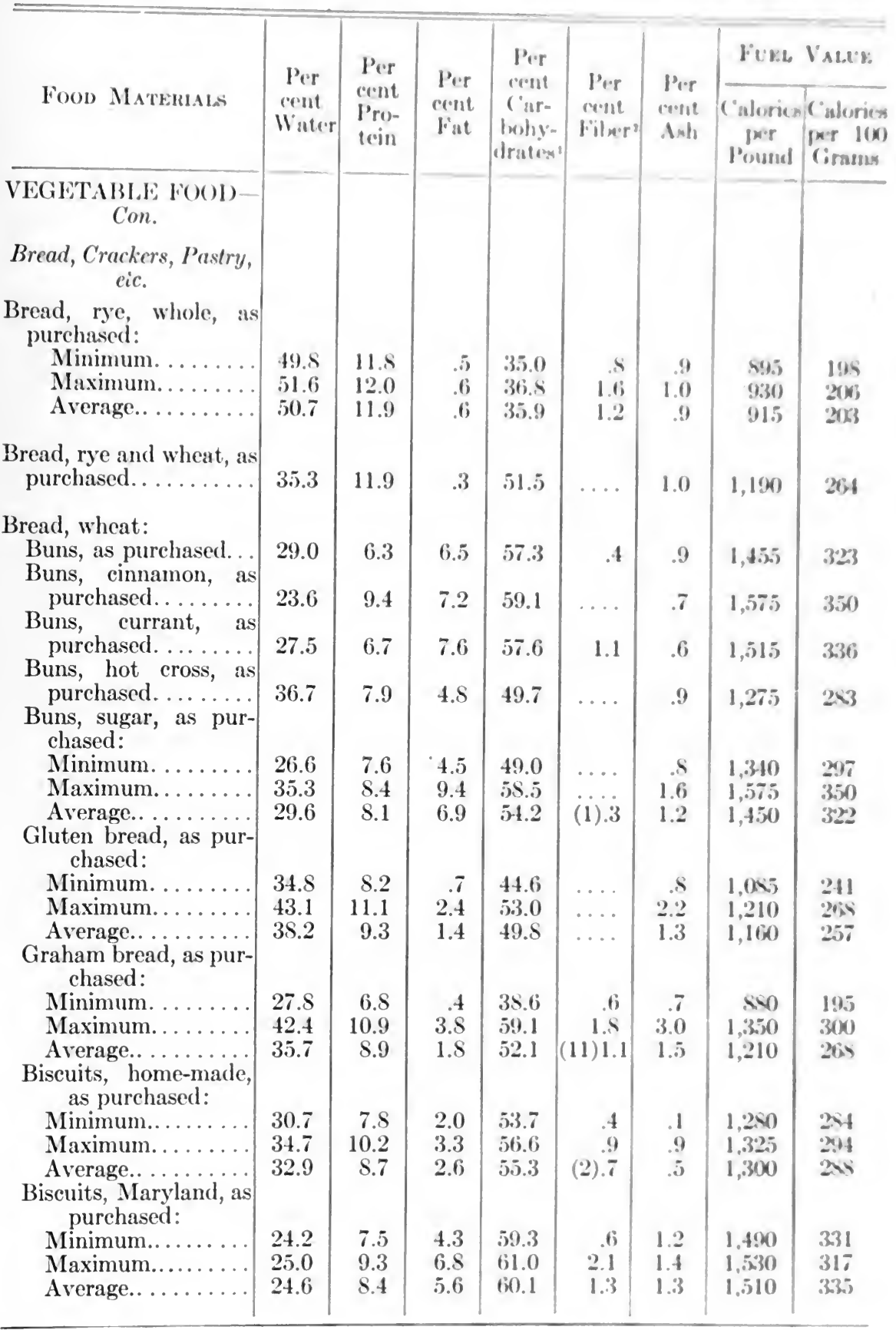

1 Fiber included.

2 Number of determinations in parentheses. 


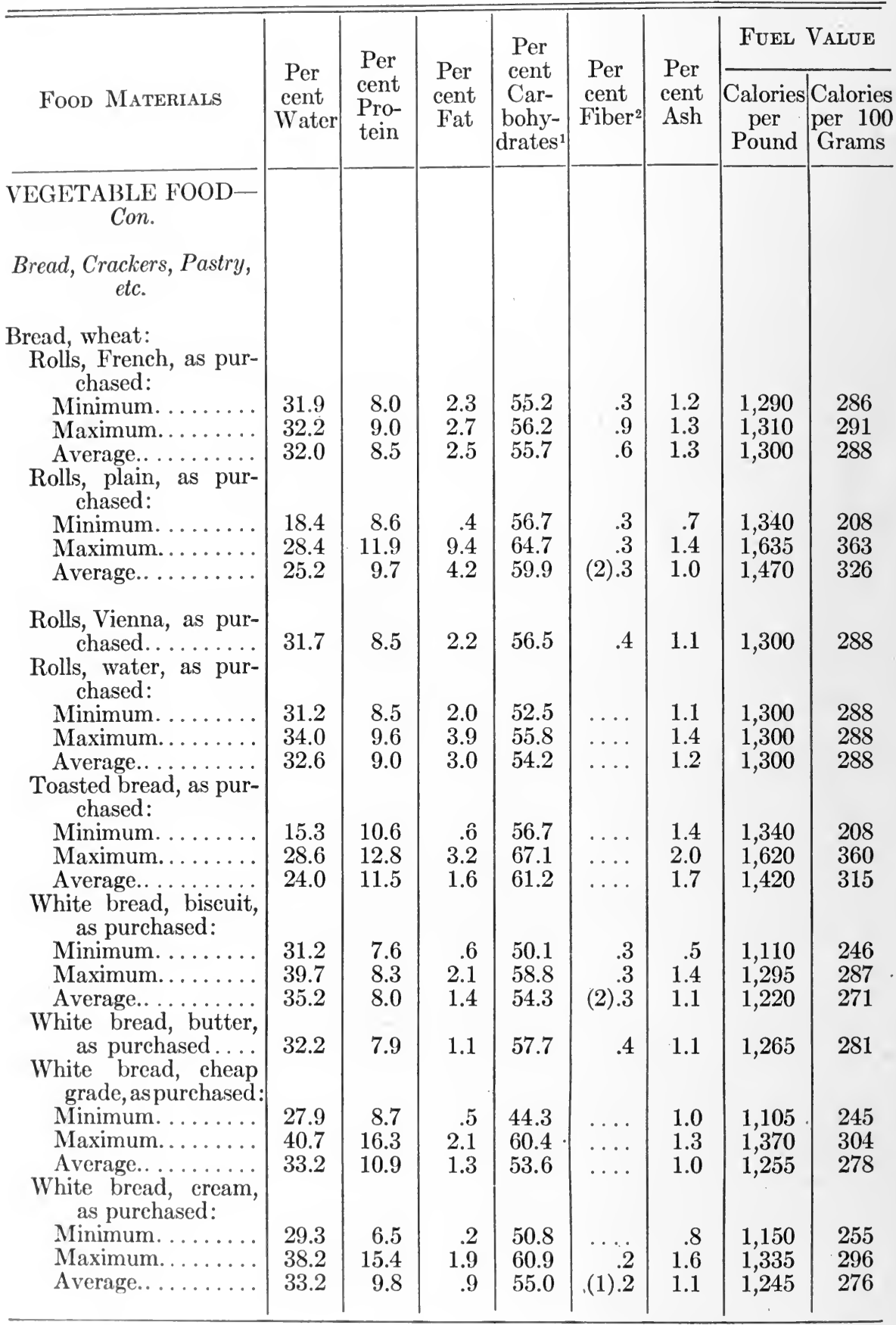

1 Fiber included.

2 Number of determinations in parentheses. 


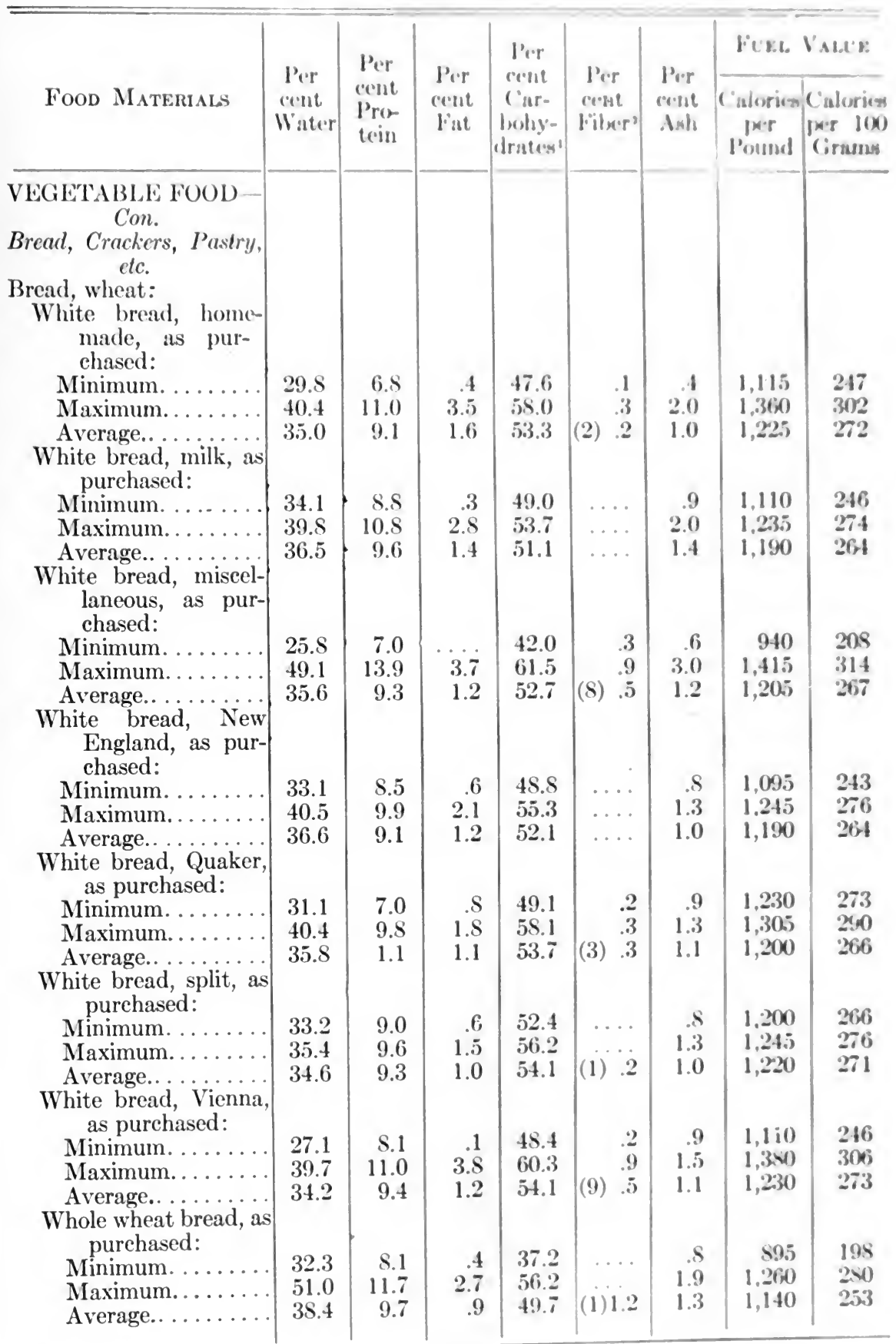

1 Fiber included.

2 Number of determinations in parentheses. 


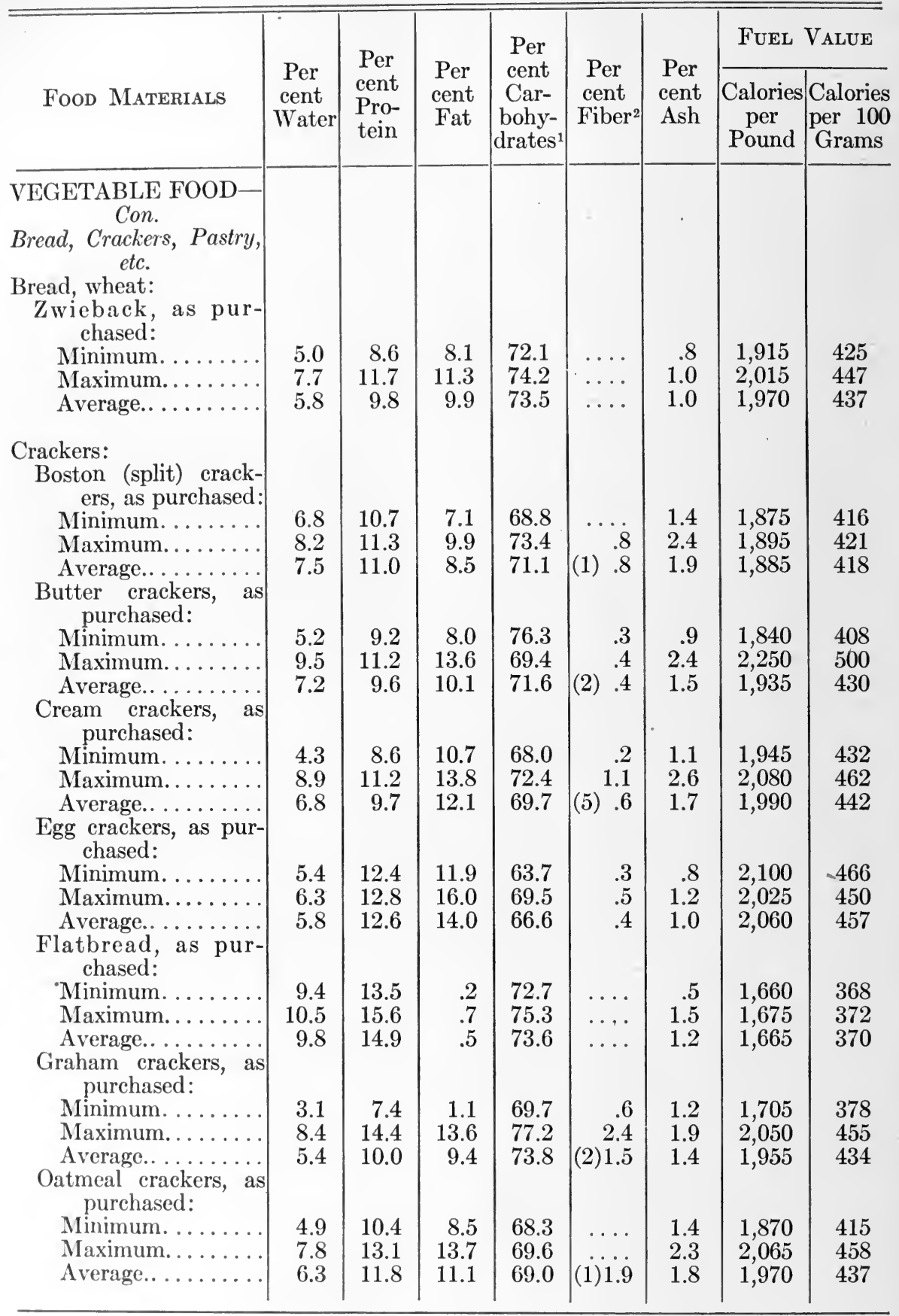

1 Fiber included.

2 Number of determinations in parentheses. 


\begin{tabular}{|c|c|c|c|c|c|c|c|c|}
\hline \multirow[b]{2}{*}{ FoOd Materialas } & \multirow{2}{*}{$\begin{array}{c}\text { Per } \\
\text { cent } \\
\text { Water }\end{array}$} & \multirow{2}{*}{$\begin{array}{l}\text { Per } \\
\text { cent } \\
\text { Pro- } \\
\text { tein }\end{array}$} & \multirow{2}{*}{$\begin{array}{l}\text { liner } \\
\text { cinne } \\
\text { liat }\end{array}$} & \multirow{2}{*}{$\begin{array}{l}\text { Per } \\
\text { cont } \\
\text { Car- } \\
\text { bohy- } \\
\text { iratew' }\end{array}$} & \multirow[b]{2}{*}{$\begin{array}{l}\text { Per } \\
\text { cent } \\
\text { l'itx:rs }\end{array}$} & \multirow[b]{2}{*}{$\begin{array}{l}\text { Per } \\
\text { cent } \\
\text { Asts }\end{array}$} & \multicolumn{2}{|c|}{ 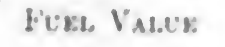 } \\
\hline & & & & & & & $\begin{array}{l}\text { Caloricy } \\
\text { pour } \\
\text { Pound }\end{array}$ & $\begin{array}{l}\text { Calorics } \\
\text { per 10x) } \\
\text { Cirauns }\end{array}$ \\
\hline \\
\hline & & & & & & & & \\
\hline \multirow{2}{*}{\multicolumn{9}{|c|}{$\begin{array}{l}\text { Crackers: } \\
\text { Oyster crackers, as } \\
\text { purchased: }\end{array}$}} \\
\hline & & & & & & & & \\
\hline $\begin{array}{l}\text { Minimum. . . . } \\
\text { Maximum.... }\end{array}$ & $\begin{array}{l}3.5 \\
6.5\end{array}$ & $\begin{array}{r}9.1 \\
17.3\end{array}$ & $\begin{array}{l}1.5 \\
13.0\end{array}$ & $\begin{array}{l}69.1 \\
77.5\end{array}$ & & $\begin{aligned} 9 \\
59\end{aligned}$ & $\begin{array}{l}1,855 \\
2655\end{array}$ & 412 \\
\hline Average... . . . . . . . & 4.8 & 11.3 & 10.5 & 70.5 & (1) .2 & 2.9 & 1,965 & 436 \\
\hline \multicolumn{9}{|l|}{$\begin{array}{l}\text { Pilot bread, as pur- } \\
\text { chased: }\end{array}$} \\
\hline Minimum. ....... & 7.9 & 10.4 & $\therefore$ & 70.3 & .3 & .9 & 1,665 & 370 \\
\hline Maximum... & 9.9 & 12.4 & 10.2 & 78.0 & .3 & 1.1 & 1,930 & 425 \\
\hline Average.. . . . . & 8.7 & 11.1 & .5.() & 74.2 & (2) .3 & 1.0 & 1,800 & $4(x)$ \\
\hline \multicolumn{9}{|l|}{ Pretzels, as purchased: } \\
\hline Minimum........ & 8.1 & 9.1 & 3.9 & 71.1 & .4 & 3.2 & $1,65 i$ & 367 \\
\hline Maximum........ & 11.0 & 10.3 & 3.9 & 74.5 & $\therefore$ & 4.9 & $1,7.40$ & 346 \\
\hline Average.. . . . . . . . & 9.6 & 9.7 & 3.9 & 72.8 & (2) .5 & 4.0 & 1,700 & 377 \\
\hline \multicolumn{9}{|l|}{ Saltines, as purchased: } \\
\hline Minimum. . . . . . . . & 4.6 & 9.9 & 12.7 & 67.1 & .3 & 2.3 & $1,99 i$ & 443 \\
\hline Maximum......... & 6.7 & 11.2 & 12.5 & 69.9 & .6 & 2.5 & 2,025 & $4: 0$ \\
\hline \multirow{2}{*}{\multicolumn{9}{|c|}{$\begin{array}{l}\text { Soda crackers, as pur- } \\
\text { chased: }\end{array}$}} \\
\hline & & & & & & & & \\
\hline Minimum. . . . . . . & 3.7 & 8.8 & 7.7 & 70.5 & . & 1.8 & 1,550 & 411 \\
\hline Maximum..... & 8.4 & 10.7 & 10.0 & 75.4 & & 2.6 & 1,990 & 440 \\
\hline Average........... & 5.9 & 9.8 & 9.1 & 73.1 & (1) .3 & 2.1 & 1,925 & 427 \\
\hline \multicolumn{9}{|l|}{$\begin{array}{l}\text { Water crackers, as pur- } \\
\text { chased: }\end{array}$} \\
\hline Minimum........ & 4.7 & 10.4 & .2 & 72.9 & .2 & .5 & 1,730 & 354 \\
\hline Maximum......... & 9.5 & 12.5 & 10.1 & S0.8 & .8 & 2.0 & 1,910 & 424 \\
\hline Average.......... & 6.4 & 11.7 & ¿.0 & 75.7 & .4 & 1.2 & 1,535 & 407 \\
\hline $\begin{array}{l}\text { Cracker meal, as pur- } \\
\text { chased: }\end{array}$ & & & & & & & & - \\
\hline Minimum........ & 9.2 & 9.6 & .6 & 68.3 & .1 & .5 & 1,690 & 375 \\
\hline Maximum..... & 9.3 & 12.2 & 11.3 & 77.4 & .3 & 1.6 & 1,925 & 427 \\
\hline Average.. ..... & 9.2 & 10.9 & 6.0 & 72.9 & .2 & 1.0 & 1,810 & 402 \\
\hline \multicolumn{9}{|l|}{ Cake: } \\
\hline \multicolumn{9}{|l|}{$\begin{array}{l}\text { Baker's cake, as pur- } \\
\text { chased: }\end{array}$} \\
\hline Minimum........ & 28.3 & 4.6 & 3.4 & 53.3 & $\ldots$ & .7 & $1,2 \mathrm{j}$ & $2<5$ \\
\hline Maximum........ & 34.4 & 8.0 & ¿.!! & 60.5 & $\ldots$ & .9 & 1,460 & 324 \\
\hline Average............. & 31.4 & 6.3 & 4.6 & 56.9 & $\cdots$ & .8 & 1,370 & 304 \\
\hline as purchased....... & 20.5 & 6.2 & $\therefore .1$ & 64.1 & ... & 1.1 & 1,650 & 3606 \\
\hline
\end{tabular}

1 Fiber included.

2 Number of determinations in parentheses. 


\begin{tabular}{|c|c|c|c|c|c|c|c|c|}
\hline \multirow[b]{2}{*}{ Food Materials } & \multirow{2}{*}{$\begin{array}{c}\text { Per } \\
\text { cent } \\
\text { Water }\end{array}$} & \multirow{2}{*}{$\begin{array}{l}\text { Per } \\
\text { cent } \\
\text { Pro- } \\
\text { tein }\end{array}$} & \multirow{2}{*}{$\begin{array}{l}\text { Per } \\
\text { cent } \\
\text { Fat }\end{array}$} & \multirow{2}{*}{\begin{tabular}{|c|} 
Per \\
cent \\
Car- \\
bohy- \\
drates $^{1}$
\end{tabular}} & \multirow{2}{*}{$\begin{array}{c}\text { Per } \\
\text { cent } \\
\text { Fiber }^{2}\end{array}$} & \multirow{2}{*}{$\begin{array}{l}\text { Per } \\
\text { cent } \\
\text { Ash }\end{array}$} & \multicolumn{2}{|c|}{ Fuel Value } \\
\hline & & & & & & & $\begin{array}{c}\text { Calories } \\
\text { per } \\
\text { Pound }\end{array}$ & $\begin{array}{c}\text { Calories } \\
\text { per } 100 \\
\text { Grams }\end{array}$ \\
\hline $\begin{array}{l}\text { VEGETABLE FOOD- } \\
\text { Con. }\end{array}$ & & & & & & & & - \\
\hline $\begin{array}{c}\text { Bread, Crackers, Pas- } \\
\text { try, etc. }\end{array}$ & & & & & & & & \\
\hline $\begin{array}{l}\text { Cake: } \\
\text { Coffee cake, as pur- } \\
\text { chased: }\end{array}$ & & & & & & & & \\
\hline Minimum........ & 11.0 & 4.9 & 4.7 & 52.4 & .2 & .6 & 1,395 & 310 \\
\hline Maximum........ & 32.0 & 9.0 & 10.5 & 78.8 & 6 & 1.1 & 1,820 & 404 \\
\hline Average........... & 21.3 & 7.1 & 7.5 & 63.2 & (4) .4 & .9 & 1,625 & 361 \\
\hline $\begin{array}{l}\text { Cup cake, as pur- } \\
\text { chased: }\end{array}$ & & & & & & & & \\
\hline Minimum. ........ & 14.8 & 5.2 & 2.5 & 63.2 & . . & .8 & 1,600 & 355 \\
\hline Maximum........ & 16.3 & 6.6 & 15.6 & 73.8 & & 1.2 & 1,920 & 426 \\
\hline Average........... & 15.6 & 5.9 & 9.0 & 68.5 & (1) .3 & 1.0 & 1,765 & 392 \\
\hline $\begin{array}{c}\text { Drop cake, as pur- } \\
\text { chased........... }\end{array}$ & 16.6 & 7.6 & 14.7 & 60.3 & .1 & .8 & 1.885 & 418 \\
\hline $\begin{array}{l}\text { Frosted cake, as pur- } \\
\text { chased: }\end{array}$ & & & & & & & & \\
\hline Minimum........ & 11.4 & 5.0 & 7.5 & 58.3 & . & 1.0 & 1,545 & 343 \\
\hline Maximum......... & 26.5 & 7.5 & 10.6 & 71.0 & . & 3.4 & 1,835 & $407^{\circ}$ \\
\hline Average........... & 18.2 & 5.9 & 9.0 & 64.8 & $\ldots$ & 2.1 & 1,695 & 37.6 \\
\hline $\begin{array}{l}\text { Fruit cake, as pur- } \\
\text { chased: }\end{array}$ & & & & & & & & \\
\hline Minimum........ & 14.4 & 4.8 & 9.3 & 60.9 & . & 1.4 & 1,720 & 382 \\
\hline Maximum........ & 18.4 & 6.7 & 12.6 & 67.5 & & 2.2 & 1,790 & 397 \\
\hline Average.......... & 17.3 & 5.9 & 10.9 & 64.1 & $\ldots$ & 1.8 & 1,760 & 391 \\
\hline $\begin{array}{l}\text { Gingerbread, as pur- } \\
\text { chased: }\end{array}$ & & & & & & & & \\
\hline Minimum. . . . . . . & 16.1 & 5.4 & 8.4 & 62.3 & & 1.5 & 1,630 & 362 \\
\hline Maximum......... & 21.5 & 6.3 & 9.5 & 64.7 & .9 & 4.3 & 1,705 & 378 \\
\hline Average.......... & 18.8 & 5.8 & 9.0 & 63.5 & (1) $\quad .9$ & 2.9 & 1,670 & 371 \\
\hline $\begin{array}{l}\text { Miscellaneous, as pur- } \\
\text { chased: }\end{array}$ & & & & & & & & \\
\hline Minimum........ & 12.0 & 5.1 & 6.7 & 53.6 & . & 1.1 & 1,380 & 306 \\
\hline Maximum........ & 33.2 & 7.1 & 14.7 & 64.7 & . & 2.3 & 1,940 & 431 \\
\hline Average........... & 21.9 & 5.9 & 10.6 & 60.1 & $\ldots$ & 1.5 & 1,675 & 372 \\
\hline $\begin{array}{l}\text { Sponge cake, as pur- } \\
\text { chased: }\end{array}$ & & & & & & & & \\
\hline Minimum. ....... & 6.3 & 5.7 & 6.4 & 57.3 & . & 1.2 & 1,665 & 370 \\
\hline Maximum........ & 22.7 & 7.3 & 13.0 & 71.1 & ${ }^{\circ}$ & 2.5 & 1,995 & 443 \\
\hline Average........... & 15.3 & 6.3 & 10.7 & 65.9 & $\ldots$ & 1.8 & 1,795 & 398 \\
\hline $\begin{array}{l}\text { All analyses, except } \\
\text { fruit, as purchased, }\end{array}$ & & & & & & & & \\
\hline average. .......... & 19.9 & 6.3 & 9.0 & 63.3 & (7) .4 & 1.5 & 1,675 & 372 \\
\hline
\end{tabular}

1 Fiber included.

2 Number of determinations in parentheses. 


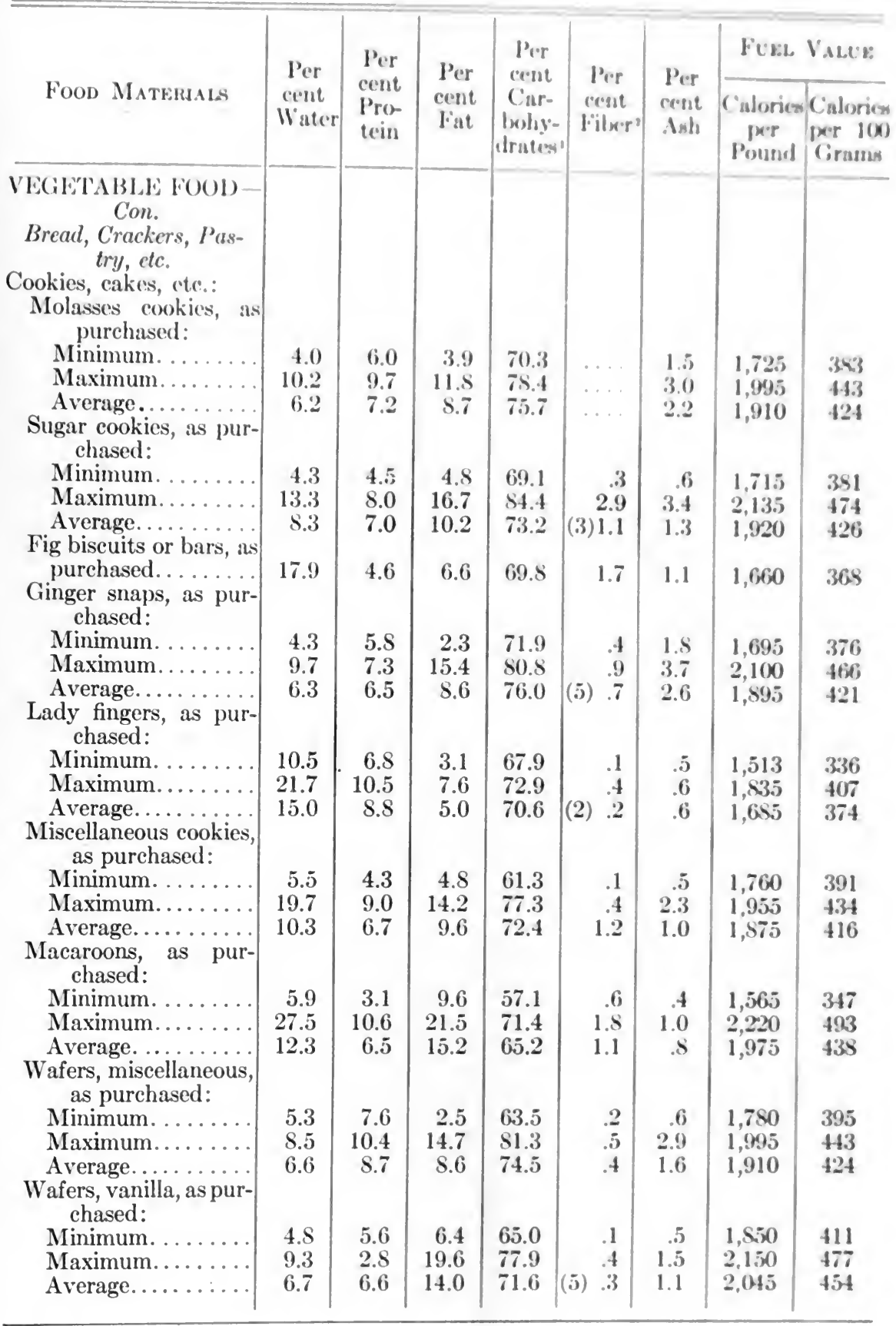

1 Fiber included.

2 Number of determinations in parentheses. 


\begin{tabular}{|c|c|c|c|c|c|c|c|c|}
\hline \multirow[b]{2}{*}{ Food Materials } & \multirow[b]{2}{*}{$\begin{array}{c}\text { Per } \\
\text { cent } \\
\text { Water }\end{array}$} & \multirow{2}{*}{$\begin{array}{l}\text { Per } \\
\text { cent } \\
\text { Pro- } \\
\text { tein }\end{array}$} & \multirow{2}{*}{$\begin{array}{l}\text { Per } \\
\text { cent } \\
\text { Fat }\end{array}$} & \multirow{2}{*}{$\begin{array}{c}\text { Per } \\
\text { cent } \\
\text { Car- } \\
\text { bohy- } \\
\text { drates }^{1}\end{array}$} & \multirow[b]{2}{*}{\begin{tabular}{|c|} 
Per \\
cent \\
Fiber $^{2}$
\end{tabular}} & \multirow[b]{2}{*}{$\begin{array}{l}\text { Per } \\
\text { cent } \\
\text { Ash }\end{array}$} & \multicolumn{2}{|c|}{ Fuel Value } \\
\hline & & & & & & & $\begin{array}{c}\text { Calories } \\
\text { per } \\
\text { Pound }\end{array}$ & $\begin{array}{l}\text { Calories } \\
\text { per } 100 \\
\text { Grams }\end{array}$ \\
\hline $\begin{array}{l}\text { VEGETABLE FOOD- } \\
\text { Con. }\end{array}$ & & & & & & & & \\
\hline $\begin{array}{c}\text { Bread, Crackers, Pas- } \\
\text { try, etc. }\end{array}$ & & & & & & & & \\
\hline $\begin{array}{l}\text { Cookies, cakes, etc.: } \\
\text { Wafers, all analyses, as } \\
\text { purchased average }\end{array}$ & & & & 72.9 & & & & \\
\hline $\begin{array}{l}\text { purchased, average. } \\
\text { Miscellaneous cakes, } \\
\text { as purchased: }\end{array}$ & 6.6 & 7.6 & 11.6 & 72.9 & (10).3 & 1.3 & 1,985 & 441 \\
\hline Minimum. . . . . . . . & 3.2 & 4.2 & 1.7 & 62.9 & .2 & .6 & 1,560 & 346 \\
\hline Maximum........ & 17.9 & 13.1 & 17.0 & 84.6 & .7 & 1.9 & 2,060 & 457 \\
\hline Average............. & 8.2 & 7.6 & 9.0 & 74.0 & $(16) .3$ & 1.2 & 1,900 & 422 \\
\hline $\begin{array}{l}\text { Doughnuts, as pur- } \\
\text { chased: }\end{array}$ & & & & & & & & \\
\hline Minimum......... & 11.0 & 5.1 & 16.4 & 45.8 & .6 & .4 & 1,795 & 398 \\
\hline Maximum......... & 25.8 & 7.6 & 25.7 & 63.2 & .3 & 1.9 & 2,155 & 478 \\
\hline Average............ & 18.3 & 6.7 & 21.0 & 53.1 & (2) .7 & .9 & 2,000 & 444 \\
\hline Jumbles, as purchased: & & & & & & & & \\
\hline Minimum........ & 6.7 & 6.3 & 10.9 & 51.9 & .2 & .6 & 1,745 & 387 \\
\hline Maximum........ & 24.8 & 7.9 & 15.7 & 72.1 & 1.0 & 1.3 & 2,025 & 450 \\
\hline Average........... & 14.3 & 7.4 & 13.5 & 63.7 & $(3) .5$ & 1.1 & 1,890 & 420 \\
\hline $\begin{array}{l}\text { Pie, apple, as pur- } \\
\text { chased: }\end{array}$ & & & & & & & & \\
\hline Minimum. ....... & 40.2 & 2.6 & 7.7 & 40.3 & $\ldots$ & .9 & 1,180 & 262 \\
\hline Maximum........ & 45.5 & 3.8 & 11.3 & 46.2 & $\ldots$ & 2.8 & 1,320 & 293 \\
\hline Average.......... & 42.5 & 3.1 & 9.8 & 42.8 & $\ldots$ & 1.8 & 1,270 & 282 \\
\hline $\begin{array}{l}\text { Pie, cream, as pur- } \\
\text { chased: }\end{array}$ & & & & & & & & \\
\hline Minimum........ & 27.8 & 2.1 & 6.9 & 42.3 & • & .5 & 1,425 & 316 \\
\hline Maximum........ & 37.2 & 5.6 & 17.9 & 55.8 & $\ldots$ & 1.5 & 1,580 & 351 \\
\hline Average............ & 32.0 & 4.4 & 11.4 & 51.2 & . & 1.0 & 1,515 & 336 \\
\hline chased............ & 62.4 & 4.2 & 6.3 & 26.1 & & 1.0 & 830 & 184 \\
\hline $\begin{array}{l}\text { Pie, lemon, as pur- } \\
\text { chased........... }\end{array}$ & 47.4 & 3.6 & 10.1 & 37.4 & $\ldots$ & 1.5 & 1,190 & 264 \\
\hline $\begin{array}{l}\text { Pie, mince, as pur- } \\
\text { chased: }\end{array}$ & & & & & & & & \\
\hline Minimum........ & 34.1 & 4.5 & 9.7 & 30.4 & $\ldots$ & 1.3 & 1,115 & 247 \\
\hline Maximum........ & 51.1 & 7.5 & 14.5 & 44.0 & & 4.4 & 1,535 & 341 \\
\hline Average............ & 41.3 & 5.8 & 12.3 & 38.1 & & 2.5 & 1,335 & 296 \\
\hline $\begin{array}{l}\text { Pie, raisin, as pur- } \\
\text { chased........... } \\
\text { Pie, squash }\end{array}$ & 37.0 & 3.0 & 11.3 & 47.2 & & 1.5 & 1,410 & 313 \\
\hline $\begin{array}{l}\text { chased............. } \\
\text { Pudding, Indian meal. }\end{array}$ & 64.2 & 4.4 & 8.4 & 21.7 & & 1.3 & 840 & 186 \\
\hline as purchased.... & 60.7 & 5.5 & 4.8 & 27.5 & $\ldots$ & 1.5 & 815 & 181 \\
\hline
\end{tabular}

1 Fiber included.

2 Number of determinations in parentheses. 


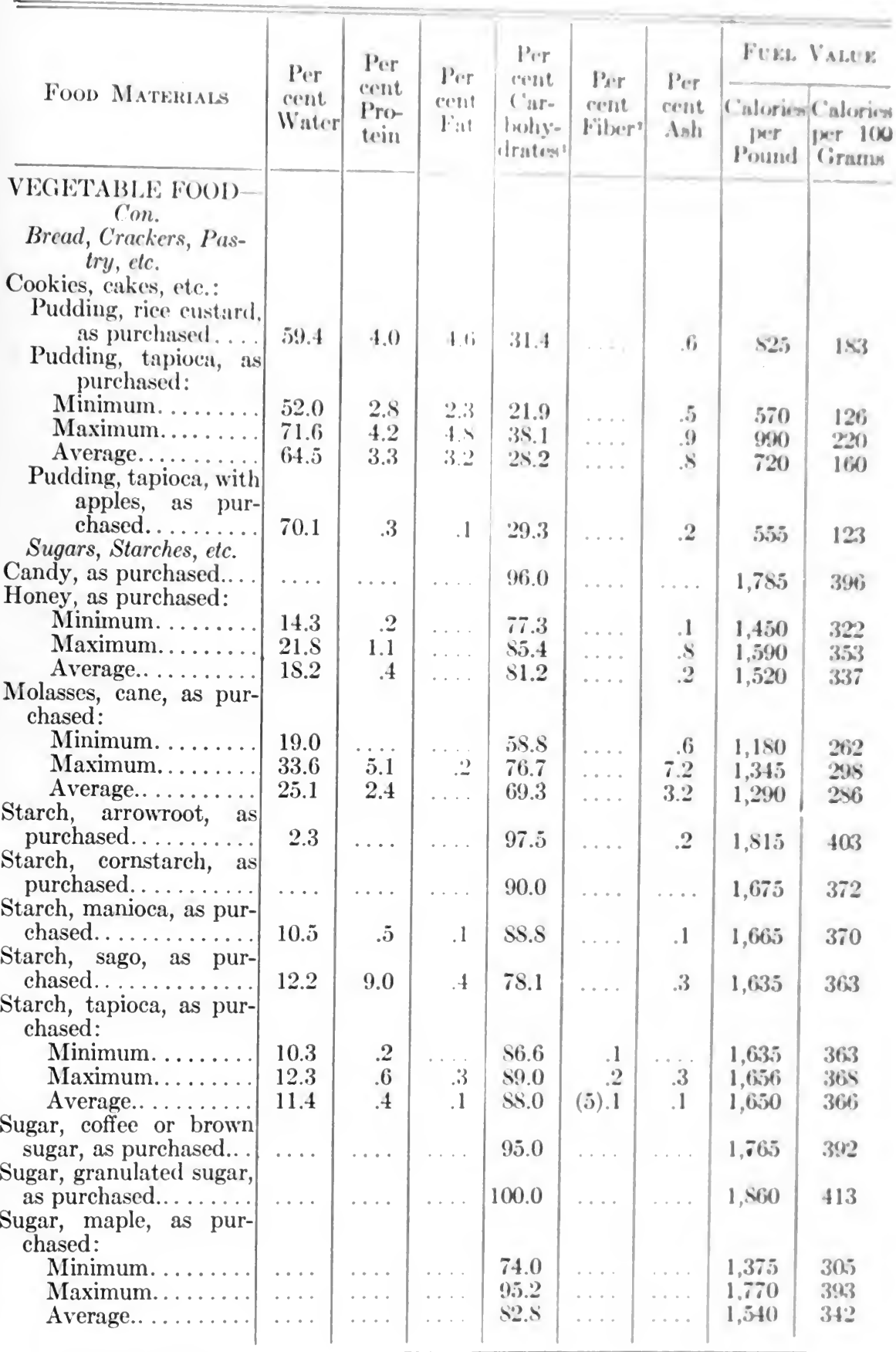

1 Fiber included.

2 Number of determinations in parentheres. 


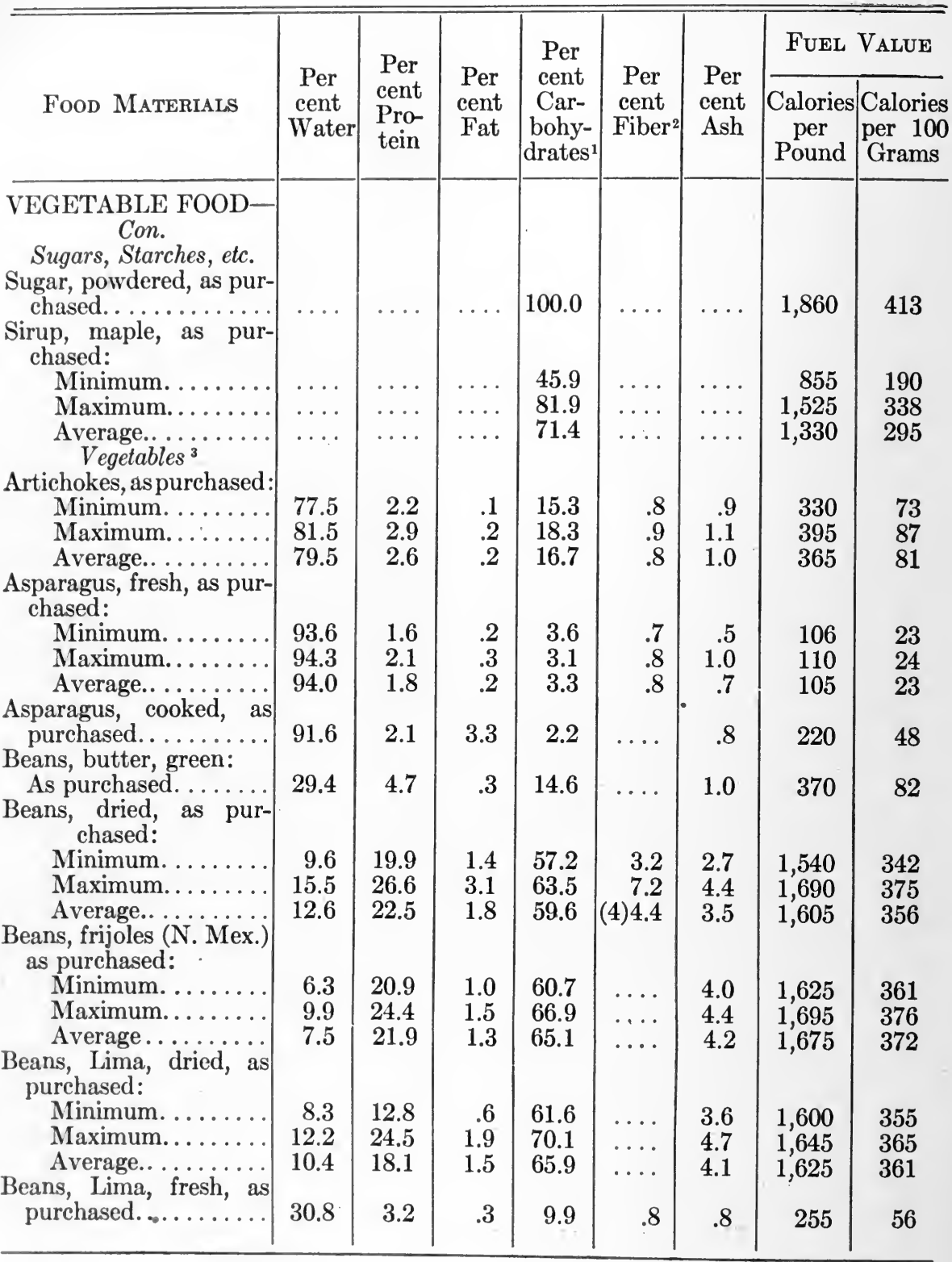

1 Fiber included.

2 Number of determinations in parentheses.

3 Such vegetables as potatoes, squash, beets, etc., have a certain amount of inedible material, skin, seeds, etc. The amount varies with the method of preparing the vegetables and eannot be accurately estimated. The figures given for refuse of vegetables, fruits, etc., are assumed to represent approximately the amount of refuse in these foods as ordinarily prepared. 


\begin{tabular}{|c|c|c|c|c|c|c|c|c|}
\hline Food Materials & $\begin{array}{c}\text { Per } \\
\text { cent } \\
\text { Water }\end{array}$ & $\begin{array}{l}\text { Per } \\
\text { cent } \\
\text { Pro- } \\
\text { tein }\end{array}$ & $\begin{array}{l}\text { Per } \\
\text { cent } \\
\text { Fint }\end{array}$ & $\begin{array}{c}\text { Per } \\
\text { cent } \\
\text { Car- } \\
\text { bohy- } \\
\text { drates ' }\end{array}$ & $\begin{array}{l}\text { Per } \\
\text { crint } \\
\text { Fiber? }\end{array}$ & $\begin{array}{l}\text { Per } \\
\text { cent } \\
\text { Ash }\end{array}$ & $\begin{array}{c}\text { Calories } \\
\text { jeer } \\
\text { Pound }\end{array}$ & $\begin{array}{l}\text { Calories } \\
\text { per } 100 \\
\text { Cirmuns }\end{array}$ \\
\hline $\begin{array}{l}\text { VEGETABLE FOOD- } \\
\text { Con. }\end{array}$ & & & & & & & & \\
\hline $\begin{array}{c}\text { Vegetables } \\
\text { Beans, mesquite, dry, as } \\
\text { purchased.. }\end{array}$ & & & & & & & & \\
\hline $\begin{array}{l}\text { Beans, string, cooked. . . } \\
\text { Beans, string, fresh: }\end{array}$ & $\begin{array}{r}4.8 \\
95.3\end{array}$ & $\begin{array}{r}12.2 \\
.5\end{array}$ & $\begin{array}{l}2.5 \\
1.1\end{array}$ & $\begin{array}{r}77.1 \\
1.9\end{array}$ & $\cdots$ & $\begin{array}{r}3.4 \\
.9\end{array}$ & $\begin{array}{r}1,765 \\
95\end{array}$ & $\begin{array}{r}392 \\
21\end{array}$ \\
\hline Minimum........ & 83.5 & 1.7 & .2 & 5.1 & 1.2 & .7 & 165 & 36 \\
\hline Maximum......... & 91.7 & 2.8 & .4 & 12.6 & 2.6 & .9 & 300 & 66 \\
\hline Average... . & $\$ 9.2$ & 2.3 & .3 & 7.4 & (2) 1.9 & .8 & 195 & 43 \\
\hline As purchased..... & 83.0 & 2.1 & .3 & 6.9 & 1.8 & .7 & 180 & 40 \\
\hline $\begin{array}{l}\text { Beets, cooked......... } \\
\text { Beets, fresh: }\end{array}$ & 85.6 & 2.3 & .1 & 7.4 & $\cdots$ & 1.6 & 185 & 41 \\
\hline Minimum.......... & 79.5 & .9 & .1 & 3.8 & .6 & .7 & 95 & 21 \\
\hline Maximum........ & 94.1 & 3.0 & .2 & 16.3 & 1.7 & 2.0 & 36.5 & 81 \\
\hline Average.......... & 87.5 & 1.6 & .1 & 9.7 & (1S).9 & 1.1 & 215 & 47 \\
\hline $\begin{array}{l}\text { As purchased...... } \\
\text { Cabbage: }\end{array}$ & 70.0 & 1.3 & .1 & 7.7 & $\cdots$ & .9 & 170 & 37 \\
\hline Minimum......... & 86.0 & .2 & .1 & 3.4 & .5 & .4 & 100 & 22 \\
\hline Maximum. . & 94.3 & 2.9 & .7 & 8.0 & 1.6 & 2.4 & 225 & 50 \\
\hline Average.. . . & 91.5 & 1.6 & .3 & 5.6 & (8) 1.1 & 1.0 & 145 & 32 \\
\hline $\begin{array}{l}\text { As purchased. . . . . } \\
\text { Cabbage, curly, as pur- }\end{array}$ & 77.7 & 4.1 & .6 & 6.2 & $\ldots$ & 1.8 & 215 & 47 \\
\hline $\begin{array}{l}\text { Cabbage, curly, as pur- } \\
\text { chased................ } \\
\text { Cabbage sprouts, as pur- }\end{array}$ & 87.3 & 4.1 & .6 & 6.2 & $\cdots$ & 1.8 & 215 & 47 \\
\hline $\begin{array}{l}\text { chased............. } \\
\text { Carrots, fresh: }\end{array}$ & 33.7 & 1.8 & .4 & 1.7 & 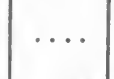 & .6 & So & 17 \\
\hline Minimum.......... & 83.1 & .7 & & 6.5 & .6 & .6 & 155 & 34 \\
\hline Maximum... & 21.1 & 2.0 & .7 & 13.8 & 2.3 & 1.6 & 295 & 65 \\
\hline Average..... & .88 .2 & 1.1 & .4 & 9.3 & $(1.5) 1.1$ & 1.0 & 210 & 46 \\
\hline As purchased. ..... & 70.6 & .9 & .2 & 7.4 & $\ldots$ & .9 & 160 & 35 \\
\hline $\begin{array}{l}\text { Carrots, evaporated..... } \\
\text { Cauliflower, as purchase }\end{array}$ & 3.5 & 7.7 & 3.6 & S0.3 & $\ldots$ & 4.9 & 1,790 & 397 \\
\hline Minimum. . & 90.8 & 1.6 & .2 & 3.4 & $\ldots$ & .6 & 110 & 24 \\
\hline Maximum. & 93.8 & 2.0 & .8 & 6.0 & & .8 & 175 & 35 \\
\hline Average..... & 92.3 & 1.8 & .5 & 4.7 & (1) 1.0 & .7 & 140 & 31 \\
\hline $\begin{array}{l}\text { Celery: } \\
\text { Min }\end{array}$ & 93.1 & 1.0 & .1 & 3.0 & & 9 & & \\
\hline $\begin{array}{l}\text { Minimum. . } \\
\text { Maximum. }\end{array}$ & 95.0 & 1.4 & .2 & $\begin{array}{l}0.0 \\
4.6\end{array}$ & $\cdots$ & 1.1 & $\begin{array}{r}75 \\
115\end{array}$ & $\begin{array}{l}16 \\
25\end{array}$ \\
\hline Average... & 94.5 & 1.1 & .1 & 3.3 & $\cdots$ & 1.0 & S5 & is \\
\hline As purchased..... & 75.6 & .9 & .1 & 2.6 & $\ldots$ & .5 & 70 & 15 \\
\hline Collards: & & & & & & & & \\
\hline Minimum. . & 85.8 & 3.3 & .5 & 6.2 & $\ldots$ & 1.4 & 205 & 45 \\
\hline Maximum... & 88.3 & 5.7 & .7 & 6.5 & $\ldots$ & 1.6 & 250 & 55 \\
\hline Ave & 87.1 & 4. & .6 & 6.3 & ... & 1.5 & 225 & 50 \\
\hline As purchased.... & 39.5 & 1.5 & .2 & 2.9 & $\cdots$ & .6 & 90 & 20 \\
\hline
\end{tabular}

1 Fiber ineluded.

2 Number of determinations in parentheses. 


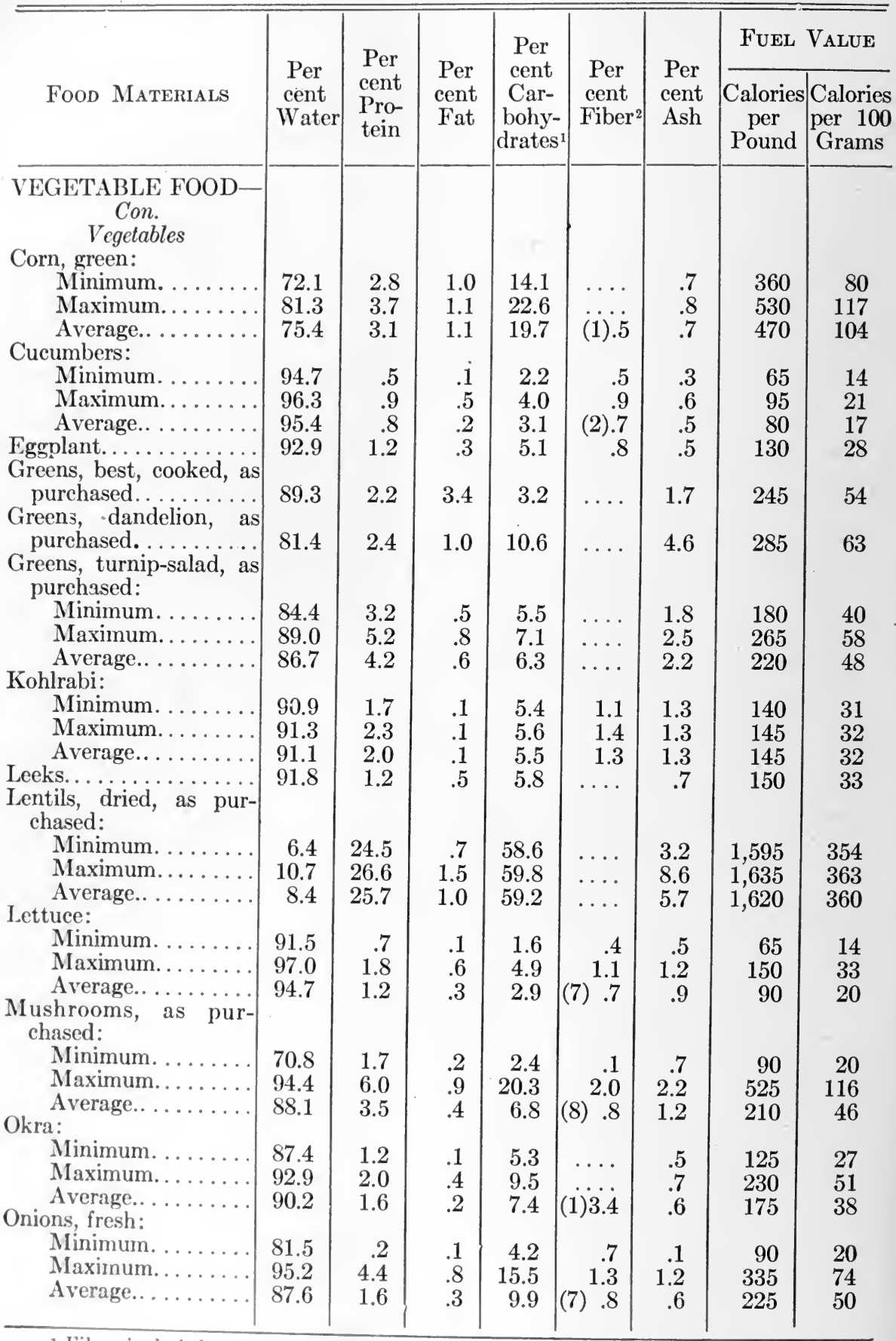

1 Fiber included.

2 Number of determinations in parentheses. 


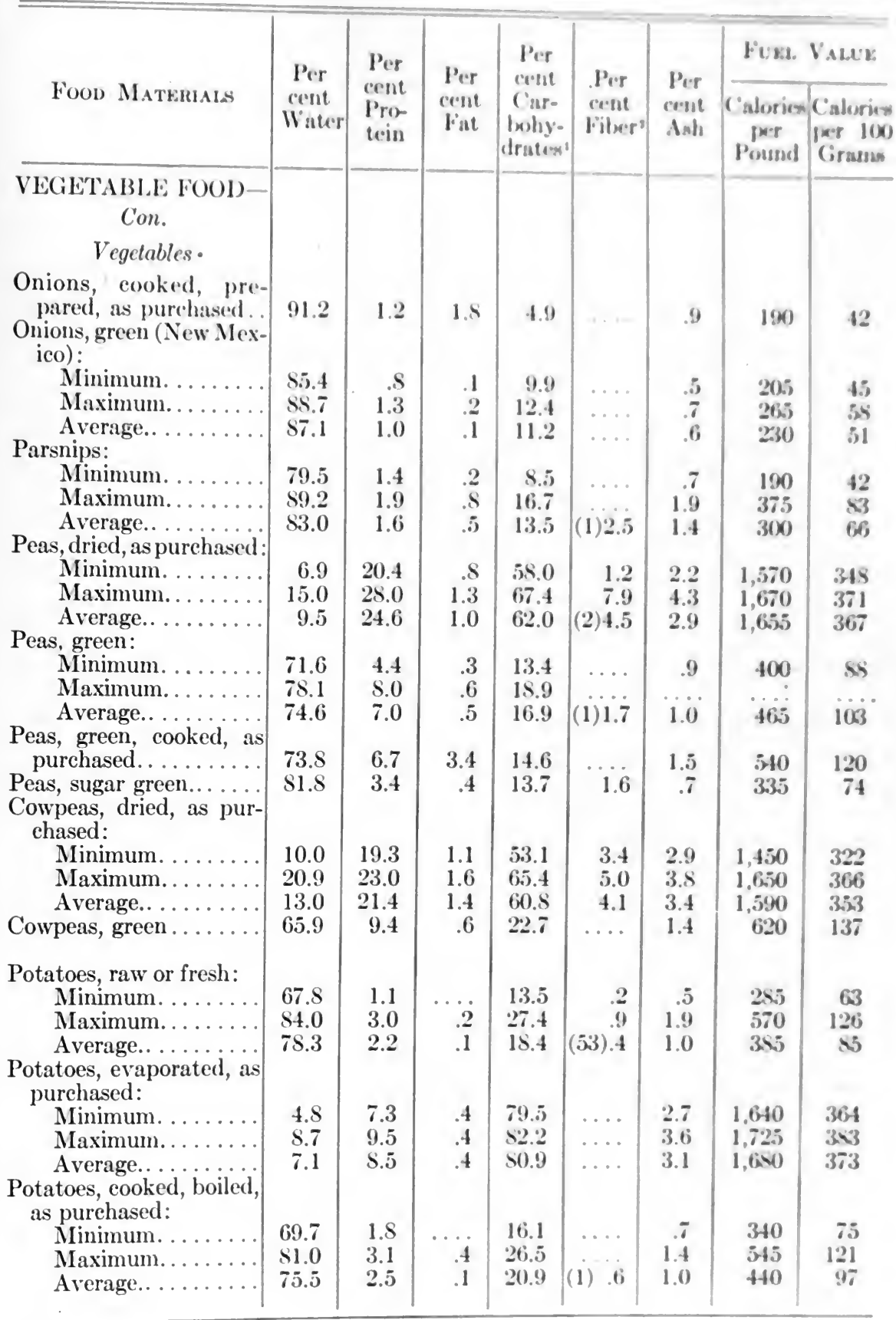

1 Fiber included.

2 Number of determinations in parentheses. 


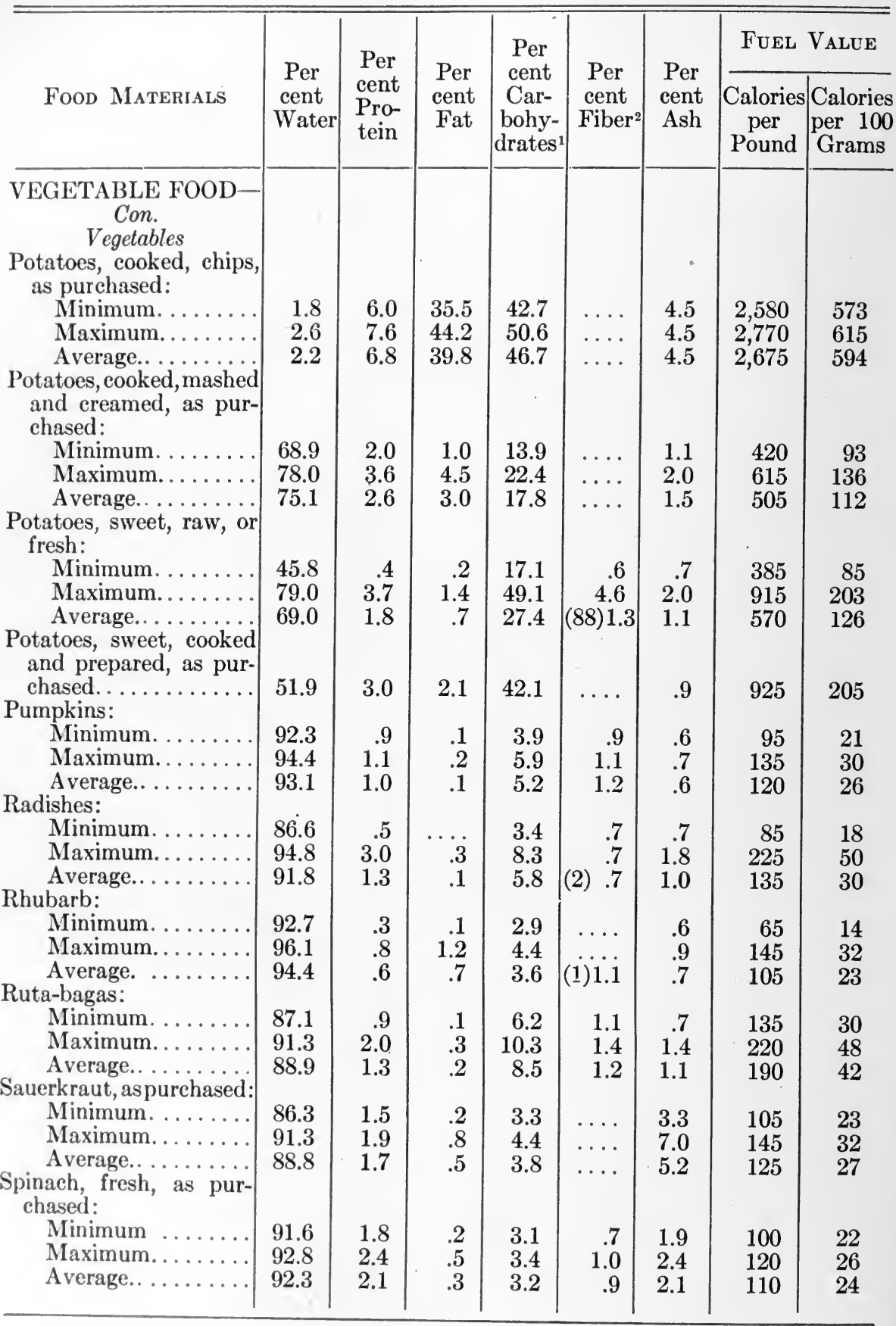

1 Fiber included.

2 Number of determinations in parentheses. 


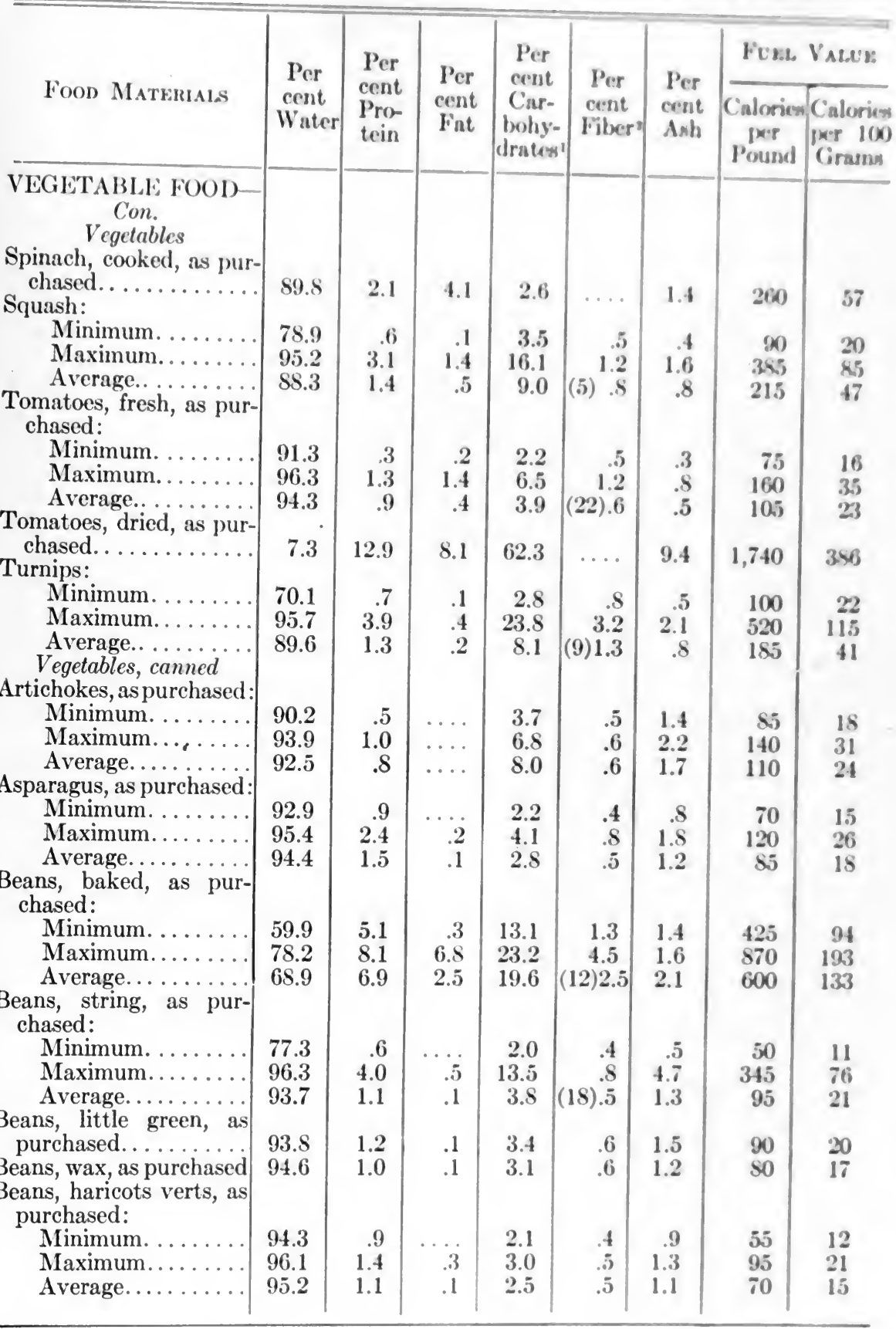

1 Fiber included.

2 Number of determinations in parentheses. 


\begin{tabular}{|c|c|c|c|c|c|c|c|c|}
\hline Food Materials & $\begin{array}{l}\text { Per } \\
\text { cent } \\
\text { Water }\end{array}$ & $\begin{array}{l}\text { Per } \\
\text { cent } \\
\text { Pro- } \\
\text { tein }\end{array}$ & $\begin{array}{l}\text { Per } \\
\text { cent } \\
\text { Fat }\end{array}$ & $\begin{array}{c}\text { Per } \\
\text { cent } \\
\text { Car- } \\
\text { bohy- } \\
\text { drates }^{1}\end{array}$ & $\begin{array}{c}\text { Per } \\
\text { cent } \\
\text { Fiber }^{2}\end{array} \mid$ & $\begin{array}{l}\text { Per } \\
\text { cent } \\
\text { Ash }\end{array}$ & 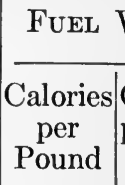 & $\begin{array}{l}\text { Calories } \\
\text { per } 100 \\
\text { Grams }\end{array}$ \\
\hline \multicolumn{9}{|l|}{$\begin{array}{l}\text { VEGETABLE FOOD-- } \\
\text { Con. } \\
\text { Vegetables, canned } \\
\text { Beans, haricots flageo- } \\
\text { lets, as purchased: }\end{array}$} \\
\hline & 80.4 & 4.0 & & 10.8 & 1.0 & 9 & 280 & 62 \\
\hline Maximum......... & 83.9 & 5.2 & $\ddot{1}$ & 13.4 & 1.0 & 1.7 & 350 & 77 \\
\hline 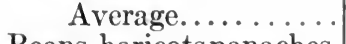 & 81.6 & 4.6 & .1 & 12.5 & 1.0 & 1.2 & 320 & 71 \\
\hline $\begin{array}{l}\text { Beans, haricots panaches, } \\
\text { as purchased....... }\end{array}$ & 86.1 & 3.7 & $\ldots$ & 9.2 & 1.0 & 1.0 & 240 & 53 \\
\hline $\begin{array}{l}\text { Beans, Lima, as pur- } \\
\text { chased: }\end{array}$ & & & & & & & & \\
\hline 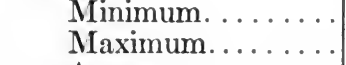 & $\begin{array}{l}75.7 \\
83.9\end{array}$ & $\begin{array}{l}3.2 \\
5.6\end{array}$ & $\begin{array}{l}.2 \\
.6\end{array}$ & $\begin{array}{l}10.5 \\
17.9\end{array}$ & $\begin{array}{r}.9 \\
1.4\end{array}$ & $\begin{array}{l}1.0 \\
2.6\end{array}$ & $\begin{array}{l}280 \\
445\end{array}$ & $\begin{array}{l}62 \\
98\end{array}$ \\
\hline Average........... & 79.5 & 7.0 & .2 & 18.5 & 1.2 & 1.6 & 360 & 80 \\
\hline $\begin{array}{l}\text { Beans, red kidneys, as } \\
\text { purchased............ } \\
\text { Brussels sprouts, as pur- }\end{array}$ & 72.7 & 7.0 & .2 & 18.5 & 1.2 & 1.6 & 480 & 106 \\
\hline $\begin{array}{l}\text { chased.............. } \\
\text { Corn, green, as pur- } \\
\text { chased: }\end{array}$ & 93.7 & 1.5 & .1 & 3.4 & .5 & 1.3 & 95 & 21 \\
\hline Minimum........ & 68.3 & 2.0 & .5 & 9.8 & .4 & .5 & 250 & 55 \\
\hline Maximum........ & 86.1 & 3.7 & 1.9 & 25.8 & 1.2 & 1.6 & 610 & 135 \\
\hline Average............ & 76.1 & 2.8 & 1.2 & 19.0 & $(43) .8$ & .9 & 455 & 101 \\
\hline $\begin{array}{l}\text { Corn and tomatoes, as } \\
\text { purchased: } \\
\text { Minimum. }\end{array}$ & & & & & & & & \\
\hline $\begin{array}{l}\text { Minimum.......... } \\
\text { Maximum....... }\end{array}$ & $\begin{array}{l}83.6 \\
91.5\end{array}$ & $\begin{array}{l}1.2 \\
2.1\end{array}$ & $\begin{array}{l}.4 \\
.4\end{array}$ & $\begin{array}{r}6.4 \\
12.7\end{array}$ & $\begin{array}{l}.4 \\
.6\end{array}$ & $\begin{array}{r}.5 \\
1.2\end{array}$ & $\begin{array}{l}160 \\
295\end{array}$ & $\begin{array}{l}35 \\
65\end{array}$ \\
\hline Average............... & 87.6 & 1.6 & .4 & 9.6 & .5 & .8 & 225 & 50 \\
\hline $\begin{array}{l}\text { Macedoine (mixed vege- } \\
\text { tables), as purchased: }\end{array}$ & & & & & & & & \\
\hline $\begin{array}{l}\text { Minimum. ......... } \\
\text { Maximum........ }\end{array}$ & 91.5 & .7 & & 2.3 & .4 & .8 & 55 & 12 \\
\hline 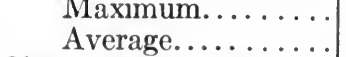 & $\begin{array}{l}95.9 \\
93.1\end{array}$ & $\begin{array}{l}1.7 \\
1.4\end{array}$ & $\cdots$ & $\begin{array}{l}5.7 \\
4.5\end{array}$ & .7 & 1.2 & 135 & 30 \\
\hline Okra, as purchased: & 80.1 & & & 4.5 & .0 & 1.0 & 110 & 24 \\
\hline $\begin{array}{l}\text { Minimum. ......... } \\
\text { Maximum......... }\end{array}$ & 94.0 & .5 & 8 & 3.3 & .4 & .3 & 75 & 16 \\
\hline 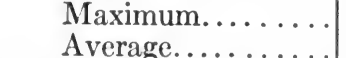 & 94.9 & .9 & .2 & 3.9 & 1.4 & 1.7 & 95 & 21 \\
\hline $\begin{array}{l}\text { Average............. } \\
\text { Okra and tomatoes, as } \\
\text { purchased: }\end{array}$ & 94.4 & .7 & .1 & 3.6 & .7 & 1.2 & 85 & 18 \\
\hline Minimum. ....... & 91.4 & 1.1 & .2 & 4.8 & .4 & 1.4 & 125 & 27 \\
\hline Maximum........ & 92.3 & 1.2 & .3 & 5.7 & .6 & 1.8 & 135 & 30 \\
\hline $\begin{array}{l}\text { Average............. } \\
\text { Peas, green as purchased. }\end{array}$ & 91.8 & 1.1 & .3 & 5.2 & .5 & 1.6 & 130 & 28 \\
\hline Minimum......... & 77.5 & 1.6 & $\cdots$ & 4.9 & .6 & .3 & 130 & 30 \\
\hline Maximum......... & 92.7 & 6.1 & .8 & 17.4 & 1.5 & 2.0 & 405 & 90 \\
\hline Average...... & 85.3 & 3.6 & .2 & 9.8 & $\mid(83) 1.2$ & 1.1 & 255 & 56 \\
\hline
\end{tabular}

1 Fiber ineluded.

2 Number of determinations in parentheses. 


\begin{tabular}{|c|c|c|c|c|c|c|c|c|}
\hline Food Materialas & $\begin{array}{l}\text { Per } \\
\text { cent } \\
\text { Wnter }\end{array}$ & $\begin{array}{l}\text { Per } \\
\text { cent } \\
\text { Pro- } \\
\text { tein }\end{array}$ & $\begin{array}{l}\text { Per } \\
\text { rent } \\
\text { Fist }\end{array}$ & $\begin{array}{l}\text { l'er } \\
\text { cent } \\
\text { Cor- } \\
\text { Inohye- } \\
\text { drates' }\end{array}$ & $\begin{array}{l}\text { Per } \\
\text { cent } \\
\text { Pithers }\end{array}$ & $\begin{array}{l}\text { Per } \\
\text { cent } \\
\text { Ash }\end{array}$ & $\begin{array}{c}\text { Calorices } \\
\text { poer } \\
\text { Pound }\end{array}$ & $\begin{array}{l}\text { Calorics } \\
\text { jer } 100) \\
\text { Cirmus }\end{array}$ \\
\hline $\begin{array}{l}\text { VEGETABLE FOOD- } \\
\text { Con. } \\
\text { Vegetables, canned } \\
\text { Potatoes, sweet, as pur- } \\
\text { chased: }\end{array}$ & & & & & & & & \\
\hline$\underset{\text { Maximum........... }}{\text { Minimum. }}$ & $\begin{array}{l}42.0 \\
68.4\end{array}$ & $\begin{array}{l}1.3 \\
2.6\end{array}$ & .3 & $\begin{array}{l}292 \\
53.6\end{array}$ & & 1.8 & $\begin{aligned} 2800 \\
1,065\end{aligned}$ & $\begin{array}{l}128 \\
236\end{array}$ \\
\hline $\begin{array}{l}\text { Average........... } \\
\text { Pumpkins, as purchased: }\end{array}$ & 5.5 .2 & 1.9 & .4 & 41.4 & (i) $\mathrm{s}$ & 1.1 & 820 & 152 \\
\hline Minimum.......... & $\$ \$ .2$ & .5 & .1 & 4.7 & .6 & .4 & $10 x)$ & 22 \\
\hline Maximum........ & 94.3 & 1.2 & 4 & 9.6 & 1.5 & 1.5 & 205 & 45 \\
\hline $\begin{array}{l}\text { Average.......... } \\
\text { Squash, as purchased: }\end{array}$ & 91.6 & .8 & .2 & 6.7 & (5) 1.1 & .8 & 150 & 33 \\
\hline Minimum.......... & 85.6 & .2 & .1 & 8.2 & .3 & .2 & 1855 & 41 \\
\hline Maximum........ & $\$ 9.9$ & 1.6 & 1.2 & 13.9 & 1.1 & .7 & 26.5 & 28 \\
\hline $\begin{array}{r}\text { Average } \ldots . . . . . \\
\text { Succotash, as purchased: }\end{array}$ & $\$ 7.6$ & .9 & .5 & 10.5 & (2) .7 & .5 & 23.5 & 52 \\
\hline Minimum. . . . . . & 71.4 & 2.9 & .7 & 14.9 & .7 & .4 & 375 & 83 \\
\hline Maximum........ & 79.9 & 4.4 & 1.7 & 22.4 & 1.1 & 1.4 & 540 & 120 \\
\hline $\begin{array}{l}\text { Average............ } \\
\text { Tomatoes, as purchased: }\end{array}$ & 75.9 & 3.6 & 1.0 & 18.6 & $(10) .9$ & .9 & $45 i$ & 101 \\
\hline Minimum........... & 92.5 & .3 & .1 & 1.4 & .4 & .2 & 80 & 17 \\
\hline Maximum........ & 97.9 & 1.7 & .3 & 8.1 & .7 & 1.2 & 135 & 30 \\
\hline Average......... & 94.0 & 1.2 & .2 & 4.0 & $(11) . j$ & .6 & $10 ;$ & 23 \\
\hline $\begin{array}{l}\text { Pickles, Condiments, etc. } \\
\text { Catsup, tomato, as pur- } \\
\text { chased: }\end{array}$ & & & & & & & & \\
\hline Minimum........ & 27.7 & 1.1 & .1 & 8.5 & $\ldots$ & 2.5 & 185 & 40 \\
\hline Maximum........ & $\$ 7.8$ & 2.0 & .4 & 16.1 & $\ldots$. & 3.8 & 353 & 75 \\
\hline Average........... & $\$ 2.8$ & 1.5 & .2 & 12.3 & $\cdots$ & 3.2 & 265 & 35 \\
\hline $\begin{array}{l}\text { Horse-radish, as pur- } \\
\text { chased: } \\
\text { Minimum. . . . . . . }\end{array}$ & 85.4 & & 1 & 96 & & 1.5 & 210 & 46 \\
\hline Maximum............ & $\begin{array}{l}80.4 \\
87.5\end{array}$ & $\begin{array}{l}1.2 \\
1.6\end{array}$ & .2 & 11.3 & $\cdots$ & 1.6 & 245 & $\begin{array}{l}70 \\
54\end{array}$ \\
\hline Average............ & S6.4 & 1.4 & .2 & 10.5 & $\cdots$ & 1.5 & 230 & 51 \\
\hline $\begin{array}{l}\text { Horse-radish, as pur- } \\
\text { chased................ }\end{array}$ & 4.3 & 11.0 & .8 & 77.7 & $\ldots$ & 6.2 & 1,685 & 374 \\
\hline Olives, green........... & 58.0 & 1.1 & 27.6 & 11.6 & $\ldots$ & 1.7 & 1,400 & 311 \\
\hline Olives, ripe........... & 64.7 & 1.7 & 25.0 & 4.3 & $\ldots$ & 3.4 & 1,205 & 267 \\
\hline $\begin{array}{l}\text { Peppers (paprica), green, } \\
\text { dried, as purchased ... } \\
\text { Peppers, red chili, as } \\
\text { purchased: }\end{array}$ & 5.0 & 15.5 & S.5 & 63.0 & & 8.0 & 1.820 & 404 \\
\hline Minimum. . . & 3.9 & 8.2 & 6.3 & 67.3 & $\ldots$ & 7.4 & 1,770 & 393 \\
\hline $\begin{array}{l}\text { Maximum... } \\
\text { Average.... }\end{array}$ & 6.4 & 11.1 & 10.3 & 71.9 & $\cdots$ & S.0 & 1.595 & 421 \\
\hline Average. . & 5.3 & 9.4 & 7.7 & 70.0 & $\cdots$ & 7.6 & 1,500 & 400 \\
\hline
\end{tabular}

1 Fiber ineluded.

2 Number of determinations in parentheses. 


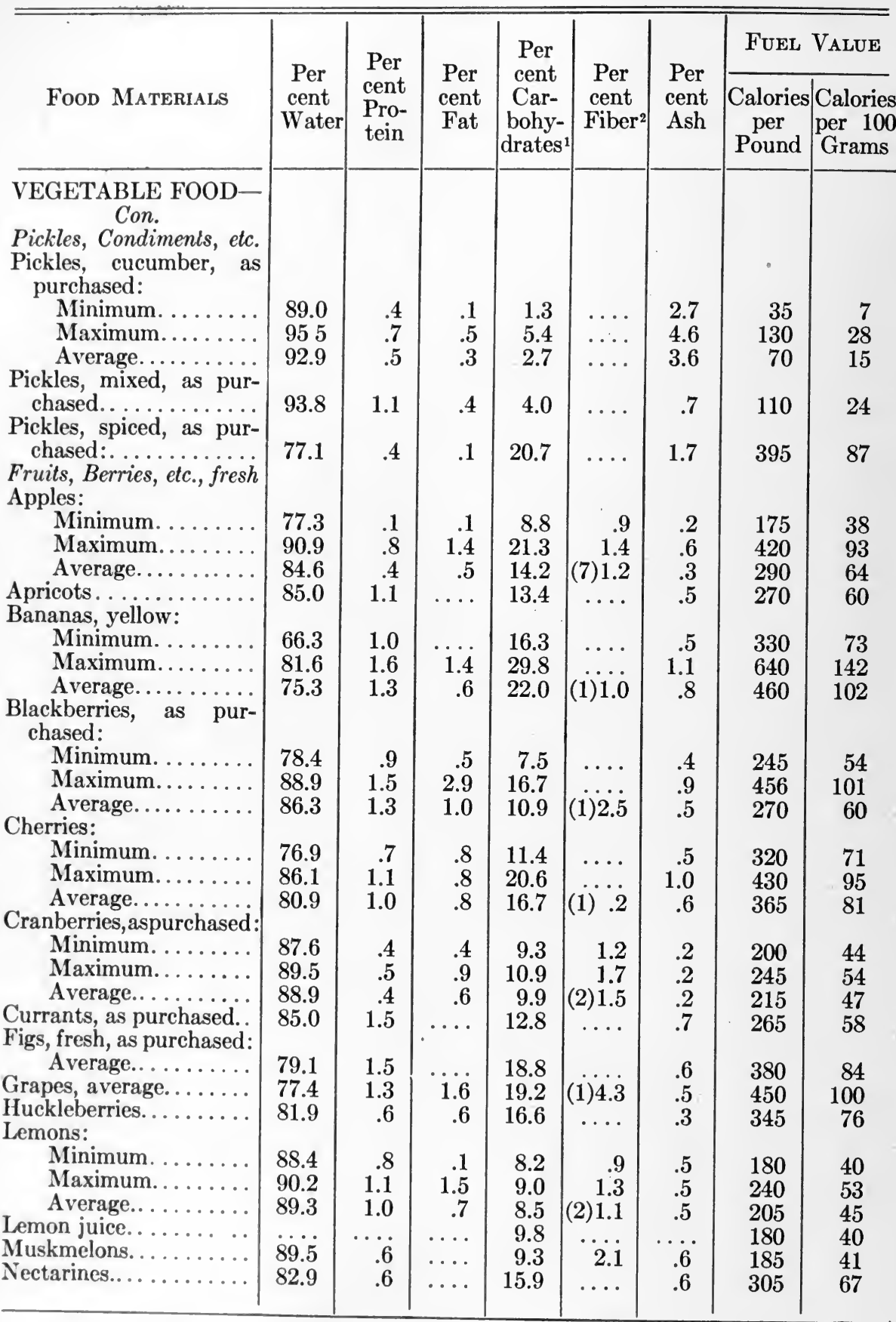

1 Fiber included.

2 Number of determinations in parentheses. 


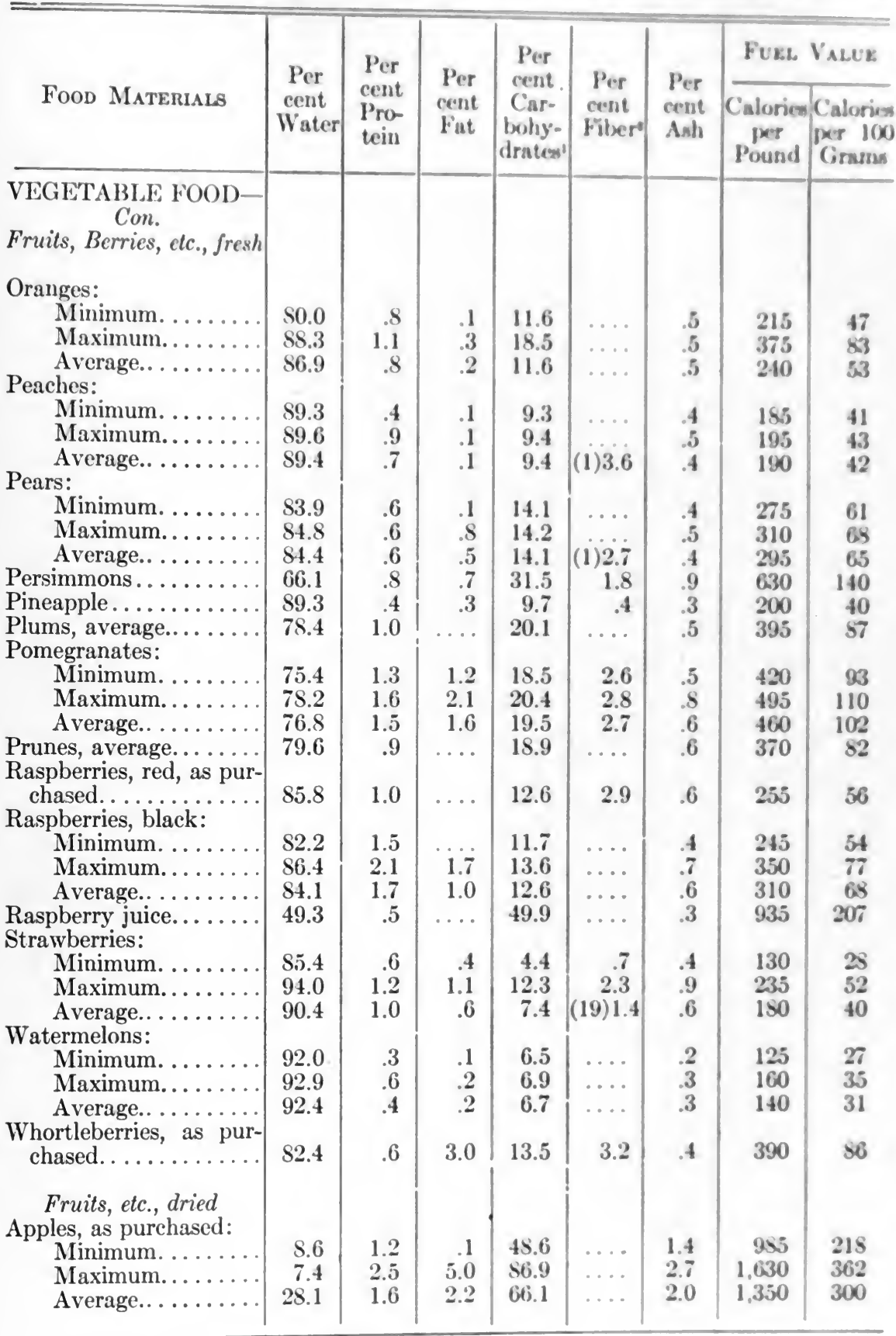

1 Fiber included.

2 Number of determinations in parentheses. 


\begin{tabular}{|c|c|c|c|c|c|c|c|c|}
\hline \multirow[b]{2}{*}{ Food Materials } & \multirow{2}{*}{$\begin{array}{c}\text { Per } \\
\text { cent } \\
\text { Water }\end{array}$} & \multirow{2}{*}{$\begin{array}{l}\text { Per } \\
\text { cent } \\
\text { Pro- } \\
\text { tein }\end{array}$} & \multirow{2}{*}{$\begin{array}{l}\text { Per } \\
\text { cent } \\
\text { Fat }\end{array}$} & \multirow{2}{*}{$\begin{array}{l}\text { Per } \\
\text { cent } \\
\text { Car- } \\
\text { bohy- } \\
\text { drates }\end{array}$} & \multirow{2}{*}{$\begin{array}{l}\text { Per } \\
\text { cent } \\
\text { Fiber }^{2}\end{array}$} & \multirow{2}{*}{$\begin{array}{l}\text { Per } \\
\text { cent } \\
\text { Ash }\end{array}$} & \multicolumn{2}{|c|}{ Fuel Value } \\
\hline & & & & & & & $\begin{array}{l}\text { Calories } \\
\text { per } \\
\text { Pound }\end{array}$ & $\begin{array}{l}\text { Calories } \\
\text { per } 100 \\
\text { Grams }\end{array}$ \\
\hline $\begin{array}{l}\text { VEGETABLE FOOD- } \\
\text { Con. } \\
\text { Fruits, etc., dried }\end{array}$ & & & & & & & & \\
\hline $\begin{array}{c}\text { Apricots, as purchased: } \\
\text { Minimum. ........ }\end{array}$ & 26.4 & 2.9 & 1.0 & 62.7 & $\ldots$ & 1.4 & 1,230 & 273 \\
\hline Maximum........ & 32.4 & 6.4 & 1.1 & 63.3 & $\ldots$ & 3.4 & 1,330 & 295 \\
\hline Average.... & 29.4 & 4.7 & 1.0 & 62.5 & $\ldots$ & 2.4 & 1,290 & 286 \\
\hline Citron, as purchased: & & & & & & & & \\
\hline Minimum........ & 12.4 & .4 & .6 & 72.5 & $\ldots$ & .8 & 1,380 & 306 \\
\hline Maximum......... & 25.6 & 6 & 2.5 & 83.7 & $\ldots$ & .9 & 1,675 & 372 \\
\hline $\begin{array}{l}\text { Average........... } \\
\text { Currants, Zante, as pur- } \\
\text { chased: }\end{array}$ & 19.0 & .5 & 1.5 & 78.1 & $\ldots$ & .9 & 1,525 & 338 \\
\hline Minimum......... & 35.3 & 1.0 & .4 & 60.0 & $\ldots$ & 2.2 & 1,195 & 265 \\
\hline Maximum. . & 35.1 & 4.7 & 4.7 & 85.3 & $\ldots$ & 9.1 & 1,690 & 375 \\
\hline Average.... & 17.2 & 2.4 & 1.7 & 74.2 & $\ldots$ & 4.5 & 1,495 & 332 \\
\hline Dates: & & & & & & & & \\
\hline Minimum. & 9.9 & 2.1 & .6 & 70.4 & $\ldots$ & 1.1 & 1,355 & 301 \\
\hline Maximum. . & 20.8 & 2.2 & 5.1 & 86.3 & $\ldots$ & 1.5 & 1,670 & 371 \\
\hline Average....... & 15.4 & 2.1 & 2.8 & 78.4 & $\ldots$ & 1.3 & 1,615 & 358 \\
\hline Figs, as purchased: & & & & & & & & \\
\hline 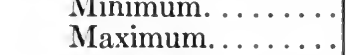 & $\begin{array}{l}11.6 \\
25.0\end{array}$ & $\begin{array}{l}2.6 \\
5.7\end{array}$ & $\begin{array}{r}7.3 \\
.3\end{array}$ & $\begin{array}{l}68.3 \\
83.1\end{array}$ & & $\begin{array}{l}2.2 \\
2.5\end{array}$ & $\begin{array}{l}1,355 \\
1,595\end{array}$ & $\begin{array}{l}301 \\
354\end{array}$ \\
\hline Average............ & 18.8 & 4.3 & .3 & 74.2 & $\ldots$ & 2.4 & 1,475 & 327 \\
\hline $\begin{array}{l}\text { Grapes, ground, as pur- } \\
\text { chased............. }\end{array}$ & 34.8 & 2.8 & .6 & 60.5 & 3.7 & 1.2 & 1,205 & 267 \\
\hline $\begin{array}{l}\text { Pears, as purchased..... } \\
\text { Prunes: }\end{array}$ & 16.5 & 2.8 & 5.4 & 72.9 & $\ldots$ & 2.4 & 1,635 & 363 \\
\hline Minimum. ....... & 16.9 & 1.4 & & 68.1 & & 1.5 & 1,340 & 297 \\
\hline Maximum..... & 27.5 & 3.2 & $\ldots$ & 78.6 & $\cdots$ & 3.0 & 1,500 & 333 \\
\hline Average...... & 22.3 & 2.1 & $\cdots$ & $73.3^{\circ}$ & $\cdots$ & 2.3 & 1,400 & 311 \\
\hline $\begin{array}{l}\text { Raisins: } \\
\text { Min }\end{array}$ & 71 & 23 & & & & & & \\
\hline $\begin{array}{l}\text { Minimum. ... } \\
\text { Maximum... }\end{array}$ & 21.0 & $\begin{array}{l}2.3 \\
3.0\end{array}$ & $7 . .5$ & $\begin{array}{l}71.3 \\
78.8\end{array}$ & & $\begin{array}{l}2.0 \\
5.0\end{array}$ & $\begin{array}{l}1,540 \\
1,805\end{array}$ & $\begin{array}{l}342 \\
401\end{array}$ \\
\hline Average........... & 14.6 & 2.6 & 3.3 & 76.1 & $\ldots$ & 3.4 & 1,605 & 356 \\
\hline $\begin{array}{c}\text { Raspberries, as pur- } \\
\text { chased.............. }\end{array}$ & 8.1 & 7.3 & 1.8 & 80.2 & & 2.6 & 1,705 & 378 \\
\hline $\begin{array}{l}\text { Fruits, etc., canned } \\
\text { Jellies, Preserves, etc. } \\
\text { Apples, crab, as pur- } \\
\text { chased............. }\end{array}$ & 42.4 & .3 & 2.4 & 54.4 & & .5 & 1,120 & 148 \\
\hline Applesauce, as pur- & & & & & & & & \\
\hline $\begin{array}{l}\text { chased ................... } \\
\text { Apricots, as purchased. }\end{array}$ & 61.1 & .2 & .8 & 37.2 & & .5 & 730 & 162 \\
\hline $\begin{array}{l}\text { Apricots, as purchased.. } \\
\text { Apricot sauce, as pur- }\end{array}$ & 81.4 & .9 & $\cdots$ & 17.3 & $\cdots$ & .4 & 340 & 75 \\
\hline chased......... & 45.2 & 1.9 & 1.3 & 48.8 & $\cdots$ & 2.8 & 1,000 & 222 \\
\hline
\end{tabular}

1 Fiber included.

2 Number of determinations in parentheses. 


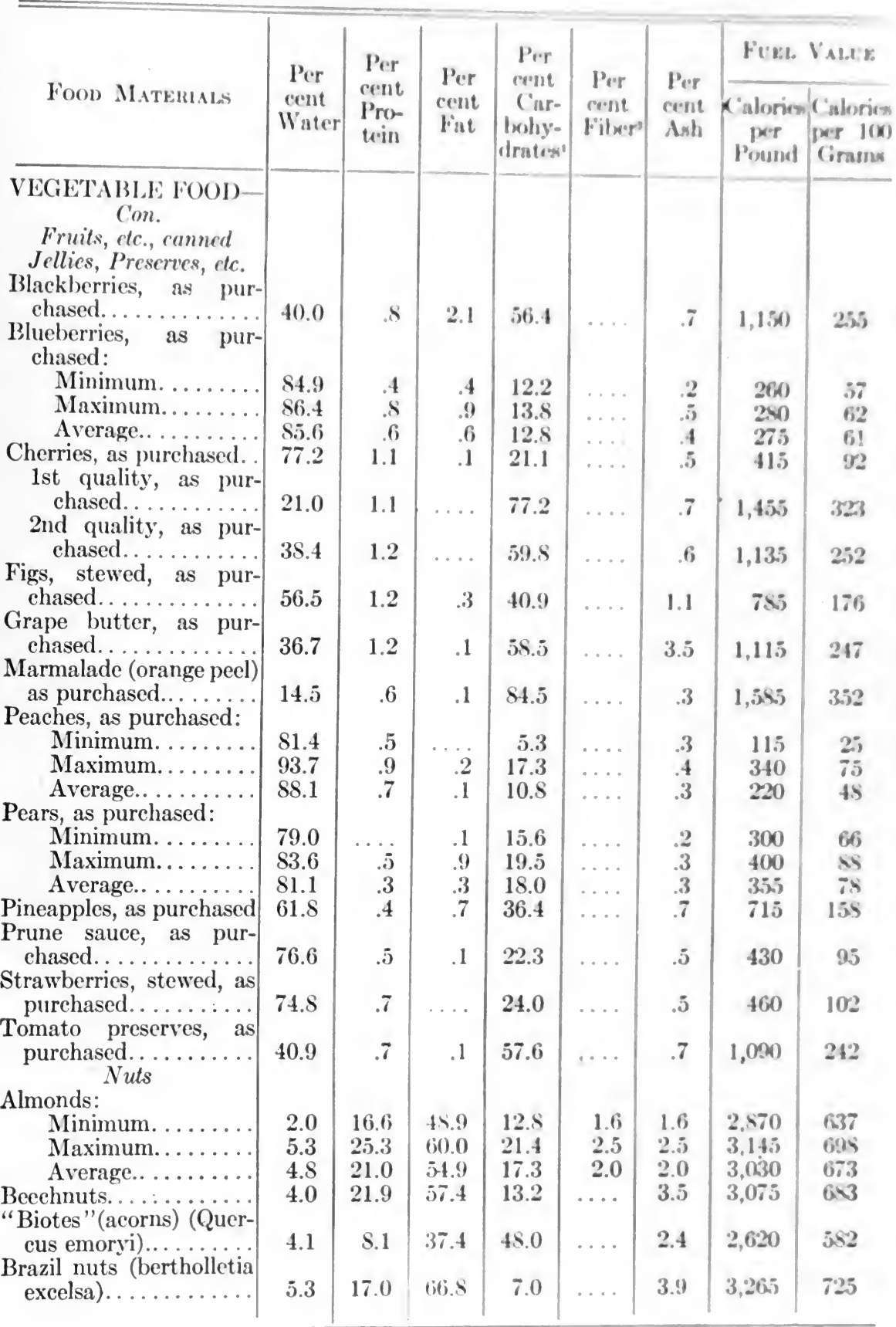

1 Fiber included.

2 Number of determinations in parenthenes. 


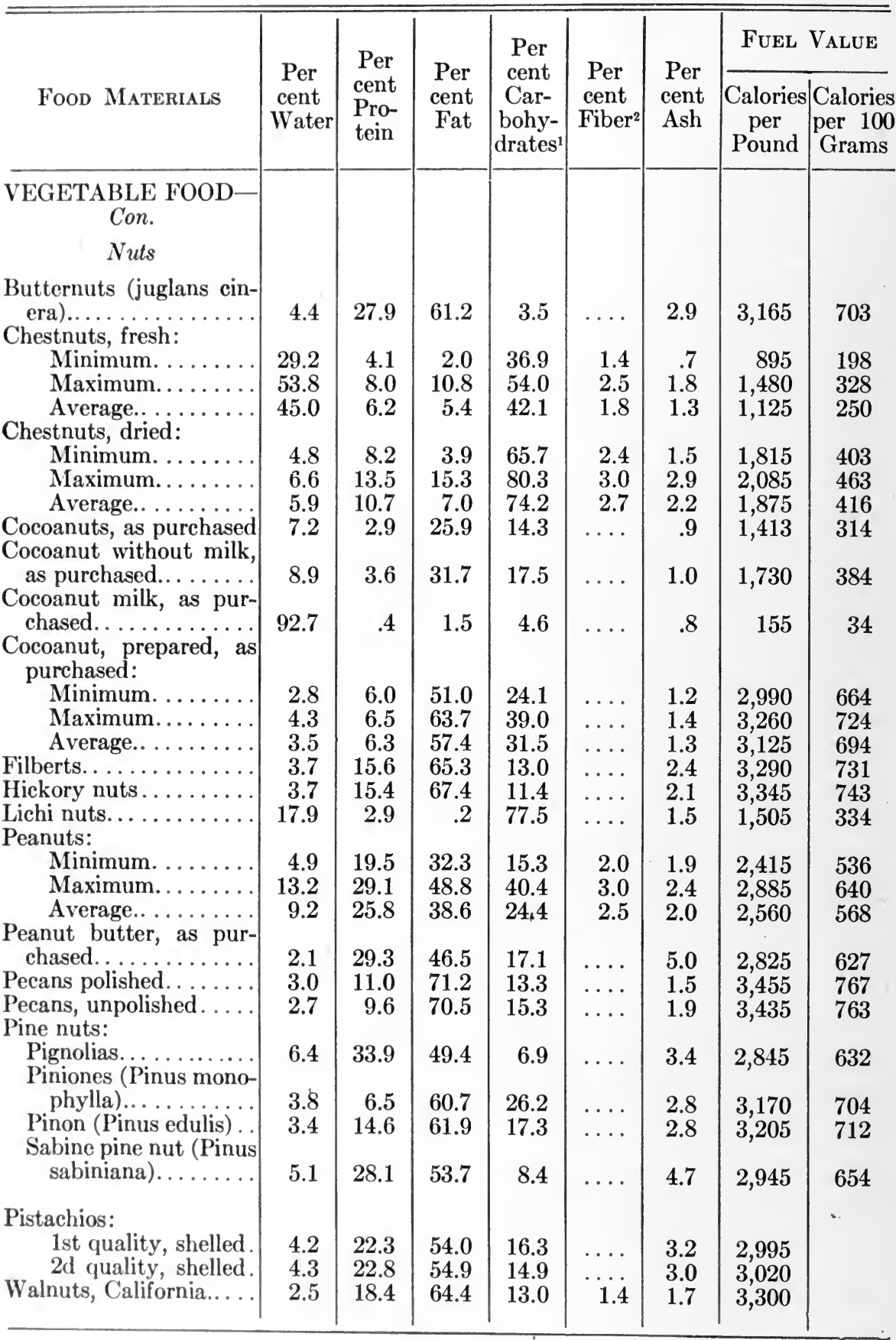

1 Fiber included.

2 Number of determinations in parentheses. 


\begin{tabular}{|c|c|c|c|c|c|c|c|c|}
\hline Food Materiatas & $\begin{array}{l}\text { Per } \\
\text { cent } \\
\text { Water }\end{array}$ & $\begin{array}{l}\text { Per } \\
\text { cent } \\
\text { Pro- } \\
\text { tein }\end{array}$ & $\begin{array}{l}\text { Per } \\
\text { rent } \\
\text { Fint }\end{array}$ & $\begin{array}{l}\text { Per } \\
\text { cent } \\
\text { Car- } \\
\text { bohy- } \\
\text { dratess }\end{array}$ & $\begin{array}{l}\text { Per } \\
\text { cent } \\
\text { Pitser }\end{array}$ & $\begin{array}{l}\text { Per } \\
\text { cont } \\
\text { Asts }\end{array}$ & 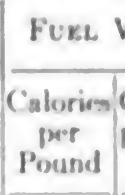 & $\begin{array}{l}\text { Value: } \\
\text { Caloriox } \\
\text { per 100 } \\
\text { Grams }\end{array}$ \\
\hline \multicolumn{9}{|l|}{$\begin{array}{l}\text { VEGETABIE FOOD - } \\
\text { Con. }\end{array}$} \\
\hline Nuts & & & & & & & & \\
\hline \multicolumn{9}{|l|}{$\begin{array}{l}\text { Walnuts, California, } \\
\text { black: }\end{array}$} \\
\hline Minimum. . . . . . . & 2.5 & 24.9 & 54.7 & 7.4 & 1.6 & 1.8 & 3,070 & \\
\hline Maximum........ & 2.5 & 30.3 & 57.8 & 16.1 & 1.8 & 2.0 & 3,140 & \\
\hline $\begin{array}{l}\text { Average............. } \\
\text { As purchased. }\end{array}$ & 2.5 & 27.6 & 56.3 & 11.7 & 1.7 & 1.9 & 2,105 & \\
\hline $\begin{array}{l}\text { As purchased. . . . } \\
\text { Walnuts, California, soft }\end{array}$ & .6 & 7.2 & 14.6 & 3.0 & $\ldots$ & .5 & 805 & \\
\hline \multicolumn{9}{|l|}{$\begin{array}{l}\text { Walnuts, California, soft } \\
\text { shell: }\end{array}$} \\
\hline 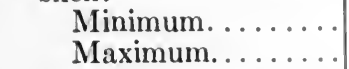 & 2.5 & 14.3 & 60.0 & 14.5 & 1.4 & 1.2 & 3,195 & \\
\hline 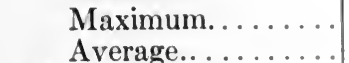 & 2.5 & 20.4 & 67.0 & 19.1 & 3.2 & 1.6 & 3.370 & \\
\hline $\begin{array}{l}\text { Average.. } ;, \text {....... } \\
\text { "Malted nuts," as pur- }\end{array}$ & 2.5 & 16.6 & 63.4 & 16.1 & 2.6 & 1.4 & 3,243 & \\
\hline chased........................ & 2.6 & 23.7 & 27.6 & 43.9 & $\ldots$ & 2.2 & 2,240 & \\
\hline \multicolumn{9}{|l|}{ Miscellaneous } \\
\hline Chocolate, as purchased: & & & & & & & 2720 & \\
\hline Average.......... & 5.9 & 12.9 & 48.7 & 30.3 & $\ldots$. & 2.2 & 2,560 & \\
\hline $\begin{array}{c}\text { Cocoa, as purchased: } \\
\text { Minimum....... }\end{array}$ & & & & 35.3 & & 5.4 & 2.235 & \\
\hline $\begin{array}{l}\text { Minımum...................... } \\
\text { Maximum. }\end{array}$ & $\begin{array}{l}3.2 \\
5.4\end{array}$ & $\begin{array}{l}20.6 \\
22.7\end{array}$ & $\begin{array}{l}27.1 \\
31.5\end{array}$ & $\begin{array}{l}35.3 \\
40.6\end{array}$ & $\cdots$ & 8.9 & $\begin{array}{l}2,235 \\
2,370\end{array}$ & \\
\hline Average............. & 4.6 . & 21.6 & 28.9 & 37.7 & $\cdots$ & 7.2 & 2,320 & \\
\hline $\begin{array}{c}\text { Cereal coffee infusion }(91 \\
\text { parts boiled in } 20\end{array}$ & & & & & & & & \\
\hline $\begin{array}{l}\text { parts boiled in } 20 \\
\text { parts water)........... }\end{array}$ & 98.2 & .2 & $\cdots$ & 1.4 & $\cdots$ & .2 & 30 & \\
\hline $\begin{array}{l}\text { Yeast, compressed, as } \\
\text { purchased........... }\end{array}$ & 65.1 & 11.7 & .4 & 21.0 & $\ldots$ & 1.8 & 625 & \\
\hline
\end{tabular}

1 Fiber included.

2 Number of determinations in parentheses. 


\begin{tabular}{|c|c|c|c|c|c|c|c|}
\hline \multirow[b]{2}{*}{ Food Materials } & \multirow[b]{2}{*}{$\begin{array}{l}\text { Per cent } \\
\text { Water }\end{array}$} & \multirow[b]{2}{*}{$\begin{array}{c}\text { Per cent } \\
\text { Protein }\end{array}$} & \multirow[b]{2}{*}{$\begin{array}{l}\text { Per cent } \\
\text { Fat }\end{array}$} & \multirow[b]{2}{*}{$\begin{array}{l}\text { Per cent } \\
\text { Carbo- } \\
\text { hydrates }\end{array}$} & \multirow[b]{2}{*}{$\begin{array}{l}\text { Per cent } \\
\text { Ash }\end{array}$} & \multicolumn{2}{|c|}{ Fuel Value } \\
\hline & & & & & & $\begin{array}{l}\text { Calories } \\
\text { per } \\
\text { Pound }\end{array}$ & $\begin{array}{l}\text { Calories } \\
\text { per } 100 \\
\text { Grams }\end{array}$ \\
\hline $\begin{array}{c}\text { ANIMAL AND } \\
\text { VEGETABLE } \\
\text { (Unclassified Food } \\
\text { Materials) }\end{array}$ & & & & & & & \\
\hline $\begin{array}{l}\text { Soups, homemade } \\
\text { eef soup, as purchased: }\end{array}$ & & & & & & & \\
\hline 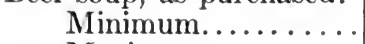 & 92.3 & 2.7 & .3 & & 1.1 & 110 & 24 \\
\hline Maximum........ & 93.5 & 6.2 & .5 & 2.2 & 1.2 & 130 & 28 \\
\hline Average. .......... & 92.9 & 4.4 & .4 & 1.1 & 1.2 & 120 & 26 \\
\hline Bean soup, as purchased. & 84.3 & 3.2 & 1.4 & 9.4 & 1.7 & 295 & 65 \\
\hline $\begin{array}{l}\text { Chicken soup, as pur- } \\
\text { chased................ } \\
\text { Clam chowder, as pur- } \\
\text { chased: }\end{array}$ & 84.3 & 10.5 & .8 & 2.4 & 2.0 & 275 & 61 \\
\hline Minimum.......... & 81.6 & .7 & .5 & 2.5 & 6 & 80 & 17 \\
\hline Maximum......... & 95.7 & 2.9 & 1.1 & 11.0 & 3.4 & 305 & 67 \\
\hline $\begin{array}{l}\text { Average. . ........... } \\
\text { Meat stew, as purchased: }\end{array}$ & 88.7 & 1.8 & .8 & 6.7 & 2.0 & 195 & 43 \\
\hline 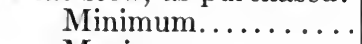 & 82.6 & 3.7 & 2.0 & 4.3 & 1.0 & 255 & 56 \\
\hline Maximum........ & 87.6 & 5.6 & 6.4 & 7.9 & 1.3 & 445 & 98 \\
\hline $\begin{array}{c}\text { Average. .............. } \\
\text { Soups, canned }\end{array}$ & 84.5 & 4.6 & 4.3 & 7.5 & 1.1 & 370 & 82 \\
\hline $\begin{array}{l}\text { Asparagus, cream of, as } \\
\text { purchased............. } \\
\text { 3ouillon, as purchased: }\end{array}$ & 87.4 & 2.5 & 3.2 & 5.5 & 1.4 & 285 & 63 \\
\hline Minimum........... & 96.5 & 1.7 & & .1 & .4 & 40 & 8 \\
\hline Maximum.......... & 96.7 & 2.6 & .2 & .3 & 1.4 & 50 & 10 \\
\hline $\begin{array}{l}\text { Average. ........... } \\
\text { Celery, eream of, as pur- }\end{array}$ & 96.6 & 2.2 & .1 & .2 & .9 & 50 & 10 \\
\hline $\begin{array}{l}\text { chased................. } \\
\text { Chicken gumbo, as pur- } \\
\text { chased: }\end{array}$ & 88.6 & 2.1 & 2.8 & 5.0 & 1.5 & 250 & 55 \\
\hline - Minimum.......... & 86.8 & 3.0 & .2 & 3.8 & 1.3 & 135 & 30 \\
\hline Maximum......... & 91.7 & 4.6 & 1.7 & 5.5 & 1.4 & 260 & 57 \\
\hline $\begin{array}{l}\text { Average.......... } \\
\text { Chicken soup, as pur- } \\
\text { chased: }\end{array}$ & 89.2 & 3.8 & .9 & 4.7 & 1.4 & 195 & 43 \\
\hline Minimum ......... & 93.2 & 3.2 & & 1.2 & .9 & 90 & 20 \\
\hline Maximum........ & 94.5 & 3.9 & .2 & 1.7 & 1.2 & 105 & 23 \\
\hline Average.............. & 93.8 & 3.6 & .1 & 1.5 & 1.0 & 100 & 22 \\
\hline $\begin{array}{l}\text { Consommé, as purchased. } \\
\text { Cream, corn of, as pur- }\end{array}$ & 96.0 & 2.5 & $\ldots$ & .4 & 1.1 & 55 & 12 \\
\hline 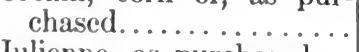 & 86.8 & 2.5 & 1.9 & 7.8 & 1.0 & 270 & 60 \\
\hline $\begin{array}{l}\text { Julienne, as purchased... } \\
\text { Mock turtle, as pur- } \\
\text { chased: }\end{array}$ & 95.9 & 2.7 & $\ldots$ & .5 & .9 & 60 & 13 \\
\hline Minimum.......... & 88.9 & 4.5 & .5 & 1.6 & 1.2 & 160 & 35 \\
\hline Maximum......... & 90.8 & 5.9 & 1.3 & 3.9 & 1.4 & 210 & 46 \\
\hline Average........... & 89.8 & 5.2 & .9 & 2.8 & 1.3 & 185 & 41 \\
\hline
\end{tabular}


Oxtail:

ANIMAL ANI)

VEGETABLE- -

(Unclassified Food Materials)

Soups, canned

Mulligatawny, as purchased:

Minimum..........

Maximum..........

Average. ..........

Minimum

Maximum .............

Average.

Pea soup, as purchased

Minimun........... .

Maximum..........

Average. ..........

Pea, cream of green, as purchased...........

Tomato soup, as purchased:

Minimum..........

Maximum..........

Average.............

Turtle, green, as purchased...............

Vegetable, as purchased. Miscellaneous

Hash, as purchased

"Infants' and invalids" foods," as purchased. Minimum.......... Maximum.......... Average. ...........

Mincemeat, commercial, as purchased:

Minimum

Maximum .............

Average.........

Mincemeat, homemade, as purchased:

Minimum..........

Maximum..........

Average...........

Salad, ham, as purchased.

Sandwich, eggs, as purchased................

Sandwich, chicken, as purchased...............

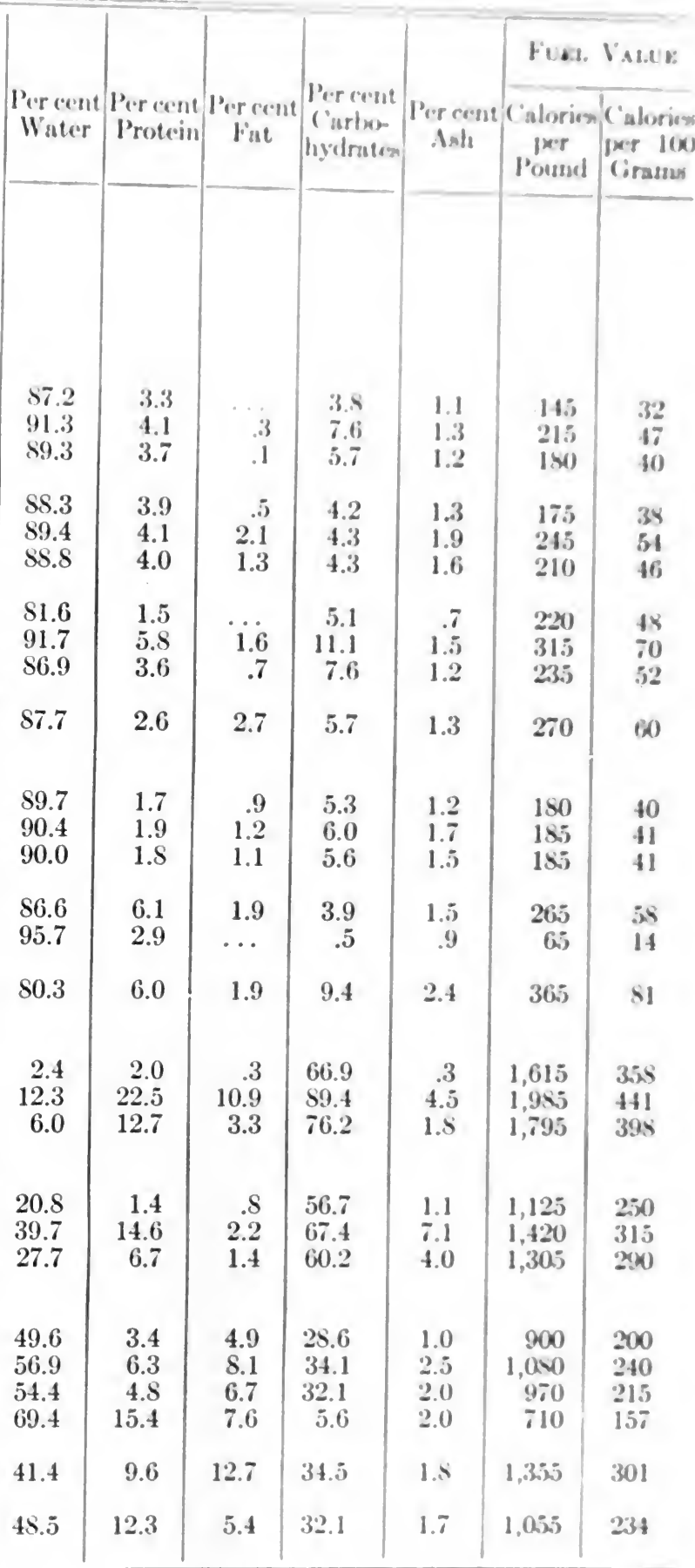




\section{REFERENCES}

1. Aтwatro and Bryat. Composition of American Food Materials,

U. S. Dept. of Agric., Ottice of Exper. Sta., Bull. No. 28.

2. Aтwatra and Bmant. U. S. Dept. of Agric., Bull. No. 28.

3. Pensox, Gronge. Report on Arts and Manufactures, 3, 1795, pp. $383-400$.

4. E⿺xноғғ. Gehlen's Nenes J. Chem., 4, 1805, pp. 315, 455; 5, 1806, p. 131.

5. Aтwatro, W. O. (On the proximate composition of several varieties of American maize.) Am. J. Sc. \& Arts, 47, 1869, No. 11, p. 352.

6. Aтwatkin and Bryant. U. S. Dept. of Agric., Office of Exper. Sta., Bull. 25.

\section{BIBLIOGRAPHY}

Atwater and Bryant. The Composition of American Food Materials,

U. S. Dept. of Agric., Office of Exper. Sta., Bull. 28 (Revised). Bugie and Kierio. The Bacterial Content of the Flesh of Normal Beeves, Ztschr. f. Fleisch u. Milchhyg., 1912, vol. xxii, pp. 69-80. Bixtos. Some Postmortem Alterations of Meat, J. Roy. Inst. Pub. Health, 1911, vol. xix, pp. 60-469.

(

U. S. Dept. of Agric., Bur. of Chem., 1910, Circular 62.

Fimatt and Grindeley. A Preliminary Study of the Effect of Cold Storage upon Beef and Poultry, J. Industr. \& Eng. Chem., 1909, vol. i, pp. 413-436, 580-597.

Farmingos. The Need of State and Municipal Meat Inspection to Supplement Federal Inspection, U. S. Dept. of Agric., Bur. of Animal Industry, 1908, Circular 154.

Grasuler. Studies of the Effect of Different Methods of Cooking upon the Thoroughness and Ease of Digestion of Meat, U. S. Dept. of Agric., Office of Exper. Sta., 1907, Bull. 193.

Har... Market Classes and Grades of Meat, Illinois Agric. Exper. Sta., 1911, Bull. 147 .

and Emm Eтt. Relative Economy, Composition and Nutritive Value of the Various Cuts of Beef, Illinois Agric. Exper. Sta., 
Hoagland. The Action of Saltpeter upon the Color of Meat, U. S.

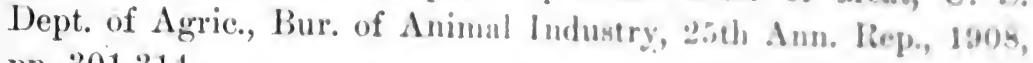
pp. $301-314$.

Holmes. Meat Supply and Surplus, U. S. Jept. of Agrice, Bur. of Statistics, 1907, Bull. $5 i$.

Langworthy and Hunt. Mutton and Its Value in the Diet, U. S. Dept. of Agric., Farmers' Biull., 1913, p. 526.

Leiguton and Dovglas. The Mest Industry and Meat Inspection.

Melvix. The Federal Meat Inspertion Service, U. S. Depto of Agric., Bur. of Animal Industry, 1!nu, (ircular 125.

Moulton. Changes in Composition of Mature Beef Animals during Fattening, Proc. Sth Internat. ('ongr. of Applied Chem., 1913, vol. xxvi, pp. 157-168.

Richardon and Shemubel. The leterioration and Commercinl Preservation of Flesh Foods, J. Amer. (hem. Soc, 1908, vol. xxx, pp. $1515-1564$.

Deterioration and Commercial Preservation of Flesh Foods, II; The Storage of Beef at Temperatures Above the Freezing Point, J. Industr. \& Engin. Chem., 1909, vol. i, pp. 95-102.

Roberts. Annual Production of Animals for Food and Per Capita Consumption of Meat in the United States, U. S. Dept. of Agric, Bur. of Animal Industry, 22d Ann. Rep., 1905, pp. 27\%-290.

Trowbridge and Grindeey. Proteins of Beef Flesh, J. Am. Chem. Soc., 1906, vol. xxviii, pp. 469-505.

Wilder. The Modern Packing House.

Wiley and Bigenow. Preserved Meats, U. S. Dept. of Agric., Bur. of Chem., Bull. 13, part 10.

Wright. Chemical and Bacteriological Study of Fresh and Frozen New Zealand Lamb and Mutton, J. Soc. of Chem. Industry, 1912, vol. xxxi, pp. 965-967. 



\title{
CHAP'TER XX
}

\section{UNUSUAL ANIMAL, BIRDS, RFP'TIIE, FTC, SOMFTIMFS USFil) fOR FoOI)}

\begin{abstract}
Mammals: Armadillo; Ass; Bear; Benver; Buthulo: Cat: Camel: Dong: Elephant; Horse; Mule; Hippopotamus; Harth Hong: \%ebra: Kanga roo; Lion; Lynx; Hama; Monkey; Mice: Oprossum; Muak Ox: Porcupine; Reindeer: Rhinoceros; Rats: siquirrel; Whale: Walrus. Insects: Ants: Caterpillars; Grasshoppers: Locusts: Motho.

Fowl: Ostrich; Peafowl; Pelican: Parrots: Cuckoo: Penguin; Swana Fish: Eels; Sharks; Shell Fish-Sinails.

Reptiles: Crocodiles; Frogs; Snakes; Tonds; Turtles; Tortoimen Vine yard Snails.
\end{abstract}

The information here presented has been collected principally from the writings of 1)r. Pavy (6t) and from various sources and works on travel. This compilation, alphabetically arranged, shows that almost an endless variety of animals have been used as food in various parts of the world, and supplies in concise form what is known regarding their edible qualities. In many instances, even today, their consumption occurs upon such an extensive scale as to justify their mention from an alimentary point of view. In many others, however, their mention is recorded as a curiosity in dietetics. The statements here recorded are authenticated by reference to original sources found in the reference bibliography at the end of the chapter.

Agoutis.-The agoutis, found in the West Indies, Guiana and Brazil, at the first settling in the West India Islands, were exceedingly numerous and constituted a great part of the food of the Indians. The tlesh is white and tender, and, when well cooked, is nuch esteened by the natives.

Albatross.-The albatross is eaten by the atwrigines of New Yealand(9). Its eggs are considered excellent ( 4$)$.

Armadillo.-The armadillo is eaten in South . Imerica, and its flesh is fat and excellent(5). The hunters rosst it in its shell( 4$)$. 
Amblyrhynchus.-Amblyrhynchus, a genus of lizard resembling the iguana found in the Galapagos Islands, is esteemed by the natives as a delicate kind of food(4).

Axolotl.-The axolotl of Mexico is esteemed an agreeable article of food, dressed like stewed eels(4).

Ants.-White ants are eaten by the natives of Australia(12) and by those on the banks of the Zonga, where they are highly appreciated(34). The larvie of ants are eaten by the Bushmen(8). Scopoli speaks of the larrae of the musca putris as a dainty (48). Aelian mentions the circumstance of an Indian king treating some of his Grecian guests(2) to the larrae of insects(48). The larvæ of the Cerambyx heros is believed to be the cossus of the ancients, by whom it was considered a dainty.(4).

Bear.-The bear supplies food to several nations of Europe, and its hams are considered excellent(5). The flesh of the brown or black bear, which is eaten by the common people of Norway, Russia and Poland, is difficult to digest and is generally salted and dried before it is used(60). Two bears were eaten in Paris during the siege(10), and the flesh was supposed to taste like pig $(14)$. The Indian tribes of the interior of Oregon eat bears(15). The Polar bear is stated by Sir John Ross to be particularly unwholesome, although the Esquimaux feed upon it without any apparent inconvenience(5).

Bandicoot. - The bandicoot is eaten by the aborigines of Australia(16) and by the lowest caste of Hindoos(4).

Beaver.-The flesh of the beaver is much prized by the Indians and Canadian traders, especially when it is roasted in the skin after the hair has been singed off(4). It is also used in South America, and is said to be an excellent food $(60)$.

Bison.-The flesh of the bison, or European aurochs, was once the support of many Indian tribes; it nearly resembles ox beef, but is said to be of finer flavor and easier to digest. The hump is baked and eaten as a great delicacy $(5)$.

Buffalo.- In the remote past the flesh of the buffalo, or bison of North America, was eaten by the North American Indians(24), the Sumatrans(25), and the islanders of Savu(9). Catlin calculates that about 250,000 North American Indians subsisted almost exclusively on this animal throughout every part of the year(26). The beef is tough, dark colored and occasionally of a musky flavor. The chine is considered good and is eaten to some extent(5).

Bustard.-The bustard is a good food and much esteemed in some places(4). 
Birds' Nests.-Birds' nests of a spercial kind are an article of ford much prized in China on account of the nutritive properties which they are supposed to possess. They are of a gelatinous nature and chiefly uned for making soup. 'They are furnishond he scveral specien of swallow and are found in the eaverns on the seashore of the fiastern Archipelagon. It has been ascertained that they consist in great part of a peculiar muens which this bird secretes and disgurges from its month in great abun. dance. The nests adhere to the rock and are collected after the young are fledged, with the help of ladders or ropes. Tho cleansing of the nowts for the markets is a long and tediuns process and a number of permon are employed at Canton in conducting the operation(37). The prepared article, which has the appearance of dried gelatinous-looking fragments, may be purchased in some of the Landon shops.

Blaps. - The blaps sulcata is eaten, cooked with butter, by the E.gyptian women(4). They also eat the Siarabeus sacer to make themselves become prolific(48). The women of Arabia and 'Turkey eat a species of tenebrio fried in butter to make themselves plump(38).

Bees.-Bees are eaten by various peoples(48). The Monrs in west Barbary consider the honeycomb, with young bees in it, delicious. One writer, however, thought it insipid and that it sometimes produced heart$\operatorname{burn}(39)$.

Cats.-Cats are eaten by the Chinese $(9)$, and in the island of Savu are preferred to sheep and goats(9). Fivo thousand cats are said to have been eaten in Paris during the siege(10). According to the same authority, the cat is good food. A roung one, well cooked, is better than hare or rabbit. It tastes something like the American gray squirrel, but is even tenderer and sweeter $(10)$.

Cavia.-Several species of cavia, especially the guinea pig, the spotted cavy, the long-nosed cavy and the rock cavy, were once used as food in Great Britain, Brazil and other parts of South America(60).

Camel.-Camel is eaten with relish in Africa, and its milk is believed to neutralize the injurious qualities of the date(6). The flesh is alleged to produce serious derangement of the stomach among the Arabs(27). A camel eaten during the siege of Paris is said to have tasted like veal(14). Camel's hump, which is spoken of as furnishing the desert with a savory dish, may be procured in a preserved state at some of the dried provision establishments at the west end of Iondon.

Collard Pecari.-The collard pecari, or tajacu (Dientyles torquatus). an inhabitant of South America, is considered a gand fond, and its flesh greatly resembles pork. Dicotyles labiatus is also hunted by the natives 
of South America for food(4). The aborigines of the Amazon, however, who eat Dicotyles torquatus will not touch Dicotyles labiatus(2).

Cuckoo. - The enckoo is not an uncommon dish on the Continent, and the Arabs consider it a great delicacy $(5)$.

Crane.-The crane was eaten by the Romans. It is mentioned in England as being served as a sumptuous dish at splendid entertainments as early as the Norman Conquest and as late as the reign of Henry VIII. At the Enthronization Feast of George Nevil, Archbishop of York, as Edward IV, there were served 204 cranes, 204 bitterns and 400 heronshaws (4).

Cormorant.-The Manx, like the Scotch, make a rich soup out of this $\operatorname{bird}(42)$.

Crocodile.-The crocodile is eaten and relished by the natives of parts of Africa(5) and Australia(3). Dr. Livingstone writes: "To us the idea of tasting the musky-scented, fishy-looking flesh carried the idea of cannibalism" (34). The eggs are dug out of the ground and devoured by the natives. Dr. Livingstone says of them: "In taste they resemble hens' eggs, with perhaps a smack of custard, and would be as highly relished by whites as by blacks were it not for their unsavory origin in men-eaters" (34).

Cannibalism.-There is reason to believe that the practice of eating human fiesh has not at all times been confined to the lowest savages, but it is difficult to obtain much satisfactory information respecting it.

There is little doubt that our ancestors, the ancient inhabitants of Britain, were guilty of eating human flesh. St. Jerome specially charges the Attacotti, a people of ancient Scotland, with preferring the shepherd to his flock (51).

Axthlopophagy Cannibalism in the New World.-During the winter of 1609 and 1610 famine with its horrors came to the Jamestown Colony in Virginia, and transformed the eivilized Englishmen into cannibals. According to Lossing (63) they subsisted on Indians, whom they slew and ate. Sometimes they even ate their own companions who had perished from hunger.

In the present day the Polynesian Islands are the chief home of such cannibalism as still exists in the world. The Tannese say to anyone condemning their anthropophagous habits, "Pig's flesh is very good for you, but this is the thing for us." They distribute human flesh in little bits far and near among their friends as delicate morsels. Cannibal connoisseurs, it is asserted, prefer a black man to a white one, as the latter tastes salty. (35). 


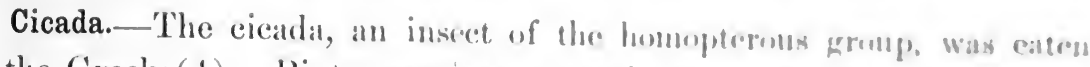
by the Greeks(4). P'into mentions a peopice whon uned fliom an an articlo of food (48).

Caterpillars. - These insects were eaten by the amoinut lamans, and

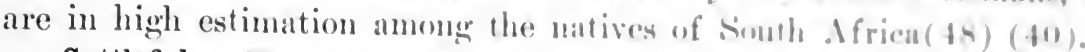

Cuttlefish.-The cuttlefish is used as a find in some parth of Europe(4). A bivalve allied to the oyster, called Anomia rphippiom, which is found on the eoasts of the Mediterranesn is considerod not inferior to the common oyster( $: 37)$.

Dogs.-Dogs are eaten by the Chinese $(1,4,9)$, the Vew \%onland. ers(11), the South Sea Islanders(9), some African tribes(9) and by certain hill tribes in the Philippines. One thousand and two hundred dogs, it is stated, were eaten in Paris during the siege(10) and tho flesh brought from two to three franes per pound(:38). Wild dogs are eaten by the natives of Australia(12). In New Kealand(11) and the South Sea Islands(9) the dogs are specially fed and futtence, and Finopean dogs are considered unpalatable(11). Captain ('ook lookerl upon a South Sea $\operatorname{dog}$ as little inferior to an English lamb(9). Fantened dogs' flesh is a favorite food of the Warori, an $\Delta$ frican tribe(1:3).

Dugong.-The Indian dugong is considered grood ford $(t)$.

Elk.-The elk is eaten in Norway, Lapland and Sweden, where its flesh is much estecmed(60). The young are said to be particularly delicious(4). The tongue and nose are considered great delicacies(4).

Elephant.-The elephant is eaten in Abysinia and other parts of Africa, also in Sumatra(5). Some steaks that were cut off Chunee, the elephant that was shot at Exeter Exchange, on being cooked were declared to be "pleasant meat"(5). The three elephants that were enten in Paris during the siege were pronounced a great success. The liver was considered finer than that of any goose or duck(14). Dr. I.ivingstone writes: "We had the foot cooked for breakfast the next morning. and found it delicious. It is a whitish mass, slighty gehutinous and sweet. like marrow. A long march, to prevent hilionsuess, is a wise precantion after a meal of elephant's foot. Elephant's trunk and tongue are also good, and after a long simmering much resemble the hump of a butsalo and the tongue of an ox; but all the other meat is tough, and from its peculiar flavor only to be eaten by a hungry man" (::4).

Earth Eating.-Earth eating may be appropriately referred to here. as some earth used as fond in certain localities has heen found on monsist, in part, of the remains of minute animal organisms. Humlmolds. on his return from the Rio Negro, saw a tribe of Ottomacs who lived 
principally during the rainy season upon a fat unctuous clay which they found in their district(54). This appears to have consisted of a red, earthy matter (hydrous silicate of alumina), called "bole." It is also eaten by the Japanese after being made into thin cakes, called "tanampo," which are often offered for sale. These cakes are bought and eaten by the women to give them slenderness of form(4). Ehrenberg found that this earth consisted for the most part of the remains of microscopic animals and plants which had been deposited from fresh water. A kind of earth known as bread meal, which consists for the most part of the empty shells of minute infusorial animalcules, is still largely eaten by the lower classes in Northern Europe; and a similar substance, called mountain meal, has been used in Northern Germany in times of famine as a means of staying hunger. The Wanyamwezi, a tribe living in Central Africa, eat clay in the intervals between meals. They prefer the clay of ant-hills.

The colored inhabitants of Sierra Leone also devour the red earth of which the ant-hills are composed(55). Johnston asserts that the African earth did not injure the negroes, but that when they were carried as slaves to the West India Islands they were found to suffer in their health from the clay they there used as a substitute(56). It has been found that much of the clay eaten by many of the inhabitants of the torrid zone is mere dirt and has no alimentary value. The Agmara Indians eat a whitish clay, which is rather gritty, and has been shown by careful analysis to be destitute of any organic matter which might afford nutriment(14). One of the earliest notices of the practice of dirteating is given by Sir Samuel Argoll, with respect to Virginia, in 1613. "In this journie," he says, "I likewise found a myne, of which I have sent a triall into England; and likewise a strange kind of earth the virtue whereof I know not, but the Indians eate it for Physicke, alleging that it cureth the sicknesse and paine of the belly"(57). In Guinea the negroes eat a yellowish earth called cavuac. In the West Indies a white clay like tobacco pipe clay is eaten, and this the eaters prefer to spirits or tobacco(58). In 1751 a species of red earth or yellow tufa is reported to have been still secretly sold in the markets of Martinique(56).

Earth Hog. - The earth hog (Orycteropus Capensis) is a native of the Cape of Good Hope. Although its food (ants) gives its flesh a strong taste of formic acid, it is relished both by the Hottentots and Europeans. The hind quarter is especially esteemed when cured as ham(4).

Frogs.-Frogs are eaten by the Chinese(9), the natives of Australia(12) and many other countries. The Rana esculenta is highly 
prized in France for its hind legs, which are the part eaten. These may be seen sometimes skewered together in the windows of some of the pror vision establishments of Paris. Itloupts have been made at differens times to acclimatize the liuna cosulcuta in liuglund. This met with some sucess in Cambridgeshire, whore it is said their very remarkable and sonorous croak has procured for then the title of the "Cambridgenhire nightingales"(61). The Rana tauriua, or bull-frog, is a native of North America and is highly prized and thought by the Ancricans to rival turtle(39). This large edible fron has long since been introduced into France by the Société d'Acelimatication(33). A large froge, called "Mat. lametlo," which when cooked looks and tastes like chicken, is eaten by the South Americuns(40).

Grasshoppers.-Grasshoppers are eaten by the Bushuen(3).

Gull.-The flesh of the gull 'sten before it cun fly is excellent. Later it becomes fishy. It is often hrought to market in Roman Catholic countries during Lent(4). The "ungs of the Xema ridibunda are well flavored and the young birds were at one time in high repute in Fingland at the tables of the wealthy $(4)$.

Grubs.-Grubs of all kinds are eaten by the natives of Australia(12, 16), and the chrysalis of the silkworm is eaten by the Chinese (45).

Hedgehog.-The hedgehog is cunsidered a princely dish in Barbary, and is eaten in Spain and Germany (5, 60). It is frequently eaten by the sick among the $\Delta$ frican $A$ rabs, in the belief that its flesh is medicinal ( $i$ ).

Hippophagy.-Horse flesh is eaten largely by various nations. The Indian horsemen of the Pampas live entirely on the flesh of their mares and eat neither bread, fruit nor vegetables(31). Horse tlesh is eaten by the Jakuts of Northern Siberia(28), the Tartars and natives of South America(5) and by the Islanders of Savu(9). Mr. Bicknell, in his paper on "The Horse as Food for Man"(39), mentions fifteen European states, besides France, where horse flesh is eaten. The Icelanders have practiced hippophagy since the eighth century. The Russians have always eaten horses, and in Denmark the people returned to the custom of their forefathers in 1507. Wurtemburg was the first of the German states to adopt the practice and commenced it in 1541 . Bavaria, Baden, Hanover, Bohemia, Saxony, Austria and Prussia followed in subsequent years. A Perlin newspaper in 1863 reports that there are at the present time "seven markets for horse flesh in that city. in which, during the first ten months of 1862 , there were seven hundred and fifty horses slaughtered. No horse is allowed to be slaughtered and sold without the certificate of a veterinary surgeon"(32). The Health 
1)epartment of New York ('ity has recently (1916) allowed the sale of horse tlesh in the eity markets.

Acerding to Pliny, the Romans at one time ate the ass. The wild ass is still in much esteem among the Persians, who consider it as equal to venison(5). One thousand donkeys and two thousand mules are reported to have been eaten in Paris during the siege(10). The flesh of the latter is delicious and far superior to beef. Roast mule is, in fact, an expuisite dish( 32$)$. Ass's flesh forms the basis of the renowned sansages of Bologna(37). At a banquet given by an Academician in Paris, having MM. Velpean, Tardien, Latour and other notabilities as gnests, the "bifticks" and "filets" prepared from the flesh of an old sheass were unanimously pronounced, it is stated, to be more tender, succulent and delicate than similar plates prepared for comparison, from the horse(32).

Hippopotamus.-The flesh of the hippopotamus supplies a substantial meal to the African, and when young is delicate, but when old is coarse, fat and strong and inferior to beef(5). The young meat is much esteemed by the Hottentots and natives of Abyssinia(4). Dr. Livingstone writes: "The hippopotamus hunters form a separate people, called Akombwi or Mapodzo, and rarely - the women, it is said, never-intermarry with any. other tribe. The reason for their keeping aloof from certain of the natives on the Zambesi is obviously enough, some having as great an abhorrence of hippopotamus meat as Mohammedans have of swine's flesh"(34). The hippopotamus that was killed and partly burnt in the fire at Crystal Palace, London, a few years back, was eaten by Dr. Cripp and some of his friends, who reported that the flavor of the flesh was excellent and its color whiter than any veal(14).

Holothuriæ.-Holothurix (sea cucumbers) are eaten largely by the Chinese(1), the natives of the Indian Archipelago(4), the Australians (4) and South Sea Islanders(47). They are also taken on the coast of Naples and eaten by the poorer inhabitants(4).

Iguana.-The iquana inhabits South America and the West Indies, where it is esteemed a delicate food(4), although it has been generally considered unwholesome(39). Its eggs are nutritious and agreeable(60).

Jerboa.-The common jerboa (Dipus Egyptius) is eaten by the Arabs, who esteem its flesh among their greatest dainties(60). The Alagtaga (J)ipus Jaculus) is larger than the eommon jerboa, and called by the Aralis the lamb of the Israelites. Many authors consider it to be the conery of the seriptures, a kind of rabbit, and the monse of Isaiah(4). 


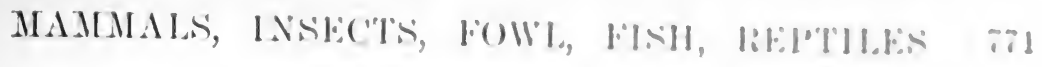

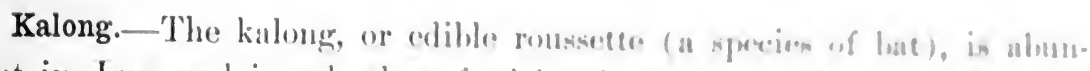

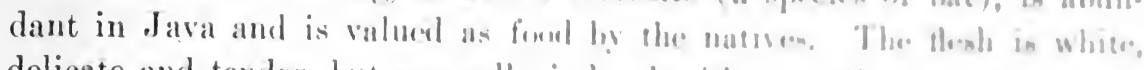
delicate and tender, but generally imbined with a moll of munk (i).

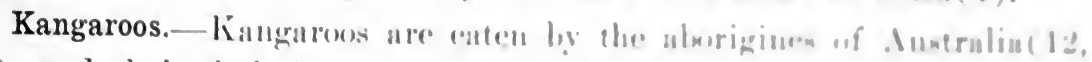

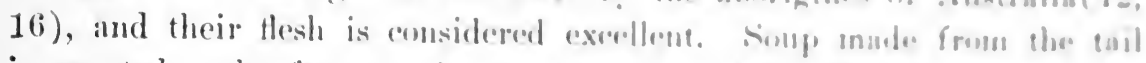
is reputed to be fin superior to ox-tail somplt). Is is imported into England with the Australian ment in sealed tins. Thres kangarone wro eaten in Paris during the siege (10). The woubat in anten by the natives of Australia(12) and its flesh is said to le proferuble to that of all other animals of Australia(4). Wallabies are also eaten by tho nations of Australia(5).

Lion.-The lion is eaten sometimes in Africa, lut its them in not $\operatorname{grood}(6)$.

Lizards.-Lizands alre eaten by the ('hinese(!), the Bushmen(:3) and the natives of Australia(12).

Llama.-The flesh of the llama is said to resemble mutton(60).

Locusts.-Locusts are eaten in grent quantities, both fresh and salted(39). They have a strongly vegetable taste, the flasur varying with the plants on which they feed. Dr. livingstone considered them palatable when roasted $(40)$. They are eaten by the Persians, Lgyptians and Arabians(48), the Bushmen(3) and North American Indians(4:3), and by many others. Diodorus Siculus and Ludolphus hoth refer to a race of people in Ethiopia supporting themselves upon locusts(45). Ludolphus remarks: "For it is a very wholesome and sweet sort of diet. by means of which a certain Portugnese garrison in India, that was ready to vield for want of provision, held out till it was relieved another way." Madden states in his "Travels": "The Arabs make a sort of hreal of locusts. They dry them and grind them into powder. then mix this powder with water, forming them into round cakes, which serve for bread."

Lynx.-The Canadian lynx is eaten by the Indians, and its flesh is said to be white, tender and to resemble that of the Ameriean haro( $f$ ).

Manatee.-The manatee, sea-cow, or woman-fish, a native of the seas of the West Indies and South America, is said (o) be an excellent fomd $\$$ ). Dr. Vogel found the flesh very well flavored and the fat like pork (1t). Paren states that the flesh is whitish and grend to eat, and that the animal's milk has an agreeable flavor $(2 \tau)$.

Marmot.-The marmot of the Alps affords nourishment to the priser inhabitants of Trrol, Sarny and other parts. Three other spmeies are 
also eaten, namely, the Maryland Marmot, Bobath, and the Cassin or Earless Marmot(60).

Mice and Rats.-Mice and rats are eaten in Asia, Africa(5), Australia(12) and New Zealand(11), and considered delicate morsels. The taste of rats is pronounced to be somewhat like that of birds(10). The Chinese eat them(1), and to the Esquimaux epicures the mouse is a real bonne bouche(3). Rats and mice were eaten in Paris during the siege $(10)$.

Monkeys.-Monkeys are eaten by the Chinese(1), the natives of Ceylon(3), the Indians, the negroes and whites in Trinidad(3), the Dyaks of Borneo(3), the Africans of the Gold Coast(3), the aborigines of the Amazon(2) and the Indians of British Guiana(4). The flesh is said to be palatable(5). Algot Lang, an explorer in the upper Amazon, told the author in 1915 that he had often eaten grilled monkey with relish.

Moths.-Moths of several varieties are eaten by the natives of Australia(12); one species, called Bugong, is said to be more prized by the Australian than any other sort of food. The bodies of these insects, it is stated, are large and contain a quantity of oil; they are sought after as a luscious and fattening food $(12,48)$.

Musk-ox.-Captain Ross considered the flesh of the musk-ox excellent and free from any particular musky flavor, though the skin has a strong smell(5). The tongue and nose are considered great delicacies (4).

Opossum.-The opossum is eaten in America (5), Australia(16, 12, $5)$ and the West Indian Islands. Young ones are roasted for the table, and the flesh is white and of good flavor(5). They are considered by the natives of South America equally as good for food as the flesh of the hare or rabbit, especially the Virginian opossum(60). The Southern negroes prize it very highly as a food.

0strich.-The ostrich affords an abundant banquet to many savage nations of Africa, where it is sometimes kept in a tame state for breeding(5). Dr. Livingstone writes that the flesh is white and coarse. When in good condition it resembles in some degree that of a turkey(40), but the flesh is only good when young, for when it is full grown the bird is very fat(4). Three ostriches were eaten in Paris during the siege(10).

Parrots and Cockatoos.-Parrots and cockatoos are eaten by the natives of Australia(12). The flesh of parrots, when young, is delicate and is largely eaten in Brazil(5). Toucans are eaten by the aborigines of the Amazon(2) and in Brazil(4).

Pea-fowl.-The pea-fowl is occasionally eaten, and its flesh is reputed to be good, but the beauty of the peacock's plumage renders it too valu- 
able a bird to form an ordinary article of food. In olden times the pess. cock occupied its place at the table as one of the dishess in the merosd course at every great feast. At the present time n few of the old colonial homes in the South grow the pea-fowl for the table. 'Ihe author han often eaten roasted pea-fowl, which equals roast turkey in delicacy.

Pelican.-The pelican is eaten by the nativen of Auntrulia (12).

Penguins.-Penguins are eaten by the aborigines of New Yraland(9).

Porcupine.-The poreupine is considered delicious food in south America and India and resembles the sucking pig(5). The Intch and Hottentots are fond of it (3) and it is frequently brought of the table at the Cape of Good Hope(60). It is eaten in Sicily and Malta(60) and sold in the markets of Rome(5).

Reindeer.-The reindeer is eaten in Siberia(28) and is the favorite food of the Esquimaux(19). It is the principal nourishment of the Iaplanders. The tongues are excellent when salted and the milk is sweret and nourishing $(60)$. The sinewy parts of stags are highly prized by the wealthy Chinese (29).

Rhinoceros.-Rhinoceros is eaten in Abyssinia and by some of the Dutch settlers in the Cape Colony. It is in high esteem(3).

Seal.-The seal is all in all to the Greenlander and Esquimanx $(4)$. It is eaten by the Kamschadales (4), the inhabitants of the const of Iabra. dor(17), Vancouver Island(18), etc. Its flesh is coarse and oily: nevertheless, it was formerly served up at feasts in England, together with the porpoise(5). The liver, when fried, is esteemed by sailors as an agreeable dish(4). A seal eaten during the siege of Paris was said to taste like lamb(14).

Sharks.-Sharks are eaten by the Gold Coast negroes(3) and the natives of New Zealand(11), but not by the natives of western Aus. tralia(3). The natives of the Polynesian Islands feast on them in a raw state and gorge themselves so as to cause vomiting(3). 1)r. Hector writes as follows of edible sharks: "Tlie Manris are large consumers of sharks, or mango, as they term them, of various species, but chictly the smooth-hound (Mustellus antareticus), dogtish of two species (Scyllium laticeps and Acanthias vulgaris) and the Tope.

"Galeus canis, a species of seal, may be seen at certain seasons at any Maori settlement by the seaside, hanging on poles in thousands. and rendering the neighborhood extremely unpleasant. The species mosi valued is, however, the smooth-hound. It is the only shark which is properly edible, as it lives on shellfish and crabs and has the same cloun feeding habits as the skate. In the Hebrides and north of smotand 
the flesh of this harmless little shark is considered to be a great delicacy, but I have never heard of its being eaten by the white settlers in the colony" $(45)$. The fins of sharks are highly prized by the wealthy Chinese(29).

Sloths._-Sloths are eaten by the natives of Australia(12).

Snail.-The vineyard snail (Helix pomatia) is used as food in many parts of Europe during Lent(4). It is reared and fattened with great care in some cantons in Switzerland as an article of luxury and exported in a pickled state. Many other snails are eaten by the poor, and none are known to be hurtful(39). The common garden snail (Helix aspersa) is used in some parts as a cure for diseases of the chest(4). Sulils on the Continent, and even slugs in China, have a reputation for delicacy and nutritive power(46). Garden snails may be found on the menus of fashionable New York restaurants.

Snakes.-Snakes are eaten by the Chinese(1), the natives of Australia(12), and by those of many other countries, but the flesh is reckoned unwholesome and liable to occasion leprosy(3). A nutritious broth for invalids is made in some places from the flesh of the poisonous viper(39).

Spiders.-Spiders are eaten by the Bushmen and the inhabitants of New Caledonia(3). Several species of beetles are eaten by women of different nations, in the belief that they will cause them to grow fat and become prolific in child-bearing.

Spotted Crake.-The spotted crake, or speckled water hen, is highly esteemed in France for the flavor of its flesh. Few birds can match it in autumn as a rich morsel for the table(4).

Squirrels. - The squirrel is eaten by the natives of Australia(12), the North American Indians(23), and is a favorite dish in Sweden and Norway (5). The flesh is said to be tender and to resemble that of a barnyard fowl (60). It is sometimes eaten by the lower classes in England(5) and in the United States, and when fried, broiled or stewed makes an appetizing morsel.

Swans.-Swans were eaten by the ancients, and often appeared of old at great banculets in England. They are eaten by the natives of Australia(12), and the flesh of the cygnet, which is said to have a flavor resembling both the goose and the hare, is still considered a delicacy in Europe $(\cdot t)$.

Swordfish.-The flesh of the swordfish (Ziphias Platypterus of Shaw) was known in early timies as an article of food, and its fame is not undeserved. The flesh near the vertebræ is pale salmon-colored, and any epieure of fish might- be recommended to try a cutlet from it. Lower 
down it is red and like coarse beef(43). A species of searus, or parrot fish, was highly esteemed by the Roman epicures, und the Grecks still consider it to be a fish of exyutsite Havor(t).

Tapir.-The North American Imdian compares the flesh of the tapir to beef (5). Although much estecmund, it is considered by the inhubitanes of South America to be inferior tw lwef(60).

Toad. - T'he toad is eaten hy the un wroes( bombina is eaten in some places like limb(3:)).

Tortoise.-Land tortoiscs are entron hy the natives of the Amazon(2), of India(t), of South Africa(f(1) and by the North American Indians(43). Payen considers the How of the tortoise a wholesone food $(37)$ and Dr. Livingstone fomm it a very agreeable diah(40). It is said to resemble veal (40).

Trionyx Ferox.-The flesh of the trionyx ferox is considered very delicate food, and on the coasts of Xirth America it is angled for with a hook and line baited with small fish $(t)$.

Turtle.-The flesh of the marine turtle is largely eaten and highly esteemed, besides yielding in this comntry the choicest of soups. The fresh-water turtle abounds in the marshes of Provence on the shores of the Rhone and in Sardinia(37), and is eaten by the inhabitants, as it is by the natives of Australia(12).

Walrus.-The walrus is eaten by the Esquimaux(19) and highly appreciated by Aretic explorers(20).

Whale.-The whale is eaten laruely by the natives of Western Australia, New Zealand (3), the poorer sort of Japanese(21), the rude listoral tribes of Northern Asia and America(3), the natives of Vancouver Island(18) and the Esquimanx(3). Blubber is used as food in Vaneouver Island(18) and by the Eaquimanx(22). The blubber and flesh of the narwhal, or sea unicorn. is considered a great delicacy by the Greenlander(t).

Wolves.-Wolves are forbidden among the African Arabs, but are not infrequently eaten by sick persons, in the belief that their flesh is medicinal (7). The mountaineers of the American Sahara eat the small prairie wolf (eanis Latrans).

The Zulus. - The Zulus are so fond of carrion, or decomposed tlesh with worms in it, that, aceording to a letter of Archbishop Colensos, pub lished in the London Times, they uned their word (ubomi), representing it as a synonym for their highest mution of happiness(:36). 


\section{REFERENCES}

1. Bowring, Sir John. The Population of China, Statistical Soc. J., vol. $\mathrm{xx}, \mathrm{pp} .41-53$.

2. Wallace, A. R. Narrative of Travels on the Amazon and Rio Negro, London, 1859, pp. 485-485-485-485-485.

3. Simmonus, P. L. The Curiosities of Food; or, the Dainties and Delicacies of Different Nations Obtained from the Animal Kingdom, London, 1859, pp. 38-38-92.

4. Baird, W. Cyclopædia of Natural Sciences, London, 1858, pp. 171, et seq.

5. Webster, T. An Encyclopædia of Domestic Economy, London, 1844 , pp. $379-439-224-220-197-315$.

6. Daumas. The Horses of the Sahara and the Manners of the Desert, translated by James Hutton, London, 1863, pp. 308304.

7. Lyon, G. F. A Narrative of Travels in North Africa in 18181820, London, 1821, pp. 62-51.

8. Burton, R. F. The City of the Saints, and Across the Rocky Mountains to California, London, 1861, pp. 38-38-80.

9. Cook, Captain. Cook's First Voyage in: Hawkesworth's Voyages, 3 vols., London, 1773, pp. 196-196-447-688-688-688 -761-761-761.

10. Shepard, N. Shut Up in Paris, London, 1871, pp. 299-219-219. 11. Dieffenbach, E. Travels in New Zealand, 2 vols., London, 1843, pp. $17-17-43$.

12. Eyre, E. J. Journal of Expeditions of Discovery into Central Australia in 1840-1841, 2 vols., London, 1845, pp. 250$250-250-250-250-250-250-250-250-250$ $-250-251-251$.

13. Burton, R. F. The Lake Regions of Central Africa: A Picture of Exploration, 2 vols., London, 1860, pp. 28-273.

14. Food Journal, London, pp. 240-370.

15. Wirkes, C. Narrative of the United States Exploring Expedition, 1838-1842, 5 vols., London, 1845, p. 452.

16. Dawsos, R. Present State of Australia, 1830, pp. 67-67.

17. Hrsp, H. Y. Explorations in the Interior of the Labrador Peninsula, 2 vols., London, 1863, p. 4. 
18. Sprost, G. M. Scenes and Studies of Suvage Life, London, 1868, pp. $53-61-455$.

19. Lunnock, Sur Jous. Prehistoric 'limes, as Illuntrated by Ancient Remains, and the Manners and Customs of Modern Savagen, Iondon, 1869, pp. 485-485.

20. Kaxe, E. K. Aretic Explorations: The Second Girinell Expedi. tion in Search of Sir John Franklin, 1853-1855, 2 vols, I'hila. delphia, 1856, p. 15.

21. Thunberg, C. P. Travels in Europe, Africa, and Asia, 1870-1879, 4 vols., London, 1595 , p. 35.

22. Richanoson, Sin Joun. Arctic Searching Expedition, 2 vols, London, 1851, p. 243.

23. Schoolcraft, H. R. Historical and Statistical Information Respecting the History, Condition, and Prospects of Indian Tribes of the United States, 3 vols., Philadelphia, 1851-1853, p. 250.

24. Sullivan, E. Rambles and Scrambles in North and South America, London, 1852, p. 122.

25. Marsnex, W. The History of Sumatra, London, p. 56.

26. Catlin, G. Letters on North American Indians, 2 vols., Iondon, $18+2$, p. 122.

27. Tennent, Sir Emerson. Ceylon: An Account of the Island, Physical, Historical and Topographical, 2 vols., Iondon, 1559, p. 76.

28. Wrangei.I, F. von. Narrative of an Expedition to the Polar Sea in 1820-1823, edited by Lieut. Col. Edward Sabine, London, 1844, pp. 23-75.

29. Barrow, Sir Jorn. Travels in China, London, 1806, pp. 551 , et seq.

30. Journal of the Society of Arts, London.

31. Head, Sir F. B. Journeys across the Pampas, 1828, p. 120.

32. Medical Times and Gazette, Tondon, pp. 140-142.

33. SARCEY, F. Paris during the Siege, Iondon, 1871.

34. Livingstone. Narrative of an Expedition to the Zambesi and its

Tributaries, 1858-1864, Iondon, 1565, pp. 39-169-443$452-465$.

35. Kolben, P. Present State of the Cape of Good Hope, Iondon. 1731, p. \$3.

36. Quarterly Review, London, p. 424. 
37. Parfen, A. Precis Théorique et Pratique des Substances Alimentaires, Paris, 1865 , pp. $36-162$.

38. The Lancet, London, vol. iii.

39. Ençelopedia Britannica, Seventh Edition, 21 vols., Edinburgh, 1842 , pp. $349-724-724-727$.

40. Livingstone. Missionary Travels and Researches in South Africa, Tondon, 1857, pp. 42-42-135-156-542.

41. Archrologia, pub. by the Society of Antiquaries, London.

42. Teignmoutr. Sketches of the Coasts and Islands of Scotland and the Isle of Man, 2 vols., London, 1836, p. 220.

43. Loskiel, G. H. History of the Mission of the United Brethren among the Indians in North America, 3 parts, London, 1794, pp. $32-32-65-65$.

44. Simisox, She Geokgis. Narrative of a Journey Round the World during the Years 1841-1S42, 2 vols., London, 1847.

45. Hectok, James (Geological Survey Department). Fishes of New Zealand: Notes on the Edible Fishes, Wellington, 1872, pp. 120, et seq.

46. Letneвy. On Food: Cantor Lectures, London, 1870.

47. Scherzer, K. Narrative of the Circumnavigation of the Globe in the Austrian Frigate "Novara" in 1857-1859, 3 vols., London, $1861-1863$, p. 568 .

45. Transactions of the Entomological Society, London, volume iii, p. 129.

49. Axprews (of Wyntown). The Orygynal Cronykil of Scotland (with notes by David Macpherson), 2 vols., London, 1795.

50. Linusay, Robert (of Pitscottie). The Chronicles of Scotland, edited by J. G. Dalyell, Edinburgh, 1814.

51. Chamizirs, R. The Book of Days, 2 vols., Edinburgh. Page 688.

52. C'hambers' Eneyclopredia, 10 vols., London, 1868.

53. Turver, Rev. George. Nineteen Years in Polynesia, London, 1861.

54. Humbolit, Alexander von. Views of Nature, translated by E. C. Otte and H. G. Bohn, London, 1850, pp. 4-43.

55. Journal of the Statistical Society, London, p. 72.

56. Jonsston, J. F. W. Chemistry of Common Life, revised by G. H. T.ewes, 2 vols., London, 1859, p. 201.

57. Argoted, Sir Samuel. Touching his Voyage to Virginia, 1613 (Purchas his Pilgrimes, vol. iv, p. 1765). 
MAMMALS, INSECTS, FOWI, FISH, RFPTII.S 779

58. Encyclopadia Metropolitana, 25 vols., Jondon, 1845, p. 550.

59. Gart. Medieal Notes of the Upper Amazon, pub. in Am. J. Med. Sci., and quoted in the Jancet, Dec 14, 1872.

60. Fonssur, J. S. Dictionary of Diet, London, 1835.

61. Nature (a weekly periodical, London), pp. 453-520.

62. Maunirus. Transactions of Royal Society of Arts and Sciencess.

63. Lossina, B. J. Our Country, vol. i, chap. ii, p. 193.

64. Parr, Wirlasis. Work on Foods, Iondon. 



\section{N D E X}

$\Lambda$

Abies Nigra or black spruce, 657.

Absinthe, composition of, 588 .

injurious effects of, 589 .

Absorption, actual course of, 164.

of bread, 387 .

by capillary blood vessels of the villus, 172.

of earbohydrates, 184

behavior of intestinal wall to, 186 .

course of, in system, 185.

in stomach, 185.

changes in organic foods during, 177.

course of, in cecum, 167.

duodenal, 166.

in ileum, 167.

in lower intestinal, 166.

in stomach, 164.

and dialysis, 204.

and diffusion, 204.

energy controlling, 178.

of fats, 169,459 .

extent of, 182 .

function of leucocytes in, 181 .

lost fraction in, 181 .

manner of, 178.

mechanism of, 178.

part played by bile and pancreatic juice in process of, 180 .

processes involved in, 183.

theories of, 178 .

and filtration, 207.

of fruits, 479.

in large intestine, 174.

of fats, 176

of legumes, 441.

as a living and not mechanical action, 208.

lymphatic, 171.

of milk, 312 .

modern theory of, 202.

and osmosis, 172, 204.

of peptones, 168 .

percentage of protein, fat and carbohydrates absorbed from dry substances in various foods, 163.

physical and chemical agencies formerly held in explanation of, 204.

physiological test of digestibility of food, 162 .

physiology of, 161 .

of proteins, accompanying changes of villus and epithelium, 189 .
Aboorption, of proteine, allumenars and peptones, 184.

amino-acids resulting from hydrolyoin of complex protrinn, 108.

courae of emino-acide In nyotem, 190.

extent of reduction trefore, 190 .

final proceseses of, 202.

foreign. 190.

form of, 189.

in form of amino-acids, 196.

manner of, 188 .

normal course of, 198.

normal forms of, after, 194.

relation of amino-acids to. 185, 198.

relation of, to infant's diet, 190 .

of ptomains, 668 .

quantity and quality of fool ingosted, 161 .

of rice, 390

rôle of white blood corpuscles in, 203.

of saline solutions, 169 .

of salts, 168.

in small intestine, power of, 174.

of saline solutions and water, 169.

in stomach, 141, 183.

of sugar, 168.

of vegetable fats and oils, 467 .

of vegetable foods, 371 .

of water, 167, 169.

in large integtine, 175.

lymphatic. 171.

Acetic acid, 95.

Acids, acetic, 67 .

amino-, 67.

amino-acetic, 67 .

aminopropionic, 67,68 .

entering into formation of glycerin esters of fats and oils. 08 .

caproic acid. 99.

caprylic and capric acids, 99.

erucic acid, 99.

hypogeic acid, 92.

lauric acid. 99.

oleic acid, 09.

muristic acid. 99.

palmitic acid, 99.

stearic acid, 99.

in fruits, 47\%.

of meat, 278.

organic. See Organic Acids.

phytic, 100.

propionic, 67 .

Acorns. 506, 637.

Acrodynia, simulated by ergotism, 673 
Actinomycosis, etiology of, 679 .

Adulterited foods, and adulterants of, tilble of, $686,687$.

Adulterants, of food, 682 .

Adulteration, 683.

of heverages, 683.

of bread, 683 .

of butter, 683.

in canning of foods, 684 .

of coeoa, 683 .

of cotfee, 683 .

of honey, 684 .

of lard, 683.

of liqueurs, 683.

of malt liquors, 682 .

of maple sirup, 683.

of olive oil, 683 .

of pickles, 652 .

of sirup and molasses, 625.

of teas. 683.

types of, 681 .

of wine, 682 .

Aesculus hippocastanum or horse chestnut, 657.

Agar agar, 451.

Agoutis, as food, 763.

Agriculture, early, in America, 34.

influence of, upon civilization, 36 .

introduction of, 33 .

primitive milling, 36 .

stationary, 34 .

use of fertilizers, among early Indians, 36.

Alanin, 70.

formula of, 67 .

Albatross, as food, 763.

Albuminoids, 55, 78.

definition of, 696 .

Albumins, 75 .

Albumoses, absorption of, 194 .

Albumosuria, causation of, 192.

Alcohol, absolute, 569 .

amount of, capable of complete oxidization, 582 .

amylic, 93.

comiposition of, 93.

conversion of monosaccharids into, 85 .

cumulative e' "ect of, 592.

cyelic, 93.

effect of, on digestion and secretion, 574 .

on excretory organs, 581.

upon the lieart, 570.

on mental processes, 580.

on metabolism. 580 .

on muscular activity, 573, 592.

on temperature, 572 .

cthyl, 93, 569.

as a fat-sparer, 578.

forl value of, $93,577,579,580,592$.

habitual use, result of, in case of sickness, 593.

local effects of. 570.

morlerate daily use of, 593 .

and physical labor, 573, 574.
Aleohol, how produced, 569.

taken on empty stomach, 574 .

triatomic, 93.

use of, in disease, 593.

in fevers and other wasting diseases, 593.

vascular paralysis due to prolonged overindulgence in, 573.

Aleoholic drinks, brandy, 585 .

constituents of, 569 .

gin, 587.

liqueurs, 587.

low, 567 .

rum, 586 ,

special characters of, 569 .

whiskey, 582.

Aldehyds, 94.

Algae, 450.

Alimentary glycosuria, 86.

Alimentary toxemia, 193.

Alimentary tract, anatomy of, 108.

bacteria of, $213,214$.

definition of, 108 .

esophagus, 110.

large intestine, 113.

mouth, 108.

palate, 109 .

teeth, 110.

pharynx, 110.

small intestine, 111.

stomach, 111.

Allantiasis, 669.

Alligator pear, 495 .

Allspice, 645.

Almond oil, 469 .

Almonds, 506.

bitter, 506.

green, 507.

Amblyrhynchus, as food, 764 .

American foods, chemical composition of (tables), 738-747; bread, crackers, eakes, pastry, puddings, 738743; sugars, starches, 743-744; vegetables, 744-747.

American Indians, early agriculture

Amids, 83. among, 34, 35 .

Amino-acids, absorption of proteins in form of, 196.

chemical formulae of, 67-70.

course of, in system, 199.

deaminization of, 72 .

derivation of, from organic acid, 67 .

as final cleavage products of protein digestion, 199.

free, present in muscles and other tissues, 200 .

not incorporated into body, breaking down of, 201.

as means of carrying protein from alimentary canal, 202.

methods of separating, 70 .

protein, 67.

table of, 67 . 
Amino-acids, relation of, to protrin al. sorption, 195. 196.

resulting from hydrolysin of complex proteins, 195.

ultimnte fate of, after entrering bloced stream, 200.

Amino-acids and peptids, vs. bleod pro. trins, 196.

Aminolysins. 101.

Aminopropionic neid, 67, 68.

Aminovalerianic acid, formula of, 71 .

Ammonia, free, 241.

in water, 241 .

characteristic of sewage pollution. 241.

Amylase, 157.

Amylic alcohol, 93.

Amylolytic action, 129.

Anchylostomiasis, source of infection, 667.

Angostura bitters, 589 .

Animal fats, bonc marrow, 466 .

butter, 461 .

butterine, 466.

composition of, 98 .

lard, 465.

oleomargarin, 466.

pemmican, 466 .

sources of, 461.

suet, 466.

tallow, 466.

various, 466.

Animal flesh. See Meats.

Animal food, average chemienl composition of, 702-728. See also special subjects.

eggs and egg products, 349.

fish and shellfish, 300.

fowls, domestic and wild, 296.

gelatin, 293.

meat extracts, 287.

meats, 277 .

milk and milk products, 307.

relative cost of vegatable and, 375 .

unusual, 763.

agoutis, 763 .

albatross, 763 .

amblyrhynchus, 764 .

ants, 764 .

armadillo, 763 .

axolotI, 764 .

bandicoot, 764 .

bear, 764 .

beaver, 764 .

bees, 765 .

birds' nests, 765 .

bison, 764 .

blaps. 765 .

buffalo, 764 .

bustard. 764 .

camel, 765 .

carrion. 775.

eaterpillars, 767 .

cats, 765 .

cavia, 765 .
Inimal forml, unusual, cleada, 867.

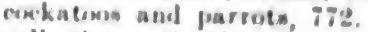

collaril perari, iCs.

cormorant, iths.

eratue, ibte.

cromolile, ibts.

creksins, itits.

cuttlefinh, 7637.

decomprasd flesh with worms in it, 778.

dingm, 767.

dugong. 767.

earth eating, 567 .

marth hog, itis.

elephant, 767.

- $1 \mathrm{k}, 767$.

frogs, 768 .

grasshoppers, 769.

grubs, 769.

gull, itis.

herlgehog. 768 .

hippophagy, 6 69.

hippopotatnus, 770 .

holothuriace ito.

human flesh, 7ig6.

iguana, 770 .

jerloa, 760 .

kalong. 731 .

kangaroos, 771 .

lion. 731 .

lizards, 771.

llama. 771.

locusts. 771 .

lynx, 771.

inanatee, 771 .

marmot, 771 .

mice and rats, 772 .

monkeys. 772 .

moths, 772.

musk-ox, 772 .

opossum, 772.

ostrich, 772.

parrots and cockatoos, $7 \%$.

pea-fowl, 7i:

pelican, 773.

penguins, 773.

porcupine, 773.

rats and mice, 792.

reinderer. 773.

rhinoceros, 773.

seal, 773.

sharks, 773.

sloths, 774.

snail. 77.

snakes, its.

spiders. $7 i t$

spotted crake, 774.

squirrels. 774.

swans, 754.

swordfish, it4.

tapir, 775.

toad. 775 .

tortoise, 735.

trionyx ferox, 775. 
Animal tooa, umusual, turtle, 765 .

walrus, 775.

whale, 775 .

wolves, 775 .

of the Yulus, 775.

viscera of animals. 294.

Animal and vegetable foods, unclassified, average chemical composition of, 758 .

relative values of, 49 .

Animal viscera, composition and description of, 294.

definition of, 294 .

as food, blood, 295.

brain, 296.

heart, 295.

kidneys. 294.

liver, 295.

lungs, 295.

pancreas ("belly" sweetbread), 295.

stomach, or tripe, 295.

thymus gland " "neck" or "throat" sweetbread), 295.

tongue, 295.

Animals, domestication of, 32 .

unusual, sometimes used for food. Sce Animal Food, Unusual.

Anise, 647.

toxic substances contained in, 658 .

Ant, as food, 764 .

Anthrocyans, 102.

Anthrozanthins, 101.

Apigenin, 101.

Apples, chemical composition of, 480 .

custard, 490.

fermented liquor of, 481.

geographical distribution of, 480 .

kinds of, 480 .

mammee, 496.

May, violent catharsis due to, 661 .

red, litmus contained in, 659 .

rose, 491 .

sour, 489 .

star, 492.

sugar, 490 .

wholesomeness of, 481.

Apple brandy, 585.

Apple ciller, 481 .

Apple vinegar, 605.

Apricot brandy, 596.

Apricot, kernel oil, 471.

Apricots, 483.

Araben, 85.

Arboreal ancestors, modifications due to evolution from, 42.

Armadillo, as food, 763 .

Arrowhead tubers, 426.

Arsenice introduced into food, 686.

Artichoke greens, 437.

Ash of body, minerals composing, 261.

Ash or mineral waters, use of term, 697 .

Asparagus, 436.

toxic substanees of, 658 .

Auto-intoxication, causation of, 193.
Avitaminoses, cause and characteristic syndromes of, 680 .

Axolotl, as food, 764 .

\section{B}

Bacillus coli communis, in water, 243.

Bacon, digestibility and use of, 285 .

Bacteria, of alimentary canal, 213, 214.

in food. Sce Food Infection.

in milk, 328.

classes of, 328 .

sources of, 330 .

in water, 242

bacillus coli communis, 243.

cholera germs, 243.

detection of, by chemical analysis, 245.

typhoid bacilli, 243.

Bacterial activity, experiments to determine nature of, 211.

phases of, 214.

relation of, to food metabolism, 212.

underlying principles governing, 212.

in water, 240.

See also Bacterial Metabolism and Bacteriology.

Bacterial decomposition of food, in gastro-intestinal tract. See Bacterial Activity.

Bacterial metabolism, action of carbohydrates in media, 221.

action of protein a:id protein derivatives, in media, 221, 222.

formation and elimination of waste products arising from, 216.

nature of, 214.

necessity of nitrogenous diet in, 217.

in normal digestive processes, 213 .

phases of energy or catabolic, 214.

structural, 214.

preparation and utilization of energy in, 217.

prominent features of, 214.

reactions of bacteria in media containing both utilizable nitrogenous substances (proteins and protein derivatives) and carbohydrates, 221.

relation of products of, to nutritive environment, 223.

specificity of microbe action, 216.

syntheses of, 217.

transformations of, final, 215.

preliminary, 215.

utilization of protein derivatives in, 218.

Bacteriology, of alimentary canal, normal and abnormal flora, 229 .

of cecum, 228.

gastro-intestinal, 223.

in adolescents and adults, 225 .

in infants, 224. 
Bacteriology, of intestinal contontm, nef fects of abmormal conditions upon 2.2s.

effect of cathurtics on, 22g.

of lurge intestine, 228.

of mouth, 226 .

regional, 226 .

of small intratine, 227.

of stomach, 227 .

Bunanas, 502.

toxic sulstances in, 65s.

Bandicoot, as food, 76.1.

Barbadoes cherry, 491.

Barberries, 499.

toxic substance in, 658 .

Barley, 401 .

composition of, 401 .

pearl, 401 .

Barley sheaths, actinomyeosis lue to, $1 i$ i:

Baths, mud, 537.

"Bausteine," 199.

Bay leaf, 640 .

Beans, analyses of, $744-745$.

bolicohs, 444.

broad or Windsor, 440, 444.

butter, 444.

comparison of peas and, 446 .

green, 439.

composition of, 440 .

kidney, 444.

lima, 444.

shelled, 439.

soy, 444.

Bear, as food, 764.

Beaver, as food, 764 .

Beechnut, 507.

Beef, average chemical composition of. canned beef, 707 .

cooked beef, 706, 707 .

corned and pickled beef, 708 .

dried beef, 709 .

fresh beef, $702-706$.

canned, average chemical composition of, 707 .

cooked, average chemical composition of. 706.

corned and pickled, average chemical composition of, 708 .

cuts of, 699 .

dried, average chemical composition of, 709.

factors influencing quality of, 283.

fresh, average chemical composition of, 702.

tenderness and toughness of, $282,283$.

Beef bouillon, 291.

Beef extracts, 287.

constituents of, 288 .

nutritive value of, 287 .

percentage composition of, 288 .

stimulating effect of, 287 .

Beef fat, or tallow, 466 .

Beef juice, 289.

raw, 289. lhoref juice, raw, cumprosition of, ez(m).

II me $^{\circ}$ of, 2 sis.

Beref unral, 292.

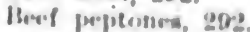

percentage cromponition of preparations of. 2028.

Hoef promluetw, percentage componition of.

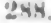

Beref tajw'worm, Bebis.

lieef tora, $2 x i !$.

altuminoid material in, 291.

proparation of. 2*is.

prepurutiun of, 281 .

Berfuterak, rhemical compraition of, as compared with egow, milk, croams cherese and white freal, 3 is.

Beer, action of, on digmation, 366 .

herb, stis.

ginger, 368.

spruce, ses.

invention of, 31.

"small," 367.

Bees, as food. 76.:

Beret root nugar. Sire Singar, bert.

Beets, 421.

composition of, $4 \geq 1$.

litmus contained in, 659.

Benedictine. 589.

Bengal isinglass, t5l.

Benzoic acid, 96.

Berberin, 658.

Beriberi, due to "polished rice" 662. 679.

etiology of, 679.

occurrence of, 679 .

Berries, average chemical conjpoition of, frewh, 752 .

barberry, 499.

blackleerry, 499.

blue, 498 .

eloudberry, 500 .

cranberry, 501.

currants, 501 .

description of, 493.

dewberry, 500 .

elderberry, 499.

gooseberry, 500.

huckleberiy, 499.

loganberry, 500 .

raspberry, 500 .

roebuck berry, 500 .

service leerry, 499.

strawberry, 501.

whortleberry. 498.

Betaimidazoleethylamin, formation of from histidin, 220.

Betain, 83.

Beverages, 539.

adulteration of. 653 .

aleoholic. Stre Alewholic Drinks.

artificial, of procibiculturists of pront time. 31.

chicolata, 555 .

cider, bir? 
Beverages, cocoa, 551, 558.

coffee, 545 .

deleterious effects in use of, 559 .

effect of caffein in, 558.

guarana or Brazilian cocoa, 556.

kola, 556 .

low alcoholic, 567 .

malt liquors, 559.

nutritive value of, 558 .

perry, 602.

of precibiculturists, 29.

tea, 540 .

vinegars, 602.

wine, 594.

Bile, eolor of, 119. composition of, 119.

part played by, in fat absorption, 180 . physiolory of, 119.

use's of, in intestines, 119.

Bile-pigments, 119.

Bilirubin, 119.

Biliverdin, 119.

Birds' nests, 765 .

Biscuits, 385.

Bison, as food, 764 .

Bitter almond, hydrocyanic acid yielded from, 658 .

Blackberry, 499.

Blackberry wine, 499.

Black jack, 622 .

Blaps, as food, 765 .

Blood, animal, as food, 295.

mineral content of, $257,261$.

Blood corpuscles, white, rôle of, in absorption of food, 203.

Blood protein, amino-acids and peptids vs., 196.

Blood vessels, capillary, absorption by, 172.

Blueberry, 498.

Bodily structure and function, changes in, due to evolution from an arboreal ancestor, 42 .

due to evolution of diet, 40 .

Body, ash of, 261 .

chemical constituents of, 52 .

proximate principles, 54.

constituents of vegetable foods vs. those of, 366 .

clementary composition of, 53.

function of salts in, 262 .

importance of mineral salts to, 255 , 260.

mineral content of, 255.

bromin, 274.

calcium, 265.

chlorin, 273.

fluorin. 274.

iodin, 273.

iron, 266 .

magnesium, 265.

manganeas, 275.

oxalic acid, 274.

phospliorus, 271.
Body, mineral content of, potassium, 269. silica, 274 .

sodium, 269.

sulphur, 272.

mineral salts in, form of, 259 .

Boiling, of milk, 313, 321 .

of water, application of, to cookery, 20 . listory of, 17.

Boletus edulis, 450 .

Bone marrow, 466.

Bones, mineral content of, 257, 261.

Boneset, medicinal action of, 658 .

Bonnyclabber, 338 .

Boric acid, ill effects of, on huiman economy, 685.

as preservative, 685 .

Brain, animal as food, 296.

mineral content of, 261 .

Brandy, apple, $\mathbf{5 8 5 .}$

apricot, 586 .

definition and process of making of, 585.

effect of age on, 586 .

fictitious, 586 .

Brazil nut, 507.

Bread, absorbability of, 387 .

adulteration of, 683 .

analysis of, 738 .

aërated, 386.

average chemical composition of, 734 .

blending of different wheats in, 384 .

digestibility and absorption of, 387 .

good, characteristics of, 387 .

historical tracings of making of, 384 .

hot, and biscuits, 385 .

leaveners of, 386 .

nutritive value of, 389 .

percentage composition of certain root vegetables and, 424 .

process of home baking, 385 .

sawdust and woody fiber, 389 .

sour, 385.

stale and slightly dried, 386 .

white, chemical composition of, as compared with egg, milk, beeksteak,

Bread fruit, 489 . cream cheese, 354 .

Jread nuts, 508 .

Brewing, discovery of art of, 559 .

Broccoli sprouts, 434.

Bromin, presence of, in body and in foods, 274.

Bromin and iodin, waters containing, 528.

Brussels sprouts, 434 .

Buckwheat, active principle of, 661 . cultivation and description of, 404 .

Buckwheat flour, composition of, 404 . use of, 404.

Buffalo, as food, 764 .

Bustard, as food, 764 .

Butter, adulteration of, 683 . antiquity of, 461 . average chemical composition of, 726 . chemical characteristics of, 462 . 
Butter, composition of various grades of, 464.

creamery, 463.

imitation, 463.

dairy, 463.

digestibility and value of, 341.

digestion of, 465.

estimuted yenrly output of, in this coun. try, 46.3.

factory, 463.

futty acids in, 462.

making of, 462 .

percentage of fat in, 465 .

production of, in Inited States. 341.

rancidity in, causes of, $462,463$.

renovated. 463.

Butterine, 466.

Buttermilk, 336.

analysis of, 337.

average chemical composition of, 726 . use of, 337 .

Butter muts, 508.

Butyric acid, 95.

\section{C}

Cabbage, composition of, 432,434 .

cultivation of, 433 .

red, litmus contained in, 659 .

varieties of, broccoli sprouts, 434 .

brussels sprouts, 434 .

cauliflower, 434.

kale or borecale, 434 .

seakale, 434 .

Cacao beans, treatment of, 552 .

Cacao fat, 470 .

Cacao nibs, 553.

Cacao shells, 553.

Cacao tree, fruit of, 552.

geographical distribution of, 551 .

habits of, 552.

Cadaverin, formation of, from lysin, 220.

Caffein, effect of, in beverages, 558 .

Caffeone or caffeol, in coffee, 548.

Cake, analysis of 740,741 .

Calcium, importance of, to body, 264.

Calcium balance, disturbance of, in dis. eased conditions. 259.

Calcium-containing foods with content estimated, 265.

Calories, per pound, per gram, American fools. $738-747$.

Camel, as food, 765 .

Candle nuts. 508.

Candy, hard, 628 .

soft. 628 .

white, 627 .

Cane sugar group, or disaccharids. 87.

Canned food, tin and lead poisoning from, 685 .

zine found in, 685 .

Cannibalism, 24, 766.

anthropophagy, in the New World, 766.
C'anninge of foxels, adultoration in, Ges

fruitu, tist.

ment, likt

vogutuliton, tikit.

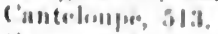

(inger, ils.

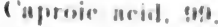

Coprolie and eaperie aetiolo, 99.

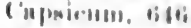

('ursmer) 19:3.

('araway navl, mit.

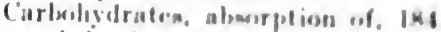

Inehavior of intogational wall tos, INB.

contres of in eratem, 18s.

disucecharids, | sis.

in stomach, Ix.

artion of in mevlia, 228.

claseification of, disacrharide, 87.

monomsccharids, 84.

polymaceliaricle, colloidal, 89.

tet ranuchiaridx, 8:

trisaccharide, s9.

comprosition of, 84 .

course of, in syatom, I 5.3 .

by portal syxtoun, iks.

determination of 697 .

disacharidw. difference of, from tnono. saccharids, 87.

lactuse, 88.

maltose, 88.

saccharose. 87.

fermentation of, 187.

in fruits. 4is.

hydrolysis of. 185.

inversion of, in small intestine, 185.

monosaccliarids, classes of, 84 .

hexoses. 85.

pentosess, 85.

tetroses, 84.

trioses, 84.

nature of, 84 .

percentage of, absorlen! from dry sub. stances in varions fooks. 183.

polysaccharids, colloidal, cellulose, 91.

dextrin. 90.

glyeogen, 90.

inulin. 92.

lichenin, 91.

maltodextrins. 91.

pectose hoodies, 92.

starch, 89.

trisaccharids, melitose, s9.

melizituse, s?.

in vegretalble foods. peetin or pretone bodies. 369.

starch, $36 \%$.

sugar. 367.

(arbon dinxil, presence of, in water, 240.

Cardamon, biti.

('armotes. 305.

('surobl besans. 493.

Carotin. 101.

Carrion. as fool of \%ulus, 705 .

Carrots, comprosition of, 422, 424. 
Carrots, cultivation of, 421. nutriment of, cooked and raw, 422. toxic substances contained in, 658 .

Casein, as $\mathrm{erg}$ substitute, 358. in milk, $30 \mathrm{~s}$.

(aseinogen, 192.

('ashew nuts, 508.

('assia, 643.

('aterpillars, as food, 767.

Cathartic action, of May apple, 661. of persimmons, 661 .

Cathartics, effect of, on bacterial population of intestines, 229.

Catnip, medicinal action of, 658 . medicinal nature of oil of, 661 .

Cats, as food, 765 .

Cauliflower. 434.

Cavia, as food, 765 .

Caycnne pepper, 646.

Cecum, bacterial activity in, 228 . digestion in, 167.

Celeriac, 427.

Celery, 435.

toxic substances contained in, 658 .

Celery salt, 435 .

Celery seed, 648 .

Cellulose, 91.

as covering of starch granules, 369 .

as factor in digestion and absorption of vegetables, 372 .

Cereal hreakfast foods, cost of, 406 . differences in composition of, 408 .

importance of, 404 .

prepared, 409.

ready to eat, cost of, 406 .

manufacture of, 406 .

sold in bulk and in packages, 408 .

total nutrients and fuel value of, 407 , 408.

uncooked and partially cooked, 405.

Cereal coffee infusion, average chemical composition of, 757 .

Cereals, average chemical composition of, $729-734$.

barley, 401 .

bread, 384.

buckwheat, 404 .

comparative cost of nutrients and energy in flours and, 394 .

composition of flour and of, 376 .

eorn, 392.

flour, 380 .

(grass) and other, most important of, 376.

kaoling, 403.

millet, 401 .

oats, 398.

origin of, 375 .

proso millet, 402.

quinoa, 403.

rice. 389 .

rye, 400 .

wheat, 376 .

Chamomile, medicinal action of, 658 .
Champagne, 597.

Chartreuse, 589.

Cheese, 341.

average chemical composition of, 726 .

comparative food value of different varieties of, 344,345 . cooked, 344.

Emmenthal or Gruyère (Swiss cheese), 345 .

Parmesan, 345.

cottage (pot or green cheese), 343.

cream, ehemical composition of, as compared with eggs, milk, beefsteak, and white bread, 354 .

digestive qualities and nutritive value of, 347 .

flavor of different varieties of, 346 .

fresh, 344 .

fuel or caloric value of, 348 .

general chemistry of, 346 .

hard, 344.

Cheddar, 344.

Gorgonzola, 344.

Roquefort, 344.

Stilton, 344.

making of, 342 .

manufacture of, in America, 349.

nutritive value and digestive qualities of, 347 .

origin and mode of manufacture of, 241.

percentage composition of different varieties of, 346 .

skim milk, 344 .

Cheshire, 345.

Edam, 345.

Gloucester, 345.

soft, Brie, 344.

Camembert, 343.

English cream, 343.

Limburger, 344.

Neufchâtel, 343 .

subjection of, to moulds and resulting flavor, 349 .

use of, 347 .

of, in invalid diet, 348 .

varieties of, cooked, 345 .

hard, 344.

skim-milk, 345 .

soft, 343.

Cheese poisoning, 671.

Chemical composition of American foods (tables), 738-747.

Chemical constituents of body and of food, 52.

proximate principles, 54 .

Chemical test of food value, 57 .

Chemistry and physiology, of digestion, 52.

of proximate principles of food, 63 .

Cherry, 484.

composition of, 484 .

maraschino, 484.

Surinam or Barbadoes, 491.

Cherry bounce, 484. 
Cherry brandy, 484.

Cherry laurel leaves, 642.

Cherry pits, hydrocyunic acid yivldurl from, 658 .

Chestmuts, $50 \mathrm{~s}$.

Chick-pea vetch, poisoning due to, 675.

Chicken, digestibility of, 296 .

tlesh of, 297.

varieties of, 297.

Chickory, 438.

Chinquapin nuts, 508.

Chlorids, in water, 242.

Chlorin, presence of, in foods, 273.

Chlorin-containing foods, with contrut estimated, 273.

Chlorins, in water, 242.

Chlorophyll, 101.

Chocolate, source and preparation of, 5.5 .5 .

Cholera germs, in water, 243.

Chop, chemical composition of, in com. parison with poultry, 298.

Chromoproteins, 80.

Cica of maize, 31.

Cicada, as food, 767 .

Cider, American varieties of, analyzes of 604.

composition of, 603.

definition and manufacture of, 602.

Cider or apple vinegar, 605 .

Cinnamon, 643.

oil of, 644 .

Citral, 94.

Citric acid, 96.

Citron, 485, 512.

Citrus fruits. See Fruits, Citrus.

Clamis, 307 .

Climate, fruits in relation to, 475 .

relation of, to diet, $3 i$.

Cloudberry, 500.

Cloves, 643 .

oil of, $6+3$.

Coca, physiological action of, 558. use of, 558 .

Coca erythroxylum, alkaloid cocain derived from, 658 .

Cocain, alkaloid, plant derived from, 6.5.

Cockatoos, as food, 772 .

Cocoa, 551 .

adulteration of, 683 .

Brazilian, or guarana, 556.

"caracas," 553.

chocolate, 555.

composition of, 554 .

composition of commercial varieties of. 554.

"flake." 553.

prepared, nutritive and sustaining quality of, 555 .

"rock," 553.

toxic substances containel in, 659 .

see also Cacao Beans, ('acao Nibs, Cacao Shells and ('acuo Trees.

Cocoanuts, 494, 509.

parts of, 470 . foeronnuts, am molurce of tat, fio.

fiecoanut sil, dit

corl liver oil, not

foftee, minle ration of, 531, 6x3.

untual erop uf, sis!.

Braxiliun, 54\%.

fivlon, ist.

rompromition of. SIs.

ruw atid rountorl, sis

extructe nul emences of, sost.

Jumaica, 37\%.

Java, itis.

Mexhn, itt.

Mymrio sti.

oil of, s5\%.

origin allel cultivation of, ins.

preparation uf. for driskink. S19.

derection, 3.31 .

in bingland and lnitorl sitater, six).

French method, s50.

infunion, iso.

percolation, 550 .

'Turkinh method, 551.

Vienna methexl, 550.

roasting of, 547.

sulstitutu for, 35l.

twic subatances containml in, 6.9.

trestment of beans, 54.5.

varieting of. 546 .

('offece tree', i3 45 ).

Cold slaw, ti5:.

cold storage, preservation of fruits br. 5).

Collagen, 278.

Collard pecari, as fool, 763.

('olon, ascending. 115.

descending. 115.

sigmoid, 115.

transverse, 115.

Condiments, 603.

action of, 639 .

on food, 27.

average chemical composition of, 751 .

from barks, cassia, 643. cinnamon, 643 .

from buds and llowers, caper, 682. cloves, b43. satfron, 643 .

for children and young prople, 639.

classes of, (ito).

contra-indications to. 633.

as food of precibiculturiats. 27.

history of, 27 .

from immature and ripe fruits, allopice, liti.

eapsicum. cayenne pepler. tist.

juniper berries, tite.

pepper, 6if6.

vanilla lean, 647.

from routs or rontestalks. garlice iff

ginger. 844.

Jormeradiah. B4.5.

sussafrax. 615.

turmeric, itst 
Condiments, from seeds, anise, 647.

caraway seed, $(547$

cardamon, (it7.

celery seed, 64s.

coriander seeds, 648 .

cumin seed. 648.

dill seed, 648 .

fennel seed, 648 .

grains of paradise, 648 .

mustard, 648 .

nutmeg, (i49.

tonka bean. 648 .

sources of, 640 .

from stems and leaves, bay leaf, 640 .

cherry laurel leaves, 642.

fennel, 642 .

mace, 640 .

mint, 641 .

parsley, 642.

peppermint, 641 .

sage, 640 .

spearmint, 641 .

summer savory, 641.

sweet basil, 641 .

sweet marjoram, 641 .

tarragon, 642 .

thyme, 642.

wintergreen, 642.

use of term, 638 .

value of, 639 .

Confectionery, adulteration of, 628 .

hard candy, 628 .

making of, 627 .

materials used in, 627.

products included under, 627.

soft candy, 628 .

sugar drops, 627.

white candy, 627.

Cookery, development of, 14.

among American Indians, 20.

boiling of water, application of, to cookery, 20.

history of, 17.

by other primitive peoples, 21 .

underground oven, 16.

utilization of discovery of pottery, 19 .

discovery of, 14.

evolution of, 14.

fire applied to meat. 15 .

svistematic use of fire, 14 .

Cocking among American Indians, 20.

of eggs, 355 .

of green vegetables, 431.

of meat, advantages of, 15 .

evidences of, among primitive men, 15.

method of, used by other primitive peoples, 21.

of protato, white, 412.

of vegretables, 16 .

Copper, in preserved food, 685.

Coriander, toxic substances contained in, 658 .

Coriander seeds, 648.

Cormorant, as food, 766 .

Corn, analyses of, 394 .

average composition of corn products and, 395 .

as cause of pellagra, 396,659 .

composition of, average, 395 .

composition of cooked preparations of, and wheat bread, 398 .

fuel value of, 395 .

green, 398.

history of, 392 .

milling of, 394.

normal crop of, 396 .

parts of grain of, 392 .

rank of, as food grain, 392.

subject to smut before ripening, 661 .

varieties of, 393 .

Corn breads and puddings, 397.

Corn meal, 396.

action of cooking on, 397.

white and yellow, 397.

Corn meal mush, 397.

Corn oil, 471.

Corn products, average composition of corn and, 395.

spoiling of, 396 .

Cottonseed oil, 470.

Cow's milk, chief protein of, or casseinogen, 192.

Crabs, 304.

Crackers, analysis of, 738, 739 .

average chemical composition of, 734 .

Cranberry, 502.

Crane, as food, 766.

Crataegus, medicinal action of, 658 .

Cream, Devonshire, 336.

formation of, 335 .

Crême de menthe, 590 .

Crocodile, as food, 766 .

Crystalloids, osmotic pressure exerted by, 206.

Cuckoo, as food, 766 .

Cucumbers, 512.

toxic substances contained in, 659 .

Cumin seed, 648.

Curacoa, 590.

Currants, 498, 501.

Custard apple, 490.

Cuttleflsh, as food, 767.

Cyclic alcohols, 93.

\section{D}

Dahlias, 426.

Dandelions, 438.

Dasheen, 428.

composition of, 415 .

Date palm wine, 494 .

Dates, 493.

Deaminization, 72.

Decomposed flesh, as food, of Zulus, 775 . 
Deficiency discases, avitaminomen, 6 sot. beriberi, 64, 67!).

due to lack of vitumines in milk, 316, 317.

pellagra, 64, 675.

seurvy, 64.

Deglutition, act of, 126.

inhibitory influcuce of, 128.

muscular nature of net of, 127.

stages of, 126.

variation in aet of. in different animala and with different consistencien of food, 127.

Desiccated eggs, 35ti.

Desicented Milk, 324.

composition of, 325 .

composition of easein and dried milk. preparatious, nutrients, per cent. 325.

methods of making, 324 .

use of, 325 .

Desiccated potato, 412 .

Dewberry, 500.

Dextrin, 90.

Dextrose, 85.

Diabetic sugar, 85.

Dialysis, and absorption, 204.

definition of, 204.

Diarrhea worm, 667.

Diarrheal diseases, in bottle-fed babies, 688.

Diet, classes of mammalia in regard to, 1 . carnivora, 2.

frugivora, 2 .

herbivora, 2.

evolution of, See Evolution of Man's Diet.

imperfectly balanced, diseases due to, 664.

infant's, relation of proteins to, 190 .

modifications due to, 40.

of North American Indians, 22.

of precibiculturists, 21.

of primates below man, 5 .

of primitive man, 2 .

supposed and actual, 4.

See also Food of Evolving Man.

relation of climate to, 37 .

seasonal variation in 40 .

Diet epochs, cibicultural, 32.

domestication of animals, 32.

introduction of agriculture, 33.

relation of climate to diet, 37 .

seasonal variation in, 40 .

precibicultural cookery period, 13.

development of cookery, 14 .

early preparation of food, 13.

preservative methods, 13 .

precookery, 10 .

homosimian period, 10 .

diet of, 12 .

earliest weapons of man, 11.

early hunting period, 10.

later hunting period. 12.
Hict eporlon, prownokery, mimian perpust. III.

Dietary exrellenere attainment of arme of 50.

Dictetic error cauning dismace, bes?

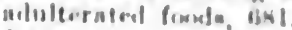

fromle containinge microurganioms, 1.4:

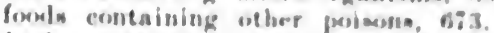

foode containing paranitow of uva, cass.

forda contuining ptomaina, Gobs.

imperfectly balanerl diet, bets.

insulticient foul, this.

overonting. beis.

and varioun foed poisons. chis.

Diffuse ability, degrem of, $20 \%$.

D)tfinion and alomorption, 201.

definition of. 204.

laws of, 205 .

physiologicul importance of 207, 208.

Digestibility, of hreall. 387.

of food. physiologgical teat of. 162.

quantity and quality ingeated, 161.

of green vegetablea, 431 .

cooked. 433.

raw, 433.

of meats, $2 \times 6$.

of sugar, 631, 634

of sweet portatoes. 414.

Digestion, aborption of food. See Absorption.

action of malt licpuors on, 566.

action of water on, 5:0.

actual course of, in cecum, 165.

in duodenum, 166.

actual course of, experiments show. ing, 164.

in ileum, 167.

lower intestinal, 166.

in stomach. 164.

agents of chemical clanges in, enzymes. 146.

ferments, 145.

agents conducise to, 121.

aid of water in, 249, 250 .

aim of, $10 \%$.

of butter, 465 .

in eccum, 167.

changes of organs of, in evolutiot of man. 43 .

chemical changes occurring in, 145

chemistry and physiology of, 52.

disturbing effect of sugar on, 634.

duodenal, libi.

effect of alcohol upon, 5it.

effect of liqueurs on, 591 .

effect of wines on. 600 .

as essential factor in life, 107.

of fats. 45!.

of fruits, 4i9.

of fungi, 451 .

gastric, 156 .

course of. 164.

problem of. $156,158$.

in ileum, $16 \%$. 
Digestion, limitation of powers of, 133 . in lower intestines, 166 .

natural divisions of process of, 116 . overtaxing of powers of, 133 .

processes of, absorption of food, 141.

bacterial activity in, 213 .

bacterial decomposition of food in gas-

tro-intestinal tract during, 211.

deglutition, 126.

enzymatic, 146.

fermentation, 145 .

insalivation, 123.

maceration of food in stomach, 134.

mastication of food, 121.

movements of stomach, 134 .

nerve action in, 128.

physiology of enzymes and hormones as applied in, 145 .

protective system in, 132.

regulation of temperature, in stomach, 140 .

secretion and action of digestive juices, 129.

sterilization of food in stomach, 140 . stomach as a reservoir for chymification of food, 133.

of rice, 390 .

varying faculty of, in man's evolution, 40.

of vegetable foods, 271.

Digestive apparatus, 108.

glands of, 115 .

glandular organs of, gall-bladder, 119.

liver, 118.

pancreatic gland, 117.

salivary glands, 116.

spleen, 118.

See also Alimentary Tract.

Digestive glands, 115.

Digestive juices, correlation of functions of body by chemical action of, 132.

saliva, 129.

secretion and action of, 129 .

of stomach and intestine, secretion, 130 .

Digestive organs, absorptive power of, in large intestine, 174 .

in small intestine, 169 .

in stomach, 163.

evolution of, summary of, in connection with evolution of teeth, 47 .

number of, in higher grades of animal life, 107.

Digestive processes, functions of stomach, 133.

Dill, toxic substances contained in, 658 .

Dill seed, 648 .

Diphtheria bacilli, in milk, 688.

Disaceharids, 610 .

classes of, lactose, 88.

maltose, 88.

saccharose, 87.

difference of, from monosaccharids, 87.

Distillation of water, 245 .
Dogs, as food, 767 .

Domestication of animals, 32 .

Drinking water. See Water, Drinking of.

Ducks, flesh of, 299.

varieties of, 298.

wild, 299.

Dugong, as food, 767.

Duodenal digestion, 166 .

Duodenum, anatomy of, 113.

Dysentery, chronic, due to ameba coli, 665 .

\section{E}

Earth eating, 767.

Earth hog, as food, 768.

Eating, purpose of, 232 .

Economic test of food value, 60 .

Eczema, due to sugar, 632.

Edible portion of food, definition of, 695 .

Egg candling chart, 352.

Eggplant, 513.

toxic substances contained in, 661 .

Egg products, 356.

desiccated eggs, 356 .

ova, 356 .

pidan-Chinese preserved eggs, 358 .

Eggs, appearance of different grades of before the candle, 350 .

average chemical composition of, 725 .

chemical composition of, as compared with milk, beeksteak, cream cheese, and white bread, 354 .

chemical composition of whole egg, egg white, egg yolk, desiccated egg, and egg substitute, 357 .

comparative nutritive value of meat and, 355.

as complete food, 351 .

composition of, 351.

general percentage, of white and yolk of, 353 .

of white, 353 .

of yolk, 353 .

cooking of, 355 .

desiccated, 356 .

digestibility of, 355 .

edible, varieties of, 349 .

energy properties of, 356 .

preservation of, 356 .

preserved, Chinese, 358.

varieties of, 349 .

white of, 352 .

yolk of, 353.

Egg substitutes, 356 .

casein, 358.

Elastin, 278.

Elderberry, 499.

active principle of, 659 .

Elementary composition, of human body, 53.

Elements, and their compounds, 53 .

found in human body, 52 .

necessary to value of foodstuffs, 53 . 
Elephant, us food, 767 .

Elk. as fool, itit.

Endive, 437.

Entrokinuse, 158. activating functions of, 1,58.

Euzymatic processes, cosential facts, ro garding, tabulation of, $14 i$. nature of, 146 .

reversibility, 150 .

specific action, 150 .

timperature control, 150.

Enzymes, 65.

action of, 147 .

specific, 150 .

of hormones: secretin and gastrin. 153.

of pepsin, 153.

of trypsin, 152.

active and insctive, 147.

amylolytic, 148.

amylase, 157.

classification of, according to nctivity. 148.

coagulating, 148 .

fat-splitting. 148 .

lipase, 157.

hormones, secretin and gastrin. 153.

interaction of, in succus entericus, 158. lipolytic, 148 .

list of, concerned in processes of diges oxidizing, 148 . tion and nutrition, 149.

peptolytic, 148 .

proteolytic, 148 .

enterokinase, 158.

pepsin, 153.

trypsin, 152.

stimulation and action of, during insalivation, 124.

sugar-splitting or inverting, 148.

invertase, 157.

temperature of action of, 150 .

transformation by, of purin bodies, 82 .

Erepsin, 158.

Ergot, source of fluid extract of, 661 .

Ergotism, 674.

convulsive and gangrenous, 674.

differentiated from erythromelalgia, Raynaud's disease or acrodynia, 675.

epidemics of, 674 .

symptoms of, 674 .

test for detecting presence of, in flour, 675.

Erucic acid, 99.

Erythromelalgia, simulated by ergotism, 675.

Esophagus, anatomy of. 110.

Esters, definition of, $\mathbf{9 6}$.

glycerin, of oils and fats, acids entering into formation of, $98,99$.

natural and artificial, 97.

phospho. See Phospho Esters.

of sterols and fatty acids, of waxes, $9 !$. rintrorn, volatile, $9 \%$

uned for artificial flavors, 97.

Fithyl alevoluel, U3.

fivolution of man, in paxtlily atrueture and function. fo.

from an aptroreal anerntar, 12.

of digometior urgano, 13,

due to variation in dfet, fi).

mammary, dur en artificial ionding of children, 4.4.

dietetic advanre in, 9.

digentive organn in, 43.

and colithe, $x$.

influence on, of diotary evolution, 4.

from primateon. $x$.

in whape and development of akull, $y$.

terth in, 15.

Folution of man'w dirt, with changer in bodily atructure and function, 40,

diet epochs, 8 .

diet of primates below man, 3.

evolution of digextive organ and, 13.

evolution of teeth and, 45.

food of evolving man, 2.

general advanees in, 9.

influence of cultivation of nutritive properties of vegretables. 5.

influence of, on general evolution, I.

influencing factors in. 7 .

Evolution of teeth, 45 .

Fixeretions, mineral content of, 256.

Fxeretory organs, effect of alcohol on, 381.

Fixtract, becof, 287.

meat, 287.

Fixtractives, of meat, 280.

\section{F}

Fats, absorption of, 169.

extent of, 182.

function of leukocytes in, 181.

in large intestine, 176.

lost fraction in, 181.

manner of, 178 .

mechanism of, 178.

part played by bile and pancreatic juice in process of. 180 .

processes involved in. 183.

in rectal feeling, 176.

theories of, 178.

animal. Sre Animal Pats.

assimilation of, 459 .

characteristics of, 97 .

chemical. 458.

common forms of, 459 .

dependence of muscular action on, 460 . desaturation of, 179.

eaten in excess of daily requirmmento. 179.

as psters of triatomic alcohol glycerin. 97.

"fatty" or "fixed oils" or "oilw," 27.

fish. 467 . 
Fats, importaner of, 459 .

to health, 460 .

of meat, 278 .

in milk, 308 .

natural glyeerids contained in, 98.

neitral. 179.

vs. oils, 460 .

oceurrence of, 97.

sulubility of, 97 .

sources of, 457.

storage, 179 .

use of term, and examples of, 697.

in vegetable foods, 370 .

volatile or essential oils, 97.

Fats and oils, animal. See Animal Fats. classes of, 457 .

economy of, 461 .

fixed, 457 .

substanes of 457 .

uses of, summarized, 472.

vegetable. Sce Vegetable Fats and Oils.

Fatty bodies, 458 .

tluid and solid, 458 .

Feces, mineral content of, 257.

Fenuel, 642.

Fennel seed, 648.

Fermentation, application of, to the "germ theory," 146.

of carbohydrates, 187.

of malt, 561 .

in process of digestion, 145.

of wine's, 595.

Fermented liquors, as beverages of precibiculturists, 31 .

Ferments, characteristics of, 146.

definition of, 145 .

Ferruginous salts, importance of, to body, 264.

Fertilizers, use of, among early Indians, 36.

Fig, cultivation of, 488 .

description of, 487 .

fertilization of, 488 .

nutriment of, dried and fresh, 489 .

Filberts, 509 .

Filtration, and absorption, 207.

definition of, 207.

Fire, applied to meat. 15. systematic use of, 14 .

Fish, average chemical composition of, conkiod, 723.

frosh fish, $720-723$.

preserverd and canned, 723.

comparative cost of nutrients and energy in, 282.

comparative value of meat and, 304 .

cooked, analysis of, 302 .

conked (boiled). analysis of, as served at table: 301.

and disestse, 302 .

flowh of, 300 .

as fool of precibiculturists, 25.

most digestilule of, 301.

preservation of, 300,303 .
Fish, produced in America, 303. shell. See Shellfish.

use of, 300 .

as food in coast countries, 302 .

as invalid food, 301 .

as seasonable food, 300 .

Fish fats, 467 .

codliver oil, 467.

Fish poisoning, 670 .

Fish roe, value of, 303 .

Fish tapeworm, 666.

Flavors, fruit, 97. imitation, 97.

Flesh, decomposed, as food of Zulus, 775.

Flies, infection of food by, 689 .

Flour, best for food, 381 .

comparative cost of nutrients and energy in cereals and, 394.

composition of cereals and, 376 .

methods of making, modern process of milling wheat, or patent roller process, 380 .

primitive, 380 .

probable origin of, 380 .

relative composition of various grades of, 381 .

relative food values of various grades of, 381,382 .

straight run, 381 .

whole wheat, 383 .

Flours, meals, etc., average chemical composition of, 729-734.

Fluorin, presence of, in body and in foods, 274.

Food, absorption of, 141.

rôle of white blood corpuscles in, 293 .

adulterants of, 682 .

adulterated, and adulterants, table of, $686,687$.

adulteration of, 681,683 .

amount of actual nutrients obtained in, chart of, 59.

animal. See Animal Food.

appetizing of, by condiments, 27.

arsenic introduced into, 686 .

azotized, 55.

canning of, 684 .

chemical constituents of body and, 52 .

classification of food, 55.

chemistry and physiology of proximate principles of, 63 .

complete, eggs and milk, 351.

definition of, 232,638 .

digestibility of, physiological test of, 162.

quantity and quality ingested, 161.

early preparation of, 13.

elements of, 234 .

function of water as, 248 .

idiosynerasies regarding, 690 .

imperfectly balanced, 664 .

infected, meat, 688 .

milk, 687 .

oysters, 689 . 
Food, infection of, ly tlies, 6s8.

by other poisons, 673.

by parasites, 665.

by ptomains, biss.

insalivation of, 12:3.

insullicient, discuses calused by, 663.

maceration of, in stomach, 13i.

mastication of, 1:21.

mineral content of, 258.

bromin, 274.

calcium, 265.

chlorin, 273.

fluorin and silica, 274.

iodin, 273.

iron, 266.

magnesium, 265.

manganese, 275.

oxalic acicl, 274.

phosphorus, 271.

potasinu, 269.

sodium, 269.

sulphur, 272.

misbranding of, 681 .

of Nortli American Indians, 22.

nutritive constitnents of, tissue formers, 56.

overburdening digestive powers of stomach with, 133.

overeating, 663 .

parasites found in, 665 .

perfect, conditions to be fulfilled by. 313.

of precibiculturists, 21 .

preservatives of, 684 .

preservative methods for, among Indians, 13.

proximate principles of, 54.

carbohydrates, 84.

chemistry and physiology of, 63 .

hydrocarbons, 92.

inorganic salts, 102 .

proteins, 6 \%.

table of, 76,77 .

water, 103.

purpose of eating. 232.

quantity and quality of, ingested, 161.

raw, tapeworm due to, 666 .

salt content of, 258 .

sterilization of, in stomach, 140.

vitamines in, 64 .

waste of, by use of too much at one meal, 133.

chiefly affecting proteins, 133.

Food analysis, method of arriving at, 696 .

Food analysis taliles, explanation of terms used in. 695.

sources and methods of computing, 694 .

historical aspect of, 604 .

terms used in. Sce Food Materials. composition of,

Food materials, average diemical composition of, animal and vegetable foods, unclassified, 758 .

beef, canned, 707 . fixal maturgiale, average clomatral compeos

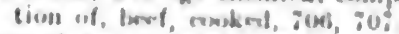
croruml and piekled, ios.

elrierl, ions.

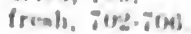

lerrier, frowh, is:.

lereal, erackern, pantry, i3t.

listler, ists.

luttermilk, i:s

erreal cotfin infuaion,

crereala, 7:20.734.

churear, izts.

comera and clumulato, 787.

condiunenta, 7:sl,

"gxw, 72:5.

finh, cookon!, 723.

froesh, izil i:3].

prenerviol and ransoml, iz3.

fours, menla, 729731.

froges loge, i24.

fruite, eannesl, 158 .

dried. 753.

fresh, 7is:.

gatne, 719.

hash, 75!?.

infants' and invaliols' foomls. 759.

jelliens, 7.54

lamb, $: 11$.

meat preslucta, $72 x$.

milk and milk products, 726 .

mincrment, 759 .

mutton, canned, 713.

frests, Fl:

nuts, 7.55.

pickles, 751.

pork, canned, 718.

fresh, 713.

organs of, 716.

pickled, salterl and smoked, 71\%.

sausage, 718.

poultry, il!.

preserves, 754 .

salad, 759.

sandwich, 759.

shellfish, cammed, 725.

fresh, 724 .

somps, 758 .

veal, fresls, 709.

veal organs, ili.

vegetable and animal, unclaseifed, 758.

yeast, compressul, $75 \%$.

coinpusition of, ash or usinoral waters. $69 \%$

carbohivilates, 697.

wible jortion, 693.

futs. 69\%.

fuel vulue, 697 .

protein. ti?ti.

refuce, $6: 05$.

Food metaluliem, relation of hacterial ac tivity to, 212

Foml of evolving man, animal. 2

factors determining chosion of, : 
Food of evolving man, vegetable, 2.

fruits, 2.

roots, 3 .

roots eaten by North American Indians, 3.

seeds, 2.

Food poisons, 662 .

Food principles, 64 .

Foods, classification of, 232 .

nitrogenous, 55, 231 .

non-nitrogenous, 55 .

elassification of nutritive constituents of, 56 .

comparison of fuel value and cost of, 315.

containing micro-organisms, 687.

containing ptomains, 668.

containing vitamines, 235 .

fats and oils, 457 .

as mixtures of foodstuffs, 234.

percentage composition of milk, milk products and some other, 329 .

respiratory or calorifacient, $\mathbf{5 5}$.

vegetable. See Vegetable Foods.

Foodstuffs, 233.

"accessory substances" of, 234.

adulteration of, 681,683 .

constructive, 233.

containing toxic or medicinal substances, alphabetically arranged, 657-662.

chamomile, 658 .

peppermint, 658 .

elements of, 234.

necessary to value of, 53 .

and vitamines, 234 .

Food value, tests of, 57 .

chemical, 57.

economic, 60 .

physical, 57.

physiological, 60.

Foot and mouth disease, infected milk from cattle with, 672 .

Formaldehyd, as food preservative, 685 .

Formic acid, 95.

Fowls, average ehemical composition of, 719 .

chemical composition of, in comparison with steak and chops, 298.

domestic, 296.

chicken, 296.

ducks, 298.

geese, 298.

guinea fowls, 299.

peafowl, 297.

pigeons, 299 .

turkey, 297.

unusual, sometimes used for food. See wild, 299. Animal Food, Unusual.

danger of "hanging," 299.

meat of, 299.

Frogs, as fool, 768 .

Frogs' lengs, 305 ,

avrage chemical composition of, 724 .
Fructose, 86 .

Fruits, absorption of, 479.

ampelidaceous or vine, currants, 498. grapes, 496.

anacardiaceous, mango fruit, 492 .

mango chutney, 492.

anonaceous, custard apple, 490 .

papaw, 490.

pawpaw, 490.

sour apple, 489 .

sugar apple, 490.

average chemical composition of, canned, 754.

dried, 753 .

fresh, 752 .

berries, 498 .

barberry, 499 .

blackberry, 499.

blue-berry, whortleberry, or bilberry, 498.

cloudberry, 500.

cranberry, 502 .

currants, 501 .

dewberry, 500.

elderberry, 499.

gooseberry, 500 .

huckleberry, 499.

loganberry, 500 .

raspberry, 500 .

roebuck berry, 500 .

service berry, 499 .

strawberry, 501

canning of, 684 .

chemical composition of, 477 .

acid and carbohydrate content of, 478 . acids, 477.

carbohydrates, 478 .

varying composition, 478 .

citrus, citron, 485.

description and varieties of, 484 .

grapefruit, 487 .

kumquat, 487.

lemon, 485 .

limes, 485 .

or ange, 486.

shaddock, 487.

classification of, 476 .

digestion of, 479 .

dried, proper method of cooking, 482 .

drupaceous, apricots, 483 .

cherry, 484.

damsons, 482.

peaches, 483 .

persimmon, 483.

plums, 482.

prunes, 482.

ebenaceous, persimmon, 492.

fermented liquors from, apple brandy, 585.

apple cider, 481 .

apricot brandy, $\mathbf{5 8 6}$.

blackberry wine, 499 .

cherry bounce, 484.

cherry brandy, 484 . 
liruits, fermented liquors from, prescli brandy, 483. perry, 481 .

garden, 512.

cantcloupe, 513.

cit ron, 512.

cueumber, 512.

eggplant, 513.

gherkin, 513.

melons, 513.

muskmelon. 513.

pumpin, 514.

squash, 514.

vegetable murrow, 514.

watermelon, 513.

herb-like, hunnus, 502.

pineapple. 503.

prickly pear, 504.

immature or ripe, condiments from, 645 . importance of, 47 ?

juices of, as beverage of precihicultur. ists, 31 .

leguminous, St. John's bread, 493. tamarind, 493.

miscellaneous tree, alligator pear, 495. mammee apple, 496 .

olives, 494.

pomegranate, 495 .

moraccous, bread fruit, 489 .

fig, $48 \pi$.

mulberry, 489.

myrtaceous, guava, 491.

rose apple. 491 .

Surinam cherry, 491.

palmaceous, cocoanuts, 494.

dates, 493.

passifloreous, 498.

pomaceous, apples, 480 .

pears, 481 .

quince, 482.

preservation of, by cold storage, 515 .

in relation to climate, 475 .

sapotaceous, mammee sapota, 491 .

sapodilla, 491 .

star apple. 492.

tree, anacardiaceous, 492.

anonaceous, 489.

citrus, 484 .

drupaceous, 482.

ebenaceous, 492 .

leguminous, 493.

miscellaneous, 494 .

myrtaceous, 491 .

palmaceous, 493.

pomaceous, 480 .

sapotaceous, 491 .

Fruits and berries, as food of precibicul. turists. 26.

Fruit sugar, 86.

Fruit transportation, recent progress in. 476.

Fuel value, definition and determination of. 697 .

Fungi, digestion of, 451 .
Fungi, mlilile, ttw.

boletum odislim, (51).

comprenition of, ftx.

keneral conmicleration to otwerve, ff?.

lichena, algare 148.

morel. fisti.

mushroom, 14:1

meralow, 4t?

purumol, 4.5.

truftlew, 119.

fungi meawersl, agar agar, tal.

\section{(3)}

Galactome, 86 .

Galnctotoxixmus, 672 .

Call-bladider, anatomy of, 119.

(inllic acid. 96.

(inme, average chemical componition of. 719.

big. as ford of precibiculturinta, is

danger of "hanging," 299.

high, 299, 300.

infection from, due to fool urwon which animal has been forling. bit.

Game birls. Sce bowls, will.

Garlie, 429, 644.

active principles of, 660 .

Garden fruits. See bruits, garden.

Gases, in solution in water, 235.

Gastric digestion. courke of, 164 . problem of, 156, 159.

Gastric juice, anulysis of composition of, 131.

juice, excitation of secondary serrotion of, 156.

excitation of secretion of, factora enter. ing into. 156.

by hormones, 155.

factors in secretion of, 130.

first stimulus of, 130 .

production and excitation of, factors an tering into, 156.

quality and quantity of secretion of. 131.

steps in merhanism of secretion of. 130. Gastrin, 6.5, 15.5.

(iastro-intestinal hacteriologr. Sirs lhac teriologv. censtro-intestinal

Gastro-intestinal tract. of nowly Imen in funt, bacteriological condition of, 2.5.

Geese, flesh. of, 29?

pnte de foie gras, 293.

wild, 299.

Celatin, analysis and fuel value of, 293.

chinf peculiarity of. 294.

composition of. 203.

pereentage of. in fish. 301.

preparation of. 293.

purest form of, 294 .

"fierm theory" of divease, 146

Gherkin, 513. 
Gin, definition of, 587 .

fictitious, 587 .

Holland, 587 .

Irish, 587.

"Old Tom," 587.

(iinger, preparation of, 644 . properties of, 645.

Ginger beer, 568 .

Glanis, gall-bladder, 119.

pancreatic, 117.

salivary, 116.

spleen, 118.

Glandular organs of digestion, gall-bladder, 119.

liver, 118.

panereatic gland, 117.

salivary glands, 166.

spleen, 118.

Glialin, in wheat, 379 .

Globulins, 78 .

Glucoproteins, 80 .

(ilucosamin, 87.

Gilucose, Sí.

artificial, 627.

definition and manufacture of, 626 . use of, 626 .

Gilucose vinegar, 605.

(ilutelins, 78 .

(iluten, of wheat, 378 .

Glutenin, 379 .

Glycerids, unsaturated, process for saturating, 459 .

Glyceryl esters, 458.

acids entering into formation of, 98 , 99.

Glycin, 70.

formula of, 68 .

(i) yecoll, 70 .

(ilycogen, 90.

Giveolipins, 100.

Gilycollic acid, 95 .

Glycoproteins, 80 .

Gilicosuria, alimentary, 85 .

(ioat meat, 284.

Conseberry, 500.

Grain. Siec Cereals.

Grain poisoning, 673. actinomycosis, 679 . beriberi, 679 .

Grain poisoning, cause of, 674. lupinosis. or lathyrism, (i75. pellagra, 675 .

sitotoxisms, or ergotism, 674.

Grain whisky, 58.3.

Grains of paradise, 648 .

Cranadilla, 498.

Grape cure, 496.

(irajofruit, 487. active principles of, 6tio.

Girape sugar, or dextrose, 85.

Grape sugar group, or monosaccharids, 84.

Cirapes, composition of, 497 .

cultivation of, 4!ti.

dried, or raising, 497 .
Grapes, European, and attempts to grow in United States, 496.

indigenous to America, 496.

nourishing and therapeutic value of, 496 . tannin and tartaric acid in, 659.

utilization of, 497 .

Grasshoppers, as food, 769 .

Green vegetables, 430 .

artichoke greens, 437 .

asparagus, 436 .

beans and peas, 439 .

celery, 435.

chicory, 438.

composition of, 430, 431, 432.

cooking of, 431 .

dandelions, 438.

digestibility of, 431 .

cabbage, 433.

cooked, 433.

raw, 433.

endive, 437.

food value of, 430 .

greens, or "pot herbs," 439.

lettuce, 435 .

okra, 438 .

peas and beans, 439 .

rhubarb. 435.

shelled beans, 439 .

sorrel, 438 .

spinach, 434.

tomatoes, 437 .

turnip tops, 439.

water cress, 436.

Greens, or "pot herbs," 439.

Ground nuts, 509.

Grubs, as food, 769 .

Guanidin, 83.

Guarana, composition of, 557.

fruit of, 556 .

source of, 556 .

therapeutic use of, 557.

Guava, 491.

Guinea fowls, 299.

Gull, as food, 769 .

\section{H}

Ham, curing of, 286.

value of, 285 .

Hare, flesh of, 286.

Hash, average chemical composition of, 759.

Hazel nuts, 509.

Heart, animal, as food, 295.

effects of alcohol upon, 570 .

Hedgehog, as food, 769 .

Hekt, 31 .

Hexoses, 85.

Hickory nuts, 509.

Hippophagy, as food, 769 .

Hippopotamus, as food, 770 .

Histidin, formation of betaimidazoleethylamin from, 220. 
Histons, 79 .

Hoarhound, medicinal nature of oil of titil,

Hog fat, or lard, t(bi).

Hogs, raising of, for pork, 2s5.

Holothuriae, as ford, iot).

Honcy, adulteration of, 684 .

unalysis of, 630 .

conposition of, 1330 .

definition of, 628 .

description of, $(330$.

food and fucl value of, 629.

as food of precibiculturists, 27.

poisoning by, gathered from poisonoum flowers, 6330.

production of, in United States, and States prolucing, 6i31.

therapeutic value of, $62 \%$.

use of, in place of sugar, 629 .

varicties of, 631 .

Honey bee, methods of aiding in prolucing greater amounts of honey, 631 .

value of, 630 .

Hops, as a hypnotic, sedative and anaphrodisiac, 659 .

Hormones, 65.

characteristics of, as chemical messen. gers, 154.

chemical action of, 155 .

gastrin, 65, 153.

secretion, 65, 153.

Horseflesh, as food, 256 .

Horseradish, 425, 645.

sulphur compounds of, 659 .

Huckleberry, 499.

Human flesh, as food. 24.

Hydrocarbons, classification of, 93.

alcohols, 93.

aldehyds, 94.

benzoic acid, 96.

butyric acid, 95 .

citric acid, 96.

cyclic alcohols, 93.

esters, 96.

esters, volatile, 97.

gallic acid, 96.

glycollic acid, 95.

lactic acid, 95.

malic acid, 96.

oils and fats, 97 .

organic acids, 94 .

oxalic acid, 95.

phospho esters, 100.

salicylic acid, 96.

succinic acid, 96.

tannic acid. 96.

tartaric acid, 96.

terpenes, 93.

triatomic alcohols, 93 .

waxes, 99.

composition of, 92 .

organic acids, acetic, 95 .

formic acid, 95 .

percentage of, absorbed from dry sub. stances in various foods, 163.
Hydrocyanie acid, girlefed frum hiters al monston, preach and elocery puts, 6.64

Ilydrogen, mulphuretion, 1as.

Hyilrulynim, of complas proteins, aminas. ariul iroulting frum, 135.

IIypogeic acid, 9:3

\section{I}

Iceland mown, modicinal peopertion of, Gro.

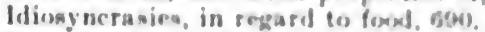

Inuana, as ford. $7 \%$.

Ileum, digention in, 167.

Indol, definition of, 218.

formation of. from eryptopplian. $21 \mathrm{~s}$.

Infantw, gastro.intestinal bacteriolugg in, $2 \cdot 28$.

Infant's diet, relation of forreign pooteine to, im.

Infants' and Invalide' foods, averageo cheru. ical compasition of, $75 \%$.

Inorganic salts, 102.

Inorganic aubstances in vegetable forma 366.

Inosit? 87.

Inositol, 94.

Insalivation, act of, 123.

function of saliva in process of digos. tion. 124.

influence of temperature on, 125.

a reflex action, 126.

stimulation and action of enzymes dur. ing. 124.

Intestinal digestion, 166 .

Intestine, large, absorbing power of, 176.

absorption in, 174 .

absorption of fats in. 176.

absorption of salt in. 175.

anatomy of, 113.

bacterial activity in, 228.

coats of. 115.

small. absorption in, $169,174$.

anatomy of, 111 .

area of. 169 .

bacteriology of, 227.

duolenum, 113.

inversion of carbohydrates in, 18.5.

jejunum, 113.

Intestines, digestive juices of, 130

uses of bile in. 119.

Inulin. 92.

Invalid diet, use of cheese in, 345 .

Invertase, $15 \%$.

Invert-sugar, 86.

lodin, in foods. 273.

percentage of. in animal foots, 273.

in fresti fouds. 273.

Iron. in animal fools, 267.

effect of habitual consumption of forde por in, 267 .

form of. $26 k$.

importance of, to body, 266. 
Iron, occurrence of, 266.

percentage of, in dried substances, 269. in fresh substances, 267 .

in various foods, 268 .

in vegetable foods, 267.

sources of, 266.

Iron-containing foods with content estimated, 267, 268.

\section{J}

Jejunum, anatomy of, 113.

Jellies, average chenical composition of, 754.

meat, 293.

Jerboa, as food, 770 .

Jerusalem artichoke, 416.

composition of, 415 .

Juices of fruits, as beverage of precibicul. turists, 31 .

Juniper berries, 646 .

Junket, 338 .

\section{K}

Kale or borecale, 434 .

Kalong, as food, 771 .

Kangaroos, as food, 771 .

Kaoling, 403.

Kephir, 338.

double fermentation in, 339.

Kidneys, animal, as food, 294.

Kirschwasser, 590.

Kohl-rabi, 425.

Kola, composition of, 556 .

increase of power of endurance for mental and physical strain by, 556 . origin of, 556 .

Kreptoxismus, 669 .

Kumiss, 338.

double fermentation in, 339 .

making of, 339,340 .

Kilimmel, 590 .

Kumquat, 487.

\section{L}

Lactic acid, 95.

production of, from milk, 331 .

Iactose, 88.

Lamb, average chemical composition of, 711 .

cuts of, 701 .

as food, 284.

"spring," Canadian goat meat sold for,

Iard, 28.5 . 284.

adulteration of, 683 .

krades of, 46.5.

Inthvism, 675.

Isuric acid, 9?.
Lavender, medicinal nature of oil of, 661 .

Lead poisoning, from preserved food, 685 .

Leben, 341.

Lecithins, 100.

Legumes, absorption of, 441 .

beans, bolicohs, 444 .

broad, 444.

butter, 444.

kidney, 444.

lima, 444 .

soy, 444.

chemical composition of, and resulting utilization of, 442 .

chief nutrient value of, 441 .

dried, 441.

composition of, 443 .

flatulence attributed to, 443 .

lentils, 447 .

peas, canned, 447 .

chick, 446.

cow, 446.

field, 445 .

garden, 446.

peculiar characteristics of, 441 .

utilization of, resulting from chemical composition, 442 .

varieties of, 443 .

Lemons, active principles of, 660 .

composition of, 485 .

uses of, 486.

varieties of, 485 .

Lentils, 447.

Lettuce, 435 .

active principles of, 660 .

Leucin, 71.

Leucocytes, function of, in fat absorption, 181.

Leukomains, foods containing, 668.

Levulose, 86.

Lichenin, 91.

Lichens, 447, 450.

Licorice, active principles of, 660 .

Lily bulbs as food, 428 .

Limes, 485.

active principles of, 660 .

Linseed oil, 471.

Lion, as food, 771 .

Lipase, 157.

Lipochromes, 102.

Liqueurs, absinthe, 588 .

adulteration of, 683 .

alcohol content of, 589 .

Angostura bitters, 589.

artificial essences in, 588 .

Benedictine, 589.

Chartreuse, 589.

composition of, 588 .

crême de menthe, 590 .

curacoa, 590 .

definition of, 587 .

effect of, on digestion, 591 .

harmful influences of, $\mathbf{5 8 8}$.

Kirschwasser, 590 .

Kïmmel, 590 . 
Liqueurs, Maraschino, 690.

Mead, 590.

Mesenl, 590.

metheglin, 581

ratufin, 581.

vermouth, 591.

Liquors, fermented, as beverage of pres cihiculturists, 31.

Litchi nuts, 509.

Lithium, waters containing, 528.

litmus, in fruits and regetables; 6.59.

liver, matomy of. 118.

animal, as food, 295 .

as bodyguard of systom against poisons, 668.

mineral content of, $257,261$.

Lizards, as food. 771 .

Llama, as food, 771.

Lobster, 304.

Locusts, 493.

as food. 771 .

Loganberry, 500.

Lotus, 428.

Lungs, animal, as food, 295.

Lupinosis, or lathyrism, 675.

Lycopin, 101.

Lymph, mineral content of, $257,261$.

Linx, as food, 771 .

Lysin, formation of cadaverin from, 220.

\section{M}

Mace, 640.

Maceration of food in stomach, 134

Magnesium-containing foods with content estimated, 265.

Maize, early cultivation of, among Indians, 35.

Malic acid, 96.

Malt liquors, action of, on digestion, 566 . adulteration of, 682 .

beers, American, composition of, table of, 563 .

boiling of the wort, 560 .

comparison of. 564 .

composition of, 561 .

tables of, 564, 565 .

consumption of, 567.

contents of, 562 .

"findings" in, 562.

low alcoholic, 567.

nourishment in, 566 .

origin of, 559 .

Porter, 562.

preparation of, 560 .

cooling of the wort, 561 .

fermentation, 561 .

germination of malt. 560 .

malt substitutes used in, 560 .

worting. 560.

"priming" of, 562.

stout. 562.

Malt sugar, ss.
Male vinegar, bos.

Male whinkey, 582.

Malcorlexitrino, 91.

Maltome, 88.

Mamusualia, claness of, an rrgarcls allet, I

Mammary function, changer in, due to as tifleial fowling of childen, is.

Mammede applos ters.

Manminew mR pota, 491.

Munuter, an food, :il.

Manganewe, prowence of, in body and in fords, 275.

Mango chutury. 4!2.

Mango fruit, 4 in.

Manna, Iaxative and nutrition qualition of, 66 .

Maple map, olstaining and trevatuent of, 617.

Maple nugar, B17.

manufacture of, $\$ 18$.

alulteration of, 683.

content of, B18.

weight of, to gallon, 617 .

Maple tree, average yifld of sugar per seasors from, B18.

Maraschino, 590 .

Maruschino cherry. 48\$.

Marmot, as food, 771.

Mastication of food, act of, 121.

in animals, 122.

movements contributing to, 121.

prime importance of, 122.

promotion of secretion of saliva by, 192. results of, 122, 123.

time consumed in, 122.

Matzoon, 341.

May apple, violent catharwis due to, 661 .

Mead, 590.

Meals, hours for, 134.

length of intervals between. 133.

Meat, analysis of variety of, 2*2.

Meat, average percentage of waste in, 280. cauning of, 289,684 .

comparative nutritive value of egov and, $35 \%$.

comparative value of fish and, 304 .

composition of, 277 .

acids, 278.

chemical. 280.

extractives, 280.

fat. 278 .

mineral substances, 278.

muscle juice, 279.

muscle tiswle, 978.

vitamines, 279.

water. 251.

cooking of, advantages of. 1:5.

evidences of, among priuitive men. 15.

cuts of. 698 .

beref. 699 .

Inmb. 701

mutton. $; 01$.

pork. iul. 
Meat, cuts of, veal, 700 .

digestion of, cooked and raw, 15.

in diet of North American Indians, 23. food value of veretable foods vs., 367 .

of fowls. sce Fowls.

hare and rabbit, 286 .

horseflesh, 286 .

importance of, 277 .

process of barbecuing or roasting of, 284.

raw, 15 .

ise of, 16 .

stale, 300 .

tolugh, action of papaw on, 490 .

tubereulous, 688 .

varieties of, beef, 282.

goat, 284.

lamb, 284.

nutton. 283.

opossum, 286.

pork, 285.

raccoon, 286.

venison, 284.

Meat extracts, beef bouillon, 291 .

beef extract, 287 .

beef juice, 289 .

beef poptones, 292 .

beef tea, 289 .

constituents of, 288 .

meat powders, 292.

nutritive value of, 287.

stimulating effect of, 287.

Meat jellies, digestibility of, 293.

preparation of, 293.

Meat poisoning, 669 .

botulismus or allantiasis, 669 .

from unwholesome diet of animal before killing, 673 .

kreotoxismus, 669.

Meat powders, 292.

Meat products, animal viscera as food, 294.

average ehronical composition of, 728 .

extracts, 287.

gelatin, 293.

jellies, 292.

Meats, comparative cost of nutrients and encrey in, 282.

comparative digestibility of, 286 .

Medicinal substances, foodstuffs containing, 657-662.

Melitose, s!).

Melizitose, 89.

Meloris, 513.

cantelonine, 513.

muskmeingl. 513.

watiormelon, 513.

Mental proressess, effect of alcohol on, 580 .

Mescal, ¿!)().

Metabolism, bacterial. See Bacterial Met. abolism.

coffrects of aleohol on, 580.

iufluence of nature of diet on products of. '213.
Metabolism, relation of bacterial activity to, 212 .

of salts of body, 256 .

Metaproteins, 83.

Metheglin, 591.

Mice and rats, 772 .

Microbe action, specificity of, 216 .

Microörganisms, food containing, 687 .

Milk, absorption of, 312 .

adulteration of, 334 .

advantages of, 315 .

in disease, 316.

fluidity, 315.

food value, 315 .

alkaline fermentation of, 332 .

average chemical composition of, 727 .

bacterial content of, $\bullet 328$.

classes of bacteria, 328 .

in bitter milk, 331 .

in slimy or ropy milk, 332 .

in sour milk, 331 .

sources of, 330 .

as beverage of precibiculturists, 30 .

bitter, 331 .

boiled, 321 .

boiling of, 313 .

certified, 318.

certified regulations of New York Medical Society for, 318.

requirements for, general, 319. special conditions, 320 .

standards of American Association of Medical Milk Commissions, 319 .

changes in separation of fats as cream, 331.

changes in, souring, 331.

chemical composition of, as compared with eggs, beefsteak, cream cheese and white bread, 354.

chemical nature of, 317 .

clean, production of, 332 .

clotting of, 310 .

boiling diluents to prevent, 312 .

colored, 332.

comparative analysis of milk products and, $\overline{3} 36$.

comparison of cow's and human, 325, 326.

composition of, 308 .

accessory substances or vitamines, 316.

casein, 308.

comparative, in different animals, 309.

fat, 308 .

fractional, 327.

milk sugar, 308 .

salts and suspended matter, 308.

'Tibbles' tables of, for various milks, 327.

variation in, 326 .

composition of some succulent vegetables as compared with, 419 . 
Milk, cosstituents of, orgunic aml inor. gunic, Balwexk' inhle of, 311.

Van Slyke's tuble of, 310.

definition of, 307 .

desiresitorl. 324.

composition of, 325 .

composition of eascin nnd lries milh preparations, nutrionts, per cont. 325.

methods of making. 324.

uso of, 325 .

digestion of. 310 .

fermontution of, double, in kumise and kephir. 3339.

tlavors in, 332 .

lluidity of, 315.

as a fool rather than heverage, 315.

food value of, 30!9, 315 .

comparison of, by weight and cost with other foods. 30.4 .

handling and eare of, 333 .

transportation. 333.

human, mincral content of, 261.

infected, 672 .

from cattle with foot and mouth dis. ease, (iiz).

mieroörganisms in, 687.

modified. 325.

ingredients of, 326 .

not a perfect food, $309,313,314$.

pasteurized, 320 .

home, 321 .

summary of, 322 .

percentage composition and fuel value per pound of whole milk and some milk products, 335.

percentage composition of, together with milk products and other foods, 329.

preservatives in, use of, 334 .

production of clean, 332 .

separation of fats of, as cream, 331 .

skim, 334.

skim, composition of, 334 .

slimy or ropy, 332.

souring of, $3 \dot{3} \dot{1}$.

sterilization of, 323 .

process of, 323 .

transportation of. 333 .

treatment of, boiling, 321 .

desiccating. 324 .

general requirements for, 319 .

modified. 325.

pasteurization, 320 .

home. 321 .

summary of, 322.

special conditions for, 320 .

sterilization, 323 .

vitamines, of, 316 .

importance of, 316 .

where found, 317 .

Mlk infection, diarrheal diseases from, 688.

diphtheria bacilli from, 689 .
Milk infertion, araplat fover efuilerenico isuo (11, ) 14:

tulwereirluillo, GAN

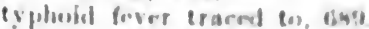

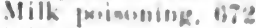

llilk produrts, average elomical crenjes nitlons of, ist?

tronnselablere, 334.

linter, is il

linserernilk, istis.

rharenr. 341.

comparative analyoin of milk and, 336

cress In. 335.

junkert, 3374.

kephir. 338.

kumion. 338

le.teres, 311.

untzห⿻上丨 341 .

untrientw and enerky in, 324.

percontage componition and forl values [n'r justurl of. 342.

percentago componition and fuol value pere poumd of whole milh and. 33.7.

percentago composition of, tangether with milk and mouse other fonoto, 329.

skim milk. 334.

whey, 337 .

yanirt, 341 .

yogheort, 310.

Milk sllgar, 88, 308.

Millet, 401 .

composition of, 402.

proso, 402.

varieties of, 40:2.

Milling, primitive, 3t.

Mincemeat, average chemical compaition of, 759 .

Mineral content, of bloml. $25 \%, 261$.

of boty. 25.5, 25ti.

function of $26 \%$

of bolles. 257. 54 il.

of brain. $20 i 1$.

of excretiuns. 256 .

of food, 2is.

bromin. 274.

calcium, 2his

chlorin, 273.

fluorin, 274 .

iodin. 273.

iron, 2titi.

magnesium, 20.5.

mangunes, 270.

oxalic acid. 27.

phosphorus, 271.

potassium, 269.

silica. 274.

soxlium. 2oi?.

of human milk. 261.

of liver. 2357. 20il.

of Irmuh, 261 .

of ineat. 27!?.

of muscles, 237. 261. 
Mineral content, of organs, 257.

of spleen, 261 .

sulphur, 272.

of sweat, $25 \%$.

of urine, 257 .

Mineral salts, in body, calcium, 264.

ferruginous, 264 .

sodium chlorid, 263, 264.

daily requirement of, for average adult, 258.

for infants, 259.

derived from food, uses of, 264.

form of, in body, 259.

functions of, in body, 262.

importance of, 255.

to body, 255, 260.

uses of, to body, 264.

utilization of, $\mathbf{2 5 9}$.

in vegetable foods, 371.

Mint, 641 .

Modified milk, 325.

ingredients used in, 326 .

Molasses, 6i2.2.

adulteration of, 625 .

composition of, difference in, between molasses and successive crystallizations of sugar, 623 .

produced by open kettle process of boiling, 623 .

Monkeys, as food, 772.

Monosaccharids, 84, 610 .

classes of, pentoses, 85 .

tetroses, 84.

trioses, 84.

conversion of, into corresponding alcohols, 85 .

hexoses, 85 .

dextrose, 85.

galactose, 86 .

glucosamin, 87 .

inosite, or muscle-sugar, 87.

invert-sugar, 86.

sorbinose, 87 .

levulose, 86 .

Moonshine whiskey, 584.

Morel, 450.

Moths, as food, 772 .

Mouth, anatomy of, I08.

bacteriology of, 226 .

palate, 109.

teeth, 110.

Mud baths, 537.

Mulberry, 489.

Muristic acid, 99.

Muscle juice, of meat, 279.

Musele, mineral content of, 255, 257, 261 .

Muscle-sugar, 87.

Muscle tissue, of meat, 278 .

Muscular action, dependence of, on fat, 460 .

Muscular activity, effect of alcohol on, 573,592 .

Muscular work, sugar as food for, 636 .

Mushroom, edible, description of, 449 .
Mushroom, meadow, 449. parasol, 449.

Mushrooms, toxic substances contained

Muskmelon, 513. in, and tests for detecting, 660 .

Musk-ox, as food, 772 .

Mussels, 307.

Mustard, 648.

sulphur compounds of, 659 .

Mustard oil, 471.

Mustard seed oil, 470 .

Mutton, 283.

average chemical composition of, canned, 713.

fresh, 712 .

cuts of, 701 .

factors influencing quality of, 284.

Mutton fat, or suet, 466 .

Mydriatic alkaloids, contained in potatoes, tomatoes and egg plant, 661 .

Mytilotoxismus, 671 .

\section{N}

Nerve action in digestive processes, 128.

Nervous tissue, mineral content of, 257.

Nickel, in preserved food, 685 .

Nitrates, in water, 242.

Nitrites, in water, 241.

Nitrogen, amount of, required daily by adult, 231 .

in solution in water, 239.

Nitrogen starvation, 280.

Nitrogenous extractives of proteins, betain, 83 . amids, 83.

guanidin, 83.

Nitrogenous foods, 55, 231.

Nitrogenous matter in cheese, 347.

Nonproteid, definition of, 696 .

Nucleoprotein, 73.

Nucleoproteins, 81

Nutmeg, preparation of, 649. tree producing, 649.

Nuts, acorns, 506.

almonds, 506.

average chemical composition of, $\mathbf{7 5 5}$.

beechnut, 507 .

Brazil nut, 507.

bread nuts, 508.

butter nuts, 508 .

candle nuts, 508.

cashew nuts, 508 .

chestnuts, 508 .

chinquapin, 508 .

cocoanuts, 509.

digestion of, 505 .

filberts, 509 .

as foods or as luxury, 504.

as food precibiculturists, 26 .

food value of, 504 .

increased appreciation of, 506. 
Nuts, fucl value of, 505 .

ground nuts, 509.

huzel nuts, 509.

hickory nuts, 50!?.

kola or Goorit-nut, 536 .

litchi l.uts, 5099.

nutritive value of, 504.

paradise nuts, 509.

peunuts, 510 .

pecan nuts, 510.

pignolia muts, 510.

pine nuts, 510 .

pistachio nuts, 511.

supuenin nuts, 511.

walnuts, 511.

\section{o}

Oatmeal, composition of, 399 .

cooking of, 400 .

digestibility of, 400 .

food and fuel value of, 400 .

Oats, active principles of, 660 .

composition of, 399 .

and of oat products, table of, 399 .

definition and market form of, 398 .

Oil, of cinnamon, 644 .

of cloves, 643 .

of coffee, 559 .

essential or volatile, 457 .

fats vs., 460.

fixed, mustard, 648.

of tea, 559 .

use of, by precibiculturists, 30 .

vegetable. Sce Vegetable Fats and Oils. volatile, of nutmeg, 649 .

See also Fats and Oils.

Oils and fats, 97.

acids entering into formation of glycerin esters of, 98.

Okra, 438.

Oleic acid, 99.

Olein, 458.

Oleomargarin, 466.

Olive oil, adulteration of, 683.

Olives, 494.

Onions, 429

active principles of, 660 .

composition of, 424 .

Opossum, as food, 772 .

meat of, 286.

Orache, 438.

Orange, chief varieties of, 486 .

composition of, 486 .

cultivation of, 486 .

Oranges, active principles of. 660 .

Organic acids, acetic acid, 95 .

benzoic acid, 96.

butyric acids, 95 .

citric acids, 96.

formation of, 94 .

formic acid, 95 .

gallic acid, 96 . 1)rganic urida, alscullic acha, 95.

lactic aciol. Dán.

malio nicid, (ors.

excurrence of, 95.

walic ardul. 0.5.

aulievlle ariol, 90s.

muccinic achl, bes.

tanuic arid, ios

turturic: ariol, mes.

Crganic matter, promence ot, in water, 280.

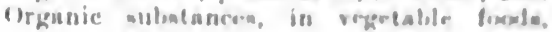
$317 \%$.

()ruithin, formation of putreacin from. 2:"s!

()suosis, and alowerption, :004.

definition of, gus.

as explanation of phenomena of atmorp tion, 172.

phyniological importance of. 207. 200

Osmotic promature, deflinition of, an appolind (1) molutions. 31\%\%.

exerted by eryatalloida. 206.

exertml liy protoin. 20t?

Ostrich, an food, 732.

Overeating, chronic, condition due to, 664.

diseases due to, 663.

temprary, conditions due to, 663.

Oxalate of lime, preance of, in terols. 97

()xalates, in sorrel and tomatoes, Gi2.

Oxalic acid, 95.

presence of, in foods, 274 .

Oxalic acid poisoning, due to use of rhubart, leaves as greens, biz.

Oxydase, in tea, 541.

Oxygen, in solution in water, 239.

Oyster plant, 425.

Oysters, danger of infection from, 673.

infection by, $6 \mathrm{~s} 9$.

food value and culture of. 305 .

\section{$\mathbf{P}$}

Palate, anatomy of, 109.

Palm oil, flis.

Palm sugar. 618.

Palmitic acid, 99.

Palmitin, 45s.

Pancreas, anatomy of. 117.

animal, as food. 295.

induction of activation of, 153.

Pancreatic juice, part played by, in fat aborption, 180.

Pawpaw, 490.

action of, on tough meats. 4 .

Paracresol, formation of, from tyronin. 219.

Paradise nuts, 509.

Parasites, ameba coli. 665.

Anchylostomum duodenale, 666.

Asenris lumbrimiles. 66es

billarzia hacmatobia or blood Alske. 600.

Bothriocephalus latu*. B66.

coccidium oviforme, 663. 
Parasites, diseases due to fools containinc. or ova of, 665 .

listoma hepaticm or liver fluke, 666.

Filaria, or Dracunculus medinensis, 667 .

Filaria sanguinis hominis, 667 .

intestinal, 666 .

()xyris vermicularis, or pin-worm, 666.

Rhabdonema intestinale, 667 .

sources of, in food, 665 .

Tenia cueumerina, 666.

Tenia echinococens, 666.

'Penia mediocanellata, 666.

Tenia saginata, 666.

Penia solimm, (666.

Trichina spiralis, 667.

Trichocephalus dispar, 667.

trichomonas intestinalis, 665 .

Parrots, as food, 773 .

l'arsley, 642.

toxic substances contained in, 658 .

Parsnips, 422.

toxic substances contained in, 658 .

Passaflora edulis, 498 .

Pasteurization of milk, home, 321.

summary of, 322 .

Pasteurized milk, 320.

Pastry, average chemical composition of, 734.

Pâté de foie gras, 299.

Pawpaw, 490.

digestive ferments of, 661 .

Peach bran'y, 483.

Pach pits, hydrocyanic acid yielded from, 658 .

Peaches, 483.

Peafowl, flesh of, 297.

as food, 772 .

Peanut oil. 469.

l'eanuts, 510.

Pears, alligator or avocado, 495.

Pears, use of, as food, 481 .

varieties of, 481 .

l'eas, analyses of, 747 .

cannel, 447.

chick, 446.

comparison of beans and, 446 .

('ow, 446 .

green, $439,440$.

firld, 445 .

garden, 446.

green, composition of, 440 .

Pecan nuts, 510.

Perctin, 369 .

Pectin bodies, in apples, 480 .

Prectose bodies, 92, 369.

Pelican, as fool, 773.

l'ellagra, alarming increase of, throughout United States, 678.

chronic nature of, 678 .

as a defirieney disease, 678 .

as due to rollodial silica in drinking water, 675 .

to eorn, 396, 659, 678 .

to lack of vitamines, 677 .
Pellagra, as due to restricted one-sided, mainly carbohydrate diet, experiments on, 677.

to vegetable diet, 676 .

etiology and pathology of, recent investigations into, 675 .

endemic-epidemic nature of, 675 .

general conclusions on, 676 .

problem of, 675 .

Pemmican, 466.

Penguins, as food, 773.

Pennyroyal, active principles of, 661 .

Pentoses, 85.

Pepper, 646.

Peppermint, 641.

medicinal action of, 658 .

medicinal nature of oil of, 661 .

Pepsin, action of, 153.

Peptids, 83.

Peptids and amino-acids vs. blood protein, 196.

Peptones, 83.

absorption of, 168, 194.

Peristalsis, 127.

appearance of, 139 .

pyloric action, 137.

views on, 136 .

Perry, 481.

definition and manufacture of, 602 .

Persimmons, 483, 492.

cathartic action of, 661 .

Pharynx, anatomy of, 110.

Phenol, formation of, from tyrosin, 219.

Phospho esters, aminolipins, 101.

glycolipins, 100.

lecithins, 100.

phospholipins, 100.

phytic acid, 100.

sulpholipins, 100.

Phospholipins, 100.

Phosphoproteins, 80.

Phosphorus, form of, in foods, 271. percentage of, in fresh foods, 271.

in various foods, with content estimated, 272.

in water-free substances, 271.

presence of, in body and in food, 271.

Physical test of food value, 57 .

Physiological test, of food value, 60 .

Phytic acid, 100.

Pickles, 65l.

adulteration of, 652 .

average chemical composition of, 751 .

cold slaw, 652 .

sauerkraut, 652 .

sktshi, 652.

Pickling, common household method of, 651.

Pidan, 358.

Pie, analysis of, $\mathbf{7 4 2}$.

Pigeons, 299.

Pigments, 101.

classification of, 101. 
Pignolia nuts, 510.

l'ineapple, so3.

digestive forments of, bisl.

Jine nuts, 5/1).

Pistuchio nuts, 511.

l'lums, 452.

Poisoning by eherege, 671.

by fish, 6 ifo.

by grain, tiT3.

actinomycosis, 679.

beriberi, (if!).

lupinosis, or lathyrism, 675.

pellagra, 675.

sitotoxismus, or ergutism, 674 .

by meat, 6iti, 673.

by milk, 672.

protein, 192.

ptomain. See Ptomain poisoning.

by shellfish, $671,673$.

Polysacchurids, colloidal, 89.

cellulose, 91.

dextrin, 90.

glycogen, 90.

inulin. 92.

lichenin, 91.

maltodextrins, 91.

pectose bodies, 92 .

starch, 89.

tetrasaccharids, 89.

trisaccharids, 89.

Pomegranate, 49.5.

anthelmintic properties of, 661 .

Poppy seed oil, 469.

Porcupine, as food, 773.

Pork, average chemical composition of, canned pork, 718.

fresh pork, 713 .

pickled, salted and smoked, 717 .

pork organs, 716 .

sausage, 718 .

cuts of, 701 .

ham and bacon, 285 .

infected with Trichina spiralis, 667.

manners of eating, 285.

Pork tapeworm, 666.

Potassium, in body, 269 .

containing foods with content esti. mated, 270.

Potato, composition of sweet and white, 416.

sweet, composition of, 414, 415, 416.

cultivation of, 413 .

digestibility of, 414 .

keeping of, 413 .

presence of sugar in, 414.

varieties of, 413.

toxic substances contained in, 661 .

white, composition of, 410,412,415, 416.

cooking of, 412 .

desiccated. 412.

food value of, 412,413 .

history of, 410 .

structure of, 410 . l'otulome analyelw of. iti.

l'ottery. himturis ut unom ut, 19. utilization of dimeneresy ot, in

loultery. Aire fiunla.

l'run nim, 70.5

l'reciliculturionta leveragers of, 29.

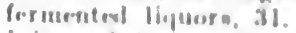

juices of fruite, 31

wilk. 30.

(ii), 30).

sutor, 29.

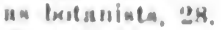

foresl of, :1.

of backwaril pesplea, 24

bic қанmе. "24.

condimentw, $2 \bar{T}$.

finfs f(xm). 25.

fruits and laorries, 26

lumey, 2i.

human fleab, 24.

of Sortlı American Indians, 22

sereds, largar, and nutw, 2h.

vegetable foods, 23.

Preservative methods among the Indians, 13.

I'reservatives, borax and horic acid, GAt. copper, ti85.

formaldehyd, 685.

ill effects of, 68.5.

nickel, 68.5.

proper use of, 68.5 .

salicylic acid, 6.5.

substances used as, 684.

sulphite and bisulphicte of sodium, 685 . sulphurous acid, 65.5.

Preserves, average chemical componition of 754

Prickly pear, 504.

Primates below man, diet of, 3.

Primitive man, diet of. 2 .

methods of cooking used by, 21 .

Primitive milling, $\mathbf{3 6}$.

Prolamins 78.

Proso millet. 402.

Protamins, 79.

Proteans, 83.

Proteid, distinction between protein and. 697.

use of term, 696 .

Protein, absorption of, in rectal ferling. 175.

blond, amino-acids and peptids in.s 1806.

distinction between proteid and. $69 \%$

foreign, absorption of, 190.

relation of, to infant's diet, 190.

form of, absorled, 18?.

meaning of, 693.

normal forms of, when aboortued. 194

percentage of, absorbed from dry sub. stances in various fockls, lois

relative aloorption of, in various formla. 373.

use of term. 696

Protein poinoning. albumonuria, 192. 
Protein poisoning, auto-intoxication, 193. causation of, 192 .

sulphuretted hydrogen, 193.

Protein value, in vegetable foods, 374.

Proteins, absorption of, accompanying changes of villus and epithelium, $18 !$.

albumoses and peptones, 194.

amino-acids resulting from hydrolysis of complex proteins, 195.

course of amino-acids in system, 199.

extent of reduction before, 190 .

final processes of, 202.

form of, 189 .

in form of amino-acids, 196.

manner of, 188.

normal course of, 198.

normal forms of, after, 194.

relation of amino-acids to, 195, 196.

relation of, to infant's diet, 190 .

action of, 73 .

in media, 221, 222.

albumoses, absorption of, 194 .

aunino-acids in, 67.

table of, 66 .

basic, 79 .

chemical classification of, 73 .

by American biochemists, 75 .

chemistry of, amino-acids, 67.

disintegration products of, 70 .

chemistry and physiology of, 65 .

chiefly affected in waste of food by overtaxed digestion, 133.

classification of, in order of formation, 196.

coagulable, 75 .

coagulated, 83.

complex, amino-acids resulting from hydrolysis of, 195.

conjugated, 80 .

chromoproteins, 80.

glyco- or glucoproteins, 80 .

lecithoproteins, 82.

nucleoproteins, 81 .

phosphoproteins, 80 .

of cow's milk, or caseinogen, 192.

definition of, 65 .

derivatives of, utilization of, in bacterial metabolism, 218.

derived, 82.

primary, protein derivatives, coagulated proteins, 83.

metaproteins, 83.

proteans, 83 .

peptids, 83 .

peptonis, 8.3 .

proteoses, 83.

digestion of, 74 .

factor of, 693 .

ingested, final processes of, 202.

mineral content of, 262 .

nitrogenons extractives of, amids, 83.

betain, 83.

guanidin, 83.
Proteins, osmotic pressure exerted by, 206.

peptones, absorption of, 194 .

relation of, to infant's diet, 190 .

simple, albuminoids, 78 .

albumins, 75 .

globulins, 78 .

glutelins, 78 .

histons, 79 .

prolamins, 78 .

protamins, 79.

in vegetable foods, 370 .

of wheat, 378.

Proteoses, 83.

Proximate principles of food, 54.

chemistry and physiology of, 63 .

hydrocarbons, 92.

inorganic salts, 102.

table of, 76,77 .

water, 103.

Prunes, 482.

damsons, 482.

Ptomain poisoning, botulismus, allantiasis of sausage poisoning, 669 .

galactotoxismus, or milk poisoning, 672 . ichthyotoxismus, or fish poisoning, 670 . kreotoxismus, or meat poisoning, 669 .

mytilotoxismus, or shellfish poisoning, 671.

symptoms of, 669 .

tyrotoxismus, or cheese poisoning, 671 .

Ptomains, absorption of, 668 .

foods containing, 668.

liver as bodyguard of system against, 668.

Ptyalin, 122, 129.

Pumpkin, 514.

toxic substances contained in, 659 .

Pumpkin seeds, use of, as anthelmintic and as food, 661 .

Purin bodies, compounds of, 81 .

pyrimidin bases, 82 .

transformation of, by enzymes, to other members of group, 82.

Putrescin, formation of, from ornithin, 220.

Pyloric action, 137.

Pyrimidin bases, compounds of, 82 .

\section{Q}

Quince, 482.

Quinoa, 403.

composition of, 403.

nutrients, per cent, 403.

\section{R}

Rabbit meat, 286.

Raccoon, flesh of, 286.

Radishes, 423.

composition of, 423,424 .

sulphur compounds of, 659 . 
Raisins, 497.

Rape oil, 471.

Raspherry, 500 .

Ratufia, is!) 1.

Rats and mice, as food. 770 .

Ravenud's disease, simulated by ergotion, 675.

Rectal foeding, uhsorption of futs in, liti. absorption of protcin in, 175.

absorption of sult und woter in, 175.

advantage of, in absorptive power of large intestine for salt and water. 175.

Rectum, Instomy of, 115.

Refuse, detinition of, 695.

Reindeer, as food, 773 .

lienuet, in cheeso manufucture, 342.

Reptiles, unusual, sometimes nsed for food. Sece Animul Food, unuual.

Reversibility of enzyme action, 15\%.

Rhinoceros, as food, 773.

Rhubarb, 435. contraindications to use of, 661 .

Rice, 389 .

composition of, 390 .

cultivation of, 390 .

digestion and absorption of, 390 .

"polished," beriberi due to, 662, 679.

its insufficiency, 391.

Roebuck berry, 500 .

Root fond of North American Indinns, 3.

Root vegetables, arrowhead tubers, 426 .

beets, 421 .

carrots, 421.

celeriac, 427.

common succulent, 418.

dahlias, 426 .

garlic, 429 .

horseradish, 425.

kohl-rabi, 425.

nutritive fond value of, 420 .

parsnips, 422.

salsify or oyster plant, 425.

shallot, 430 .

skirret, 425.

succulent, composition of, 420 .

turnips, 423.

water chestnuts, 426.

vautia, 417.

Roots, condiments from, 644.

as food of precibiculturists, 22, 25.

as staple of diet of primitive man, 3 . 22.

starch-bearing, composition of, 418 .

Roots and tubers, 409.

classes of, 410 .

composition of, 420 .

dasheen, 428.

Jerusalem artichoke, 416.

lotus, 428 .

onions, 429 .

potato, sweet, 413 .

white, 410 .
Routm and tustera, otaclige. 11:.

eapionera, f:20

taro tofiern. 11i.

loware appule, 1:01.

liowemary, movlicinal nature of oul of enol

Ituin. Berluerara, inal

improvement of with ager, swi.

Iamaica, ives.

proceme of, sets

lige, component rlementio uf, tom.

joimoning from, 67t.

mubject to atuut juat before riperning. ifibl.

ilse of, 400.

\section{S}

Saccharin, effect of, B2t,

nature of. 62\%.

negutive qualition of, 626.

use of, 1326.

siaccharose, 87.

Saffron. 1343.

medicinal action of, 6.5.

inge, $B+10$.

medicinal action of, $6.3 \mathrm{R}$.

medicinal nature of oil of, 661.

Siago, 428.

Sitads, 632.

average chemical enmposition of, 33.

salicylic acid, W.

as food preservative. 68.5.

Saline solutions, absorption of, 162.

Suliva, action of, 12!.

amylolytic action of. influener of tom. perature on, 123.

composition of. 1:4.

function of, in process of digmation. 124. secretion of. a reflex action. 126.

Salivary glands, parotid, 116. of primitive man. 41 .

sublingual, 117.

submaxillary, 116.

Salsify, 125.

silt, absorption of, in large intestine, $1: 3$. in rectal ferding. 173 .

action of, as condiment, $2 i$.

composition of, 6.50.

waporation of brine from salt springs. 6.50 .

mines containing. 150 .

value of, to animal life, 256.

to man. 250.

various actions of, Bs.

salts, aburption of, 16.5 .

inorganic, 102.

present in milk. 30 s.

sundwich, average chemical composition of. 739 .

Sispolilla. 4!91.

Supucaia nuto. 311

Sarnaparilla. nioz.

Siesafras. 645.

antiseptic volatile oil of, 669. 
Sauerkraut, 652.

Sausage, average chemical composition of, 718.

Sausage poisoning, 669 .

Savory, medicinal action of, 658 .

Scallops, 207.

Searlet fever, due to milk infection, 689 .

Scleroproteins, 78 .

Sea foods. Sce Shellfish.

Seakale. 434.

Seal, as food, 773 .

Seasonal variation of diet, 40 .

Secretin, 65.

action of, $154,157$.

action of condiments on, 28.

activity of, 154.

effect of alcohol upon, 574 .

Seeds, condiments.from, 647.

large, as food of precibiculturists, 26.

small, as food of precibiculturists, 25.

Serin, formula of, 71 .

Service berry, 499 .

Sesame oil, 469.

Shaddock, 487.

Shallot, 430 .

Sharks, as food, 773.

Sheep, age for killing of, 284.

nature and use of, 283.

varicties of, 284 .

Shellfish, average chemical composition of, canned, 725 .

fresh, 724.

chemical analysis of, 304 .

crustaceans, 304.

carmotes, 305.

clams, 307 .

crabs, 304.

lobster, 304.

mollusks, 305 .

mussels, 307 .

oysters, 305 .

prawns, 305.

scallops, 307.

shrimps, 305.

snails, 307 .

Shellfish poisoning, 671 .

Shrimps, 305.

Silica, presence of, in body and in foods, 274.

Sirup, adulteration of, 625 .

color of, 623 .

definition and kinds of, 622 .

sorghum, 624.

Sirups, commercial, 624.

composition of, percentages, 625 . mixed, 624.

Sitotoxismus, 674.

Skim milk, 334.

composition of, 334 .

Skirret, 425.

Sktshi, 652.

Skull, evolution of man in shape and development of, 9.

Slippery elm, as a demulcent, 662.
Sloths, as food, 774 .

Snails, 307.

as food, 774 .

Snakes, as food, 774.

Sodium, in body, 269.

Sodium-containing foods, with content estimated, 270 .

Sodium chlorid, amount of, necessary for health, 269.

importance of, to body, 263, 264.

use of, as condiment, 264, 269.

waters containing, 528 .

See also Salt.

Sorbinose, 87.

Sorghum sirup, 624.

Sorrel, 438.

oxalates contained in, 662 .

Soups, average chemical composition of, 758.

Sour apple, 489.

Soy bean oil, 471 .

Soy bean sauce, 445 .

Soy beans, composition of, 444 .

food value of, 444 .

preparations made from, 445 .

Spearmint, 641.

medicinal nature of oil of, 661 .

Spices, contra-indications to, 639.

rôle of, 639 .

value of, 639 .

See also Condiments.

Spiders, as food, 774.

Spinach, 434.

composition of, 432 .

winter, or orache, 438 .

Spleen, anatomy and physiology of, 118. mineral content of, 261 .

Spotted crake, as food, 774 .

"Spring lamb," Canadian goat meat sold for, 284.

Spruce beer, 568.

Squash, 514.

toxic substances contained in, 659 .

Squirrels, as food, 774.

St. John's bread, 493.

Stachyose, 89.

Stachys, 417.

Star apple, 492.

Starch, 89.

Starches, analyses of, 743.

as carbohydrate in reserve, 367 .

cellulose covering of, in vegetables, 369 .

conversion of, into soluble starch and dextrin, 369.

in vegetable foods, 367 .

Starch granules, action of cooking on, 369 .

formation of, 369 .

digestion of, ptyalin in, 122.

Steak, chemical composition of poultry in comparison with, 298.

Stearic acid, 99.

Stearin, 458.

Sterilization, of food, in stomach, 140. of milk, 323 . 
Sterilization, of milk, procens of, 323.

Sterols, 93.

Stimulants, definition and uction of, 368 . see also Alcohol and Alcoholic Drinkm.

Stomach, absorption in, 163. of curbolividrates, 185.

matomy of, 111.

bacteriology of, 227.

course of digestion in, 164.

functions of, absorption of food, 141. maceration of food. 134.

juices of. See Gastric Juice, 130.

movements of, study of, by merus of Röntgen rays, 134.

regulation of temperature, 140 .

as a reservoir for cliymification of food, 133.

sterilization of food, 40.

Stomach and intestines, animal, as food, 295.

Strawberry, 501.

Succinic acid, 96.

Succus entericus, 157.

interaction of enzymes in, 158.

Suet, 466.

Sugar, absorption of, 168 .

Sugars, analyses of, 743 .

as an article of diet, 609 .

by natives of India, 637 .

assimilation of, 633 .

comparison of different kinds, 634 .

beet, physical properties of, compared with those of raw cane sugar, 616.

manufacture of, 615 .

burnt, or caramel or black jack, 622 .

by-products in manufacture of, mo. lasses, 622.

sirup, 622 .

cane, "first," 614.

manufacture of, 611-614.

physical properties of, compared with those of raw beet sugar, 616 .

raw, 612,614 .

raw and refined, 614.

"second," 614.

"third," 614.

as circulating carbohydrate, 367 .

concentrated nature of, 635 .

consumption of, per capita, in different countries, 635.

per capita, in leading countries of the world, 620.

in United States, 619.

cube, 621 .

dangers incidental to great increase in dietetic use of, 636.

diabetic, 85 .

digestibility of, 631,634 .

effect of, in lessening muscle fatigue, 637.

as a fat-sparer, 636.

fattening properties of, 636 .

fermentation, tendency to, 632 .
Sugarm, fermentation, types of, 633. variction of, 632.

an forot. fuel valuse of, 635, 636 .

for mumcular work. B3B.

fuel value of, an a tomel, 635, 63es.

granulatol, 6:1.

inflummation of nkin due to, 631.

influeser of, on health of gruwing ehifl. dren, B316.

invert. 86.

irritating effect of merong molutions of on timulsew, Ba!.

lonf, 6:0.

maple, ohtrining wap from tree for, 618.

mistuate of, 638.

palm, B1x.

powdered, 621.

presligented, 631.

production of, comparimn of. from sugar cane, wugar bert, wightoum cane, maple tree sap and palsu tree sлp. 619.

by countries, 619 .

as a proteid-sparer, 636.

rock candy, 6:1.

sorghum, source and cultivation of, 616 . adaptable for growing on small scale. 617.

See Sugar, sorghum.

sources of, in nature, $B 10$.

date palm trees, 618 .

maple tree. 617 .

sorghum plant, or "Chinese sugar cane," 616.

sugar beet, 614 .

sugar cane, 609.

undigested, 631.

use of honey in place of, 629 .

varieties of, monosaccharids, or glu. coses, 610 .

in vegetable foods, 367.

disaccharids, or sucroses, 610.

Sugar apple, 490.

Sugar beet, composition of and its juice. 615.

cultivation of, 615 .

history of, 614.

Sugar beet industry, 615 .

Sugar cane, composition of, and its juice, 611.

countries producing, 610 .

description of, 609 .

"graining or crystallization" of, 61 .

history of, 609. 610 .

juice of, procedure with, 611.

"massa cuite," 613.

procedure with. 611 .

propagation of, 611 .

Sugar drops, 627.

Sugar industry, development of. 635.

Sugar refining, principles of, 620 .

sugars requiring. 620.

Sugar vinegar, 605.

Sugars, amylose group of, 89. 
Sugars, cane sugar group, or disaccharids, 87.

grape sugar group, or monosaccharids, 84.

raflinose group of, $\$ 9$.

Sulphite and bisulphite of sodium as food preservative, 685.

Sulpholipins, 100 .

Sulphur, presence of, in foods, 272.

sulphur-containing foods, with content estimated, 272

Sulphuretted hydrogen, toxic effects of, 193.

Sulphurous acid, as food preservative, 685.

Summer savory, 641 .

Sunflower seed oil. 471 .

Swallowing. See Deglutition.

Swans, as food, 774 .

Sweat, mineral content of, 257.

Sweet basil, 641.

Sweet marjoram, 641 .

Sweetbreads, pancreas ("belly"), 295. thymus gland ("neck" or "throat"), 295.

Swordfish, as food, 774 .

\section{$\mathrm{T}$}

Tallow, 466.

Tamarind, 493.

Tannic acid, 96 .

Tapeworms. See Parasites.

Tapioca, 429 .

toxic substances contained in, 662 .

Tapir, as food, 775 .

Taro tubers, 417.

Tarragon, 642.

Tartaric acid, 96.

Tea, adulteration of, 683 .

amount of, consumed, 545 .

caffein in different varieties of, 543 .

China and Indian, 541.

composition of cup of, 542 .

cultivation of, 540 .

"drawing" of, 542.

green and black, 540 .

composition of, 541 .

before and after preparation of tea leaves, 542 .

oil of, 559 .

proper method of infusing, 544 .

quality of, 541 .

tannin in different varieties of, 543.

toxic substances contained in, 659 .

Tea plant, 540.

Teeth, evolution of, 45 .

summary of. in connection with evolution of digestive system, 47 .

form, structure and number of, 110 .

Temperature, eflect of alcohol upon, 572.

Terpenes, 93.

Terrapin, 305.
Tests, of food value, 57.

chemical, 57.

economic, 60 .

physical, 57.

physiological, 60 .

physiological, of digestibility of food, 162.

Tetrasaccharids, stachyose, 89.

Tetroses, 84.

Thermal saline waters, 530.

Thyme, 642.

medicinal nature of oil of, 661 .

Thymus gland, animal, as food, 295.

Tin poisoning, from preserved food, 685 .

Tissue formers, 56 .

Toad, as food, 775 .

Tomato seed oil, 471 .

Tomatoes, 437.

oxalates contained in, 662 .

toxic substances contained in, 661 .

Tongue, of animals, as food, 295.

Tonka bean, 648 .

Tortoise, as food, 775 .

Toxemia, alimentary, 193.

Toxic substances, foodstuffs containing, $557-662$.

Toxins, 668 .

Triatomic alcohols, 93.

Trichiniasis, cause and prevention of, 667 . symptoms of, 667 .

Trionyx ferox, as food, 775 .

Trioses, 84.

Tripe, 295.

Trisacchirids, melitose, 89. melizitose, 89.

Truffles, 449.

Trypsin, action of, 152 .

Tryptophan, formation of indol from, 218.

Tuberculous meat, 688 . milk infection, 688 .

Turkey, flesh of, 297. varieties of, 297. wild, 299.

Turmeric, 644.

Turnip, composition of, 424. cultivation of, 423 .

sulphur compounds of, 659 .

use of, as food, 423.

varieties of, 423 .

Turnip tops, 439.

Turtles, 305 . as food, 775 .

Typhoid fever, due to milk infection, 689. due to oysters, 689 .

due to water, 243 .

Tryosin, formation of paracresol from, 219.

formation of phenol form, 219.

Tyrotoxismus, 671 .

\section{U}

Urine, mineral content of, 257.

Ustilago maidis, source of, $66 \mathrm{i}$. 
Vanilla, active principles of, 662.

Vanilla bean, 6is?.

Veal, average chemical composition of, fresh, iog.

venl orguns, 711. cuts of, 700 .

Vegetable and animal foods, relative values of. 60 .

unclassified, average chemical composi. tion of, 758 .

Vegretuble futs und oils, 467.

absorption of, 467 .

slmond oil. 469.

apricot kernel oil, 471 .

cacio fat, 470.

cocoanut oil, 470 .

corn oil, 471 .

cottonseed oil, 470.

linseed oil, 471.

mustard oil, 471 .

mustard seed oil, 470 .

olive oil, 469.

palm oil, 468.

peanut oil, 469.

poppy seed oil, 469.

rape oil, 471 .

sesame oil, 469.

soy bean oil, 471 .

sunflower seed oil, 471.

tomato sced oil, 471.

value of, 467 .

Vegetable foods, algae, 450.

average chemical composition of, 729. 757. See also special subjects.

bulky, digestion and absorption of, 372 .

carbohydrates in, pectin or pectose bodies, 369 .

starch, 367 .

sugar, 367.

cellulose as factor in digestion and ab. sorption of, 372.

cereal breakfast foods, 404 .

cereals, 375 .

barley, 401 .

bread, 384.

buckwheat, 404.

corn, 392.

flour, 280.

kaoling, 403.

millet, 401.

oats, 398.

proso millet, 402.

quinoa, 403.

rice, 389 .

rye, 400 .

wheat, 376 .

chemical characteristics of. 365 .

constituents of, inorganic substances, 366.

nutritive substances, 367 .

organic substances, 367 .

is. those of human body, 366 .
Viegretalife formle, ront of, 130 .

digention and abourptions ot, 371.

of lwsthy vegrtablo focols, Ji:

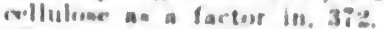

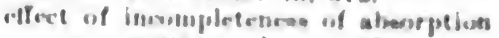
un nutritior valur of, Jis

factora muresure! in, 372

relative abouspetion of protrin in va. rinum foment. 373.

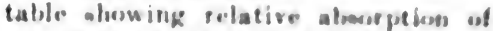
monse animal and vogrtable fionds, 372

futw in, 3io.

funel valuo of, va. morat, $36 ;.$

fungi, licberum, algar, 167.

fungi mortwerl, agat akar, 431.

greerll vegetsablos, 430.

urtichoke kreens, 437.

амратацик, 436 .

culbuger, 433.

celery, 43.i.

chickory, 438.

composition of, 430, 431, 432.

cooking of, 431 .

dandelions, 43x.

digestibility of, 431.

cookerl, 433.

raw, 433 .

endive, 437 .

food value of. 430 .

greens or pot herba, 439.

lettuce, 43.5 .

okra, 43s.

orache, 438 .

peas and treans, 439.

rhubarb, 435.

shelled berans, 439.

sorrel, $43 x$.

spinach, 434 .

tomatoes, 437 .

turnip tops, 439.

water cress, $43 t$.

inferior substances in, 370 .

inorganic substances in, 366.

legumes or pulnes, dried, $4+1$.

lentils, 447 .

peas, $4+5$.

lichens, 447, 450 .

mineral salts in, 371 .

of North American Indians, 22.

nutritive substances of, cartoliydrates, 3 iit.

futs, 370 .

inferior, 370 .

proteins, $3 \% 0$.

water and mineral salta, 3:1.

nutritive valuo of, 37t.

effect of incompleteness of alusirption on, 373 .

protein value: the vongtarian ques. tion. 374.

organic substances in. 3r:

protrins in. 370.

relative cost of animal and, 375. 
Vegretable foods, roots and tubers, 409 . arrowhead tubers, 426.

celeriac, 427.

clitsses of, 410.

dahlias, 426 .

dasheen, 428.

garlic, 429 .

Jerusalem artichoke, 416.

lily bulls, 428 .

lotus, 428 .

onions, 4:?.

potato, sweet, 413 .

white, 410 .

sago, 428 .

shallot, 430.

stacliys, 417.

tapioca. 429.

taro tubers, 417.

water chestmuts, 426.

yautia, 417.

root vegetables, beets, 421 .

carrots, 421.

common succulent, 418.

composition of, 420 .

horse radish, 425 .

kohl-rabi, 425.

nutritive value of, 420 .

parsnips, 422.

radishes, 423 .

sulsify, 425 .

skirret, 425.

turnips, 423.

vitamines in, 378 .

water in, 371.

Vegetable narrow, 514.

Vegretables, canning of, 684 .

eooking of, 16 .

as food of precibiculturists, roots, 25 . seeds, small, 25.

influence of cultivation of nutritive properties of, 5 .

as main food of primitive man, 2 .

oil-bearing, percentage composition of, 468.

various, analyses of, $745-746$.

Vegetarian question, 374.

Venison, 284.

Vermouth, 591.

Vinegar, 603.

cider or apple, 602, 605.

glucose, 605 .

malt, 605

meaning of term, 605.

"mother" of, 603.

perry, 602.

sugar, (30).

wine, 605.

Vinegar plant. 603.

Viscera, animal, as food. S'ee Animal Vis-

Vitarnines, 6.4. cera as Food.

sction of, 234.

"curative"," 235.

dentruction of, by heat. 279.
Vitamines, foods containing, 235.

growth-producing, foodstu.গs containing, 235.

importance of, 378 .

of meat, 279 .

in milk, 316.

importance of, 316.

where found, 317 .

nature and rôle of, 234

pellagra due to lack of, 677 .

Volatile esters, 97.

\section{W}

Walnuts, 511

Walrus, as food, 775 .

Water, absorption of, 167, 169.

in large intestine, 175.

in rectal feeding, 175 .

lymphatic, 171 .

action of, on digestion, 520 .

appearance of, 238 .

bacteria in, 242 .

bacillus coli communis, 243 .

cholera germs, 243.

detection of, by chemical analysis, 245.

typhoid bacilli, 243 .

bacterial activity in, 240 .

as beverage of precibiculturists, 29 .

boiling of, application of, to cookery, 20 .

history of, 17.

chemical and bacteriological analysis of, 245 .

color of, 239.

composition of, 238.

course of, in system, introduction, 171.

lymphatic absorption, 171 .

diaphoretic function of, 250 .

as digestive aid, 249,250 .

distillation of, 245.

diuretic function of, 250 .

for drinking, chemical and bacteriological analysis ot, 245 .

distillation, 245.

temperature of, 250 .

time of, 250.

eliminative function of, 248 .

function of, as food, 248.

ice and snow, 244.

impurities of, 522 .

medicinal use of, by primitive people, 30.

necessity of, 249,519 .

odor of, 239.

parasites found in, 665,667 .

percentage of, in fish, 301 .

in meat, 281.

physical and chemical properties of, 238.

potable, 522 .

as proximate principle of food, 103. 
Water, pure, 237.

qualitative examination of, table ahow ing roagents necersary for, 246, 247 .

river, 245.

sources of, 244.

ice und snow, 244.

river, 245.

springs and wells, 2.4.

spring. 244.

substanees in solution and suspension in, ammonin, 241 .

bacteria, 242.

carlon dioxid, 240.

chlorins and chlorids, 242.

nitrates, 242.

nitrites, 241.

nitrogen and oxygen, 239.

organic matter, 240 .

sulphated iron, 532.

taste of, 239.

therapeutic value of, 250, 25I.

uses of, in human system, as aid in di. gestion, 249.

diuretic and diaphoretic, 250 .

eliminative, 248.

as food, 24 .

summary of. 251.

value of, 237 .

in vegetable foods, 371 .

well, 244.

Water chestnuts, 426.

Water cress, 436.

sulphur compounds of, 659 .

Water cures, 537.

Water drinking at meal time, 519, 538.

conclusions on, 538.

effect of, 538 .

Watermelon, 513.

Waters, alkaline, alkaline acidulous, 525.

alkaline muriated acidulous. 525.

alkaline saline acidulous, 525.

simple acidulous, 525.

springs supplying, in United States, 527.

table of, 529.

arsenic and iron, 532.

bitter or purgative, 523 .

analysis of, 525 .

bromin and iodin, 528 .

calcic, 535.

chemical composition of, 536 .

sources of, in America, 536

carbonated iron, 532.

chalybeate and ferruginous, 532.

American, 533.

carbonated iron, 532.

iron and arsenic, 532.

purgative chalybeate, 532.

sulphated iron, 532.

table of, 534 .

classification of according to Rivers Pollution Commission, 521.

according to Rosena11, 521.
Winterm, arroriling to Rnornau, hard, s:I. moft. $8: 1$

ferrugincilu, 83:

iron, Imueriran, s.33.

iron and armenic, 83: cartomated, 53: mulphaterl, $33: 2$.

mineral, s23. nIkalinn. 8'as.

ralcic, bis:

chalylwato atol ferruginous. 332.

purgative or hitter, 5:3.

naline, sax.

nulphuroun, 533.

thermal, 536.

purgative or bitter, 523.

analysis of. 225.

table of soes

purgutive ehalyluente, 332.

saline, bromin and iodin, 328.

lithium present in, 32x.

simple modium chlorid, 52x.

table of, 531.

thermal saline. 5.30.

sxlium chlorid. 528.

sulphurous. 533.

American sources of, 535.

table, 522.

analysis of, 523.

table of, 524.

therapeutie, 523.

therapeutic effects of, 523.

thermal, mud baths, 53i.

principal springs of, in United Statos. 536.

thermal saline, 530 .

Waxes, definition of, 99.

Wiether, flesh of, 2st.

Whale, as food, 775 .

Wheat, 376 .

analysis of, and of products of roller milling. 381 .

cerealin layer of, 378 .

composition of, cerealin layer, 378.

germ, or embryo, 378.

gliadin, 379 .

gluten. $37 \mathrm{~s}$.

glutenin, 378.

interual substance or kernel, 378 .

percentages, of entire grain, 379.

percentages, of parts of grain, 379.

rements of component parts of grains of, 37 is.

importance of, as formlatuff. 376.

origin of. as frodstuft, 376.

Whesat breal, eomposition of comkd enrn preparations and, 395.

Whey, composition and nutritive ralue of. 337.

formation of, 331 .

home-made, 337.

Whey cure, 337.

Whiskey, definition of, 552. 
Whiskey, grain, 583.

Kentucky Bourbon, 583.

malt, 58:.

Monongahela. 583.

Moonshine. 584.

patent-still, 584 .

pot-still, 584.

Scotch and Irish, 583.

sour mash. 5.S4.

sweet mash, 584.

Whortleberry, 4!s.

IVine, adulteration of, 682 .

composition of, 594 .

how produced, 594 .

preparation of, 595.

process of fermentation of, 595 .

acid, 597 .

aroma and bouquet of, 598 .

aromatic, 596 .

classification of, according to character and composition, 596 . composition of, 598 .

table of, 599 .

daily use of, 602 .

effect of, on digestion, 600 .

natural, 596 .

perfect, 597 .

rough, 597 .

sophisticated, 598 .

as source of nutriment, 601.
Wine, sparkling, 597. champagne, 597.

strong dry, 596.

strong sweet, 596. use of, 601 .

Wine vinegar, 605.

Wintergreen, 642.

Wolves, as food, 775 .

\section{$\mathrm{X}$}

Xanthophyll, 101.

Xylan, 85.

Y

Yautia, 417.

Yeast, compressed, average chemiical composition of, 757 .

Yoghoort, bacteria and making of, 340 . composition of, 340

digestibility of, 341 .

\section{Z}

Zinc, in preserved food, 685 .

Zulus, carrion or decomposed flesh as food of, 775 . 






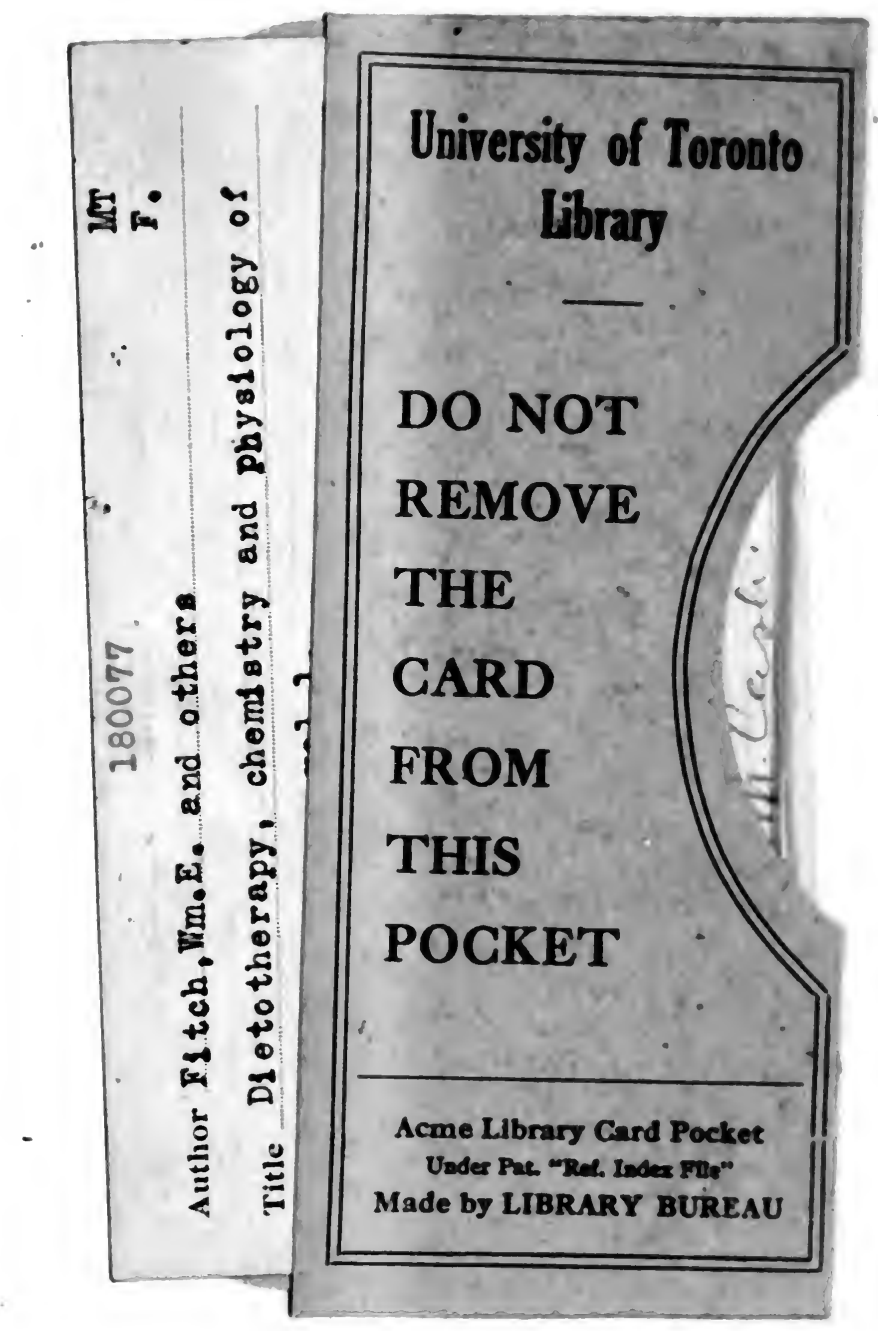


n

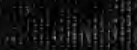

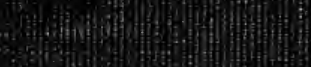

S.4.

3.

(X)

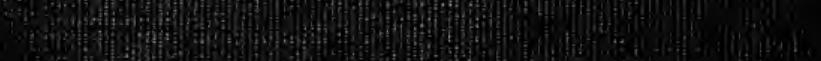
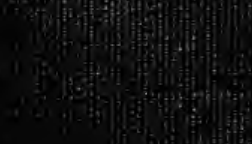

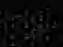

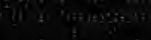

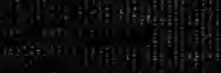

$\omega_{0}+x+2$

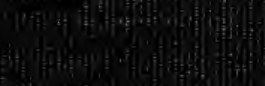

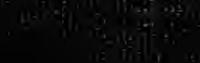

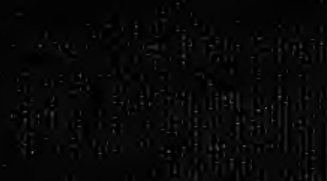

$30 \sin 5$

-

(o.t.

1.4.

4

(3) 